16,

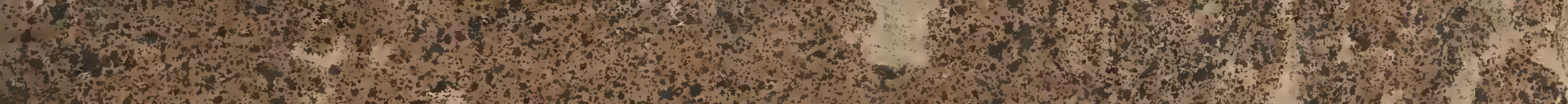
W.

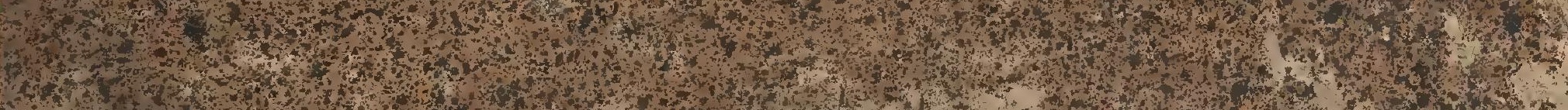

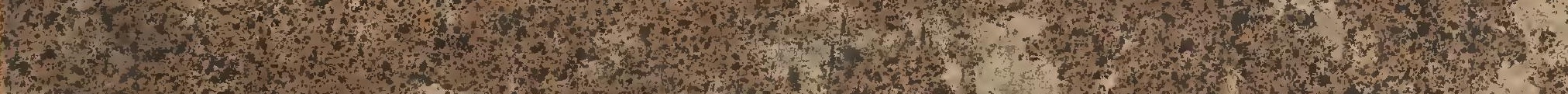

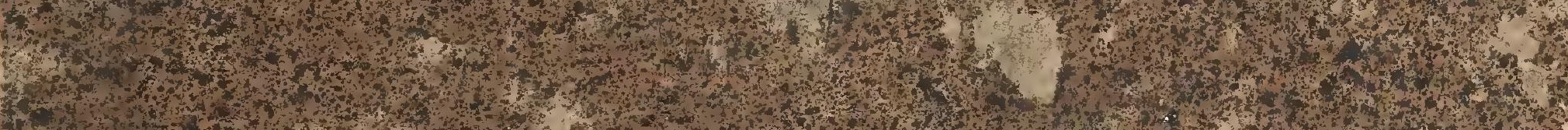

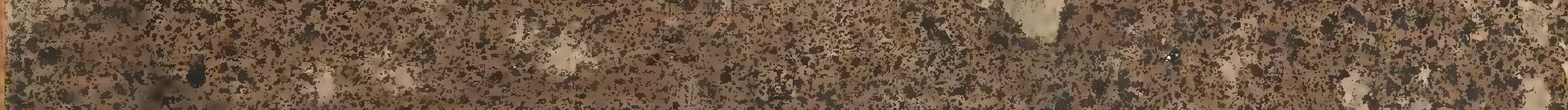

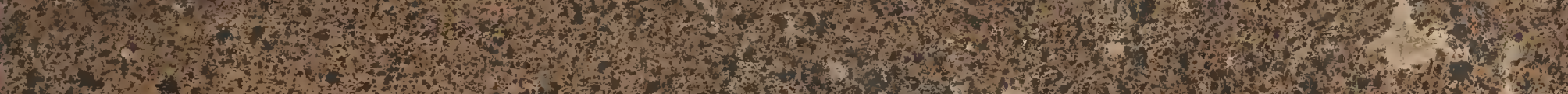

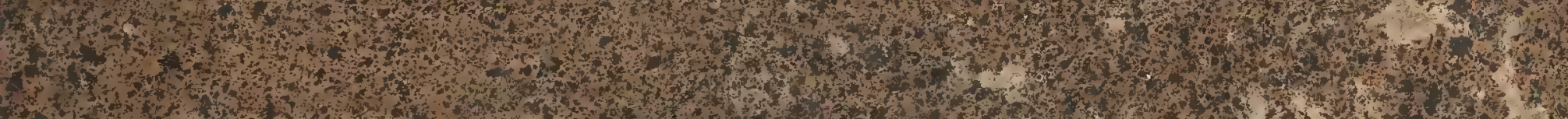

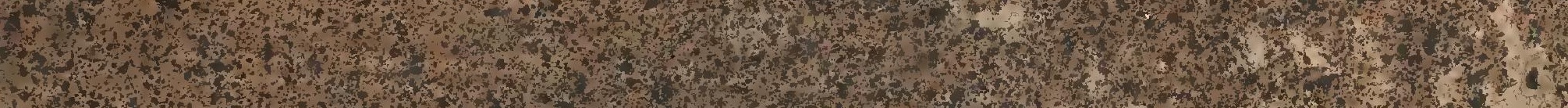
31
3

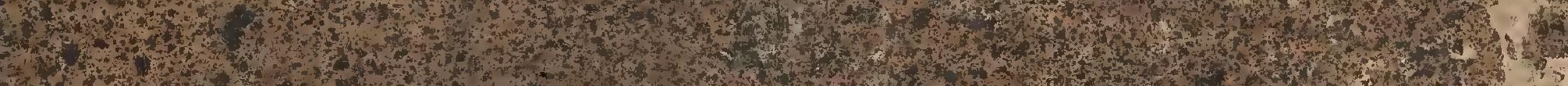

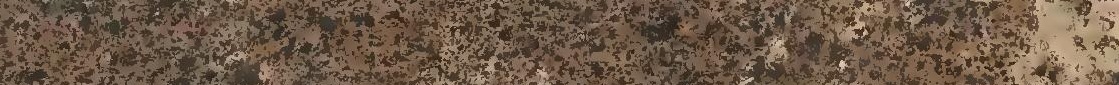

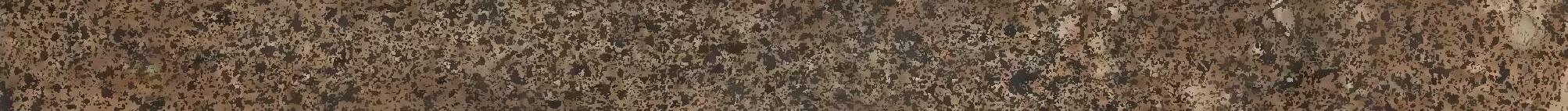

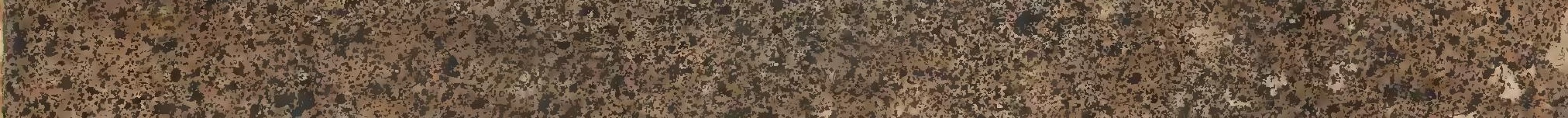

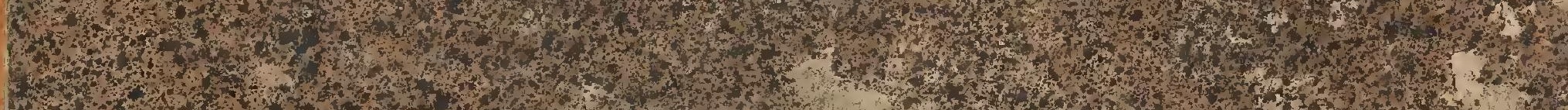

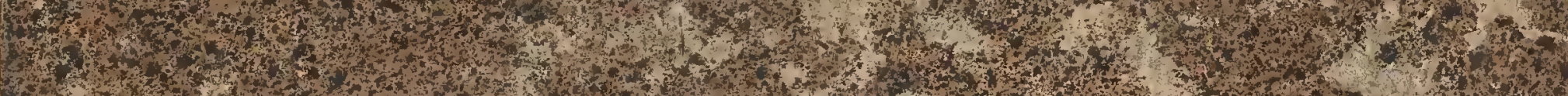
W

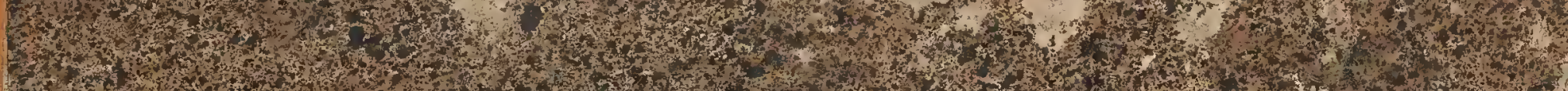

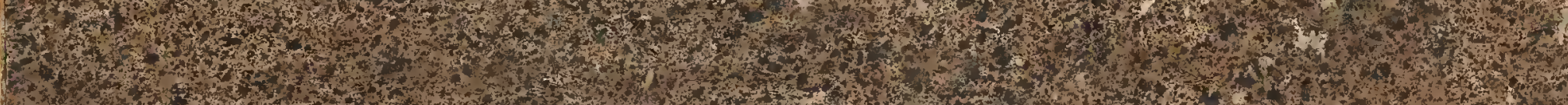

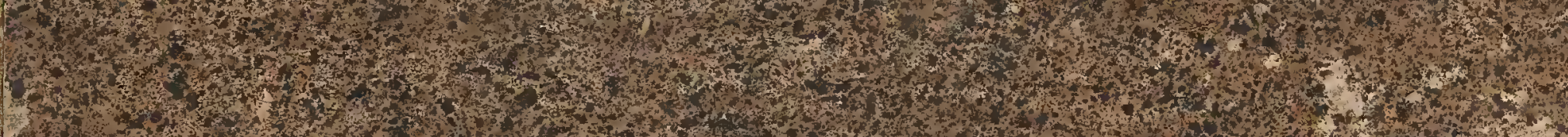
13.5.

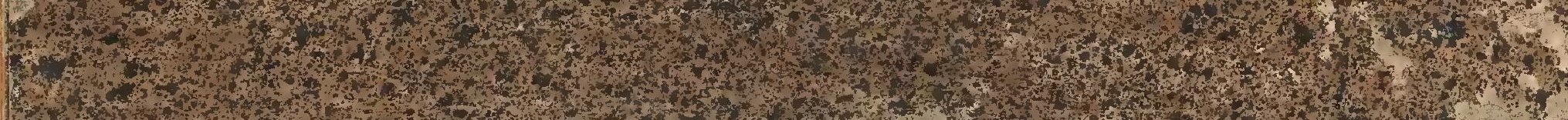
1.7.

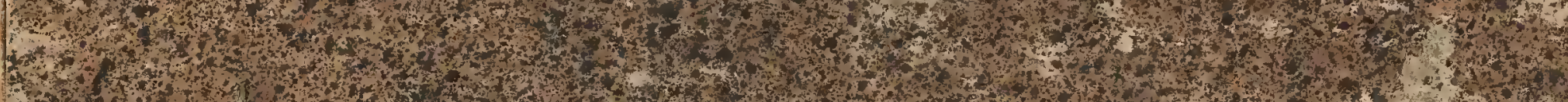

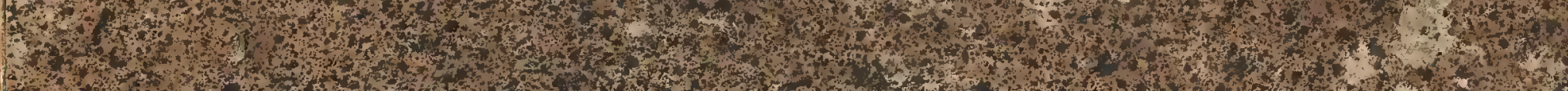

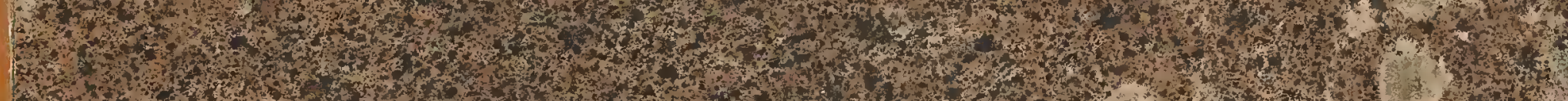

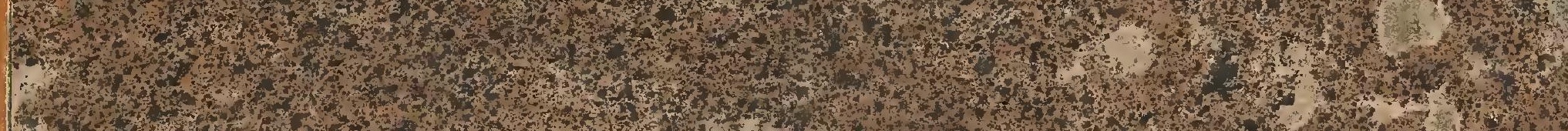

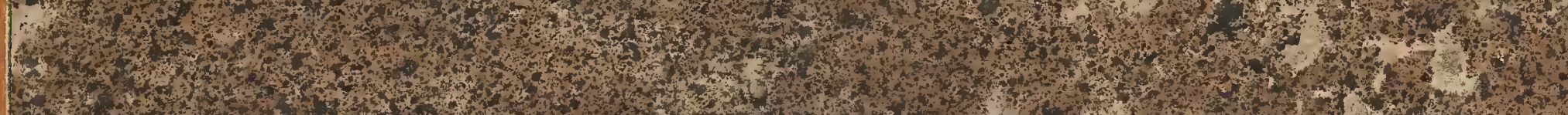

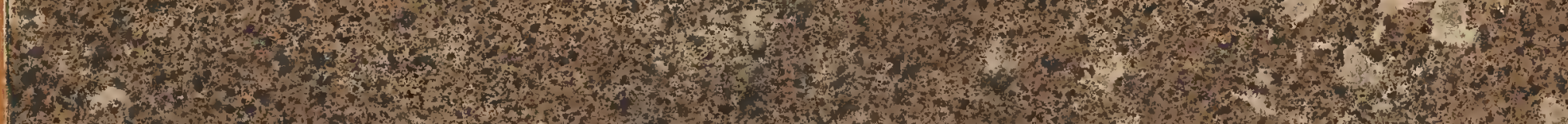

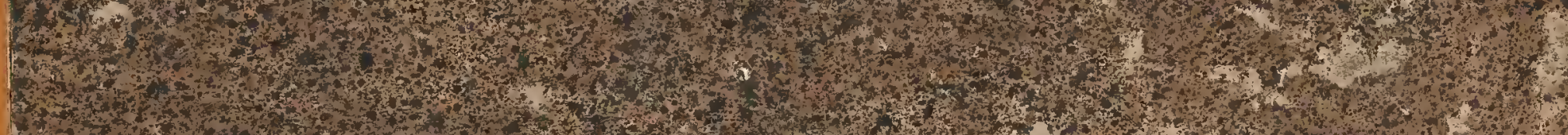

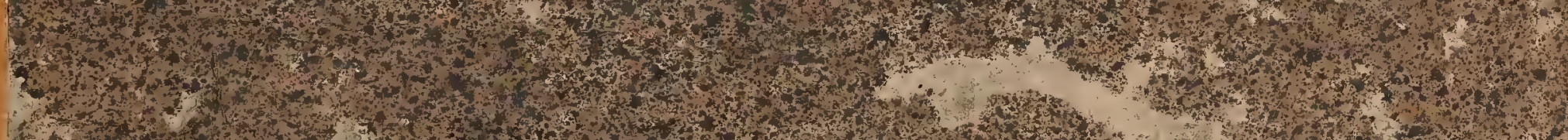

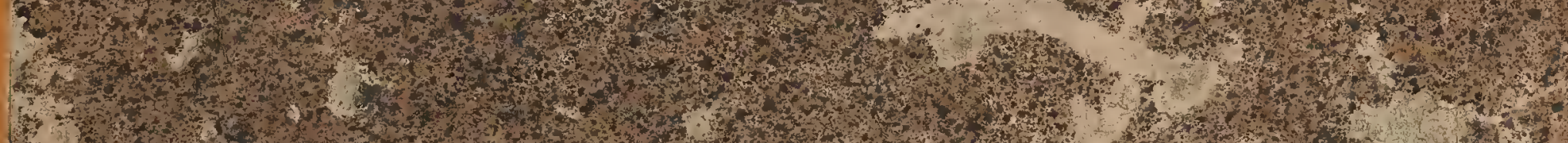

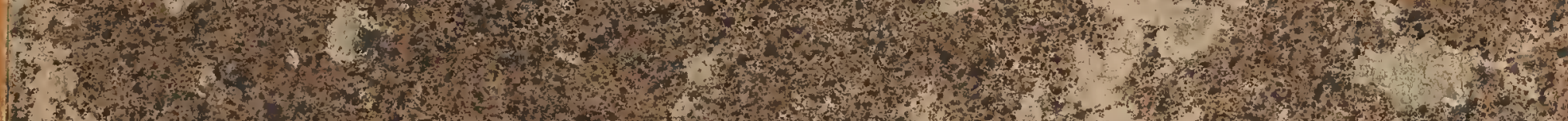

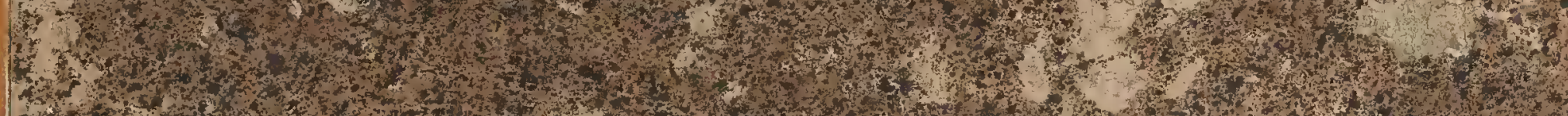

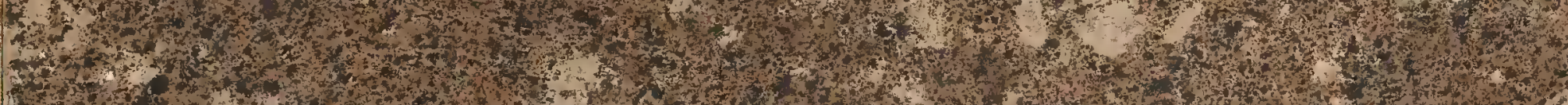

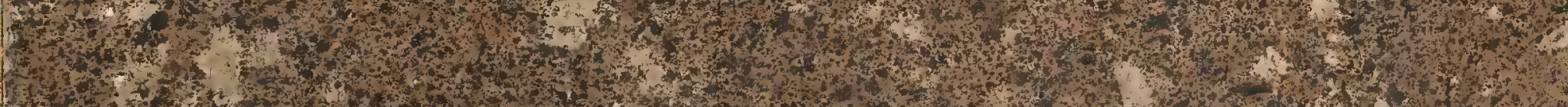
1.

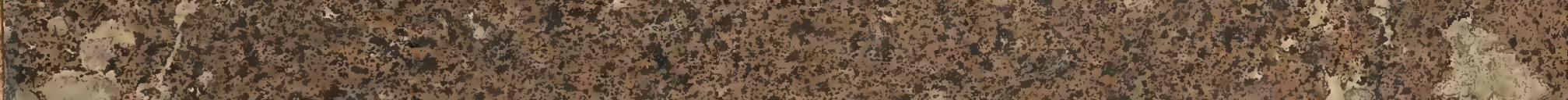

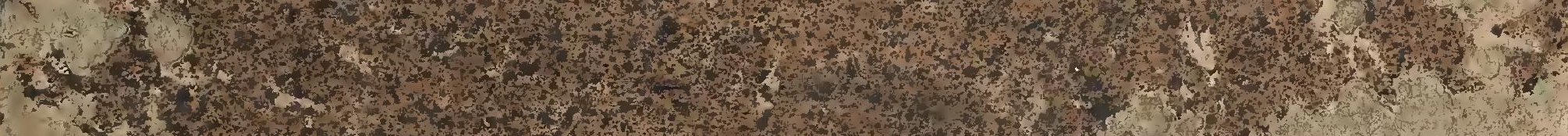
i f 
The Dibner Library of the History of

Science and Technology

SMITHSONIAN INSTITUTION LIBRARIES

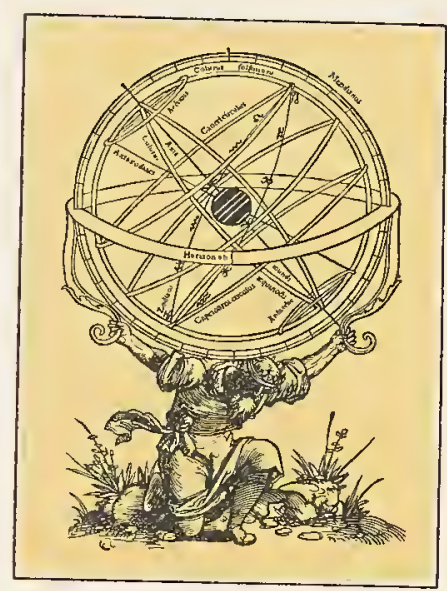

BURNDY

LIBRARY

प1e

Chartered in 1941

N

Gift of
BERN DIBNER 


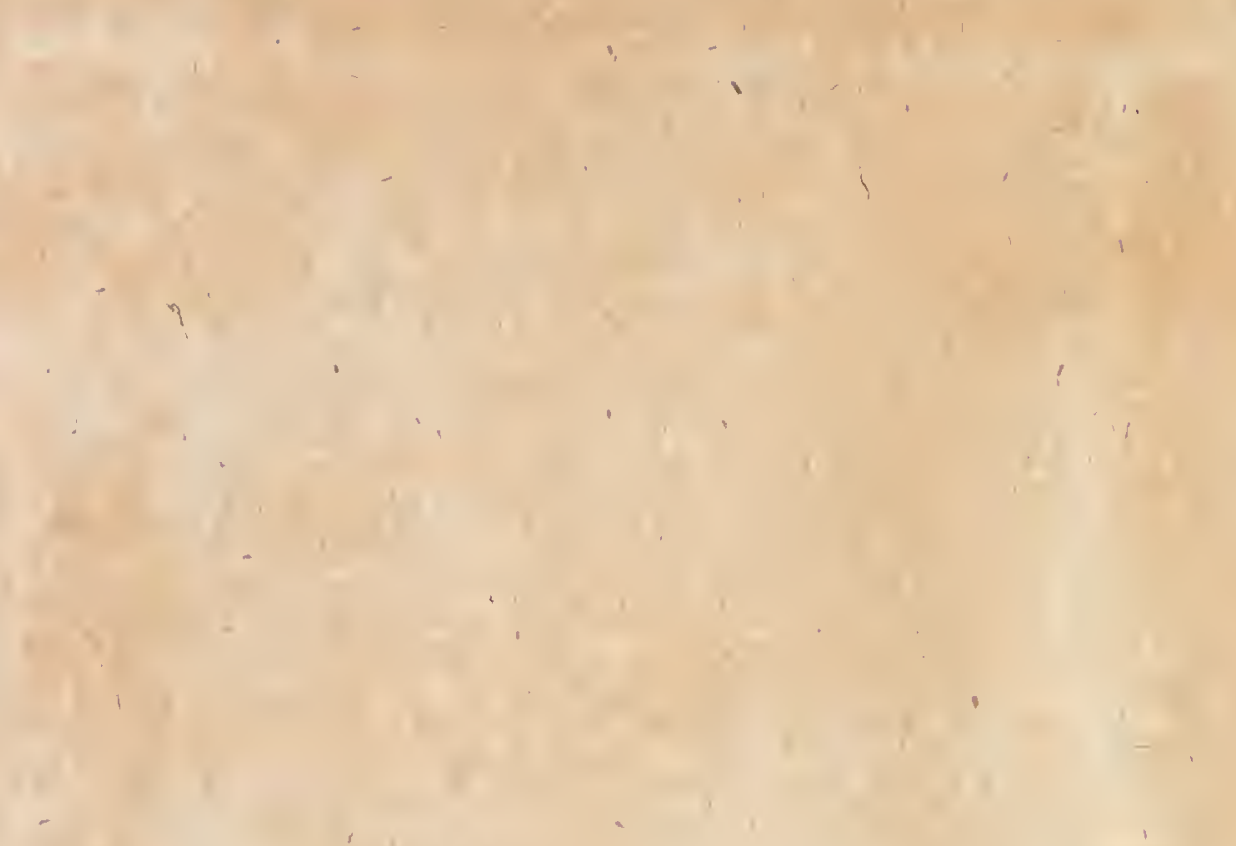


\section{EMANUELIS SWEDENBORGII}

SACR死REGIÆ MAJESTATIS REGNIQUE SVECI在 COLLEGII METALLICI ASSESSORIS

\section{REGNUM SUBTERRANEUM}

S I V E

M I N E R A L E

D E
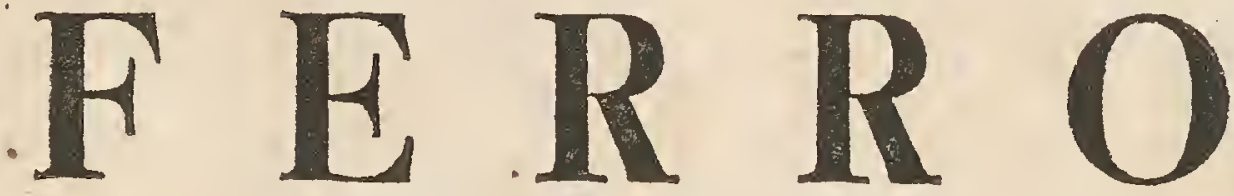

DE QUE

MODIS LIQUATIONUM FERRI PER EUROPAM PASSIM IN USUM RECEPTIS: DEQUE CONVERSIONE FERRI CRUDI IN CHALYBEM: DE VENA FERRI ET PROBATIONE EJUS: PARITER DE CHYMICIS PRAEARATIS ET CUM FERRO ET VICTRIOLO EJUS FACTIS EXPERIMENTIS \&c. \&c.

C U M FIGURIS $\mathbb{N}$ IEIS.

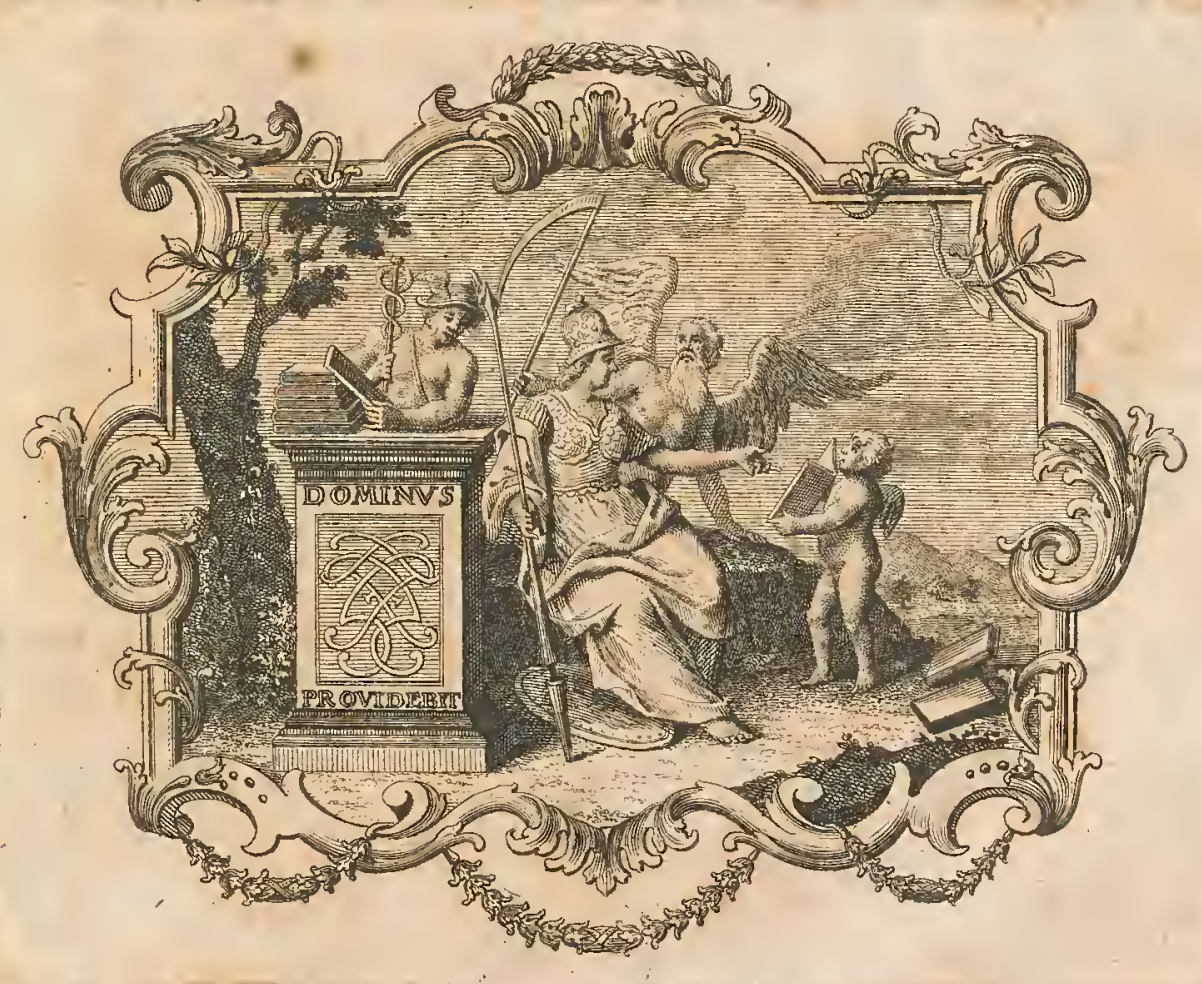

DRESDEET LIPSI E,

SUMPTIBUS FRIDERICI HEKELII,

BIBLIOPOLA REGII M DCC XXXIV. 



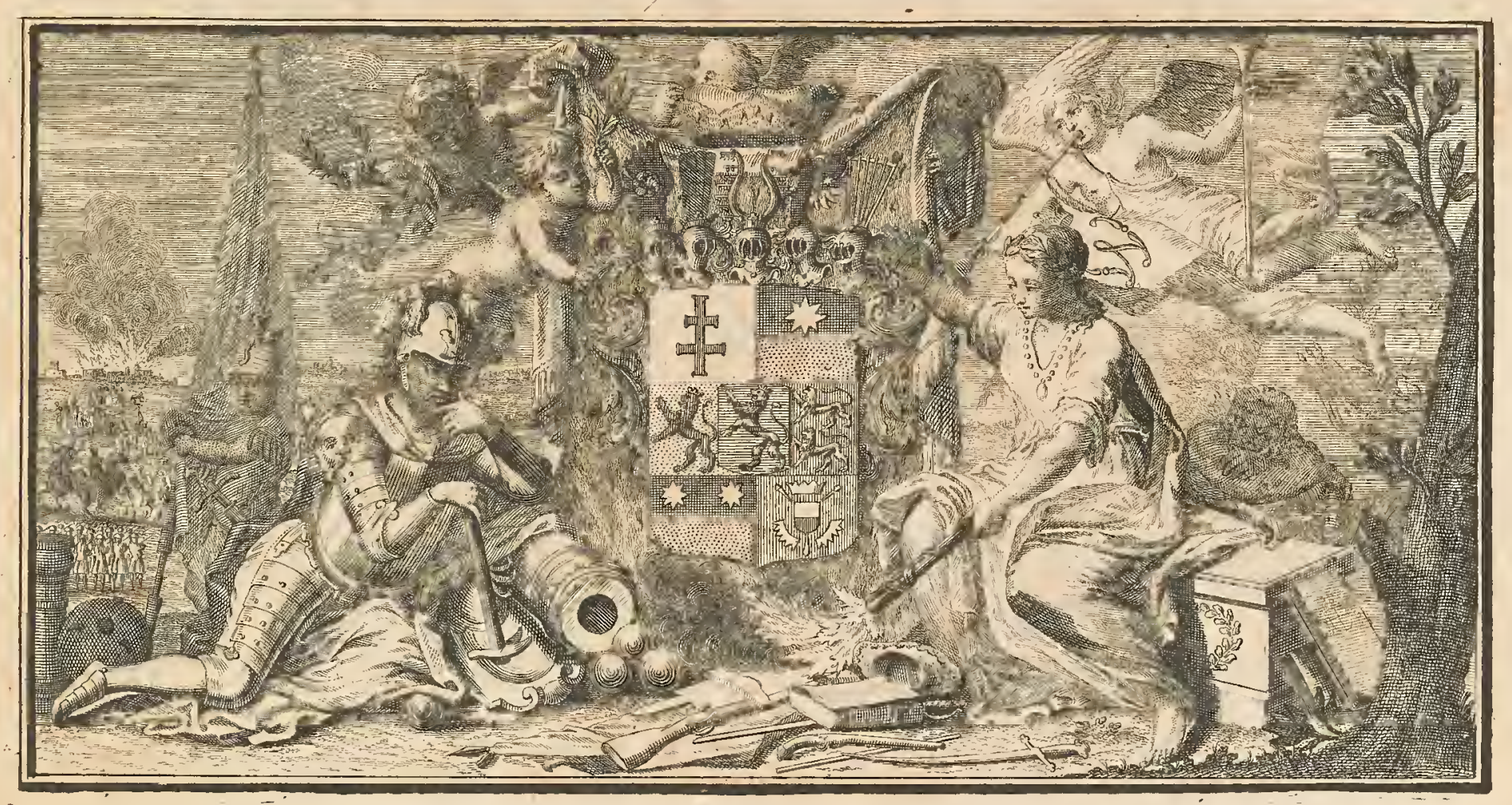

\section{SERENISSIMO PRINCIPI}

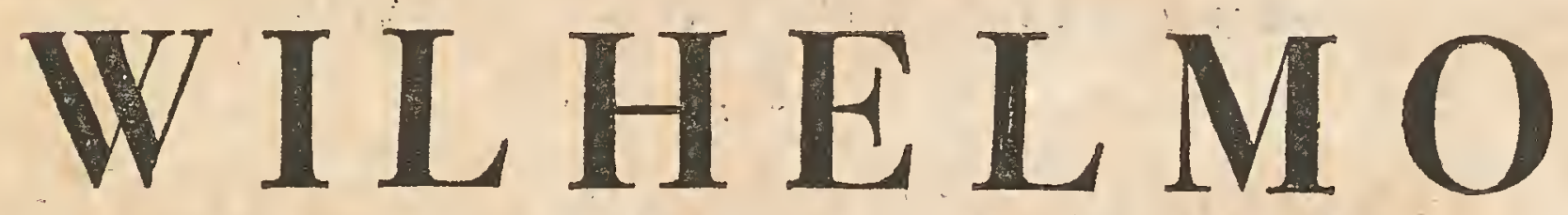

\section{HASSI Æ LANDGRAVIO, PR INCIPI}

HERSFELDI\&, COMITI CATTIMELIBOCI, DECI㾁，ZIEGENHAINI 压，NIDD压 ET SCHAUMBUR GI \&c. \&c.

POTENTISSIMI SVECORUM REGIS, HASSI $\mathbb{E}$ LANDGRAVII IN TERRIS H REREDITARIIS

\section{I C A R I O,}




\section{EXERCITUS EQUESTRIS FOEDERATI}

BELGII GENERALI LOCUM TENEN T I,

\section{LEGIONIS PRÆTORIANÆ DESLILTORIÆ \\ C H I L I A R C H Æ,}

NEC NON

\section{OPPIDI TRAJECTI MOSANI SUPREMO}

PRÆEECTO BELLICO

\&c. \&c. 


\section{PRINCEPS SERENISSIME.}

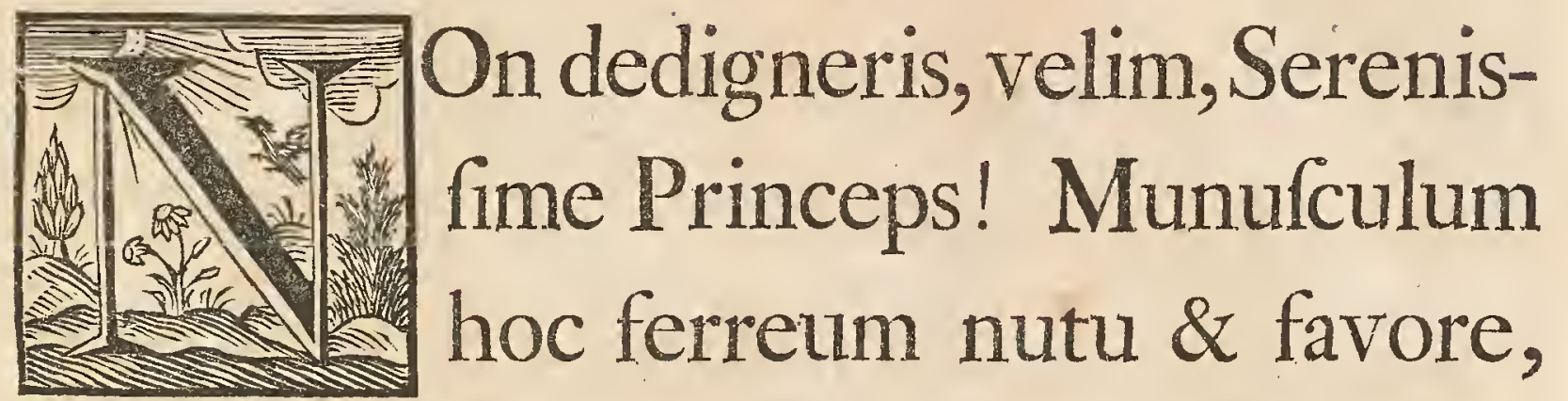

quamvis vilius fit, quia ferrugineum, quam ut tam Illuftre Nomen frontem opufculi ejus coronet ; fed fi fub clypeo \& tutela tanti Principis lateat, inde ex radiis color ejus obfcurior in candidiorem \& argenteum tranfibit. Si fortaflis meminerim, in Terra Svionum ex metallorum profapia vix preter ferrum \& cuprum nafci, \& natale ejus folum præcipue fub Arcade Hyperboreo effe, ubi Frater Tuus regnat, inde illud mereri aliquem faventiorem nutum poffe, augurari liceat. Quid melius apportem, quam telluris patrix prolem? quid dignius, quam Svionum Martem, (hoc no-

$$
\text { a } 3 \text { mine }
$$


mine ferrum infigniverunt Veteres) qui in regno Fratris Tui dives eft in armis, quia ferri potens; qui toties victor per obftantes catervas explicuerat arma patrix, \& de tot gentibus debellatis per ferrum fuum triumphaverat; fic quia de folo \& patria Martis venit munufculum hoc votivum ferreum; fpes me alit, fore ut oblatum faventer ideo excipias, præcipue, quum animus dantis pro falute $\&$ profperis Tuis fatis vota calide fundens, venerationis Tui,SerenisfimePrinceps! plenior \& opulentior fit. Hrc

\title{
SERENITATIS VESTRA
}

\author{
Perhuinillimus cultor
}

EMANUEL SWEDENBORG. 


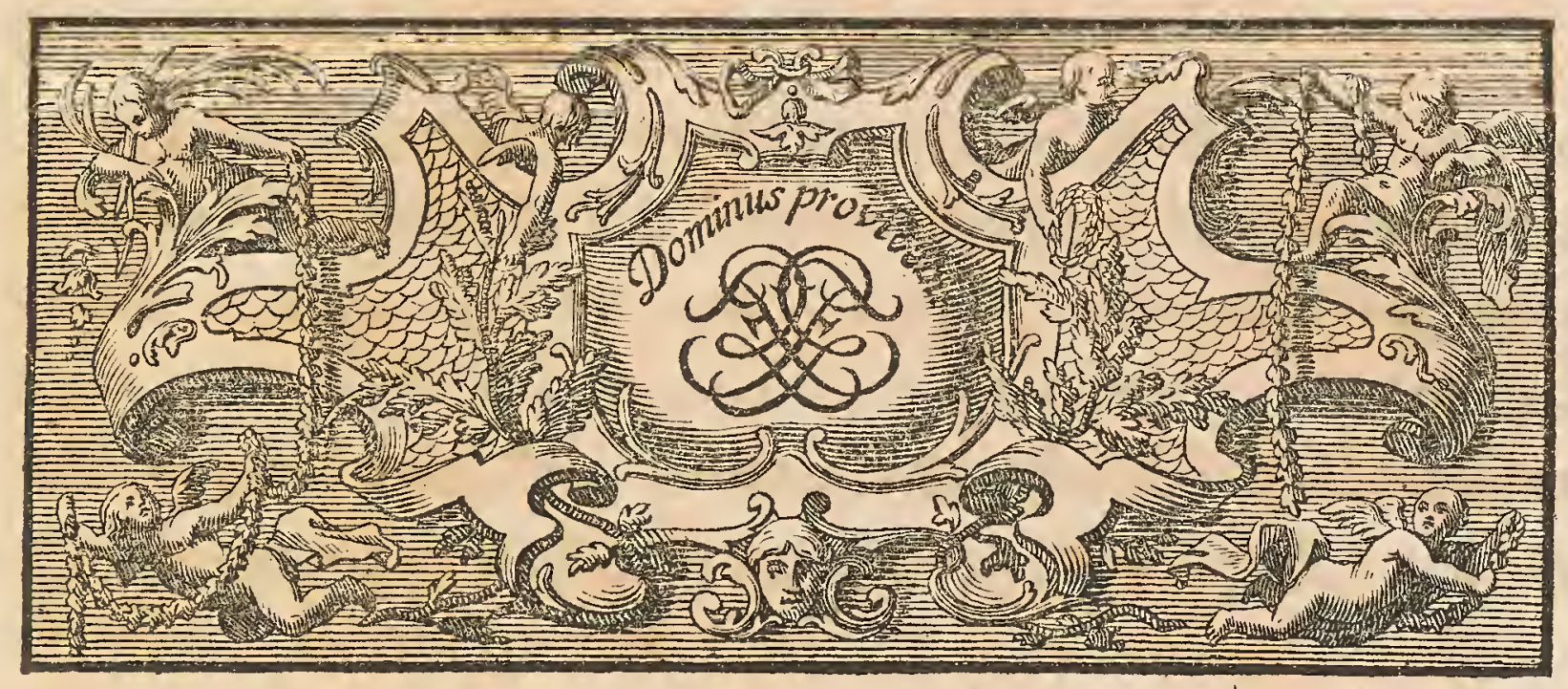

\section{P R $\mathbb{E}$ F A T I O.}

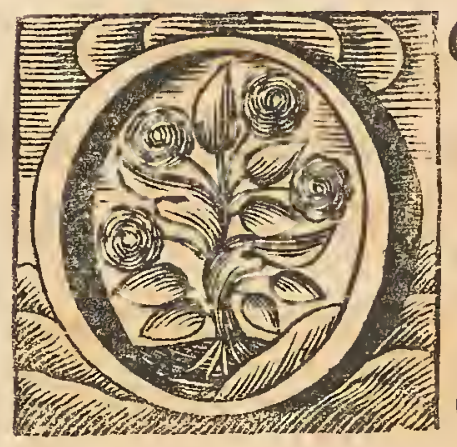

Culis Tuis, benevole Lector! fubjicio primam partem regni noftri fubterranei five tractatum prafentem de Ferro; animus eft, ordine reliqua Metalla eodem modo tradere, pariter etiam Salia \& Lapidum genera, \& fic totum Regnum Minerale percurrere. Vaftum quidem aggredior opus, \& navicula quafi, \& velis exiguis lacerisque magnum permetiri conor Oceanum, adeo ut jufte verear, ne

\section{- - Gemeat fub pondere cymba}

- Sutilis, \& multam accipiat rimofa paludem. Virg. Enneid. VI.

Ufque tamen fatius exiftimo periculum facere, \& ex portu navigare, quam fpei \& animi inopis omnem conatum linquere.

Quodlibet metallum, five ferrum fit, five aliud, in tres Claffes difpertiri volui; primam Claffem adornabunt proceffus \& modi liquatorii præcipue per Europam pasfim in ufum recepti : \& quia notiores mihi liquationum modi in Svecia funt, quam alibi, hinc etiam defcriptioni illorum, quam aliarum regionum diutius immoror. Secundam Claffem conftituunt Proceffus liquationum minores five probatorii, qualiter fcilicet vena aut metallum in foco minori five in furnis pro- 


\section{P R E F A T I O.}

batoriis examini fubjicitur, \& interiora indagantur, ut inde certior ejus ufus in opere majori obtineatur. Ad tertiam Clafem pertinet recenfio omnium Proceffuum Chymicorum, quot \& quales a pluribus inftitutos videre contigit; una etiam in medium afferuntur Experimenta \& numerofa fcrutinia ejusdem metalli per fólutiones, chryftallifationes, præcipitationes aliasque chymice factas metamorphofes detecta.

Quod primam Claffem cujufcunque metalli vel mineralis five modos liquatorios venarum concernit, tenendum eft, quod fcientia illa non modo ufibus humanis maxime inferviat; inde enim non modo docemur, mineralia rite perfcrutari, \& divitias opesque in venis reconditas facilius eveftigare, eveftigatasque plenius educere; fed etiam eadem locuples experimentorum penum exhibeț, quale Chymia per fuos focos inftrumentorumque congeriem. Quot enim nonvarietates fe offerunt in folutionibus \& aperitionibus cujusvis venæ per ficcum ignem inftitutis, in illarum \& metallorum commixtionibus cum menftruis, lapidibus \& phlogiftis multiplicis generis; quot non in ipfis furnis \& ignibus, qui contextum \& compagem cujusque in partes minimas dirimunt $\&$ intime luftrant : patent etiam innumera Orbi literato arcana, quæ tantummodo funt cognita \& tanquam vủlgaria genti ignobili fabrorum, liquatorum \& id genus aliis, obfcurisfimæ turbæ, quæ Cyclopum inftar nigra vultu incedit, \& ex qua nihil candidi aut ingeniofi fperari poffe putaremus : fed fcientia illorum unice eft practica, \& experientix documentisque veris innixa; in qua ratione multis fcientiis anteferri vel cum illis æquiparari meretur; omnia enim cum ipfo opere conveniunt; exinde fequitur, quod ex hac parte operis noftri luculentiores \& certiores habeantur rerum quarundam naturalium indagines, quam aliunde; præcipue fi Metallurgica fcientia cum Chymica confortium ineat, \& focias manus jun- 


\section{P R $\#$ F A T I O.}

gat, adque unam eandemque metam utraque fic tendat. Sed in ai rem ab aliquibus mihi dici prefcio, Liquationum Modos \& proceffus fuforios diverfarum regionum, qui per tam fpatiofum tempus \& diu: turnum \& plurium frculorum laborem, fudorem \& experientian exculti \& inveftigati fint, non ita leviter propalandos, \& orbi notos \& familiares reddendos effe : nulla non metallica gens eft, quæ nori fuamet arcana poffideat, qux palam facere crimen putat: funt, qui fcalas \& regulas fervant, \& in illis dimenfiones \& rationes exactisfime incifas, ad quarum normam, pariter per ungues \& pollices fuos, fo$\cos$, furnos, receptacula, præfurnia, canales fpiraculorum $\&$ follium \&c. diligenter exftruunt, qux inftrumenta, ut a fociorum oculis removeantur, in angulis recondunt, \& interea peritiores fociis fe æftimant \& jactant. Sunt etiam illis fimiles multi melioris notæ \& fortis homines, qui pari modo folis fibi fapere volunt, quique arcanorum poffeffores \& cuftodes dici amant, ut inde eruditi ab ineruditis audiant : hoc genus hominum, nihil eft, quod non invidet publico; \& fi quid in lucem prodit, ex quo incrementum capiet ars \& fcientia, obliquis oculis \& torvo vultu illud tuentur, auctoremque fortasfis ut arcanorum propalatorem carpunt: illorum gratiam captare me non poffe fcio: ipfisfima caufa eft, quod minus eruditos fe illico putent effe; quum multi fciant, quod illi fciunt. Sed ah! quantum diftat invida hæc gens a mufeo virginum doctarum, aque aris \& facris Apollinis, \& quam vilis \& dejecti animi eft \& illiberalis faciei! nullus enim fibi foli fapere debet, fed aliis totique orbi literato. Concédere etiam poffum, quod dicta gens fortaffis alicujus momenti arcana poffideat, quæ pretio quodam levi acquifiverant ab illis, ubi omnis fcientia venum proftat; unde etiam quia venalis, aliquot nummis parabilis eft: cur itaque talia publico invidenda funt? cur furripienda luci noftri ævi? quodcunque fcitu dignum eft, in commune \& medium forum

portan- 


\section{P R \& F A T I O:}

portandum eft; jus gentile hoc fvadet; officium cujusvis naturale, \& leges reipublicx orbis literati hoc jubent: nifi enim illuc omnes operam feramus, ut fcientiæ magis magisque \& artes floreant, \& ad optatam \& per omnia fæcula defideratam metam perveniant, tempore non feliciores \& fapientiores effe poterimus : talia itaque in Claffe prima publico fiftuntur, nec curo fi rumpantur ilia Codro, modo lxtentur fapientes, \& eis ufui \& emolumento \& fcientix incremento fint. Quo diutius Tellus habitatur incolis; quoque pluribus obfervatis ingenia abundant, \& quo pluribus ingeniis orbis literatus, eo fperanda funt plura \& femper nova huic arti incrementa, qualia intra $f_{x-}$ culi tempus tantummodo in Metallurgia infinita habuimus.

Quod tertiam obfervationum Claffem concernit, ex variis Autoribus in unum congefta vides Experimenta chymica, fed felectum habere volui; adducens modo illa, ģux a fide dignioribus laboratoriis prodierant; \& Alchymiftarum figmenta ficco pede pertranfivi, \& vix nifi fummis labris tangere volui, officiant latis ne frugibus berbec: Turba illa vafta farragine figmentorum incoctisque dapibus vollumina fua complent; pro luce jactant umbras, pro corpore larvas, pro factis fcenas, \&.prout Virgilius canit

Fermento atque acidis imitantur vitea forbis.

Sed quia non mihi vacavit tempus, nec copia fuit, omnia per novum ignem \& labores fub examen mittere, volui tamen aliqua proferre, quæ a famigeratioribus jactarentur: fed profpiciendum tamen eft, ne fidem nifi vifis \& exploratis habeas; \& quia non potui huc transferre omnia illa experimenta, quæ publicx lucis facta funt, præter quod indies \& quotannis multa nova veniant, inque focis laborantium excludantur; hinc cuivis integrum eft, ad quod etiam quemlibet exhortor, ut foliis chartæ nitidæ intertextis, infcribat, quicquid defideratur, \& inferendo quod omiffum eft, telam fic inceptam perficiat. 


\section{P R 死 F A T I O.}

Voluiffem etiam thẹoreticam difquifitionem cujusvis metalli fub finem \& in claffem quandam ultimam adjicere, \& per principia ab experimentis petita ufum elicere: fed inter metalla omnis generis, pariter ac inter fulphura, falia \& lapides, nexus quidam \& affinitas admodum propinqua eft, adeo ut qualitas \& textura unius non detegi ac perluftrari poffit, nifi etiam fimul alterius: invicem fe arcto admodum complexu tenent; in finu metallorum eft fulphureum quid, lapideum \& falinum, præter quod unum metallum arctacompede quafi liget alterum; unde experimenta circa unum genus facta nequaquam indagandæ indoli ejus fufficiunt, nifi etiam in opem vocentur phænomena cum alio \& affini metallo, cum fulphuribus omnis generis \&c. \&c. inftituta. Nec ad cognitionem corporum duriorum \& metallorum five in regnum fubterraneum \& minerale intromitti poffumus, nifi a principiis \& priori mundus elementaris pateat, \& nifi æther, aer, ignis, aqua \& reliqua hujus mundi elementa penitus indagata fint; adeo ut nifi elementorum natura prius deteita fit, nequicquam laborat orbis in exploranda indole ullius corporis durioris: hæc eft caufa, quod non cuivis operi adjungere potuerim applicationem theoreticam; omnia illa in unum volumen \& fafciculum transferre preftat.

Quid itaque in regno hoc fubterraneo \& minerali de ferro actum fit, ex brevi hoc indice videre licet. Agit quippe

Claffis prima de modo liquationis vene ferree Svecie communi, pag. I. de fornacibus so officinis ferrariis in Svecia p. 62. de argento nativo in ferri fodina invento $\mathrm{p} .67$. de recoctione ferri in officinis ferrariis Svecia p.72. de liquatione vena paluftris Svecia p. 105. de vena lacuftri ibidem p. IIs. de ferro Svecano Osmund p. IIg. de modo liquationis Roslagia Sveciee p..I25. de recoctione ejus in focis ferrariis Roslagive P. I33. de modis liquationum \&o recoctionum ferri Gallie P. I42. Leodii p. i48. Italia p. 149. circa Le/fo \& Palagio P. 153. Anglice p.154. Marylandiae Indie P. 162. Rus/iae \&o Siberie p. 164. Norwegie P. 168. 


\section{P R 压 F A T I O}

Silefice p. 170. Saxonice p. 171. Hercynia p. 175. Fordenbergii, Stiria do Carintbice p. 177. de modo inufitato Saltzburgi p. 184. Secundum Agricolam p. 188. tentamen cum lignis \& terra combuftibili p.igo. de induratione ferri penes Indos p. 194. de modo convertendi ferrum crudum ftatim in chalybem pasfim Svecie p. 195. Gällice p. 208. Saltzburgi p.210. Carintbice, Tirolice o Stirice p.2Ir. Secundum Agricolam p.213. ars emolliendi ferrum Secundum Dominum Reaumur p. 215. \& fundendi in formas p. 218. experimenta cum diverfi generis materiis, ut emollefcat p. 225. cum cautelis circa emollitionem p. 23r. de exfinitionibus ferri p. 239. de liquatione ferri ope menftruorum p.247. de modo albandi vel argento fimile reddendi ferrum p. 248. de ferruminationibus p. 249. de confervatione a rubigine p. 250 . de modo fecandi ferrum in contos variis in locis p. 252.

Clasfis II. De probatione vene ferrece per magnetem p. 257 . de probatione ejus in tigillo p. 260 . de probatione ejus in aurum or argentum p. 263. de modis explorandi qualitatem ferri crudi \& malleati p. 265. de notis ex fractura ferri ex Dno Reaumur p. 276, chalybis of ferricomparatio p. 278. diverfa genera vena ferri in variis locis p. 284. ferrum in terra \&o limo, vegetabilibus of animatis p. 292. de lapide bamatite of fobifto p. 295 .

Clasfis III. Limatura Martis p.30r. crocus Martis aperiens p. 303. dito adfringens $\mathrm{p} .305$. dito ad vitriarium ufum p. 307. preparatio coloris rubri Svecia of alibi p. 399. crocus Martis antimoniatus p. 316. tinctura Martis aperiens ơ Mars diaphoreticus p. 3 12. \& 316 . tinctura Martis $\mathrm{p} .323$. dito adftringens $\mathrm{p} .324$. aqua acidulas referens $\mathrm{p} .326$. flores Martis p. 329. oleum Martis p. 330. fal vel victriolum ex Marte p. 331. varia ex hematite $\mathrm{p} \cdot 336$. pondus pecificum ferrip. 340. Solutiones ferri in acidis $\mathrm{p} .342$. efferve/centice of mutationes chymica cum ferro, ejus. victriolo of vittrioli oleo p. 345. collectanea de ferro p. 360. particula of elementa ferri of ejus victrioli in fontibus of acidulis diver/is, cum cbymicis circa aquas inflitutis experimentis p. 366 . 


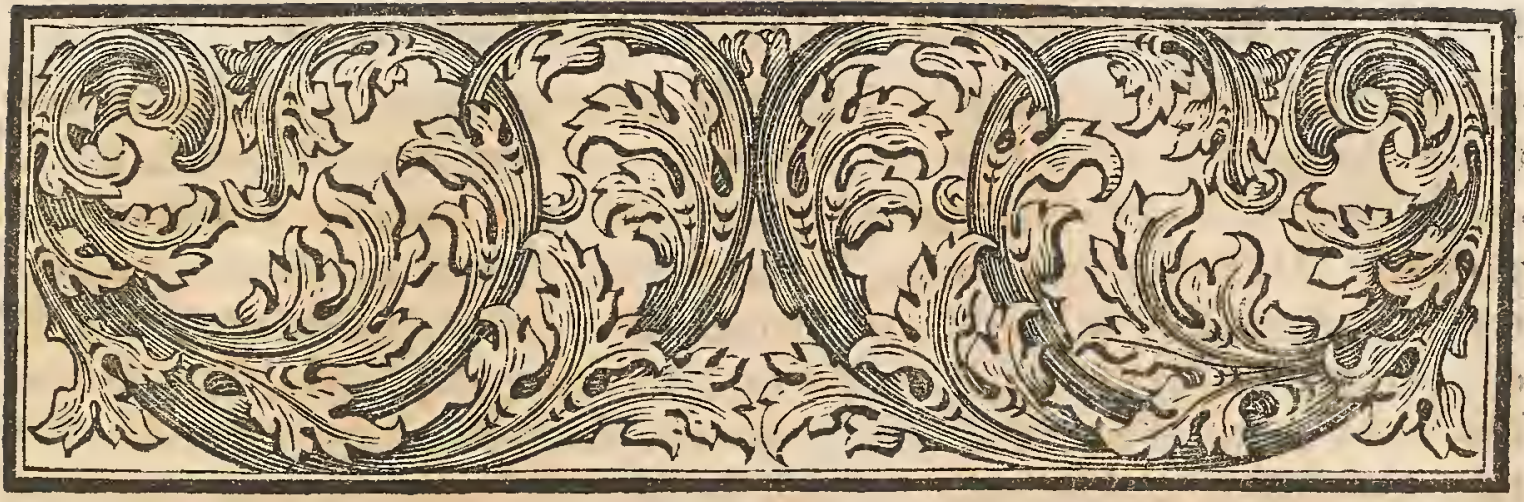

\section{CLASSIS PRIMA.}

\section{PA R A G R A P H U S PR IM A.}

\section{Modus adurendi, liquandi coquendique venam ferri plurimis in locis Svecice ufitatus.}

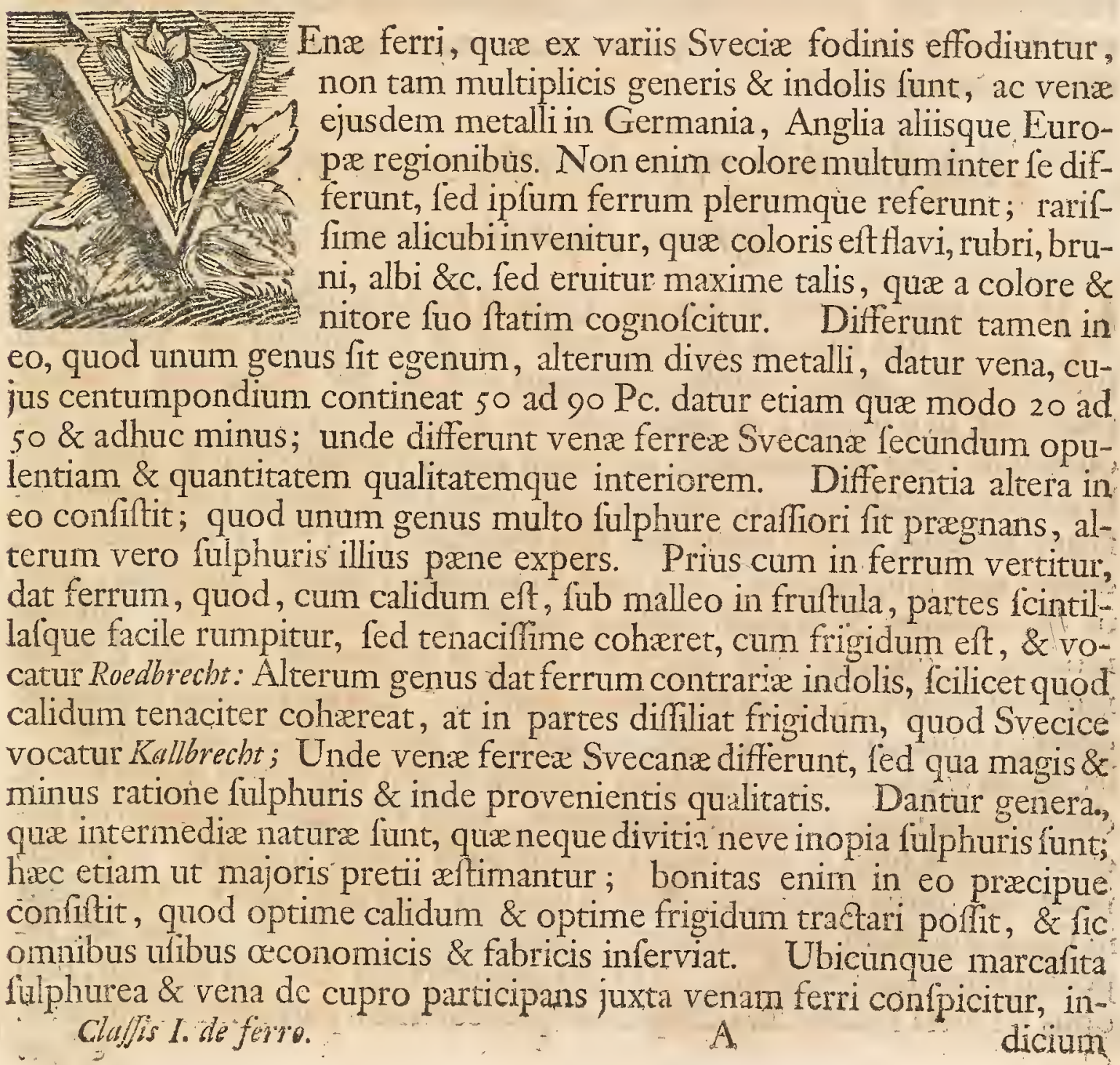


dicium ftatim eft, venam illam fulphuris effe participem, \& indolis primum memoratæ, præfertur tamen venis, quæ perparum fulphuris poffident; hre pofteriores non nifi ad certos ufus oeconomicos idonex reddi poffunt. Differunt etiam venæ ferrex Svecix ratione matricum, reperiuntur utplurimum in lapide qui corneus vocatur, in genere quodam talci, in calcario, in fpatho, in quartzio', in alius generis lapidibus multis. Differunt etiam ratione fluiditatis, dum in fornacibus fuis liquantur, fed hæc differentia utplurimum debetur lapidi inhærenti : fi enim multum calcis crudæ vel lapidis calcarii fecum fert, fluidior ftatim in foco apparet lapis ferreus, nam menftruum in finu fuo quafi recondit, fluiditatemque fibi fuppeditat; at fi fipathum fit durumque genus corneum \& talcum, difficile in fluorem redigitur, \& confequenter ægre feparatur metallum a lapidea ejus parte; aliter vero fe habet, fi minus vel plus fulphuris poffideat. Dantur etiam alix fpecies venæ ferrex, qux.non ex petra dura \& monte eruuntur, fed qux in locis paludinofis, in ftagnis, lacubus \& fluviis reperiuntur; hæ quia diverfimode tractantur, hinc defcriptionem illarum fiftam, quum de modis illas tractandi acturus fum: Communitervenæferrex Svecanæ eandem vel fimilem faciem externam præferunt, præter ultimo memoratam ; non multa colorum varietate fe diftinguunt, nifi tantum exigua, quod color ferreus, qui ei ineft, differat aliquantum ratione cœrulitatis, five quod obfcurius aut pallidius cœrulefcat; qux varietas matrici ejus five lapidi immixto, fecundum majorem vel minorem quantitatem, etiam debetur.

\section{Aduftio five proparatio vene crude ad ignem liquatorium.}

$\mathrm{Q}$ Uum lapis ferreus ex fodinis erutus ad fornaces translatus fit, non procul ab ipfa fornace comburendus eft \& ad liquationem fequentem preparandus; modus combuftionis pari ratione per totam fere Sveciam peragitur, five multo five nullo fulphure fateat vena: foffa effoditur par quantitati venæ comburendæ, vel etiam folum planum eligitur, quod vallo a tribus partibus circumdatur; nulla certa ratio dimenfionis harum foffarum habetur, dantur enim quæ profunditatis 2,3 vel 4 ulnarum fint, dantur qux longitudinis $3,6,10$ ad 20 ulnarum, pariter latitudinis, adeo it dimenfiones fecundum nullam datam normam capiantur; eligitur modo area, quam fepiunt muro vel vallis, ut dictum eft, in quam dein cutiulatim inferre \& aggerare venam poffint. Locus omnino ficcus effe debet; utque eo ficcior evadat, fubfternitur pulvis ex cumulis fcoriarum lectus, ut \& glarea venæ collapfæ; fundum tamen hunc non modo foriæ diminutæ fed etiam integræ conftituunt; ratio eft, quia recrementa illa ficcioris naturæ funt, \& quia poris copiofis quafi patent hiantque, \& lapidis inftar, qui porus appellatur, fiftulof funt, omnem inde liquorem recipiunt in feque abforbent, ficque locum fundumque ficcum \& omnis humoris fuperflui immunem reddunt. At vero ubi locus per fe ficcus offertur, non opus eft dicta recrementa dilaplarumque fcoriarum pulverem fubfternere. 
Ufque tamen majoris fecuritatis gratia, ut area hujus fovere ab humore prorfus libera fit, folum vel arte vel fponte inclinatum eligunt; inclinatio erit verfus anteriora hoc eft verfus aperturam, ut humor fiperfluus vel inde emanet, vel fic melius per ignis vim exhalet \& difcutiatur : fed folertia talis ufque a multis negligitur.

Sublternuntur dein trabes aut validiffimi arborum trunci; aptiflima huic ufui eft arbor ficca, qua per anni tempus foli expofita jacuerat; \& ex qua humor nativus vel vegetabilis jufto tempore exfudare potucrat: lignum enim humidum \& recens ignis vim minuit, \& vaporibus fuis humidis \& frigidis calorem temperat; hinc arbor his ufibus infervitura quo ficcior, folidior craffiorque, eo melior. Accumulantur ejusmodi trabes ad altitudinem $2 \mathrm{vel} 3$ ulnarum : infuper immittunt venam, \& quidem fruIta ejus grandiora proxime fuper ipfas arbores lignorumque ftruem, \& dein accumulant venam minorum partium, \& quidem ufque in pyram quadrangulam vel alius forme: alii etiam intermittunt, hoc ef, ditinguunt venas ftratim per feriem carbonum, filicet ut calor penetret melius rogum exftructum. Ultimo, quum accumulata fic vena fuerit, fuperinducitur pulvis fcoriarum mixtus cum glarea ven:e collaplie, qua circumcirca tegitur, ne pateat igni exitus, nifi in locis ubi igni exitus concedendus fit. Infuper aliquot fragmenta lapidis caicarii pyræ fuperinjiciunt, vel alibi inferunt, fcilicet ut eodem igne in calcem cremetur lapis, \& fic idoneus reddatur ufui liquefactorio; dictus lapis utiliffmus eft ad fluiditatem venis in liquationibus fubminiftrandam; eo major hujus lapidis copia re-, quiritur, quo magis expers calcis eft vena, quoque minus fluida per le apparet. Dantur etiam ven $x$, qux abundant lapide calcario, \& in quibus lapis rivulorum alborum infar \& venularum intertextarum confpicitur, ad quarum liquationem \& folutionem nullus amplior lapis requiritur, quia iplamet fufficientem fecum ejus copiam ferunt; prout vena ferri Danmorienfis five Roslagienfis, quæ fola fornacem \& ignem fine adjumento \& adjectione ullius calcis transmittitur. Submittitur dein ignis, qui accenfus per majus vel minus tempus fovetur, \& quidem fecundum quantitatem venæ \& magnitudinem pyræ per I, 2, 3 ufque per 8 dies durare folet; fed utplurimum combuftorium hoc opus intra 3 dies peragitur. Omne genus venæ ferrex in Svecia femel tantum comburi folet, antequam in fornacem liquatoriam defertur; nullibi quantum fcio, mos eft, ut vena licet. maxime fulphurata, bis aut ter igni combutorio fubjiciatur, prout alibifieri folet.

Nec opus hoc in diutius tempus quam unius feptimanæe protrahitur, vetus \& ufitata methodus femel recepta perplacet. Vena diverforum ge-' nerum, \& interdum duorum, trium aut plurium in una eademque pyraintra idem tempus concrematur; ita tamen difponuntur, ut quodlibet genus fua loca, fuafque fedes diftinctas \& toros habeat; vena magis fulphurata locum igni proximum occupat, \& remotiorem quo minus fulphuris ei ineft; Quodlibet genus dein leparatim in fornacem portatur.

Per aduftionem hanc ven:e ferrex expelluntur fulphura nociva \& fuperflua, qux in lapide ferreo latent; quum enim ignis pertat, exhalat con- 
tinuo naresque ferit fulphur, \& apparet vapor ex ftrue exhalans, tanquám unda leviffima celerrime fluctuans \& lambens fuperficiem pyræ, qui fluctuans vapor fulphureus non aliam fpeciem habet, ac flamma levis, quxe tanquam emortua ante folem meridianum æftivum undulare videtur. Per dictum ignem non modo abiguntur fulphura, fed etiam arfenica, \& nihil non quod lapidi malignum \& liquationi impedimento effe poteft. Ipfe lapis ferreæ parti intertextus \& commixtus per ignem hunc primum etiam. in calcem quandam vertitur, \& cruditate fic abacta vena ad liquationem preparatur; unde etiam vena in fractura, peracta combuftione, pallidior five pallide livida apparet: lapis enim adưftus albefcit, \& fic per omnes lapidis ferrei fibras albedo quædam diffipatur \& difpergitur, \& fic color obfcurior in pallentiorem vertitur ; perit etiam ipfe venæ nitor, quia lapidi ufto niveo nullus nitor fed metallo tantum ineft. Per combuftoriumhunc ignem metallum, hoc eft, ferrum a lapideis fuis nexibus five a cohærentia quam habet cum lapide, aliquatenus folvitur : inhæret enim metallum intime lapidi five matrici fux; hinc nifi ignis quidam calcinatorius interveniat, e vinculis illis lapideis non facile exire poteft mars \& ab involucris illis liberari. Exinde fequitur regula ubique recepta \& vulgaris, quo melius. comburitur lapis ferreus, quod eo melius dein colliquefcat \& fundatur in fornace, quodque eo magis ejus pars metallica feparari poffit a lapidea \& a fuis recrementis; quodque eo major copia venæ fornacem eodem tempore cumque eadem carbonum quantitate transmitti poffit. Lapis enim. combuftus ferreus etiam fragilior per ignem hunc redditur, inque minora frufta \& in pulverem pilis \& marculis facile contundi \& diminui poteft.

\section{Fundamentum fornacis liquatoria.}

Uod locum attinet, ubi exftruenda eft fornax, eligitur ille qui ficcus eft, quoque ficcior eo melior ; exinde fequitur, quod locus altior præferatur humiliori, \& locus qui arena conftat ei qui ex terrestri alia ma-. teria : precipue obfervatur, ne a loco altiori in fornacis fundum infinuare fe poffit aqua \& immediate lapidem fundamenti humeetare. Subquacunque fornace fovea quædam vel exigua camera paranda eft, in quam non modo derivandus \& colligendus eft liquor, fed etiam inde in liberum aera educendus, quod fit per fiftulam vel canalem ferreum, qui inde vel fub follibus vel circa anteriorem partem fornacis educitur, \& per quem continue humidum \& vapor exhalat: nifi enim humor per talem canaliculum \& evaporationem expellatur, ftagnare infra poteft, \& fundum ipfiusmet foci continue humidum tenere, \& augmenta gradusque caloris inhibere. Et quia humor inclufus admodum noxius eft operi liquatorio, hinc fovea dieta, quavis vice, quum liquatio inftituenda eft, diligenter purgatur, ne fcilicet aliquid fit, quod exitum vapori liberum impediat. Si major copia aquæe affluat, quam ut in vaporem per unum fiphonem diffipari poffit, ut fi humida nimis fit humus, quæ fundamento proxima eft, \& contiguitatem cum pariete muroque fornacis habet; fique per continuum ignem illuc aqua alliciatur, fæpe enim accidit, quod fons aquæ non procul a fornace exfiliat; 
exfliat; tunc fovea dicta non modo amplior \& profundior reddenda eft, fed ex fovex antro bini canales ferrei educendi, per quos aqua vaporofa, quum ignis per defcenfum operattr, libere \& fufficienter exfudare poffit, utque adhuc magis defendatur fundus ab humore nocivo, foffa quoque vel circa partem vel circa totam fornacem duci folet, qux aquam allabentèm recipiat, arceatque ne ipfiffimum fundum petat.

Locus fundamenti optimus \& maxime idoneus eft, qui conftat lapillis vel glarea, \& melior adhuc qui fcoriis vel vetuftis vel recentibus. Si énim fuper cumulum vetuftum recrementorum conftruere velisfornacem, ficciffimum habebis locum; omnis enim humor vel a recrementis his abforberi vel arceri videtur; recrementa enim fiftulis \& foraminulis pléna funt, \& quia compage laxiore \& rariore conftant, ab exiguo igne calefiunt, quumque foraminula \& pori calore continuo ftipantur, omnis inde aqua arcetur. Aliquorum tamen opinio eft, non ficciffimum effe debere fundum, ne faxum foci fundamentale minus refiftere valeat vehementixignis, quod etiam accidiffe aliquibus in locis dicitur; fed hoc tribuendum potius effe faxo videtur: quædam enim faxorum genera facile \& ad quemcunque ignem fluunt, quxdam refiftunt igni vehementifimo. Si vero petra vel mons in occurfum veniat, \& infuper ædificanda fit fornax, non exftruitur immediate fuper ipfiffimum durum lapidem; fed excavatur prius in monte fovea, formaturque cavea, fuper quam locandum venit faxum quoddam fundamentale, quod ideo fit, ut locus quidam cavus fit, qui aquam fecundum petram fluentem \& quafi repentem vel ex ipfiffimo monte fe proripientem recipiat, \& tranfitum meatumque det ejus exhalationi, ne fcilicet inclufus liquor lapidem continue feriat \& ftringat, \& tandem ipfiflimum focum refrigeret; refpiratio enim femper \& anima quafi danda eft aquis fubterlabentibus; natura ignis eft, ut aquam continuoo in vaporem dividat diffipetque, utque magis magisque illam invitet \& allectet: quod fortaffis ex eo fit, quia aqua primum fe infinuans per ductus latentes creafque vias labitur, quæ, cum verfus calorem venerit, in vapores difpergitur, ficque locus evacuatur; fed meatus illi vacti \& aquæ expertes effe nequeunt, quin ita continuo nexu, diffipato uno vapore, alius aliunde per dictos meatus jam apertiores factos illuc tractus vel quafi allectus fuccedat. Antequam extruitur fornax, effodienda primum eft humus ad illam ùqque profunditatem, dum obvia fiat rupis, fi nulla rupis fe obviam fiftit, fubjiciendæ funt trabes, quæ ædificium fuffulciant, non aliter ac fieri folet füb ædificiis majoribus. Sed quoniam fornaces neceffario conftruendæ fünt juxta aquan fluentem vel lapfum cujusdam torrentis, fcilicet ut rota, qua folles elever \& deprimat, circumagi poffit, hinc delectus loci non ubivis haberi poteft; unde artis \& induftrix opus eft, fundum, quemcunque fors obtulit, idoneum reddere.

Obfervatu dignum hic occurrit, quod tanta vis refrigerandi in aqua fit, ut quamvis intermedia fit lämina vel menfa ferri admodúm craffa, \& infuper arena accumulata, \& fuper arenam faxum molare pedem craffitie zequans, adeo ut aqua a foco vel ab ipfo igne divifa fit per parietem i vel 2 ulnarum, ufque tamen non impediat, ne ignis ad gradum liguationi debiturn Clafjis I. de ferro. increfcere 
increfcere \& augeri poffit; ab una parte refrigerat aqua \& igni vel calori in ipfo lapide quafi occurrit, ab altera pellit calor \& premit frigus aqux obvix, adeo ut in duriffimo corpore pugna quafi fit frigoris \& caloris; nec calor, quamdiu temperatur a frigore aquæ, debite intendi \& liquefactorius reddi poteft. Hoc etiam a multis aliis experimentis evidens eft, fcilicet, quaindiu $a b$ una corporis durioris parte frigus occurrit, quod calor $a b$ altera nequicquam valeat; temperatus calor necintenfior fortiorque redditur, quam permittit fphæra, quam ab una parte tenet \& formavit calor, ab altera frigus : nifi calor vel frigus in corpore duro, fpatiofam aream habeat, per quam gradatim ad multam ab ignis vel frigoris fonte diftantiam \& lente diminuatur, nequaquam poteft intendi; fed de his alibi melius. Sed hæc modo accidunt; fi inclufus teneatur humor, \& vapores ex igne exciti continue feriant fundum; at vero fi liber vaporibus tranfitus fit relietus, non ita lapides \& dura obvia penetrat, fed modo fuperficietenus calidus lanbit, nec calorem pertranfeuntem in via infringit enecatque.

Ailias circa fornaces has ferri liquefactorias, multa funt qux indigitant, aquam vim ignis quam maxime infringere $\&$ adimere; , ut fi tempus pluviofum fit vel humida nimis atmofphera, ftatim humidum aerem attrahunt vel imbibunt coria vel ligna follium firantia; vel etiam fivena aquxe fub iphis follium fcamnis fcaturit, aut fi aqua ibi ftagnat, fpatium illud, quod inter aquam dictam \& folles intermedium eft, ex vaporofo halitu humidum redditur, \& talis per orificia \& labra fic attrahitur aer, perque fiftulas \& nares etiam in focum emittitur : in tali cafu debilior femper vis ignis \& liquefactio animadvertitur, quam fi aer fit aridus \& ferenus, nec ulla fub follibus lcaturiens vel ftagnans reperiatur aqua: $U_{t}$ ergo aqua talis a foco arceatur, convenientifima videtur effe conftruetio fundi, ut fi fovea dicta arcu quodam ampliori muniatur, fique arcus a duabus partibus apertusfit, ut per aperturas libere tranfire poffit raqua; fique dein fuper ipfiffimum arcum rite conftruatur focus.

\section{Confructio ip fusmet fornacis five muri quo cavitas ejus circumdatur.}

Pfe murus fornacis dein, jacto fundamento, ponitur, \& quidem craffitie 1 admodum multa; effoditur, ut prius dictum eft, humus, dum rupes occurrit durumque, cui tanta moles incumbere poffit; fi nulla obvia fitrupes, fubjiciuntur trabes, quibus fundamenti loco fuffulciatur totum ædificium, \& hic fere exdem regulæ architectonicx obfervantur, qux circa ædificia majora obfervari folent., Quod ipfum murum \& parietes attinet, vel conAtruitur ille ex puro faxo grandiori, \& vulgari, quod grifeum vel grauffen vocatur, prater murum cavitati proximum, qui conftabit alio faxi genere : vel, pars hujus redificii conftruitur ex faxis; pars vero ex trabibus magne molis, qua connexx \& complicatæ domum totam amplexu quodam continent. Quod hanc pofteriorem confluctionem attinet, qux a viliore. plebe metallica in ufu receptisfima eft, quia minori protio parari poteft, en ejus defcriptionem. 
Fornacis ftoma five ædificium, quod complectitur caminum aut cavitatem interiorem, in qua peragitur liquatio, conftare folet quadruplici muro; primus eft qui proximus cavitati aut qui actioni ignis immediate expofitus: ille eft conftare debet faxo electo \&ad hunc ufum apto, quod ignis impetum \& vim posfit tuto excipere \& fine liquatione fui exceptum fovere. Alter murus ei proximus crasfitie fere primum æquans faxo vulgari grifeo paratur. Tertius ex lapillis, fcoriis pulveratis \& materiis id genus aliis conftruitur, qui non vere murus fed aggeratio rerum mifcellanearun eft, cujus ope muri iuteriores \& præmemorati crasfiores redduntur \& continentur. Ultimum ordinem conftituunt faxa \& fimul trabes vel tigna validiora, qux invicem connexa muros predictos tanquam brachiis amplectuntur. Cavitas ipla eft figuræ rotundæ, cujus defcriptionem mox tradam, pariter murus ei proximus, qui circumibit cavitatem, fecundus fervat adhuc rotunditatem fed aliqualem: fed extima parslapidibus \& tignis contexta figuræ quadratæeft, fpatium intermedium accumulatur, ut dictum eft, recrementis pulveratis \& venarum combuftarumque, fcoriarum reliquiis \& collapfis ruderibus : Figura itaque externa fornacis quadrangula eft : fed ut idea fornacis vulgari modo conftructx plenior habeatur, quilibet murus fingillation deferibendus eft.

Quod itaque murum interiorem five igni proximum, quique vocatur Kernmur five murus nuclearis, attinet; ille exactifimæ dimenfionis \& conftructionis effe debet: reliqui enim muri, qui hunc cingunt, cum cura \& induftria quidem educendi funt, fed usque major circa hunc requiritur; conftabit enim faxis electifimis five illis, qux maxime viribus igneis refiftunt, hinc delectus omnino habendus eft; fi vulgaris fit lapis, tunc ab ignis tanto volumine vel liquitur vel in partes rumpitur; unde multoties ex folo lapidum horum promifcuo ufu infortunia accidunt, adeo ut opus inchoatum extemplo vel primis diebus finire, copia carbonum nequicquam confumta, coacti fint " in ina ditione præftantiora horum faxorum genera \& ignis melius patientia effodiuntur quam in alia; omnis hujus generis lapis nomine communi vocatur $P_{\text {ipfter }}$, fcilicet lapis., qui ambit caminum five cavitatem fornacis. Eruitur \& ufurpatur diverficolor, in quibusdam locis elt grifeus cum venis virefcentibus, ubi venæ inftar linearum vel ftriarum tranfire lapidem apparent \& illum quafi fitulofum reddere. A quibusdam ad hunc ufum adhibetur lapidis fcifîlis genus, five qui mollior reliquis eft, \& cultro quafi fcindi vel ad minimum fecundum longitudinem aliqualiter dividi poffit, fed hoc genus faxi ratum eft, nam talci inftar ignis admodum patichs eft. Datur etiam aliquibus in locis faxum coloris nigricantis, fed quod paffm fterili quodam nitido corufcet, \& quod fecundum longitudinem ftrias habeat, nec apte nifi fecundum illam dividi poflit; hoc genus etiam ad naturam talci accedit, eftque ufitatifimum in Hellfingia \& alibi ; \& ab igne temporis tractu ru befcit, \& in aere dein in pulverem, pulverilapidis lateritiifmilem, fatifit. Dantur etiam alia faxorum genera his ufibus etiam aptifima; ufurpati etram poteft arenarius vel molaris lapis. Tentatum etiam aliquibus in locis ef, loco faxorum predictorum murum hunc nuclearem \& interio- 
rem ex puris recrementis ferreis parare, fcilicet ex illis, qux ultimo ex foco prodeunt vel educuntur, \& qux referta ferreis particulis nigricant; hix quia reliquis tenaciores funt ignemque liquefactorium tolerant, unde illis loco faxorum prædictorum muri memorati formari folent, fed pluribus adhuc in locis pars muri fuperior, ubi non tam violens calor effe folet. Recrementa dicta humido aeri expofita in pulverem facile collabuntur. Periculum cum recrementis his factum nec omnifucceflu caruit, expertum usque eft, virtute igni refiftendi multa admodum pollere, fed tamen accedente humore quodam, five qui ex aere fe infinuat, five qui ex pluviis ftillat, fenfim exedi \& refolvi inque pulverem fatifcere, \& caminum fic paullatim ampliari \& inutilem reddi. Murus hic, cujus defcriptio eft data, craflitiem habere debet 2 pedum circiter, \& quibusdam in locis $2 \frac{T}{2}$, quoque craffior, eo melioris \& diuturnioris ufus; educitur plerumque ad altitudinem 12 vel I4 ulnarum. Architectus operam navabit, ut faxa hunc murum conftituentia ita aptentur, ut nulla fit rima vel nullibi fpatium cavum, quod non arena mifta cum argilla diligentiflime fit oppletum; nifi lapis cum lapide bene fic conglutinatus fit, ut locus nullibi in juncturis hiet, igni ftatim datur anfa \& via per fpiramenta coca irrumpendi, \& obices fic aut repagula rara relaxandi, \& argillacea vincula folvendi, \& lapides invicem feparatos in ipfam cavitatem aut voraginem igneam excutiendi, unde operi liquatorio vis infertur, ita ut illico finienda fit liquatio. Quod alias hunc murum attinet, a reliquis facile feparari \& dirimi potelt; unde etiam quum ignis vi exefus apparet, cumque pars refidua ignem non diu fovere poteft, diruitur \& novus loco ejus exftruitur, remanentibus muris reliquis, unde illæa fornace murus hic five integre five ad partem e novo formari poteft.

Proximus ei murus conftabit-faxis grifeis vulgaribus, Grouften, nec enim neceffarium eft, ut hæc ignem tam intenfum tolerent, quia interpofito muro pradicto ab igne funt remotiora. Murus hic craffitiem aqualem priori five 2 aut $2 \frac{\mathrm{I}}{2}$ pedum habere debet, eandemque cum priori altitudinem. Saxa etiam hunc murum conftituentia arena \& argilla mixtis quam optime firmanda funt; fi enim fpatium relinquatur inoppletum; illuc calorem penetrare \& in loco vacuo augeri animadvertitur, dum tandem lapidum juncturæ utrinque caloris vi corripiantur, unde commiffuris exefis \& vinculis quafi ruptis vel relaxatis, lapides ex muro, ut prius dictum eft, folvuntur \& in focum præcipitantur, quod cum excoctor animadvertit, operi liquatorio finem imponere \& lacunas fornacis refarcire, \& vulneribus quafi opem ferre, antequam opus denuo inchoare posfit, debet.

Spatium quod extra hunc murum eft, repletur variis hine \& indecollectis materiis, fcilicet lapillis, argilla ficca, collapfarum fcoriarum \& concrematorum lapidum glarea; fi enim faxa majora undique conquifita. illuc adveherentur, \& per machinas elevarentur, five per fcalas in altum volverentur, multi operis \& laboris foret, quam fi materia ubivis obvia \& levioris pretii locus idem repleatur: Marculis \& pilis ligneis ut \& coneu- 
frone pedum coacervatio dicta comprimitur, unde etiam muri utrinque bene continentur.

Extimus murus conftat faxis majoribus ope trabium craffiorum fuffultis \& contextis; trabes dictæ validiffme funt, \& ad quemvis parietem numero Io vel I 2 circiter, qux ad extremitates fulcis incifis junctx muros predictos omnes includunt \& connectunt.

Sed fornax ferri fuloria fic conftructa non per multum temporis fpatium durare folet; omnes'enim murorum ordines \& moles interjectæa a tignis circumipofitis quamvis inter fe firmiter connexis contineri debent; fed ille licet robuftiffim:e temporis tractu tamen moli incumbenti cedunt, \& paullatim tanquam in burim incurvantur, laxanturque juncturæe angulares, quibus laxatis \& ruptis dimidia \& plurima pars fornacis corruit ; proter quod arbores quamvis matur: \&. ficcx, usque tamen aeri pluviofo \& fimul calori expofitre fenfim emarcefcunt \& putrefiunt, \& fic ponderi facile cedunt, minanturque quotidie ruinam. Ignis etiam metuendus eft, qui contignationem talem \& parietes ligneos facile corripit, \& per totam domum diffipat \& fic brevi evertit ; quod tamen fieri nequit circa fornacem, quix nullis retinaculis \& cingulis ligneis continetur, fed puro faxo conflat.

Mos etiam fuerat murum inferiorem vel pedes quadruplicis muri, qui etiam fulcra aut Pelare vocantur, lapide ligneis truncis aut tignis intertexto conftruere, fed quia ligna talia temporis injuria paullatim loco fuo emoveri comperti funt, \& fic omne fuperinftructum adificium in obliquum trahi \& rimas ducere; hinc hodie fulcra vel partes murorum infimas ex puro faxo confruere exorfi funt.

Quum muri ad altitudinem debitam educti funt, parietes nudilignei altius adhuc \& quidem ad 6 pedes circiter educuntur, eft modo contignatio vel camera quadrangula conftans vel ex afferibus vel ex tignis, vel ex lateritio lapide, vocatur Svecice MaJungskrantz five fertum aut corona fornacis, illa includitur ejus area, five locus pro vena ferrea, excoctoribus \& famulis, qui venam \& carbones fubminiftrant, \& ignem liquationemque fervant perennem : Alii vero teftudine \& opere fornicato ornant partem hanc fuperiorem, ut fcilicet famuli \& miniftri a tenpeftatibus \& pluviis co tutiores infuper poffint opus fuum peragere, relicta modo apertura immediate fuper ipium focum, per quam fumus \& volumina ignea in liberum aerem erumpant.

Quod vero crafitiem dictorum murorum attinet, ab ipla tignorum ferie ufque ad caminum vel cavitatem diftantia aut craffities eft 9 vel Io pedum; cumque cavitas lata fit 6 pedes, hinc tota amplitudo fornacis vel latitudo cujuslibet lateris ab uno angulo ad alterum eft circiter 20 ad 26 pedum.

Ipfa itaque domus fornacis eft figuræe quadrangula, \& tota conftat faxo, fed muri qui exteriora fpectant, a duabus partibus perpendiculares $\&$ integri funt; a duabus vero non integri fed rupti, \& per obliquitatem quandam verfus focum ductideorfum tendunt \& inclinant. Una obliquitas eft abilla parte, ubi follium machine funt pofite; ratio, quodinclinet hicmu-

Clatjis I. de ferro. 
rus, eft, ut fcilicet libere poffint moveri folles, perque trudes \& vectes commode deprimi \& attolli; ; fiftulix \& canales ex follibus protenfi in medium focum intromitti, \& ignis rite animari ac vento excitatus continuo foveri ; hinc nifi verfus interiora inclinet \& quafi retrahatur murus, non locus erit machinis fpiratoriis, nec vento in medium focum irrumpendi. Altera obliquitas in illo fornacis latere facta eft, ubi excoctor \& famuli ejus labores exercent, fcorias e foco rutris extrahunt, \& ferri liquamina emittunt, \& volumen ferreum immiffis contis continuo fubigunt verfantque; terminanda enim omnino eft obliquitas muri circa ipfun focum ; \& quia comminus juxta ipfum focum opus peragendum eft, hinc non aliter illuc perveniri poteft, nifi murus verfus ipfum focum oblique \& modo dicto intret.

Quod alias ipfam obliquitatem \& muri verfus interiora inclinationem. attinet, fciendum eft, quod ipfa inclinatio in media circiter fornace incipiat, \& fic verfus focum paullatim tendat : fed inclinationis anguli \& altitudines non femper iidem ubique funt, fed jam majores jam minores, hoc eft, acutiores vel obtufiores, \& confequenter terminatur obliquitas, aut, ut modo dixi, inchoatur in medix fornacis pariete vel paullulum infra; fi enim minor in refpectu ad perpendiculum datur obliquitas, altius furgere neceffum eft planum aut fupercilium hoc obliquum, \& e e majorem parietis partem occupari : at vero quo major fecundum perpendiculum eft obliquitas, five angulus obtufior, eo minus in altum furgit planum hoc inclinatum, \& minor parietis pars quafi aufertur; unde etiam quibusdam in locis minor, in aliis vero major hujus muri inclinati altitudo eft. Obfervavi angulum obliquationis hujus in quibusdam dari 40 graduum, unde etiam elevatius fit obliquitatis planum; in quibusdam vero 50 ad 60 , adeo ut inclinationes varie differant.

Præeftat, quod planum hoc obliquum non fit altum, quodque angulus fit major \& obtufior; ratio eft, quia tunc non tam multa fornacis vel parietis pars occupatur \& aufertur; inde enim attenuatur murus fornacis caminum circumdatus, hoc eft, craffities muri \& fpatium inter cavitatem \& exteriora diminuitur. Quo enim a perpendiculo magis per obliquum accedit murus verfus focum, \& ad cavitatem approximat, eo minor eft craffities muri, \& confequenter eo minus ignex vi refiftere valet, vel impedire ne ignis rimas ducat \& per continuum fluxum juncturas relaxet, Tenfimque fornacem raram, hiantem \& fatifcentem reddat; quo in cafu vis ignis omnino debilitatur \& confequenter lentius peragitur liquefactio.

Sed quia craffities murorum eft 9 circiter pedum, hinc etiam tota obliquatio, vel bafis aut horizontale obliquationis planum æquabit 9 vel ro pedes; \& quia conftructa eft maxima pars ædificii a faxis, ne itaque per inclinationem talem corruat, vel pars hxc. obliqua \& imminens labatur, fupponuntur validiffima fulcimina ex ferro, quæ muro utrinque inferta fuftinent pondus fuperinjectum: ferrea hæc fulcra variæ longitudinis funt, prout fupra vel infra in muro aptantur, funt ad I 2 \& I 7 pedum \& craffitie $\mathrm{r}$, funtque forma triangulari; a quibusdam plures, a quibusdam pauciores fubjiciuntur; quo plures, eo validius. Hujus generis trabes ferreas vidi 
numero 3 ad 9 vel I4, quibus murus fuperimminens incubuit, unde nulla ruina potuit timeri. Quo plura fulcra fubfternuntur, eo major obliquitas \& minor plani obliqui altitudo effe poteft; nam ferreis his roboribus optime fuffulciri poffunt. Vidi tamen fulcimina vel tigna ex ferro fufo conftantia ex pondere incumbenti incurvata, interdum ctiam quum ferrum indolis fragilioris fuerit, rupta. Aliquibus in locis, fed modo ubi pauperes lares funt, plana hec inclinantia tignis arboreis fuffulciuntur; fed præter quod facile ponderi fuperincumbentis muricedant, ex flamma, quxe continue ex foco eructatur \& verfus fuperiora \&laqueare pervolvitur, concipiunt ignem, ficque fulcris confumtis corruit tota domus \& machina.

Sed quia ex nuda defcriptione cujusdam xdificii nequicquan idea fatis evidens conftructionis haberi potef, hinc velim delineationem ejus aliqualem fiftere. $A B C$ Tab. I eft cavitas five caminus ipfius fornacis, in quem carbones \& venæ injiciuntur, frve in quo liquatio peragitur. DMMD eft murus intimus five cavitati proximus, qui Kern-mur vel murus nuclearis vocatur. EE eft murus ei proximus conftans faxis vulgaribus grifeis, vel Svecice Granfen appellatis. FFFF eft locus inter muros, qui repletur glarea fcoriarum, lapillis \& aliis id genus materiis. GGGeft murus extimus, quo tanquam parietibus includuntur reliqui, \& ne divaricentur, continentur, quique precipue trabibus \& faxis conftat. HH eft concameratio vel contignatio fuperior. $P$ eft fulcrum, quod Pelare vocatur, quod ignificat columnam. II eft fundamentum quod faxis conftat. QQ eft obliquitas unius lateris, five quxe eft fupra folles; fimilis obliquitas vel paries laqueatus alter eft, ubi excoctor cum famulis opus liquatorium exercet, latus hoc vocatur Svecice Broeftet frve pectus: fulcimina, quibus fuftinetur laqueare hoc, non nifi tria hic apparent. K oft fovea, in quam humor paullatim fe infinuat. L lamina quedam ferrea fupra foveam $K$ repofita. $N$ arena infuper accumulata. $M$ faxumfocifundamentale. C focus, in quo colligitur ferrum liquatum, \& ibi fecundum regulas lequentes coquitur. OOO eft locus fupra focum, qui quavis liquefactionis vice vel amplior vel arctior redditur, \& ita formatur, ut circumcirca verfus focum inclinet, \& vena liquefacta per planum quoddam inclinatum in ipfiffimum focum feratur, vocaturSvecice of foerfelle five focus fuperior; ad altitudinem illam nufquam tamen pervenit liquamen, ut parietes hujus contingat.

Olim fimplicioris confructionis fornaces fuerant; nec enim dimenflo quxdam exacta cavitatis obfervata fuit, nec muri modo predicto aptati, nec tanta eis fuit craflities neve altitudo; ted xdificium totum rude $\dot{z}$ exiguum retulit plane conftructionem ab Agricola antiquifque aliis defcriptam : minus etiam ferri indies obtinuerunt, confumta majore carbonum quantitate; poftea vero quum fingulo die, perftante liquatione, tributum quoddam certum regi præftandum effet, 'majoris lucri \& emolumentigram tia, ampliores facti funt camini, folidiores parietes, \& altiores fornaces, focufque capacior \& dimenfionis exactioris. 


\section{Structura camini five cavitatis, quo mediam fornacem pertranfit.}

CIrca formationem cavitatis fornacis, five camini, multa exactitudo requiritur; inibi enim ignis eft, \& vires fuas in venam cxercet, \& liquefactio ipfamet peragitur; nifi jufta detur cavitati huic dimenfio, fcilicet debita amplitudo in loco ejus fuperiori, medio \& inferiori, incaffum laborant magiftri; notum enim eft, quod vires ignex augeantur vel diminuantur fecundum quantitatem five fecundum fpatium quod occupat volumen igneum; quo majus fpatium, quod ab igne repletur, five quo major quantitas ignis, eo major ejus vis \& effectus; in candelæ flamma non tantus ineft calor, quantus in frue lignea aut rogo accenfo, \& fic confequenter: Quum ergo ignis gradus in quantitate eft, fequitur inde, quod ipfa figura camini, in quo tenetur volumen ignis, multum contribuat ad liquefactionis operam; ubi cavitas eft major \& amplior, ibi vires etiam ignis auctiores \& liquefactio fortior. Quumitaque vena in caminumimmilla non fubito in liquorem folvenda fit, fed primum calefieri \& quafi torreri, dein per gradus ignefcere, tum dein candefieri \& ultimo fundi debeat, unde arte \& induftria opus eft, ut omnia hec per gradus fuccedant. Ex continua ignis actione parietes etiam magis \& magis calefiunt \& ignefcunt, unde vis accedit igni ex parietibus folis intenfiffima.

Ex plebe metallica, qux ab experientia tantum regulas fuas didicerat, \& cum multis tam periculis quam damnis edoeta eft, que conftructio alteri fit preferenda; aliqui caminum hunc vel cavitatem aretiorem reddi debere ftatuunt in parte fuperiore, \& ampliorem in inferiore, fed ampliffimum in medio; aliqui vero arctiorem illum in inferiore quam in fuperiore. Differunt etiam circa juftam amplitudinis dimenfionem, de qua melius infra. Sed quod amplitudinem attinet, quam ventrem vocant, quia ventris figuram refert, omnes in eo conveniunt, ut in medio amplior fit, \& arctior utrinque tam fupra quam infra; fed ufque adhuc differunt in eo, quod amplitudo vel plane in medio fic, vel verfus fuperiora vel verfus inferiora propius; fed nefciunt oriri talem differentiam ab ipha venarum indole; aliam figuram vel amplitudinis fitum requirit vena fìlphure prægnans, aliam fulphuris inops; aliam qux facile folvitur; aliam qua ignis multi patiens eft, antequam metallum a lapide ei inhærenti feparari pofite: quumque caufam hanc ignorant, preferunt cœec unam figuram alteri, \& fic cum ipfa experientia hallucinantur. Conticere nec poffum, quod ipfi excoctores nullam operam navent, quomodo conitruenda rite fit fornacis cavitas, fed tantummodo quomodo focus. Quumitaque ignis in foco fit inftar fcatebræ, ex qua calor \& vis ignea verfus fuperiora erumpit, \& totum volumen igneum in camino contentum animat; hinc nifi fciant utriufque rationem, \& focum cavitati analogum reddere, \& contra, fruftrafperatur fucceffus operis liquatorii.

Sciendum primo eft, quod ante 50 vel 100 annos in Svecia camini humiliores \& quadranguli in ufu fuerint, prorfus ut adhuc in quibusdam 
locis Germanix ut \& Sveciæ; quidam enim morem antiquum \& patrum: tanquam fanctum hodie fervant; fed ut animadverterint, liquationem melius in rotundis fpatiis quam in quadratis peragi, hinc figura rotunda fere ubique recepta \& quadrangulx prælata eft ; unde etiam raro hodie vifuntur camini, qui non a fummo ad imum integre rotundati fint.

Quomodo vero formetur hæc cavitas rotunda, ex delineatione videbis; parant fibi lcalam gradibus diftinctam fimilem Figuræ HHHI, Tab. II, qux fecundum figuram \& dimenfionem, quam impertiri volunt camino, in curvaturam flectitur. Locatur in medio five in ipfa linea centrali fornacis; pars ejus infima infpicata \& preferrata infiftit faxo fundamentali CD; pars ejus fuperior alligata eft arbori cuidam exinde porrecto, vel jugo aut perticx longiori; unde BIID reprefentat axem, circum quem volubilis \& verfatilis eft fcala, \& ad omnes muri interioris partes facile agi poteft, perque converfionem peripheriam \& figuram camini debitam defcribere. Cum itaque educitur murus cavitati proximus aut nuclearis, ut appellacur, circumducitur jugiter fcala $\mathrm{HHH}$, \& fecundum illam formatur plane; nec inde eximitur, quam cum murus ab imo pede ad marginem ufque fit fubductus.

Quod vero rationem attinet, quam habere debet fcala five ipfamet cavitas, qux fecundum fcalæ ductum \& rotationem formatur, varia qui ${ }^{*}$ dem effe folet; adeo ut fi latitudo fumma, qux in ventre effe folet, xquet 4 partes, tales 3 habebit pars fuperior, 4 venter \& 2 inferior; adeo ut ratio diametri, vel quod codem recidit, circumferentiæe erit ut $3,4,2$. USque tamen nihil refert, fi pars ima amplior adhuc reddatur \& $x$ qualis fuperiori, quia nihilominus muro quodam novo inducenda \& coarctanda eft fcilicet ut focus cum cavitate fuperiore apte conjungatur, \& paullatim five oblique verfus inferiora decrelcat. Plurima pars caminorum, quos luffrare mihi contigit, fupra vel circa orificium, latitudinem 8 vel 9 ulnarum, circa ventrem io ad $\mathrm{I} 2$, infra vero $6 \frac{\mathrm{x}}{2}$ ad 7 , in circumferentia habucrat: Dantur etiam minores five caminuli, qui nec tantarn aperturam, nec alvum tam latam poflident.

Ut melius conftet, qux ratio fit convenientifima, \& qüx dimenfio amplitudinumalteri proferenda, rationes petere non volui ex priori \& praceptis geometricis, fed ex pofteriori five ab experimentis. Judicia, qux ferunt periti hujus artis, mera funt experimenta \& ex qüotidiano opere petita, unde nude rationes ex ore plebis metallicx deductas huc afferre volo; hujus enim loci \& partis non eft conclufiones \& regulas inde formare.

Quoditaque primum attinet, ventrem five mediam cavitatem \& ejus amplitudinem, quæ circumferentix effe folet to ad i 2 ulnarum Svecicarum, in confiderationem venit I. Si venter nimis amplus \& diftinctus fit; tum repentina admodum exiftit partium mineralium folutio \& potius difruptio \& dilaceratio quam feparatio debita : fatim enim ut illuc venic lapis, liquitur \& guttatim inde in focum defluit; maximus ibi eft calor \& quafi centrum voluminis ignei, intenditur enim non modo ab igne, qui ex foco furfum quafi fpirat, led etiam ab igne qui fupra premit; at precipue ab ipfo tuo volumine amplifimo; quo enim major amplitudo vel quo classis I. de ferro. 
majus volumen igneum, aut quo capacior gurges igne repletur, eo intenfior caloris gradus \& violentior quafiorcus. Qum iraque vene jumdum candefact in barathrum \& voraginem illam merfantur, difcerpte fatim defluunt, \& confequenter crudx adhuc \& a partelapidea \& alia noxiore infeparatx focum iptum \& ferri liquamen contaminant; unde pars mula ferri lentefcit, inque fcorias \& freces vertitur, ficque labor \& pes nulta perit; iplum etiam ferrum adhuc quafi immaturum \& crudum exit, calor etiam focalis partim reftinguitur \& reprimitur, \& confequenter liquatio agrius \& pigrius peragitur : unde periti excoctores non amant alvum hanc fornacis amplam, quia alimenta fumta, ut dicum eft, non debite folvere \& digerere poteft.

Alia adhuc caufa eft, cur uterina pars cavitatis, qux venter vocatur, non amplifima reddi debeat, quam etian cum multo fudore \& labore edocti funt excoctores : quum latiffima in medio eft cavitas, non aliter fieri poteft, quam û́ pars ejus inferior verfus focum lit juto obliquior ; focus enim non nifi $1 \frac{1}{2}$ pedis latitudinem circiter æquat, \& paries unus foci in linea fornacis centrali fitus eft; ventris vero diameter eft 4 fere pedum, hinc multre admodum obliquitatis erit murus inter focum \& ventrem medius aut contiguus; adeo ut vena liquefacta in ipfum obliquum parietis planum onnis fere decidat; Fon eft, ut a pariete primum excipiatur, quam verfus focum inde deferri, \& quafi fecundum obliquitatem dictam glifiare poffit. (Multam obliquitatem voco illam, quim multum obliquatur \& difcedit murus a linea perpendiculari, non vero ab horizontali, quod notandum eft.) Ferrum femel liquatum fic facile congelefcit aut denfatur, hoc eft, fluiditatis fux primx motum \& indolem amittit; fi itaque pariete iimis obliquo, (in refpectu ad perpendiculum) tanquam thalano quodam exceptum ferrum liquidum aliquatenus retardetur, lentefcit \& in pariete hæret, ficque vilci \& glutinis inftar pender, nec in focum ftillat, nil tanta. liquaminis ferrei copia fit, ut pondere fuo nutans tanquam a devexo quodam clivo, fponte delabi poflit; exinde fequitur, quod ferrum reliquismetallis lentius \& frigidius in focum liquamine ferri fuiditimo \& calidifimo repletum defluens caulam extemplo luctre cuidam prebeat; exfultat illico tanquam aqua fervida in ahenis, ejectanturque fpumæ nigricantes \& fuctus. in cufpides \& acumina terminati, intumet valde volumen, \& fuper ipfus foci margines xftuat \& expanditur, non aliter ac aqua fervida in cortinis; nigris frecibus orificium ventilatorium oppletur; recrementa ex foco detracta fufci admodum \& ferruginei coloris funt, \& multo marte referta. Fiftus hic \& luctatio ftato tempore redire folet, non aliter ac febris frigi$\mathrm{da}$, ftatim enim ut tanta ferri moles in pariete collecta eft, ut verfus focum pondere fuo nutet, redit memoratus frigidus fervor: nifi excoctor fciat tunc fluctus hos compefcere, filicet recrementa ex foco detrahere, intris \& batillis uncis turgidum volumen continue agitare \& fubigere, \& freces circa aperturam venti confolidatas conto aut pertica difcutere, \& fluctuantis foci luperficiem defpumare, tunc lenta quadam tenacique materia oppleretur focus \& obftiparentur orificia, \& labor omnis operaque eluderetur fpefque inanis redderetur. 
Preter allatas rationes etiam occurrit alia, quam etiam notam expe-? rientia fecit. Ventus qui furfum per totum caminum fubvolvitur, parietes radit \& per fpiralem fluxum verfus ipfam aperturam enititur, \& ficjuxta margines evolat; fi pars hæc media cavitatis lata fir, \& a linea perpendiculari nimis obliquata, in latus hoc obliquam vel obvium impellit ventus, qui in medio.fuo curfu repercufus vel refilit vel aliunde deflectitur, \& fic tortudo fed xquali fumine verlus fuperioravolvitur. Cum ergoventus in unam partem mur filicet exfantem continue agat, non aliter fit quam ut pars illa per continuamignis \& venti actionem paullatim licuatur, \& quali exefa \& corrofa magis magifque cavetur; \& fic murus igni proximus in illo loco non modo attenuatur, fed etiam inæqualis \& diffilis inde exiftit liquationis opera, \& in loco cavo colligitur multa pars ferri liquati \& defluxi, \& quafi fupercilium quoddan clivof tramitis formatur, ibique lentefcit, \& ferrum fic tenax factum frigide in focum calidifimum ruit; preter quod murus finita operatione refarciendus fit. Hac funt vicia \& detrimenta, qux ex latitudine nimia ventris vel medix cavitatis profluunt.

Situs eciam ventris aptiflmus in fornace erit infra medietatem ejus. Obfervandum enim eft, quodvena in caminum hunc immifla omnes caloris gradus pertranfire debeat, antequam in ignem vere liquatorium intromitcitur; hinc quum pars fuperior camini parictibus fere parallelis ad altitudinem aliqualem confltit, in fuprema parte calefit lapis, dein magis magifque \& per gradus ignefcit, tum candefcit, \& tandem in ipla cavitate maxima \& in fpecu illa tanquam averni folvitur, \& unda aut imbris inftar in focum depluit; nifi amplitudo illa maxima fit lub ipla medictate, totignes non fubire poterit vena, quot ad juftam liquationen \& feparationem defiderantur, unde locus ei defignatur aptiffinus fub media cavitatis cruce.

Sed cavendum eft, ne maxima latitudo propius ad focunaccedat, inde enim exifit obliquatio illa periculofa najor, cujus mentio prius facta eft, \& planum quoddam cavum \& depreflum, in quo harebit ferrum \& plurimum coacervabitur, antequam inde in focum derivetur.

At vero fi amplitudo dicta fit fupra mediam cavitatis lineam, tunc ad fummum caloris gradum jufto citius illabitur vena, nec per incrementa jufta, prius preparata illuc tandem pervenit, in guttas \& pluviam quandam diflolvitur, antequam inde craffiora \& maligna fulphura diffpatalint:

Quod vero fuperiorem fornacis partem attinet, per. quan paullatim \& temporis quadam mora fubfidet vena, antequam in voracen illam alvum, qux omnia difcerpit, mergitur; illa fecundum regulas parictibus invicem parallelis ad aliqualem delapfum a fummo aperturx margine conftabit; muri inde paulifper recedent, \& per obliquitatem \& divaricationem quandam diducti in loco prius defignato formabunt amplitudinem maximam. Oblervanda etiam circa hanc five fuperiorem camini partem funt: I. Quum paralleli funt parietes, quod ignis gradatim augeatur, quodque minimus fic juxta aperturam \& antri orificium, quod dein increficat magis \& magis; ignis enim tam fupra quam infra operari incipit, $\&$ in venam lente defuentem agit; carbones etiam ignefcunt magis \& candidio- 
candidiores fiunt; unde calor momentis \& augmentis juftis intra parietes parallelos crefcit, \& confequenter vena per gradus calore imbuitur, difcuffis \& abactis interea heterogeneis, fic tandem preparata folvitur. At vero fi ftatim ab ipfa apertura difcedant \& oblique removeantur muri, in prima via funditur \& in guttas refolvitur lapis inhærente adhuc fulphure. 2. Confideranda etiam venit indoles ipfiusmet ven:e, fi fulphure nimio craffiori fcatet, tunc pars fuperior cavitatis cum parallelis parietibus longius defcendet, quam fi vena fulphure careat: fulphurata pars non nifi per. ignem, quem calcinatorium vel aduftorium vocant, expellitur, nifi adufta prius vena per varias quafi regiones \& temperies caloris ad locum diffolutionis defcendat, vix pars illa fulphurea \& maligna ejicitur, fed cumferro: unita totum ejus volumen confpurcat: hinc quo altior paries aut caminus diutius parallelus, eo melius abiguntur heterogenea fulphurea \&: phlogifton crafius.

Quod alias ipfam aperturam vel introitum ad cavernam fornacis attinet, illa ab aliis amplior, ab aliis vero anguftior redditur: in quibusdam, locis xquat diameter ejus non nifi 3 pedes, in quibusdam vero 6 ; fi anguftx nimis fint fauces, que ad alvum ducunt, eo minor vis ignis \& debilior ejus actio in venas; ventus in ipfa cavitate preclufus non tam feftine evolat, \& prunas fuperficiebus fuis \& favillis fpoliat, \& candorem. eis inducit; unde minoris ignis gratia opus fuforium lente peragitur. Si vero orificium hoc aut hiatus nimis panditur, tunc ventus, qui eft liquefactionis anima, in liberum aerem per os apertiffimum jufto citius exhalat, \& fine debita in venas actione evolat; exinde fequitur, quod ex multa latitudine orificii carbones accenfi nimio calore fine debita in venas efficacia refolvantur; quodque ferrum nimis cito liquidum factum fccum ferat $\&$ - in finu recondat fcorias, quibus liberari in foco necquicquam poteft; ibi enim fruftra excoquitur vitium \& inutilis bumor. unde medio ibis tutifimus, ut filicet apertura nec lata nec angufta nimis fit.

Quum aliquoties in una fornace liquationes fiunt, temporis fuccesfu fponte fua dilatari videmus dictas aperturas; ampliatam vidi diametrum ejus circiter ad unum pedem, ut \& figuram orificii rotundam in ovalem converfam, quod partim ex continuo ignis fluxu fuboriri potuit; lambit enim \& continue terit flamma \& ventus, unde etiam parietes fuperiores vitri \& marmoris inftar politi apparent; partim etiam ex vento, qui copiofe in tantum ignis barathrum per fiftulas follium intrufus in mimenfum dilatatur, \& fic dilatatus parietes præcipue fuperiores diftendit \& rumpit. Ipfa etiam apertura fuperior ampliatur facile, fi modo murus extimus aliquantifper fatifcat; ut fi trabes, quibus continetur, in curvaturam quandam flectantur, vel loco aliquantifper removeantur, ftatim locus relinquitur muris interioribus a centro five cavitate fua recedendi, quod co facilius fit, fi etiam ignis \& ventus cavitati inclufus valide impellat.

Quod autem partem inferiorem five foco proximam attinet, non multum refert, fi illa vel amplior vel anguftior fit; contrahendus enim nihileminus eft, \& novo murulo, qui focus fuperior vel offwerfelle vocas 
tur, de quo melius infra, obducendus, \& fic aretior \& contiguus reddendus cum foco \& ventre. Hinc fi principio formationis vel lata vel angufta fit pars illa, nihil refert, modo obfervetur illa dimenfio, ut murus cavitati proximus ab ima fui parte ad fupremam feu tota ejus compages non multum a centro gravium recedat, quin una pars alteri rite \& fecundum regulas incumbat.

\section{Fundamentum ipjius foci.}

D cavea fub fundamento foci aut fornacis effolfa, prius aliqualiter dictum eft; in foveam illam colligitur omnis humor \& fenfim furtimque irreptat; per cœecos enim meatus verfus ipfum calorem, tanquam allectus, facili vena fe infinuat; talis collectus humor in vapores difpanditur \& per fiftulas canalium furfum expellitur. Fovea dicta longitudinem, quam iple focus, habere folet, altitudinem non nifi palmx aut pugni, led latitudinem pedis, quo humidior locus eo amplior erit; amplitudo eft media, fi in cuniculum hunc brachium immitti poffit, \& recrementa, fi qux fint, extrahi; locus enim hic cavus quavis liquationis vice ab omni fedimento \& illuvie craffiore purgari debet, \& eximendum quicquid evaporationi remoræ effe poffit. Solum hujus cuniculi verfus anteriora declive effe debet, five ad ora aut capita canalium inde exeuntium, per quos humor vaporofus exhalabit. Cella hæc circummunitur lapide aut lcoriis electis, qualiter reprefentatur per Z Tab. I. Tegitur infuper menía aut bractea craffiore ferrea, quæ formæ quadratæe eft, lateris $2 \frac{1}{2}$ pedum, craffitiei 4 vel 5 pollicum, \& ponderis 800 fere librarum five 2 pondo nauticorum. Ferrum hoc undiquaque circumlinitur argilla, ne ullibi rima pateat aut commiffura, per quam vapor in arenam fuperiorem clandeftine fe recipiat. Aliqui loco ferri eligunt faxum etiam quadratum \& craffum, quo foveam dictam operiunt, commiffuris luto optime confolidatis. Infuper ruunt arenam, \& illam circumcirca ad omnes partes \& angulos fternunt; ut filicet eo minus pateat vapori exitus, nifi per fiphonem ex caverna dieta prodeuntem; fuper clivum hunc arenarium adxequatum, qui altitudinis $\frac{1}{2}$ vel $\frac{3}{4}$ pedis folet effe, collocant faxum grandius ex ipfo monte excifum aut effractum, \& litera $\mathbf{E}$ defignatum : fundamentale hoc foci faxum craflitiem $\frac{3}{4}$ vel I pedis requabit, \& formam vel quadratam vel aliam habebit, quamcunque eis fors impreffit, longitudinis aut latitudinis 5 pedum, fcilicet ut integre occupet \& impleat fundum, cui foci parietes infiftent. Genus lapidis ad hunc ufum eligitur vel arenarium vel etiam calcarium, vel aliud, quod ignem vel volumen ferri liquidum per plures leptimanas illæfum pati valeat. Ineptum foco eft faxum recenter ex monte effractum, quia uvidum eft, \& in intimis fibris aquam recondit, qux premente igne non aliunde nifi per ipfum ferri candentis volumen erumpere nititur, \& confequenter calorem reprimit, \& frigido quodam vapore fluiditatem ferri fiftere conatur, \& fic torporem foco ingratum inducit. Illum in finem faxa hujus generis xftui folari per tempus exponenda funt, ut humor latens paullatim exludet; vel etiam terga aut latera ejus igni focali obverClatfis I. de ferro. 
renda funt; docuit experientia, quod faxa hujus generis majora, ufibus his deftinata, inelius arefcant; fijuxta focum quendam, fed ad aliqualem diftantiam diu \& per integri anni tempus teneantur; repentina ficcatio partes humidas non expellit, fed in arctum \& quafi in carcerem cogit, e quo erumpunt, ut primum urget violentus calor; quodinterdum tanta cumvi fieri folet, ut ipfa faxi compages fimul in partes difirumpatur.

Circa omnia latera hujus faxi fundamentalis accumulatur arena mixta cum argilla, qux mixtura accedente igne valide incruftatur \& confolidatur: omnes juncturæ limo fic forinfecus oblinienda funt, ne humor per fpiracula, meatufque hiulcos \& cuniculos patulos in ipfum volumen féri fortaflis fe proripiat. Experiuntur quotidie hujus artis magiftri, quod minimus humor faxis inclufus, vel clandeftine in arenam receptus, plus damni adferat liquori ferreo in foco contento, quam fi flumen aqux ad imum $\mathrm{h}$ xi aut laminx ferrex latus continuo impelleret. Ima pars ferrivel lapidis calefacta repellit vapores, fed vapor inclufus non aliunde exitum quarit, quam verfus ipfum ignem five ubi calor eft intenfifimus : ubi enim ignis eft maximus, ibi etiam patentiores funt pori, in quos fe infiniuat humor, fortaffis etiam textura ductuium illa eft, ut contraria via nullatenus ferri poffit, hinc quia humor inclufus multum nox: infert volumini ferreo focali $\&$ ipfe liquationis operi, cavetur quam fedulo, ne pateat ullibi vaporibus via verlus interiora, \& multo minus vertus ipfa foci penetralia.

\section{Focus E ejus conftructio.}

Super dictum faxum fundamentale eriguntur tres ejusdem generis lapides, tales filicet, qui igni non cedunt; hi fpatium figuræ oblongæa tribus partibus includunt; fpatium hoc eft ipfifimus focus, qui Svecice vocatur Stelle. Bini fecundum longitudinem erecti vocantur Stelftenar five lapides laterales, unus vero fecundum latitudinem claudit latus transverlale : his tribus ita locatis circumcirca funditur \& tumulatur arena, quæ juncturas \& aperturas omnes fipet; \& adhuc magis, cum dicta arena.in vi-. trum abit urgente calore vehementiffmo, tunc nullis non rimis fe applicat; \&.imam partem cum faxo fundamentali tanquam glutinis cujusdam auxilio conjungit \& fixat, \& focum reddit ubique contiguum, adeo utunda ferrea nullibi extra focum elabi, nec humor ex arena, fi forte madefacta fuerit, tam facile in focum fe proripere poffit. Præterea accumulaturarena, qua oppletur locus inter focum \& murum fornacis intermedius, ne fcilicet quicquam inane fit; neve paries ex incumbentis voluminis ferrei pondere e loco fuo moveatur, \& confequenter rimas ducat, \& fatifcat. Lapides laterales longitudinem \& craflitiem $\frac{x}{2}$ pedis habere folent; erunt vel ex genere arenario vel ex fciffli, vel etiam ex calcario, modo ignis violèntia non domari polfint. Iple focus eft figur: oblongx, longus 3 ad $3 \frac{\mathrm{t}}{2}$ pedes, latus $I_{\frac{1}{2}}$ ad I $\frac{3}{4}$, altus $\frac{3}{4}$, capax 6 vel 7 pondo nanticorum five $3600 \mathrm{Hb}$.

Summa excoctoris ars \& peritia confintit in jufta formatione \& dimenfione foci; nifi debitam \& mutuam inter fe rationem altitudo ejus \& latitudo $\&$ vice verfa fortiatur, nullus in operatione fuforia fucceffus, nec 
ullum lucrum fperari poteft; hinc etiam magiftri hujus artis fcalas vel ftipites ad unguem fectos fervant, quibus dimenfiones dietx incifie \& in fculptæ funt, ad quarum incifuras latera \& omnes parietum rationes exa-* Ciffime aptant; fi obliquitates quædam vel orificiis vel parietibus dandæ funt, metiuntur illas per digitos vel palmas fuppofitas, per aquam fluentem, perque artificia alia viliora \& vulgaria. Focus eft tanquam calor vitalis vel cordis locus, ventus \& orificia fpiritalia repræfentare poffunt pulmones \& animiam; minima in foco labes vel minimus morbus per totum caminum five in integro corpore illico fentitur; ægrotat ftatim totum liquefactionis opus, cum ægrotar quafi focus, nec ulla folutio partium metallicarum five digeftio alimentorum debita fuficitur; caminus five ejus alvus non plus recipit, quam admittere vult focus. Exinde fequitur, fi per latentes meatus in foci fundum infinuat fe vapor, quod illico lentius fiat liquamen ferri in foco, \& confequenter lentior liquaminis dieti co,ctio aut digeftio, nec calor ejus vitalis fufficit, ut volumen ferri magnum teneatur fluidum, utque lapidea a metallicis debite fecernantur; unde talis focus multam venæe copiam refpuit.

Quod ergo amplitudinen velcapacitatem minorem majoremque foci attinet, ex predictis videretur confequi, capaciorem focum plus caloris fovere \& fufficere poffe, \& fluidius tenere volumen ferri; quam focum minoris fpatii. Fornaces veterum fed jam antiquatæ minores hodiernis fuerant, \& foci illarum non nifi 2 pondo nauticorum capaces; unde etiam nec nifí tertiam ferri liquati partem per diem fuppeditarunt, quam hodie: ratio eft, quia ex parietibus faxeis, qui tam anguftum fpatium includunt, frigidum quid jugiter exfpirat, quod ferri volumen eo facilius pervadit \& penetrat, quo minus \& tenuius eft; eique non modo torporem quendam inducit, fed ita refrigerat, ut fundo \& parietibus inhærefcat ferrum tenax \& pars recrementorum indurata, qux cum inde excuti non poteft, adhuc magis anguftatur \& coarctatur foci fpatium; dum tandem volumen totum tenacefcat, \& lentum liquamen occupet \& plane precludat focum: cumque tale frigus ipfum cor pervaferit, nulla amplius fupereft vita, fed liquationis opus exftinguitur: hinc meliores videntur effe foci capaces; dantur etiam qui ro ad 12 pondo nautica liquaminis ferri capere poffint, fcilicet ubi tormenta majora bellica funduntur, ibi enim tantum ferri in foco colligendum eft, quantum requiric moles tormenti; fed ibi plerumque funt fornaces duplicatæ, \& fimiliter foci bini, unus fcilicet prope alterum, tanquami jugales; - liquamen enim in utrisque focis collectum ad conflationem unius tormenti fimul emittendum eft. Hocideo volui adducere, ut notum fit, focos etiam ampliffimos dari, qui duplam quantitatem liquaminis continere poffint. Sed de emolumentis \& damnis, qux ex ampliatis his focis proveniunt, videbis alias.

Sed fi fpes incrementi \& fucceffus liquationis confiftat in foci dímenfione \& in fpatio ejus capaciori vel majori, facile ei dari potuifet figura, qux capacifima effet, \& plurimum fpatii includeret, ut fcilicet rotunda; ovalis aut quadrata; primo quidem intuitu ex predictis videretur felicior tunc ftatus tam in foco quan ubique in camino; fed nihilominus 
nullam aliam figuram admittere volunt periti coetores, quam oblongam, fcilicet ut longitudo fit dupla latitudinis, \& latitudo dipla fere altitudinis, aliam \& ei diverfam plane rejiciunt. Rationes in promptu funt, quæcontrarium fuadent, nimirum 1 . Si figura foci effet rotunda vel quadrata, ventus ad oppofitum ejus latus non adigi \& urgeri potuifet: nares aut canales follium faxo longiori foci five laterali uni, quod Sidfen vocatur, incubant, \& ita applicantur, ut ab illis oblique feratur ventus in parietem oppofitum, e quo repercuffus, fuperficiem voluminis ferrei radit, ut motum quendam aut undulationem ciat, antequam inde in fublime feratur. Si figura effet quadrata, ovalis aut rotunda, nequicquam, licet violentiflimus effet flatus, ad oppofitum latus adigeretur, fed in via intumefcens \& tanquam anhelans in altum fine mora tolleretur; aliter vero fi in oppofitam partem eniti potuiflet, ex illo enim in volumen ferri refliret, inque orbem ageretur, antequam evolaret; nifi hoc fieret, non excoqueretur juite ferrum, nec forix fupranatantes leviores a metallo fecernerentur; nec ventus per caminum xqualiter difpergeretur, \& fpiraliter auferretur; unde latitudo foci dimidia longitudinis eft, \& fpatium, quod percurret ventus, vi ejus proportionatum. . 2. Purgandus etiam eft fipenumero focus, \& recrementa fundo \& parietibus affixa difcutienda aut elevanda funt; \& volumen ferri liquidum rutris \& ferramentis incurvis veriandum \& fubigendum eft, quod in foco oblongo commode peragi potelt, non vero in rotundo \& quadrato, latera enim legenda \& fricanda funt; fi fpatium fit quadratum, multum opus foret contum obliquare, \& illum finiftrorfum $\&$ dextrorfum agere, \& fic angulos omnes fcrutari \& radere, \& affixas fæces in altum levare, \& dein extra focum educere. 3. Si nimis patiofus effet focus, jufto violentius xutuaret \& ferveret inibi ferrum, parsque multa nimii xeftus \& caloris gratia vel in fcorias converteretur vel plane combureretur; parietes etiam foci nimia ignis vehementia perrumperentur \& liquelcerent, quibus perruptis \& liquatis ad latera vel in profundum abiret pars multa ferri, \& in molem ingentem coacervaretur. Hx funt caufie, cur foco imprimitur figura oblonga, non vero quadrata aut rotunda, qux licet plus fpatii occupat \& plus caloris fufficit, usque tamen ob rationes allatas detrimento operi liquefactorio eft; unde nec latum unguem recedunt excoctores a menfura, quam a parente fuo vel a magiftro alio aut ab ipfa experientia didicerant.

Focus vero non conftruitur in media fornace, hoc eft, ut perpendicularis per cavitatem demifla linea in centrum ipfus foci decidat, fed in parietem foci, in quo follium nares funt repofitæ, vel ubi eft orificium fpirans; unde a linea centrali aliquantum ad unum latus removetur focus : prout $A B C$ eft perpendiculum, lapis qui parietem foci conftituit eft $C$; pondus ab $B$ per lineam centralem delapfum recidit vel in parietem $C$ vel non procul abinde: rationem addunt, fcilicet ut ventus per nares follium emiffus eo melius ad latus oppofitum pertingat, \& inde rejectus per fuperficiem ferri liquidi circulet, \& fic tanquam e centro furfum diffipetur. Nifi flaminis hæc origo in centro effet, volumen liquati ferri juxta ventum etiam frigefceret, quod non fit in centrali cavitatis linea. Alii 
vero removent aliquantifper hunc lapidem a centro, quum fcilicet vena per fe fluidiflima fit, nec facile ab afflatu frigido indurefcat aut tenacefcat:

Focus hic liquatorius jam modo conftat tribus parietibus, quibus fpatium ejus includitur, quartus oppofitum tertio transverfali tenebit locum; eft tantum obex aut ferrum multæ molis; gaudet altitudine $\frac{\pi}{2}$ pedis, longitudine $I_{\frac{1}{7}}^{\mathrm{T}}$, pondere 400 librarum fere, vocatur Svecice Damm: pars h:e anterior foci vel introitus præftruitur ponderofo fic clauftro; quod pondere fuo immotum manet. In quibusdam locis apponitur faxum adhuc majoris craffitiei \& molis : humilior eft obex parietibus reliquis foci, ut lcilicet fcorix volumen ferreum operientes infuper emitti \& fine remora extrahivel fponte effluere poffint; non enim emittuntur, nifiad fupremam parietum focalium oram prius emerferint; ad latus ejus dextrum relicta eft apertura, five inter parietem \& hunc obicem interfitium palm: latitudinem fere equans, per quod ipfum ferri liquamen emittitur. Ita ergo aptandus eft dictus obex, ut ad latus ejus effluere poffit ferri liquor in foco contentus, fupra vero recrementa ferro innatantia.

Quod aperturam hanc lateralem attinet; qux vocatur Stickbobl vel fernbohl, \& per quam forem emanabit liquamen ferri per aliquot horas in foco collectum; illa obturatur arena argillacea, quæ per violentiam ignis indurefcit \& omnem exitum præftruit, nec nifi contis adactis excuti \& fic volumini ferreo erumpendo via præberi poteft; extra ruunt arenæ cumulum, ne obturamentum hoc argillaceum incumbente ferri pondere removeatur loco \& expellatur : fi apertura obftiparetur tantum fabulo, illud ignis violentia vitrefceret plane \& exitum omnem præcluderet, hinc etiam argilla ci admifcetur. Quoties emittendum eft ferrum, adigitur validis mallei ictibus contus, cujus ope argilla perforatur \& excutitur, qua excuffa fluminis inftar emanat liquidum ferrum, quo peracto, argillacea rudis maffa iterum inferitur, adjecta etiam parte carbonum pulverifatorum, accumulata dein forinfecus arena.

Recrementa vero e foco fuper obicem dictum derivantur, \& data apertura fponte effluunt; cumque flumen fiftendum eft, \& negandus ulterior exitus, verfus labra e foco protrahuntur prunæ, \& fuperinjicitur arena cum parte pulveris carbonum, adjectis etiam lcoriis pulveratis; 'liquibus in locis nullæ ex foco prunæ prius extrahuntur, fed pulvere carbonario oppletur foramen, projectis infuper arena \& recrementis contufis bene hu-midis; facile fiftitur recrementorum effluxus, nam fuperficiem voluminis ferrei tenent, nec fecundum altitudinem multam premunt. Extra forem hanc coacervata jacet faburra cum alius generis pulvere, in formam tumuli aut acclivis foli, fecundum quod lente \& tenaci flumine labirur pars fæculenta foci : poteftque major aut minor pars recrementorum lecundum libitum emitti, fi modo magis aut minus patefiat \& pandatur apertura.

Clauftrum aut repagulum hoc non applicatur foco, nifi 4to vel 5 to die poft inchoatam liquationis operam. Primis enim diebus; cum in focum frigidum defluit vena liquefacta, parietibus \& faxis adhuc frigidis \& fortaffe humidis adhæret, \& cum fundo foci ita unitur, ut nifi ferramentis \& rutris continuo divellatur, periculum erit, ne præcludatur plane focus, 
vel ei ita cohæreat, ut dein nequicquam effiringi poffit; hinc loco clanfri dieti præftruitur cumulo arenæ, qua eruptio ferri arcetur. Et quia continuus, ut dictum eft, per primos dies labor erit in foco, \& operator omnem angulum conto aut ferro fuo rimabitur, \& quicquid obvium eft, emovebit, non tam facile huc \& illuc agi potuiffet ferrum, \& foco affixa recrementa excuti, fi obex afforet; ne itaque impedimento fit, non nifi 4 to vel 5 to die applicatur, qui dein non tantum ratione molis fux loco immotus manet, fed arena fubjecta \& in vitrum verfa cum faxo inferiori \& laterali finiAtro firme confolidatur.

\section{Apertura camini anterior \& bractea ferrea qua occluditur.}

$\mathrm{Q}$

Uum conftruitur fornax, in parte anteriore relinquitur apertura fatis ampla, per quam operator incurvato corpore commode intrare polfit, \& focum inibi aptare, \& delapfum caminum reficere, ubiquid reficiendum eft. Appofito clauftro dicto aut obice adhuc remanet apertura pradicta patens fcilicet fupra obicem; hæc munitur \& clauditur janua vel tegmine quodam ferreo, præter intercapedinem exiguam infra five verfus obicem, per quam emittuntur fcoriæ, \& ferramenta, quibus focus detergendus \& purgandus eft, inferuntur. Tegmen vel janua hæc vocatur Timp, conftatque ferro fufo, alis in locis faxo; eftque altitudinis 3 ad 3 pedum; eftque diftantia inter imum hujus marginem \& oram obicis fupremam $\frac{1}{2}$ pedis : janua hæc incubat binis fulcris lapideis utrinque fuppofitis. Ratio cur apertura talis formetur, \& ferri quadam janua præcludatur, eft, quia finitoliquationis opere non modo venæ refiduæ partim liquatx, partim combuftæ una cum prunis e camino educendix fint, fed etiam ipfemet focus cum maffa ferri rudi \& indigefta, qua Klot appellatur, \& quæ fundum lateraque foci undiquaque obfidere folet; hæc contis \& vectibus elevanda \& e foco vi brachiorum educenda eft; quod fieri nequiret, nifi in caminum ab una parte introitus pateret; ipfl etiam muri cavitatis vel camini interiores quavis liquefactionis vice renovandi \& reficiendi funt; hinc per dictam aperturam intromittitur operator. Accedit etiarn alia ratio, fcilicet, quod excoctor eo melius in focum immittere contum, \& illum circumcirca tam in latus quam in profundum agere, \& omnia loca tam proxima \& anteriora follicitare poffit, fi tenuis quxdam lamina adimpofita fit, non ita fi craffior interjectus fit murus.

Alias ferrea hæc bractea ab ignis violentia candefcere folet; fique alluit ferrum fulphure fcatens, illud corroditur, \& adjuvante calore intenfiffimo confumitur, quod ter, quater vel decies una eademque vice liquationis accidere folet; at vero fi immunis confervetur a flamma fulphuris, hoc eft, fi vena fulphuris ad oppofitam camini partem immiffa defluat, diu admodum integra manet. 


\section{FER R I S V E C I 死. \\ Locus in camino Jupra focum, qui focus Juperior vocatur.}

PArs muri interioris, qux immediate fupra focum eft, vocatur Svecice 1 oefwerftelle five focus fuperior; defcendit enim a cavitate ventris verfus parietes foci continuo quodam nexu five muro; \& quia murus primum eductus contigua ferie non cohæret cum foci parietibus, hinc novus quidam fuperinducitur, \& tanquam indufio aut tunica quadam intrinfecus inveftitur; hoc fit ad illam altitudinem in camino, ad quam vir faxo fundamentali plantis infiftens exporrectis fuper caput brachiis manum poteft extendere, hoc eft, ad 4 ulnarum altitudinem fupra focum. Murus hic duplicatus vel focus fuperior, ut appellatur, conficitur ex lapide, qua igni bene refiftit, partim etiam ex fcoriis electis, cum argilla \& arena bene conglutinatis: Reprefentatur hic murus litera OOO Fig. r. Nifi enim murus per talem loricationem redderetur cum foco contiguus, maw xima pars venæ deflueret circumcirca foci parietes; necquicquam fecundum parietes quosdam obliquos \& contiguos muri in focum directe derivaretur.

Obfervandum eft, quod murus hic five lorica muri interioris tam alte exitruenda fit, quantum fieri poffit: nifi enim alte educatur murus hic, obliquitas quædam minor exiffit, fcilicet, quæ non fatis perpendiculariter tendat a ventre verfus focum, fed planum quoddam minus acclive omnem venæ liquefactæ imbrem excipiet, \& quafi in finu aut convalle quadam retinebit, nec in focum demittet, quam cum vallis illa liquamine venæe repleta fuerit, dumque fpontaneo nifu verfus focum \& inferiora tendat; hinc multum refert, qualis formetur obliquitas, \& ad quam altirudinem conftruatur murus hic, quem loricam quandam appellare licet. Quo enim altius educitur, eo perpendicularior eft, \& eo melius fecundum perpendiculum manat liquor ferreus in focum, nec ullibi retardatur \& fubfidet.

Quoties e novo inchoanda eft liquatio, diruitur focus hic fuperior five omnis loricatio, \& nova loco ejus fuperinducitur, adeo ut focus uterque quavis liquationis vice e novo parandus fit ; focus enim inferior excuti omnino debet, nihil nifi rudera fuperfunt, \& utrinque a ferro, crudo ita ftipatur, ut ferrum inde divelli nequeat, nifi fequatur focus; qui fæpe in media ferri maffa coloris albi infertus \& quafi inclufus apparet; pariter etiam focus fuperior, qui partim incruftatus materia fcoriacea, partim etiam ferruginea, partim exefus hinc \& inde dehifcit, \& fic inæqualis redditus dirimendus omnino eft, \& novus loco ejus, quum iterum integrabitur opus, priori fimilis conftruendus.

\section{Folles \&iventus.}

Spervacaneum eft conftructionem \& ipfam fabricam follium hic tra$S$ dere; non modo a fcopo \& meta tunc aberrarem, fed etiam illud, quod prius \& fizpius a multis atum eft, agerem: Satis eft indicaffe, folles ex 
ligno abiegnò craffo formari, \& tabulata illorum fuperiòra a binis dentibus in cycloidalem figuram incurvatis, quæ alarum fpeciem referunt \& ex trabe per rotam aquaticam circumacta prominent, comprimi, \& dein a capfis binis fufpenfis, qux faxis onuftx vectium inftar funt, attolli; \& rurfus per trudes dictas deprimi \& a tollonibus elevari, ficque alternatim furfüm \& deorfum mechanifmo vulgari ferri.

Hodie parantur folles fpatiofiores \& majores illis qui olim in ufufuerant: quo enim amplior caminus \& capacior fornax, eo copia major venti requiritur, \& confequenter co capaciores erunt folles, adeo ut ratio follium inftar caminorum effe debeat. Et quia fornaces veterum minores fuerant, hinc etiam non modo exiguiores folles olim ufitati funt, fed etiam coreacei, hodie vero ampliata fornacum cavitate, ampliati etiam funt folles, \& lignei pro coreacêis in ufu funt. Olim multa latitudine gaudebant folles, fed qui nihilominus erant capaces, at hodie præferuntur longiores; hi quamvis ejusdem capacitatis cum latis \& brevibus fint, usque tamen ufum infigniorem præetant; nam non modo auras copiole attrahunt, fed etiam facilius per nares emittunt, \& vi quafi fortiore mechanica ad parietem foci oppofitum trudunt.

Quod alias dimenfionem follium hodiernam attinet, videatur Tab.III. eft longitudo tabulati fuperioris $12 \frac{\mathrm{T}}{2}$ pedum, five ad locum in follibus, ubi canales aut fiphones ferrei ex ligno exeunt, I 4 pedum: altitudo partis pofterioris five tabulati a tergo, quod quavis fpirationis \& tractionis vice elevatur \& deprimitur, $3 \frac{\pi}{4}$ pedum; huic tabulato exigua quoque curvatura datur, ut fcilicet fecundum axem eo melius agi, hoc eft, levari \& furfum ferri poffit : latitudo partis inferioris eft $4 \frac{x}{2}$ pedum, partis anterioris $3 \frac{x}{6}$ pedum; five fecundum figuram, ubi $A B$ requat i $2 \frac{\pi}{2}$ pedes, $A D=14$. $A C=3 \frac{1}{4} B F=I \frac{1}{4}$. Latitudo partis inferioris circa $B$ vel quod includit $M N=2 \frac{1}{2} \cdot \quad$ Latitudo partis anterioris circa $B$ vel $O P=3 \frac{x}{6}$ pedd. Quibusdam in locis etiam hodie, prout olim, funt eorum longitudines minores; fed hic fiftuntur folles maximæ dimenfionis. Canales folliculares five nares ex follibus prodeuntes fpiritales longitudinem 4 pedum æquant, fed ex follibus tantum $3_{\frac{\pi}{2}}^{x}$ exitant, adè ut pars $\frac{1}{2}$ pedis capiti follis inferta teneatur. Diameter foraminis unius naris æquat 3 digitos: Canales conAtant bractea ferri latis valida bene complicata, cavetur ne ullibi per ductam rimam halitus quidam elabatur. Portula, per quam attrahitur ventus five labrum tractorium, longa eft $I_{\frac{1}{4}}$ pedem, lata $\mathrm{I}$; foramen circa OP in ligno follis excavatum, quod verfus canalem vel fiftulam ferream ducit, altitudinis eft $\frac{3}{8}$ pedis, latitudinis $\frac{7}{8}$; per obliquum tendit canalis, $\&$ in via paullatim anguftatur. Lignum ubi canales ferrei penitus fe recondunt, five unde prodeunt, latitudinis eft I pedis, altitudinis $I_{\frac{1}{8}}^{\mathrm{r}}$, \& fic porro. Dens five trudes, cujus ope deprimitur tabulatum fuperius follis, Svecice vocatur Kamb five pecten, aut ala pectinata figurx cycloidalis eft : juxta ipfam. trabem, cui infixa eft, in curvaturam quandam circularem flectitur, \& dein in cunei formam per flexuram lentam abit, ficque in apicem fed obtufum terminatur, eftque longitudinis $\mathrm{I} \frac{3}{4}$ pedis, latitudinis $\mathrm{I}_{\frac{1}{6}}^{\circ}$ Quod fabricam follium attinet, obfervabit bene artifex, ut parietes illorum interiores admodum 

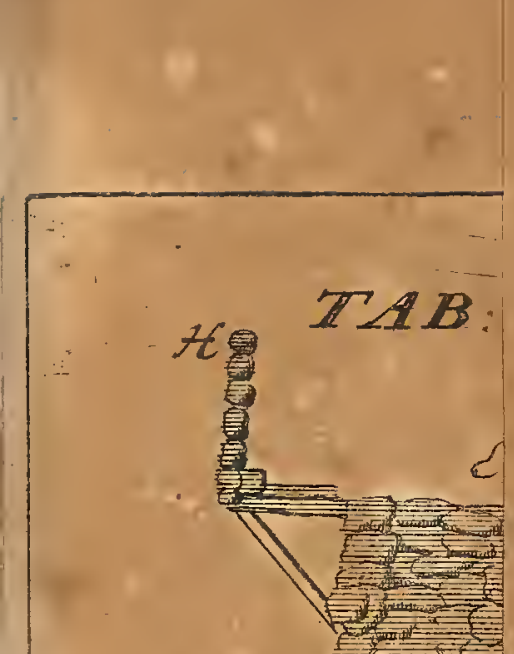

G

(1)

G

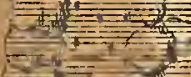

$-\sqrt{2}, 1$

请请

…
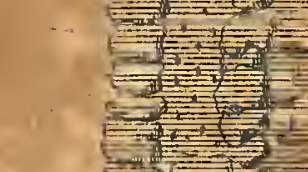

.

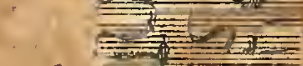

G

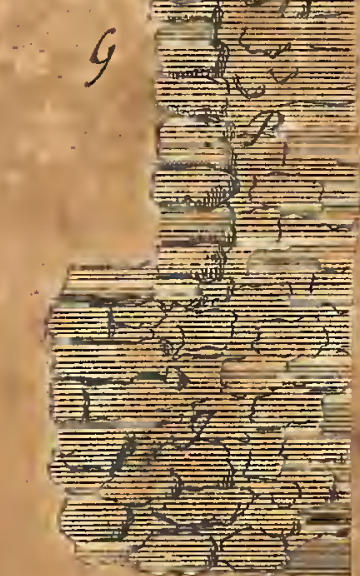

Delineatio
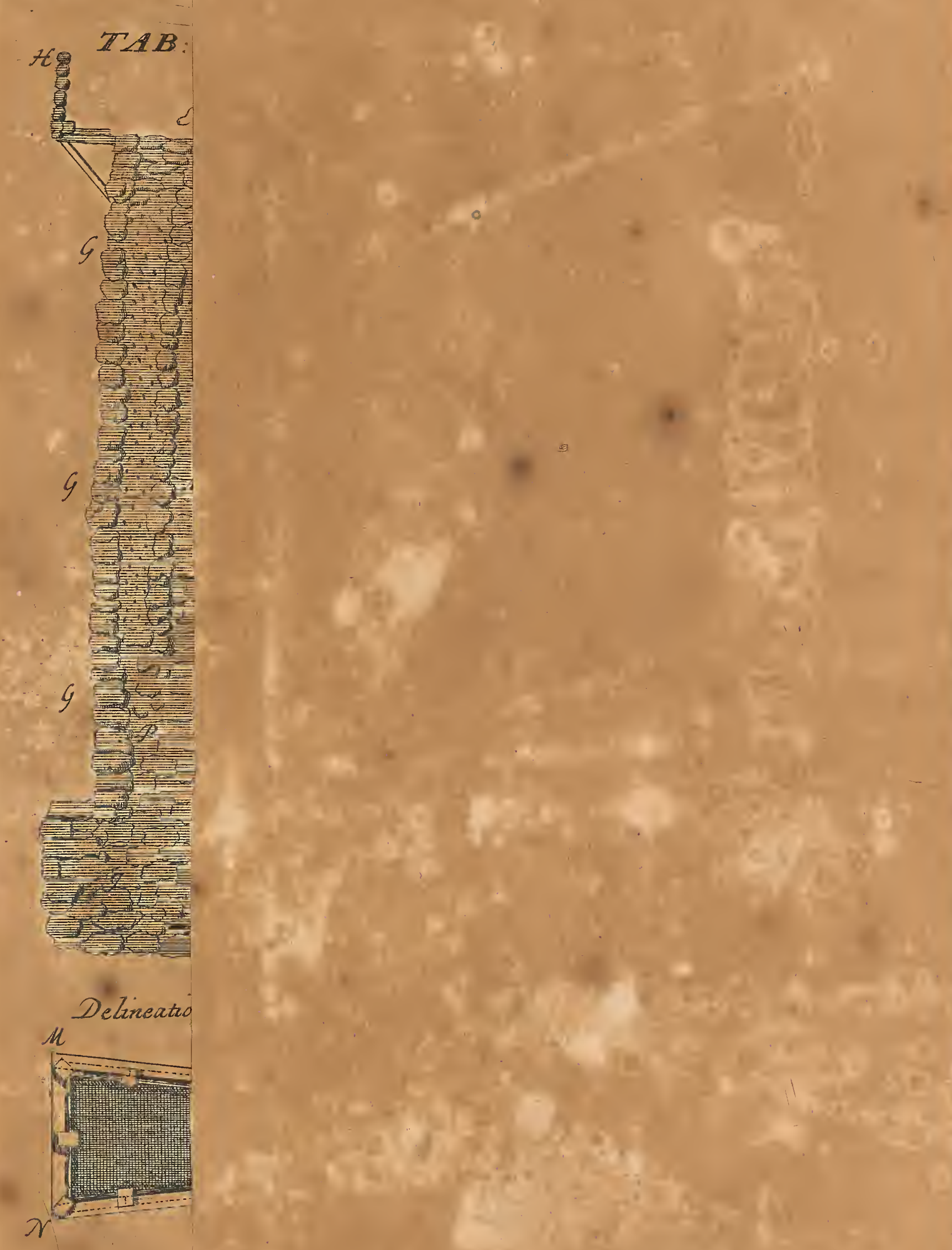



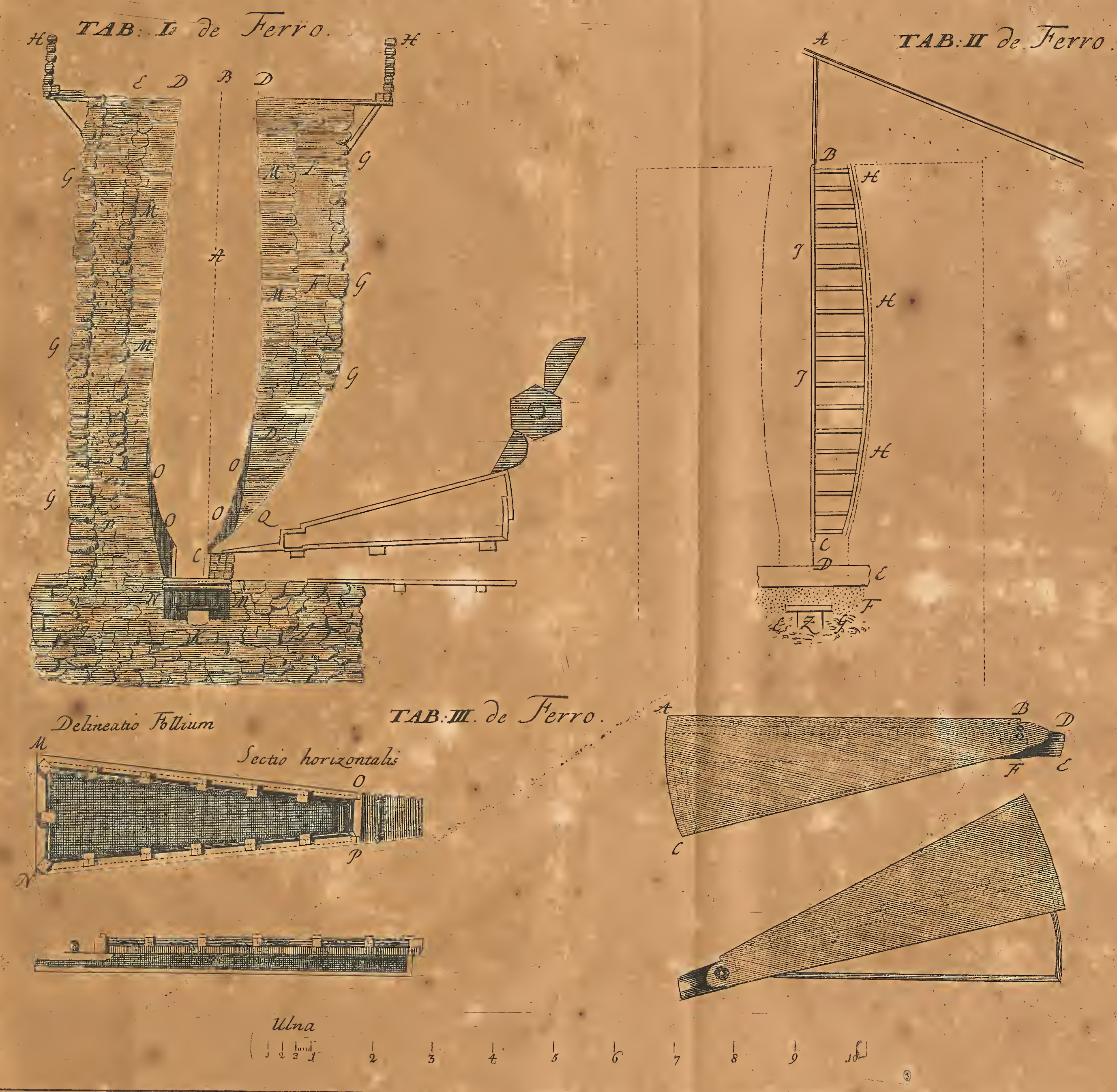




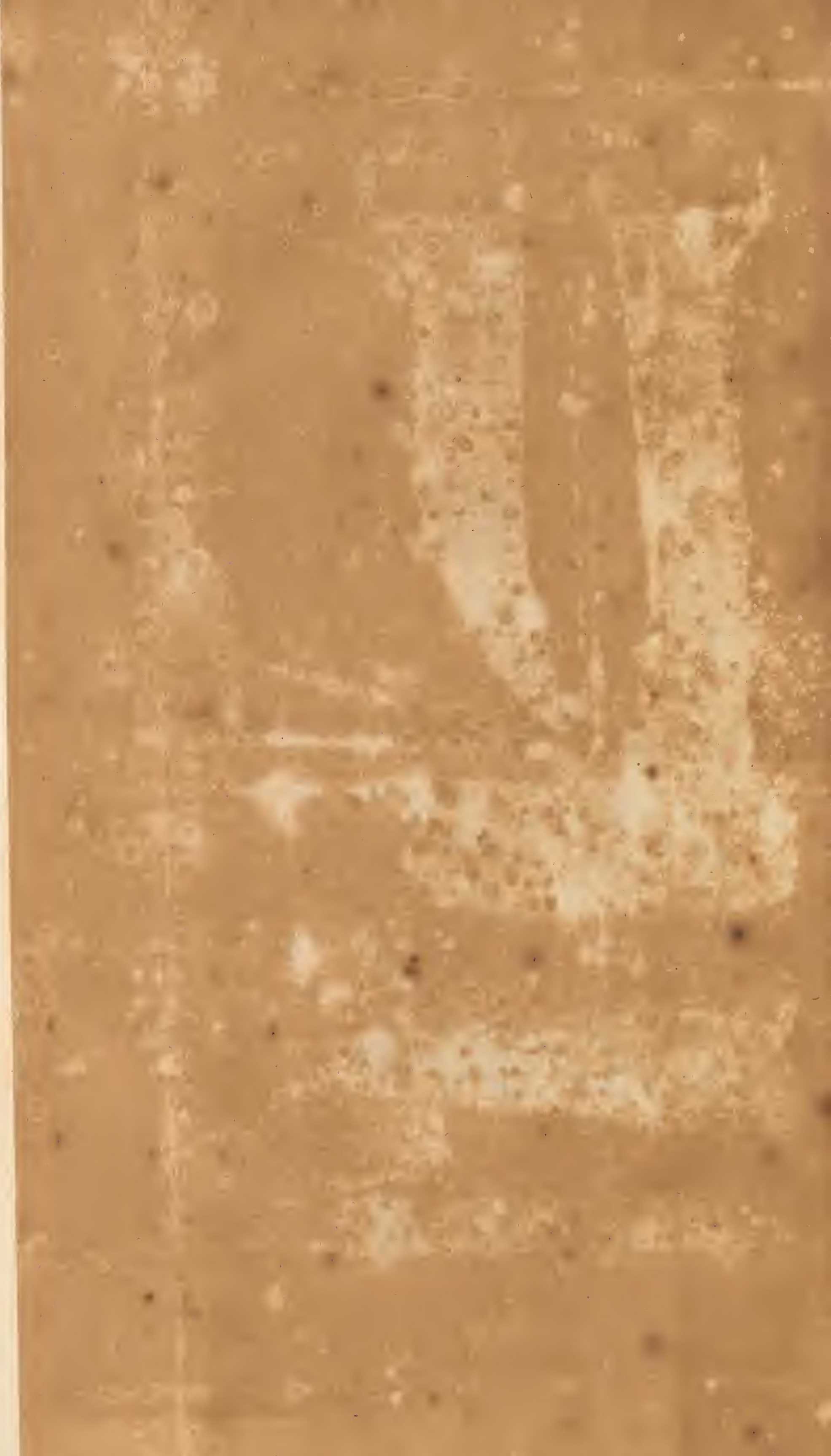


modum lævigati, \& tanquam torno rafl \& unguine illiti fint, ne fcilicet quicquam obftet, quin motus fuos reciprocosfacile agant. Lignumabiegnum eligitur maturum, quod in tabulas craffiores fecabitur; tabulæ fic fiffiad ignem vel folis vel foci diu prius ficcandx funt, quo enim ficcius, eo ad hunc ufum aptius. Regula etiam communis eft; quod folles ponderofi meliores fint levibus; hinc etiam ex tabulis craflioribus conficiuntur ; tabulatum enim fuperius vi multa pectinis truditur, hine nifi pondere fuo valeat, inflexum facile vi prefhonis cedit, \& vento aliunde quam per nares erumpendi locum dat.

Principio operationis liquatoriæ non tanta vis \& copia venti requiritur, ac dein in proceffu operis : antequam parietes camini debitumignem. receperint, nimii \& repentini caloris impatientes funt: fi enim ventus multum ignis excitaret, frigido adhuc permanente muro, tuncvel rumperentur laxa aut commiffure argillacex, vel calor nimis violento \& prono fumine verfus interiora ejus cogeretur, quod tamen per gradus \& lente fieri debet: hxc eft ratio, cur reciprocatio motuum utriulque follis, lentior effe debeat principio, quam peractis aliquot diebus. Sed motus hic follium vel tardior vel velocior redditur per aquæ in rotam ejus admiffionem; quo enim copiofior aqua admittitur, eo velocius circumfertur rota, \& confequenter crebrius aguntur folles, motus æ̇uabilis tandem proceffu. liquationis eis datur, ita ut folles fpirationes fuas æequis momentis alternent, $\& 600$ vices per quamlibet horam continuo dein peragant.

Multa etiam excoctoris ars in eo confiftit, ut fciat bene aptare canales follium fpiritales, hoc eft, nares duplicatas in orificio ventilatorio; utque fciat orificium dictum ventilatorium fecundum regulas debite formare; ifque hæc noverit liquator \& perfecerit, certus admodum de fuccellu operationis fux effe poterit. Canales ferrei fpiritales, qua ex ligno follium prodeunt, in orificii ventilatorii f́pecu fere coeunt; divaricatio vel diftantia illorum prima juxta lignum eft circiter $I_{\frac{2}{3}}^{\frac{2}{3}}$ pedis, in ipfá cavea orificii ventilatorii $\frac{1}{2}$ pedis: in fecefu orificii ventilatorii, qui Forma Svecice appellatur, quique per murum fornacis tendit verfus focum, nares folium ad 2 pedum longitudinem inferuntur, ab ipla apertura narium verfus focum vel ignem. reftar dein $I_{\frac{1}{4}}^{\mathrm{T}}$ pedis diftantia.

Ouod vero feceflum aut ductum orificii fpiratorii attinet, qui fcilicet trans murum, ut dictum modo eft, ad focum tendit, \& in quo collocantur fuftula follium, vel qui Svecice Forma appellatur, cn conftructionem ejus. Eft apertura quadam quadrangula, antrorfum vel a parte follium fatis ampla, introrfum vero aut a parte foci eft angufta, coni inftar verfus interiora ducitur : tres ejus parietes funt admodum obliqui, fcilicet fuperior \& bini laterales, non vero quartus five planum inferius : paratur hac apertura ex faxis ut \& f foriis electis argilla \& arena conglutinatis; hæc apertura, ut diEtum eft, in aretum fic contrahitur, inque foramen admodum anguftum figuræ femicircularis vel femilunaris, quod non amplius eft, quam apertura unius naris follicularis ; ventus ex fiftulis follicularibus erumpens per aperturam hanc xqualem femicircularem urgetur : interdum tamen accidere folet, quod fponte fua dilatetur pars hujus aperturæinterior, prafertim Clasis l. de ferro.

G fifuper 
fi fuper orificium ferri fulphurati flumen vel potius imber defluat; quod obvia quæcunque exedit \& refolvit; fed os fic ampliatum \& diductum ftatim refingendum \& fragmentis recrementorum argilla circumlitis farciendum eft, ut fcilicet introitus venti idemæqualifque femper permaneat. La tus hujus cavernæ inferius vel fundus bractea quadam ferritegitur, qux for ${ }^{*}$ mæeft triangularis, latitudinis \& longitudinis æqualis, fcilicet $\mathrm{I} \frac{\mathrm{I}}{2}$ pedis, craffitiei pollicis, vocatur Formplaut ; aliquantifper verfus interiora obliquatur fundus hic, fed obliquitas admodum exigua eft, fcilicet I 2 circiter graduum a plano vere horizontali; angulum hunc per digitos \& ungues metiri fciunt, fupponendo uni ejus parti tantummodo pollicem, unde ex elevatione data obliquitatem dimenfam habent.

Ideo bractea hæe ferrea fupponitur, ut fcilicet follium nares infuper relocatx poffint requiefcere, inque pofitione obliqua \& debita immote \& continenter teneri, \& ventus ex illis erumpens per planum quoddamæquale verfus ignem ferri : alias fi lapideus foret orificii hujus fundus, facile vel ab igne vel a fiftularum quodam motu alicubi excavari potuiffet, ficque ex clivo quodam obvio repercuffus aer diffiparetur. Longitudo hujus antri aut pecus eft 3 circiter pedum. Hæc omnia, qux dieta funt, in unguem quadrare debent, alias fpes opificem eludet.

Ventus itaque ex fiftulis emiftus per planum quoddam leviter obliquam in focum fertur, \& parietem oppofitum ferit; non vero fupremum. ejus parietis limbum, fed locum quendam infra marginem, fcilicet illum, ad quem afcendit volumen liquidum ferri; exinde fequitur quod ventus, qui partem voluminis ferri \& parietem obverfum ftringit, inde reverberatus in orbem circum fuperficiem liquidi ferri agatur, undamque ferream \& ejus recrementa fluida commoveat, \& tandem per totum focum. fparfus juxta parietes fpirali effluxu elevetur : hinc, cum formatur dictum orificium, bacillum quendam rectum fecundum obliquationem plani immittunt, qui fil linea recta punctum oppofitum parietis pertingat, jufta cenfetur effe obliquitas; ad eundem locum etiam oculis collimare folent, \& fic plano fuo debitam obliquationem dare.

Hic multa occurrunt notatu digna; fucceffus liquationis multum dependet a directione debita venti; ventus enim pulmonum \& animæinftar eft, calor vero vitam reprefentat: nifi pulmones fint falubres \& integri, \& liber tranfitus anime relictus, calor vitalis facile exftinguitur; en itaque precepta fequentia :

1. Si fundus orificii ventilatorii horizontalem fitum habeat, adeo ut ventus fecundum planum ejus in focum illapfus horizontaliter dein feratur, confequitur inde, quod ventus, ut primum per aperturam dictam intromifus fit, in altum feratur; ftatim enim ut flringit fuperficiem calidisfimam voluminis, vel radit aut verrit undantis liquaminis fupremam partem, nullum nifum verfus inferiora amplius habet, fed ftatim globi per fclopetum aut fundam jacti inftar, qui in aquax fuperficiem impingit, inde reflectitui; \& velut enervis aut vi omni deftitutus furfum elevatur, antequam. ad latus oppofitum pervenit, nec liquamen ferridebite commovet, perque commotionem craffiora a levioribus fecernit. Videmus in hac orificii 
pofitione aut venti horizontali directione, quod xgre liquetur ferrum, \& teparentur xgre metallica a lapideis, quodque vena in foco cruda usque permaneat; ventus modo agit in carbones, \& illas incaflum confumit inque favillas diflipat, nec in ratione ad carbonum quantitatem liquitur vena, vel filiquatur, non a partibus heterogeneis \& malignis debite leparatur. Hoc vitium ex directione nimis horizontali orificiorum ventilatoriorum provenit.

2. Si vero nimis oblique irtuat ventus in focum, tunc ftatim, ut in focum illabitur, in fuperficiem voluminis impingit \& inde verfus fuperiora refilit, antequam oppofitum parietem contingere poffit: in hoc cafu nec agitabitur liquamen feri, nec per totum focum diffulus ventus fecundum latera camini elevabiur, fed in medio foco reflexus catervatim vel conferto agmine, circa unum camini latus vel in medio tantum prorumpet; unde etiam inxqualis actio venti eft tam in liquamen foci quam in carbones, \& inde confumtis carbonibus non jufta inde folutio \& fecretio venam lequitur. An ventus per debitum inclinationis angulum irrumpat vel non, ex plurimis indiciis patet, ut fi focus non jutam venx copiam recipere, nec receptum coquere, \& quafi penfum fum abfolvere velit, fignum eft vel ninile vel nullius obliquationis in orificio ventilatorio; pariter fi omnes guttx nigrx, nullæ vero lucide fint, qux imbris inftar in focum depluunt, \& quie trans orificium dictum confpici poffunt. Sique flamma fupra fornacem altius cum fcintillis elevetur, fique volumatim vel inxquali fumine circa unum magis quam alterum latus erumpat. Nimiam obliquationem plani orificii vel pracipitem illapium venti in focum animadvertes, fi liquamen ferri prope orificium ventilatorium indurefcat \& nigrefcat; fique volumen lentius inde factum in medio vel alibi excavatum appareat, adeo ut devexum \& elevatum magis utrinque fit liquanen quam in medio, hoc fignum eft tenacitatis in liquore ferreo, \& continu: impulfionis venti in uno foci loco magis quam in altero. Peracta etiam liquationis opera exelum \& excavatum ab una magis parte videbis murum camini quam ab altera, agit enim ignis vento comitatus vel tanquam. alatus continuo in unam muri partem, debilius vero in alteram. Plura adhuc funt indicia, ex quibus non augurari tantum, fed pro certo fcire posfunt magiftri hujus artis, non debitum frtum aut obliquationis gradum datum fuiffe orificio.

3. Si nimis apertum \& diductum fit os orificii ventilatorii, adeo ut per hiatum nimis patentem \& liberrime illabatur ventus, ut fi menfuram pradictam fuperet, five quod prima ejus formatione datum fit os apertius, vel quod magis magisque pandatur ex nimia ferri fulphurati pluvia, tune nec illam vim haberet ventus, ac fi per anguítius foramen intruderetur; non enim ad oppofitum latus urgetur, fed ceu anhelans ftatim in altum effertur diperitque, nec in fluctus \& undas agit yolumen fubjectum, necab humidiore fui parte fecretus in focum venit; unde nec in foco juftefecernitur metallum a fulphure \& lapide inherefcenti, \& confequenter hec copia venx debita transmitti caminum poteft. 
4. Si vero os hujus orifici fit nimis angufum, contrarium accidit; non debita flaminis copia fuppeditatur foco, unde inertior \& pigrior exiftit liquatio; non aliter ac fi folles exigui \& leves auram \& halitum exiguum tantummodo emitterent. Hinc amplitudo debita oris eft, fi xquet umplitudinem unius naris follicularis.

5. Si orificium foret rotundum, quale folet effe in focis purificatoriis cupri \& alibi, ventus per tale os emiffus vix in oppoficum foci parietem vi debita urgeri poffe videtur; hinc figura femirotunda eft aptiffima, cujus bafis vel pars infima fit plana.

6. Nares fiftularum ita aptantur in orificio hoc, ut non propinquiores fint aperturæ vel ori quam ad diftantiam $\frac{3}{4}$ vel I pedis; fi remotiores vel propiores, ftatim diminutam vel auctam fentiri vim venti perhibent: ut fi naris remotior fit ab apertura, hoc eft, fi non tam alte fit immifla, dicunt vehementiorem fpirationem \& flatum inde oriri, quam fi ei propior admoveatur; quod primo intuitu a veritate alienum effe videtur. Quo énim propius admovetur naris ad aperturam, eo majore cum vi \& efficacia intrudi poffe videtur ventus; fed contrarium hic ftatuunt periti magiftri ; caula fortaffis eft, quod aer magis aqueus \& uvidus intromittatur, fi naris aperturæ infideat, fique ftatim, ut elabitur ex fiftulis \& tanquam ex primis labris in focum ircumpat; fi vero intercedat fpatium, videtur purgari interea aerem, \& humidiora ab interventu caloris in via difipari, \& fic aerem puriorem intromitti: vel etiam fi nimis propinquus ori fit ventus, vi qua effertur ex fiftulis incurrere planis orificii obliquis \& fic partem illam. refultare, qux alias fecundum plana illa in focum ferri poffic, vel fi quæalia caula fit, de qua alias.

Quantum in liquefactionibus differat humidus aer a puro \& ficco, admodum perfpicuum ab experientia eft; tempore hyemis litius peraguntur \& felicius liquefactiones quam ærtate; quum nubila pendent, \& aer pluvius ac vaporibus refertus eft, lentior \& debilior vis ignis vel venti in ignem animadvertitur, quam fi tempus fit ferenum \& fudum: fi fub ipfis follibus vel fedili follium locus fit uliginofus, fi terra paluftris \& uvi$\mathrm{da}$, fi fons non procul.inde fcaturiat; quia aqua continuo in vapores expanfa abinde attrahitur, \& labris follium imbibitur, ficque in focum emittitur flatus pluvialis \& aqueus, qui liquamen ferri præfertim juxta os denigrat \& obfufcat, quod fignum eft, lentefcere illico volumen ferri, \& inertius fic peragi fecretionem partium in venis.

Dicendum etiam eft, quem fitum \&locum occupare debeat orificium. hoc ventilatorium in ratione ad focum; dicendum etiam, qualis erit in ratione ad caminum. Mos penes omnes receptus eft, ut os ductus hujus fpiratorii fit in ipla centrali linea cavitatis, adeo ut fi globus per lineam centralem vel fecundum axem fornacis perpendiculariter demittatur, quod tunc parietem, in quo recumbit foramen hujus orificii, ftringat; undeunus paries foci, fupra quem formatum eft orificium, in media cavitate fornacis eft. Exinde fequitur, quod focus ad unam partem camini translatus fit, nec mediam in camino fedem teneat; quod fit propter orificii fpiratorii ftationem debitam, que erit in plano cavitatis centrali. Hoc fir præcipue ob illam 
ob illam caufam, ne volumen ferri liquidum a vento partim gelido partim humido refrigeretur, maximus enim in centro calor eft; ubi non tam facile torpet \& languefcit liquamen, ac fi a centro verfus latus quoddam. camini remotus effet focus : unde etiam teftatur ufus, fi orificium hoc removeatur a regione axilari fornacis, quod liquamen ferri ftatim corripiatur gelu quodam, quodque frigide ftipentur fauces orificii fcoriis lentioribus; in quo cafu, nifitempeftive opem ferant, \& tenaces partes inde excutiant, obturatur \& præftruitur facile orificium, \& oftium ventofum five via hæc pulmonaria clauditur, \& confequenter opus liquefactorium anima \& halitu privatum exftinguitur \& fuffocatur.

Si vena ferri fluida fit \& calcis intertextæ dives, oftium hoc fpirationis a centrali illo plano removeri folet, illud venæ genus non primo halitu \& frigida animatione refrigeratur, \& tam facile lentefcit, ac folet ferrum, quod menftrui hujus fufficiente copia non faturatum fit. Prretendunt etiam aliam caufam, cur fpiraculo huic non in medio axe locum dare velint, fed ad aliquam diftantiam abinde, fcilicet ne tanta copia venæ liquefactx accumulata fupra orificium hoc ruat: fi enim in medio eft paries unus foci, in illum dimidia pars venæ omnino defluet, \& altera pars dimidia ad diftantiam ab orificio five in focum ruet; unde fi tanta copia imbris ferrei ante ipfum ventum depluat, fequitur inde, quod multa ejus pars nondum bene foluta, vento proxima denfetur \& craffefcat, preter quod teftudo \& poftes hujus oftii five foris non illæefi \& immunes a fulphuris contactu effe poffint, cujus ope exefum foramen hoc magis magifque diducitur, unde cum opere \& fudore toties refingendum eft. Sed omnia hrec vulgi rudioris metallici ratiocinia ab experientia pe tita originem fuam debent diverfitati venarum; unum venæ genus, fcilicet quod fluidum eft \& calce interfperfum, fluiditatem fuam non amittit, quamvis removeatur flamen a centro: at vero aliud genus illico lentefcit, fi vel paullulum a centro difcedat fpiramen, ftatim enim fuperficies ei proxima infpiffatur \& rigefcit; \& rigefcentia illa magis magifque increfcit, prout major pars venæ fuperaffunditur.

Obfervandum etiam eft, quod foramen hoc fpiritale non effe debeat fupra medium lapidem lateralem foci, fed propius verfus partem itlam interiorem foci five oppofitam obici aut clauftro fupra memorato, diftat modo a muro illo $\frac{\hat{3}}{4}$ parte unius pedis : Caufam dicunt effe, quia ventus alternatim ex duplici nare five ex geminato quafi ore emiffus unam flaminis partem verfus interiora foci ferat, \& inde repercuffus orbes fuos per illam foci regionem continuo peragat: Ventus vero alterius naris oblique in parietem tendens ad angulum incidentise reflectitur in alteram foci régionem, \& recrementa, qux fuperficiem tenent, verfus aperturam foci cogit: unde etiam volumen $\mathrm{ab}$ utraque parte ftriktum continuo movetur. Sic nec ulla pars foci erit, cui non incumbant venti, \& quæ non fuperficietenus in perpetuo \& xquali motu fit.

Ex prædictis patet, quam diligens adhibenda fit cura circa ventum \& orificia fornacis anemia : a multorum annorum ufu edoctum eft, liquationis fata \& fucceffum fuum debere ventis, qui fi rite \& vi ad camini ipatium Clafjis I. de ferro. 
proportionata fpirent, obfervatis etiam preceptis hactenus traditis, fpes non eludet operatorem, fed fecundabit eventus. Interdum vero accidit, quod folles vel nimio calore aut ficcitate dehifcant, quodque ideo etiam in medio liquationis opere fiftendi \& reficiendi fint, unde per 6 vel 8 horas fxpenumero motus follium reciprocatus inhibetur, \& caminus fine ulla animatione \& flamine relinquitur iners; fi in illo cafu foramen fpirationis occludatur, \& dein refectis follium rimis ventilatio rurlus in lituatur, ulque tamen non inde ægrotare caminum, \& labem quandam feu vitium infigne traxiffe compertum eft : ufque tamen induftria \& prudentia in his opus omnino erit.

Scio etiam aliquibus in locis in proceffu ipfo liquefactionis tabulas aut radios excidiffe rotæ, vel tignum aut trabem difruptam, vel aquam defeciffe, adeo ut in arena aliud non adeffet confilium, quam ut liquationis opus fifteretur, fed ufque tamen fi nimius labor videretur per ambulationem quandam in rota vel fupra tabulata follium motus priores continuare, fuerant, qui liquamine ferri prius emiffo aperturam ipfam fuperiorem fornacis clauderent, adeo ut vivus ille ignis exftingueretur, \& interea in illo ftatu per moram 3, 7 ad 8 dierum refarcirent ruinam, \& dein opus, reclufa apertura fuperiore, ut prius redintegrarent: tentatum hoc fuife perhibent, \& tentamen fucceffu non caruiffe ; fed usque tamen non exploratum habeo, qualis dein liquefactionis redintegrate ftatus in camino per tot dies quiefcente \& ventorum experte effe potuillet.

\section{Quomodo opus liquefactorium inchoatur, $8 \mathrm{ca}$ - minus ab imo ad Jummum adimpleiur car- bonibus $\ominus^{\circ}$ dein per aliquot dies occlu- Jus tenetur.}

Q

Uum e novo exfrueta fit fornax, dumque adhuc madent commiffure argillacex, \& faxa murum interiorem conftituentia cruda \& humida adhuc fint, in focum infertantur aliquot arborum trunci aut partes ex trabe excifie, in quibus accenfus ignis per. aliquot dies cruditates \& humores infitos diffipat, caminique muros ad diuturniorem ufum præparat. Quoties inchoandum eft liquefactionis opus, conftructo prius foco tam inferiori quam fuperiori, infpiciendum eft, num fundus foci inferioris bene ficcus fit; fi non, fuperinftructo cinere vel arena \& injectis aliquibus prunis ficcatur : quo facto ab imo ad fummum adimpletur caminus carbonibus, quod Svecice vocatur, fylla ugnen, five replere caminum. Caminus hodiernus capax effe folet i 2 ad i 8 leitarum, quxvis lefta, qua Svecice $L a e f, R_{y} / s$ aut Stig vocatur, I 2 tonnas comprehendit. Olim injectis carbonibus ignem ftatim fuppofuerant, \& fine follium motu aut fpiramine per aliquot dies debiliter admodum liquefactionem peregerant. Hodie vero ignem immiffis carbonibus non ftatim fubjiciunt, fedomnem apertu$\mathrm{ram}$, ubicunque in fornace fit, tam fuperiorem quam inferiorem follicite occludunt \& obturant, prius tamen in prunas inferiores fuppofito igne, ut icilicet 
filicet calor inde per totum acervum perrepat: Apertura illa magna fuperior, per quam in caminum patet introitus, laminis vel foribus ferreis ad hunc ufum confectis bene clauditur, fuperinjecto pulvere minutorum carbonum, quo rimæ omnes ftipantur, \& calor in carbones accenfos diffipatus tenetur inclufus. Si defint laminæ ex ferro, aptantur tabulæ lignex, fuperinjectis frondibus \& infuper cumulo pulvereo carbonum, quibus etiam omnis caloris halitus precluditur. Sed ne carbones nudi totam cavitatem occupent, aliquantula etiam portio venx ferrex fuperinjicitur, fed modo 2 vel 3 vafculorum, quæ Skoflar vel fpadæ appellantur, \& vanni cujusdam vel cavatia arboris fpeciem referunt: quod vulgus in illum finem dicunt fiere debere, ut carbones illa nutriantur tanquam alimento quodam; fed. credo nihil referre, fi nudi aut tali alimento in hoc tempus deftituti fint. carbones vel non: in gradu hoc caloris, in quo per aliquot dies tenentur, nullam habent carbones vim in venam, nec vena reciprocam quandam in carbones. Suffocato fic per occlufionem quandam igne vivo, \& calore quodam nigro carbonum acervum occupante, relinquitur in hoc flatu caminus per 8 vel a quibusdam per i 4 dierum \& noctium ipatium. Si interea per parvulum quoddam foranen in operculo lamellari ferréo facum immittatur virga five bacillus, cognolici inde poteft, ad quam altitudinem fubfiderine carbones; paullatim enim diminuitur \& refolv hre maffa, confumente illam calore coeco \& latente: poft I 2 dierum elaplum fubfidentia 6 vel 7 pedum in camino circiter animadvertitur. At vero fi aperture modo dicto non bene obturate \& figillate fint, juneture enim omnes argilla func obducendx, vel fi fornax ex vetuftate rimola fit facta, vel aliis ex caufis hic vel illic dehifcat, adeo ut vento portula pateant, obfervatur illico calorem aere quodam nutritum carbonariam maf fam magis quam alias confumfiffe, adeo ut ad altitudinem 8 vel ro pedum fubfiderit.

Hic non refert, num carbones optime cremati in alvum hanc liquatoriam folummodo immittantur, vel num etiam ligna nondum plene in carbonem verfa, ut torres \& id genus alia poft cremationem carbonariam relicta recrementa carbonibus admifcentur; calore enim nihilominus imbutuntur, \& in veros carbones, finita calefactione hac, convertuntur. Expertum etiam eft, lignis fcifis loco carbonum ftipare caminum, \& fic immiffo igne illum undiquaque, modo quo dictum eft, operire, poft elapfum aliquot dierum 8 vel I 2 totam ftruem lignorum invicem bene aptatorum, in carbonarium cumulum converfam fuifle : eft enim ignis modo digeftorius vel torrefactorius, unde commifceri poffunt arbores femiufte \& trunci ficciores.

Interea calor e carbonibus in parietes \& murum camini proximum invadit, \& fecundum experientiam penetrat ad fpatium $\frac{1}{2}$ vel $\frac{3}{4}$ pedis, ad quod tactu fenfibilis eft: calor ille non videtur nifi fecundigradus effe, non vero liquefactorius, hic faxa parietis non modo ficcat, noxiosque humores expellit, fed etiam faxa preparat ad receptionem caloris vehementisfimi \& ipfus fuforii; fi enim in faxa frigida ignis vivas \& vehemens. impetum faceret, tunc vel inæqualis in fibras \& interiora urgeretur, velaquam 
hic \& inde volumatim includeret, vel faxorum compagem \& crates in partes difrumperet; at vero præeunte calore leni, pori \& meatus paullatim operiuntur \& recluduntur, \& venæ igni validiori patefiunt.

Quum ufum prædictum præftet fuffocatio \& memorata occlufio, hinc cum rurfus aperturæ recluduntur, majorem partem venx tunc indies apponere licet, quam fi ftatim flammam \& ignem apertum in carbones \& venas immiferint. Non ante plures annos adinventa eft hæc methodus, \& cum lucro \& carbonum minore jactura multis in locis in ufum recepta hodie viget; olim quum primis ftatim diebus ignis fuit apertus, vix nifi 2 vafcula venæ quavis vice fuperimponere licuit, pereunte interea \& fubfidente fine lucro multa copia carbonum; hic vero reclufis aperturis, ftatim prima vice \& fic quavis fequente fuperimponi poffunt 5 \& fic 6,7 \&c. vafcula, qux cum æquali carbonum quantitate liquari \& fundi pos-' funt, ac priora 2 vel 3 .

Alias obfervatum eft, calorem inclufum multa vi elaftica \& extenfiva pollere; quum enim fupra foraminulum in caminis ferreis factum cinis carbonum aut pulvis alius leviufculus fuperinjicitur, tunc ille palex \& ftipulx inftar in altum fertur, \& frepe ad altitudinem abinde 3 vel 4 pedum elevatur ; quod indigitat, aerem inclufum a calore expanfum \& vi extenfiva erupturum in altum ferre obvia. Nondum tamen exploratum habeo, quali vel levitate vel pondere refpectivo ad aerem gaudeat inclufum hoc calidum elementum.

\section{Aperitio five reclufio camini calefacti.}

Uum camini murus lento calore tepefactus fit, \& jam aptus recipiendi ignis gradum majorem redditus, operculum dictum five bractexe aperturam fuperiorem tegentes auferuntur, \& maffa carbonum inclufa nudatur; ad primam aperitionem calor plenus inde exhalat \& faciem intuentis ferit; ipfi vero carbones, quamvis calorem fpirent, usque tamen. nigerrimi \& fui coloris funt, nec ullibi micat ignis lucidus: Elapfo vero circiter unius horæ quadrante magis magisque apparet ignis flammans, qui carbonum nigram fuperficiem tenuiter lambit; dein mafla hæc carbonarea fuperficietenus accenfa fucceffu temporis omnis in ignem apertum abit.

Quum itaque poft tot dierum occlufionem apertus tandem fit caminus, multa circa carbones fic calefactos \& tandem nudatos occurrunt notatu digna, fcilicet

I. Quod calor tam diu inclufus non modo in carbonibus \& materiis fulphureis ligneis tam diu vivere, fed interea ad multum gradum increfcere polfit; nam ex carbonibus nudatis \& adhuc nigerrimis, \& in quibus nondum fcintilla vel mica ignis aut lucis apparet, $\mathrm{pirat}$ calor denfiffimus, non aliter ac ex foco ignito, exftinctis prunis.

2. Poft elapfum horre quadrantem apparet primum ignis vivusin carbonibus, \& hoc ex folo aeris contactu \& tanquam fponte fua fine ullo fufflamine : prorumpit primum flamma levis, qux quafi circumvolitat car- 
bonem \& innoxio igne lambit, \& circumcirca effluviis ejus pafcitur, antequam ignefcere videatur carbo. Obfervavi torrem quendam ex rima muri pendentem \& a reliqua carbonum maffa ad 2 pedes diftantem, quodille ex folo aeris contactu flammam conciperet leviffimam,jam perire videbatur, jam fponte accendi \& ad diftantiam a corpore fuo in aere ipfo vibrari \&. quafi ludere, \& hoc per octantem horæ, antequam ulla appareret ignis fcintilla in ipfo corpore carbonario, fcilicet cum materia phlogiftica circumfparfa prius depafta effe videretur; hxc figna funt, vaporem quendam fulphureum aut nitrofum inclufum diu camino \& circa corpus fuum condenfatum phosphori \& ignis fatui inftar ab aeris contactu in flammam cito refolvi, qux circum matrem fuam innoxia quafi erret $\&$ undulet, nec radices ullas agat, nifi cum foetor hic nitrofus prius deflagraverit: flamma etiam admodum levis \& perniciffima in apices terminatur jamque difparet, jamque fubito rurfus emicat, non aliter ac flamma errans in fylvis \& locis fulphureis \& paludinofis fub obfcura nocte. Ipfum hunc torrem in apertum diem protrahebam, experturus num halitus ille fulphureus ex maffa fubjecta carbonum propullularet, vel annon ex ipfo finu torris tanquam effluvia exhalarent, compertum eft, continuaffe flammam hanc in aere, \& leviorem ac acutiorem adhuc exftitiffe, nec incanduiffe lignum hoc uftum nifi poft elapfum 5 vel 6 minutorum primi generis.

3. Adhuc obfervatum eft, ignem non ex aliis carbonibus prorupiffe quam ex illis, qui immediate jacerent fub apertura. Quum enim mirarer indolem hujus flammæ, quæ tam innoxie \& fine liefione lamberet carbones; hinc etiam obfervationis gratia jubebam, ut dimidia modo pars aperturæ nudaretur, reliqua dimidia adhuc occlufa manente, apparebant tunc, ut prius diftum eft, carbones illæfi \& mortuo quodam igne foeti, fed poft alicujus temporis effluxum, ab illis carbonibus erumpebat ignis, qui immediate fub apertura jacerent, non vero ab illis, fuper quos adhuc operculum dictum, quamvis ad 6 vel 7 pedum abinde diftantiam, erat. Exhis judicari potuit, in flammam refolvi tantum illam voluminis vaporofi \& effluviorum partem, quæ immediate ab aere tangeretur, \& quæ perpendiculariter in aerem evolare poffet, non vero qux adhuc a contactu mutuo per obliquitatem vel angulum quendam impedita effet.

4. Atvero fi una recluderentur foramina inferiora fornacis, qux verfus focum ducunt, ftatim videbis fine mora \& fucceffu prædicto temporis in apertum ignem erumpere inclufum calorem; excitatur enim a transfluxu aeris, qui ab inferiori loco alvei \& torrentis inftar verfus fuperiora fluit, \& alimenta præbet calori, qui inclufus \& diu refrænatus, qua datur porta, catervatim e quolibet carbone ruit.

\section{Qua ratione imponi folent vene \& carbones, ut lique factio debite peragatur.}

Uum murus igni proximus calore primi \& fecundi gradus fit imbutus, \& ad receptionem ignis ulterioris \& fuforii rite aptus factusque, dein etiam per gradus augendus eft ignis: unde reclufo camino nulla Clasfis I. de ferro. 
in rotam admittitur aqua per 10 vel 12 horas; \& fic follibus quiefcentibus, nuilus in focum aut accenfos carbones fipirat ventus. Tandem poft elapfum dicti temporis primis diebus rotæ fuppeditatur non multa quantitas aqux, five follibus lentus motus, adeo ut tantum debilis aura focum refocillet \& carbones vivificet; ficque per gradus augetur ventus \& cum. vento intenditur ignis, quod fit circiter per 10 aut 14 primos dies. Nifi enim momenta graduum \& augmentationum rite obferventur, $a b$ ipfo initio contrahet vitium caminus, quod temporis proceffu redundabit in opus ipfum liquatorium. Detrimenta ex repentina nimis murorum accenfione oriunda videbis alias.

Quod venarum \& carbonum impofitionem (quæ vocatur OpSettning) attinet, primo poft reclufionem die non nifi 4 vel 5 vafcula venis plena quavis vice adponuntur, una cum debita menfura carbonum. Vafculum, quo ad hunc ufum utuntur famuli \& quocum impofitiones verix fiunt, conficitur vel ex ligno vel ex ferro, eft mediocriter cavum \& lpeciem vanni refert, capax 40 vel 50 茫. venæ, Svecice vocatur Tourg vel etiam Fat; per vafcula vel illorum numerum indigitatur quantitas venæ quæ imponitur. Quod vero menfuram carbonum attinet, funt corbes ex vimine aut virgis contexti; menfura hæc non multum abfimilis eft capfis aut cifiis cum rotula fuperimpofito corbe vimineo, vocatur Svecice Korg: quodlibet cifium 4 tonnarum capax effe folet, \& 3 vel 4 ejufcemodi carbone plena quavis impofitionis vice ad caminum adduci folent: 3 hujusmodi fimul fumta æquant I 2 tonnas five I leftam, qux eft communis carbonum in Svecia menfura. Carbones hi folent aperturam illam voracem fornacis fuperinfundi everfis corbibus five cifiis, \& cum ad fummum fere marginem repletus fit caminus, cum rutro dein æquatur fuperficies carbonum, poftea fuperinjicitur vena tot fcilicet vafculorum, quot defiderat focus aut digerit alvus; inmpofitio hæc carbonum \& venæ fimul fumta vocatur oppfettning five impofitio. E novo femper fuperimmittuntur carbones \& venæe, cum ad illam in camino altitudinem confumti fubfiderint, ut locus inde vacuus factus menfura vulgari adimpleri rurfus poffit, fed de his vide fequentia.

Primo itaque die numerus vafculorum venis replendorum quavis impofitionis vice erit 4 vel 5 : die fequenti cum adauctus calor murum \& focum penetraverit, vena 7 vel 8 vafculorum fuperinjicitur, tertio die adhinc magis, 9 f́ilicet vel Io; quarto I I ad I 2 ; quinto 14 ; fexto 15 ; ordine dein ad duodecimum vel decimum quartum $16,17,18,19$; dum tandem ad illum vafculorum numerum aut venæ imponend five terminum perveniatur, dum non amplius augeri poffit; dicitur tunc caminus fufficienter effe adauctus, five Svecice Fulloegt, aut plenarie auctum. Ratio eft, quia calor, ut prius eft dictum, lente \& gradatim augendus eft; nifi enim lente \& per gradus penetret calor texturam \& interiorem faxorum \& parietum compagem, frigus eis infitum \& humor venis \& fibris illorum inclufus nec ordine nec modo debito expellitur. De influxu caloris in corpora dura $\mathrm{ab}$ experimentis memoratis concludi poffe videtur, quod vis ignis in muro five in duris augeatur in ratione duplicata, quun momenta five tempora fint æqualia : auctam fuife quantitatem 
venæ a primo die ad decimum five decimum quartum ordine fequenti, fcilicet primo 5 , fecundo 7 , tertio 9 fere, quarto 10,5 to I I . decimo quarto 20 circiter, five in una ferie, $5,7,9,10, I$ I, I I $\frac{1}{2}, 12,20$. Quadrata horum funt 25,49 vel 50,75 vel 81 , I00, I 25, I 50, I 75, 200, 400, differentia lemper eft 25 ; adeo ut cum tempora fint æqualia, augeatur vis ignis in ratione parabolica five quadrata, prout dictum eft.

Quam exacte fervet hancregulam natura, liquet pariter ab experientia; fi enim intra minus temporis patium accelerantur augmentationes, hoc eft, ut primo die immittantur 4 , altero 8 , tertio i 2 valcula \& fic porro, fit hoc cum difpendio fufionis tempore fequenti, fi enim cogatur ignis jufto citius murum penetrare, reftitui hoc omnino debet in proceffu liquationis. Si fuforium opus per diutius tempus continuandum fit, hoc eft fi multa venæ \& carbonum fupellex adfit, tunc augmentationes dict:e adhuc lentius peragendx funt, nec nifi intra 14 diem ad terminum fuum perducendx; \& vice verfa, fi breve liquationis opus, aut curta fupellex ad manus fit : adeo ut fi opus fuforiun interrupta ferié in tempus 30 vel 40 feptimanarum protrahendum fit, lentiora erunt incrementa, nec nifi intra 14 vel 15 dies ad terminum fuum pervenientia; at vero fi opus brevioris temporis, nec nifi 4 vel 5 feptimanarum fit, tunc intra 9 vel I o dies ad fummam venx quantitatem aut valculorum numerum accelerari poteft. Aliqui regulam hanc vilipendentes intempeftivi lucri gratia gradus hos impofitionum non obfervarunt, \& ad fummam venx quantitatem intra Io vel i i dies properarunt, hoc eft, die decimo appoluerunt 24 vel plura vafcula, qux I 4 to vel i 5 to primum apponere debuiffent; fed poft aliquot feptimanarum elaplum cum damno \& carbonum multa jactura experti funt, quod xgrotare inciperet caminus, \& diminui inciperet quafi vis digeftoria foci, quodque recularet focus quotidianam venæ portionem, \& quafi fatiatus refpueret alimenti ufitati penfum. Ut primum animadvertit hoc excoctor, camino fuo liquatorio \& ægroto opem adferre fatagens, minorem venæ partem ei illico tradit, \& parciorem alimentorum copiam ei velut porrigit; \& fic diminuit valculorum numerum, \& pro 24 non nifi 20 vel 18 imponit, hocque continuat per aliquot dies, dum iterum convalefcat, \& venæ portionem priorem appetat \& defideret: pro valetudine reftituta Deo etiam agit grates excoctor; interdum enim nequicquam laborant, ut appetentia amiffa reftituatur. Morbus hic originem debet calori repente nimis in faxa muri aut foci intrufo \& coacto; fi enim vi multa in durum parietem agitur calor, omnis humor \& frigus in faxis latens non debite exhalare potelt, fed repentinus calor humores \& frigora partim includit, partim verfus interiora aut latera agit \& conglomerat, unde murus nondum humoris aut frigoris fui expers, cum igne, qui ad fummum perductus eft, continuo laborat; dum tandem vel in apertum ignem erumpit, vel in diverfam plagam cogit, ubi continuo contra ignem operatur, \& vim five vehementiam ejus sompefcere tanquam obnixus hoftis conatur. Accedit, quod vena propter copiam non bene liquata fed tanquam cruda inhærefcat muro, \& fic parietem calidum velamento aut tapete quafi obducat, qui fic obductus \& velatus vires \& 
calorem fuum in venam defluentem debite exferere nequicquam poteft. At if fuforium opus tantum perftet aliquot leptimanis ut 4 vel 5 , tunc itatim onerari alvus \& intra Io vel I I dies venis ad fatietatem ufque repleri poteft; non nifi poft elapfum 4 vel 5 feptimanarum febricitare folet caminus, fi nimia ciborum copia \& incoctis quafi dapibus intempefte onuftus fuerit.

Idem etiam in medio liquationis opere folet accidere ; fi enim nimia vena gravidum reddis focum tuum, \& prodigus reples voraginem illam fuperflua alimentorum quantitate, adeo ut pars omnino cruda \& incocta foco infideat, tunc vitium illico contrahit caminus, adeo ut diebus fequentibus vix nif dimidiam venix partem appetat, \& ficretrogrado paffu ad veftigia fua quafi redeat, \& vix ad dimidium numerum valculorum, quod fit cum multo carbonum difpendio.

Quo major \& capacior fornacis cavitas, eo etiam majorem copiam venæ requirit; major quavis impofitionis vice 20 ad 28 vafcula venis plena recipit, quum minor non nifi 12 ad 15 ; in quadam audivi numerum vafculorum fuiffe 30 .

Utplurimum accidit, caminum etiam capaciorem vix ultra I 5 aut 17 vafculorum venam recipere poffe, quum alius ejusdem dimenfionis \& magnitudinis 24 ad 28. Caufæ dantur plures; five enim primis diebus nimia venæ copia obrueras caminum tuum, adeo ut in foco crudx \& incoctre freces refideant. Vel fub fundo foci inclufus tenetur vapor aqueus, qui non aliunde exire poteft, verfus focum \& contra ipfum ignem fertur. Vel, faxum fundamentale foci ab reftu igneo in medio liquationis opere ruptum eft, \& per patentem hiatum verfus inferiora defluxerat volumen ferri. Vel ex vetuftate rimas duxerat fornax, \& fic variis in locis dehifcit. Vel funt carbones nimis humidi, \& humor inclufus in venas \& parietes fenfim diffunditur. Vel non adeft fufficiens menttrui, hoc eft, lapidis calcarei copia, cujus ope ferrum in foco fluidum reddendum eft. Vel, genus venæ cum alius generis venis mixtum torporem quendam liquori ferreo inducit.

Quum itaque tam lente peragitur opus liquatorium in camino $x$ grotanti, perit omnino pars multa carbonum; eadem quantitas vel menfura carbonum femper apponitur, fi vel numerus vafculorum venis replendorum fit i 5 vel fi fit 28 ; cum eadem quantitate carbonum funditur fic venæ parum aut multum, \& confequenter minor pars ferri liquati obtinetur, quod fit cum jactura infigni carbonum.

Vices impofitionum per diem folent effe I 4 ad I 8 ; adeo ut cum prxterlapfum fit tempus 24 horarum, vena \& carbones camino vicibus I 4 ad 18 fit fuperimmifla, hoc eft, femel intra quodlibet $\frac{24}{14}$ vel $\frac{24}{18}$ horæ fpatium. Primis vero diebus tardius imponitur, \& nec nifi decies aut duodecies intra noetem \& diem, dein vero citius; quum enim lentius fpirant folles, lentius etiam liquefcunt \& fubfident carbones, \& confequenter nec toties intra idem tempus fuperinfundi e novo vena \& carbones debent, ac dein cum plenus xefus \& ventus admiffus fit. Utprimum vident ad certam \& in muro determinatam profunditatem fublidiffe carbonum ab igne li- 
quatorum maffam \& quidem ad 5 circiter pedum, tunc fciunt tempus adeffe, locum \& ingluviem hanc vacuam novo carbone \& vena adimplere.

Sed ut eo melius proceffus ipfius operationis fuforix patefcat, neceffum eft, ut ferie, qua peragitur, exponatur.

Vena prius adufta fub malleo, qui ope aquæ \& rotæ elevatur, partim in fruftula, partim in pulverem contunditur; facile enim fub malleo diminui \& frangi poteft vena prius igne cremata \& pars ejus lapidea in calcem quafi redacta; expellitur inde humor, qui tenacitatem creat; \& vinculis per ignem quafi ruptis aut laxatis fragilis redditur, \& fic facile in arenam quandam fatifcit \& dilabitur: præftat, ut vena in fruftula minutim fit contula; fi enim in arenam \& pulverem, meatum omnem inter carbones patulum obftruit \& replet, \& igni vivo omnem tranfitum adimit, \& fic vim ejus inhibet \& impedit, quin in flammam erumpat. Sabulum etiam minerale facile carbonum interftitia permeat, \& non liquatum in focum ponderis fui gratia fubito delabitur:

Primis diebus, repleta carbonibus cavitate, fuperimponitur vena in medio, non vero juxta parietes; ratio eft, quia paries adhuc frigidus loco caloris frigus quoddam five minus calidum exfpirat, \& ipfum in prunis vivum ignem aliqua parte reftinguit, adeo ut ad diftantiam quandam a pariete venam non valeat fundere: \& quia nunc maximus in centro eft ignis gradus, hinc vena minutim contufa primis his diebus in medio reponitur, ut fcilicet fecundum lineam centralem deorfum fluens interea folvatur; quod non fieri poterit propius verfus parictes, nec fi julto major venæe quantitas fit fuperimpolita.

Tractu temporis cum magis magisque calefiunt, \& ignefcunt parietes, latius fuper planum hoc carbonarium vel remotius a centro fuperinjicitur vena; tandem polt 7 vel 8 dierum elapfum, vena etiam prope ipfum parietem infertur, fcilicet cum calor e pariete fpirans xquet gradum caloris in prunis, tunc per totam aperturam difpergitur glarea hxe ferrea aut metallica: tandem cum major in pariete fit calor quam in prunis, parieti advolvitur major pars venæ, quam in totam aream carbonariam alias inmittitur. Dicunt enim parietes femel accenfos \& debite ignitos tantam venæ copiam requirere, five vocabulo illis ufitato, attrahere, quantam fere totum volumen igneum parietibus his inclufum. Exinde deduci poffe videtur, e muro primis diebus exhalare calorem reliquo frigidiorem, adeo ut ei propiora pigrefcant; dein majori igne imbui faxa, dum tandem æquet ille gradum in prunis; tandem etiam fuperat; calor enim in duris major $\&$ intenfior eft quam in levibus, pariter ut frigus. Idem etiam accidit in foco, primis diebus inhæret ferrumliquidum parietibus, dum illiadhuc frigidum quid \& humidum fpirent, dein incalefcit magis \& magis, de qua re infra.

Dum iterum fubfident carbones injecti ad altitudinem 5 circiter pedum, quod fieri folet intra $I_{2}^{\mathrm{T}}, \mathrm{I}_{\mathrm{T}}^{3}$ vel 2 horarum fpatium, fuperinfunduntur novi, refupinatis cifiis, qui infuper ope rutri aut crucis cujusdam ligneæ æquantur, ut vena æqualiter fuperinfterni poffit; hoc facto, injicitur vena $4,5,10,15,24$ vel 30 vafculorum, fecundum defiderium \& appetentiam foci aut camini, de qua re prits actum eft: minerali five ferreo hoc lapide Claffis I. de ferro. 
comminuto tota carbonum fuperficies undique contegitur, adeo ut nihil nifi vena appareat, \& flamma reverberii ad parietes usque trudatur. Obfervabitur etiam, ubi caloris gradus eft maximus, five in medio five ad latera; principio operis liquatorii eft calor maximus in medio, fed fucceffu eft maximus circa latera; \& ubi intenfiffimus eft calor, ibi etiam fruftula majora venæ crematæ conjiciuntur; quo enim integriora funt, eo vehementior ad folutionem vel liquationem illorum calor requiritur.

Si diverfa venarum genera dentur, commifcenda funt; in quibusdam locis commifcentur Io ad 20 fpecies, in quibusdam modo 2 vel 3 ; fed induftrius operator indolem uniuscujusque exploratam habebit, \& fic certum cuique locum in plano dicto carbonario, hoc eft, in camino defignare fciet : genus fulphuratum accipiet locum ad parietem e diametro ventiaut orificii ventilatorii oppofitum; fulphuris enim liquati flamma faxa \& ferrum corrodit \& confequenter orificium dictum ampliat \& diducit, pariter etiam laminam ferream, qux aperturam muri pectoralis claudit. Genus venæ, in quo lapis calcarius multus fit, locum accipiet fupra ductum fpiraminis aut follium aperturam.

Plurima excoetoris ars in eo confiftit, ut fciat quantitatem certam cujufque fpeciei determinare, ut inde obtineatur ferrum bonæ indolis. Si fulphure multo fcateat vena, ut debita ratione commifceatur cum' vena, qux fulphure prorfus caret. Sique 20 genera adfint, noffe debet notam cujusvis, \& confequenter quanta cujusvis pars cum alio mifcenda fit, ut ex mixtura illa ferrum genuinum \& inculpatæe indolis habeatur.

Vena ferri non facile per fe liquefcit, nifi optime prius adufta fuerit, five ignem calcinatorium pertranfierit; quo magis ignem hunc paffa tit vena, eo facilius in fluorem vi ignis fuforii redigitur: omnes enim ligationes vel fulphurex vel aquex vel falinæ ruptæ aut laxatæ funt, unde non folum ab igne melius penetrari poteft textura ejus, fed etiam in partes rumpi \& difcerpi.

Sed quoniam per fe non facile in liquorem redigitur, præfertim fi dives fit nec multum calcis in finu fert; hinc neceffum eft, ut partem calcis uftr aut vivæ quavis impofitionis vice etiam adjiciant: utque hæc eo melius cum venis conjugium quoddam ineat, in medio five in centro aperturæ fuper ipfos carbones ultimo loco fuperinjici folet; quibusdam in locis $\mathrm{r}$, in aliis vero 2 vel etiam 3 vafcula plena, prout vena plus aut minus ejus requirit. Calx viva menftrui inftar eft in folutionibus ficcis, nifi adfit tale menftruum vel materia folvens, partes metallicæ in venis nequicquam a lapideis, hoc eft, ferrum a recrementis fuis fecerni poffunt; liquor ferri, fi calx nulla adfit, magis \& magis lentefcit, nec fcorix fupranatanteslinquunt particulas ferreas, quas in finu indivulfas tenent. Aliquibus in locis, ut Roslagix \& alibi nulla calce indigent, quia calcarius lapis ipfi venæ intertextus eft, \& intimis ejus fibris infidet, \& undique rivulorum aut venarum fanguinearum inftar tranfit \& diftinguit. Expertum etiam eft, filiceumlapidem prius calcinatum loco calcis ver: fubftitutum effe, nec fucceffu caruit periculum; lapis enim filiceus in genus quoddam calcis crematus abit: alias lapis filiceus multam fluiditatem impertiri folet venis fulphuratis' ut 
æreis five cupreis, ejus ope fecretiones facili negotio peraguntur; de quibus alias.

Qua ratione calor penetret dura corpora \& parietes faxeos, \& fenfim etiam in duris fphæram quandam moliatur, videre licet ex vapore aqueo, qui per canales ferreos five fiftulas ex caverna aut fovea predicta prodit: primis enim diebus, quum calor non adhuc plene fundum penerraverat, vapor exhalat frigidus; fed dein poft elapfum aliquot dierum vapor five halitus ille aqueus tepidior fentitur, \& tandem ad fummum gradum educto opere liquatorio calidifimus eft, adeo ut ori manus admoverinequeat; evaporatur etiam denfius aqua \& inftar fumi craffioris; quod fignum eft; calorem penetraffe fundum fuum ad foveam ufque.

Alias primis diebus adhærefcit parietibus \& fundo adhuc frigido tenax liquor ferreus, qui magis magifque denfatur; fuccedente vero temporé lenta illa adhærefcens materia folvitur \& emollefcit, fed modo fecundum longitudinem foci; adeo ut fundus primum nudetur in medio, dein ad parietes; quoque liquefcit magis pars hrec fundi foeculenta \& feparatur a parietibus, co majori ignis gradu penetratos effe parietes foci fciunt.

\section{Signa ex quibus judicat excoctor, num major vel minor quantitas vence aut carbonum im- ponenda fit.}

FXcoctoris fcientia \& officium in eo imprimis confiftit, ut genuinam raE tionem quantitatis venæ \& carbonum fciat immittere, utque ex fignis judicare poffit, num vena adhuc vel carbones adjiciendi fint: fi enim jufto major copia carbonum immiffa fit, fine ufu \& effectu in venas debito confumitur \& evanef cit quantitas carbonum, preter quod ferrum nimio igne quafi uftum \& coctum, non illius indolis fit, ac fi ratio fit jufta utriufque. Si vero major pars venæ adponatur, ferrum inde enafcitur crudum, nec a partibus foeculentis, lapideis \& fulphureis liberum exiftit, \& adhuc quafi immaturum micis grandiufculis nitet : preter quod ex onerato nimia venæ copia camino pereat velut appetentia \& fames ejus; adeo ut non arripiat magis oblatam venam ut prius; fed partem ejus refpuit. Ex his patet, quam multa in eo ars confiftat, ut fiat fufor carbonum \& venæ quantitatem debite proportionare.

Pariter etiam primis diebus fedulo obfervabit fufor, qua proportione venæ quantitas adjicienda \& qualiter augenda fit : ex prioribus liquet, augeri quotidie debere quantitatem ufque ad certum quendam diem \& vafculorum numerum aut terminum; quod ex fignis judicabit.

Sed antequam peritus excoctor fignis fuis \& indiciis fidem habere poffit, ficiet etiam qualitatem fornacis \& foci fui, hoc eft, fciet vitia aut virtutes camini: fciet conftructionem ejus, num fundus ejus humidus fit, vel num fovea fub foco parata fit juftæ dimenfionis; num liber fit transitus vapori per canales ferreos: num folum circumcirca uliginofum aut ficcum fit; num faxa foci recentia fint \& nuper ex petra excila vel non: 
num murus camini faxis genuinis vel fpuriis conftet: numvetuftus \& exefus gradum caloris debitum recipere recufet; num ex nimio ufu \& vetnftate rimas duxerit: num parte fuperiore nimis hiet \& apertus fit: num v́entre tenus nimis amplus \& obefus ; \& plura alia qux noffe omnino debet fulor, antequam ex fignis certum de impofitionibus judicium ferre polfit.

Scict etiam liquator qualitatem venx, alias indicia exploratorem fallunt; num filicet dives aut inops ferri fit; num fulphure, arfenico, aliisque malignis heterogeneis fit referta, vel num illis plane deftituta: quale genus faxi infit; cui matrici inhæreat ferrum; num facile cedat igni, num diu refiftat; num menftrui calcarii copia abundet vel non; quales inde proveniant fcorix; qualis ejus in foco fit color; qualis motus \& coctio; $\&$ qualis ejus fuiditas.

Perpendet etiam, quales fint carbones; ex quo ligno cremati, num duri aut molles; num ponderofi aut leves; num ficci aut humidi.

Cautus \& prudens excoctor opcram femper navat, ut minor pars venæ apponatur, quam requirit appetentia foci, five quam defiderat caminus; vocatur hoc Svecice, laeta ugnen kraefua, five bolla ugnen $i$ kr af fuande, hoc eft,ut plus jugiter fitiat: ratio eft, quiainde melius fecernuntur a metallo recrementa nociva, \& fic melioris notæ ferrum obtinetur: fed adhuc magis ob illam caufam, quia periculum inde evitatur, ne caminus aut focus nimia venarum aut alimentorum copia femel oneratus vitium contrahat, ut vix dimidiam venæ partem dein efuriat \& digerat quam prius.

Indicia, num major quantitas venæ vel num major carbonum apponenda fit, funt præcipue fequentia:

1. Si appareant micx quxdam vel fquamx recrementis emiffis inhxrentes \& præfertim illis, quæ ultimo cum ipfo ferro e foco folent effluere; interdum etiam fimiles mica fuper ipfum ferrum jacent; quoties ergofic fquamolix funt fcorix aut ipfum ferrum, fignum eft venæ partem adhuc requiri five caminum, ut ajunt, plus defiderare aut efurire, feu nimiam copiam carbonum in ratione ad venam effe. Micæ dictæ fimiles funt nitido fterili feu glaciei Marix, ut vocatur; primis diebus usque ad I 2 mum jugiter fcoriis \& ferro infident: at vero cum nulla augmentatio amplius neceffaria fit, fubito difparent; mox vero quum focus vel caminus plus adhuc defiderat, \& venam quafi efurit, apparet nitidum illud fquameum. \& hoc fxpe in medio fufionis opere; quod ut animadvertit fufor, jubet ftatim ut unum vel bina vafcula lapidis ferrei adjiciantur prioribus, \& fic augeatur quantitas impofitionis. Nitor etiam hic inherere folet ferramentis \& contis in focum immifis, fed fi vena ferri admodum dives fit, non multa ejus copia apparet.

2. Si recrementa ex foco emanantia fint coloris albi, præcipue in 'extremitatibus, vel $f$ alias albe viridef'cant, fignum etiam eft, majorem copiam venx imponendam effe. Primis diebus albefcunt fcorix, quod oriri videtur a lapide calcario; nam eadem quantitas hujus lapidis primis diebus apponitur quæ ultimis, licet primis diebus non nifi 4 ad 12 vafa venæ quovis die imponuntur, ultimis vero 24. Sed fi vena ferri inops fit \& re- 
ferta lapide quodam calcario vel alio, fcoriæ albe folent viridefcere. Ratio quidem eft, fi jufto minor quantitas venæ fit, quod omne metallum inibi latens plane exfudet, adeo ut in fcoriis refiduum nihil fit, nifi pars lapidea in vitrum verfa; licet etiam calor viridefcens indigitet particulas ferrietiam inibi inclufas effe: aliter vero effet, fi minus caloris, vel quod eodem recidit, fi major quantitas venæ fit.

3. Si leves admodum fint fcoriæ \& inftar aquæ limpidæ cum effluunt, nec tenaces volumina fua lente trahunt, \& in primo aere indurefcunt, fignum etiam nimis intenfi caloris eft, qui per appofitionem venæ copiofiorem temperari debeat.

4. Per orificium, per quod ventus in focum immiffus fpirat, fedulo confpiciunt magiftri; orificium hoc oculus fuforis merito appellari poteft: per illum fufionis fux ftatum explorant omnem; viam, qux illuc ducit, continuo calcare folent, \& vix intercedit horæ quadrans, quin per dictum foramen in medium ignem aciem fuam transmittant; vident enim volumen ferri agitatum, fcorias fupernatantes, \& guttas liquefacti ferri in focum decidentes: apparent guttulæ, vel quæ potius appellari poffunt, fcintillæ, partim candidæ nivis inftar, partim nigræ, inftar imbris rari in volumen fubjectum ferri vel in albifimas prunas delabentes: fi itaque pluvia hæc pluribus guttis candidis quam nigris conftet, fignum eft nimii caloris, \& quantitatis carbonum jufto majoris, \& plus venæe effe apponendum: fi guttule nigræ plures numero apparent; indicium eft, venam imbrisinftar decidentem non intime folutam effe, fed defuiffe carbones, \& intenfiorem requiri ignem. Convenientiffimus liquationis ftatus eft, fi pluvia dicta æquis partibus cang"darum \& nigrarum guttarum conftare poffit.

5. Ex fcoriis etiam per dietum orificium confpectis cognofcitur, qua ratio quantitatis carbonum \& venæ effe debeat: fi fcorix apparent coloris fufci vel nigricantis, indicium eft caloris debilioris, qui ut reftituatur, majorem partem carbonum effe apponendam : at vero fi fcorix apparent nimis lucidæ, fignum eft defiderari caloris intenfiorem gradum, \& plus carbonum effe apponendum: fi color recrementis fluidis fit viridis, \& eis æqualis ubique fluiditas, ratio jufta carbonum \& venæ cenfetur effe.

6. Si ferrum emiffum \& frigefactum calcarium quendam nitorem oftentet, fignum eft, nimiam copiam venæe effe appofitam: at vero fi ferrum in fractura glaciem referat, fignum eft exigua quantitatis venæ ratione habita ad quantitatem carbonum: utriusque jufta ratio eft, fi ferrum in fractura oftentet grana nitida, fed grifei coloris mixta cum granis fufcis: fed ex ferro ejusque colore hic non certa figna capiuntur; ipfa enim vena varietatem illam colorum \& nitoris ferro imprimit, five jufto major, five jufto minor venxe quantitas apponatur; adeo ut ex nitore five livore micarum aut granorum in ferro fracto certum judicium non poffit ferri de proportione media carbonum \& venæ; certum quidem eft, fi non fufficiens caloris gradus aut quantitas carbonum fit, quod nitor fit argenteus in granis \& ipfam venam in fractura referat.

7. Si juxta orificium, per quod ventus fpirat, in foco congelefcere videtur ferrum, adeo ut ipfum orificium videatur præcludi, fignum eft, carClafiss I. de ferro. 
bones nimium confumi, nec in debita ratione liquefieri venam; fed de his infra.

8. Si fcoriæ, quæimmediate fuper ferrum emiflum fe reponunt, fiftulofie apparent, \& coloris ferrugine \& 2 nigri, fed nihilominus pondere leves, fignum eft, rationem juftam carbonum \& venx efle : contrarium indigitant fcorix ponderof nimis \& compact \& nimia ferrugine tinctæ.

9. Ipfe fumus \& flamma, qux per fornacem furfum in liberum aera effertur, \& quæ vefpertino \& tenebrofo tempore liquide \& late diffufa ap paret, indicia prabet, qualis in ipfo foco fit venæexcoctio: fi enim altius evolat flamma mixta cum fumo, fignum eft, ebullire \& intumefcere volumen in foco, nec bene feparari inetallum a fcoriis, in quo cafu carbones fine effectu confumi folent. Funditur \& feparatur optime vena, fi flamma ex fornace exit acuta, albicans, candida, nec rubefcit nimis aut fintillas cum fumo altius ejectat.

Io. Non modo ex colore \& vibratione flammx cognofcitur ftatus liquefactionis, fed etiam ex colore parietum five murorum, quos lambit continue flamma erumpens. Ut if murus pectoralis viridefcat, a flamma filicet \& fumo, plus vena requiri fignificat; pariter fi parietes murifuperioris : fi vero nigrefcat, plus carbonum defiderari.

I I. Si maffa ferri crudioris extrinfecus fit quafi polita \& lavigata, fignificat plus venæ requiri: fi volumen ferri fcintillet, cum e foco erumpit, plus carbonum defiderari; \& plura alia, de quibus in fequentibus, cum agendum eft de divinatione coetionis in foco.

\section{De aftu EO ebullitione nimia liquoris ferrei in foco.}

FErrum reliquis metallis lentius \& frigidius in focum liquamine ferricaH lidifimo repletum defluens caufam extemplo luctx \& reagentix cuidam prxbet; exfultat illico tanquam aqua fervida in ahenis, furibundum fe gerit, intumefcit, ejectanturque fpumæ nigricantes \& fluctus tenues cuipidati five in acumina terminati; ficque volumen in fervore \& furore hoc fupra ipfos margines \& fumma foci labra xtuat \& expanditur, non aliter ac aqua fubjecto igne in cortinis. Nigris frecibus orificium ventilatorium oppletur; recrementa ex foco detracta fufci \& ferruginci coloris iunt \& multo marte referta. Æiftus hic \& luctatio partium ftato tempore redire folet, non aliter ac febris frigida; ftatim enim ut tanta ferri moles in pariete cavo collecta eft, ut verfus focum pondere fuo nutans delabatur, redit memoratus frigidus fervor; ferrum hoc impurum delaplum fermenti inftar eft; nifi excoctor fciat tunc fuctus hos compefcere, fcilicet recrementa tumida, \& jam quafi ex nimia lucta \& diftenfione defeffa \& quafi exanima e foco extrahere, dein rutris \& batillis uncis turgidum volumen continuo agitare \& fubigere, \& fxees circa aperturam venti confolidatas conto aut pertica difcutere, \& fuctuantis foci fuperficiem modo prædicto defpumare, lenta quadam tenacique materia focus oppleretur, \& obftiparentur orificia, \& labor omnis eluderetur, fpefque lucri vana redderetur. 
Plæterea fcorix fermgine tinet in finu multum ferriabfcondunt \& fecum ex foco trahunt, adeo ut multa ferri pars in furore illo aut ferventi lucta quafi pereat.

Quod itaque caufam hujus pugnx aut effervefcentix attinet, eft cadem quæ in liquidis aliis levioribus, in muftis aliisve laticibus miftis \& concretis dum fermentant : fi enim alcalia mifta cum acidis five alia, qux loco fermenti funt, in liquorem nondum fermentatum immittantur, illico folutis particulis \& ruptis clauftris partium exiguarum, bullefcit liquor; \& bullis verfus fuperficiem, hoc eft, furfum pracipitatis fpumefcit. Circaliquores hos ferreos licet graviores idem folet contingere, fi vena adhuc indiffoluta \&ab heterogeneis nondum libera in focum aut volumen fluidifimum ferri delabatur; motum ftatim excitat, \& liquorem in bullas, tumores, fpumas movet \& expandit. Vena enim dicta adhuc cruda \& non ieparata fermenti loco eft, nec ceffat fervor, quam cum materix fermentantes, quxcunque illx fint, foco vel educte, vel invicem divulfie \& feparat: fuerint: accidit in foco dictus fervor five furor æituans, quoties multa copia venæ adhuc crud: \& a partibus peregrinis nondum"liberatæ defluat: vel fi in loco parietis cavo collectum liquamen aliquantifper lentefcat, \& refrigeratum aliqualiter inde dein non particulatim \& pluviatim, ut prius, fed volumatim ex proprii ponderis nifu in ferrum fluidiflimum focidevolvatur; vidimus in hoc cafu turgefcere illico ferrum liquidum, \& male \& quafi infane fe gerere, non aliter ac fi duo fpiritus contrarii in una phiola confundantur. Non quidem obvium eft, caufas phænomeni hujus genuinas reddere: vel enim fuboritur prelium \& fluctuatio dicta ex commixtione frigidi cum calido; fi enim in calidifimum liquorem præcipue metallicum injicitur faxum quoddam vel ferrum frigidum, fit fatim pugna frigidi cum calido \& vice verfa; \& confequenter illud, quod fluidius \& calidius eft, falire \& effervefcere incipit. Vel oritur ex eo, quod vena five ferrum in pariete cavo fic collectum, five in medio camino natum \& conflatum, nec partibus extraneis adhuc privatum, pondus inter fcorias \& ferrum, medium poffideat; unde nec confortium poteft habere cum volumine puro ferri quia ponderofiori, nec cum recrementis fuperficiem tenentibus quia levioribus, fed locum intermedium intercepturum cum utrisque mif́cetur; adeo ut moto liquamine, partes hæ crudiores conterminæ jam fubmerfa in volumine ferri abfcondantur; jam caput extollunt \& f corias invadunt, \& fic errantes confundunt utrumque liquamen, \& confinia fua turbant, fcorias immergunt ferro \& ferrum fcoriis, \& totum volumen tanquam in turbine aqux cum fedimento \& fxcibus fundi milcent; in hoc cafu pugna etiam exoriri poteft, nam ferrum ut gravius partes fcoriarum ut leviores continuo a fe disjicere conatur, \& confequenter in toto liquamine difcors motus aut conflictus exiftit. Vel etiam in partibus crudis, qux in focum ex loco decliviori volumatim ruunt, humor aliquis five vapor fulphureus inclufus eft, qui in medio ferri liquore a nimio \& repentino calore, aeris aut aquæ inftar, difpanditur \& in bullas aut fpumas tumefcit. Vel etiam alia caufa datur, qux fenfus noftros adhuc latet, quxque ftum hunc fermentativum producit; non enim aliter fe res habet in li- 
quore corporum duriorum gravifimo, quam in liquore aqueo, oleofo aut fpirituofo leviflimo, modo eadem utrique fit fluiditas; particulæ enim duriorum corporum prælia inter fe cernere \& pari modo confligere poffunt, ac particulæ leviorum \& liquidorum. Hæc qux dicta funt, confirmantur ab experimentis quæ fequuntur.

I. Si carbones nimis humidi fint, ut \& vetufti \& confequenter debiles, adeo ut vena non debite liqui, \& in partes minimas \& fluorem purum folvi poffit, videmus oriri luctam memoratam; carbones enim humore quodam gravidi non primo ignis gradu, nec fecundo in defluxu per caminum candefiunt, \& quamvis candefiant, vix tamen inde omnis latex expulfus eft, fed usque particulæ vaporis inclufx fenfim cum favillis inde derafis in ignem \& venam liquandam erumpunt, \& fic ignis vim infringunt \& impetum ejus refrenant, ut filicet non bene foluta vena $\&$ adhuc cruda feu heterogeneis innexa in focum defluat, \& motum dictum ciat. Idem etiam accidere videmus, fi perparum carbonum fit in ratione ad quantitatem venæ.

2. Æftus ille focalis etiam progignitur, fi copia calcis fufficiens non adfit, vel fi lapis calcarius vilis pretii \& momenti fit; calx enim, ut dictum eft prius, in folutionibus ficcis menftrui loco eft; fique folutiones nulla vel vilis notæ calce adjutx peragantur, partes leviores a ponderofis, lapideæ a metallicis, molles a duris, mixtx' a puris, in foco non feparantur, fed pugnam mutuo ineunt, \& non nifi finito prælio pacem agunt \& in uno loco $\&$ foco conveniunt.

3. Oriuntur tales luctz utplurimum ab ipfa obliquitate parietis aut muri, qui fcilicet a ventre tendit verfus focum, quam partem focus fuperior maxime occupat; fi illa ibi obliquitas fit, ut fecundum parietem rivuli venæ liquatæ non fatis perpendiculariter poffint defiuere, fed in cavis quibusdam locis tanquam in thalamis \& toris morari \& fifti, \& per tempus ejus volumen quoddam colligi; interea enim lentefcit \& in pariete haret, ficque vifci \& glutinis inftar pendet, nec in focum itillat, nifitantaliquaminis ferrei copia fit, ut pondere fuo declinans a devexo quafi clivo fponte trahi aut delabi, vel tardo tenacique volumine fecundum parietes inftar picis deferri polfit: exinde fequitur, quod ferrum reliquis metallis lentius \& frigidius in focum liquamine ferri calidiflimo repletum defluens caufam extemplo luctx cuidam præbeat: quodque talis lenta \& craffa liquaminis derivatio autlapfus in caufa fit motus predicti, experientia teftatur: fi enim per orificium venti paullo ante motum ortum introfpicis, vel dum exoriri videtur, videbis lentam dicti generis \& piceam ferri materiem ante foramen venti volumatim delabi, \& gurgitiferreo jamdum turbato fubinde immergi, adeo ut oculatus caufam \& originem luftrare poffis. Morbus hic non abfimilis eft febri frigidæ, quæ ftatis momentis \& alternis redit; effervefcentia hæc vel 6ta quavis hora vel I $2 \mathrm{ma}$ focum occupat, qui frigefcit primum \& tremit, dein calet \& redivilcit. Si etian guttulæ nigræ nec ullæ lucidæ apparent, fignum etiam eft, frigus aut febrim dictam venturam effe. 
Finito denique opere liquatorio pars illa muri, quam infederat liquamen collectum, valde excavata \& exefa apparet, \& hoc plerumque fuper orificium venti. Ejusmodi lacunæ \& convalles in pariete a perpetuo venti allifu aut attritu formari \& cavari folent. Si enim directio venti illa fit, ut non firaliter furfum feratur, fed volumatim unam partem perpetuo lambat \& feriat, tunc igne adjutus facile fcrobem excavat \& molitur, \& juncturas ut \& compages ipfas lapidum perforat \& perterebrat, ficque cubilia ejufcemodi pro ferro liquato format.

Quum etiam focus humido in loco fit conftructus, cumque aqua fubterlabens non per fiphones ferreos vaporofa omnis exhalet, fed pars in fundum foci fe infinuans vim liquatoriam infringat, \& fluiditatem in ferro fiftat; ejufcemodi fluctuum ejectatio \& ferri acuta \& culpidata ejaculatio animadverti folet: hæc omnia teftimonia funt, oriritales motus \& inimicitias a commixtione venarum crudarum \& non bene liquatarum. Quod ut adhuc confirmetur, perhibent oriri etiam fervores dictos a vena non bene calcinata; quo enim melius torretur flammis vena, eo etiam melius feparabiles in camino funt partes ejus metallicx, lapidex \& aliix, quxe fi ligatx fint, xgre disjungi poffunt, nec nifi præeunte fermentatione \& reagentia dicta in foco. In caula etiam dicunt effe venam minutim \& quafi in farinxefpeciem contufam, qux Svecice mioelbokadt vocatur; hxc enim interftitia earbonum facile in focum ufque cruda interfluit.

Signa venturæe ebullitionis, ex quibus prevident \& præfagiunt tyrones inftare motus \& labores, funt quæ fequuntur.

I. Si recrementa denfe erumpant foco, \& tumidx exitum quærant; fique longo tractu \& tempore volvantur, fignumi eft, intumuife jamdum ferrum vel l'corias fupra ferrum natantes, \& volumen fermenti inftar expanfum viam eruptionis tumide \& craffe opplere, \& fpeciem prebere ac fi quadruplicata quantitas fcoriarum fit, non aliter ac hordeum cum aquis fubactum, vel etiam cerevifix \& forbum admixto fermento.

2. Scorix etiam foco elapfie predicere poffunt venturos motus \& in. foco oriundas moles, fi enim tumidx primum appareant, \& ttatim ut foco eruperint, detumefcant collapfix, inque fe quafi redeant, fignum eft ortæe jamdum fermentationis \& fubfecuturx fluctuationis admodum vehementis; cumque tandem refrixerint fcorix, funt leviffimæ, fiftulof bullifque pumicis aut fpongix inftar fuperficietenus refertæ.

3. Color in f'coriis concretis aut frigefactis nuntiare etiam folet ven: turam in foco coetionem nimiam, fcilicet fi coloris non amplius fui fint, hoc eft, coerulei five viridis, fed fufci \& nigricantis; ftatim enim ut crafefcunt, obfcuræ \& caliginofæe apparent ; fignum quod vena adhuc non foluta, fed ferro gravida \& fcoriis intertexta infideat: fi enim lapis a metallo nondum fit immunis, nec metallum a lapide, pulvifculo crudo mineraliftipantur \& confequenter obfufcantur fcoriæ, adeo ut nec pars lapidea in vitrum fui coloris abire poffit, nec pars ferrea inde fecedere : \& quia tanta copia incoctarum venarum infideat recrementis effluxis, hinc etiam eje ctantur copiatim hic \& inde fcintillæx, tanquam ferrum candide ignitum Claffis I. de ferro. 
malleo percuffum; quæ omnia indicio funt, multum ferri ineffe recrementis, quod inde non feparabile in fluctus movet omnem foci undam.

4. Elonginquo etiam ex ipfa flamma peritus excoctor fcire \& augurari poteft, qualis in foco ftatus fit, num turba aut requies, adeo ut peregrinus in via ad diftantiam aliquot mille paffuum ex folo profpectu focionarrare poffic, qualiter in foco fe gerat liquamen, num moveat turbas, num tranquilla fit partium motio \& coetio, num alia rerum difcrimina fint; fed hoc tantum fub nocte tenebrofa, cum flamma e fornace vibrata lumen fium late diffundat. Si enim flamma alte fuper fornacem fubvolvitur \& denfe quafi undulat, hoc eft, fi ejectentur \& furfum glomerentur flammea quafi volumina, quæ in aere rumpantur \& difpereant craffe, fignum eft turbari focum \& pari modo ejectari ferrum in ima fornacis parte ac flamma in fuprema. Color ignis \& flammæ index etiam eft motus five tranquillitatis in foco; fi rubicunda nimis fit flamma, fi fuligine \& fumo quaficonferta, fi pulvere nigro carbonario denfata; fi fcintillx rumpant flammam, \& copiofe in aere volitent, fignum eft venturæ tempeftatis in foco.

Flamma etiam, qux continuo ex foco per aperturam ejus pectoralem five anteriorem evolat, \& murum verberat, prenuntia etiam motus venturi effe folet ; fi enim inæqualis apparet \& difcriminatim erumpit, emicatque acute \& evolat ftriatim, \& fubito moritur, iterumque emicat, fignum eft inchoati jamdum fervoris in foco.

5. Murus etiàm declivis pectoralis five fornicata, five frons obliqua foci, quæ a flamma erumpente continuo libatur \& reverberatur, \& fuligine quadam obfufcatur, prodit etiam, liquamen ferri in foco inclufum vel placide vel turbulente moveri; paries colore fulco \& fumofo obductus fignificat effervefcentiam \& xftum, pariter quod non liquatur vena, quodque partes leviores \& ignobiliores non deferant ponderofiores \& nobiliores, fed quod invicem conflictentur. Fumus hic five coloratio nigra oritur ex flamma, quæ particulis fulphureis \& carbonaceis mixta denigrat teftudinem \& fornicis dict:e faxa. At vero fi murus albe virefcat, fignum eft coctionis debitre. Murus ductui ventilatorio imminens eodem colore etiam tingi \& fuffundi folet ; pariter laquearia interiora ipfius orificii aut ventilatorii feceffus; fumofus enim vapor ex foco jugiter exhalat, qui colorefuo foci parietes obducit.

6. Liquide \& oculariter luftrare licet effervefcentix hujus initium \& proceffum; fi per foramen ductus fpiratorii transmittas aciem \& penitus infpicias, primum apparent pone ipfum orificium fcorix furgentes verfus os \& contra ipfum ventum, parietem illum crebris ietibus plangunt \& tundunt, non aliter ac fluctus ponderofioris undx litora vel clauftra; in apices terminantur hi fluetus, hoc eft, verfus fuperiora attenuantur velut cufpidati, nec volumine rotundo \& fluido, ut alias, feruntur; fignum enim eft, intumefcere liquorem \& in bullas expandi : ipfæ fcoriæ dein magis \& magis nigrefcunt, \& venam nigricantem \& crudam fuperficietenus oftentant; incipit fuperficies voluminis lentefcere, \& tandem immerfæ liquori ferreo ipfum ferrum in altum fubjicere, \& $\&$ fic totum liquamen in fluctus, fpumas \& bullas levare, nec definere motum aut iram quam cum e foco extrahan- 
tur, \& alveus hic defpumetur. Interea depluit imber coloris nigri ; partes vene nondum folutæ fupra orificium pendent, \& rivi ferri tenacis lente fic fluunt, adeo ut roftri aut nafi inftar fuperimmineant ori ejus, \& fic volumatim non aliter ac picea, quxdam materies in focum calidiffimum delabuntur; \& quia frigida in calidum \& denfata five crafriora in fluidiffimum liquamen merfantur, non mirum eft, fi conflictus inde oriatur: \& quia a flabris frigidis \& fortaflis etiam aquofis fpume dicte facile duritiem contrahunt \& horrefcunt, hinc itipite quodam arbuteo vel ferro cufpidato a faucibus orificii ejus jugiter excutiendx funt; facile alias obftipant \& preftruunt viam \& ductum illum fpiratorium five animx meatum præcludunt. Quum liquor hic ferreus fic intractabilis turbine quodam jactatur, multa ejus pars etiam in ductum fpiratorium fub fcintillarum fpecie projicitur, quibus orificium fenfim oppleri \& ftipari folet, vel precipue circulus oris ejus anguftari, hinc jugiter diducendus eft. Hac \& plura alia obfervari poffunt, fi per foramen dictum intrópicias.

Opus vero \& labor eft, ut motus hi impacati fiftantur \& compefcantur; nifi enim malo huic tempeftive open feras, nequicquam dein laborem \& fudorem impendes; fero veniet medela, fi vento preclufus fit meatus \& in foco concreverit volumen, hinc quibus modis fuccurrendum fit, dicam.

I. Quum inftare laborem huncfoci animadvertunt, conto aut rutro in' focum tumefcentem inferto volumen gravidum continuo verfant \& fubigunt; quum enim agitatur liquamen fermentatum five in tumores difrentum, paulifper detumefcit, \& iras qquafi fuas \& fervores deponit; non aliter ac aqua fervens in lacu five olla, ut primum fupra labra vafis difpanditur, injecto tantum falis frigidi pugno, live tumidoliquore per cochleare circumacto \& verfato, fedatur ftatim tumefcentia inque fe paullatim redit aqua: fic etiam liquor hic ferreus ex fubactione perpetua criftas fuas dimittit \& fentim collabi videtur: per. motum five undulationem artificialem commifcentur partes tam amicx quam inimicre, \& fic fucceffu agitationis leviora a ponderofis, \& lapidea a metallicis difcriminantur, \&rquodlibet fuum in foco locum fecundum gravitatem ejus fpecificam cligit.

2. Adhuc inftant labori miniftri, \& foras rutris fuis educunt fcorias fic metallo partim exutas: feoriæ jam tumidiffimæ longo tractu \& multo volumine ex foco volvuntur, \& quia in fuperficies tenues \& bullares cavitates mire expanfix funt, hinc etiam ingens apparet illarum copia, tanquam 2 vel 3 foci illis adimpleti fuiffent, non aliter ac farina cum aqua \& lacte fubacta, admifto fermento: fed utprimum educt: aerem tangunt, tumores deponuntur \& mitefcunt.

3. Recrementa, qux orificium venti tam craffe ftipant, fedulo debent pertica five batillo ferreo habili excuti, \& foramen pantum teneri; nifi enim huic rei ftudium impendant, facile preftrui poterit via fpirationis \& pulmonaria, \& omnis calor foci quafi vitalis exftingui.

4. Præverti etiam hoc malúm poffe experti funt, fí vena debito igne torreatur prius \& adolefcat; fi non multa ejus pars in farinam fracta \& comminuta fuerit, adeo ut interftitia inter prunas legens in focum prxceps 
\& nondum præparata defluat: fi carbon es tempeftati pluviof $x$ \& humidx non fuerint expofiti; vel fi fint, quod eis admifceantur carbones fieci: pariter fi cavitas fornacis parietibus nimium cavis \& parum obliquantibus conftet, fique feceffui aut ductui fpiratorio nimia obliquitas, nec fitus nimis horizontalis detur: fique fofla fine cella fubterranea a fedimentis \& illuvie purgetur: \& fi plura obferventur, quæ ut precepta felicis liquationis agnolcunt excoctores.

Sequitur etiam ut damna \& detrimenta ex tali voluminis ferrei æftu oriunda expediantur.

1. Si fervor fit mediocris nec nimius, hoc eft fi femel quovis die vel quovis biduo recurrat $\&$ reciprocetur febris dicta, nihil damni afferriliquationi perhibent; potius enim ex motu inteitino particularum folutio \& feparatio fit, non aliter ac liquor fermentatus, difcordia ceffante, tandem clarefcit \& ferenatur; unde etiam a fedimentis \& facibus purgatur focus, $\&$ confequenter dein melius in foco peragitur liquatio, adeo ut tanquam valetudini reftitutus focus plus venx aut cibi cum ftomacho fuo beneconvenientis dein efurire videatur.

2. At vero fi crebro recurrat, \& bis aut ter five fapius quovis die, fique cum vehementia quadam xftus dictus tanquam effrænis furat, jacturam fatis infignem ferri patiuntur domini : non enim metallica pars exfcoriis debite exfudat in foco \& elixatur, led eis inharefcens foras fimul cum recrementis educitur; unde etiam forix dicta ferro apparcnt referta, quod tam ex colore quam ex pondere cognofitur.

3. Nifi etiam induftrius excoetor adhærefcentes freces ex ore ductus fpiratorii jugiter decutiat, ut apertis labris lpirare poffit ventus, etiam præcluderetur facile orificium \& fuffocaretur ignis inclufus.

4. In dicto cafu, pereunte multa parteferri, in vanum \& fine lucro \& effectu confumuntur carbones:

5 Peracto fervore, ferrum etiam filtulofum \& indolis pejoris obtinetur : finita enim lucta liquorum, fcoriarum fcilicet $\&$ ferri, fuperficiem ferri frigefacti videre licet hiatibus \& cavernulis five puftulis fed exilibus plenam; quæ veftigia funt exactæ tumefcentix.

\section{Indicia externa fatus interioris five liquationis in foco, ex. Alamma pracipue petita.}

PRius dictum eft e longinquo ex ipfa flamma alisque fignis videri \& divinari poffe, quis in foco ftatus fit, quid flamma inclufa operetur, qualis fit fubditus ignis in foco, \& plura alia; adeo ut non opus lit luftrare interiora \& vifcera rimari, qui fire cupit liquefactionis fortem: ut cedere.

I. Si flamma glauci coloris fit, fignum eft, liquationem optime pro-

2. Dein fialbefcat.

3. Si flammæ color nimis cœeruleus fit, indicium eft, crudam effe venam, \& adhucfulphure craffiori pollentem; unde fi torrefacta bene fit igne calcinatorio, color hic coruleus limpidefcit \& evanidus fit.

4. Color 
4. Color flammæ flavus fignificat liquationem nimis ficcam in foco.

5. Color rubefcens vero carbones noviter effe infufos, \& nondum candefactos \& vivos: alias fignum dant xettuantis foci five luctantis ferri; de qua re modo actum eft: \& adhuc magis fi fcintillæ cum fumo ex flamma fe proripiant, fique paries fuligine quadam infufcetur.

6. Flamma exilis nec late fupra aperturam fuperiorem diffufa fignifcat viam eruptionis ejus præclufam effe, vel a vena obftruente meatus vel a pulvere carbonum.

7. Ex altitudine \& lata difperfione flammæ judicatur de vena, quod cruda nec foluta in focum defluat, quodque xftum venturum præfagiat: Per rara \& vacua interftitia libere permeat ignis, \& in altum globatim effertur: unde optima eft flamma non multum elata.

8. Flamma fere eadem eft primis inchoarx liquationis diebus ac dein fequentibus, quamvis differat ratio quantitatis venæ, præter quod primis diebus albentior fit, poftea corulior.

9. Flamma reverberata \& per aperturam fornacis fuperiorem evolans, tantummodo circumcirca parietes emicat, non vero in medio; in caufa eft, quia verfus parietes cogitur, impediente vena in medio fuperim. miffa, ficque preclufis meatibus, juxta parietes erumpit. A binis aperturæ lateribus altior femper apparet quam alibi, fcilicet immediate fưpra aperturam muri pectoralis, five per quam emittuntur liquamina foci; pariter a parte e diametro ei oppofita; non verofuper ipfum fpiraminis fpecum aut ductum.

Ex volumine ipfiusmet ferri judicari etiam poteft, qualis ratio carbonum \& venæ fit, ut \& qualis indoles ferri : fi enim ex ferro emiffo fintilla nitidx \& corufcx tanquam ex fornacula erumpant, fignum eft duritiei in ferro; quoque major copia fcintillarum aut micarum, co durius; in quo cafu requiritur augmentum carbonum five diminutio venæ. Quum vero defideratur durities in ferro, ut filicet quun incudes majores funt fundendi, \& fupellectilia alia ferrea, quæ crebris ictibus non cedent, jufto major quantitas venæ apponenda eft, fed fit hoc diebus ultimis operis liquatorii, tunc enim nulla timentur damna, aut fortes infelices liquationis; ultima enim manus aut finis imponendus eft: at vero ad utenfilia ferri mollioris, tunc jufta pars carbonum vel etiam major apponenda eft, quod pariter ultimis diebus peragitur; illum enim caloris gradum, quem femel conceperat fornax, confervare dein nititur; hinc fi augeatur vel diminuatur ratio carbonum aut venæ non procul a fine totius operationis, nihil refert, an caminus labem aut morbum quendam contrahat, non aliter ac fi vulneraretur, qui extrema patitur.

\section{Quomodo fcorice fe habent \&O ex foco emittuntur.}

PLurima pars venæ in fcorias abit, præfertim fi metalli inops fit: fcoriæ enim confiftunt modo partibus lapideis a metallica fecretis, \& fuperClafis I. de ferro. 
natant, quia leviores, ferrum aut volumen ejus gravius; quod enim fpecifice gravius eft, locum inferiorem occupat, \& vice verfa ; hinc eodem momento, ut ex lapide exfudatur ferrum, leviora tranfit \& particulis elementi gravioris fe immergit; hinc fcoriæ maxima fui parte lapidex \& fulphurex funt, ufque tamen non plane immunes metalli, quin ferri portiuncula inibi etiam lateant, quæ vel in globulos rotundos vel ovales tranfeunt, vcl etiam difperfa una cum lapide vitrefcunt, \& vitrum vel colore viridi vel nigricanti tingunt : hinc videmus partem recrementorum \& fordium $\mathrm{ex}$ vena feparatarum mixtam effe cum copia metalli. Præterea volumen fcoriarum amplum \& multum apparet, \& confequenter citius augeri videtur, guam ferrum.

Excoetor per orificium fpirationis fedulo luftrat, ad quam altitudinem afcenderint dictx fordes \& recrementa, \& num tempus fit illas emittendi : certam habet excoctor defignatamque altitudinem, ad quam cuna enixæ fint fcorix, contum infertum \& extractum fponte foras fubfequuntur, remanentibus illis, qux ad dictam altitudinem nondum pervenerant: in foco enim retinentur, dum fumma labra oris ventilatorii pertingant, nec altius afcendere permittuntur, ne fcilicet orificio illabantur, \& flabris præcludatur via.

Expertum ceft, quod fcorix multum contribtiant ad facilitatem liquationis \& feparationis metalli a lapide; adeo ut fi defint fcorix, qux fuperiorem locum in foco teneant, \& qua velaminis inftar ferrum infra ablcondant, facile comburi \& durum evadere ferrum poterit, \& fic tenacitatem ferro debitam amittere, unde tutum fub tunica dicta \& pelle fcoriarum la tet ferrum, non aliter ac aqua fub oleo, qux nec media xftate putrefcit, nec hyeme concrefcit : frepius obfervatum eft, fi nudetur ferrum, fcoriis omnibus exemtis, quod facile in æftum \& motum intempeftum agatur:vena enim in calidifimum \& ponderofifimum liquorem labens, non ftatim qua calorem \& qua pondus concordare poteft, fed oritur quxedam quafi difcors concordia; unde etian excitur ferrum in motum, qui non definit antequam fermentatio peracta fit, \& leviora a gravioribus, hoc eft, illaqu: minorem calorem $\mathrm{ab}$ illis quæ majorem concipere poffunt, fine feparata. Quod fcorix menftrui loco fint, five quod illarum ope fecretio \& liquatio peragatur melius, expérientia dictitat. Si contintı obveletur ferrum fcoriis, inde melius coctum \& tenacius evadit, aliter vero fi privatum feriiis five nudum fit, hoc eft, fi mars nudum corpus nudofque artus quafi vefte oftendat. Ratio eft, quia vena primum foluta defiut in fcorias, qux leviores funt ut \& frigidiores quam ipfum volumen ferri; vena quamvis cruda inter fcorias adhuc morari-poteft, tam ratione ponderis quam ratione caloris, \& confequenter inibi tanquam in elemento fuo five menftruo fenfim incalefcere \& folvi; quodcunque gravius eft, tranfit fubito leviora, \& locum inter graviora petit, adeo ut per onnes gradus igneos trantire poffit vena, antequam folvatur \& feparetur : fi ruit fubito in volumen ponderofum, inibi ficce torretur \& aduritur, nec feparantur invicem partes leviores a gravioribus \& vice verfa : fi ruit ftatim in volumen calidiffmum, antequam per gradus illuc perveniat, motum ftatim \& pugnam frigidicum 
calido ciet; hinc ad feparationem partium multum contribuunt forix. Unde etiam, quum xituat \& fervet focus, detinentur diu fcorix antequam emittantur; fi enim mox emitterentur, \& in nudum ferri volumen vena collecta delaberetur, adhuc major vehementia exifteret, \& totum volumen a fummo ad imum turbaretur: at vero fi multa copia fcoriarum fupra fit, materia tenax ferri fubinde delabens, non in materiam nimis difcordem \& plane contrariam delabitur, fed in amicam, ubi facilius morari \& exfudari poteft.

Primis diebus, quum lentius augeturin foco ferrum, major copiafcoriarum detinetur in foco quam fequentibus : quo enim minor in foco $\&$ camino liquatorius calor eft, eo diutius \& altius teneri debent fcoriæ; fub illis enim fluidum \& calidum tenetur ferrum : at vero fi fubito nudetur, lentefcit \& afperatur ferri liquor, quia nihil menftrui adeft, cujus ope rurfus in liquorem diluatur. Hinc quo lentius evafit $\&$ magis diriguit ferrum, eo pigrius in foco exiftit leparatio, \& eo plus fcoriarum requiritur, hoc eft, eo denfiori quafi pelle \& tegmine operiendum \& muniendum eft volumen ejus.

In quibusdam locis, prixcipue ubi vena ferax \& dives ferri eft, five ubi non multa calcis \& lapidis copia ei ineft intertexta, detinentur intra clauttra fua fordes dicte ad multam fatis altitudinem, defenditur fic, ut prius dictum eft, liquor ferri a craffefcentia \& lentore; tunc intra quaslibet feptem aut decem horas non nifi quater vel quinquies emittuntur fcorix. At vero fí multo lapide \& calce imprægnata fit vena, fipius educitur ; \& quibusdam in locis femper fere patet orificium \& exitus, adeo ut continuus quidam \& lentus effluxus fit, in quo cafu non multi laboris eft excoctori \& famulo ejus circa focum illum \& os ejus cuftodias \& excubias agere.

Scorix per clivum arenarium deorfum oblique \& lente trahuntur \& laplu lecundo quafi feruntur; dein fuperinjecta aqua batillo quodam uncato fubtrahuntur, \& cifiis foras deportantur.

Quum itaque effluxerit debita recrementorum quantitas, clauditur ftatim apertura; protrahuntur e foco aliqux prunæ candidifime, fupra focum leviter volantes, \& fuperinjiciuntur 2 fpathæ pulveris carbonum, ut $\&$ pars pulveris fcoriarum, pariter arena cum carbone pulverato \& humectato mixta.

\section{Quomodo ferrum fuidum ex foco emittatur.}

Uum focus ferri liquore fit ad oram aperturæ ventilatorix usque repletus, adeo ut fcorits non amplius poffit obduci \& tegi, quin in dietam fpirationis aperturam irrumpant, tunc tempus eft iplum ferrum fluens \& ponderofam illam undam emittere \& focum evacuare; fed antequam recluditur orificium, per quod effluet, ferramentum quoddam magnum five contus ferreus, qui Svecice Brott/pett vocatur, in focum inferitur, adque omnia fociloca vertitur \& agitur, radendo \& rimando tam latera quamangulos, \& effringitur omne id, quod circa latera \& fundum diriguerat, \& abultima emilfionis vice eis inhæferat, nec cellat excoetor quam cum fæces \& fedimenta 
hæc avulfa lateribus \& locis fuis emota furfum ferantur; quia enim ferro leviora funt, utprimum a parietibus fuis evulfa funt, ratione levitatis fure pponte furfum emergunt. Hoc facto, immittitur rutrum, quod Svecice Lacht fpett dicitur; hoc fecundum fundum foci ducitur, \& præcipue circa anteriorem ejus partem, \& fic fundus fxce fua privatus jam raditur \& quafi levigatur ab omni inæqualitate, ne fcilicet cruftacea pars adhærefcat: hoc nifi quavis emiffionis vice fiat, accrefcere magis magisque talis materia poteft. Quumque hæc facta fint, \& quum verfus fuperficiem emerferint moles \& fordes fundi, ejusdem rutri auxilio poft moramaliquam efoco detrahuntur. Tali modo purgatur integre focus bis inter quamvis emiffionis vicem, fcilicet aliquot horis antequam emittendum eft ferrum, pariter mox cum emiffum fit. Sudat \& angit nunc tyro aut excoctor, maximus enim ejus labor eft, cum huic operi inftat, nam fuftinet comminus flammas flammarumque volumina, "è quibus undans quaficalor erumpit, quo facies \& nudi ejus artus circumfunduntur.

His peractis ex foco aliqux prunæ albicantes in aperturam per rutrum in foco circumactum factam protrahuntur, dein fuperinjicitur glarea fcoriaruin commixta cum arena \& cinere ufto, illo fcilicet qui fub ferro liquido five qui maffis ferreis calidis fubjectus fuerat, una cum aliqua parte pulveris carbonarii : hujus mixturæ ope impeditur flumen fcoriarum, ne erumpat, nec tamen ita præcluditur exitus, quin facile poffit aperiri; nam mixtura illa non in vitrum abire poteft.

Materia foci five illa, qux parietibus affixa effringitur, \& qua fuperficiem liquoris ferrei effracta tenet, non ex folo lapide \& fulphure conftat; fed etiam multa pars ferri ei intertexta latet, alias non fundum petere \& deorfum niti per volumen ferri ponderofum poteft, hinc etiam natans fuper ferri undam liquitur per aliquantum temporis fpatium, fcilicet ut pars metallica adhuc ei immixta inter fcorias debite poffit exfudari.

In quibusdam focis fieces fundi prædictx in majore quantitate apparent quam in aliis, ubi vena ferri admodum dives \& ficca eft, nec calcarii lapidis ferax: fi pars calcis fufficiens ad manus non fit; fi foci fundamentum fit humidum, hoc eft, fi vapor volumen foci per infenfibilem transpirationem refrigeret, fedimenta talia abunde inharent foci parietibus; præcipue fi multum venæ \& parum carbonum apponatur: materia illa freculenta foci nihil aliud eft, quam pars quxedam cruda \& nondum a metallo feparata, ferrum fcilicetjunctum cum lapide. Hoc etiam accidere folet, fi foci parietes frigidi fint \& vapores gelidum exfpirent. Dantur tamen foci qui ficci funt, ut \& vena, quæ præcipue inops \& pauperrima multo lapide gaudeat, quæ nulla fedimenta \& præcipitatajuxta fundum \& parietes deponunt, fed qux liquata fluidiffimæ undx fpeciem, fcoriæ vero ejus colorem turchoidis referunt. Quæcunque tamen fuiditas fit in laticeferreo, usque tamen rutris \& contis agitari debet, aut femel aut bis inter quamvis emiflionis vicem: ratio eft, ut impediatur incruftatio dicta focalis, ut \& per talem motum reciprocum \& agitationem in foco fuidius adhuc reddatur liquamen ferri, \& pars ferri in fcoriis adhuc latentis eo melius exfudetur \& eliciatur: fi enim ferrum globatim collectum in finu quo- 
dam recrementorum abfconditum effet, agitatis fcoriis, ut \& ferri volumine, pars ejus ponderofior deorfum fubfidet; pariter convertuntur \& refupinantur fcorix, \& confunduntur fic levia cum gravibus \& vice verfa, ficque demittunt fcorix, fi quid nobile in gremio abfcondant.

Emiffis fcoriis per orificium venti clare admodum confpici poteft mars in foco nudus, proditur enim colore rubicundo, quo a fcoriis, quxe magis albent, notabiliter diftinguitur. Quum itaque ferrum hoc ad oram dieti orificii adpulerit, tempus eft aperturam moliri, \& focum liquore jan multo refertum exonerare.

Antequam emittitur hic liquor rubicundus martialis, parantur in arena, qux minuta fluviatilis effe folet, loca five receptacula pro liquore emittendo; foffa quædam longa fcilicet ab apertura ad remotiffmam illius arex partem usque effoditur in arena; fpeciem etiam foffix plane refert, qux infra anguftata fit, fupra vero diducta, hoc eft, verfus fuperiora eft foffa illa magis panfa: Canalem feu foffam hanc in longitudinem ductam partiri dein folent in plures toros \& thalamos, in quos fe recipiet liquor emiffus, interjiciendo arenam inftar fepimenti, fed non ad altitudinem fuperioris marginis in foffa, quod fit illum in finem, ut ab uno loculo in alterum fupra ipfum fepimentum fluere poffit unda ferri. Si multa pars ferri fit, plures hujuscemodi foffas in arena ducunt, \& dein in loculamenta fua \& cubilia, parvis interjectis aggeribus diftinguunt; ita tamen ut hinc \& inde pateat ab una foffa ad alteram per aperturam datam excurfus ; fcilicet ut eo melius ferro repleantur omnia in arena effoffa fedilia. Numerus fosfarum proportionari folet fecundum quantitatem ferri, pariter etiam illarum profunditas: foffie vel I vel $2 \mathrm{vel}$. 3 numero funt, fedilia fivereceptacula fepibus dictis intercepta \& inclufa, numero 6, 7 vel i 2 funt, fcilicet fecundum capacitatem foci, vel etiam fecundum quantitatem ferri in foco contenti. Arena fluviatilis effe folet, nec nimium ficca, nec nimium humida ; fi ficca nimis, injecta aqua humectatur; fed videndum, ut fundus hic arenarius omnem injectam aquam bene abforbeat, nec aliqua ftagnans in fundo alicujus fedilis fedeat, adeo ut inde in arenam fubjectam non diffipari vel ab illa abforberi poffit. His factis, fuperinjicitur tenuiter arena cremata five cinis uftus: ultimo fignatur quodlibet fedile fuo numero $\&$ fuis literis fornaci propriis.

Quum itaque parati fint tori pro receptione liquoris ferrei, precluditur primum orificium ventilatorium, apponitur fcilicet rutrum fine bracteola, in quam ventus reverberatus inde refilit: nifi preftruatur via hæc vento, accidit quod aura irrumpens flammam in vacuo foco jam dominantem \& jam parietes ejus plangentem verfus orificia bina jam aperta, fcilicet per que emittuntur fcorix \& liquor ferri, agat; \& fic longius extra focunr vibrata faciem operatoris feriat \& calore nimio fuffundat: hæc eft ratio, cur orificium dietum venti præcludatur.

Locus, per quem emittitur ferrum liquidum, eft, ut prius eft dictum, inter obicem \& parietem unum lateralem; ibi enim interftitium eft arena \& argilla obturatum : jam vero cum focus ferro plane fit repletus, in comClaffis I. de ferro. o mifu- 
miffuram hanc argillaceam \& arenariam intruditur contus, \& valida brachiorum vi adigitur; fed quia multa ejus pars in vitrum concreverat, hinc vires brachii non fufficiunt, fed adigitur adhuc validis malleorum ictibus, ufque dum dicta junctura ad ipfum ferrum fit perforata : vulnere \& foramine fic facto eximitur contus, inftat illico \& fubfequitur volumen ferri, quod fluminis rapidi inftar deorfum \& præceps per clivum quendam delabitur in fubjecta fedilia, \& illa ordine adimplet : tanquam torrens rapidus fluit hic liquor ponderolus, nam inclufus in foco ad altitudinem pedis fuperincumbens inferiora premit, dum tandem altitudine decrefcente lentius fluat. Ferrum in lapfu fuidiflimum apparet \& coloris rubini, ultimo fubfequitur etiam rivulus exiguus foriaceus, qui jugiter fuperficiem fluentis ferri premit, a quo diftinguitur per colorem qui flavus eft: hic etiam locum occupat fuper volumen ferri ultimo elapfum, conftatque fcoriis, quæe de lapide \& de ferro fimul participant, quæque illius naturæ funt, ut igni maximopere refiftant.

Emiffo fic ferro, unda hæc metallica ftat rubicunda \& rutilans, fed ne fuperficietenus tumefcat in exiguas bullas, fuperimmittitur cinis calidus \& uftus, fub quo etiam melius \& lentius, quam fi aeri nudo effet expofita, indurefcit. Alias videre licet in ipfis concretionis momentis undulationes quasdam finuofas, qux hic,\&inde ferpunt \& tringunt fuperficiem calidam \& anhelam ferri, \& tandem flexibus quafi ferpentinis fuperficiem ligant. Tandem circa initia \& oras cujusvis fedilis five fuper ipfa fepimenta prædicta injicitur arena humida; ubicunque enim talis arena fuperimmittitur, fragile redditur ferrum, adco ut frigefactum facile fecundum eandem lineam difrumpatur \& dividatur ; ficque in maflas frangitur numerum fedilium xquantes.

Accidit interdum, quod volumen hoc liquidum ferri fubdita aqua intumefcere incipiat, in globos bullares paullatim elevari, \& dein furfum verfus laquearia domus ufque ejectari, \& fxpe totam domum incendiis \& adRantes imbre igneo mif́cere: in caufa eft aqua voluminibus fubjecta, qux fi ftagnet, nec ullibi exitum quam per ipfum ferri liquorem habeat, nimio calore in vapores \& bullas extenditur, qux elafticitatis \& levitatis fur gratia furfum vi leviffima fed fimul validifima per undam ponderofam, fecundum præcepta nota hydroftatica, fertur; dum tandem per fuperiorem ejus fuperficiem erumpens fecum in altum ferat ferrum, \& globos cjaculetur igneos \& metallicos, omnemque domum unda ferrea flammante complet; hoc quidem raro accidit; fed utprimum apparet, tunc vel fuperinjiciunt arenam uftam \& humidam, qua ira intercepta interdum folet refrænari, quia cruita ftatim inducitur; vel fi increbuerit hic fervor, juvatforas fe proripere, \& tutum ab imbre ignivomo locum eligere.

Quidam etiam ex excoctorum turba advenis fequens phænomenon oftentant \& venditant, fcilicet digitos \& integram palmam immittunt liquori ferreo, \& dein extrahunt illælam, vel etiam crebrius immergunt digitos, \& volumina metallica in altum cava manu projiciunt: fed antequam in ignitum hunc liquorem injicere audeant nudam dextram, fub ulnis vel alibi tenent illam, ubi fudorifero fluore perfufa tuto fatis immitti poteft 
liquamini calidiffimo; fudor enim non modo aqueus eft fed etiani falinus, qui omnes poros ftipat \& impedit, ne ignis nudam pellem ftatim perftringat: digiti etiam arciffime invicem contineri debent, ne liquor ferreus juncturas interfluat,

\section{Objervata circa ferrum crudum emi] um Eे refrigeratum.}

MAfix ferrex fecundum capacitatem fedilium fuorum diverfe magniM tudinis funt, qualibet æquare folet $\frac{x}{4}, \frac{1}{3}, \frac{\pi}{2}, \frac{2}{3} \& \frac{3}{4}$ pondo nauticum. Indurefcit ferrum hoc primum fuperficietenus, \& videre licet in ipfo ftatu indurationis calorem fluidum circa fuperficiem quafi undulantem, \& per mille vias quafi funentem \& accelerantem, non aliter ac folet aqua dum in glaciem concrefcit, fitque hoc in ipfo momento quum fiftitur \& fixatur voluminis fuperficies five in cruftam abit : \& licet fuperficies ejus indurata fit, adeo ut nec tactui nec baculo cedat, pars tamen voluminis interior adhuc fluida eft, \& fluidior quo propius ad centrum. Poft elapfum $\mathrm{I} 2$ horarum ita refrigef́cit, ut contingi nudis manibus \& brachiis poffit, \&loco fuo emoveri.

Ex fractura ferri \& interiore ejus compage facile animadvertitur, qualis fit ejus indoles, ut \& num jufta carbonum \& venæ ratio appofita fuerit: fi enim nitet micis grandiufculis \& admodum rutilis, fignum eft multæ cruditatis in ferro, qua vix per iteratam coctionem purgari poteft; oritur precipue ex vena, ut \& ex nimia ejus appofitione ultra rationem quantítatis carbonum debitam. Si ferrum emiffum non liquide \& undæ puræ inftar fluat, fed craffo \& fxculento volumine feratur, fignum eft, non bene feparatum effe ferrum a lapide, five metallum a fcoriis, fed adhuc fiecibus impurum effe.

Si ferrum elabens fcintillas fpargat, quæ fcilicet lucidæ circumcirca volumen ejus radiorum inftar exfiliunt, pariter fi flamma quædam candens apparent, fignum eft duritiei in ferro.

Si frigida perfundatur ferrum adhuc fluens \& calidum, ferrum etiam inde durifimum evadit, fed tantum ad illas partes ubi affufa eft aqua, \& ubi liquamen nimis cita refrigeratione concrevir ; intrinfecus ibi micis admodum rutilis conftat. Si ferrum fit indolis bonæ, funt mice exigux, five quædam granorum nitidorum congeries, at fi notæ deterioris fit, funt micx grandiufculæ, nitidiffmx, planiformes, inftar bismuthi \& glaciei fractr, quod cruditatis fignum effe folet. Alias ubicunque nimis cito concrefcit ferrum, ut partes ejus tenuiores, angulares \& auriculæ, ibietiam nitet granis albis ferrum; fubita enim exftinctio fitum particularum non quidem turbat, fed impedit, ne una alteri applicetur, \& in fitum naturalem relabatur, fed ut invicem teneantur divife; in illum enim fitum feparantur, cum calor pernici fluxu inde erumpere conatur: unde nitor ille oritur tantum ex partium fitu \& applicatione rariore; \& quiainitium quafi vitrificationis eft, hinc prodit fitum non abfimilem effe fitui particularum in vitro; fique adhuc repentior foret exftinctio, adhuc vitrefceret magis

fraetura: 
fractura: unde etiam ferrum in grana \& micas fic rutilantes diffinetum fragilius eft ferro reliquo; eft etiam levius: ejusdem enim voluminis maffa minus ponderare folet ac ferrum, cujus particulæ fitum naturalem \& compactiffimum occuparunt.

Si color ferro fracto fit grifeus non abfimilis panno rudi grifeo, five lanæ e nigro \& albo intertextæ, ferrum infuper ponderofum, optimæ indolis putatur effe; nullis enim ictibus mallei diffringi poteft, fed tenacisfimum eft, \& in igne tenacius illo, quod bismuthi inftar intus micat.

Ferrum micis fubtilioribus conftans, nec tam difficile in foco ferrario liquefcit, fubtilitas granorum albicantium vel oriri poteft $\mathrm{ab}$ indole ipfius venx; vel quod nimia quantitas carbonum appofita fuerit, $\&$ in chalybis duritiem combuftum, vel quod cito nimis refrigeratum fit aut concreverit, unde etiam minutim granulatum femper apparet in partibus extremis \& tenuioribus, \& in auriculis, ut vocantur, maffarum.

Si maffre fuperficietenus fint quafi lævigatæ \& planæ, fignum eft optatæ indolis.in ferro; at fi fiftulofa fit fuperficies \& in bullulas hinc \& inde elevata, fignum eft ferrum nimio fulphure imprægnatum effe.

Putant etiam aliqui cognofci poffe indolem venæ \& ferri ex ipfis guttulis per orificium venti vifis qux in focum decidunt, dicunt enim venam fulphuratam guttas dare majores \& vice verfa.

Vena fulphurea quamvis difficilis tractatu fit; usque tamen induftria \& ingenio excoctóris in ferrum non ita malignum liquari poteft: fi fcilicet illa recens \& cruda igne multo calcinatorio torreatur : exinde enim ejicitur quicquid fulphureum ineft, \& evaporatur pars maligna phlogiftica, id que eo melius, fi bis vel ter eidem igni fubjiciatur; multum etiam ad purificationem venæe a fulphure contribuit iterata frigefactio; frigefactionis iteratx ope in fitum non fuum fed alienum quafi rediguntur particulx; unde fi iterum ab igne corripiantur, facillime per poros novos \& non amplius fuos efferri poteft fulphur tam craffius quam fubtilius.

Si vena ferri nimis fulphurea fit, altitudo camini major requiritur, quam fi vena fulphuris fit egena, dum per intermediam partem camini ab orificio ad ventrem labitur, interea non liquefcit vena, fed per gradus in calores intenfiores fertur, unde in primo ignis gradu diffipantur ílphura, $\&$ dein magis magisque usque ad alvum, ubi liquefiunt venæ, \& in guttas folutx pluviæ inftar delabuntur: at vero fi caminus foret humilior, venailla fulphurea ftatim in ignem liquefactorium demiffa liquitur, antequam inde difipata fuerint heterogenea phlogiftica, quibus confpurcatur \& contaminatur focus.

Si venx nimis fulphurex fint, major etiam imponitur carbonum quam venæ quantitas, ita ut caminus five focus venam jugiter defideret aut efuriat, inde etiam vitium \& inutile fulphur excoquitur.

Alias fecundum indolem venæ fuæ novit peritus excoctor focum fecundum regulas \& artem parare; \& orificium ventofum focojufte adaptare, eique debitam obliquationem impertiri; multum vel minus aquæ rotæe immittere, hoc eft, motum follibus minorem vel majorem impertiri; prout enim requirit indoles venæ, fciet omnia fic difponere, ut nihilomi- 
nus ferrum obtineatur bonum; vel ad minimum ut heterogeneis malignis \& noxioribus privetur.

Non eadem quantitas ferri ex quavis fornace quotidie obtinetur; quantitas illa differt ratione qualitatis venx, fi fcilicet illa vel dives vel egena fit, fi facile poflit feparari vel fi non: frepe enim accidit, quod vena ferri opulenta ufque tamen parum ferri fuppeditet; quod fit, fi focus non bene \&. fecundum artem fit conftuctus; fi ventus illuc immiffus vel oblique nimis vel horizontaliter fpiret; fi caminus aut cavitas juft: dimenfionis non fit; fi imperitus \& ignarus excoctor, \& plura alia, qux multum contribuunt ad majorem vel minorem ferri quantitatem. Si opus bene fuccedit, peractis primis $\mathrm{I} 2$ diebus, obtineri folent 20 pondo nautica five 9 ad 10000 to ferri crudi; fed in plerifque non nifi I $5,12,8,7$, pondo dicta. Si vero vena fit ferri inops, fi carbones humidi, fi caminus anguitus \& exiguus ; fi fornax vetufta ; fi fundus foci nimis aqueus ; fique coctor ignavus \& ignarus, indies vix ultra 3 vel 4 pondo nautica haberi poffunt, ac fixpe cum eadem quantitate carbonum, ac fi i 5 ad 20 obtinerentur.

Intra diem \& noctem five 24 horas bis aut ter emitti folet ferrum, five quinquies intra 48 horas : fecundum morem ufitatum emittitur ferrum, cum fexies impofita fit vena cum carbone, five antequam feptima.vice recurrat ordo impofitionum; fi itaque vices impofitionum intra 24 horas fint I 8 , ter emittitur liquor ferri; five fi intra 24 horas non nifi per I 5 vices, emittitur ferrum intra 48 horas quinquies; fi non nifi $\mathrm{r}$, bis de die evacuatur tigillum foci, unde intervalla emiffionum differunt, fecundum venæ faciliorem five difficiliorem liquationem, adeo ut interdum 8 , interdum 9, io, vel I 2 horæ intercedant, antequam emittendum'fit inclufum liquamen.

Si vena fit locuples aut ferri dives, fi peritus \& induftrius excoctor, fique fundamentum ficcum nec humidum, ad unum pondo nauticum ferri confumi folent 12 ad 14 tonnæ carbonum; fi vero non, perire folent 24 , 36 ad 40 tonnæ \& plures,

Primis diebus toties emittitur ferrum, quoties fequentibus, quamvis non repletum fit tigillum foci, fed in tigillo exigua liquamiuis ferrei quantitas fit; tunc etiam quia frigidi lunt parietes, voluminis ferrei pars parietibus inhæret \& adfigitur, hinc etiam co minor ferri quantitas in tigillo erit, adeo ut vix requet I vel 2 vel 3 pondo nautica quavis emiffionis vice.

Quum ferrum liquidum omne emifum fit, adeo ut nihil fere remaneat, præcluditur apertura emiffonis argilla mixta cum 2 partibus arenæ, quæ vel in vitrum vel in fpeciem lapidis lateritii ope ignis vehementifimi coit, unde etiam valide fatis occluditur apertura, quod etiam fieri debet, quoniam volumen ferri ponderofum incumbit, \& ratione altitudinis fux: urget,

Primis diebus adhæret tigilli parietibus \& fundo pars craffa \& foeculenta, qua incruftantur lapides, fed cruftacea hæc materia temporis tractu refolvi \& liquari folet, adeo ut nudetur tandem fundus \& a ferro immediate premiatur : quinto vel fexto liquationis die nudari fundus foci incipit, \& quidem primo fecundum longitudinem ejus. Eodem etiam tenClalis I. de ferro. 
pore, fcilicet quum fundus a ferriliquore nudus contingitur, ex fiftulis five canalibus ferreis vapor calidus evaporari folet, interea exierat modo vapor frigidiufculus.

\section{Infortunia five cajus fortuiticirca liquationes.}

7 If magifter operam fuam fedulo navet, \& cautus prudenfquefit, infor-

tunia accidere poffunt; adeo ut multo minor quantitas ferri, eadem permanente confumtione carbonum, obtineatur; ut interdum in medio fufionis opere finis imponendus fit: qux infortunia ex variis canfis oriri poffunt : ut

I. Si nimia venæ quantitas apponatur, adeo ut non jufta ratio fit venæ \& carbonim, tunc adhærelcere poteft vena liquefacta parietibus camini, \& undique illis incruftari, unde perit vis jlla ignea, qux alioquin jugiter ex parietibus exhalat; \& confequenter vena parcius in pofterum immittenda eft; adeo ut fi prius obtinuerint quovis die 18 pondo navalia, dein cum eadem carbonum quantitate vix nifi dimidia pars obtineatur : unde caminus nullo modo vena fatiandus vel explendus eft, naufeam dein movet, fi eadem venæ quantitas fuppetatur.

2. Contra vero fi perparum venæ \& plus carbonum imponatur, tunc parietes nudi igni ficco expofitt lxdi facile poffunt, nifi vena fuore tanquam unguine parum obliniantur. Interdum etiam nimii caloris ope confumitur fundus tigilli, \& ferrum liquidum per rimas ductas defluit, \& fundum e novo ferreum format, qui minus aptus eft recipiendi liquorem venæ venturum. Hinc ratio carbonum \& venæ omnino fervanda eft, ne quantitas unius excedat rationem debitam alterius.

3. Si e nove conftucta fit fornax, adeo ut lapides, quibus murus intimus conftat, nondum paffi fint ignem aliquem; fique argillacea vincula adhuc humida fint, tunc fi diuturniori igne urgentur muri recentes, lædi etiam folent, adeo ut cum liquatio inibi altera vel tertia vice peragatur, recufent muri debitam venæ quantitatem: hinc in camino-novo \& adhuc humido liquatio peragitur non ultra $3 \mathrm{vel} 4$ feptimanas, dein refrigeratur, ficque tandem jufti temporis liquatio fine periculo peragi poteft : hoc tamen aliquibus in locis negligitur.

4. Si caminus ex nimia vetuftate fit quafi perefus, non multum venx appofitx appetit: lapides enim in muro non amplius recipere poffunt illum caloris gradum, quem prius cum recentes fuerant; abforbent quidem ignem, fed non $x$ que ut prius reflectunt $\&$ remittunt : tempore enim lapides funt magis porofi \& leves, quoque leviores, eo minorem ignis gradum recipiunt. Optimus eft caminus 3 tia, 4ta \& 5 ta liquationis vice, fcilicet cum vitrifacti apparent lapides five murus viridi quodam vitro quafi obduetus : accedit, fi vetuftus fit, quod plures rimas ducat, unde inæqualis venti actio in ignem prunarum exoritur.

5. Si muri intimi vel proximi cavitati, non debito glutine argillaceo fint alligati, vel fi vacuitas quxedam relicta fit inter lapides, tunc facile $f_{-}$eri poteft, quod.ignis violentiflimus exedat juncturas \& penetret interiora, \& 
ra, \& faxum unum alterumve a nexu fuo liberet, unde fequitur quod faxum illud e pariete laxatum in focum decidat; quod cum obfervatur, fcilicet cum confpiciuntur faxa natantia in foco, tunc finiendum ftatim eft opus fuforium, \& non nifirefecto prius pariete e novo liquatio inchoanda eft.

6 Detrimento etiam folet effe operi fuforio, fi fundus nimis humidus fit, hoc eft, fi aqua infra inclufa ftagnet; taceam plura adhuc fata \& infortunia, ut fi excoetor fit ignarus, \& fomno aut potui nimis indulgeat \&c.

\section{Finis operis fusorit.}

Q Uum finiendum eft opus fuforium in quibusdam locis, eadem quantitas venæ \& carbonum ultimis diebus imponitur, qux prioribus; alibi vero diminui folet quantitas venæ intra 24 horas in eadem proportione, qua prius augmentata fuit, imponuntur fcilicet vafcula venæ 18,17 , I 6 , I 4, I 2 usque ad 4: fed usque ubivis mos eft pulverem carbonum ultimo fuperinjicere, quod fieri dicitur, ne flamma nimium erumpat; poftquam fuperinjectum fuit ftratum hoc pulveris carbonum, fubfidet mafla carbonum intra i 8 vel 20 horas ad focum usque : interea bis vel $2 \frac{\mathrm{I}}{2}$ vicibus emittitur ferrum, eodem enim modo emiffonis hujus labor peragitur, ut prius.

Quum vero carbones cum vena fubfident, dignum obfervatu eft: $\mathrm{I}$. quod pulvere dicto carbonario fuperinjecto difpergantur fcincillæ ignex tanta copia, ut tabulata facile ab igne corripi poffint, non aliter ac dum procella per campum arenarium furens nimbum fulvis arenis conftantem circumferat. 2. Quum carbonum maffa ad alvum fornacis usque fubfideric, adeo ut inanis fit multa pars fuperior, fragor \& fonitus auditur raucus, non aliter ac quum fylvis immurmurat africus, intonat ventus murmure craflo, quia per cavitatem igne foetan volutatur flamma \& enititur tanquam per ruptam AEthnam rapidiflimo flumine, non aliter ac canit Virgilius, in vafio E⿸丆olus antro lucttantes bentos tempefatesque fonares emittit. 3. Altior etiam exiftit flamma fuper fornacem, cum ignis \& carbones ad mediam ejus partem confumtifubfiderint, quam cum plenus fuerit: flamma variis modis fe elevat, fed pracipue volumatim, adeo ut volumina quædam pure flammantia \& tanquam undulantia erumpant ex barathro hoc Vefuviano, \& inftar magnix molis in aerem fe glomerent; fed quæftatim a nexu inferioris flammæ disrupta in aerem furfum tendunt \& altius enifa difparent, quod apprime obfervare licet tempore tenebrofo; at vero in aprico vel cum dies ferenus fit, volumina hæc flammea non apparent integra, fed fpeciem referunt exhalationum terreftrim, quales tempore zeftivo \& calido ex humo \& agris fublimari, \& obliquis oculis confpici folent. Ipfi parietes camini apparent hoc tempore igniti inftar ferri candentis: fornax maximam ignis vim nunc pati dicitur, adeo ut fi ei refAtere valeat, fignum fit murum ignis admodum patientem effe. Alias in foco vivere folet ignis per biduum etiam per triduum, antequam exitinguitur. 


\section{MODUS COQUENDI VENAM \\ Qualis fatus fit fornacis finito opere \\ liquatorio.}

Am candet igne caminus \& parietes ejus undiquaque intus rubent: quum demum reliquiæ ferri emiffx funt, quæ I, vel 2 pondo nautica xquare folent, ductus five orificium fpiratorium obturatur argilla', \& omnis vento introitus precluditur, usque tamen motus follium continuatur per 8 vel ro dies, fed ventus exinde in laquearia fornacis exteriora reflectitur, fcilicet ne tabulata follium \& tigna, quibus connectitur fornax, a calore jam murum penetrante forte corripiantur, ignemve concipiant cæecum, flamen enim repercuffum refrigerat muros. Obfervatu dignum eft, nuod calor finita liquatione \& camino jam inani, non verfus interiora five cavitatem ut prius effluat, fed jam tranfeat murum, \& jam oppofita via, fcilicet verfus exteriora fornacis tendat; unde poft elapfum aliquot dierum in aliquibus locis magis magisque incalefcit murus exterior, qui ideo vento refocillandus \& refrigerandus eft, alias lignea fulcra \& vincula ab igne poterunt accendi, ut \& bitumina, quibus tabulata follium funt inuneta, dilui \& liqui. Alias cum inftat máximus ignis in medio liquationis proceffu, non nifi per $I \frac{I}{2}$ vel 2 pedes in murum intrat calor, quod fignum eft, poros tunc verfus ignem patere \& fic efformatos vergere; dein vero occlufis poris, qui ad fuperficiem cavitatis tendunt, viam fibi parat calor in oppofitam partem. Idem etiam concludi poteft ex vapore, qui ex foffa per canales five fiphones ferreos exhalat; aqua vaporofa, finito opere liquatorio calidior fentitur, quam cum perftat ipfum opus, \& vehementifimo igne incalefcere videtur focus, quod fignum eft, calorem altius jam penetrarefundum quam prius.

Obex ferreus anteriori parti foci objectus effringitur \& loco fuo emovetur; pariter aufertur janua ferri obici fuperinftans; factaque fic magna feneftra five apertura foci penetralia patent; oppleturjam focus mixtus cum vena, vena partim foluta, partim femiufta, partim liquata unam maffam conflare videtur, adeo ut cumulatio rerum indigeftarum locum illum oppleat. In perplurimis moles rudis \& indigefta ferri, fundum foci ad altitudinem $\frac{x}{2}$ pedis occupat; in aliis vero exefo \& exufto foco \& ejus parietibus, moles ingens $5,7,10$ ad I 2, ponderibus nauticis gravis foci latera occupaverat: fed ubi vena facillime liquitur, non nifi exigua moles \& fepe nulla eft; at vero ubi difficile in liquorem folvitur, major \& interdum ingens exiftit; vocatur talis maffa Svecice Klot: dantur etiam in quibusdam 2 vel 3 ejusfcemodi pondera, unum quod fundum tenet, alterum quọd latera, \& fic porro. Maffie hæ non puro ferro conftare folent, fed eis intertexta apparet vena cruda, ut \& lapis calcarius \& ipfe paries tigilli, paries a ferro utrinque fæpe inclufus tenetur : hæ moles non niff fubjectis \& valide adactis contis elevari poffunt, exque foco machinarum ope edici, auxiliante vi plurium virorum. Si moles jufto majores fint, non procul a fornace inutiles relinquuntur; non enim in focum ferrarium transferri vel tolli poffunt, nec igne domari aut liquari. 
Si quis finita operatione fuforia defpiciat in cavitatem fornacis, obTervare licet $a b$ inferiore ejus parte obductum effe murum materia quadam lapidea, eadem fere qua fcorix conftant; infra vero cruftam hanc craffiorem effe \& ferrugineam, five ferro plenam. In quibusdam fornacibus apparent parietes adhuc integri, fed murus undique vitrificatus five obduetus vel loricatus vitro viridefcente. At vero in fornacibus, quarum lapides non ita refiftunt igni, videre licebit nurum $a b$ una vel altera parte \& præcipue in media ventris amplitudine exefum \& multa fui parte excavatum: fi enim planum orificii ventilatorii horizontalem fiturn habuerit adeo ut venti horizontalis fpiratio fuerit, exefus apparet murus fupra dictum orificium; at vero fi fitus orificii fuerit nimis obliquus, exefus apparet marus fupra orificium emiffionis ferri att fcoriarum : obfervari etiam debet, quod pars fuperior cavitatis ob nimiam violentian ignis videatur tanquam dilatata; ad minimum peraecis aliquot liquationum vicibus, diductx apparent fauces illius aperturx, vel ampliatus oris ejus circulus; caufa eft, quia tigna, quibus murus fornacis continetur, fenfim laxatis nodis \& ligaturis, \& incumbente murorum pondere dehifcant \& recedant, fique ab ipfa apertura magna faxa fe retrahant, \& confequenter os illius voraginis pandatur, unde etiam fipe in ovalem figuram mutata comparet.

Supra ventrem vel mediam fornacis amplitudinem rubedinequadam apparet murus obductus \& quafi tinctus, \& quidem ad diftantiam 3 ulnarum ab ipfa apertura; quod fignum eft, craffiorem parten fulphuris exvena exfudaffe \& murum rubedine tinxiffe: ibi etiam apparet muras quafi politus \& lubricus \& tanquam oleo inunetus, plane ut lapis quen unda continue lambit aut cavat; quod a continuo fluxu \& vibratione flamnz \& venti oriundum videtur.

\section{Objervata circa fornacem dirutam.}

Crca infpectionem fornacis dirutx vel circa rudera ejus obfervare licuit effectum ignis continuum in faxa \& in juncturas ipfas argillaceas: fi infpiciatur argilla, qua firmati funt lapides muri, notare licuit z.. quod calor vifibiliter penetraverit murum ad diftantiam 3 pedum a cavitate, ad quam diftantiam argillain juncturis fedens primum eft coloris albi, proxime lutei, fed tamen friabilis \& intra digitos in pollinem teri poteft; verfus interiora recipit color brunus lateritius, laterem enim omnimode refert; adhuc propius verfus cavitatem apparet colore bilofo, ibi argilla per ignem indurata eft unctuofa \& lievis tanquam oleo tincta; quod fignificat principium vitrificationis ; inde evadit coloris obfcuri, tum obfcure coerulefcentis, tandem abit in vitrum quoddam, vergit tum ad colorem viridern, fed proxime ad cavitatem eft argillà dicta flave colorata, dein albefcit \& nitet inftar porcellini aut argillæ Indica. Glarea \& lapillus in argilla inclufus coloris albiffmi eft, licet ipfa argilla fit coertlei, lutei, rubicundi \& bilofi.

Quod ipfam diftantiam attinet, eft argilla proxima cavitati albicans dein flava; ad diftantiam inde 2 digitorum vertitur in colorem coeruleum; ad 3 vel 4 digitorum fit color obfcurus magis \& tranfit in obfcure ceeraClafis I. de ferr\% lum: 
lum: ad diftantiam 5 vel 6 digitorum eft coloris brunei, materia tảnquam unctuofa, fed definere hic incipit vitrificatio; ad diftantiam 9 digitorum refert lapidem lateritium; verfus interiora pallefcit rubedo, \& albelcit magis \& magis argilla usque ad illam diftantiam, ubi in pulverem ex folo contactu dilabitur; \& fic porro.

Ipfe lapis, quo conftructus eft murus intimus, rubrum colorem contraxit, eo rubicundiorem, quo propior igni five cavitati fuerit: fi lapis dictus frangitur, animadvertere licet ductum quendam pororum a cavitate verfus interiora directe tranfeuntem, a calore aut igne horizontaliter influente formatum. Lapis exemtus muro, \& aeri expofitus vel aquis immiflus in pulverem collabitur.

Ipfe lapis in muro colorem etiam mutat; primum eft quafi vitrificatus, fed vitrum multis in locis tanquam fiftulofum apparet, ad diftantiam $\frac{\mathrm{I}}{2}$ vel I pollicis virideficit, tandem rubefcit, ut prius dictum eft.

Quod alias mutationem colorum attinet, videri etiam in fcoriis poteft; fi ferramentum frigidum in focum inque ferrum liquidum immittitur \& dein extrahitur, illud circumcirca fcoriis incruftatur: Scoriæ quæ proximæ ferro funt, ad craffitiem aliquot linearum purifimum \& pellucidifimum vitrum referunt, at quæ inde diftant, funt coloris viridis, cœrulei aut alius fecundum naturam venx. At vero fi ferrum, quod immittitur, calefactum prius fit, nulla talis vitrificatio apparet.

Paffim etiam ex fcoriis erumpunt fintillæ nitidifimæ, quæ pure ferrex funt; tumet \& fcinditur in illo loco fcoriarum maffa, ebullefcit parumper, perque bullam erumpit copia f cintillarum; fique colligantur fintillæ, conftare videntur puro ferro. Statim vero ut rima illa in fcoriarum fuperficie ducta ob repentinam congelationem præcluditur, ferrum dein in loco quodam cavo \& rotundo in globi majoris aut minoris formam colligitur: globuli hi ex fcoriis poffunt colligi, fi modo fcoria in pulverem contundantur, quod fit aliquibus in locis.

\section{De fornacibus ferri fuforiis in Svecia; ut $\Theta^{\circ}$ de officinis ferrariis.}

$Q^{\mathrm{L}}$ Uamvis inftitutum meum non fit, illa, qux ad hiftoriam regni mineralis fpectant, tradere, ut hic enumerationem fornacum ferri liquatoriarum, usque tamen quia recenfio illarum brevis eft, libet nomina dare, ut filicet numerus illarum habeatur"; pariter etiam focorum ferrariorum \& fabrilium in Svecia.

\section{In Provincia Cuprimontana.}

Fornaces ferri liquatorix, : I. Braufalle. 2. Futebo. 3. Ramshytta. 4. Laxioebytta. 5. Nysbytta. 6. IVikmansbytta. 7. Granfioebytta. 8. Dreckie. bytta. 9. Sundsbytta. I0. Roersbytta. Ii. Ebrebyita. 12. Hinsbytta. 13. Longsbytta. 14. Becka in orfa. 15. Walla. I6. Ingeborbobytta. I7. Rosberga. 18. Hedebytta, I9. Kyrkiebybjtta: 20. Roffebytta. 21. Bioerkbyita. 22. Hwatbo. 
23. Wéftanberg. 24. Aubsgars. 25. Forsbytta. 26. Pellebo. 27. Nobrsaubri. 28. Weftanfioe. 29. Norbytta. 30. Prefthytta. 3r. Norgowik. 32. Brunswik. 33. Soerwik. 34. Persbo. 35. Pergsbo. 36. Enkullen. 37. Klensbytta. 38. Go= nes. 39. Rafiwola. 40. Bioernbytta. 41. Sunnanfioe. 42. Abeckshytta. 43. Saxhytta. 44. Krabbfoebytta. 45. Snoeaun. 46. Thurbo. 47. Haggie. 48. Wabnbo. 49. Hallfioen. 50. Bioernfioe. 51. Marnes. 52. Flatenberg. 53. Siarbo. 54. Munckbo. 55. Spiutzbo. 56. Stimmerbo. 57. Skisbytta. 58. Ingzvalsbo. 59. Bommarsbo. 60. Gitsberg. 61. Brefioe. 62. Finbo. 63. W aftanfroe. 64. Matsbo. 65. Saxhytta. 66. IWad. 67. Tolfsbo. 68. Hornshytta. 69. Halfraebo. . 70. Perlarsbytta. 71. Wefterby. 72. Morbytta. 73. Wibberbo. 74. Ferfioebo. 75. Malingsbo. 76. Kioerkby. 77. Billfioe. 78. Klothytta. 79. Laxioebo.

Officinæ ferrarix in ditione Cuprimontana. I. Grengshammar. 2.Rysbytta. 3. Ramsbytte Smedia. 4. Nornsbruk. 5. Pinck Smedia. 6. Thurbo. 7. Longforsbammiare. 8. Drackiebammare. 9. Stiernfundshammare. Io. Roers. bytte Smedia. II. Ebrefmedia. 12. Laungsbytte Hambrar. 13. Fredshammare. I4. Horndabl. 15. Tyskebo. 16. Ra/sberga. I7. Hede. I8. Kyrkieby. 19. Rauffe. 20. Bioerkefmedia. 21. Hwatbo Smedia. 22. IV aftanbergsmedia. 23. Aubsgars/media. 24. Fors Smedia. 25. Pallebofmedia. 26. Lodwika. 27. NorJaubn. 28. IV eftanfioe. 29. Nybammar. 30. Sunnanfioe. 31. Kleensbytia. 32. Gones. 33. Grafivendabl. 34. Haggie. 35. dito. 36. Byfmedia. 37. Flatenberg. 38. Morgaurden. 39. Marnes. 40. foci ferrarei in Larsbo. 41. Saxebammar. 42. 'Malingsbo. 43. Nyfors ES Korslongen. 44. Laxioebo. 45. Tolfsbo. 46. Jerfroebo. $47 \cdot$ Wad.

\section{In Weflimannia.}

Fornaces liquatorix: I. Gixeliobohytta. 2. Rofendablshytta. 3. Lyfy. dablshytia. 4. Flenge. 5. Carsbo. 6. Fraggliytta. 7. Weflerdiupkierra. 8. Halfivarsbenning. 9. Braufors. I0. Callmora. II. Oeflerdiupkierra. I2. Tackberadshytta. 13. Fliken. 14. Ingolsbenning: 15. Rabbatsbenning. 16. Heftebytia. 17. Andersbenning. 18. Nolanfioebytta. 19. Werlingsberg dito. 20. Nybytta. 21. Melingsbytta 2. 22. Baftmora Hyttan. 23. Ulfsbobytta. 24. Strikebobytta. 25. Moren. 26. Hyppenbenningshytta. 27. Onfioebytta. 28. Effwesbobytta. 29. Hedkiera Hytta. 30. Sundbo Hytta. 3r. Hoegforshytta.. 32. Laungfroebytta. 33. Hefbeckshytta. 34. Asbenningshytta. 35. Bernebohytta. 36. Hoekmorabytta. 37. Klinckbobytta. 38. Raufsbytta. 39. Nickebobytta. 40. Karbenningsbytta. 4I. Aubecksbytta. 42. Nybytta. 43. Prefthytta. 44. IV aubladablsbytta. 45. Engelsbergshytta. 46. Englickebenning. 47. Stabeck. 48. Trummelsberg. 49. Ombenning. 50. Skilau. 51. Baggau. 52. Hoekiers. 53. Glyfsau. 54. Uggelfors. 55. Longwik. 56. Allmenningsbo. 57. Fremsbytta.

Officinx ferrarix in Weflmannia. I. Giaefroebruk. 2. Persbo. 3. Roferz. dabl. 4. Lyfydabl. 5. Wefterdiupkierra. 6. Rabbatsbenning. 7. Wraftanfors. 8. Fagerfar. 9. Simbla. I0. Asbenning. II. Hoegfors. 12. Biurfors. I3. Heflbeck. I4. ibidem. 15. Soederboerend. 16. Hedauker. I7. Forsbammar. 18. dito. I9. Oblsbenning. 20. ibidem. 21. Hennebo. 22. Hockmora. 2,3. Klinckbo. 24. Raufsbytta. 25. Nickebo. '26. Carbenning.' 27.Aubeck. 28. 
Nybytta. 29. Prefthytta. 30. Matsbo. 31. Engelsberg. 32. Englickebenning. 33. Stabeck. 34. Trummelsberg. 35. Sivanau. 36. Forsbammar. 37. Traung fors. 38. Sura. 39. Ramnas. 40. dito. 41. dito Ramnas. 42. Seglingsberg. 43. Wirsbo. 44. Backbammar. 45. Floo. 46. Oeftanfors. 47. Baggau dno. 48. Prafby. 49. Prafthammaren. 50. Waftragaurds. 51. Bergmans Hammaren. 52. Skarwiken. 53. Heed. 54. Fors. 55. Glyfsau. 56. Allmenning. 5\%. Stelleberg. 58. Sumnanfors. 59. Darbo: 60. Lauckman. 61. Kaublswa. 62. Gislarbo. 63. ibidem inferior 6. 64. Carmansbo. 65. Wallbrecka. 66. ibi. dem Juperior. 67. Nybammar. 68. Berents Hambrar duo. 69. Beck. 70. Norrbammar Eै Holms. 71. Forna. 72. Flena. 73. Keybo. 74. ibidem. 75. Prejthammar. 76. Gurnilbo. 77.Killingsbammar. 78. Beckbammar.

\section{In Provincia Orebroenfi.}

Fornaces ferri fuforix : I. Sablbo. 2. Sykfors. 3. Tlnas. 4. Saxhytta. 5. Bowiksbytta. 6. Skiar EO Finhytta. 7. Grytbytta. 8. Skierfwingefors. 9. Ekeberg. IO. Sundsbytta. II. Troefshytta. I2. Hulibytta. I3. Klofioebytta. I4. Brunsbytta. 15. Sikfors. 16. dito Ekeberg. 17. Skaulbytta. In ditione Nora. 18. Bengttorp. 19. Bleckskerg. 20.Born. 21. Boxbo. 22. Dalkarsbytta. 23. Fingerbo. 24. Fogdebytta. 25. Finshyita. 26. Foersbytta. 27. Fefioebytta. 28. Elfshytta. 29. Pershytta. 30. Gamelhytta. 31. Gomlewikers. 32. Holmshytta Ev Belgfioeboda. 33. Hommanstorp. 34. Haukansbo. 35. Kaufalle. 36. Lockbytta. 37. Findesby. 38. Moosbytta. 39. Persbytta. 40. dito WVi. kersbytta. 41. Nybytta. 42. Moorshytta. 43. Elfbytta. 44. Ramshytta. 45. Ringshytta, 46. Timansbytta. 47. Skioerbytta. 48. Snoebergsbytta. 49. Waftgioetbhytta. 50. Wafsla. 51. Streckorbytta. - 52. dito fuperior. 53. Oeskebo. 54. Oeskewik. 55. Aubshytta. 56. Bredfoebjtta. 57. Bioerckfroebjtza. 58. Grangshytta. 59. Jublfioebytta. 60. dito Grengshytta. 61. dito Fubifroebytte. In Linde. 62. Torpbyttan. 63. Munckbyttan. 64. Forbobyttan. 65. Snuggan. 66. Fantbyttan. 67. Martshyttan. 68. Siggeboda. 69. Siggebobyttan. 70. Garphyttan. 71. Reboda. 72. Gullmedshytian. 73. Danshytäan. 74. Grentshyttan. 75. Nyberge. 76. Fingelsbyttan. 77. Wafslebyttan. 78. Gujstebyttan. 79. Hammaren. 80. Gufsleby. 81. Ajpa. 82. Bioerckbyttan. 83. Ramshyttan. 84. Refa. 85. Lehrberg fuperior. 86. irem inferior. 87. Loea orientalis. 88. Loea occidentalis. 89. Grymfioe. In Nericia. 90. Blackfa. 91. Klauckarebyttan. 92. Cantebo. 93. Mosbytan. 94. Garphyttan. 95. Tolsbo. 96. Tmningshyttan. 97. Gillaubsbytta. 98. Oerbobyttan. 99. Brobyttan. 100. Kinckbyttan. IOI. Bioerckbyttan. 102. Nekbyttan. 103.Mullbyttan. 104. Gammelbyttan. I05. Dormbyttan. 106. Rebobytta. 107. Nybytta. I08. Lekbytta. I09. Kenekbyttan. Io. Snoebergsbyttan. II. Oeblsdahlshytan. In Wermlandia. II2. Immetorpshyttan. II3. Sibbo. II4. Granbergsdabl. II5. Quarntorp. I16. Stroemstorp. II7. Linnebeck. II8.Haullfoe. II9. Lontorp. I20. Knapfors. 121. 2wegges. I22. Aufroebyttan. I23. dito Aufroebyttin. I24. Holmshytia. 125. Taffaubna. 126. Wiakkebeck. 127. Tgelbeck. I28. Torpskoga. 129. Trehoer. ming. I30.Afphytta. I31. Brattfors. 132. Paradis. 133. Forsbytta. 134. Gras= Bofioe. 135.Baublbyta. I36. Kablbytta. 137. Finshytan 138. Storbron. 139. 
Hacktorsbytian. I4O. Moegfoen. I4I. Skaulkiern. I42. Stoepfoen. I43. Sivartaubn. I44. Fogdebyttan. I45. Habors. I46. Norrmarks. 147. Stielp. 148. Mokerns. 149. Grundfroe. 150. Dalkarsfioe. I51. Nesrems. 152. Saxaubytta. 153. Moeriekern. 154. Oerlingen. 155 Bön. 156. Torskbecken. 157. Daimmbyttan. 158. Gaufeborn. 159. Haurfion. 160. Laungbainsbyttan. I6I. Laungbanfande. 162. Hedenskug. 163. Auskagen. 164. Skarpbyttan. I65. Swartsangen. 166. Kroppa. I67. Herrbult. 168. Ny'roppa. 169. Biurbecksb;tan. 170. Kongskoug. 171. Sunnemo. 172. Uddebolm. 173. Elfsbacka. 174. Mongsbytta. In Weftrogothia. 175. Granwik. I76. Torpa. 177. Almenes.

Officina ferrarix. 1. Stiernfors. 2. Sykfors. 3 Kierfwingbobren. 4 Kierfwingboren ad aquilonem. 5. Finne-five Stiarbyttebamrar. 6. Finmauling five Elfdala. 7. Jerle. 8. Broefstorp, ut E Hammarby. 9. Hogby. IO Damsbjtta. 11. Fibbhytte Plautbammar. 12. Bredfoe. 13. Stenfa. 14. Norrby. 15. Sivirckefta." 16. Storboda. 17. Rauckbammar. 18. Ekeby. 19. Froetuna. 20. Finnauker. 21. Groenbo. 22. Kaufalla. 23. Roefors. 24. Auby E5 Soerby. 25. Oefterbammar. 26. Eblholmen. 27. Froewi; Erfwalla. 28. Wedewaug. 29. Bolbren. 30.Dalkarsbytie Hamrar. 31. dito Dalkarshyttan. 32. Bioernbammar. 33. Andershammar. 34. Afpa. 35. Wafslelyttan. 36. Ramsberg. 37. Praftbammarn. 38. Wretbammaren. 39. Oefrabammaren. 40. Loerabammare. 41. Kyfnabben. 42. Grymfioe. 43. Kaubrberg: 44. Bergshytte. 45. Nybammar. 46. Hegernas. 47. Moskange. 48. Sundbo. In Nericia. 49. Axberg. 50. Froeszidabl. 51. dito. 52. Klauckarebyttan. 53. Garphyttan. 54. item. 55. Lavafors. 56. dito. 57. Willingsberg. 58 Brefiwen. 59. Kraukfors. 60. Minckefors. 6r. Swartau. 62. Hafslefors. 63. Oeblsboda. 64. Kortforfen. 65. Malauben. 66. Degerforfen. 67. Kaurberg. 68. Roefors E' Brauttfors. 69. Ablgrena. 70. Afpa. 71. Skogaholm. 72. Haddebo. 73. Gryets. 74. Skylberg. 75. Skagersholm. 76. dito. 77. Foerswiks. In Wermelandia. 78.Bofors. 79. item Bofors. 80. Bioerkbobren. 8r. Lannfors. 82. dito Lannfors. 83. Laungbabn. 84. Apphyite. 85. Auminnefors. 86. Biurbecks orientalis. 87. item occidentalis. 88. Gresbofioe, 89. Ourlingsbamim. 90. Saxau. 91. Bratbfors. 92. Lefroefors. 93. Henicke. 94. Storfors. 95 dito. 96. Heitielfnam. 97. Lillefors. 98. Krauppa. 99. Bofioe. IOO. Skarpbytia. IOr. Sivartfaung. 102. Acktiers.' '103. Matlaungen. 104. Elfbro.' 105. Nicklasdann. 106. Spiutbecken. IO7. Wafgaubla. IO8. Bioerneborg. Iog. dito. no. Beck. II. Cro= notorp. In. Emtekerms. In3. Jonsbobles duo. II4. Haukansbobl. II5. Lyefors. II6. Molkom. II7. Elfsbacka duo. II8. Nes. ing. Lindefors. I20. Boeckels. I21. Hoekebro. I22. Rouglanda. 123. Foeske. I24. dito. 125. Norum. I26. Glumferud. 127. Aubraus. 128. Forfnes. 129. Alfruns. 130. Gunnersd. 13r. Docmble. 132. dito. I33. Moelnbacka. 134. dito. 135. 2warntorp. I36. Ranfeter. 137. Mellan duo. 138 Munckefors. 139. dito. 140. Borgivik. 141. dito. I42. Edswalla duo. I43. Stoenme. I44. S'wanebolm. I45. Glasfors. 146. dito. 147: Kauhlfeterud. I48. Rautneholm. 149. Rautinedabl. 150. Skarped. 151. Gaulfioe. I52. Bioerkoe. 153. Torsby. 154. Bada. 155. Oblby. 156. Uddebolms. 157. Stierns. 158. Brunsberg. I59. Rinnefors. 160. Elgau. 161. Upperud: "162. Forsbicka: 163. Persby. 164.Hackefors. 165. Withlanda. Clathis t. de ferro. 


\section{MODUS COQUENDI VENAM In Uplandia \& Roslagia.}

Fornaces ferri fuforia: : I. Elfcarleby. 2. Hytto. 3. Harnes. 4. Soederfors. 5. Ullfors. 6. IVe fslanda. 7. Stroemsberg. 8. Hillebobla. 9. Carls. bolm. 10. Tobo. II. Wattholma., I2. 13. Oefterby dua. I4. Gyrno. I5. Loefo fad. 16. Aukerby. . 17. Forsbobl. 18. Wigelsbo. I9. Berkinge. 20. Benbobl. 21. Stockeby. 22. IVellnora. 23. Edsbro. 24. Cornas.

Officina ferrarix. I. Elfcarleby. 2. Harnes. 3. Soederfors. 4. Lulffors. 5. We slanda. 6. Siroemsberg. 7. Hillebobla. 8. Watibolma. 9. Oefterby. 10. Ciymo. II. Loefflad plures. 12. Bondebammaren. 13. Aukerby. 14. Forsmark. 15. Harg. I6. Wellnora. 17. Skiebo. 18. Ortala.

\section{In Geftricia \& Hellfingia.}

Fornaces ferri fulorix : I. Skommarbyttan. 2. Groenzfoncka. 3. Edske. 4. Hillewik. 5. Aumoth. 6. Axmar, E plures alid.

Officinæ ferrarix. I. Gammelftilla. 2. Hofors. 3. Wibyge 4. dito. 5. Diernes. 6. dito. 7. Hobammar. 8. Preflbytta. 9. Baggebytta. Io.dito. in. Wefterbafbo. 12. Kalfnas. 13. Stenshytta. 14. Fogerftad. 15. item. 16. dito. 17. Wall. 18. Ilgglebo. 19. Gyfinge. 20. 21. Opfioe E' Staublio. 22. Hammarby. 23. Hammarby. 24.Hoegbo. 25. Autterfad. 26.dito. 27.Brobygge. 28. dito. 29. Jerbo. 30. dito. 31. Norberg. 32. Wackmyra. 33. Forsbacka. 34. Tollfors. 35. Oslattfors. 36. Axmar. 37. Wifors. 38. Wikgroe. 39. Aubro. 40. Aumoth. 41. Sunnes. 42. Liufna. 43. Gullgrufiva. 44. Kyblfors. 45. Wauxna. 46. Longiwind. 47. Iggefund. 48. Stroem. 49. Gallftroem. 50. Loegdoen. 5I, Auwiken. ' 52. Hoegfors. 53. Graninge. 54. Sollefta.

\section{In Sodermannia.}

Fornaces ferri fuforix : r. Swerta* 2. Bioerndam \& plures alia.

Officinx ferrarix. I. Nefineqwarn. 2. Aublberga. 3. Scaffioe. 4. Wyb. rain. 5. Norsbammar. 6. Smedstorp. 7. Staublboga. 8. Sponga. 9. Bills. bro. IO. Hoeglioe. II. ForfJa. I2. Br.émbobl. I3. Aukers. I4. Lenna. I5. Ebrendabl. 16. Lundbolm. I7. Skiepfta. 18. Skougtorp. 19. Eskelfuna. 20. Torfilla. 21. Nesbulta. 22. Nygivarn. 23. Brenninge.

\section{In Oftrogothia.}

Fornaces : I. Folkkfroem. 2. Grytgiobl. 3. Dunckeroe. 4. Diuperoe. 5. oefterby. 6. Katterum. 7. Aufebro. 8. Diupshytta. 9.Rambninge. I0. Erftorp. II. Hermmingstorp. I2. Finfpaung. I3. Ballersm. I4. Boberg. I5. $\mathrm{Ny}$ bytan. 16. Rausla. I7. Sliperau.

Officinæ ferrariæ. I. Godegaurd. 2. Skroenarebo. 3. Swartebo. 4. Bor gaurd. 5. Folchfroem, 6. Grytgioebl. 7. Saungstorp. 8. Holmfioefors. 9. dito Songstorp. IO. Hefla. II. Lotorp. 12. Boergioebl. I3. Ifunda. I4. Boerfioe. I5. Rernaninge. 16. Finpong. 17. Diurshytta. 18. Orga. I9. Skierblacka. 20. Lam da. 21. Hundetulla. 22. Refsla. 23. Carlftroem. 24. Qwarm. 
Ex fupra cinumeratis officinis funt plures, qux $3,4,6$ ufque ad 10 focis ferrariis conftant: adhuc multo major foret fornacum \& officinarum fabrilium numerus, fi etiam recenferentur illæ qua in ditione Jonekopienfi, Callmarienfi, Cronebergenfi, in Smalandia, in Bothnia occidentali \& orientali, hoc eft, in Lapponia \& Finnlandia funt; fed pergendum ad illa eft, qux majoris emolumenti funt.

\section{De argento nativo in media fodina pure ferrea Noormarkienfi Wermlandice anno 1726 invento; deque objervatis cum argento dicto $8 \mathrm{cum}$ ma- trice ejus five argilla, in qua inclufum jacuit, factis.}

$A B$ inftituto meo non alienum effe, nec me a via multum difcedere arbi$A$ tror, fi hic fubjungam hiftoriam \& obfervata circa argentum nativum nuper in fodina Noormarkienfi pure ferrea inventum \& erutum: inferro enim nobilifima hxc proles tanquam in matris cujusdam finu aut utero recondita jacuit, qua quidem diu gravida fuit, dum tandem poft elapfum. multi temporis fpatium anno 1726 foetum dictum excluderet; ante $70 \& 80$ annos aliquid etiam fimile vifum fuiffe memorant annales. Stratum quoddam five Skioehl Svecice vocatum ipfam fodinam pertranfivit, quod illam in binas partes $a b$ oriente verfis occidentem divifit. Quia fodina hæc Noormarkienfis in puteos vel cavernas plures difpefcitur, una illarum, qu:e Erattfors Grufwan vocatur, erat ipfifima ejus parens five in parentis utero locus: dictum ftratum, quod fodinam Brattfordienfem biffecuit, argilla quadam pingui conftabat ad latitudinem $\frac{1}{4}$ ut \& paffim $\frac{x}{2}$ ulnx; fedftratum hoc non conftabat ubique ejusdem generis argilla, hoc eft, nobiliore argentifera, fed craffiore coloris lutei \& vulgari; usque tamen utrinque ad parietes five prope ipfam ferri venam in confiftentiam quandam lapideam aliquibus in locis induruife videbatur argilla. Huic argillæx rudiori intertextæ \& infertæ confpiciebantur glanduli five nuclei argillæ adhuclenioris \& fubtilioris, coloris obfcure cœrulefcentis, ut \& interdum flavefcentis, quæ a reliquo argillæ genere tam colore quam qualitate liquide diftingueretur: in his glandulis argillaceis genus quoddam fpathi albi pellucidi, etiam flavi \& regularis inclufum apparuit; alibi etiam argentum nativum, quod fatis copiofe tam in granis infinitis parvis inftar fabuli, quam in fruftis majoribus confpiciebatur : fruftula hæc argentea diverfiformia erant, vel enim in apices \& aculeos terminabantur, vel nexibus fercentinis hinc \& inde amplectebantur argillam matrem; jam piciformia \& fabarum inftar in maflam conglomerata videbantur; \& fic variis figuris in matrice fua, prout folet argentum nativum, ludebant. Vidi fruftum, quod xquaret 15 femuncias, vidi quod 6, 10, I 2. Ex ipfa argilla hac fubtili \& bolari emicuit argentum in granis, nam illa ad lapidem vel cotem trita ni- 
torem argenti puriffimi exhibebat, vel oculis armatis luftrata argenti arenain prebebat, erat fimul ponderofifima; per cupellam abftracta relinquebat $38 \frac{1}{2}$ marcas five $77 \mathrm{Hb}$. ex centumpondio. Usque tamen non diu vitam egit proles hæc optatifima \& pulcherrima martis, fed præterlapfis aliquibus menfibus quafi patris in gremio exftinguebatur; namiplumftratum verfus profundiora magis magisque anguftatum evanefcebat, \& in ferro dein, ut prius condebatur: difparuit in Auguto menfe anni 1727 ; \& dein quamvis ad 8 vel 9 ulnas profundius itum fit, usque tamen nec ftratum nec argentum redire animadverfum eft: fed circa bina extrema, hoc eft, ad latus orientale \& occidentale hujus fodinæ, cxftant adhuc duo ejus brachia, remanetque fic adhuc ftratum utrinque $\frac{1}{4}$ vel $\frac{1}{5}$ partem ulnæxquans, fed conftat modo argilla \& limo rudiori \& acri, non vero medullari \& ar ${ }^{\perp}$ gentifera, nec fpathi pellucidi reliquïs, quod multis modis experti funt \& adhuc indies experiuntur : ad utrumque illum finem, ubi adhuc ftratum. dietum argillaceum exftat \& petram dividit, nulla ferri vena eft, adeo ut argentum hoc nullibi nifi intra amplexum ipfus ferri \& martis viguifle videatur. In ipfa argilla fubinde etiam apparuit vena quadam ferri mollita $\&$ in pollinem fubtilem refoluta. Ferri vena argillaceo ftrato proxima nullam argenti micam continuiffe per probationes cum illa inftitutas com pertum eft.

Alias in fodinis ferri Svecix paffm occurrunt indicia argenti frve venæ argentex, ut in media fodina Danmorienfi Roslagix vena quædam argenti ante plures annos apparuit. In fodina Uthoenfi \& Singoenfi dantur ftrata venis argenti, fed multo marte afperatis \& confpurcatis conftantia. Vense ferri fodine Grengiesbergenfis partem argenti ineffe ex probis compertum eft. Referunt etiam in fodina Bisbergenfi argenti nativi particulas olim inventas fuifle. Norwegix, ubi tanta argenti nativi copia quotannis eruicur, ochracea \& ferruginea quædam materia fequitur premitque veftigia Lunæ huc \& illuc per campos illos fertiles argenti; unde concludi poffe videtur, areto admodum vinculo \& connubio unitum effe ferrum cum argento: hic enim confpicitur duplex vel triplex fratorum ordo, quorum unum cum altero parallelum \& locium eft, \& unanimo \& xquo paffu ad eandem plagam tendit, conftatque hoc argento hoc vero ferro. Vel in penetralibus ipfis \& magna aula Martis incarcerata jacet argenti quxdam vena : vel argentum \& ferrum venis \& fibris alterius invicem innexum eft, ut non nifi arte Vulcani polfint feparari.

Sequuntur jam tentamina \& pericula quxdam chymica cum argilla medullari fibtili \& coerulefcente five matre argenti, cujus mentio facta eft. a Doctore Brandt in Laboratorio Chymico Collegii Metallici Stockholmenfi facta, ut

In retortam exiguam lapideam mittebantur i 2 femunciæ argillæ præ: dista argente:e corulefcentis, applicato dein recipiente \& perlutatis júneturis fubmittebatur ei ignis; quo cum dicta retorta oblcure canderet, liquor quidam inde afcendere animadvertebatur, fed nullus adhuc fumus arfenicalis: at vero cum integre candeiceret retorta, fumus quidam arfe- 
nicalis per aliquot horas continuas apparebat. Igne dein remoto, \& furno cum retorta frigefacto, inibi confpiciebatur argentum in exilia grana, qui acuum grana referebant, colliquatum, \& argilla combufta coloris bruni in pollinem friabilis, quæ ignis liquatorii prædicti vi in fluorem redigi $\&$ in maffam conflari nequiit.

Sed ut videretur, num inde omnis pars arfenici expulfa foret, in furno docimaftico, vel etiam fub tegula alibi liquabatur argilla, tam per fe fola, quam etiam cum plumbo, usque tamen nullum arfenici refidui fignum dabat.

Pondus argillæ in retortam immiffæ fuit, ut dictum eft, I 2 femunciarum, fed finito deftillationis igne refidux in retorta erant $9 \frac{7}{8}$ femuncix argillæ cum argento; liquor vero afcendens æquabat $\frac{7}{16}$ partes unius femuncix, arfenicum $\mathrm{I}_{\mathrm{I} \overline{\mathrm{I}}}$; adeo ut per defillationem inde abactum fit pondus $2 \frac{1}{2}$ femunciarum. tabatur.

Liquor prædictus cum fpiritu nitri albefcebat, cum alcalinis præcipi-

Arfenicum vero coloris cineritii aut grifei erat fed impurum, ab arfenico vulgari non multum differens; in quibusdam menftruis acidis, ut in fpiritu falis \& aqua regis folvebatur.

Expertum dein eft, num aliqua pars ferri in argilla fic combufta lateret, quia in ipfa ferri vena quafi nata \& orta, fed applicato magnete nihil ex pulvere ejus attollebatur; five quod nihil ineffet, five quod in crocum. \& ferruginem verfum effet ferrum, cum qua nequicquam laborat magnes. Nec potuit ex argilla fic calcinata fpecies quxdam vietrioli ullo modo elixari.

Spiritus aceti, qui alias folvit ferrum \& zincum, argillæ huic fuperinfufus, nullo modo tingebatur; fed quod usque aliquæ ejus particulæe folverentur, inde concludi potuit, quia in menftrum hoc immiffo oleo tartari per deliquium pulveris inftar ad fundum quid præcipitabatur; fed pulvis non nifi quam materia quadam terreftri conftabat, quae etiam ab aceto aliquatenus corrodi \& folvi folet.

Argilla dicta in aqua regis magis quam in aceto folvebatur, colore etiam immutato, fed per inftillationem olei tartari per deliquium viridefcebat menftruum; \& fimul ejus ope calx quædam coloris grifei præcipitabatur. Expertum etiam eft, num calci fic precipitatx aliquid metalli ineflet, fed per tentamina inftituta nihil metalli inde obtineri potuit.

- Argillæ prius combuftæ 2 centumpondia ponderis probatorii mittebantur in duo crucibula five tigilla fuforia, I filicet centumpondium in quodlibet, una cum fale tartari puro \& bene calcinato menftrui loco; quibus colliquatis granum fatis magnum \& ponderis $59 \mathrm{Hb}$. metallicum in quovis tigillo obtinebatur: fed obferv́atu dignum eft, quod granum quodlibet in binas partes appareret divifum, tanquam non conftaret unius fed duplicis generis metallo; una ejus pars puri argenti fpeciem referebat, altera vero bismuthi. Rarum admodum in liquamine five regulo hoc vifebatur phænomenon; partes illæ binæ, quibus conftabat regulus, non mixtæ invicem unum folidum granum conftituebant, ut alias fieri folet, cumbina

Clafis I. de ferro.

metalla 
metalla in tigillis una funduntur, fed bina erant, \& unum juxta alterum vifibiliter diftinctum jacebat, quodlibet globi cujusdam fegmentum referens; per ictum levem mallei feparabatur una pars ab altera, bismuthica ab argento: granum bismuthicum xquabat 22 marcarum pondus, quod dein cum cineribus clavellatis per fe in regulum liquabatur; argentea vero ponderis erat 96 marcarum; quod cum per cupellam abftraheretur, obtinebatur argentum puriffimum expers fumi alcalini 94 marcarum \& 2 femunc. at vero per calculum fubtracto grano five fuperpondio plumbeo, remanebant 77 marcx \& $7 \frac{5}{\mathrm{I} \sigma}$ femunc. argenti puriffimi; adeo ut fecundum hanc probationem contineret centipondium hujus argilla 77 marcas $7 \frac{\mathrm{I}}{\mathrm{I} \sigma}$ femunc. five $38_{2}^{\mathrm{r}}$ 括. argenti.

Experimentum dein factum eft cum fale alcalino, quocum colliquabatur in crucibulo argilla dicta; fcilicet, folvebatur fal alcalinum in aqua, \& argilla a folutione per colationem \& decantationem feparabatur, qux dein ficcata pondus $4 \mathrm{I}$ 话. æquabat, five refiduum ponderis prædicti 59 th. fupplebat. Elixata fic per aquam argilla \& per magnetem explorata nullam partem ferri voluit offerre; bismutho vero pulverifato \& per magnetem explorato, ferri particulas ineffe compertum eft.

Sed quia digna examine occurrit pars illa altera feu bismuthica, hine circa illam pericula fequentia facta funt. In aqua forti integre folvebatur, ipfaque folutio viridefcebat, fed inftillato oleo tartari lactefcebat, \& fimul precipitabatur calx alba, fed tandem tranfibat albedo in colorem flavum. Ipfa hæc folutio per aquam puram pariter albefcebat, \& calx itidem alba precipitabatur.

Solvebatur etiam bismuthum hoc plene in aqua regis, menftruum viridefcebat, non fecus ac cuprum inibi effet folutum; cum illo tamen difcrimine, quod folutio cupri in aqua regis per oleum tartari colore cœruleo tingeretur, fed hæc nullam coloris alterationem ab oleo dicto tartari fubiret. In folutionem infufa aqua nulla mutatio animadvertebatur, nece folutione calx præcipitabatur.

A f piritu aceti non folvi potuit materia hæc peregrina bismuthica, usque tamen ramenta exiguiffima inde feparata fuiffe, ex eo exploratum eft, quod inftillato oleo tartari quid ad fundum precipitaretur; aliter nec fit, fi genuinum bismuthum folvitur in aceti dicti fpiritu calido aut ferventi, \& in menftruim dein infunditur oleum tartari.

Bismuthum hoc argenteum nec a firitu falis ammoniacı corrodebatur, preter quod Śpiritum colore cœeruleo tingeret, prout tingi etiam ex sere folet.

Porro bismuthicum hoc granum per fe in tigillo fundebatur, fed fundi non potuit nifi igne admodum forti; interea nullus inde fumus fpargebatur: contra vero bismuthum vulgare facile \& fere in quovis igne liquitur, \& inde fumus exire folet.

Adhuc tentamen cum bismutho hoc novo factum eft, ut fcilicet indagine multiplici indoles ejus \& differentia a bismutho communi plene conftaret; in quem finem iterum in tigillum cum 2 partibus cinerum clavellatorum, \& 2 partibus filicis indebatur, infuper applicato \& lutato ti- 
gillo alio refupinato; peracta fufione, \& exemtis reclufisque tigillis, circumcirca parietes adhærefcebant fcoriæ coloris cœrulei.

Ex his \& prædictis differentia utriusque bismuthi innotefcere potuit; feilicet, quod novum hoc genus fcorias coruleas fuppeditaret, quod fragile effet \& facile fub malleo in pulverem frangeretur, quod :egerrimeliqui \& in fluorem redigi poffet; quod nullum fumum difpergeret: at bismuthum verum fcorias flavas relinqueret; nec fub malleo facile frangeretur; mediocri igne in liquorem abiret; \& liquatum emitteret fumum; ut \& plura alia.

Solutio bismuthi genuini per aquam fortem \& per aquam regis non viridefcit, fed adjecta aqua pura lactefcit, precipitata calce quadam alba; novum vero hoc genus per aquam fortem \& regiam folutum viridefeebat, fed per affufam aquam nihil inde precipitabatur. Bismuthum vulgare per affufum fpiritum falis ammoniaci nullo colore tingitur prout hoc Noormarkienfe.

Sed licet materia hæc in multis difcrepet a bismutho communi; usque tamen ex plurimis fignis, ut \& ex fcoriis cœrulefcentibus \& aliis, agnolcenda videtur effe pro fpecie bismuthi fed ferro confpurcati.

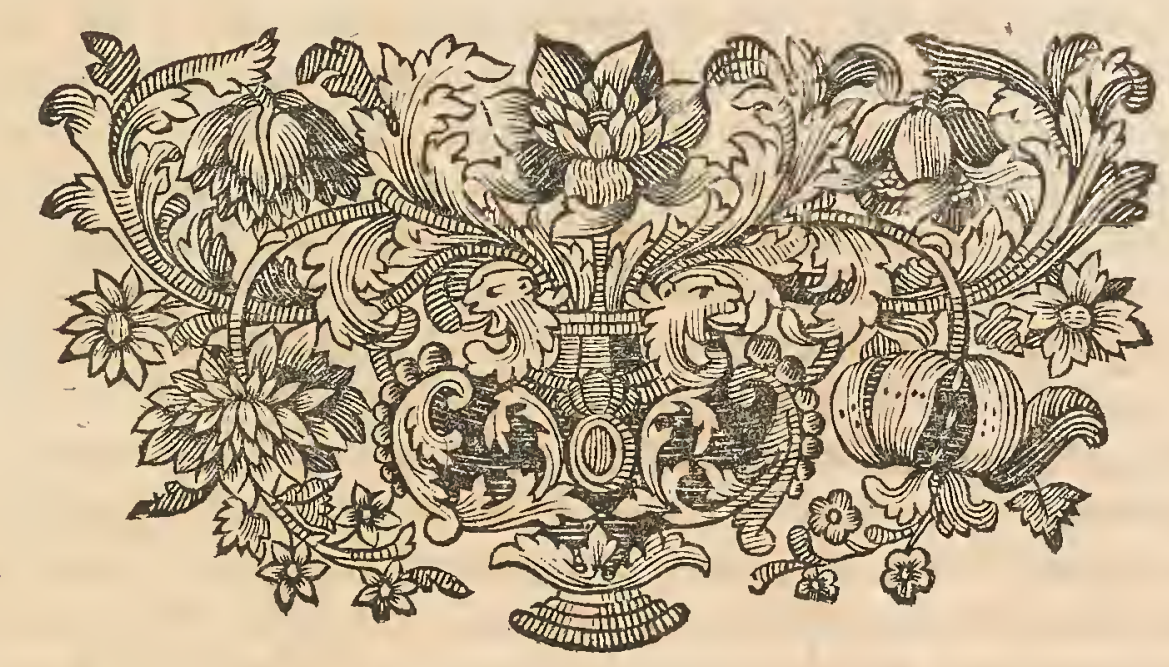




\section{PAR A GR A PHUS II.}

\section{De officinis $\mathscr{E}^{\mathscr{S}}$ focis ferrariis, deque ferri crudi liquatione $\mathcal{S}^{3}$ recoctione, pariter de exten- fione ejus Jub malleo Svecia.}

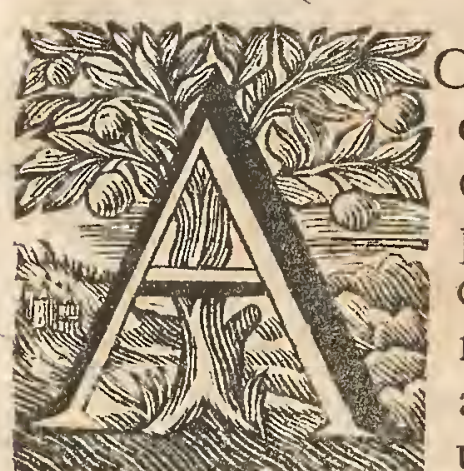

Ctum jam eft de vena ferri ejusque præparatione \& liquatione in Svecia paffim ufitata; jam vero agendum eft de ferri crudi renovata coctione in focis ferrariis, pariter de extenfione fub malleo. Non ubivis Sveciæ idem eft mos fundendi \& malleabile \& purum reddendi ferrum crudum, differt paffim in provinciis aut ditionibus metallicis, fed differentia non tantieft, ut cujuscunque modum fingillatim exhibere ideo neceffum fit, preter Roslagienfem, qui prorfis difcrepat ab reliquis. Vocatur hic modus Germanicus five Tyska Smidet; at vero alter feu Roslagienfis modus Gallicus, hoc eft, Fran $y$ ska Smidet, de quo etiam infra fuo loco feparatim.

Ipf $x$ domus five officinæ ferrarix, in quibus camini, folles, foci, cum malleis \& incudibus, hoc eft, in quibus machinæ omnes pyrotechnicx, pneumaticx \& aquaticx funt, non unius \& certæ dimenfionis effe folent; fecundum aream \& loci opportunitatem jam latior jam anguftior eft domus : eligitur utplurimum locus lati campi, fi clivi aut convalles fint, applanatur folum, ut fcilicet area detur ampla; quo enim amplior, præfertim fi inibi fint camini bini veltres, eo melius quisque ex fabrorum turba opus fuum peragit, \& maffas ponderofas ferriverfare, \& bacilla longiora fub malleo diducenda vertere poteft, de qua re infra.

Pariter etiam caminus, qui ab Agricola vocatur fornax, Svecice Herd, non unius ejusdemque ubique dimenfionis \& amplitudinis eft, fed anguftior aut major redditur fecundum opportunitatem loci \& amplitudinem areæ, quæ juxta torrentis fluvii aquam omnino eligenda eft: undenec reddi poteft certa regula \& ratio dimenfionis ejus; vidi enim caminos, prout illos vocare volumus, fatis amplos, vidi exiguos; communis illorum menfura effe folet 4 ulnarum in longitudinem, $3 \frac{\mathrm{r}}{2}$ in latitudinem. Qui hodie in ufu funt, a binis lateribus funt aperti, adeo ut in aream camini ipfe faber inclinato tamen corpore poffit intrare; a binis vero reliquis non, fed prxclufus ibi eft caminus muro faxeo. Quia a bina parte apertus ftat caminus, hinc fulcimentum quoddam five ligneum, five ferreum uni ejus angulo fupponitur columnæ inftar, five confructum ex faxis, fed plerisque in locis ab incudibus \& malleis fractis \& antiquatis, ne fcilicet fornix incumbens ruat : pariter ad alterum angulum, ubi excipit murus faxeus, fulciminis loco fubftrati funt incudes rupti \& mallei ex nimio ufu \& crebris ictibus vulnerati. Supra vero excipit fornax quadrangula, qux in apertum aera per tectum educitur, coitque \&terminatur in aperturam pro 
evolatione fumi \& fintillarum fufficientem; unde fornax hæc in aretius verfus fuperiora contrahitur, definitque in tubum quadrangulum fimilem: fornaculis vulgaribus fupra tecta ædificiorum eductis. Magna illa apertura anterior, ubi faber ftat, \& maffam recoquendam ferri in foco verfat, humilis effe folet; fi non, lamina quxdam ferrea five lignea pilei aut tegumenti loco apponitur, ut filicet a nimio ignis 2 ftu \& flammæ continua vibratione facies ufque illæla fervetur. Per unum parietem patet foramen quoddam quadrangulare $\frac{1}{2}$ ulnæ latum, hoc eft, in muro a tergo; quod inlerviet ferruminationibacillorum fractorum, ferrea enim bacilla in medio foco ad candorem ufque fubinde calefacienda, \& dein fub malleo reunienda funt; fed hodie multis in locis nullum tale foraminulum exftat.

Quantum præferenda fit area camini ampla angufte, ex eo judicari poteft, quod in amplis certus defignari poffit locus pro carbone, \& quidem pro carbone integro \& comminuto, pro pulvere carbonario; prater quod. faber ab igne remotior animam fuam nimis calentem liberius hic quafi trahat, \& brachia fua nuda circumferre poffit.

Sed ex delineatione melius, quam ex defcriptione, camini hujus conAtructio hauriri potelt: en itaque focum leviter delineatum, ubi (II) repræfentant folles cum fuis tollonibus, trudibus, perticis, jugis \& trabe quæ a rota aquatica circumducitur. (A) Tab. IV ipfum caminum \& fornaculam ex lateritio lapide conftructam. (BB) vincula qux hic loci funt lignea ad angulos invicem connexa, ut filicet coftæ fornacis, ne dehificant, contineantur. Apparet hic caminus utrinque, ut dictum eft, apertus. (C) paries a tergo, in quo foramen quadrangulare exftat. ( $\mathrm{H}$ ) funt in=" cudes ferrei a mallei ictibus rupti \& lacerati fulcri loco. (Z) eft malleus vetuftus, per cujus os vel collum, ut a fabris vocatur; patet via fcoriis ex foco emanaturis, vel per quod infertis contis maffa foco inhærens elevatur. (E) eft ipfiffimus focus. ( $\mathrm{G}$ ) eft lignum cavum five alveus aqux recipiens: aqua inde per fitulam aut bulgam $(\mathrm{H})$ haufta in focum nimis ardentem effunditur; vel etiam in alveare hoc fcorix pulverifandx, five conti igne nimis rubentes immittuntur. Camini hujufcemodi in quavis officina funt plerumque duo, in quibusdam 3 , fed rariffime; in multis etiam non nifi I : fufficit unus malleus cum incude, ferro dilatando, quod in binis focis five catinis ferrariis recoquitur. Externa officin: aut donus fabrilis facies exhibetur $T a b . V:(F) \&$ (E) funt $x$ diculæe vel binæ cameræ pro machinis aquaticis \& rotis. (MKY) funt pertic: quibus fublatis aqua præceps.in rotas volvitur. (CC) eft longus alveus feu aquæ ductus, per quem aqua e lacu verfus rotas ducitur. (DD) funt tubi fornacum, per quos fumus \& fcintillarum fumen in liberum aera erumpit.

Simpliciffima olim camini ferrarii conftrutio fuit, pariter hodie in locis ubi pauperes lares funt. Caminus a tribus lateribus integre patuit, nec nifi area prorfus patula cum foco exftitit, tantummodo ad unum latus fcilicet a parte follium murus ad altitudinem 3 ulnarum lateritius vel faxeus fuit eductus, cujus ope præcipue munita funt tabulata \& fedilia follium, ne ligna pice obducta ignem a fintillis accipiant: nudus ita \& fine vefte quafi patuit caminus, nec fumus nifi per aperturam quandam in ipfo tecto faClalfis I. de ferro. 
Etam exitum habuit : unde fæpe acciderat, quod fumus fcintillis fotus \& igneus vel afferes vetuftos \& ficcifima tecta, vel parietem ligneum per plures annos e fumo \& igne denigratum \& toftum corripuerit; \& nifinfpera fit continuo aqua, cuftodias affidue agente fabro, domum \& officinam totam incendio periife notum eft: aliquibus in locis funt adhuc 2 parietes lateritii, fed caminus infuper apertiffimus, adeo ut fumus femper igneus etiam in apertum colum per aperturam quandam in teeto factam erumpat. Olim fimplices hujufcemodi camini in ufu fuerant, quales etiam apud Agricolam depictos videas, fed ætas fequior \& eruditior pofteros fuos fornaces melioris ulus exftruere docuit.

Hic etian mentionem facerem camini ferrarii Stiernfundix a Dno Chrif. Polhemio exftructi, qui fuperne arcu five fornice duplicata tegitur, per quam exitus ad unum angulum pro fumi evolutione factus eft; ' fed quia autor experientiffmus ftructuram camini fui ipfemet non tanti facere vifus eft, hinc defcriptionem ejus fuperfedeam.

\section{Confructio foci fabrilis.}

Ocatur hic focus fabrilis locus in area camini factus pro receptione ferri, five in quo recoctio aut ipfanet liquatio ferri crudi peragitur: $\mathrm{ab}$ aliquibus catinus, ab aliis tigillum dictus. Speciatim vocatur hic locus Hard Svecice: fed quocunque utaris nomine, fufficit per focum hic intelligere locum illum in area camini ex ferreis laminis paratum, in quo recoquitur ferrum crudum.

Fundamentum pro camino ficcum eligendum eft, non aliter ac fundus fornacum fuforiarum; fi enim humus infra fit uliginofa \& cacis quibusdam fcatebris vel fubterlabentis aquæ venis madens, aqua inde fe fub fundum foci facile infinuat, \& fic per meatus \& poros latentes, verfusipfum ignem tendit, \& vim ejus infringit, aut frigore quodam labefactat; hinc videndum eft, ut humus foco fubjecta fit humoris expers; fed usque majoris fecuritatis gratia, fovea quxdam infra paratur, non aliter ac fub foco fornacis liquatoriæ, \& inde educitur canalis vel fipho ferreus, per quem exhalct vapor, nec permittitur, ut inclufus ftagnet, utque in fibras \& compagem fixi fundamentalis urgeat. Canalis hic inde educitur vel fubfedile \& machinamenta follium, vel verfus anteriorem foci partem. Stiernfundie vero area camini \& foci fuperinftrueta eft muro integro fornicato, e quo per apertum latus exhalat aqua vaporifera, unde etiam focus admodum liquatorius \& ficcus ent. Plurimis vero in locis caverna talis fubterranea nulla effoditur, ubi fcilicet humus aridiffma omnem liquorem in fe abforbet. Si fundamentum focihumidum fit, exinde contumax \& difficilis exiftit liquatio, ferrum quafi non fufile eft, nec a fcoriis \& malignitatibus fuis feparabile, multa ejus pars in fcorias vertitur, nec fuam \& debitam vim in ferrum videntur exercere carbones, multa carbonum pars ut \& multa ferri fine ufu confumitur; verbo, ferrum inde illiquabile, \& refractarium redditur. 


\section{TAB:IN. de Ferro.}
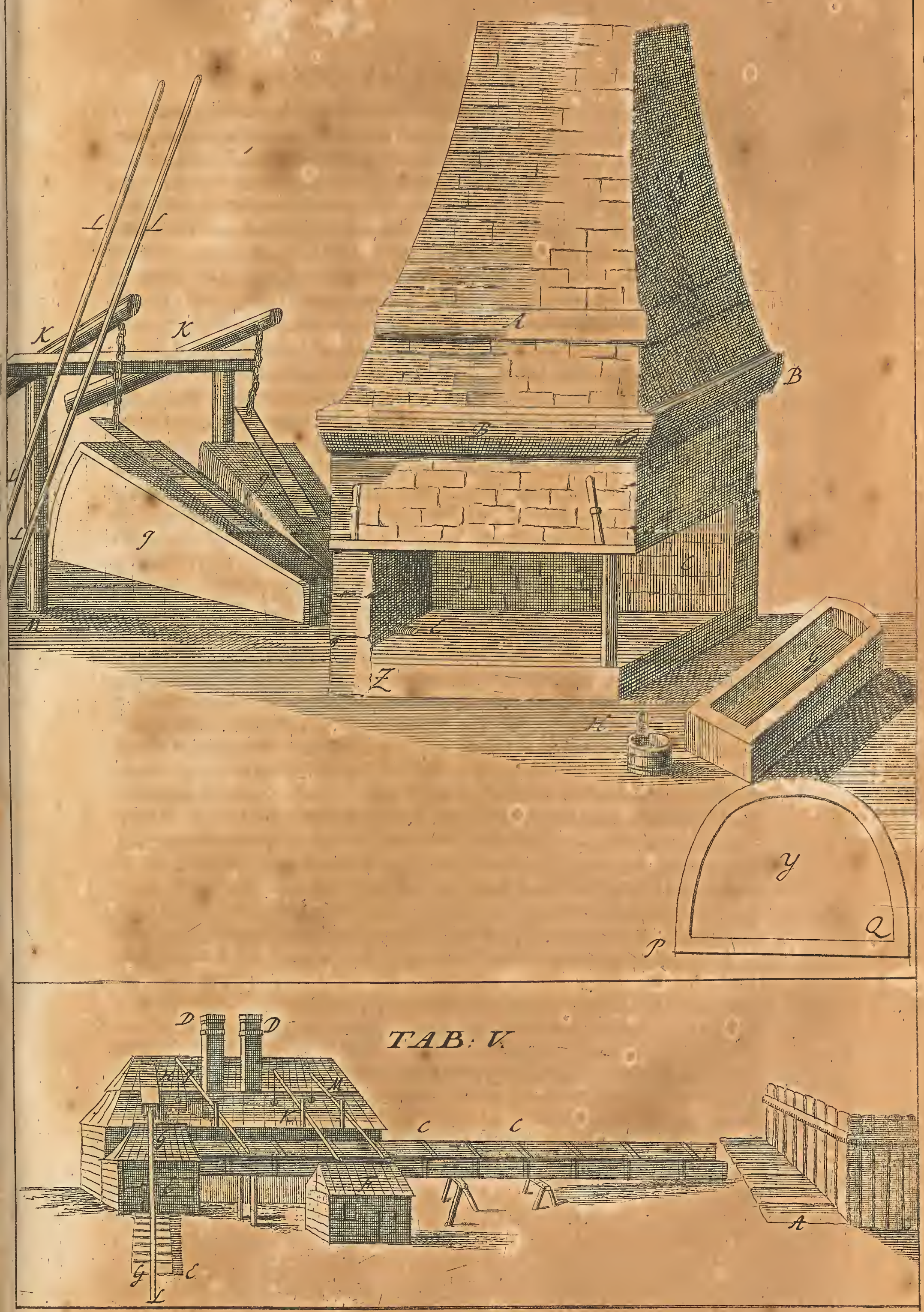


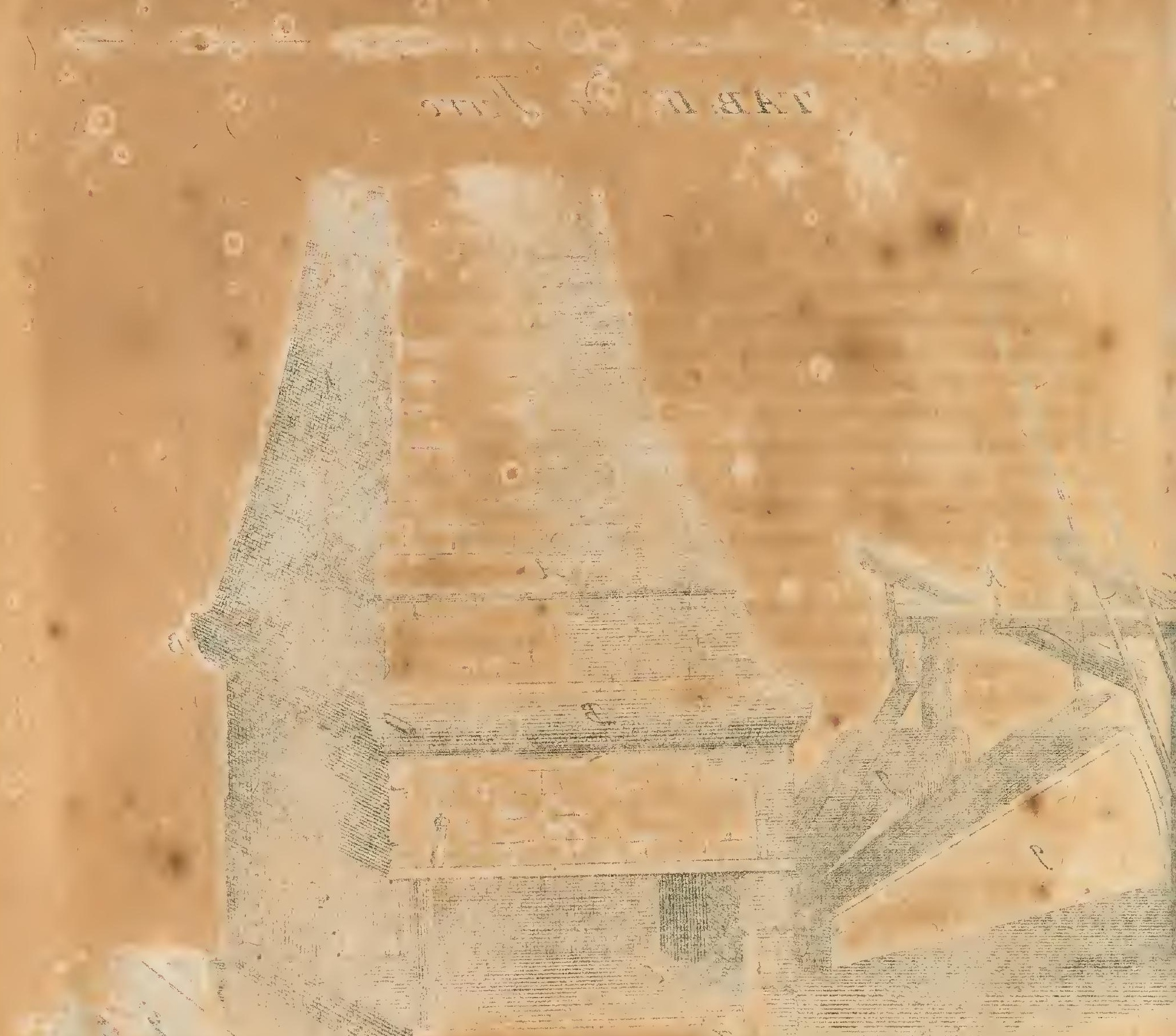

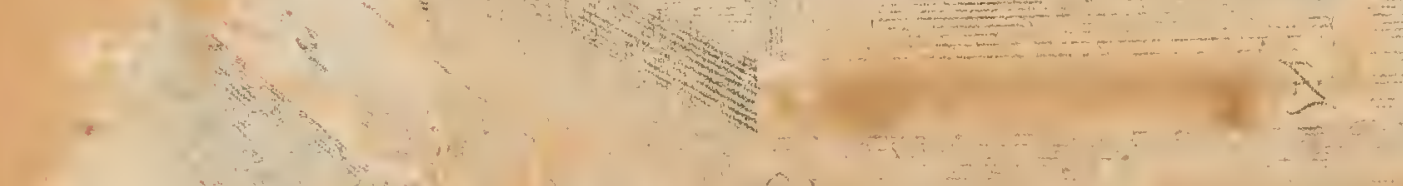

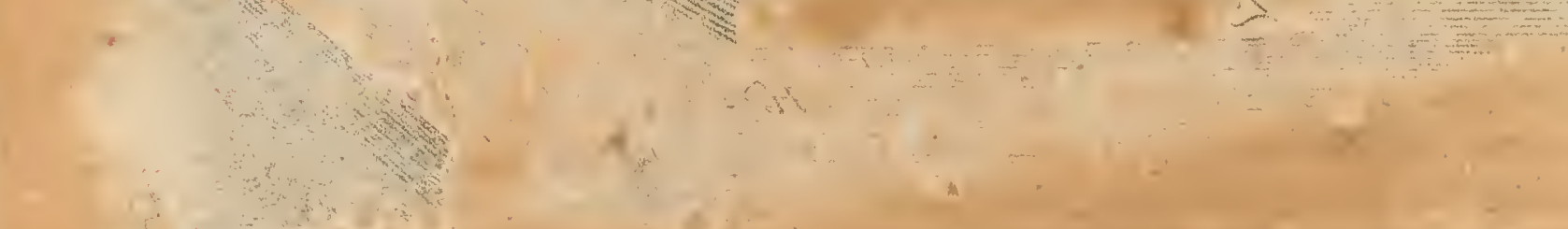

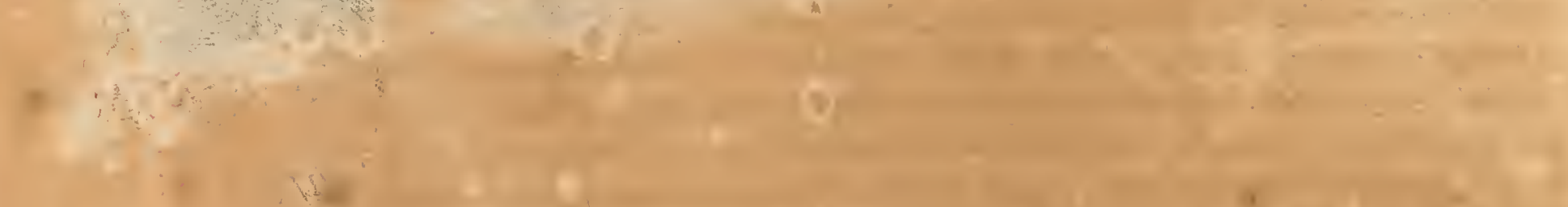


Super foveam pofito faxo quodam grandiori, fuperinfruitur area camini, \& dein ad unum latus ejus, fcilicet ad quod applicati moventur folles, conditur focus five catinus prout Agricolæ audit. Focus hic, in quo peragitur ipfa ferri crudi recoctio aut purificatio, figure pæene quadrangulæe eft, conftatque fundo \& parietibus ferreis; ferrum, quo parietes conftent, non recoctum \& purum, fed ex vena fúum \& crudum effe deber; 3 ferri lamina conftituunt 3 parietes, una vero fundum; fundamentalislamina craffa eft 4 digitos, longa I ulinam \& 2 digitos, lata I ulnam, pondus ejus eft 2 pondo nauticorum circiter: lamina, qux parietem conftituit, quxelibet longa eft I ulnam 2 digitos, lata 14 digitos, craffa 3 vel 4 .

- Saxo fundamentali fuperinftruitur carbo in pulverem comminutus, ut \& fcorix fimiliter pulverate, infuper relocatur lamina dicta ferrea fundamentalis, cujus dimenfionem nunc exhibui : dein eriguntur circumcirca laminam jacentem horizontalem tres aliæ laterales, que a tribus partibus includunt fpatium foci: binx fic laminx in fitu fuo tenentur erectx, \& a tergo fulciuntur acervo pulveris carbonarii, qui parietem verfus in. teriora quafi trudit, \& fimul arcet, ne humor exteriorem ejus parten con tingat focumque fic ardentem refrigeret: unum latus confituit, ut dietum eft, murus medius inter folles \& focum, per quem infertatur conus fpiratorius, in quo relocantur fiftula follium, de quo infra; hic etiam five fub iplo cono erectus etiam fat paries ferreus, fed a parte anteriore nulla reponitur lamina, loco ejus tantummodo malleus vetus \& multo ufu \& ictibus crebris collo vel capitetenus muletatus aut faucius ; quamque accefferit hic malleus, qui quartum parietem conftituit, foci fpatium inclufum eft; per aperturam mallei patet via fcoriis emanaturis. A malleo hoc ad oppofitum latus 3 ad $3 \frac{\mathrm{I}}{2}$ pedum diftantia effe folet, aque eodem latere ad coinum fpiratorium 2 pedum \& 2 digitorum. Sique lamina fundi locum fuum non integre repleat, parietes dicti ferrei extra marginem ejus aliquantifper etiam removeri folent. Ex dimenfione data lamine fundamentalis datur etiam amplitudo ipfusmet foci, qux rationem eandem habet, focus fcilicet xquat longitudinem I ulnx \& 2 digitorum, latitudinem I ulnæ, altitudinem 12 vel 14 digitorum.

Qui artem hanc fabrilem profitentur, multam operam impendent, ut foco juttam menfuram \& amplitudinem impertiantur; led adhuc majorem, ut cono ventilatorio cupreo, in quo locantur fiftula vel nares ferreæ folliculares, dent obliquitatem \& fitum debitum; qui tamen variandus eft fecundum indolem ferri, ut \& fecundum qualitatem foci: fed de cono dicto vide fequentia, pariter de vento.

\section{De cono Spiratorio cupreo, ut E de fifulis tra. Etoriis E firitalibus, deque vento.}

COnus quidam ex cupro paratus figurx hyperbolicx in orificium formæ demilunaris aut femicircularis terminatur, exque lamina cuprea admodum crafta \& invicem complicata contexitur, ille trans murum prius 
memoratum exfertatur; illum lcilicet in finem, ut fiftulæ folliculares inibi relocatæ ventum per unam aperturam in focum trudant, ficque concentratus ventus vim in ferrum obvium liquandum ipfumque liquamen præftantiorem exhibeat, pariter ut ventus in focum immiffus non ftatim juxta murum five in primo foci limite tanquam laffus \& hebes animam exhalet \& pereat, fed cono in multum foci protracto \& exporrecto procul a dicto muro ftatim in ipfum focum intret fpirans. Longitudo coni hujus hyperbolici cuprei fpiratorii erit 8 partium, qualium latitudo maxima $6 \frac{\mathrm{r}}{3}$ eft partium, \& latitudo minor $3 \frac{\mathrm{r}}{4}$; figuram orificii ejus videas Lit. $(Y)$, in qua eadem oris ejus femicircularis amplitudo \& dimenfio obfervata eft, que in ipfo cono confpicitur, quamvis non ubivis loci eadem pateat orificii coni apertura, polcit iplum ferrum differentiam. Fiftulx vero five nares ferrex, qux ex follibus exeunt \& per quas e follium alveis aut pulmonibus truditur aura five halitus per conum verfus ipfum foci penetrale, non nimis prope aperturam coni, nec abinde remote nimis funt relocandx, fed media quxdam diftantia eligenda eft, alias ventus vel jufto fortius intenditur, aut obtufus aut acutius nimis fpirat. A naribus dictis ad os ipfum coni utrique nari commune reftare folet $\frac{x}{2}$ pedis diftantia : obliquitas etiam eadem datur filtulis qux cono.

Conus hic fpiratorius protrahatur aliquantum extra murum in ipfum focum, a quibusdam magis, ab aliis vero minus, tam fecundum regulas a magiftro traditas, quam pr:ecipue fecundum ferri \& foci indolem : diftare orificium ejus a pariete utplurimum $\frac{\pi}{2}$ pedem folet.

Quod vero obliquitatem iftius coni attinet, non horizontaliter jacere debet, horizontaliter enim tunc in ferrum oppofitum evolaret fpiramen, fed obliquandus eft aliquantifper verfus fundum : multa fabri in eo confiftit peritia, ut exactiffimæ obliquationis menfura \& angulus ei detur; communiter ita dirigitur ventus, ut juncturam lateris oppofiti \& fundi fringat, hoc eft, ut ventus in focum inanem erumpens tam partem fundi remotifimam, quam partem lateris oppofiti imam, ficque confinium aut commiffuram perftringat : aliqui ita deprimunt narem hujus coni, ut non confinia laminarum feriat aura, fed verrat fundum; aliqui vero alius elevant conum, adeo ut nulla fui parte fundum petat, fedtantum parietem oppofitum : fed quia hoc non abfque caufa fit, hinc videbis in fequentibus rationem.

Bafis hujus aperturæ five diameter inferior femicirculi (PQ) horizontalem fitum non habebit, fed obliquum quendam, adeo ut orificium hoc in refpectu ad lineam horizontis five fundum, obliquandum fit, utque obliquis tanquam hircis intueatur focum; fed magis aut minus fecundum indolem ferri.

Conus hic fpiratorius non medium focum fpectabit, hoc eft, ventus inde efflans non dividet focum medie in binas partes; nec fuper medium parietem fuum relocabitur, adeo ut per lineam centralem foci tranfeat ventus emiffus, fed verfus interiora five pofteriora foci : paries ille lamellaris, fuper quem relocatur conus, in 3 partes divifus fit, locum divifionis fecundre tenebit conus; adeo ut a pariete interiori foci diftet ${ }_{3}^{\frac{1}{3}}$ parte; a pa- 
riete anteriori, vel a malleo, qui aperturam anteriorem claudit, $\frac{2}{3}$ partibus.

Paratur apertura per murum dictum quadrangula, \& ei infertatur conus dictus ex lamina cuprea complicatus \& ferruminatus; incumbitque parieti ferreo. fuppolito : fuper conum dictum fpiratorium jam infertum relocatur bracteola ferrea; his pofitis conus argilla ad murum adglutina* tur \& affigitur, adeo ut indivulfa infideat. Infuper bacillum quoddam ferreum cavitati coni a parte pofteriore infertum clavis affigitur, ut fcilicet in fitu teneatur immotus; quod fit illum in finem, ne conus a fitu ei dato turbetur, vel ne antrorfum magis vel aliunde feratur.

Induftrius faber fciet cono fulorio fitum \& obliquationem debitam impertiri, non horizontalem nec obliquum nimis; unde quilibet faber, qui: artem fuam callet, proprias pofidet menfuras baculo aut ftipiti cuidam incifas, fecundum quas altitudines coni \& foci fui adaptare novit; illas etiam tyroni \& filiis luis tanquam arcana artis tradit, aliis vero invidet.

Accidit interdum fi diverfi generis ferrum recoquendum fit, quod menfuræ altitudinum \& obliquationum coni ex ufu edoctæ liquationi \& purificationi ejus nonjufte infervire poffint; hincin medio recoctionis opere variandus frepe eft fitus coni:vel enim protrahendus magis in focum eft, vel retrahendus verfus murum, vel obliquandus, vel in fublime magis tollendus; ad minimum aptandus, donec obtineatur fitus ferro dato conveniens; quod ni obfervetur, vel pereunt carbones fine effectu, vel perit ferrum, \& in fcorias quafi vertitur \& evanefcit, vel infeparatum remanet a recrementis crudis, vellente peragitur opera recoctionis, cum pluribus aliis incommodis \& dipendiis ex venti non debita directione oriundis.

Si longius e foco eductus \& exporrectus ille conus fit, hoc eft, fi ultra menfuram $\frac{x}{2}$ pedis prætentus, liqui melius ferrum inde perhibetur. nam ad foci alterum \& oppofitum parietem brevior eft via, unde ferrum in foco plenius a vento perftringitur. At vero fi nimium immittatur in focum, facile etiam iplummet cuprum liquatur; \& ferrum, quod occupat inferiorem foci partem, nullo vento agitatum facile tenacefcit, \&induratur, ficque a ferro reliquo fluidiffimo lecernitur. At vero fi ductus hic fpiratorius retractus nimis fit verfus murum tergalem, etiam minori vi \& flamma in obvium ferrum operatur : accedit, quod in hoc coni firatorii pofitu, pars muri tergalis, cui infidet conus, a nimio igne \& flamma inde reflexa \& reverberata incandefcat, \& fic ab ignis continuo fluxu fenfim corrofa \& liefa attenuetur; unde etiam videtur in hoc cafu murus penitus candens, \& circumcirca conum ejufque nafum exefus, \& fæpe igne ad alteram ufque partem penetratus, quod noxam liquationi \& damnum ipfimet cono \& æri inferre folet. Illum etiam in finem murus circumcirca, \& præcipue fubter conum ventilatorium redditur craflior : locus ille vocatur Svetice Huggftad.

Si coni fpiritalis fitus nimis horizontalis \& apertura ejus altior a fundo foci exftet, tunc ventus in aerem diffipatur, antequam ferrum invadit $\&$ debitum effectum edit : in hoc cáfu confumuntur non debita ratione carbones, quorum jactura multa elt, ventus enim nec fundum petit, fed clalfis I. de ferro. 
ferrum ftringens illico furfum fertur, ufque tamen fitum horizontalioren amant quidam fabri, quia liquatur bene ferrum in hoc fitu, \& recoctionis opus vividius \& vegetius peragitur, licet cum difpendio carbonum. Exipfa flamma \& ferro, quod foco immiffum eft, apparet ftatim, num conus hic fublimior \& elevatior fit, maffa enim ferri altius jacet, \& carbones infuper accumulati clivum quendam formant; flamma etiam elatior inde efflatur.

At vero fi obliquus nimis fit fitus hujus firaminis, adeo ut ventus cono emiffus verfus fundum ruat, tunc difficilius \& ægrius peragitur coctio; ægre liquatur ferrum: nam flamma non jufta vi \& vigore pollet, quamvis carbones non inaniter confumantur.

Communiter obfervandum eft circa pofitionem coni ventilatorii, quod fpiramen foco immiffum non verrere fundum, nec parietem oppofitum directe verberare debeat, fed juncturam fundi \& parietis feriet; in quio cafu ventus perțringit imam partem maffe ferri crudi foco \& cono dicto fuperimpofiti. Alias communiter metiri folent altitudinem di尺ti coni, fi feilicet orificii ejus margo fuperior fit in linea recta cum fupremo margine parietis oppofiti; ipium itaque orificium coni fub dicto plano erit, \& refpiciet inferiorem laminx e diametro oppofitx partem; hoc eft, pars illa fuprema orificii $\mathrm{z} 2$ digitis exftare debeta fundo, ad eandem fcilicetaltitudinem, ad quam paries ferreus.

Quod adhuc directionem venti attinet, cavendum omnino eft, ne ventus e nare emiffus verfus unum foci angulum fpiret, fcilicet verfus angxlum remotiorem in foco, vel ne aliquantum illuc defleetatur; compertum enim eft, perire tunc multam ferri partem \& quafi in fcorias verti: fi enim ventus ad oppofitum parietem tendit, liquitur bene ferrum, \& liquatum a frecibus \& recrementis fuis bene purgatur ; ut malum hoc evitetur, vertitur potius os coni, ut anteriorem foci partem refpiciat.

Os coni fpiratorii femicirculare fic foco obvertitur, ut bafis five diameter illius quafi inclinata anteriorem foci partem refpiciat; fed inclinatio hre bafeos orificii major minorque erit fecundum indolem ferri variam : major inclinatio erit, fi ferrum fit fulphuris expers, fcilicet fi facile frangitur frigidum, quod Svecice vocatur Kallbrecht, non enim tam craffo \& obefo volumine in oppofitum ferrum effertur aura, fed acutius ftringit \& quafi fecat, prout vulgus fabrorum loquitur : torquetur fic melius hæc ferri fpecies, cogiturque ut heterogenea inclufa deferat, utque in melioris indolis ferrum \& vere purificatum tranfeat. At vero fiferrum multo fulphure fcatet, hoc eft, fi facile frangitur calidum, quamvis tenax fit frigidum \& vocatur Kivedbreckt, tunc area five bafis ipfius orificii non tam multum obliquabitur, ufque tamen non parallelum fitum cum horizonte aut fundo foci tenebit; in hoc fitu latius \& quafi plenius emittitur in ferrum obvium aura, \& illud non tam acute ftringit.

Sed hæc qux de directione venti \& pofitione coni fpiratorii dicta funt, melius ex ufu quam ex preceptis difcuntur; difficilis etiam præceptorum eft in talibus intellectus, nifi oculus fimul preceptis adfuefcat: plurima fabrilis f́cientia in eo verfatur, ut ventum ficiat dirigere, \& conum fipiratorium foco jufte applicare: nifi hoc noverit, vel carbonum vel ferri 
jacturam patietur, vel ferro inhærens vitium nequicquam excoquere tentabit.

Circa conum hunc fpiratorium, qui ex cupro paratur, obfervandum eft, quod non facile ab igne \& liquamine fluido ferri liquefcat \& confumatur, nifi incuria aut pellacia fabri in caufa fit; interdum a liquamine ferri undiquaque circumdatur tanquam inibi reconditus \& fepultus, pariter etiam per mediam flammam interlucet, usque tamen illafus a Vulcano remanet; ratio eft, quia flumen aereum continuo ductum ejus interiorem replet, \& fic ab una ejus parte ignem arcet, qua libera \& illiefa manente, pars altera fruftra $a b$ æftu \& igne oppugnatur. Nifi tyro, qui fabrilia tractat, fedulo infpiciat conum, \& fintillarum flumen illuc infperfum detergat \& decutiat, immunemque igne fervet cavitatem \& ductum coni, facile liqueturæs \& ferro fe addet. Duæ precipue funt caulæ, curæreus hic ductus ab igne ambiente liquari foleat: $r$. fi precludatur orificium \& exitus vento, adeo ut fruftra laboret ventus per tenacem \& orificio inhærentem maffam aperturam quandam moliri, fed intus inclufus quafi fuffocatur; tunc $\mathrm{ab}$ igne extrinfecus urgente facile liquefcit $\mathfrak{x}$ \& \& confluit conus. nam aer inclufus calefcens nullo amplius frigore temperat unam ejus partem, quin ignis penetret laminam complicatam jam omnimunimine deftitutam, \& illam in ferri liquamen folutam demittat. 2. Altera ratio eft, fi ferrum nimis crudum fit, five fi cruditas multa adhuc inhærefcat maffex ferri ignitz; quodcunque enim crudum eft, quod Svecice vocatur Raudt, non liquitur facile, fed in micas \& fcintillulas urgente multo igne difcerpitur, quxque ex maffa difcerpte micx huc \& illuc jactantur, qua plurimam partem in ipfum antrum coni firatorii illabuntur, quibus firepleatur conus vel ftipetur, illico folito plus incalefcit; in hoc cafu etiam periculum fubit, ne colliquetur, nulla ejus pars nec interior nec exterior $a b$ igne immunis remanet : hoc cumminiftri animadvertunt; maffam ferri tam crudi e coni orificio ftatim removent, ne fcilicet flumen fcintillarum cono fpiratorio illabatur, fed aliunde per focum diffipetur. Infuper vento obvertunt terga illius maffix, adeo ut pars illa crudior, prout appellatur, refupina jacens micas fuas \& particulas furfum fpargat, fuperinjecto pulvere fcoriarum, cujus ope crudiora in liquorem aguntur. Subinde etiam videri folet, orificium hoc coni fpiratorii occludi a frece \& fcoriis, adeo ut fpiraculum recrementis obductum \& ftipatum fqualeat; qux nifi batillis jugiter excutiantur, facile conus illis inductus \& foedatus liquitur.

Notatu dignum eft, quod catinus five tigillum bracteis ferreis conftans, in quo toties peragitur liquatio, \& per aliquot menfes recoquitur \& ebullit ferrum, tamen igni refiftat, \& indemne illæfumque permaneat, nec aliqua fiui parte, una cum reliquo ferro, liquefcat; cum tamen eodem igne \& flabro continuo impetatur \& urgeatur, quo ferrum ei immiflum eft \& creditum. Ex his tamen videre licet, liquationem ferri in ferro crudo optime peragi; \& illud indemne \& illæfum ideo permanere, quia non abomni parte circumfunditur igne \& vento : parietes enim tigilli ab una fui parte æeftus ventofi immunes funt, unde non penetrantur, \& in commune liquamen cum contento fuo rediguntur: non altius enim ire poteftignis \& fer- 
vor, quam ufque permittit calor ab una parte, \& frigus ab altera reciprocum; nifi caloris æqualis fphæra ab utraque fit, defenditur ferrum, \& in ipfiffimo rogo \& flamma immune perftat. Accidere quidem folet, quod fundus tigilli aut foci etiam candefiat, in quo cafu non colliquefcit, fed volumen innatans ferri fecum quali conjungit, adeo ut utrumque tenaciter adhærefcat, \& ut labor fit a pariete illam evellere: hinc per vices refrigerandus eft focus, \& quidem indies, cum inibiopus peragitur; vel enim nudatur fundus, \& a ventilatione quadam fic refocillatur; vel etiam relinquitur diu nudus \& aeri frigido exponitur; vel etiam aqua in focum fic nudatum infpergitur: qui mos in quibusdam officinis effe folet, fed jam in plurimis obfolevit.

Quod alias fpirationem attinet, non femper idem \& xqualis, dum perftat excoctionis opus, permanet, fed jam intenditur, jam vero relaxatur \& lentior redditur: principio cujusvis coetionis, cum focus adhuc frigidus eft, \& non multus ignis ferrum, focum \& carbones jamdum occupavit, lentus follibus datur motus; pertica enim elevatior tenetur, cujus ope gubernaculi inftar moderari \& partiri aquam \& confequenter ventum folent; at vero proceffu operis magis magisque deprimitur pertica five manubrium clautri, in rotam admittitur aqua; \& crebrius aut copiofius fpirant folles; in media operatione liquationis ventilatio ad fummum perducitur gradum, circa finem iterum diminuitur. Alias motus follium admodum inæqualis eft, per vices quafi retardatur rota, jam cito tanquam rupto clauftro ruit, jam vero lente movet follem, \& fic per vices. Et quia lentius hic vertuntur rotæ, five reciprocantur folles, quam circa fornaces ferri fuforias, ubi xqualiter moventur, hinc per horarium tempus vix nifi 400 vices aut reciprocationes peragere videntur.

\section{Solutio E coctio prima ferri crudi.}

FOcus cum fuis parietibus paratus, cono ei adaptato, purgatur, ne quic1 quam ei infideat, quod remoram aut noxam adferat recoctioni, \& infuper fcopis verritur: in focum ita inanem immittuntur fcoriæ ex priore coctione poft finitum opus relictx; vel fi nullæe ejus generis in promptu fint, affumuntur reliquix fcoriarum vetufte: his adimpletur ad tertiam partem focus, \& infuper ut \& circumcirca fuperinjicitur pulvis carbonarius novus, pariter etiam vetus, \& cinis circumcirca focum ex fcintillis, uftis carbonibus, fcoriis comminutis \&c. per aliquot liquationum vices collectus, qui in tigillum fcopis \& rutris corraditur: cinis hic, ut dictum eft, conftat partim fruftulis ferreis \& l'cintillis, partim fcoriis, partim pulvere carbonario five favilla carbonum aduftorum, quibusad $\frac{2}{3}$ partes repletur focus. Nifi fubjiciantur dictx fcorix ferro, tanquam pulvini loco, dicitur ferrum penetrare cinerem \& foco tenaciter inhærefcere, nec liqui debite, \& confequenter nec a crudiore fui parte fecerni. Nam fcoriæ quia. fluidifimæ menftrui loco funt, fundum quafi unguine quodam oblinunt, feparantque ferri liquorem a fundo, adeo ut eo melius crudiora inde posfint feparari: in fluorem fecum redigunt duram ferri materiam; \& quia 
jamdum fcoriis repletus eft focus, leviora in flumine illarum feparantur a ponderofis, recrementa a metallicis, quod fine recrementorum copia \& liquore prævio fieri omnino nequit.

Hoc facto ope cylindrorum \& trudium, aut vi brachiorum portatur maffa cruda in caminum, \& foco ita inaptatur, ut cono fpiratorio oppofita jaceat; promovetur maffa fupra marginem unius parietis in focum, adeo ut ei una fui parte immineat, altera vero extra focum fit; verfus conum. fpiratorium e diametro transfertur, nec nifi 4 vel 5 digitis ab orificio ejus diftabit. Altitudo ejus aptanda eft fecundum altitudinem orificii coni fpiratorii, pars ima maffe in eodem plano horizontali effe debet cum ora fuperiore coni, unde aura inde fpirans imam maffx partem verrit \& ftringit, \& eo melius fi etiam eadem obliquitas detur maffæ quæ data eft cono; ita femper collimandum eft, ut ventus radat inferiorem molis ferrex partem. At vero fi ferrum fit inops fulphuris \& fragillimum cum friget, tunc obvertitur femicirculus orificii coni firatorii, ita ut pars venti etiam oppofitam maffam directe ftringat, pars vero imam ejus partem, fic ut aura quafi biffecet maffam. Pondusitaque ferri foco admoti non idem femper eft, interdum æquat $\frac{1}{2}$ pondo nauticum, interdum ${ }_{3}^{2}$ partes ejus ponderis, alibi etiam I integrum, prout filicet conti aut bacilla fub malleo diducenda craffiora vel tenuiora effe debeant.

Si una talis maffa non fufficit, apponuntur binæ vel tres, ufque dum pondus defideratum fimul conftituant; una tunc locatur fupra alteram, ita tamen ne planis applicatis omnino junctx, fed aliquantifper interpofito fruftulo ferri feparate fint : hoc fit præfertim fi duplicis aut triplicis generis ferrum adfit, quod omnino commifcendum eft, ut genus bonx indolis obtineatur; fi filicet adfit genus fragile cum friget, quod Svecice vocatur Hallbrecht, aut fi genus fragile cum rubet five cum candet, quod Svecice vocatur Roedbrecbt, hæc genera commifcenda omnino funt in foco, ut obtineatur ferrum intermediænaturæ: genus primo memoratum, fcilicet quod frangitur facile cum friget, fupponitur alteri; utrumque fic pofitum applicatur, prout dictum eft, fecundum viam venti.

Maffis ferri fic pofitis ad levam \& dextram pulvis carbonarius corraditur; dein fuperinfunduntur maflæ carbonum cumulo, fub quo fepultæ plane \& tumulatæ jacent, adeo ut nullibi appareat ferrum, fed coacervatus in foco carbo: quibus dein fuppofito igne, in rotam admittitur aqua, fubtracta aliquantifper pertica feu vecte juxta caminum pendente, \& fic hauritur in folles aura \& per nares emittitur, quæ principio lenis \& lenti motus erit.

Maffx fub carbone vivo fic reconditæ paullatim ab igne ventofoconfumuntur, guttatim enim in focum liquitur pars obverfa vento , qux fic exefa fpatium adhuc amplius inter orificium coni relinquit, quo animadverfo, maffæ prædictx propius ad conum vel firaculum fubjectis contis \& trudibus admoventur, \& ei ad eandem diftantiam ad quam prius applicantur, fcilicet ut a primo venti fonte diftent modo $s$ ad 7 digitis, \& ut iterum pars oppofita fenfim in liquorem folvatur.

clailis I. de ferro. 
Confumtis jam carbonibus novi jugiter adjiciuntur, jacent enim cu-mulati ad pedem five inferiorem foci partem, raftris aut batillis in focum inde feruntur; fcilicet ut ferrum jam qua partem candens igne \& carbone continuo opertum fit. Faber etiam nunc quam fxpiffme explorat \& fcrutatur angulos foci \& fundum; \& ubicunque prefentit fruftula ei adhærentia, illa verfus orificium fpirans fublevare folet, f́cilicet ut denuo vento objecta colliquefcant, \& in unum \& commune liquamen omne ferrum fe recipiat.

Jucundum admodum vifu eff, acie conum cupreum transmiffa tueri ferrum liquef'cens, \& oculis luftrare liquationum momenta; liquide enim per coni aperturam confpicitur ferrum candens, quia e diametro oppofitum jacet cono \& in via ipfufmet venti. Ipfum ferrum apparet hic candens \& niveum, hic vero fanguinis inftar rubelcens, maffa figuræ inæqualis \& rudis eft; exinde videre licet guttas liquidi ferri per vices depluere, non aliter ac vilui fe offerunt illæ per orificium fpiratorium in fornace fuforia confpectx, de quibus prius; quedam funt coloris candidi, quxdam vero obfcurioris \& nigrefcentis : apparent etiam fcorix fundum foci occupantes, quæliquorem non candidum aut rubrum fed mixtum quafi cum nigro, non aliter ac cum nebula aquam obfufcant, reprefentant. Si nudetur ferrum, remotis inde carbonibus; pars illa ignita vento obvia rubet adhuc magis, \& ftatim fponte fua a contactu aeris inde diffiunt \& difcerpuntur micx \& granula ignea ferri, qux majorum fcintillarum fpeciem referunt, \& hoc majore copia, quo crudius eit ferrum : nam a ferro nimium crudo unda talium fcintillarum defiuit : at vero fi ferrum coopertum fit prunis five igne ambitum, non inde particulæ prout in aere exilliunt, fed pars illarum in guttas deliquitur.

Interea maffa ferri jam candentis forcipibus vel potius contis ita verfatur in foco, \& ad auram five os Roli applicatur, ut flamma ad omnia latera xqualem exitum habeat, adeo ut videatur maffa tanguam in medio flammæ volumine quai merfa natare; diligenter infpicient, ut erumpat ubique ventus xquali flumine: fique ullibi intercludi videatur exitus, vel fi ad unam partem magis quam ad alteram fibfiderit, vel fi carbonum pulvis aut fragmenta ferri exitum precludant, ftatim ita aptant maffam inque flammeaunda vertunt, dum ignis ubique \& circumcirca eructetur æqualis; aperit hic fores, hic claudit, circumagit, ftipat, elevat, deprimit, impenditque laborem, ut in elemento fuo igneo undique æquilibret: hac ratione augetur \& exaltatur vis liquatoria, \& ferrum nec violento nec parco nimis igne funditur.

Si flammam vident multum xftuantem, \& e carbonum maffi fe alte ejectantem, adeo ut illa imperet in foco, ftatim temperare folent reftum illum \& iram; quod fit vel obturando foramina, per qux erumpit, vel fiperinfundendo aquam : fitula enim aut bulga aquam ex alveo propinquo. hauriunt, \& in flammantem nimis ignem immittunt, alias flamma laxatis quaf frenis in carbones furit, illofque inaniter confumit, nec furorem fuum in ferrum hoftemque, fed in carbones \& amicos exercet. 
Subinde etiam per fpiratoriam viam oculos intorquet luftratque faber, num ferrum fcintillet, operiatque fcintillis meatum venti; quod fi animadvertit, batilli ope excutit impedimenta, viamque Æolo facilem patulamque reddit.

Cum tandem maffa ferri videtur in focum undique delicuiffe, nec amplius partem reftare, quæ in undam ferream non dilapfa \& refoluta fit; tunc perfcrutatur pertentatque faber omines foci angulos, \& ubicunque conto obvium fentit fruftum induratum ferri, evellit effringitque, \& ante os ventofum relocat, ficque colligit fparfum ferrum, \& iterum iterumque furfum levat, \& in ipfo flumine venti reponit, dum in unam maffam inque unum volumen redegerit omnes ferri partes, quæ verfus loca frigida foci fe receperant. Jam copia carbonum diminuta apparet, nec novi carbones confumtis adjiciuntur, fed volumen ferri liquati jam feminudatum eft, ipfaque jam coetio inchoatur : coquitur \& fervet ferrum non aliter ac aqua in tripode ; jam videre licet integram liquaminis fuperficiem intumefcentem \& lente elevatam tanquam in bullam magnam, non aliter ac fifermentum fubeffet; inflatur \& intumet magis magilque, fi tumorem \& motum non velint compefcere, mobilitate jam viget ferrum, quodalias tam durum \& rigidum eft, elevatur duim ipfum focum exfuperet \& tranfcendat: magifter foci derepente aufert inde prunas, fub quibus æeftuat Mars, \& nudat liquamen, ficque iram \& fervorem fiftit diminuitque. Excoctio hæc in femihoræ tempus protrahi folet, fed penes fabrum eft, ut diutius perftet. Quia recrementa noxiora \& vitiofa excoquenda funt, \& ferrum illis ejectis ductile \& malleabile reddendum, hinc onnino fluidum erit, inque fuore \& motu quodam per tempus tenendum; quod nifi fiat, nequicquam leparantur graviora a levibus, metallica a fcoriis : hinc navatur opera, ut ferrum in xftum \& effervefcentiarn dictam perveniat, inque illum finem admovent fomenta \& nutrimenta igni fortiora, apponunt lcilicet carbones electifimos, integros \& majores, qui ignem fortiffimum fovent, \& undulationem dietam perpetuam fervant, fed non multam illorum copiam, paucos tantummodo, ratio eft, quia peragenda eft coctio non igne claufo fed femiaperto; melius exfudat vitium igne aperto quam claufo, qui ut ufque fortis fit, nutrimenta ut dictum eft fortiora adhibentur. Datur etiam ferrum, quod xgerrime in liquorem talem poflit folvi, cum quo nequicquam. laborat faber, ut debito modo faliat ebulliatque alius liquoris inftar, remanet tamen ufque lentum \& tenax \& tanquam illiquabile, \& confequenter non demittit cruditates vitiofas, hinc artis' $\&$ laboris opus eft, ut tale ferri genus in fluorem folvatur, alias refractarium, contumax \& immalleabile, finita coctione, permanet.

Hic etiam meretur methodum fabris ufitatam chalybem fibi in foco ferrario acquirendi tradere : cum enim prima hac vice excoquitur ferrum \& liquamen jam fuidiffimum eft, ei innatare folent maffulx \& frufta chalybea, qux nec angulum foci nec fundum, fedipfiffimum volumen hinc \& inde fluctuantia tenent: funt fruftula dicta, qua fuperficiem ex volumine exftantem, inæqualia \& rudis figuræ, infra vero feu qua parte immerfa funt liquanini ferreo, tunt form a rotundioris, \& liquide colore fuo diftinguun- 
tur a ferro ; præter quod chalybs in flumine ferreo natet, folutus fe ferro non facile addat, nifi vento \& Eoli ori admoveatur : ante ventum deliquitur, \& fic in ferri amici gremium \& volumen fe una recipit : at vero nifivento admovetur, fruftra liquatur in fluore ferreo. Fruftula hujuscemodi 6, I 0; 15 librarum dari folent: perhibent fabri optatæ bonitatis aciem \& chalybem effe, \& inftrumentis aut ferramentis chalybe acuandis omnino infervientem \& aptum: necferrum alius aut deterioris naturæ fieri, fi materia hæc immerfa \& foluta ferro accedat, vel fi illa privetur. Ex omni ferro chalybem obtineri poffe dicunt, fed ab uno genere plus quam ab alio; fed usque tamen nihil referre, an ferrum fragile fit cum friget, Kallbrecbt, vel num fragile cum calet (Roedbrecbt, ) fed ratione ad ferri indolem variare ufque naturam ipfiusmet chalybis: in fractura eft coloris grifei ad albedinem quandam vergentis, granis exilibus \& duriffimus. Maxima tamen ars converfionis ferri in chalybem perhibetur in eo confiftere, ut conus fpiratorius ad debitum gradum verfus focum obliquatus fit; fi enim a gradu obliquationis vel aliquantifper declinet, nullum aciei granum obtincri poffe ex ufu comperti funt; obliquius hic dirigi ventus debet: regulas \& normas habent, fecundum quas conus aptandus fit, qui nec abinde latum unguem deviare debet, fique fiat, fit cum jactura defiderati chalybis. Sed de his melius in tractatione de chalybe.

Quum ferrum fudat \& exultat in toco, \& ipfamet coctio \& effervefcentia perftat, orificium ftipatur fcoriis quibusdam nigris longius inde nafi inftar prominentibus; fi enim ventus, qui partim eft frigidus, partim humidus, per ductum patentem \& pervium in volumen ferri irrumpit, ledaturftatim tumor \& fervor: hinc non multa aura nunc refocillandus \& refrigerandus eft focus, fed ilicet ut fcoriæ cono \#olico excutiuntur \& patet via vento, tumidum ejus liquamen refedit \& ferrum ante liquidum deturgefcit \& in maffam tenacem confuit.

Statim ut liquor hic coquens fiftitur \& concrefcere incipit, aperitur via fcoriis, quod fit per collum aut os mallei, qui anteriorem partem foci conftituit; per illud inferitur \& adigitur batillum five contulus, \& ftatim facto ore emanat flumen fcoriarum, fed non diu apertum tenetur, ftatim occluditur; quod fit illum in finem, ne nimia parte fcoriarum privetur focus : fcorix enim menftrui folventis loco funt, illarum ope non modo liquitur bene ferrum, fed a recrementis fuis feparatur, \& fic fufile ut \& ductile redditur \& purificatur.

Mafla five moles ferri magna \& ponderofa ægrius in liquorem \& coctionem agitur, quam maffa exigua aut levis, major pars carbonum \& vehementior ignis ad ejus folutionem requiritur, alias ferrum ponderis unius nautici liquari poteft fpatio bihorii.

Tandem peracta hac prima coctionis vice, omnes prunæ e foco plane deterguntur, aque omni pulvere \& cinere carbonario nudatur focus \& relinquitur maffa ferri fola, fiftitur itidem ventus, \& candens moles in foco fic prunis \& igne deftituta per fpatium integræ horæ relinquitur, nec loco fiuo emovetur, quam fuperinducta nigra quadam crufta: aliquibus in officinis mos eft, ut ftatim accingant fe fabri ad recoctionis fecundæ vicem, 
utque molem jamdum ignitam \& candentem iterum obvertant vento, \& novam coctionem \& liquationem inchoent.

\section{De alter a recoctionis vice five de liquatione ferri iterata.}

Uum induruerit hæc moles ferri, illa admodum adhærere folet parietibus \& fundo foci, nec inde avelli \& leparari poteft nifi vi \& ope contorum: inter molem \& parietem intrudunt contum \& magis magisque urgent; dum moliendo tandem divellant maffam a cono fpiratorio, qui in mole hac ferrea pæene delitefcit \& reconditur. Si moles hæc fundo adhærefcit, etiam inde feparatur; contum cufpidatum per mallei vetufti aperturam, qui anteriorem partem foci conftituit, fub ipfam molem indunt, \& malleis five marculis ferreis adigunt, dum inter foci fundum \& molem dictam bene fit intrufus; dein vi brachiorum mafiam tanquam per veetem fenfim fublevant; fique vis brachiorum non fufficit, infiftunt conto \& illum toto corporis pondere deprimunt, dum e foco avulfa moles tandem elevetur. Accidit interdum quod facilis feparatio molis fit a fundo, quodque levi motu \& percuffione inde foluta recedat. Caufa quod inhærefcat parietibus \& fundo ferrum, eft, quod focus ex multo ufu excavatus \& exefus fit, hinc moles cavitati hujuf́cemodi applicata dure admodum haret. Pariter fi focus nimis calidus \& quafi ignitus fit; propinquius enim confortium \& amicior nexus eft ferri, fi utrumque candens fit, aliter vero nulla figunt mutuo ofcula, fi unum fit frigidum, alterum calidum: hinc etiam refrigerandus fubinde eft focus. Quibusdam in locis divellitur ftatim moles adhuc candens e parietibus, \& ad diftantiam a pariete refrigeratur.

Quum tandem a pariete foci foluta \& feparata fit moles, plane convertitur, adeo ut pars ejus inferior fuperiora refpiciat \& viceverfa, apparet rudis \& indigefta, fupra ad planitiem quandam vergit, infra vero ad rotunditatem. Moles fic obverfa \& refupinata non ad diftantiam quandam a vento ut prius relocatur, fed elevatur fupra ipfifimum conum fpirantem, adeo ut una molis pars incumbat limbo \& orx ejus fuperiori, altera foci fundo vel recrementis in foco relictis ad eandem obliquitatem, quam habet ventus aut conus fpirans ; unde aura juxta molis inferiorem partem fpirat, \& finum illum totum verrit \& ftringit. Faber admodum gnavus \& fedulus effe folet in aptando molis hujus fitu, ut filicet rite \& fecundum ventum jaceat, utque totum ventrem præbeat $\mathbb{E}$ olo, \& fic ubique aqualiter recipiat flamen.

Converfa \& aptata fic mole, pulvis circumjacens carbonarius \& cinis crematus rutris in focum undiquaque corraditur, quo circumdatur maffa denuo liquanda : dietus vero cinis tantum ad latera, non vero ad anteriorem partem maflæ confertur; verfus anteriora carbones integri \& ficcio. res accumulantur, qui ignem non modo fovent $\&$ intendunt, fed quiflam. mam nutriunt, cum qua ventus tanquam alatus in ferream molem fertur, Clalfis I. de ferro.

$\mathrm{Y}$ illam 
illamque vi adaucta fringit. Jam iterum detracta pertica vel fublato ve ete \& clauftro in rotam aqua fremens admittitur, \& moventur alternis, ut prius, folles, \& ventus in focum intromitritur, fed principio debilis, mox auctior \& intenfior. Intromiflo vento circumfunditurferrea mafla carbonum clivo, \& fic fervet iterum opus. Attente jam flammam \& ignem fuum pectat \& notat magifter, ex illo anguria \& indicia fua capit, qualis in foco fit liquatio, \& qux in mole ferrea pars plus aut minus folvitur : continuo movet \& verfat hanc maflam, relocatque in medio igne, qui flammans xqualiter ab omni latere ejus prorumpet, in flamma veluri natabit malla, tanquam in elemento illo librata; fi ullibi flumen majus flammans apparet, ftipat \& obturat locum, alibi vero aperit; ubi datur flamme exitus, hic conto fuo molitur aperturam \& diducit quali labra, ut exfpiret libere flamma; hic ingerit pulveren carbonum \& fcorias, ferrumque tundit, ut melius repleat locum; hic elevat maffam datque viam patentem vento \& flamma fimul erupturis; hic vero deprimit, regitque non aliter ac navita cymbam in fuctibus; cumque æqualifima eft ubique flammæ circumfluentis eruptio, maxima vi in ferrum agit ignis \& ventus: imprimis oblervatur, ut flamma remotifimam a vento partem continuo fringat, tunc enim liber eft meatus per onnem maffe ambitum planumque ejus inferius: cavetur tamen, ne a parte remotifima preclufa fit via flammx \& circum focum erumpat volumatim, tunc ignis non omni vi fua agit in ferrum, fed tantummodo in partem ejus, \& pars nullius venti \& flammæ eft particeps. Præterea fi ventus verfus conum refectatur, periculum fubit cuprum, per quod tranfit ventus, ne a nimia flamme reverberatione fundatur. Ix ipla flamma \& cumulo carbonario judicari poteft de obliquatione coni; fi altius elevata appareat maffa ferri, \& clivus carbonum fublimior aut altior fit, fignum eft, elevatuin etiam exftare conum, nec multum obliquum effe; at vero 18 humilis \& deprefia in foco veluti natet moles ferri, \& carbonum clivus non tam alte fupra focum exitat, fignum eft, conum admodum effe obliquatum. Qunm carbones primum fuperimmifi confunti funt, iterum novi adjiciuntur, adque eandem altitudinem ad quam prius. Moles ferri dicta fub carbonibus omnino tumulanda \& recondenda eft, nec ullibi patebit nuda; 2 vel 3 menfura five crates carbonum quavis vice requiruntur; fed $\mathrm{fi}$ elevatior jacet mafla ferri, adhuc major pars carbonum requiritur, quoniam amplior \& latior effe debet clivus, dum plene contegatur.

Interea maffx ferri crudi ad focun volvuntur, e fub eodem carbonum cumulo, fed ad diftantian 2 pedum a cono fpiratorio reconduntur; ut fcilice ignis maffàs has frigidas lambere \& contingere poffit, ficque fenfim calefacere; fcilicet ut cum eadem carbonum quantitate \& cum codem igne ad citiorem folutionem preparentur. Prout ignefcit magis moles in medio foco jacens \& colliquatur, eo propius conofpiratorio five vento admovetur, inque ignem per gradus fortiorem, fruiturque fic maffa nova ferri eodem igne eisdemque carbonibus, qui fic ad utriufque ferri folutionem contribuunt. 
Maximum in eo jam verfatur fabri ingenium, ut ignem fuum \& flammam æqualiter circum molem ferri liquandam diftribuat \& partiatur; unde, ut dictum eft, dat ei fores \& exitus ab omni parte molis in media quafi flamma fe librantis; fi alicubi minor animadvertitur, fublevat partem illam \& aperit forem vento, contra fi jufto majus alicubi flammæ volumen erumpic, ficque aptat, verfat, deprimit, elevat, ftipat, aperit, dum xqualitas habeatur: perlpiciet ufque, ut major flammæ torrens fit verfus pofteriorem molis partem, fi major verfus anteriorem, liquaretur facile conus \& ignefceret circumcirca murus, \& utrumque a nimio igne corriperetur; fignum etiam tunc eft, molem hanc obviam \& contrariam vento jacere, fcilicet quia ventus verfus originem fuam retro flectitur. Regula fabris notiffma eft, ut moles hac ferrea $a b$ omni parte æequaliter debeat diminui \& exedi, hinc ita verfat \& agit molem, ut vento opponat omnem ejus partem \&angulum, \& lente in circulum quendam circumagat; \& paullatim jam vertat hanc partem \&olo, jam proximam, jam remotiorem, prout in:qualem animadvertit ejus diminutionem, ubicunque quid prominet, \& a circulari figura extra ambitum exftat; hoc ftatim ita applicat, ut citius quam reliqua partes folvatur : hinc fenfim circumcirca confumitur moles ferrea. Alias videre licet, quod citius folvatur pars molis pofterior five a vento remota, quam illa que vento proxima eft.

Jam nec multa carbonum copia requiritur, fed fere femiaperta liquitur mafla, quie ultimo tam comminuitur, ut tandem non amplius coh:erefcat, fed in frufta divifa collabatur, hec circum focum fparia iterum colligit faber \& auræ fux apponit, iterumque colligit \& ante narem flantem aut animantem relocat, operamque hanc repetit, dum in unam maflam omne fuum ferrum coegerit; jam nudatur fere fuis prunis \& fomentis igneis ferrum, \& urgetur interea multo flamine: \& quia levifimæ prunx voluminis ferrei fuperficiem circumfparfa fint, hinc jam videre licet, in leves has prunas tanquam in feftucas \& ftipulas furere ventum, ejectat altefcintillas \& fcorias fupranatantes tanquam in imbrem dividit difpergitque circumcirca per caminum, grandine quadam ignea \& flumine fcintillarum replet caminum \& multam officinæ parten, fcintillx in altum fe glomerant, \& per parabolicas curvas extra focum denfær relabuntur; hicjam ideam \& typum quendam exigux cujassdam $\mathbb{E}$ thnæ furentis videre licet, qux adfantes foco removet \& terrificat: fcintillæ in folum delapfix non ferro fed materia, qua recrementa, confiftunt; funtque plerumque formæ rotundæ five ovalis, ftatimque ut folum contingunt, nigrefcunt: hæc eft iplamet recoetio ferri, qux perdurat 7 vel 8 minutis; fed ipfamethec liquationis opera fpatio 2 circiter horarum.

Secunda hac liquationis vice etiam fundo \& angulis foci inhrefefere obfervantur fruftrula ferri crudioris \& tenacis; verfus angulos \& in firigus fe recipiunt partes ferri, \& ni in communem undam ferantur, tenacius adhuc crafiefcunt, hinc per contum indagantur \& loco fuo emoventur ferunturque verius conum fpirantem \& auram, ficque immerguntur foluta volumini reliquo: iterum elevanturfrufta, quæ fe ad angulos receperant, \& iterum pœenam fuam luent, tanquam profugi caftris fuis excefferint, coram 
Folo: quoque deterioris notx eft ferrum, eo crebrius e latebris füis effringendum eft ferrum \& coram vento fiftendum, \& colliquatum foco immergendum: \& quia ventus fine ope flammix \& ignis non valet tenaciffimas has partes difrumpere $\&$ in liquorem folvere, hinc carbones majores \& electi fuperimmittuntur, quorum ope tandem victx in tumulo \& liquamine communi una fepeliuntur.

Scoriæ hac fecunda liquationis vice ter emittuntur, fcilicet primum poft elapfum $\frac{1}{3}$ partis unius horx, polteaquam cum in focum miffus fit ventus. Scoriæ hæ quia particulis ferri admodum foetæ funt \& fimul confant heterogeneis fluidifimis, hinc in alveum aqua plenum injiciuntur \& aquis fubmerguntur, ut fic exfinctæ in pulverem aut glaream quandam. dilabantur, qux glarea dein ad ufus confervatur: altera vice emittuntur e foco fcorix poft elapfum $\frac{\mathrm{I}}{2}$ vel $\frac{2}{3}$ partis unius horæ, fed quia non multi momenti funt, hinc rejiciuntur. Circa finem recoctionis hujus ultimo e foco emittuntur. Oblervatum etiam eft, quod modo exigua foriarum pars ultimo effluat, f coetioni nimis indulgeant, hoc eft, fi coctionis ultimæ opus diu perduret. nam in fcintillas abit multa recrementorum pars \& inde diffipatur, antequam effluendi ei locus \& venia detur.

Jam etiam jucundum eft obliquis hircis trans coni fpirantis duetum in oppofitam ferri molem tueri, quam videre licet candentis nivis inftar, non aliter acipfe funt prunæ, quæ ante os lpiraculi plumarum inftar leves \& albifimæ volitant. Alias videndum eft, ne æris lpiratorii labris fcoriæ inhæreant, quæe excutiendæ funt, ne invius reddatur vento conus.

Plurimis in locis peractis his duabus liquationum vicibus, fub malleum portatur ferrum \& in bacilla procuditur; nec opus habent pluribus, fi ferrum fit bonæ indolis, nec multa impuritate fodum pollutumque. Quibusdam in officinis adhuc tertia vice funditur, præcipue fi frecibus fuis non privari poffit binis prioribus; purificatur enim, quo magis coquitur, quoque pluries, eo purificatius redditur. Peragitur hæc tertia liquatio eodem modo quo fecunda.

Ventus principio erit levis \& exiguus, dein fortior; \& tandem diminuendus eft, quo propius ad finem accedit.

\section{Deufu carbonum in focis ferrariis, quum ferrum crudum recoquitur.}

FLectus carbonum omnino habendus eft, non enim ex omni arbore veniunt carbones ejusdem bonitatis: nec carbones ejusdem generis illum ufum preftant in focis ferrariis, quem in focis fornacis fuforiæ. Carbones qui duri funt, hic minus utiles funt, quam qui aliquantum molles, ut carbones quercini \& fagini, qui eduri \& ponderofi, debilem admodum ufum in foco hoc fabrili proftant: ferrum enim non modo cremant, fed etiam indurant \& fubfantiam nervolam \& ductilitatem ei tollunt; paricer etiam carbones ex betula cremati, quamvis etiam hi mixti cumcarbonibus arborum molliorum in focisferrariis fape adhibentur, at vero in 
fornace fuloria eft durum hoc genus priftantiffimum; expinu vero \& abiete funt optimi: palmam vero omnibus preripiunt illi, qui ex fylva tenera \& propaginibus medix xtatis, hoc eft, ex adolefcente arbore funt confecti, at vero fi confecta atate \& annofa fit nimis fylva, quia non modo fuccum fuum vitalem amilerat, fed \& rigorem tempore contraxerat, hinctrunci nimis eduri facti, ob caufam allatam, non illius utilitatis in foco fabrili funt.

Ars \& fcientia fabri in eo multa confiftit, ut fciat carbonibus parcere, nec multam fylvam in favillas \& fumum fine effectu debito \& proportio nato in ferrum diffipare $\&$ diffundere, \& fic bona heri fui fine ufu \& fructu dilapidare; \& quia artis \& fcientix opus eft, hinc operæ pretium eft tradere modos, quibus confumi nequicquam carbones folent, \& quibus eis debite parci debeat.

1. Pars multa carbonum in fumum \& aerem vane refolvitur, nifi carbones, qui extra focum jacent, feparentur diligenter ab illis, qui ipfiffimum focum tenent, \& qui liquationi ferri funt dicati: ignavus minifter foci accumulat acervum carbonarium circumcirca focum, \& patitur ut regnet ubique \& fine limite Vulcanus, tam extra fedem fuam quam intra, hinc incaffim perit carbonum cumulus \& facratur Vulcano, fed ipfemet facris fuis ridere videtur; hoc enim vel ignaviæ vel pellacix fabri adfcribi omnino debet : hinc faber optime gnarus dirimit \& feparat carbones intra focum $a b$ illis qui extra funt, nec patitur ut ignis depopuletur omnem viciniam, \& tanquam efferus \& effiæenis in circumjacentia furat.

2. Non modo pof́cit prudentia fabri, ut prævideat, ne extra focum exfpatietur ignis, fed etiam ne in ipfo fuo foco, hoceft, in ipfis fuismetregnis tanquam laxis frænis dominetur, tunc etiam fumptuofus admodum focus eft : hoc ne fiat, exhauriunt ex alveari aquam fitula, \& ipfum focum flammamque dominantem fuperinjiciunt, \& tanquam denfoimbre \& alpergine copiofa aqux exftinguunt impediuntque, ne extra fores fuas erumpat: hinc etiam fuperinjecta unda extra ftatim nigrefcit carbonum maffa, \& flamma ignifque verfus interiora fe recipit, \& per tempus intra carcerem fuum fe tenet concentratum, dum iterum fuperinfundatur aqua. Si enim verfus interiora fic cogitur flamma, \& clauduntur ei fores, per quas erumpat, inclufus \& tanquam domitus in officina fua in ferrum melius agit, \& interea carbones non confumuntur inaniter, fed fumptibus his parcitur.

3. Carbones etiam perire \& tumulari in foco fine debito in ferrum ufu poffunt, fi nimia copia illorum affundatur \& fic alimentis nimium oneretur focus; in vitium enim vertitur quodcunque nimium eft. Sciet itaque faber rationem carbonum \& ignis fui ad ferri liquationem proportionare.

4. Si conus fpirans horizontaliter nimis fit locatus, ảdeo ut ventus ex nare cjus emiffus, pæne recta linea in oppofitum ferrum aut parietem feratur; in hoc calu pereunt etiam carbones, \& combuftibile in favillas liquitur, nec eadem in ratione ferrum, quod fubtus jacet; ventus nimis horizontalis fuperiora petit iplamque carbonum maffam, non vero inferiora ut ferrum; quocunque enim ventus fe glomerat, ftragem mifcet, \& quia Clafis I. de ferro. 
horizontalis nimis eft, hinc in carbones virtutem fuam exercet, \& illos nequicquam confumit: unde fitus nimis horizontalis coni fpiratorii aut direStio venti carbonum copiam confumit.

5. Qui carbonibus \& nimiis fumptibus norunt parcere, non maffam ferri prima vice liquatam \& recoctam in foco frigefcere diu patiuntur, fed ftatim circumvertunt exponuntque jamdum candentemigni \& vento: quidam enim ignavia caufa, licet genus optimum ferri fit, ufque tamen per $\mathrm{x}$ vel 2 horas linquunt ferri maffam in foco, dum filicet duritiem contraxerit, \& interea contra vim ignis \& venti lorica duriflima fe muniverit; hine cum talis maffa admodum frigida iterum obvertitur igni, diu etiam ei refiftit, nec cedit, ' nifi multa copia carbonum fuperinfula fit, five fub illis profunde admodum fepultum fit ferrum : major enim quantitas carbonum requiritur ad opus liquationis, quam fi maffa adhuc candens igni \& vento obvertatur.

6. Sciet etiam magifter foci in ufum vocare partem pulveris carbonarii, quum enim ingnefcere bacilla adque extenfionem fub malleo prepara. ri debent, ignitio talis in pulveris carbonarii igne tam bene poteft peragi, ac in igne carbonum integrorum; hinc illi qui artis gnari funt, cumulum quendam carbonum comminutorum in angulo camini ad ufis fervant, quo fubinde foci finum implent, \& loco carbonum fubftituunt.

7. Oleum \& operam fuam etiam perdunt miniftri officinex, fi carbones nimis humidi fint; peragitur inde lente recodio; nam ignis ejufque virtus refrænatur \& temperatur quafi a vaporibus aqueis, quijugiter ex carbone exhalant; unde major pars carbonum adhibenda eft, ut idem in ferro candor \& ignis habeatur, hoc eft, major quantitas illorum in ultimos rogos ideo mittenda eft.

8. Ad confumtionem inanem carbonum contribuit etiam multum ipfifimum ferrum, fi illud magnx molis fit, ferrum fub altiori cumulo omnino fepeliendum eft \& igne fpatiolo circumdandum, fi mafie fint magnx: mafie alias folent $I, \frac{3}{4}, \frac{2}{3}, \frac{1}{2}, \frac{1}{3} \& \frac{1}{4}$ partem ponderis nautici pendere, fi itaque ferrum diminutum fit \& modo aquet $\frac{\mathrm{T}}{2} \mathrm{Vel} \frac{1}{3}$ partem ponderis nautici, facilius liquitur, quam moles major \& ponderolior: hinc fi carbonum fumptibus velis parcere, minora ferri frufta adhibenda funt.

9. Olcum \& operam fuam etiam perdunt fabri, quibus non fufficicns aqua fit pro mallei fui ponderofifimi elevatione; fi enim lente iofus \& vices fuas peragit malleus, quod a defeetu aqux in rotam ejus illaplure oriri folet, tunc lentius procuditur ferrum, \& quavis vice ad minus intervallum extenditur, unde fxpius in focum \& iterum fub mallenm ferendum eft, \&. confequenter carbonum pars major adhibenda.

Ut itaque difpendia tanta carbonum ex pellacia \& ignavia fabrorum oriunda evitentur, fancitum eft in Svecia, ut ad ferrum i ponderis nautici tam ad ejus recoctionem quam ad ejus extenfionem fub malleo non ultra 24 tonnas, quas fimul vocant Storfig, confumendum fit; quod vero minus impenditur, hoc lucro fabris cedit, frn magis, damno. Scio tamen aliquibus in locis non plus quam I 8 tonnas carbonum, \& a magifro quodam. fabrorum I 4 ad recoctionem I ponderis nautici \& extenfionem ejus con- 
fumtum fuife. Hinc etiam multis in locis carbones refidui funt, qui $O e f$ werkubl vocantur, quique dein lucro cedunt fabris, \& ab illis pro certo pretio emuntur. Multa etiam carbonum jactura debetur ipfi illorum indoli, ut, prout jam dietum eft; fi humeetati nimis fint, pariter fi comminuti; fi ex fylva nimium tenera confeeti; fi jufto fint molliores; fi citum \& repentinum ignem, cum cremarentur, transiverint; fi leves \& confequenter non multi ignis capaces fint, \& plura alia, per qux facilis eft carbonum jactura.

At vero fi carbones humidifunt, fequitur quidem inde, quod I. lentius peragatur liquatio, quia ignis diminuitur ex frigore vaporofo aqua, quiod focum una occupat, \& ipfum ferrum invadit. 2. Unde etiam, cum non rite in catino fuo coquitur ferrum, remanet crudum, nec demittit partes omnes feculentas, quibus exui omnino debet, antequam ductile reddi poffit. 3. Quum carbones funt humidi, apparet bacillum ferri in foco candefaciendum coloris candefcentis, tanquam igne fuo fatis effer imbutum: fed licet candor hic fuperficietenus apparear, intrinfecus tamen coloris non ejusdem nec candefcentix debitx eft, fallit imago tuentem: rationem addunt, quia multa copia fcoriarum crudarum occupat focum, qux coloris albefcentis funt, \& fi ferrum five bacillum circumdant, ficque ludunt fub fpecie candoris aut candefcentix. 4. Quamvis multa pars carbonum pereat, fi humidi,fint carbones, \& ferrum remaneat crudum; ufum tamen quendam preitat humor in carbone; ferrum enim durum inde emollefcit \& tenacelcit quod fragile eft: contra vero, fi ficci nimis tint carbones, indurefcere ferrum perhibetur, quia nimio igne crematur: unde regula penes fabres nota eft, quod ferrum emollefcat carbone madente, \& durefcat carbone nimis ficco cum recoquendum eft; nonvero cum candens reddendum eft, \& fub malleum portandum.

Alias folent aquam infpergere \& irrorare, quum animadvertunt flammam in foco perque carbones nimiam dominari, ficque intra caftra fua Vulcanum cogere; quod fit vel illum in finem: i. ne flamma carbonarium acervum nimium depopuletur \& confumat, \& præcipue illum qui extra focum jacet, quique nullum ferrum fubter fe habeat, quod in liquorem redigat. 2. Si ignis \& flamma veríus interiora \& penetralia foci cogitur, nec permittitur caftris aut carcere fuo excedere, tunc inclufus ignis majore vi \& ira in ferrum operari folet; increfcit fic in foco calor. 3. Nec modo increfcit fic inclufus calor, fed etiam ipfiffimum ferrum ex aqux irroratione meliorefcit, lentefcit inde quod durum, inque bacilla melius fub malleo educi poteft, contra vero fi nimia ficcitas fit. 4. Quum fubinde exftinguitur flamma late per focum dominans, ftatim explorari poteft, ad quod latus maximus ignis fit; exftincto enim fuperficietenus carbone, illico erumpit ad illam parten ignis, ubi maxima vis venti urget \& latiffima patet apertura; unde ftatim aptatur fic moles in foco, ut æqualis circumcirca fluat ignis. 


\section{MODUS RECOQUENDI FERRUM De emifione fcoriarum ex focis ferrariis, ut $E^{\circ}$ de ufuillarum circa recodionem ferri.}

Corix plurimum in recoetione ferri crudiufum preftant; illarum enim gratia ferrum liquari poteft, illis non aliter ac fal in undis folvitur; menftrui ac folventis loco funt; nifi enim ferrum liquens in talem undam defuat, leviora a ponderofis, lapidea a metallicis, \& calida a frigidis nequicquam fecerni poffunt; hinc quantitas fcoriarum in foco neceflaria eft. illa enim non modo leparationem creat, fed etiam ferrum purificat, liquabile \& ductile reddit: peritus itaque faber fciet ufum fibi ex illis parare.

Scoria, qua diverfis temporibus ex foco ferrario emanant, non unius fed multiplicis generis funt, unum genus ad certos ufus feponunt fervantque miniftri foci, aliud vero rejiciunt: ut 1. Scorix, qux primum e foco emittuntur, fcilicet cum altera vice recoquitur ferrum, funt optimi generis, \& ferro \& lapide fuidifimo foet met facile liquuntur, fed etiam fecum in liquorem agunt ferrum crudum, ficque menftrui aut folventis infar funt. Hx cum emanant, ftatim in alveare aqua plenum conjecta in glaream quandain folvuntur; ficque in uno loco circa caminum ad ufum paratie refervantur. Quoties enim animadvertitur ferrum in uno aut pluribus locis crudum five tanquam lievigatum, \& fimul fanguinei ruboris, \& fic a reliquis partibus cruditatis expertibus per colorem fuum facile diftingvitur, thatim fuperinjiciuntur tales fcoria in lacu five ftagno illo in glaream folut:e, qux cruditatem dictam auferunt, domantque \& tollunt indolem fcintillandi, inque fiuorem una cum reliquo ferro precipitant. Si ferrum non facile liquelcit, vel fi nimio igne uftum non multam partem fcoriarum emittit, tunc fi apponantur aliquot fpathæ harum fcoriarum, illum ufum præetant, ut non modo temperetur inde calor, \& ferrum liquefcat, aque nimio \& uftorio igne defendatur, fed ut etiam malleabile \& ductile reddatur, quod fine fcoriis his durum \& fragile fieret. Ufus precipuus harum ficoriarum eft, cum altera vice recoquitur ferrum, \& candefacienda funt bacilla, quod in his illarum ope facilitetur ignitio, \& magis magisque mollita \& ductilia reddantur. Focus ad aliquam partem his fcoriis fluidis repletus effe deber, quumque bacilla nimio igne apparent ufta, illis tanquam undx cuidam immerguntur, \& extracta iterum igni ficco exponuntur, unde in illis ad libitum ignis \& candefcentix gradus temperatur; ex quibus judicari poteft, quam utiles fint forix circa alteram recoctionis vicem, ut \& circa candefactionem bacillorum.

Prima infpectione fciunt ftatim fabri, num nimium aut perparum excanduerit ferrum fub malleo extendendum; fi enim fcintillas lucidifimas difpergit, qux præcipue flammis intermixtæ per carbones erumpunt, fignum eft nimia excandefcentix, ficque ftatim immergitur ferrum liquori fcoriarum, \& in illis tanquam in unda quadam reftinguitur, five in debitum \& minorem caloris gradum redigitur: pariter vident fignum nimixe candefcentive ex ipla flamma, ut fi albida nimis aut candide lucida appareat.

Lima- 
Limaturæ Martis circa truńcum aut incudem collectæe etiam his fcoriis adjici folent, \& fimul maffa non bene liquabilis fuperinjici ; unde in fluorem reducitur, \& ipfiffimum pondus ferri una augetur. Limaturafive famenta hæc, quæ bractearum, lquamarum aút filamentorum fpeciem referunt, in focum etiam mittuntur, fi fcoriæ fundum foci occupantes nimis crudx fint; ut fi ferrum nimis ficco igne confumatur \& ductilitatem amittat. Certa quantitas horum ramentorum aut fcoriarum non determinari poteft, interdum poftulat ferrum majorem, interdum minorem copiam : fi per fe fluat optime ferrum \& relinquat fcorias optatx. indolis, tunc minor requiritur copia, major fi pejoris notx ferrum fit; vidi $1,2,5$, 6,7 pathas his ramentis ferreis aut fcoriis plenas fuperinfulas: Præcipue fi aliquibus in locis maffex aut molis converiæ ferri pars cruda fit, huic fuperinfternitur pulvis dictus fcoriarum, ut prius dictum eft. Hinc ratio habetur ferri ejufque tam indolis quam ficcioris aut fluidioris naturæ in liquatione.

Scorix liquidx in foco figna fatis manifefta produnt, quale fitferrum, num notæ melioris aut deterioris, num crudum adhuc, num purificatum; quis in illo gradus liquationis \& purificationis fit; num ferrum tenax aut contumax; num mite vel refractarium; fufile aut illiquabile \&c.. Si enim contus ferreus aut aliud ferramentum fabrile immergitur liquori fcoriarum, ex fcoriis tunc illi adhærefcentibus dicta qualitas exploratur; ut fi adhærefcant ferro arcte nimis fcoriæ, nec crufta attracta ulla percuffione aut ictu cujusdam mallei inde excuti facile poteft, fignum eft ferri durioris, contumacis \& combufti; quod cum vident, fuperinjiciunt glaream prædictam fcoriarum electarum, qux fe fcoriis his refractariis addunt, \& ferrum indole fua noxiore privant : in hoc cafu quavis vice immittuntur fcoriarum dietarum 3 fpathie five plures, dum fufficiens talium fcoriarum in fundo liquor appareat : ter aut quater intra vicem quamvis recoctionis injici folent, \& quidem juxta partem pofteriorem molis ferrex. Et quia liquatio in liquore fcoriarum deteriorum peracta damno effe folet ferro, hinc reparatur hoc damnum communiter per adjectionem ramentorum ferri circa incudem magnam collectorum ; unde non modo pondus ferri augetur, fed etiam ferrum mitius \& tenacius redditur.

Si fcorix inhærentes conto fint coloris viridefcentis aut ad nigrum vergentis, fignum etiam eft ferri deterioris ; contra vero, fi candefcant. Nec optimæ notæe eft color rubefcens. Ex hujusmodi fignis judicant magiftri foci de qualitate ferri \& liquationis fuæ; hinc non multa intercedunt momenta, quin iterum explorent ftatum foci \& qualitatem fcoriarum, quam emendant vel per adjectionem multam ramentorum ferri vel alius ferri melioris, vel per adjectionem fcoriarum, qử menftrui inftar è ferri liquore feparant illud quod noxium eft.

Prinçipio recoctionis focus ad multam partem repletur fcoriis optimi generis, adeo ut in liquore \& menftruo apto fiat folutio, \& fic meliorefcat ferrum. Sub finem etiam tanta pås fcoriarum relinquitur, quanta ad novam coctionem neceffaria \& fufficiens fit. Scorix etiam peracta coctione refidux multam ferri partem in finu fuo condunt cuftodiuntque, Clafis I. de ferro. 
quamvis leves fint \& in tumores aut bullas extenf : Quod illis multum ferri infit, apparet ex colore ferrugineo, tum etiam ex iterata illarum folutione.

Alias penes fabros viget ufus, ferrum crudifinum \& deterrimum ope fcoriarum fufile non modo fed etiam ductile \& malleabile reddendi: fi ferrum fit crudum \& multa vena adhuc fatens pollutumque, \& fragillimum cum friget, modo in undam fcoriarum meliorum, five illarum, qux ex ferro fulphurato fuppeditantur, immittatur; inde exuitur pars illa noxia \& iplamet damnofa fragilitas \& cruditas, fed etiam particulæe exiles fulphureæinfinuant fe ferro, qux ad ductilitatem ejus contribuunt: at vero fcorix poft coctionem peractam relictx notæ \& ufus funt pejoris.

Quum immoror defcriptioni fcoriarum, obfervatu jucundum occurrit, quod fcoriæ candentes in alveum aqua plenum immiffx, in glaream quandam dilabantur; fique cum ignitæ funt, fatim immittantur undis \& illis circumcirca operiantur, nec batillo contufæ comminuantur, accidere folet, quod fub ipfa aqua in mille partes cum fono \& fragore vehementiffimo diffliant; quod etiam fxpe conjunctum effe folet cum periculo adftantium, hinc tenent regulam, ut acri \& igni fcoriis inclufo apertura detur. Alias videre licet ipfum ignem in fcoriis fub ipfis aquis diu viventem \& lucentem; nec ignem folum fed etiam flammam, que fibi ex fruftis fcoriarum per aquas viam molitur. Alias fi pars fcoriarum ex aque fuperficic exftet, pars vero intra aquam lateat, tunc pars illarum fubmerfa aquis primum quidem exftinguitur fenfimque nigrefcit, five crufta ferruginea obducitur; pars vero qux ex aquis trepidis prominet, rubefcit diu, vifque inclufa ignea omnis fe illuc recipit, \& tandem poft aliquot momentorum elapfum fpatium color igneus \& rubicundus verfus unum quoddam punctum fe recipit, quod poftremo exftinguitur, atque fuomet colore fe ubique induunt fcoriæ.

Alias etiam fi ferrum ignitum \& candeficens verfus frigidam aquam valide impingitur, ut fi contus aut bacillum ferreum candelcens multa vi brachiorum verfus aquam percutirur, fonus inde ingens editur, non diffimilis fono fclopeti, non aliter ac in ferrum frigidum verfus corpus durum violenter effet percuffum : pariter etiam bacillim ferreum fub malleo fuperinfufa aqua \& medium locum inter malleum \& ferrum tenente, fragor inde tantus fpargitur, ut furditatem quandam tympano auris poflit incutere : refiftentia enim tanta eft calidi \& frigidi, five ignis \& aqua, utmutuo concuffe inimicifimam vocem \& fonitum emittant.

\section{De jignis liquationis in foco ferrario per ignem 8 f tammam.}

MOdo indigitatum eft, indubia figna de indole ferri peti ex fcoriis, in quas liquitur ferrum; alia tamen ufque dantur, qua evidenter fatis produnt ferri naturam \& ipfum liquationisftatum; filicet coloripfiusmet flanmx; flamma enim e foco per carbones fe vibrans fub varia colorun 
fpecie ludit, \& variegata Protei inftar diverfas figuras recipit : ex illa fciri poteft, num liquatio rite peragatur, num crudum fitferrum, num fatis purum \& defiecatum, num contumax \& immite. Et quia diverficolor apparet flamma a principio recoctionis ad finem ufque, hinc gradum \& proceffum liquationis extrinfecum fic cognofeere licet. Alias communis regula fabris eft, quod idem fic color flammæ quæ f́coriis, fi modo libere evolet flamma, intermixtæ enim fcoriarum particulx in altum una cum igne tolluntur, ficque colore fuo imbuunt ignem volantem : hinc fi flamma rubicunda auroræ aut fanguinis inftar, five coloristyrii \& croceifit, fignum eft, durum effe \& inductile ferrum, \& appofitione multa fcoriarum meliorum \& ramentorum ferri indigere, \& a recrementis \& faecibus purgandum effe; at vero principio liquefactionis rubet \& badii coloris femper eft flamma, pariter etian crocei; fed ufque tamen nulla inde indicia tune peti pof funt, quia flamma per fe candidifima, ufque tamen rubefcit ex multa infperfione \& commixtione pulveris carbonarii; quum enim niger ignitufque fimul pulvis, qui finul craffiffimus eft, lucidifimæ flammæ intermifcetur, vertitur color in rubrum, badium aut purpureum; quod fit etiam fi alius generis fumusfit, qui ignem in fe fovet arripitve, Dein yero fuccelfu liquationis tranfit color a luteo in candide coeruleum, \& demum in can: defcentem, albicantem five helvum : quoque albentior flamma, eo melion in foco peragitur liquefactio.

Si virore quodam aut gramineo colore tincta apparet flamma, fignum eft, fulphuris copia fatere ferrum, quo liberari omnino debet: nimium enim fulphur fragillimum reddit ferrum cum rubet. Altera recoctionis vice, quum abundat fcoriis focus, tunc color flammx, ut dictum eft, imitatur colorem fcoriarum, apparetque lutea, five gilva, fed plerumque hinc $\&$ inde mixta cum viridi; at præcipue ubi carbones nondum vivi interjecti funt : fi vero perparum fcoriarum in foco fit, alius ftatim flammæ color fubit. Si vero nimis albefcit flamma, quod plerumque conjunctum effe folet cum fcintillis albiffimis, denfis \& volatilibus ferri, fignificat liquationem nimis fortem ; \& nifi removeatur inde ferrum aut diminuatur ignis, cremari folet bacillum, quod in foco candefaciendum eft.

Scintillæ, qua exfliunt ex foco, non unius femper naturæ \& coloris effe folent: fi pallidx, volatiles, fubtiles \& lucidiffimx; ex ferro puro conftant; fi rubicundiores \& craffiores, ex fcoriis: fcintillæ ferrex funt exigur, vividæ \& precipue formæ rotundæx aut ovalis, ex quibus ftellatus quafi redditur ignis, floridus, latus \& vegetus; qua vero ex fcoriis, funt crafiores \& languidiores, \& interdum, non quidem femper, formæ angularis.

\section{Diffectio molis magne candentis fub malleo.}

A Ltera recoctione peracta \& ferro fatis fic purificato, \& jam in maffam quandam conflato, ftatim vel poft fpatium $\mathrm{x}$ aut $\mathrm{I}_{\mathrm{z}}^{\mathrm{T}}$ minuti elapfum loco fuo emovetur. Jamque moles dicta rudis \& indigefta apparet, \& pulvere multo carbonario \& fcoriis obfita: fed antequam fub malleum portatur, pulvis dictus carbonarius, ut $\&$ adhærentes ei fcorix excutiuntur, dum fer- 
lúm appareat nudum : ficque volvitur ex foco \& camino in pavimentum aut folum officinæ. Quod figuram hujus molis attinet, eft ab una parte plana, ab altera vero rotunda, fed usque tamen inæqualis; cumque delapfa fit in folum, malleis \& marculis ferreis hinc \& inde percutitur \& tunditur, illum filicet in finem, ut pars omnis angularis tive inæqualitas, ubicunque prominet, reddatur plana \& adxquetur; alias enim apte füper incudem ferri \& ibi verfari commode nequit, urgentibus magni illius mallei ictibus; fi alicubi angulus exitat, ab incude facile in truncum aut folum devolvitur. Quim vero nondum elevata fit moles hxc candens, effluit hinc \& inde fanguinis inftar e venis, rivus fcoriarum, exque venis in ipfa mole latentibus exftillat unda rubens: alibi vero erumpunt denfo flumine fcintillæ; hic apparet \& vibratur flamma; hic in ipfo corpore molis candor emicat; hic rubedo, hic vero luteo colore rutilat; luditque moles hæc multiplici \&' jucunda varietate colorum igneorum; ignisque in mafla hac majore repræfentat, qualis fe habeat in minore.

Moles hæc rudis \& indigefta ope ftateræ aut vectium a 4 viris in truncum \& fuper incudem fublevatur; fublato prius ad altitudinem maximam malleo, adeo ut locus fit inter malleum \& incudem fufficiens: qux tandem cumapte füper incudem relocata fit, in rotam admittitur aqua, \& circumagitur fic trabs, qux magnis dentibus tollit brachium ex quo pendet malleus, qui fic lapfu \& pondere graviffimo fed adhuc curto \& brevi pertundit molem; ficque per crebrosictus æquatur maffa attenuaturque magis \& magis, quia $a b$ altitudine majore jam labens malleus ponderofiores ictus \& profundiora vulnera figit, continuaturque malleatio, dum maffa in placentre craffioris formam \& orbitam contufä \& attenuata fit. Principio reciprocantur lente ictus \& cunctanter quafi elevatur malleus, led dein cum certa vulnera poftunt dari \& maffa fuper incudem teneri, admittitur plus áquæ in rotam, ficque elevatur \& delabitur citius malleus. Feftina hæc repercusfio admodum neceflaria eft, alias enim moles fic pertufa jamdum ignita \& mollis indurefcit, nec cedit enfi aut cultro, cujus ope diffecanda eft.

Tandem cum attenuatum \& in placentam quandam formatum fit candens hoc ferrum, fecatur dein in 5, aut 6 aut 7 partes. Iplamet divifio aut difectio magnæ hujus molis fit per ferrum quoddam, cunei aut fpathx formam referens, fimile figuræ appofitæ $(a b c$, ) circa $(m)$ ad rotunditatem quandain accedit, ibi non acutum eft fed rotundum; (b) eft manubrium ferreum non longum, quod tenetur dextris interjecto linteo aut ftupa: ficque verlat, infert, attrahit, fublevat \& intorquet inter malleum \& dilatatam jam molem bipennem, ut vi alte labentis mallei in maffam hanc mollitam profundius mergatur, dum tandem ad incudem usque penetret cuneus divifor; hoc facto extractus cuneus aquis trepidantibus immergitur, iterumque aptatur \& promovetur in maffam, ut biffectio ad alteram maffix extremitatem usque continuetur: quodlibet fruftum a corpore fuo divulfum in truncum fubque iplam trabemignitum decidit: nificulter immergatur fubinde aquis, ignefit \& emollefcit, nec acie aut duritie ulla proditus cicatricem in ferro moliri amplius poteft. 
Properandum omnino eft, ne frigefcat maffa \& inde refiliant ictus. Partitur fic faber maffam fuam vel in 5 vel 6 vel 7 partes xequales, prout requirit opus: \& prout bacilla aut conti, qui procudendi funt, craffiores aut tenuiores, leviores aut ponderofiores effe debent; interdum etiam fecundum maflæ majorem aut minorem molem, quæ finon fufficiat pro 6, dividenda omnino eft in 4 aut 5 partes.

Primum fruftum mox ut leparatum decidit a mole, chelis forcipis prenditur a tyrone \& in medium focum \& ignem portatur; retineturque ibi, dum reliqua moles in fuas partes fit fecta: alterum frufum evulfum corpori fuo etian ftatim defertur in focum, proxime tertium \& fic reliqua, quartum, quintum \& fextum. Interea in malleum \& incudem fuperinfunditur frigida, nimio enim æeftu incipit calefcere, nam continuo maffam candentem tundit, \& vulneribus calidis involvitur; nifi aqua fubinde reftinguatur ex calore emollefcit acies ejus, ficque ferrum nequicquam amplius domat.

Hoc facto eximitur foco primum fruftum, \& fub malleo eo usque percutitur \& verfatur, dum formam oblongam acceperit, dumque ita undique adæquatum fit, ut ruditates \& inæqualitates omnes fint abaetæ; pariter reliqua frufta; aptiora tunc igni \& illorum ulteriori eductioni in bacilla, redduntur.

\section{Ferri diffecti extenfio in bacilla five contos.}

FRufta ferrea fub malleo fic lævigata $\&$ xquata in focum \& ignem dein

portantur; unum continuo tenetur in medio igne nec procul a vento, ut candefcat, utque candens fub malleo poffit extendi \& excudi; alterum jugiter tenetur proximum igni intenfifimo, fcilicet ut interea calefiat, \& calefactum loco prioris poffit fubftitui. Fruftum quod candefaciendum eft ad extenfionem, pervices vertitur, adeo ut jan unum ejus latus, jam alterum vento fit oppofitum; ficque xqualiter $a b$ omni latere igne mollefcat; quod etiam num factum fit, fubinde explorat faber, extrahéndo ferrum dictum, \& infpiciendo aut luftrando, num gradum caloris debitum aut colorem vere igineum receperit; ex colore cognolcit ipfiffmum gradum candefcentix; niff faber a multa experientia hoc bene edoctus fit, falfa imagine facile eludi poteft : fique videat bacillum fuum nondum bene candefactum, illud propius ad ventum \& conum fpirantem infert, additque carbones \& auget calorem, dum tandem colore vere igneo fe imbuerit; cumque videt ferrum ignem debite paffum effe, inde portatur ignitum fuper incudem : ftatimque alterum fruftum loco ejus fubfituitur.

Antequam eximit ferrum fuum e foco, oculis, ut dictum eft, fedulo perluftrat, qualis fit igneus ejus candor ; fi peritus fit, qui fabricis pr:eeft, ftatim cognofcit, qualem imbiberit ferrum caloris gradum, num adhuc multum aut parum ignis defit, num adhuc verfari fub malleo debeat vel non : jufti caloris fignum eft, fi color ignitus in ferro candidus fit $\&$ ad cœrulum aliquantifper vergat, adeo ut variegatio ignis fit inter candidum \& cœerulum five coloris glauci. Si adhuc in ferro defit calor, tunc vel diutius ante Vulcanum \& \&olum tenetur, vel intenditur calor in foco: at Claffis I. de ferro. 
vero fi jufto ignitius fit ferrum, quod variis fignis proditur, tune removet illud a vento, \& fupra ignem aut prunas relocat, ut in igne minus intenfo temperetur ejus calor: fi adhuc nimis ufum \& ignitum fit, immergit illud liquori fcoriarum, qux in fundo foci fluunt, ficque tanquam in aqua quadam fuperfluus ejus ignis reftinguitur temperaturque, \& in gradum debitum redigitur.

Accidit interdum quod intuentem fallant colores ignei qui in ferro funt; fcoria enim cruda \& pejoris fortis imbuunt fxpe ferrum colore carulefcenti five glauco, ficque fpecie \& imagine falfi eludunt magiftrum, dantque fignum ignitionis juftx, cum tamen extima tantum crufta ignem illum preferat: magiter fæe elufus hoc dolo ferrum fuum fub malleum portat, vix dimidium ignis gradum paffum, fed mentitum ignem cum damno fuo ftatim agnofcit : unde etiam nofle debet faber indolem fcoriarum, qure in foco fluunt. Sxpiffme immergit ferrum fuum undis foriarum \& inibi circumvertit, quod extractum ficoriis inunctum \& circumcirca illitum apparet; intra talem cruftam candefcit melius ferrum, nec a nimio igne tam facile læditur: alias ne aduratur violentiflimo igne ferrum, temperatur, ut dictum eft, in fcoriis fluidis, in quibus minor caloris gradus eft. At vero fi fcoria crudx fint, illis evacuandus eft focus, \& melioribus dein replendus.

Opus malleationis quavis vice perftare folet $\mathrm{I} \frac{\mathrm{x}}{2}$ five 2 horarum fpatio, \& interea retinentur fcoriæ foco inclufx, nec inde emittuntur; multum. enim ufum jam præftat liquor fcoriarum. Hoc etiam tempore tam ignis quam ventus fortiflimus effe debet, nec tamen multa copia carbonum jam onerandus eit focus, fufficit mediocris.

Flamma per prunas hic inde fparfas \& raras jam erumpit ad $\frac{\pi}{2}$ pedis altitudinem, fpeciemque præbet columnæ cujusdam, eftque coloris a viridi flavefcentis, fitque color in afcenfu adhuc intenfior; at vero in locis ubi ventus non eft impetuofus, nec tam alte fupra focum evolat, eft flamma violacea \& corulefcens : Interdum flammæ intermixtæapparent fcintillu$1 x$ lucidæ \& candidæ five pure ferrex; quas ut primumanimadvertit, tunc vel fuperinjicit carbones, vel etiam ferrum fuum, ex quo fcintillarum grando erumpit, involvit \& fubmergit fcoriis liquidis, ficque igneam vehementiam in ferro reftinguit ; fed utplurimum fuperinjiciunt pulverem aut glaream fcoriarum comminutarum, quæ pariter fuperficie quadam obducere ferrum poteft; ficque ceflat fintillatio; vel etiam removent ferrum fcintillans a vento, inque minorem ignis gradum transferunt, aut ad fuperficiem prunarum elevant. Utplurimum fcintillat ferrum cum comburitur: nifi oculis jugiter luftret bacillum fuum faber \& fedulo notet ignefcentiæ gradum, facile comburitur; ficque perit \& diminuitur ferrum tam ratione ponderis, quam ratione bonitatis.

Quum vident ignem, qualis fit in ferro, medelam fciunt fatim ei afferre ; led quodlibet ferrum non eodem modo ad debitum ignitionis gradum redigi poteft; ita combuftum effe poteft, ut nequicquam reftinguas ignem in fcoriis fluidis, fruftra in minorem ignis gradum transferas, hinc ciunt cuivis morbo medelam fuam parare: ad minimum ferrum femel 
combuftum ductilitatem fuam \& tendinofam fibrilemque partium texturam amittit, quæ fruftra reparari poteft, unde fucceffiva \& per gradus adaucta candefcentia præftat.

Sed antequam fubmittit ferrum fuum malleo, in intenfiffimum ignem fed tantum intra aliqua momenta transfert, adeo ut leviter intenfifimo igne penetretur; fi diutius, periculum cremationis fubit.

Cum tandem debitus ignis candor acquifitus fit, eximitur ftatim foco, $\&$ forcipe prenfum fuper incudem fubito fertur. At vero fi fruftum vel bacillum nimis fcintillet, tunc involvitur pulveri fcoriarum frigidarum; unde ftatim vigor fcintillandi moritur, præcluditur illis meatus, nec ferrum fub malleo percufum tantum fintillarum flumen amplius ejicit fpargitque. Alias cum ferrum hoc ex foco ad malleum protrahitur, flavefcit ex unda circumdata fcoriarum, quæ inftar imbris aut rivuli cujusdam defluit in folum, \& in globulos quosdam formata frigefcit.

Fruftum itaque ferreum candens forcipe tenaci prenfum fub malleo dein procuditur; inque medio fui primum attenuatur, adeo ut utrinque moles, peracta hac prima extenfione, relictx maneant. Primum tenetur ferrum transverfim fuper incudem, \& fic alternis jam ab una parte jam ab altera preffioni \& lapfui mallei fubmittitur, ficque continuo vertitur, dum forma quadrangula ei impreffa fit. Si bacillum efformandum fit, quod a bina parte erit latum, prima hac transverfali extenfione latior paullum $\mathrm{ab}$ una parte figuratur, hocque continuatur in longitudinem 2 ad 3 pedum: hoc facto urget contum hunc quadrangulum longius extra incudem, truditque vi fub ipfam trabem magnam, cujus ope incurvatur, ficque inde fecundum transverfam incudis partem tractim \& fucceflive pro quolibet mallei ietu educitur, \& diffingitur; \& a binis partibus latius redditur. Hoc facto ducitur idem bacillum fecundum longitudinem incudis aut mallei, \& continuo fub malleo vertitur, adeo ut jam lata ejus pars jam transverfa ietibus exponatur, converfioque dicta celerrime peragenda eft, præcipue fi depreffa pertica citius elevetur 'cum brachio malleus, cita admodum intervalla pofcit lapfus; nec licet bina vulnera in uno loco ei incutere, aut cicatrices in uno loco binas figere : tanta velocitate interdum agitur rota cum. malleo, ut celerem \& multam in vertendo ferro operam adhibere neceffum habeat faber. Secundum longitudinem attenuato jam bacillo, iterum in transverfam incudis partem cum ferro fe confert faber, urgetque contum truditque iterum fub trabem, \& inde illud fubfecutivis ictibus attrahit, dum adhuc fecundum latitudinem magis diducatur, \& formam bacilli exactiorem accipiat: fed quia vulnera in ferro adhuc confpicua admodum funt, hinc iterum transfert bacillum fuum in alterum latus five fecundum longitudinem incudis, fiçque lentiori motu ictuum æquatur tam fecundum latam quam fecundum craffam bacilli partem. Ultimo ut levigetur magis \& quafi poliatur, malleo jam lentius moto, a puero infpergitur aqua, quæ in ipfum malleum infunditur, ab illo dein rélapla in omnem fuperficiem $b a-$ cilli diffunditur, \& fimul in vaporem quendam, urgente calore, diffipatur: tunc malleo vi fua multa premente cum fragore multo ictus gemunt \& crepitant, auditurque ex collifione fonus, qui furditiem auribus incutere pof- 


\section{MODUS RECOQUENDI FERRUM}

fit; quod ab interpofitione aqux \& ejus feftina diffipatione oririneceffum eft : lævigatur fic ferrum, exque frigida hac percuffione omnis inæqualitas \&. fcabrities tollitur. Interea alterum fruftum ferreum ante conum fpira: torium relocatum incandefcit, \& eodem modo fub malleo diducitur: quumque fic diductum in medio fit, iterum in ignem fertur, \& pars una; qux adhuc relicta eft integra, ad eundem ignem \& ventum emollefcit; ficque fertur fub malleum, \& in bacillum vel contum ab una parte extenditur, quod vocatur, Utreckia $i$ kolf.

Bacillum fic femiexcufum exponitur dein nudo aeri ut refrigefcat; ficque unum poft alterum in folo officinæ: interea cum alterum fruftum extenditur, tertium admovetur vento \& igni, ficque fucceflive. Sique neceffum fit aut urget opus, defertur femiexcufum fic ferrum extra officinam \& aeri pluviofo nudum exponitur, five immergitur lacui aut undis, ut eo citius refrigefcat. Quum itaque 4 vel 5 fruftula ferri femiextenfa fint, bina in focum mittuntur, nec procul a vento, ubi tenetur dum fextum aut ultimum fruftum pari modo fub malleo fit procufum, dein ordo obfervatur continuus, ut bacilla bina femiextenfa ad latus Foli five in fecundo ignis gradu relocentur, dum unum immediate expofitum eft vento \& igni maximo focali, ficque femper 4 bacilla, jam prima, fecunda \& tertia vice extenfa in foco continuo tenentur.

Quodlibet fegmentum molis aut fruftum ter, quater, aut quinquies fertur fub malleum, prout citius vel lentius movetur rota vel malleus, five prout longius aut porrectius effe debeat bacillum; quavis vice extendi folet ad diftantiam 3 vel $3 \frac{1}{2}$ pedum. Sique numerentur ictus, quibus bacillum quavis vice percutitur, funt plerumque prima vice 450 , altera 380 vel 400 , tertia 500, quarta 400 circiter, five cum extenditur totum bacillum 1700 : fed differt hoc fecundum majorem vel minorem gradum ignis in ferro.

Circa extenfionem ferri fub malleo obfervetur : I. Quod cavendum. fit, ne malleus ictus fuos ingeminet \& multiplicet in uno loco, fi enim in partem cjus latiorem duplicato aut triplicato feriat ictus, dilatatur mox bacillum \& attenuatur in uno loco; cumque dein obvertitur pars transverfa in medio quafi complicari folet, unde infabre redditur; hinc continuo vertendum eff, jamque pars lata jam transverfa malleo fiftenda, adeo ut in uno loco non major fit impreffio quam in altero. 2. Alias in bracteolas \& limaturas quasdan refolvi folet ferrum, fed fuperficietenus füb malleo, quæe tamen ufque inhærent ferro; hæ vel bipenni excutiuntur, dum adhuc fub malleo tenetur ferrum; vel fi grandiores funt, biffecatur bacillum \& dein modo folito ferruminatur. Quod caufam attinet, vel oritur talis difcerptio bracteolarum ab iplius ferri indole; quod fi fragile fit cum calet aut multo fulphure fcatet, lamellatim \& particulatim non modo dividitur, fed. etiam non cohærens maffa tanquam putris gleba refolvitur urgente malleorum ietu. Si vero non nimio fed aliquali fulphure fit refertum, tuncin bracteolas tales dividi folet, quæ micarum aut fquamarum inftar fuperficiem ejus tegunt, indeque a valida mallei preffione fponte excerpi videntur: oriri etiam fquamea talis fuperficies folet ex humidis carbonibus; ex 
candefactione ferri perexigua; ex cruditate ferro infita; exque ipfiusmet ferri malignitate ; exque aliis plurimis caufis.

Unius feptimanx opus perfare folet I 32 horis : qualibet vice cum peragitur excoctio \& in bacilla ejus extenfio 8 vel $8 \frac{4}{5}$ horis; at vero fi in una officina duo foci lunt, non nifi $4 \frac{2}{5}$ horis : intra feptimanæ tempus five intra fpatium I 32 horarum I 7 vel I 8 vicibus liquitur \& excoquitur ferrum crudum \& in bacilla excuditur; fique quavis vice fecatur moles in 6 bacilla, per feptimanam habentur 90 bacilla, 9 ad 10 pondera nauticacirca quemlibet focum, five 18 ad 20 ad utrumque; differt tamen pondus, fi bacilla tenuiora vel fi craffiora procudenda fint, fi breviora aut longiora: ex uno foco feptimanx fpatio prodire poffunt I 2 vel $\mathrm{i} 4$ pondo nautica: audivi per feptimanam excocta \& diducta fuiffe 35 ad 40 pondera nautica ex 2 focis; quod tamen rarumeft.

Circa finem cujusvis feptimanæ, 6 frufta ferrea tantum qua angulos æquata ad fequentis feptimanæ opus \& extenfionem relinqui folent; 1cilicet ut uno eodemque igne, quo liquitur \& coquitur ferrum crudum, etiam candefieri poffint, \& fub malleo in bacilla aut contos extendi. Vidietiam in foco relictam molem frigefactam nec denuo recoctam ad opus fequentis feptimanx, ufque tamen hoc non lucro cedit, quia major carbonum pars requiritur fi frigida fit moles, quam fi calida, ut recoquatur.

\section{De induratione incudum majorum.}

$\mathrm{I}_{\mathrm{t}}^{\mathrm{N}}$ Ncudes magnæ trunco fuo alte admodum immittuntur, fuppofitis interdum laminis ferreis, quia enim ex continua percuffione mallei incus profundiorem fibi locum femper cavat \& molitur, hinc ne profundius fubfidat, quam ut malleus nihilominus ei fe applicare poffit, hinc fupponun. tur bractex ferri numero vel $\mathrm{I}$, vel $3 \mathrm{vcl} 6 \mathrm{ad} 7$, quarum ope tenetur incus ad eandem altitudinem elevata. Obfervandum etiam eft, quod iple truncus profunde admodum folo officinix infoffa fit, fubjecto ponte quodam ex trabibus \& tabulatis conftante, fuper quem non fixiflimus hxrebit truncus, fed qui ponti huic infiftens percuffioni cuilibet mallei ponderofisfimi cedat, \& rurfus inde refiliat, ficque in loco fuo fecundum ictus mallei reciprocato motu quafi titubabit \& fimiles faltus faciet. Pariter etiam ipfum fulcrum aut fcamnum ipfi axi trabis magnx fuppofitum; hocetiam incubat tabulatis dictx conftructionis, \& fimul cum malleo five dentium majorum preffione reciprocat motum. Undulatio hæc \& imitatio motuum in trunco \& Camno præmemoratis facilitat extenfionis opus, adeo ut bacillum fub malleo certius teneri \& commodius extendi poffit, ut \& exactior politiorque ei figura dari: inque hac reciprosatione machinamentum hoc validiffmis motibus jugiter actum \& turbatum nec tam facile laxatur rumpiturque.

Incus ferro crudo conftans 3 vel $3 \frac{\mathrm{x}}{2}$ pondera nautica folet xquare, a parte fuperiore chalybea duritie pollet, ut filicet ictibus tam crebris mallei illæfa diu fubfiftat: alias a mallei collifu vulnus recipit, quod dein fe communicat cum ferro five bacillo aut conto, qui infuper procuditur. Quxclatis I. de ferro. 
cunque labes aut nævus in incudis plano fuperiori apparet, hac imprimitur etiam \& fignatur bacillum infuper excufum \& lievigandum: hinc pars Illa incudis fuperior edura effe debet; in quem ufum in foco iterum excandefit fruftum chalybeum, fcilicet quod prius in foco paratum fuit, de quo fupra actum eft: ferruminatur dein \& applicatur chalybs candefactus parti fuperiori incudis modo fabris ufitato, filicet dum utraque pars ferruminanda ad niveam quandam excandefeentiam prius redacta fre: dein xquatur pars illa creberrimis ictibus malleorum fabrilium, nec ullibi relinquitur locus, qui a plano malleorum continuo planum incudis verberantium intactus \& impertufus fit, applicant etiam normas \& regulas fuas, ut æqualifima \& omnimodo plana fit fuperficies illa, planiffima erit in medio, ubi immediate recipit ictus mallei, hocque ad dirantiam $\frac{x}{2}$ pedis, fed planum hoc utrinque dein ad quamvis extremitatem obliquatur: fed cum Cyclopes hi infant operi fuo \& continuo ictu xquant incudem, incubabit tunc incus trunco, in quo cavernula jamdum facta eft, hic fupponuntur bractex quædam ferrex \& fuperinfunditur aqua, cumque incumbit incus bracteis fuis, partim etiam ab illa parte immerfa aquis cubat; unde quum continuis idtibus ab altera parte percellitur, hæc intincta aquis impedit, ne calor a parte fuprema ad inam decurrat. Ut adhuc xquatius fiat planum incudis fuperius, quavis ietus vice immergitur malleolus vel ligo aquis, \& fic irroratus tundit ignitam incudis fuperficiem, ut adhuc melius, auxilio aqux illam laviget poliatque. Quum perftat hoc opus, fi ignita hxc fuperficies incudis ferramento vel malleo teratur, ex folo frictu exfiliunt inde fcintillulæ frequentes, coloris albifimi fimiles illis, qux oriuntur ex collifione chalybis cum filice. Lxvigato fic plano fuperiori incudis, e loco fuo ad rivulum aquæ fluentis defertur, ubi pars illa mallei aquata obverfa aquis intingitur, ita tamen ut vena fuperficiem illam fummis labris modo contingat \& quafi lambat; in quo fitu relinquitur fpatio plurium horarum, nec inde eximitur, quam cum pars illa exitinda fit, \& confequenter indurata, quod eo melius fit, quia aquis frigidifimis \& femper novis intingitur; in quem finem etiam fupponitur lamina quxdam ferrea, fecundum cujus aream levi quodam flumine continuo labitur aqua, \& in lapfu partem incudis ignitam \& obverfam lambit.

\section{De motu citiori vel lentiori malleimagni.}

Alleus in ferrariis officinis ufitatus magne quidem molis eft \& pon12 deris, ufque tamen qua pondus multum differe, in quibusdam eft ponderis 45 librarum majorum five Lis.spund Svecice, in quibusdam 6o, five inter $900 \&$ I $200 \mathrm{tb}$. Multo fatis labore conficitur malleus, ut filicet frufta tam ingentia non modo formentur, fed etiam apte conjungantur; ad quod opus confumi folent i 2 leftx five i 44 tonnæ carbonum. At vero incudes vel conficiuntur ex ferro crudo \& circa fornaces ultimis diebus funduntur in arena; vel etiam ex ferro puro in focis ferrariis, qui tamen prioribus minores effe folent; confumuntur ad unius incudis confectionem $\mathrm{r}$ o leftx carbonum, durities vero in plano fuperiori, mallei parti fimili obvertendo, modo fupra memorato acquiritur. 
Quæ emolumenta \& qux difpendia ex rot: aquatic majori aut minori motu, hoc eft, ex lentiori aut citiori mallei reciprocatione oriuntur, exinde videre licet; ut I. fi lente nimis peragat vices \& ictus fuos malleus, ipfa moles magna candens in tot partes \& frufta fecari apte nequit, in quot fi crebrius elevetur malleus; quum enim cunctatur malleus \& moras nectit, frigefcit interea moles ferri, \& tandem refitit ictibus, \& fecuris aut cultri fecantis aciei, unde iterum pars refidua molis in focum referenda eft, utque iterum candefiat, carbones funt confumendi : aliter vero fit fi malleus maturet laplus fuos, quod fit non folum cum lucro temporis, quam etiam cum lucro carbonum. 2. Ipfa etiam bacilla five frufta jamdum veruta quavis vice longius exporrigi poffunt, fi feftinus fit lapfus mallei; quum enim igne adhuc emollitum permanet ferrum, extenditur intra idem tempus ad $\frac{\mathrm{r}}{2}$ vel I pedis majorem longitudinem; at verofie retardetur malleus, frigeficit \& nigrefcit bacillum, antequam debitx extenfionis fit, unde in priori cafu non opus habent nifi 3 vicibus, cum in hoc 4 aut 5 , antequam diducatur plane ferrum. 3. Ex lenta agitatione mallei plurafic exiftunt incommoda, primum eft fupra memoratum, fcilicet quod pars refidua molis diffectx iterum in foco candefacienda fit, \& candefacta iterum dividenda. Alterum, quod bacilla quater aut quinquies in focum fint remittenda, cum alias non nifi ter, quod etiam cum jactura temporis \& carbonum fit. Tertium, fi crebro in ignem relatum candefiat ferrum, magis magisque comburi folet, fitque inde fortis deterioris: quicquid enim nervolum inibi eft, exficcatur \& ductilitate fenfim privatur, prater quod pondere paullatim diminuatur ferium. Accedit quartum, quod bacillum fub lento malleo frigidum tandem percutiendum it; ferrum enim durum profunda vulnera non poteft accipere, led irriti refiliunt ictus; \& malleus cum duro corpore toties collifus tandem etiam vulnera accipit, vel circa caput, vel circa colli juncturas vel etiam alibi dehifcit, redditurque inutilis \& emeritus, \& fic novus formandus \& loco ejus fubftituendus eft. Hæc funt difpendia ex lento nimis mallei ope oriunda, ex quibus de compendiis \& emolumentis lapfus feftini judicium ferri poteft.

\section{Obfervata quadam generalia de ferrojam in bacilla extenjo, छo purificato.}

TOta \& indoles ferri crudi vix nifi per ignem focalem explorari poteft, 1 reliqua figna admodum fallunt: ferrum crudum fragillimum ductile fxpe purum fuppeditat: ferrum crudum in fractura micis \& oculis minutis referta interdum dat ferrum fragile cum friget, interdum fragile cum. rubet: fed fi interior ejus textura micis grandibus \& luminibus diductis corufcat, \& finul fragillimum eft \& leve, fignum quidem indubium ent indolis deterioris: fed tamen, num fragile fit ferrum cum friget, aut fragile cum rubet, explorandum omnino eft in foco ferrario; fi enim maffa ferri tenacifima fir calida, \& fimul tenacifima cum in contos excula fit, optimum genus eft ferri; at fi tenax cum friget, fed fragile cum calet, eft lul-

phuratum 
IO4 MODUS RECOQU.FERRUM CRUDUM SVECIE.

phuratum nimis, \& contra; unde inftituuntur probationes indubiæ per extenfiones ferri in contos \& bacilla; figna etiam interea capiuntur ex fcoriis ut \& ex flamma \&c. de quibus modo actum eft. Datur etiam ferrum, quod prima extenfionis vice tenax apparet, altera vero rubefcit, nec amplius ad candorem five candefcentiam fuam redigi poteft, fubque malleo dilabitur in frufta. Datur etiam quod nec calidum nec frigidum cohæret, eftque pefinum.

Alias ctiam ex ipfis fiffuris \& rimis bacillo cuidam impreffis aut inductis judicari poteft de indole ferri excufi; fi enim rimæ aut fiffurx dantur fecundum longitudinem bacilli, nec inde quid concludere licet : ferrum enim optimum ejuscemodi rimas ducere poteft; fepe complicatur, prefertim in illis locis ubi nimium dilatatur, at vero fi fifure angulis bacilli transverfim incifix ĺcabram \& infabrem reddantfaciem, fignum eft, fulphuratum genus ferri effe; nam ferrum hoc calidum non patitur ictus mallei, fed hinc \& inde frangitur dum calet aut rubet; undefi vitio illo fatet, confpicitur ferrum hiulcis cavernulis circa angulos paffim bipatens: pariter fi anguli rudes \& incomti fint, minimisque rafuris conferti; nam circa angulos tale ferrum acui \& infpicari nequit. Sunt præterea plura adhuc indicia, qux in fecundam operis noftri claffem transferre volui.

Obfervatum tamen multoties eft, unum idemque bacillum una fui parte conftare ferro optimo, altera vero vitiofo; fi enim duplicis generis ferrum in foco commificendum excuditur, fape vilior pars unum latus occupat, melior vero alterum; confpicitur filicet circa unam extemitatem nervofum \& fibris continuis hærens; circa alteram vero micis \& oculis malignis conftans. Pariter in uno eodemque bacillo ferrum vile \& probum loca fua fortiri \& alternare folet, fi contus ab una parte magis aduratur quam ab altera.

Ferrum purum non eodem pondere ex foco redire folet, quo crudum immittitur; pars enim lapidea, fulphurea \& cruda per ignem hunc iteratum \& focalem multa expellitur, nec nifi illa prius expulf purificari \& ductilis reddi poteft; communis jactura eft $\frac{6}{26}$ five $\frac{3}{13}$ partium ferri crudi: quum enim foco traduntur 26 partes, reddi debent 20 partes ferri emalleati. puri, fin minus, hoc damno cedit fabro; fin magis, lucro; quod etiam lege fancitum eft; fi minus, dicitur periiffe fabroferrum, five Svecice Bortfmidt jernet, fi magis, vocatur lucratum effe, Svecice Smidt oefiverjern: hinc operam impendit magifter foci, ut reftituat ferrum fuum cum jactura dictarum partium conceffa, quæ in fcorias \& fumum abactæ funt. At vero fi ferrum detur nimis incoctum \& crudum, hoc nequicquam tenax \& ductile redditur, nili cum majori adhuc ferri \& carbonum difpendio, quod

nifi prius notum faciat hero fuo, pondus ultra rationem fancitam \& conceffam amiffum rependet.

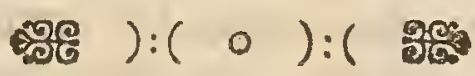




\section{PARA GRAPHUS III.}

\section{De vena ferripaluftri, ejusque coctione 89 pra: paratione Svecice praeerim in Angermannia \&? Dalekarlia, five de ferro, quod Svecice vocatur Myrjern.}

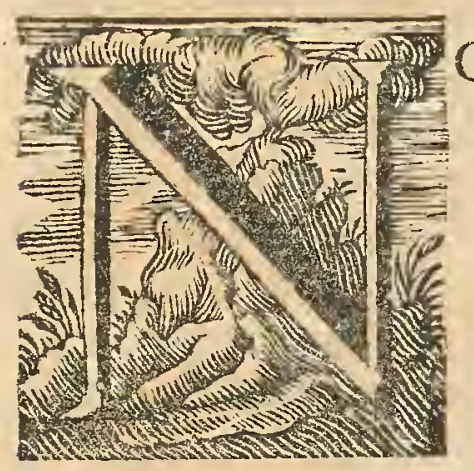

On quidem merito appellari hæc vena ferri poteft; non enim frangitur in dura caute, ut venæ de quibus in @phis præcedentibus actum eft, fed colligitur: in humo molli \& præcipue in locis paludinofis \&interdun udis. Obfervatu etiam dignum eft, quod præcipue reperiatur in locis verfus feptentrionem. nivalibus \& frigidiffmis, non vero item in regionibus calidioribus Svecix: Solum ejus natale eft maxime in Jemptia, Dalekarlia, \& Bothnia occidentali : alibi etiam veftigia ejus confpicua funt, fed in exigua tantum quantitate, quæ tam ob paupertatem ferri in illa contenti, quam etiam ob exiguam copiam in ferrum liquari non poteft: vena hæc Svecice vocatur (Myrmalm) five vena ferri paluftris, fimilis eft terræ cuidam rubræ aut ochræ, quæ in maffas etiam conflata fub humo paludis fuperficiali latet, eftque non unius fed diverfi coloris, de quibus infra.

Vetuftifimus ferri liquandi mos Svecix in ufum antiquitus receptus ex minera hac paluftrifuiffe videtur; nam antequam terr: venas aperire \& in vifcera ejus ire noverant, terræ fuperficiem fcrutati funt, \& inde metalla fua legerant. Vetuftifimum hunc Svionum gentifuife ritum parandi fibi ferrum in bipennes, haftilia, ancilia, \& tela mucrone aut umbone quodam prætenta recudendum, ex ipfis cumulis antiquis multa \& grandæva fylva contectis augurari licet, adeo ut hoc genus ferri fuerit de quo poeta, quod Noricus excoquit ignis; vocantur etiam hodie cumuli paganorum; ipfa etiam fimplicitas uftrinarum argumento effe poteft.

Minera hre lutofa five paluftris eft ad primum confpectum coloris obfcure rubefcentis aut caftanei feu badii; fed humore expulfo \& fub dio ficcata magis rubefcit, fed tamen albentius, \& ineft ei gravitas major, quann alius generis terris \& lutis. Aliquibus in locis, ut in parochia farboaubs dieta, in Wermzlandia eruitur dieti generis minera non folum in paludibus \& locis udis, fed etiam in pratis \& viretis admodum ficcis, in ipfis fylvis, pracipue in planis declivibus feu obliquis collium; inque vallibus jam exficcatis; fortaffis ubi antiquitus aqua ftagnans paludem formaverat, fed tempore arefcens ficcum folum reliquerat, unde adhuc in paludis vetuftx acclivo margine \& finuolo limite confpicuus eft fundus hujus ochræ ferax; eft etiam fimiliter coloris rufi, fed vergit tamen ad album, tam ficca, ut aduri ftatim \& liquari polfit; fed tamen adhuc in locis illis non pinguis herba Clalfs I. de ferro.

$\mathrm{Dd}$ venit. 
venit. Paludes hujus generis præftant, quæ inclinantes \& aliquantifper devexæ ant declivæ folem meridianum profpiciunt, humus ibi melioris notie venam five ochran recondit : fed fi folum declive boream fpectat, datur vena vilioris pretii \& fulphuris egena vel expers, quæ ferrum fragile fuppeditat. Dantur hujus mineralis diverfæ fpecies, quæ per colores præcipue internolcuntur : datur nigricans, carbonis inftar, \& vocatur Brandoerk, fed quia peffimi generis eft, raro in ufum effoditur. Altera fpecies aliquantum vireficit, inftar coloris fubbuxei five praffini fpadicei, cui aliquid acutum \& fali non abfimile ineffe videtur; ad tactum enim digiti falis comminuti feu pulveris lapidei minutim granulati fpeciem refert; fed genus hoc altius fe recondit, \& a colore vocatir terra viridis five (Groenoercke;) eftque fic vena' non infimæ fed mediæ fortis, pariter ferri ferax. 'Tertium genus obfcure rubet, unde etiam nuncupatur (Roedoercke, ) ad tactum eft tanquam fal craffe granulatum, fub dente tenax tanquam refinofum : in fruftula confluit hoc, quæ vocantur (Skioelugnar;) quæ cum reliquo hujus generis minerali commixta \& calcinata in pulverem dilabuntur: dives eft fpecies, præcipue quæ in parœcia Lima eruitur, adeo ut ex 100 reftituat 49 partes ferri. In Angermannia dantur præcipue tres fpecies, una coloris badii vel fere bruni, ex qua coquitur ferrum, dum rubet, fragile five fulphureum : altera eft coloris fufci \& fubnigri, contrariæ indolis, fcilicet fragilis cum friget : tertia eft coloris a rubro bruni, ditiffima \& ferri feraciffma, pariter optima. Omnes tres fpecies non feorfim funduntur, fed commixtæ per unam eandemque fornaculam transmittuntur, ut ex commixtis fic ferrum optatx indolis prodeat.

Qui periti glarex five ochracex hujus materiæ exploratores funt, ex nuda paludis infpectione fciunt, an fubtus vena talis lateat : fi enim palus ubique plana \& xquata fit, fciunt nullam hujus generis mineram aut venam fubeffe; at vero fi planities paluftris in tumulos quosdam aut colliculos fupinos divifa fit, hoc eft, fi fupercilia parva clivolx humi hic \&ibi confpiciuntur, norunt reconditas ibi \& fepultas jacere venas quælitas.

Nec vero ex ipla forma \& planitie paludum concludunt, an crefcat fubter ferrum, fed etiam ex fruticibus \& gramineo genere quod infuper vegetat : quxlibet humus fuam herbam \& plantam præ aliis amat \& alit; unde humus hrec multo ferro foluto prægnans, fuccum aut lac reddit fino vegetabili: hinc fi alicubi apparet gramen palufte denfum, quod folito crafloris caulis \& rigidum eft, ibietiam fciunt arenam fubtilem martialem fubeffe, indicatque hoc vegetabile locum, fi modo palus ferrugine:e naturef fir.

Ubi etiam in vicinia funt lacuftres aquæ, præfertim tales quæ originem trahunt ex palude, ciri etiam poteft $a b$ illis tanquam $a b$ indice non dubio abinde velad I 00 vel 1000 vel ad 10000 paffuum diftantiam in ipfamet palude matre alicubi glaream martialem recondi : fi enim dicta aqua fuperficietenus rubeicit, vel pellicula unctuofa tenaci \& rubiginofa obducitur; fique illam tanquam vix indicern ad originem \& fcatebras remenfis veftigiis fubfequntur, ipfam arenam ferri in latebris \& ventriculis paludis latentem tandem folent indagare; ad minimum tali foetu gravida eft palus 
vicina. Quo enim remotius abinde unguine hoc martiali tingitur \& coloratur aqua, eo ditior judicatur effe in palude ferrigaza; at fi limpidiffima \& fui coloris fluat, in fpe fua fruftrari folent quxelitores. Alia adhuc indicia fiunt indigenæ, fed fufficiunt prædicta, Cilicet, quæ ex ipfa figura \& fuperficie paludis, quæ ex herbis \& graminibus inde vegetatis, ut \& ex aquis propinquis, quæ lecum venam talem ferunt, petuntur.

Tempore xftatis inveftigatur \& effoditur humus hæc ferri ferax, cum fcilicet omnem humorem paludibus exficcaverat firius, \& quum tuto fuperambulare loca hre alias mollia \& uliginofa poffit indagator: dicto tempore hic dextra baculum quendam abiegnum vel etiam pilum infpicatum $\&$ præferratum forma quadratum \& terebræ inftar contorfum cum manubrio tenet, quod in terram tentando ad altitudinem circiter unius ulnæ fubigit \& demitcit, perque fenfationem in manu explorat, num glarea martialis \& ad quam altitudinem fubter delitefcat : fi enim humus mollis \& cedens fit, nec ulla fentiatur frictio, fignum eft, pulverem nullum mineralem in loco illo fublatere; at vero fi fenfatio fit fimilis fenfationi, acfi baculum torqueres in cadum fale culinari plenum vel in farinam craflorem, vel acfi corium cultro hebetiori f́cinderes, fignum eft terræ quafitæ mineralis. Si vero per demerfonem baculi nulla in manum recurrat friCtio aut tremulatio, fed tamen terebra hæc extracta prodat circum fe ruditatem quandam fimilem ruditatigranorum falis, nihilominus inde judicant, humum infra fuperficiem tali glarea fœtam effe; unde etiam folfam moliuntur, \& penitius oculis \& manibus inveftigant, qualis generis fit.

Experiri etiam folent arenam hanc ferream gutatione; fi enim lolvitur facile in ore, \& fimul conglutinat dentes inftar refinx, fignum eft indolis melioris; contra vero fi fabuli inftar dentibus illifa reffitat.

Quod alias itratificationes humi \& glareæ attinet, primum \& fupremum locum occupat humus nuda aut fterilis paludinofa ad profunditatem $\frac{x}{4}$ vel $\frac{x}{2}$ ulnæ: excipit dein ipfamet glarea martialis ad crallitiem $\frac{\mathrm{I}}{4} \mathrm{vel} \frac{2}{4}$ vel $\frac{3}{4}$ partium ulnæ, hic enim occurrit ftratum ejus craflus, hic vero tenuius, prout ipfum ejus folum natale fert. Tertio occurrit vel arena pure lapidea vel terra mollior paludinofa; adeo ut binæ terræ fpecies prolem hanc nobiliorem intermediam in finu fuo quafi fervent nutriantque. Circa iplam fuperficiem raro invenitur nifi tantum ad profunditatem $\frac{1}{4}$ ulne, ubiftatim evanefcit. Sub arena hac vel humo fundamentali fruftra quæficus eft mons ferreus five petra ferri ferax, prout aliquibus in mentem venerat.

Si per totum campum ferri feracem baculo præferrato explores \& rimeris ubique naturam humi, obfervabis glaream hanc ferream non unum eundemque in palude locum obfidere, fed ftratorum aut rivulorum inftar hic \& inde pererrare \& fecare paludem; hic enim ftratum ejus craflus eft \& dilatatur, hic in callem anguftum coit, hic expanditur; quo obfervato veftigia fua remetitur rimator \& ad alia loca fe flectit, qua percurrit : ficque paludern ductu quodam continuo, non fecius ac aqua fluviatilis pra"ta, aut ftrata venarum montes, pererrat. Sedulus indagator veftigia hre premens ad ipfam originem \& tractum, ex quo excurrunt hæ venætandem perveniet. Tractus illi diverfe amplitudinis effe folent, in quibusdam paludibus 
ludibus diametrum 50 ulnarum requant, in quibusdam vero 6 vel 8 , eftque vel figuræ oblong: vel rotundæ, fed utplurimum inæqualis.

Ut prius diotum eft, transcurrit utplurimum vena hxc radices tumulorum aut tumorum, quibus paffim elevatur area vel planities paludis; fed etiam quam maxime arborum radices fe circumdat; ibi enim fuccus mineralis quafi fiftitur \& retardatur, ibique torum fibi format, in quo fe reponat; implicatæ apparent radices \& intertextx terra martiali: optimæ indolis vena \& in maxima copia circa radices has eruitur. Alias etiam amat radices arbuftuli cujusdam fylveftris, quod algæ fpeciem refert, \& Svecice Liunggreas vocatur, illas circumcirca aretiffmis quafi complexibus implicat \& ligat; adeo ut mafiæ hujus venæ conglutinat:e loco fuo natali exemta undique dein appareant filamentis \& ductibus fubtiliflimis perforat: ; eftque hoc genus venæ ditiflmum \& vocatur.in illis locis Pipmalm five vena arundinea vel perforata. Raro alias invenitur in locis planis \& xquatis paludum nifi ad altitudinem $\frac{\mathrm{I}}{4}$ ulnx, fed ferri admodum inops eft, videtur enim fuccus fuens ferri nullum ibi feceffum aut portum nactus fuiffe.

Referunt etiam incolæe venam hanc fub tumulis vel alibi reconditam quotannis vifibiliter accrefcere, \& loca illis femel exinanita præterlapis annis rurfus oppleri.

$V$ ena hxc non femper glaream refert \& in arenulas divifa jacet, fed interdum in maffas majores conflata eruitur: maffula talis vel fruftum in fractura nitet, eftque coloris bruni non abfimilis venæ fluviatili, de qua in Spho fequente, eftque alias fimilis corio feeto.

Eruitur itaque qux intermedia jacet, præfertim illa quæ radices arborum \& plantarum cingit; relinquitur vero, quæ ejusdem ftrati fupremam \& imam partem tenet, adeo ut pars modo medullaris eligatur, quia feracilfima ferri eft; ut fi ftratumfit craflitie unius pedis, extrahitur modo media hujus frati pars ad craffitiem $\frac{T}{2}$ pedis.

Per fe admodum ferri egenum eft hoc genus venæ, nam datur cujus centumpondium modo reddat 5, datur quod reddat 20 partes ferri, hoc eft, quod reddat 5 ad 20 P. ut \& plus.

Qualiscunque fit hrec vena, ufque tamen nullo magneti obfequitur, nif prius ignem combuftorium communem pertranfierit; apparet enirn ochræe \& ferrugini fimilis, quæ nec a magnete attrahitur : ipfifimum etiam ferrum ex vena hac palufri excoctum facilius in crocum \&rubiginem folvitur, quam aliud ferri genus.

\section{Modus adurendifive calcinandi venam banc paludinofam.}

Ttum hoc minerale tempore verno, five utprimum terra frigore con1 ftricta foluta apparet, effoditur; \& quidem omnis humus operiens primum eximitur \& inde effertur; ne ipfi terræ ferri feraci detrimento fit : f enim pars ejus immixta fimul igni fornacula fubjicitur, detrimento \& multæ 
jacturæe eft : hinc ejecta humo graminea effoditur ftratum martiale \& in cumulos congeftum foli objicitur, ut humor in vapores exhalet, ficque ufque ad ferum autumnum relinquitur, antequam aduratur \& liquetur. In quibusdam locis, ubihumus ficcifimam ochram ftatim fuppetit, non tempore opus eft ut ficcefcat, nam per moram confumitur, \& per ipfam aquam pluvialem putris redditur, \& ferro fuo orbatur.

Vena hæc ferri arenaria per calcinatorium five combuftorium ignem transmittenda omnino eft, antequam in uftrina liquetur: nifi enim prævia fit combuftio, in ferrum dein liqui nequit, nec enim recrementa $\&$ partes terreftres omnes abinde feparari per ignem nudum liquatorium poffunt; fed manent commixta, ipfumque ferrum fcoriis pollutum.

In Dalekarlia mos eft vel circa uftrinam vel in ipfo loco, ubi effoditur vena, rogum hunc calcinatorium exftruere; quavis vice igni fubjiciuntur: 20 cantheria fivé effedæ venarum. Ligna adhibentur majora, filicet quæ 8 aut 10 ulnarum longitudinem xquent: ligna hæc integra in 3 ordines dilpefcuntur, ita tamen ut unus illorum ordo transverfim relocetur fupra alterum, \& tertius fupra hunc, quovis latere ftruis fex ulnas æquante; cavetur ne ligna nimis rara cubent; quibus fuperinjicitur terra hæc martialis ad $\frac{\mathrm{r}}{4} \mathrm{vel} \frac{2}{5}$ ulnæ altitudinem, feu quantum a fubmifis lignis candefieri poffit; immittitur dein ignis ad omnes pyræ aut ftruis partes, fcilicet ut in flammam omnis accendatur, \& igne fic lato includatur vena fuperimmiffa. Cumque ftrues lignorum aliquantum fit confunta, elevantur trabes uftæ hic \& inde, illum f́cilicet in finem, ut per laxatas juncturas lignorum defluere poffit apte vena jamdum fatis combufta ; per interftitia lignorum delabitur fic vena verlus fundum; ubi refrigeratur fponte fua: Interea fuperinjicitur adhuc plus lignorum \& infuper venæ arenarix five paluftris, dum omnis glarea mineralis, quæad manus fit, eodemigne poffit cremari. Tandem materia cremata vel tabulatis tegitur, vel domum defertur, utab aqua pluviali immunis fervetur.

Alius vero mos eft Jemptix, Angermannix five Bothnix occidentalis. Supponuntur binæ trabes, \& infuper conftruntur 3 ordines ligni fe¿ti, ficci \& majufculi, ipfaque pyra fic fub dio conftruitur ad longitudinem \& latitudinem 6 ulnarum, adque unam caplam aut cifum venis plenum requiri plerumque folet menfura unius ulnæ cubica ligni; fuperinfunditur dein vena, fed modo ad altitudinem 1 pedis; arida erit vena \& in fole prius ficcata, ut co melius in illam effectum fuum edat ignis. Accenfa pyra peragitur calcinatio patio 24 horarum: finita vero calcinatione in maffas \& moles quasdam quafi conglutinata apparet.

Alias ad Graninge in Angermannia tentatum etiam eft, venam hanc non prius combuftam uftrinie \&igni liquatorio concredere; putarunt enim recrementa noxia per fuforium ignem valide fatis difcuti poffe; fed in balinco tantum ficcarunt illam, adeo ut igne leni torrefacta in iplomet foco relinqueret heterogenea vitiofa : fed caruit tentamen fucceflu; ferrum quod obtinebant, non modo fcoriis inquinatum erat, fed etiam cum ferrum inde excoctum in contos aut bacilla extenderetur, $\frac{2}{3}$ partes illius amiferunt, cum tamen communis jactura non fit ultra $\frac{1}{3}$ partem. Ex quibus Clalfis I. de ferro. $\mathrm{Ee}$ con= 
concludunt, venam hanc per ignem calcinatorium omnino transmittendam effe; per ignem \& fecundi gradus inde multa diffipantur, quæ alias in igne fuforio remanerent inclufa, quxque texturam ferri crudi fimul ingrederentur.

\section{Modus confruendi uftrinam.}

TN Dalekarlia exftruitur uftrina in planitie quadam, ubi foffa paratur pro1 funditatis 3 pedum, longitudinis 5 , latitudinis 4 ; amplitudo fundi eft 2 pedum, fine canali pro humoris exhalatione \& fine faxo fundamentali, \& ejufcemodi foci conftructione, qualis in fornace majore : fed confruitur, ope faxorum planorum in dicta foffa, oblita argilla : fundus modo conftat terra ficca fcoriis quibusdam commixta.

At vero Angermannix aliter : conftat ibi uftrina duobus orificiis ventum fpirantibus : catinus vel focus non abfimilis eft foco, in quo purificari cuprum folet, fed profundior eft illo, qui in ufu eft Dalekarliæ, ut \& fuperne amplior. Folles è corio facti rota aquatica moventur; unde etiam majores funt uftrinx, \& major copia venæ in illis quavis vice poteft liquari; ufque tamen non ubivis Angermannix hoc ufitatum eft." Pariter etian in occidentali parte Dalekarlix ut in Lima exftruuntur uftrinæ majores, duobus flabellis applicatis, latiores etiam funt, \& formatur apertura, per guam fcoriæ emittuntur, in quibus duplex quantitas venæ in eodem tempore fundi poteft.

Alias Angermanniæ conftat fundus lamina quadam faxea, eftque focus profunditatis $I_{\frac{1}{2}}$ uln $x$, a pertura ejus fuperior diametri $I_{\frac{\pi}{2}}^{\mathrm{I}}$ ulnæ \& form rotundæu ufue ad aperturam fpirantem. Focus vero infra formatus eft figurx quadratæ $\frac{3}{8}$ ulnx, cum angulis femirotundis; diftatque orificium fpirans a fundo patio 4 digitorum.

Alias nullibi ex foco hoc datur apertura, per quam emittantur fcorix, prout circa fornaces ferri fuforias vulgares; fed fi multa copia fcoriarum fit, adeo ut alcendant verfus orificium fpiratorium; tuncillæe per orificium hoc commune emittuntur; fed communiter relinquantur recrementa hæc fluida in uftrinx foco ad finem totius liquationis, cumque frigefiunt, occupant fuperficiem ferri.

Sed ne tam parce conftructionem hujus parvi, fed propter antiquitatem \& fimplicitatem memorandi xdificii præteream, plenius defcriptionem ejus tradere libet. Conftuitur in locis ficcioribus, in fylvis, vel in obliquo \& devexo đollis alicujus plano, ubi a vento \& tempeftate immunior fit: melior tamen ei eligitur locus, fi copia detur, juxta rivulum quendam, qui rotulam circumducat, \& elevet flabella; qua alioquin fine aqua prope fluente calcari debent. Fundatur fupra nudum folum, ubimurus primum ponitur craffitiem $\frac{T}{2}$ vel $\frac{3}{4}$ ulnx adxquans ; infuper locatur faxum commune five coloris cani aut grifei $\frac{x}{2}$ peden crafum : infuper formatur catinus five focus, cui datur figura oblonga, \& longitudo I $\frac{x}{4}$ ulnæ, latitudo $\frac{\pi}{2}$ vel $\frac{3}{4}$ ulnx, altitudo perpendicularis I ulnæ. Ubi jam terminatur hoc ferrei liquaminis receptaculum, excipit cavitas fornaçulæ, qux coni 


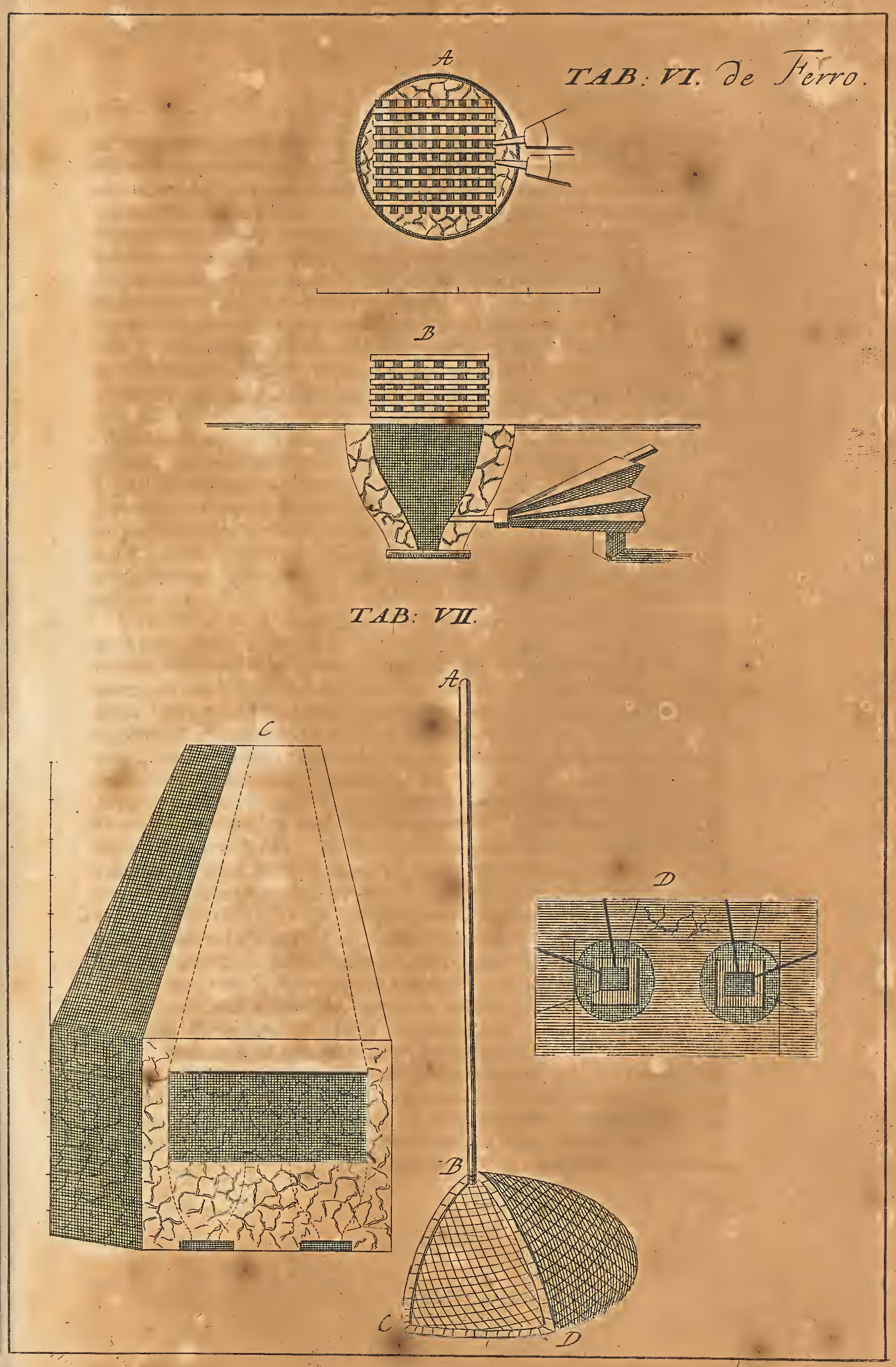


i. $\quad(n, \cdots)$
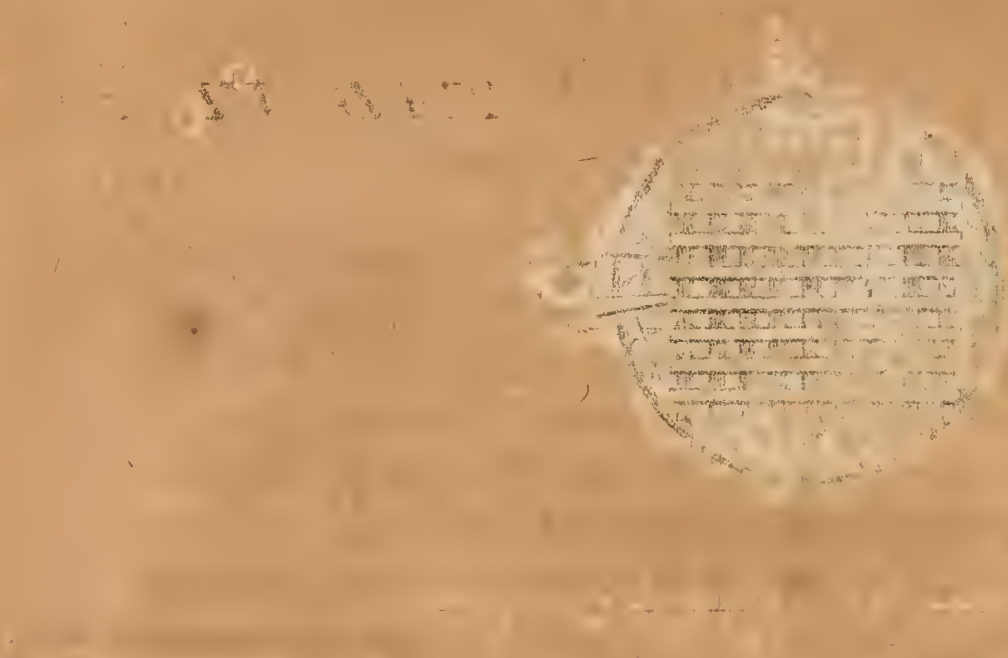

+. 18

$+2$

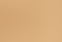

$1=$

$\frac{i}{1}$

$\frac{1}{1}$

4

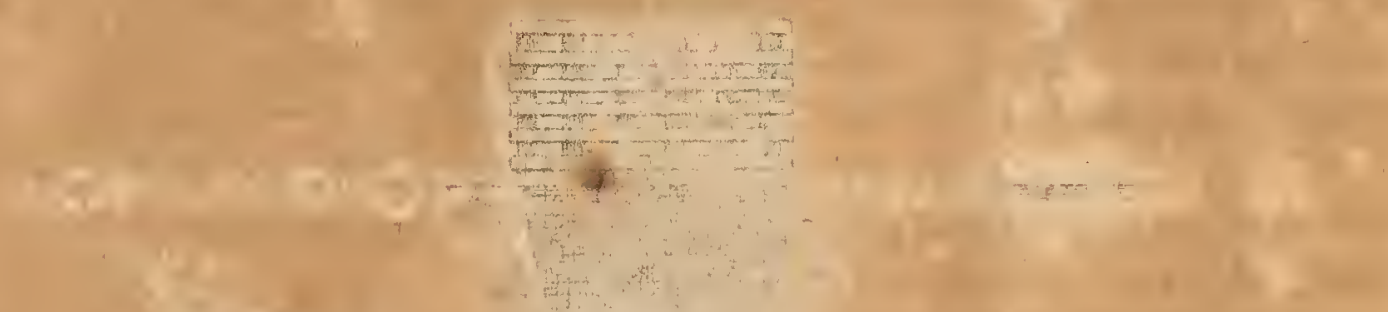

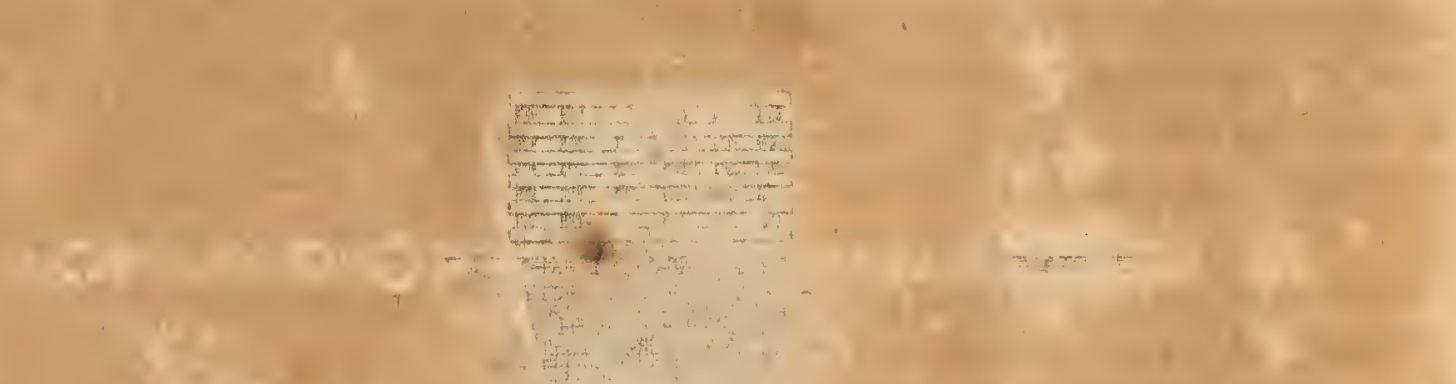

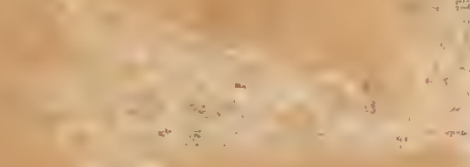

(4) $+5:=$

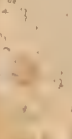

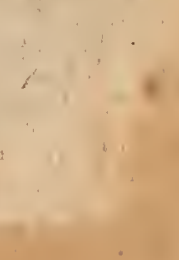

$$
\text { 13. a : a }
$$

$\vdots$

1.9<smiles>CCCC1CCCC1</smiles>

e

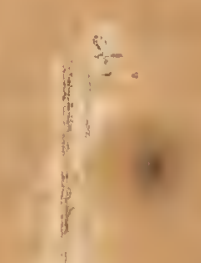

.

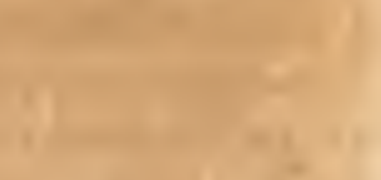
1

$\sqrt{3}$

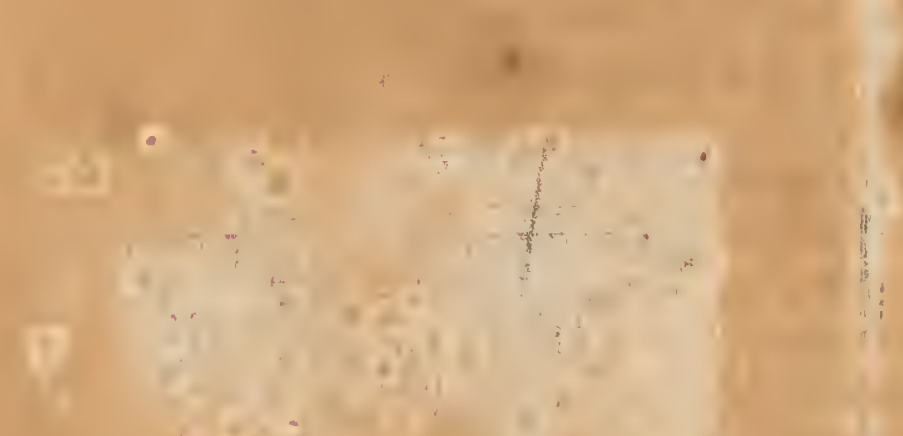

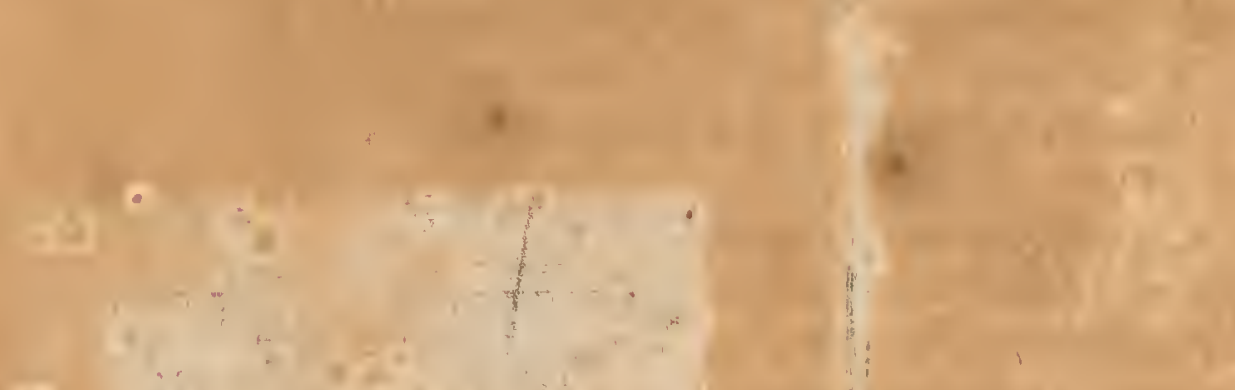

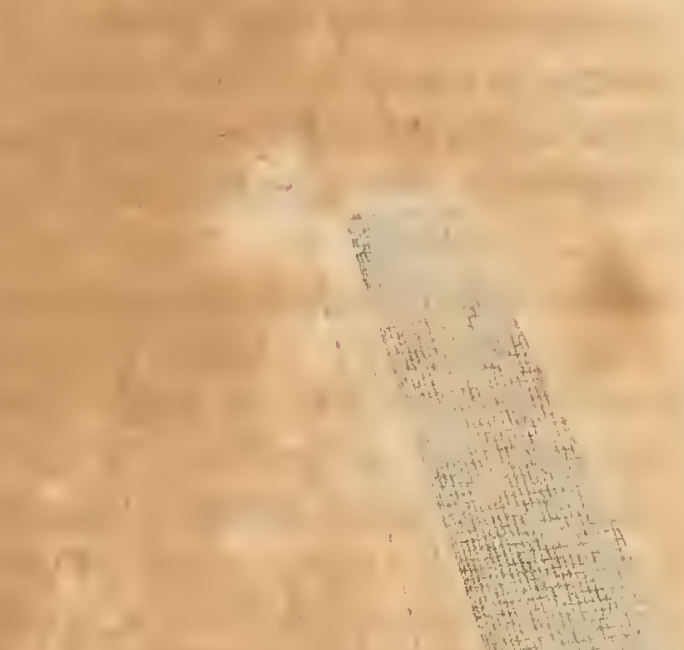

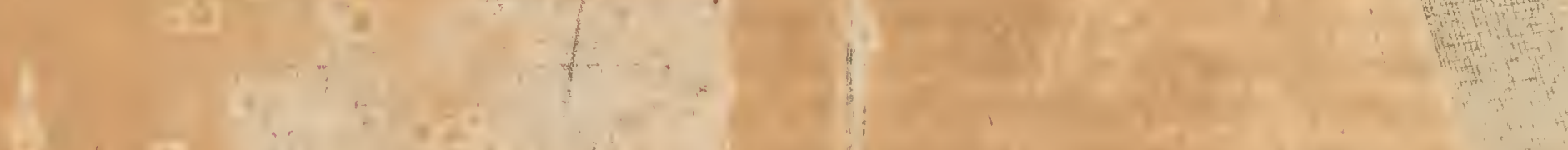

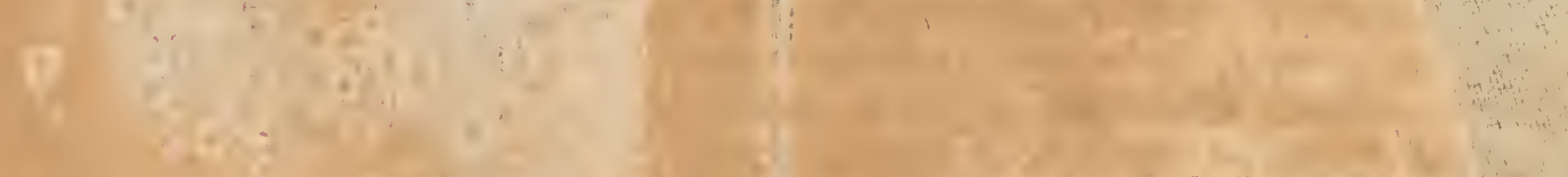

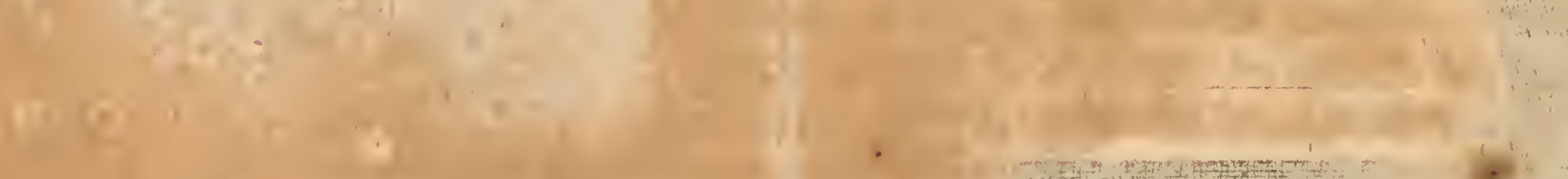
12. 
inftar verfus aperturam fuperiorem ad diametrum $2 \frac{\mathrm{T}}{\mathrm{z}}$ ulnarum ampliata furgit : a fundo hujus foci ad fummum marginem aperturæ fornaculie datur altitudo $4 \frac{1}{2}$ ulnarum, craflities $\frac{T}{4}$ ad $\frac{x}{2}$ ulnæ. Parietes interiores optimi generis argilla, pariter \& parietes foci, oblinuntur. Fundus hujus foci fuperinfternitur pulvere carbonario, fed tantum prima vice, cum opus in noviter exftructa \& recenti fornacula inchoandum eft; dein vero copia talis pulveris ex carbonibus refiduis ad fundiconfervationem fubminiftratur. Infra aptatur orificium fpiritale, per quod flabella ventum in focum immittant; cujus alcitudo a faxo fundamentali eft $\frac{x}{2}$ ulnx: orificii hujus fundus non multum verfus interiora inclinat, tantum ut gutta aquæ immifla ufque fponte defluere pollit. Parietes fornacula tignis, quibus connectuntur, ad diftantiam $\frac{\mathrm{r}}{4} \mathrm{vel} \frac{3}{4}$ ulnæ a muro ejus faxeo circumdantur:intervallum vero pulvere terreo bene compacto ufque ad fummam fornacula oram repletur \& $\&$ tipatur. Dum fervet opus, fi ignis murum transmeare velle videatur, \& contignationem corripere, compefcitur hoc alpergine aquæ. Duo folles coriacei adhibentur; fique duo applicantur, vocatur uftrina Twekielling; fin uno, Enkielling. Diameter rotæ eft 3 ulnarum ; \& trabs, quam circumducit rota, 6 ulnarum. Si fimplex follis adfit, movetur ille, a fomina vel viro; fomina interea dextrafulum \& ftamen fuum tenet, urgetque utrumque opus, tam pedibus manibusque fedula eft, in fpemque laborat.

Ad Graninge Angermannix ad hunc ufum exftrueta fuit fornacula alius figur:e, fcilicet murus a folo ad fummitatem erat altitudine 3 ulnarum, confans faxo grifei coloris : fpatium ipfusmet foci erat longitudine $5_{7}^{\mathrm{I}} \mathrm{ul}$ narum, \& profunditate 3 ad murum pofteriorem, qui craflitie erat $\frac{3}{4}$ ulnæ, quum defivit pars hæc muri perpendicularis, excepit alter in obliquum educus ad altitudinem io ulnarum ufque ad aperturam, ubi contrahebatur; cavitas camini latitudinem $\frac{3}{4}$ ulnæ \& longitudinem I ulnæ habebat. Focus erat duplex, uterque circa extrema conjunetus, eratque quilibet focus altitudinis 2 ulnarum, pariter diametri 2. Fundus muniebatur lamina ferri crudi crafliore, quæ fub orificio fpiranti fitum horizontalemad altitudinem abinde 4 digitorum nacta eft. "Uterque focus oblitus erat argilla communi ; latus foci a fundo ad orificium fpirans perpendiculariter erat eductum, pars reliqua magis \& magis ampliabatur. Ex orificio dieto fpiranti ufque ad fundum erat forma foci quadrata ad profunditatem 4 digitorum \& amplitudinem $\frac{\mathrm{r}}{2}$ ulnæ. . In nova hac fornacula apertura quædam pro emiffione fcoriarum ad latus unum facta eft ejusdem altitudinis \& latitudinis cum foco: perdurante liquatione apertura illa occlufa erat arena \& f coriis comminutis; plane ut circa fornaces majores.

Ipla uftrinarum conftructio melius videri poteft ex delineationibus : veterem \& ufitatam videas $\mathrm{Tab}$. VI in (A) \& (B), ubi (A) repræfentat fectionem fornaculæ horizontalem, una cum lignis ordine fuperimpofitis; Figura (B) fectionem ejus perpendicularem. Fig. C novam. uftrinam duobus focis præditam : Fig. (D) fectionem focorum hori. zontalem. 


\section{Modus coquendivenam banc ferriin ufrinis.}

Uum peragenda eft fufio, repletur uftrina lignis ficcis, quæ accenduntur ufque dum calefacta fit fornax; repletur altera vice lignis aridis \& Iciffis ; quibus accenfis fuperimponitur aliqua pars glarex calcinatx; quumque ligna in prunas fint converfa, folles \& flabella moventur, lentius principio, dein celerius; \& ftatim ut glarea prius impofita liquefcit, adhuc pars glarex imponitur; \&.fic quibusdam in locis fepties.

Ferrum in medio fundo reperitur undique circumdatum fcoriis, fiftitur dein flamen \& ope forcipis elevatur maffula, quæ dein in medium dividitur; \& ope marculi aliusve inftrumenti e parietibus \& fundo excutiuntur fcorix quxe rejiciuntur. Obfervetur etiam, quod liquamen ex hac minera proveniens nufquam tam liquidum fit, ut liquamen ex vena montis; craffum enim eft, \& lentum, ut \& granulatim, \& facile infpiffatur. Septem iftiusmodi fufiones fpatio 24 horarum peragi folent, \& quavis vice obtinentur $I \frac{1}{2}, 2$ vel $2 \frac{1}{2}$ libre majores ferri, quod dein in foco ferrario purificatur. In fimplici fornacula, qux Enkielling vocatur, fexies, fepties aut ofties per diem noetemque peragitur \& renovatur liquatio, \& quavis vice obtinentur circiter 30 ad 40 to ferri. Circa fornaculam duplicatam five Tivekielling diotam binæ maffre quavis vice colliquatæ colliguntur, \& intra octiduum obtinentur 16 maflulx five 1024 to ferri, five I pondo nauticum \& 12 librx majores.

Quod vero fornaculam aut ufrinam Dalekarlix \& alibi etiam ufitatam attinet, quum illa parata fit, \& ligna in ordinem prædictum repofita, ignis in caminulum hunc per orificium fpirans immittitur, quo accenfo confumuntur celere fatis ligna fuperimpofita, \& convertuntur in carbones vivos five prunas minores; quod cum factum fit, imponitur una fpatha venæ vel glareæ hujus calcinatæ, quæ inter prunas novas fternitur : quumque flamma pervaferit glaream, adeo ut prunarum modo alpectus fit, iterum fpatha una glarex fuperinjicitur, quod pari modo continuatur ad impofitiones 24 vel 30 five ultra. Quum vero prunæ ad mediam partem formacis fubfiderint, imponitur modo dimidia fpatha mineræ. Obfervandum eft, quo pluries peraguntur impofitiones, eo majorem quantitatem glarea mineralis quavis vice apponi poffe, calidior enim uftrina redditur. Quum prunx tandem ad orificium fpirans fubfiderint, ventus \& follium motus reciprocus fiftitur, \& ope ferri aut conti uncinati refidux prunxprimum ejiciuntur; mafla ferrea five panis coctus tunc nudatur in medio.foco relictus, qui ope forcipis adhuc ignitus \& candens elevatur, \& dèin fcorire, dum focus illis plane evacuatus fit, quod poft fufionem peractam qualibet vice fieri debet. Prima liquatione, cum uftrina nondum calefacta fuerit, obtineri folet maffa ponderis vix $\frac{\mathrm{r}}{2}$ librarum majorum, fed elapfis 3 diebus \& noetibus \& calefacta fornacula $i \frac{\mathrm{T}}{2}$ vel 2 talium librarum. Maffa foco exemta \& forcipe prehenfa fubjicitur malleo \& in formam fere rotundam contunditur, ne fcilicet eminentix quædam exfent, quæ inde effringi poffint. Opus hoc exiguum fuforium quavis vice intra fpatium 2 horan 
rum peragitur: intra binas horas tanta copia ligni ab uno viro fcindi poteft, quanta ad proximam liquefactionis vicem requiritur.

Circa liquationem hujus generis venæ in ufum vocandum eft lignum ficcum, torretactum \& pingue, quod flammam optine non modo arripiat fed \& foveat. Fornaciadfunt duo operarii, unus qui plantis premit \& fubigit folles, fi aquis non moveantur, alter qui dividit \& miniftrat ligna.

Tentatum etiam eft ad Graninge loco lignorum carbones fubftituere, ficque liquationem hic ut in fornacibus ufitatis peragere, fed fucceffu caruit periculum, \& ferrum inde fcoriis inquinatum obtentum fuit, unde ad liquationem hujus venæ flammeus \& vivus ignis omnino requiritur.

Si etiam vena non calcinata fed cruda fuperimponitur, ferrum inde contaminatum fcoriis \& impurum educitur, cujus plurima pars dein infoco ferrario \& purificatorio perire folet.

Obfervandum etiam eft, fi uftrina hæc nimium calefiat, quod ope aqux aliquantifper refrigeranda fit, alias fi nimis calida \& ignita fit, dicitur non tantam ferri copiam a glarea exfudari poffe.

Quum fic ferrum adhuc impurum, crudum nec fatis coctum obtentum fit, purificatur \& recoquitur iterum in foco fabrili, pari flabellorum ventum fuppeditante : cumque bene liquatum coctumque fit, incudi imponitur, \& mallei ictibus ita contunditur, ut omnes freces inde difcutiantur; unde ferrum redditur tenax : licet fere dimidia pars pereat.

\section{De chalybe ex ferri boc genere proparato.}

G

Enus hoc ferri cum induruerit eft fimile chalybi. Narrant enim

indigenæ, ex hoc ferro optimum genus chalybis poffe parari, fed qui illam naturam poffideat, ut facile emollefcat $\&$ in ferrum redeat fi in igne teneatur. Hinc etiam Dalekarli circumferre folent utenfilia \& inftrumenta chalybeata, ut fecures, falces \& id genus alia ex hoc genere ferri fabricata.

Quum inde præparandus eft chalybs, maffa in plura fruftula dividitur; fed'eliguntur frufta extrema, qux in medio funt, tenaciora dicuntur effe, quam ut in aciem converti poffint. Extremæ illæ partes iterum foco \& igni committuntur, fed cavetur, ne in fluidum volumen liquefcant; if hoc fortaffis accidit, fruftra tentatur converfio ejus in chalybem: ideo illi$\mathrm{co}$, ut hoc animadvertitur, fiftitur ventus, ut iterum infpiffari \& lentefcere liquamen poffit; tunc auxilio fcoriarum rurfus liquatur, \& bonæ indolis ferrum reportatur, ficque iterata vice converfionem eandem in chalyberm tentant. Si vero funditur ita, ut non liquide fluat, fed craffefcat, inque moleculas fe dividat, ftatim circumvertitur, ut ab altera parte etiam calefiat, ficque præparatus obtinetur chalybs, fed adhuc tenax, antequam frigida exftinctus fit. Ferrum hujus generis modo etiam communi in chalybem cremari poteft.

Sed quod fornacularum conftructionem attinet, videas Tab. VIII.IX.X. in una tabula videre licet terram hanc martialem nondum calcinatam in A. ftruem feu cumulum minerx calcinatorium in $B$. mineram hujus generis Clafis I. de ferro. 


\section{I4 DE VENA ET FERRO PALUSTRI SVECIÆ.}

calcinatam in $M$. inftrumenta diverfi generis D.E.F.G.H.L.K. Apparet etiam hic ipfa uftrina, qualis ejus facies extrema fit. In altera figura reprefentatur fuprema ora five margo fornaculx in A. B. contignatio, qua circumdata eft fornacula in B. C. F. G. fundus foci in G. G. locus inter contignationem \& murum terra adimpletus medius in CD. muri craffties in $\mathrm{DE}$. aperture fuperioris amplitudo in $\mathrm{EE}$. focus, ubi liquamen ferreum colligitur in $\mathrm{H}$. faxum fundamenti in II. locus pro follibus in KK. orificium fpiritale in L. ubi cavitas fornaculæ incipit, in $M M$. In tertia Tabella apparet fuprema contignatio fornaculx in A. fupremus margo parietis in $\mathrm{B}$. pars ejus infima in D. craffities tignorum in $\mathrm{B}$. C.D.E. craffities muri FG. amplitudo aperture fuperioris GG. focus five catinus $H$. apertura pro emittendis fcoriis I. locus follium in K.K. foramen venti L. bina flabella $M$. vectes five ftateræ quibus flabella moventur in $\mathrm{N}$.

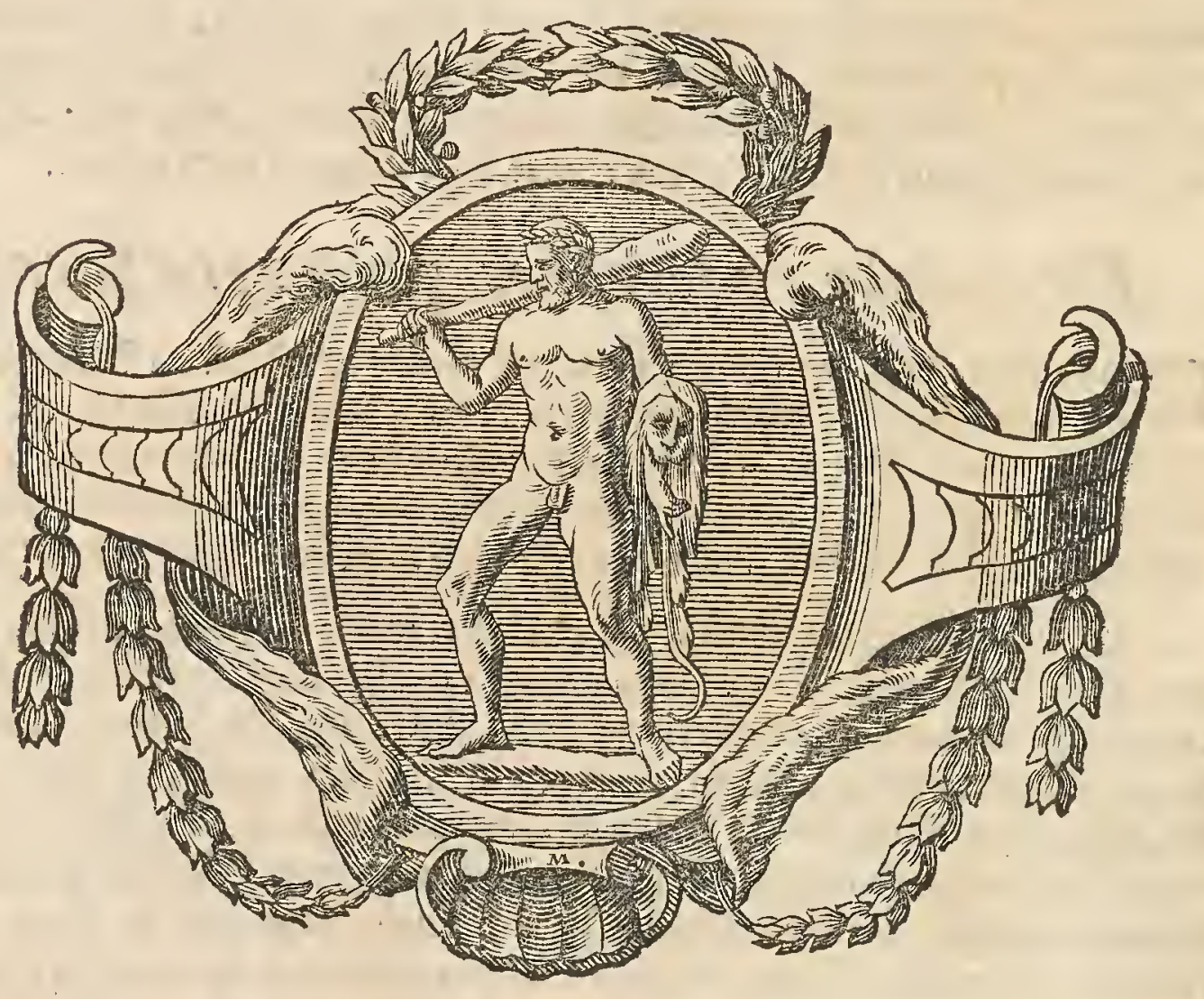






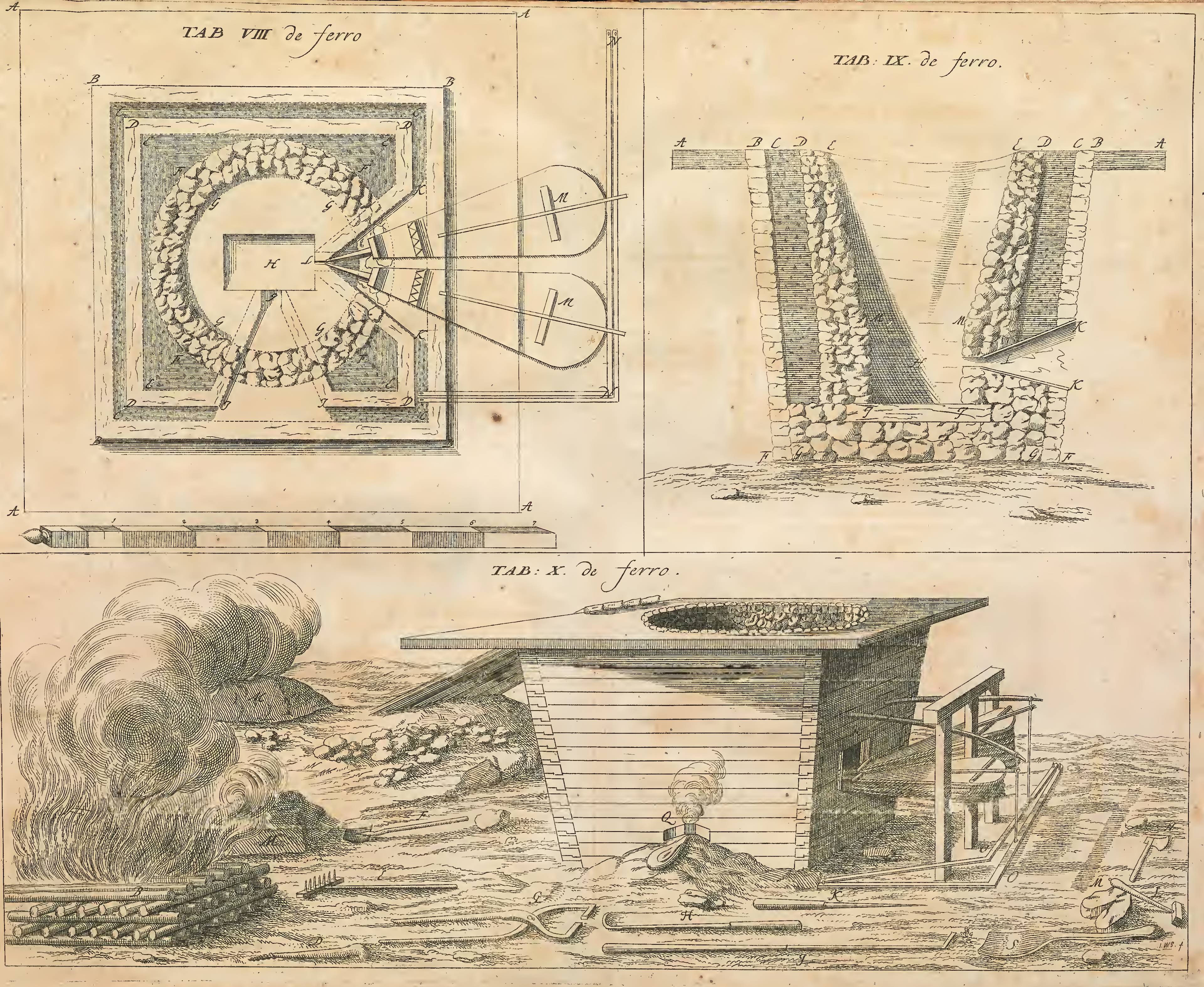





\section{PARAGRAPHUS IV. \\ De vena lacuftri five fuviatili ferri in Svecia, deque ejus coctione in ferrum.}

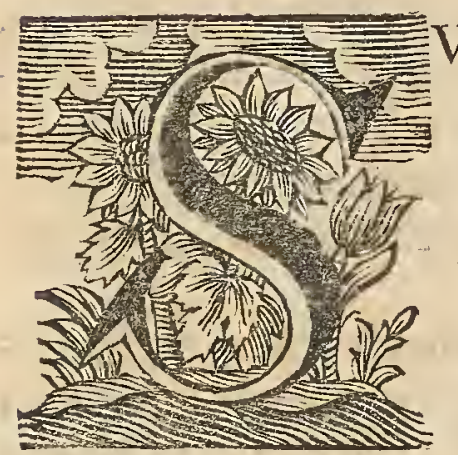

Vecix paffim exantlatur ex ipfis lacubus \& fluviis vena ferri, non multum abfimilis illi, de qua actum eft in Spho priore; \& quia genefin \& natales fuos debere videtur fucco illi paludinofo ferreo, unde etiam con- fpicue admodum aliquibus in locis derivari a palude vicina videtur; hinc proximum ei locum damus. Non folum in Angermannia \& Dalekarlia, five in locis Oftrogothia, qux foli auftrino propiores funt, fundi lacuum ferri folent intumefcere \& imprægnari.

Plura circa hanc ven fpeciem occurrunt notatu digna, ex quibus non modo de conceptione \& productione vena ferrex, fed etiam de ejus maturatione concludi poteft. Ferrum enim fenfim generari videtur in aquis ftagnantibus \& cum humo paluftri commixtis \& quafi fermentatis, precipue cum etiam igni folari \& frigori brumali expofita fint. Sed de his alias,

\section{Vena lacuftris ferri.}

$\checkmark$ Ena hujus generis in Angermannia formx eft rudis \& inxqualis, five inftar fpongiarum, coloris bruni : feparatim inque fuis locis in lacu adinvenitur; habetur etiam in fruftis parvis, fcilicet ad latæ palmæ magnitudinem: five enim eft figuræ planæ, five rotundæ, quamvis rudis; in fractura refert plerumque fpeciem corii lecti, craflitiem etiam ejus xquare folet. Non duritie multa pollet, fed inter digitos quafi friabilis eft. Quod originem ejus attinet, videtur derivari fenfim a palude vicina, unde fe fub 1pecie fucci fubtilioris in aquam exonerat: ex qua caufa non remotius a ripa folet inveniri, quam ad difantiam 18 ulnarum; ibi etiam affigitur laxis \& lapillis fundi : reperiri ideo licet fruftula tali materia confantia cum incluto lapide, vel cujus lateri adhæret lapis. Quumque evacuatur fundus minera, adeo ut nihil amplius refiduum fit, poft elapfum 20 vel 30 annorum fpatium rurfus renafcitur \& colligitur. Hoc etiam genus mineræ quamvis diverfum a priori, nec magnetis vim attractivam fequitur, nifi igni prius fubjectum.

Inops metalli eft minera hæc fluvialis, fed prævia calcinatione optime poteft liquari. Adminiculo cymbarum ex fundo tempore artatis depromitur; inftrumentum prope repræfentatur, cujus ope in fundo lacus colligitur \& elevatur. Bini enim pifcatores mineræ auxilium fibi invicem ferunt, unus demiffo in fundum dicto inftrumento radit ipfum fundum, alter auxilio baculi cujusdam in occurfum inftrumenti hujus \& in finum ejus 
fert, quod continuatur dum repletum fit, elevatur. dein \& in cymbam effunditur. Inftrumentum hoc $(\mathrm{Bm})$ longum $\mathrm{I}_{4}^{\mathrm{T}} \mathrm{ulnam}$, conftat lino craffiori, manubrium $(A B)$ longum eft 5 ulnas. Per unum diem e fundo depromi poffunt 4 tonnæ vel cadi mineræ auxilio 2 virorum: quibusdam in locis fundi rara admodum jacet, in quibusdam ad craffitiem $\frac{3}{4}$ uln $x$, qux etiam maxima craffities vel altitudo effe folet. Inter cannas \& flipulas arundineas reperitur quam maxime, \& videtur radices illarum quafi fequi velle. Lapides, quibus inhærefcit fedimentum hoc ferreum, funt plerumque filicei aut communes coloris grifei ; interdum tam arete adhæret, ut ægre inde divelli poffit, nec nifi per ignis vim. Unde neceffum eft, utcalcinetur; nam multis heterogeneis icatet, quæ inde per calcinationem partim feparanda funt.

Per totam Smalandiam funtlacus, in quorum fundo reperitur fpecies hæc venæ, inde enim exemta in fornaces ferri majores transfertur, \& in ferrum crudum, modo fere vulgari, funditur. In Smalandia \& provinciis ei vicinis, tanta illius copia datur, ut fornaces plures fuforix illa plane poffint fubminiftrari : hic Mars uvidus amat fundos lacuum.

Ipfamet vena diverfiformis eft, vel eft globofa \& figuræ ovalis, vel inæqualiter granulata fabuli inftar ; fed utplurimum accedit particula cujusvis figura ad rotundum, \& xquant grana hordeorum, tritici, aut etiam fabas. In medio aut in fractura funt coloris flavi \& rubiginofi, fed ponde. 're leves; vel etiam circumdantur crufta five cortice leviori, non aliter ac glans five nux avellana, in qua putris nucleus inclufus eft. In perplurimis particulis evolutis \& fractis confpicitur appofitio quædam partium \& convolutio crebra cruftalis. Color in aliquibus magis minufque nigricat, in quibusdam flavefcit, eftque hoc genus melius priori.

Alioquin vena hæc admodum levis eft, nec pondere quodam nec colore indicat metallum aut ferrum in finu : fub ipfa aqua dicitur ponderofior, quod oriri videtur ab aqua finuofas ejus rarasque partes opplente; expulfo vero humore, quod fit vel in aere ventofo vel in fole aprico, redditur fui ponderis \& naturæ. Alias quo levior vena, eo vilior \& minus ferri compos. Quod pondere fuo careat vena, multum etiam ex eo venit, quia textura admodum foluta \& emarcida, inque croci aut ferruginis fpeciem difpanfa effe videtur.

Ubi gaza hæc martialis in fundis lacuum invenitur, altitudo aquxutplurimum 6 pedum effe folet, quamvis etiam fubinde fub majore aut minore alcitudine reperiatur; eftque in certis lacuum locis, amat diftantiam quandam a litoribus \& altitudinem prædictam in alveis, fruftra tamen alibi illam inquires. Quod vel oritur ex palude vicina, ex qua derivatur mineralis vapor, feque in certam abinde diftantiam exonerat; vel materia fundi iftus vaporis amica \& concors cum illa facile fe confociat, non aliter ac magnes cum ferro; ad minimum amare videtur unum magis locum in lacu quam alium.

Obfervatu adhuc dignius eft, quod regeneretur dicta vena, locumque eundem quafi injuffa occupet, quum femel fundus illa evacuatus fit, fed hoc non nifi præterlapfis aliquot annis. Tempus quod intercedit, dum 
renalcitui, non in omnibus lacubus unum idemque eft, intra 10,20 aut 30 nova lemper proles aut feges martialis prodit, redditurque ubere illo fertilis femper campus, non aliter ac ager qui alternis annis femper nova fegete virecit; eftque thelaurus hic perennis \& inexhauftus. Hoc etiam indicat, matricem effe iplam paludem, ex qua continuo in undas fluit luccus in ipla palude exclufus.

Tempore hyemali plerumque expifcatur hac vena, commodiffime tunc glaciei infiftere poffunt; facta enim per glaciem apertura, demittunt bulgam aut fitulam, vel etiam rete quoddan in finum incurvatum, ex conto aut pertica longiore penders, ficque radendo fundum excipitur quicquid obvium eft levaturque commode fic fupra glaciem. Fit idem etiam tempore æeftatis ope cymbarum, prout dictum eit.

Sed quia vena hac diverfi generis eft, unum dives, alterum egenum ferri; unum prabet ferrum vitiofum \& vilifimum, alterum vero bonum \& optatum, hinc fecernendum omnino eft. Pifcatores hujus venævel ex pondere vel ex colore vel ex figura, ftatim fciunt qualitatem, vel etiam ex fignis, qux fuppeditant ipfe aqux, aut qux præbet indicia ipliflima materia fundi.

Alias quia in uno eodemque loco reperiri folet vena nota melioris ut \& vilioris, hinc fatim circa iplam aperturam in glacie vel in cymbis fupra lacum, cum exantlata fit, vilior pars a nobiliore fecernitur; bulga quxdam perforata illa repletur, qux in aquam demerla aliquibus vicibus fuccutitur; quia enim elementum grave motum facilius mover partes ponderofiores quam elementum leve, hinc aqua partem venæ leviorem clevat, nec ita graviorem : hinc per iteratas in aqua fuccufiones, demerfiones \& elevationes vena levior furfum \& fupia ponderoliorem effertur. Pariter etiam fecernitur pars hujus venze levior a ponderola per jastationem ejus contra ventum, non aliter ac hordeum aut fruges in areis a paleis aut avena; vena qux jacta remotius abit, eft ponderola \& melior, quam illa qux vento obniti non valet.

\section{Modus calcinandi venam lacuftrem.}

A Rena hæc mineralis ferrea, quum calcinanda fit, conftruitur cumulus conftans 50 ad 100 carrhis, \& relocatur fuper ftruem quandam ligneam, quxaltitudinis eft I ulnæ, \&longitudinis vel latitudinis $6 \mathrm{vel} 7 \mathrm{ul}-$ narum: peragitur calcinatio fpatio 2 dierum five 48 horarum.

Tandem peracta calcinatione circa confinium ftrati lignei five loco inferiori coalefcere videtur in maflas, quod fignum calcinationis debitro effe lolet. Fluit etiam vena fic calcinata melius in fornace.

\section{Modus fundendi vonam lacuftrem.}

Tlekarlix \& Angermannix funditnr hac vena in uftrinis non aliter ac paludinofa. Alibi vero in focis ferrariis in genus quoddam ferri crudi quod Osmund vocatur. Sed in Smalandia in formacibus magnis \& alClaljis do de ferro.

$\mathrm{Gg}$ cioribus, 


\section{8 DE VENA ET FERRO LACUSTRI SVECIAE.}

tioribus, qux illis fimiles funt, de quibus in \$pho ima aetum eft. Alritudo fornacis 24 ad 26 pedum effe folet, diameter ejus fuperior $4 \frac{1}{2}$ pedum, inferior 5 vel 6; venter amplitudine latis multa gaudet, ufque tamen poft liquefactionem non apparet exefus, quod fignum eft, mineram non effe admodum fulphuream. Focus conftruitur ex faxo arenario unum pedem craflo.

Octo primis diebus, in quibusdam locis, ardent fine vento carbones, \& interea quotidie imponuntur I vel 2 menfur: aut vafa mineræ dictæ. Quo tempore præterlapfo, moventur folles \& admittitur flamen. Diebus fequentibus augentur vices impolitionum ad 6, 7, 8 intra fpatium 24 horarum, fed dein poft 10 vel 12 dies, ad i 2 vel I 3 vices intraidem tempus, five femel tempore quovis bihorii. Sedquia vena hxc ferriegena eft, non multum ferri inde obtinetur. Alias eodem modo peragitur hic fuloria opera, prout in fornacibus, quarum jamdum in 5 pho $\mathrm{Ima}$ dedimus defcriptionem.

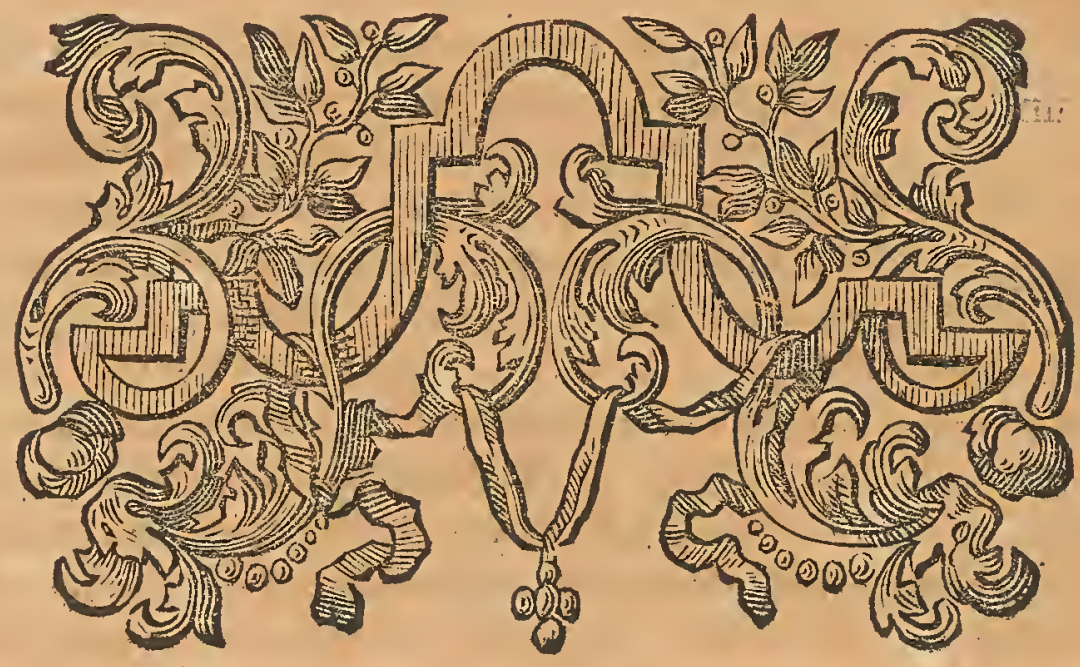




\section{PARAGRAPHUS V.}

\section{De ferro Svecano Osmund vocato, deque ejus preparatione Svecia.}

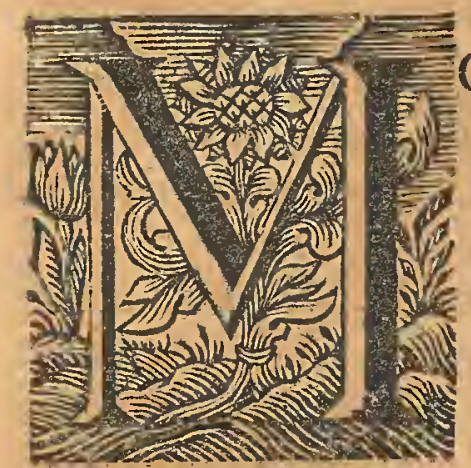

Odum parandi ferrum Osmundicum Svecix, tradidit genuine Dominus Petrus Saxholm Svecus, hinc etiam defcriptionem ejus huc qua partem tranfcribere volui.

\section{Hujus ferri modus coquendi an- tiquior.}

Uantum ex veterum monumentis, virorumque fide digniffimorum relationibus hujus rei veritatem elicere licuit : omnium primo, quando hæc ferri fpecies vigere inciperet, fuit illud ex glarea vel cœerulea vel rubicunda aliave fimili materia e paludibus \& locis tefquis eruta, conflatum. Quum primum rudis illa congeries foli vel igni fuiffet tamdiu expofita, ut vapores craffiores humidi potuiffent exhalare; femel, iterum bis, ter vel quater batillo in fornaces, quas ad ipfum terræ orificium exftructas carbonibus impleverant, quo liquefieret, immittebatur. Erat autem ipfa fornacis ejufcemodi ftructura, ut a tergo feu parte poiteriore prope terram minori quodam ore ad interiora panderet aditum, cuiflabella, opera humana mota, adhibebantur. Antiquis enim temporibus ufus machinarum hydraulicarum plane erat ignotus. A frontificicio major erat apertura, qux tamen, quamdiu ipfa perficiebatur coetio, lapidibus apte implentibus fuie occlufa, donec glarea probe diffoluta liquefceret; tunc autem exemtis lapidibus, ipfa maffa, qualis confluxerat, extrahebatur. Ut autem, fi qux refidux erant, impuriores adeoque inutiles particulæ fortiori Vulcani minifterio expellerentur, alteri coctioni eadem deftinabatur quantulacunque moles. Illa autem concoctio, eodem, quo prior, modo perficiebatur, hoc tantum difcrimine, ut eam a fe Vulcanus multo tum puriorem demitteret; quippe qux fine ulteriori preparatione, variis utenfilibus fabricandis maxime erat idonea. Binis vel ternis ejusmodi coctionibus perficiendis, tnus dies \& nox fufficiebat.

\section{Recentior ferrum Osmund percoquendi ratio.}

SUccedente modo tempore, quum uberiores hujus metalli aperirenturveS nx, ufufque machinarum hydraulicarum paullatim innotefceret, ad rivulos \& amnes officinas ferrarias minutas pari fere ratione, qua jam excitatæ conficiuntur uftrinæ, ædificarunt: in illis autem, quemadmodum in hifce hoc tempore fieri confuevit, e metallis contritis atque fubactis ferrum crudum conflatum eft. Qux vero ex hac coctione maffa prodibat, non, ut poftulabat modus coquendi antiquior, \& fupra commemoratum eft, eidem eft denuo fornaci immiffa; verum altera ejus concoctio foco fa-

brica 
bricx elaboratorix fuit concredita : in quo cum ferrum rite effet fufum, adeo erat purgatum \& emollitum, ut manibus artificis, quodcunque fua induftria expofceret, obfequium præltaret. Utut vero fuerit hrec a fuperiori diverfa fundendi ratio, nihilominus tamen antiquitus fibi inditum nomen ipla conco tio retinuit \& Osmundsjern cognominatum fuit. Quod vero de ferri fufionibus in genere adpofite admodum dicitur, id fine dubio de noftro quoque obfervandun venit, fuccedente feilicet tempore majus majufque fientiz huic incrementum acceflit faciliorque evafit, quod \& hodie cognofcere licet corum induftria, qui his negotiis animum adplicuere,

\section{Struit fabricam modo coctionis novilfimo accom. modatam.}

TOc vero tempore, qux huic ferro coquendofabricx erant aptæ, plu1 rima cum aliis officinis ferrar is communia habent, in nonnullis tantum $\mathrm{ab}$ is difcrepant, quæ tanquam fibi propria vindicare queant. Quæ nbique funt obvia, obiter tantum \& quafi per tranfennam, confpicabimur. Structura fabricx hujusfcemodi interior cum aliis officinis, in quibus ferrum crudum malleorum ope diducitur, coincidit. Ex tignis enim longioribus, figura quadrangulata, adiculam exftutunt: eaque ubi ad pedem testi opus perductum eft, tribus potiffimam contignationibus folet jungi. Medis vero vices interdum fupplet tignum transverfarium magnum; cui fulcra innixa ad ipfum tectum fuftentandum fuam accomimodant operam. Tignum transverfarium minus, cui fuperimponuntur vel etiam fubjunguntur tollones, folles, follium fedile, trunculi, tigilla quorum ope folles deprimuntur; ftipites horum tigillorum quafi directores; ab utraque parte ne ulterius, quam e re eft, divagentur, cohibentes, cum trabes axi infixx deprimunt folles; ceteraque ejusmodi non tantum ad noftram fpectant fabricam, fed in alisis etian officinis eccurrunt. De rota aquatili, ejus axe, nec non de canteriis, \& qui illis imponuntur afferes, ut tollonibus in follium fublevatione moderanda normam præfcribant, iden efto judicium. Iplum vero focum feu fornacem liquefactoriam quod concentit, ea, quam noftre fecimus confiderationis, fabrica ab aliis diffentit; ut \& quoad pleraque inftrumenta fabrilia, qux heic non eodem, quo alibi modo efformata deprehendimus. Ad ipfum itaque focum accuratius perluftrandum primo nos convertimus. Quando fundamentum iplius muri, quantus quantus in hifce fabricis comparet, ponunt, magni congefti lapides nativi rudes apte difiponuntur, iplumque opus glarea \& terra interiora, \& qua inter lapidum angulos vacua relinquntur, occupantibus, ad id primum perducitur faftigii, uti de loco, in quo concoetio perficietur, tempus fit cogitandi; quum eo usque perventum eft, ab co latere, ubi operarii carbo. nes immittent, ferrum coquendum Vulcano tradent, coctumque extrahent magna eft apertura relinquenda. Ab ea vero parte, quæ follibus obvertitur, requiritur minus quoddam quadrangulatum orificium, per quod lamina ferrea complicata, fiftulas follium fpirales fibi infertas habens in ipfum focum immittitur. Ulterius, relicto jufte dimenfonis fpatio, quod ipfe 


\section{DE FERRO OSMUND SVECI 压}

coctionis locus occupabit, nec non intra aptos limites cohibita ea muri parte, qux focum a duobus lateribus ambit. Muri lapidei parietes exteriores fux altitudiniadferuntur: eo quidem pacto, ut quando ad aperturæ majoris, quam fupra nominavimus, fupremam partem pertigerint, ut lamina ferrea fuftentatoria imponenda fit. Quo altius deinde opus exfurgit, eo etiam arctius atque anguftius, inftar metæ reddatur. Nunc ad interiora ipfius foci confideranda properemus. Omnium primo fundiloco lamina quædam interdum lapidea, interdum ferrea fubfternitur, quæ duos eft craffa digitos, octodecim vero ab omnibus lateribus lata. Ponunt etiam nonnunquam minorem, ubi follium languidiores flatus majori perficiendx coctioni impares exiftimantur. Quod autem hujus laminæ materiam fpectat, ficut lapideam minoribus obnoxiam effe incommodis indubium eft, ita ejus quoque ufum præ ferrea frequentiorem novimus. Subftrata fic prima illa lamina, a lateribus tres aliæ non nifi ferreæ eriguntur, quæ inftar parietum foci funt atque videntur. Eft eadem harum ac primæ illius crasfitudo, decem vero digitos earum altitudo plerumque complectitur. Harum vero ẹ eft ftatuendarum ratio, ut eam quam ad latus follibus proximum collocamus, mediam tranfeat lamina illa complicata, ut ab utraque illius parietis parte, tam ab ea quæad parietem interiorem tendit, quam ab altera, quæ foci frontifpicium fpectat, octo numerentur digiti. Ipfe quidem focus exacte quadrangularis eft, verum quandoquidem laminarum illarum, quæ parietum vices fuftinent, duæ ipfius foci terminos tranfcendunt, aliisque muniis inferviunt, hinc earum longitudinis nonnulla oritur varietas. Illa fcilicet lamina, quæ follium flatibus e diametro opponitur, unum cubitum longitudine adimplet. Alter paries tres quartas partes ulnæ continet. Tertius vero vocatus Formweggen, ulnam cum dimidia ejus parte complectitur. Ratio, cur primus \& tertius fecundurm longitudine fuperet, hæc eft, quod hi duo majores, poftquam ipfius focilimites fupergreffi funt, laminæ cuidam, quæ quarto foci lateri, a frontifpicio aperto, fuperimpofita eft, fuftentandx inferviunt. Per hoc latus apertum via fcoriis emanaturis paratur, quæ inter fabros Slaggboblet \& Lacktboblet cluit. Sic rite ftuctis parietibus, in conftituenda lamina illa ferrea complicata, quæ a parte inferiore plana eft. A dorfo vero \& lateribus rotunditatem æmulatur, fumma opus eft circumfpectione. Ab ea parte, ubi primum intromittuntur fifulæ fpirales follium, amplior eft ejus apertura; dein vero quo propius ad extremum ejus orificium defcenditur, per quod flatus in focum erumpent, eo magis tanquam infundibulum quoddam, fua latera coarctat. Jufta autem ejus conftitutio hoc modo perficitur. Per parietem follibus proximum in ipfum focum palmum intromittitur, ita ut intervallum, quod oris illius laminæ extremitatem \& parietem ex adverfo oppofitum intercedit, I4 digitorum longitudini refpondeat. Præterea circa hanc laminam notandum, quod ejus os interdum deprimatur, interdum elevetur, fic verbi gratia, quando ferrum hujus fpeciei divifum in fornace fundetur, os laminæ extremum a fundo foci 6 tantum digitos fublevatum eft. Quando deterioris fortis feu non divifum hujus generis ferrum conficiendum eft, ficut major eft moles quæ diffolvetur, \& flatus e loco fublimiori, ob exClallis I. de ferro. 
ftantiorem fubftratam materiam immitti debet, ita etiam elevatio lamina complicatæ feptem digitorum fpatium requirit.

\section{Enumerat inftrumenta in bac officina ne- celfaria.}

Q Uandoquidem jam focum probe inftruximus, videatur'Tab.XI. \& follibus, quxque eos commoveri faciet, machina aquatica fabricam noftram ornavimus, injectis ftatim carbonibus in fornacem, atque ferro quod in Osmund mutabitur, Vulcano commiffo; qui fuccederet ipfa concoctio, experiri luberet, nifi operariis noftris ulterius profpiciendum foret, inftrumenta parando idonea. Prout itaque nobis quodque obvenerit; accuratiori nos ordini non adftringentes, inftrumenta recenfebimus. Inter reliqua confpicuum, admodum truncum craffiorem altum humi defixum putaverim, qui repræfentatur in delineationem fub numero (a); cui lamina ferrea numero (b) eft impofita, quam interdum rotundam, interdum quadrangulatam, fexangulatam aut etiam oetangulatam confpicere licet: $\mathrm{Hu}$ jus margines eum in locum elevatæe funt, ut ne particulæ, qquxinter tundendum vel fecandum e ferro Osmund deterunt, decidant \& perdantur. Centrum vero ejus eft perforatum, cui foramini apertura quxdam, quæ in fubjecto trunco hifcit, exquifite refpondet, ubi-ipfa incus poftmodum defigitur. 'Duos præterea obfervamus contos, quorum major Lettpett Fig. (c) minor Loppspett, Fig. (l) nuncupari folet. Forcipes quoque heic comparent totidem, alteram quæ magnitudine fuperat, Lopptong Fig. (e) alteram vero minorem Holltong Fig. (f) appellant. Porro fecuris Fig. (g) fingulari modo formata, ut \& clava ferrea Fig. (h) in hac officina requiruntur. Tum malleolus quidam dictus Kotthammar, a duobus lateribusfere complanatus, cetera rotundus; ut $\&$ uncus ferreus, (e) heic adeffe debent. Ulterius habebitur quoque ligo, quo ferrum minutum feu contufum in focum immittere, \& poft peractam concoctionem eodem ligone ferrum durum pulveremque carbonarium e foco extrahere confuefcunt opifices. Siftitur jam contemplandum pilum quoddam, quod carbonarium dicas, quia carbonibus igni vel adaptandis vel $\mathrm{ab}$ eo removendis infervit Fig. (k). Alterum rotundum Fig. (d). cujus eft officium purgare laminam illam complicatam, quo flatibus fiftularum follium fui meatus plane liberi relinquantur. Denique \& nominandus eft malleolus quidam dietus Stockbanmar Fig. (m), quo cum fcoria a lamina complicata removetur, pangere folent. Pilam non prætereo aquariam (n), \& urnain (o), qux illi adimplendæ fervit; nec non vas carbonarium cum occa (Harkan) Fig. (p). Ceteris tamen ejufcemodi minoris cenfus inftrumentis omilfis, ne fi talia recenferentur, quod narratur, omnibus \& lippis notum \& tonforibus effe, merito quis dicat. 


\section{TAB: XI. de Ferro.}

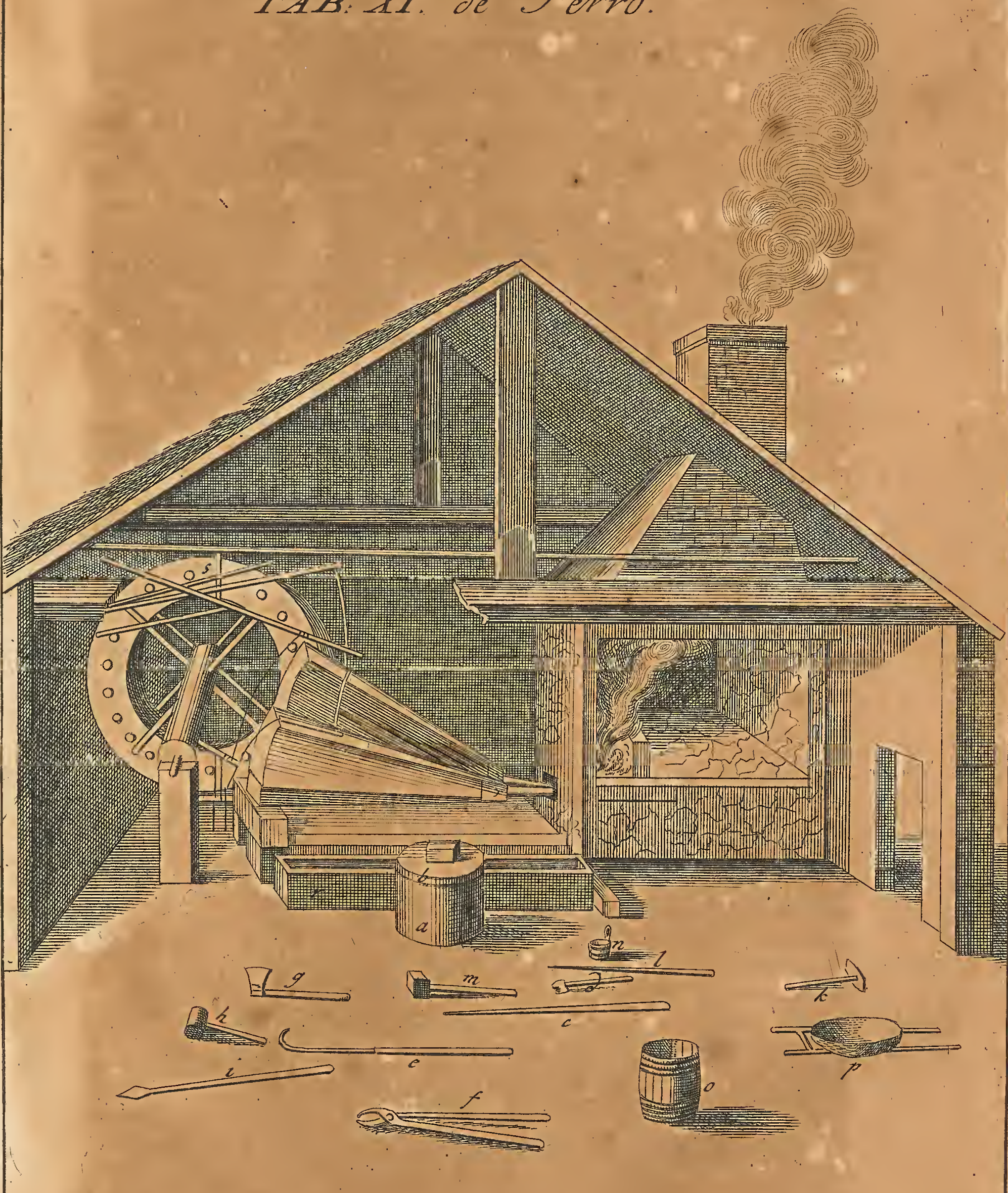


i

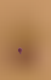

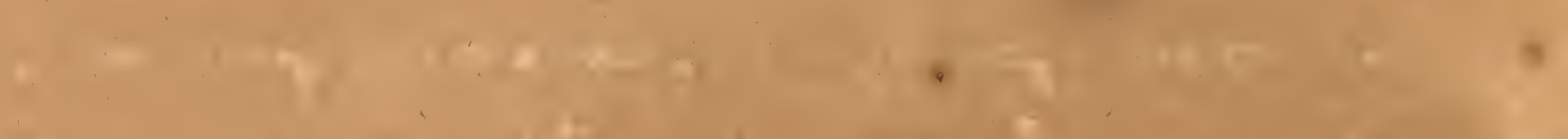

,

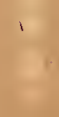

4

a.

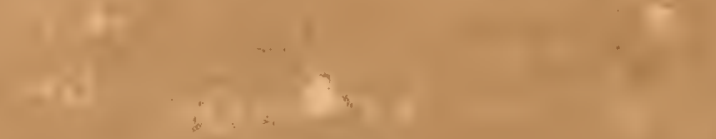

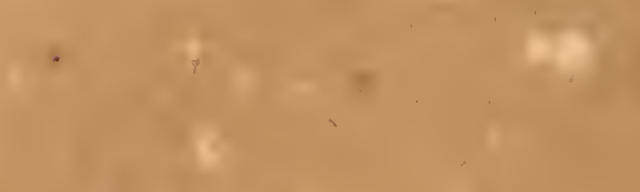

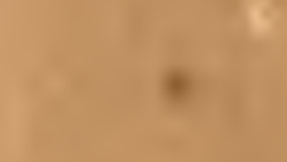

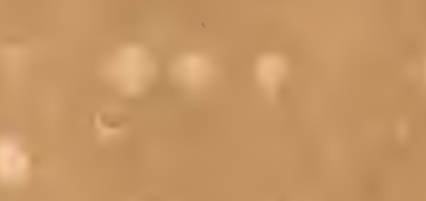

B

$e^{2}+2+4$

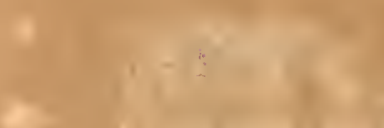

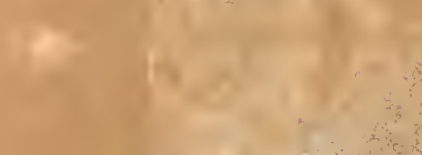

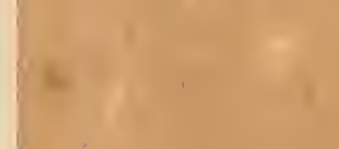

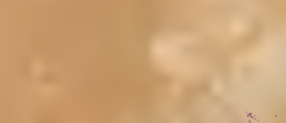

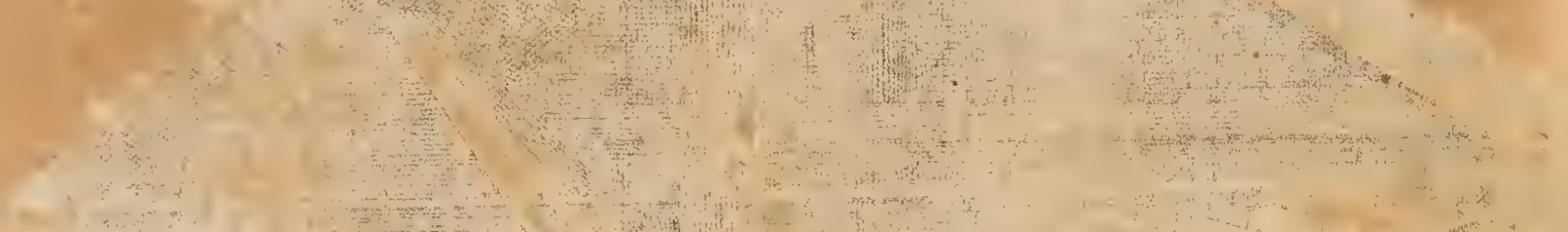

1

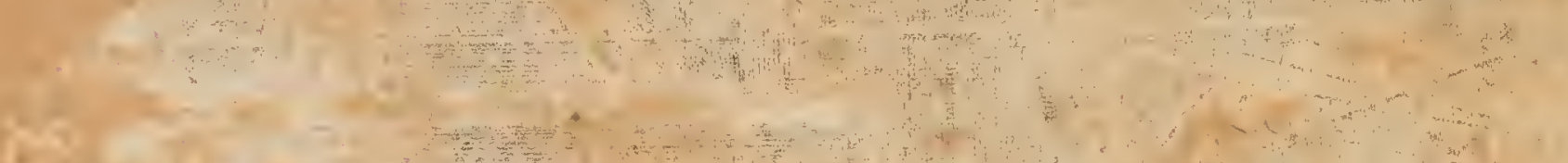

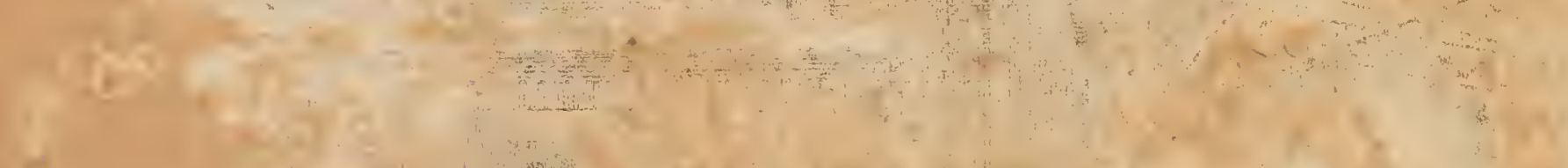

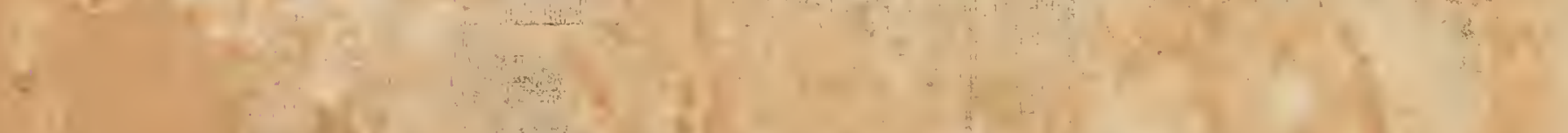

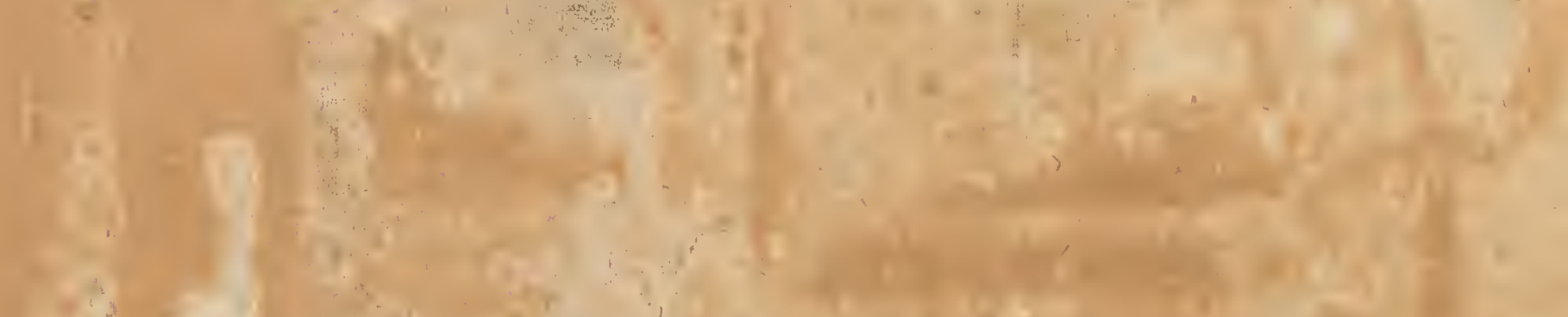
Q.

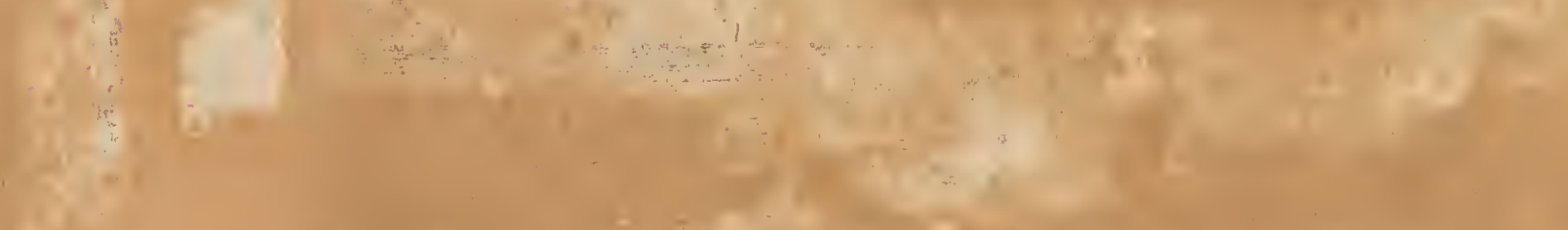
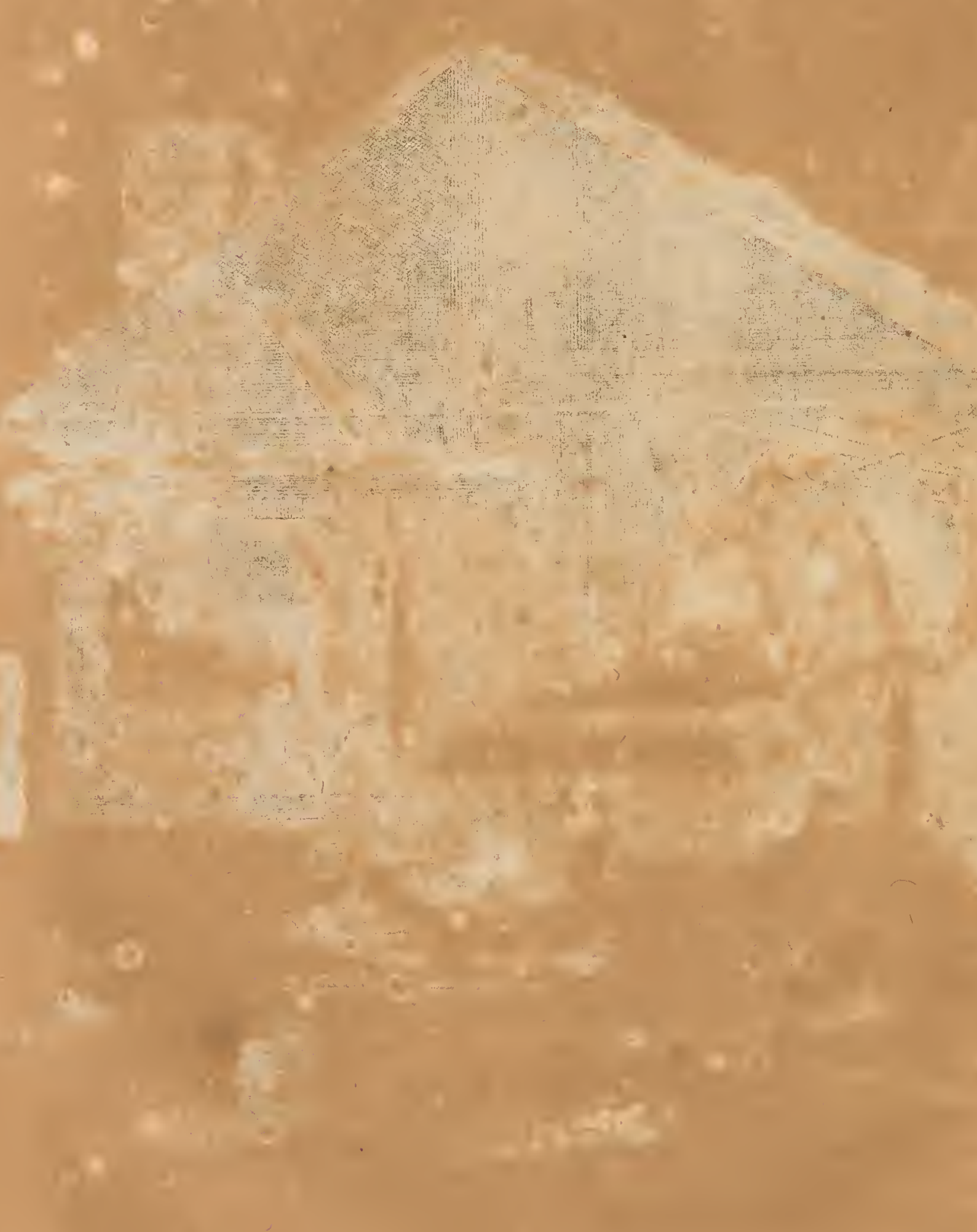


\section{DE FERRO OSMUND SVECIÆ. \\ Ratio bujus ferri coquendi novifjma, $0^{\circ}$ boc tempore ufitata.}

$\mathrm{Q}$ Joniam nunc inftrumentis etiam neceffariis operarii noftri inftructi funt, nihil ulterius impedit, quo minus focum carbonibus, pulvere carbonario, vel ut alii, carbonibus contufis ac ferro duro, vel fi hoc defit ferro minuto impleamus, aut etiam contulo, eamque maffam, ex qua osmund conficitur, apponamus parieti priori, qui flatibus fiftularum fpiralium maxime obvertitur. Porro adhibito carbonibus igne, \& quo fuam commodent operam folles, fublato repagulo, quod aquam cohibet, per canalem illa in rotam immittatur, five in partem ejus incidat fuperiorem, five in mediam, feu denique inferiorem: dum fic moventur rota atque folles, ut quaffante aere excitetur ignis, hic poftmodum ita ferrum lambit, ut fudet illud fenfim ac diffolvatur. Guttæ autem dimanantes, quæ inferiora fornacis petunt, ibi etiam coagulantur, \& quoniam ulterius non ferit ignis tam vehemens, etiam denfantur. Illa decidentium particularum coagulatio dedit operariis noftris occafionem, maffam illam, qux ad imum fornacis ita confluxit, Loppa nuncupandi. Habilem vero quandocunque coagulatam effe molem fulpicantur, unco illa dignofcitur ; fique prolperé ceffit, contis effringitur, forcipe eximitur : e foco vero extractam laminæ, qux incudem ambit, imponunt, ibique clava ferrea, quo formam, quam cupiunt, nancifcatur, pulfant. Succedit malleolus raior, cujus ope abraduntur fcorix. Forcipe dein tollitur, \& fi apta judicatur, incudi impofitam fecuri in certas partes diffecant num. 42. ita tamen ut fingule partes fupernæ, non fecus ac digiti manui confpiciuntur inférti, cohæreant : quo facto $W$ ald Osmund, Gran Oßsmund appellatur. Si vero tantx fuerit magnitudinis maffa coagulata, ut fecuris ope commode in debitas partes dividi nequeat, fed integra fit relinquenda, nomen a coagulatione impofitum neque poftea refpuit. Quod ad materiam, ex qua hæc ferri lpecies noftra xtate conficitur, neque ferrum quod frigidum facile rumpitur, nequeillud quod ignitum fragile eft, idoneum cenfetur; fed melioris erit indolis, quod ejus productioni deftinabitur. Quantitatem quod fpectat, ut tantus prodeat ferri divifi proventus, quantus uni vafi complendo fufficiat, unum pondus nauticum ferri crudi, fpectati valoris requiritur, aut etiam triginta pondera minora ferri minuti leu contufi, ejus vicem fupplebunt. Carbonum, qui dum coctio perficitur, ignem alent, una crates infumitur. Quum vero vas ferri non divifi parabitur ex reliquiis, quæ dum ab opere faciundo ceffatur, in uftrinis remanent, tum \& ferri \& carbonum major erit copia. Quo rite peragatur coctio, incumbit operariis, dum ferrum funditur, tam infra quam fupra laminam contis effringere, ne quid fundo adhæreat. 'Siquidem vero in ipfius coctionis explanatione occupati fumus, nonnulla etiam de ipfis operariis addere lubet. Eft itaque hoc imprimis notandum: in officinis, quæ huic ferri fpeciei præfertim accommodatæ funt, nullos certos conftitutos effe fabros ferrarios, qui hanc fundendi artem quafi profiteantur, \& fuam collocent operam iis in locis, ubi merce- 


\section{DE FERRO OSMUND SVECIÆ.}

dis uberioris fpem fovent; quemadmodum faciunt malleatores; verum hifce fabricis ipfi plerumque poffeffores prefunt, nifi ii fint, quorum honos \& dignitas aliorum circa hoc negotium uti jubet minifterio. Proinde neque in hifce fabricis opus eft coadjutoribus feu vicariis, qui alternis vicibus curam gerant ferri coquendi; fingulis enim diebus horis vefpertinis curfus machinarum fiftitur, ardorque fornacis fopitur, tempore vero matutino opus iterum, fi ferat \& poftulet occafio, aggrediuntur, neque enim per totum annum huic labori incumbunt; fed certis ejus temporibus, prout vifum fuerit. Quando autem huic operi manus ferio admovent, fi profpere omnia cedant, unus faber cum fuo tirone qualibet feptimana tantam procudit hujus ferri copiam, quantam i i vel 12 vafa capere poffint. Alias ferrum hoc per totum regnum ad fabricatores divenditur, qui exinde clavos, foleas, catenas, feras, claves, cardines fabricant, aliasque ferramentorum minutiffimorum fpecies, qux tamen eximii funt ufus, ideoque paffim venales proftant. Ferrum noftræ fpeciei indivifum officinarum ferrariarum poffefforibus maximam partem cedit, qui in fabricis fuis in laminas illud diducendum curant; quod fieri confuevit in officinis quibusdam parochiæ Norenfis. Ex illis autem laminis varia deinde conficiuntur utenfilia, ut laminæ portarum, tectorum, thoracium, frictoriorum, focorum, nec non efculentorum vafcula, ur catini, orbes, cochlearia, crateræ \& hujusmodi plura, quæ ufíbus quotidianis inferviunt.

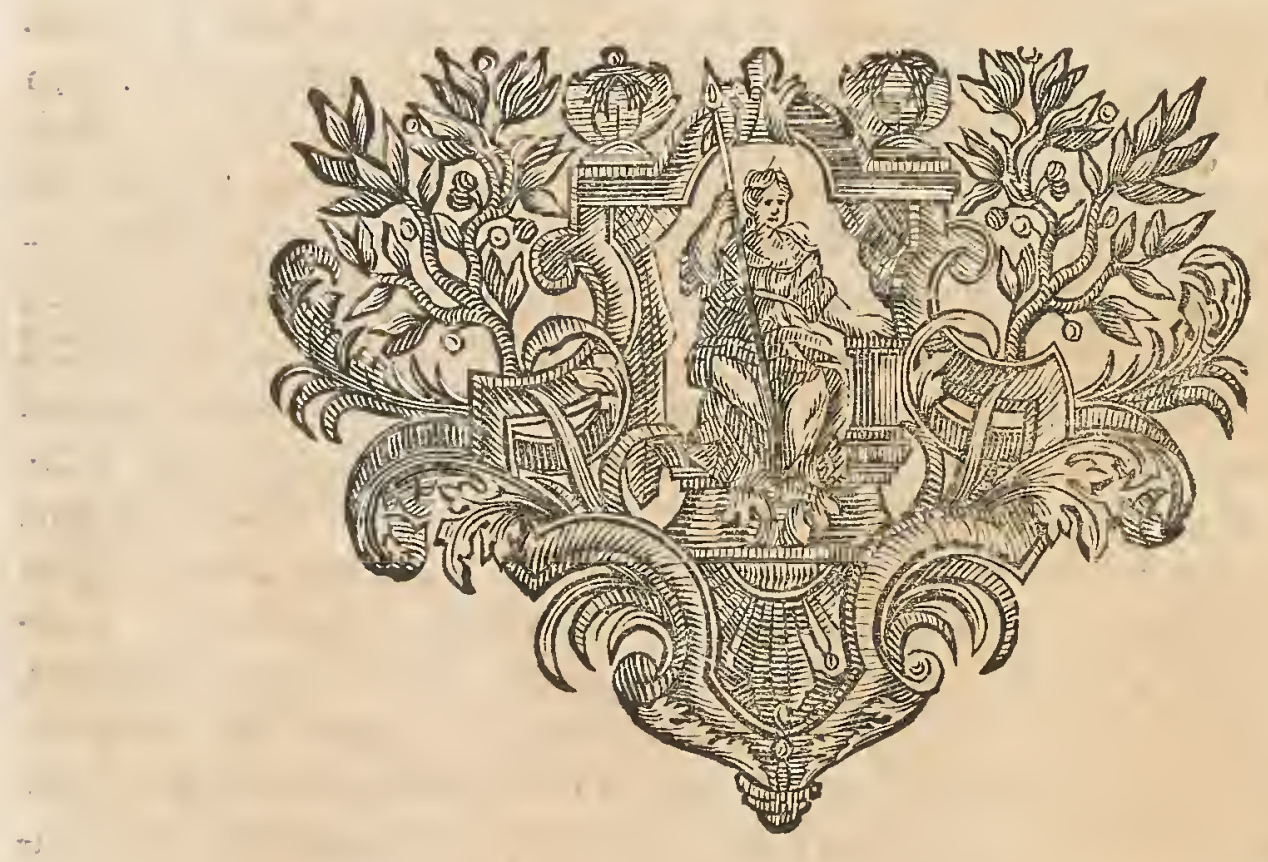

PARA. 


\section{PARAGRAPHUS VI.}

\section{Modus adurendi, liquandi, coquendique venam ferri Danmorien em in Roslagia Srecia.}

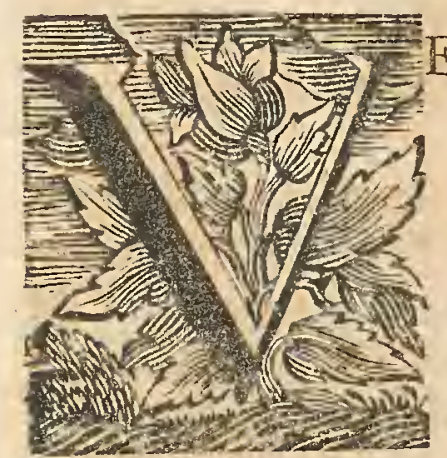

Ena eruitur ex fodinis Danmorienfibus, prout vocantur, \& quidem ejus tam uber eft proventus, ut plurimis fornacibus quotannis fufficiat. Ipfa vena praftantifima eft, cui plurimorum locorum alia tam propter puritatem quam opulentiam concedit; adeo ut ab illa. nulla alia prior \& ufibus convenientior effe putetur : calide enim tenaciffimum eft ut \& frigide ferrum inde elicitum, \& utenfilibus diverfi generis accommodatiffimum, \& in aciem fubtilem \& fabricis exactioris lim 2 convenientem converti potelt: Ideo etiam in Europa \& Indiis defideratiffimum, \& reliquis fpeciebus ferri charius divenditur. Ipfum ferrum tanquam filis aut lamellis complicatis per totam compagem contextum apparet.

Vena eft ponderofiflima, coloris ferrei \& lividi, ipfumque fuum ferrum refert ; conftat granis minutis \& fubtiliffimis chalybis inftar ; led hic \& inde ftriatim intertexta filis lapidis calcarii \& quartzii fubtilifimis, qux fanguinis \& arteriarum inftar omnem ejus compagem ftriis decuffatim currentibus transmeant, \& lineis \& fibris ita grana pure ferrea interftinguunt \& ligant, ut livorem \& albedinem quandam inducant, coloremque ferreum nigrum cum albo temperent, unde etiam fluidifima eft, nam fecum fert menftruum fuum \& lapidem folventem.

Frufta hujus venæ fuperficietenus nigriora \& lubrica quafi funt \& obducuntur quafi membranula, qua conftat lapide comeo ; vidi etiam fragmenta extrinfecus amiantho viridi inveftita, \& fecundum plana regularicer divifibilia, nam genus hujus mineræ optimum quafi teffellatum eft, five in teffellas rhomboidales quafi fiffle. In fodinis vicinis, Silfwerbergs Grufwor appellatis, eft idem genus venæ, quod in fodina magna, quæ vocatur Stor grufwan, fed viridefcit magis, \& aliquali fulphure pollet. Non procula vicinia harum fodinarum, pluribus retro annis, inventa fuit fodina alicujus argenti potens ; pariter etiam hic \& inde nuclei \& glandulæ venæ argentex in ipfo venæ ferrex finu paffim confpicux fact funt, fed tamen rara eft proles, quia matre nobilior. Nec procul abinde fodina vetus, hodie vero antiquata vifitur, quæ puteus fulphureus vocatur; omnis enim lapis inde olim eductus in pulverem vifus eft fatifcere, fcilicet propter ei inhærentem copiam fulphuris. Optimum venx hujus genus fuppeditat $\frac{2}{3}$ partes ferri, five 66 th. ex centumpondio, ita ferax ferri eft, adeo ut tam quantitate ferri quam etiam qualitate multis anteferenda fit.

Quod autem tractationes \& modos calcinationis \& liquationis hujus venæ attinet, multa habet communia \& affinia cum liquationibus venæ vulgaris, de qua jamdum multa dicta funt; fed quia in aliquibus etiam differt Clatis 1. de ferro. 


\section{DE FERRO ROSLAGIENSI SVECIZE.}

2 venarum vulgarium liquationibus, \& fimul quia optimum \& fluidifimum eft venæ genus, nec vitiis inquinatum, hinc operæ pretium effe duxi, proceffum liquationis ejus tradere, fed illa tantum adducendo; in quibus differre videatur a methodo communi jamdum tradita; ut inde dijudicari poffit, quomodo fe in fornace \& in foco gerat vena ferri fluidifima, \& labis aut vitiorum immunis.

\section{Modus venam Danmorienfem calcinandi.}

$\mathrm{V}^{\mathrm{E}}$ Ena quamvis noxio fulphure non polluta, tamen igni calcinatorio fubjicitur; \& fortiori quin cumuli aut pyræ celfiores \& capaciores minetxe exftruuntur; quo enim major ftrues \& coacervatio, eo fortior pervadit venam ignis. Sed tamen non certa dimenfio cumuli aut fovex, ubi cremationi defignatur vena, ubivis obfervatur, hic major, hic vero minor: circa Loefftadium vidi aream iftius fovex longitudinem 22 ulnarum xquare, latitudinem 17 \& 18 ; fed 'murum, quo cingitur aut includitur area fover, effe modo $x_{\frac{1}{2}}$ ulnam altum; circa unum parietis angulum datam effe aperturam, per quam intrare \& exire liceat.

Supra totam hanc fovex calcinatorix (qux Svecice Roffgrop vocatur) aream fubfternuntur ligna craffiora \& trabes, \& quidem fecundum longitudinem fover, \& ad altitudinem 3 vel $3 \frac{1}{2}$ ulnartum, adeo ut ordo arborum, vel lignorum $x_{4}^{\frac{1}{4}}$ ulne alcitudine exfuperet murum: infino loco vel fundo arex proximo fubmittuntur trabes non fectx, cui fuperinjicitur vena grandiufcula nec comminuta, ad altitudinem $\mathrm{I}_{4}^{1}$ ulnx; fuccedit dein alter ordo, relocantur fcilicet ligna feeta fuper venam, \& infuper vena minutior ad altitudinem debitam; ultimo contegitur cumulus pulvere carbonario cum alio pulvere commixto.

- Tgne ad angulos fuppofito \& accenfa pyra, ardet cálcinaturque fic vena fpatio 2 vel 3 dierum \& noctium.

Arbitrari quidam poterunt, non omnem venam ferri calcinatorio igni fubjiciendam effe, \& ignis exfortem fore illam, qux non multo fulphure aut aliis vitiis inquinata fit ; ufque tamen Danmorienfis vena calcinanda eft, quamvis labis velut infons fit, nec nimio nec exiguo fulphure gaudeat: nifi enim calcinetur, xgerrime dicunt liquari poffe in fornace, minorem. ferri copiam fuppeti, fi incalcinataliquationem fubeat. Ipfa cnim fibrarum compages \& venarum contextus igne leniori folvitur, \& paratior aptiorque redditur fubeundi ignem fuforium majorem.

Si frufta venæ hujus calcinatæ penitus infpicias, animadvertes læum \& vegetum nitorem ejus rapuifie igrem : ubicunque nitor prius emicuit, dein fucceffife videtur hebes \& evanida quadam albefcentia, ex illo oriunda, quod lapis calcarius, quo intertexta eft vena, in calcem redactus, rivulos \& fibrillas fuas magis per totum venæ corpus diffuderit, ficquenitorem metallicum \& floridum exftinxerit \& hebetaverit. Quædam etiam frufta membranula quadam cornea obducta effe dicebantur; peracta calcinatione, ubi vena apparct membrana dicta inveftita, ibi hepathici coloris eft, ut \& flave rubefcit. Si humectetur vena calcinata, variegat color in coeruleum, viridem 
viridem \& purpureum, luditque quafi æmula cum iride: nam varietas hæc colorum apparet in circulos æquales \& lineas æque a fuperficie ejus dittantes quafi diftineta, oriunda ex gradu majori minorive caloris. Membranula certis in locis victriolo quafi albo ftrata \& obdueta videtur, fed modo calcarius pulvis eft; hinc etiam infipidus,

\section{Modus conftruendi fornacem \& formandi cavi tatem ventris.}

Ocus convenientifimus pro contructione fornacis hic ut alibi eligitur;

fub fundamento paratur fofla vel cellula quxdam ad latitudinem $\frac{1}{2}, \frac{2}{3}$ \& I pedis circiter: fupra quarn relocatur faxum craffiufculum, aliis vero in locis lamina crafla ferri, de qua in Spho I ma. Arena circum hochaxum infternitur, \& fuper arenam lamina craffa faxea ponitur more etiam alibi confueto. Ex foffa exeunt bini fiphones ex ferro, unus per ipfum murum anteriorem, five ubi emiffiones peraguntur, alter fub flabellis: $\mathrm{Va}$ por ex dietis fiftulis exhalat calidus non nifi quarto die ab incepta fufione; ex fiftula vero fub follibus relocata poftea prodit. Ipla fornax confiruitur dein ex puro lapide grifeo communi, cum fulcris vel columnis pure faxeis, nec ullibi intertexitur tignis, ut alibi mos eft. Altitudo interioris cavitatis five camini fornacis a fundo foci eft $\mathrm{I} 2$ vel $\mathrm{x} 2 \frac{\mathrm{r}}{2}$ ulnarum; conftruiturque caminus ex faxo arenario: ipfe catinus vel focus etiam eodem genere faxi, quia igni multum refiftit. Diameter cavitatis circa aperturam fuperiorem eft 6 vel $6 \frac{\mathrm{T}}{\mathrm{q}}$ pedum, ventris $7 \frac{\mathrm{r}}{2}$ ad 8 pedum; diameter partis inferioris fecundum libitum, nam coarctatur five loricatur dein ad altitudinem 3 uinarum, five ad illam, ad quam manu pertingere poteft operator faxo fundi infiftens. Alias in ipfa regione Roslagienfi differunt fornaces \& camini qua dimenfiones; circa unam obfervare licuit diametrum partis fuperioris 7 ad $7 \frac{5}{2}$ pedum, fed igni \& flammx temporique edaci amplitudoadfcribitur. Obliquitas murilaqueati fuper folles, \& pariter ad frontifpicium, ubi emittitur ferrum cum lcoriis five ubi locus emiffionum eft, altior eft, \& fulcitur, ne corruat, undecim ferramentis five quafi roboribus ferri crudi: lapis ibi gradatim fupra fornicatus jacet: aliis vero in locis fatis effe dicitur, fr obliquitas fuffulciatur 5 vel 6 ferreis ejufcemodi molibus. In edita hac fornacis parte ad extremos margines aut imbricem circumcirca eductus eft murus coctilis vel lateritius, qui includit fpatium fupernum, \& miniftris \& venarum carbonumque bajulis dat locum commorandi, \& ibi operam commodandi ; fcilicet fornacem vena \& carbone fuo, quoties requirit, donandi replendique.

Circa Loefftadium fuerant binæ fornaces contiguæ, five uno muro circumdatx, diftantia inter cavitates vel caminos utrosque eft modo 6 vel 7 ulnarum. Frontifpicium five pars pectoralis utriusque, five ubiemiffiones fcoriarum \& ferri fiunt, ad unum idemque fornacis latus, diftant modo invicem aliquot ulnis. In tam contiguis \& propinquis caminis optime fimul peragitur liquatio; adeo ut unus ignem nec ninuat, nec augeat, 


\section{DE FERRO ROSLAGIENSI SVECI E。}

nec mutuetur alterius. Et licet femel contigerit, quod a fufore relatum eft, ut inter utrumque fiffura aut coeca fuiflet apertura, quodex eo concludere potuit, quia carbones unius camini adhuc inaccenfi ab igne alterius candefcere inciperent, ufque tamen communicato fic calore, nihil alterutri ex actione in fuum ferrum deceffiffe compertum eft.

\section{De foco, vento $8^{\circ}$ meatu fpiratorio.}

Uper laminam faxeam fundamentalem confruitur modo ufitato focus $\checkmark$ ad latitudinem $I_{2}^{\mathrm{r}}$ pedis, longitudinem confuetam five 3 pedum, fcilicet ad capacitatem $8 \mathrm{vel} 9$ ponderum nauticorum ferri ; ad altitudinem 4 palmarum latarum. Pars anterior foci præcluditur obice five claufro faxeo non ferreo ut alibi, faxum eft figurze quadratx. Janua five apertura fupra obicem aut repagulum hoc clauditur lamina faxea nec ferrea ut alibi; janua hæc, quæ alias Timp vocatur, igni huic validifimo fpatio 20 feptimanarum reffitere folet, cum alibi crebrius intra unam liquationis vicem confumatur, quod etiam oriri videtur ex fulphurata venæ indole, qux ferrum pariter ac faxum lente \& paullatim exedit. Apertura emiffionis ad latus obicis dicti obturatur argilla craffiore cum fabulo mixta; qux mixtura circa quamvis emiffionis vicem excutitur, quod etiam facilinegotio fieri poffe dicitur.

Hic etiam obfervatur idem orificii ventilatorii fitus in foco, qui alibi, fcilicet ut in linea centrali cavitatis fit, adeo ut fecundum axem cavitatis demiffum pondus perpendiculariter in orificium fpirans decidat.

Orificium fpirans hic paullulum amplius eft, quam aliis in fornacibus; fiftule folliculares ad diftantiam fatis multam removentur a margine ipfius introitus in focum, fuper laminam quandam ferream funt relocatx: lamella illa ferrea non ad ipfam aperturam vel ad focum tendit; fed extra illam ad fpatium dimidii pedis continuatur orificium ope argillix. Lamina hxc ferrea, in fitu horizontali jacet, adeo ut ventus in focum intrufus non oblique ftringat fuperficiem ferri fluentis, vel ad partem oppofitam five ad confinium parietis oppofiti \& voluminis ferrei penetret: non tamen inde ut in aliis caminis agit ventus in carbones magis quam in venam, nam fluidiffima eft vena; videtur hæc venæ fpecies talem fitum orificii \& directionem venti poftulare. Si qux fcorix orificio inhærefcant ventoque viam pracludant, illico excutiuntur. Folles ejusdem amplitudinis funt, ut in aliis hujus generis fornacibus, fed motus illorum aliquantum eft acceleratior.

\section{De ipfa coctione \& liquatione vence.}

Conftructa fic fornace \& parato foco, ftatim inchoatur opus liquatorium; \& quamvis caminus recens fit \& frigeant adhuc lapides, \& madeant juncture, ufque tamen ignis vehemens inibi continuatur, in tantum temporis patium, quantum alias in camino veteri \& ficcifimo ignibufque bene affueto, nec illis curæ eft murosfenfim ficcare, \& commifluris argillaceis humorem paullatim excutere. 


\section{DE FERRO ROSLAGIENSI SVECIIE. I 29}

Repletur caminus I 6 leftis carbonum, tantæ capacitatis eft; appofito etiam dimidio vafe venæ calcinatæ \& comminutx, fcilicet ut alimentum fit igni : accenditur tunc ftatim ignis, \& fic accenfus continuatur fpatio 4 dierum \& noctium, quibus peractis admittitur aqua in rotam \& ventus in focum, a quo tempore augetur quantitas venæ imponendæ intra 8 ad i 4 dies \& noctes, fecundum indicia ex igne, fcoriis \& ferro petenda.

Quum tandem incrementa appofitionum ad fummum pervenerint, hoc eft, quum adhuc magis non augeri poffit quantitas imponendæ venæ, tunc fpatio quolibet 24 horarum five diei \& noctis, impofitionum vices folent effe I 8 , \& quavis vice I 7 vel I 8 vafa, una cum I crate carbonum plena five lefta, hoc eft, i 2 tonnis carbonum, quæe etiam ratio effe folet venæ\& carbonum ad finem ufque operis. Vas illud, quo folent uti circa appofitionem venæ, ferreum eft, capaxque 50 vel $5 z \mathrm{tb}$, exinde per calculum fciri poteft, quantum venæ quotidie transmittitur per caminum, \& quantum ferri inde obtinetur, ficque quantitas ferri, qux fit in vena. Circa Loefftadium, ubi cum omni fucceffu peragitur hodie liquationis opus, quovis menfe confumuntur 500 crates five leftx carbonum, fed alibi, ut \& circa Tobo 6, ad 700 .

Prout đictum eft, datur duplicis generis vena, quia ex binis fodinis, ex Storgruf wan \& Silfwerbergs-Grufworne dictis eruitur; vena ex fodina priore, feracifima ferri eft, \& omnis labis exfors; at vero vena ex altera, quamvis etiam fine nota \& nævo, fed magis viridelcit, putatur fic fulphuris pluris compos, hinc 2 vafcula hujus generis fuperimmittuntur in caminum cum I4 vel 15 vafculis generis prioris, ex qua commixtione optimumillud ferrum, quod vere Oregrundicum cluit, conflatur. Alias per fe fuidifima eft vena, quia lapis calcarius compagem ejus, tanquam arteriolæ, interfperfus meat, hinc nulla pars calcis hic ut alibi apponitur : olim tamen calce ufi funt, led hodie experientia edocti fundunt puram venam, augentque fic cum eodem carbone proventum ferri fui.

In \$pho Ima oftenfum eft, fitum dari meatui fpiratorio obliquum, adeo ut ventus in oppofitum parietem poffit urgeri, \& fic confiniumvoluminis ferrei \& parietis dicti ftringere ; hic vero datur aure directio quadam horizontalis, unde nec ad oppofitum latus videtur conniti poffe, fed in prima firatione anhelans furfum per caninum auferri. Perhibent tamen magiftri, cum hac directione venti liquationem melius peragi, majorem copiam ferri obtineri, \& ipfum ferrum melioris pretii \& indolis parari, quam fi obliquitas orificio \& confequenter vento data fit, ficque ferrum contrahere poffe albedinem quandam granorum. Sed quia fluidiffimum eft venæe genus \& fuo menftruo \& calce comitatum unitumque, pariter ferrum hic requiritur non multæ coctionis, nec multr in foco agitationis, ut eo melius recoqui \& facilius purificari in foco ferrario poffit, hinc horizontalis hæc aura huic venæ non vero aliis apta effe videtur.

Multo major pars ferri provenire videtur ex venx eadem quantitate, fi vena prius calcinata bene fit, \& cruditates immundiores \& craffiores per
clabsis I. de ferro.
$\mathrm{Kk}$ primun 


\section{DE FERRO ROSLAGIENSI SVECI Æ.}

primum ignem expulfx: nifi enim vena prius combufta tranfierit ignem calcinatorium, animadvertitur fubinde in foco æftus quidam \& fervor, non aliter ac aqua cum xeftuat \& ebullit in aheno. Accidit etiam interdum quod in ipfomet foco fonus audiatur inftar illius ex fclopeto, \& tanquam. rumperentur foci parietes \& teftudo, quod unice oritur ex lapide venæ crudx in focum illapfix; excipit enim illum liquor ferventiffmus ferri: unde cum fonitu in elemento igneo \& calidiffimo in partes diffolvitur.

Quum incipit coctio quxdam five ebullitio in foco, \{cilicet quumvena non fatis liquata illuc decidat, rubefcit ftatim flamma ex fuperiore parte fornacis erumpens, ipfa flamma fumo videtur commixta, \& ideo nigrefcit etiam paries fuperior cavitatis : flamma circa inferiorem partem fornacis erumpens celerrimo motu vibratur \& per vices rumpitur. Si trans orificium ventilatorium infpiciatur liquamen ferri \& fcoriarum, fpeciescoetionis apparet, ejicitur volumen \& partim verfus ipfum orificium eructatur \& confurgit, congelefcit etiam \& nigrefcit materia, \& in orificii aperturam fcintillas ejectat. Coctioní five fervori huic in foco enato non ftatim obviam eunt, \& medelam ei afferre volunt, fed continuata per aliquantum temporis fpatium coetione, tandem contum ferreum in focum immittunt, \& liquorem denfatasque \& lentas fcorias fubigunt: quo facto extrahuntur fcorix, quod continuatur, dum coctio finita fit.

Si flamma alte feratur fupra fornacem, fignum effe dicitur, fufionem rite peragi, \& liquefcere bene venam, \& volumen ferri liquidiffimum effe in foco: at vero fi flamma exigua non alte volet, fignum eft, carbonibus \& vena nimis ftipatam effe fornacem; dicitur tunc invalefcere vel xgrotare. Si flamma fonorum quoddam murmur edat, fignum etiam effe dicitur optime peragi fufionem, contra vero fi exigui foni fit : fonus hic furde admodum auditur, cum focus nimis combultus fit.

Focus hic raro inquinatur fcoriis, unde nulla moles ferrea, quæ Klot Svecice nuncupatur, finita fufione, derelicta apparet, uti in fornacibus, ubi vena fcatet fulphuribus, arfenicis aut lapide tetræ indolis \& difficilis liquationis. Principio fufionis recrementa quædam circa anteriorem partem foci reperiuntur, qux ftatim extrahenda funt. Purgatur etiam hic focus, ut alibi, quavis emiffionis ferri vice.

Scorix emittuntur, quoties requirit opus, fi paríetes \& faxea lamina fupra obicem locum tenens candefcat, emitti frepius debent fcoriæ, quam fi frigidior appareat lamina : cum ardor penetrat murum, perpetuus fcoriis effluxus relinquendus eft. Scorix congelefentes hic coloris pallidi funt, non ferruginei.

Ferrum emittitur ter quavis die \& nocte, hoc eft, fpatio quovis 24 horarum tres emiffiones ferri fiunt: quum enim vena cum carbonibus fexies impofita fit, tempus eft emittendi volumen ferri in foco contenti.

Foffa quxdam paratur in arena candida fubtili, five tori in quos emittendum eft ferrum, arena dicta hic multa aqua humectatur; quo facto ex 4. … c... cutitur 
cutitur argilla \& aperitur foramen, ficque torrentis inftar limpidifimum ferrum erumpit, effluitque in toros, \& formatur in maffam longam \& extenfam, fcilicet in quibusdam locis in 9, 10 , vel i i ulnarum. Maffe cujusvis pondus effe folet $8,8 \frac{\pi}{2}$, 9 vel $\mathrm{I}$ o ponderum nauticorum leviorum five Stockholmenfium, tale pondus nauticum æquat 400 ib metallicas, five 320 vulgares; hinc quavis feptimana obtinentur I 89 pondera talia nautica; fed quoniam pondus nauticum ferri crudi continere debet $520 \mathrm{tb}$, hinc fi reducantur 189 pondera, quæ per feptimanam e foco educuntur, inde quavis feptimana fuppeditantur 126 talia pondera nautica, qualia funt in ditionibus aliis metallicis Svecix communia, confumtis tunc i 25 leftis carbonum.

Indicia etiam hic capiuntur ex fcoriis, coloribus \& flammis, num fufionis opera fuccedat bene vel non, eadem ferefunt, quorum mentio fupra eft facta; fi enim fquamæaut micx inftar nitidi fterilis fupra ferrum vel fcorias appareant, fignum eft, majorem venæ quantitatem requiri. Si etiam tranfpicere velis meatum fpiratorium, videre poteris ftatum liquati ferri \& gradum liquationis, fcilicet quanta pars guttarum nigrarum, quanta lucidarum fit, num vena nimis liquefcat inque guttaslucidas omnis folvatur, vel num parce nimis, vel num guttæ non bene folutæ nigre focum obfufcent. Unum etiam indicium hic occurrit, quod circa reliquas fornaces me non obfervaffe memini, num fcilicet plus vel minus venæ appetat vel defideret caminus, fcilicet fi maffa ferri emiffa 9 ad I I ulnarum longa, æqualis ubique appareat, fignum eft, juftam effe rationem ferri \& carbonum in samino : at vero fi verfus medium fit depreffior, fignum contrarium eft.

\section{De ferro crudo Roslagienf E Oregrun- dienfi.}

FErrum crudum, quod ex fornacibus prediatis educitur, conftare folet granis exiguis admodum lucidis, \& coloris micántis in fractura; fragile iniuper eft, adeo ut ope mallei in partes rumpi poffit : nec in ferro crudo his locis amatur tenacitas, ut ubivis circa alias fornaces, nec color in fractura grifeus \& livida exfanguilque facies partium interiorum; perhibent caufam, quod ferrum minutim granulatum \& parum coctum facilius infoco liqui \& recoqui poffit, ægrius vero fi vena multam coetionem \& liquationem prius fubierit, hinc magis incoctum requiritur ferrum, quia nihil ominus nobiliffima \& præftans indoles ipfi venæineft, adeo ut non tantum depravetur ex minori liquationis gradu, quin in fe iterum in foco ferrario redire poffit. Utque granulatio hæc minuta \& oculi pufflli rutilantes obtineantur, fitus orificii \& directio venti horizontalis contribuit; multaque vena onerandus eft caminus; nec opus eft, ut efuriat \& defideret dapes fuas, quas in os ejus ad fatietatem potes fere immittere.

Ferrum hoc in fractura nitens \& granulatum temporis tractu in aperto aere corulefcit, \& rubiginem facile attrahit. Circa caminum fuforium 


\section{DE FERRO ROSLAGIENSI SVECIË。}

ferri ad Alkarleby, ubi vena Danmorienfis mixta cum vena Uthoenfi imponitur, obtineri folet ferrum crudum, quod in fractura coloris fufci \& grifei apparet, color fcilicet in media mafla fubfufcus \& grifeus eft, at circa fuperficiem albus \& nitens.

Sunt etiam camini fuforii Roslagix, quinectantam copiam ferriquotidie fuppeditant, quamvis eodem genere venæ gaudeant; ut circa Ofterby, ubi quavis vice non nifi I $2 \frac{2}{2}$ valcula venæ imponere licet, fed vena hujus vafculi pendet 60 to ; vices impofitionum effe folent 16 , vel ad fummum I 7. Circa Tobo funt quotidie impofitionum vices i 6 vel I 7 , \& quavis vice I 8 vafcula venæ, fed vafculum vena plenum 45 祜. pendet. Circa Allzarleby imponuntur i 8 valcula venæ. Vices impofitionum intra fpatium 24 horarum funt 44 vel 15 ; quinquies emittitur ferrum intra 48 horas: quavis emiffionis vice obtinetur mafla 6 ponderum nauticorum leviorum, vel fpatio feptimana 70 ad 77 talia pondera.

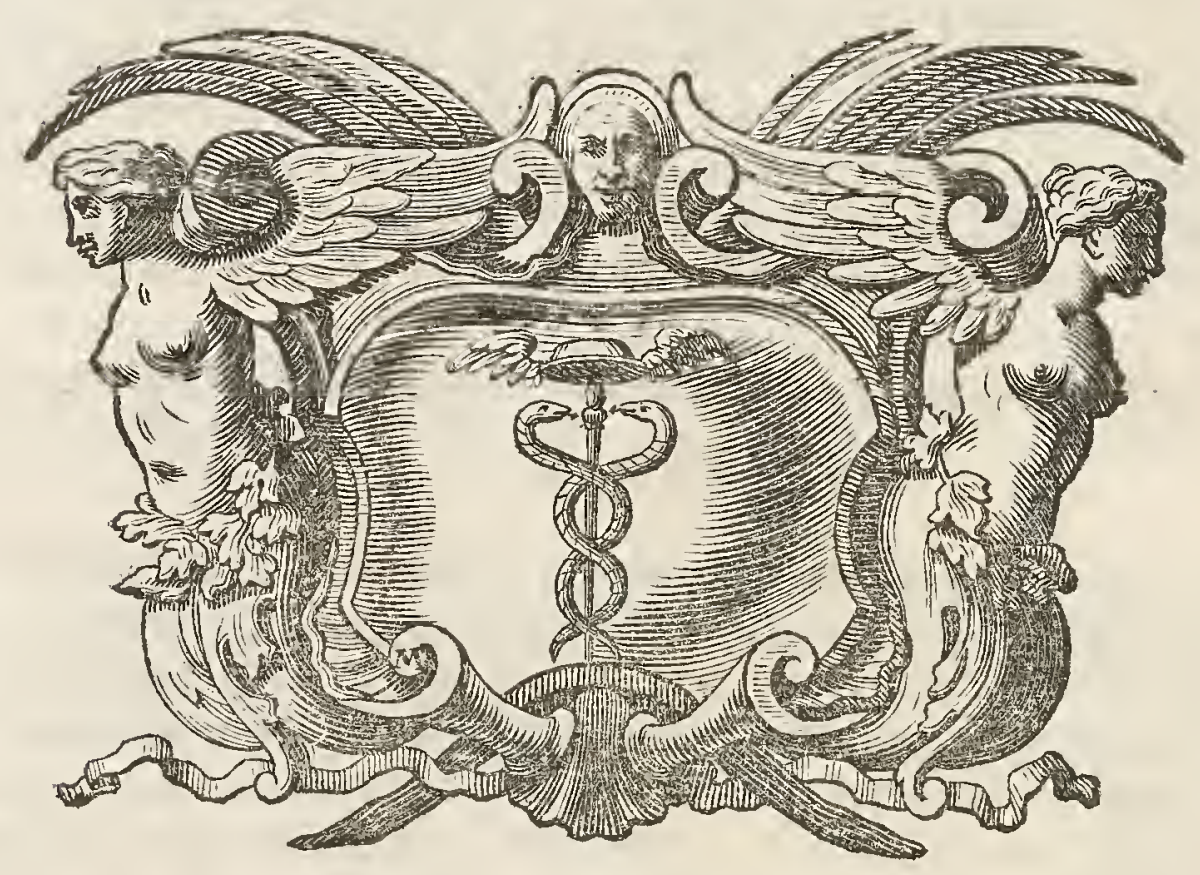




\section{PARAGRAPHUS VII.}

\section{De officinis \& focis ferrariis Roslagia, deque ferri crudi liquatione \&o recoctione, pariter de extenfione ejus Jub malleo.}

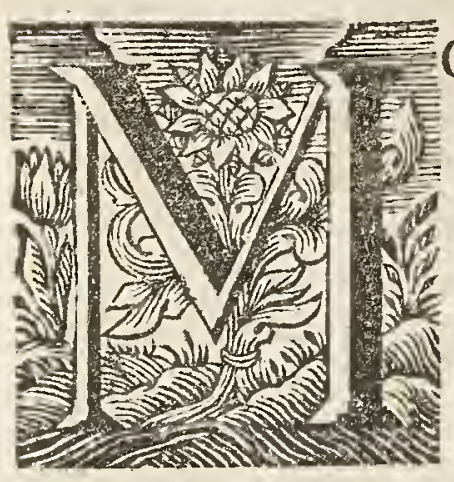

Odus recoquendi diducendique ferrum Roslagiæ multis paffibus \& parafangis diftat, differtque a modo fupra relato; prior Germanicus, hic vero Gallicus vel Vallonicus nuncupatur: hoc modo five Gallico per feptimanx tempus 50 ad 60 pondera nautica ferri recoeti procudi poffunt, fed Germanico non ultra I 6 ad 20: hinc propter infignem illam differentiam methodus hxc etiam integre defcribi meretur.

\section{De camino ferrario.}

CAminus ferrarius ejusdem dimenfionis \& conftructionis hic eft, ac caminialii in Spho 2 da defcripti; nec alia intercedit differentia, quam quod ad anteriorem partem camini velamen feu tegumentum quoddam ex lapide lateritio fit confeetum, circa altitudinem cum facie fabri operantis; hoc enim ideo, ne per continuum intuitum in flammam vifus \& acies operatoris hebetetur : hic enim faber continuolabore ferrum fufum recoquendumque fubigit, verfat \& inquietat, \& perenni infpectione flammam ignemque quafi laceffit $\&$ infeftat. Ad latus alterum vel huic oppofitum eft etiam magna apertura 3 pedes longa, \& 2 vel $2 \frac{\mathrm{T}}{2}$ lata, extra quam parvula cafa vel xdicula eft, per aperturam illam fuper cylindros urgetur \&involvitur in caminum \& verfus focum moles illa longa ferrea. Caminus xquare folet longitudinem $3 \frac{1}{2}$ vel 4 ulnarum, \& latitudinem 3 ad $3 \frac{\pi}{2}$.

\section{De uno foco ferrario, qui liquatorius vocatur.}

TN qualibet officina funt bini foci, fed non fimiles \& pares ut alibi; in uno liquatur \& recoquitur tantum ferrum crudum, adque extenfionem fic præparatur, \& vocatur focus fusorius five Svecice Smeltarebaerd; in altero vero non nifi candefit ferrum jam in frufta aptatum \& fub malleo elongandum \& exporrigendum, focus hic vocatur extenforius five Reckarebaerd. Focus prior live fulorius longus eft $2 \frac{1}{2}$ pedes, latus $2 \frac{x}{4}$, \& altus $I \frac{x}{4}$; lamina fundamentalis ferrea ejusdem dimenfionis; bini parietes etiam ex ferro in bracteas fufo conftant ut alibi, \& vocantur Haerdweggar: fed conus fpiratorius hic non incubat laminx cuidam ferrex, fed faxo, ipfique muro infidet. Parietes foci etiam perpendiculares funt. Ad partem anteriorem foci hic etiam jacet malleus vetuftus, per cujus aperturam derivantur efoco fcoriæ, quum opus fit; vel loco ejus facta eft apertura figuræ oblong:

claflis I. de ferro.

I. 1

Ver- 


\section{DE FERRO ROSLAGIENSI SVECI A.}

Verfatur ars fabri in eo, ut fiat parare \& condere rite catinum five focum, ut debitas ei dimenfiones impertiatur; aptetque foco firo ventum, ut fcilicet cum minore jactura carbonum \& citius peragatur liquatio; fed inter fe etiam variant fabri, quisque fuum focum experientix convenientiffimum format, formationenque fibi tantum familiarem \& propriam alteri invidet \& celat ; hinc etiam circa finem feptimanæ fux deftruit iple focum fuum deletque veftigia, ex quibus ratio dimenfionis capi polfit; quoties vero incepturus opus fuum eft, ineunte nova leptimana, fecundum. normas \& rationes tipitibus quibusdam \& regulis impreffas conftruit focum eique dimenfronem fuam tribuit. Exinde etiam fequitur, quod non certa hic tradi poffit menfura foci, quia unus prefert figuram exacte quadratam, alius vero oblongatam, tertius profundiorem.

\section{De cono ventilatorio.}

Conus cupreus hic paratur ut alibi, fed craffior. Orificium refertfiguram femicircularem ut alibi, cum illa tantum differentia, quod apertura vel os fit amplius, adeo ut major quantitas venti eodem tempore per illud hic poffit intromitti in focum, nam multum aure \& fpirationis hic requiritur. Conus hic cupreus fpirans five in quo fiftulæ folliculares jacent, depreffior in foco relocatur hic quan alibi; adeo ut dorfum ejus five pars coni fuperior convexa in eodem plano horizontali fit cum fupremo margine parietis oppofiti. Pars plana five inferior coni non amplius videtur a fundo foci diftare, quam ad altitudinem $\frac{3}{4}$ pedis circiter. Nec locus cono datus eft, ut in medium focum fpiret, hoc eft, ut aura medium focum fecet, fed diftat conus a parte anteriore foci five a malleo, per quem fcoriæ emittendx funt, 7 partibus; hinc ad parietem foci interiorem reftant 5 partes. Conusita obliquus eft, utventus per illum emiffus fundum foci radat verratque, nec procul a junctura fundi cum lamina oppofita appellit. Dum. aptatur conus hic five foramen Eoli, multa exactitudo requiritur, \& ad menfuras rite \& ad amuffim captandas multum artis \& operis impendunt.

\section{Modus, quo liquatur छ coquitur ferrum.}

FOcus hic repletur ftatim carbonibus integris, majufculis \& electis, quorum copia haberi poteft, quoniam carbones comminuti \& iple pulvis carbonarius circa alterum focum meliorem ufum præitant quam integri. Moles ferri crudi longa ex æedicula illa vel cafa extra officinam exfructa, contis moli fubjectis \& fuper cylindros ligneos per aperturam camini verfus ipfum focum devolvitur; jacetque fic moles oblique verfus focum, ipfamet obliquatio 20 circiter graduum effe videtur, unde per planum hoc obliquum \& fuper cylindros facile verfus focum promoveri poteft; aptatur: ita ut extrema ejus pars igne \& carbone circumdata directe a flamine poffit ftringi, in quem locum jugiter protrahitur, quum extrema ejus pars igne fuerit exefa \& confumta. Admiflo vento tantum illa pars molis ferrex colliquelcit, quix vento eft oppofita; nec plus ferri quavis vice ex dicta mole 
DE FERRO ROSLAGLENS SVECIAE 135 mole funditur, quam quæ fufficiat uni bacillo ferreo, quod fub malleo diducendum eft.

Quum peragitur liquefactio, contum fuum continuo tenet faber in foco, \& ferrum liquefactum agit \& commovet ; jam ferrum in angulis foci fui reconditum inde verfus flamen dimovet, jam leparat illam partem ferri a parietibus \& fundo, quæ illis fortaffis adhærefcit; jam protrahit illud, quod fub ipfum fpiramen \& flamen fe receperat, \& ante os venti producit, nec patitur, ut particula ferri e via lpirationis remota fit, Si pars extrema molis infpiciatur, quæ colliquefcit, videre licet modum colliquationis; pars illa rudis \& inæqualis \& coloris coerule albefcentis apparet, inde continuo guttatim ftillat ferrum, quod verfus flamen ex quovis angulo educendum eft. Faber dein colligit, ut dictum eft, omnes ferri liquefacti partes hinc $\&$ inde difperfas in unam quandam maffam five panem, cuirei multum laborem impendit. Elevat dein paullulum panem hunc colleetum fupra prunas, \& partern ejus inferiorem obvertit vento, \& carbonibus inde remotis nudus per fpatium I vel $\mathrm{I}_{\frac{\mathrm{T}}{2}}$ minuti relinquitur, qua ra. tione purificari ferrum dicitur. Sed maxima ars \& induftria in eo confi- ftit, ut fedulo \& diligenter circumagitetur maffa fluida; alias non bene purificari \& recoqui ferrum perhibent.

Perdurante hac liquefactione, augetur \& diminuitur, fecundum neceffitatem, ventus : manubrium five remigium vectis aut repaguli aquatici, quod prope focum pendet, manu finiftra vel fubducit vel deprimit, \& fic gradum f pirationis vel auget vel diminuit, quod crebro fit, intercedentibus modo aliquibus momentis; alias citius quam alibi moventur folles.

Quælibet liquatio hic perdurare folet fpatio dimidix horæ; at vero fi multum laborem faber diligens impendat, peragitur eadem opera fpatio quadrantis horæ; led in hoc cafu occupatiffimus erit faber in continua liquaminis circumagitatione, \& venti folliumque debito \& proportionato regimine. Si vero maffa aut panis, qui apud illos vocatur Loupe, major formandus fit, majus etiam temporis fpatium requiritur.

Quavis vice non major pars ferri crudi colliquatur, quam quæ apta fit \& fufficiat uni bacillo aut conto fub malleo extendendo; unde hic non major moles paratur, quam qux fufficiat diductioni vel extenfioni unius bacilli : unde nec opus eft, ut moles quædam formetur, qux denuo recoquenda fit, quxque ope fecuris fub malleo fecanda, \& de qua frufta diffecta iterum candefacienda; fed hic ftatim eademque opera parati habentur panes jufti ponderis : hinc etiam nec in panem ejusdem ponderis femper colliquefcere poteft ferrum; unde dantur bacilla vel conti duplicis vel triplicis generis aut ponderis; exempli gratia unum genus five contus formx quadrat:e 1 digiti, alterum $I \frac{r}{2}$, tertium $2 \frac{1}{2}$ digitorum, \& fic porro.

Unum vas vel una tonna carbonum confumitur fere ad cujuslibetpanis liquamen, aliis vero in locis Roslagiæ $\mathrm{I} \frac{\mathrm{T}}{2} \mathrm{vel} 2$ tonnæ carbonum. Ex una mole ferri crudi, 9 vel I I ulnas longa, 35 dicti generis panes, five bacilla aut conti procudi folent: datur officina, ubi vix nifi 28 tonnæ carbonum impendantur ad integra molis liquationem, cum in vicinis 35 . 


\section{I36 DE FERRO ROSLAGIENSI SVECIA.}

Quum ferrum liquefactum in unam maffam fit collectum, eximitur foco, \& fuper parvam quandam incudem I 5 vel i 6 ictibus mallei percutitur, æequatur fic undiquaque, \& quicquid ad angulos inæquale apparet, excutitur. Maffa hrec candens fpeciem refert cafei excavati, formæ eft rotundx, fed non multx craflitiei, in medio depreffa \& cavata, inque cavitate illa maxime etiam candefeit. Magifter foci liquatorii panem hunc malleolo percuffum fub malleum majorem transfert, \& illum in fruftum quoddam oblongum format, quod vocaturSvecice, Smida ut til Kolf; quodcum factum fit, remittit frufum hoc in focum, immergitque igni \& vento apponit: cumque unum ejus latus candefactum fit, obvertitur vento alterum; ferrum hoc per idem fere temporis fpatium candefit, per quod in maffam prius potuit colliquari; nam cum paratur panis, etiam fruftum tale cum eadem opera \& finiul in foco candefit. Ferrum hoc oblong: figuræ, merfum in focum, \& vento hinc \& inde obverfum, cum eximitur, exefum \& diminitum apparet ; vi enim ignis \& venti difperiiffe videtur pars ferri : exemtum fic traditur fabro, qui foco extenforio praeft, quique ferrum hoc dein in bacilla \& contos fub malleo extendere novit : unde tyro forcipe prehendit hoc fruftum candentifimum foco liquatorio exemtum \& prima vice ad 3 pedum longitudinem diducit.

Ex hoc foco nullx emitti folent fcorix, fed continentur tanquam inibi inclufie, vel enim in aerem dilipantur, vel igne confumuntur, vel in ferro remanent; circa finem operis, rudis tantum maffa in foco manet. Et quoniam nihil fcoriarum ex foco hoc emittitur; putant etiam magiftri, qui præfunt officinis vel fabricis, nullam etiam ferri jacturam effe.

Alibi vero Roslagix, ubi ferrum crudum non folummodo ex vena pua Danmorienfi, fed etiam ex Uthoenfi aliave, paratur, ex foco hoc liquefactorio emittuntur lcorix, fed modo bis intra 24 horas; \& nifi emittantur fcorix, perhibent ægre five ficce, ut vocant, operam liquatoriam \& recoctionem ferri peragi.

In liquamen hoc ferri agitatum fubinde injiciuntur fcorix ut \& limatura Martis circa truncum malleatorium colleetx, inde fluidius reddiferrum dicitur. Circumagitari etiam ideo continuo debet ferrum, ne fcilicet liquidum ftet, \& in æftum \& coctionem liquor ferreus agatur, fi enim excoquere incipit, ut alibi, detrimentum inde capere ferrum perhibetur : hinc fi animadvertatur in ferro liquato aliqua coctio aut ebullitio partium, tunc emittuntur fcorix, quod tamen alias nunquam fieri folet, unde limpida talis liquatio evitatur, inde ferrum non modo depravari, fed \& multam ejus partem perire perhibent.

Hic etiam fiftere \& inftituere libet comparationem quandam inter recoctionis Germanica modum, \& Gallicum hunc aut Vallonicum : I. In officinis Germanicis five illis, quæ in $\$$ pho 2 da defcriptæ funt, bini quidem foci funt, fed fimillimi, \& uterque ejusdem ufus. In officinis his Gallicis pariter duplex eft focus, fed unus infervit tantummodo liquationi \&recoctioni ferri crudi; alter vero unice excandefactioni ejusdem ferri, quod in foco priori recoctum eft, fcilicet ut ignitum in bacilla poffit apte diduci: unde qua ufum variant ipfi foci 2 . In officina Germanica conftruitur 
etiam aliter catinus, vel focus, quam in Gallica : in priore funt 3 parietes lamellati ferrei, hic veronon nili bini, nec conus fpiratorius incubat ferro, fed infidet ipf muro. 3. Conus fpiratorius in focis more. Germanico conftructis altius relocatur a fundo, hic vero humilius. Ipii etiam folles moventur lentius in officina priore, quam hic, ubi clavus finiftra jugiter tenetur \& fecundum modum liquationis jam alrius elevatur jam deprimitur. Orificium coni fpiratorii hic etiam amplius eft, ut filicet per diductum magis os fpiret plenius aura. 4. Præcipue tamen confiftit differentia in modo ipfius coctionis : in foco Germanico (fic appellare illum lubet, hunc vero Gallicum diftinctionis \& intellectus gratia) integrum fere pondus -nauticum ferri, five una aut plures maflie quavis vice liquefunt; hic vero in Gallico non integra maffa, fed ex maffa tantilla pars, quanta uni bacillo extendendo apta \& fufficiens cenfetur, non enim magis deliquitur ex hac maffa, quam ejus $20 \mathrm{ma}$ aut $30 \mathrm{ma}$ pars. 5. In foco Germanico coquitur ferrum recoquiturque, ficque iterum iterumque liquatur; hic vero lemel tantum; cum enim tanta pars ferri delicuerit, quanta ad unum contum fufficiens fit, eximitur ftatim, nec rurfus obvertitur \& Eolo fintitur, inque focum denuo deliquefcit ; fed prima liquatione peracta ferrum foco exemtum malleis fubjicitur: hoc peragitur fpatio $\frac{1 \cdot}{4}$ vel $\frac{1}{2}$ hor: ; cum in foco Germanico peragendum fit liquationis \& recoctionis opus quavis vice fpa tio aliquarum horarum. 6. In foco Germanico relinquitur ferrum diutius in foco : in hoc vero continuo movetur \& agitatur, inque panem \& placentam undique colligitur. 6. In foco Germanico bis aut ter excoquendum eft ferrum; hic vero non nifi femel, nee permittitur, ut liquoris inftar exæltuet aut effervefcat, prout ferrum in foco Germanico, fed contis \& batillis continuo agitatur, (pirante etiam aura vehementiore, unde lentefcit facile \& congelefcit liquamen inque maflam duriorem coit. 8.Ex foco Germanico fubinde emittuntur fcorix, ex hoc vero nulla, fed pars recrementorum vel remanet, \& inde in foco extenforio primum exludat. 9. Ad focum Germanicum adhibentur carbones mixti, minores filicet cum majoribus, pulvis cum integris; hic vero non nifi qui integri funt, quique multum ignis impertiri pofint : pulvis vero omnis carbonarius, five carbo comminutus ad alterum focum fcilicet extenforium defertur.

Ex his videre licet, quantum difcrimen intercedat inter modum recoctionis ferri 9 pho 2 da traditum, \& hunc; dantur adhuc plures differentix, fed minoris momenti. Obfervanda etiam differentia ipfus ferri: nam in focis Germanicis ferrum crudum defideratur, quod tenax fit, quodque in fractura infar panni grilei apparet : hic vero defideratur ferrum, quod crudius fit five quod minus coctum, \& quod fragile, \& cujus fractura fulgurat micis \& granis exilibus : nifi enim tale adfit ferrum, difficilior \& $x_{-}$ grior exiltit ejus liquatio in foco, fubactionis \& agitationis ope in foco melioref́cit aque crudiore fui parte liberatur; ferrum crudum quod tenaxeft, $\&$ in fornace fuforia bene coctum non modo igni refiftit diutius \& ægrius fe domare patitur, fed etiam minor ejus jactura eft : hic enim nec ferri difpendium nec augmentum illis damno aut lucro cedit, hinc amant tantummodo ferrum, quod facile liquefcit, \& facile in panem fubigi \& cogi poffit, clalfis 1 . de ferro.

$\mathrm{Mm}$ \&ipfa- 


\section{I38 DE FERRO ROSLAGIENSI SVECIAE.}

$\&$ ipfamet opera citius peragi; quod etiam codem fere recidit, quantum enim lucrantur circa fornacem venx fuforiam, in eo quod multum venx \& parum carbonum apponere liceat, ferrumque non bene coctum educere, tantum hic in focis ferrariis perdunt.

\section{De foco altero, qui focus extenforius dicitur.}

FOcus alter, in quem transfertur ferrum jamdum in formam quandam. oblongam excufum, \& qui vocatur Reckarebaerd, alius ftructuræe eft. Caminus fimillimus eft camino prius deferipto cum tegmine \& umbraculo lateritio, ne acies oculorum nimio igne obfundatur, interea ejusdem etiam conftructionis \& dimenfionis eft. Focus vel catinus vero plane ab altero liquefactorio differt, latitudinem habet 2 pedum, fcilicet a cono fpirantiad parieten oppofitum, longitudinem 3 ad 4 pedum; in longitudinem ideo eft productus, quia bacilla ferrea candefacienda, fecundum longitudinem fociinferuntur. Paries foci longus, five ille, qui fecundum longitudinem ejus eft erectus, non perpendicularis ftat, fed inclinat paullulum verfus exteriora, adeo ut latior fit fupra quam infra, fed obliquitas eft admodum exigua.

Quod vero conum fpirantem five orificium ventilatorium attinet, eadem hic erit ejus altitudo a fundo, eadem in focum longitudo, eadem obliquitas cum cono jam dum defcripto, \& qui in foco liquefactorio in ufu eft.

Focus hic non carbonibus eleetis \& integris, fed comminutis \& in pulverem dilapfis repletur, qui pulvis una cum aliquibus carbonibus minutis circumcirca \& in ipfum focum conjicitur, coacervantur \& accumulantur ad aliquam altitudinem, adeo ut tanquam tumulus quidam aut rogus pulvere carbonario confans hic appareat: coacervatio illa conftare videtur 8 vel 9 tonnis pulveris carbonarii: intermifit quidem pulveri funt carbones, fed tales, qui foco liquefactorio non idonei alias rejiciuntur; quoque major copia carbonum comminutorum fit, eo melius fuccedere candefactionem bacillorum contorumque narratur, unde etiam colligitur undique pulvis, relictis carbonibus integris \& majufculis in ufum foci liquatorii.

Quum pulvere carbonario repletus fit focus, fuperinjicitur unum vas five menfura carbonum meliorum, in quos immittitur ignis; quumque, ut prius dictum eft, ad unam partem excufum fit frufum ferri, quumque excudendum fit vice altera, tunc pars illa nondum extenfa orificio fpiratorio aut vento adaptatur, cui etian propius admovetur, quum excudendum fit. Pars refidua ferri, quæ non adhuc fub mallco diducta eft, non e diametro oppofita vento tenetur, fed aliquantifper ad alteram cjus partem, quoniam non ille gradus caloris requiritur, fed ante ventum tenetur femperferrum, quod procudendum eft; nam ;caloris gradus in ferro apprimis temperari potelt, fi vel vento ex oppofito teneatur, vel ad hanc five illam ejus partem, vel fi fupra aut infra; vel fi majori copia pulveris carbonarii iminergatur, vel fi minori.

Ex plurimis fignis judicari poteft, quomodo candefiat ferrum, an liquide vel an ficce, ut vocant: fi enim ferrum candens fit coloris rubicun- 


\section{DE FERRO ROSLAGIENSI SVECI}

di aut rubicunde obfcuri, ut \& fi flamma etiam obfcurior appareat, fignum eft, non bene fed ficce candefieri ferrum: idem etiam apparer ex eo, quod fcorix 2 gre velint emanare; dicunt enim in hoc cafu recipere fe fcorias verfus conum fpirantem, nec ideo per aperturam datam velleeffluere: circa orificium dictum ventilatorium folent forix congelefcere. At vero fi ferrum fit plene candidum, \& fintillas licet exiguas copiole fpargat, quæ pariter albicantes funt, fignum eft, candefactionem vel ignitionem ferri optime peragi in foco: optimum candefcentia indicium' eft, fi color fcintillarum \& flammæ paullulum corulefcat. Alias apparet hic ferrum candens coloris corule albefcentis. Aliis in locis fintillatio hre fignum eft nimii caloris \& ferri adufti hic vero ferri fatis candefacti \& ad extenfionem preparati.

Temperatur alioquin nimia candefcentia in ferro ope areno \& fcoriarum: infpicitur enim per vices ferrum, num filicet multum caloris vel num perparum acceperit, quod ex colore judicatur; fi enim excoktor videt ficce nimis in foco peragi candefactionem, fuper ferrum candens fternit arenam mixtam cum fcoris diminutis, hocque interdum circum omnia latera ferri, quo facto iterum in Vulcanum mergit, mittitque fic vel ante Aolum vel ad tergum ejus, fcilicet fecundum gradum caloris quem accipiet

Ex hoc foco emittuntur fiepe fcorix, cilicet bis, ter, quater vel qumquies quovis liquationis intervallo, quod vocatur foum, unum intervallum eft, quum 7 panes in bacilla aut contos fint diducti, bonique indici effe putatur, fi abundet focus fcoriis, opus alias nimis ficce peragitur.

Carbones ad hunc focum fumuntur tantum comminuti \& pulverifati, nec'ad alium ufum idonei; nec tanta ỉlorum copia, quanta circa focum priorem vel liquefactorium, vas non repletur nifi ad $\frac{2}{3}$ partes. In una officina, quæ fimplex vocatur, ad diductionem 35 bacillorum in foco liquefactorio confumuntur tantum 28 vafa carbonum electorum, in foco altero 20; alias in foco hoc altero I vas vel tonna carbonis comminuti ad cujusvis bacilli extenfionem requiritur, aliis vero in locis Roslagix $I_{\frac{\pi}{2}}, 2 \mathrm{ad}$ $2 \frac{\pi}{2}$ vala vel tonnx : \& fic porro.

Malleus in officinis his perpetuo tundit \& ferrum diducit, adeo uc irrequietiffimus fit, inde etiam malleus cum incude valde incalefir: hoc ut præcaveatur, nam ex calore molleícit ferrum, in truncum, cui immerfaftat incus, perpetuo influit aqua, adeo ut incus aqua circumquaque circumambiatur. Quumque bacillum extenditur \& dein planum redditur, puer ope baculi aut tipitis aquam percutit, unde gutte aqux frigidx in ferrum fubfiliunt, \& bacillum ignitum, pariter etiam malleum \& incudem irrorant \& humedant, quod continuatur dum bacillum applanatum fit.

Quod vero quantitatem ferri attinet, quod patio cujusvis feptimans in una officina extendere poffunt: in officina fimplici, ut vocatur, ubi tot numero fabri, tirones \& coadjutores non funt, ac in aliis, quavis teptimana procudi folent 40 pondera nautica majora five 44 Stockholmenfia; atvero in aliquibus, ubi plures fabri, vicarii \& numerofa turba coadjutrix adef, quavis feptimana obtinentur 66 pondera nautica Stockholmenfia. Experimentum etiam factum eit, fpatio unius feptimane in contos protenfa 


\section{DE FERRO ROSLAGIENSI SVECIA.}

fuiffe in una officina 72 pondera nautica Stockholmenfia. Unius feptima næ opus perftare folet 128 horis circiter.

Quod jacturam ferri crudi attinet, fabris nihil interef, num multavel exigua ejus pars dilpereat; putant aliqui non multum perire, quoniam fcorix e foco liquefactorio nullix emittuntur, ufque tamen jactura feri mula eft, qux calculo fic fubduci poffe videtur : fcilicet, in una officina quavis feptimana liquari \& in bacilla procudi folent $I_{\frac{1}{2}}$ moles five maffx ferri; unius molis pondus eft 9 ponderum nauticorum circiter, inde obtinentur 66 pondera nautica Stockholmenfia ferri in bacilla extenfi, unde ab 104 ponderibus ferri crudi habentur 66 ferri puri \& extenfi. Sive in officina fimplici liquantur intra feptimanam $7 \frac{\mathrm{x}}{2}$ moles ferri crudi, five quod eodem recidit, 67 ponderanautica, \& inde obtinentur 42 vel 43 pondera nautica ferri puri, unde diminuitur ferrum ratione ut 104 ad 66 , five ut 67 ad 42 , vel ut 26 ad $17 \frac{1}{2}$, unde fequitur fubducto calculo, $\frac{1}{3}$ partem ferri crudi perire ; quum modo Germanico recoquendi ferrum non magis quam $\frac{3}{13}$ partes:adeo ut differentia fit ut $\mathrm{z}$ ad 9 . Diminutio vel jaetura hrec multum adfcribenda eft ipfimet indoli ferri crudi ; amant enim fabri ferrum intus granulatum, albicans, incoctumque, hinc non mirum eft, fi major inde exiftat ejus jactura.

Pondera hic ufitata a vulgaribus admodum differunt; unum pondus, quod Wicht vocatur, xquat $I_{\frac{1}{2}}^{\mathrm{T}}$ pondus nauticum Stockholmenfe. $2_{\frac{1}{2}}$ Wicht conficiunt I pondus, quod Mill vocatur, five $3 \frac{3}{4}$ pondera nautica.

Operarii in quavis officina funt octo: duo fabri, unus qui foco liquefactorio, alter qui foco extenforio praet : pro $3 \frac{3}{4}$ ponderibus nauticis vel pro uno Mihl ut vocatur, obtinet quifque $\mathrm{I}_{\frac{\mathrm{T}}{2}}$ thalerum cupreum : tiro $\mathrm{I}_{\frac{\mathrm{T}}{4}}$ thalerum, 4 miniftri tirones, quilibet I thalerum, \& puer dimidium: præter hæc falarium quoddam annuum eis datur, quod vocatur nummus vinarius five Svecice Winpenningar.

Officium pueri, qui Goujar vocatur, eft, ut aquam in bacillum, quod fub malleo extenditur, infpergat, ut bacillo fignaturam imprimat, ut uncum quendam ei fubtendat, ut fuper incudem bene libretur.

Quum férrum qua partem fit diductum, transfertur ad cupam, labrum vel canaliculum aqua plenum, cui adhuc calidum immergitur, illico tamen eximitur \& fuper oras dicti canalis relocatur; deinde aliquo tempore elaplo rurfus intingitur aquis modo quo prius, \& momento eximicur, \& iterum fuper marginem iftius canalis reponitur: ultimo plane demiffum in aquam reftinguitur; quibus peractis in focum extenforium remittitur, ut f́cilicet pars reliqua extendatur.

Si acciderit, quod focus extenforius reficiendus fit, adeo ut per aliquod tempus ibi excandefieri nequeat ferrum, ut \& fi aqua, five pulvis carbonarius defit, inftant nihilominus operi liquatorio ferri circa focum alterum, inque frufta numerofa oblonga formatur ferrum, qux dein fub malleo ad go fere ponderum nauticorum quantitatem per feptimanam extendi poffunt.

Hic etiam videre licet difcrimen inter Germanicum morem extenfionis ferri in bacilla \& Gallicum. Focus Germanicus alter non eft diff- 
DE FERRO ROSLAGIENSI SVECI E. 141

milis priori, in utroque peragitur femper idem opus: Hic vero in foco altero unice candefiunt bacilla, nec inibi inftituitur ulla ferri crudi liquatio aut coctio. 2. Catinus vel focus Germanicus formæ fere quadrat:e eft: at vero hic Gallicus figuræ eft oblongioris ; paries etiam vento oppoficus verfus fuperiora obliquatus eft. 3. Peragitur ignitio \& candefcentia bacillorum unice in igne pulveris carbonum mixticum carbone minuto; aliter vero in foco Germanico. 4. Alia funt figna ignitionis five candefcentix ferri in foco Germanico quam in Gallico: in hoc candefcentia ferri ad albedinem livore aut corulo intermixtam requiritur, pariter defideratur tantus in ferro candor, ut fcintillulæ undique ex bacillo ignito torrentum aut radiorùm inftar effluant, non vero ex ferro, quod in foco Germanico candefit. 5. Hinc etiam minor carbonum pars ad liquationem ejusdem ponderis ferri \& diductionem requiritur in officinis Gallicis quam Germanicis. 6. Preter quod ipfummet opus citius peragatur; intra unius feptimanæ fpatium a fabris Gallicis liquari \& procudi poffunt in una officina duobus focis conftanti 40 ad 60 pondera nautica ferri; cum illi, qui fabricam Germanicam, exercent, intra idem \& majus tempus vix nifí i 6 ad 22.

Prolixum foret reliquos fabricandi, efformandi \& diffigendi ferrum modos, in officinis aliis Svecix familiares tradere: funt enim, qui opusfabrile Gallico etiam more urgent, fed quia intermixtam alius generis venam polfident, quæ non eodem modo ante os 太olicum intabefcit, fed lentius quafi liquitur \& feriori igne carpitur, unde non fimili arte fabra inde vitium excoquere licet, nec omnia fimul in unum panem incoquere; fed partes inde rudiores difcriminatas per meatum emittere, feu catinum aut ahenum hoc, ferro liquido demiplenum fxpius quafi defpumare coacti funt: aliter etiam ignem \& ventum fuum moderari debent, ne vitium ipfi ferro xftuofius inardefcat: viam illis præmonftrante experientia, dum fcilicet emollefcat rite ferrum, \& ductile, mite \& facile evadat, utque fub malleo affabre diffingi \& quafi elimari poflit.

Quidam tamen alius venæ compotes hanc artem imitaturi officinas fuas parili modo inftruere connifi funt; maffas triangulas longiores fundendo; in focum ante ventum parili ufu devolvendo; \& paullatim in fimiles panes \& orbes liquando; volumen ferrenm perpetuo per contum fubigendo; \& fic in alium focum extenfioni dicatum remittendo; fed eventus non fecundare conatum voluit : ferrum enim recoquendum non fimilis indolis \& faciei fuerat, nec ita liquabile in tigillo defluere, fed in focis penetralibus contumacius ignem pativelle vifum eft, partim le in fcorias dirimendo, quibus fæpius ideo orbandum effet ferri liquamen. Hincjacturam tam ferri quam carbonum experti ad officinæ fuæ veteres ufus \& popularem morem redire libuit. Ferrum enim Danmorienfe facile liquitur, \& liquatum cito in panem coit, nec opus habet iterata coctione, quianon multo fulphure noxioque lapide pollutum, hinc neciterum iterumque recoquendum eft, \& multo æetu diffipanda ei inhærentia vitia. Ex quibus confequitur, unumquodlibet ferri genus fuum recoquendi modum requirere, aliumque \& minus fibi popularem recufare.

Clajps I. de ferro.

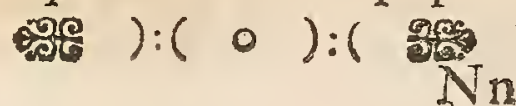

PARA 


\section{PARAGRAPHUS VIII. \\ Modus coquendi venam ferri Gallie.}

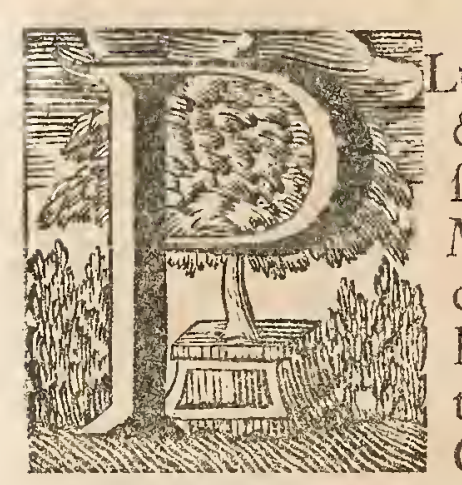

Lurimis in locis exfructx funt fornaces pro liquefaEtione venx ferrex \& prxparatione ferri crudi Gallix; Ccilicet in Nivernois, fournau de Sauvage, de Chante Merle, de Bizy, de la Fanoderie, de Corbolin, de Pot, de Chaudaux, de Guichy, de Cramin, de Raveau, de la Bloufe, de Premiere, de Moulin Biloufe, de Montigny, de Cigograe, d’Azy Valotte, de Sardole, de Charbonnerie. In Berry, fcilicet de Melian, de Groffouvre, de Soutet, de Torteran, de Feuillardes, de Prefly, de Courbanfon, la Cailloderie, Bonnau, Creufon, Ardante vel Claviere, Morcuit, la forge neuve, Bigny, Ivoye le Prez. In Turaine fcilicet Previlly. In Poitou le Meilleuret, Charnuil \&c. Alias etiam plures funt in Lotbaringia, Champagnia circa Barferobe, ad Trois, circa Ardennes adDagny \& Gironne, pariter in Normandia, Britannia, aliifque locis.

Galli:e non datur plurifariam vena in montibus \& dura caute, fed utplurimum jacet (parfa circa humum inque locis paludinofis; ficque fruftula venæ ferri immerfa terræ \&hinc indehumo \&argilla operta colliguntur; dein per lavationem five aqux fluentis immifionem pars ei inharens terreftris eluitur; quumque adufta \& calcinata fit, inops ferri vena transmittitur perfornacem. Ferrifodina etiam reperiuntur in Fay \& Perige, fed vena e montibus illis cruta fulphure pollere dicitur; ufque tamen ferrum inde excoquitur, fed notæ pejoris: ex fignaturis \& literis impreffis fciunt incolæ quodnam genus fit, quod tamen certis quibusdam ufibus inque penuria ferri melioris defideratur. Optimum \& molliffimumgenus habetur in Bourgogne, Nivers, etiam aliquibus locis in Champagne, ut \& fer de roche, ut vocatur. Quod vero producitur in Normandia, Britannia \& Perigordia, fragile efle dicitur.

In tracu illo verfus Leodium, ut in Campania, Lotharingia, Britannia \& Normandia ejusdem fere conftuctionis funt fornaces ferri fuforiz ac Leodii, de qua infra; ante $20 \mathrm{vel} 30$ annos folles coriacei in ufu fuere; effoditur etiam hodie vena ex terra. Quovis die \& noete vel fpatio 24 horarum 16 vel 20 vices appofitionum funt; \& quavis appofitionis vice $\mathrm{I} 5 \mathrm{ad}$ I 6 vafcula venæ, \& 3 corbes, five crates carbonum fuperimmittuntur, una cum 2 valculis lapidis calcarii; inde obtinentur 2000 ad 2500 话 ferri crudi, quod in moles longiores effunditur; qualibet moles i 2 ad 1500 tb ponderis circiter eft : longitudinis $5 \mathrm{vel} 6$ ulnarum, latitudinis i 2 digitorum. Carbones cremantur ex arbore duriore, fcilicet ex caftanea, ex' fago, ex quercu, unde etiam genus çarbonum duriufculum eft, \& multi ignis. Hac ante plures annos. 
LIQUATIO VEN死 FERI GALLI Fornax ferri fuforia ad Grolfouvre non procul
ab Allier, Gallice.

耳Odie fornaces ferri fuforix meliores funt quam olim, quarum delcriptionem aliqualem jam dedimus : quod vero fornaces hodiernas attinet, in exemplum vocare illam volo, quxe exftructa eft ad Groflouvre non procul ab Allier, reliquxe ei fere fimiles funt. Altitudo ejus eft 25 pedum Gallicorum, vel 27 Svecicorum ex fundo foci : intus funt formæ quadratæ, in medio eft cavitas latiffima, inde contrahit fe verfus fuperiora: apertura fuperior, per quam vena \& carbones immittuntur eft latitudinis $2 \frac{\pi}{z}$ pedum: verfus fundum etiam eft figuræ quadratæ, amplitudinis 7 pedum, in medio, ubi ampliffima eft cavitas five alvus quadrata $7 \frac{\pi}{2}$ pedum. Focus altus eft i 9 vel 20 digitos, longus 3 pedes, latus i 8 digitos; orificium ventilatorium medio foco infidet.

Folles funt lignei \& fecundum Dominum Reaumur in officinis ferrariis fequentis dimenfionis: longitudo illorum $7 \frac{1}{2}$ pedum, elevatio quavis vice 14 digitorum, latitudó maxima 42 digitorum, minima 14 digitorum, quovis quadrante hor: 206 vicibus elevatur follis, uterque fimul 4 I 2 , hinc fubducto calculo concludit, quavis elevationis vice extrudi $2015 \mathrm{I} \frac{1}{2}$ cubulos voluminis aerei. Sed circa fornaces ferrifuforias funt folles multo majores, qui quavis elevationis vice trudunt 98280 cubulos voluminis aerei; \& quisque quolibet quadrante unius hore elevatur 120 vicibus, vel ambo fimul 240.

Impofitiones fiunt quovis $\mathrm{I}_{4}^{\mathrm{T}}$ horx fpatio, five cum carbones ad altitudinem 4 pedum \& 2 digitorum fubfiderint; conftatque qurevis impolitio 9 raifees vel corbibus carbonum plenis, \& 12 vafculis venæ, filicet 3 valculis venæ melioris, \& infuper 3 vel 4 vafculis lapidis cujusdam filicei, qui mentrui loco fit : alibi etiam alia datur ratio commixtionis. Ad unum mille vel milliere ut vocatur, ferri, requiruntur 2 tonne carbonum. Spatio fex dierum \& noetium decies emittitur ferrum, \& exinde obtinentur to moles longiores ferri, qux Gueufes, pariter utSvecice, appellantur.

\section{Opus liquatorium vence ferri in Delpbinatu Gallice.}

TN Delphinatu circa urbem Alvar in provincia Savoye, in monte magno 1 Vanche dicto, funt fodinæ magnæ, Iongitudinis 300 ad 600 ulnarum, qua hodie etiam fedule elaborantur : fed loco follium ufurpantur machinæ quxedam hydraulicx, quarum ope ventus non aliter ac per follem producitur. Idem etiam mos eft quibusdam in locis Italix:

Exftruitur fornax circa rivulum fluentis aquæ, machina hæc vocatur trombe, plerumque circa pedem collis vel montis cujusdam, ubi rivulus torrens labitur; aqua per canales ducitur in hanc machinam vel trombe. Modus hic parandi ventum ante 90 annos Italixeft inceptus \& inde in alias regiones dein translatus, fi narratis fides habenda fit.

Ipfam 


\section{LIQUATIO VENÆ FERRI GALLIÆ.}

Ipfam machinam exhibet figura. A Tab. XII. Eft canalis ligneus non amplus, per quem aqua e loco altiori derivatur in quemlibet locum huic operi idoneum. B eft pars fuprema five apertura canalis perpendiculariter relocati, qui vocatur trombe; eft enim fipho perpendiculariter erectus, intus in rotundum excavatus. Dictus fipho conftat trabe divifa vel diplicata, \& dein mutuo applicata five conjuncta: diameter partis ejus fuperioris ad (C) eft I 2 digitorum, inferioris ad (E) eft Io digitorum. (CC) vocatur trianguillon, coarctatur infra in orificium rotundum diametri 5 digitorum, quod ideo factum eft, ut aqua eo melius parte fuperiore contineatur, utque defuper ad perpendiculum in faxum fubjectum delabatur: fi fipho vel trombe fit altitudinis 20 pedum, trigonum hoc debeteffe 4 pedum; fcilicet ut referat quintam fiphonis altitudinem.

Duo funt orificia vel fpiracula ab inferiore trigoni dicti parte D.D.D.D. utrinque fcilicet a trabe fecundum ejus longitudinem; illum in finem, ut aer eo melius per illa tanquam per aperta ora aut fauces illabi \& attrahi poffit: ad diftantiam adhuc duorum digitorum funt bina orificia ejusdem generis ventum attrahentia, in eundem filicet finem formata. (E) eft tota facies fiphonis, qui binis trabibus conjunctis conftat, eftque aliquibus in locis ex ferro, quod ftanno denique obductum eft. Dictus fipho immerfus five infertus eft receptaculo cuidam fubjecto ad profunditatem $I \frac{\pi}{2}$ pedis. (F) oftendit dictum repolitorium five vas rotundum, cujus altitudo eft 4 pedum, \& diameter pariter 4 pedum. (G.G.G.G.) funt bini ftipites vel bacillalignea in crucem relocata, qux portantlapidem quendam rotundum diametri I I digitorum, in quem per fiphonem delabitur aqua, qux fœeta \& impregnata aere, in lapfu multam venti copiam a fe diffipat $\&$ difpergit; nam fequitur \& fubit una a latere ventus. $(\mathrm{H})$ ' reprefentat' lapidem dictum rotundum, inter quem \& inferiorem partem vafis apertura eft 5 vel 6 digitorum. (I) fignificat aliud receptaculum, per quod aer, ex lapfu aqux per fiphonem oriundus vel expulfus, in canalem truditur, \& confequenter via reeta in focum aut fornacem, non aliter ac ventus ex ficca atmofphrra ope follium illatus; receptaculum hoc vocatur Cuiffon, eftque figuræ quadratæ 10 digitorum, fed ad quamlibet longitudinem poteft formari : obfervetur tantum, ut perpendiculariter erigatur, ne fcilicet aqua irruat. (K) eft canalis, per quem ducitur aer immediate in focum fornacis, diametri 5 digitorum, \& longitudinis fecundum libitum five fecundum difantiam. $(\mathrm{L})$ reprefentat valvulam ex corio factam, quæ ibi vocatur. Arret five baffecule, facta ex ligno fed tecta corio; quæ fi - deprimatur, exitus datur vento \& impeditur ne in focum irruat; alias clauditur valvula hæc arctiffime fponte fua per aerem. $(M)$ eft canalis fornaci.proximus ferreus, \& alteri canali bene applicatus, intratque in ipfum focum. (X) eft focus. (O) fornax fuforia; aqua vero circa lapidem fluens ab omni parte inde emanat. (P) eft orificium formæ quadratx juxta fundum receptaculi, cujus latus æquat unum pedem: inde fluit in (Q) five in receptaculum alterum vel Caffette ex afferibus factum, longitudinis 3 pedum \& latitudinis I pedis : in medio hujus receptaculi eft (R) valvula vel Pallette, qua claufa impedit, ne ventus illuc erumpat, fed modo 


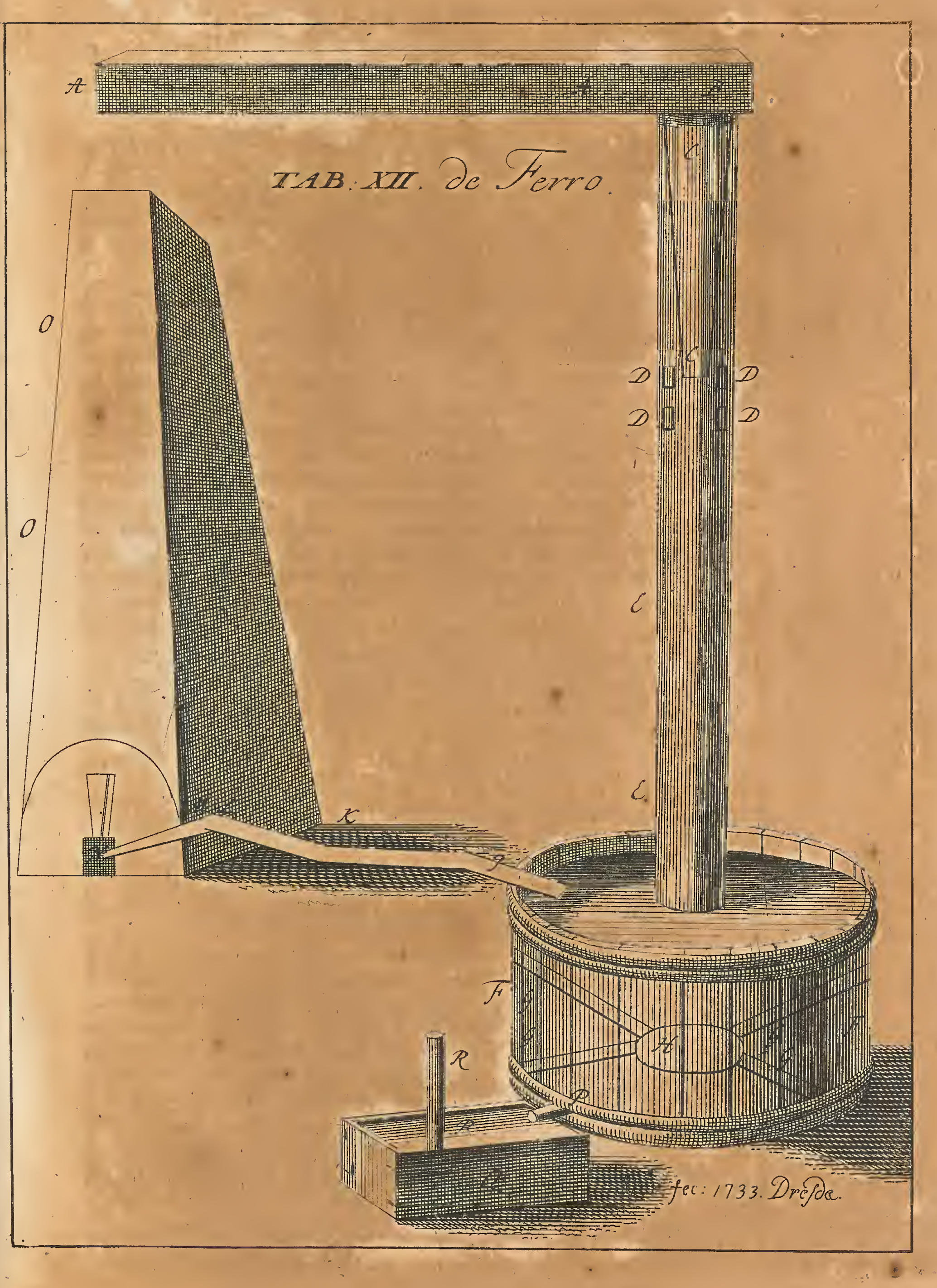




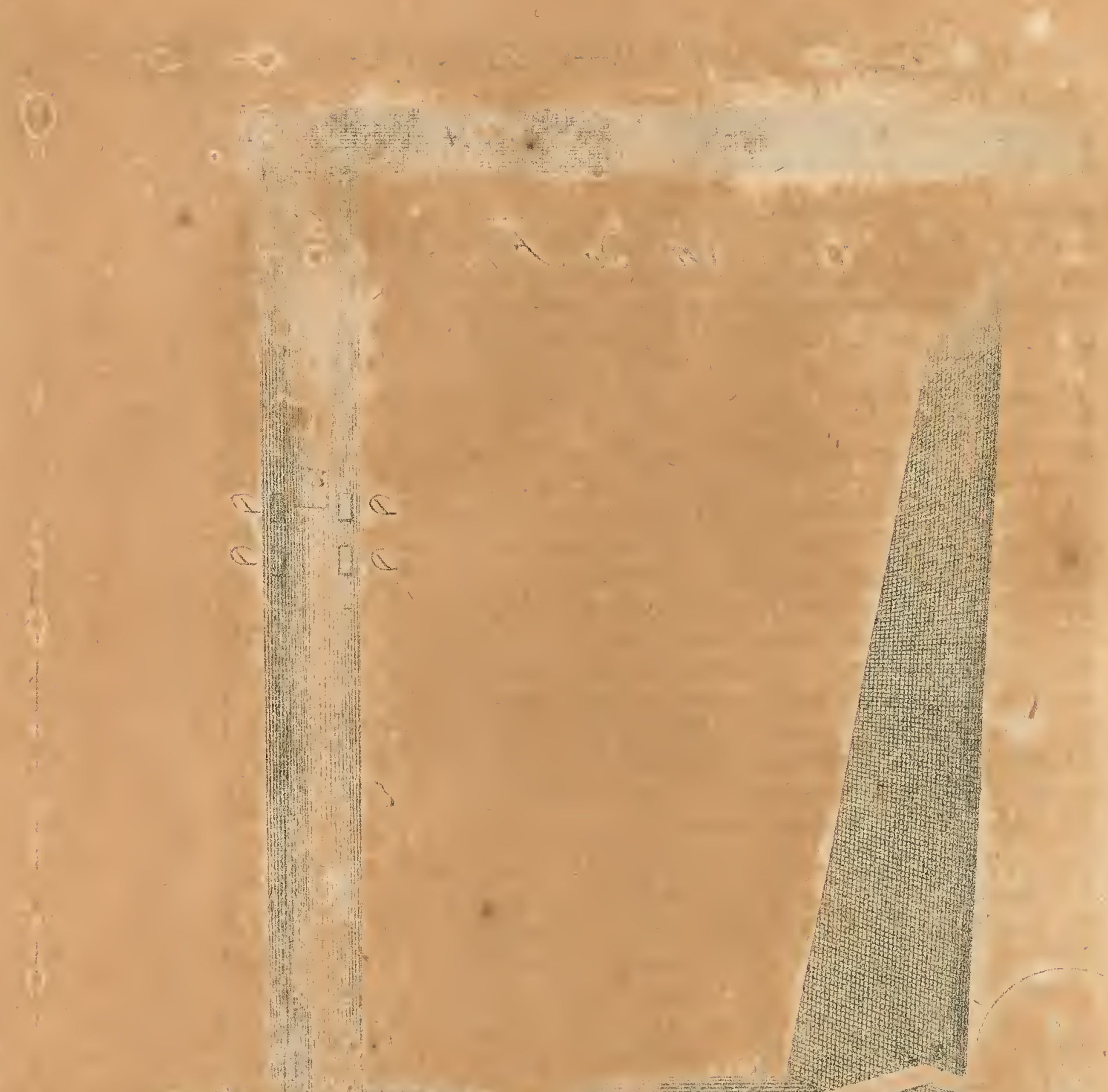

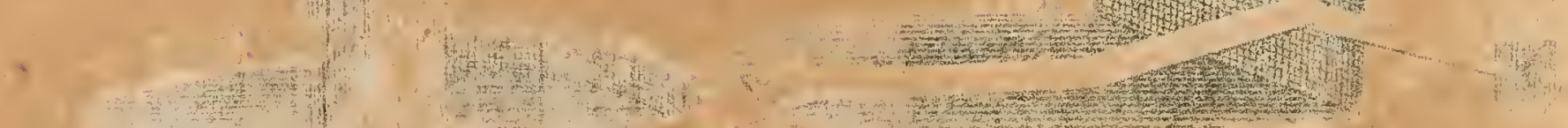

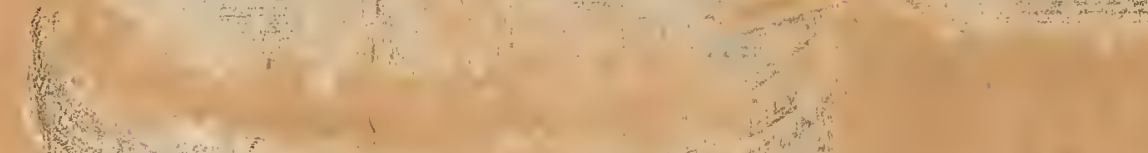

Hets

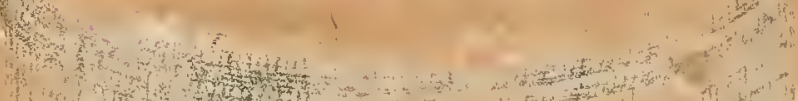

Wh Hot

What a a d

H. WWy

- 13 HW

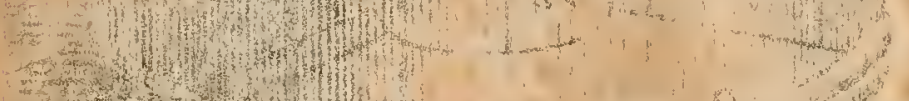

$=2+4+1+2)$

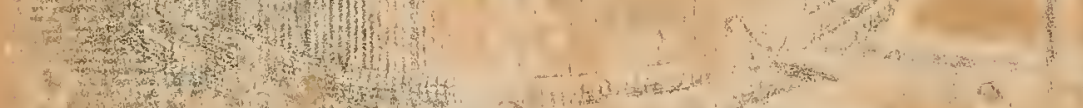

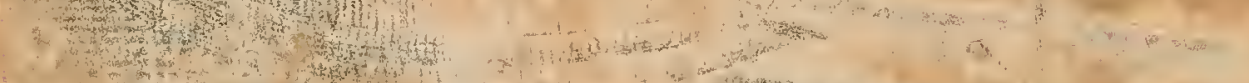

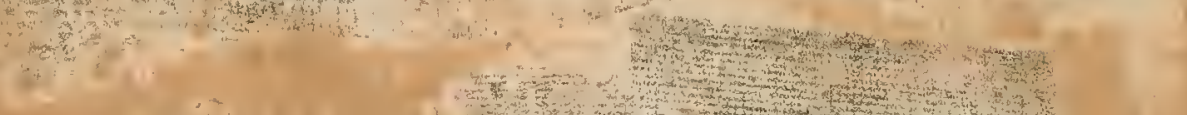

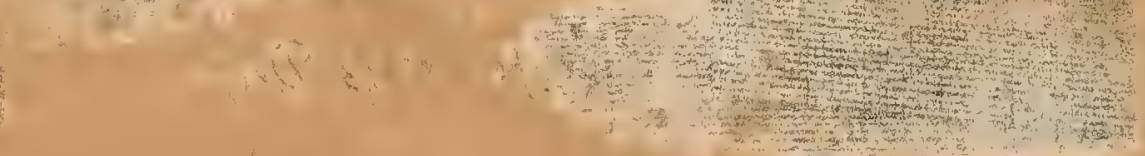

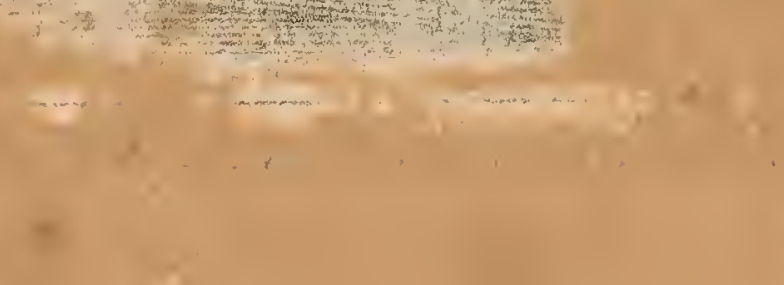


LIQUATIO VENÆ FERRI GALLIÆ. I 45 illa aquæ pars, qux in receptaculo nequeat teneri, \& qux fupra valvulam fit, illa continuo effluit fuper parietes vafis vel receptaculi.

Si auxiliante loci opportunitate fipho potuiffet exftrui longitudinis 30 vel 36 pedum, non opus foret pluribus fiphonibus: at vero fi altitudo modo fit 20 vel 24 pedum, tunc 3 hujufcemodi fiphones requiruntur: quo enim altior eft fipho, eo major quantitas venti fuppeditatur. Hoc modo obtinetur ventus admodum fortis, æqualis \& continuus, fed autumant, illum humidum feu jufto frigidiorem effe.

\section{Fornaces ferri fusorice protormentorum bellico. rum confectione confructe in Gallia.}

A Nte plures annos Dux de Nivers fufionem tormentorum Galliæ inI ftituiffe perhibetur, \& illum in finem operarios ex Svecia acquifiviffe, fed principio irritum fuife laborem \& tentamen, tandem in regione Perigordienfi opus illud continuatum fuife, \& vocatis ex Anglia artificibus opus increvifie, \& jam fornaces ad numerum i I vel plures exftructas confici: quædam etiam fornaces duplicatæfunt, hoc eft, cum 2 caminis \&focis contiguis intra eosdem parietes, unus juxta alterum, fcilicet ut quantitas liquoris ferrei in binis fociś fic poffit colligi \& dein collectus fimul emitti ad conficienda tormenta gravifíma \& multx molis'. Sunt etiam fornaces pro tormentorum fufione circa. Angulefme, tormenta inde mittuntur ad Rochefort, pariter funt quædam in Bourgogne \& alibi.

Principio varii generis vena probata fuit, jam vero, ut reor, ufurpatur funditurque illa, quxe frangitur circa Nortrow, Effidueil, Marveil \& la Chapelle Poumier, ubi fodinæ non multum invicem diftant; veria ex illis effoffa non in profundum tendit, fed ftratim verfus horizontem in campum quafi exfpatiatur, nec fe penitius demittit.

Fornaces altitudinem 24 àd 26 pedum habebant \& conftabant puro faxo, muri pectorales conftructi erantmagnis faxis molaribus vel arenariis, quie Quaderfteen vocantur. Caminus five cavitas fornacis interior erat figuræ rotundx, apertura fuperior amplitudinis 2 ulnarum; amplior vero, ubi majora tormenta fundebantur: verfus medium fornacis ampliabat $\mathrm{fe}$ cavitas, \& abinde rurfus verfus focum fe contrahebat. Focus longitudine erat $I_{\frac{T}{2}}, I_{3}^{\frac{T}{3}}$ ad 2 ulnarum, \&latitudine I ulnæ. Folles coreacei olim erant, $\&$ rotæ aquaticx exiguiores.

Quavis vice imponebantur modo 2 vel 3 vafcula venæ, una cum 3 menfuris feu corbibus carbonum ex arbore caftanea crematorum plenis, \& fpatio 24 horarum 18 ad 20 vices impofitionum effe folebant : quovis biduo vel triduo emittebatur liquamen ferri; etiam intra minus aut majus tempus, fecundum magnitudinem aut molem tormentorum. Quum probarentur tormenta, quæ ex vena circa Marveil effolla confecta funt, compertum eft fragilioris ferri fuife; ufque tamen vena hrec ratione fluidita. tis fux mifcetur cum aliis, quæ refractarix nec bene fufiles funt.

Clalis I. de ferro.

Oo

Modus 


\section{Modus recoquendi ferrum crudum \& Jub mal. leo dilatandi Gallice.}

Ominus Reaumur in pulcherrimo tractatu de converfione ferri dilataDi five puri in chalybem, fiftit etiam modum preparandi chalybem ex ferro crudo Gallix ufitatum; utque comparationem facit chalybis ex ferro crudo facti cum chalybe ex ferro extenfo \& puro, primum defcribit fed breviter modum ferrum crudum recoquendi in focis ferrariis Gallix: ex quo videre licet, modum hunc eundem effe cum illo, qui \$pho feptima traditus eft, quique ideo vocatur Gallicus : defcriptio ejus eft talis.

Si parandum fit ferrum molle, accipiunt ferrum crudum quod albide nitet ; una extremitas maffie ferri crudi transfertur in focum ferrarium ex laminis ferri confructum, qui profunditatem habet 7 vel 8 digitorum. Focus repletus eft carbonum tanta copia, ut maffa ferri crudi etiam circumtecta jaceat. Bini funt folles fatis magni, quorum longitudo eft $7 \frac{1}{2}$ pedum, elevatio quavis vice 14 digitorum, latitudo maxima 42 digitorum, minima 14 digitorum, quovis hor:e quadrante 206 vicibus elevatur, \& uterque fimul $4 \mathrm{I} 2$, adeo ut quavis elevationis vice extrudantur $2015 \mathrm{I} \frac{\mathrm{T}}{2} \mathrm{cubi}$ voluminis aerei, fed hrec de follibus. Hinc extremitas maffer vento expofita liquefcit, ut in focum guttatim decidat, non aliter ac cera Hifpanica ante ignem candelæ. Operator manibus tenens contum quendam ferreum colligit metallum fic liquefcens, fubigitque fillud; $\&$ undiquaque vertit, dum mafiam habeat colleetam poinderis 80 vel $90 \mathrm{tb}$. circiter, quæ vocatur wne loupe: hrec materia circumdata eft carbonibus vivis feu ignitis, \& circumcirca, hoc eft, circulariter reverberatur igne \& flamma. Dignifimum hic confideratu eft, quod ope conti ferrei perpetuo circumagatur \& quafi fubigatur maffa liquefacta: quo mediante omnes particulæ ferri liquefacti fucceffive exponuntur actioni immediatx ignis \& flammæ. Experientia magiftra eft, quo melius fubacta fit hæc mafta, quoque melius \& diutius calefacta, eo mollius inde ferrum haberi, fed ufque cum diminutione. Multa etiam pars fulphuris ut \& falis, pariter ferri expellitur, \& contra, quo plus habetur ferri emolliti, eo plus jacturæ: hinc copiofa pars terræ \& materiæ vitrificatæa abigitur quum tenetur in foco, \& magis adhuc expellitur fub malleo illo grandi. Aliquibus vicibus fubjicienda eft maffa hæc malleo, \& toties prius eft calefacienda. Hæe Dominus Reaumur.

\section{Opufculum ferri novum in provincia Ba- yonne Gallice.}

A Parte feptentrionali provincix Bayonne, diftantia unius milliaris ab A urbe Dax in regione Chalofe, initio anni 172.3 exftruetus eft pro liquatione venæ ferræ focus quidam, non abfimilis foco ferrario communi, opertus ad partem anteriorem, cum illo tantum difcrimine, quod infrafit 
LIQUATIO VEN无 FERRI GALLIFE. I47 rotundus; eft etiam aliquantum amplior, quam focus ferraríus communis, adeo ut continere poffit $I_{\frac{1}{4}}$ ad $I_{\frac{T}{2}}$ centumpondia ferri.

Repletur hic focus primum carbonibus, conjicitur dein infuper vena ferri, qux immifla colliquefcit, \& verfus fundum foci pertranfit carbones; interea volumen collectum ferri continuo movetur \& vertitur, ufque dum focus ferro fit repletus : quumque in maffam quandam fubactum \& colleEtum fit ferrum, quæ maffa vocatur Loupe vel Renard, fed alibi hournade, emittuntur fcorix, \& dein in 5 vel 6 frufta lecatur, qux fingillatim malleo fubmittuntur.

Vena, qux fic funditur, non frangitur in montibus aut ftratis, fed in terra quadam coloris rubentis, nec ad multam profunditatem : eft genus egenum, nam i 5 vel i 8 ejus centumpondia fuppeditant modo I hournade vel $I_{\frac{x}{3}}$ centumpondium ferri.

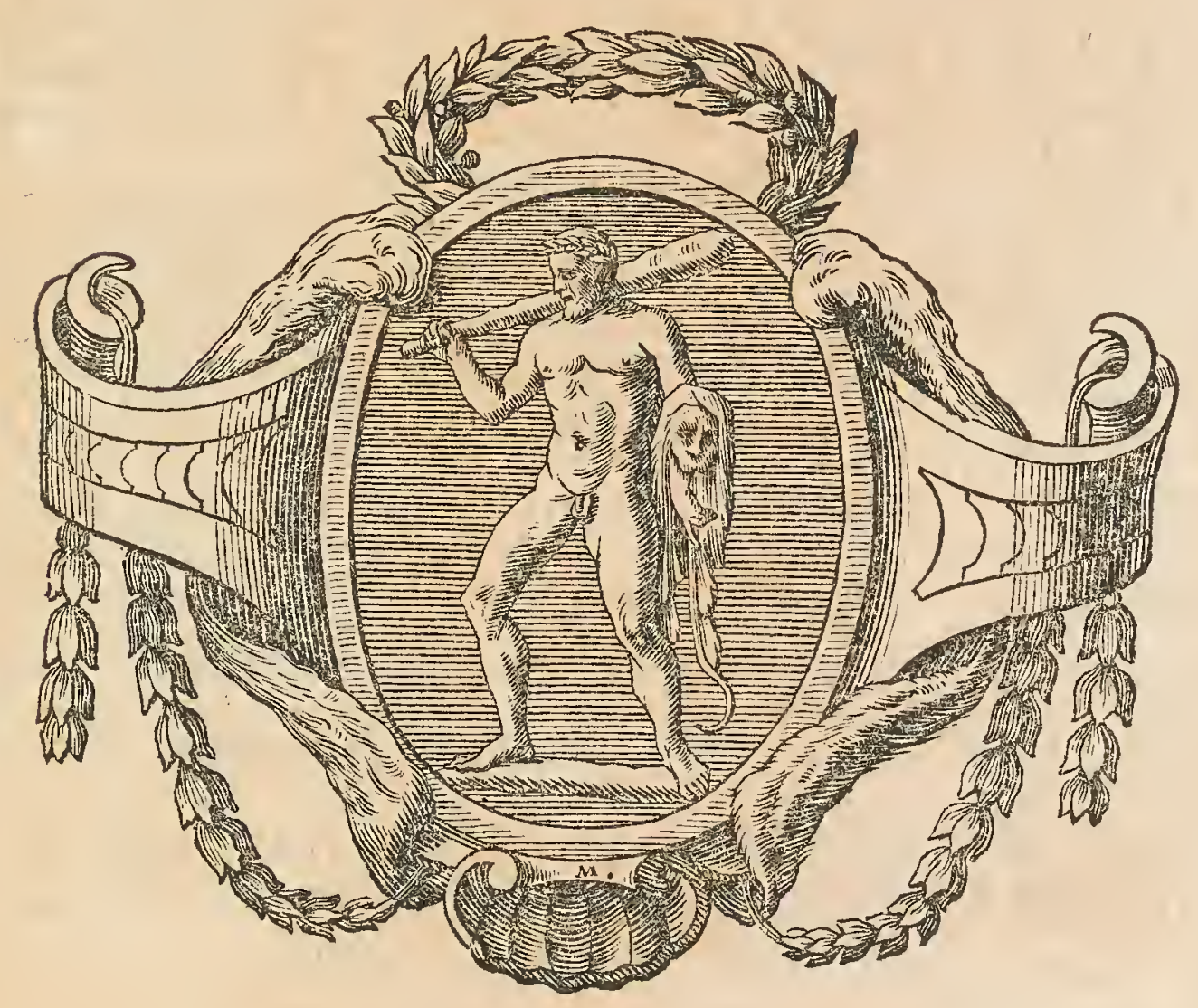

PARA- 


\section{PARAGRAPHUS IX.}

\section{Fornaces ferri fuforie circa Leodium ${ }^{2} \mathrm{C}$.}

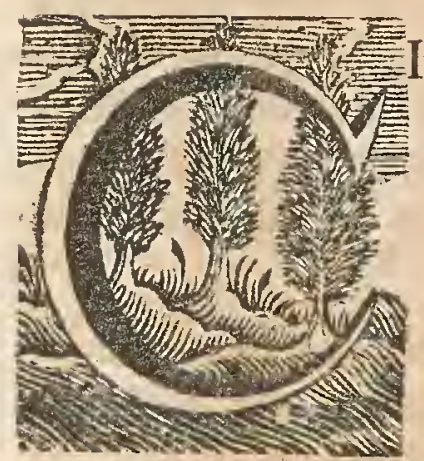

Irca Leodium funt etiam fornaces \& foci ferrarii, ut verfus Huy \& Namur, ubi etiam foci liquatorii ferri crudi \& extenforii five officinæ ferrarix funt. Quædam etiam funt prope Limburg, Mets \& Luxemburg: ferrum inde transportatur per fluvios Weftret \& Ouiter Leodium \& fic Amftelodamum. In provincia Leodienfi ante aliquot annos non nifi 8 fornaces ferri fuforix fuére.

Vena ex qua funditur ferrum, variis in locis colligitur, eftque plerumque coloris flavi \& rubri, defumiturque e paludibus \& humo, \& fruftula ideo multa terra obfita: calcinatur primum tantummodo 20 horarum fpatio; peracta calcinatione remanet ufque color ruber: ferrum quod inde obtinetur, compactiffmum \& fonorum eft, cum percutitur, unde etiam tenue, illud fcilicet genus, quod in varii generis utenfilia, in tripodes, urnas, caminulos, furnos \&c. funditur: alias ferrum extenfum Leodienfe non melioris eft notx, fed frigidum facile frangitur.

Fornax conftruitur ad altitudinem 20 pedum; fupra focum eftlatitudinis 5, circa ventrem vel maximam cavitatem eft 6 vel 7 pedum, eftque infra formæ quadratæ. Apertura fuperior lata eft 2 \& longa 3 pedes, figuræ oblongæ. Conftuitur ex optimo lapidis genere, qui bene refiftit igni, adeo ut per integrum annum opus fuforium inibi poffit continuari. Quovis bihorio e novo femper inmponitur vena filicet 20 ad 22 vafculorum, \& bis quovis die emittitur ferrum, hoc eft, fpatio quovis duodecim horarum, \& quavis emiffionis vice 1700 libre vel $3_{3}^{\underline{I}}$ pondera nautica obtinentur, five intra 24 horas 7 dicta pondera. Tempore æeftivo funduntur diverfi generis utenfilia \& fupellectilia, hyemali vero moles ferri crudi, qux dein liquantur in foco ferrario \& excuduntur. Quovis die confumuntur i 2 carrhæ venæ. Folles prius ex corio funt facti, longitudine 6 vẹl 7 ulnarum.

Quum diducendum eft ferrum fub malleo, ex $100 \mathrm{Hb}$. ferri crudi, peracta liquatione \& extenfione, remanere folent 86 libræ ferri puri, adeo ut modo jactura fit $14 \mathrm{tb}$. ex 100 .

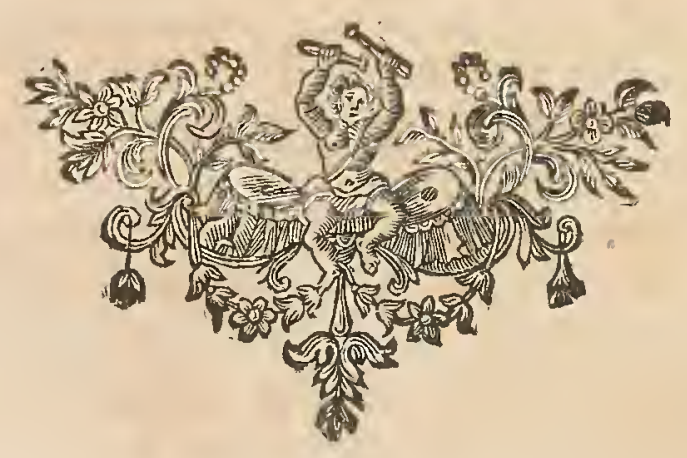

PARA- 


\section{PARAGRA PHUS X. \\ Modus tractandi venam ferri Italia. \\ Modus adurendi fundendique venam ferri Breflejae.}

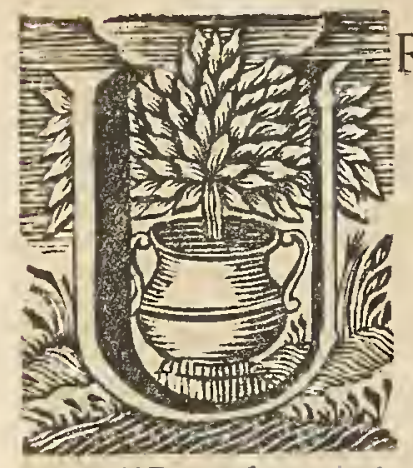

bs Breffeja, ubi fornaces ferri fuforiæ funt, fub ditione reipublicæ Venetianæ eft. Plurimæ ibi funt ferrifodinæ, fed in profundum raro-tendit vena, nifi ad 2 I vel 24 ulnas. Vena fulphure videtur deftituta, unde ferrum inde obtentum frigide frangitur : hinc fecernitur vena bonæ indolis ab illa quæ pejoris notæ eft: ftrata venænec lata funt; vena Rozza Efeluaggia prout vocatur, ferrum fuppeditat fragile.

Vena bonx indolis, qux non fulphurata eft, quod etiam per odorem explorant, ftatim in focum ferrarium fine prævia calcinatione mittitur. Genus vero magis fulphureum aduritur primum, perque ignem illum pravium mitiorem expelluntur craffiora enodaturque compages lapidis. Vena autem calcinanda fecernitur prinum; accumulatur dein fubjectis carbonibus, fed ftratim, nam cum fuperinjecerint unum venx ftratum, infternunt rurfus carbones, infuper venam in pulverem contufam ad 2 pedum altitudinem; fupra hanc iterum ftratum carbonum, \& infuper venam, hocque in pyramidis feu pyræ fpeciem. His peractis, accenditur cumulus, qui eo usque flagrat ignemque \&, calorem fervat, dum a fe ipfo reftinguatur.

Interea praparatur fornax five Cannechio, ad altitudinem circiter 24 pedum ; conftruitur ex faxo fciffili, Telgfeen Svecice vocato, conglutinantur faxa quam optime mixtura facta ex créta, arena \& pulvere carbonario. Apertura fuperior fornacis eft 3 pedum in forma quadrata, verfus inferiora contrahitur five arctatur, adeo ut diameter vel latitudo tandem fit $\frac{3}{4}$ partium ulne. Foffa fub fundo fornacis modo folito conftruitur, \& exitum habet aqua exhalans ad unum latus fornacis. Saxum fundamentale oblinitur mixtura predicta ad i fere palmæe craflitiem.

Apertura, per quam emittitur ferrum, munitur faxis illius generis qux bene refiftunt igni, \& dein per dictam mixturam obturatur. Planum quoddam extra focum paratur ex pulvere carbonum, fuper quod defluet ferrum emiffum liquidum. Ad latus eft orificium ventilatorium; ufurpantur folles coriacei; quibusdam in locis acquiritur ventus ope rivuli fiuenris aqux per fiphonem aut canalem in faxum quoddam delabentis, fed de hac machina hydraulico-pnevmatica actum eft prius. Canalis ventilatorius leviter appofitus eft; \& ad libitum poteft eximi, \& novus loco ejus inferi.

Vena calcinata fuper lamellas lapidis fcifflis, qux longitudinis I 2 pedum \& latitudinis 6 funt, reponitur, \& aqua abluitur, quæ illuc per cana-

Clalfis I. de ferro.

$\mathrm{Pp}$

lem 
lem derivatur, impuritates \& partes terreftres ope alluentis aqux inde deterguntur: Venæ circumactx toties affunditur aqua, dum tandem limpida inde effluat: ficcatur dein in plano quodam obliquo, dum omnis humoris expers fit; fic tandem ad fornacen fertur \& funditur.

Primum repleturfornax carbonibus, qui per orificium ventilatorium injeetis prunis accenduntur, adjuvante levi flamine, dum ignis plane accenfus fit: quumque hi carbones fubfiderint ulque ad fundum, \& novis iterum repleta fit fornax, tunc primum moventur folles \& admittitur ventus, \& frmul unum vas vena plenum quod vocatur Zeritto, pondus circiter $\frac{\pi}{2}$ centumpondii æquans, apponitur, \& infuper ${ }_{-4}^{1}$ pars centumpondii aren cujusdam flavæ, menftrui vel fluoris gratia, cujus ope alias ferruminationes folent peragi; infuper imponuntur carbones \& dicta arena, quantum requirit capitque fornax, ficque continuatur usque ad finem feptimanæ.

Quum fufor vel il fonditore per orificium ventilatorium infpiciens animadvertit liquefactam bene efle venam \& foriis undique contectam. auxilio \& vi conti cuppidati aperitanteriorem partem foci, quæ oculus alias vocatur; emittitur fic una cum fcoriis ferrum; obturatur dein ab auxiliatore dicta apertura ope cretæ mixtæcum argilla. Si liquidum, purum defpumatumque bene fit ferrum, in globos bellicos, qui bombre \& granate vocantur, effunditur, alias etiam in maffas ferri crudi fub malleo dilatandi; fi enim excudendum fit, prius aliquantifper refrigeratur, dum ope mallei in partes minores polfit diffringi. Continuatur opus hoc fuforium, fi copia carbonum \& venæ lit, ad finem ufque feptimanx; fique dies feftusintervenit, finitur liquatio; \& interea repletur fornax carbonibus die Lunæ rurfus accendendis; alias peragi folet opus hoc tantum 2 vel 3 diebus. Tempore unius feptimanx obtineri poffunt 60 vel 70 Cantara vel centum: pondia ferri.

\section{Modus Jub malleo extendendi ferrum crudum Breflejice.}

CAtini vel foci malleatorii five ferrarii I ulnam alti funt, cum foffa quadam evaporatoria fub fundo foci ; fuper dictam folfam relocatur lapis calcarius craffitiei $\frac{x}{2}$ pedis, \& infuper pulvis carbonarius ufque ad focum bene compactus. Latera muro clauduntur preter locum quendam circa murum lateralem, ubi ferrum quoddam repofitum ef multis foraminibus pertufum, fcilicet ut fuppeditetur fecundum modum loquendi illis ufitatum la lattarvola: omnia bene luto \& argilla muniuntur, \& orificium ventilatorium in medio foci pariete relocatur, inque focum vel extra murum. fuum extenditur ad 4 digitorum diftantiam, adque 6 Unzers ut vocantur, fupra fundum : dein ad craffitiem unius palmæ pulvere carbonario humectato inducitur fundus foci, qui dein repletur carbonibus, denum admittitur ventus. Quum carbones hi fint confumti, iterum novi immittuntur, \& infuper frufta ferrea; unum filicet poftalterum, qux carbonibus prorfus conteguntur, \& iterum fuperinjicitur pars ferri, quanta ad reple- 


\section{TAB: xm. De Ferro.}

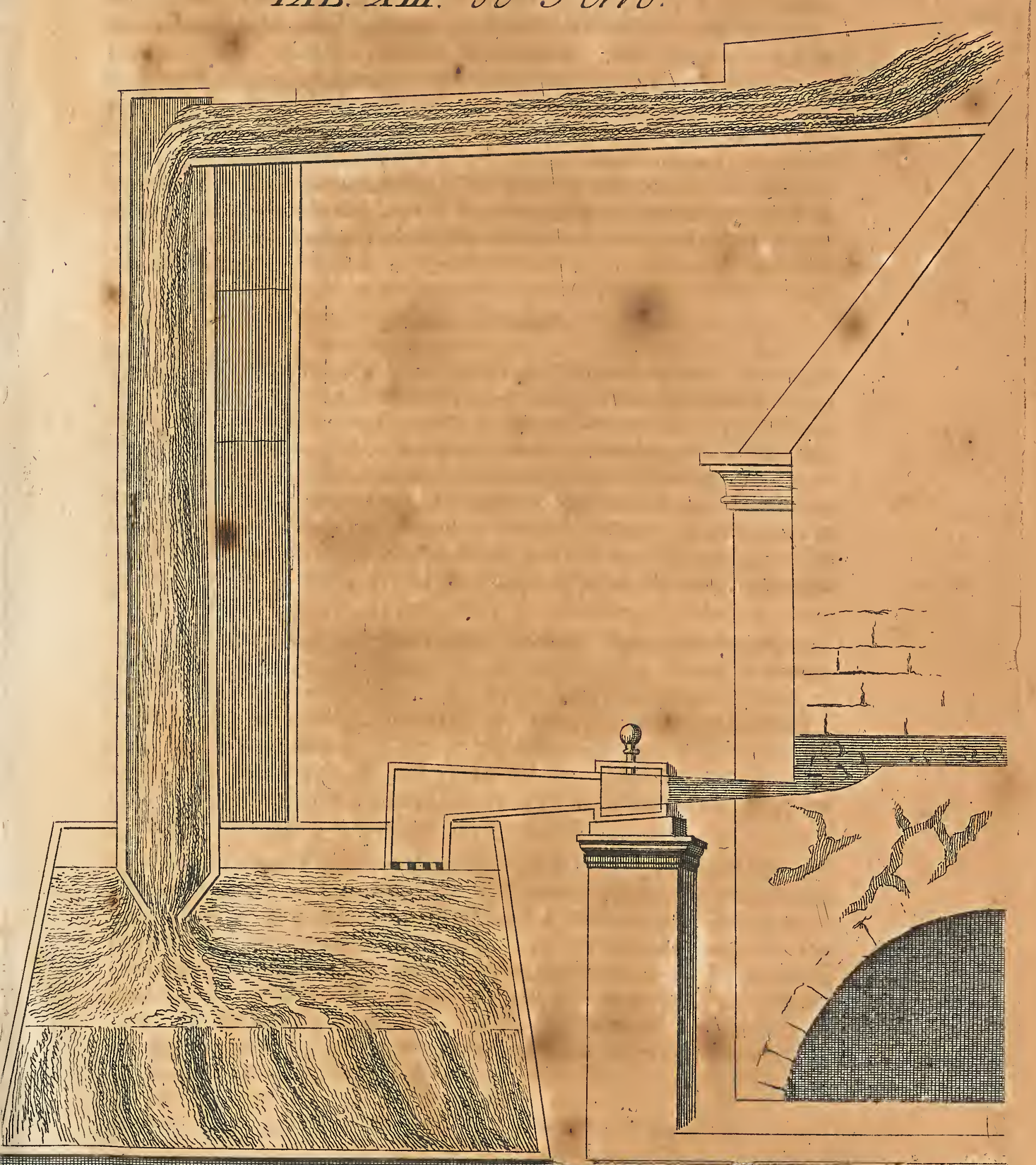

1) tat 


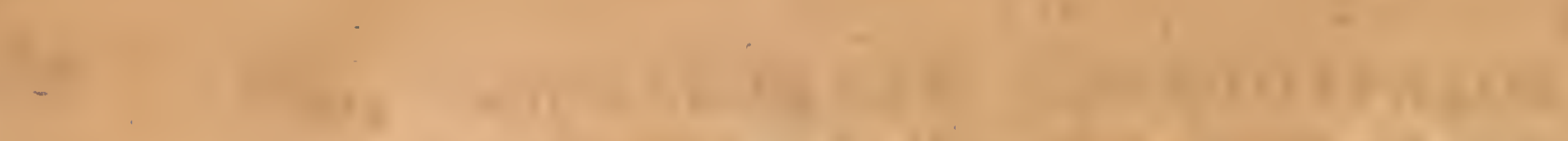
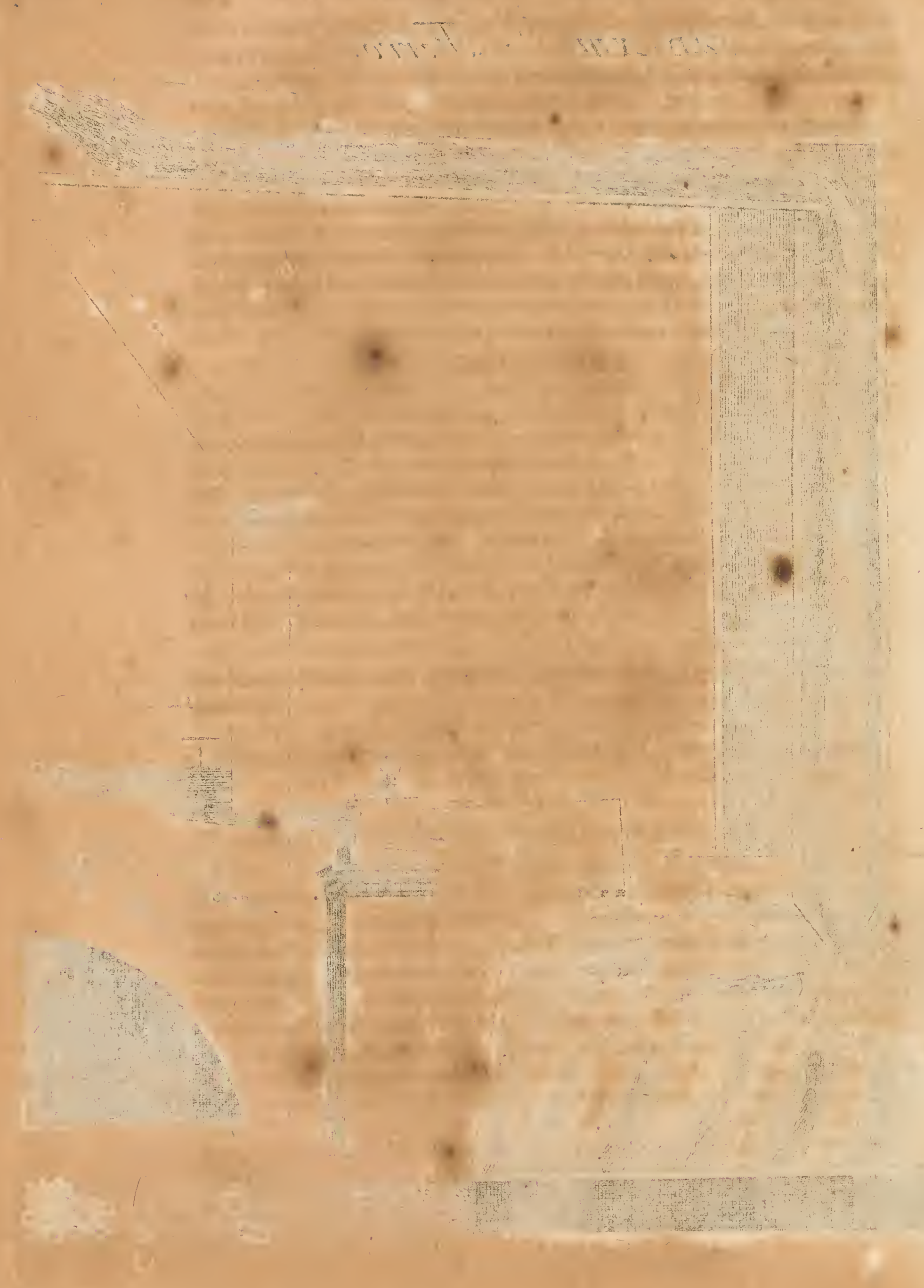
LIQUATIO VEN㤅 FERRI ITALIÆ. I5: tionem foci fufficere poffe videtur, quod continuatur, dum fcorix a ferro fecernantur, qux dein per unum foramen ferrex laminæ, de qua modo, emittuntur; fique plus fcoriarum adhuc remanere videatur, emittitur ru1fus pars refidua, emiffioque illa repetitur, quoties aliquid fcoriarum fuperfit, hoc eft, ufque dum ferrum recrementorum \& impuritatum planefit expers : quo facto, arripit tunc faber five qui foco proeft, contum cufpidatum 10 pedes longum, illumque in igne focali candetacic ufque dum fcintillet, ficque calefactum in maffam ferream jam ignitam \& tenacem adigit inferitque, \& illam fic prehenfam ex foco tollit portatque ad incudem, ubi illam in contos aut bacilla more folito extendit. Interea famulus evacuat plane focum, cumque frigefactus fit, illum e novo exltruit præparatque ad ufum.

\section{Alibi Italice.}

FErrum quod in Romania confumitur, adfertur ex Ancona : alias hic \& ibi funt opera ferri liquefactoria fed minora : vena illuc tranfportatur ex infula Elva, fub ditione Pontificis \& Duçis Florentini ; quæ partim liquatur in fornacibus, partim in focis ferrariis. Fornaces conftructx funt circa Conckam 40 milliaribus ab urbe Roma diftantem, fcilicet circa Nottonam, Cifterna, Montevana, Canizio \& alibi in territorio Neapolenfi. Operatio fuforia ibi per 2 vel 3 menfes interdum continuatur, præcipue circa Biombino \& Cervetto; fed quoniam non multum difcrepant a modo fundendi nuper in hac $\$$ pho tradito, hinc remitti ad defcriptionem illam lector poteft.

Alioquin circa Romam foci quidam exftructi funt, qui Ferrarier vocantur, unus ftatim prope portam St. Giovani; conftat 2 focis; inque uno funditur ferrum vetuftum collectum una cum regulis ferreis in focis minoribus ferrariis relictis; adjicitur etiam aliqua pars ferri crudi, quod vocatur vena di ferro, quodque illuc exBiombino adfertur. In altero \& vicino foco candefit ferrum, \& primum fub malleum majorem mittitur, dein excuditur ope malleorum manualium. Ventus in focum acquiritur per machinam prædictam hydraulico-pnevmaticam.

Focus primus repletur carbonibus, \& infuper injicitur pars ferri vetufti \& comminuti, ut \& reguli prædicti, \& infuper carbones una cum ferro crudo; ventus tunc admittitur, \& in maflam colliquefcit ferrum fpatio 2 horarum. Cumque ferrum hoc adhuc tenax \& lentum fit, contus ei ferreus inferitur, ficque mafla extracta fub malleum portatur, \& extenditur dein ferrum in contos, qui longitudine funt 4 ulnarum, craffitie 2 digitorum. Spatio feptimanæ fundi poffunt 3 milliers ferri, vel quovis die 4 vel 6 centumpondia. Carbones ex arbore caftanea \& fago conficiuntur, adque unum milliers sequiruntur 20 facci. 


\section{Alibi.}

A Lias quum a Roma Florentiam peragitur iter, funt foci extenforii infignes in via : ferrum crudum illuc defertur ex Biombino, \& ventus ope machinarum hydraulico-pnevmaticarum acquiritur; fique ventus fortior defideratur, duo canales ventilatorii in eundem focum ducuntur; alias vis venti augeri \& diminui poteft, fimodo aperiantur vel precludantur foramina illuc ducentia per piftilla.

Vena illius indolis eft, ut non calcinata ftatim mittatur in focum, fcilicet cum prius ope malleorum pulverifata fit ; illico, ut in focum delata eft, funditur. Qualibet quarta hora maffa ferri liquati parata eft, qua vo catur il Mazaro, \& ponderis eft $1_{\frac{1}{2}}$ centumpondii : quovis die \& nocte 4 Mazari vel 6 Cantari, vel fpatio feptimanx 36 ad 40 centumpondia funduntur fubque malleo extenduntur. Vena commifcetur plerumque cum fruftis \& fragmentis ferri vetufti, filicet cum globulis bellicis, quæ bombæ vocantur, \& aliis ferramentis : vel fi defit ferrum vetuftum, loco ejus ap ponitur ferrum crudum, ícilicet ut eo melius in fluiditatem quandam reduci poffit \& liquefiat vena, \& ex ferro eo melius leparentur fcorix \& impuritates. Circa unam officinam funt 4 operarii: Ad quodvis centumpondium ferri requiruntur $2 \mathrm{vel} 3$ centumpondia venæ. Videantur de his Tabule XIII \& XIV.

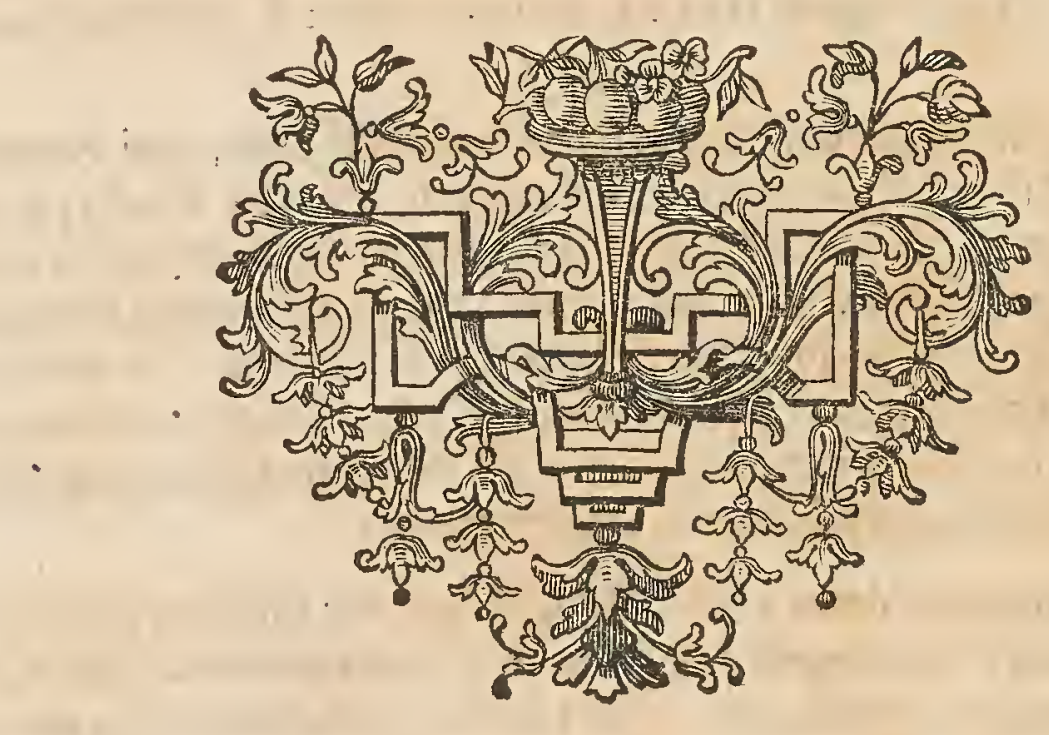




\section{PARAGRAPHUS XI.}

\section{Vena ferriut \& officina ferrarice circa Le $\int 0 \Theta^{\circ}$ Palagio non procul a St. Sebaftian.}

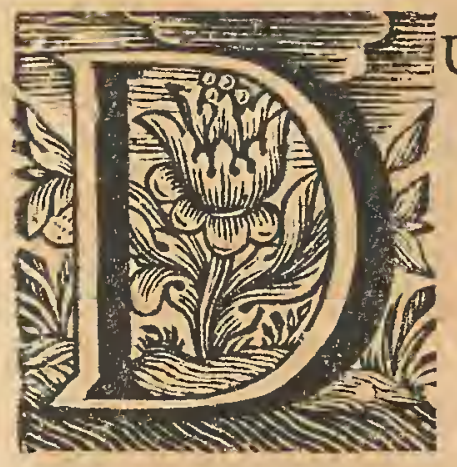

Uobus vel tribus milliaribus a St. Sebaftian non procul a Leffo \&Palagio circa fluvios hic \&inde fparfim funt foci ferrarii, qui Svecice Renmuerck vocantur, ftructi; fodinæ abinde funt circiter $\mathrm{I}$ ad $\mathrm{I}_{\frac{\mathrm{T}}{2}}$ milliaris diftantia: vena vix profundius perquiritur, quamad 40 vel 50 ulnas, poftea derelinquitur. In ftratis reperiebatur vena ad magnitudinem capitis humani in argilla, quæ frufta facie externa coloris brunei erant, fed fracta nucleum oftentabant coloris nigricantis; ad latera ftrati erat modo argilla dura cum arena mixta, nec accubat mons, ut alibi, unde vena ope cuneorum inde effringebatur. Officina quævis ferraria conftat duobus focis: vena quibusdam in locis per 2 \& 3 dies \& noetes calcinabatur, antequam funderetur; in quibusdam vero nulla calcinatione opus erat; prælertim cum nulla ineffet fuperflua pars fulphuris. In focum unum mittebatur vena fub malleo quodam prius divifa \& pulverifata modo Genuenfi una cum carbonibus comminutis mixta, inibi dein fundebatur ante ventum. Maffa ferri crudi in foco hoc parata inde transferebatur in alterum focum, ut fcilicet denuo liquelceret \& fub malleo extenderetur. Spatio integr: feptimanæ 40 ad 50 quintals ferri crudi fundi \& excudi potuerant: ex vena fumebatur $\frac{\mathrm{r}}{4}$ vel $\frac{\mathrm{r}}{3}$ pars, \& plus.

Trabs vel truncus, cui incus immerla that prope ipfum caminum \& humiliter fatis eft repofitus, ne filicet faber maffam ponderofam ferri illuc cum multo labore portare \& transferre debeat, fed ftatim a foco in incudem transmittere. Sunt rotæ aquatice exigux; folles etiam coriacei. Carbones ex arbore caftanea \& fago.

Ad officinas ferrarias, 'quæ litoribus propiores funt, apportatur vena ex Bifcaja, eruiturque non procul a Bilboa, \& per undas ad St. Sebaftian transfertur; eftque ditior quam illa qux effoditur ad Guipufcoi. Suntque ergo opera ferraria in provinciis Guipufcoa, Navarra \& Bifcaja; fed ubique funt officinæ \& foci ferrarii, quales jamdum. defcripti funt.

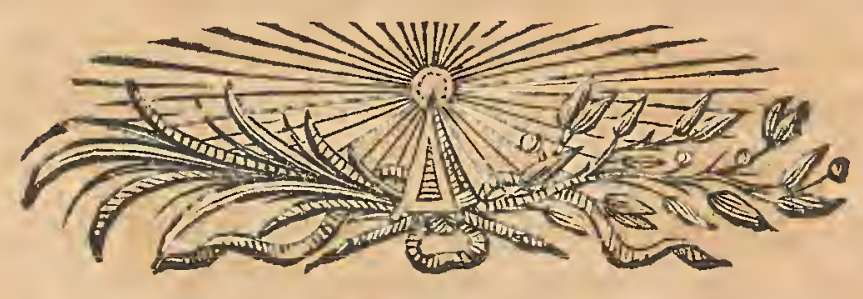

Claffis L. de ferro. 


\section{PARAGRAPHUS XII. \\ Modus venam coquendi, ferrumque crudum recoquendi Anglia.}

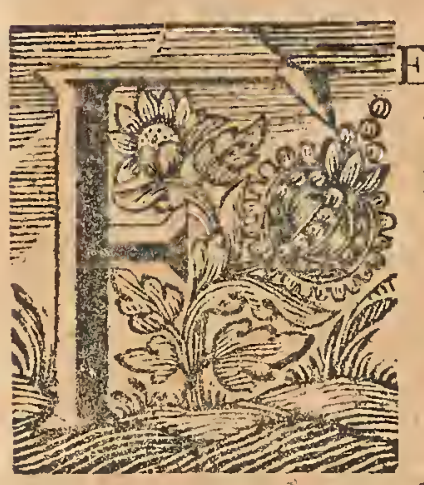

Erri vena, qux Anglix effoditur, exploratur \& inveftigatur utplurimum per terebras, quas in agros \& terras ad infignem fiepe profunditatem intrudunt ficque aperturam fibi moliuntur, de qua terebratione agere conftitui in tractatione de fale communi : venam interdum folent invenire fub terra circa altitudinem ro vel 20 pedum, quum prius ftrata arenaria \& argillacea transmifli fint: fub majore adhuc altitudine fub argilla coerulea pingui \& agros focundante. Proxime fupra venam aliquibus in locis ftratun habetur faxeum; genus hoc fixi menftrui folventis aut lapidis calcarii loco una cum vena apponi folet, filicet $\frac{\mathrm{I}}{\mathrm{I} 4}$ ejus pars, una cum $\frac{\mathrm{I}}{4}$ parte calcarii lapidis: Hoc genus venæe calcinatum induit colorem purpureum. Hac venx fpecie poliri etiam folent vitra loco fimiridis.

In aliquibus provinciis terra ubique apparet fœta \& fœcunda vena quadam ferri, fed qux diverfe qualitatis eft, hic pauperior, hic vero ditior.

Vena etiam ferri multoties Angliæ reperitur in locis paluftribus \& quidem fratim ad crafficiem I pedis vel amplius, quod genus dives admodum eft : cum vero liquanda fit, mif́cebitur cum alia venæ folidioris fpecie, ne fcilicet caminus fornacis per illam obturetur \& quafi precludatur. Hoc'venæ genus, quum primum eruitur, eft coloris flavi \& quafi unctuofum : at vero diu expofitum aeri, ficcefcit, \& in pulverem coloris nigri dicitur collabi.

Vena etiam in ipfis montibus, hoc eft, in faxo folidiori Angliæ frangitur; led genus hoc venæ interdum metalli inops eft, unde cum vena priore commifcetur. Eft etiam aliud venæ ferreæ genus coloris grifei, quod juxta ipfam montis fuperficiem folet apparere, ad latitudinem plerumque $\frac{\mathrm{I}}{2}$ ulnæ \& adhuc minorem, vena hæc vocatur Pinmine; non durum eft genus, fed inftar cretæ aut argillæ induratæ, unde frufta vel majora vel minora exfindi poffunt; cumque fruftula hæc dividuntur, nucleum quendam mineralem intus recondere videntur.

Vena etiam coloris fubcorulei eruitur præfertim in Dean Foreft, ponderofa admodum cum micis exiguis candidis \& nitentibus, unde etiam fiagile redditur inde ferrum, nifi cum fcoriis vetuftis vel cineribus carbonum foffilium commifceatur.

Commixta etiam invenitur ferri vena cum lapidibus varii generis, \& pariter ac cupri vena inter lamellas lapidis lciflilis, ut \& in carbone folfili; prafertion in Staffordshire; nomen etiam habet ex coloribus.

Fornaces 


\section{LIQUATIO VEN EE FERI ANGLI Fornaces ferri fuforia in Anglia.}

Iquationes ferri ex vena \& extenfiones ejus in officinis in Anglia admo-

dum vigent florentque, \& intra fequiores annos increbuiffe tam numerum fornacum quam etiam officinarum, ipfamque artem incrementa cœpiffe dicitur. Fornaces fuforix \& camini ferrarii plures funt in provincia Lancashire, pariter etiam in Lichtonbeck, Cunfey \& Backbarrow. Fodinæ funt ad Henningwood in Lowfonefs \& ad Adgarley circa urbem Ullverffon: vena ex fodinis effoffa eft pinguis \& imprægnata, coloris rubri: illa vero quæ obtinetur circa Whitehavers ditior adhuc eft, nam ex 5 tons five $37 \frac{1}{2}$ ponderibus nauticis Svecicis obtinentur 3 tons five $22 \frac{1}{2}$ pondera nautica ferri, adeo ut ratio fit 100 ad 60 five 60 Pc. . Utque eo melius fluant venæ, apponuntur etiam recrementa vetufta, five quæ prius ex fornacum focis emiffa funt, \& ferro fœeta \& prægnantia.

In provincia Lancashire circa fornaces ferri fuforias five liquationes venæ, ulus quidem eft carbonum ligneorum, fed in illorum defectu \& penuria, in auxilium vocatur humus combuftibilis five terra pinguis : fed compertum eft, ferrum inde fulphureum \& ægrum difficileque tractatu reddi, calidum enim in partes frangitur, nec contus inde procudi poteft, nifi qui undique fiffuris \& rimis hiet; unde nec multi ufus eft, nifi cum genere ferri alio melioris commifceatur.

Liquationes venarum ferri maxime florent circa Starbridge. Fornaces ferri fuforix ibi funt admodum altie, fcilicet a faxo fundamentali ad aperturam fupremam camini altitudo eft 26 pedum Svecicorum: formantur tamen non eodem modo quo in Svecia; facies fornacum externa, pariter interna differt a facie \& ftructura fornacum aliarum regionum; extra funt figuræ quadratx, quodlibet latus I'2 ulnarum longitudinem xquat; nam pars exterior fornacis paralelis muris ad tertiam partem altitudinis educta eft, inde excipit obliquitas, murus enim dein in aretius contrahitur \& obliquus afcendit ufque ad fummitatem, ubi intra parietes eft 20 ad 22 pollicum amplitudinis in forma quadrata. Focus figuram oblongam, fupŕa longitudinem 2 pedum \& 4 pollicum, fcilicet a parte anteriore ad parietem oppofitum five tergalem, latitudinem i 8 pollicum habet, infra vero vel juxta faxum fundamentale longitudinem 2 pedum \& latitudinem 17 pollicum : altitudo eft 5 pedum ad locum, ubi declinant foci parietes, totum hoc fpatium conftituit focum, quod ex declinatione melius videre licet. Intus conftruitur lapide lateritio vel alio genere quod bene refiftit igni, extra vero alius generis faxis. Ipfemet focus 4 faxis durioribus conftat, eftque cujusvis lapidis pondus fere i vel $I \frac{T}{2}$ ton. Lapis maximus ipfum fundum foci conftituit, 3 reliqui parietes ejus : accedit 5 tus fuper aperturam emiffionis relocatus. Accidere etiam interdum folet, quod qua partem confumantur lapides, adeo ut focus principio i 7 pollices latus ad latitudinem 3 pedum ampliatus reddatur. Orificium ventilatorium etiam lapideum eft: munitur pars inferior orificii lamina ferrea, fuper quam recubant fiftulx aut nares follium. Folles partim funt lignei, aliquibus in locis adhuc coriacei. Coreacei longitudine funt I 8 pedum, laticudine 4 


\section{LIQUATIO VENÆ FERRI ANGLIÆ.}

pedum \& 2 digitorum : fiftulæ folliculares five roftra longitudine I pedis \& 4 digitorum. Lignei vero conftant tabulis quercinis 5 digitos craflis circa latitudinem maximam follis, alibi vero $\sigma_{\frac{1}{2}}$ digitos : ubi caput follis eft, five ubi minima latitudo five cardo, profunditatem 7 digitorum \& latitudinem 8 habet : longitudo follium ligneorum eft i 8 pedum, latitudo 4 \& interdum magis. Valvulæ fuctoriæ five attractoriæ venti five columellæ longitudinis funt 17 digitorum \& latitudinis 16 : fiftul: folliculares funt longitudine 4 pedum \& 6 digitorum; extra folles prominent ad longitudinem 3 pedum \& 3 digitorum : diameter aperturæ narium eft 2 digitorum : folles intus ftanno obducti funt ad altitudinem ufque 7 pedum a fiftulis : putatur eo facilius propelli ventum, \& ignem, fi quis per fiftulas in interiora attrahatur, exftingui \& emori. Rota aquatica eft 22 pedum, profunditas alarum eft 23 digitorum, \& inter illas diftantia 6 digitorum. Trabs eft diametri 2 pedum \& 9 digitorum, \& longitudinis 24 pedum.

Calcinatio venæ non peragitur in loco ad illum finem conftrueto intra muros, fed fub dio in nudo folo; fupponiturque primum ftratum quoddam carbonarium; carbones ad hunc ufum minores eliguntur, qui fcilicet circa fornacem fuforiam non bene pofint ufurpari, vel qui ex fornace, peracta fufione, extrahi folent; fuper ftratum hoc carbonarium locatur vena; iterum carbones, ficque vena, quod continuatur ftratim ad altitudinem defideratam : accenfis dein carbonibus qui infra funt, arripit omnis cumulus ignem, comburiturque fpatio I feptimanæ aut diutius; cavendum tamen eft, ne xftus vehemens nimis fit, adeo ut pars venæ, qux igni fit proxima, liquefcat.

Diverfæ fpecies venæ commifcentur ut Ironftone \& Iron-ore, \& quum certa ratione prius fint commixtx, apponuntur. Circa fornaces has in Starbridge funt 2 genera venx; primum five Ironftone effoditur ex terra molliore aut argilla, \& fruftatim reperitur non procul a fuperficie; ficca admodum eft \& ferri egena : alterum vero genus ditius eft; dux ejus partes dant unam ferri : hoc alterum genus etiam in 2 fpecies fubdividitur, una ejus fpecies fulphure pollet, altera vero fulphuris eft inops.

Circa opus hoc fuforium ufurpantur carbones quercini \& majufculi, qui majores funt, confervantur, ut adhibeantur circa focos ferrarios : adque fufionem I ponderis nautici dicitur non majorem quantitatem carbonum confumi, quam dimidiam leftam five 6 vel 7 tonnas. Ad Lancasbire commifcentur terræ combuftibiles cum carbone ligneo, fed ferrum inde inquinatur fulphure fitque fragile cum candet. Interdum vel aliquibus in locis ufurpare volunt carbones foffiles, fed qui in cineres aut in Cindres, ut vocantur, primum combufti aut calcinati fint ;- fed expertum effe dicunt, minorem inde quantitatem ferri obtineri, quam fi carbone ligneo utantur; nam ex nudo carbone ligneo, prout mihi relatum eft, fpatio feptimanæ obtineri folent 15 vel 16 tons ferri, at fi eis commixti fint cineres carbonum foffilium, obtinerimodo 5 vel 6 tons, ut taceam inde reddi ferrum fragile cum calet, \& notæi vilioris, vixque ullis utenfilibus aptum.

Fornax repletur primum carbonibus, qui cum ad altitudinem 5 pedum fubfiderint, imponuntur rurfus 3 corbes carbonum, \& infuper'ro 
vafcula venæ, rurfus quum fubfiderint ad 5 pedes in camino, 3 corbescarbonum cum 10 vafis venæ. Vafcula replentur quibusdam in locis 20 peciebus venæ, fcilicet 18 ex vena qux Ironftone vocatur, \& 2 ex pulvere minerali poft calcinationem in fabulum collapfo. Spatio 12 horarum impofitiones funt 6: emittitur ferrum bis, fed interdum non nif lemel intra 24 horas; at quavis emiffionis vice obtineri folent, non quidem femper, $7 \frac{\mathrm{r}}{2}$ pondera nautica ferri, quod dividere \& partiri folent in 23 maffas. Scorix partim funt virides \& vitrificatæ, \& feruntur inde ad furnos vitriarios, fed vitrum inde obtinetur fragile; quod ut ne fiat, eligende funt fcorix qux ferri immunes funt.

Quavis vice imponuntur 4 vel 5 corbes carbonum, \& infuper vena; infuper carbones \& fic venæ pars altera, \& fimul $\frac{\pi}{8}$ vel $\frac{7}{7}$ Bushel lapidis fupra memorati; cavendum tamen eft, ne nimia quantitas imponatur.

Si fornaces majores fint, emittitur ferrum per aperturam folitam in toros \& cubilia ad illum finem parata, at vero fi minores, colligitur volumen ferri liquati in uno loco aut receptaculo, \& inde in menfuras debitas effunditur: bis fpatio 24 horarum emitti folet ferrum, \& quavis emiffonis vice quantitas I $200 \mathrm{Vel}$ I $300 \mathrm{ft}$. five 4 ponderum nauticorum obtineri. At fi tormenta majora fint furidenda, in foco retinetur volumen ferri per fpatium 2 dierum, magis minulque fecundum qualitatem venx \& ipfiusmet fornacis.

Quod conftructionem ipfam fornacis attinet, illam quodammodo videre licet ex delineatione appofita: Tab. XV delineatio reprefentat fornacem ad Glocefter in Suffex, quxe etiam altifima \& celeberrima illius regionis eft: altitudo ejus eft 28 pedum, quum alibi fint 24. (A) Tab.XV oftendit partem fuperiorem fornacis, ubi impofitiones dict $x$ fiunt; ibifornax latitudinem habet 22 digitorum in forma quadrata; aliis vero in locis eft fornax minus lata; extra eft 4 vel 5 pedum in forma quadrata.

(BB) funt parietes fornacis, qux altitudinem habent 28 pedum: ad (CC) eft altitudo 20 pedum, fed aliis in locis non nifi 15 vel I 6 , ubi fornax modo 24 vel 25 pedes alta eft.

(CC) eft amplitudo maxima fornacis, fcilicet fupra (DD) I vel $I \frac{\pi}{2}$ pedis, amplitudo interior fornacis eft ibi $7 \frac{\mathrm{T}}{2}$ pedum, ab altero latere eft amplitudo 8 pedum, alii folent ei impertiri figuram quadratam 8 pedum, (DD) incipiunt obliquitates aut Boshes, ut vocantur, facta fecundum delineationem, illum fcilicet in finem, ne vena \& carbones in focum fatim illabantur, quorum ope impediri ipfamet liquatio poffet. Bosbes ampliffimæ funt verfus fuperiora, juxta focum vero differunt ad $\frac{x}{2}$ pedem.

(EE) funt ipfrmet obliquitates, quix I 8 digitorum funt; fique adjiciatur altitudo foci vel tigilli ( $G$ ) five I 8 digitorum, qux fimul faciunt 3 pedes, eft altitudo horum parietum ( $a b Z$ ) ufque ad $(G)$ five fupremam partem foci: altitudo (DD) ad (KK) eft 7 pedum. Predicta hrec ratio obfervatur, fi fornacis altitudo fit 24 vel 25 pedum; at vero fi adhuc altior fit, tunc dictæ Boshes adhuc altiores effe debent longioresque ferme in data ratione. (FFF) eft craffities horum parietum, quæ etiam variat fecundun majorem vel minorem amplitudinem foci.

Clallis I. de ferro.

$\mathrm{Rr}$

Per- 


\section{LIQUATIO VEN无 FERRI ANGLIAE.}

Peracto opere fuforio fubruuntur hi parietes; faxa vero fundamentalia diu confervantur, antequam inde eximantur.

$(G)$ eft focus, qui longitudine eft 5 pedum, fcilicet ab apertura anteriore ad latus oppofitum, latitudine vero 2 pedum \& 2 digitorum, \&altitudine I pedis \& 6 digitorum; ad quam altitudinem etiam alcendit ferrum liquefactum, hoc eft, ad ipfum orificium ventilatorium. Sed hac dicta amplitudine gaudet focus, fi tormenta majora fint fundenda, at vero fi tantum utenfilia, caminuli, ollæ \& id genus alia, focus longitudinis erit 4 pedum, latitudine 18 digitorum, \& altitudine 10 vel i 2 digitorum.

(H) eft apertura anterior, per quam emittitur ferrum. (I) eft orificium ventilatorium, quod propius jacet ad parietem, emifironis laterioppofitum, fcilicet ad diftantiam modo 8 digitorum, ad latus anterius; ita applicatum eft orificium, ut ventus ad latus oppofitum poffit pervenire, quum focus plenus fit. Obfervatur hic, quod non liquefeat vena, quam cum ad dictum orificium ventilatorium prrvenerit. (K) oftendit fundum fornacis. H:e qux jam relata funt, debentur Clariff.Domino Commiffario Kahlmeter Sveco.

\section{Fornaces ferri fuforice pro tormentis bellicis Anglice.}

FOrnaces pro fundendis tormentis bellicis Anglix in provinciis Suffex \& Kent plures funt: provincix non procul a mari diftant, venaque ibi reperta eft indolis optimæ.

Fornaces eodem modo conftructx funt ac predictx, quibusdam in locis funt dure fimul junctx intra eosdem parietes; hodie vero non nifi uno camino five cavitate \& uno foco conftat fornax hæc tormentorum fuforia, idem enim præftat una ac olim binæ, modo focus ampliatior \& fornax capacior ac ppatiofior redditur. Alias vena imponitur \& funditur eodem modo, ut in fornace vulgari, cujus defcriptio jamdum facta eft. Tempore hyemali inibi funduntur tormenta, æitivo vero ferrum crudum. Fornaces in Suffex aliquantum majores funt quam in Kent: circa Tunbridge refertur quavis I 6 ta hora duo tormenta fundi poffe, quorum quodlibet I 500

Weight pendet. Foffæ aut receptacula fecundum morem ex argilla, adjectis etiam capillis \& fimo, parantur, unum fcilicet prope alterum in terram perpendiculariter effoffun.

Princeps Robertus plura experimenta hic inftituit fufionem per carbones foffiles peragendi, præfertim per illos qui vocantur Pickkobl, opus ętiam per aliquot feptimanas continuatum effe dicitur, fed focum repletum recrementis \& præclufum materia tenaciore \& quafilimofa fuife; præter quod ferrum nimis fulphureum redditum fit.

Idem Princeps Robertus alia etiam experimenta circa ferrum inftituere annifus eft, hujus rei \& chymixe bene peritus; hinc diverfigeneris $1 \mathrm{a}$ lia aliaque ferro liquido admifcuit; illum in finem, ut tormenta redderentur omnis rubiginis expertia, nam interior tormentorum canalis \& ductus 


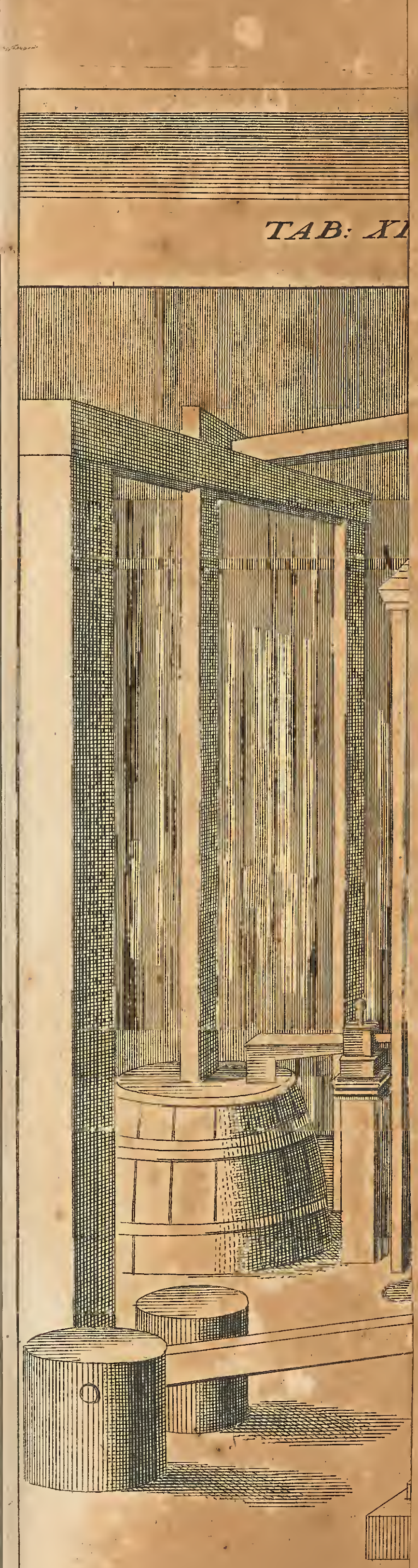





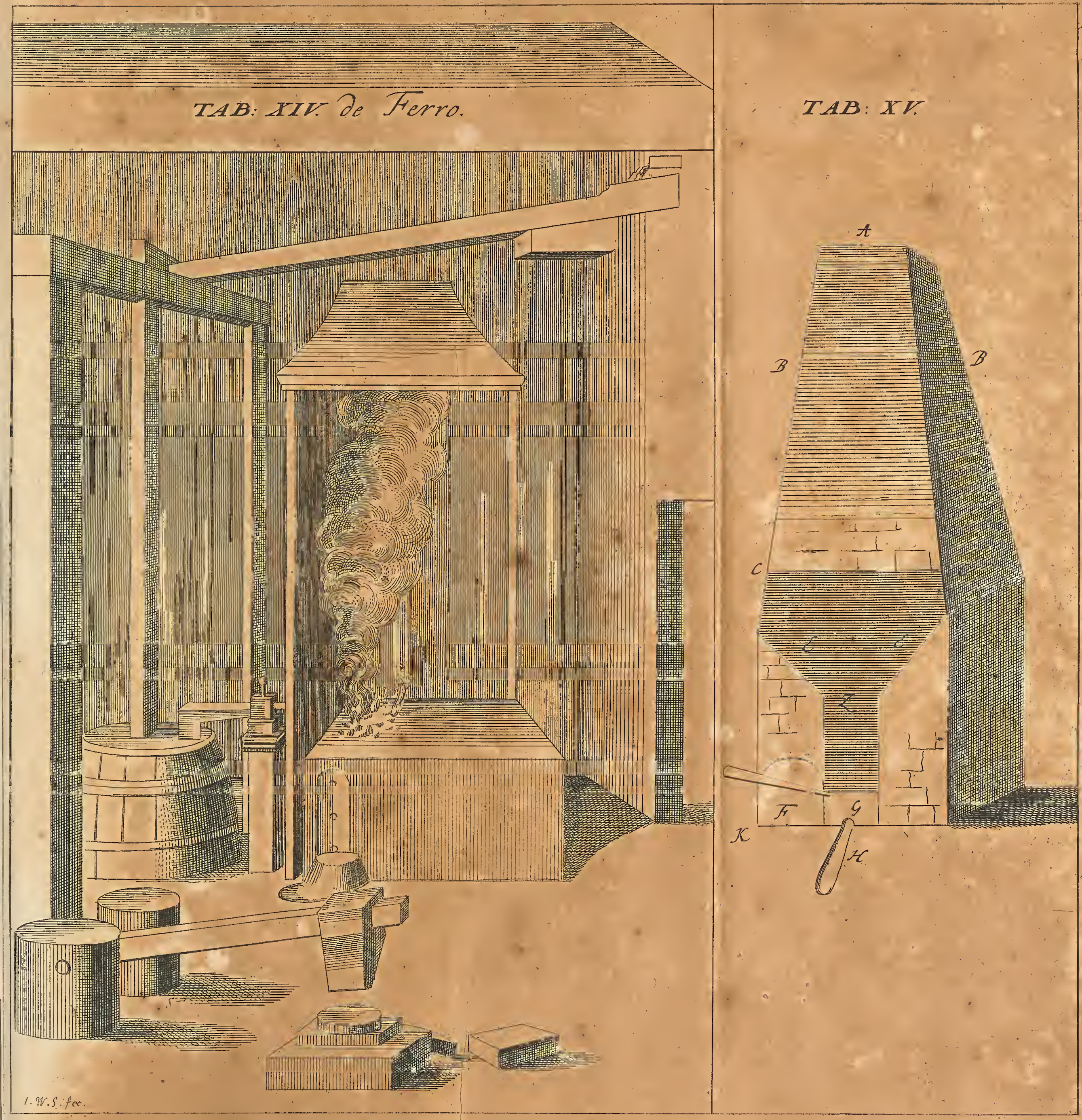




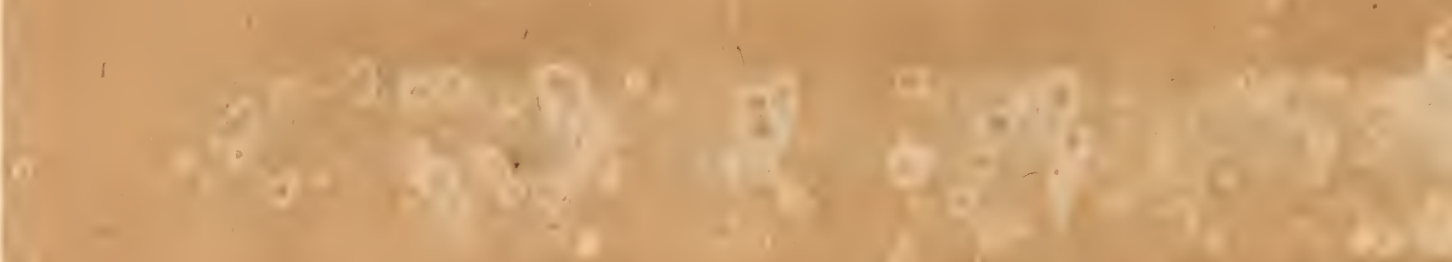

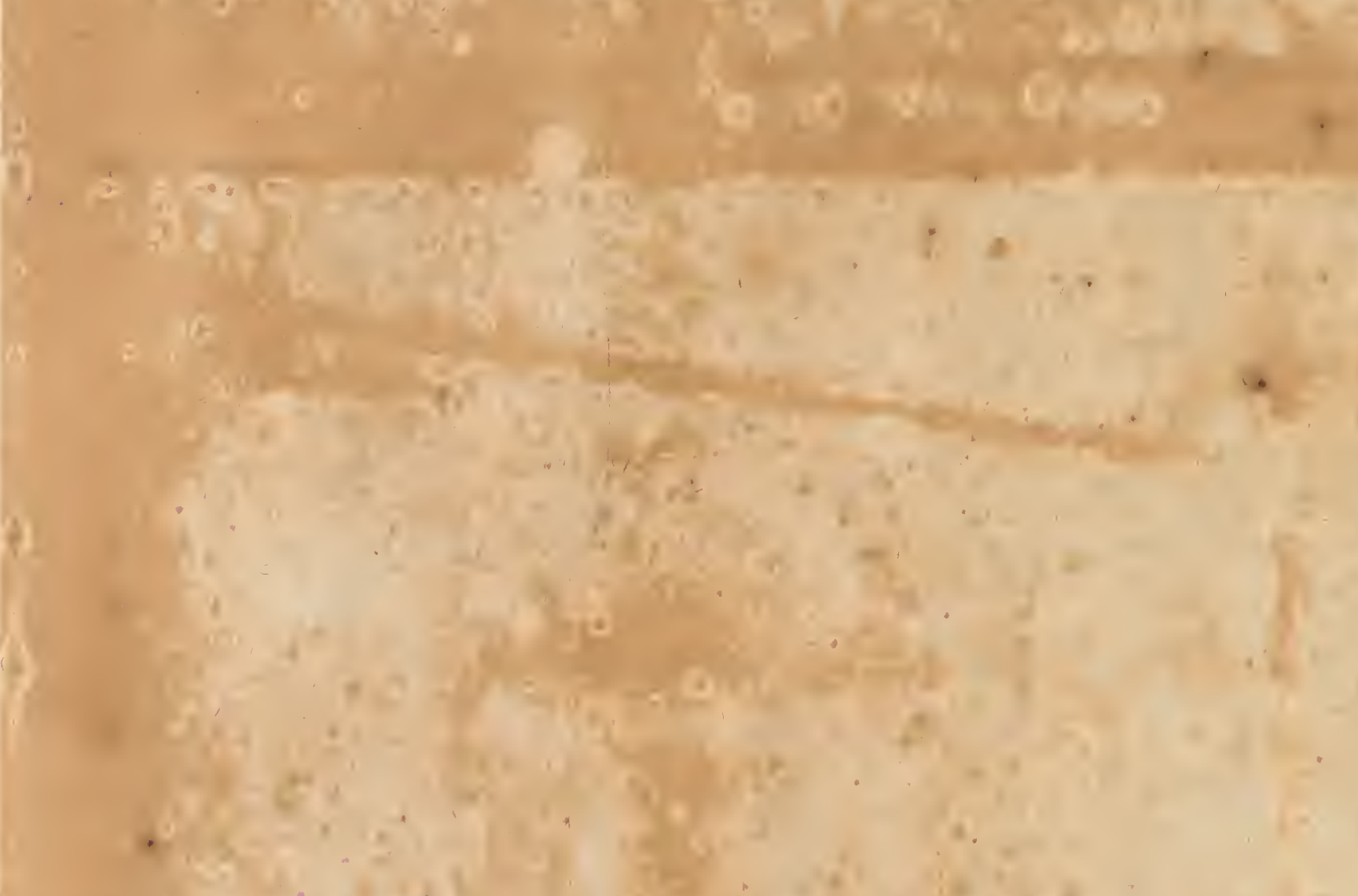

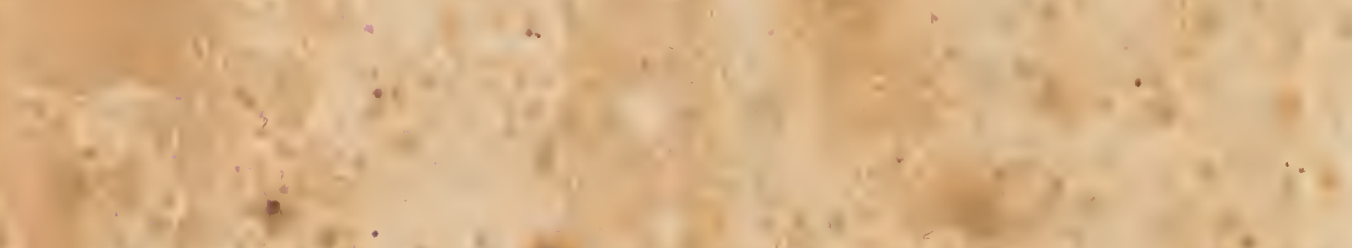
1,

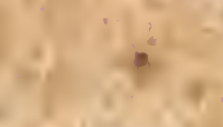

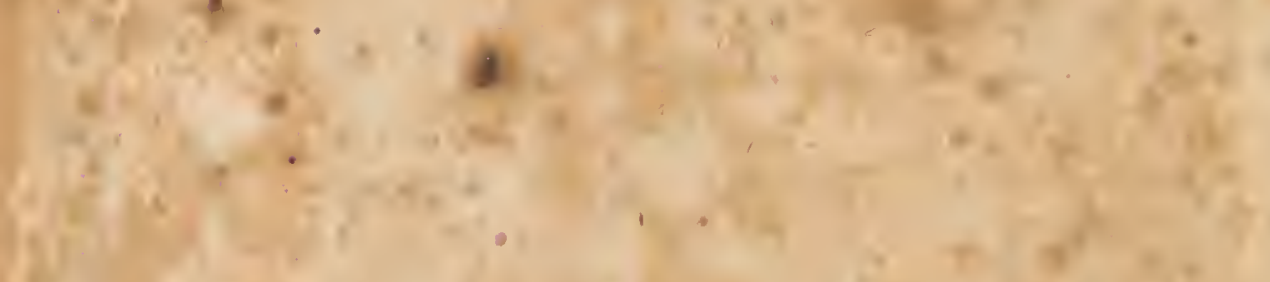

1.2.

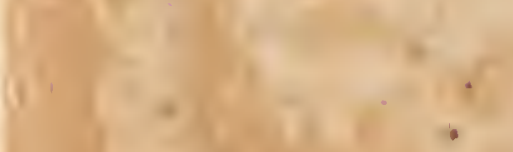

4. $35-$

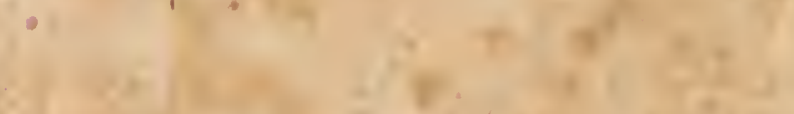

s

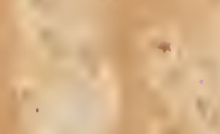

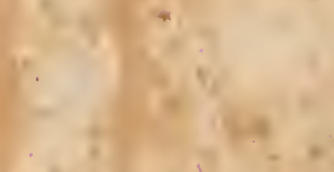

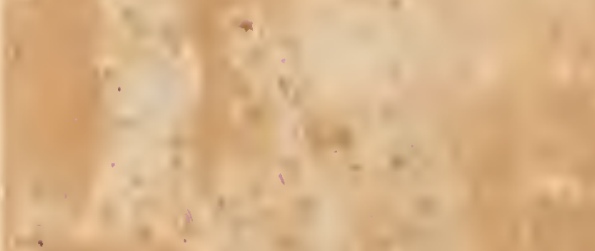

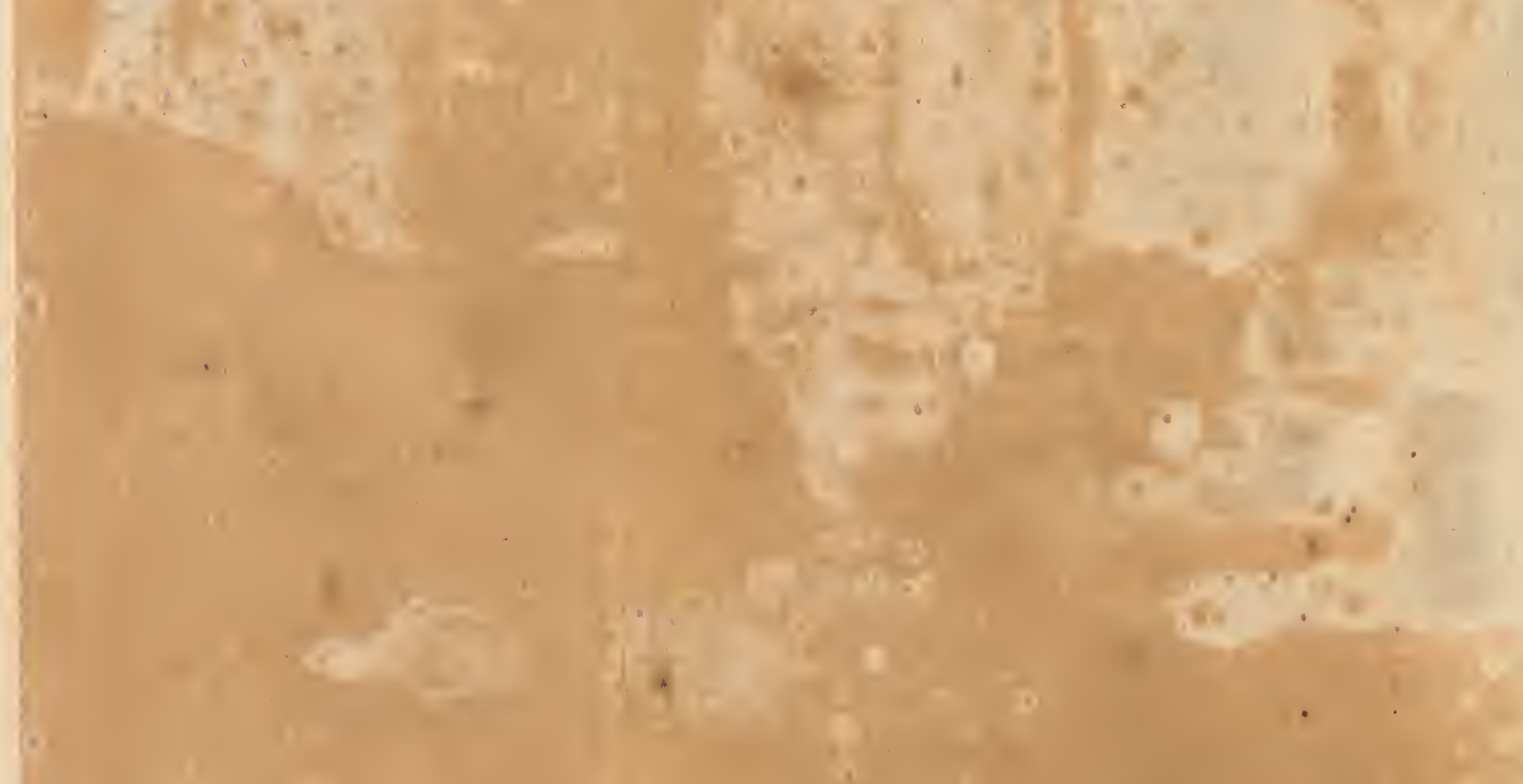


LIQUATIO VEN屟 FERRI ANGLIE. 759 rubigine folet atteri exedique, \& inxqualior faberque fic reddi : \& reor aliquantum etiam fucceflife tentamen, adeo ut rubiginis intra 9 vel 7 annos redderentur immunia. Pariter etiam tentavit tormenta leviora fun-. dere, quæ tamen eundem cum gravioribus ufum præitarent.

Vena, quæ hic frangitur, mitior eft, quam in aliis Angliæ provinciis, hinc quafi dicata eft tormentis fundendis, ad quod opus vena requiritur admodum fluida, qua nec multo fulphure fcateat, unde tormenta bullis quafi, puftulis \& cicatricibus inæqualia fiunt: nec omnis fulphuris expers deber effe vena, facile tunc in partes a crebris tremulifque percuffionibus \& quaffationibus difflire poffunt tormenta; quod evitatur, fi vena de utraque qualitate participet,

\section{Officine \& foci ferrarii Anglia.}

Fficinx ferrarix vel compofitz \& duplicatx funt, vel etiam fimplices; in officina duplicata funt 3 foci, \& unus modo malleus : binifoci vocantur Fineries \& tertius Chaferie : priores dux funt figuræ oblong:e ex laminis ferreis conftructe, qux 2 pedum \& 3 digitorum longitudine \& I 8 digitorum latitudine circiter funt : lamina fundamentalis craffitiem 2 pollicum habet, \& fupra fundum, qui pulvere carbonario conftat, libere jacet. Ad partem foci anteriorem, five ubifabriftant laboremque fuum exercent, repofita jacet moles ferrea, formæ quadratx latitudinem foci æquans, in medio eft apertura, ut fcilicet per illam emitti poffint fcorix : utque contineatur focus \& indivulfus ftet paries, affulcitur fruftis ferreis. Non eandem in omnibus focis dicunt effe profunditatem, fed variare fecundum indolem venx; ad Milliron focum conftructum effe profunditatis 9 digitorum: laminas, quibus parietes conftent, affixas effe muro; murum tergalem effe lamina quadam tectum, fuper quam relocentur mafie ferri crudi, qux in focum colliquandæe fint; quumque emiffe fint fcoriæ \& ferrum jamdum condenfatum \& tenax, fub malleum inde ferri : ibi in aliqualem longitudinem educitur, frufto ferreo ad unam extremitatem relicto, \& vocatur Anconies vel Blooms: alias vero ferrum hoc in bacilla attenuant,

Focus tertius eodem modo conftructus eft, quo bini priores, cum illo tantum difcrimine, quod aliquantum major fit \& profundior, longitudinis fcilicet 3 pedum, latitudinis 2, \& profunditatis I pedis \& 4 digitorum. Folles hic funt longiores, fed ex illis fpirat ventus lentius quam ex prioribus. Incus \& malleus conftat ferro fufo : mallei pondus effe folet 600 ad 660 战. Ex 8000 ft. ferri crudi obtineri folent 6000 itb. ferri purificati \& in bacilla extenfi.

Moles dictæ vel maffx, quæ vocantur Piggar, in focum liquefactorium five Finery mittuntur, exinde tanta pars (patio quovis horæ funditur, quanta requiritur ad I. Weight, quod vocatur Loop: inaffa candens percutitur malleis manualibus, ne fcilicet in partes fub malleo magno dilabatur; fub malleo magno fecatur dein in frufta formæ cubicx, cujus latus eft circiter $\frac{\pi}{2}$ ulnæ. Dein fertur hic cubus ferreus in eundem focum, \& per fpatium unius horæ tenetur in fudore calido, dein fub malleo primum in media 
parte extenditur in longitudinem 3 pedum, relietis ad utramque extremitatem fruftis, quie in altero foco candefact: in contosintegre excuduntur:

3 Load carbonum in foco Finery appellato confumuntur ad I tonn ferri; \& I Load in altero foco, qui Chafery nuncupatur. In uno foco per: feptimanam fundi \& purificari poffunt 2 tons, fed in Cbafery extendi circiter 5 ad 6 tons.

\section{Tentamen novum Anglice venam ferri fundendi in caminis reverberii per carbones lapideos jive folfiles.}

A Nho I 729 tentamen factum effe Anglix, \& 3 milliaribus a Whitbavers A inftitutum venam ferri per carbones aduftos foffiles liquandi narratur, \& diu poftea ejus rumor increbuit : refertur, venamferriex CumberIandia huic periculo infervituram apportatam effe : ipfam venam fub malleo vel pilo præferrato in glaream, \& carbonem foffilem fub mola comminutam effe. Venæ pulverate 8 menfuras five 172 libras primum in furnum anemium, feu quem reverberii vocant, ad hunc ufum aptius exftruEtum \& laqueatum, immiffas effe, \& intra 8 vel 1 o minutorum tempus crematam \& calcinatam ; \& expertum effe ex 8 menfuris $6 \frac{1}{2}$ vel I 43 libras refiduas manfiffe : cum refiduis adhuc dimidia menfura alius venæ commixta, adeo ut fimul pondus I 54 librarum xquaret, utrumque in pulverem fub molendina fubtilem tritum fuiffe; huic pulveri minerali adjectas effe 5 menfuras five 35 . libras carbonum fofflium; pariter unam menfuram argillæ figulinx, \& ope 2 cyathorum vel fitularum aqux bene unitam \& fubactam. Demum talem mifcelam fưrno anemio injectam, \& per aream ejus undique ftratam, vento illuc per ora patentia invitato per tempus circiter unius horæ \& 40 minutorum relictan effe, orificio furni non nifi femel intra dictum tempus patente : interea a coco hoc igne liquatam venam in molis aut maffix indigeftx formam confluxiffe; \& dein ex feceffu illo exemtam malleis ligneis tufam \& exercitam effe, ut freces \& recrementa fuperflua demitteret: quo facto, iterum eidem furno \& igni per femihorium commiffam effe, ut amplius defrecaretur, \& 2 eftuante fine flabris vivis igne purior redderetur, \& vitium per plures excandefcentias excoqueretur; \& dein fub malleo 35 librarum tunderetur, \& in formas diffingeretur. Dicitur ferrum candens molle apparuiffe, \& notas ab ictibus mallei profunde fatis recipere potuiffe; confumtis interea 286 libris five $6 \frac{1}{2} \mathrm{men}$ furis carbonum. Sed ufque tamen confitiffe, venam ferri ab igne ficciori, qualis eft furni reverberii; quidem liqui \& in fluorem redigi; fed a fuis vitiis \& abftrufis venenis \& freculenta parte non nifi per ignem multo vento foetum \& tumidum defæcari poffe, nec partes noxias penitus inhærentes excoqui fed potius incoqui: accedit, per fulphur foffili carboni, licet per morem fuetum cremato, inhærefcens, ita inquinari ferrum, ut, quod mite \& ductile ei ineft, contumax \& immite reddatur; five partem ejus meliorem, precipue quum de vena agitur, in fcorias verti; vel in fumum 
LIQUATIO VENÆ FERRI ANGLIÆ. I $6 \mathrm{r}$ avolare, (nam fulphureus vapor ipfum ferrum imprimis corripit, eftque \& diffipat;) vel ferrum inire, \& compagem ejus inquinare, ut dein frigidum \& calidum fathifcat. Non enim per fulphureum \& pyrium ignem redditur Mars mitis \& tractabilis, inde exalperatur magis. Cyclopes, qui fulmina Jovis fulphure fumanda fabricant, carbone hoc, deftituti ligneo, ferrum fibi parent.

\section{Modus carbones foffles cremandi, perqueignem quendam calcinatorium Julphure Juperfuo illos privandi, Anglia.}

Uoniam fulphure abundant carbones foffiles, hinc non apti funt liquationibus quorundam metallorum, prefertim ferri, nifi prius fulphure priventur, hinc primum ope aduftionis convertuntur in Charcoales. Pyram five rogum quendam conftruunt ex meris carbonibus foffilibus: juxca fundum locant majores, pariter circumcirca; in medio pyræ parant quandam aperturam five cavernulam, quæ magnitudinem pilei circiter æquat; infuper \& circumcirca accumulant fparfim carbones, ufque dum ad altitudinem debitam eductus fit rogus. Dictam cavernulam five hiatum replent ftipulis ramalibus five aliis fomentis, quæe facile arripiunt difperguntque ignem : \& quia hreca parte fuperiore accenduntur, progreditur ignis fenfim verfusinferiora \& circumcirca; unde fequitur, quod vis ignea primum interiora carpat \& exanimet, dein viam verfus latera moliatur. Si ignis alicubi jufto fortior fit, adeo ut in favillas aut cineres colliquefcere videantur carbones, ftatim in illo loco tegitur rogus humo aut pulverulenta alia materia, cujus ope via præcluditur igni, ficque partim reftinguitur, nec permittitur, ut per integrum cumulum fecundum omnem vim \& libertatem fuam dominetur, totumque acervum in cineres \& caput mortuum vertat. Tandem exftincta flamma \& igne fedato, apparent carbones æqualiter circumcirca cremati; fed ut eo melius exftinguatur, fuperinjicitur pulvis \& intercluditur meatus vapori igneo. Hoc modo fulphure fio fpoliantur carbones foffiles in Anglia vertunturque in cineritiam quandam fed ufque adhuc combuftibilem materiam, qux Cendres vocatur, cumque frigefactus plane fit cumulus, ademto pulvere nudatur; carbones refiduifulphuris craffioris expertes dicuntur liquationibus metallorum cupri ferrique idonei effe, qui tunc vocantur Charcoal, fed quod ferrum atti net, illud ejus ope reddi inutile compertum eft.

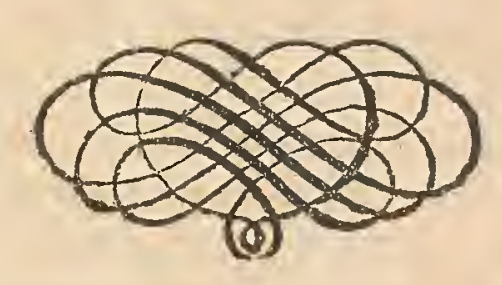

Clafis I. de ferro. 


\section{PAR A GRAPHUS XIII.}

\section{Modus venam ferri coquendi, ferrumque cru. dum recoquendi Marylandice Ee Penfiranice in India occidentali.}

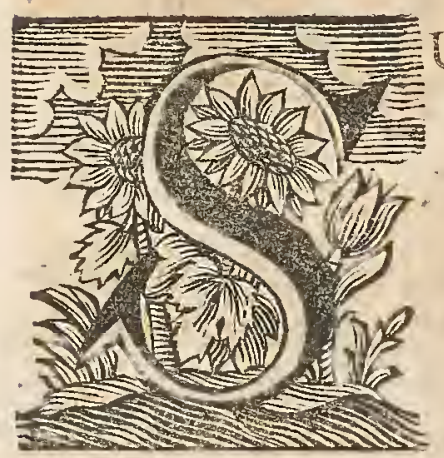

Unt aliquot fornaces pro ferrex venæ coctione, \& pariter officinæ pro ferri crudi recoetione, non ita pridem exftructæ, pracipuum opus vocatur Principio, in fuperiore parte provincix Maryland, flumini Principio nuncupato adjacens, unde etiam nomen trahit; aqua ejus a 25 pedum altitudine labi dicitur. Ad opus hoc ferreum appellunt biremes ut \& navicula vena ferri onufx, qux abinde 50 milliaribus foditur. Vena narratur coloris cani aut grifei effe, nec abfimilis vafis figulinis Hollandicis, dimidia fui parte ferro pollens. Ferrum hujus venæ reliquis palmam præripere dicitur. Ante 9 circiter annos ab adminiftratore regionis Sir Wiljam Keith ferri coquendi opus circa flumen Chriftinx exftructum. eft; quod primis duobus annis copiam latis infignem ferri elargiretur, fed quod tertio, deficiente vena, derelictum fit. Perhibent venam illius regionis multi quidem ferri compotem effe, fed nimis ficcam \& fine fluore calcario, cujus nulla copia detur, in ferrum nequicquam liquari poffe. Ad diftantiam unius milliaris abinde etiam fornax fuforia exftructa eft; fed, ut dictum eft, ob ficcitatem nimiam venæe \& penuriam calcis nec ibi inftituitur labor liquatorius; fed eliquatur jam vena in ipfis focis aut tigillisferrariis, ferri crudi recoctioni alias dicatis. Simile opufculum eft prope xedem facram St. James ad fluvium Hvitleer poffeffore Dno Joh. Ball, ubi pariter in tigillis fabrilibus aut malleatoriis coquitur \& recoquitur vena \& ferrum; fed officina modo unius foci eft. Aliud majus ad fluvium Skullkill exftruetum Dni Samuel Nuts, cum fornace \& focis ferrariis. Aliud adhuc 6 milliaribus abinde circa ejusdem fluminis ripam, poffidente Dno M. Rutter. Adhuc circa flumen Delavare funt bina ejus generis opera, unde copia ferri crudi in Angliam transmitti dicitur, pariter ex fornace prememorata Principio dicta. Sunt alias pluries exftuctx officinæ, ubi vena in tigillis vulgaribus funditur; quæ Blommeries vocantur, hodie 5 circa flumen diEtum Delavare conduntur, præter quas enumerantur adhuc 4 vel plures.

Modus liquationis crude., Vena primum fubjectis lignis \& partim carbonibus alte fuperacervatur, \& fic accenfo multo igne fufficienter crematur, adque liquationem more folito preparatur. Sic calcinata comminuitur in fruftula ova gallinacea magnitudine fere æequantia, \& per corbes in fuperiorem partem fornacis elata fuperimmittitur, cujus menfura eft unius Peck, prout vocant: binæ dictæ menfuræ Peck vocatæ five 18 vafcula venæ fuperimponuntur, \& infuper 24 Bushils carbonum; hocque quovis bihorio, vel citius aut ferius, fecundum defiderium aut appetentiam fornacis 
FERRI LIQUATIO PENSILVANI E. ${ }^{1} 6_{3}$

\& tigilli liquantis: adjicitur etiam lapis calcarius, vel ejus loco teftæe oftrearum aut conchilium. Liquamen fpatio quovis 24 horarum ter emittere affolent, \& quavis emiffionis vice i 5 centumpondia ferri crudi lucrari, feu intra diem \& noetem 45 centumpondia. Liquamen emiffum in arenam derivatur, \& in moles mediocres, qux vocantur Pigs, vel etiam in tripodes \& alia culinæ apta utenfilia formatur \& effunditur. Solent etiam aliquoties ferrum fuum fluidum e tigillis focalibus cochlearium ope exhaurire, præcipue quum utenfilia dicta formanda fint. Ipræ fornaces funt a fundo ad fupremum marginem 25 pedes altæ; folles longiffimi, lati 5 pedes. A-: perturæ, in quas immittitur cum carbone vena, eft figuræ oblongæ, longi tudinis circiter 4 pedum.

Recoctio ferri crudi fit in officinis \& tigillis : perhibetur ex pigs vel ex maffis grandiufculis ferri intra diem \& noetem recoqui \& elaborari unum: ton Anglicanum ferri; quod $7 \frac{\mathrm{T}}{2}$ pondera nautica Svecana $x$ quat; five 2000 illorum pondufcula vel Wights nuncupata : conftatque illis unum ton 35 pounds fterling, fecundum illius regionis valorem: unum vero ton ferricrudi 9 vel so circiter dictorum pounds.

Liquatio vence immediata in officinis \& tigillis five in illorum blommeries. Per ignem fuum focalem quavis vice transmittere folent venam 3 pecks feu I bushil prius calcinatam, \& in nucum vel glandium magnitudinem contufam; funduntque dein in maffam pondus 60 vel 70 Wights xquantem, qux intra 4 horas in virgas feu bacilla etiam extenditur. Mallei pondus eft 300 Wigths. Vena e diffitis admodum locis \& ficcioris indolis cum fumtu apportatur; \& illis, qui illam fubminiftrent, pariter qui carbones \& ligna, \& qui focis præfint, cum tironum \& coadjutorum turba, ftipendia majora pacifcenda funt.

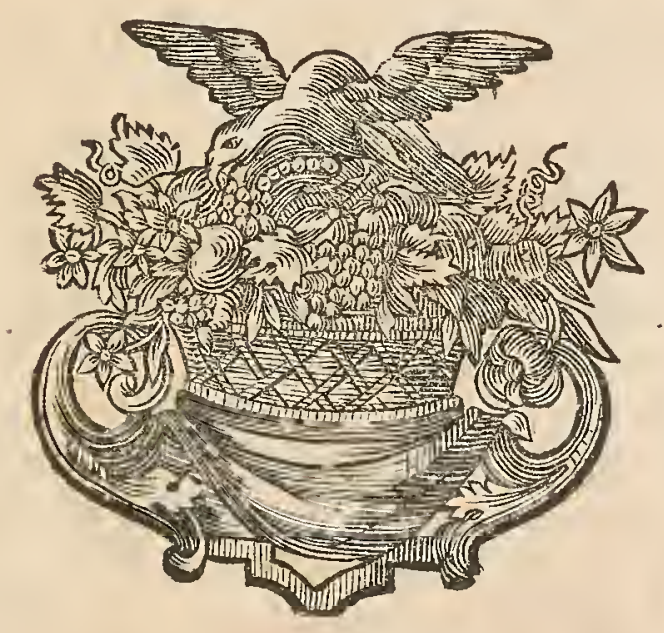




\section{Fornaces ferri fuforice, ut $\Theta^{\circ}$ officince focique fer. rarii in Rufia \& Siberia.}

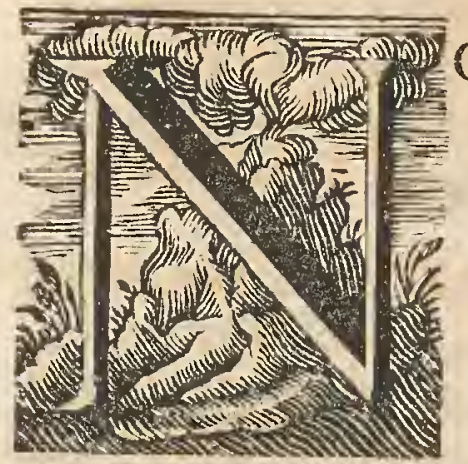

On multis retro annis exftructa \& inchoata effe opera ferri fuforia \& extenforia Ruffix \& Siberiæ, notum eft ; \& hodie ad illum numerum increviffe, ut tantus ibi quotannis ferri proventus habeatur, quantus non folum ufibus regni Ruffici fufficiat, fed etiamut aliqua ejus pars ad exteras regiones inde exportetur: ufque tamen provincix, in quibus fornaces \& opera dicta funt conftructa ipfaque vena effoditur, longiffime a mari diftant, unde multo cum labore, viæque tædio \& impenfis a locis tam remotis ad portum quendam maritimum ferrum transferri debet. Provincix jam plures vena tam ferri quam etiam paffim cupri abundant, \& in quibus vigent hodie labores liquatorii: prælongum foret omnes illas ditiones defcribere, hinc chartam geographicam exhibere velim, quæ provincias metallicas infigniores comprehendit, \& ipfamet loca fignis fuis notata, ubi fcilicet exftructe fint fornaces, pariter etiam officine ferrex, fiftit: incipit enim $7 \mathrm{vel} 8$ dierum itinere a Tobolskoi occidentem verfus circa opus ferreum Kamiencka ufque ad urbem Kungur, non procul a fluvio Kama, inde pergit boream verfus ad provinciam unius Woywodis jurisdictioni fubjectam Wergaturia vocatan : verfus auftrum ad regionem Bafcirorum ufque tendit. Incolæ regionis circa urbem Kungur a multis retro annis artem fuforiam ferri exercuiffe perhibentur, at ferrum ex materia quadam terreftri coloris bruni \& rubicundi conflaviffe, unde etiam notæ vilioris fuife. Celeberrimum ferri opus a Dimidoff extructum fuiffe, in plures officinas \& fornaces ferri fuforias divifum, qux quidem tractum fatis infignem complectantur, fed tamen ufque officinas non tam multum remotas \& invicem diffitas effe, Opus maxime famigeratum ferri Ruffie vocatur Sekoffke, quod initio conftabat 3 officinis ferrariis \& una fornace fuforia ferri. Dimidoff hic modo artem fabrilem calluit \& profeffus eft, a $C$ Æ $S A-$ re Petro Alexowitz dono accepit non modo officinas predictas, fed etiam alias circa Kofka, eique addixit ditionem quandam fatis infignem 7 fere milliaria Svecana in quadrata forma complectentem, cum immunitate, ut illuc tanquam in afylum criminis rei aufugere poffent, fic tanquam ad metalla damnati; utque officinas \& opera ferraria exftrueret, quot ei volupe foret, modo Cxfari quotannis 3000 Pud ferri extenfi, quodlibet pud pro 30 copekis, præeftaret. Interea exftruxiffe dicitur so officinas ferrarias circa Sekofka, 8 focos fabriles minores, pro diductioneformationeque ferri in utenfilia, qui Svecice Kniphambrar vocantur, una cum 4 fornacibus venæ ferrex fuforiis. Circa Benge opus ferrarium eft conftans I2 officinis \& 8 focis fabrilibus minoribus. Ad Siovoli funt 2 officina. Circa Togilla funt 2 fornaces \& 8 officinæ cum 4 minoribus. 


\section{MAPPA GEOGRAPHICA}

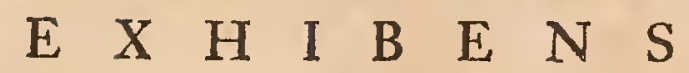

FODINAS ET OPERA FERRI ET CUIPRI

$\begin{array}{llllllllllll}S & I & B & E & R & I & E & N & S & I & A\end{array}$

PARITER JURISDICTIONEM

W E R K A T U R S K A

CUM

PAROECIIS, OPPIDIS, VILLIS, VICIS, MONASTERIIS,

$$
\text { UT ET }
$$

FERRI ET CUPRI FODINIS ET OPERIBUS.

IN

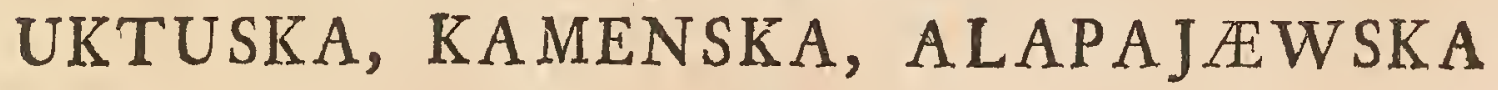

E T

F \&DKOWSKA, JERNBRUCK.

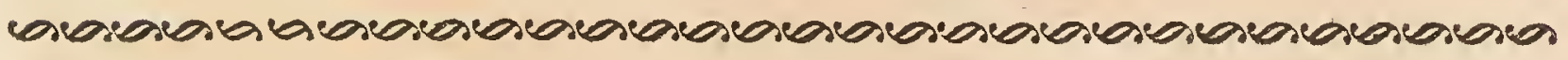

\& Significat Cupri Fodinas \& Opera.

o Ferri Fodinas \& Opera.

R. Rivos vel Fluvios.

¿ Monafteria.

- Villas aut Vicos.

袁 Villas majores, ubi funt 死des Sacra.

at Alias.

Villas minores, ubi funt ecclefia.

酋 Templa Tartarorum.

Y Villas Tartarorum.

Ruska. Rusficum.

S Svecicum.

Jernbruck. Opera Ferri.

Kopparbruck, Kopparberg. Fodinas aut Opera Cupri.

Lagfagu. Jurisdictionem.

Cetera funt nomina locorum.

Dresdæ \& Lipfiæ in Officina Libraria HEKELIANA 1734. 

Quum fufio venæ peragitur in fornacibus, qux ad Dimidoff pertinent, quotidie imponi folent 242 Pud venæ, pariter 50 corbes aut menfuræ carbonum, una menfura 6 tonnarum Svecicarum capax; bis de die emittitur ferrum in foco collectum, \& quavis vice 80 ad 90 pund, feu magis minusve fecundum qualitatem venæ fortemque liquationis, quæ non femper eadem manet. Quum ferrum hoc crudum recoquitur in foçis ferrariis \& in contos fub malleis extenditur, ex 100 ponderibus modo 60 remanent, adque extenfionem 60 puud, 25 menfurx five 200 tonnæ carbonum confumuntur. Siferrum per integrum annum in officina quadam recoquitur, hoc eft, fi perenne fit opus, excudi quotannis poffunt 5000 puud: unum puud rquat 36 ad $37 \mathrm{tb}$. Svecicas.

In Siberia ad Cæfarem pertinet opusferreum circa Alapaika, conftatque duabus fornacibus; vena circa prædium Lapaika vocatum eruitur. Anno 1717 venam ferriferaciorem \& ditiorem non procul ab ipfa fornace inventam inveftigatamque fuiffe referunt, adeo ut hodic intra 24 horas in fornace obtineantur 180 ad 200 puud ferri crudi, quum prius non nifi 100. Ad officinas ferrarias circa Capaika dicitur quotannis procudi i 1000 puud ferri, quum prius non nifi 5000 ad 6000 , led non per integrum annum peragi opus extenforium. Non procul ab Alapaika circa villam Dolmaziowam ad rivulum quendam fluentis aquæ officina exftrueta eft pro extenfione ferri in laminas, ex quibus lebetes \& cortinæ pro coctione five evaporatione falis communis in Solikamsky conficiuntur. Circa Ostus funt duæ officinæ five 8 foci ferrarii, una cum fornace fuforia duplicata, nam intra cosdem parietes 2 camini funt, eftque hoc opus admodum infigne \& elegans : hic quotannis extendi poffunt roooo puud : fed ex 250 puud ferri crudi non nifi ro I puud ferri puri aut malleati obtinentur. Sed narratur opus hoc circa Octus exftructum jam ad fluvium Ifet effe translatım, \& integrum hoc opus vocari Catharinæberg. Ferrum ibi excufum inde transfertur ad locum quendam qui vocatur Sufawo ad fluvium Utka, fed $40 \mathrm{vel}$ $50 \mathrm{Wurft}$, prout milliare illis appellatur, per terram antequam illuc pervenitur, omne ferrum illius regionis ad hunc locum transfertur, \& exinde per fluvios aquafque Petersburgum ufque : Fluvius Utka fatis amplus eft; fed non nifi tempore veris inde tranfportatur ferrum, in alterum ufque annum retinendum eft, nam tempore veris intumefcit fluvius, \& vehendis navibus, quæ Columenckor vocantur, aptiffimus; tempore autem æhtivo fubfidit fluvius Sufarwa, \& jufto rapidior fluit Utka. Opera ferri, quæ a Dimidoff poffidentur, exinde diftant circiter 100 Wurft. Naves, five Columeinckor, quotannis novæ exftruuntur, nam quæ femel iter hoc permenlix funt, redire iterum nequeunt; inde fertur dictum ferrum per fluvios Camam, Wolgam, Twerzam \& fupra lacum Ladogan Petersburgum; facilius adhuc tranfportatur ferrum per canales inter fluvios Twer \& Emfam con Ptruendos.

In Siberia plura funt opera ferrea, opus Kaminsky vocatum 50 Wurft diftat ab octus, conftatque 2 fornacibus ferri fuforiis optime æedificatis, fed non illius altitudinis, ut alibi :-vena abinde 4 Wurft colligitur, conftatque modo lapidibus aut fruftulis faxeis coloris rubri, pariter genere quodam Clafis I. de ferro. $T \mathrm{t}$ telios 


\section{FORNACES FERRI FUSORIÆ RUSSIÆ.}

terræ rubræ feu ochraceo, hujus generis vena per integros campos ad amplitudinem fape unius milliaris apparet fparfa, quacumlibet copia \& ubicunque lubet, colligi poteft, nec profundius 6 ulnis in terram itur effoditurque, frufta ponderofiflima hujus venæ vix ultra 2 puud pendent. Prope cavernulas aut puteos, ubi effoditur, calcinatur etiam dicta vena, dein comminuta ad opus fulorium transfertur ; fub malleo aut pilis circa fornacem pulverifatur. Quavis vice 18,20 ad 24 vafcula venæ cum 3 vel 4 valculis lapidis calcarii mixtæ fornacem transmittuntur, exinde obtinetur ferrum crudum reliquo ferri genere mollius : anno 1723 ex eodem venæe genere tormenta bellica, globi, lebetes ollæque \&c. fula funt. Adhuc ad Kaminsky funt 2 officinæ five 3 foci, pariter 4 foci pro chalybis præparatione. Ad diftantiam abinde 3 wort circa eandem fluminis aquam funt 2 officinæ five 4 foci, qux fimul quotannis præterpropter ferri proculi 20000 pund, \& chalybis 800 fuppeditant. Operatores \& miniftri plures hic funt quanı alibi ; carbones modo ex betula cremati in hunc ufum adhibentur, qui aliis jufto funt duriores: ferrum fragile videtur effe cum candet, ufque tamen pars ejus in laminas ampliores dilatatur.

Sunt adhuc plura ferri opera, fed in ditione Petersburgenf, fcilicet Carelix, \& quidem in diftrictu five principatu qui vocatur Oloneska, qui nomen nacta eft ab urbe Olonetz: pars ejus aquilonaris cum Lapponia \& mari albo, pars orientalis cum lacu Onega \& fuvio Sweri fe conjungit: Quxdam in hac regione ferri opera Dano cuidam Battnare \& dein Rofenbuich vocato natales \& originem fuam debent : unum opus vocatur Petrofskoy favod circa partem lacus Onegæ borealem, Olonets vero circa aufralem, fed diftat abinde I 30 Wurft conftatque 4 fornacibus \& 4 officinis.

In officinis indies colliquatur maffa ferri 20 ad 24 puud, ferrum hoc dein elaboratur \& fabricatur in enfes, gladios, lclopeta, inque fupellectilia. 6o Wurft a Petrofskoy eft opus ferri Uftrika fawod vocatum circa rivulum, qui inde in lacum Onegam decurrit, conftatque 2 officinis: adhuc alterum quod vocatur Powenitz $96 \mathrm{Wurf} / \mathrm{t}$ verfus boream a Petrofskoy diftans, fundunture etiam hic ut ad Petrofskoy tormenta. Opera Tillekin \& Alexivocata jam derelicta jacent. Omnia ferri opera Careliis condita venam fuam ex palude circa Konfofero excipiunt, confiftit illa modo glarea quadam paludinofa \& lutei coloris.

Bini adhuc principatus five Woinodskaper funt, qui a Carelienfi dicto feparantur, fcilicet Bejchecony \& Affjufina: Hic ita vigent ferventque ferri opera, ut in quolibet prædio aut villa confpiciantur foci fabriles, ferrum. fuum ex vena paluftri præparant; terram hanc paludinofam in uftrinas aut fornaculas mittunt; folles moventur brachiis; ferrum crudum in uftrinis coctum in focum exiguum fabrilem dein transmittitur, ubi etiam ventus ope follium manu agitatorum acquiritur, \& dein marculis aut malleis ferreis excuditur; per feptimanam, li faber diligens fit, procudi poffe dicitur 80 puud ferri, fed ferrum vilioris fortis. Circa urbem Galetz ruftici pariter ex terra paludinofa ferrum fibi copiole preparant.

Thule urbs admodum infignis eft, fed cives plerique artem fabrilem profitentur; in uftrinis pariter prxparant ferrum ope follium manu eleva- 
FORNACES FERRI FUSORI E RUSSI Æ. 167 torum \& deprefforum. Ferrum hic conficitur ex fpecie quadam terrærubræ five ex fruftis argillaceis, tanquam petrificatis: fruftula hic reperiuntur jam majora jam minora; \& in ipfis campis circumcirca urbem dictam colliguntur eruunturque vendunturque in medio urbis foro. Alias opus quoddam ferreum non procul ab urbe exftructum conlpicitur, quod etiam a Dimidoff poffidetur. Inter Thule \& Mufcow apparet etiam opus quoddam ferreum 5 officinis \& aliquibus fornacibus conltans, ad binos fratres, qui Moellers appellantur, pertinentibus; excudi hic quotannis folent 20000 puud ferri, \& inde ad Archangel tianfportari. Hic etiam Cafar Petrus Alexowitz binos vel tres contos ferreos propria manu fub malleo extendiffe perhibetur. Non proculaburbe Serpentow, opus etiam ferreum Cxfareum exfat 5 officinis \& aliquot fornacibus conftans, cujus etiam mentionem facit Baro Herberfein \& Guaginus. Inter Thule \& Weronits funt opera fequentia, filicet Lipsky s 07 Wurft five milliaribus Ruficis diItans, five 445 a metropoli Mulcow, conftatque 4 officinis \&4 fornacibus, ibi etiam armamenta bellica parantur. 20 W $u$ urft abinde ad fuvium Weronits opus ferreum eft Ko fminsky vocatum, confiftit 2 officinis \& una pro conficiendis anchoris, nec procul abinde jacet Borna conftans 2 officinis \& 2 fornacibus, vena ex terra effoditur circumcirca Thule, unde etiam hic fragile datur ferrum cum candet. Plurimi etiam fabri incolunt viciniam urbis Paulawæ, qui gladios enfefque Damaícenos, ut vocantur, fabricant.

Quod ergo venam ferri Siberienfem \& Rufficam attinet, raro invenitur in petris aut fratim in duris cautibus, fed utplurimum eruitur ex terra; foluti fparfique per campos jacent lapides minerales ad aliquot ulnarum profunditatem : datur etiam vena quæ fpeciem refert lapidis cujusdam fcifilis, qui argilla in lapideam duritiem concreta conftare videtur: in quibusdam locis ferrum modo ex terra paluftri \& recrementis five exmateria ochracea exfudatur.

Ferrum non nifi duobus in locis per terras tranfportandum, pariter ut merces reliqux folent, fcilicet non procul ab Ilinisk, ut \& circa Fenifciski; alias per fluvios Utkam, Camam, Wolgam \& Twerzam \& lacum Ladogam ad urbem aut portum Petersburgenfem, \& inde aliqua ejus pars adregiones exteras.

Opera ferri Siberienfia \& Ruffica ortum fuum utplurimum debent Dominis Nariskin \& Moellers. In Siberia extare dicuntur opera quinque publica five Cæarea, \& viginti feptem privatorum: publica Siberiæ funt Newianskoi vel Alapaiskoy, Kamenskoy, Uctuskoy; \& bina in Ruffia, fcilicet Petrowfskoy \& Olinitzskoy. Optimum memoratorum operum dicitur effe Tetkonskoy poffeflore Mikita Demidow, ipfum etiam hoc ferrum a multis laudatur. Videatur mappa five Tab. XVI.

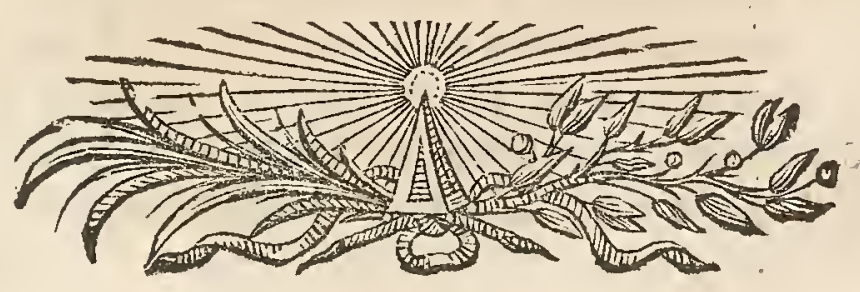




\section{PARAGRAPHUS XV.}

\section{Fornaces ferrifuforice, ut $\mathscr{E}^{\circ}$ officine focique ferrarii in Norvvegia.}

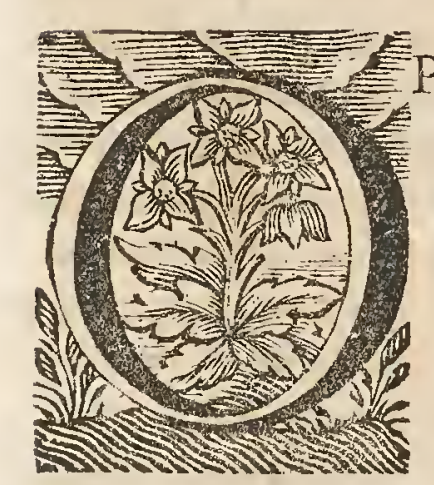

Pera plura ferri tam fuforia quam in contos extenforia dantur Nórwegix, quorum defcriptionem generalem hicquoque traderem, fed quia fornaces illorum pariter etiam officinæ ad imitationem fornacum \& officinarum Svecicarum condite videantur, hinc irritus foret labor, conftructiones, liquationes extenfionesque ferri denuo fiftere.

Quod ipfas fornaces \& officinas Norwegicas ferri fpeciatim attinet, illas enumerare libet, ut I. Opus ad Leffö, anno 1710 iterum inceptum renovatumque, vena ex 2 fodinis facili negotio frangitur, fpatio unius anni plus ejus effoditur, quam opus aliquot annorum requirit: tertio quovis anno peragi dicitur in fornace fufio. Valculis 30 venæ admifcentur 4 lapidis calcarii. Ex centumpondio venæ obtinentur modo 25 ad 30 th. ferri crudi, per feptimanam funduntur 60 pondera nautica circiter. Scorix pulverantur, exque illis colligitur ferrum, quod inibi latet: peragitur comminutio five pulveratio a 9 pilis preferratis, quæ aquæ auxilio elevantur, fcorixque cifte cuidam inclulix fic diffringuntur. In una officina 6 vel 7 ponderum nauticorum ferrum quavis feptimana excuditur. 2. Opus ferreum ad Edswald conftat una fornace fuloria, \& una officina ferraria 2 focis conftanti: fornax ex puro faxo integre conftructa eft. Altitudo camini five cavitatis a faxo fundamentali fociad aperturam eft 12 ulnarum; diameter aperturæ fuperioris $2 \frac{1}{2}$ ulnarum; in medio $3 \frac{1}{2}$ : focus modo Vallonico eft exfructus. Diameter rotæ aquatica eft $5 \frac{1}{2}$ ulnarum. Calcinantur fimul 200 ad 250 tonnæ venæ, fubjectis lignis craffio ribus ut \& carbonibus, dein fuperinjicitur venaftratim cum carbone. Mediam pyram meatus quidam vel for̈amen adfundum usque pertranfit, per quod immisfus ignis lignorum fubjectorum ftruem accendit perque totum cumulum undiquaque fpargit; perftat dein ignis calcinatorius per 4,5 vel 6 dies \& noctes: hoc modo calcinatur vena cujusvis fodinæ fingillatim. Vena fic calcinata pilis in pulverem quendam contunditur. Opus fuforium hic 20 ad 30 feptimanis, perftat. Decies vel duodecies indies imponitur vena, qualibet vice 20 ad $24 \mathrm{Vafcula}$, five $\frac{1}{2}$ tonna aut 30 libræ majores (Lifspund) venæ ad 12 tonnas carbonum. Bis indies emittitur ferrum; led quavis emiffionis vice non magis quam 2 pondera nautica ferri. Vena hrc nullius calcis indiget, nam calce referta eft. In officina liquatur fimul, fed binis in focis, $I_{2} \frac{T}{2}$ pondus nauticum ferri crudi, quod intra 12 horas coctum extenfumque, fuppeditat I pondus nauticum ferri, confumtis 3 ad $3 \frac{1}{2}$ leftis carbonum. Olim conftitife hoc opus 4 fornacibus \& 6 officinis perhibent. 
3. Quatuor abinde milliaribus eft opus fuforium Hackendalen vocatum, conftatque I fornace \& 2 officinis : fufio in fornace per 10 ad I 2 feptimanarum fpatium continuatur; imponiturque vena decies vel duodecies intra 24 horas, \& quavis vice I 2 tonnæ carbonumi cum 23 ad 24 vafculis venæ; inde obtinentur 4,5 vel 6 pondera nautica ferri crudi: vena fatis fulphurea eft: caminuli, fornaculæ, ollæ \&c. ibi funduntur : ferrum hic excufum vilioris pretii eft. Continuatum fuiffe hic opus fuforium per integrum annum dicitur. Lapides foci hic longitudine funt $3 \frac{\mathrm{T}}{4}$ pedum, altitudine $\mathrm{I} \frac{\mathrm{T}}{2}$ : faxum fundamentale $2_{\frac{\mathrm{T}}{2}}^{\mathrm{T}}$ pedes longum, \& $2 \frac{3}{4}$ latum.

4. Circa Barum optimi ferri genus procudi in Norwegia dicitur. Sunt etiam plura adhuc opera ferri, ut opus Dickemarkenfe \& Sibade vocatum. Aliud Kongself five Haffel. Pariter Edfoff, ubi videre licet fornacem. duplicatam, 2 officinas ferrarias, 4 furnos chalybeos: peragihic fufionem per integrum annum \& interdum binos: decies aut duodecies imponitur vena cum carbone; quavis impofitionis vice 24 vafcula venæ, \& I 2 tonnæ carbonum: bis emiffum ferrum pendet preterpropter 3 pondera nautica. In officina, quavis feptimana, recoqui \& extendi poffunt I 8 ad 20 pondera nautica.

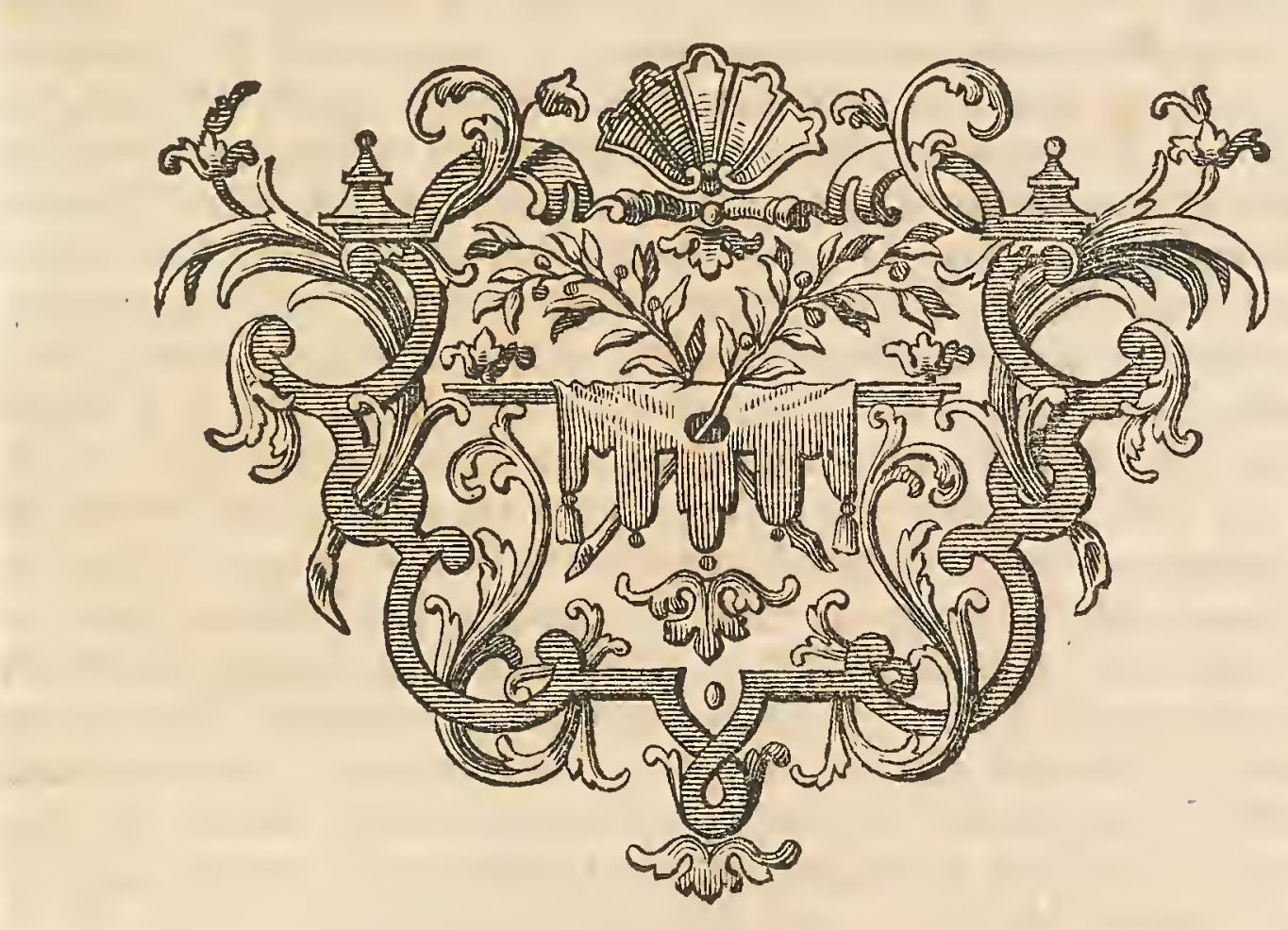




\section{PARAGRAPHUS XVI.}

\section{Modus tractandi venam ferri Silefie.}

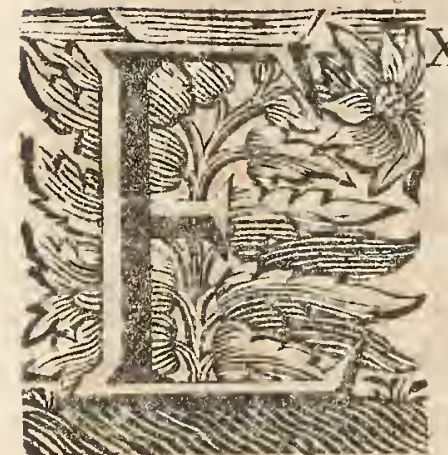

Xhibetur modus tractandi venam Silefienfem in Bres. lauifchen Natur-und Medicin-Ge fchichten pro anno I 7 ! 7 ; fcilicet quod ibi lapis fit coloris e flavo brunei, admodum friabilis; optimus qui ponderofus, pr:efertim qui albe coerulefcit \& fimilis eft fmalto : addunt etiam dari fragmenta intermixta inftar pyritis dura, qux alias nullius momenti fint, nifi quod caufari poffint aliqualem in fufionibus fluiditatem. Lapis hic primo transmittitur per cribrum, ut filicet pulvis vilioris notæ \& fubftantia lapidex inde fecernatur, \& integrior puriorque reddatur vena; ficque in cumulos confertur : inde dein ad fornaces \& officinas transmittitur. ' $O$ pera dicta ferrea funt plura, ut in Malmits, Ober-Fylau \& Altenhammer; eadem hæc vena etiam extra ditionem Silefienfem effertur, filicet ad fornaces liquatorias venæ ferrex in Heilingenfee, Schnellfurth, Lipfchau, Neuhammer, Lors, Eifenberg, Halbau, Neuhaus, Schnellforthell, Muhlbock, Nickolfchmide, Zerbeutel, Tíchimdorff \& Lortzendorff. Venam hanc primum cum calce aut cum menftruo fuo commificent, \& rite commixtam in focum immittunt, fed per vices : quod fit modo fequenti, focus quidam fatis amplus in camino conftruitur, cui a tergo aptantur folles, a quibus exeunt nares aut fiftulæ lpiratorix ; infra eft locus five apertura facta pro emanatione fcoriarum : in medio foco eft puteolus, cui fuperimminent quafi folles \& fiftul: : in puteolum mittuntur carbones, mox vena comminuta, fed ftratum fuper ftratum; ficque accenfus ignis ope venti per gracus augetur, utque fubfident carbones, fuperinjiciuntur novi, ufque dum vena colliquata fit: idem labor per 5 vel 6 horas continuatur, injiciendo jam carbones, jam infuper venam per vices; tandem liquamine ferreo repletur puteus: abrafis dein carbonibus five nudato liquamine, apparet terrea maffa admodum rudis \& incomta, qua aliquantifper elevata, fcorixe quæ ferrum lupernatant deorfum per aperturam priedictam fub ipfos folles defluunt: Maffa ferri, qux jam loupe vocatur, inde fublata ad incudem vi duorum virorum transfertur, ubi malleo in panem rotundum, pileum magnitudine \& palmam craflitie xquantem, diducit. Excrebris mallei ictibus facile in unum confluere hocferrum dicitur, \& quicquid fcoriarum in ferro adhuc latet inclufum, inde expelli \& extorqueri. Maffa hæc fub malleo in panis formam compreffa in partes oblongas dein auxilio cultri fecantis fcinditur; quæ vocantur Daulinge. Hæc iterum ignecandefacta in bacilla aut contos more ufitato diducuntur.

Si vena ab heterogeneis bene fit repurgata, tunc ad unam maffam, qux loupe vocatur, requiri 8 menfuras Breslavienfes, \& exinde obtineri 2 centumpondia ferri puri extenfi. 


\section{PARAGRAPHUS XVII. \\ Modus venam ferri coquendi recoquendique
Saxonice. \\ Modus venam ferri coquendi recoquendique
Saxonice.}

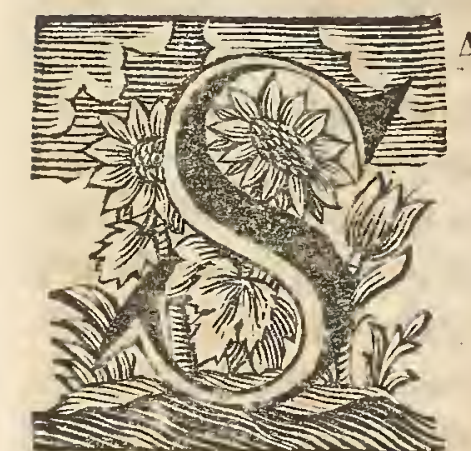

Angerhufii 4 milliaribus ab Eislebia \& pluribus aliis in locis funt opufcula quxdam ferraria, qualia plurima Germaniæ quæ vocantur Rennwerck. Vena ex monte quodam, qui Dowenberg appellatur, defumitur; matrix flavi eft coloris, infperfa vena grifei \& albefcentis. Strata non funtlata. Officina hac conftat 2 focis, inque uno funditur dicta vena in ferrum; inque altero liquatur ferrum, ut candens fub malleo extendi poffit. Furnus longitudinem habet 8 pedum, latitudinem 4 , focus profunditatem $1 \frac{1}{2}$ pedis, qui multo pulvere carbonario conftat: ad latus emittuntur per aperturam quandam fcoriæ. Conus ventilatorius ex ferro paratur ; \& folles ex ligno. Vena ope mallei tuforii, fubjecto faxo quodam duro in pulverem comminuitur : quumque calefactusfit \& repletus carbonibus focus aut catinus, apponitur pulvis ferreus utrinque circa orificium fpirans fuper ipfos carbones, adeo ut vena poft cribrationem relicta majufcula \& nucum magnitudinem xquans fenfim cum carbonibus posfit colliquelcere \& fubfidere; quod cum factum fit, adhuc plus apponitur, femper tamen aqua irroratur vena: per vices etiam ante ventum aut fpiramen educitur vena liquefacta, ufque dum 2 tonnæ venæ appofitæ fint. Si aqua non defit, quotidie produci poffunt 5 maffx, quæ Loupen vocantur, vel I 3 pondera nautica per feptimanam; quxlibet maffa vel loupe dividitur in binas partes, qux dein in altero foco calefiunt, \& in minora dein frufta fecantur, \& fub malleo, qui 3 centumpondia æquat, extenduntur in contos longitudinis 3 ulnarum \& latitudinis $2 \frac{\mathrm{r}}{2}$ digitorum.

Spatio 4 vel 5 horarum mafla una confici \& in contos diduci poteft; \& interea confumuntur 4 corbes carbonum. Opufculum hoc ferreum non ipfemet quidem vidi, fed ex viro fide digno relata refero, qui opus hoc oculatus ante plures annos luftrarat, pariter etiam fequentia circa Rothendahl

\section{Defcriptio fornacis fuforice ferri operisque fer- rarii ad Rotbendabl.}

FOrnax ferri fuforia ad Rothendahl confruitur ex multis faxis arenariis, quarum quxque longitudinem habet $1 \frac{3}{8}$ uln $x$, latitudinem $\frac{3}{4} \&$ craftitiem $\frac{x}{2}$. Fornacis cavitas verfus fuperiora coarctatur. Vena ex fodinis Bohemicis illuc adfertur, eftque coloris rubri, admodum dives, datur etiam fchiftus \& hæmatites aut Glaskopff: fluida admodum eft vena, pars ejus non ideo prius calcinatur, fed cruda ftatim apponitur, \& modo 2 vafcula 


\section{$172 M O D U S$ VEN A M E T FERR U M}

venæ fuper 4 menfuras carbonum, quæ Kübell vocantur. Appofitio fit femel quavis hora, \& emiffio bis quavis die; quavis emiffionis vice obtineri folent $7 \frac{3}{4}$ ad 8 centumpondia ferri crudi.

Quod iplam fornacem attinet, conftruitur illa eodem modo quo fornaces Bohemix; altitudo camini five cavitatis, a faxo fundamentaliad aperturam fuperiorem eft i 2 ulnarum, eftque intus formæ quadratæ. Quumque xedificanda fit fornax, fpecus aut cellula primum effoditur facta pro evaporatione aqux, fupra quam relocatur faxim fundamentale craffitiei $\frac{1}{4}$ ulnæ. Si fundamentum fit humidum, fub iplo faxo dicto ftratum quoddam argillaceum ad craffitiem $\frac{1}{4}$ ulnæ formatur, argillæ commilcetur pulvis alius: at vero hoc ftrato non opus habent, fi fundus fit ficcus : fupra faxum hoc fundamentale e diametro contra aperturam vel latus emiffionis erigitur faxum arenarium, altitudinis $I \frac{3}{4}$ ulnæ, in forma quadrata $\frac{1}{2}$ ulnæ. Lateri folles recipienti applicatur lapis fectus, qui vocatur Hals, in formam quadratam craflitiei $\frac{1}{2}$ ulnix, fupra medium ejus formatur orificium ventila torium, quod a parte anteriore amplitudinis eft 4 digitorum \& tegitur lapide fecto longitudinis I I ulnæ, craffitiei 22 digitorum \&latitudinis I ulnæ, \& fupra relocantur ordine lapides fecti, quorum latus quadratum æquat ulnam. Contra orificium ventilatorium 3 vel 4 ordines lapidum vulgarium reponuntur, qui longitudine funt $\mathrm{I}_{4} \mathrm{ulnx}$, adeo ut eandem altitudinem. a faxo fundamentali cum faxo tergali habeant : fub muro pectorali fuper faxum fundamentale relocantur duo lapides, qui craffitie funt $\frac{\mathrm{r}}{2}$ ulnæ, \& diftant invicem fpatio $\frac{1}{2}$ ulnæ, quod etiam foci latitudo eft, \& qua altitudinem \&latitudinem applicantur ad lapides priores five ad extremitates illorum: fupra hos binos lapides reponitur alius, qui vocatur Timpelftein, quique longitudinem $\mathrm{I}_{\frac{2}{2}}^{\mathrm{r}}$ uln $x$, craffitiem $\frac{3}{4}$ ulnæ \& altitudinem $\mathrm{I}$ uln $x$ quat, unde circumpofitus \& parietibus fuis inftructus eft focus, eftque ille longitudine 22 digitorum, latitudine $\frac{x}{2}$ uln $\&$ altitudine $\frac{\pi}{2}$ uln $x$, fcilicet ab ima parte lapidis luperimpofiti vel Timpen usque ad faxum fundamentale: ab exteriore parte lapidis Timpen applicatur alius lapis, qui vocatur Kockelfein, qui pariter cum fuis extremitatibus fulcitur faxis binis predictis angularibus, eftque hic lapis longitudine $I_{\frac{1}{2}}$ ulnæ, latitudine ${ }_{5}^{\frac{1}{2}}$ uln $æ$ parilique altitudine: fub hoc lapide eft apertura pro emittendis fcoriis \& ferro. Supra Timpen, ut vocatur, ponitur lapis vulgaris, qui longitudine eft $\mathrm{I}_{2} \mathrm{I}$ ulna, altitudine \& latitudine $\frac{x}{2}$ ulnæ, \& fic una altitudo circumcirca ex faxo fundamentali, fcilicet $1 \frac{3}{4}$ ulnie. Ex hoc ordine magis \& magis ampliatur cavitas fornacis interior fcilicet conftans lapide vulgari, ufque in formam quadratam 3 ulnarum ab omni latere, contrahitur dein verfus fuperiora, ubi apertura eft $I_{4}^{\mathrm{I}}$ ulnæ in forma quadrata: hæc eft ipfiusmet muri conftructio in fornace; extra hunc murum conjicitur terra, \& ultimo munitur \& veftitur pars exterior trabibus \& tignis, prout in Svecia.

Antequam inchoatur opus fulorium, carbones aliqui mittuntur ante aperturam emiffionis qui accenduntur. quod fpatio 24 ad 48 horarum continuatur, filicet ut humor omnis illius loci exhalet, ubi tigillum anterius fit formandum: tigillum hoc vel focus ex lapide \& argilla proxime ante aperturam emiffionis conftruitur, \& 3 lapidibus circumdatur; dein 
præparatur receptaculum pro fcoriis circa unum fulcri fornacis latus. $\mathrm{Re}$ pletur demum fornax 30 Kïbell vel 5 carrhis carbonum, qui accenduntur ope carbonum ante emiffionis aperturam conjectorum : primum imponitur I modius lapidis calcarii cum vena commixti, quumque hrec mixtura fubfiderit, imponuntur 5 modii carbonum \& 2 valcula venæ, quæ patio 2 horarum fubfident, \& augentur fic ordine impofitiones venæ, dum ad 5 vafculorum perventum fit, quod fit poft 24 horarum elapfum; tunc primum apparent in foco fcoris: quumque illi apparent, admittendi funt folles; admiffo vento, imponuntur 6 vel 7 vafcula venæ fpatio $4 \mathrm{vel} 5 \mathrm{fe}-$ ptimanarum: dumque fornax fumme calefacta fit, iterum 2 vel 3 vafcula venæe prioribus adjiciuntur, fi modo permittat venæ qualitas: reciprocantur \& redeunt impofitionum vices quovis $\mathrm{I}_{2} \mathrm{~h}$ horæ præterlapfu, fitque prima emiffio quum admittuntur folles, \& altera præterlapfis abinde $14 \mathrm{vel}$ I 6 horis, fed non debita quantitas ferri obtinetur, nifi cum ter emittatur ferrum intra fpatium diei \& noctis, tunc quavis emiffionis vice obtineri folent 7 vel 9 centumpondia; perque integram fufionem interdum 2000 centumpondia. Ipfa vena infignis admodum qualitatis eft, adeo ut nulla calcinatione opus habere dicatur, quin cruda ftatim imponi poffit, modo in magnitudinem ovorum columbinorum prius contula fit, \& dein mixta cum $\frac{1}{4}$ parte lapidis calcarii : obtinenturque i $\circ \circ$ centumpondia ferri ex I 50 carrhis venx, \& quxlibet carrha illius ponderis eft, ut a binis equis trahi poffit.

Cum demum eandem fornacem videre mihi contigit, obfervavi illam e novo exftructam; a binis lateribus, ubi fcilicet folles cum illorum loculamento \& fedili erant, \& ubi frontifpicium five ubi emittuntur liquamina, concinne laqueatam \& fornicatam effe: orificium ventilatorium ex cupro horizontaliter applicatum, cui figura coni data fit. Tigillum five ferri liquati receptaculum e lapidibus arenariis paratum; quorum duo ad latera xquarent crafitiem $\frac{3}{4}$ ulnæ, longitudinem $I_{\frac{1}{4}}$ uln $x$, faxum fundamentale latitudinem I I $_{4}^{\mathrm{I}}$ ulnæ, qualis etiam tigillo detur amplitudo. Altitudinem fornacis effe prope 9 ulnarum, intus formæ quadratæe, apertura quadriformi fuperne gaudentis ; ventrem five mediam cavitatem effe ampliffimam, \& fornacem verfus inferiora arctiorem. Emiffiones fieri bis vel $2 \frac{1}{2}$ vicibus quavis die \& nocte ; \& qualibet vice ro vel 12 centumpondia circiter emitti, adeo ut per feptimanam I 30 centumpondia, vel qualibet hora unum obtineretur; tigillo 12 centumpondiorum capaci manente; confumtis $I_{3}^{2}$ Kübel carbonum ad quodlibet centumpondium.

Nec præterire volo uftrinæ cujusdam defcriptionem, quam Bohemix annotavi, non procul ab Alfattel, fub eodem teeto exftruct:e cum focis aliquibus ferrariis, qux modo altitudinis 4 vel $4 \frac{\mathrm{T}}{2}$ ulnarum a folo ad fupremam oram effet: ipfe caminus vel cavitas $I_{\frac{1}{4}}$ ulnæ diametro in medio, fed tamen formæ rotundæ: ubi intra feptimanæ tempus 30 ad 40 centumpondia mineræ apponerentur, \& quovis die I Fuder carbonum; inde eduatis i 2 centumpondiis ferri. Ipla minera erat paluftris, cruftacea, pulve rea, \& coloris flavefcentis. 
I74 MODUS VENAM ET FERRUM COQ. SAXONIE.

\section{Extenfio ferri crudi Jub malleo, jive recoctio ejus Saxonia.}

Entumpondium ferri crudi I 40 libras folet conficere, quumque liquefactum fit in foco \& extenfum, pondus I 20 玷. remanet, adeo ut pereant 20 partes ex I4O. Ferrum hoc crudum in bacilla excudendum, tèr liquatur \& recoquitur in foco, \& dein immittitur contus cufpidatus ferreus in volumen, cui adhærens inde ad malleum fertur, ubi dein extenditur in bacilla debitæ magnitudinis. At vero fi ferrum adhuc magis purificandum \& coquendum fit, ut illud quod in laminas fanno obducendas, diducendum eft, major pars fcoriarum \& fecum in foco retinentur: quxe fcorix dein fub malleo quodam comminutx iterum per fornacem transmittuntur.

Alibi ut prope Hansjurgenftadt obfervare licuit officinas ferrarias; in quibus catini vel tigilla parantur modo folito a bracteis ferreis, quarum craffifima eft, qux remotior : tigillo datur profunditas 8 pollicum, longitudo I uln dum obliquatus tigillum intrat. Per feptimanam funduntur 32 centumpondia ferri, confuntis 75 Kübels carbonum, five ad quodlibet centumpondium I lefta. Quavis vice recoquitur pondus ferri crudi I ad I I centumpondia circiter. Iple caminus foriis in fcintillas diffpatis denfatus ftipatuique eft. In officina, ubi ferrum in bracteas fanno obducendas extenuatur, quavis vice 70 ad 80 bractex fub malleo extenduntur, qua. rum qualibet dimidiam libram pendet. Per feptimanam confumuntur 90 Kiiblels carbonum.

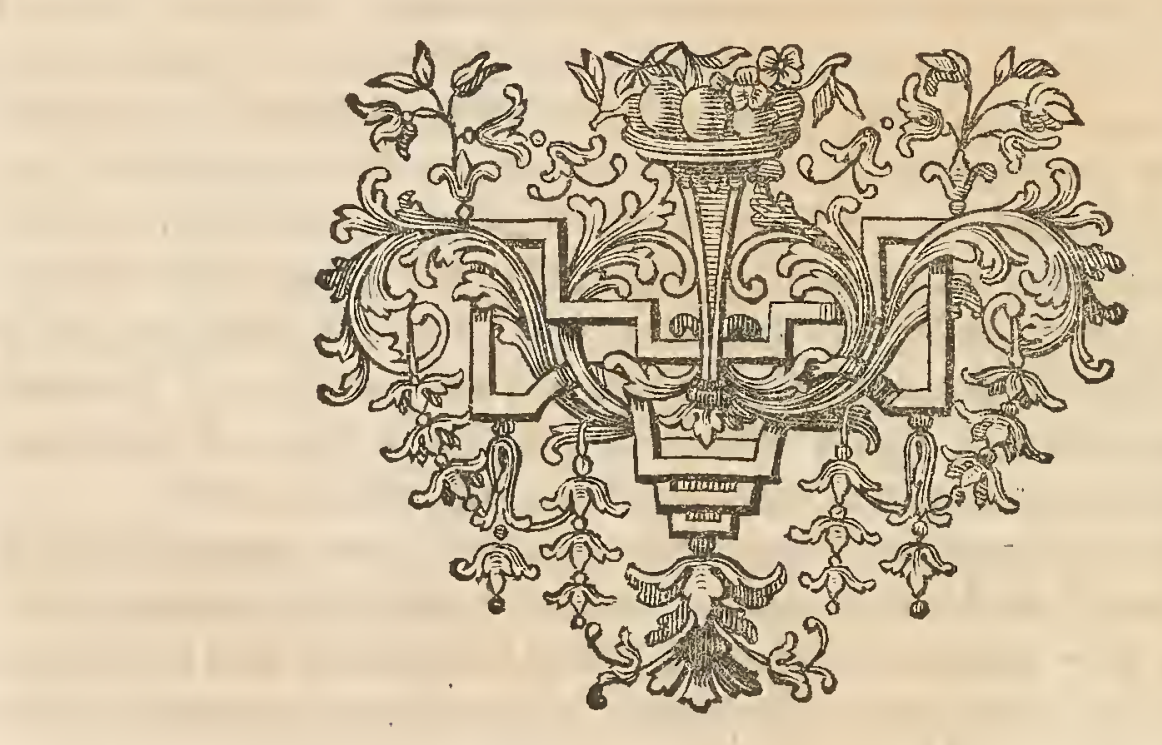

PARA. 


\section{PARAGRAPHUS XIIX. \\ Modus renam ferricoquendi recoquendique Hercynice.}

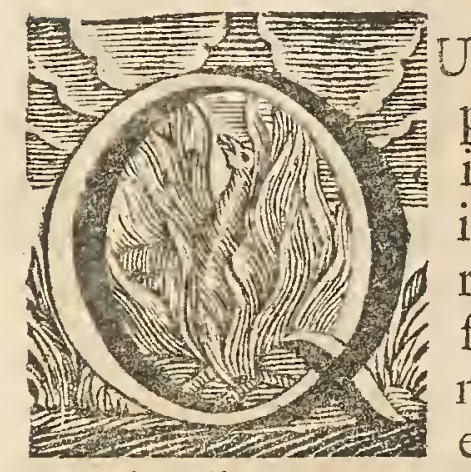

Uod ipfas fodinas \& venam ferri in Hercynia attinet, plura ejus genera dantur, ut fcilicet fodina Lodebleir in Braunfump, ubi vena datur coloris nigref́centis \& indolis bonx; Ei ex oppolito Sone Grube coloris fere rubri; juxta hanc, fodina ubi Kurin \& menftrum frangicur, quod loco lapidis calcarii ufurpatur. Vena fodine Muffelberg eft rubefcens : ad Holtzfein eft nigricans : ad Silberbohm eft coloris fere bruni; ad Mittelberg rubefcit; ad Stollberg dantur venæ diverfi generis. Circa montem quendam marmoreum frangitur etiam vena ferri, erantque ante aliquot annos f́pecies 12 aut plures, hodie quot fint, nelcio, Hæ diverfimode \& quidem fecundum cujufcunque indolem calcinantur, fcilicet unum genus fpatio 24 horarum, alterum per duplum temporis, etiam per feptimanam, ut $\&$ bis vel ter. Centumpondium hujus venæ continere folet $30 \mathrm{ad} 60$ 㘧. ferri, fed hrc tantum in ditione Blanckenburgenft.

Alias eft mons Yberienfis longitudine quadrantis milliaris, altitudine $\frac{\pi}{8}$ partis milliaris, conftat partim lapide fcifili obfcure grifeo : ad partem ejus auftro-occidentalem funt ftrata conftantia vena ferri rubicunda, ftrata invicem parallela funt: in cavernis reperitur etiam vena ferribruneicoloris cum argilla nigrefcente: vena fpeciem refert hæmatitis, aut fchifti, quem vocant Glaskopff \& Blutflein, nam apparet ftriata. Proter venam in cryptis datur lapis ftillatitius ftiriarum glacialium inftar; ipfa fodina vocatur Oberfiege: aliis in locis ejusdem montis funt glandulæ \& ftrata venæ ferrea admodum ditia; transfertur hinc vena ad fornacem ferri fuforiam qua Gittel vocatur.

Plures adhuc reperiuntur ferrifodinæ in Hercynia, unde etiam plura genera venæ dantur, ut Glaskopff, cujus centumpondium conţinet 40 ad 50 It. ferri: reperitur etiam vena ferri teffulata fuppeditans ferrum 30 ad 40 Pc. Datur etiam vena ferri alba continens i 4 vel i 5 Pc. Unde etiam Hercynix commifceri folent 10 ad 12 genera venæ, aliquibus vero in locis modo 2 vel 3 fpecies.

Pluribus in locis funt fornaces \& officinæ ferrarix, ut ad Zorgewiede \& Taune; ad Gittel \& Stollberg, in Rubelande, Bos \& Voigtsfelde, \& alibi.

Fornaces funt altitudine 22 ad 24 pedum, cavitates illarum funt quibusdam in locis rotundx, in aliis vero quadratx; diameter partis fuperioris eft 3 pedum circiter, \& circa partem inferiorem funt ampliores, pracipue fornaces figuræ quadrat $x$, quæ fpeciem quandam pyramidis truncatæieferunt.

Tertia pars fornacis fuperioris ex lapide lateritio eft conftructa, reliqua lapide validiori \& igni refiftenti. 


\section{I76 MODUS VENAM ET FERRUM COQUENDI HERCVNIE.}

Quum calcinata fit vena, fub malleo in pulverem contunditur, qui fpeciem pulveris rubri refert. Vena qux ad Gittel fertur, aliqua non calcinatur, nec pulverifatur, fed in fruftula modo comminuitur. Lapis calcarius uftus mifcetur etiam cum ipfiffima vena, qux loco menftrui effe folet.

Quum fornax fufficienter calefacta fit, per feptimanam confumi folent 50 cantheria carbonum, \& obtinentur I 30 ad 150 , circa alias fornaces 170 ad 190 centumpondia ferri, differentia oritur ex venæe, qualitate. Quavis impofitionis vice $\frac{1}{4}$ pars unius Fuder venæ immittitur: quumque emittitur ferrum, formantur inde moles i I ad I 2 centumpondiorum, fed alibi non nifi 4 vel 5 . Unum centumpondium hic conftare dicitur I I 4 th. circiter circa officinas, fed in urbe i i $2 \mathrm{fb}$. Colonienfibus: I Fuder venæ a pari equorum trahi poteft; conftatque Io menfuris; menfura eft ulnæ diametro juxta fundum, fed aretior fupra, altitudine dimidix ulnæ.

Scoriæ ex fornacibus emifle comminuuntur fub malleis, fcilicet ut obtineatur omnis pars ferri quæ inibi latet: lamina appofita cribri inftar eft, fed cribrum grandiufculis foraminibus patens, adeo ut digitus per foramen poffit transmitti; canales inde longiores prodeunt, in quorum fundo retardatur pars ferrea, leviora vero per aquam auferuntur. Pars ferrea iterum una cum ipfa vena transmittitur per fornacem.

Orificium fpiratorium alte fatis repofitum eft, fcilicet ad 3 pedum diftantiam a faxo fundamentali. Focus conftat faxis grandiufculis, qux magnitudine funt $\mathrm{I}_{2}^{\mathrm{I}}$ ulnæ in forma quadrata, extra \& intra $\frac{3}{4}$ partis unius ulnæ. Tigilli longitudo eft $3 \frac{1}{2}$ pedum. Ex vena rubri coloris prius memorata liquefiunt 30 Fuder vel 480 centumpondia ; exque quovis Fuder vel ex quibusvis i 6 centumpondiis venæ obtinentur 3 centumpondia \& 38 it. ferri crudi; exque 480 centumpondiis venæ Ioo centumpondia ferri. Emittuntur I I vel i 2 Fuder fcoriarum, qux ferri feraces funt, vetuftiores venam ipfam qualitate ferme, ut narrant, xquant.

\section{Officine ferraria O $^{\circ}$ recoctio ferri crudi ibidem.}

TN officinis ferrariis non nifi unus focus ufurpatur; fundus ejus \& pa1 rietes conftant laminis ferri fufi craffitiei 3 vel 4 digitorum; fubter foffic \& canales facti funt pro exhalatione humoris fe illuc infinuantis. Mallei pondus effe folet 5 centumpondiorum. Quavis feptimana in aliquibus officinis extendi poffunt 50 ad 60 centumpondia ferri, alibi vero ubi durius ferri genus eft, non nifi 24 cum jactura $\frac{1}{3}$ partis ferri, confumtis ad quodlibet centumpondium $4 \frac{\mathrm{T}}{2}$ menfuris vel $\frac{\mathrm{r}}{2}$ carrha carbonum. Ferrum Gittellenfe reliquis ferri generibus quia tenacius, præferri dicitur.

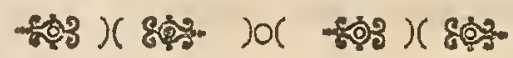

PARA- 


\section{PARAGRAPHUS XIX.}

\section{Modus venam ferri coquendi recoquendique Fordenbergi, Stiria \& Carintbia.}

\section{Fordenbergi.}

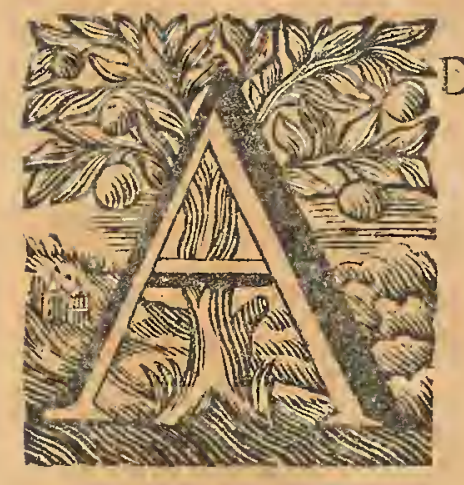

D Fordenberg erant ante 20 aut plures annos fornaces numero $\mathrm{I} 6$, in quibus liquatio per totum fere annum peragebatur; vena effodiebatur ex fodinis \& puteis numerofis circa Eij/en-Ertz.

Vena coloris erat nigrefcentis, matrix vero brunei; erantque ftrata plurima hoc genere venx conftantia, fed tegebantur \& quafi velabantur lapide quodam duriori five fpecie talci aut glaciei Marix, qui igni validiffime poterat refiftere; hinc genus hoc lapidistanquam igni inimicum, nec facile a flamma domandum, optime prius a vena fecernebatur, antequam transmitteretur percaminum. Sub vena nobiliore \& matura eruebatur etiam alia, qux immatura \& nondum fatura ferri genuini fuiffe putabatur: hinc cum eruebatur, non mixta cum priori junctim transmittebatur per ignem fuforium, fed juxta fornacem tenebatur a reliquis venæ generibus feparata, illum in finem, ficut ajebant, ut interea maturefceret: maturari enim illam putabant intra fpatium aliquot annorum, \& maturam deinde conjunctim cum reliqua in ferrum colliquefcere potuiffe. Ad diftantiam 60 circiter ulnarum a puteo feu antro Foder - Stollen appellato, fpecus aut crypta confpiciebatur, fed bene claufa januis, ferris \& repagulis, in quam nulli licuit intrare nifi cum venia: intus confpiciendus prebebatur flos ferrugineus, Eifen-Blütben nuncupatus, qui fub tecto ope aque ftillatitix, non aliter ac ftalactites in cavernis Baumannianis aut aliis videbatur in formam corallinam five in virgulta \& ramufculos concretus: apparebat dicta vegetatio metallica five lapidea ftiriarum glacialium inftar; qua tempore hiberno ex imbrice tecti videntur pendere. Raro in cryptam admittitur quidam fpectator, \& aperitur janua, ne fcilicet chryftallifatio illa celebris \& perelegans a fuligine \& nigredine imbuatur; facile etiam \& a minimo tactu \& contufione dilabuntur rami aque caule \& trunco fuo recidunt. Ex dictis fodinis cum multo labore \& per difcrimina viarum ad Fordenberg usque deferebatur vena.

Juxta eandem fluviatilem \& torrentem aquam conftrueta apparet ordine una fornax poft alteram, quarum nomina præterire volo, quoniam non mihi pro certo conftat, qux hodie adhuc fuperftites funt, vel num novæe fint adjectr. Quælibet fomax tecto quodam munita eft, \& ædiculam prope conftructam calcinatoriam habet.

Fornacis altitudo eft I 4 pedum, diameter cavitatis ejus fuperioris proxinie fupra focum 4 pecum, loco vero fuperiori 2 pedum. Ipfemet murus cavitatis argilla optime loricata \& oblita erat.

Clalis I. de ferro.

Yy

Quum. 


\section{I78 MODUS LIQUATIONIS FORDENBERGI,}

Quum predicta vena calcinaretur, fublocabatur primo ftratum quoddam carbonum \& infuper vena ad craffitiem ${ }_{2}^{\mathrm{I}}$ pedis, dein ftratum carbonum, \& infuper vena, \& fic triplici ferie ; ultimo coacervabatur vena in pyriformam quantitate defiderata. Ignis dein fubjiciebatur, qui continuabatur tempore 3 feptimanarum, ut filicet per diutinam calcinationem. aptius tam in pulverem poffet contundi, quam dein in camino melius in ferrum colliquefcere. Vena comminuta aut pulverata ope rotevel aquatice vel alius qux brachiis circummoveretur, in fuperiorem forracis partem fublevabatur.

Quum itaque caminus plene ftipatus repletusque foret carbone, fuperimponebatur modulus venæ, qui unius tonnæ menfuram æquaret. Repletio hac carbonaria, intercedente aliquo tempore fubfidebat, illam igne ficco paullatim exedente: quo facto fuperinjiciebantur 8 menfur: carbonum, qux: in corbes divif effent, \& infuper vena fed ftratim, quod fieri folebat fpatio i 5 horarum, cum his alimentis permittebatur vena, exefis confumtilque igne carbonibus, ufque ad focum fubfidere ; ficque apparebat in foco maffa, quæ Hallmasen vocabatur, per fpatium i 5 horarum modo predicto collecta.

Folles hic, non ut alibi, applicati erant illi fornacis lateri, ubi mafla ferri colliquata foco eximebatur. Scoriæ etiam prope ipfas filtulas fpiratorias follium emittebantur.

Quum maffa ferri eximeretur, animadvertebatur femper fuper illam pars ferri adhuc liquidi, quod feorfim \& a ferri maffa inferiore feparatin emittebatur, quod vocatum erat $K r$ ogloch, eratque materia ferri optimi \& electiffimi, genus hoc idoneum cenfebatur, five verteretur in chalybem, five fabricaretur in utenfilia. Hoc volumine inde feparato, materia refidua inferior, Hallmaffen, focó eximebatur, quxe maffa dilatata latitudinem 5 pedum occuparat, eximebatur inde ope vectium \& auxilio 2 virorum; cumque adhuc calida effet, dividebatur in binas partes, parsque unaquxque ponderis 10 centumpondiorum effe folebat; unde quolibet die \&noEte mafta obtinebatur conftans 20 centumpondiis.

Methodus hæc fundendi venam ferri, \& operam fuforiam quovis die e novo inchoandi, \& maffam concretam ferri foco eximendi, a multis five ut ajunt, $80^{\circ}$ retro annis ufitatam effe perhibent; \& quamvis confiteantur, majorem quantitatem ferri obtineri pofle, fi more Carinthix ufitato continuo \& non interrupte perageretur fufio ; ufque tamen ipfam indolem venx.fux requirere ajebant, ut interruptæ \& breves liquationum vices effent; putabant enim mineram fuam ignem continuum \& ficintenfiorem non pati poffe, nec genus illud nobiliffimum ferri, quod fuperficiem maftie teneret, aliter obtineri poffe. Alias qualibet feptimana 7 hujufcemodi maffas ferri concreti in foco fuo obtinere potuerant.

\section{Stirice.}

Ena hic fundebatur eodem modo inque ejusdem generis fornacibus, ac circa Fordenberg : fed fornaces hic erant triplicis generis, fcilicet majores 
TAB: XUII: de Ferro.

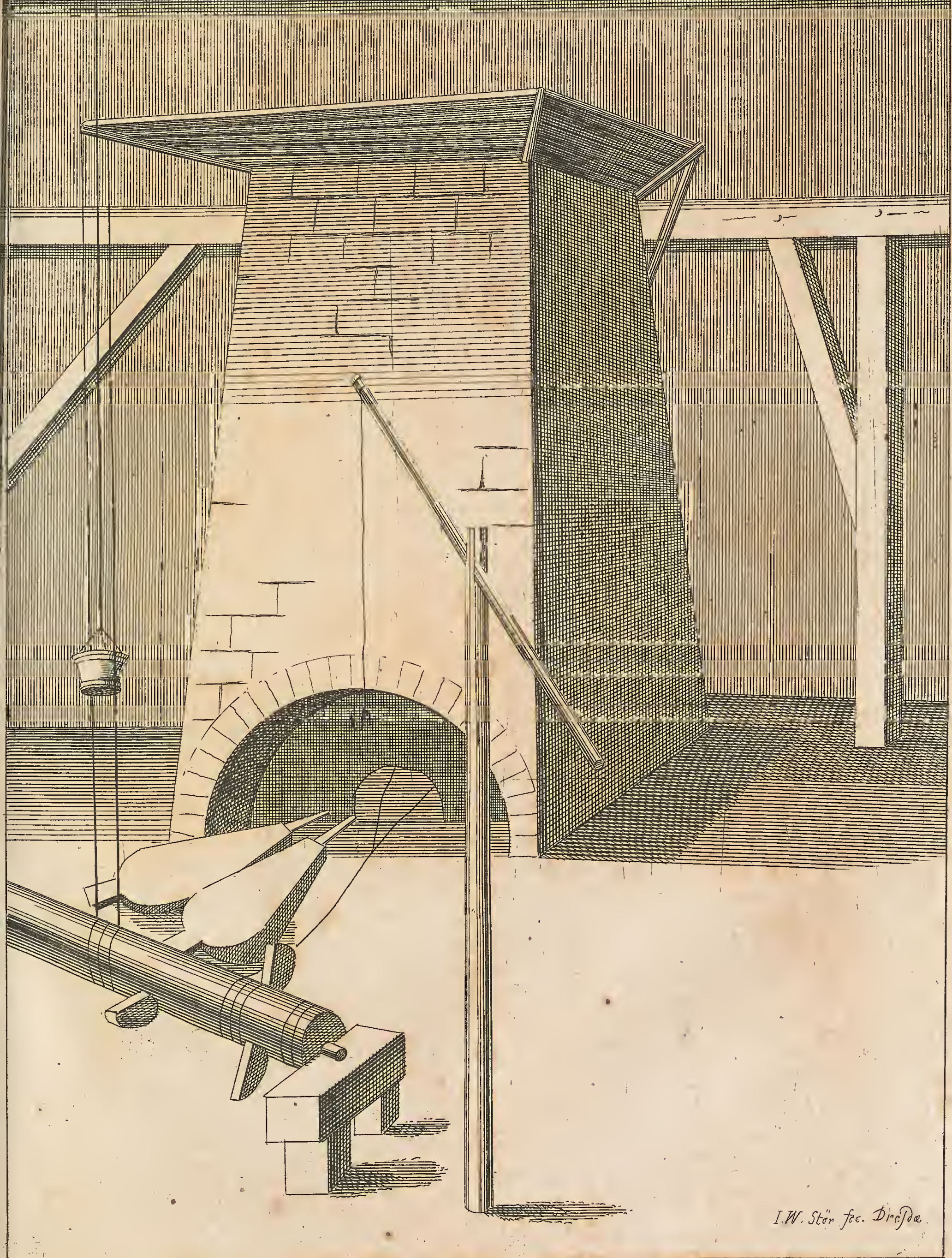



jores, mediocres \& exigux. Quod exiguas attinet, illæ plurimum in ufu erant. Majores vero, quæ vocantur Stuck-Ofen modo fequenti erant conAtructix.

Fornax ex lapide grifei coloris in forma quadrata, cujus quodque latus 4 vel 6 ulnas occuparet, conftruebatur. Murus extimus five lorica camini aut cavitatis craffitiem I ulnæ fupra, infra vero $I_{\frac{I}{2}}$ ulnæ æquabat. Circa pedem hujus fornacis five partem inferiorem laqueare quoddam humile erat, fub quo relocabantur folles cum fcamnis \& reliquis machinamentis. Cavernula five fovea duplex inque crucem ducta fubibat lapidem fundamentalem five focum. Altitudo fornacis eadem fere erat cum altitudine fornacum majorum, qux Hocb-Ofen Germanice vocantur. Intra murum hunc exteriorem fornacis educebatur caminus, qui juxta focum conftabat lapide Bergenfi, ubi 3 pedum in forma quadrata erat. Foci altitudo erat $I_{\frac{1}{2}}$ ulnx, exque illo fenfim aut per gradus verfus fuperiora ampliabatur caminus, dum tandem in rotundam figuram abiret, qux rotunditas a foco tribus ulnis tantummodo incipiebat; amplitudo diametri ejus erat 3 ulnarum, fed inde rurfus coaretabatur \& anguftior verfus fuperiora reddebatur, dum tandem a fundo eductus fuiffet caminus ad altitudinem 18 pedum; qui definebat in aperturam I ulnx, per quam filicet immittebantur carbones \& venæ. Ad illud fornacis latus, ubi reponebantur folles \& ubi laqueare prius memoratum erat conftructum, altitudo erat I ulnæ, \& murus craffitiei I pedis, altitudo a fundo 9 digitorum. Moles quædam ferri transverfim inferta \& collocata fuit, infuper murus argillaceus ad craffitiem I pedis. Profunditas illa fornacis erat, ut ferrum fuper ipfam humum \& folum potuiffet effluere; nam extra fornacem foffa quadam parata erat, pulvere carbonario humectato repleta. Orificium ventilatorium argilla replebatur, quod etiam coni truncati fpeciem referebat, nam verfus interiora arctius erat, verfus exteriora vero amplius. Ipfamet fic conftrueta fornax fpeciem referebat cadi Italici, qui ad utrumque latus in anguftum coit, in medio vero amplitudine multa pollet. Folles qui hic adhibebantur, erant admodum humiles, nec nifi ad dimidiam altitudinem elevati, ac folent folles vulgares fornacum, nec longitudine majore gaudebant quam folles, qui ufurpantur circa focos fabriles, nec fcamnis \& fedilibus fuis alligati jacebant, fed mobiles, ut fcilicet inde facile poffent loco moveri, quoties fcilicet ferrum effet eximendum. Sed videantur Tabulw XVII \& XVIII.

Fornaces mediocres \& exiguæ erant eodem modo conftructæ \& figuratx, differebant tantum in eo quod minores effent; mediocres enim a parte inferiore erant 2 pedum in forma quadrata, in medio 5 pedum, apertura partis fuperioris unius; altitudo 14 pedum. At vero fornaces minores parte inferiore erant formæ quadratæ 2 pedum, diametri 4 pedum in medio, \& aperturæ fúperioris I pedis. Fornacem talem per plures annos durare potuiffe dicebant, antequam reficienda effet; tigillo tantum quater quovis anno renovato. 


\section{MODUS LIQUATIONIS FORDENBERGI,}

Ex figura appofita videre potes ipfam fornacis conftructionem melius quam ex defcriptione, unde oculis illam fine ulteriore deductione fiftere volui. Tab. XVII \& XVIII.

Quum opus fuforium inchoaretur, replebatur primum fornax carbonibus; carbones tunc molliores cum durioribus commifcebantur, quique etiam ftatim accendebantur, admiffis etiam in motum follibus, fcilicet quum carbones prima vice fubfidiffent; cumque repleretur carbone, infuper vena injiciebatur : obfervatum etiam eft, bis fubfidiffe carbones, antequam vena inciperet liquari.

Vena calcinabatur prius \& contundebatur, quavis vice bina vafcula apponebantur, pondus venæ cujusvis vafculi $\frac{1}{2}$ centumpondii partem $x$. quabat, at vero fi inops metalli effet, accipiebantur 3 vel 4 valcula, iniuper I corbis carbonum, quorum 4 unum faccum conficiebant, \& 5 facci unum fafciculum qui vocatur Knippa, $2 \frac{\mathrm{I}}{2}$ fafciculi five Knippor I Foder. Dein continuato opere quovis $\frac{3}{4}$ horæ fpatio femel imponebatur vena, \& intra 24 horas 30 vel 32 vicibus, qux in unam maffam omnis colliquabatur.

Modulus aut menfura venæ, quæ quavis vice apportabatur, longa erat 2 ulnas \& 7 digitos, lata $\frac{1}{2}$ ulnam \& 7 digitos, profunda $\frac{\pi}{2}$ ulnam. Pondus 9 centumpondiorum.

Peractis his filicet 32 impofitionum vicibus, nempe hora feptima vefpertina, ad unum latus removebantur folles, ne impedimento effent, fcilicet ut libere emitti poffent fcorix, dum nudaretur ferrum. Scorix non tam leves \& candidæ erant, ut illæx quæ emanarant ex fornacibus, de quibus infra agendum eft, Floß-ofen appellatis, erant nigriores \& ponderoliores, tanquam fcoriæ ex ftanni vena provenientes; \& quoniam nullius ferri confortes effe putabant, in aquam projiciebantur. Quum emanaverint fcorix, irrorabatur multa aqua pulvis carbonarius; qui pulvis in foffa quadam ad parietem foci anteriorem fervabatur ad ufum, fcilicet ut inde fenfim in ferrum candens laberetur, ficque per gradus \& paullatim frigefaceret ferrum; quum dein pulvere evacuata effet folla, apparebat ferrum coloris nigre rubefcentis, ficque tandem infundebatur frigida. Ut primum ferrum coloris obfcuri effet, parietis anterioris pars ex argilla confecti una cum orificio venti ope conti ferrei excutiebatur, moles ipfamet ferri transverfim pofita aqua etiam refrigerabatur, argilla dein a ferro optime corrafa, pariter pulvere carbonum, quo tegeretur quafi maffa ferri candens, comprehenfa tandem 3 uncis ferreis, qui a catena ferrea \& cylindro vecteque quodam penderent, attollebatur, quum fcilicet circumferebatur rota, circum trabem volvebatur \& contorquebatur catena, fic masfam prehenfam loco fuo levabant; quæ dein in binas partes dividebatur, quarum qualibet $\frac{\mathrm{r}}{2}$ centumpondium pendebat.

Exemta hac maffa, replebatur ftatim foffa dicta; ipfumque orificium ventilatorium, ut prius, reficiebatur ex argilla ; \& folles mobiles loco fuo emoti jam in priftinam fedem miffi, ope rotæ in motum fuum reciprocum agebantur.

Intra patium horarium eximi potuit fruftum five maffa dicta ferri, quod fit in vehementiflumo calore, nec nifi cum multo fudore. Pondus 


\section{TAB: IVIM. de Ferro.}

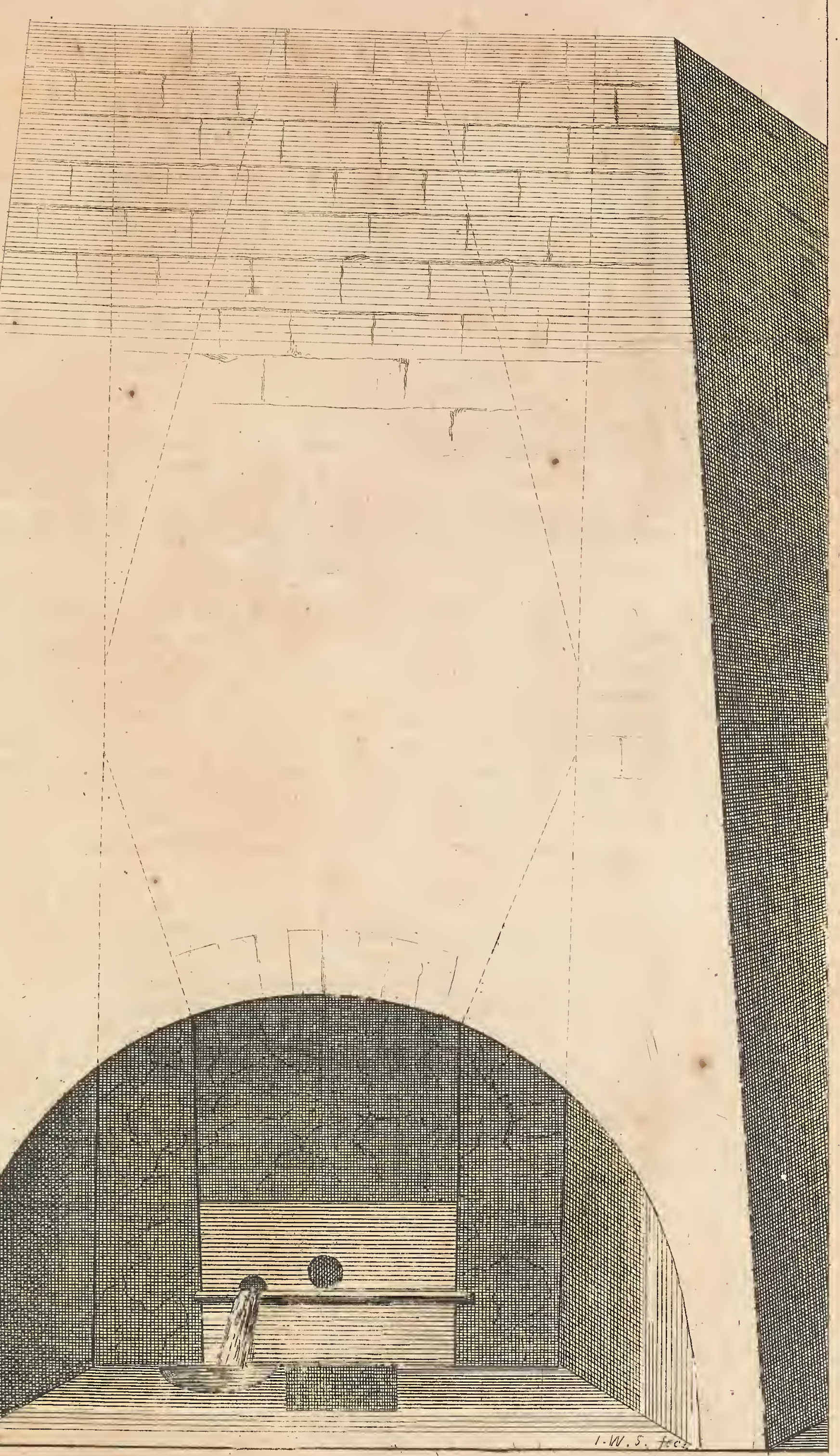



talis maffe, fpatio quolibet 24 horarum exemtæ, I.I vel I 2 centumpondia æquabat. Genus ferri, quod ex his fornacibus \& liquationum more proveniebat, non ita crudum \& heterogeneis conlpurcatum erat, proutferrum aliarum fornacum, hinc nec e novo, ut ferebant, recoquebatur, fed ftatim tenax \& malleabile fuiffe dicebatur.

Licet fornaces effent diverlix dimenfionis \& amplitudinis, ufque tamen nullum interceffit difcrimen inter majores \& minores, nec alia inftituta in majoribus ratio fufionis quam in minoribus erat, nifi quod maffa ferri quibusvis 12 horis ex fornace majore eximeretur, quum quavis $6 \mathrm{ta}$ hora ex minore. Pondus mafle ex minore fornace provenientis æquabat $2 \frac{\mathrm{I}}{2} \mathrm{vel} 2 \frac{\mathrm{T}}{4}$ centumpondia ; hinc preterlapfis 24 horis maffx 8 ad 10 centumpondia obtinebantur. Impofitionum vices vulgares erant 20,22 , ad 24, quavis vice 2 vafcula vena \& I menfura carbonum, quarum 3 unum faccum conficerent, imponebantur. Hæc de modo coquendi venam ferri Stirix, prout mihi a fide dignis relata funt.

\section{Fornaces ferrifuforia altiores Flo/s-Ofen appel- latee Carintbice.}

CArinthiæ in ufu erant fornaces altiores \& majores, quæ alias $F l_{0} / s=O f e n$ appellantur, nec multum differunt a fornacibus Germanicis. Vena illuc deferebatur ex montibus Loëllinger; eratque coloris caftaneo-brunei \& partim flaventis \& rubefcentis : fed antequam in fornacem deferretur, calcinabatur ope carbonum comminutorum, qui circa fufionem ejusdem venæ non effent idonei. Juxta fundum cavex calcinatorix relocabantur ligna fecta, ut filicet carbones eo melius ignem conciperent; infuper carbo dictus comminutus, \& fupra carbonem vena ferri. Quum tandem calcinata effet vena \& dein frigefacta, contundebatur in fruftula minora nucum magnitudinem fere rquantia; inde in fuperiorem partem fornacis attollebatur.

Fornacis murus exterior lapideus erat \& validus, eodem fere modo conftructus quo Germanix, formaque quadrata: quodlibet latus I $2 \&$ interdum 14 ulnarum, craffitie 5 vel 6 , cum binis arcubus, uno fcilicet a parte fornacis anteriore, altero ad latus, fub quo repofiti erant folles: arcus laxo duriori \& validiori conftabat ; in medio educebatur caminus, murusque qui illum proxime circumdaret, qui conttabat lapide arenario rudi \& ad rubrum colorem vergenti, qui illuc transferebatur ex Crain. Saxum fundamentale ejusdem generis erat 4 pedes longum, 4 latum, \& I pedem \& $\mathrm{I} \frac{\mathrm{I}}{\mathrm{2}}$ digitum craflum. Saxum vero parietis anterioris 4 pedes longum, $\mathrm{I} \frac{\mathrm{I}}{2}$ pedem altum, 4 digitos craffum: faxum fuper hoc relocatum 3 pedes altum, I 7 digitos craftum. Saxum in quo orificium fpiratorium quafi exfciffum exftabat, 5 pedes erat longum, I 8 digitos altum, \& 20 digitos crasfum. Ex hujusmodi faxis conftruebatur pars inferior fornacis circa focum, fed fupra conftabat laxo grileo vulgari. Saxum fundamentale horizontaliter relocabatur, fixa reliqua infuper, adeo ut tigillum latitudinem haberet Clafis I. de ferro. 


\section{I82 MODUS LIQUATIONIS FORDENBERGI,}

24 digitorum \& longitudinem 26 : Saxa hæc ita erant feeta, ut latius effet tigillum a parte fuperiore quam ab inferiore, adeo ut ad altitudinem $2 \frac{x}{2}$ pedum ex faxo fundamentali exftaret, in forma quadrata 2 pedum $\&$ Io digitorum : infuper ampliabatur magis \& magis tam tigillum, quam ipfa cavitas; non tamen abibat magis in formam quadratam, fed fenim in rotundam; circa altitudinem 9 pedum ampliatus apparebat diameter ad 72 digitos, inde contrahebatur rurfus ufque verfus aperturam, quæ formx quadratæ unius pedis tantum erat; integra ejus altitudo a faxofundamentali ad aperturam fuperiorem erat 24 pedum : tectum erat fornicatum, ut eo melius fervaretur opus immune ab aquis pluvialibus \& tempeftatibus, qux ignem turbarent. Orificium pro emiffione ferri ad dextram partem juxta faxum fundamentale erat factum. Circa latus finiftrum, ad altitudinem, ad quam eniti folebat ferri liquamen, erat apertura pro fcoriis emittendis facta, quæe emittebantur, antequam apertura pro ferro recluderetur. Orificium, per quod ventus fpiraret, a faxo fundi i 4 vel I 5 digitos altum erat, led in media fornacis longitudine : at vero fi maffi ferreæ majores defiderarentur, elcvabatur orificium dictum adhuc ad I digiti altitudinem : orificium hoc ventilatorium non conftruebatur ex argilla, fed in ipfo faxo dicto apte incifum aut exfcifum apparebat, adeo ut ne unguem latum a centro declinaret, fcilicet ut flamen exacte ftringeret integrum focum, qui multre exactitudinis effe debuit: Quumque orificium hoc jufte incifum effet, immittebantur guttulæ quxdam aquex, qux fi celeriter in focum defluerent, indicium erat nimix obliquitatis; at vero fi lentius manarent five in uno loco fubfifterent, fignum erat fitus nimis horizontalis; hinc aptabatur ita orificii obliquitas, ut aqua lente \& fenfim poffet illabi: in hoc plurima fuforis ars confiftebat.

Multum etiam referre dicebant, ut folles debite aptarentur : his in locis ufurpabantur folles coreacei, non multæ elevationis, fed longiores.

Fornax hujus generis e novo exftructa replebatur primum carbonibus, quibus accenfis fine vento bis fubfidere permittebatur, antequam vena imponeretur : dein immittebatur vena quavis vice ad menfuram cubicam $\frac{3}{4}$ uln $x$ in quovis latere, cujus pondus effet 2 centumpondiorum, \& infuper 2 facci carbonum; quumque fubfiderint, iterum imponebatur, quod iterabatur quovis $\underset{\ddagger}{3}$ horæ patio ; quumque hoc factum eflet quinquies, (hoc enim intra 3 vel $3 \frac{1}{2}$ horas peragebatur) tantum liquaminis ferrei in tigillo collectum apparebat, ut emitti poffet : in illum finem per lignum quoddam locus torufque in arena formabatur fecundum capacitatem maffe ferreæ. Antequam ferrum emitteretur, aperiebatur primo foramen fniftri lateris pro fcoriis, qux enanarent, frque illæ effent fiftulof \& coloris albi, bene peractam fuiffe operam fignificabat; fi vero effent coloris brunei nigricantis, fignum fore multum adhuc ferri in illis reconditum latere ; indicabat etiam tigillum nec juftam adeptum effe dimenfionem, aut orificium ventilatorium fuam obliquitatem. Emiffis jam fcoris aperiebatur orificium pro ferreo liquore, quo emiffo, obturabatur iterum orificiun; ferrum frigefactum ponderatum dabat 4 vel 5 cèntumpondia; continuabatur fic opus, filicet fpatio quovis 3 vel $3 \frac{\mathrm{I}}{2}$ horarum emittebatur 
ferrum, emiffionumque vices erant 7 intra $2 A$ horas; ferrum interea emiffum 35 centumpondia xquabat; ad quamlibet emiffionem vel maffam inde collectam 3 impofitiones requirebantur, five 9 aut io centumpondia venæ, una cum 8 vel 9 faccis carbonum, magis minusve prout illi duri vel molliores effent; duri enim cum mollioribus, \& molles cum duris commifcebantur; nifi commifcerentur, nullius ufus fore dicebantur,

Opus fuforium in hujus generis fornacibus continuari folebat fpatio 28 ad 33 feptimanarum, jactitabant quidam ex turba liquatorum fe artem calluife, qua prima ftatim feptimana vel principio fufionis tantam copiam ferri potuerint producere, quantam alii, quum opus fuforium per 3 vel 4 feptimanas jamdum continuatum fuiffet: artem in illo conftitiffe dicebant, ut bis aut ter imponerentur fcorixi cum lapide fcifili commixtæ, quibus colliquatis, obductum fuiffe dixerunt parietem cavitatis veluti quodan vitro, ficque putabant integrum venæ pondus ftatim prima feptimana imponi potuiffe.

Scoria fubnigri coloris ponderofiores, in quibus ferri quid reconditum effet, fub malleo quodam aquatico comminuebantur \& contundebantur, pulvis dein in foffa quadam lavabatur: ferrum quod inde obtineretúr, una cum vena reliqua transmittebatur per fornacem, \& cum volumine ferri commifcebatur.

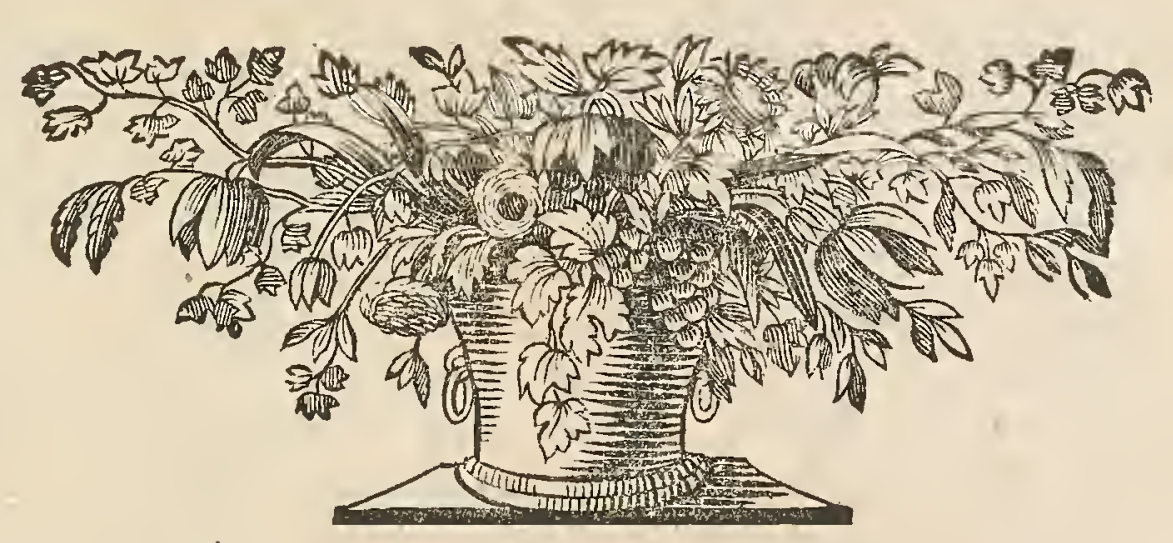




\section{PARAGRAPHUS XX.}

\section{Modus inufitatus venam ferri tractandi prope Flactre in ditione Saltzburgenfi.}

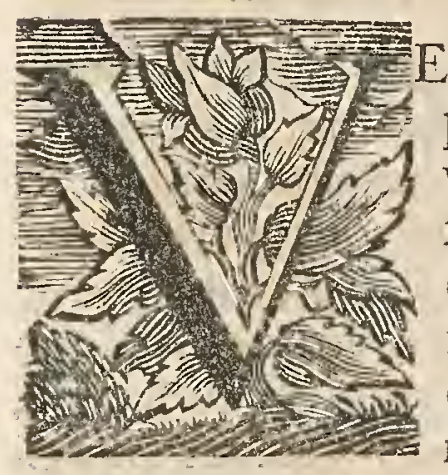

Ena qux in fornace hic fundebatur coloris erat nigri, partim brunei, partim etiam flavi, exque montibus vicinis multa ejus copia eruebatur, frangebatur hic ftratim, alibi vero apparebat copiofe dilatata in glandulas \& campos. Menfura ufitata venæ longitudinem $I_{2} \frac{T}{2}$ ulnæ, latitudinem I; ut \& profunditatem eandem xquabat \& vocabatur Korren: menfura vero minor $\frac{3}{4}$ ulnam in forma quadrata, ex quibus tres unam menfuram majorem conflituebant five unam carrham. Vena dein in fruftula contundebatur, ad magnitudinem nucum majorum \& minorum. Vena duplicis erat generis, unum notæ deterioris, alterum melioris, coloris fcilicet brunei \& flavi; hoc genus feorfim confervabatur, nam ad confetionem chalybis maxime idoneum cenfebatur. Genus prius feu note pejoris in foffa quadam, qure ad illum ufum exftructa erat, calcinabatur \& quidem cum lignis craffioribus \& igne fatis vehementi.

Quod fornacem \& ejus conftrutionem attinet, externa ejus facies fimilis erat fornacibus Germaniz exftructis \& prefertim Saxonicis, cum illa tantum differentia., quod laqueare quoddam five arcus ante locum emiffionis exftructus effet, \& fimul quod aliquantum effet humilior, ad altitudinem modo 3 ulnarum. Fornax a faxo fundamentali 24 pedes erat alta usque ad aperturam fuperiorem : faxum fundamentale in forma quadrata $I_{2}^{\frac{1}{2}}$ ulnæ erat. Cavitas fornacis inde dilatabatur usque ad medium five ad altitudinem abinde 12 pedum, ubi latus quadratum erat 3 ulnarum, inde contrahebatur rurfus cavitas, forma quadrata ubique usque ad aperturam fuperiorem fervata, ubi latus ejus quadratum crat I ulnæ.

Infuper tectum quoddam fornicatum erat, ne fcilicet aqua pluvialis in fornacis partem fuperiorem \& aperturam decideret, \& flammamignemque infeftaret. Ipfa cavitas vel murus intimus fornacis tegumento vel lorica faxea validiore continebatur; faxum fundamentale obliquabatur paullulum verfus partem anteriorem five ad aperturam per quam emittebatur liquamen ferri, Ccilicet ut omne ferri volumen ad faxum fundi usque emanare poffet. Orificium folliculare ex faxo fundamentali ad elevationem I 3 digitorum factum erat; maxima exactitudo requirebatur, ut aptarentur jufte flabella, fcilicet ut ventus debite ftringeret volumen ferri in foco contentum, \& totam fornacem æqualiter permearet. Murus ipfus fornacis validiffimo lapidis genere eductus erat. Ignis fuforius inibi continuari potuit fpatio 20 ad 30 feptimanarum.

Principio fufionis, five primis 3 aut 4 feptimanis non tanta quantitas ferri obtinebatur, quanta dein, cum calefacta demum effet fornax, five ad caloris 
caloris debitum gradum redactus murus: initio enim fpatio cujuslibet hebdomadx obtinebantur modo 80 ad 90 centumpondia, poft elapfum 6 vel 7 feptimanarum major quantitas; adeo ut fpatio I diei \& noetis 28,30 ad 40 impofitionum vices effent, magis minusve fecundum fluiditatem venæ; quavis vice una menfura, quæ vocatur Kübel, imponi folebat, usque tamen menfura dicta non femper ad fummum replebatur; quum enim vena fluidioris indolis effet, menfura plenior erat; at fi naturæ immitis \& refractarix, palmi altitudo ei deeffe folebat: menfura talis plena $I_{\frac{1}{4}}$ centumpondium pendebat, pondus erat Viennenfe. Vena ditior \& pauperior plerumque commif́cebatur, adeo ut fimul poffent colliquari; hinc fpatio 24 horarum imponebantur 35 ad 50 centumpondia venæ calcinatæ; \& infuper $\frac{1}{2}$ faccus carbonum ad quamvis menfuram vel Kübel; carbones durioreshic optimum ufum præftabant: primum injiciebantur carbones \& infuper vena, qux ope rutri aut marculi tridentis adæquabatur : 4 facci carbonum conficiebant fimul I fafciculum five Knippa Svecice, prout appellatur, $2 \frac{1}{2}$ Knippor unam menfuram, qux vocatur Foder, quxeque ab equis jugalibus feu binis commode trahi poffet.

Semel imponi folebat vena fpatio quolibet $\frac{3}{4}$ vel I horæ, \& peractis 4 vel 6 impofitionibus, obtinebatur mafla ferri, qux ibi $F l o f s$ appellabatur, ponderis $2 \frac{\mathrm{I}}{2}$ ad 3 centumpondiorun, fed fecundum qualitatem illius venx commune pondus maffie erat 3 centumpond: \& iftiusmodi maffie quovis die \& noete fexies vel lepties acquirebantur, adeo ut fpatio quovis 24 horarum obtinerentur 18 vel 20 centumpondia Viennení, confumtis 3 ad 5 Knippor carbonum : hinc per leptimanam I 26, 1 30 ad I 40 centumpondia ferri crudi, \& ex vena meliore, quæ vena chalybea vocabatur, 200 centumpondia; ad quod confumi folebant $245 ; 279,3$ I 5 ad 350 centumpondia venx fecundum bonitatem \& qualitatem ejus, ut \& carbones 44 Knippor vel I 80 faccorum.

In parte inferiore fornacis, ubi ferri volumen colligebatur, five in loco foci ad altitudinem $\frac{3}{4}$ ulnæ latitudinem fuam confervabat, fed fubji. ciebatur faxum quoddam validum $\frac{\mathrm{I}}{2}$ pedem craflum inftar fulcri, pariter ad latus dextrum, ut locus ille plane repleretur. Juxta faxum fundamentale apertura emiffionis ad illam amplitudinem parata erat, ut brachium commode potuiffet inferi. Ad latus finiftum pariter relocatum erat faxum laterale, quod tamen non illius altitudinis effe debebat, ac illud quod pofitum effet ad latus dextrum, fed modo ad $\frac{1}{2}$ ulnxe altitudinem a faxo fundamentali, adeo ut locus fuperior ad $\frac{\mathrm{r}}{4}$ ulnæ diftantiam apertus eflet, qui obturabatur argilla, fcilicet ut ad libitum aperiri poffet \& fcoriæinde emitti. Saxis his lateralibus ope uncorum ferreorum profunde infertorum cavebatur, ne faxum inde dimoveretur. Bina hæc faxa fimul vocabantur paries anterior five Foerrwégg.

Quum eo usque perventum effet, ut vena in ferrum colliquata emitteretur, apericbatur primum orificium, quod argilla modo erat obturatum, fupra faxum illud anterius; quo aperto defluebant fcorix, quæ admodum fluidæe effent, unde maffa ferri plane nudabatur: fcoriæe apparebant coloris viridis erantque limpidx, \& poris fiftulisque refertæ, \& confequenter. le?
Claffis I. de ferro.
Aa
viflima, 


\section{METHODUS LIQUANDI CIRCA FLACTRE}

viflimx, adeo ut nulla pars ferri in illis occuli \& latere poffe videretur. Cauiam quod paries anterior uncis ferreis alligaretur, effe dicebant, ne rimas duceret, quum aperiretur orificium pro fcoriis emittendis ; fi enim rimas duxiffet, poffet ferrum cum multo damno intempefte effluere, jam enim fine periculo in foco retinebatur, dum fcoria \& recrementa cujuscunque generis inde emanaverint. Emiffis fcoriis, aperiebatur ad latus dextrum illud orificium, per quod ferri liquamen emittendem erat; prius enim formabatur torus \& cubile quoddam in arena pura, fecundun figuram \& magnitudinem delideratam pro ferro recipiendo; Guumque emis. fum effet ferrum, pars refidua propius adhuc ad faxum fundamentale excutiebatur, adeo ut ex foco poffet effluere quicquid fluidum effet; nifi enim omnes ferri reliquire emitterentur, adeo ut nihil effet refiduum, damno futurum dicebant emittendo volumini ferreo fubfequenti. Obturataiterum argilla fervabantur orificia usque ad alteram emiffionis vicem. Folles coreacei hic in ufi erant.

\section{Modus purificandi ferrum boc crudum.}

FErrum quod ex fornace hac emiffum effet, fluidiffimum erat, quoniam confertum multo fulphure; unde nec ftatim, ut aliud ferri genus, \& peracta recoctione five liquatione in foco ferrario, fub malleum potuit mitti \& in contos extendi; liquefaciondum primo erat in camino quodam ferrario, in quo focus formabatur fimilis foco purificatorio cupri, profundus fatis \& formæ rotund $x$, fcilicet diametri I ulnæ, \& profunditatis $\frac{3}{4} \mathrm{ul}$. næ, conftructus ex bonæ indolis lapide, qui dein argilla bene obducebatur, fimillimus, prout jam dictum eft, foco purificatorio cupri minori. Canalis five conus fpiratorius conftabat ferro, $\&$ in focum hunc extra murum ad longitudinem $\frac{\mathrm{T}}{4}$ uln protrahebatur, admodum etiam obliquabatur fcilicet in medium foci. Supra tigillum hoc five focum relocabatur dieta maffa ferri, \& ibifundebatur, eodem modo prout ferrum in focisfuis: maffa hxc co usque colliquefcere debebat, dum ferrum bene colliquatum \& limpidum inftar cupri foluti evafiffe confpiceretur; perftabat opus hoc liquefactorium fpatio 3 horarum, interea confumtis carbonibus volumen hoc diligenter circumagitabatur; cumque liquefactum plane ftaret, in volumen hoc immittebat magifter ferrum quoddam frigidum non procul a cono ventilatorio, quo explorabat, num fatis liquidum flueret, \& num focus adhuc plane effet repletus; quum liquidum bene ftaret, apparebat materia quædam, quæ Span nominabatur, circumcirca ferrum dictum frigidum, non aliter ac cuprum pariter immiffo conto ferreo frigido, tunc plurima pars fulphuris jamdum evanuiffe putabatur; atvero, fin non bene liquatum. effet ferrum, materia illa fe non undiquaque circumdediffe ferrum videbatur, fed modo interrupte \& particulatim hic \& ibi inhærebat; quum itaque inæqualis hujus materix adhærefcentia effet, intendebatur adhuccalor, ușque dum liquefactum plane effet; quo facto auferebantur carbones \& fcorix fupranatantes, \& ferrum liquidum fic per aliquantum temporis linquebatur in liquamine \& fluore fuo, fcilicet dum crufta, qux fuperficiem 
METHODUS LIQUANDI CIRCA FLACTRE, 187 obducebat, congelefceret; dein fuperinfundebatur aqua, \& brąctex vel laminæ ferri ftratim inde excerpebantur, non aliter ac fierifoletcirca purificationem cupri. Opus hoc perftare folebar fpatio 4 horarum, nam intra i 2 horas tres hujusmodi maflas purificare debuit, intra quod tempus confumebantur 2 Knippor carbonum; ex quavis maffa ferri crudi peribat plerumque $\frac{1}{2}$ centumpondium, Inftituebatur operatio hac purificatoria ferriideo, ut ferrum privaretur omni fuo fulphure, nam fulphure admodum imprægnatum erat.

\section{Modus iterum recoquendi purificandique boc ferrum.}

$\mathrm{R}$ Ecoquebatur modo dißto ferrum; cumque omni parte fulphurị crasfioris per recoctionem talem privatum effet, exinde quidem durius evafiffe videbatur; usque tamen fub malleo adhuc extendi nequiit, nifi iterum recoqueretur. Cruftæ dictæ ferreæ in camino quodam calcinatorio ope lignorum adurebantur; tres ordine camini erant, unus prope alterum, \& inibi igne calcinatorio tam diu urgebatur ferrum, dum inciperet liquefcere, quod a flamma præcipue lignea fiebat : laminx fic calcinatæ \& mox refrigeratx modo ufitato in ferrum fundebantur; quod hic vocabatur Auffitizen, \& quavis vice liquefieri debebat I centumpondium \& $20 \mathrm{lb}$. Viennenf. quod fiebat in focis vere ferrariis fecundum morem Bohemix \& Saxoniæ receptum; exque I centumpondio \& $20 \mathrm{tb}$. obtinebatur x centumpondium five 100 16. ponderis Viennenfis ferri purificati \& fub malleo extenfi; exinde videre licuit jacturam effe 3 th. ex centumpondio. In fafciculum quendam combinabatur ferrum $2 \frac{T}{2}$ centumpondiorum, qui vocabatur Sobm; quatuor tales fafciculi Meuler, filicet Io centumpondiorum.

Quomodo dein chalybs ex hoc ferro conficiebatur, infra exponetur.

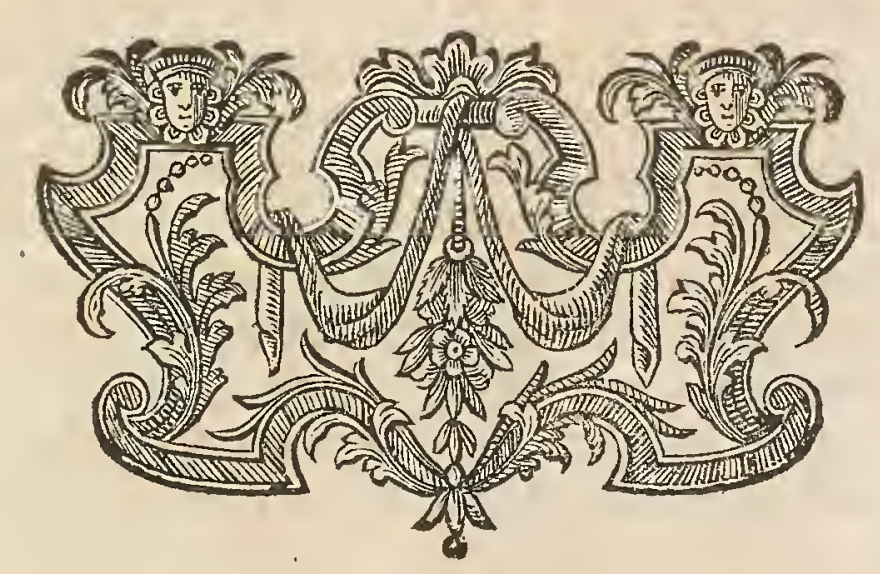




\section{PARAGRAPHUS XXI.}

\section{Tractatio rena ferri fecundum Agricolam.}

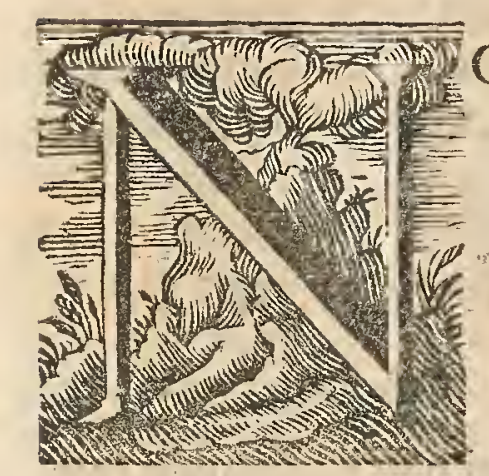

On fuperfluum \& ex re effe putem, hic etiam modum ab Agricola in re fua metallica traditum venam ferri fundendi recoquendique exhibere: nam ex defcriptione illa comparatio quædam inftitui poffe videtur inter novam fundendi ferri methodum \& antiquam. nam quocunque modo vena ferri tractata fit, oculis tuis, benevole leetor, libet fiftere. Ipfiffima ejus verba funt, prout fequuntur.

"Ferri vena, cui præcipua bonitas, excoquatur in fornace, quæfecun„dx fere fimilis fit ; etenim focus exiftat altus pedes tres \& dimidium, la„tus \& longus ad pedes 5 ; in cujus medio fit catinus altus pedem, latus „, „effe poteft, prout ex vena plus minusve ferri conficitur. Magifter, certa ,venæimenfura detur, five ex é ferrum multum five paucum conflare pof"fit, laborem in hac re infumpturus primo in catinum conjiciat carbones, "atque ipfis tantam ferri venam comminutam, \& cum calce aquis nondum ,reftincta permiftam infpergat, quantam batillum ferreum capit. Tuni ,iterum ac frepius carbones injiciat, \& eis venam infpergat, \& quidem uf"que dum acervum clementer affurgentem conftruat; quem tandem car"bonibus incenfis igni, follium artificiofe in fiftula collocatorum flatu ad "ardendum excitato, excoquat; quod opus perficere potef, horis modo "octo, modo decem, nunc vero duodecim; ne autem ignis ardor ei faci"em, ut folet, adurat, totam pileo tegat; cui tamen fint foramina, per qux "cernere \& fpirare poflit : ad fornacem fit pertica, qua toties res poltulat; "poftulat autem, cum folles nimis acrem flatum infpirant, vel ipfe venam „reliquam \& carbones adjicit, aut recrementa detrahit, fores canalis, per „quem aquæ defluunt in rotam, axem, qui folles comprimit, moventem ,fiftat, \& verfari permittat.- Quo fane modo ferrum confluit, \& mafla „pendens duo triave centumpondia, prout vena ferri fuerit dives, poterit "confici. Mox magifter viam recrementorum conto aperiat, quæ cum ,tota defluxerint, maffam ferream refrigerari finat: poftea ipfe \& miniftri "trudibus ferreis commotam de fornace in terram dejiciant; eamque mar„,culis ligneis, quibus manubria fint tenuia, fed quinque pedes longa, per„cutiant : ut \& recrementa, quæ adhuc ad eam adhærefcunt, decutiant, ac ,ipfam adunent fimul \& dilatent. Etenim fi ftatim incudi impofitam per„cutiet magnus malleus ferreus, ab axis, quem verfat rota, dentibus fubla,tus diffipetur : attamen non multo poft, forcipibus fublata \& eidem mal,leo fubjecta acuto ferro in partes quatuor, vel quinque vel fex, prout ma"gna fuerit vel parva, fecetur : ex quibus in altero camini foco recoctis \& „,rurfus incudi impofitis, fabri formant mallas quadrangulas, vomeres, con,tos; fed imprimis bacilla; quorum 4 aut 6 aut 8 pendunt quintam cen- 
TAB: XIX. de Ferro.

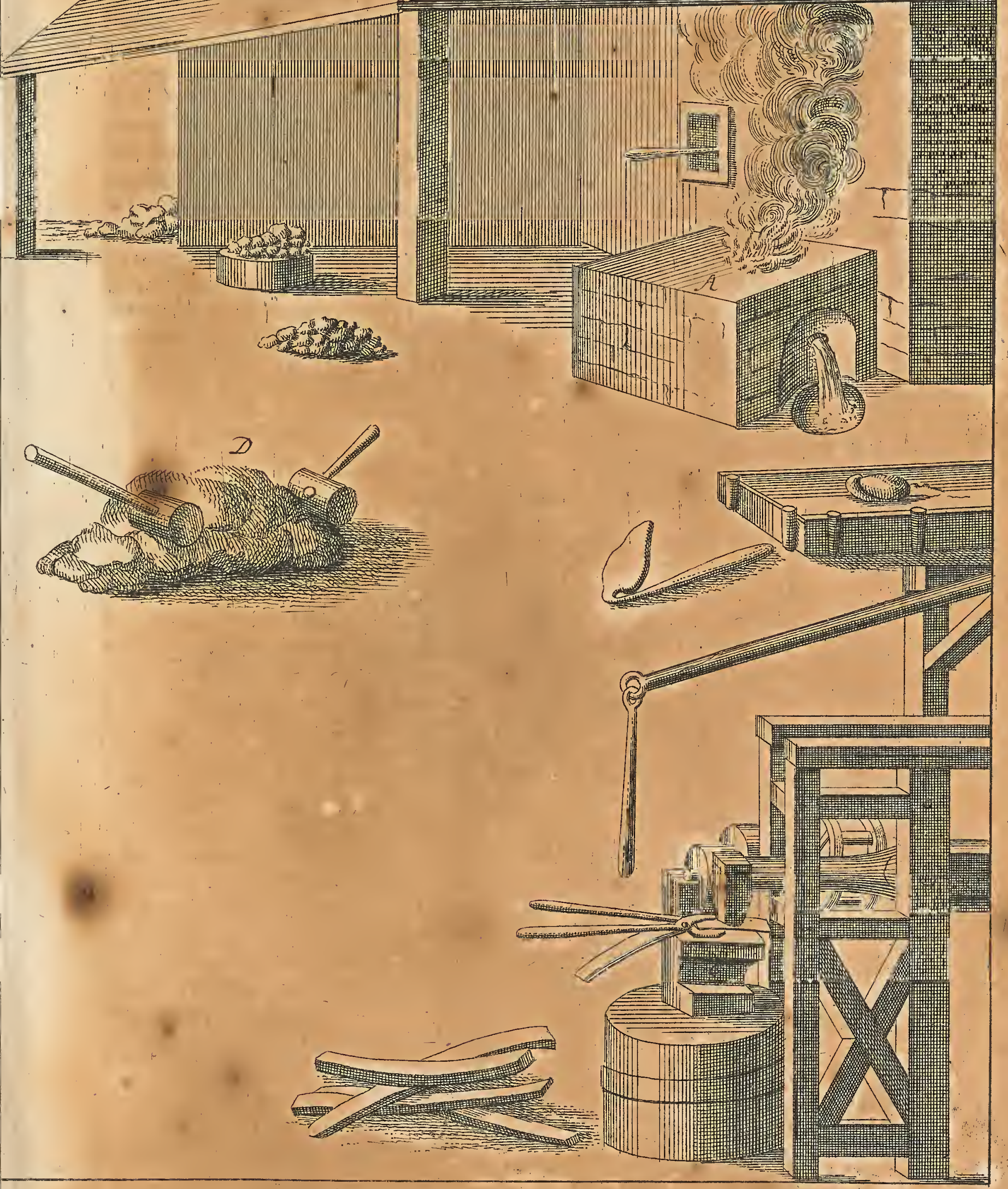




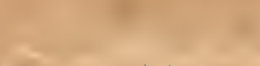

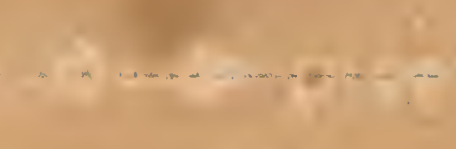

(2)
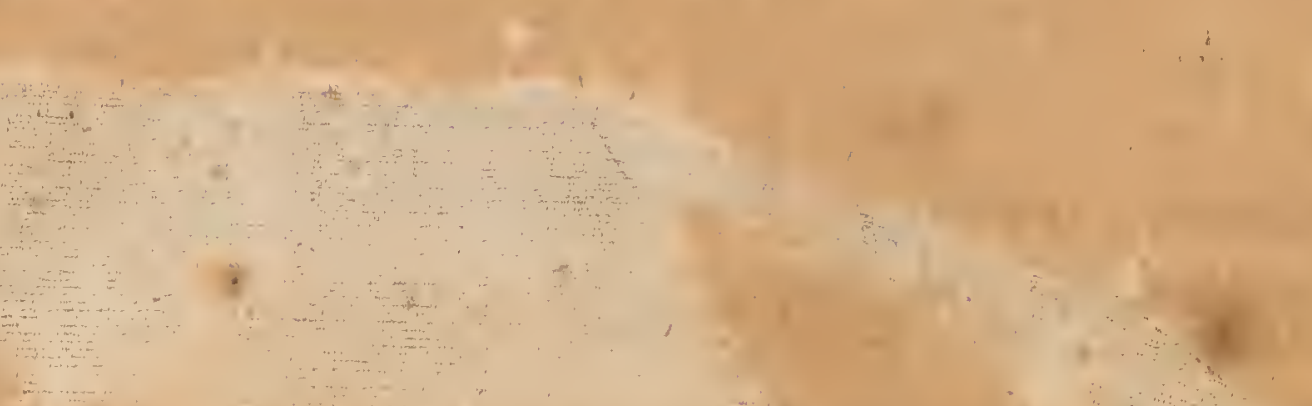

$\sqrt{3}$

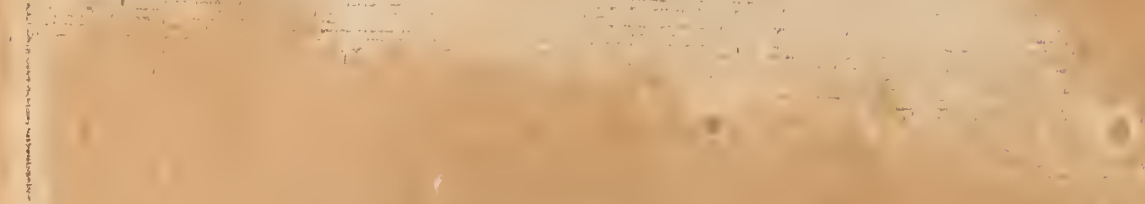

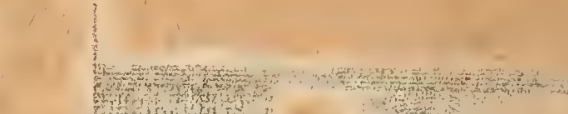

.

21.tin

(
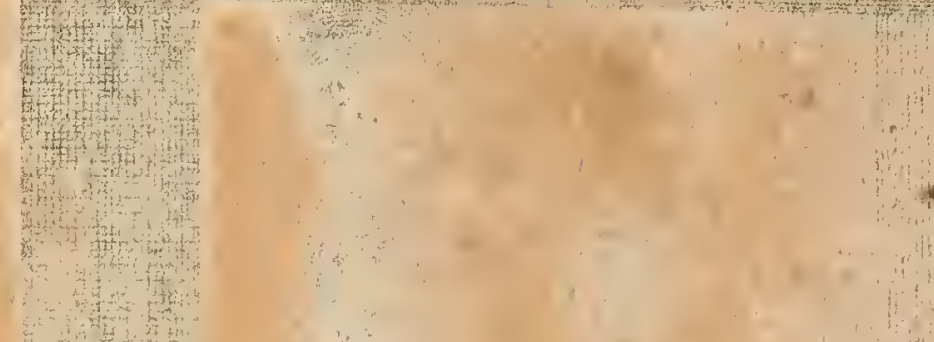

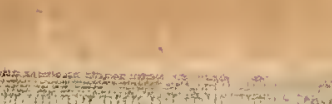

intent

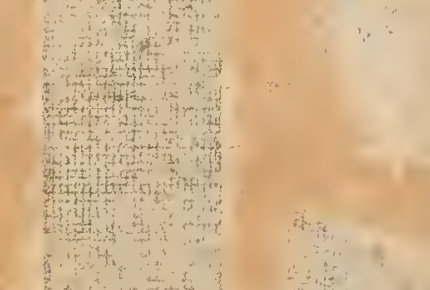

$\sum_{i \rightarrow \infty}^{+\infty}$

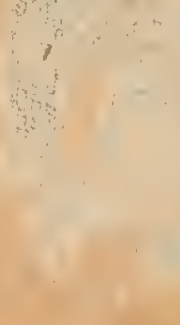

$+4$

$+4+2+4$

(4)

$x^{2}+4$

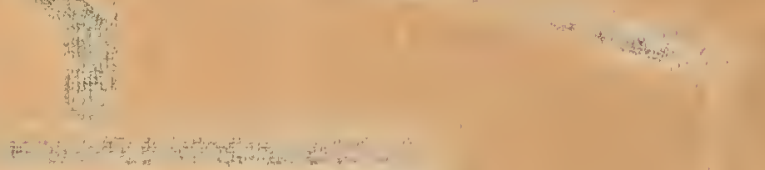

and

ty

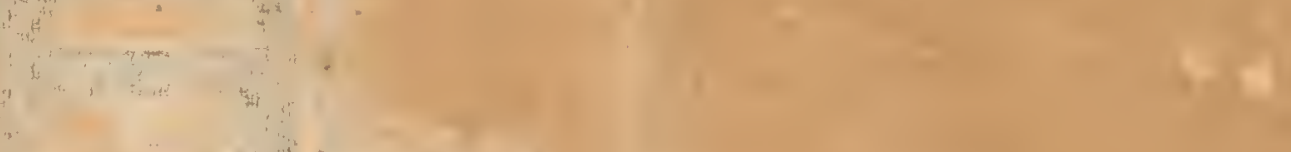

(4)

to

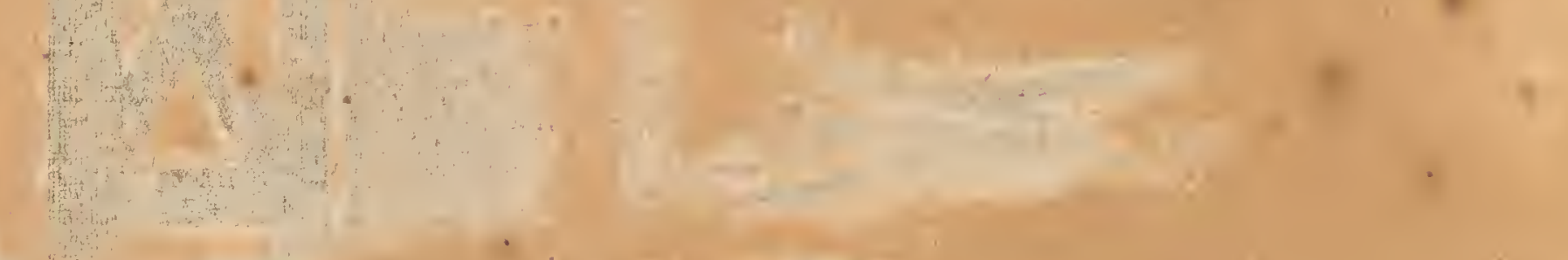

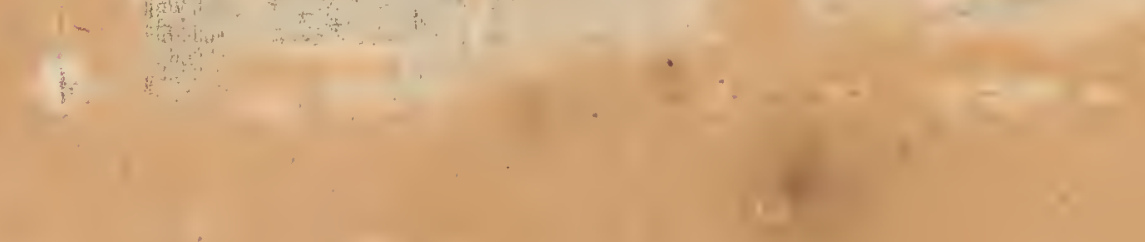




\section{LIQUATIO SECUNDUM AGRICOLAM. 189}

tumpondii partem, atque ex his denuo varia inftrumenta confici folent." Ad quamque autem mallei percuffionem adolefcens cochleari aquam in" candens ferrum, quod formant fabri, infundit; atque hinc eft, quod per-"6 cüffiones tam magnum fonum edant, ut longe ab officina audiatur. Maf-“ fa autem de fornace, in qua ferri vena excoquitur, dejecta, in catino re-" manere folet ferrum durum, \& quod difficulter ducitur; ex quo confici“ poffunt præferrata pilorum capita \& duriffima quæque opera. A eft fo-“ cus Tab. XIX, B acervus, C via recrementorum, D maffa, E marculi" lignei, F malleus, G incus. Sed ad ferri venam, quæ vel ærofa eft vel“" cocta, difficulter liquefcit, majore opera \& acriori igne opus eft : etenim" ejus partes, in quibus metallum ineft, non modo a reliquis, quæ nullum" in fe continent metallum, oportet fecernere \& pilis ficcis frangere; fed \& " urere, ut alia metalla atque fuiccos nativos exhalent ; \& lavare, ut levia" quæque ab eis feparentur. Excoquantur vero in fornace primx affimili," verum multo ampliore \& altiore, ut multam venam multosque carbones" continere poffit: nam partim vente fragmentis, qux majora nuce non" fint, partim carbonibus compleatur, quas res excoctores gradibus, quifint" ad alterum latus fornacis, afcendentes injiciant. At ex tali vena modo" femel modo bis cocta conflatur ferrum, quod idoneum eft, ut in foco" fornacis ferrarix recalfiat, \& magno illo malleo ferreo fubjectum dilate-" tur, atque ferro açuto in partes fecetur. A eft fornax Tab.XX," B gradus, C vena, D carbones."

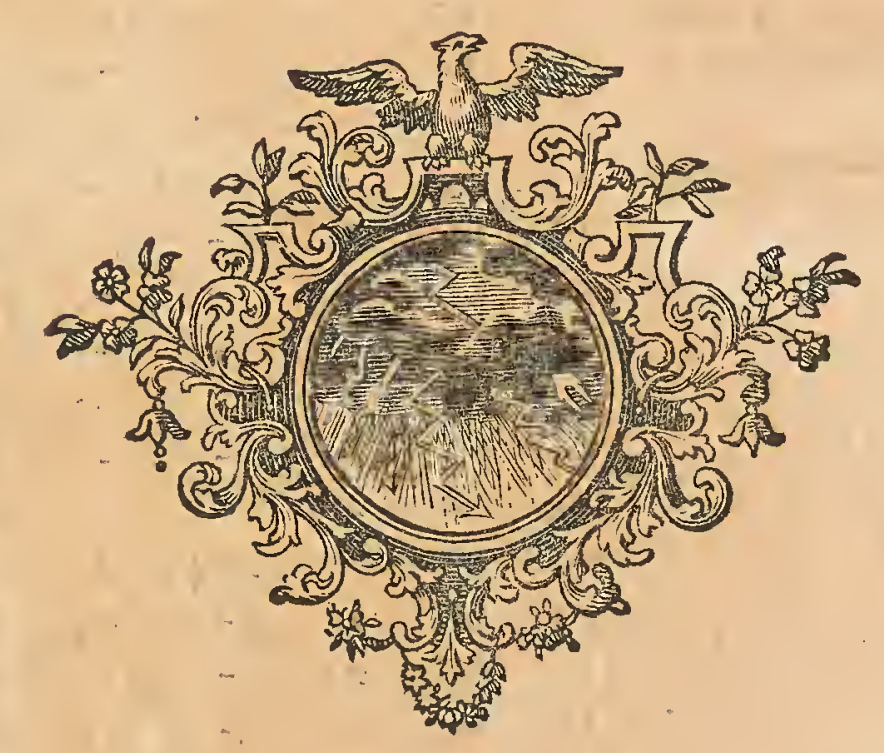

Clafsis I. de ferro.

$\mathrm{Bbb}$

PARA- 


\section{PARAGRAPHUS XXII.}

Tentamen venam ferri lignis fectis, pariter ter. ra combufibili, cum carbone mixtis, fundendi.

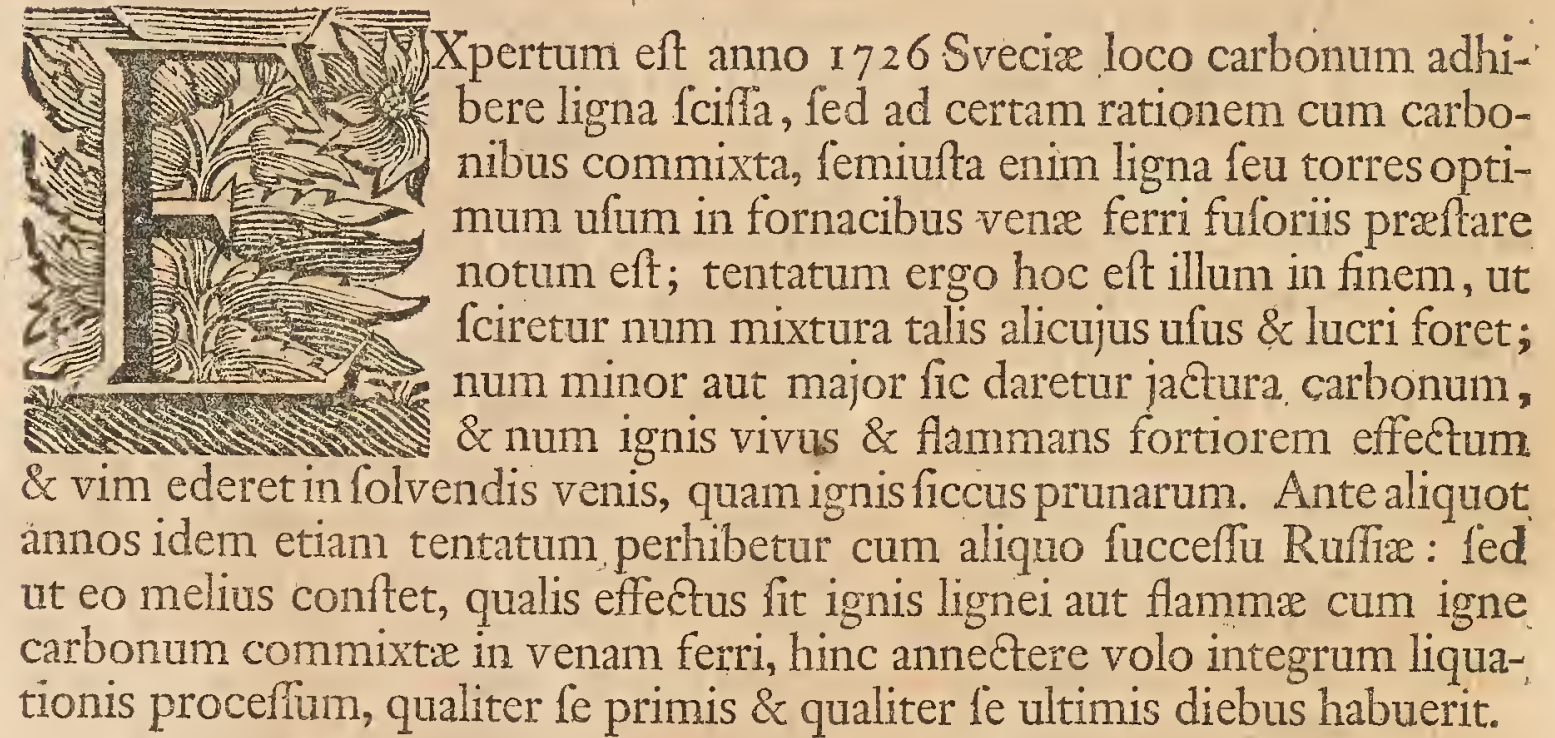
tionis proceffum, qualiter fe primis \& qualiter fe ultimis diebus habuerit.

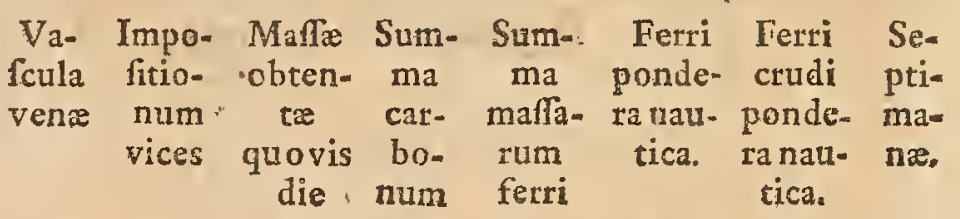

Jan. 7 Replebatur caminus antequam admiffus eft ventus

23. Cum admifus eft ventus

\begin{tabular}{|c|c|c|c|c|c|c|}
\hline - & 10 & - & - & - & - & - \\
\hline$=$ & I4 & - & - & - & - & - \\
\hline 12 & I 5 & - & - & - & - & $=$ \\
\hline 12 & 15 & 2 & - & - & $4 \frac{x}{2}$ & - \\
\hline I 2 & 15 & I & - & - & $3 \frac{\pi}{4}$ & - \\
\hline 13 & 15. & I & - & - & $\begin{array}{l}14 \\
3\end{array}$ & - \\
\hline 13 & 15 & I & - & - & $3 \frac{\pi}{4}$ & - \\
\hline 14 & 15 & 2 & - & - & 8 & - \\
\hline $14 \frac{1}{2}$ & I4 & I & - & - & $4 \frac{I}{2}$ & - \\
\hline & & & 104 & 8 & - & $2 \sigma_{\overline{4}}^{I}$ \\
\hline 14 & 14 & 2 & - & - & 9 & - \\
\hline 14 & 14 & 2 & - & - & 8 & - \\
\hline 14 & 14 & 2 & - & - & 83 & - \\
\hline 14 & 13 & 2 & - & - & $8 \frac{T}{4}$ & - \\
\hline $14 \frac{\mathrm{T}}{\mathrm{x}}$ & 14 & 3 & $=$ & - & $I I_{\frac{4}{4}}^{\frac{I}{4}}$ & $=$ \\
\hline 15 & 14 & 2 & - & - & $7 \frac{3}{4}$ & - \\
\hline 16 & 14 & 2 & - & - & 9 & - \\
\hline$I \sigma_{\frac{1}{2}}$ & 13 & & 97 & 15 & - & $62 \frac{\mathrm{r}}{4}$ \\
\hline 17 & $\begin{array}{r}3 \\
I 4\end{array}$ & $\begin{array}{l}3 \\
2\end{array}$ & $\tilde{-}$ & . & $\begin{array}{r}12 \frac{3}{4} \\
8 \frac{1}{4}\end{array}$ & - \\
\hline
\end{tabular}




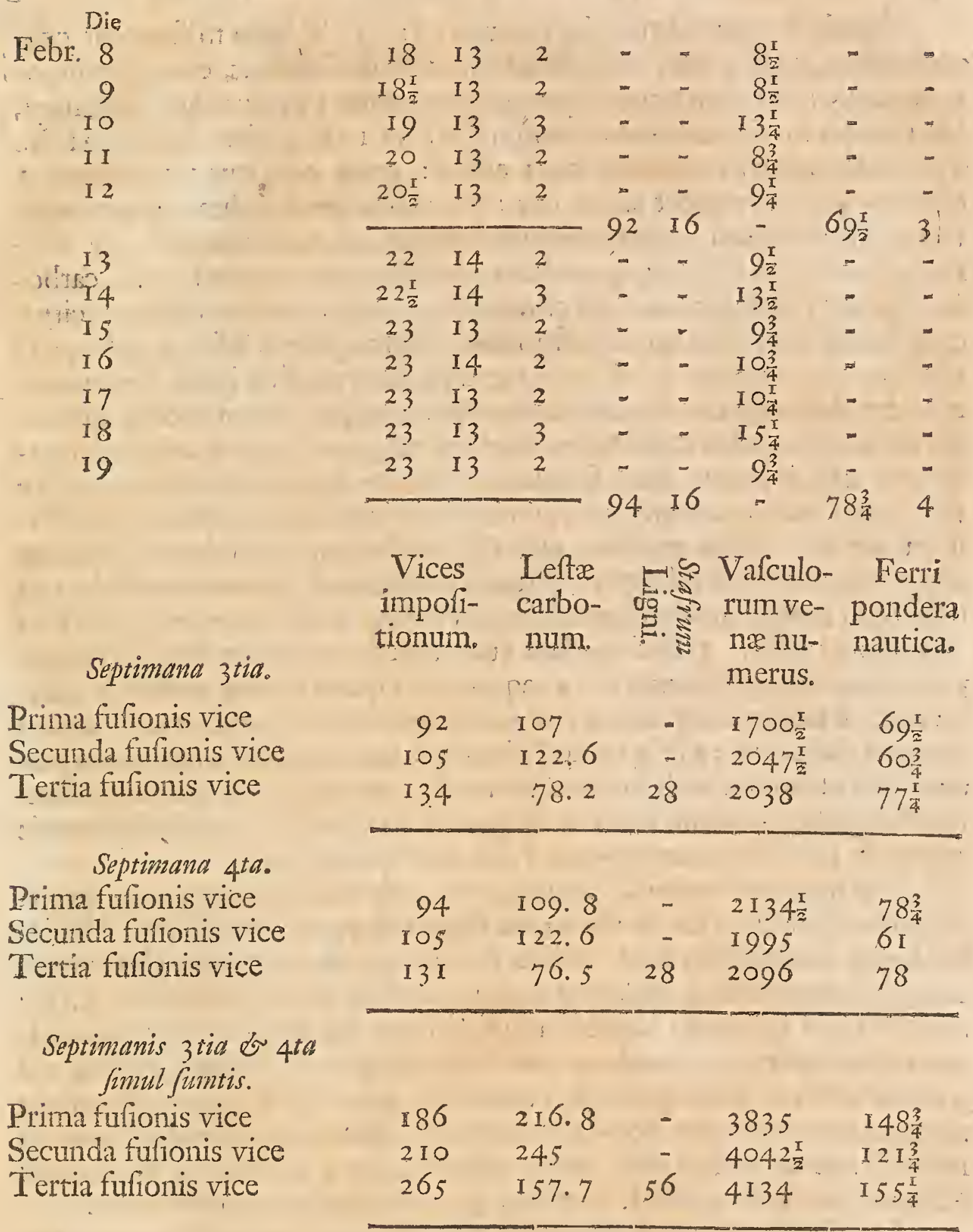

Ex tabula appofita videri etiam poteft, quot impofitiones quotidie factæ fint, quantum venæ \& quantum carbonum, quotve vafcula venæ quavis impofitionis vice, \& quantum ferri quovis die, ut \& quavis feptimana fit obtentum; videri etiam poteft, qualem effectum ediderit calor ex carbonis \& ligni mixtura excitatus, \& qualem ex nudis carbonibus, qui ex comparatione utriusque dignofci poteft: obfervandum eft, quod ligna debeant effe breviora, ut cum carbonibus melius commifceri poffint; pariter etiam optime ficca. 
Ex tabella præcedente obfervatum eft: I. Si ligna mifceantur cum carbonibüs, quod plures impofitionum vices dari poffint, eodem tempore manente; exempli gratia, feptimana -3tia erant I 34vices impofitionum, fed utendo méris carbonibus non nifi 92 ad 105 , pariter feptimana 4 ta I 3 i vices, quam fi carbones meri effent: quod numerus impofitionum ejussdem feptimanæ effet 94 ad 105 : vel etiam quod in fummam adjectx vices impofitionum intra feptimanæ tempus, ad numerum 265 afcenderent, quum alias ad 2 İo; quod ideo accidiffe putandum eft, quia carbones circuinjecti flammeo igne citius deflagrarent; unde confumtis citius carbonibüs, plures etiam impofitionum vices requifitas effe: acceditquod effectus \& vis ipfius venti augeatur ope flamme five ignis flammantis. 2. Licet plures fuerint impofitionum vices, usque tamen eadem quantitas carbönum, cum carbonibus adjecta fint ligna, eodem tempore confumpta effe videtur; nam fecundum probam confumtæ fuere 154 leftx $\& 7$ tonnæ carbonum una cum 56 menfuris (Stafrum appellatis) ligni fcisfi \& truncati; fique menfura talis ligni reducatur in carbones, adeo ut una menfura reddat vel æquet i 7 tonnas carbonum, proveniunt inde 233 leftx \& I I tonnæ: at vero circa fufionis vulgaris methodum confumt: funt 2 I 6 ad 24.5 leftx. 3. Sed eandem quantitatem carbonum intra idem tempus majorem quantitatem venæ requifiviffe, quam fi nudi carbones adhibentur, ex tentamine videmus; impofita funt vafcula venæ41 34, fed circa modum vulgarem 3835 ad $4042 \frac{\mathrm{I}}{2}$ circiter \& confequenter 4 . majorem partem ferri prodiife: fcilicet circa tentamen cum lignis i $55 \frac{\mathrm{L}}{4}$ pondera nautica ferri, circa modum fufionis vulgarem $1.21 \frac{3}{4}$ ad $148 \frac{1}{4}$, unde differentia 20 ad 25 ponderum nauticorum fuife animadvertitur:

Sed quoniam multa differentia intercedit inter fufionem, qux prima feptimana five 3 tia vice, \& illam qux altera vel quarta peracta eft, ratione habita ad quantitatem ferri; fcilicet quod intra idem tempus obtinuerint I $48 \frac{x}{2}$ pondera nautica, quamvis modo impofita fint vafcula vena 3835 ; at vero circa fufionem alteram $121 \frac{3}{4}$ pondera nautica ex vafculis $4042 \frac{2}{2}$; ratio hujus difcriminis videtur vel fuiffe differentia qualitatis in vena, vel partem ferri aut venæ parietibus adhæfiffe, quæ vigente opere liquefacta tunc primum in focum decidiffet: unde videmus, exactiffimum hujus rei inftitui examen non poffe, niff per multiplicatas crebrasque \& diutinas fufiones, inque 5 tam, 6tam \& 7 mam usque feptimanam continuatas.

Concludi tamen inde poteft I) roo pondera nautica ferri parari per $150 \frac{x}{3}$ leftas carbonum (tunc enim ligna in carbones funt reducta); fecundum vulgarem \& ufitatam vero methodum I oo pondera nautica ope I47 leftarum carbonum. 2) Secundum methodum novam cum lignorum carbonumque commixtione inftitutam impofita effe 266 I valcula venx, \& inde emiffa $\mathrm{I} D O$ pondera nautica ferri; fed eandem quantitatem ferri feu 100 ponderum nauticorum per modum vulgarem lucratos effe, impofitis modo 25.91 vafculis ven $x$, licet altera vice plus, fcilicet $33 \mathrm{I} 3$, fecundum indicem in tabula . Hinc ratione habita ad fufionis prioris vicem, nullam vel exiguam modo interceffiffe differentiam, fed in ratione ad alteram, majorem exftitiffe, docetur. Usque tamen ex his concludi poffe videtur, ufum 
ufum vulgarem cum carbonibus nudis, huic novo cum lignis anteferendum efle.

\section{Cum terra combuftibili.}

Uidam etiam periclitati funt venas metallorum, ferri \& argenti, per humum paluftrem combuftibilem fundere; \& eo usque progreffum fecille narratur, ut dimidiam, \& dein $\frac{2}{3}$ partes hujus terræ cum $\frac{\mathrm{r}}{3}$ parte carbonum fuperimnittere auf fint : fed terras fuas primum per ignem ficcum \& bene opertum vitiis ex fulphure \& oleo maligniori \& putriori provenientibus \& jugiter comitantibus privafle: additur, ex 4000 fruftulis terræ crudæ 2 Fudgrs circiter combuftx \& fulphure privatæ obtinuiffe; \& cinereum aut carbonarium caput, perufta terra, melioris \& purioris nota reddi, fi diutius in tali igne detineatur, fi usque fere per 30 ad 72 dies pariter fi tegumento denfo pulvereo interea claufa terra intus bene xfuet, \& nocivos fuos halitus per gradus \& moram diffipet. Non multos latet, humum hanc paluftrem, lutulentam, putrem \& coenofam infignem ufum proftare circa evaporationes diverfi generis falium, ut communis, victrioli, aluminis, \& in nullis non focis, ubi flamma \& xftus inde erumpens aheni cujusdam aut cortinæ latera ferire poffit; pariter in focis culinæ, ut penes multas gentes in ufum eft receptum: fed penes judicem adhuc eft, num ejusdem emolumenti fit in focis, ubi fortifimum adeft flamen, \& ipfum metallum immediato ejus ignis contactu domandum, \& in minimas \& fuidas partes dirimendum eft. Compertum eft, quod glebæ hujus generis, quia tenues \& leves funt, a vento præfertim fortiter \& plenis buccis lpiranti diffipari \& dilabi le patiantur; præcipue fi prope \& e diametro contra os Folicum fe fiftere aufint, \& nifi latera in defcenfu premant; nam in aliqualem flammam \& mox in fumum difperguntur. Et nifi prius ab immundo \& putidiori fuo fulphure per ignem prius defæcatæ fint, quod tabe quadam ipfum liquamen metalli, præcipue ferri, imbuiffent \& polluiffent, \& quali veneno fuo totam illam undam infeciffent; \& quamvis prius per ignem lentum \& bene claufum malignitas oleofa \& fulphurea expulfa fit, quod tamen ufque tantum frecis retinuiTent, ut ei non fine periculo vena precipue ferri concredi polfet : præter quod favilla \& cinere quodam immundo \& fabulolo volumen ferreum confpurcaviffet \& infeftaviffet. Sunt præcipue tria talis paluftris \& combuftibilis fæecis genera, unum radicum caulibus \& termitibus nondum emarcidis \& putribus factis prorfus conftans, quod crematum non tamen multum fubftantiæ carbonariæ fuppeditat, exilia enim radicum filamenta invicem complicata \& nodata ufta, ftamina etiam fimiliter tenuia relinquunt, per quæ non multam vim exercere poteft Vulcanus : alterum genus fimilibus caulibus fed jamdum putrefactis \& in humi cujusdam fpeciem verfis, aliis etiam conofis materiis intermixtis, conftare videtur, quod in cinerem quendam aut \& in fterilius quoddam caput per ignem combuttorium converti folet. Tertium ex puris fedimentis aqux paluftris in puteo in paludibus effoffoftagnantibus \& conglutinatis ; quod compreffum, \& in lateres formatum meliorem ignem fubminiftrare videtur: fed quid lucri in fornacum focis inde redire poffit, in tomo de argento videre licet.

Clalis I. de ferro.

$\mathrm{Ccc}$

PARA- 
I 94

\section{PARAGRAPHUS XXIII. \\ Iraditio quorundam de induratione ferri penes Indos.}

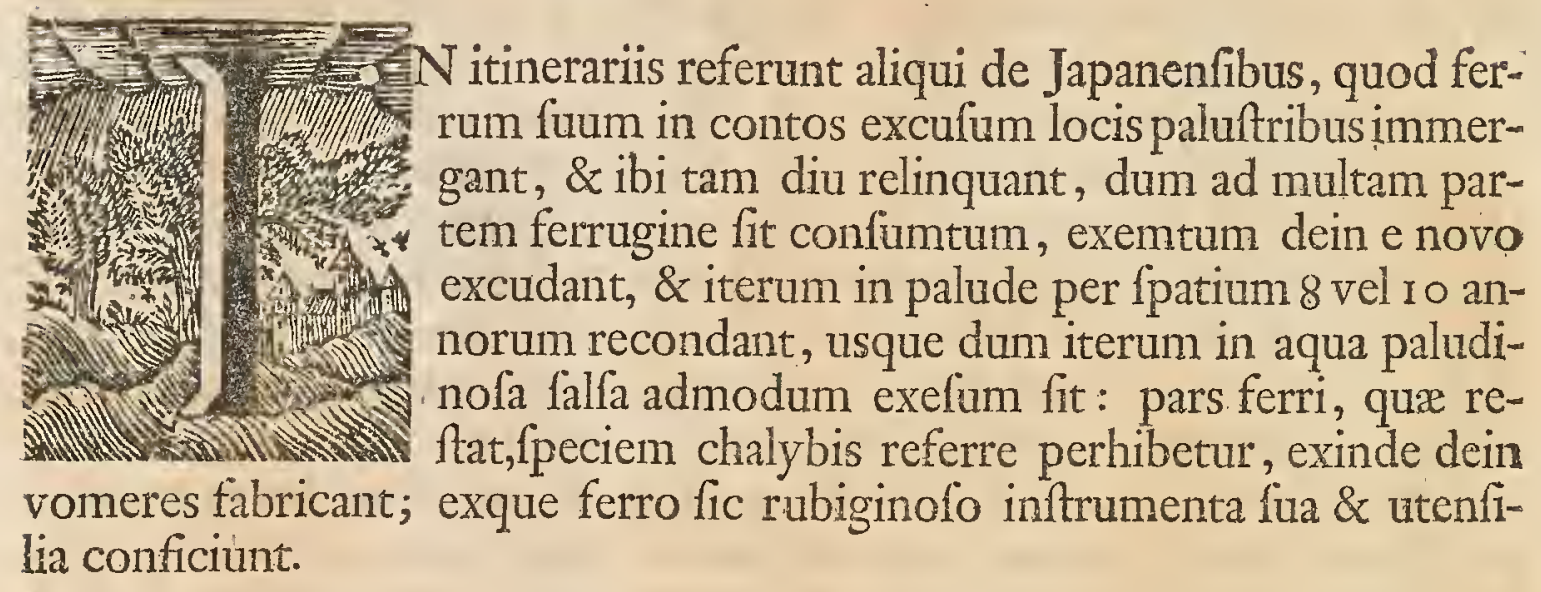

In regione orientali Celebum in diftrictu Tambaco dicitur ferrum effodi, quod fepiffime recoquitur \& iterum exflinguitur, hocque continuatur, dum duritiem optimam acceperit, unde nobile chalybis genus confici: ad quod etiam ipfammet aquam contribuere perhibent. Hæc ex Rumphio Dn. Valentini in Mufeo.

Traditio alias eft, Chinæ incolas \& Japanenfes artem callere, qua ferrum ad illam mollitiem usque redigere poffint, ut impreffiones \& figuras non fecus ac plumbum poflit recipere, \& dein duritiem ei debitan reftituere: hoc etian Beccherus de fe jactare videtur. Unde iftius mentionem tantum

hic facere lubet; alioquin modum emolliendi ferrum ingeniofifimi Dn. Reaumur in fequentibus videbitis.

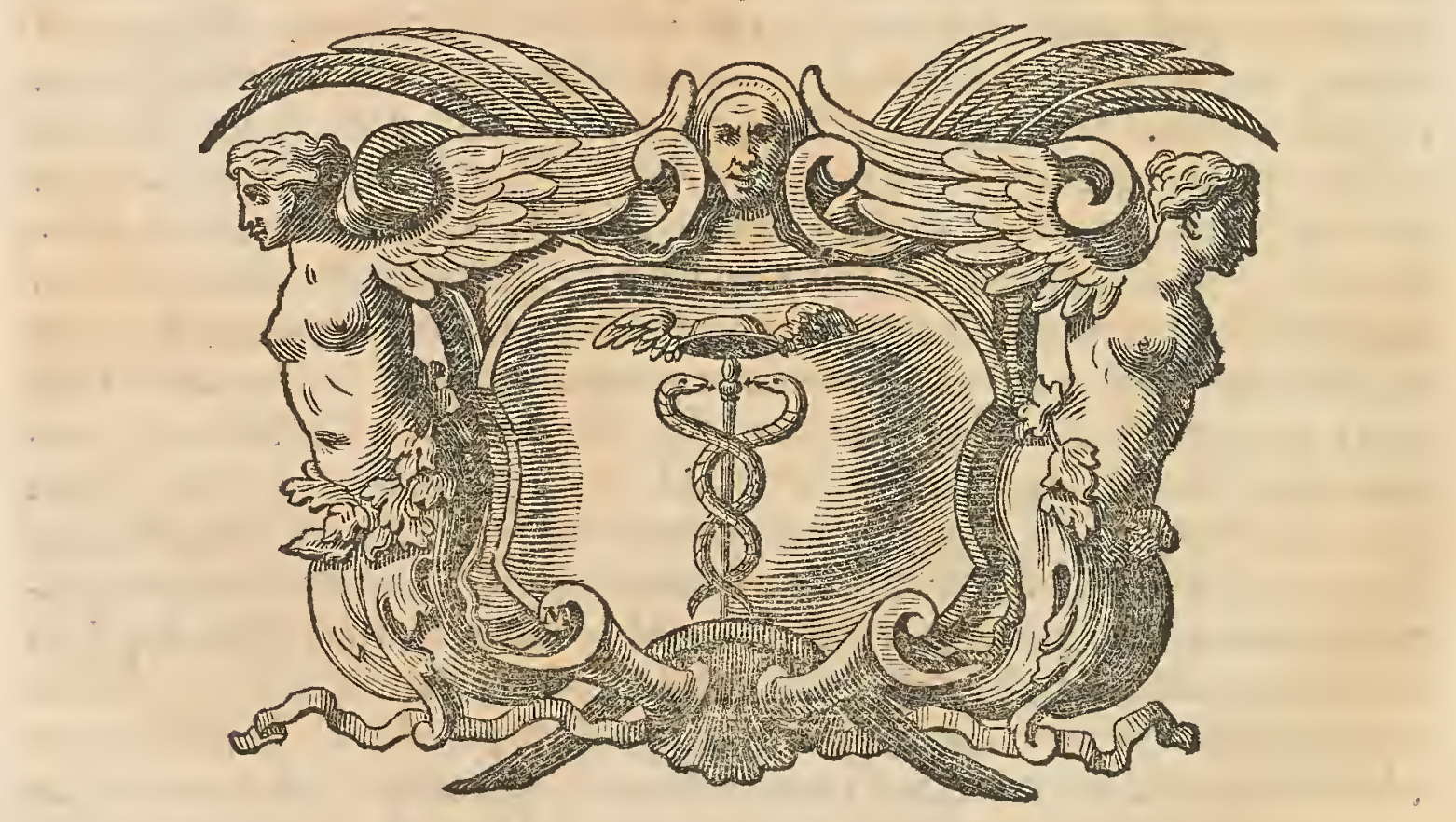

PARA- 


\section{PARAGRAPHUS XXIV.}

\section{Modus convertendi ferrum crudum fatim in duritiem chalybeam per recoctionem ejus in foco ferrario, qualis tam Svecioe quam alibi in ufu eft.}

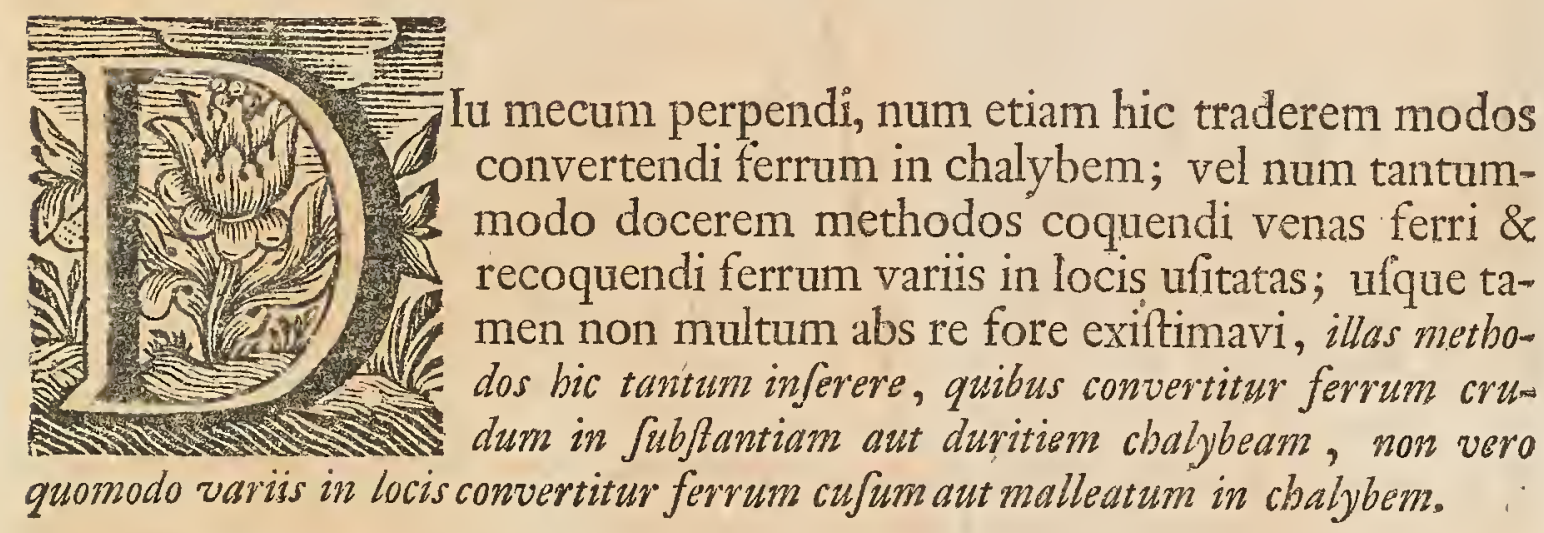

Quod primum attinet, fcilicet quomodo convertitur ferrum crudum in duritiem chalybeam, hujus loci effe omnino putem; quandoquidem. hæc induratio in ipfomet foco ferrario cum ferro adhuc crudo peragitur; cumque eodem igne, quo recoquitur alias ferrum ; hinc mancum mutilumque potuiffet videri hoc opus, nifi reçoetionis hujus methodos etiam fubjunxero.

Quod alterum attinet, fcilicet quomodo ferrum jamdum extenfum in chalybem fit cremandum, alius laboris \& operis eft; jamdum enim purificatum eft ferrum, jamdum fudaverat in fornacibus \& focis fuis, \& ignes fuos ad purificationis defideratæ gradum tranfierat; jamdum ferrum eft: \& quia hoc alius indaginis eft, hinc feorfim de methodis circa crematio. nem hanc ferri in chalybem paffim ufitatis agere conftitui : fed quia experientifimus Dnus ReAumu R opus de modo convertendi ferrum cufum five recoetum in chalybem auro contra charum \& experimentis electiffmis \& fuis inclytum noviter edidit, hinc nihil nifi additamenta quædam, quum de illis acturus fim, fiftere potero, fcilicet qualis fit ufus convertendi dietum ferrum variis in locis receptus: fed de his alias.

Jam quia noftrum inftitutum eft, ferri naturam ex datis tentaminibus \& experimentis rimari, hinc ut modo dictum eft, tantum exhibere conor methodos converfionis ferri crudi in duritiem chalybeam; de qua re illuftrifimus Dominus REAumur in opere laudatiffimo nondum egiffe vel admodum parce tetigife videtur; in \$pho fequenti fubjungam modum emolliendi ferrum ex opere laudato Dni Reaumur defumtum. 


\section{Modus convertendi ferrum crudum fove ex vena jemel coctum, fatim in duritiem chaly- beam, Svecice.}

NOn procul ab oppido Hedemohra in provincia Dalekarlenfi Svecix - circa Wik aut Trollbo, opus admodum elegans exftructum eft, ubi ferrum crudum ftatim in chalybem ope ignis \& venti ejufque regiminis, focique fabricx, vertitur: ipfum ferrum crudum ad huncufum aptifimum paratur funditurque in fornace circa Wikmanshyttan; vena ex fodina non procul inde diffita; Bisberget appellata, electifimæ indolis effoditur; ipfum ferrum ex vena illa excoctum multiæftimatur, \& huic negotio aptiffimum : eftque vena fubnigri coloris, nec compacta, fed quafi ab infinitis granis vel arena quafi conflata, \& in pulverem vere martialem intra digitos collabitur ; infignis ponderis, fuppeditatque ferrum tenacifimum \& meris fibris tendinofis, connexum. A camino vel fornace fuforia Wik. mansbyttan dicto defertur ferrum crudum ad Trollbo, ubi in duritiem chalybeam vel aciem vertitur. Eft hic caminus ferrarius in hunc ufum exftructus fimillimus caminis ferrariis officinarım majorum; caminus hic fimili modo in fornaculam afcendit coitque, per quam fumus \& fcintillarum flumen elabitur.

Iple focus, in quo ferrum crudum recoquendum eft, eft ejusdem figure; qualis in ferrariis, fed aliquantum minor: locus in area camini ab una parte carbonibus eft dicatus, qui ibi feparati jacent. Parietes foci conftant laminis ferri crudi fufi, pariter etiam fundus lamina craffa ferrea. Conus, per quem ventus in focum intrat, ex cupro, fuper unum parietsm ferreum aut laminam apte cubat. Latitudo tigilli eft it4 digitorum circiter, longitudo hajor; non tamen multum refert, qua longitudine fit, five majorefive minore. A labro coni firatorii inferiori uqque ad laminam fundi eft profunditas $\sigma_{\underline{\underline{z}} \text { digitorum. Dimenfiones altitudinum latitudinumque } \mathrm{cu}-}$ pri fpirantis, pariter tigilli quam exactifime oblervandx funt; inkis enim confiftit plurima ars, ipfiufque recoctionis arcanum, fine jufta illius aptatione omnis opera irrita cadet. A parte anteriore hujus tigilli eft apertura figurx oblongx, per quam fcorix fuperflux emittuntur ; \& per quam ipfi conti ferrei intrudi folent, quum ferrum liquefactum \& in maffam conflatum, vulgo Smeltan appellatam, a fundo eque loco fuo elevandum fit. Conus cupreus, quo mediante ventus in focum lpirat, ad altitudinem $6 \frac{\mathrm{x}}{\mathrm{z}}$ digitorum a fundo, ut dictum eft, elevatur; admodum exigua ei datur inclinatio, nec major, quam ut aqua poffit per planum ejus obliquum verfus focum defluere; linea recta per conum inclinatum ducta non laminæ fundi extremum marginem, ut alibi, fed parietis oppofiti imum vel pedem tangit. Bucca vel os coni ventilatorii eft femidivifæ \& dividuæ lunæ infrár, fecundum figuram fimilium in aliis hujus generis focis ferrariis ufitatorum, cum illo tantum difcrimine, quod hic minor aretiorque fit, fecundum Tabul. XXI; ubi altitudo $(A B)$ eft minor, quam in ejusdem generis aliis focis. Canalium nares, quæ ex follibus prodeunt, in cono hoc altius 


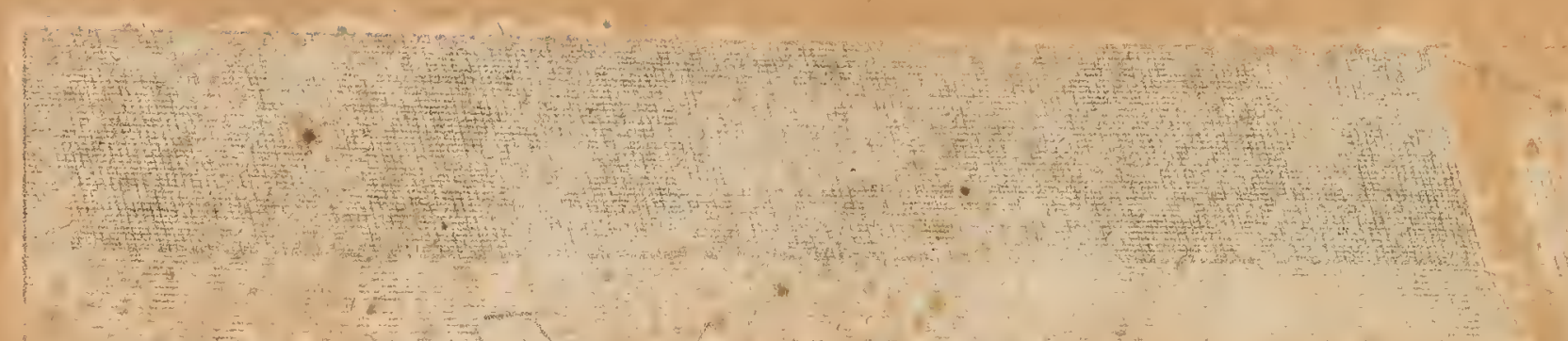

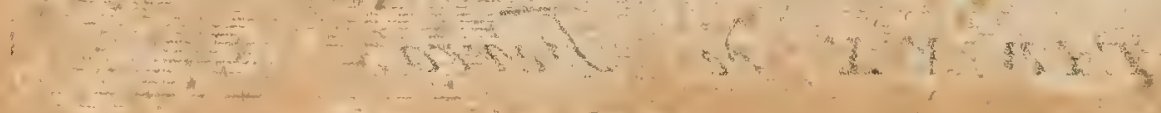

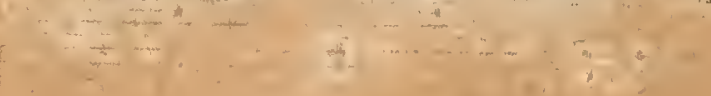

,

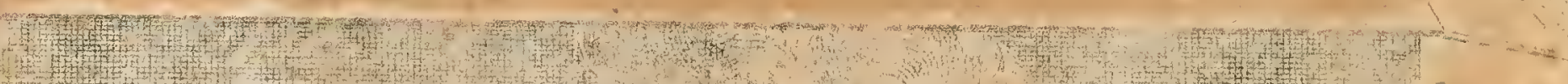

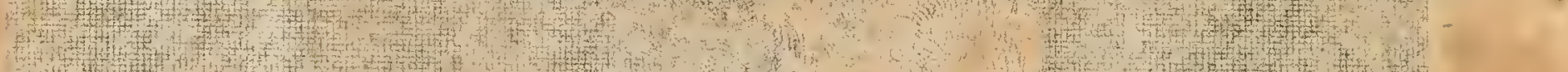

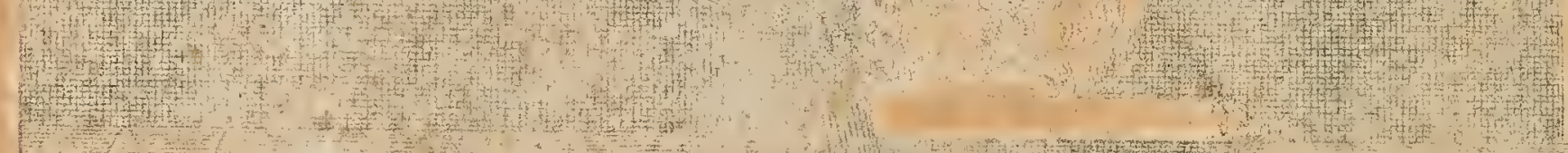

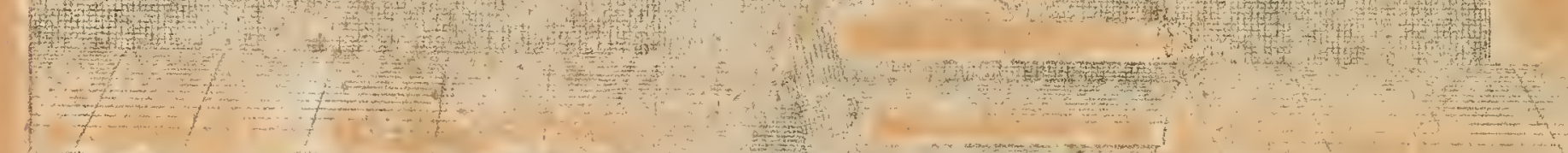

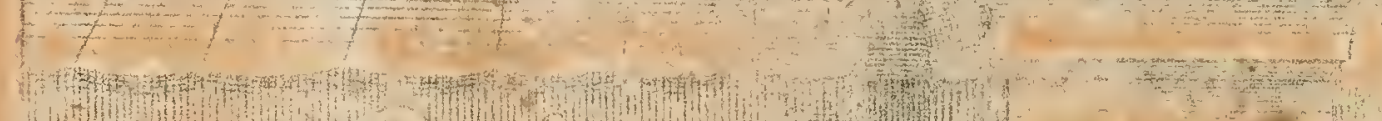
HIS

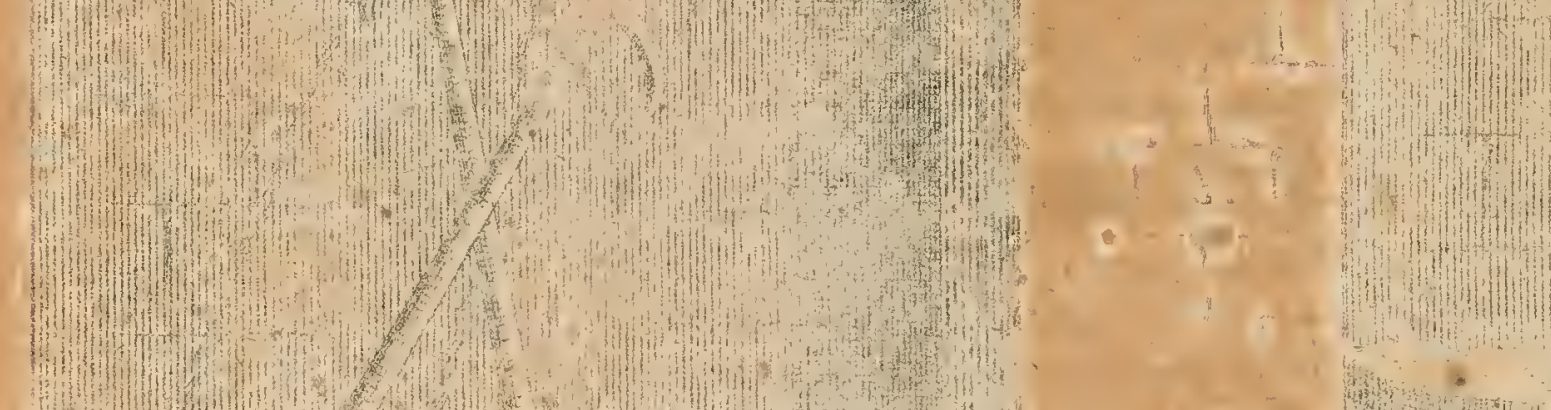

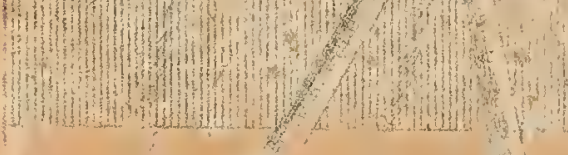

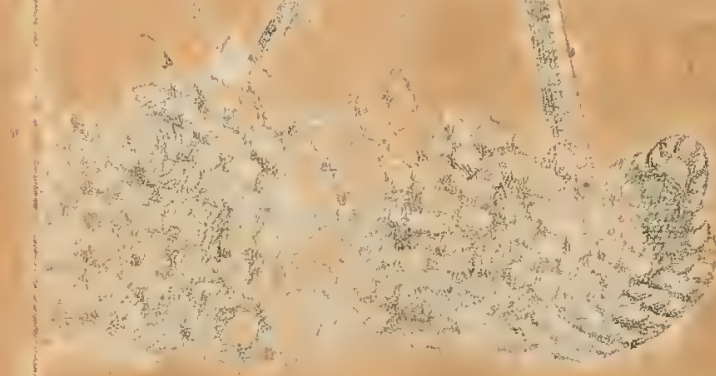

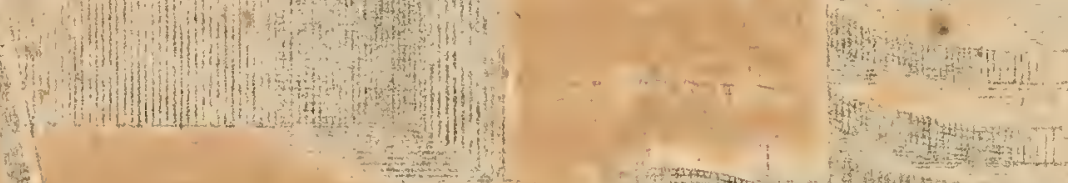
18 
altius jacent. Artis \& fcientix opus eft, ut ad unguem \& regulam jufte aptetur conus; pariter etiam nares in cono; fed adhuc magis, ut ajunt magiftri, in motu æqualiffimo follium, \& ipfius venti jufta diftributione : fique fortuito folles, coni, aut nares loco fuo turbentur, dicitur, ipfam reliquam artem convertendiferrum in chalybem magiftrum peritiffimum eludere fruftrarique; hinc etiam folles eorumquefcamna \& fedilia, omniaque qux ad ufum pnevmaticum pertinent machinamenta, ita conftructa effe debent, ut bene aptata, immotaque loculamentis $\&$ arietibus, quicunque fit motus, incubent $\&$ infideant. In rotam etiam aquaticam, qua folles alternis moventur, defuper illabetur aqua, non vero in latus ejus; aut in tabulata circuli imæ partis; eo enim validior \& gravior eft aquæ vis mechanica; \& ventus fortior æqualiorque fic fubminiftratur. Si etiam conus fpirans, per quém ventus in focum admittitur, jufto obliquior fit, ita ut pars venti fundum ftringat, ex violento ignis gradu ferrum locum fundi tenens xeftu ventofo correptum concremari dicitur; non enim hic ut in focis vulgo ferrariis a copia fcoriarum, ut tutus \& immunis fit, integitur fundus, led a ficciori flumine exeditur facile comburiturque: lamina fundi illefa \& immunis diutius hic non fervari folet, nifi modo per fpatium 2 vel 3 feptimanarum, quin novanda fit : appellit etiam jugiter ventus ftringitque parietem oppofitum lateralem; ubi locus, quem ventus continuo flumine lambit, \& laceffit, confumi \& cavari etiam animadvertitur; ipfeque paries lateralis crebrius hic quam alibi reficiendus novufque priori fubftituendus eft. Labor hic interdiu tantum perftat, non vero noetu; quovis die non nifi 3 vel 4 recoctionis vices peraguntur.

Quovis mane, cum inchoatur opus, in focum mittuntur fcorix, dein carbones, \& aliqua pars pulveris carbonarii, quæ inibi fimul commifcentur, infipper ferrum crudum; optimum ad hunc ufum eft ferrum in minores maffas fufum vel in fragmenta divifum; fuper ferrum dictum fuperimmittuntur carbones. Mafta hæc ferri crudi tenetur in igne carbonum ufque dum candefiat, fed neutiquam tam diu, dum fundi incipiat; quumque integre \& penitus candens apparet, fiftitur ventus, \& mafla candens rudis portatur fub malleum; malleus ponderis eft $\mathrm{I} 8 \mathrm{ad} 20$ librarum majorum five Lifspund, cujus ope in frufta minora difcerpitur: ictibus enim tam diu percutitur, dum tota divifa in partes 3 vel 4 tb. abeat. Si ferrum fit fragile cum ignitum eft, quod Svecice Roedbrecbt cluit, five fulphure nimio prægnans, non fecus ac vitrum frigidum in partes diffilire folet; at vero fi ferrum fit tenax cum candefcit, \& fragile cum friget, quod Kallbrecht audit, diutius mallei ictibus vulnerandum eft, antequam fruftatim diffringitur. Si in fragmenta majora fub malleo dilabatur ferrum, rurfus fuper incudem fublata ictibus ingeminatis impetuntur, donec divila fint in portiunculas ufibus fuis aptatifimas. Fruftula hæc rudiformia fic fub malleo parata inde in caminum feruntur \& prope tigillum ita relocantur, ut fub oculo \& ad manus fint fabro, dum res poftulat, illa foco per vices immerfuro. Primum itaque partem aliquam dictorum fragmentorum trahit in tigillum, qux mox carbonibus fuperinfufis in tigillo tumulat; quo tempore lentius moventur folles, requiritur enim fpiramen debilius, ufque dum 
ferrum dictum liquefactum fit; interea ope conti culpidati rimatur \& pertentat magifter focum, num aliquid ferri verfus angulos \& extra viam venti in fugam \& afylum fe receperit, quod fi animadvertit, elatebris ftatim effringit, \& fpiramini \& Vulcano e diametro opponit. Quum ergo colliquatum fit ferrum, adeo ut inftar liquoris fluidi tigillum \& ejus fundum.occupet, augetur velocitas \& vis venti; quod fedulo notant, quum bene liquidum jamjam in chalybem convertendum, five cum in ftatu medio inter ferrum \& chalybem fit. Per indicia quxdam cognofeere licet, quando liquefcit jufte ferrum in duritiem chalybeam jam tranfiturum; exploratur enim per contum tactumque ferri liquati; per fintillas fcoriarum ferrique trans carbones furfum elatas; dignofcitur etiam per flammam; flamma enim principio operationis fubnigre flavelcit, dein candefcit \& albelcit, \& precipue quum emifix funt fcorix. Quum in fluore fuo diu fatis detentum fit ferrum, emittuntur tandem fcorise in puteolum vel cifternam juxta pedem hujus camini factam; quibus emifis lentefcit \& indurefcit ftatim ferrum. "Perfentirietiam poteftope batilli ferrei, qualis fit maffa ferri aut chalybis liquati, num mollis adhuc cedat conto, num dura ei refiftat, hoc eft, num in chalybem induruerit. His peractis adhuc in focum perducitur pars fragmentorum ferri, qux adjiciuntur prioribus jam liquatis \& excoetis; qux eodem modo liquantur ; unde continuata liquatione, augetur in tigillo maffa. Adhuc tertia \& quarta vice in focum deferuntur fragmina ferri crudi; intra 4 horas fic quater in focum perducitur \& colliquatur ferrum femper novum; unde etiam quater increlcit liquamen. Ex his jam acquiritur mafla chalybea ponderis circiter 4 ad 5 librarum majorum (Lisspund) five $100 \mathrm{Hb}$. minorum. Quum maffa hre chalybea ignem fatis paffa fit, per aperturam inferius factam contus culpidatus intruditur, cujus ope elevatur ; elevata jam apparet formæ rotundx; a fuperiore parte aliquantifper cava, quæ e foco fublata malleo apportatur ut primum attenuetur, \& dein ope ferri cuneiformis feu cultri ferrarii in 4 partes rquales, eodem fere modo, quo in officinis ferrariis, diffecetur. Non unius \& $x$ qualis femper ponderis mafia qualibet vice acquiritur, interdum major interdum minor, nam dividitur panis hic jam in 3 , jam in 5 partes; prout majus vel minus temporis fpatium permittit. Maffa hre chalybea ex foco fublata rubentior apparet maffa ferrea candenti in ferrariis; erumpunt quidem inde more folito fintillæ, fed fubtilifimæ, copiofe ex unis quafi locis effluentes, fed non longius abinde feruntur.

Quum liquatur ferrum hoc in chalybem, fi ventus vel inæqualis fit; vel conus fpirans in loco fuo non debito \& in fitu vere naturali fedeat; vel alia forte caufa fit; fæpe nullæ dantur in foco fcoriæ, unde etiam ægre in liquamen bene fluidum funditur ferrum; fed deficiente menftruo hoc fcoriaceo aduritur, \& fragilitate acquifita vilioris pretii redditur. Hinc ut eo melius temperetur dicta acies, adjicitur una alterave fpatha arenæ fluviatilis. Lamina fundi diu quidem non refitit, Coriis ei adhærefcentibus, quod fit cum damno \& jactura chalybis.

Partes hx quatuor fub malleo fectx igni focali rurfus committuntur, ut modo excandefcant, \& candentes in contos fub malleo extendantur; 
fit hoc eodem tempore, quum ferrum e novo funditur \& in chalybem coquitur; primum in ignem focalem mittuntur 2 partes, fed una propior vento quam altera, quumque una debite incanduerit, exemta ad incudem fertur, \& ictibus mallei validis ad dimidiam fui partem extenditur; in locum ejus tunc admovetur vento altera, qux candefacta eximitur \& fub malleum etiam portata in contum pariter exporrigitur, ut prior: dein fruftum tertium \& quartum : tandem excuditur pars altera ejusdem conti, \& heic omnes in formam $\mathrm{I} \frac{\mathrm{r}}{4}$ digiti quadratam; \& in longitudinem 4 ad 5 pedum Svecicorum : vocatur hoc genus lapidis Smeltareftaul five chalybs fabrilis vel liquatorius. Prima hac vice non opus eft, ut exactiffime extenfus fit chalybs, nam iterum iterumque dein extendendus eft. Extenfio ejus fub malleo peragitur modo confueto, ut ferrum in officinis, primum fecundum latitudinem, \& fic porro. Chalybs extendendus non coloris erit albe fed rubre candefcentis; unde color candefcentix in chalybe videtur differre a colore candefcentix in ferro; ictus mallei funt crebriores. Porro quum extenfus eft chalybs, in fluvii percurrentis aquam projicitur, hon alium in finem, quam ut eo facilius in frufta poffit rumpi, nam in plura dein frangendus eift, de qua re infra. Chalybs hic crudus, nondum fubftantia vere chalybea penitus conftans in fractura grana minutiora oftendit; interdum circa centrum major aut minor circulus apparet coloris obfcurioris, fed ufque in granis ejusdem indolis.

Rudis \& cruda hæc chalybis materia ex hac in aliam officinam non procul inde diffitam fertur, ubi in chalybem melioris notx \& fubtiliorum granorum formari, \& iterum atque iterum extendi folet. 'In officina illa eft malleus exiguus ponderis fere $2 \frac{\mathrm{r}}{2}$ librarum majorum, quæ Svecice $\mathrm{Li} / \mathrm{s}$ pund appellantur, \& incus non inelegans cum trunco (Steffock Svecice nuncupato) humiliter ad folum collocato. Solium tripes prope truncum adftat, in quo ledens magifter, chalybeum contum diffingendum celerrime fub malleo hinc $\&$ inde verfat $\&$ format ; axis qui a rota aquatica celeriter admodum circumvertitur I 2 dentibus prædita, malleum feftine elevat, \& efficit ut celerrimas vices oculi ictus fugientes peragat : momenta lapius hujus mallei celeritate fere æquant momenta penduli in horologio parvo portatili, adeo ut induftrius faber in formatione \& converfione ipliusmet conti fub malleolo attentis oculis \& affueta manu momenta obfervaturus omnem operam impendet. Caminulus in hac officina cum foco exiftuctus, a priori jam defcripto aliquantum differt: folles quidem ejusdem. magnitudinis funt. Conus, per quem ventus in focum admittitur, eadem. etiam fitus obliquitate gaudet, eadem etiam magnitudine, figura \& orificio ; differt tantum in eo, quod apertura ipfius orificii altius aliquantum levata fit, five (A B) Tab.XXI major; adeo ut orificium hoc fpeciem arex circularis dimidiatæ referat, alterum vero fegmentum arex figuræ ovalis. A cono hoc ṕpiratorio, qui Forma cluit, ad fundum hujus foci eft altitudo tantum 2 vel 3 digitorum; tigillum alias latitudinem Io ad I digitorum \& longitudinem I 4 ad I 6 xquat; quamvis, ut ad amuffim \& normam ita conftruatur, non neceffum fit, ut in officina præmemorata; nihil enim refert, fi cuprum Eolicum hic, qua altitudinem in tigillo, aliquot digitis 
differat. In camino hoc a parte anteriore eft apertura figuræ oblongæ, per quam fcoriæe emittuntur, \& fubter puteolus formatus, in quem deriventur.

Chalybs in priore officina ruditer excoctus, \& in contos quadrangulos extentus, hic in partes frangitur; in lapidem enim angularem fubjectum vi dejectus, vel impofitus faxo malleo quodam percuffus in partes facillime diffilit, quoniam in aqua eft extinctus \& fic fragilis \& edurus factus. Fragmenta hre chalybea, antequam in hunc focum immittuntur, ordine quodam concinno \& ab ufu edocto fecundum delineationem difponuntur \& quafi ftratificantur; reponuntur duo fragmina conti aptiffima fecundum latitudinem foci, quibus tanquam fulcris fuperimmittuntur 7 aut 8 alia fecundum longitudinem, fcilicet c. c. c. c. c. infuper transverfim alia minora \& majora inæqualis longitudinis, circa quæ obfervatur, quod unum fruftum chalybeum alterum a latere non contingat : ex mutuo enim contactu dicitur ledi fruftum. Super hanc feriem duplicatam chalybearum partium corbis unus carbonum electorum mittitur, \& dein in illos ignis \& ventus. Et quoniam feries hre five tranfenna fragmentorum chalybis locum fuum nacta fit fuper conum fpiratorium, hinc admiffo vento fonus fortior auditur, quia fub illis ventus cum fibilo per interftitia \& juncturas fragmentorum, perque carbones \& ignem erumpit. Elaplo fere $\frac{x}{2}$ vel $\frac{3}{4}$ hor: fpatio, candefacta apparent chalybea in ordinem hunc difpofita fragmina, quod cum factum fit, filtitur iterum ventus, \& fic unum fruftum poft alterum foco fuo feorfim eximitur; primum quod fupremo loco ad manum jacet, \& fatim fub malleo in bacilla in:equalis longitudinis $\frac{1}{2}, \frac{3}{4}, I, I \frac{1}{2}$ aut 2 pedum tenuiora excuditur. Hic bini fabir, five magifter cum tyrone fuo juxta truncum \& parvam incudem quilibet folio tripedi infidet, unus a quovis latere mallei; cumque extenfus videtur chalybs ad unam partem, tyro ex oppofito fedens illum recipit, \& demiextenfum ad alteram partem dilatat, unde integre \& eadem vice idem fruftum extenditur. Quo facto, cumque adhuc cander, in labrum aut cifternam ligneam frigida \& currente femper aqua plenam projicitur, ut inibi in chalybem indurelcat: bina fragmenta majora in frigidam non immittuntur. Dein omnia hac bacilla fic iterum extenta in unum fafciculum colliguntur, \& ita combinantur, ut ex compofitis una quafi facies appareat; ita enim unum applicatur alteri, majus cum minore, \& bina illa majora in aqua non exftincta, quorum mentionem fecimus, unum fupra, alterum infra, lamellas arete conjunctas, claudunt: quæ fic in unum fafcem numero 16 ad 20 connexa fiftuntur: ficque in manipulum quendam colligata iterum in ignem \& focum deferuntur, ac indivulfa auxilio forcipis tenentur, \& fic ad candefentiam ufque calefiunt. Caufa præcipua hujus colligationis eft, ut omnis chalybs unum corpus, cujuscunque fit naturx, conftituat; fique uni fruftulo aut bacillo lamellari aliquid ineffet, quod ignem nimis aut non jufte paffum fit, hoc mixtum cum lamellis melioris duritiei maffam fimilis notæ \& corporis, penitufque uniformem fuppeditet; pariter ut acies fic quafi tendinofam fuam indolem acquirat. Hrec frufta feu ligamina chalybea adhuc magis in igne ope argillæ liccatæ \& pulverifatæ ferruminantur quali \& mutuo fibiadaptan- 
tur : quumque fafciculus hic complicatus fruftorum chalybeorum ab una parte candens apparet, pulvis argillaceus jam memoratus fuperinfternitur tam fecundum longitudinem quam etiam in medio; quo fuperinftrato convertitur fafciculus, \& momento converfionis aliqua pars fcoriarum fubterfluentium infunditur, \& dein alteram partem argilla etian fuperinfternitur; fcilicet ut eo melius combinetur complicata hæc fruftorum compages. Maffa hæc dein igni eximitur, \& ope mallei cujusdam minoris aut manualis percutitur, ut adhuc in fitum quendam compactiorem torqueatur: dein iterum ad ignem fertur, \& eodem modo quo prius pulvere argilliæ \& aliqua parte fcoriarum fuperinfunditur, tandem per ignem pulveremque inftratum, perque mallei percuffiones in unum \& aretius corpus conflatus excuditur in contos quadrangulos, fed ab una tantum parte; quorum. quodlibet latus æquat fere 4 digitos : mox exponitur aeri, ut refrigelcat: altera pars, quæ nondum extenfa ef, in igne primum candefacta, eodem modo dein extenditur; \& redditur in medio contus chalybeus craflior, quam circa bina extrema : ad quod opus duæ modo ignitionum \& extenfronum vices, qux Utreckningar Svecice appellanțu, requiruntur. Longitudo conti chalybei effe folet 9 ad 1 o pedum, qui dein in manipulos colligantur; quolibet manipulo 8 to. majores, (LiSpund) \& 3 in. minores, five I centumpondium fere pendente. Genus hoc chalybis ejusdem, finon melioris eft qualitatis cum chalybe Carinthix \& Stirix.

\section{Objervationes quadam circa converfionem banc ferricrudi in chalybem.}

Mlta adhuc occurrunt circa hanc materiem fcitu \& obfervatu digna, 1. 1 qua in iplum contextum defcriptionis inferere commode non potui, hinc feorfim illa fub obfervationum titulo adjicere lubet.

I. Optimum genus chalybis immediate a ferro crudo conficiendum eft, fcilicet ut a principio in igne preparatus naturam vere chalybeam induat; enfes, clypei, tendines \&c. ab hujus generis chalybe parantur: Acies enim ex ferro confecta non illius qualitatis efle putatur, in illa perire quafi duritiem, fi per ignem crebro transmittatur ; \& in ferrum quafi redire concupifcere, expulfis in foco particulis falino-fulphureis, quæ in poros ejus fe infinuarant. Chalybs vero ex ferro crudo praparatus, nec nifi multa arte \& 2 gre in ferream mollitiem relabi poffe perhibetur.

2. Ferrum quod durum \& firmum eft, ad hunc ufum eligitur tanquam optimum, quodque tenax \& bonx indolis ferrum fuppeditat : fed quod mollitie gaudet, inidoneum cenfetur ; ipfe etiam chalybs, qui inde para* tur, ad naturam ejus quodammodo accedere videtur, jufto mitior \& cedentior eft, unde nec ad inftrumenta, in quibus durities multa requiritur, aptiffimus. Si ferrum crudum tam firmum fit, ut non frangatur ignitum, chalybeum factum ad inftrumenta utiliffimum eft. At vero fi chalybs praparetur ex ferro crudo molliori \& tenaciori, ut ex Danmorienfi, ex vena fodinarum, qux Klacka \& Taberg audiunt, quia mollius eft genus, chalybs etiam Clalfis I. de ferro. 
inde emollefcere dicitur \& cedentioris aciei genus fuppetere, aptumque enfibus \& tendinibus fabricandis, prafertim fi rite preparetur. Chalybs ex ferri crudi nimis duri genere crematus, dicitur fraglis \& enervis, nec refiftendiobnixus prodire: aliter vero, fiferrum duriufculum fed ufque tenax adit. Ut jtaque chalybs bonx indolis obtineatur, eligendim eft ferrum, quod in $f 8 c 0$ facile fluit: exinde enim penitius a vento penetrari poffe dicitur; \& effe illius generis ferrum, quod coloris grifei eft, \& cui fundendo aut parando minus venæ quam carbonum apponitur. Ferrum quod fragile eft, cum candet, quod Roedbrecht Svecice nuncupatur, \& cui ineft copia fulphuris, ut \& ferrum quod tenax eft cum candet, fed fragile cum friget, utrumque evitatur: exinde enim xgerrime hoc modo paratur chalybs, fique converfionem ejus in chalybem moliri velint, vix nifi ferrum durum, combuftum, putre deperditumque obtinent; unde nec quodlibet ferri genus ad chalybem idoneum eft : hrec etiam eft ratio, quod aliquibus in locis Germanix vena ferri vera chalybea audiat, quia facilior ejus in verum chalybem converfio eft. Si ferrun paulifper de fulphure mitiori participet, dicitur optimum effe, exinde in chalybe tenacitatem defideratam. obtineri: fulphuratum genus fxpius fub malleum portandum effe, exque iterata percuffione aliquantum emollefcere: at fragile cum friget, tanquam nullius pretii \& utilitatis hic rejici. Si vero non adfit illius venæ fupeliectile, qui fuppeditet ferrum durum \& fimul tenax, admiferi folet aliqua pars vene fulphurex, fed prudens ratio habenda eft, ut ex mixtis aciesbonæ indolis poffit parari.

3. Ferrum, quod in chalybem eft vertendum, exfoco fornacis fuforie in toros in arena fluviatili pura efformatos effunditur, exinde melius obtineri ajunt chalybem ferrea indole exutum privatumque, \& facilius peragi converfionem: nec in pulvere fcoriarum vel hi arena craffiore, fed in arena lacuftri five fluviatili fubtiliori \& pura. nam pulvis fcoriarum facile liquefacit ferrum. Juvat etiam, ut ferrum crudum non crafum fit, fed tenue; ita enim facilius liquatur, \& in chalybem etiam minore cum jactura carbonum vertitur.

4. Primum genus chalybis vocatur Smeltâre-Staubl, five chalybs fuforius, aptus aciei inftrumentis agreftibus inducendx; pariter etiam, ut ex collifione ejus cum filice ignis excudatur : fed nondum paratus factusque cenfetur enfibus, tendinibus \& cylindris chalybeis; putatur enim nimis durum \& fragile genus efie, hinc etiam in foco altero five in officina, quæ vocatur kackar-Sinedian, elaborandum \& purificandum eft.

5. Mafra ferrea in chalybem jam in primo foco liquefacta, eximitur igni \& candens immergitur argillre pulverilatre, antequam fub malleo elaborandum \& diffingendum eft.

6. Scorix ex primo foco quater emittuntur, antequam maffa fit parata $\&$ fub malleo in partes 4 diffecta, hoc eft, femel quavis vice, quum e novo ferrum divifum in focum ducitur protrahiturque.

7. In altero foco ignefiunt fragmenta chalybea ad candorem ufque, caveturque ne intendatur ignis, in maffam quandam facile coire poffunt, 
quod detrimento foret arti transmutorix ferri in chalybem; hinc iplemet caloris gradus fedule obfervandus eft.

8. Ad opus hoc chalybeum optimi effe dicuntur carbones ex fago \& quercu, ufque tamen carbones ex pinu \& betula in hunc ufum cum emolumento etiam adhibentur : carbones recentes \& ficci funt proftantiores, vetuftis \& humidioribus, qui nullam utilitatem præftant; unde carbones, qui hic ulurpandi funt, cum cura \& ex lignis fcifis \& ficcioribus funt cremandi : carbones etiam ficciffmi effe debent, unde fub tecto jugiter confervandi. Carbones recentes optimi funt quia ficciffimi, quibus fortiter liquatur ferrum: obfervandum eft, quod hic molliores five debiliores non commifendi fint cum earbonibus duris ut \& ex betula; etiam purifimi \& expertes lapidis \& terræ erunt: una menfura carbonum ex betula tantum præftare dicitur, quantum $I \frac{\bar{z}}{2}$ vel 2 menfuræ ex abiete vel ctiam ex pinu. Ad ignitionem alteram chalybis \& extenfionem ejus fub malleo (quod Garfning Svecice vocatur) requiruntur etiam carbones optini, ut cx betula, fago aut quercu; carbones foffles hic etiam ufum quendam preftare polfunt, quia illorum ope bene ferruminatur \& combinatur chalybs.

9. Folles mediocris magnitudinis erunt, quoque compactiores \& materia duriori contantes, eo meliores. Ad elevationem follium rres pectines aut veetes requiruntur, non vero duo ut in officinis ferrariis; nam violentior hic aura requiritur. Aliqui venditant folles coriaceos ex duplicato corio confectos ligneis meliores effe. Nares etiam in conum fpiratorium longius five altius promovendx funt. Moveri etiam debent flabella per pectines incurvatos, quod etiam Stirix \& Carinthix fit; tunc enim celerior eft follium motus \& citior elevatio vel reciprocatio: quo enim celerius moventur, eo fortior, lætior \& vividior ignis \& pronior ferri in chalybem metamorphofis eft. Quoque durior defideratur chalybs, eo ficciores \& fortiores eliguntur carbones, \& ferrum crudum minoris molis. At vero quum extenuandus in contos eft chalybs, ad, illum focum non opus eft, ut folles in tam citas reciprocationum vices incitentur, nec nifi a duobus pectinibus moventibus five prementibus.

Io. Quod diminutionem ferri attinet, antequam in chalybem rite convertitur ferrum, multam jacturam fui patitur ferrum, \& fere dimidise partis; nam ex 26 libris ferri crudi refidua manent modo I 3 libræ chalybis ; at vero gnavus \& induftrius opifex ex 26 libris 14 libras chalybis lucrari poffe dicitur. Jactura ejus in foco five igne primo, ex 60 vel 64 libris eft circiter 24 librarum, inque altero 8 , five quod eodem recidit, in primo igne pereunt 3 partes, qualium in altero tantum una.

1 I. In foco altero vel in igne fecundo multa pars fcoriarum emittitur, \& quandocunque libet, focus illis evacuari poteft. Recrementa, quæ exhinc effuunt, admodum rubent \& crafforis fluminis \& fubftantix funt. Ufque tamen obfervandum ef, ne perparum fcoriarum relietum in foco fit, hoc eft, ne focus plane illarum fit expers : in quo cafu nimis uftus ficcatufque chalybs deterioris notæ redditur.

Ut ex ferro crudo chalybs bonx indolis praparetur, alterum etian requifitum eft, ut debite cremetur, alias fruftra tentatur ferri converio in chalybem 
chalybem bonæ indolis. Ex odore etiam fentiri poffe dicitur, num aduratur nimium chalybs, tetrum tunc odorem fpargit. Ut jufte cremetur. ferrum, eft artis \& fcientix opus, fcilicet ut ferri natura plane per cremationem diffipetur \& pereat; ferrum denique tam bene liquefcet, ac prius in foco fornacis fuforiæ, alias ferrum ab igne \& vento non jufte penetratus in chalybem nequicquam vertitur. Ut itaque crematio rite peragatur, tigillum non amplius, quam ut capax fit 3 vel 4 librarum majorum (five Lißspund) vel minus parabitur; nam minor quantitas ferrifluidius \& durius liquefcit quam quantitas major, \& melius penetratur, quam fi maffa formetur 8 vel g talium librarum; aliqui majores adhuc maffas conglomerant formantque, operam citius \& intra idem tempus peragendi gratia; fed ufque tamen chalybs, inde derivatus, non expers ferri effe folet. In Stiria maffæ minores formantur, unde etiam obtinetur chalybs optimæ notæ.

Profunditas hujus tigilli fub orificio venti erit 6 pollicum; latitudo I 2 pollicum, orificium ventilatorium anguftum, nec nifi unum pollicem latum, ut fit ventus penetrantior, acutior \& fortior. Canalis fpirans longior fupra quam infra formatur, ut fcilicet flumen venti etiam verfus fundum tigilli dirigatur, unde etiam admodum obliquabitur: pars anterior coni non elevanda eft amplius fupra fundum quam ad 5 pollices, filicet fi ferrum crudum non facile fluat, fed duriufculum in igne fit; at verofiferrum fit fluidius, tigillum profundius parabitur; nimirum 7 vel $7 \frac{x}{2}$ pollicum, nec conus venti tam obliquus erit : fi vero obliquior teneatur, tam fortiter peragi operam dicunt, ut nulla obtineatur mafla chalybea. Conus in focum ad longitudinem 2 pollicum exporrigendus eft : tigillum jufto elevatius erit, ut co calidius in foco peragatur opera. Murus etiam, in quo fitus eft conus venti, verfus anteriora obliquandus eft, pariter lamina ferri fundum tenentis verlus anteriora, \& videndum, num inde calidius fiat, pariter ut apertura fcoriarum bene obturata teneatur. Si ferrum fundamentale non bene refiftit vento \& igni, loco ejus ufurpari poteft faxum.

Quum itaque ferrum in foco liquefactum tenetur, continuanda eft ventilatio, dum omnis pars foriarum per ignem evaporata \& disjecta fit, adeo ut nulla pars ferri nifi in chalybem converfi remaneat, nec ulla fibra aut filamentum ferreum. Nifi ferrum liquide per fe fluat, fuperinjicienda eft arena fluviatilis ticca \& pura five cinis ex betula, exinde liquamen calidum, fuidum \& durum evadit; minime vero loco ejus pulvis fcoriarum. Ut primum augentur in foco fcoria, adeo ut fupra liquamen aut maflam chalybeam fluitent, emittendx funt; alias impediunt, ne ferrum rite in chalybem convertatur. Si vero liquide nimis peragitur opera, ut filicet nulla obtineri poffe videatur maffa chalybea, tunc fuperinjiciendum eft aliquid fcoriarum, fed tantillum, ne, fi nimis, inde ferrea evadat. Utque obtineatur purior \& ferri magis expers, in foco ter convertendus \& fundendus eft chalybs, antequam inde obtineatur mafla : quæ cum fere confecta fit, fuperinjicitur aliquantula pars ferri crudi attenuati \& minuti, quodque ex minore copia venæ quam carbonum fit confectum, fcilicet I vel 2 libræ minores, ut inde omne ferrum in chalybem jufte convertatur. 
I 2. Maffa fic parata fubmittitur malleo minori, cujus pondus eft i 6 librarum majorum. Si inftrumenta ex optimo chalybe defiderantur, octuplo coaptantur \& colligantur bacilla attenuata, \& fic quafi ferruminata excuduntur, quod bis aut ter ad inftrumentorum quxdam genera fieri debet. Ferruminatur chalybs per arenam fubtilem, ne cremetur. Quum extenditur chalybs, diminuuntur i 6 Pc. five 3 libræ minores ex una majori; quum vero iterum complicatur \& excuditur, pereunt circiter $30 \mathrm{Pc}$. fi vero chalybs defideratur, qui cum pyrite aut flice collifus bene fintillet, non ita multum \& crebro fub malleo extendi debet. Ad unum centumpondium chalybis, vel ut illis calculus ef, ad 3 libras majores confumi folent $2 \frac{\mathrm{r}}{2}$ leftx vel 30 tonnæ carbonum.

1 3. Probari \& examinari chalybs hujus generis folet, num bonæaut genuinæ indolis fit vel non; fcilicet, fi bene poffitferruminari; ut $\&$, fifub malleo, tanquam genus optimum ferri, extendi; fique nullas rimas ducat; omnia figna indolis optimx. Chalybs, in quo majufcula grana apparent, \& ufque tamen ferri \& fcoriarum eft expers, eft durifimus; oriturque ex eo, quod tale chalybis genus mediocriter fit crematum. Signum etiam melioris indolis in chalybe eft, fi non emollefcit, quamvis frepius ab igne in ignem transferatur : pariter fi durum \& forte fit, \& fimul nervofum. Chalybs bonæ indolis, quum frangitur, crepitat editque fonum quendam fingularem, quafi non bene frangi fe patiatur. Signum etiam boni chalybis eft, quod ignem copiofum emittat. Dum probandus eft chalybs, tendines ex illo conficiuntur, quales in fclopetis, five Svecice Fiedrar, nam hoc genus chalybis cujuscunque generis tendinibus \& enfibus, acubus, filamentis chalybeis parandis infervit: Si 6 vel 7 limæ cuneo aut pilo chalybeo fuccelfive parari \& pertundi poffint, antequam cuneus iterum cote acuendus fit, fignum eft generis optimi, quodque infervire poffit omnis generis inftrumentis. Tria præcipue chalybis genera funt, quæ quafi familiam ducunt, \& ex quibus nihil non ex chalybe parabile concinnari queat, quanıvis aliqui enumerent 8 ad $\mathrm{s} \circ$; nam fecundum diverfum ejus ufum magis minusve dein indurari poteft; \& tot genera, quot defiderantur, parari.

\section{Alibi Suecice.}

O Fficina chalybea ad Qwarnbacka ante plures annos \& quidem tempore regis Guftavi Adolphi exftructa effe dicitur. Sunt duo foci ad chalybis confectionem exftructi, iple caminus tam altus eft, ut faber ereeto non vero inclinato corpore adfare pollit. Hic loco laminarum ferrearum in fundo \& circa parietes utuntur genere quodam lapidis ad talci fpeciem accedentis, qui Stellfteen Svecice appellatur. Folles lignei funt ejusdem magnitudinis ut in officinis ferrariis. Duo funt mallei, \& quilibet pondus I ponderis nautici xquat. In focum qualibet vice mittuntur Io libræ majores ferri, quod optime excoquitur, pari modo ut fieri folet in igne ferrario, led lcoria quam fixpiffime emittuntur, adeo ut maffa illa ferrea non femper mixta fcoriis fed ficca quafi fundatur, quod vocatur Svecice, gau tort uti Herden: quumque excoquitur ferrum, fuperinfternuntur Clalis I. de ferro. Fff lixpe 
fxpe cineres mixti cum victriolo \& alumine, putant enim ex hac mixtura chalybem paratum melius poffe elaborari. Heic fabri non tanti faciunt, fi minus aut plus ferri fimul excoquatur, interdum majorem interdum minorem ejus copiam immittunt. Quum itaque ferrum in maffam conflatum fit, eximitur maffa \& fub malleo in partes fecatur, \& partes dein in contos extenduntur; conti dein in minora fragmenta divifi, unum fragmentum fupra alterum in crucem \& tranftri fpeciem relocatur, ficque in foco reponitur; infternitur etiam dicta mixtura vel cementum, \& dein in contos rurfus extenditur, quod fapiufcule iteratur; dum obtineatur genus chalybis defideratum.

Genus chalybis craffum, quod vocatur Fatfaubl five chalybs in cadis, nam in cados immitti folet, paratur ex ipfa maffa, qux primum e foco exemta fub malleo excuditur, \& in aqua dein reftinguitur, unde etiam indurefcit. Genus chalybis melius, qui vocatur Klingftaubl, five chąlybs pro enfibus, quater excuditur, five quater lamellatim, in crucem aut in tranftri formam, ut dictum eft, coaptatur, \& quavis vice, ficque quater malleo extenditur. Optimum genus chalybis, quod Fiederfiaubl vocatur five chalybs pro tendinibus, oeties commifcetur \& emalleatur, \& quavis vice in aqua exftinguitur. Literæ \& incifurx imprimendx funt chalybi, quoties ignem tranfierit, ut fciant, quodnam ejus genus fit. Præterea gnari opifices ex granis \& micis in fractura judicare fciunt de qualitate ejus ; fi enim ftrix apparent \& macula obfcuriores, fignum dicunt nondum bene excoeti chalybis aut fub malleo procufi, aut rite commixti effe; optimum, fialbicet inftar argenti.

Incus pendet I pondus nauticum, latitudinem duarum palmarum $x$ quans. Qualibet feptimana confici poffunt i 4 centumpondia chalybis rudioris five chalybis in cadis, (Fatfauhl,) I 2 centumpondia chalybis pro enfibus, (Klingfaubl, ) vel 8 centumpondiachalybis pro tendinibus five Fitedevftaubl. Centumpondium hic conftat 8 libris majoribus (Lif.pund) five I 60 libris minoribus.

Ad unum centumpondium chalybis optimi five chalybis pro tendinibus confumuntur I $3 \frac{1}{2}$ libre majores ferri crudi, \& 26 tonnæ carbonum. Ad unum centumpondium ex genere medix bonitatis five chalybis pro enfibus ro libræ majores ferri crudi \& 24 tonnæ carbonum. Ad unum centumpondium chalybis rudioris five chalybis in cadis 10 libræ majores ferri crudi, \& 9 tonnx carbonum. Hodie vero maxima parte circa fabricas ad Wedewang \& 2 warnbacka utuntur chalybe ex ferro in furnis chalybeis concremato.

\section{Modus fabris ufitatus chalybem fibi acquirendi in focis ferruriis, quum ferrum crudum re- coquitur, Svecice.}

MOdum hunc chalybem acquirendi fabris ufitatum in ipfismet focis \& $1 /$ tigillis ferraris fupra in 9 pho 2 da hujus clafis quidem tradidi, mere- 
tur tamen, hic etiam methodum illam inferere, ubi de converfione ferri crudi immediata in chalybem agitur. Quum in focis ferrariis prima vice excoquitur ferrum, quumque liquamen jam fluidifimum eft, ei innatare folent maflule five frufta chalybea, qux nec angulum foci nec fundum fed ipfifimum volumen hinc \& inde fluctuantia tenent: funt fruftula dieta, qua fuperficiem ex volumine exftantem, inæqualia \& rudis figuræ, infra vero feu qua parte immerfa funt liquaminiferreo, funt formæ rotundioris, \& liquide colore fuo internolcuntur a ferro; præter quod chalybs in flumine ferreo natet, folutus fe ferro non facile addat, nili vento \& Eoli ori admoveatur : ante ventum deliquitur, \& fic in ferri amici gremium \& volumen fe una recipit : at vero nifi vento admovetur, fruftra liquatur in fluore ferreo. Fruftula hujuscemodi 6,10 , I 5 libiarum dari folent: perhibent fabri optate bonitatis aciem efle, \& inftrumentis aut ferramentis chalybe acuandis \& indurandis omnino infervientem \& aptam : nec ferrum alius aut deterioris naturæ fieri, fi materia hæc immerla \& foluta ferro accedat, vel fi illa privetur. Ex omni ferrochalybs obtineri poffe dicitur, fed ab uno genere plus quam ab alio ; fed ufque tamen nihil referre, an ferrum fragile fit cum friget, vel num fragile cum calet; fed ratione ad ferri indolem variare naturam ipfiusmet chalybis : in fractura elt coloris grilei ad albedinem quandam vergentis, granis exilibus \& duriffmus. Maximam tamen artem converionis ferri in chalybem perhibent in eo confiftere, ut conus fpiratorius ad debitum gradum verfus focum obliquatus fit : fi enim a gradu obliquationis vel aliquantilper declinet, nullum aciei granum obtineri poffe ex ufu comperti funt; obliquius hic dirigi ventus debet : regulas \& normas habent, lecundum quas conus aptetur, qui nec abinde latum unguem deviare debet : fique fiat, fit hoc cum jactura defiderati chalybis.

\section{Modus chalybem parandi ex ferro vene paludi- nofer Dalekarlice in Suecia.}

GEnus hoc ferri cum induruerit eft fimile chalybi. Narrant enim in-

I digenæ ex hoc ferro optimum genus chalybis poffe parari; fed qui illam naturam poffideat, ut facile emollelcat \& in ferrum redeat, fi in igne tenetur. Hinc etiam Dalekarli per Sveciam circumferre folent inftrumenta chalybeata, ut fecures, falces \& id genus alia ex hoc genere ferri fabricata.

Si narratis fides habenda, vertitur ferrum hoc ex vena illorum paludinofa oriundum modo fequenti in chalybem : tenetur ferrum fupra focum in igne \& flamma intenfifima, ulque dum plane liquelcat inque focum liquefactum defluat, \& inibi inftar aqux limpidum fit; dein multo adhuc igne urgctur, ficque relinquitur in foco, dum per 1e, carbonibus fubtractis, refrigelcat.

Sed verus mos ferrum hujus generis in aciei rigorem indurandi eft fequens : Maffa, quæ in uftrinis fupramemoratis concrevit, in partes \& fruftula 
fruftula inæqualis formæ fub malleo tunditur \& difcerpitur; fed eliguntur modo partes extrem $x$, non vero mediæ, quæ tenaciores dicuntur effe, quam ut duritiem, quam in chalybe amant, trahere pcfint. Dict: partes foco \& igni iterum creduntur, \& primum cremanturigne non fuforio ; fi enim in fluorem folveretur ferrum, fruftra tentari ex ferro chalybem perhibent: quod tamen, cum accidit, confilium in arena capientes, fiftunt flabra fua, ut liquidum factum ferrum inipiffetur \& lentefcat ; muxque auxilio fcoriarum in fluorem, \& confequenter in ferrum optatæ indolis deliquant, ex quo iterum chalybis fubftantia lperari poffit. At verofi nonliquatur ferrum, fed craftum manens in moleculas quafi diftinctum abeat, circumvertitur, ut ab altera parte fimilem fudorem \& fenfum caloris accipiat; \& confequenter paratur fic in aciem, quæ exftincta aquis rigefcit.

\section{Modus ferrum crudum necdum recoctum in cha- lybem five in duritiem chalybeam converten- di, in Delphinatu Gallia.}

TN Delphinatu circa urbem Alwor \& in monte magno Vanche funt pluI rimæ ferrifodinx, ex quibus copia venæ effoditur. Ferrum crudum exinde ortum in focum, qui vocatur $l$ 'Affinerie, mittitur, qui reliquis eft profundior: ventus e follibus fpirans directe in maflam immiflam dirigitur, ficque vena paullatim funditur. Ipfe focus conftructus eft a laminis ferreis, quibus circumdatur ; inibi non circumagitatur ferrum, ut alibi mos eft, fed in quiete relinquitur, dum iple focus ferrc fit plenus; quod cum factum fit, fiftitur ventus, \& aperitur foramen ad emifionem factum, per quod volumen effluit in maffis mediocres \& exiguas; maffis his eximitur pars luperior \& cruftacea, quæ obtegit volumen ferreum, quoniam illa fcoriis tantummodo conftat; reliquum vel materia fub crufta latens fub malleum mittitur, \& in contos folit: formæ extenditur. In altero five vicino foco, qui vocatur Chanfferie, ferrum ad candefcentiam ufque ignitur, inibi non tanto igne eft opus ut in priori: In volumen ferreum immittitur etiam genus quoddam arenæ, cujus ope calor temperari dicitur: contus inde excufus in frigidam mittitur, ut indurefcat \& in confiftentiam chalybeam vertatur; obfervandum quidem circa hanc operationem eft, quod contus candens in frigidam immittendus fit.

\section{Accuratior bujus converfionis ferri crudi in chalybem Gallice a Domino Rew. nur fa- cta defcriptio.}

Dominus Reaumur in tractatu ingeniofifimo \& plurimis experimentis conferto \& celeberrimo de modis convertendi ferrum excufum in chalybem, tradit etiam modum Galliis ufitatum preparandi chalybem 
ex ferro crudo, fcilicet ut comparationem chalybis ex ferro crudo \& ferroculo facti eo melius filtat. Relatio ejus eft fequens:

Chalybs præparari folet ex ferro crudo albicanti vel albide nitenti; eligitur tamen ferrum, quod ad colorem grifeum aliquantifper vergit. Maffa hæc ferri rudis cum una fui extremitate in focum transfertur, pariter ut ferrum; tigillum eft profundius tigillis ferrariis : quibusdam in locis profundum eft 2 ad $2 \frac{1}{2}$ pedes; hic in requie relinquitur maffa, fimpliciter modo contecta prunis; flamma per ventum excitata dirigitur modo contra ferrum quod liquandum eft. Quumque tigillum ad libitum five quantum opus it, partem ferri liquefacti receperit, adeo ut fere illo fe adimpleverit, fiftuntur folles \& flamina. In quibusdam locis aperitur \& recluditur foramen circa fundum tigilli factum, \& permitcitur ut liquamen chalybeum in maffas tenues effiuat. Aliis vero in locis relinquitur quiete in foco, ut ibi indurefcat \& fixetur ; quumque crufta five ftratum fupremum craflitiem I digiti circiter æequans fixatum fit, inde ftatim eximitur; fed antequam cruftx ferrex auferuntur, tollitur primum crufta five ftratum materia vitrificata fupranatante \& omnium primo refrigerata conftans; cumque emittitur, ut modo dictum eft, volumen, videre licet hujus materix ftratum five crultam in fuperficie maffæ. Hoc modo leparatur quidem ferrum a materia fua terreftri, fed fuperftites manent adhuc partes fulphureæ \& falinæ.

Quibusdam in locis, ubi optimus chalybs hujus generis preparatur, confant quidem parietes foci hic ex laminis ferri, hic vero ex faxo; fed intus loricati five inveftiti ftrato quodam pulveris carbonarii, adeo ut ferrum liquefactum inde capfula pulvere carbonario conftantis fpeciem referat.

Quidam etiam operarii in focos projiciunt cornua, fuliginem \& fimiles alias materias.

Maffa hæc fic liquefacta dein in alium focum transfertur, qui vocatur Chaufferie, inibi calefacienda, dum partes falinæ \& fulphureæ fuperfux abactæ \& qua partem expulfi fint. Hic non opus eft, ut materia vitrificata feparetur, nec ut ignis violentus fuppeditetur, fed excandefcet tantum chalybs : nec ut fubigatur \& circumagatur, ut ferrum in foco' fuo. Induftrix \& artis eft, ut momenta \& tempora fciant, dum igni eximenda fit acies : fi enim diutius tenetur in igne \& fudore fuo, in ferrum mutari dicitur; hinc quamvis cautiflime peragatur opera, accidit tamen, quod una portio dictx maffre conftet ferro, \& quidem ad $\frac{\mathrm{r}}{4}$ interdum ad $\frac{\mathrm{I}}{3}$ fui partem; nec dabile eft, ut maffa undiquaque \& æqualiffime calefiat, quin aliqua pars fortius incalefcat, quæ in ferrumiredit: hinc etiam una pars conti fub malleo exçufi frepe ferrea datur, altera vero chalybea; quod nec multum refert, nifi ipfemet chalybs venas quasdam ferreas recondat, quæ interdum prope centrum, interdum circa fuperficiem, fecundum differentiam caloris ut \& fecundum ictus mallei, qui ab uno loco in alterum partem ferream transferre \& abigere poffe videntur, confpiciuntur. Exinde fluit, quod difficillimum fit hac via chalybem obtinere venis ferreis plane deftitutum. Circa plerasque officinas chalybeas, cum iterum in focum mittitur chaclalfis I. de ferro. 
lybs, projiciunt arenæ quandam fpeciem \& materiam vitrificatam in pulverem redactam : arena enim obducit $\&$ incruftat maffam metallicam, \& impedit ne nimius calor illam urgeat, \& confequenter ne in ferrum redeat.

In quibusdam aliis locis paratur chalybs immediate ex vena: permittunt enim, ut in ipfa fornace, in qua liquatur vena in ferrum, refrigefcat; qux maffa dein figuram rotundam five bullæ depreffæ \& divifæx fpeciem refert. Maffa hæc finditur in frufta fecundum fectiones parallelas ; frufta dein immediate transferuntur in focum illum, qui vocatur Chaufferie; qux calefacta fuper incudem in bacilla extenduntur; fed bacilla fub malleo excufa in medio conftare puro ferro, obfervatum eft, verum circa extremitates chalybe, quamvis uno eodemque modo ubique fint calefacta \& excufa. Prope circumferentiam maffi:, chalybeum omne eft; reliquum videtur effe ferreum. Fragmenta, qux feparata funt ab ipfa maffa, prout referunt operarii, fuppeditant chalybem melioris notx.

Iterum alio in loco laudatifimus Dominus Reaumur memorat, ferrum crudum multam fimilitudinem habere cum chalybe : conftare nimirum parte terreftri, fulphurea, falina \& metallica ; in ferro crudo bẹne puro \& admodum nitenti videri : I. Quod fit gradus fupremus ad chalybem : 2. Si per combuttionem ejiciatur pars ejus fulphurea, quod inde obtineatur chalybs intractabilis \& fiffuris plenus; fed cum calidus eft, quod malleo refítat; quumque exftinguitur frigida, quod admodum durefcat. 3. Si calefiat hoc ferrum, adeo ut ejiciantur- partes inflammabiles \& falinæ, quod prodeat chalybs non refractarius, quique durefcerè poffit per exftinctionem in frigida. 4. Si hoc genus memoratum ferri ad certum gradum calefiat, quod obtineatur chalybs facilis tractatu, fed quod nequaquam poffit indurari per exftinctionem frigidam. 5. Sique hocgenus iterum calefiat, quod exeat chalybs, qui vocatur Acier pamé.

Obfervandum etiam dicit circa converfionem ferri crudi in chalybem, quod ferrum crudum quam optime purgandum fit a partibus fuis terreftribus : \& quod videatur chalybs dicti generis non tam liber \& infons partis terreftris ac chalybs ex ferro cufo paratus. Cavendum etiam effe, ne comburatur hoc ferrum femel purificatum, quod fit ope fabuli \& fcoriarum pulverifatarum. Ferramenta multo ufu trita \& exefa, ut clavos \&c. liquefieri poffe, \& facilius in chalybem converti \&c.

\section{Modus ferrum crudum in chalybeam duritiem convertendi Saltzburgi.}

A $D$ chalybem eligitur vena optima coloris brunei \& flavi, qux primum
eft calcinanda, dein transmiffa per fornacem in maffas chalybeas fun-
denda, parantur maffie graves tantum quatuor centumpondia, Focus
pro chalybe conftructus fimillimus eft foco Saxonix in officinis illorum
ferrariis, qui Frifch vel Zerrenbert vocantur: differt tantum in eo, quod co-
nus, per quem ventus tranfit in focum, hic aliquantum obliquior fit, qux-
libet maffa fingillatim funditur; liquamen inde oriundum non limpidefed 
craffufcule fluit. Prima vice in igne tenenda, five in fluore quodam relinquenda eft fpatio r 2 horarum, \& recrementa fuperflua interea per aperturam anteriorem eodem fere modo quo in ferrariis emittenda funt, interea dicitur agitari conto fubigique \& verti maffa. Maffa refidua, peracta hacoperatione, foco eximitur; \& in partes fub malleo fecatur, quarum quælibet in aqua exftinguitur. Quibus factis iterum in ignem eundem focalem remittitur, \& inibi tanquam in continuo fudore fpatio 6 horarum detinetur, emiffis tunc etiam fcoriis: eximitur etiam hac vice foco, \& fuper incudem in partes dividitur, \& denique frigida exftinguitur; per talem operationem \& exftinctionem in frigida indurefcit admodum materia chalybea; ufque tamen in verum chalybem non adhuc converfa eft, adeo ut in contos vere chalybeos poffit excudi; hinc adhuc tertia vice in focum eundem refertur maffa, \& inibi 6 horarum fpatio iterum tenetur, quo facto exemta in contos craffiores diducitur, ac demum in aqua exftinguitur. Conti hi craffiores in partes fingillatim franguntur, \& in tenuiore $\delta_{\frac{1}{2}}$ digiti craflitiem $x$ quantes fed quadrangulos excuduntur : quavis vice candentes erunt, quum frigidis immittuntur, ut indurentur ; utque frigidior adhuc fit aqua, in illam portio falis culinaris dicitur immitti : quum enim excufus eft chalybs, calefaciendus dein ad candefcentiam ufque eft, \& in aqua fale imprægnata ficque frigidiore facta exftinguendus. Genus hoc chalybis multi pretii xeftimatur ; \& $\frac{1}{4}$ pars unius centumpondii in fafciculum quendam ligatur, qui Biffon vocatur. Ex 4 centumpondiis ferri crudi obtineri $2 \frac{1}{2}$ centumpondia genuini chalybis dicitur; parte reliqua five $1 \frac{1}{2}$ centumpondio in recrementa \& fumum abeunte. Carbones ita commifcentur, ut dimidia parte fint molliores, dimidia vero duriores, confumtis quavis vice 6 faccis. Intra unam feptimanam auxilio 3 virorum, i 5 vel i 6 centumpondia chalybis genuini conficiuntur. Secundum hanc methodum plurima pars chalybis, quæ pro chalybe Stiriæ five Steiermarkiano venditatur, in $\mathrm{Ca}$ rinthia conficitur.

\section{Modus ferrum crudum in duritiem chalybeam convertendi Carintbia, Tirolice $\mathscr{S}^{\circ}$ Stiria.}

DN Carinthia, Stiria \& Tirolia funt plurimi foci conftrueti pro ferri ut \& 1 chalybis præparatione. Quod vero focos chalybeos attinet, obfervatum eft, quod conftructifint eodem modo, quo foci Saxonici, qui Frifcb vel Zerrenfeuer appellantur. Conus, per quem in focum tranfit ventus, profunde fatis \& oblique intrat. Qualibet vice, quod Flofs appellatur, in focum mittitur \& funditur quantitas fere $4 \frac{1}{2}$ centumpondiorum, quod in fudore \& coctione quadam per fpatium 3 vel 4 horarum detinetur, ufque tamen ope contorum vel inftrumentorum ferreorum jugiter circumagitatur maffa liquefacta; \& quavis vice fuperinfternitur lapis filiceus calcinatus \& pulverifatus: dictus pulvis filiceus ejus indolis effe dicitur, ut ferrum in chalybem vertendum non multam recrementorum copiam fuffciat; pariter ut ejus ope impuriora fecernantur bene a ficoriis. Quum per fpacium 
fpatium 3 vel 4 horarum in coctione fua fic detentum fteterit, emittuntur fuperfluæ \& in foco collectx fcoriæ per aperturam quandam ad recrementorum horum emiffionem factam, licet ufque fuper materiam chalybeam aliqua pars relicta maneat, quæ tamen ex factis oblervationibus, nihil nifi quam ferrea quadam materies eft, quæ fcilicet in chalybem nequeat verti : hæc materia fupra chalybem ftratim \& quafi lamellatim excerpitur, \& in contos ferreos feorfim fub malleo extenditur: quibus factis eximitur foco chalybs \& fub malleo in 4 partes fecatur, quarum quxlibet in frigida exftinguitur; \& dein e novo iterum in foco prædicto funditur. Methodus fundendi fectas has partes eadem eft cum methodo jamdum defcripta, operaque hrec repetitur ter vel quater fecundum qualitatem ferri, five prout in fubftantiam chalybeam poffit converti. Demum quum obfervatur, ferrum in genuinum chalybem plene effe converfum, in contos fub malleo extenditur ad longitudinem 3 pedum, \& qualibet vice candefactum reftinguitur in aqua argillacea, \& cadis dein inditur, cuilibet inclufis $2 \frac{x}{2}$ centumpondiis. Ex $4 \frac{1}{2}$ centumpondiis, qux vocantur fimul ein Flo $\beta_{\text {, }}$ $\frac{1}{2}$ pars unius centumpondii purum ferrum remanet, reliquum in chalybem convertitur; vel melius, ex I o centumpondiis, quæ fimul Meuler vocantur, 3 centumpondia in ferrum \& fcorias abeunt: fpatio unius feptimanæ Io centumpondia chalybis ab uno magiftro cum duobus miniftris aut tyronibus conficiuntur. I 2 Knippor carbonum ad ro centumpondia confumuntur. Optimum hic eft, fi carbones duri \& molles commifceantur; fique alterutrum eligendum fit, præftant carbones duri. Mallei pondus eft 2 centumpondiorun; incus figuræ eft vulgaris. Pars ferrea, quæfupra chalybem remanet, excoquitur iterum in foco, \& dein in ferrum procuditur, Io centumpondia ferri intra 48 horas elaborantur. Folles ex corio facti funt, putant ligneos his ufibus non aptos effe. Optimum genus chalybis venit ex Carinthia, ubi plures ejus generis officinæ funt.

Circa $\mathbb{W}_{\text {eith }}$ conficiuntur etiam quotannis 6000 Pufchen fere: fed genus hoc chalybis non tantum xeftimatur ut reliquum; autumant caulam oriri a differentia aqux fluviatilis, in qua exftinguitur: methodus enim eadem eft, tam hic Carinthiæ \& ad Mundem, mixtura etiam eadem, lapis filiceus, qui adjicitur chalybi in foco, ex fuviis purifimus colligitur, dein etiam crematur \& pulverifatur, fcilicet ut ope ejus in fuorem optime agatur chalybs; quumque in contos excufus fit, colorem fuum genuinum oftendit, \& fimul grana chalybea nitidiffima : hic ex $1000 \mathrm{fb}$, ferri Flofien obtinentur 600 ib. puri chalybis.

Ex ferro crudo conficitur etiam modo fere precedenti chalybs Galliis, ut in provinciis Champagne, le Nivernois, la Franche - Comté, le Dauphiné, le Limoifin, le Perigord, etiam in Normandia. De quibus fupra. 


\section{Immediata converfio venoe ferrece in chalybem Stirice, ad Fordenbergam \& alibi.}

$\mathrm{D}$ Iffert hæc methodus a priori in eo, quod immediate convertatur vena in chalybem, quamvis aliqua modo pars remaneat ferrea, aliqua vero converfa fit in chalybem; peragitur immediata hæc converfio in Stiria ad Fordenberg \& quidem plurimis in locis, ut \& Galliis in Rouffillon \& precipue dans le Pais de Foix. In ipfo foco funditur vena ferri, \& formatur. plane fecundum figuram foci in maffam vel panem, qui infra rotundus eft, fupra vero planus, \& ibi vocatur un Mafjet: mafla hæc foco exemta lecatur in 5 vel 6 portiones, quarum unaquieque in foco iterum calefit, \& fub malleo in contos debita longitudinis diducitur. Sed una hujus conti pars fiepe conftat puro ferro, altera vero puro chalybe ; \& modo $\frac{\mathrm{I}}{4}$ vel $\frac{\mathrm{I}}{5}$ pars mutata in chalybem effe videtur reliquis pure ferreis manentibus. Hec etiam eft caufa, quod aliqui putent, certam dari venam chalybeam; datur enim vena ferri, qux in chalybem pronior eft quam altera.

\section{Conver io ferri crudi in chalybem Jecundum Dominum Agricolam.}

A Rs hoc modo ferrum igni \& additamentis perficit, \& ex eo efficit"

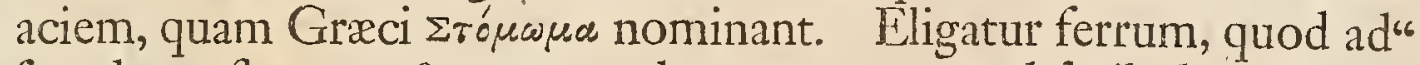
liquefcendum eft aptum \& prxterea durum, atque quod facile duci poteft." Nam etfi ex venis, quie ipfi cum aliis metallis communes funt, conflatum"، liquefcat, tamen aut molle eft aut fragile. Tale vero candens primum" in minutas particulas fecetur, \& cum lapidibus liquefcentibus comminu-"6 tis permifceatur: deinde in foco fornacis ferrarix fiat catinus ex eodem" pulvere madido, ex quo fiunt catini, qui funt ante fornaces, in quibus ve-" næ auri vel argenti excoquuntùr, cujus latitudo fit ad lesquipedem, alri-“ tudo ad pedem. Folles autem fic collocentur, ut ventum medio catino" per narem infpirent. Tum catinus totus optimis carbonibus complea-"6 tur, \& circumcirca ponantur faxorum fragmenta, qux ferri particulas \& $\$$ carbones fuperfulos coerceant. Sed quam primum carbones omnes ar-"6 ferint \& catinus excanduerit, folles ventum infpirent, atque magifter fen-" fim infundat tantam ferri \& lapidis liquefcentis mixturam, quanta fibi" infundenda videbitur, in quam cum liquefacta fuerit, mediam 4 ferri mas-" fas, quarum fingulæe pendantlibras 30, imponat: \& acri igni 5 vel 6 horis" coquat, \& bacillo immifo ferrum liquatum lepius agitet, ut ejus tenuifi-" mam quamque particulam maffarum parva foramina combibant; quar particulæ fua vi confumunt \& dilatant craffas maffarum particulas, quæe molles \& fermento fimiles fiunt. Poftea magifter miniftro adjutus, mas-“ fam unam forcipe extractam incudi imponat, ut malleus a rota viciffim" fublatus \& demiffus ipfam dilatet; quam confeltim adhuc calidam in aquam injiciat \& temperet; temperatam rurfus incudi imponat, eamque“ eodem malleo percuffam frangat; mox infpiciens fragmenta confideret, "6 Clalfis I. de ferro. Hhh utrum 


\section{MODUS CHAL. PARANDI EX FERRO CRUDO.}

„utrum aliqua ex parte ferrum adhucappareat, an totum quodammodo fit „denfatum \& mutatum in aciem. Dein aliam atque aliam maffan forci„pe prehenfam \& extractam in partes fecet; tum mixturam recalfaciat, \& „ad eam addatrecentis partem; qux \& in locum illius, quam combibe„runt maffie, fuccedit, \& vires ejus, quar reliqua fuit, reficit, \& maffarum "particulas, rurfus in catinum imponitas facit puriores, quârum quamque, "ltprimum excalfacta fuerit, forcipe prehenfam malleo fubjiciat, \& in ba"cilli figuram formet. Quod, cum adhuc excandelcit, in frigidifimam "aquan proftuentem, qux prope fit, injiciat; quo modo repente denfatum. ,in meram acien vertitur; quæ ferro eft multo durior \& candidior.

\section{Modus convertendi ferrum in chalybem jecun. dum Dominum Vanoccio.}

DOminus Reaumur hunc etiam modum tradit \& tentaminibus illuItrat; modus eft fequens. Teneatur ferrum five vena ferreatin fufione; inque ferrum hoc fufum immergatur aliud, quod cufum eft; \& per aliquantum temporis in liquanine teneatur; extractum dein ferrum jacturam ponderis multam paftum effe, led partem refiduam in chalybem converfari cife refert. Fruftum enim craffitiem modo unius digiti æquans per quadrantem hore in ferro hoc fulo detentum vel etiam per dimidiam horam, multam fui partem amifffe compertum eft. Si vero craffius. adhuc fit ferrum, non in chalybern verti pofle, nifi diutius inibi teneatur, quamvis fine diminutione effe nequeat: fed ferrum craffum non item fundi poteft, ac ferrum attenuatum. Hic modus convertendi ferrum in chalybem partina accedit ad modum convertendi ferrum crudum in chalybem, partim ad ferrum cufum, hinc quia de utraque methodo participat, hic illam inferere volui.

Hixc volui in medium afferre de converfione ferri crudi in chalybem: quod vero methodos converfionis ferri in bacilla aut contos excufí in chalybem ope furnorum chalybeorum, de illis fingillatim agendum eft; illie enim integrum volumen poftulant, interea de modo hoc fequenti confu-

las ingeniofiffmi Domini Reaumur $l^{\prime}$ art de convertir le fer forgé en acier: Hic tantum ea tradere volui, quæ ab illo pr:etermiffa funt.

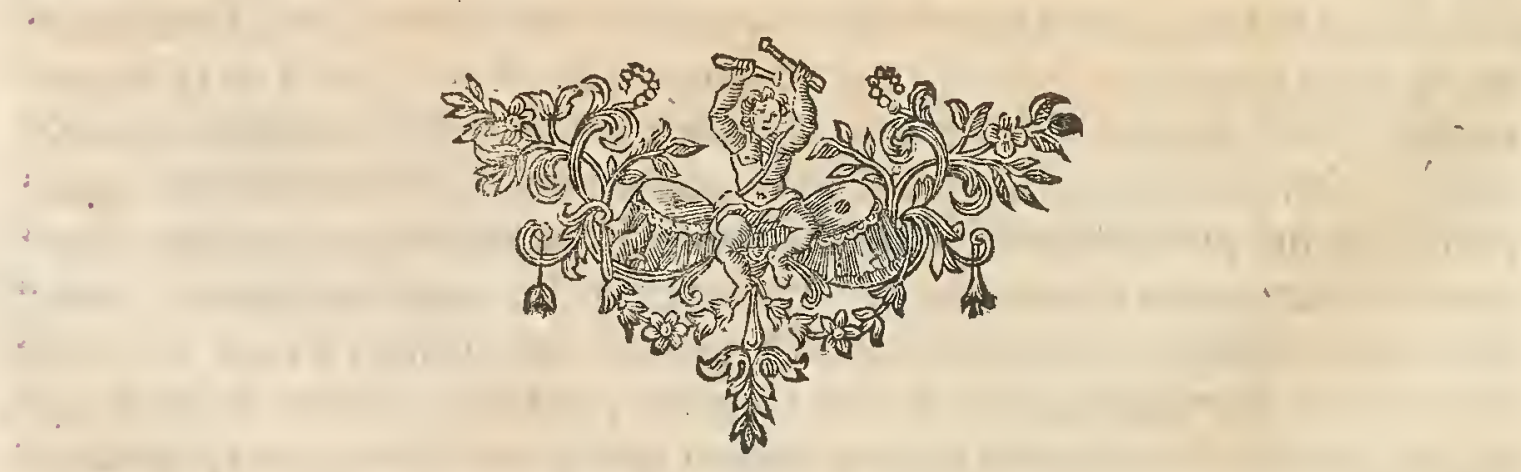




\section{PARAGRAPHUS XXV.}

\section{Ars emolliendi \& ferrum purificandi; tradente Clariffimo Domino Reaumur.}

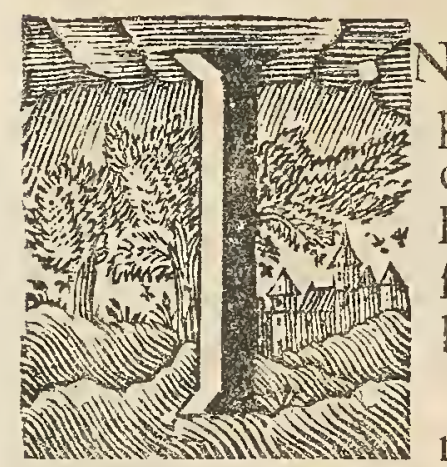

Ngeniofifimus Dominus Reaumur in tractatu fiepius laudato five l'art de convertir le fer forgé en acier docet methodum fundendi ferrum, obtinendique illud tam purum, ac ferrum in tigillo fuo recoctum ac fub malleo extenfum : agit primum de variis peciebus ferri fufi illarumque diverfa indole.

Ferrum fufum vel crudum, ait, eft duplicis genefractura eft coloris venæ, vel ex gradu \& diverfitate caloris \& commixtionis in fornace, per quam transmittitur vena : fed bic modo de diverfatate colortm. In fracturis ferri coloris grifei dantur multa, quæ ad pullum \& nigrum colorem vergant; interque grifeun \& albefcens genus in fraetura funt varii \& intermedii colorum gradus, prxter quod varix albedinis fpecies interfint. Eft etiam fpecies ferri, quæ in Champagne, ubi ferri crudi aut fufi fractura videtur alba, fed ubique fparfa maculis grifeis \& nigricantibus, vide Fig. 6. Ferrum hoc fractum candidi coloris purius eft illo, quod coloris eft grifei, plus enim ferri continet, adeo ut major quantitas ferri puri five malleati obtineatur ex ferro coloris candidi quam grifei, grifeo dicit majorem partem terreftrem five plus materix vitrificati ineffe.

In fractura ferri candidi apparet textura compactior; fique accuratius infpiciantur grana, fpeciem micarum referunt, fed quarum una tanquam absque intervallis premit alteram, prout in fracturis ferri extenfi. Interdum videre licet in fracturis ferri candidi radiationes quasdam, radiorum enim fpecies funt, qui verfus centrum coeunt Tab. XXII Fig. 3,4 . Radiatio illa fere fimilis eft radiationi partium in regulis antimonii, fed non ita diftineta. Candor vero in hoc ferro crudo fracto non fpeciem micarum prout in ferro malleato five in chalybe præbet: candor enim in ferro cufo \& chalybe in frigida exftincto corufcat \& niter, fed in altero hebetatur \& languet candor : differentia eft fere eadem, qux eft argenti languidi \& nitentis. Fractura ferri grifei magis fpongiofa eft, quam ferri candidi; accedit illa magis ad chalybem exfinctum, eftque interdum granulata, fed grana funt majufcula non bene rotundata, quorum unum non bene cohæret cum altero.

Ferrum fufum, quod nec grifei nec candidi coloris eft, præditum eft cingulo ex crufta provenienti, quæ diverfi generis micis conftet : fed pluris ideo xftimatur, quod in bonæ indolis chalybem convertibile fit. 


\section{A R S E M OLL IE N I FER R M.}

Si per microfcopia diverfi generis fracturæ ferri crudi examinentur, illud, quod bene candidum eft, conftare videtur textura compactiori; obfervare licuit micas planas hic \& ibi confperfas, fed minores quam in fractura chalybis. Sed fracture grifex fpongiofie apparent, adeo ut fit veluti fpecies \& collectio diverfarum chryftallifationum Fig. 5 , vel potius vegetationum chymicarum cum infinitate frondium, fed quarum quxlibet conftat micis exiguis, quxe mutuo in fe quafi agunt. Sique particula quxdam hujus ferri exigua inftar fubtiliffmi grani fabuli fit, apparet illa magis tranfparens, \& vivacitas \& fplendor coloris ejus accedit ad fplendorem \& nitorem adamantis. Alias diftingui poteft ferrum grifeum a candido, guod hoc referat magis chalybem politum; \& genus candidum, argentum levigatum.

Alias regula generalis eft, quo candidius hoc ferri genus fit in fractura, eo etiam durius; fi enim candidum fit, tam forfici quam limæ refitit. Dantur quidem fpecies coloris grifei vel brunei vel nigricantis, quæ cedunt lim: Fig. 7. Quoque magis ad nigredinem quandam accedunt, eo melius lima tractari fe patiuntur.

Si utenfilia fundenda fint, ut caminuli, arex, laminæ laterales cujusdam fornaculæ, ollæ, tripodes, tormenta, \& hoc genus alia, conftabunt ferro grifeo. Sed licet limæ \& forfici cedant, ufque tamen non tractari, prout res poftulat, per limam, \& polituram admittere poffunt: cedunt enim lime non aliter ac partes lapidis fciffilis, abeundo in grana : in fabulum quafi per forficem redigitur, \& ita frangitur, ut plura grana fimul cohixreant; unde hoc genus nequicquam per limam in opus elegantioris faciei formari \& elaborari poteft. Alias quum ferrum hoc lima vel forfice abraferis, nullus inde candor aut nitor exiftit, qualis in ferro malleato, color. modo lividus \& languidior apparet. Quicquid alias formandum eft ex ferro grifeo, vitium hoc commune trahit, quod ictibus mallei nec frigidum nec calidum refiftat, quin frangatur, unde una pars nequaquam applicari \& couniri poteft cum altera, quod tamen in his operibus neceffarium eft. Si itaque inftrumentum quoddam vel aliud utenfile fundendum fit, quod candorem aut nitorem quendam oftentet, ferrum coloris candidi effe debet; fundi enim hoc genus ferri optime poteft.

Facile paratur ferrum candidx fracturæ; \& quidem illius candoris, qui fere argenteo affimiletur. Ferrum enim fracturæ grifex in tale genus absque artificio convertibile eft ; nam quum ferrum grifei coloris multas partes terreftres poffideat, fi modo defæcetur, inde candidius evadit, fcilicet fi altera vice fundatur vel recoquatur; quoque frepius recoquitur, eo magis candor in eo augetur : nam ferrum candidum majore parte metalli, gaudet: unde per reiteratas fufiones \& recoctionum vices grifeum in candidum commutatur : ferrum enim nivex fracture candorem infigniorem accipit, fi iterato fundatur; fed grifeum pluries recoquendum eft. Quod alioquin obtinetur per iteratas fufiones; idem etiam lucrari licet, fi volumen ferreum in liquatione diu teneatur, fique per vices \& fæpius inde abftrahantur fcorix qux fupernatant. Sed obfervandum eft, quod optime fundendum fit ferrum, adeo ut omnes liquefactionis gradus tranfire debeat. 


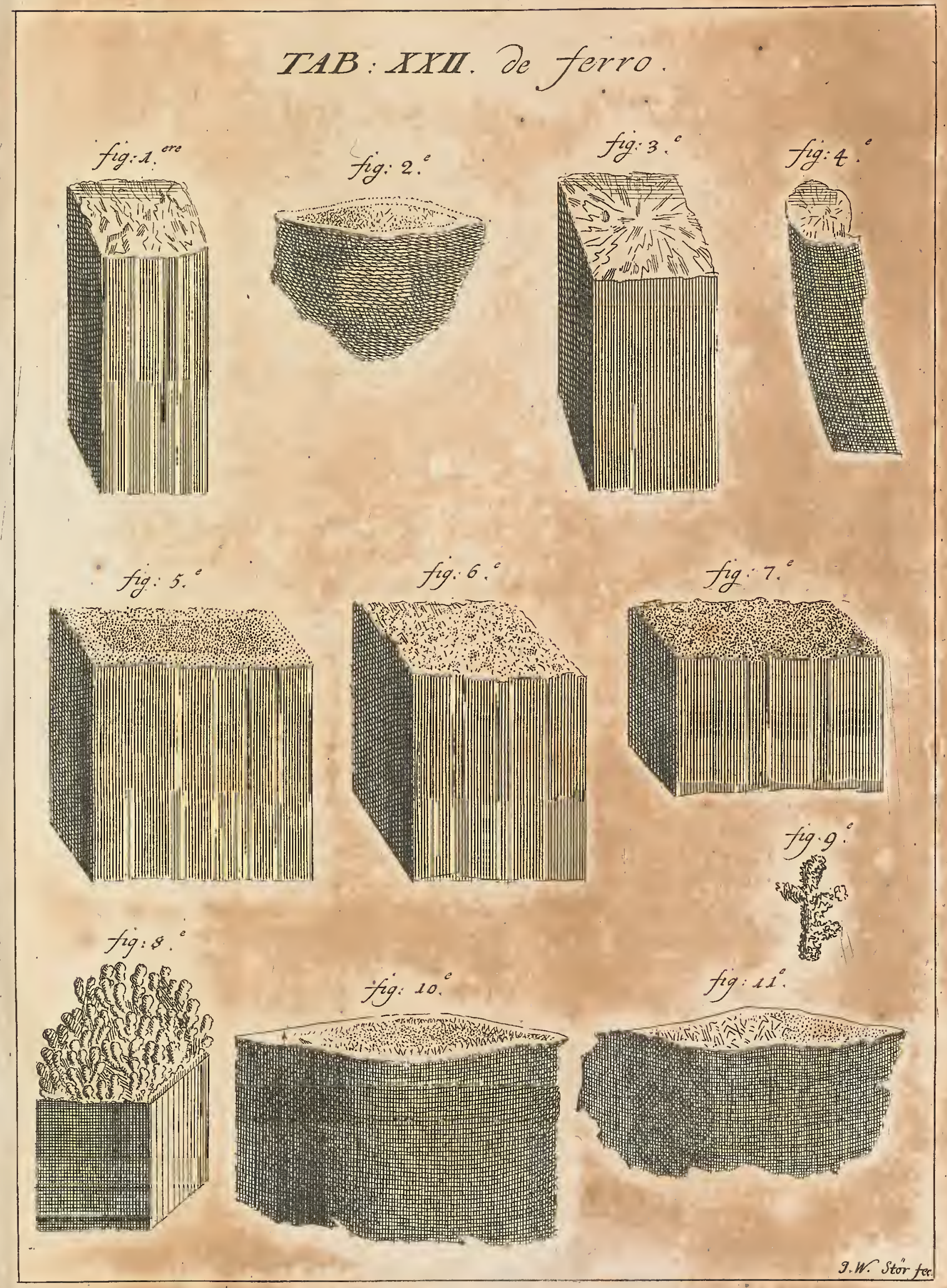




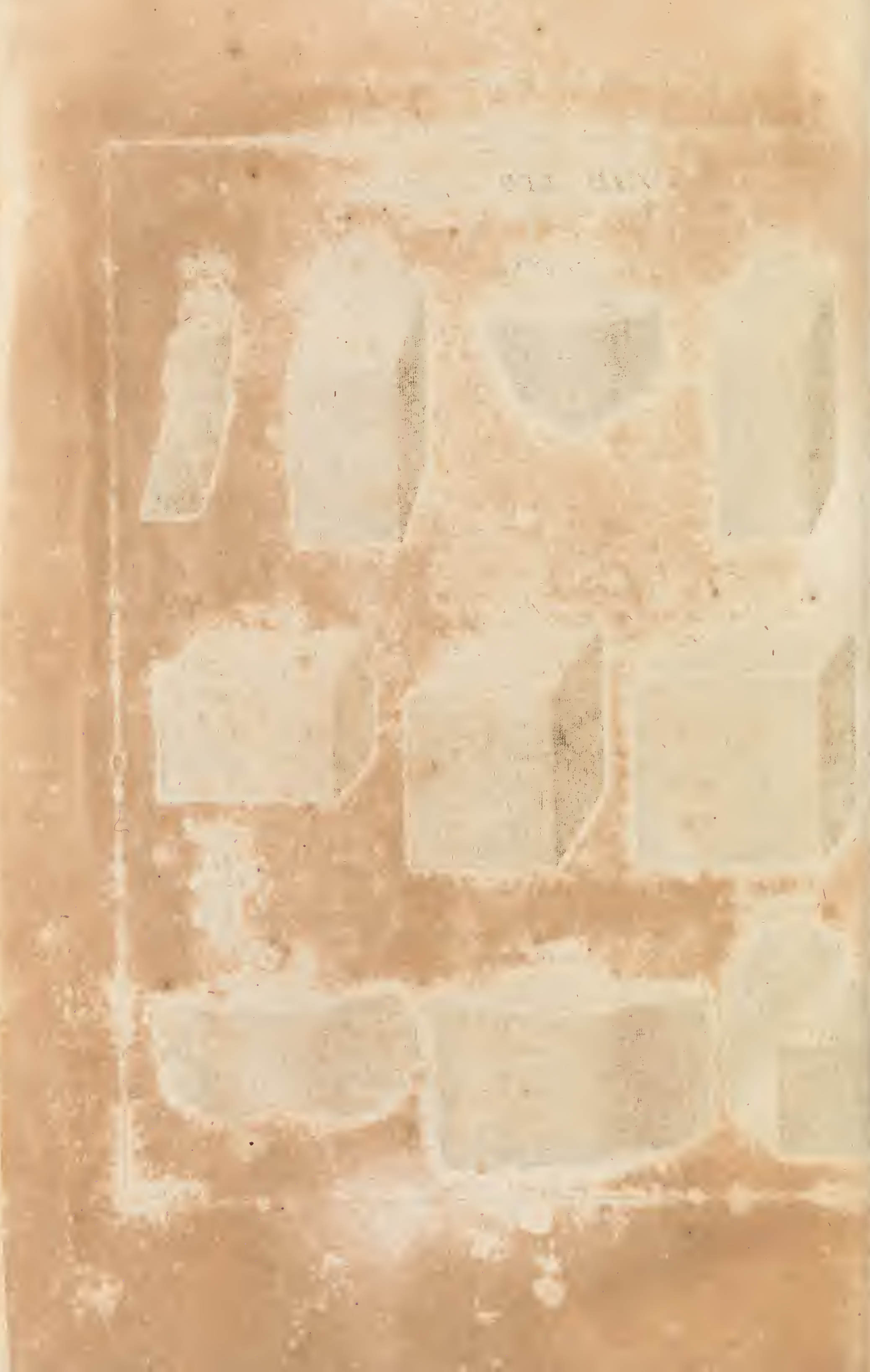


Comprobatum hoc iri arbitratur clariffimus auctor per experientiani circa ferrum ex vena coctum in fornacibus, ubi non primis diebus \& vicibus fed fequentibus fuppeditetur ferrum grifei coloris, quamvis idem genus venæ fit, qua alias reddit ferrum candidum, fcilicet, quia formax ftatim prima vice non ad illum caloris gradum pervenit, ad quem fecunda: alias fuforibus illius regionis regulam conftantem effe, ait, quo major quantitas carbonum fit in ratione ad quantitatem venæ, ferrum inde liquatum eo colore magis grifeo imbui.

Ad candorem in ferro nihil magis contribuere poffe, quam ut fecunda vice fundatur, \& præfertim in maffam tenuem, expertum fe effe fatetur: fed cuni experimentum inftituerit, inque formas effuderit ferrum fuum grifeum, in fractura colorem diverfum obfervaviffe, \& quibusdam in locis grifeum, ut prius, in aliis vero candidum ; \& porro, ubi grifeus color adeffet, ferrum ibi craffius exftitiffe, quam ubi candidus: at vero ubitenuior effet maffula, colorem ibi fuife plane candidum, vide Tab. XXII Fig. I o. Perfpexit etiam fuperficiem vel partem fuperficiei proximam fuife candidam, pariter omnia foliola \& ornamenta tenuiora, fed ubicunque craffum quid exciperet, grifeum colorem illico apparuiffe; unde ex obfervatis concludit, partes tenuiores utplurimum effe candidi coloris. Accidere etiam maffam æqualis craffitici ab una parte candidam effe, ab altera vero grifeam; vide Fig. I I.

In Nivernois \& alibi Gallix, ait, fundunt \& recoquunt ferrum crudum, fimul 2 vel 3 centumpondia ejus, qua in chalybem volunt convertere; quumque fufum eft, recluditur apertura ad latus foci facta, per quam defluente liquamine, formatur maffa figurx irregularis \& craffitiei $\frac{\mathrm{I}}{2}$ vel. 2 pollicum : quix refrigerata ftrato quodam heterogeneis conftanti operitur \& fuperinduitur, fed quæ facile inde poffit feparari \& excerpi: maffa enim ferri cooperta eft tunica tenuiore nigricante \& vitrificata, qux non alia fit, quam fpecies fcoriarum in vitrum converfarum \& cum ferreis particulis mixtarum; vitrum enim ferro levius eft, hinc etiam verfus fuperficiem emergit antequam refrigefcit. Ferrum ab hac materia fecretum, effe ideo purius \& candidius ait. Hinc concludit, quod ferrum tenue candidum magis fit, quoniam purius. Auctor etiam ad illuftrationem hujus rei fequens experimentum a fe factum refert; fcilicet fe ferrum 9 th. in catillo liquefeciffe, \& liquefactum effudiffe, quod non modo candidum obfervaviffet, fed etiam pondus ejus so unciis diminutum effe animadvertiffet : ufque tamen diminutionem hanc non unice deberi purificationi, putat; quodque expulfum fit, tantum materix terreftris fuiffe, fed etiam quod plurimæ fcintillæ ferruginex fimul avolaverint.

Non fufficit, ut ferrum candidum tantummodo obtineatur, ars vero adhuc major in eo confiftit, ait, ut ferrum hoc candidum tractari fimul poffit ; \& ei durities nimia \& rigor fragilis auferri, in quo confiftit pracipue ars emolliendi ferrum.

Bini funt modi emolliendi ferrum: I. Ut emolliatur, quum tenetur in ipfa liquatione, in illum finem, ut utenfilia \& ornamenta, quæ conftabunt ferro fufo, poliri \& reparari commode poffint. . 2. Vel, fi effundaClafis I. de ferro. 
tur ferrum bene purificatum fed duritie fua pollens, ut dein arte quadam emolliri \& tractabile reddi poffit. Perinde eft, num una velaltera methodo emolliatur ferrum, modo ufibus idoneum reddatur.

Quidam operarii tradunt, artem hanc antiquitus cognitam fuiffe, fed temporis tractu periifle. Quidam etiam Gallus ante 20 annos eandem artem calluiffe putatur, experimentum etiam feciffe. Sed modus, quem auctor tradere vult emolliendi ferrum, eft cum ferro femel fufo. Tentamina videas in fequentibus.

\section{Tab. XXII.}

Fig. I. Fractura ferri crudi candidi inæqualitates quasdam in fuperficie habentis.

Fig. 2. Fractura ferri crudi candidi, quale effe folet, cum altera vice recoetum vel liquatum fit ferrum.

Fig. 3. Eft fractura ferri crudi candidi, in qua radiationum fpecies \& lufus apparent: fed radii; qui verius centrum tendunt, non femper tam vifibiles funt in ferro, ac confpiciuntur in delineatione appofita.

Fig. 4. Eft adhuc fractura ferri candidi, ubi radii etiam verfus centrum tendunt, fed debiliores, quam in Fig. 3 tia.

Fig. 5. Fft fractura ferri crudi grifei fimilis fractura chalybis frigida exftincti; color ejus ad bruneum accedit, \& grana funt majufcula.

Fig. 6. Fractura ferri crudi; in cujus fundo candidi coloris fpecies quadam ftellularum fparfim apparent.

Fig. 7. Eft fractura ferri crudi coloris brunei \& fere nigricantis; quod a fractura Figuræ 5 tæ tam colore, quam granis, differat, in qua pauciora fint grana invicem diftineta; \& ubi confperfa appareant micæ.

Fig. 8. Eft portio Figuræ 5 per microfcopium oculis repræfentata, qux ex infinitis frondibus compofita apparet.

Fig.9. Eft frons divulfa ex Fig. 8. ut obfervari inde polfit, quod quxlibet frons vel termes conftet exiguis quibusdam micis, quarum una fupra alteram hreat.

Fig. ro. Fractura ferri fuli non bene jamdum purgati, quod non candidum nifi circa extremitates tenuiores B B. \& circumcirca fit factum; parte tota media coloris grifei manente.

Fig. I 1. Fractura ferri fufi bene purificati, fed ubi tamen aliqua pars coloris grifei remanet; fed minor quam in Figura præcedente. (A) eft pars dicta grifea.

\section{De diverfis modis ferrum in formas E arenam fundendi.}

Uo fundendi ferrum præcipui modi funt, dicente laudatifimo auctore, unus in crucibulis \& catinis, in quibus per calorem, qui tranfit parietes crucibuli vel catini, fuidum redditur: Alter, ut circumdetur carbonibus \& flamma, ficque immediate exponatur actioni ignis: prater alios plures, ut in tigillis vel in medio carbonum igne. 
TAB: XXII De ferro.

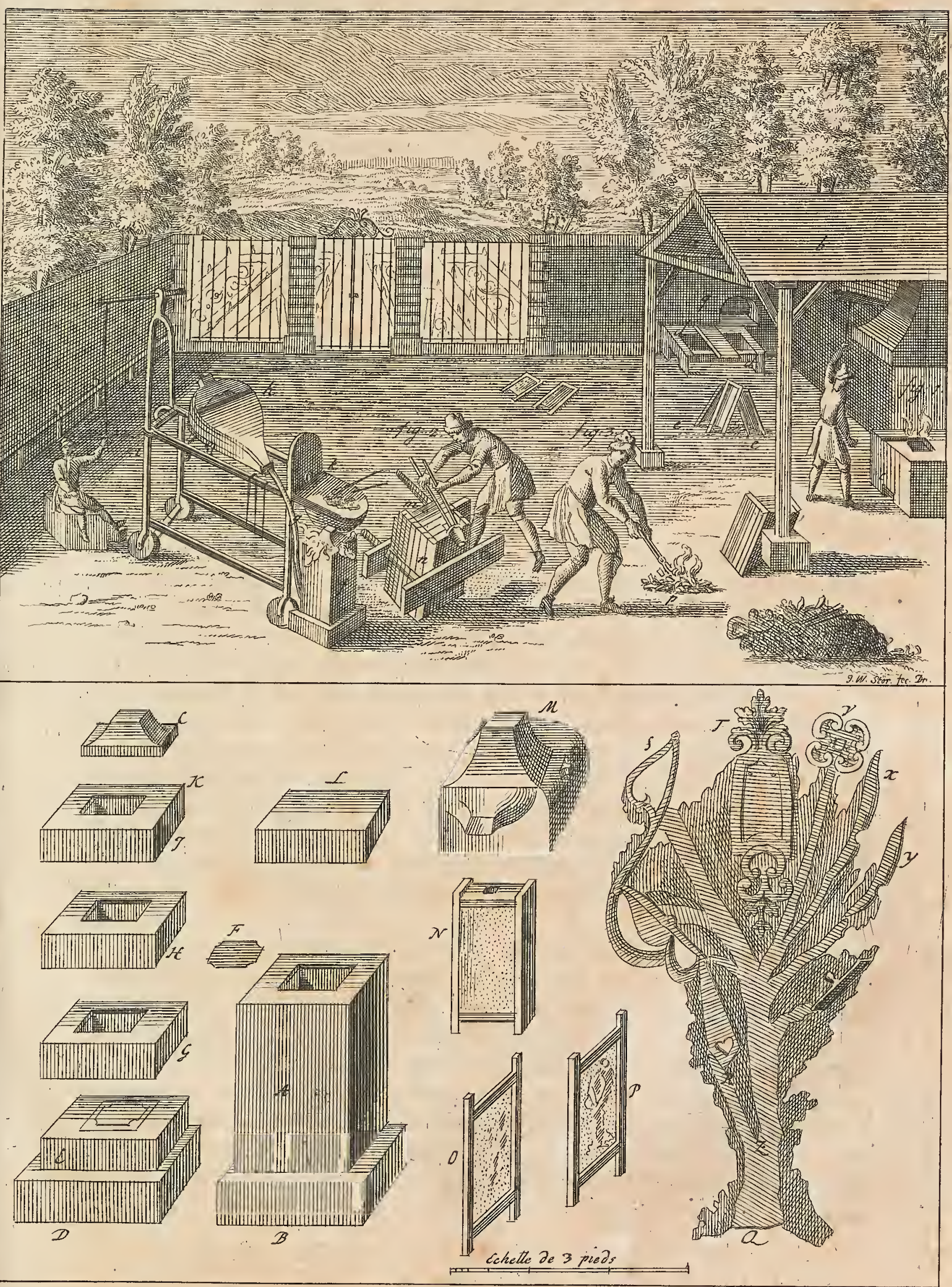





\section{A R S E M L L I E N I F E R R M.}

Qui fundunt cupri metallum, eodem modo liquefaciunt ferrum, quo cuprum, inque ejusdem generis catinis \& crucibulis, pariter ut in eodem furno. Vide Tab. XXIII (c). Tenetur ferrum diu fatis in fufione, fed eo citius liquefcit, quo in minora frufta fit fractum; frufta enim majora fundi poffunt; adque illum finem utuntur tigillis, quæ $30 \mathrm{ad} 40$ librarum metalli capacia fint.

Fornaculie excoctoribus hujus generis ufitatæ non quidem multi fpatii funt; minores vel majores poffunt formari \& fimul portatiles Tab. XXIII (f) \& (A). Mentionem facit fabricæ alicujus uftrinæ, quam portatilem in hortum aut aliunde pro libitu fecum transferre, \& liquationes oculo tefte ubivis inftituere poffit, quæ modo 4 vel 5 laminis mutuo aptandis \& reuniendis conftet: fed quod vulgo ex lateritiis fegmentis aliæ immobiliores formentur; quæ videantur Fig. D. E.F. G. H. I. Furnus ille portatilis ex argilla, ex qua conficiuntur tigilla, Fig. (L), qui debitæ craffitiei, \& in cujus medio foramen erit formæ quadratæ; cineritio (E) unum fegmentum conftituente: Canalis, per quem ex folle fpirabit ventus, fub lamina quadam in uftrinam incurvatus intrabit : Flabellum etiam portatile (i.k.): qui quum e loco movendus fit, toties refarciendus, \& juncturis terra fabulofa conglutinatis, recomponendus eft.

Si partes minores fundendæfunt, quod focus vulgaris loco uftrinæinfervire poffit, addit, in quo per fpatium $\frac{\mathrm{T}}{2}$ horæ $\mathrm{I}$ vel 2 libræ ferri apte liqui \& fundi poffint. Auctor fe ufum effe tigillis cylindricis majoribus, narrat.

Modum hunc fundendi ferrum dicit optimum effe, quamvis fit fimplex, fcilicet quum fundendx \& efformandx fint partes exiliores \& fubtiles, ideo quod metallum liquidiffimum inibi reddatur. Si tigillum fit magnum, omnem inibi contentam materiam non $x$ qualiter liquelcere, nec æquis gradibus ignis \& caloris exponi poffe, quod obfervare liceat, quum in ipfo tigillo congelefcat ferri metallum, una ejus parte coloris candidi, altera vero grifei apparente. Vidiffe fe, 'refert auctor, ferrum eo candidius factum, quo melius liquatum; \& grifeum manfiffe, ubi minorem ignis purificantis gradum fubierit.

Multam fatis quantitatem ferri in tigillo ejus fimul fundi poffe, modo formatum fit tigillum capax, \& ei circumductum fit cingulum, quod parietem repræfentet, intra quem carbones teneantur, vide Tab. XXIII (m). fed confumi hic plus carbonum, quam in fornaculis Ipredictis excoctorum.

Antequam immittatur ferrum in tigillum dictum, juvare, ut prius ad candorem vel rubedinem calefiat. Quumque aliqua ferri pars teneatur in fufione, non immittendum effe ferrum, nifi prius bene calefactum; alioquin illud, quod jamdum in fufione ftet, refrigerari.

Nondum expertum effe, an in furnis reverberii liquefieri etiam poflit ferrum, in quibus cuprum aut metallum in tormenta \& campanas folet fundi: iplos fulores autumare, non in illum gradum inibi auctum iri calorem, ut ferrum rite liquari poffit, majorem vero caloris gradum obtineri, fi flabellis \& vento excitetur ignis. Quum enim ferrum tigillo inclufum poffit 


\section{A R S E M L LIENDI FERRUM.}

liquefcere, eo magis \& celerius, fi non inclufum fit, fed immediate expoftum flamini inque medio carbonum igne.

Sed quoniam ferri liquamen effundendum fit, hinc focum fabrilem vulgarem nullius ufus effe; fed in ufum forte venire poffe focum, l' Affingrie dictum, in officinis ferrariis conftrui folitum, ubi ferrum eliquatum in chalybem preparetur; adeffe enim ibi par follium per aquam currentem actorum, \& ferrum ope venti liquidum factum, in receptaculum aut catiinum ad 2 vel 3 centumpondia emitti. Quibusdam in locis dari exitum fub ipfis tigillis, putandum fic effe, hujus generis focos \& tigilla huic ufui adaptari poffe, modo emittatur volumen, quum calidifimum fit.

Fornaculas ad imitationem fornacum majorum conitruetas, in quibus funditur ferrum, aptifimas effe, in quibus etiam quantitatem ferri poffe liqui.

Effe, qui artem hoc modo fundendi ferrum unice profiteantur, fed Parifis hodie vix nifi unum aut alterum; \& quoniam methodus infignis enolumenti fit, \& paucis cognita, hinc conftructionem fornaculi illorum \& modum fundendi integre tradit. Emuntur, dicit, colligunturque ferri vetufti fragmenta, vide Tab. XXIV (a.b.) Similis alias eft uftrina effigiei fornacis majoris pro liquatione venx ferrex conftructx, compofita ex binis partibus, una fpecieni cätini vel tigilli referente; (A.A.B.B.) altera ambicu quodam in formam coni truncati conftante, qui catino fuperimponitur, vide (F. G.H.I.) tigillum vocatur Poche, \& modus fundendi fondre à la poche: huic ufui adaptatur olla vetufta aut tripus ferreus, vịde (A. B. B. A.) \& (L. M.M. L.): Tigillum ex argilla cum fabulo mixta ad craffitiem $I_{2}^{x}$ pollicis formatur : ambitus ex eadem argilla, qua tigillum. Alteram partem uftrinæ videas in (E. G. H. I.) altitudinis 15 vel i 6 pollicum, quamvis altior dari poffit; intus loricata \& obducta ejusdem generis argilla eft, qua catinus. Apertura fuperior anguftior inferiore eft. Ex follibus oblique applicatis ventus erumpens non in fundum uftrinx, fed in imam partem lateris oppofiti dirigitur.

Quum itaque uftrina hoc modo conftructa fit, \& fimul bene cautum argillæ \& lutationis ope, ne flamma ullibi per juncturas erumpat: mox per aperturam fuperiorem immittuntur aliqua prunæ, \& infuper carbones nigri, quibus facile per ventum accenfis, repletur uftrina carbonibus. Quum carbones omnes accenfi fubfiderint, novi adjiciuntur, ufque dum parietes bene calefiant; quod cum animadvertitur, prima ferri liquelcendi portio imponitur, adque fupremum ufque repletur carbone. Ferrum fectum in portiunculas thaleros imperiales aquantes liquefcit, antequam tigillum - contingit, non item fi frufta ferri majufcula forent. Bis iterumque inferuntur carbones, qui \& pertica ferrea inferta circumaguntur, ut angulis \& parietibus fe juftius applicent ; \& infuper ramenta aut fegmenta ferri; quod repetitur, quoties opus fit.

Per orificium fpiratorium exploratur, qualis fit liquationis ftatus; apparet enim ibi ferrum guttatim fillans, \& novæ guttæ pedetentim defluentes : fi uftrina intus fit coloris candidi, pariter etiam ferrum \& ipfiemet prunx, indicium eft optatum; contra vero fi modo rubefcant : dete- 


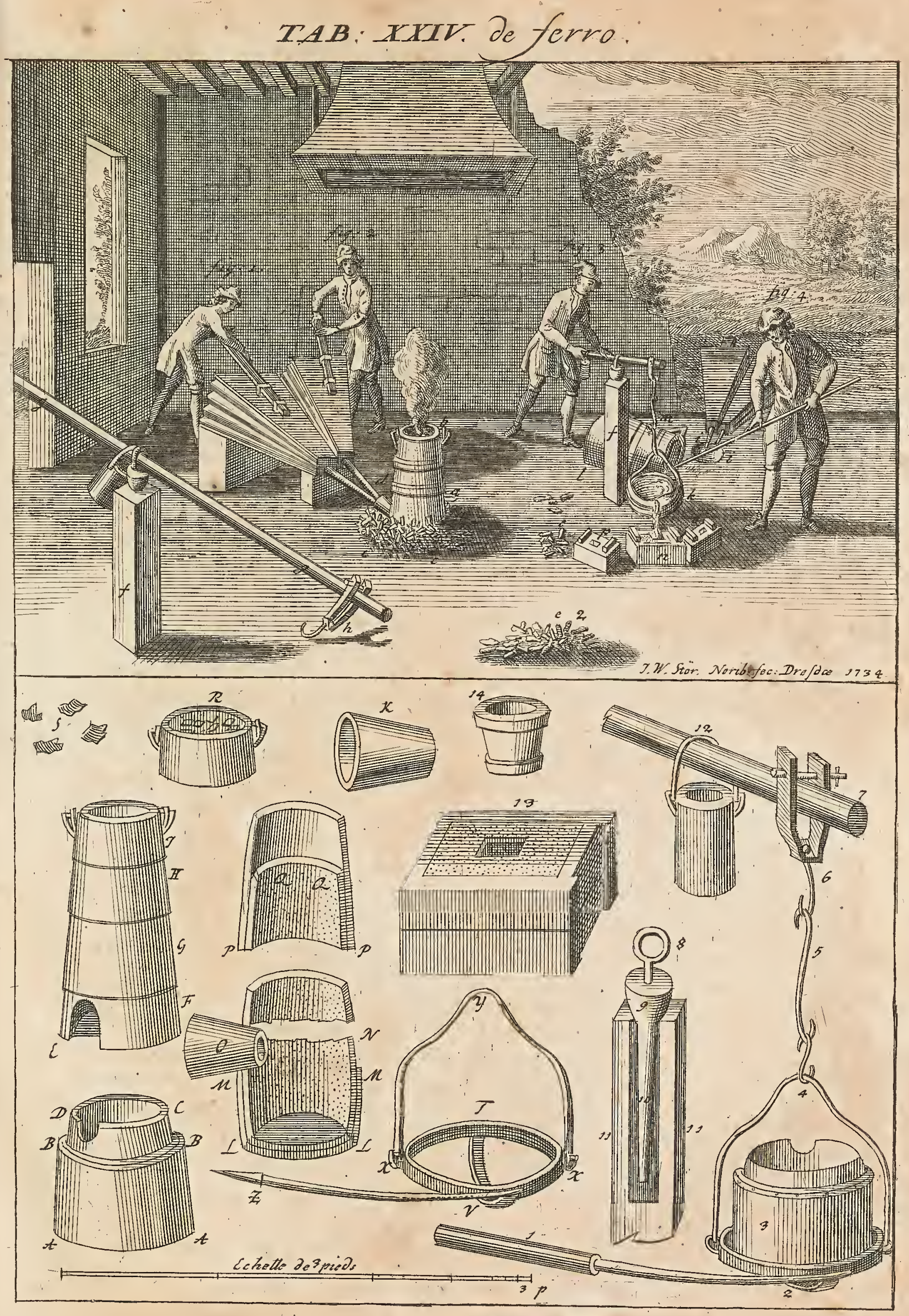



rioris adhuc ominis eft, fi orificium venti inquinari fcoriis incipiat; \& liquamen denigretur, a fiece tunclenta obturari folet foramen, quod ne fiat fedulo cavendum eft: in quo cafu in fornaculam demittitur batillum, cujus ope auferuntur heterogenea, quibus dictum orificium pracludi folet. Materia quædam tenax vitrea, circa orificium hos venti conglutinata, pariter etiam ferrum non liquatum, volumini liquidiori immerfum in caufa fxpe affolet effe : quodcunque enim non bene liquefactum fub orificium hoc decidit, non amplius liquitur ; ipfaque fepe fubfantia liquida ferri congelefcit: nifi excoctor viam \& meatum vento jugiter aperiat, carbones accenfi in ferrum vim fuam incaflum exferunt.

Quum itaque omne ferrum uftrinæ \& igni fit commiffum ; infpicitur, num adhuc pars ferri refidua nondum colliquata fit, quas ope conticujusdam aut alius ferramenti, agitatis \& circummotis prunis verlus tigillum defertur: utque colliquefcant melius, ipfum liquamen etiam commovetur: quumque putant, omne ferrum effe liquefactum, fiftuntur folles, eximiturque uftrina, quod fit, perticam inferendo anfis, quibus alligata eft, ficque portatur inde in locum, ubi liquamen eft emittendum. Quidam vero alio mechanifmo po̊rtatilem hanc machinam efficiunt, ut (f.g.), cujus ope ab uno loco in alterum per multam viam, transferri poteft.

Quum tigillum eloco fuo emotum fit, liquamen ferri adhuc carbonibus \& f coriis five materia vitrea coopertum eft, quæ materia tam ex ferro, quum recoquitur, quam etiam ex cinere \& favilla carbonum originem trahit. Ope ferramenti cujusdam ad hunc ufum parati auferuntur primum carbones ; ut vero fcorie auferantur, linteum humeetatum baculi extremo appenfum \& annexum verfus fuperficialem vitream ferri materiam demittitur, quo humectata \& indurata, ab aditante ty rone elevatur, quod fepties, octies, aut pluries dum omnis fublata fit, continuatur five dum appareat ferri volumen liquidum, \& Coriis plane nudum.

Per aquam, qua irrorantur fcorix vel luperficies liquaminis, videtur etiam luftrari \& purificari ferrum : quoties enim auferuntur fcorix, toties irroratur fuperficies, \& locus datur fucceffive novis verfus fuperficiem e ferro emerfuris: hinc humectatio \& elevatio repetita juvat, quoties tuto poffit iterari ; usque dum ferrum fubdelitelcens de fluiditate fua nihil amittat.

Melius adhuc conftrui poteft hxc uftrina, fi loco ollæ \& tripodis vetuft, catinus ex ferro malleato argilla meliore obducto formetur, Tab. XXV. fique pars fuperior altius educatur. Uftrinam fibi parari curaviffe refert auctor, cujus delineationem videas Tab. XXV.

Si utenfilia grandiora funt fundenda, canales in fitu obliquo locati ab ipfo uftrinx tigillo ad locum ducentes, in quem effluet liquamen, posfunt applicari : fin vero minora, poteft volumen fèrri ope cochlearis in formas \& typos exhauriri. At vero fi ferrum purius \& defacatius fit, \& in fiactura candidius, raro eloco in locum reque fluidum transferri fe patitur, ut dein ommes partes \& finus tenuiores \& fubtiles ad unguem adimpleat; nifi cochleare \& infundibulum, cujus ope exhauriendum eft, bene candefactum fit, \& nifi typi \& effigiati tori, in quos effundendum eft, prope uftrinam fint.

Cladsis I. de ferro.

$\mathrm{Kkk}$

Optime 


\section{A R EMOLLIENDI FERRUM.}

Optime perfpiciendum eft, ut metallum bene liquidum fet co ipfo momento, quum effundendum eft; quod fit per folum ignem.

Receptacula etiam, in qux hauriendum eft, ficciora erunt, juvat etiam, ut fint calida; quo enim calidiora funt, eo minus crafelcit metallum : fed ufque eft cavendum, ne per calorem rimas ducant; profpiciendum etiam, ne ferrum effufum particulatim hic \& ibi rumpatur; illud enim facile rumpitur, quod tenue eft formandum. Ferrum bene purificatum, inftar vitri in partes abit, precipue fi fubito refrigeretur : unde idem hic eventus preveniri poteft eodem modo quo circa vitra, qux portantur in calfactorium, ubi paullatim refrigefcere finuntur; hic etiam furni ejusdem artis poffunt conftrui, Tabula XXIII $(\mathrm{g})$, qui lignis calefieri queant: utque primum receptaculo aut typo fuo eximitur ferrum fufum, candens in furnum hunc poteft transferri: alias ope fafciculi lignei fermm eodem in loco ubi effulum eft, calefieri poteft; vide Tab. XXII (p). Nihilominus fi plurimx partes exiles, ut foliola in arena formanda frn tacile posfunt rumpi \& difcerpi; Tab. XXII, (N.P.) \&c. rarum vero eft, quod partes crafliores rumpantur.

Accidife etiam refert auctor, ferrum fufum \& lente refrigeratum, poft elapfum aliquot horarum, ut \& dici fpatian, fe ruptum ivife; quod circa vitra etiam accidere folet.

\section{Defcriptio Figurarum.}

Tabula XXIII.

a. b.) Eft cectum, fub quo opus peragitur; fit plerumque in officinis fufow rum memoratorum.

c) Eft uftrina; fectiones Es paries reprefentantur alibi.

Fig. I ) Vectis cujus ope folles reciproce aguntur.

d. d.) Cap.ula, que continet arenam, qua recepcacula funt replenda. da funt.

e. e.) Sunt receptacula pro recipiendo ferri volumine, queque prius ficcan-

f) Eft uftrina portatilis, in quam ventus per follim vulgarem fpirat.

马) Canaliculus, per quem veintus in focum ducitur.

i. K.) Efl focus portatilis, quo fi uti velis, pentus intrabit juxia (K).

Fig. 2) Effunditur ibi ferrum liquidum tigillo contentum.

m) Efl cocblea, cujus ope receptaculum pro bolumine ferreo comprimitur.

(m) Sunt tria receptacula fimul collocata. (O) Eft veceptaculum apertum.

Fig. 3 ) Tenetur carbonum bel lignorum fafcicultus fupra ferrum, quod effun$\operatorname{ditur} \operatorname{in}(0)$

q) Efl furnus, in quem transmitti poffunt partes ferri effufb, prout eximuntur receptaculis; ut foilice ibi lente refrigefcant.

A) Eft uftrina portatilis.

B) Eft lapis, cui impofita ef.

C) Eft ejus operculum.

D. F. F. G. H. I. K.) Sunt ońnes partes, quibus Figura pracedens componitur, invicem feparate.

D) $E f$ 
A R E EMOLLIENDI FERRUM. 223

D) Eft faxum.

E) Pars, que conflituit cineritium, circa quod limbus quidam eft, filicet ut lamina ferri ( $\mathrm{F}$ ) contineri poffit. (G. H.I.K.) Junt relique ejusdem partes.

L) Eft frufluhum argillse mollioris forme quadrate, que modo fe perforatur, confituit partem priori fimilem.

M) Ambitus ille circa focum collocandus, qui Gallice bocatur Serre-feu, qui in camino vulgari loco foci etiam infervire poteft. ribus.

N) Receptaculum, in quod effundendum eft metallum.

O.P.) Eft idem receptaculum, fed apertum, cum fabulo Es inibi figuratis ope-

Q.R.S.T.U.Y.Z.) Eft ferrum in receptaculum (N) effufum: barie

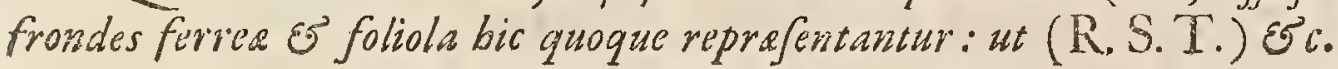

\section{Tabula XXIV.}

Fig. I $\varepsilon^{3} 2$ ) Sunt qui reciproce mobent folles.

a. b.) Ef pars fuperior uftrine, cujus pars inferior terre E pulveri fcoris. ceo Es carbonario oft infolfa.

b) Ef apertura, per quam immittuntur carbones \&s frufta ferri.

c. c.) Eft pulvis carbonarius, quo circumdatur pars inferior uftrine.

d) Eft canalis per quent é follibus intromitcitur ventus.

e) Elt cumulus carbonum.

e) Ef cumulus fragmentorum ferri.

f) ER arbor, cui infixus eft vectis, cujus ope facile e loco fuo moveri $\xi_{0}$ fub. levari potef uffrina Es itgillum, quod filicet inferiorem partem uffrine componit.

g. g.) Eft vectis. tigillum.

h) Eft uncus, qui applicatur anfe ufrine, unde fublevari Es tolli inde poteft

Fig. 3.4.) Occupati funt circa effuffonem ferri, liquati.

Fig. 4.) Manubrium cocblearis: a quodam vertitur tigillum, adeo ut exinde effluat liquismen.

i. i.) Foramen, ante quod tigillum ef relocandum.

k. k.) Tigillum.

m) Anfa cocblearis.

n) Receptaculum, in quod effunditur ferrum.

o) Receptaculum jam repletum.

p) Receptaculum, quod implendum efo.

AA. BB C. D.) Eft tigillum, quod confituit inferiorem partem uftinc. (A A. BB.) Eft tripos vel olla Detufa. (C) Eft argilla Jipra partem inferio. renn. (D) Eft orificium, in quod inferenda eft fffula follucularis.

E.F.G.H. I.) Eft ambitus ipfe uffrince, qui tigillo applicandus eft. (E. G. H. I.) funt dinerfe partes, quibus confat. (E) apertura, que canalem rbo cipiet.

K) Ef canalis feorfom reprefentatus.

LL. MM. N. O.) Eft fectio tigilli.

M.L.L.M.) 


\section{A R S E M L L E N I F E R R M.}

M.LI. M.) Eft tripus vel olla vetufta intus argilla arene cominixta inducta. (Mn) eft pars conflans argilla, que fupra dictam ollam afcendit. (O) Canalis in fuo loco: Jupra (N) ef fectio partis.

(F) Figuræ (E.F. G. H. I.)

P.P. QQ.) Eft fectio partium G. H. pars ejus ab (PP) ufque ad QQ eft argilla quadam inducta.

R) Eft pars fuperior (I). Infuper repofita funt frufula ferri prout apponi folent, fubjectis carbonibus.

S) Diverfa ferri fegmenta.

T. VV.XX.) Furramentum in quod mittitur tigillum.

Z.V.) Eft manubrium ferreum, cujus pars ligno conflat.

I. 2. 3.) Significat tigillum in cocbleari repofrum.

4) Anfa que pendet ab unco.

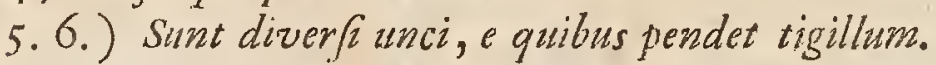
lineata.

8.9. 10. r.x.) Eft fectio portionis Figure (f), in loco fuperiori tabelle de-

8.) Annulus, per quem tranfit bectis. tigilli.

12.) Pondus, quod ad alterum latus vectis fufpenditur, ad equilibrationem

13.) Eft receptaculum, in quod effunditur liquamen ferri.

14.) Mortarizes ex ferro fufo five crudo factus.

\section{Tabula XXV:}

Fig. I.) Reprefentat ipfum uffrine fitum, quum inibi peragitur liquatio metalli cujusdam.

Fig. 2.) Eft pofitio uftrine, quum inde effunditur ferrum liquidum.

a. a. a. a.) Fig. 1 \& 2, funt rote, Juper quas tota bec macbina defertur.

b b.c. d.) Sunt 4 fulcra perpendicularia cum aliis transwerfim locatis.

d) Eft fitcrum reliquis altius, quoniam illis partibus innititur, quarum ope agitantur folles.

f) Eft follis, e quo canalis exiens Fig. I. in orificium bentilatorium inferitur, antequam obvertituruftrina, prout oflenditur Fig. 2.retrabi folet follis, quod etiam facile fit, vide (hh.)

g) Iufrina in fitu perpendiculari Figur. I. Et in fitu obliquo Fig 2. (i i) ope axium (i i) converti potef. Horum etiam ope relocatur uftrina alius bel depreffius fecundum libitum. muntur.

1) Fig. 2. Eft operator, qui tenet cochleam, cujus ope receptacula compri-

o) Scala bel gradus per quos afcendit artifex, quum carbones vel ferrum imponet.

p) Pertica, cujus ope deprimitur follis.

A. A. BB.) Eft ambitus ejus. (BB. C.) ef tigillum frve fundus uftrina. BB funt duo cingula, quorum ope füblevata tenetuir uflina.

D) Portula vel apertura, per quam emittitur ferrum fufum: infervit etiam ufui: dum ferrum unco preditum immittendum fit, Ev ejus ope fcoris Jupra ferrim natantes extrabends. 


\section{TAB: XXV. de ferro.}

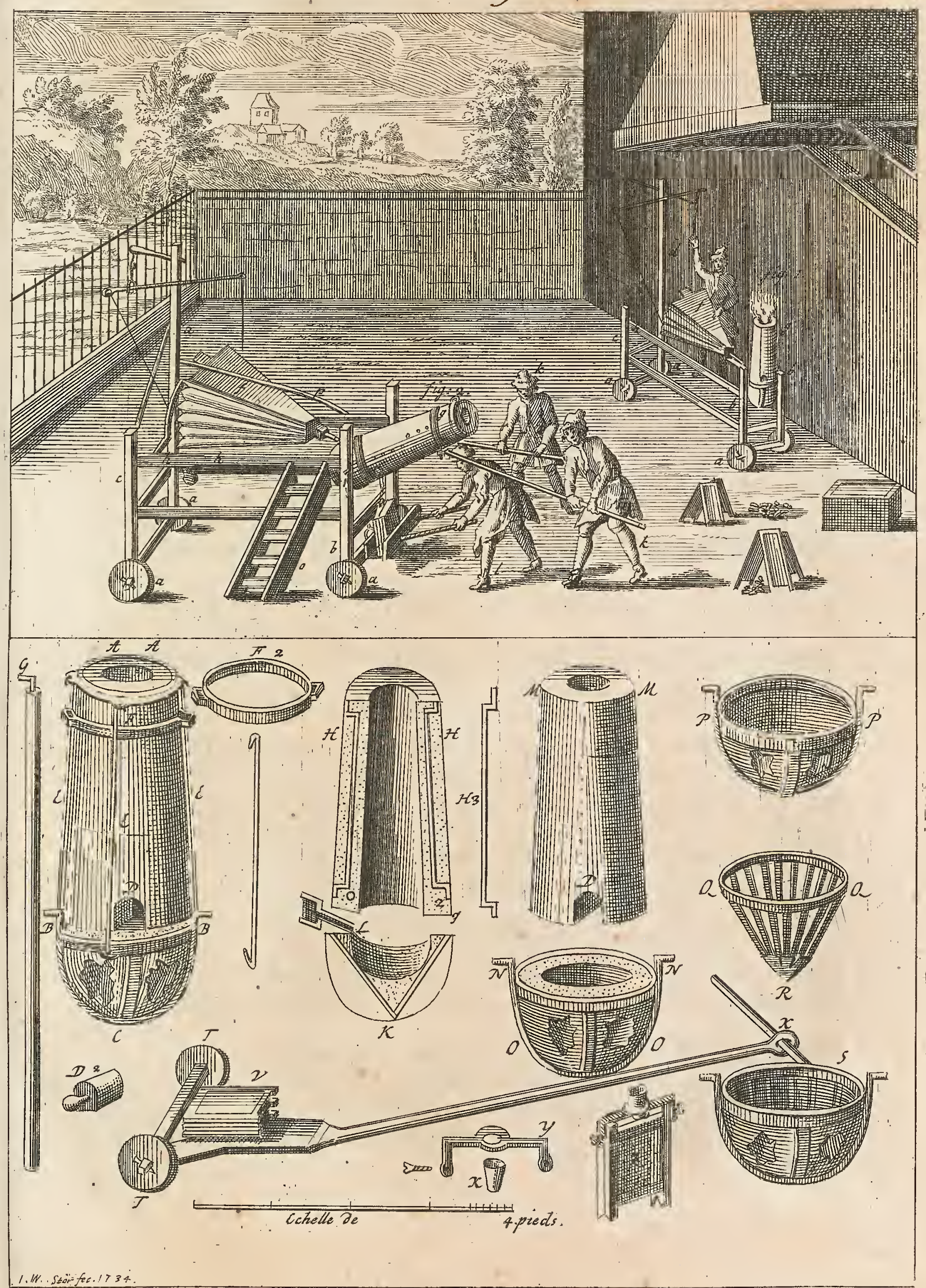



D 2) Portula bec feparation reprefentata.

EE) Bacilla ferrea partem fuperiorem Ev inferiorem tigillicolligantia.

FF 2) Cingulum circa ufrinam.

HH. I. K.) Eft (ectio uftrine, ut confpiciantur ejus interiora. (I) Eftaper. wura, per quam emittitur ferrum.

L) Eft canalis, cujus directio eff fecundum lineam punctatam.

O.HH. 2) Efl fectio utriusulue partis ambitus ufrine, five lamine ferred parietibus ejus alligate: queque contribuit ad continendam argillam.

H 3) Eft lamina dicta ferri feparatim reprefentata.

MM) Ambitus feparacim delineatus. (D). Eft apertura, perquamextrabuntur fcoris.

NN. OO.) Tigillum, cujus pars interior undique obducta eft argilla, que feparation reprafentatur. ( $\mathrm{OO}$ ) aperture, per quas immittuntur carbones, quibus precavetur, ne fundus tigilli refrigeretur. repleta.

P P.) Eft Juperficies exterior tigilli, E pileus, cujus pars interior nondum eft

QQ) Species cribri vel tranftri conici, quod locatur in capacitate (PP.)

S) Tranfrum in loco fuo pofitum, Es paratum, ut terra vel argills obduch. sur, unde evadit famile (NN. OO.)

TT. X.) Cỉfum, in quo typi bel recepiacula ponuntur, ut (V.)

$X)$ Infindibulum, quod in receptaculo reponitur. Utque ex uffrina melius educatur metailum, canaliculi vel ductus ex furno cxeuntes formari polfunt, fed qui prius calefaciendi Junt, quam per illos liquamen met alli poffit transmitti. bulum.

Y) Eff fruftum ferri, quod receptaculo adjicitur, quodque portat infundi-

Z) Receptaculum, in quo infundibulum eft repofitum.

\section{Experimenta cum diverfa generis materiis, qua. rum ope emollefcere polfit ferrum.}

$Q^{2}$

Uoniam fruftra tentatus eft modus a clariff. auctore emolliendi ferruni per viam fufionis, hinc aliam methodum fe excogitaviffe, infit, cujus ope ferrum jamdum fufum \& capfula inclufum, dein mediante igne circumfuio emollefcere poffet. Certum eft, ait, quod chalybs, qui multa copia falis \& fulphuris gaudet, proxime accedat ad naturam ferri crudi.

Illum in finem capfulæ cuidam fe inclufiffe, refert, ferrum candidarum micarum fufum, fed tenue. Quibusdam capfulis etiam immiffo offe calcinato \& in pulverem comminuto; aliis vero creta. Continuato per aliquot horas igne, ferrum exemtum, quod alias durum fuiffet, tam emollitum apparuifie dicit, ut limæ, non aliter ac ferrum malleatum, cederet.

Sed adhuc experimentum nullum feciffe cum ferro fufo craffiori, hinc etiam pyxidi cum offe calcinato indidife ferrum fufum craftitiei i ad $I_{2}^{x}$ pollicis, quod ubique ornatum effet partibus tenuibus \& foliolis \&c. cum. ferro incluio per biduum expofita igni, \& dein exemta vidiffe, ait, partes Clalfis I. de ferro. 
hujus ornamenti ferrei tenuiores fquamis quafi obfitas \& ideo evanefcere incipientes; illis quidem omne ferrum circumftipatum fuiffe, fed partes tenuiffimas his quafi exeerptis evanuiffe; reliquam ferri partem limæ optime ceffiffe. Examinata caufa, vifum effe, materias terreftres \& alcalinas fulphuris in ferro latentis partem imbibiffe, \& ftratim fuperficiem terere \& attenuare voluiffe, dum ferrum omni fubftantia ligatrice fuperficietenus fpoliatum iret; dictasfquamas, nec diffimiles ramentis vel limaturæ, qux ex ferro fub malleis magnis percuffo decideret, fuiffe : \& eo majorem denfioremque fquamarum apparuiffe copiam, quo diuturnior effet ignis. Hinc nihil tale circa ferrum, quod non nifi per aliquot horas teneretur in seftu, animadverti. Commifcuiffe dein pulverem carbonarium fubtiliorem cum creta vel etian cum offibus calcinatis \& pulverifatis : ab experimentis tunc conftitiffe, ait, carbonem pulverifatum nullam partem fuperficiei exediffe, licet in igne diutiffime detentum eflet; ex quibus concludit auctor, hoc artificio emollefcere poffe ferrum, nec ullam partem etiam in igne lentiffimo confumi.

Experimenta adhuc alia feciffe cum diverig generis falibus, cum foda, alcalibus variis, fale marino, num filicet illorum ope emollefceret ferrum: falia per fe fola \& non commixta, dicit haud multam emollefcentiam produxifle, fed ferrum in fquamas etiam feparatum fuifle.

Hinc aliud experimentum aggreffum effe; \& commifcuiffe duas partes offis calcinati, unam carbonis pulverifati, \& unam falis marini. In alia capfula mixturx prædictx etiam fal vitri adjeciffe; in alia victriolum, rurfus in alia alumen, inque alia cineres clavellatos, fcilicet loco falis marini, in alia nitrum per tartarum concentratum, in alia tartarum. Omnia hæc falia aliqualem emollitionis effectum ediffe, xgre tamen inde deduci poffe, num ad ferri emollitionem citiorem contribuerent. Mixturas falium alcalinorum magis emollitionem ferri acceleraviffe vifas, quam reliquorum falium genera, eisque palmam præripuiffe cineres clavellatos: qui fic cum profectu compofitioni præmemoratæadjici poffent, fed ignem non lentiorem fore.

Addidiffe etiam fe, narrat, experiundi gratia, antimonium \& fublimatum corrolivum, \& hoc ideo, quia putarent aliqui illius ope ferrum admodum mollitum reddi : fed dictum fublimatum potius retardaviffe effectum materiarum, cum quibus effet mixtum: Antimonium vero grana \&. interiorem ferri texturam inquinaviffe, \& emollefcentiam impediviffe; edidiffe adhuc illum effectum, ut, licet antimonium cum fua mixtura capfulæ exigux inclufum effet, tamen mixturam reliquarum capfulæ majori inditarum etiam effectum impediviffe; pyxide harum optime perlutata, ufque tamen ornamenta \& ferramenta tenuiora induruiffe, \& quædam in fquamas foluta abiiffe. Viride xris vero non tam nocivum fuiffe.

Loco pulveris carbonarii pulverem corii five calceorum calcinatorum dein adhibuife, qui etiam effectum quendam edere videretur; ambigit tamen, num pulveri carbonario palmam præripiat.

Cum oleofis etiam tentavit; mixturam distam febo liquefacto humectando \& inungendo, fed mixturam febo inunctam minorem effectum, quam ejus expertem, edidifle. 
Loco offis calcinati \& cretæ appofuiffe calcem vivam, pariter etiam calcem exftinctam, argillam figulinam in pulverem redactam, \& vitrum contufum. Calcem emolliviffe ferrum, fed ei non dediffe tantam tenacitatem, quantam materiæ reliqux: terram figulinam \& argillam emolliviffe, fed fimul fuperficiem in fquamas divififfe. Gyplum vero plurimam fqamarum copiam produxiffe. Hinc examinatis omnibus prædietis, mixturam nullam meliorem vifam effe, quam cum offe calcinato \& creta. Sed offa calcinata cretæ praferenda effe oblervavit, \& meliorem omnino ulum preftitiffe, licet hoc in tentaminibus parvis obfervari non poffet. Licet. idem caloris gradus effet, at duplo lentior ignis mora, vix tamen cretam fimilem effectum cum offibus preftitiffe. Adhuc magis, offa femper emolliviffe ferrum, ut tentantem fpes nunquan falleret: Sed interdum vix evitari potuiffe, quin creta emollefcentiam femel inductam adimeret, \& duritiem redonaret, præfertim fi calor igneus nimis fortiter in ferrum vim fuam exerceret, \& ultra gradum infra determinandum : fi enim exacto tempore non eximeretur igni ferrum, ferrum in eandem fuam duritiem redire vifum effe; pariter etiam partes ferreas femel emollitas. Addit, accidife, quum ferri eodem igne codemque in furno calefacti una portio non æqualiter eundem caloris gradum reciperet, quum reliquæ partes ultra gradum debitum effent calefacta, quod vel particulatim vel integre duræ remanfiffent; \& licet emollitum prius, ufque tamen durum evafiffe ferrum. Offa vero calcinata fecure \& non ambigue ferrum emollire, \& eo citius, quo major gradus caloris fit. Cretam vix voto refpondere, nifi partes tenuiores fint emolliendæ, vel nifi calore admodum leni partes ferri majores imbuantur; hoc eft, nifi ferrum modo in colorem cerafi ignefcat: hinc præter inconvenientiam, quod creta molle quid ferro inducere nequeat, nifi tempore diuturniori, etiam ufum ejus periculof $x$ aleæ videri, in eo quod principio tribuat, dein refumat $\&$ deftruat. Rationem, quod creta partes exiguiores emolliat, \& mollitum iterum induret, fecus ac osfa ; \& ignem moderatum poftulet, allegat effe, quod offa vi calcinationis fulphuream fuam partem amififfe videantur, pariter etiam falia fua volatilia; unde fulphura ex ferro emanantia locum in calcis offex interftitiis fortiri poffe, non vero in pulveris cretacei, in quo fulphura \& falia volatilia ad certum caloris gradum remaneant fixa. Quod offa calcinata omnis fulphuris \& falis volatilis expertia fint, concludit ex eo, quod optimi generis cupelle \& catilli ab illis formentur.

Quum itaque circa emollitionem ferri in ufum optime vocari poffint offa calcinata, fed quæ mifcenda \& temperanda fint cum pulvere carbonario : ratio mixturæx confideranda venit, unum enim retardat, alterum vero accelerat effectum; ab experientia format regulam : quo claudatur melius pyxis, eo minorem quantitatem pulveris carbonarii adhibendam effe: \& fic fine periculo apponi poffe unam partem pulveris carbonarii ad binas offum calcinatorum, licet carbo non emolliat ferrum, ufque tamen illud non indurare : expertum etiam effe, carbonem pulverifatum diuturnum ignem paffum folum per fe aliquam emollefcentiam etiam caufatum effe. Calcinatum corium idem etiam producere vifum effe. Quum pulvere offium 
offum calcinatorum femel repleta fit capfula, non majorem dein quantitatem ad iteratam ejus operationem requiri, quam, quæ per.ignem deperdita \& confumta fit; \& fic eandem materiem iterum iterumque in ufum vocari poffe. Auguratur, quia mixtura multum fulphuris \& falis imbiberit, ut diutius infervire nequeat, eundem pulverem elixari \& calcinari poffe, \& demum tuto in ufum adhiberi, pariter carbonem prius ufitatum. Addit, tutifimam effe mixturam ex una parte carbonum \& binis offum calcinatorum, \& illam ter aut quater ufurpari poffe, antequam carbones recentes adjiciendi fint.

Offa eo ufque, dum friabilia \& admodum candida evadant, calcinanda effe docet, nec damno effe, fi ufque ad combuftionis gradum. Ofla calcinata dein in pulverem admodum fubtilem terenda non effe.

Nihil referre, quanta copia offium pulverifatorum fit, fufficeretamen, ut ornamenta \& opuicula ferrea invicem divifa inibi locum fortiri polfint, ne contactu mutuo aliqua fui parte lædantur.

Tentamen etiam feciffe cum conchiliis marinis calcinatis, ut cum oftreis, tefis limacis, \& id genus aliis : \& quoniam per calcem communem emollelceret ferrum, etiam hoc calcis genere emollitum fuife expertum effe.

Tentaviffe cum offibus fepix, generis cujusdam pifcis, qux calcinata etiam emollirent ferrum. Sed ferrum cum diverfi generis calcibus prodictis in fquamas fuperficietenus folutum abiiffe, plane ac cum offa fine mixtura pulveris carbonarii adhibita fuerint. Hujus pifcis ofla cum multis aliis copia circa litora colligi poffe; fed præftantiora effe offa prædicta calcinata.

Pariter factum effe experimentum cum ovo \& crufta ejus teftacea, \& eundem effectum edidifie, qualem calces priores.

Quod capfulas attinet, illas ex argilla in lamellares formas fubacta \& diducta parari poffe ; fed loco illarum etiam parietes ex ferro crudo aut fufo adhiberi, pracipue in illo cafu, quum vehemens ignis defideretur. Circa ufum parietum ferreorum obfervaffe, quum detineretur talis capfula per aliquot dies in igne, ad fuperficiem laminarum, ubi ignis vim maximam exerceret, affixum vidiffe fratum quoddam pulvereum \& pulverem admodum rubuifle, colorem ejus interdum etiam ad violaceum accefliffe. Stratum hoc fatis craflum ortum effe ex particulis ferri concremati; nec aliud fuiffe, quam crocum quendam Martis autumat. Dein pulvere hoc ex ferreis laminis abrafo ferrum emolliendum circumdediffe, quo compertum effe, ferrum citius quam ab aliis fubfantiis perfecte emollitum fuifie. Utque adhuc melius hujus rei veritas conftaret, ftratum croci hujus collecti cum fuo ferro in tigillum mififie; alterum veroftratum ex mixtura hujus croci \& offium calcinatorum formavifie; tertium ex offibus calcinatis; cumque debito tempore igni expofitum \& dein exemtum foret, obfervatun effe, optime emollitum effe ferrum, fcilicet dicto croco Martis, dein mixtura croci \& calcis offium ; ultimo ipla calce offea circumdatum effe: unde concludit, crocum dictum Martis meliorem adhuc ipfis offibus effetum edere. Crocum hunc alias facile parabilem effe, fed num 

in opere majori eundem ufum præftet, in dubium vocat. Addit, non violento nimis igne urgendam effe capfulam, cui inclufus fit crocus, in illo enim cafu maffam compactiorem evadere ferro fufo emolliendo nimis adhærentem, quæ tamen ope ictuum mallei poffit fecerni, fed fieri nequire absque periculo operis artificiofi aut omamenti tenuioris. Si violens in furno ignis fuerit, ad laminarum ferrearum fuperficiem dictum pulverem aut crocum non apparere, grana enim uniri \& inde formari fquamas (pongiofas, tamen in locis, ubi fe fiftant hæ fquamæ, non fenfibilicer diminutum apparere ferrum.

\section{De furnis ad emollitionem ferri fufíidoneis.}

Uoniam ferrum circumdandum eft pulvere fubtiliori, hinc neceffum effe, ut capfulis vel pyxidibus includatur; \& ut pyxides perlutentur. Pcrlutationem tamen hic non tam neceffariam videri, quam circa ferrum, in chalybem vertendum : füphura enim \& falia hic in ferrum non infinuanda effe, fed ab illo potius extrahenda: juvare tamen ut perlutetur pyxis, quia mixtura etiam conftat carbone pulverilato, qui ubicunque patet aer \& apertura, facile concremetur. Alias regulam generalem effe, fi pateat igni liber introitus, ferrum aliquamdiu igni expofitum, in fquamas fuperficietenus folvi.

Capfulam longiorem fed anguftam repleviffe, ait, ttrato offis calcinati, ut \& ferri fufi p:ene ad dimidiam altitudinem; dein fuperimpofuiffe laminam argillaceam, ita ut omnis communicatio ejus cum fuperiori prexclufa effet: fuperiorem partem pariter repleviffe ftratis offis calcinati \& ferri, fed captula plane aperta relicta, fcilicet ut fulphura \& falia libertatem exhalandi nancifcerentur; examine dein facto cum ferro, quod infra \& quod fupra in capfula jaceret, fe non multam differentiam comperiiffe, quin capfula etiam aperta poffit relinqui.

Differentiam inter furnos, in quibus convertitur ferrum in chalybem, \& hos jam memoratos, non effe multam, modo quod applicentur folles, hic vero per aperturas datas admitti ventum, licet non multam ejus copiam. Per foramina introfpici poffe, qui gradus caloris, num diminuendus vel augendus fit: altitudinem hujus furni in refpectu ad alterum ad ${ }_{3}^{\frac{r}{3}}$ partem diminui polfe. Opus per ligna \& flammam poffe peragi. Capfulas etiam ex laminis ferreis componi. Magnitudinem furni proportionandam effe ad quantitatem operis, hinc etiam nullas dimenfiones tradi neceffum effe. Ignem eo diutius fervandum, quo majoris capacitatis fit; fed ne ligni fuperflua copia confumatur, nimium non ampliandum effe.

Quod itratificationem ferri attinet, fufficit ut a pulvere offeo frufta ferrea bene invicem feparentur, preter quod partes ferri craffiores relocentur in loco furni, ubi intenfior calor exiftit. Obfervetur etiam, ut omnis arena abftergatur ferro, ubi enim arena remanet, ibi nec emollefcere ferrum; arenam etiam liquatam fuperficiem ftipare \& iplum ferrum operire, quæ difficulter inde auferri poffit.
Clalisis I. de ferro.
$\mathrm{Mmm}$
Calo- 


\section{ARSEMOLLIENDI FERR UM.}

Calorem nec nimis violentum effe debere, tamen quo craflius ferrum, eo intenfiorem calorem requiri.

Conftructionem furni melius ex ipfa delineatione quam ex defcriprione haurire licet.

\section{Defcriptio Figure. \\ Tabula XXVI.}

Fig. I.) Planim furni.

A.A.A.A.) Sunt quatuor meatus, per quos aer in furnum immittitur. prolongari poffuist fecundum opportunitatem loci.

BB.) Aperture, per quas immittitur lignum.

C. D.) Sunt bine lamelie, que compofure fomul formanit capfulam in medio.

E.F.) Sunt bina lamine, qua una cum faciebus interioribus furni, componunt receptacula vel capfulas ad extremitates. (E.H.F.G.)

E. C. D. F.) Sunt due lamine, que impediunt, ne cooperiantur lannine, inter quas repofite funt. obfervandum ctiam eft, quod in quibusdam locis forriati fint margines aut limbi, qui impediunt ne ad latus ferantur.

F. G.) Lamina exigua, que ficut lamine (D. F, \& F. G. ) fulcit laminam (F) capfuld circa unam extremitatem repofite.

Fig. 2.) Reprafentat unum latus aut faciem furni, ubi apertura eft, per quam repletur capfula in medio.

A) Eft apertura, per quam intrat ventus.

BB.) Porte, per quas immitritur lignum.

C. D. EE.) Apertura per quam immittitur lignum, Ev repletur capfula maa gna media.

FF.) Sunt bine lamelle exigus, que impediunt, ne loco emoverantur capfuld, quum incurvantur; ille non intromittuntur ufque ad fundum laminarummajorum.

$\mathrm{G)}$ Indigitat opus, quim repleta fit capfula.

IH. IH. IH.) Sunt ligamenta circa furnum, que ad libitum augeri poffunt; rupta circa $(\mathrm{H})$. Quodlibet cingulum in eodem loco fpeciem annuli refert.

KK.) Eft bacillum verticale, cujus extremitates funt furno affixe, $E^{2}$ Jupres quas ligamina funt connexa.

FF) Eft folum, quod elevatius eft Jupra planum ipfiusmet furni. Apertura (A) illo etiam poteft operiri.

Fig. 3.) Reprefentat alterum latus furni.

A) Eft adbuc una apertura, per quam in furnum admitritur ventus.

FF.) Lamine exigue, quibus fuffulciuntur lamine majores.

G) Altera lamina parba.

I.K.) Apertura unius capfule extreme. Pars cujusbis cinguli, quod capfulam repletam pertranfibit, bic non apparet.

L. M.) Demonfrat omnes partes argillaceas, quibus precluditur apertura capfule, quum repleta fot. Xbi ligamina tranfunt partes dictas.

Fig. 4.) Compofitio onnium partium argillacearum, gum una pars fupra alteram relocata fit, quibus formatur murulus, qui clandi debet Fig. 2. apertura (C.D.E.F.) 


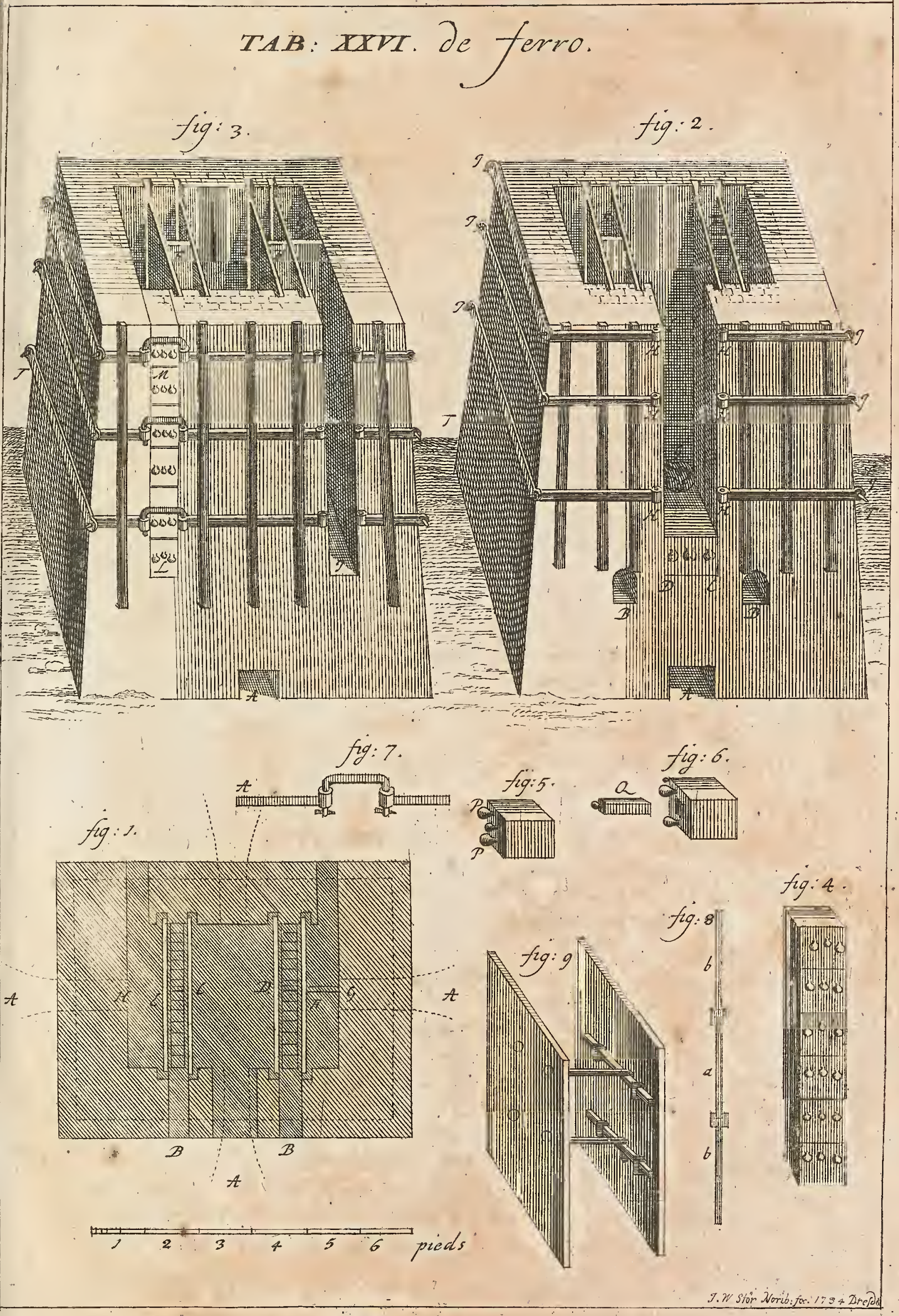




furnus.

Fig. 5.) Eft una pars argillacea (PP.). Sunt piffilla, quorum ope duci poteft

Fig. 6.) Eft eadem pars, fed cui ademptum eft obturaculum (Q.)

Fig. 7.) Reprefentat, quomodo applicentur partes rupte ligaminum fupra aperturas cap Jularum.

Fig. 8.) Eft fectio trium laminarum, quarum una relocata ef fupva alteram. Lamella (a) intrat limbum lamellarum (b b.)

Fig. 9.) Commonftrat, quomodo bine lamins invicem polfint applicari, fcilicet lamine capjule medis.

Cautelec que circa recoctionem \& emollitionem ferri duri, ut E gradus emollitionis qui obfer. vandi fint: pariter modus quo refitui duri. ties, छ ad quem gradum emolliri posfit ferrum, ab eodem auctore.

I conti ferrei in furnum immittantur, explorari poteft effectus ignis \& mixtur: in ferrum ; fed in anteceffum cognofci debet, quales fint mutationes in ferro.

Quum ferrum furno fit exemtum \& frigefactum, ex nuda infpectione judicari poteft, num ad partem vel integre fit emollitum; ferrum enim in arena fufum eft coloris cœrulefcentis: fique adhuc confervet colorem vel fi color ei ademptus fit \& in ferrugineum mutatus, fignum eft, ferrum nondum effe emollitum. Primus modus experiundi ferrum, num durum fit vel molle, eft per limam, raro enim vulneratur a lima ferrum, quod coloris eft cœrulei : fi vero color fit lividus \& bruneus ad coloren fabarum Indicarum Caffe vocatarum, vel adhuc nigriorem vergens, tuto concludi poteft, fuperficiem ejus effe mollitam.

Quum ferrum fuperficietenus coloris fit brunei, limæ cedit, ad minimum juxta fuperficiem, ubi emollitum eft. Si frangatur ferrum nondum integre emollitumut (E.) Fig. XXVIII obfervare licet varietatem. quandam colorum per totam fracturam difperfam; fiferrum fuerit album, dein minus albidum erit: fi grifeum, dein magis bruneum erit \& fere nigrefcens. Ferrum fufum coloris nigricantis in nigredinem majorem variatum apparebit; hæc variatio coloris fe ufque ad centrum frufti ferrei, antequam emollitio quædam in ferro facta fit, extendit; ferrum, quod inftar folii tenue eft, vix emollefcit, antequam omne ferri corpus, qua colorem, transmutatum fit.

Præcipua mutatio circa ferrum emolliendum exiftit in textura ejus; fi ferrum fit in fractura album, jam nulla grana comparere, nec mice nifi agre diftingui \& quafi rarefcere incipiunt : circumcirca fuperficiem animadvertere licet cingulum quoddam granulis conftans: ubicunque ferrum accepit granula, illis in locis emollitum eft. Tab. XXV III Fig. (E.) fenfim extendunt fe granula, \& tandem penetrant ufque ad centrum (FF). 


\section{A R S E M L L I E N I F E R R M.}

Quum pars interior ferri ad centrum ufque granulata fit, ferrum eft emollitum; \& ubicunque granis pollet, limæ cedit. Sed in locis, ubiamolliri incipit, granula funt modo confperla \& invicem feparata, \& fecundum emollitionis gradum propius ad invicem accedunt (Fig. G.) \& fecundum gradum emollitionis color ferri fufi lividior fit; ferrum fracturacandidioris evadit coloris grifei plus quam in ipfo chalybe, inque illo genere, quod non facile fub malleo excudi poffit. Notandum etiam eft, quod in medio granorum fint ftrata granis majulculis \& nigerrimis conftantia. Fig. K.K.L.

Recoctio hæc reddit ferrum coloris lividi; fi vero calor recoetionis adhuc majori tempore continuetur, formatur circa fuperficiem cingulum candidum, coloris magis corulcantis quam in chalybe, verbo, qui accedit ad colorem ferri candidioris. Cingulum hoc etiam compofitum eft ex micis, qux inter fe relinquunt vacuitates, conftatque genuino ferro, eftque malleabile inftar ferri communis.

Si recoetio adhuc magis continuetur, extendit fe amplius hoc cingulum (Fig. K) tota pars inferior clarior magis magisque evadit, \& tandem plane albefcit. Sed adhuc magis obfervanda eft mutatio iplius texturx: eft enim ferri fufi genus, quod in fractura fimillimum eft ferro micis conftanti primi \& fecundi,generis, de quibus actum eft in chalybe; hoc pariter ac illud micas majores exiguioribus mixtas multi nitoris oftendit; fatendum eft; ferri fufi micas adhuc magis corufcare. Datur etiam ferruṇ fufum, quod poft multam coctionem in fractura fimillimum eft ferro granis conftanti ( Fig. M.) fed nitet minus, quam genus aliud ferri fufi, adque illumgradum nitet, ad quem ferrum malleatum in fractura, unde videtur in ftatum eundem cum ferro malleato reductum.

Quum itaque hoc ferrum receperic colorem lividum, \& fractura granis Fig. F. G compofita fit, fique ferrum hoc limx cedat, candefiat \& frigida reftinguatur prout chalybs, exinde lequitur quod duritiem inducat, adeo ut lima nullum in eis morfum poffit edere : fi vero rurfus fiper prunas candefiat, tunc rurfus limæ cedit, non aliter ac chalybs communis: hinc concludi poteft, ferrum hoc fufum reductum effe in fpeciem chalybis communis. Sed ufque chalybis hoc genus non ita durum effe debet, quin deftruenda fit durities, adeo ut non magis per reftinetionem induretur, quod fit per continuationem recoctionis : at vero, quum cingulum grifei coloris granulis conftans candidum, \& micis vel lamellis compoltum evadit, tunc eft ferrum purum; fi in hoc ftatu reftinguatur frigida, ad primam luperficiem cedit limæ, puta, ubi eft ferrum; fed in illo loco, ubi ceflat cingulum, non cedit limx. Quum vero per reftinctionein ufque ad centrum induratum fit, \& dein prunis impolitum dum rubefcat, \& lente refrigeretur, tunc rurfus cedit lime, non aliter ac chalybs nondum frigida reftinctus.

Alias fi ferrum hoc fit admodum craftum, fuperficies tamen ferrea effe poteft ope recoctionis, parsque ejus quæ fequitur, chalybea, \& centrum, fi nondum fit emollitum, reftare in priftino ftatu, feu ferrum effe crudum. Verbo, fi ad certum quoddam punctum emolliatur ferrum, exiftit fpecies 


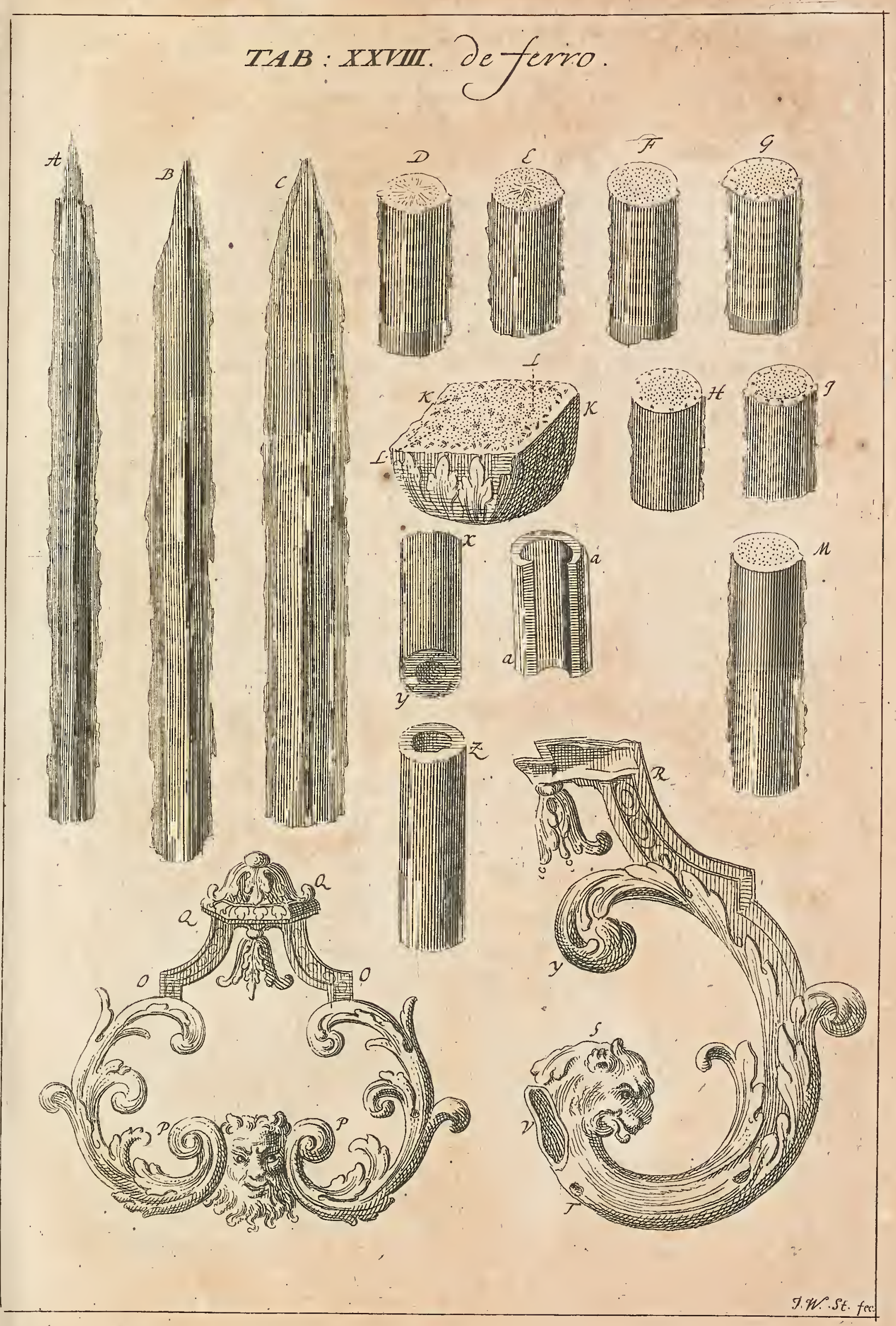



quxdam chalybis; fique ignis adhuc magis continuetur, fit chalybs ferro inveftitus; \& tandem fi adhuc magis, redditur purum ferrum.

Dictum eft, quod fractura granis nigricantibus fit confpería Fig. L. Hæc grana nigricantia monftrare quafi poffunt, unde colores brunei ortum trahunt: ope microfcopii videre licet, nulla grana ibi adeffe, fed modo cavitates majores quam alibi; \& fic cavitatem unam alteri fere contiguam effe, \& inde in ferro fulo colorem bruneum five lividum produci.

Circa prima auctoris experimenta obfervatum eft, quum ferrum quoddam craffufculum \& ponderofum concinne elaboratum ut Fig. QQ. O O. PP. Tab. X X VIII emollire vellet, exemtum furno leve \& multo minoris ponderis acprius prodiiffe; fed cum illud adhuc penitius intueretur, obfervaviffe illud plane excavatum, non abfimile fiphoni vel canalifuperficie nuda obducto, Fig. R. S. T. Tota pars interior vacua erat, confervata tantummodo figura \& fuperficie exteriore, foliolis tantum deperditis, in fquamas fcilicet comminutis : cumque adhuc intimius infpiceret, obfervaviffe foraminula Figuræ $\mathrm{T}$. per quæ fubftantia centralis eliquata effluxiffe videtur; unde etiam leve factum effe. Ferrum effluxum etiam repertum eft circa fundum furni, in forma maffæ inæqualis \& rudis.

Idem experimentum iterandi gratia, cylindrum quendam ferreum folidum \& immiffum receptaculo circumdedit materia qua emolliretur. Quod primum igni leni expofitum eft, ut bene emolliri poffet, quumque primus caloris gradus effectum fuum juxta fuperficiem præftitifet, adauxit ignem ad illum gradum, ut liquefcente ferro medietas cylindri evacuari, \& confequenter cylindrus folidus in canalem quendam cylindriacum converti Fig. $Z$. poffet.

Ufque tamen experimentum hoc non femper fuccedere voluiffe, inquit, cum enim ignem violentum non daret, nifi cum jamdum multa pars emollita effet, exinde folidum remanfffe ferrum; interdum cum citius adaugeret ignem, partem interiorem liquidam factam effluxiffe, crufta nimis tenui remanente : fed ne opificem fallat, docet immittendas effe perticas probatorias, ex quarum fractura exploretur, ad quem gradum emollitum fit ferrum. Facilitari adhuc effluxum medullarem ferri poffe, \& exitum quocunque in loco libet, affignari, modo loca illa fabulo five alia quadam materia, cujus ope emolliri nequeat ferrum, inducantur.

Opera ferri fufi tenuia, quod filicet emollitum eft ufque ad centrum, fi ad colorem cerafi ufque candefiant, poterunt plicari, fi modo leniter tractentur.

Opufcula dicta concinne fabricata ferri ufque ad unum punctum emolliri poffe dicit : fique dein candefiant, tamen fub malleo rumpi, \& fiffuris conferta apparere; per emollefcentiam attrahere fibi naturam chalybis contumacis \& refractarii : verum fi diutius peritet ignitio, chalybem vulgarem inde crematum obtineri.

Se reduxiffe refert ferrum crudum, in illum tenacitatis gradum, ut ignitum poffet tractari, non aliter ac ferrum recoctum \& in contos diductum; cumque emalleatum fit, nullibi apparuiffe fifuram vel rimam ; fed Clasfis 1. de ferro. 


\section{ARS EM O,LLIENDI FERR UM:}

docet in hunc finem continuandam effe diutius recoctionem quam alias, per quam mollitiem laudatam induet.

Hoc adhuc melius fuccedere, fi recoctiones vel calefactiones in capfulis aliquoties reiterentur, inde majorem mollitiem acquiri, quam per recostionem in foco ferrario: partes tenuiores hoc modo emolliri poffe, adque.illum gradum, ut fub malleo poffint plicari. Hujufcemodi calefa ctiones ferro craffiori mollitiem, flexibilitatem \& tenacitatem quandam fuppeditare, præfertim fi genus ferri fit huic operi aptum.

Huc uque actum eft de ferro fracturæ candidæ, fed ferrum coloris grifei, quodque cedit fere limæ, antequam in ignem mittitur, adhuc majorem emollefcentian polliceri videtur ; fed cum jamdum fit coloris brunei, qui prima calefactionis vice adhuc magis augetur, ideo colorem note vilioris ei imprimi dicit. Ferrum hoc in capfulis calefactum cedere quidem optime limis \& emollefcere, fed nunquam illam tenacitatem recipere, quam ferrum candidx fracturæ : ferrum enim grifeum, peracta emollitione, ignitum tub malleo tamen excudi nequire, \& adhuc minus calidum plicari, prout ferrum fracture candidx: Ratio allegatur, quod partes terreftres \& fe vitrificantes non per ignitionem fed per liquefactionem auferri poffint. Ignis calefactorius fi adhuc diutius ufque ad colorem bruneum adque nigricantem, qui ei naturalis eft, continuetur, quod tandem incipiat clarefcere \& candorem quendam recipere, ut ferrum, cujus mentio prius facta; ufque tamen obfervatum, ait, ferrum hujus generis nunquam illum candorem attrahere, quem ferrum fracturæ candidæ.

Unde concludit, unum ferri genus non eundem flexibilitatis gradum cun altero acquirere poffe, quamvis ope calefactionis easdem nubeculas \& varietates colorum acceperit; fed unum palmam præripere alteri : ferrum habuiffe, quod ad illum gradum flexile \& molle evaderê, ad quem neutiquam alia ferri genera. Hinc neceffum effe, ut tentamini fubjiciantur omnia ferri genera, fed ufque aptifimum predicat efie ferrum fibrofum. Vidiffe etiam opufcula ex ferro grifex fracturæ, colorem optimum traxiffe, emollita, ut commode potuiffent poliri, modo in capfula debite continuata fuerit ejus calefactio.

Circa chalybem effe obfervatum, quod ferrum in aciem converfum quoad pondus fuum fit adaucum; at vero pondus ferri emollefcentis ratione exigua diminutum : ponderavife enim ferrum antequam igni emollituro committeretur, emollitione peracta exiguam aliquam differentiam effe animadverlam.

Ope Hammx lignex peragi hoc opus poffe; fed adhuc melins \& promtius, fi loco ligni ufurpentur carbones, in quibus ignis auxilio follium \& venti excitetur; fed cavendum effe, ne inibi ferrum fundatur. Caloris etiam gradus per bacilla probatoria, de quibus fupra actum eft, optiine polfe notari.

Si loco calcis offex ufurpetur creta, argilla aliave materia alcalina, cavendum effe, ne calor nimis violens fit: Normam fore, ut ferrum capfulis inclufum ad colorem cerafi redigatur; fed fequi inde, ignem eo diutius duraturum effe. 
Srepius tamen accidere, ut non omnes operis ferrei partes aqualiter: emolliantur ; præcipue cum inæqualiori craftitie pollentes, locis in furno, ubi major vel minor caloris gradus fit, aptari nequeant: fed huic malo obviam iri poffe, fi in capfula iterum, fecunda vel tertia vice candefiant.

Præftare etiam, in promptu habere diveri generis furnos, adeo ut opera craffiora in furno majori, \& tenuiora in furno minori calefiant.

Quod impenfas attinet, refert auctor, opus five malleum portx fibi non amplius 20 libris feu livres conftitife, quum tamen, if a fabris emeretur, qui auxilio mallei aut limæ opus hoc parant, conftaret 700 livres: \& fic porro.

Obfervandum etiam effe, quod flamma poffi impedire emollefcentiam, \& duritiem quandam inducere ferro jamdum emollito, nifi junoturæ quam optime fint perlutatæ.

Quum audor laminis ferreis uteretur, oblervafe refert, partem vicinam materix offex \& carbonarix emollefcere, fed partem exteriorem hminæ, five qux flammæeffer expolita, induruiffe. Hic altera calefactionis vice fuperficiem laminarum invertifie, adéo ut quæ prius interiora, jam exteriora fpectaret; inde accidife, ut pars interior prius dura emolleferet, \& pars exterior prius emollita indurefceret, quod etiam experimenti gratia, pluries factum eflet: unde fequi, fi flamma ferrum immediate tangat, fecundum thein priorem, durum illud reddi. Et quamvis ferrum purificatum \&malleatum fit, ufque tamen, fi igni nudo exponatur, indurefcere ; ferrum cujuscunque generis cremari, inque fquamas diffpari, \& duritiem, tanquam vitrificatum ellet, accipere.

Cremato ferro, adeo ut inde delabantur fquamx, effe dictas fquamas duras, interdum circa partem inferiorem molles; indigitare videri fquamas, tanquam ferrum non effet emollitum, quum tamen optime mollitum fit. Partem illam crematam firmiter adharefcere corpori reliquo, adeo ut lim: omnimode refitat ; fed fi malleo percutiatur, inde fuperficiem fquamis vel materia ferrea confantem dilabi, \& reftare ferrum, quod limæ optime cedat.

Quum ferrum hoc peracta recoctione fatis diutina, capfulæeximatur, coloris effe coerulefcentis, nitidifimis quafi adamantibus circumfufum: verbo, fi ferri fuperficies colorem bruneum fabis Indicis Caffe fimilem non oftentat, cujus mentio fupra eft facta, fignum effe, qua fuperficiem aduftum \& in fquamas reduetum efle, quæ tamen per continuas mallei percuffiones inde quam optime feparari pollint.

Neceffum etiam effe, ut ferramenta dicta prius emollita, \& e quibus ope limæ duriora fint abrafa, dura iterum reddantur; nifi enim opulcula ferrea dura fint, non admodum polita \& corufcantia reddi poffe, gradum enim politura fecundum gradum duritiei proportionari folere; pariter ac faxa. Nifi enim durities infit, vix etiam confervari polituram, fed cito evanefcere, unde etiam chalybem per exfinctionem in frigida eo duriorem reddendum effe, quo politior defideretur. Quum itaque ferrum ad gradum chalybis fit emollitum, non dubitari porte, quin per reftinctionem in frigida ad libitum dein poffit indurari: at vero fi nimis fit emollitum, 


\section{A R E M OLLIENDI FER R M}

adeo ut in naturam ferri excufi five recocti fere fit converfum, tunc per dictam reftinctionem in frigida vix poffe indurari.

Expertum etiam effe, ferrum ad quemlibet gradum indurari poffe, fi reftinguatur in pyxide, quod Gallice vocatur le trempe en paquet; chalybem nullam meliorem duritiem, quam per hujus generis exftinctionem recipere pofle, hinc etiam perfectiffme fic poliri. Minus etiam temporis requiri, modo dicto reftinguendi ferrum fufum quam ferrum malleatum.

Dictum prius effe, ferrum in materiis, quæ convertere poflint illud in aciem, calefaciendum effe, fi exftinguendum fit in pyxide; fufficere, ut inibi brevi tempore calefiat, antequam frigida extinguatur. Auctor in igne diutino ferrum émollitum, cui duritiem vellet dare, tenuiffe, ait, circumjectis eisdem materiis, quarum ope ferrum in chalybem folet verti, quum dein eximeretur, priftinam fuam duritiem recuperaffe, \& obfervata fuife loca, quie limæ nullatenus cederent; loca vero alia parumper tantummodo emollita vifa fuife, colorem candidum mutatum etiam fuife in bruneum: cumque adhuc continuaretur calor, omnem duritiem prius deperditam refitutam vidiffe: at vero fi ignis non violentus nec diutinus fit, duritiem inde non augeri; acquiri etian tenacitatem.

Quum itaque calefactio dicta emollefcentiam quandam ferro fufo inducat, fequi, multo majorem effeetum \& ufum in ferrum purificatum \& excufum preftituram effe, modo non admodum craflum fit. Sed fi ferrum malleatum recoquendum vel in capfula emolliendum fit, ignem nimium non effe debere, quum ei noxæ efle poflit.

Tale ferrum certo temporis fpatio in igne detentum \& dein exemtum tam molle apparuifle, ac charta glutine denfata, ita enim plicari \& torqueri potuife. Fila etian ferrea hoc modo mollita ad omnes partes \& quoties liberet, contorqueri potuiffe, tanquam ex plumbo confecta. At vero cum fila ferrea diutiori calore effent excercita, tam fragilia inde evafiffe, ut ad contactum frangerentur. Ferrum per longiorem operationem nimia fulphuris \& falis copia fpoliari, inque eundem ftatum redigi, ac fi igne nimio adureretur : ferrum indurefcere ex nimia inhærente falis \& fulphuris copia ; fi vero perexigua fit, in fquamas, foliola \& micas abire ; non aliter quam argilla, quæ $f_{1}$ nimia aqua humeetetur, diffolvi, fi vero exigua nimis, friabilem reddi: parem rationem effe cum fulphure in dicto metallo. Notandum etiam effe, ferrum malleatum fecundum diverlam qualitatem majori vel minori igni poffe refiftere; fed una confiderandam venire ejus craflitiem: quam optime fuccedere cum ferro tenui.

\section{Defcriptio Figurarum.}

\section{Tabula XX VIII.}

A. B. C.) Sunt bacilla ferri fu/ dinerfe craffitiei, probationi infervientia. unius extremitas in aculeum definit, quod ideo factum, ut conti crasfiufculi loco tenuiorum etiam commode posfint infervire.

D). Fractura unius conti, nondum emolliti.

E) Fractu- 
E) Fraetura conti, qui emolliri incipit; circa limbos granis fubtilioribuspol let; reliquis in locis incipit etiam granis conjpergi, fed nulla adbuc granulatio eft in medio.

F) Fractura conti adbuc magis emolliti, ubique funt grana E5 majori copia quam in pracedenti.

G) Fractura conti ferrei, qui adbuc magis eft emollitus: circumdatus eft cingulo candido, quod naturam babet ferri purificati aut malleati: pars refiduct repleta eft granis magis bruneis $E$ crasfiufculis, quam funt illa in Figura Juperiore.

H) Fractura conti ferrei, qui adbuc magis eft mollitus, quodque inibi granulatum eft, conftat granis majufiulis $\& 5$ nigrioribus quam in Figura (G).

I) Eft fractura conti ferrei, qui adbuc magis eft emolitus, quique incipit candorem fuum recipers, ubi grana etiam non funt tam nigra ut in priore.

KK. LL.) Eft fractura frufti ferri fufa, quod effectibe circumdatum eft cingulo crasfiori, cuijus textura $E$ color fimilis eft illi, que in ferro malleato bifitur, in medio eft granulatum fecundum indolem cbalybis.

LL) Signiffcant loca obfcuriora per lineas punctatas, que fimplici appectu fimilia funt granis, fed que ad vitrum microfcopii reprefentant modo vacuitates.

M) Fractura conti, qui recepit granum candidum, acceditque ad illud ferri genus, quod vocatur ferrum granulatum.

QQ. OO. PP.) Eft malleus porte, qui cavus factus fuit, preter loca (QQ), ubi crasfior eft, propter ignem minus violentum, cum funderetur.

R. S. T.) Eft pars iffus mallei ex reliquo ejus corpore feparata, fcilicet ut videri pos fit, ad quem gradum excavatus fit. Aperturs (R. V.) ideam difinctio. rem dicte excabationis fiftic.

X.Y.) Eft fruftum ferri fuf fonile illi, circa quod experimentum eft inflitutum, quale circa malloum procedentem. (Y) eft locus, per quem facillime ema. mabit ferrum fufum, $f$ fabulo aut alia quadam materis emollitionem impediente opertus fit. Z) Eft cylindrus in cylindrum excavatum mutatus. (a a). Canalis excavatus fecundum totam longitudinem apertus.

\section{De diverfigeneris opuculis ex ferro fufo factis, deque cautelis, quomodo fundi E⿱ recoqui ferrum debeat.}

Pera craffiora foliditate fufficiente gaudent; unde non opus eft, ut per modum emollitionis traditum tenacitatem quandam acquirant; fatis elt, ut fuperficietenus emollefcant, adeo ut limis cedant. Si vero perforanda funt, tunc amplius adhuc funt calefacienda, fed foramina melius parantur in ipfa arena, in quam funditur: fi vero ductus fpirales vel cochleares habebit, fufficit, fi modo pars fuperficialis fit emollita.

Si folidum quoddam corpus fundendum fit \& fatis craflum, tunc in arena vel loculo ad hoc opus parato ferrum alicujus craffitiei, vel portio conti cujusdam reponi poteft, vel etiam filum ferreum craffitiei I digiti. Ferrum enim fufum optime uniri poteft cum ferro malleato ibi repolito, adeo ut in unum corpus coalefant. Operatores cupri hanc artem etiam 
bene callent, adeo ut ferrum in medio cupri fit, alias fragile nimis evadit cuprum.

Quod tormenta bellica attinet, mcliora funt \& præftantiffima quæ ex ferro malleato formari poffunt; hoc a multis tentatum fuit, fed labore femper irrito, ferrum enim malleatum optime refifit vi percuffionis five ex globo five ex pulvere pyrio oriundx. Tormenta quæ conftant ferro malleato, etiam leviora funt, \& tamen reliquis firmiora \& validiora ; refiftunt enim, ut dictum eft, melius viribus pulveris pyrii, pariter etiam globo ferrco, qui excutitur \& juxta parietes violenter effertur. Hujus generis tormenta, quoniam leviora \& ufque validiffima, in navibus multum ufum præftare poffent. In prælio navali poterunt tormenta graviora verfus unam navis partem gliffare \& pondere ipfam evertere : preterea etiam nec facile rumpuntur, quod alias fit frpe cum periculo \& internecione adftantium : obtineri itaque hic finis poteft, fi tormentum ex ferro crudo conftans dein emolliatur : tormenta illa diu fatis in materia prædieta, quæ emollitionem caufatur, calefacienda funt. Quibusdam in locis, tormenta ftatim ut arenx funt exemta, calefieri folent, \& carbonibus vivis immediate circumdari; ufque tamen hoc non multum effectum præftat. Tuto igne vehementiori \& diuturniori calefieri poffunt, non enim fundi, nec in fquamas folvi, ut ferrum tenue. Furnus etiam conftrui poteft fimilis furno prius delineato, inque medio ejus relocari tormentum, modo furnus debitæ profunditatis fit : nec opus eft, ut receptacula plene claufa \& perlutata fint, folutio enim ferri in fquamas.non metuenda eft. Dominus de Villons formationem tormentorum ex ferro malleato diu fed fruftra tentavit, eo tandem pervenit, ut interiora illorum ferro malleato, exteriora vero metallo aut cupro repleret.

Experimentum non modo cum calce offium factum eft, fed etiam cum argilla, calce, \& gypfo calcinato : calx meliorem effectum præfticit quam argilla; gypfum vero minimum, potuit cnim excavare ferrum : led ut actionem gypfi temperaret, circumdedit ferrum fuum ftrato tenuiori gypfeo, \& leliquam partem capfulxe offe calcinato adimplevit; exinde fquamis non ad multam craffitiem circumdabatur ferrum; crafities, quam occuparunt fquamæ in ferro, proportionata erat ad craffitiem ftrati, quod confabat gypfo, etiam ad diuturnitatem temporis aut ignis; hinc fi per fquamas diminuendum fcrrum fit, ignis xqualifimus efle debet.

Quoniam mentio facta eft gypfi, en experimentum. Clariff. auctor ferrum pulvere gypleo fe circumdediffe, ait, \& exemta capfula brunee rubente, vidifle flammulas plurifariam ex pulvere hoc propullulantes, colorem fulphuris communis vibrantes. Ipfum ferrum, gypfo circumdatum, odoien fulphureum teterrimum fparfife. Obfervatum etiam effe, ferrum candidum in fquamas magis quam ferrum fracturæ grifex effe redactum, \& ferrum malleatum citius quam ferrum fufum.

Ultimo fiftit delineationes plurium decoramentorum ferro fufo conftantium, \& arte prædicta nova emollitorum, ut malleos portarum folis opereque decoro infignitos, cum anfis cleganter quafi cælatis, \& plura alia.

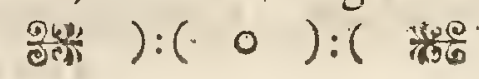




\section{PARAGRAPHUS XXVI.}

\section{Tentamina E experimenta miscellanea circa emollitiones, liquationes, ferruminatio- nes $E^{\circ}$ c. ferri.}

\section{Circa emollitiones $\mathscr{E}^{2}$ exfinctiones ferri.}

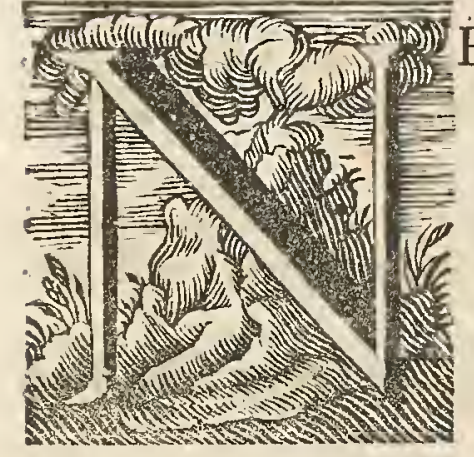

E quid defit, velim etiam aliorum tentamina vel effata de emollitionum \& exftinctionum ferri modis adjicere; adducendo modo illa, quæ a famigeratiori quodam auctore ejusque laboratorio prodierant: quamvis etiam illa nugarum \& fxcis alchymifticx plena effe, oculis non femiapertis, videre liceat; fed ne tamen illa ficco pede tranfire videar, fumnis modo labris, ut ajunt, tangere velim; fed cave tamen, officiant letis ne frugibus berbs. Turba illa vafta farragine figmentorum incoctisque dapibus volumina fua complent; pro luce jactant umbras, pro corpore larvas, pro factis fcenas; \& ut Virgilius canit:

\section{Fermento atque acidis imitantur vitea forbis.}

Sed quia mihi nondum vacavit tempus, nec copia fuit, omnia per novum ignem \& laborem fub examen mittere, velim tamen in forum proferre aliqua, qux a diverfis jactantur; fed iple tibi profpicias, ne fidem nifi vifis \& exploratis habeas: nec transferre omnia illa huc potui, qux publicæ lucis facta funt; præter quod indies \& quotannis plura e focis laborantium excludantur : hinc cuique integrum eft, ad quod etiam quemlibet exhortor, ut foliis chartæ nitidæintertextis, infcribat quicquid defideretur, $\&$ inferendo quod omiffum eft, telam hic inceptam perficiat.

Venditant aliqui ferrum emollefcere \& inftar plumbi mite \& flexile evadere, pariter etiam chalybem, modo ab igne \& in exftinctione \& frigefactione jufte temperetur : nobiliffimi Boylei verba funt in tractatione de firmitate: chalybis fruftum quamvis fufficienter fuerit candefactum, fi candens illud immerferis aqux limpidx, reddere illud potes non folum valde durum, fed etiam valde fragile; cum fi refrigefcere illud in aere fiveris, \& minus durum futurum fit \& magis tenax, atque fi idem aqua frigida extinetum, iterum candefacias, donec colore coruleo faturetur, comparare molle \& admodum flexibile fiet; neque hoc ex ulla falinæ partis per ignem jactura; cum fi emollitus hic chalybs rurfus candefiat \& fubito, five aqua five alia ratione refrigeretur, \& duritiem \& fragilitatem denuo acquiret. dos; ut

Alias Dominus Beccherus multos venditavit ferrum emolliendi mo-

I. Victriolum \& nitrum ana per alembicum deftillare jubet, \& inibi fruftulum ferri mifcere, quod dein in fimo equino per fpatium I 5 dierum jaceat, inde putat ferrum emollefeere, ut inftar plumbi fcindi polfit.

2. Pariter 

Ringuatur.

2. Pariter fi candefactus chalybs in aqua Amilzar, ut vocatur, ex3. Si

3. Si recipiatur metallum quodcunque, \& in fanguine bovino aut vaccino exftinguatur, exinde inftar plumbi dicit emollefcere.

4. Si auripigmentum, calx viva, ramenta chalybea \& ferrum in igne una per diem teneantur, inde inftar plumbi emollefcere ferrum dicit.

5. Ferrum etiam inftar cer emollefcere perhibet, fi chalybs per 3 dies in calce viva, gummi, fanguine \& excrementis hirci recondatur. fit infufum.

6. Pariter 11 chalybs in oleo exftinguatur, quod in plumbum fepties

7. Chalybem etiam emollefcere, adeo ut inftar plumbi fcindi poffit, fi primum candefiat, ut fere liquefcat \& dein fuperinfternatur pulvis her bæ fternutatorix.

8. Pariter etian emollefcere dicit chalybem in excrementis bovinis cum fucco oleris mixtis exftinctum: fic etiam in fuccis herbarum varii generis, inque aqua vel fucco fabarum. exfinguatur.

9. Pariter duritien a chalybe expelli, fi 15 vicibus in aqua falis alcali

Alii adhuc plura figmenta adjiciunt, fvadentque ut ferrum in argilla, calce \& fimo vaccx inclufum fuper flammam ligni teneatur, \& dein fponte fua frigefiat.

Ut fundatur plumbum vel folum cum Mercurio in tigillo una cum oleo, quod fepties repetatur, \& inibi fepe exftinguatur ferrum, exinde mollifimum fieri ajunt.

In mixtuira ex fimo vacce, calce, argilla \& fanguine bovino per 3 ho: ras candefiat ferrum.

$\nabla e l$, in mixtura calcis, ceræ \& argillx.

$V e l$, in mixtura calcis \& faponis Venetiani.

$V e l$, in fale Armeniaco, fale communi \& tartaro ana coquatur ferrum infufo infuper aceto vini, mixtura hac ferrum circumtegatur, lente dein ficcetur, inque calore prunarum 5 horis candefiat.

$V_{e l}$, if patio herario in fale Armeniaco \& tartaro pulverifato ferrum coquatur.

Vel, etiam $f$ in aqua aut folutione aluminis exftinguatur.

$V e l, f 1$ fexies exftinguatur ferrum in aqua vel vino frigido, in qua plumbum fulum extinctum fit.

$V e l$, fi ferrum candens in pulverem calceorum crematorum mittatur.

$V e l$, fi fpatio 14 dierum in lixivio facto ex cineribus \& calce viva relinquatur chalybs.

Alius vero fuadet, ut tartarus \& fal commune in tigillo quodam fimul candefiant; dein fulphur, fal Armeniacum ana, drachma Mercurii fublimati in aqua puteali vel aceto temperetur \& fuper marmor pulveriletur, hifque ferrum vel chalybs oblinatur, \& linteo involutum candefiat, poltea calce viva, \& demum arena clara teratur.

Jam quia in medium allata funt quorundam effata de emollefcentia ferri per exltinctiones in liquidis \& mixturis quibusdam factas; jam fub- 
nectere velim tentamina Clariff. Domini Reaumur circa exflinctionis ferri aut chalybis in variis generis liquoribus inftituta, ex quibus veritas dictorum conftare poterit: verba ejus funt, quæ fequuntur.

Omnis ars in eo confiftit, ut chalybs ad rubedinem candefactus in frigida exftinguatur, unde admodum durefcit; at vero fi fuper prunas fuas aut in libero aere refrigefcat, mollefcit.

Chalybs per exftinctionem in aqua adaugetur qua volumen aut maffam, ita ut Dominus Perrault obfervaverit filum exftinetum frigida idem foramen non potuiffe tranfire. Dominus Reaumur femper etiam invenit volumen auctum in chalybe exftincto, adeo ut diameter corporis chalybei ad certum gradum calefacti \& dein exflincti ad diametrum voluminis non exfincti fuerit ut i 45 ad I 44 circiter, \& confequenter volumen chalybis exftincti ad volumen chalybis non exftincti ad minimum ut 49 ad 48 , nam per' exftinctionem acquirit ad minimum $48 \mathrm{vam}$ partem voluminis fui: fed de his videas Claffem III.

Quod vero differentiam ponderis attinet, chalybs non exfinctus ponderis exacte I unciæ eft, calefactus ad rubedinem cerafi $\&$ frigida exftinctus $\frac{x}{2}$ granum perdit, quod fere nullius momenti eft. in aere.

Chalybs in vacuo exftinctus æque mollis remanet, ac fi exftinctus fit

Granum chalybis non exftincti eft congeries infinitorum granulorum; fed hrec etiam ex aliis particulis etiam compofita effe videntur.

Filum chalybis longiufculum per foramen quoddam effe ductum; refert, portione hujus fili calefacta, fcilicet ad partem 3 digitorum, fecundum delineationem, quæ etiam exftingueretur, notatum fuiffe femper locum, ubi maxime calefactum fit filum; filum hoc verticaliter pofitum, \& ope ponderis appenfi tenfum dum confringeretur, expertum effe, illud femper difruptum iri in illo loco, ubi calidiffimum exfingueretur, quia ibi durius. Ne filum, fi alicubi effet incurvatum, per tenfionem in lineam rectam adhuc facilius rumperetur, paravife machinam cum lamina quadam in medio, cui impofitx prunx partem fili fuperiorem calefacerent, notatum iterum effe, in ipfo loco exftinctionis difruptum effe.

Grana chalybea in frigida exfincta non tam pulchra funt, antequam fub malleo excufus eft chalybs, quam dein cum ictus mallei crebros fit paffus.

Chalybs facilius calefcit quam ferrum, \& pariter citius refrigeratur, inde etiam fequitur, quod idem gradus caloris plus augeat volumen chalybis quam ferri : autor contum ferreum ut \& chalybeum, utrumque ejusdem longitudinis fcilicet 12 digitorum, \& quidem eodem caloris gra$\mathrm{du}$, adque eundem colorem, quantum oculis luftrare poffet, candefecit; chalybs in eodem gradu caloris longitudine 3 linearum augebatur, fed ferrum modo 2 linearum. Longitudo femper major facta eft in chalybe quam in ferro, quocunque caloris gradu utrumque candefieret, \& chalybs plerumque fuperabat ferri longitudinem $\frac{x}{3}$ partis augmento. Ferrum etiam frigefactum ad priftinam fere longitudinem redibat, non vero chalybs. vide Claft. III.

Clatiss I. de ferro.

Ppp

Quum 
Quum chalybs \& ferrum aquæ immergeretur, calor inibi per 1patium temporis inerat; fique fruftum craffum effet, diu fatis in aqua apparebat rubrum.

Regula eft: . ex duobus generibus chalybis, qux ratione fubtilitatis differant, illud quod fubtilius eft, majorem caloris gradum recipere, fi iden utrique gradus detur.

Chalybs in calefactione varios coloris gradus in fe recipere folet; $\mathrm{co-}$ lor incipit a rubedine, qui eft primus candefcentix gradus: primum enim inducitur color bruneo-rubefcens; dein rubedo in clariorem \& vivaciorem tranfiens, quod operariis vocatur rubrum cerafi : fi augeatur adhuc magis calor, rubedo hæc incipit evanefcere, vel potius in mifcelam flavedinis abire, \& fic debilitari; cumque ad fummum perductus fit calor, exiftit albedo flavefcens. Ex his coloribus de ignitione chalybis aut ferri fui judicant opifices, quum exftinguendus fit.

Norma generalis eft, quo calidior reddatur chalybs, grana ejus eo majora \& albentiora evadere; \& contra quo minus calefiat ante exftinctionem, eo fubtiliora \& grifei \& liventioris coloris : at verofi intenfus fit calor, nec procul a liquatione, grana nec tam albefcere, nec oculis tam grandibus micare, ac fi minus calefactus exfinguatur.

Altera regula eft, chalybem co duriorem fifti, quo calidior exftinguatur; refert tamen fxpenumero accidiffe, ut chalybs multx fubtilitatis durior factus fit, quum ad albedinem vel fufronis gradum calidus exttingueretur, quam fi ad colorem cerafi. Ratio allegatur, quod ultimus gradus ignis hoc genus chalybis debilitet; quodque deftrui plane poffit, \& in ferrum fere reduci : hinc regulam hanc ufque generaliter veram efle.

Tertia, quod chalybs fubtilior ope calefactionis \& exftinctionis majorem duritiem accipiat, quam chalybs not:e craffioris, fi nimirum idem gradus caloris utrique detur. Hinc quo fubtilior eft chalybs, eo minor calor requiritur.

Acciderat, quum chalybem crebro in furnum mitteret \& materia vulgari circumdaret, adeo ut nimium fulphuris imbibiffet, quumque extremitas una hujus chalybis fub malleo extenfi \& ad colorem cerafi calefacti exftingueretur, ut exinde chalybs hic in portiunculas \& particulas abierit \& dilapfus fit; etiam alia fegmenta integra ab aqua extracta \& leviter malleo percuffa, in grana inftar lapidum diffilierint.

Quarta, chalybem non admodum fubtilem, fed in qua durities acquirenda fit, calide omnino exftinguendum effe, fcilicet cum prius adeptus fit colorem cerafi ad albedinem vergentis.

Regula generalis eft, quod exftinguendus fit chalybs eoc 3 momento, quum attingit gradum caloris debitum: operatores hinc chalybem fixpius igni exemtum folent perluftrare, num gradum caloris \& coloris debitum adeptus fit: dein fatis calefaetum eximunt igni, dumque ad debitum calorem coloremque redierit, frigefaciunt, quod tamen vitium efle putat; hinc juxta focum aqua in promptu effe debet. Per bina frufta chalybea frepius hoc expertus eft, calorem debitum, puta ad colorem cerafi uni impertiendo \& eodem momento exftinguendo, quum adhuc elevatiorem \& 
majorem alteri daret, fed extra ignem, dum ad eundem calorem rediret, tenuit; dein in fracta utriusque parte oblervavit, grana in priori fuiffe fubtiliora, æqualiora \& melius relocata quam in altero.

Quidam opifices chalybem fuum ultra gradum debitum, antequam exftinguatur, candefaciunt, \& candefactum fub malleo tamdiu verfant tenduntque, dum gradum caloris colorisque juftum defideratumque recipiat, quo momento frigida illum exfinguunt, fed grana non tamen ufque illius pulchritudinis, ac fi debito tempore ftatim exftingueretur, apparent.

Quo frigidior eft aqua, eo durior \& fragilior evadit chalybsinibi exftinctus, \& confequenter grana craffiufcula accipit : hinc, fi tempeftas frigida fit, durior fit chalybs, quam fi calida; quidam hujus eventus gratia $a b$ experientia edoeti minorem caloris gradum chalybi fuo dant tempore xftivo quam hyberno. Auctor chalybem ad colorem cerafi redactum, in aqua ebulliente exftinxit, unde non ita durus evafit, ut lima refifteret, nec tamen fragilis factus, quin fub malleo planus reddi poflet. Chalybem dein adhuc majori caloris gradu candefactum, in aqua calida ebulliente exftinxit, inde factus eft durus, non aliter ac $\mathbb{f i}$ exftinctus effet in frigida, quum fcilicet adeptus effet colorem cerafi.

Quidam etiam exftinxiffe ajunt chalybem in plumbo frigido, hoc eft, chalybem candefactum immifife in maffam plumbi frigidam; maffam in loco illo parum liquefcere compertum eft, fed extremitatem plumbo immerfam five exitinctam xque duram ac in frigida exftincta foret, evafiffe.

Chalybs in ftanno exftinctus ejusdem qualitatis fere exivit ac e plumbo; differentia erat, quod majori vi in tannum quam in plumbum intruderetur, quia ftannum non tam facile liquelcit.

Chalybs exftinctus in bismutbo ut \& in regulo antimonii eandem duritiem contrahere videbatur, ac fi in aqua.

Chalybs etiam exftinctus eft in Mercurio: fed Mercurius ipfa aqua calidior factus eft. Paravit illum in finem binas capfulas, quarum unam replevit aqua, alteram Mercurio, \& in utraque filum chalybeum exfinxit; aqua cum adhuc vix tepida effet, Mercurius tam incalelcebat, ut digitus vix tactum fufferret. Quum exftinguitur chalybs in Mercurio, nullus omnino fibilus auditur, at vero multus in aqua, ubi etiam ebullitionis fpecies eft. Chalybs in Mercurio exftinctus granis majufculis apparet, quam. chalybs exftinetus in aqua: hinc in Mercurio non exftinguendus eft chalybs tam calidus ut in aqua, nam Mercurius exfinguit chalybem.

Experimenta etiam plura exftinctionis chalybis in aqua falibus varii generis impragnata fecit: capfulas æquales paravit, unam aqua communi frigida adimplendo; alteram aqua fale communi ad faturitatem imprægnando; tertiam fale vitri; quartamfale Armeniaco; quintam falpetra; fextam alumine: feptimam victriolo; \& femper comparationis gratia duo fila eodem gradu ignis calefacta \& codem momento igni exemta aqux tam fale quodam imprægnata, quan aquæ dulci immifit, nullum tamen obfervavit in duritie difcrimen, quin limæ æqualiter refifterent. Chalybs ad diverfos gradus in plumbo calefactus eft $\&$ in aqua exftinctus, cumque in aqua debitam duritiem non fufcepiffet, animadverfum eft, quod in aqua 
fale quodam faturata nec fufciperet; ex quibus experimentis tanquam teftimoniis indubiis, nulla fere pes chalybem in folutione quadam lalis melius quam in ipfamet aqua relicta eft.

Chalybs calidiffimus factus, \& quidem ultra colorem cerafi, fi peraala exftinctione fuperficies ejus appareat alba \& nitida, nec f́coriis quafi obfita \& obfcura, vocatur Gallice l'acier decoubert; at vero fi chalybs minus calefactus \& exftinctus prodeat albidus, dicitur nudari vel aperiri chalybs: chalybs ergo fi exftinguatur in folutione quadan falis, melius quam in aqua communi fe nudare \& aperire folet, qui effectus e falibus provenit; fal enim materias fcoriaceas \& recrementa fuperficiei chalybeæ alias inhæ* rentia diffipat \& diffolvit.

Chalybs in aceto vini exftinctus fe nudat quam optime; majorem duritiem ut \& fragilitatem obtinere quam in aqua communi videtur.

Chalybs exitinctus in rapis, ut \& in fucco raparum, non magis quam in aceto vini videtur induruiffe, quod tamen a multis ut arcanum quoddam venditatur.

Chalybs quamvis paulifper \& vix ad rubedinem hoc eft ad rubedinem obfcuram calefactus \& dein in aqua forti exftinctus, ufque tamen durus evadit, non aliter ac in aqua circa rubrum cerafi exftinctus. Si in priori gradu immergatur aqux, cedere videtur limx, non vero fi talis immergatur aque forti.

Chalybs exftinctus in fpiritu falis, nullum talem effectum prodit, qualem cum exftinguitur in aqua forti.

Oleofa vero inflammabilia funt, \& multum gradưm caloris recipiunt, antequam inibi chalybs plene exftingui poffit, ut oleum lini, olivarum; pariter in febo, fpiritu vini, firitu terebinthina, refrna. Sed opifices ut neceffariam etiam interdum volunt duritiem quandam amollitam, ut in quibusdam inftrumentorum fpeciebus, hinc acus magneticas ad flammam candelæ candefaciunt, \& febo, ut duritien defideratam acquirant, immergunt.

Chalybs exftinctus febo, butyro, cera, oleo, refina, fpiritu vini, fapone, non tantum indurefcit ac in aqua frigida : fi exftinguatur in fpiritu vini circa colorem cerafi, non refiftit limæ, fed eft fimilis chalybi exftincto in aqua ebulliente; at vero chalybs exftinctus in fpiritu vini ad gradum caloris adhuc majorem, duritiem eandem cum chalybe exftincto in aqua accipit.

Alius etiam modus eft exftinguendi chalybem opificibus ufitatum, icilicet qui vocatur Trempe en paquet; non permittunt ut candefiat chalybs in igne aperto \& inter prunas \&c. fed chalybem fuum pyxidi includunt, perlutatis bene juncturis, adeo ut nullibi pateant aeri introitus : pyxis argillacea effe debet; chalybs intus inclufus certis quibusdam materiis circumdatur, \& inibi cum pyxide fpatio unius vel plurium horarum calefit, \& eo iplo momento quum eximitur, in aquam frigidam projicitur. Materiæ, quibus chalybs inclufus circumdatur, fuligine vel carbone conftare folent; fed quilibet opifex fuam methodum, fuamque mixturam, velutarcanum cuftodit. Optimus hic eft modus; alias durities quædam chalybi 
quidem in aperto igne acquiri poteft, fed fimul fragilis admodum fit \& granis grandiufculis conftans. Maximam fic duritiem acquirit \& una corpus fuum flexibile \& fubtilitatem granorum confervat; unde hic modus reliquis omnino anteferendus eft.

Per hunc modum, non tantum duritiem chalybi impertiri folent, fed etiam ferro, quod æque durum evadit ac chalybs; hoc fieri folet cum limis.

Obfervandum eft, quod induratio in pyxide nusquam peragatur, nifi paratum prius confectumque utenfile, illud tunc pyxidi inditur \& exftinguitur, adeo ut mallei ictibus non ulterius percuti debeat.

Circa hunc exftinctionis modum regulx fequentes obfervandx funt: x. Quod illæ materix optime fint, quarum ope chalybs bene indurefcit, \&

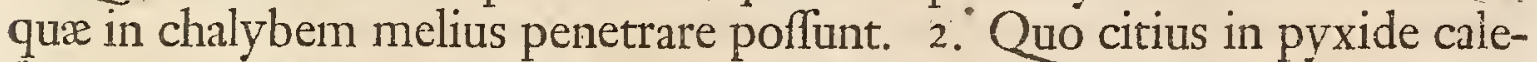
fcere poffit, \& quo minori igne, eo melius; optimum eft, fi caloris gradus modo fit ad rubedinem obfcuram.

Ferrum pyxidi inclufum, materiis circumjectis in bonum chalybem convertitur, optima materia eft $\mathrm{x}$. Fuligo \& reliquis anteponenda. 2 . Tentatum eft cum corio calceorum vetufto \& in carbonem ufto, quod nec inutile deprehenfum eft, nee tamen fuliginem vifum fuperare. 3. Fuligo in paftam quandam fubacta cum urina, optima eft; \& a maxima parte artificum ufitata ; urina vetus \& craffa eligitur. 4. Corium calceorum vetuftorum \& in carbonum fpeciem combuftorum mixtum cum urina putri $\&$ vetere in paftx fpeciem, non meliorem effectum videtur edere, quam fuligo cum urina commixta. 5. Flores fulphuris cum 2 partibus fuliginis mixti, ferrum non durum potuerunt reddere. 6 . Sal commune pulverifatum cum fuligine mixtum durum reddit ferrum intra tempus xquale ac urina cum fuligine, \& fere eundem duritiei gradum imprinit. 7 . Tentatum etiam eft cum fale communi mixto cum pafta ex urina \& fuligine facta. Etiam loco falis communis acceptum eft fal armoniacum pulverifatum cum eadem pafta; pariter fal vitri; ut \& cineres clavellati. Compertum eft, quod ferrum maximam duritiem acceperit a mixtura dicta faEa cum fale Armeniaco; minus cum fále marino ; fed reliqua falia nullum effectum dare videntur. 8. Loco falium prædictorum miffefunt fæeces torrefactx; in alio tentamine victriolum; fed ufque præftabant mixturx cum fale communi \& fale ammoniaco paratx; fal ammoniacumalias optimum eft compertum. 9. Fimus columbarum combuftus optimum effectum dat \& quidem æequalem cum fuligine mixta cum dimidia parte falis communis. Ex his deduci poteft, quod etiam experientia comprobat, optimum effe, fi fimus columbarum combuftus cumque urina humeetatus cum fale ammoniaco vel fale marino mifceatur, inde brevi tempore indurefcit chalybs. Io. Si loco fuliginis carbones foffiles in pulverem. comminuti adhibeantur, qui pulvis cum fale communi commifcebitur, indurefcit admodum ferrum; fperatque auctor majorem inde effectum, quam. ex fuligine oriundum.

Obfervandxe etiam funt colorum varietates in chalybe pyxidi exemto, \& igni carbonum impofito, quibus ignis non multum inelt, fed qui Clafis I. de ferro, 
lente calefaciunt; fit chalybs albicans tanquam politus; his datis varietates jucundx obfervantur in fuperficie chalybis. . I. Albedo chalybis incipit magis albefcere. 2. Nubeculam debiliorem flavefcentem mox accipit. 3. Increlcit flavefcentia magis \& magis, ufque dum fiat coloris aurei. 4. Quum chalybs adhuc magis incalefcit, difparet color aureus, \& mifcela ejus cum purpura exit, dum purpura totam fuperficiem invadit. 5. Purpura nube quadam le obvelat, \& tandem in violaceum colorem tranfic. 6. Violaceus color transmutari videtur in cceruleum altiorem. 7. Diffipatur paullatim coruleum \& quafi clarefcit. 8. Ultimus color, qui oculo detegi poteft, eft color aqueus, eftque ille etiam ultimus gradus corulei. Si xqualiter calefactus fit chalybs, xqualiter etiam per totam fuperficiem difpergitur hic color, fed fi calefactio fit inæqualis, inæqualitas colorum per fuperficiem chalybeam difperfa etiam apparet.

Si chalybs bene politus tit, apparent hi colores vividifimi \& pulcherrimi; fique calor non amplius augetur, in chalybe hic color fixus remaner, apparetque tanquam beneficio artis ei inditus.

Color ruber folus ad ipfum centrum corporis chalybei penetrat; reliqui vero, ut purpurei, violacei, cœrtlei fuperficiem modo ejus tenent: fi chalybs hic fubito coloratus lente frigefcat, confervatur color tanquam impreflus, fed ope lima ftatim auferri poteft.

Ferro etiam hujuicemodi colores induci poffunt, fed colores non ita corufci ac radiantes, ut in chalybe.

Chalybs hoc modo coloratus rubiginem minus attrahit, quam chalybs albicans, hoc colore non præditus. Maxime confervatur color aqueus, fi inductus fit. Oleum etiam impedit, ne ferrum vel chalybs rubiginem attrahat.

Pariter etiam, quum exftinguitur chalybs in aqua, apparent iidem colores in fuperficie ejus; inque réditu a calore ad frigus coloratur eodem modo vel in aqua vel in aere, unde deduci poteft, colorationem hanc non ex fumo quodam carbonum provenire, fed ab exhalatione particularum interiorum.

Sit chalybs ad illum gradum calefactus, dum granum albicans vel mixtum acceperit \& dein exftinguatur; chalybs hic in binas partes dividatur; una pars calefiat in pyxide ufque ad colorem cceruleum vel aqueum, refrigefactus dein frangatur, \& utraque fractura comparetur; invenietur tunc, quod unum fruftum chalybeum granis fubtilioribus gaudeat, quodque grana pofterioris frufti liventiora fint.

Bini exftinctionis modi funt; unus, quum chalybs exftinguendus integre in aqua relinquatur, ut inibi refrigefat; inde refrigefactus in prunas aufertur \& calefit, prout opus requirit. Alter, quum chalybs immerfus aquæ ftatim eximatur, cumque exemtus fit, permittatur, ut dicti colores in fuperficiem ejus fubeant, adeo ut fponte fua fe refrigeret; quumque ad colorem debitum redit chalybs, iterum in aquam immiflus relinquitur, dum plane fit refrigeratus.

Sit exempli gratia culter vel inftumentum, quod duritiem poftulat, hoc permittunt, ut colorem aureüm recipiat, in hocmonento fatim etiam, 
immergunt aquæ, nec patiuntur, ut color violaceus fubeat. At vero fi defideretur chalybs, quod corpore flexibili gaudeat, permittunt ut colorem cœruleum accipiat, quo accepto illico aquis immergunt. Aliqui vero amant, ut chalybs omnis generis colores tranfeat, nec altera vice immergatur aqux.

Eft etiam terminus, quem fi chalybs in pyxide calefactus tranfcendit, amittit omnem duritiem, quam fibi acquifiverat. Ad terminum hunc pervenit chalybs, fi ad illum gradum in pyxide calefiat, quem habuit, quum frigida exftinguitur. Chalybs enim circa gradum caloris albentem exftinctus omnem fuam duritiem amittit, fi iterum ad rubedinem nebulofam calefiat.

Alias quum in foco candefiat chalybs, colorum varietates non licet obfervare; lumen enim colores obfufcat hebetatque; hinc aliis artificiis uti folent, ut debitum in chalybe caloris gradum fciant: vel chalybem, antequam in focum mittatur, oleo oblinunt, oleum flammans indigitat, num gradus ignis plenus vel plenior reddendus fit vel non : vel utenfile fuum. chalybeum calefactum fruftulo ferri duri radunt, ex rutilatione ignea in fuperficie de gradu caloris dijudicant.

Sed de his prolixius in tractatione de chalybe.

\section{Modi liquandi ferrum malleatum ope menftruo- rum pafim ab auctoribus collecti.}

HIc etiam idem obfervandum, quod in principio hujus paragraphi di1 ctum eft; fcilicet mifcellanea hæc \& variorum auctorum obfervata, non pro genuinis agnofcenda effe, nifi prius experientia tefte in igne comprobata fint.

I. Dominus Kunckel in arte fua vitriaria tradit; fi ramenta ferrilixivio cinereo primum, dein aqua vel aceto laventur, \& dimidia quantitas fulphuris pulverifati commifceatur, inque tigillum immiffa ad fluorem ufque in igne reverberii, non aliter ac cuprum, teneantur; tunc quam optime colliquefcere \& fundi ferrum perhibet.

2. I $\frac{\mathrm{T}}{2}$ libre optimi chalybis in tigillo candefiant, pariter 24 femuncix alius generis chalybis; apponantur 8 vel 10 femuncix arenicis prxparati, teneatur mixtura in igne, dum inftar aque fluat.

Preparatio dicta arfenici fit recipiendo I libran arfenici, 2 falpetre, quæ mixta pulverifentur, mixtura ficcetur \& in vas fietile mittatur, quod operiatur; vas dictum per 3 horarum fpatium in igne circulatorio teneatur; fumus nocivus per foramina emittatur ; quumque nihil fumi amplius evolet, foramina luto præcludantur, dein fponte refrigeretur, inde obtineri dicitur lapis coloris viridis, qui nifi confervetur, in deliquium abit; ex hoc lapide fumantur 5 femuncix; ex borace 3 femuncix; mixtura pulverifetur \& in tigillo colliquetur, dein effundatur, unde habetur menftruum dictum arfenicale, quod ni confervetur, in humorem deliqueicit.

3. Recipiantur 2 partes cinerum, 2 calcis vivæ; in aceto vini coquantur, \& mixtura calida in cineres \& calcem effundatur, unde lixivium fortis- 
fimum haberi dicitur: ramenta ferri vel chalybis per 6 dies \& noctes in hoc lixivio digerantur, laventur dein \& ficcentur; lixivium novum rurfus fuperinjiciatur perque fpatium 4 horarum infuper maneat, tunc colore cupri tingi dicitur, ficcetur dein \& cum borace fundatur, tartaro calcinato operiatur addita parte arfenici, fecundum modum prædictum preparati, inde inftar argenti fluere perhibetur.

4. Recipiatur una libra ramentorum ferri, \& 8 femunciæ pulveris fequentis, una in tigillo liquefiant, \& maffa effundatur. Pulvis conficiatur ex arfenico, tartaro, fale alcali, falpetra ana mixtis, pulverifatis \& fufis.

Quod alias attinet menftrua, quorum ope optime liquidum poffit reddi ferrum, pariter ut vena ejus, vide fis claffem fequentem de probatione venæ ferrex in ferrum \&c.

\section{Modi chalybem albandi five illum argenti fimilem reddendi.}

Ulta de his tradit Dominus Beccherus, \& plurimi præter illum alchy11 miftx; Beccherus jubet, ut recipiantur ramenta chalybea \& fal auripigmenti, inque vas novum figulinum bene lutatum indantur, vas in camino calcario per noctem teneatur, interea ferrum inftar plumbi fluere dicit: dein ejiciatur pars fuperior, reliquum quam optime lotum in tigillum mittatur, tigillum in vafe figulino fubter perforato reponatur, quod carbonibus repleatur, flamine urgeatur ignis, quod fi fepties repetatur, inde chalybem inftar argenti albefcere venditat.

$V e l$, fumantur 100 femuncix lapidis magnetici, 6o auripigmenti, 8 vitri, mifceantur, mixtura cum 2 vel 3 partibus aquæ lavetur, iterum beneficio aqux \& falis abluatur, inde haberi ferrum album putat.

$V e l$, recipiantur filamenta chalybis, laventur, ficcentur, admifceatur arfenicum vel auripigmentum I libræ, mixtura facco vellinteo indatur, linteum vel faccus cera circumdetur; fumatur dein oleum mixtum cum fimo afinino, quibus faccus cum ipfamet cera obtegatur, ficcetur, dein in igne reverberii fpatio 3 horarum teneatur, tum refrigeretur, apparebit, ut ait, ferrum liquefactum \& inftar argenti album. Si fundus frangitur, quod tamen præcaveri poffe dicit, fi cum arfenico lavato, ceruffa \& vitro repetatur; hoc eft; ad I partem filamentorum chalybis apponantur 6 femuncix arfenici vel auripigmenti, I vitri, 2 ceruffe lavatx, in vafe figulino fubter perforato, inde obtineri ferrum argento fimile narrat. Hre Beccherus.

Alii vero fuadent, ut recipiantur 8 femuncix tartari, 2 falpetræ, 4 ramentorum plumbi, pulverifentur \& cum oleo in paftam commifceantur; huic I 8 femuncix ramentorum ferri admifceantur; mixtura in tigillum miffa vitro Venetiano operiatur ; tigillum etiam bene lutetur, fluat inibi, dum margines tranfcendere \& exfultare incipiat, tunc effundatur, unde ferrum tenaciffimum \& inftar argenti albicans obtineri dicitur.

Aliter. Tartarus, falpetra, arfenicum ana cum ramentis chalybeis ana in tigillo fundantur, liquamen dein in conum effundatur, unde maxima 
pars in fcorias convertetur; exque 32 femunciis habebitur maffa alba 2 vel 3 femunciarum: maffa, fi cum argento mifcetur, fiet fragilis.

Aliter: Tartarus, falpetra, oleum una cum ramentis ferri aut chalybis mifta in tigillo fundantur, five mafla prædicta in ferri ramenta conjiciatur, inde fundetur inftar argenti, \& maffa inftar reguli antimonialis fragilis obtinebitur. Dicunt etiam ex maffa hac pulverilata Mercurium elici poffe.

Aliter: 6 Librx limaturæ Martis \& falpetra, tartarus decrepitatus, cineres clavellati, arfenicum album, fapo Venetianus ana commixta in tigillum fuforium mittantur, inque fluore per fpatium 4 horarum teneantur; cumque refrixerit maffa, diffringatur tigillum, inde obtinebitur regulus Martis albus inftar argenti, fed qui pulverifari poffit. Regulus hic iterum fundatur, \& in tigillo per fpatium bihorii teneatur, unde magis \& magis albefcet. Quod etiam tertia vice repeti poffit; inde albefcet \& fluet materia, inque formas poterit effundi. Dicunt, materiam hanc prorfus nullam rubiginem poffe attrahere, licet in aere humidifimo relicta fit.

Aliter : fumantur 8 femuncix tartari calcinati, duo nitri, 4 plumbi, commixta una cum oleo in pafte confiftentiam formentur. Ad 6 femuncias hujus materiæ recipiantur i 8 partes ramentorum ferri, mifla in tigillum operiantur vitro pulverifato, \& tigillum luto fapientiæ claudatur, ita ut nullus inde vapor poffit exire; dein cum multis carbonibus reverberetur \& diu latis in fufione teneatur; aperiatur \& mox in alium ignem mittatur, ad ebullitionem \& effervefcentiam ufque fluat, tunc effundatur, inde haberi ferrum tam album dicitur, ut inftar argenti appareat.

Plura adhuc e chymicorum ficriptis excerpta non addere vacat.

\section{De ferruminationibus.}

FErri frufta \& lamellæ conjungi, conglutinari \& ferruminari poffunt vaI riis modis, præcipue per arenam \& ferri multam candefcentiam, fed ab artificibus traduntur etiam modi plures.

I. In officinis utuntur fabulo five arena pluviatili fubtiliore, quæ bene liquefcit, \& in vitrum aut forias in igne folvitur.

2. Si frufta ferri ambo bene candefiant, \& fuperinfternatur vitrum Venetianum pulverifatum, quod in ipfa fractura vel loco combinationis prene liquefcant. ri, vel

3. Fieri etiam poffe traditur per 2 femuncias orichalci, \& 2 lithargy-

4. Si juncturæ quam optime poliantur \& dein applicentur, interjecto vitro Venetiano pulverifato, ut candefiant.

4. Ex aqua gummi \& creta pulverifata fiat mafla, qua oblinanturjuneturx, \& ferrum in igne fic teneatur.

5. Sine igne. Recipiantur 2 femunciæ falis Armeniaci, I falis communis, 2 tartari calcinati, 2 metalli campanarum, 6 antimonii, pulverifentur, pulvis mixtus in linteum I digitum craffum mittatur \& dein ficcetur; tigillo indatur, fupra quod aliud relocatum fit; ficque in igne teneatur dum confluat mixtura, fracto dein tigillo eximatur maffa \& pulverifetur; hoc

Claljis I. de ferro.

$\operatorname{Rrr}$ pulvere 
pulvere oblinantur juncturæ; borax in fpiritu vini folvatur, penicillo vel pluma in folntionem miffa pariter in pulverem merfa ferrum oblinatur, inde coctio quxdam incipiet, quæ cum definit, paratum erit.

\section{Modus confervandi ferrum a rubigine.}

\section{Trba pfeudometallurgica hic etiam multa prædicant, \& quia mala mix- ta funt bonis, illa adducere volo.}

I. Dominus Kunckelius in arte fua vitriaria fuadet, ut accipiatur lithargyrus, \& cum oleo lini fuper porphyrum in pulverem impalpabilem teratur; in pyxidem ex ligno tiliæ factam mittatur, qux in fundo tam tenuis fit facta, ut fere tranfpici poffit : pendeat pyxis in aere \& fole, vel alias in calore, tunc oleum purum \& dulce penetrabit fundum pyxidis, cujus ope ferrum \& omnia ex ferro facta utenfilia, ut gladii \&c. a rubigine poterunt confervari.

Alias abftergitur facile rubigo a ferro, fi linteolum inter ligna extenfum teneatur, \& infuper aqua glutine imprægnata irroretur, \& vitrum pulverifatum in aquam hanc glutinofam infternatur : iterum eadem aqua irroretur, \& pulvis vitri füperinfternatur, quod tertia vice iterari poffit.

2. Accipiatur oleum optimi gencris, \& plumbum fufum inibi quinquies vel pluries exftinguatur; oleum fic præparatum in calice fervetur, \& ramenta plumbea immittantur \& bene agitentur; dein ramenta plumbi cum oleo illo fuper porphyrum, non aliter ac folent pictores, teratur, in vitro dein relinquatur, tunc ad fundum cadit plumbum \& oleum fupernatat; hinc habebitur oleum præparatum, cujus ope confervari diciturferrum a rubigine.

3. Tigilla, in quibus argentum frpe fufum eft, pulverifentur, \& pulvis cribretur; 32 femuncix hujus pulveris fumantur, 64 fmiridis calcinati \& præparati; venæ argenti 32 ; quæ fi non adfit, perinde erit; pulverifata bene cribrentur, \& cribrata mifceantur cum 96 femunciis ramentorum ferri, inde paratus erit pulvis; quumque ufurpandus eft, linteum oleo præparato illinendum, \& infuper fternendus pulvis, cujus ope ferrum terendum erit, quum rubiginem velis abigere; hujus etiam ope confervabitur ferrum, ne rubigine cito inquinetur. Qnod fmiridem attinet, ille calcinabitur, inque igne candefiet, eximetur \& pulverifabitur.

4. $\frac{1}{2}$ libra pinguedinis ungulis hircinis exemtix; $\frac{T}{2}$ libra olei amygdalarum, 8 femuncix camphore, 24 fulphuris cum ufto \& pulverifato plumbo, commixta in paitam coquantur, hac teratur ferrum, inde nulla rubigo attrahi putatur.

Plumbum cum fulphure cremetur hoc modo : fundatur plumbum \& infuper fternatur fulphur pulverifatum \& ope ferrei inftrumenti circumagitetur, inde obtinebitur pulvis niger.

5. Sumatur pumex, five lapis qui Bimften vocatur, ftannum, cinis, fimiris, pulverifata cribrentur, pulvere hoc linteum vel lignum illinatur, ficque ferrum teratur. 
6. Recipiantur 8 femuncix magnetis, 8 ramentorum ferri, 8 pumicis, 8 pinguedinis ungulis hircinis exemtæ, $\mathrm{I}$ alius pinguedinis; hæc prius pulverifentur \& mafla cum pinguedinibus formetur, fcilicet terendo fuper marmor : hujus ope ferrum a rubigine admodum confervari dicitur.

7. Hæmatites in olla tecta reponatur, \& olla in furno figulino, per combuftionem fit hæmatites fragilis, qui dein fub faxis molaribus per aquam in pulverem impalpabilem comminuatur; relinquatur deín in vafe, ut ad fundum fubfidat pulvis, aqua dein per inclinationem effundátur; pulvis relictus ficcetur, ficque præparatus erit : cum hoc pulvere ferri \& chalybis utenfilia quam optime poliri \& a rubigine confervari poterunt.

8. Oleum, pulvis cinnabarinus \& hæmatites commifceantur, quibus commixtis teratur ferrum, tunc nullam amplius rubiginem attrahere dicitur.

9. 4 libre filicis calcinati \& pulverifati, 2 femuncix tartari, 2 pariter aluminis, cum aqua vel oleo commifceantur, \& mixtura abftergatur rubigo ; fique dein tenuiter illinatur oleum laterum, nulla amplius rubigo timenda effe perhibetur.

I0. Ramenta plumbi cum oleo fimul coquantur, dein in fole vel calore mediocri per aliquot dies teneantur, unde mixtura hæc pura reddetur; hoc oleo illinendum efle ferrum.

I I. Calx viva fuper ferrum fternatur, calx ope aqux humectetur, inde rubigo exedi dicitur, dein carbone, qui in oleo exftinctus fit, teratur: hunc modum ad confervationem ferri a rubigine optimum cenferi. dicitur.

12. Per pinguedinem fuillam bene confervari ferrum a rubigine

13. Fiat amalgama Mercurii cum Saturno, quo illinatur ferrum.

14. Accipiatur oleum, in quo fæe exftinctum fit plumbum, pinguedo ovina \& cera cum oleo folvatur, \& mifceatur ; qua mixtura oblinatur ferrum. Hactenus de his fatis.

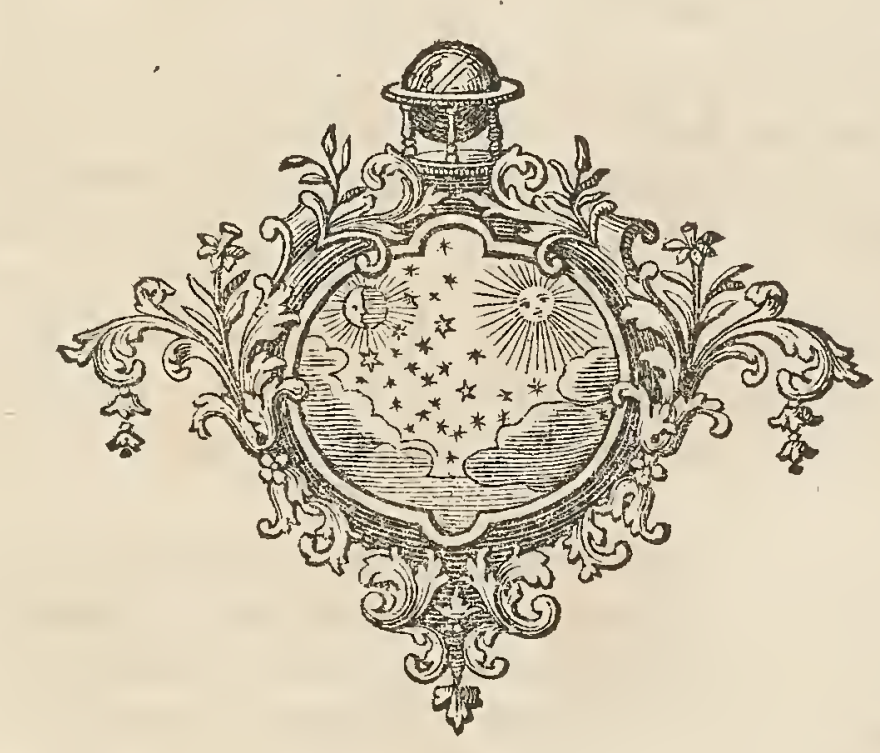

PARA- 


\section{PARAGRAPHUS XXVII.}

\section{De modo dividendi fecandique ferrum in contos Eిvirgas tenuiores, dilatandique intercylindros in regione Leodienfi, Anglia \& Svecia. Leodii.}

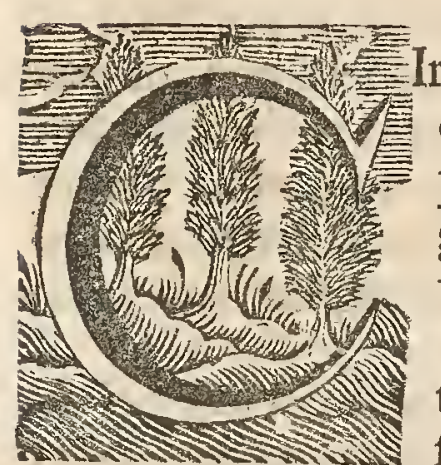

Irca Leodium hinc \& inde fparfa funt opera, "quorum ope attenuatur ferrum \& in contos minores fecatur, præter quod tales machinæe etiam Germanix ut \& Anglix fint confructie, videatur Tab. XXIX, qua ad vivum aliquatenus operationem repræfentat.

Sumitur ferrum jamdum in bacilla excufum, 2 digitos plerumque craffum, \& 4 latum, frangiturque in frufta aut portiones longitudinis circiter unius ulnæ.

Furnus in quibusdam officinis eft fimplex, in aliis vero duplicatus; in hunc conjiciuntur dicta fragmenta ferri; fub foco cineritium eft; inque ipfum furnum fere 200 portiones vel fragmina ferri conjiciuntur, fed ita, ut unum locum oblique fupra alterum occupet, illum in finem, ut ignis \& flamma undique \& libere illa poffit transmeare, unde in illum fitum difponuntur, ut fimul quafi arcum forment, fub quen carbones fofiles mittuntur ; frufta ferri lic calefacta \& reverberata, exemta per binos cylindros chalybeos transmittuntur.

Quumque fruftum ferri, quod I ulnam longitudine, 5 digitos latitudine \& I craffitie æquat, per dictos cylindros transmiffum fit, tam in longitudinem quam in latitudinem diducitur attenuaturque, adeo ut fruftum dictum ab altera cylindrorum parte prodiens, in longitudinem 2 ulnarum \& latitudinem 6 digitorum fere exporrectum fe exhibeat : frufta hrec ferri jam quodammodo dilatata altera vice in furnum miffa candefiunt, quo facto rurfus transmittuntur per cylindros, \& beneficio compreffionis, in longitudinem fere 5 ulnarum educuntur; quumque a machina hac extenforia prodierit ferrum, a viro quodam adftante forcipe prehenditur \& per aliam machinam ex orbitis chalybeis ordine difpofitis confectam transmittitur, ficque ferrum hoc attenuatum \& dilatatum in plures partes feu contos quadrangulos, numero 3,4 vel 6 fecundum libitum fecatur \& finditur: fi quotidie continuetur opus, quotannis 5 ad 6000 pondera nautica fic fcindi poffunt.

Illum ufum præftat machina hre fectoria vel diviforia ferri ; ut dein in varia utenfilium genera commode \& quidem cum minore impenfa \& jactura tam carbonum, quam laboris \& temporis fabricari poffit.

Obfervandum etiam eft, quotiescunque ferrum hoc per cylindros transmittendum fit, \& in bacilla tenuiora comprimendum, quod aqua tenuis \& lentus rivulus jugiter fuper dictos cylindros inque candens ferrum fluet; 



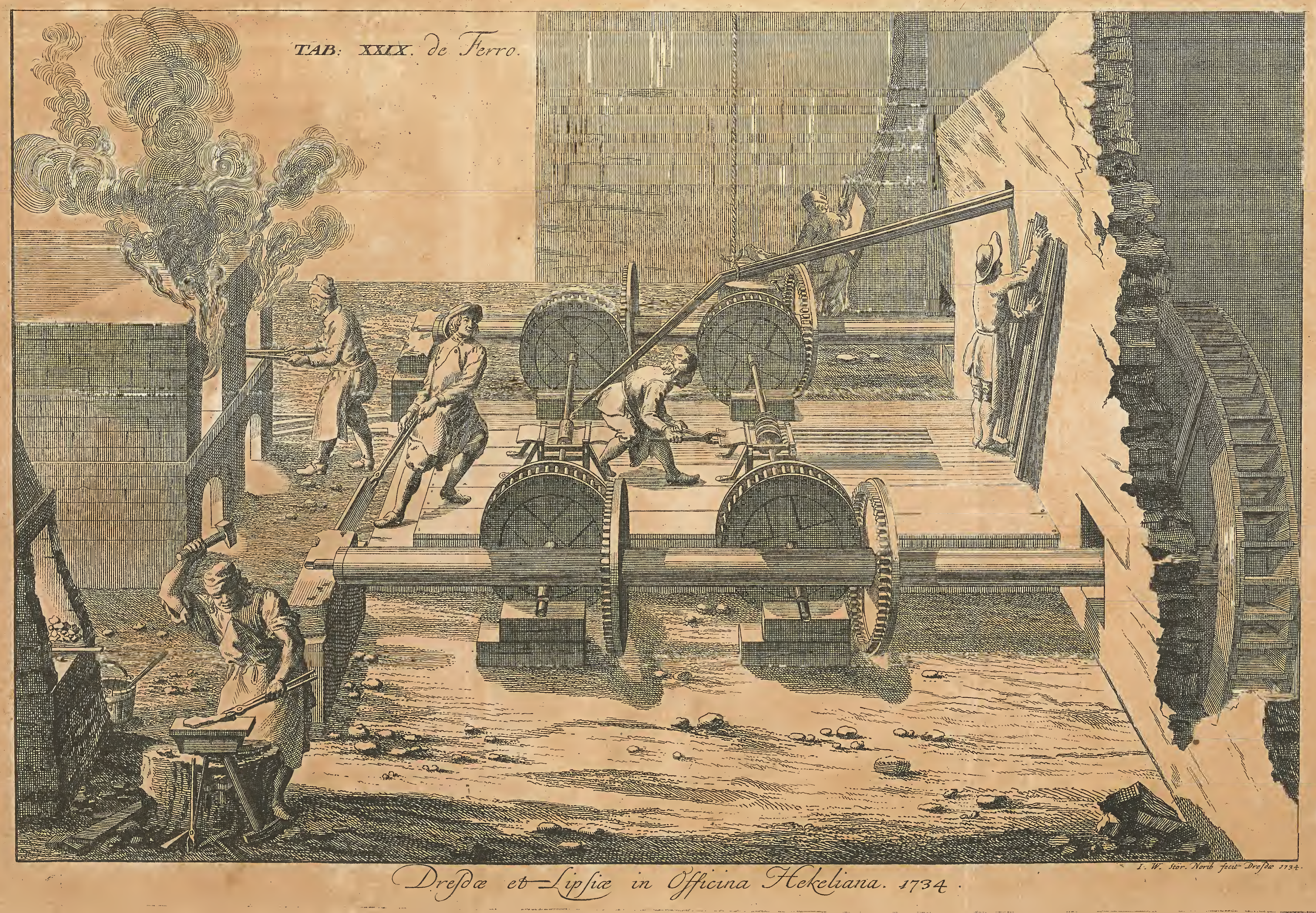





\section{DIDUCTIO FERRI INTER CYLINDROS. 253}

fine aqua ferrum candens ægre admodum tranfigi cylindros poffe dicitur; preter quod chalybea cylindrorum fuperficies nimium calefieret \& fic mollefceret. Quod vero ipla machinamenta \& furnos attinet, melius illa ex delineatione appofita quam ex defcriptione capi poffunt.

\section{Angtioe.}

A Nglix funt etiam plures machinæ, quibus ferrum fecundum longitudinem fuam attenuatur, $\&$ in partes, contos $\&$ cingula, quibus cadi circumligantur, fecatur \& diducitur. Attenuatur etiam ibi ferrum in laminas, qux dein partim obducuntur ftanno, fed per attenuationem hanc perire dicitur $\frac{\mathbb{I}}{20}$ pars ferri, \& adhuc magis fi ferrum non fit bonæ indolis.

\section{Suecia.}

Tuper etiam ad Wedenang Sveciæ exftructum eft opus fectorium ferri: 1 Ex delineatione videri poteft proportio partium. (A) fignificat rotas aquaticas majores, Tab. XXX, cum binis trabibus five axibus majoribus. Diameter rotarum eft 17 ad 18 pedum. Trabes, quæ a rotis circumferuntur, 22 pedum longitudine funt. (C) \& (E) funt rotæ dentatæ, qux diametro $5 \frac{1}{2}$ pedum funt, dentes numero 28 . Rotæ ei correfpondentes funt diametri 6 pedum ; rotæ dentatæ aliquantum altius repofitæ. (D) funt cylindri vel axes ferrei quadranguli, qui trabibus inferuntur. (E) locus pro cylindris, quibus attenuatur ferrum. Ad pofteriorem partem operis hujus diductorii ferri eft furnus reverberii pro candefactione ferri exftructus : a tergo hujus furni eft officina fabrilis, ubi inftrumenta conficiuntur; inibi etiam eft incus magna, fuper quam orbitæ illæ ferrex pro fectione ferri fecundum longitudinem dilatati preparantur: incus longitudine eft 20 digitorum \& latitudine 9. (F) eft opus fectorium, adque angulum domus eft furnus major pro candefactione ferri. Domus prexter officinam fabrilem \& furnum reverberii longitudine eft 40 pedum \& latitudine 30. (G) funt orbitx chalybex, quarum ope fecatur ferrum: (H) funt cylindri, quibus attenuatur: dicti cylindri funt de ferio facti, orbitx vero fub malleo exculia. Furnus major reverberii altus aliquantifper eft, intus eft fornicatus inftar furni panifici : fuppofiti funt conti craffiores ad difantiam mutuam unius pollicis, fupra quos tanquam in fpeciem tranftri reponitur ferrum, quod attenuandum \& fecandum eft.

Hic non carbone forfili utuntur, ut folent Leodii, fed lignis fectis $2 \frac{\mathrm{x}}{2}$ vel 3 pedes longis. Furnus hic fpatio 24 horarum calefit; dein immittitur ferrum quavis vice ad $6 \mathrm{vel} 7$ pondera nautica: cumque fatis ignitum \& candefactum eft, ope forcipis inter cylindros infertatur ficque attenuatui, \& dein in contos minores fecatur : fpatio annuo attenuari \& fecari poffunt 2600 pondo nautica.

Opufculum etiam in contos laminasque tenues fecandi attenuandique cuprum \& ferrum in ufu eft ad Afwedfadiam Svecia; orbitz fectorix aut diviforix ferri hic funt duplo majores; nec modo illis fecatur ferrum, fed Claffis I. de ferro. 


\section{DIDUCTIO FERRI INTER CYLINDROS.}

precipue cuprum. Ferrum vero hic non attenuatur, fed bacillus candefactus ftatim in 3 vel 4 partes aut contos quadrangulos fecundum longitudinem dividitur. Conti hic non prodeunt reeti, ut in machinis prædictis, fed incurvati \& flexi; ufque tamen eisdem ufibus apti.

\section{Macbina Sectoria ferri ad Stiern Jund Suecice.}

A Lia plane \& nova fecandi ferrum in contos methodus confpicitur Stiernfundii a nobilifimo \& experientiffimo collegii regii commerciorum confiliario Domino Chrift. Polhemo ante plures annos adinventa; hic in furno, qui longitudinem ipfius bacilli ferrei æquat, bacillum ad candefcentiam calefit, nec dein attenuatur, fed ftatim fub machina quadam fecundum longitudinem in 3 partes dividitur; ferrum premens vel fecans $a b$ utraque parte inftar forficis acutum eft, quod inter bina ferramenta lateralia xque acuta, ope rotæe aquaticx \& vectis valide comprimitur; bacillum candens huic forfici infertum fic ordine \& paullatim hoc eft fucceffive fecundum longitudinem in 3 partes fecatur: exit hoc bacillum fectum admodum incurvum \& rude, fed ftatim in furnum remittitur, fubque malleo circumcirca æquatur. Ferrum hoc in fafciculos dein combinatur, vocaturque Klippjern five ferrum fectum.

FINIS CLASSIS PRIM A.

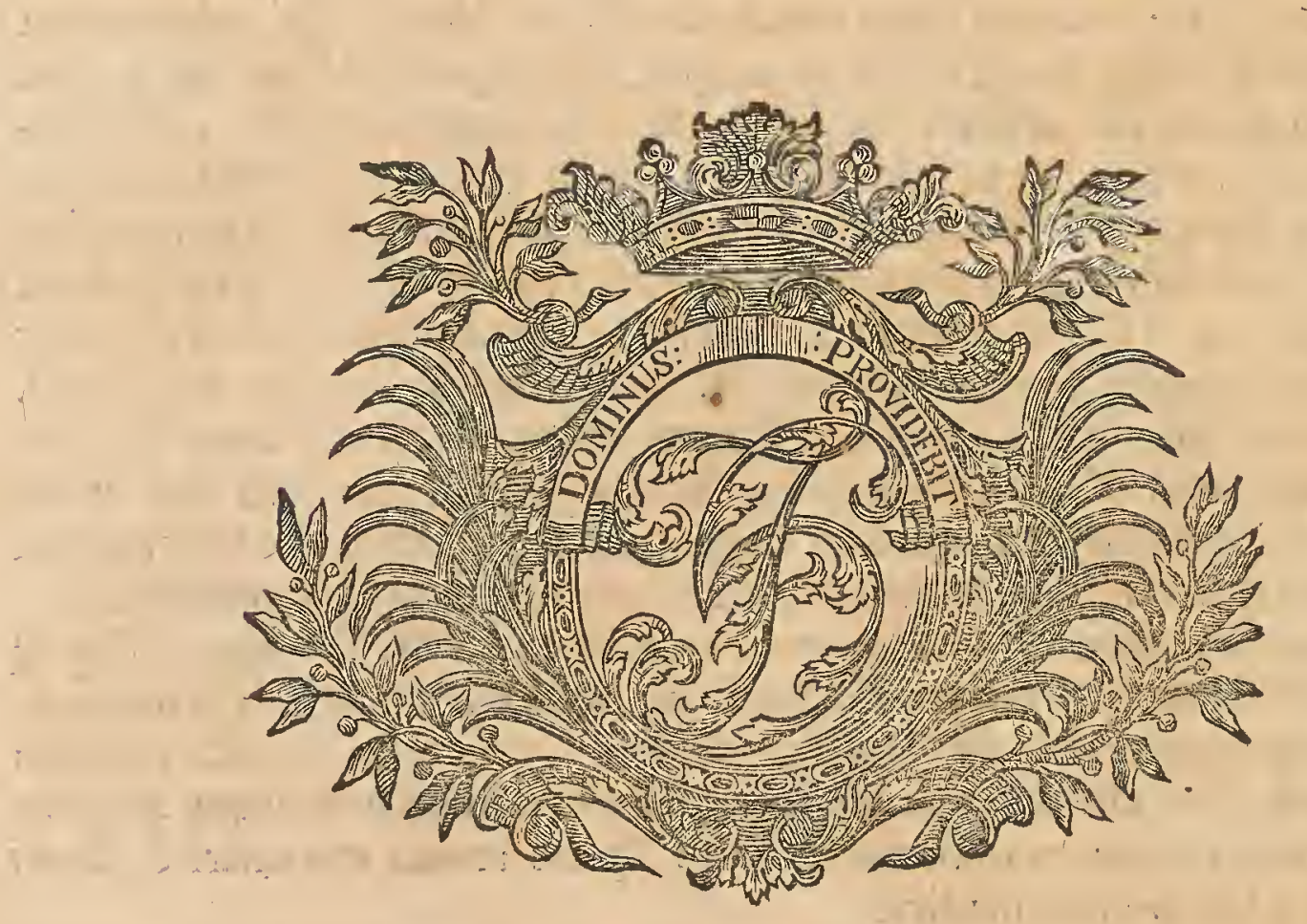




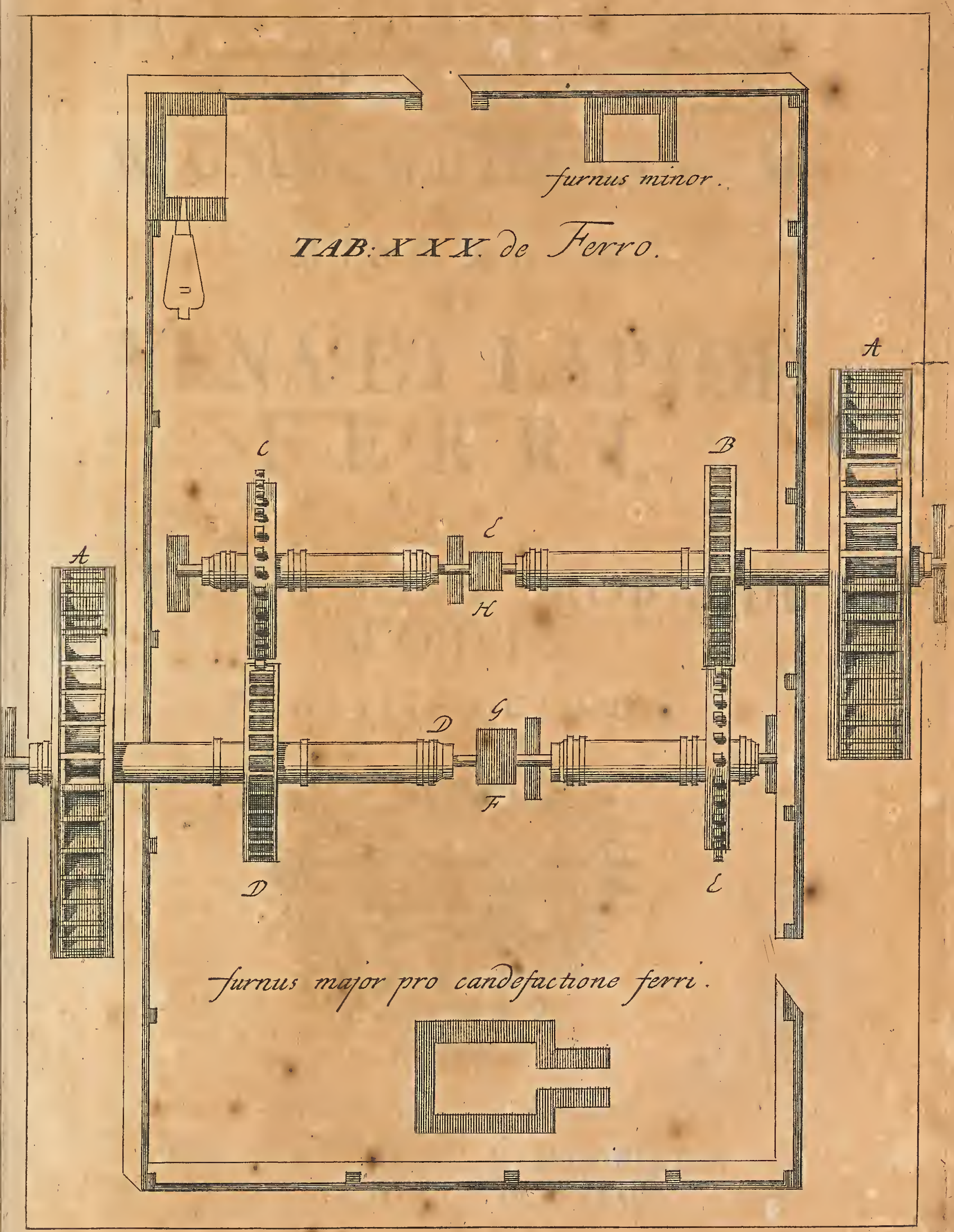




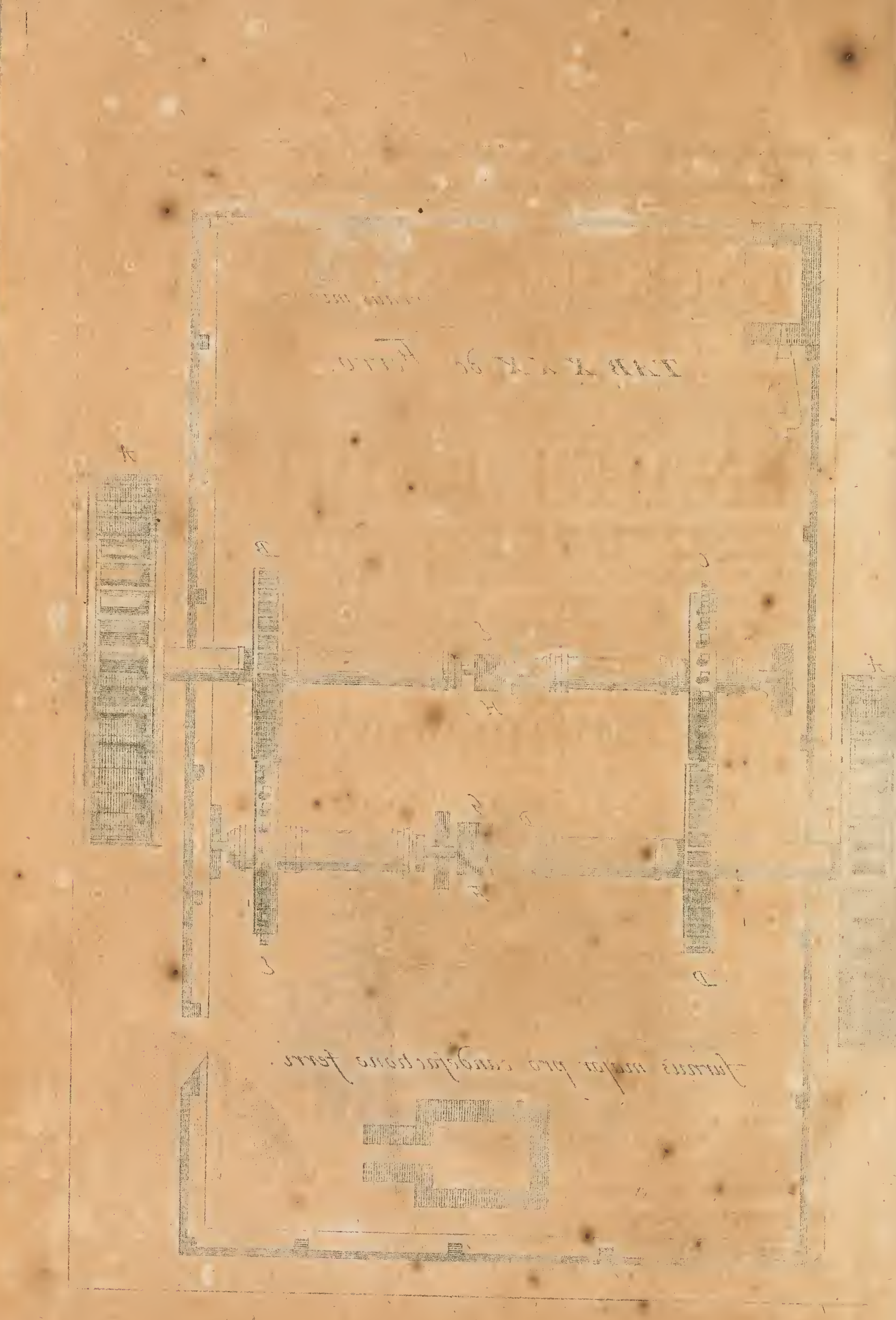


EMANUELIS SWEDENBORGII, ASSESS. COLLEGII METALLICI SAC. REGIÆ MAJEST. REGNIQUE SV.ECI $Æ$

\section{REGNUM SUBTERRANEUM} S I V E

M I N E R A L E

D E

\section{VENA ET LAPIDE \\ F E R R I, \\ U T E T \\ DE \\ VARIIS EJUS PROBANDI M O D I S.}

C LASS IS SECUNDA.

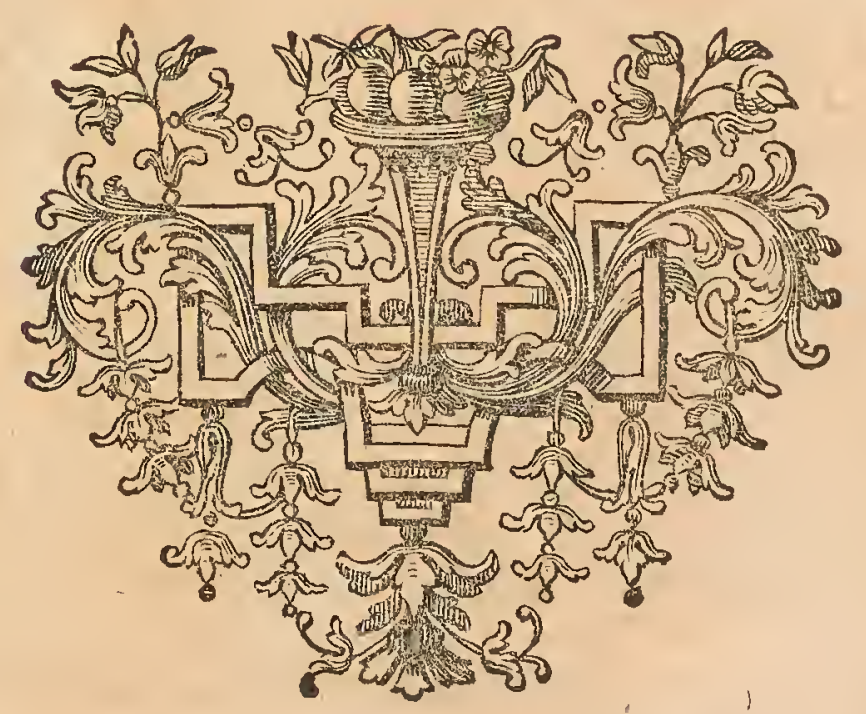

$D R E S D \not E \sigma L I P S I \not E$,

APUD:FRIDERICUM HEKELIUM, HBLIOPOL. REGIUM M DCC XXXIV. 


$$
\text { (1) }
$$

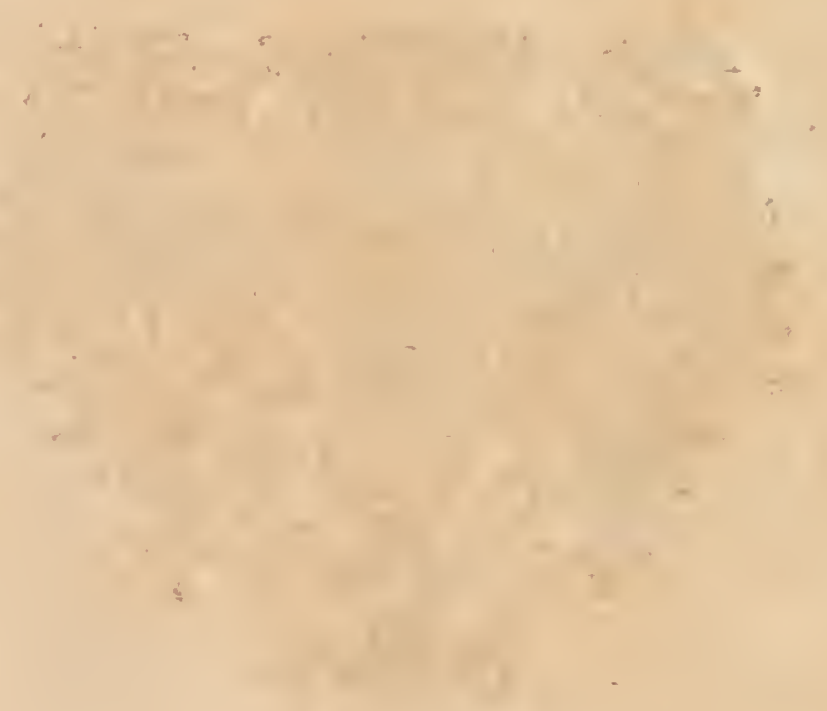

$+2$ 


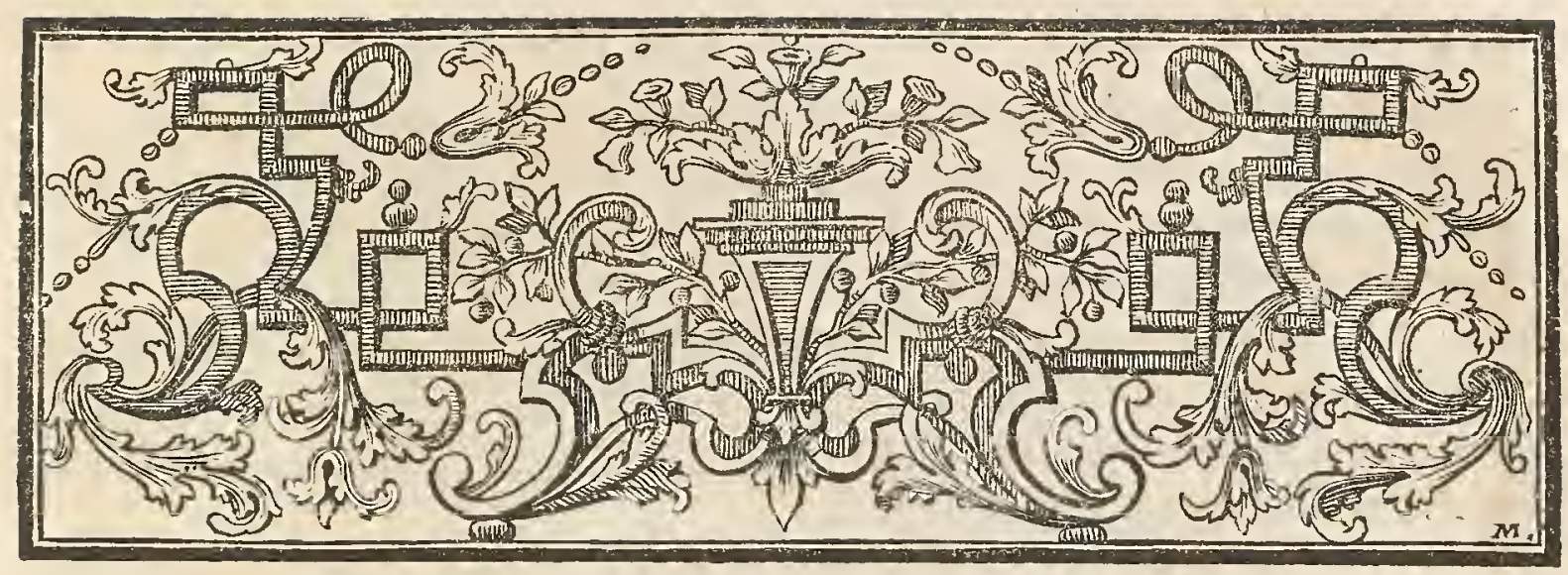

\section{CLASSIS SECUNDE PARAGRAPHUS I.}

\section{De probatione vence ferrece per magnetem.}

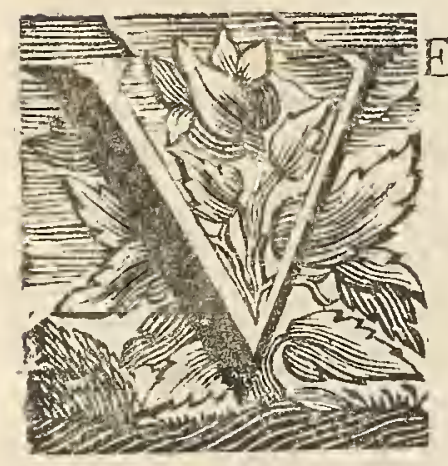

Eteres parvi fecerant probationem venæ ferrex, tam propter vilitatem metalli, quam quia ignem vehementiorem requireret: hinc probationem ejus per magnetem fufficere polfe putarant; de modo ferrum probandi ita differit Dominus Erkerus.

Si probare velis venam ferri, calcinetur primum (alii vero probant illam non calcinatam;) dein pulverifetur, inque pulverem involvatur magnes bonx indolis, tunc quicquid ei ferri ineft, adhærefcit \& magneti affigitur; pulvis affixus pede leporino abftergatur, iterumque pulveri involvatur magnes, quod tamdiu repetatur, dum nulla pars pulveris lapidem hunc comitetur, refiduus eft modolapideus, five qui ferrum non fapit ; exinde videre licet, num venaferri dives aut egena fit, quoniam magnes nihil aliud aufert quam particulas ferreas.

Quod vero venam chalybeam attinet, de qua loquitur Dominus Erkerus, qux non diffimilis admodum erit ven: ferrex \& fpathum flavefcens referet, illam a magnete crudam non attolli dicit, pariter etiam fpecies alias venæ ferrex; at vero fi vena illa calcinetur, colorem accipiet venæ ferri ditiflim $x$, \& tunc primum fublatum iri a magnete narrat, \& quidem libentius quam iplam ferri venam. Cumque quantitas hoc modo exploratafit, iterum \& ulterius in focis a fabris experiundum effe fuadet, nimirum quam dives \& cujus indolis \& pretii fit.

Sed ex hoc probandi modo fuperficialiter tantum cognolci poteft, num vena alicujus ferri potens fit; tamen nihil certius quam per folum infpectum inde exploratum fiftitur: multx enim partes lapideæ fimul cum particulis ferri auferuntur, quæ tamen magnetem quamvis lapide fuo onuftæ in altum fequuntur, unde nequaquam in familiam puri \& genuini ferri Claffis II. de ferro. venire 
venire poteft omne id quod magnetem comitatur, nifi in pollinem fubtiliffimum \& fere impalpabilem comminuatur vena, \& crebrius per aquam lota, \& pariter per ignem combufta fit ; quod fi fapius iteretur, vix dum fperatur pulvis genuinus ferreus.

Effe etiam plures venæ ferrex fpecies, quæ non attrahantur a vi quadam magnetica, ut, narrante Domino Erkero, illæ, quæ multum fulphuris poffident, inde etiam fuadet, ut prius calcinentur, alias fine privio igne per magneten non explorari poffe.

Præterea non latet, magnetem corpufcula multa ferrea falinis uncis $\&$ chelis illigata, vi fua conjunctiva vel repuliva non contingere velle; nec ferrum purifinum in crocum five rubiginem verfum ; nec ochram Martialem, nec venam paluftrem, nec lacuftrem ; fubinde nec ramenta ab incude decidua; nec ferrum ab antimonio prehenfum; nec a multo fulphure crudo incarceratum, ut pyrites incombuftos \&c.

Plurima alias cum magnete experimenta inftituta funt, qualiter illius vi attrahatur ferrum metallis, fulphuribus falibufque commixtum, referre tantum illa volo que ab eruditiflimo Domino He N C E L L o in Pyritbologin allata funt. Si pyrites, ait, cui admixtum eft ferrum, in igne valido comburatur, inque terram bruneo-rubram reducatur, pulverem refiduum vel terram, non magis quam paleas \& fipulas a magnete attrahi; at vero fi pulvis ille in ferrum fundatur, iterum a magnete corripi. Alias nullum genus pyritis effe, quod non a magnete attrahatur, quum inde fulphur abactum fit; fint quxcunque genera pyritis, victriolica, aquatica, faxea \&c. nec relinqui pyrites cupreos, non obftante, quod inibi aliquid cupri fit, modo non permultum : fulphur arfenicale Saxoniæ etiam a magnete fublevari.

Tentatum effe cum pyrite cupreo variis ex fodinis collecto; quem poft fulphuris inde factam fublimationem fubtractum effe a magnete, fed non cum illa celeritate qua pyrites inops \& ferreus : differre vim attra\&ivam hujus pyritis fecundum combuftionem, \& inde factam fulphuris diffpationem. Sed ufque tamen difficile probatu effe, quantum cupri in finu ferri fit, dum a magnete attolli fe patiatur, prafertim quum experientia fxpe teftis fit, in pyritibus plurimam partem cupri \& exiguam ferri fæpe latere. Praterea etiam alias quasdam fubftantias pyriti ineffe pofle, qua vim attractivam magnetis impediant. Commifcuiffe auctor in tigillo ramenta ferri $\frac{T}{2}$ centumpondii refert, \& cuprum $\mathrm{I}_{\frac{1}{2}}$ centumpondii, uncie regulum obtinuerit $\mathrm{I}_{2}^{\frac{\pi}{2}}$ centumpondii \& 4 librarum; qui in particulas divifus a magnete attraheretur, licet ratio ferri ad cuprum adeffet ut i ad 2 , fi non major pars cupri; exinde concludit, magnetem ferrum attrahere poffe, licet dupla quantitas cupri infit.

Tantum etiam auri commifceri, quantum cupripoffe, \& ufque tamen a magnete allici.

Pariter etiam ex argento.

In ftannum intrare etiam ferrum \& regulum componere, in quem fatis valide agat magnes; de qua re etiam videas fequentia ex Rceslero. 
Ex ferro \& zinco regulum quiafi argenteum oriri \& tenacem, cui etiam adhæreat quam optime magnes.

Si commifeeatur ferrum cum bifmutho; obtineri inde regulum admodum fragilem \& bifmuthicum, \& quamvis fint $\frac{3}{4}$ partes bifmuthi, ufque tamen ferrum inibi latens a magnete auferri.

Magnetem trahere etiam ferrum, cum orichalco commixtum, in quo etiam lapidem calaminarem effe ex colore flavo appareat.

Magnetem etiam fibi fubmittere regulum arlenici, qui ope ferrifactus fit : etiam ipfum auripigmentum \& arfenicum ex minera vel marcafita arfenicali fublimatum \& cum ferro per fufionem commixtum.

Magnetem non fibi confociare velle antimonium mixtum cum ferro, plurimis modis expertum effe, nec cum ferro mixtum lapidem de tribus, ut vocatur; quamvis cum ferro in unum metallum coiverit.

Addit, magnetem virtutem fuam exercere, fi ferrum \& fannum ana mifceantur, vel fi regulus conftet $\mathrm{I}_{\frac{\mathrm{T}}{2}}$ centumpondio ftanni, \& fic porro.

Quod ftanni mixturam cum ferro attinet, Dominus Roslerus fequentia tradit. Quoniam multis in locis Germanix vena ftanni mixta fit cum vena ferri, fxpe ut centumpondium contineat 20 ad $28 \mathrm{t}$, qux pars beneficio magnetis non feparabilis fit; unde etiam fuadet venam ftanni primum in pulverem contundere, pulverem dein in furno calcinatorio comburere, \& per ignem fic ferrum mortificare, denique ope aquæ ftanneum a pulvere ferreo feparare. Verum ope magnetis feparari etian poffe, vena prius in pulverem bis iterumque contufa, \& pulvere dein bis iterumque ficcato, ficque fi repetitis vicibus pars venæ ftannex auferatur; quod etiam fieri poffet in ipfo fcamno lavatorio, quum pulvis humidus fit, fcilicet transferendo magnetem fuper dictum pulverem, vel magnetem hinc \& inde appo-

ponendo; quicunque pulvis ad magnetem fe applicet, ope aquxe inde abftergi commode poffe. Plura de his videas

in magnete.

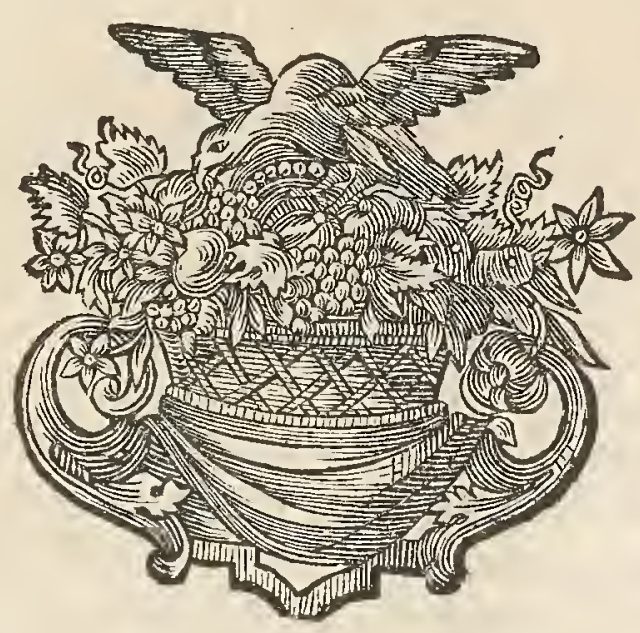

PARA. 


\section{PARAGRAPHUS II. \\ De probatione vence ferrece in tigillo.}

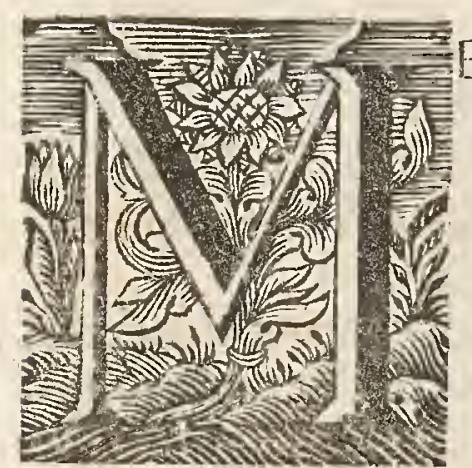

Elius fuccedit, fi infituatur examen venx ferrex eodem modo fere quo cum vena cupri : fumatur filicet I centumpondium venæ ferri, 2 centumpondia menftrui nigri, I falis Armeniaci, $\frac{1}{2}$ boracis, $\frac{1}{7}$ fuliginis, I tartari, I felis vitri fine clasgall, $\&_{4}^{\frac{1}{4}}$ pulveris carbonarii : addere etiam potes vitrum Venetianum five chryftallinum, quæ fimul commixta fuppeditant menftruum venx ferrex probandx aptiffimum. Sed antequam ad iplam probationem accedis, vena eodem fere modo, quo vena cupri primum in granula tundatur, \& fic prima vice calcinetur; dein minutius teratur, \& iterum calcinetur, quod per vices fiat ; \& adhuc, minutius pulverifetur, ufque dum fatis calcinata nihil fulphuris amplius fpiret, five ufque dum pollen fere impalpabilis reddatur, dunque amplius comminui in minorem nequeat; fed cum dicta calcinatione initio lentius procedendum eft: fed hoc, fi vena alicujus fulphuris, arfenici \& multi phlogifti fit particeps; fi vero nullius, proftat tamen calcinatio, exinde enim melius puriusque fluit vena in ferrum. Vena fic calcinata ponatur dein in crucibulo mixta cum menftruo prædicto, \& fale communi tegatur ad craffitiem $\frac{r}{7}$ digiti; tigillum aliud infuper repoftum allutetur, ne pulvis carbonarius illaplus mixturam inquinet. Tigilla hæc pellutata in focum (quil Svecice AEfbia vocatur) transportentur, ubicrucibulum quoddam inverfum a canali ventilatorio 3 digitis remotum infra ventum ad I digitum repofitum fit; infuper relocentur tigilla fic unita probatoria; circumcirca abinde ad diftantiam palmi ex lapide lateritio conftruatur murulus cingens, qui carbones apte poffit includere. Foculo hoc carbonibus mediocris magnitudinis \& fupra ipla tigilla adimpleto, pruna quædam fuperinlocatur, qua mediante omnis focus in plenum ignem abeat, unde tigillum per gradus calefit; quumque fal fuperinjectum decrepitaverit, admittitur aura, quæ fpatio $\frac{\mathrm{I}}{2}$ vel $\frac{2}{3}$ horæ continuetur, magis minusve fecundum capacitatem foci, vim venti, \& indolem venæ. Obfervandum, ne tigilla interea carbonibus fpolientur \& nuda ftent, fed carbone femper tecta. Peracta liquatione ope circuli ferrei foculo exemtum tigillum, inter lapides fuper lamina quadam ferrea reponatur, ubi aliquantilper percutiatur, dum. granula hinc inde fparfa \& collecta in regulum confluxerint. Ex flamma dijudicari poteft, quandoliquatio peracta fit: menftuum enim, quum adhuc cum ferro aut folutione laborat, magis flavefcit ; dein vero cœrulefcit. Venæ ferri immitiores, prout hæmatites, fchiftus \& Giaskopf, ut vocatur \&c. prius cum colophonio in catillo calcinandæ funt, \& fal culinare, quo tegatur mixtura, cum tefta ovi commilcendum, iplaque liquatio probatoria per fpatium integra horæ peragenda. 


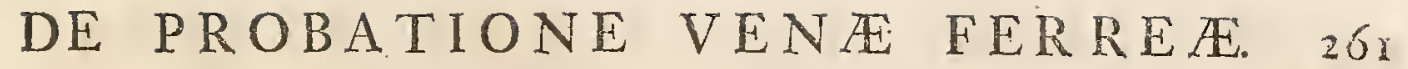

Sal alcali etiam in ufum adhiberi poteft, præfertim fi vena fale quodam minerali maligno fit commixta.

Tentatum etiam eft loco memoratorum menftruorum cineres clavellatos adjicere, fed omnem venam in forias nigras abiifie, \& feparationem in regulum renuife; compertum eft.

\section{Aliter.}

GEcundum alios, cum uno centumpondio venæ pulverifatæcommifcenda funt I femuncia vitri plumbei, 3 drachma menftrui, circa probationes venæ cuprex in ufum recepti, de quo infra, quæ fimul in tigillum mittantur, tigiflum ad $\frac{1}{2}$ pollicis eminentiam fale communi tegatur, \& dein claudatur operculo, ficque foco ferrario vel alio anemio committatur; mixtura hac cum ferro liquefacta, tigillum igni eximatur \& frigefactum frangatur, \& granum ferreum fic auferatur, unde exploratur quantitas \& qualitas venæ probationi fubjeete. Menffrum memoratum conficitur ex $\frac{1}{2}+\frac{1}{1}$. falpetræ, 4 femunciis faponis Venetiani, cum tantilla parte felis vitri \& vitri Venetiani.

Obfervandum eft $\mathrm{I}$. quod in opufulo probationis, vena ferri vehementiorem ignem flagitet, quam vena argenti \& auri. 2. Si vena cruda ftatim in tigillofundatur, quod, quia multi fulphuris compos eft, qualitas ejus vix explorari poffit, pereunte multa parte ferri; unde fequitur, quod vena prius calcinanda fit. 3. Si cum vena ferri una commifceatur vitrum $V$ enetianum vel aliud, quod obtineatur inde mafla aut recrementum coloris ferruginei: at vero fi venis ferri, út \& cupri adjiciatur dictum vitrum, quod inde dentur foriæ coloris graminei live viridis.

\section{Aliter.}

Equuntur jam aliquæ probationes, quarum mentio fit in collectaneis chymico-metallurgicis curiofis; fed quatenus fide fint dignæ, experientiæ cujusvis relinquitur; fufficiunt interea tres priores; funt ergo que fequuntur.

I. Duæ partes menftui nigri \& vitri pulverifati ana; I pars capitis mortui poft deftillationem aqux fortis; ut \& pulveris carbonarii ana; $\frac{\mathrm{r}}{8}$ pars antimonii; pulverifentur \& in debita ratione venæ ferrex adjiciantur; inde obtineri veram quantitatem ferri perhibetur.

2. Bine partes vitri Venetiani ; I pars menftui nigri, pulveris carbonarii, capitis mortui pof deftillationem aquæ fortis ana. $\frac{1}{8}$ pars antimonii \& arfenici ana; pulverifata bene commifceantur; \& venæferrex in debita quantitate apponantur; tigillum hac mixtura repletum, ante ventum reponatur; inde habebitur quantitas ferri.

3. Binæ partes felis vitri \& tartari ana: I pars vitri Venetiani pulverifati, falis alcali, pulveris carbonarii ana; pulverifentur \& commifceantur, \& ut prius fundantur.

clabis II. de ferro.

Uuu

4. Una 
262 DE PROBATIONE VENA FERREZE.

4. Una pars venæ ferri ; 2 partes menftui nigri \& felis vitri ana : $\frac{x}{2}$ pars pulveris carbonarii : pariter pulvis vitreus albus \& arena comminuta fecundum libitum; mixta bene in tigillum una cum fale fufo immittantur ; tigillum tegatur : ignis primum fit lenis; dein calefacto tigillo aptetur ventus; peraeta liquatione in fundo habebitur granum ferri, non aliter ac granum cupri.

5. Una \& dimidia pars capitis mortui poft deftillationem aquæ fortis obtenti \& tèr cum urina incoeti, \& dein cum aqua pluviacili foluti, filtrati \& tandem in lal coagulati : I pars arfenici albi, nitri, tartari ana; omnia pulverifentur, \& pulverifata commifceantur. 2 partes hujus mixturx ad unam partem venæ ferrex accipiantur ; fundatur dein, inde regulus pulcherrimus obtineri dicitur ; fique adhuc pulchrior defideretur, fundendum effe cum eodem menfruo.

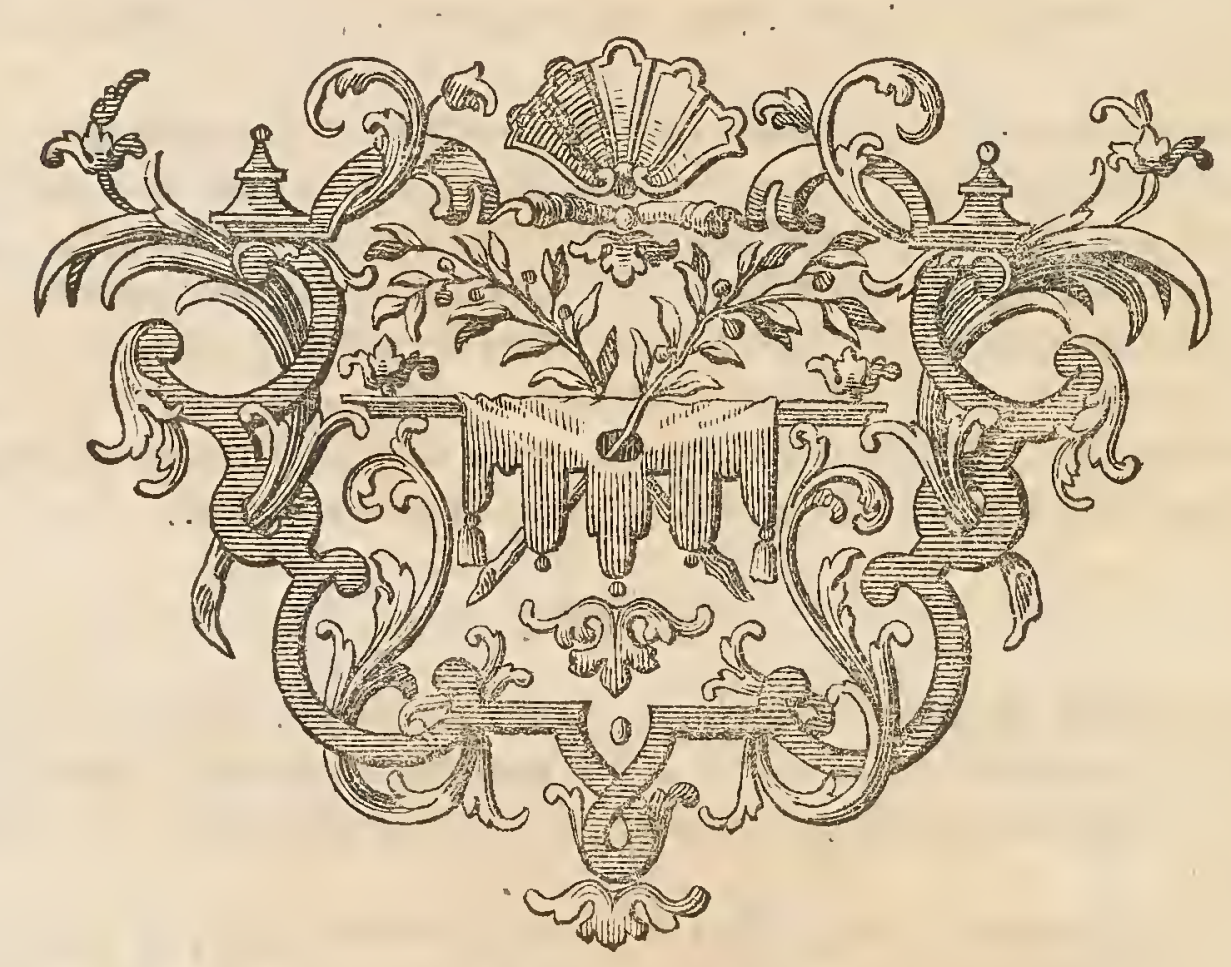

PARA- 


\section{PARAGRAPHUS III.}

\section{Probatio ferri ut $E^{2}$ veno ferrece in aurum Eे argentum.}

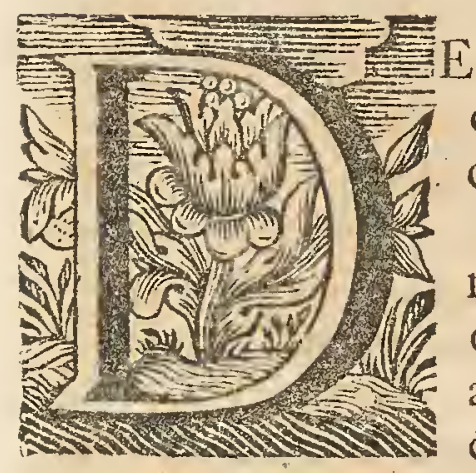

E hac probatione fufius agendum eft in tractatione de auro \& argento; ufque tamen non fupervacuum duco, hic etiam unam alteramve methodum tradere.

I. Secundum Dominum Kellnerum in arte feparatoria, lixivium quoddam ex cineribus fagi \& urina conficiendum eft; \& ferrum candefactum inibi per aliquot vices exftinguendum, ufque dum fragile factum fit, \& optime in pulverem poffit teri : præparandum dein lixivium eft, ex parte calcis \& nitri; ferrumque in pulverem redactum inibi coquendum. Maffa dein in pulverem comminuatur \& cum vena plumbi commificeatur, ad quam adjecta fit aliqua pars antimonii, mixtura tum fundatur in tigillo, \& regulus tandem in catino abftrahatur: habebitur dein aurum in argento, fi aliqua pars admixta fit.

II. Ferrum circa liquationes majores cupreas collectum candefiat \& aliquoties in urina exttinguatur, ufque dum in pulverem facile poffit comminui. Pulvis in furno calefiat \& in mortario contundatur, \& eiaqua fortis fuperaffundatur, inde folvetur ferrum \& calx aurea ad fundum intacta decidet, qux colligatur, edulcoretur \& modo vulgari fundatur; inde habebitur aurum, fi quid inibi latuerit.

III. Chalybs Stirix calcinetur \& cum fulphure reverberetur, ufque dum in pulverem rubrum \& leveni deciderit; ad hunc pulverem apponatur fextuplum plumbi; hoc eft, 6 partes plumbi ad i partem pulveris una cum menftruo ex vitro arfenicali \& falibus facto, inque tigillo, quod intus creta oblitum fit, fundatur; in igne per fpatium 6 horarum teneatur, dum inftar aqux fluat; tandem refrigeretur. Regulus tum excutiatur (fcorize apparent nigræ, fed inftar vitri claræ); regulus dein debito modo in catillo abftrahatur. Prxdicti 3 modi a Domino Kellnero traditi funt: funt etiam plures ab aliis, qui fequuntur.

IV. Ferrum comminuatur in ramenta fatis exigua; I centumpondium hujus ferri fundatur una cum I 6 centumpondiis plumbi granulati \& I centumpondio vitri plumbei, plane ut vena fulphurea immitis \& refractaria, exinde fiunt fcorix; aurumque \& fimul argentum recipiet fe in plumbum, quod ope ignis abftrahendum fit, exinde habebitur aurum \& argentum.

- Melius putatur effe, fi ferrum prius cum 2 partibus antimonii in regulum redigatur, \& regulus dein cum plumbo fundatur, plumbum more folito in catino abfrahatur, vel in fcorias cum nitro redigatur.

$\mathrm{V}$. Dimidium centumpondium limaturæ Martis in vitrum evaporatorium mittatur, fuperinfundatur acetum admodum forte; vitrum dein, 


\section{PROBATIO VENÆ FERRE无 IN ARGENTUM.}

ne vapor exhalet, claudatur; reponatur fic in arena calida; cumque per diem faturatus fit liquor, eximatur materia fundi \& cum I centumpondio. vitri plumbei commilceatur; apponantur etiam 8 centumpondia plumbi, fundantur non aliter ac venæe immitiores; inde obtineri dicitur quantitas auri \& argenti. Loco aceti etiam ufurpari polle phlegma fpiritus falis aut victrioli.

VI. Mifceatur $\frac{\mathrm{T}}{2}$ centumpondium limaturæ Martis cum I fulphuris, qua in calore mediocri teneantur, dum fulphur modo deliquetur, aque fulphure penetretur ferrum, inde ferrum quafi ex metallo \& indole fua reducetur \& transvertetur ; fulphur inde per combutionem \& ignen calcinatorium expellatur; refrigeretur dein, reliquum pulverifetur \& cum duabus partibus vitri plumbei ut \& cum 12 plumbi mifceatur; inftituatur demum calcinatio tum liquatio, pari modo, quo fit cum venis argenti diffcilioribus.

VII. Sumatur $\frac{\text { I }}{2}$ pars limaturæ Martis, $\frac{x}{2}$ marcafitæ aquaticæ, quæque argenti fit expers; pariter 12 partes plumbi; \& inftituatur dein probatio pari modo, ut circa probationem marcafitx crudx in argentum. Sulphur, quod marcafitz ineft, ferrum dividit domatque \& in fcorias redigit, preparatque ut plumbum facile intret: quod xgre fieret, fi ferrum a fulphure prius non effet folutum.

VH1. Dimidia pars ferri \& I antimonii fimul in tigillo fundantur, in catino dein calcinentur, tum pulverifentur \& cum menftruo, ut \& cum plumbo commifceantur; \& inftituatur operatio pari modo, quo circa venas difficiliores \& duriores argenti.

IX. Commifceatur ferrum cum vena plumbi, \& trans pulverem carbonarium eodem modo quo Gofslarix fundatur, nam in vena plumbi eft antimonium, quod ferrum corripit \& fere confumit vel in fcorias redigit.

Plura de his videas in auro \& argente.

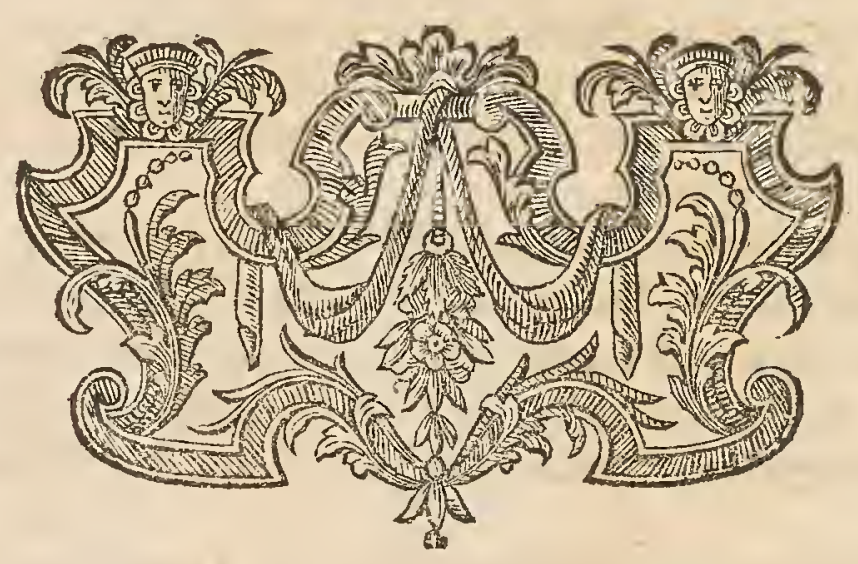




\section{PARAGRAPHUS IV.}

\section{De modis probandi explorandique qualitatem. ferricrudi pariter ac ferrimalleati.}

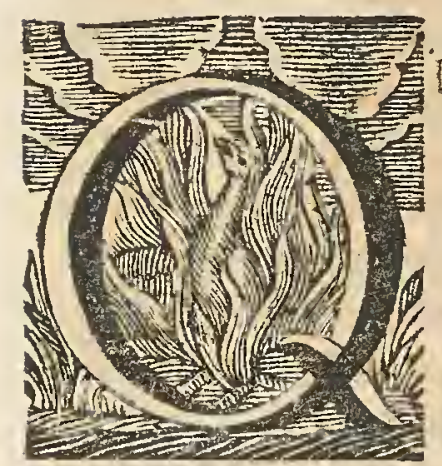

Uod ferrum crudum attinet, judicatur primum de qualitate ejus ex fracturæ colore \& granis, ex lévitate \& pondere, ex tenacitate aut frangibilitate; fed pr: cipue ex fractura ; fi enim conftet micis grandiufculis \& lucidis, ac fimul fragile fit, fignum eft venam non bene coctam liquatamque, vel malignitates illam comitantes non inde omnes abactas effe. Sed quia indicia fepe exftantifima oculos fallunt, hinc nihil certius de genuina ejus indole judicari poteft, nifi in foco fabrili modo vulgari liquetur recoquaturque, inque contos aut bacilla extendatur : quo facto, facile videri poteft, cujus not: fit, \& num ufibus aptum fit vel non; aliis ratiociniis \& fignis vix tam tuto confidendum eft : datur enim ferrum crudum fragillimum, ufque tamen in ferrum purum tenaxque, cum ignes focales tranfierit, converti poteft. Datur etiam ferrum crudum tenax, quod tamen ægre liquatur, \& quod fulphure confpurcatum in partes fub malleo abit, nec in contos apte diduci fe patitur; hinc recoețio ferri crudi omnibus probis anteferenda eft.

Qualitatem ipfiffimam ferri crudi explorant fabri vel per fcorias illarumque colorem, fluiditatem \& indolem; vel per flammam \& plura alia figna, fed præcipue per commixtionem ejusdem ferri cum ferro not: melioris vel vilioris : fi enim ferrum crudum detur, quod folum \& fine ulla commixtione alius ferri in optimum genus diduci \& attenuari poffit, convenientiffimum judicatur : datur quod omnino commifcendum eft cum fpecie ferri melioris crudi, ad $\frac{1}{10}, \frac{\pi}{8}, \frac{1}{6}, \frac{\pi}{4}, \frac{7}{2}, \frac{2}{3}, \frac{3}{4} \&$ c. partes, ficque mixtum reddat ferrum defideratiffimum $\&$ optim: notæ.

Præcipue exploratur ferrum crudum, fi in laminas tenuiores excudatur: fi enim ferrum non optimigeneris fit, in laminas excudi nequit, nifi in fragillimas, in quibus infuper rimæ, fiffuræ \& inæqualitates injucundæappareant, vel qux plura alia figna funt, qux in ferro lamellato fe confpicienda præbent.

Quod vero ferrum excufum attinet, exploratur ejus qualitas precipue in fracturis : unum genus quod tenax eft, cun candefcit \& vocatur Kallbrecht, facillime frangitur, adeo ut bacillus fimul in plures partes divifus rumpatur : ratio eft, quia hoc ferri genus omni fulph hure combinatorio \& glutine metallico deftitutum eft : gradus etiam dantur, unum genus fragilius altero, quoque fragilius, co deterioris notæ. "Talé etiam ferri genus lievigatum admodum apparet, \& fub malleo bene xquari poteft, nam ictibus mallei facillime cedit, nec in angulis \& marginibus incifura transverfales con/piciuntur, nam tenaciffimum eft \& inftar vitri candentis, cum calidum. Ex micis \& granis ferri hujus fracti cognofcitur dein ipfamet clalfis $I$ I. de ferro. $\mathrm{XXX}$ ejus 
ejus nota; fi enim micæ fint oculorum \& jubarum inftar grandiufculæ \& corufcx, fignum eft ferrum maximopere adhuc crudum \& incoctum effe, nec ufibus multis aptum. Aliter vero fi grana fint exilia, de quibus infra. Alterum genus ferri cufi eft, quod fragillimum eft cum candet, fed tenaciffimum cum friget, vocaturque Svecice Roedbrecbt; hoc quidem ex granis \& micis, non tamen apte \& indubie poteft explorari; ferrum enim optimum tenaciffimum etiam effe debet : provenit enim tenacitas frigida five fragilitas calida ex fulphuris fui copia. Hoc ferri genus non bene cedit malleo, fub quo nec poliri \& levigari commode fe patitur, prefertim anguli non acuti \& continuo acuminati reddi, fed fiffuris infinitis in transverfun ductis hiantes \& fcabri: fed ufque tamen melior hujus notæ certitudo acquiritur in foco fabrili, fcilicet fi in lamellam aut utenfile quoddam tenue formetur; fi enim fulphuratum nimis fit, in lamellas \& utenfilia ejus generis dum fabricatur, in nultas partes fub ictibus diffilit.

Datur etiam ferrum, quod ab utroque genere participat ; quod fcilicet tenaciffime cohæret frigidum, pariter etiam calidum, in quo jufta ratio fulphuris \& temperata commixtio partium ferrum conftituentium fit: hoc admodum tenax eft, optime cudi poteft, lævigari \& poliri, \& textura quadam fibrofa fecundum totam longitudinem bacilli cohæret.

Datur etiam genus peffimum, quod nectenax eft frigidum, nectenax calidum, quod difficile fub malleo diducitur, \& diductum in partes abit, fi $\because$ vel minime incurvetur; hoc a fuis \& peritis magiftris plane rejicitur.

Supereft, ut modum examinandi probandique ferri indolem Svecix Anglixque \& alibi in ufu receptum exhibeam, qui precipue familiaris eft, quum copia divenditur, \& in exoticas regiones per fpatiofa maria transmittitur, utplurimum enim qualitatem ferri fui exploratam tunc habere defiderant., Primum externam ferri faciem luftrant, ex qua utcunque de indole ejus divinant ; fi circumcirca precipue ad angulos fiffuris \& rimis fit confertum \& fcabrum; fignum eft tabe quadam calida feu fulphurea illud effe infectum: pariter notant, num affabre formatum \& levigatum fit. Dein bacilla plura, ex 100 circiter 2 vel 3, per crenam in trabe ductam, feu per foramen in palo terræbene infixo, fingillatim transmittunt, \& primo in levem quendam finum incurvant \& flectunt, \& iterum in lineam fuam reetam reducunt; fi flexuram patiatur, \& iterum in rectam integrum redire velit, tenacitatis cujusdam fignum eft : iterum in curvam urgetur, inque fimilem circulo, \& fxpe in plures circulos circumvolvendo, inque eandem rectam, fi velint, retorquendo, quod indicium eft tenacitatis defideratie. Tertio, folent etiam contum dubix indolis in cuneum quendam prxferratum five hypomochlion acutum vi brachiorum projicere: vel ferrum infuper locatum vi malleorumaut ligonum percutere; fi ictus ferro modo vulnera dent, nec ferrum inde in partes diffiliat, pariter nota tenacitatis eft: prater adhuc plures modos ferrum tenacitatis vel fragilitatis arguere. Quarto, fi vero ferrum rumpatur in partes, quod frepe fimul in $2,3,4$. vel 5 folet, feu.in plures aut pauciores fecundum gradum fragilitatis continuum per totum bacillum, ex granis tunc in fracturis ftatim judicatur, qualis fit ejus indoles; iterum iterumque frangitur in plures, ut fimul dijudicari poffit, num idem 
idem vitium fecundum totam ejus feriem \& longitudinem fe extendat, fexpe enim vitium unam bacilli partem occupat \& defoedat, altera meliore manente, frpe etiam nimis uftum in loco fracturæ finiftr indolis judicium fubit, quum utrinque tamen lætiora in eodem bacillo dentur figna \& grana. Quinto transfertur inde in focum fabrilem, \& quale fit in igne \& fub malleo exploratur, num ignitum vulneribus mallei mollius cedat, vel num ictibus obnitatur; \& qualem fcintillarum aut ramentorum copiám emittat : bacillum feu fragmentum ejus huic examini fubmiffum præcipue in foleas \& clavos acutioris cufpidis feu minores extenuatur ; quæ fabricata iterum ut in partes frangantur, torquentur, utque difrupta grana iterum oftentent, hoc eft, qualia fint ante \& qualia poft ignitionem : utplurimum in lamellas attenuari folet, quas dein huc \& illuc torquendo \& inflectendo, exftantiffime per numerum plicationum ipfum tenacitatis gradum explorant \& fibi palpabilem fiftunt : ignitum etiam in fpiras \& helices contorquetur, in fila craffiora educitur, \& in diverfi generis opufcula tenuia, quæe plicata \& flexa indicant corporis nervofi refiftentiam; \& denique rupta per granorum aut filamentorum ordinem, dimentionem, lumen \& colorem.

Alias quia ex granis optime de qualitate ferri cufi judicari poteft, \& clariffimus Dominus RE a u M u R follicite granorum textum \& figuras comparate ad textum \& figuras in chalybe defcriplit, pariter etiam delineavit hinc præftat illa, una cum ipfa illarum figuratione fiftere.

\section{De notis \& qualitatibus ferri ex fractura ejus dignojcendis ex Domino Reaumur.}

R Egula generalis prima eft, quod ad chalybem ufurpari non debeat ferrum multifariam fciffum, \& bracteolis \& fiffuris plenum ; eft eligendum illud, quod concinne \& pulchre eft excufum : quod fciffuris hiat, poft malleationem chalybis inde confecti apparent demum nevi quam plurimi; \& fape in ferrum redire folet, vel ægerrime tractari fe patitur, inidoneum etiam eft fabricandis utenfilibus.

Ferrum fulphuratum in chalybem converti non debet, fivequod Gallice Rumbelin, Svecice Roedbrecht appellatur, fcilicet illud quod candens vel calidum fub mal!.so in plures partes rumpitur, nec pati poteft ietus ejus.

Optime rognofcitur ferrum ex moleculis, colore, granis, fibris, filis \&c. fi fragitur. Alias in binas claffes dividi ferrum poffe videtur; fcilicet fi in fractura grana \& lamellas diverf $z$ figure poffideat, vel fi fibras oftendat. Hæ binæ claffes in feptem alias fubdividi poffunt.

Peffimum genus eft quod fimile eft Fig. I. Tab. XXXI. In fractura apparent lamellæ albæ, fplendentes, nitidiffimæ inftar fpeculorum, fed figuræ irregularis, funt etiam irregulariter fitæ, fed plerumque grandes \& magnitudinis inæqualis; funt interdum quæ 2 lineas diametro æquant; fed fpatiola intermedia funt granis exiguis referta.

Alterum genus fimile quidem eft priori; lamellæ enim æqualiter nitent, fed funt multo minores quam illæ, quarum mentio eft facta, funt 
etiam dimenfione æqualiores, nec tam irregulares ut prædicx ; non multum fpatii intermedii apparet, nifi quod granis fit repletum. Datur etiam genus hujus ferri lámellis majoribus confperfum: vide Tab. XXXI Fig. $2,3,4$.

Tertium genus conftat adhuc lamellis candidis \& fulgentibus, fed qux minores funt quam in ferro fecundi generis; differt in eo, quod totum fpatium hujus generis lamellis non fit occupatum; funt etiam fpatiola granis fubtilibus plena coloris grifei, fimillimis qux funt in chalybe medix indolis, vide Fig. $6,7,8$. Sed differt a chalybe, quod grana ferrinon xque fint rotundata ac illa qux in chalybe: diverfus fitus eft fpatiorum granis his fubtilioribus vel majoribus conftantium; fpatia interdum longitudinem 3 vel 4 linearum \& latitudinem I linex æquare folent: minorem tamen partem fracture ufque occupant.

$\therefore \quad$ Quartum genus fimile eft priori, fed in illo fpatia, quæ granis his fubtilibus conftant, funt majora; vel dimidiam partem vel majorem occupant : ipfemet lamelli nec illum nitorem oftentant, quem lamelix tertii generis: vide Fig. 9.

Quintum genus aliquas lamellas non poffidet, fed tota fractura nudis granis apparet referta : grana ejus differunt a granis 3 tii \& 4ti generis; illius enim grana funt ampliora, vide Fig. I o. Cæateroquin datur hujus'generis ferrum, quod pofidet grana adhuc minutiora, planiora \& mixta cum lamellis quibusdam Fig. I 2 \& melius in Fig. I I \& I 4.

Sextum genus ferri nec conftat lamellis nitidis nec granis, ad minimum funt lamellæ raro tam planx, ut ad lamellas; \& rarotam convexie ut ad grana poffint referri; ufque tamen propius ad lamellas quam ad grana; fed-nitore non gaudent, quo lamellæ primi generis : plerumque heic funt fibræ fubtiles; apparet Fig. I I, quantum reprefentari poffit. Grana hæc ad oculum nudum funt tam grandia, quam funt reliqua ad oculum microfcopio armatum, fed planiora.

Septimum genus in fractura nihil nifi fibras oftendit, \& fimile quid ligno rupto vel fracto, quod genus vocatur ferrum molle. Dantur etiam. plures fubdivifiones, fed quoniam de predictis participant, in vanum foret alias adhuc repartitiones formare. Putat fextum genus ferri facile in ferrum feptimi generis poffe converti, fi rite tractetur : fi etiam ferrum primi generis fub malleo Trepius excudatur, arbitratur inde ferrum $4 \mathrm{ti}$ generis polle obtineri, fed cum jactura ferri \& temporis, vide tale ferrum Fig. 15 .

Addit quod hx varietates fxpe reperiantur in uno eodemque bacillo, fi diverfis in locis rumpatur; feque vidiffe dicit ferrum, in cujus fractura omnes he varietates apparuerint. Ufque tamen ferrum communiter fibrofum, licet grana identidem appareant, ut fibrofum confiderari debere, \& vice verfa.

Primüm genus ferri rejiciendum effe, ut inidoneum converfum eun-: $d i$ in chalybem; chalybem inde factum malleum non pati; a minimo ictu. in partes rumpi, \& pleniffimum reddi fiffuris. Dictum eft, quod chalybs, qui jufto diutius in igne detentus fit, evadat malleatu difficilis; fic etiam; 


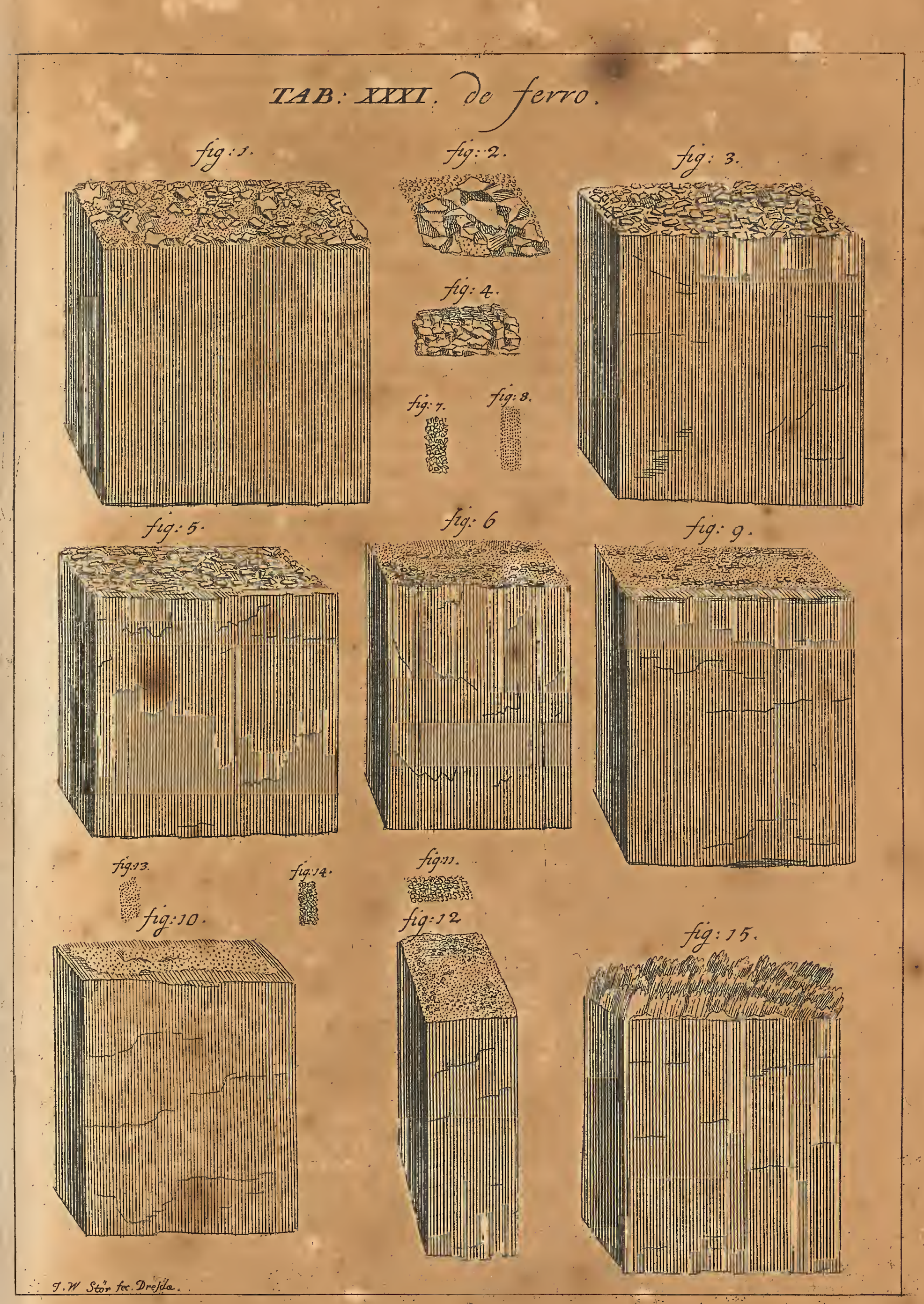




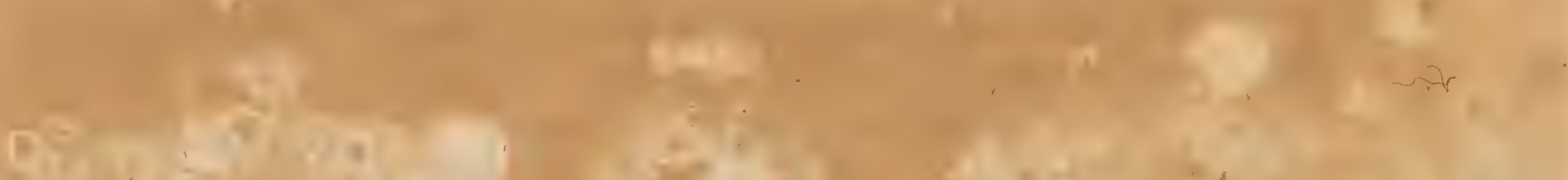
4.

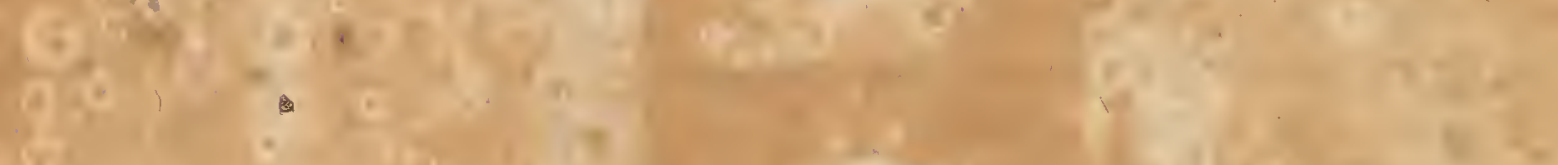

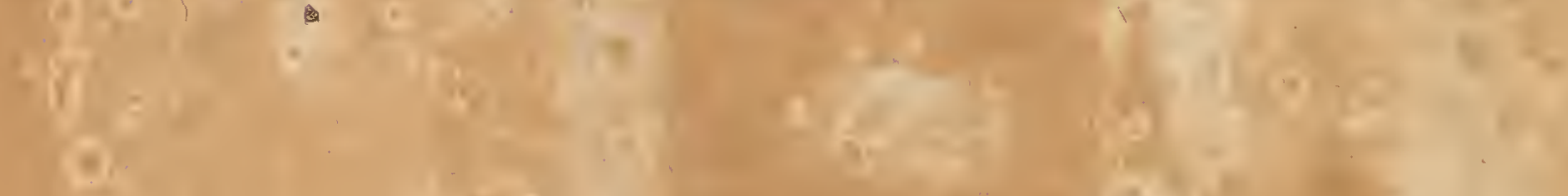

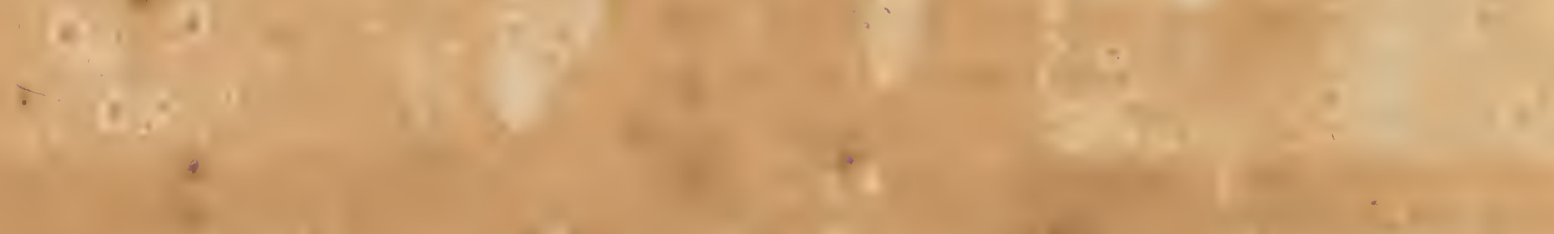

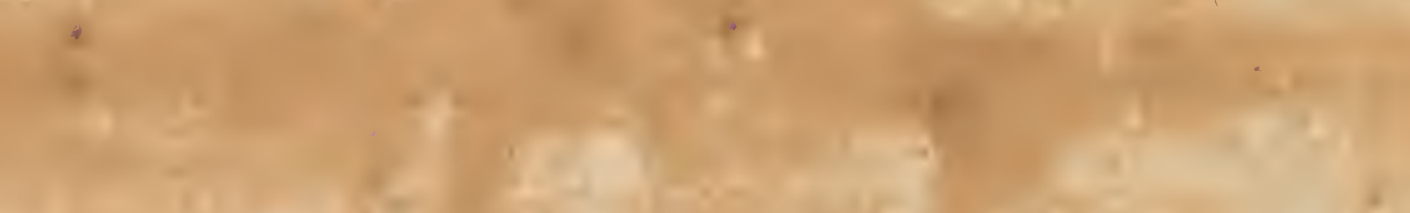

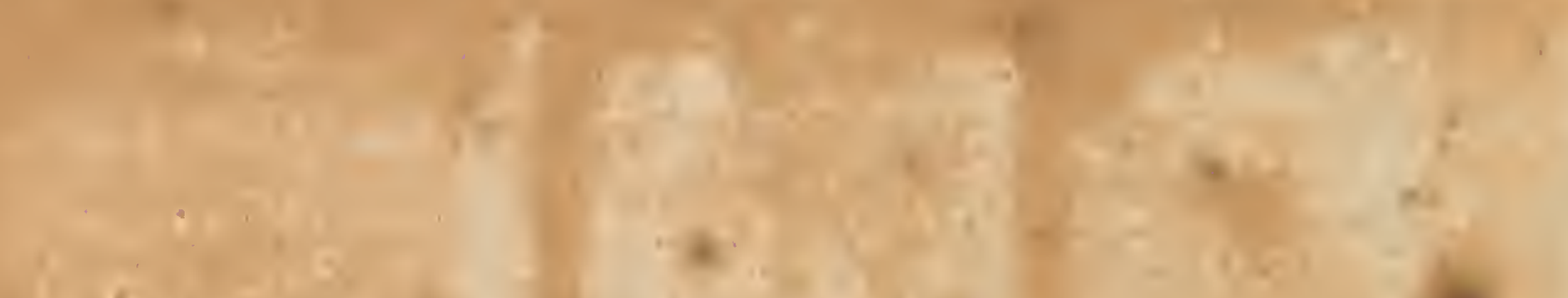
.

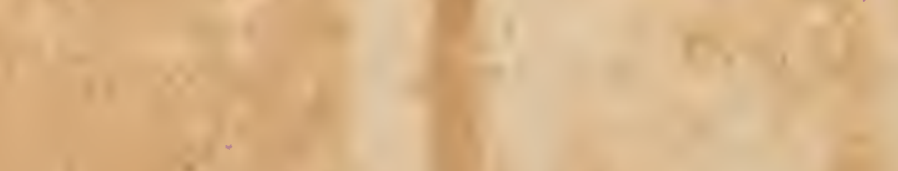

$+$

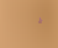

$$
1
$$$$
\text { . }
$$

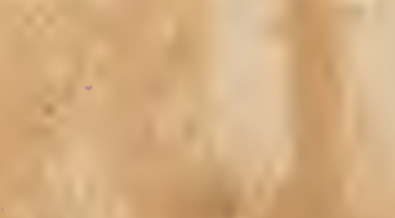

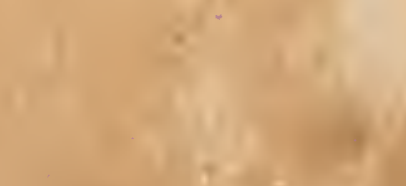

$+9$

$+$

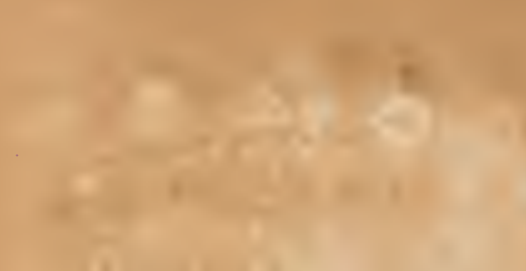
A $4+2=5$

(c) -39

(a)

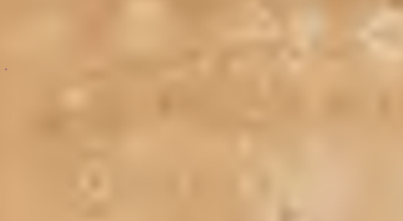

is

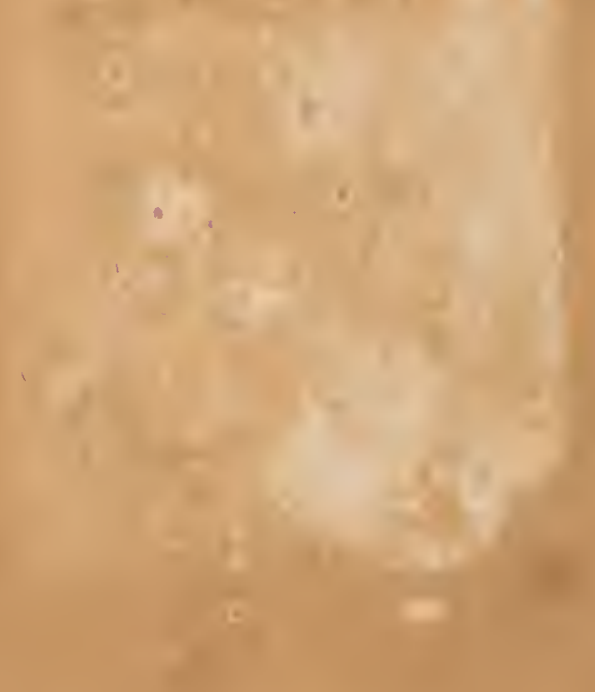

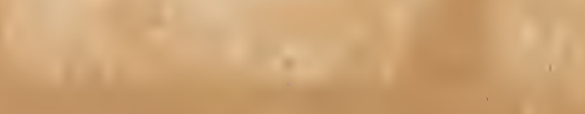

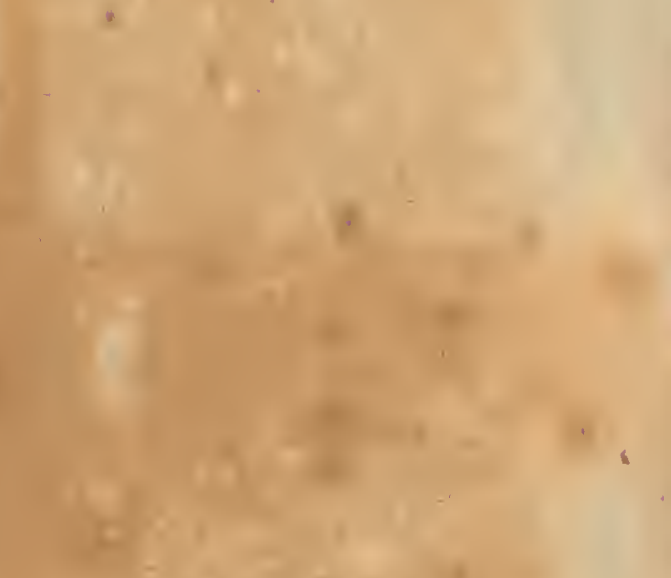


hoc genus ferri in chalybem verf, quantumvis exiguum ignem modo paffum fit.

Secundi generis ferrum nec eligendum effe, ut in chalybem convertatur; melius quidem effe priori, fed ufque tamen chalybem inde factum immitem \& intractabilem reddi; quanvis etiam ferrum hoc a fabris, quum útenfilia aut inftrunienta, quæ polienda \& concinne leviganda fint, ufurpari poffit: auctor adjicit, ex hoc genere ferri etiam bonæ indolis aciem obtinuiffe, fed inde bonitatem fuam acquifiviffe putans, quod citius exemtum furno in bacilla tenuia excufum fuerit. Huic generi ferri dandam effe materiam vel mixturam debiliorem; quod non requirat multum temporis vel durationis in igne: hoc genus in chalybem facilius converti, quam ulla alia; fed in eodem fere tempore cum primo genere. Grana etiam ope ignis adhuc magis \& facilius feparari.

Tertium genus ferri in bonæ indolis chalybem transmutari, præfertim fi fub malleo altera vice extendatur; nec efflagitare mixturam admodum fortem, ignem tamen breviorem quam genera alia. Chalybem inde durum admodum fieri, quique majorem nitorem poffideat, quam chalybs, de quo in fequentibus agendum fit. Chalybem generaliter confervare eundem colorem, quem poffederit ferrum; illum enim ex ferro nitenti confectum, etiam nitidum reddi ; quique ex ferro obfcuriori \& liventiori, fieri coloris grifei.

Quartum genus ferri tuto admodum eligi poffe, \& in chalybem verti; chalybem inde paratum effe coloris grifei ; \& quam optime poffe fub malleo extendi, \& exinde opera perfectiora fabricari; ipfum chalybem ex hoc ferro oriundum non quidem illam duritiem poffidere, quam reliqu:e fpecies: circa ferrum hoc diuturniorem moram caloris non requiri, licet ignem diutinum non extimeat, quia moleculis \& granis conftar; materiam falino-fulphuream enim ufque ad centrum ejus non impediente pororum contextu facile penetrari ; infuper mallei ictus quam optime pati, quamvis multum ignem paffus fit. Infinitam illam granorum feriem apparere, tanquam in ferro præexftitifet ; ipfum enim ferrum repræfentare naturam quandam jamdum chalybeam, fed immaturam : cum enim in frigida exftinguatur, refiftere limis, non aliter ac chalybs calida exftinctus.

Quintum genus ferri longius tempus requirere, antequam in chalybem converti poffit, quam priora: ineffe enim moleculas grandiores, quæ difficilius aperiantur, \& tranfitum dent materix, qux influat. Ex hocgenere dari etiam ferrum, quod in chalybem coloris grifei convertatur, qui bene elaborari, \& optime ferrum frigidum fcindere poffit: fed fi diutius in igne teneatur, \{ciffuris obftipari; nec tam fortem materiam ei fuppeditandam effe, qualem generi 4to, ufque tamen hoc genus inter fe admodum differre.

Sextum genus, quod nec lamellas nec grana poffideat, non femper in infignioris notæ aciem transmutari, fed qux immitior \& fabricatu difficicilior evadat; inde fæpe oriundum, quod bacilla illius generis craffiora fint; fi vero in tenuiora excuderetur, loco feptimi generis fortafis fubftitui poffe.

Clafjis II. de ferro. 
Septimum genus, fi non fulphureum nimis fit, chalybem perfectiflmum fubminiftrare, at reliquis peciebus diuturniorem ignem pofcere: fibras enim ope ignis prius fcindendas effe, \& fores igni materiaque influendæ aperiendas. Hoc genus ferri mixturam admodum fortem etiam pati pofle.

Si quartum genus fibras etiam interlperfas granis poffideat, adhuc melius effe, \& reliquis anteferendum.

Prout color fulgidus \& maxime nitens non indicium nobilioris chalybis det; hinc vice verla nec indicium boni chalybis, if ferrum coloris fit nimis obfcuri \& nigricantis.

Regulam generalem effe, quo minor particularum contextus fit in ferro, eo fitum omnium regulariorem effe, \& ferrum co aptius; ut in chalybem converfum eat: fi enim moleculix fint exigux, fignum effe ferri melioris \& aptioris : quo etiam fubtiliora fint grana, \& fubtiliores fibra, co in chalybem effe paratius \& convenientius.

\section{Signa Oे $^{\circ}$ indicia mutationis ferri in cbalybem.}

Halybs per fe non fragilis ef, infit auctor, antequam aqua fit exftinctus, hoc eft, antequam fubito fit frigefactus : fi enim chalybs in foco relinquatur, \& ibi reftinguatur, fit inftar ferri : hinc explorari potef, num ferrum in chalybem fit converfum, modo verius incudis cujusdam angulum valide projiciatur, vel malleo, fuper angulare \& acuminatum quoddam ferrum repofitum, percutiatur; fi rumpatur, fignum eft chalybis, fi vero non, fignum eft, chalybeam qualitatem nondum ad centrum penetravifle.

Textura interior valde differt, ait, in chalybe a contextu interioriferri ; fi enim chalybs pejoris notre fit, tive qui fub malleo tractari nequeat, textus apparet finilis textui feri primi generis vel peffime notx: fed differentia hujus chalybis \& ferri pejoris eft, quod in chalybe fint micæ vel lamella regulariter pofitx, inter fe formæ regularis, illarumque planum femper parallelum cum utraque extremitate bacilli; nec quod tot tantumque inclinantia inter illas plana compareant, ut in lamellis ferri pejoris, nec inter illas copia patiorum inanium confpicua. Altera differentia eft, quod color in chalybe magis lividus fit \& obfcurus, quam color in ferro dicto communi, funt nitore deftitutx micx: fuperficies micarum apparet magis fcabra \& afpera, lumen enim ab illis debilius refiectitur. Micæ in hoc genere chalybis nec lemper ejusdem magnitudinis \& coloris funt, nec in eodem puncto omnes lividx.

Prima mutatio in ferro fibrofo contat in eo, ut fibræ rumpantur; \& primum quidem illie fibræ, qux fuperficiei funt proximx, proximæ enim. funt actioni ignex, \& fic ordine \& fucceffive interiores, \& ultimo fibre centrales ferri: fi ferrum rumpatur, antequam plene converfum fit, tunc. in centro \& circumcirca centrum apparent adhuc fibræ, dein verfus fuperficiem nihil videre licet quam lamellas : quæ anguftum quoddam cingulum formant, quod dein magis \& magis ampliatur, \& ufque ad centrum 
penetrat. Laminæ primæ vel quæ primum loco fibrarum fuccedunt, funt nitidx, fulgentes \& limiles illis, quæ funt in ferro primi generis; differunt tantum in eo, quod regularius fint pofitx, nec interftitia adhuc facta fint chalybea, quamvis ad converfonem quandam difpofita fint. Continuato igne, laminx albedinem \& fulgorem fuum infenfibiliter perdunt, fiuntque obfcuriores \& grifei coloris, qualis color in nullo ferri genere apparet: quumque lamellæ verfus fuperficiem magis magifque grifei coloris evadant, tunc fibræ centrales in micas aut lamellas fulgidas quafi fecantur.

Alias in uno codemque bacillo ferreo funt lamellæ tam lividæe, obfcur: quam fulgentes, ut \& fimiles Figur: 4 Tab. XXXII: centrum fibras fuas etiam amittit, \& primo micas nitidas, dein minus \& minus fulgentes recipit, dum tandem nube quadam fenfim adumbretur. Quumque hoc peragitur, mutatur etiam ftatus illarum, qux fuperficiei funt proxima, dividuntur lamellæ in micas \& grana, tum in granula minora, vide Tabul. XXX II Fig. 5. Et circa quendam terminum difparent plane lamellæ, nec videre licet nifi grana complicata pauxillum plana, \& coloris magis grifei, quam in lamellis aut granis in medio.

Quod jam dictum eft de hujus ferri converfione, idem accidit circa converlionem ferri 3 tii \& 4 ti generis, cui nullx fibre infunt, fed modo micæ \& grana. Primus effectus ignis in tale genus ferri eft, quod grana in lamellas vel micas fulgentiores \& majores reducantur, quam ill: funt, quæ prius in ferro exftiterant; nam uniri \& combinari plura grana videntur, ut unum majus formetur; majores ha mice regulariorem fitum recipiunt, fed prædictæ fenfim \& per gradus illuftrem fuum \& nitentem colorem amittunt; apparet, quod ignis tanquam minore vi ad combinationem horum. granorum in micas fulgentiores \& majores, quam ad biffectionem fibrarum \& reductionem in hujufcemodi micas, opus habuiffet.

Exacte admodum cognofci poteft, adjuvante fola infpeetione, quando ruptus fit chalybs, num ferrum in chalybem faturum jam plenefit converfum vel non, quodcunque fibrofum \& corufce lamellatum eft, ferrum omnino eft, centrum bacilli illam qualitatem habere' folet. Varias etiam ob caufas accidit, quod ab una parte bacilli purus fit chalybs, ab altera lamellis corufcis modo conftans, quum in aliis partibus exdem obfcure liveant. vide Tabulas XXXI \& XXXII Fig. 6.

Per infpectionem etiam cognofci poteft, non modo num ferrum fit fufficienter chalybs converfus, fed etiam num ferrum ad chalybem aptum fuerit vel non: fi enim omnes micx vel lamella difparuerint \& grana obfcure livefcant, prout in Fig. 8 Tab. X X XII, fignum eft, nimium ignem fuiffe, \& chalybem immitem nec bene tractabilem : contra verofi granula cingulum quoddam exiguum forment, fignum eft, quod chalybi fufficiens calor fit datus, fcilicet dum evaferit durus, \& fub malleo facile tractári potuerit. Si vero cingulum hoc tam craffum fit, ut craftities ejus plus fpatii occupet, quam micæ \& lamellæ, rarum eft, quin chalybs in hoc ftatu in rimas findatur; fique non, fignum eft, ferrum effe optimæ indolis. Debet ergo fpatium a micis vel lamellis occupatum majus effe fpatiogranorum.

Quod- 
Quodcunque fpatium granis refertum eft, nimium ignem eft paffum, \& ulteriorem gradum quam requirit chalybs; ufque tamen inhiberi nequit, quin aliqux ferri partes gradum illum transfcendant, quum reliquse ad gradum debitum perveniunt. Hinc ferrum a fuperficie ad centrum ufque differt variis chalybis gradibus; nam chalybs in centro admodum. differt ab illo in fuperficie, ut \& intermedie.

Signa ergo converfionis ferri in chalybem funt fequentia : primum apparent micæ corufcantes, xquales \& meliori ordine repofit: quam in ferro: micæ evadunt fenfim liventiores \& fimul in grana diminuuntur, \& tandem in tam pufilla, ut nudis granulis conftet; cumque grana nitent, funt adhuc ferrea: led cum incipiunt livere, in chalybem convertuntur, fed in molliorem : cum adhuc magis livent, in chalybem optima indolis eft converfum ferrum : fi adhuc minutiora fiant grana \& liventiora, fuppeditant chalybem duriorem. fubtiliorem fed tractatu difficilem. Sidemum micx ejusdem fubtilitatis fiant, ac grana, fignum eft, chalybem intractabilem effe.

Ex his fequitur, fi ferrum fit craffum, quod omnes memoratæ differentix inibi occurrant \& ad oculum appareant : hinc ferrum attenuatum in chalybem xqualiffimæ bonitatis converti poteft.

Ferrum primi \& fecundi generis aliter in chalybem convertitur: pars fuperficialis non modo in micas regulares abit, fed etiam micx difparent in grana, antequam pars ejus interior nitorem fuum amiferit, quæ conftat micis; hoc eft, jufto citius convertitur pars fuperficialis in chalyben , \& materias falinas \& fulphureas imbibit, nec jufta proportione continuatur converfio verfus interiora ; nec pars interior prius in chalybem convertituri, quam pars proxima fit nimius chalybs, quod accidere folet, quamvis bacilla fint admodum tenuia.

Ferrum quarti generis transformatur in lamellas vel micas minores, quam ferrum, quod prius minutim eft granulatum \& micis confperfum; apparet tanquam quælibet mica in grana fe convertat, in reliquis vero quod plura grana in unum majus le combinent.

Datur etiam chalybs malleatu difficilis, quamvis infperfa fit pars lamellarum vel micarum, fed ufque tamen funt coloris ad grifeum magis vergentis.

Hinc fequitur, quod grana recipiat diverfi magnitudinis; prout recipit diverfos livoris gradus, quod precipue oritur ex differentia ferri. Hinc non modo exploranda venit differentia micarum \& colorum. fed etiam differentia ferri, quod chalybem producere poteft, cujus figna varie differunt.

Alias apparent in fuperficie chalybis jam dum facti bullæ quædam \& élevationes fphæricæ cavæ, vel fphæroidis ellipticæ, funtque differentis magnitudinis \& fitus; unum bacillum ferreum interdum 3 vel 4 majores bullas \& infinitas minores, interdum minores, non vero majores recipit, rarum eft, quod nulla fit. Hae figno funt, quod ferrum magnum ignis gradum fit paffum, vide Fig. 4, 6,7,GG. gg. Tab. XXXII; necapparent 


\section{TAB: XXXII. De ferro.}
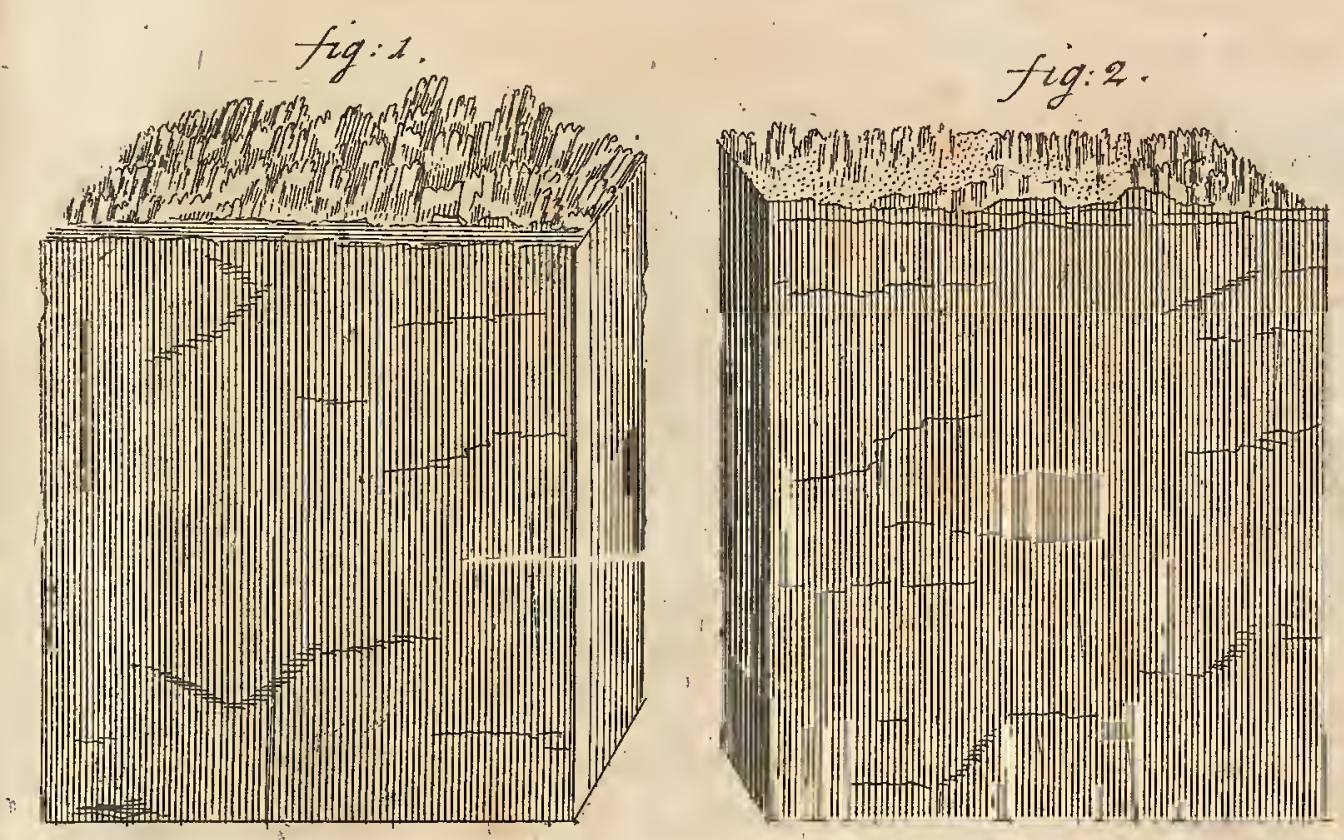

fig: 3
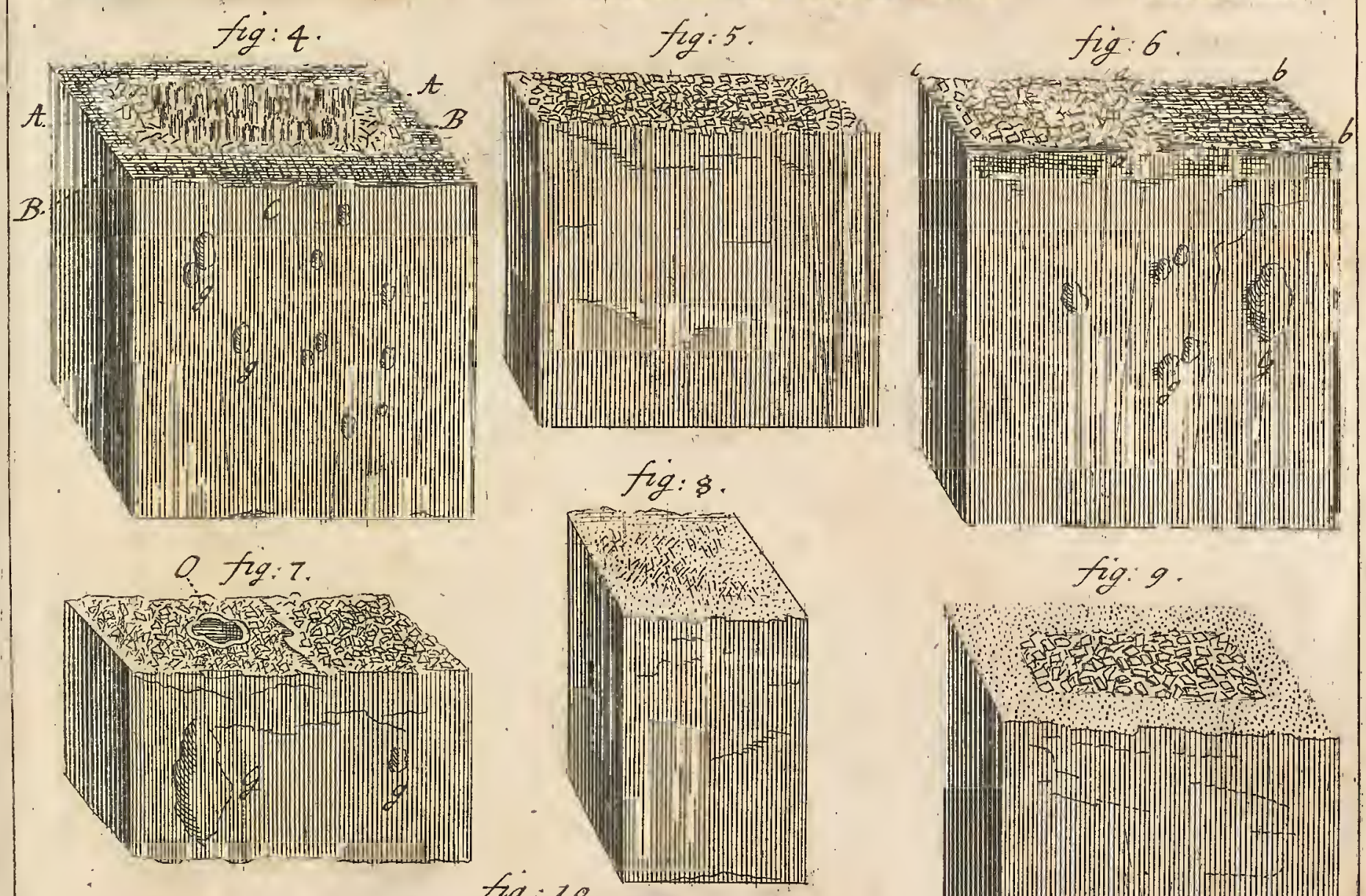

fig: 10 .

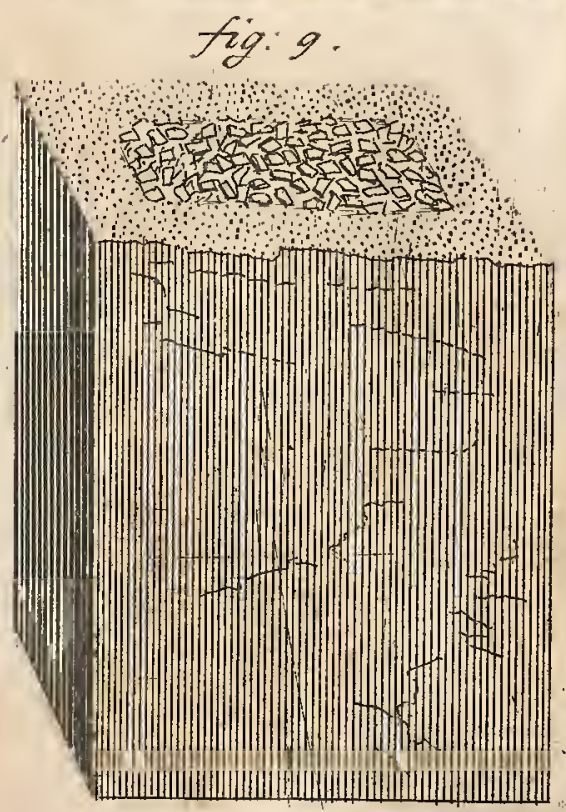



modo in fuperficie, fed etiam in folido corpore ferri tanquan cavitates I vel 2 lineas diametro æquantes Fig. 7 . 0 .

Experimentum fecit autor, ut firet, ex quanam re provenirent dictx bullulx \& elevationes, fcilicet num ex falis copiofa influxione : cum partem falis certo cuiquam loco applicuifet, nullx tales propullulationes funt animadverfx; fed videbantur oriri ab expanfione beneficio fulphuris facta, in locis ubi cedentiffimum effet ferrum.

Bullæ dictæ indigitant ignem nimis violentum \& diuturnum fuife, \& materiam fortem \& nimia vi agendi præditam : ferrum enim nondum ad dimidiam partem in chalybem converfum interdum infinitas tales bullas in finu fuo \& fuperficie recipit, quod fignum eft caloris nimis violenti ; t vero fi ignis mediocris \& diuturnior fit, vix fphærule hæ dimidiatæ apparent.

Præterea apparet extenfio quædam per totum corpus chalybeum five ferreum, longitudo bacilli ferrei i 5 digitorum augetur in longitudinem I 5 digitorum, \& $I_{\frac{\mathrm{r}}{2}}$ linex.

Augetur etiam pondus ferri in chalybem converfi; ferrum quoddam 3 libras minus quam $1 \frac{1}{2}$ grana pendebat; fed in chalybem converfum, pendebat 3 libras \& 128 grana; exactitudinis caufa adimantur adhuc 20 gra$\mathrm{na}$, reftat tamen augmentum 108 granorum; ponderis augmentum fipatio 4 vel 5 dierum poft ipfam converfionem apparet, hoc eft, augmentatio 36 granorum in qualibet libra, five $\frac{1}{\mathrm{I} Z 5}$ pars priftini ponderis. ' Experimentum etiam hocfactum eft cum ferro Svecano, cum quo eadem ponderis \& voluminis incrementa obfervata funt.

Si ferrum in chalybem converfum refrigefcat in ipfo furno, indurefcit quidem, fed non in illo gradu, quo fi exftinguatur; duritiem fereferri durioris imitatur \& fimulat; fed fi chalybs dein calefiat $\&$ exftinguatur, duriffimus inde evadit. Si chalybs ignitus \& furno exemtus fatim exftinguatur, fragilis fit, \& lamellas amittit, \& grana ad caloris gradum proportionata fubeunt, quem fcilicet gradum habebant, cum exftingueretur : fed micx non tam æquales funt, nec tam pulchræ, ac cum fub malleo fimul extenditur.

Ex bacillis probatoriis licet cognofcere, quando calor ad debitum gradum pervenerit; \& chalybs fat caloris paffus fit: tunc enim furnus refrigerandus eft, antequam aliqua pars chalybis eximitur. Materia etiam combulta in cineritium poteft demitti; \& janua claudi; quæ fi libere aeri exponatur, in cineres facile folvitur, cinifque ufui ulteriori ineptus evadit.

Chalybs dein fub malleo excudendus eft, fed antequam hoc fit, calefaciendus in foco modo vulgari : led fi chalybs de ferro optimo non factus fit, \& multum ignis paftus, tunc ictus mallei ægre perferre poteft, evolat enim copia fintillarum, \& fifuris hiulcus redditur. Optinum eft, ut chalybi calor debilis primum fuppeditetur, ut fcilicet ad rubedinemnon vero ad albedinem calefiat : datur etiam chalybs, cui candefcentia alba ftatim dari poffit, fed preftat ut primus calor mediocris fit. Putat ergo, melius effe, ut chalybs in furnis reverberii, in quibus calefieri folet ferrum per cylindros transmittendum \& attenuandun.

Claflis II. de ferro. 
Chalybs excufus non majorem partem amittit, quam alias ferrum malleatum : in ferro Svecano 4 ti generis expertus eft perire $\frac{x}{T \overline{2}}$ partem, quum fcilicet excufum fit in contos quadrangulos 2 digitoslatos \& 4 lineas craflos.

Chalybs latitudinem multam habere non debet, quum tenuis eft, quoniam fub malleo facile plicatur fecundum Fig. so Tab. XXXII. Et licet plica per extenfionem difpareant, ufque tamen aperiuntur, quum utenfilia funt formanda. Mallei exigui funt meliores majoribus.

Quotiescunque calefaciendus eft chalybs, dein etiam exftinguendus eft; poftque exftinctionem melius a plerifque operatoribus de qualitate ejus quam prius judicari poreft.

Exftinguitur chalybs, cum ad colorem cerafi reductus fit, qui color fufficit ad duritiem ei inducendam : in fractura chalybis exftincti apparent grana fubtiliora, magis minufque fecundum qualitatem chalybis \& gradum caloris quem receperat; led de his alibi melius.

\section{Defcriptio Figurarum.}

\section{Tab. XXXI.}

Fig. I. Fractura ferri majufculis micis conftantis.

2. Fractura ejusdem ferri, ubi adbuc grandius expofita funt mice, illarum. que inclinationes.

3. Fractura ferri fecundi generis.

4. Fractura ejusdem ferri grandius reprefentata.

5. Fractura ferri fecundi generis, fed ubi mice funt minores.

6. Fractira ferri tertii generis, fed in quo mice funt mixts cum granis.

7. Reprefentat feorfim grana micarum precedentium, fcilicet Figure 6.

8. Grana Figure 6ta Jeparatim.

9. Fractura ferri 4 ti generis, ubi mice pauciores. funt, quam grana.

I O. Fractura ferri sti generis, pars que ibi unita apparet, non eft genuina ferri fracti figura, ,ed per forficem fecti. ris refert.

I I. Fractura ferri, que majufcule reprefentatur, Ef fere fpeciem 6ti gene-

12. Fractura ferri quadrati 5 ti generis, grana inibi funt fubtiliora granis Figure 10. Habet eitam micas fubtiles.

13. Grana Figure I 2 ma.

14. Lamelle vel mice Fig. I 2 me.

I 5. Fractura ferri feptimi generis fibrofi, quod speciem quafs foliorum refert.

Tabula XXXII.

Fig. I. Ef fractura ferri fibrof 7 mi generis; cujus fibre funt craflores $E^{2}$ multa illarum pars combinata, nec diffincte exbibet folia.

2. Fradtura ferri tam fibras quam grana reprefentantis.

3. Fractura ferri cum micis grandioribus, granis $E^{2}$ micis mixti.

4. Fractura ferri fibrof parte quadam in chaljbem berfo. Cinctura micis liventibus conflans, que chalybea eft E reprefentatur (AA), fed (BB) Juperfi. 
ciem micis fulgentibus conftantem Jignificat. In boc loco funt fibre rupte $E$ ad converfionem in chalybem proxima: fibre centralem partem adbuc occupant.

5. Fractura ferri bons indolis in chalybem conver 2 ; prope fuperficiem major pars micarum apparet quam circa centrum.

6. Fractura ferri, cujus pars (a a. bb.) in chalybem optime eft converfa; parte (a a, cc.) remanente adbuc ferrea: quod factum eft, quod capfula rimas docente ferrum adureretur: $(\mathrm{G})$ ef bulla major. $(\mathrm{g})$ eft bulla quedam minor.

7. Fractura chalybis jufto dustius in igne detenti. Simt ibi lamelle quibusdam in locis linentiores, quam opus requirit, in aliis. funt jufto minores. (Gg) funt in fuperficie eminentie bullares. (O) eft bulla in medio ferro dilataia.

8. Fractura ferri, quod lamellas exiguas, quum in chalybem conneritur, Semper recipit.

9. Fractura ferri fecundi generis, in cujus medio adbuc funt lamelle fulgide, nec in aciem adbuc transmutate; illud, quod circumcirca eft, in cbalybem eft trans. verfum, fed loco lamellarum bic funt grana fubtilifima.

I O. Bacillum chalybeum latum fub malleo plicatum (b): que plice dein, cum exfinguitur $\mathcal{E}$ in utenflia quedam fabricatur, aperiuntur.

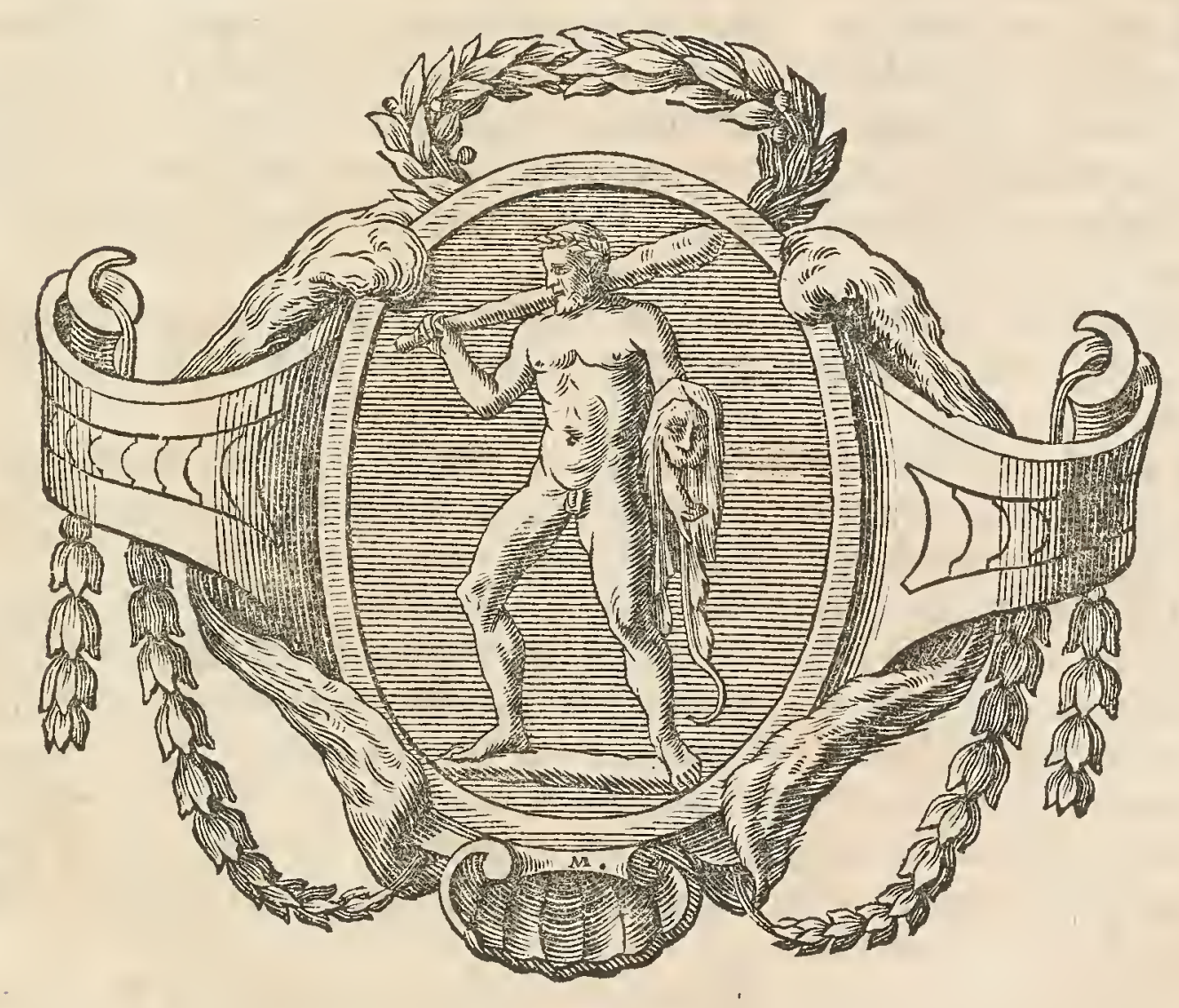

PARA- 


\section{PARAGRAPHUS V.}

De notis 8 qualitatibus chalybis ex fractura pracipue dignojcendis, ex Domino Reaumur.

\section{Characteres, ferri \& chalybis \& quomodo invi- cem differant.}

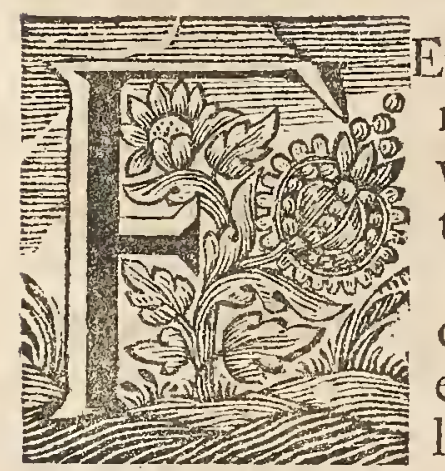

Errum exfinctum, ait, fit fragile, durum, granis parumper rotundatis conftans: chalybs in in ipfo foco vel furno fenfim refrigefat, vix a ferro dignolci poteft, mollitie fere ferrum æmulatur.

Differentia ferri \& chalybis in eo etiam confiftit, quod chalybs promptius quam ferrum calefiat : fi enim æqualis fit calor, tunc chalybs cirius accipit colorem igneum quam ferrum, qui color certum caloris gradum denotat : fcilicet fi ejusdem dimenfionis aut magnitudinis fit frultum chalybeum cum ferreo.

Verbo, chalybs nihil aliud eft quam ferrum a fulphure \& fale penetratum. Omnis chalybs reduci poteft in ferrum, fi in magno calore teneatur, vel in calore mediocri led diutino: operatores talem chalybem vocant acier furcbauffé; vocatur acier pamé, qui per exftinctionem in frigidis duritiem ampliorem non recipit. Hoc genus chalybis jam in ferrum eft verlum.

Eft genus chalybis, qui odorem fimilem fulphuri communi a fe fpar. git : acidum victriolicum Martis \& oleofum fimul unita fulphur hoc componunt.

Chalybs per nimium calorem fere in ferrum reverfus difpofitionem partium priorem confervat : fi enim chalybs exferro fibrofo fit factus, redeunt fibræ multo fubtiliores quam fuerunt prius.

Chalybs malleatu difficilis in bonum chalybem reftitui poffevidetur, fi igne prunarum diutius calefiat, dumque fulphur \& fal fuperfluum inde disjectum fit. Sed alimenta flammx \& ignis non illis materiis conftabunt, quarum ope in chalybem tanta pars le iterum infinuare poffe, quanta inde evaporata fit; hinc cum hujus generis chalybs capiulx inclufus \& igni ex politus fit, in chalybem tractabiliorem vertitur. At vero fi ignis nimis violens fit, \& flanma fe illuc infinuet, inde non melior redditur, fed in fquamas veluti dividitur.

Quum chalybs intractabilis cum marga pulverifata, cum argilla, cum glarea, cum creta, cum calce viva, calce exftincta, cum gyplo, cum pulvere vitreo, cum oflibus calcinatis, in capfula lutata \& igni dein expofita detentus fir, exinde chalybem enollitum fuiffe, fed offa calcinata \& cretam in emollienda acie reliquis præripuifie palmam, expertum eft. 


\section{DE NOTIS EX FRACTURA FERRI PETENDIS. 277}

Marga \& argilla effeetum lentiorem dabant, fed chalybem interdum in fcorias \& fquamas reducebant. Per gypfum fundebatur plane chalybs, cum ei ignis latis fortis fit datus; quum vero mediocris, chalybs fcoriatus evafit : pulvis vitreus ad mollificationem chalybis nihil contribuit.

Quod cretam attinet, pulverifanda eft, \& cum tertia parte carbonis pulverati commifcenda, \& fic ftratim cum chalybe reponenda, eodem modo quo chalybs paratur : requiritur modo $\frac{1}{4}$ pars temporis, quam cum ferrum in chalybem fit convertendum, modo fit idem furnus. Ratio eft, quod materia cretacea fuperfluum ei inhærens fulphur \& fal auferat.

Quomodo chalybs in ferrum redeat, ab experimento videre licet: fi chalybs in capfula dicta calefiat, dein exftinguatur \& frangatur, apparet circa fuperficiem crufta five limbus tenuis inftar papyri puro ferro conftans, interiora funt chalybea: fi aliud ferrum pariter fed diutius calefiat, exftinguatur \& frangatur, fit inde limbus dictus craffior : in aliud fruftum ferreum adhuc diuturniori tempore teneatur in igne, craffefcit ita crufta dicta, ut verfus centrum penetret, \& lenfin durante igne in ferrum convertatur ; inde enim fulphura \& falia effugiunt, dum nihil amplius ex illis remaneat: fitque hoc non ope ignis violenti fed lentioris.

Quum chalybs mitis \& tractabilis reddendus fit; notandum eft tempus, quum bacillum ferreum crufta aut limbo tenuiffimo ferreo obducatur.

Putare quis poteft, inquit, quod cruftula hæc ferrea, quæ chalybem. circumdat, chalybi damno lit; led preter quod limis abrafa decidat \& detergatur, quum utenfilia aliaque inftrumenta paranda fint, etiam alicui emolumento erit, quum cultri acutiores formentur ; nam laminie chaly-, bex triplicis generis complicandx funt, \& in unum corpus ope ignis \& mallei confolidandx, ex qua maffa dein inftrumenta prædicta conficiuntur. Triplex genus chalybis effe folet, unum optinn indolis, alterum mediocris, tertium rudioris : in chalybe cmollito jamdum exiftit genus hoc triplex combinatum, ferrum fcilicet fuperficiem infidet, prope fuperficiem eft ruditer chalybeatum, \& verfus interiora eft chalybs optimus. Ad diverfi generis utenfilia requiritur chalybs, qui a duabus laminis ferreis $a b$ utraque parte quafi cingendus vel obducendus fit, hinc non opus eft ferro, fed adhæret affigique poteft crufta cujuscunque craffitiei. Præterea in chalybe recoeto fedet chalybs optimus in centro, cum alias in chalybe vulgari fit juxta fuperficiem, quod minoris emolumenti eft.

Tentatum etiam eft, chalybem igni aperto immediate exponere; bacillis ferreis per integrum diem in igne mediocri per folles \&ventum non reverberato relictis; cum dein excuderentur, tertiam partem diminutam apparuiffe, \& limbum ferreum, quo circumdarentur, craffitiem fere infenfibilem habuiffe. Hinc actionem immediatam ignis in chalybem, non multum ufum preftare, concludit.

Ferrum pejoris notx in tali furno primum ab auctore recoctum eft, illum in finem, ut inde ferrum aptum ad chalybem obtineretur : dein ferrum fic emollitum in furnum cum materia conveniente, fcilicet qua alias in chalybem verteretur, miftum eft : fed chalybs inde factus nihilominus, pejoris indolis manfit.

Clalfis II. de ferro.

Aa a

Chaly- 


\section{DE N O T IS E X FR A C T UR A \\ Chalybis diverje qualitates, illarumque mutua comparatio.}

Mlta inhærere vitia poffunt chalybi, quamvis facie externa genuinus 1V appareat; -fiffuris enim fcatere poteft, ut Fig. I Tabul. X XX II I: quando etiam partes angulares hic \& ibi funt incilæ, ut Fig. 2, quod genus difficile eft laboratu. Si etiam rimæ vel nævi fint, ut Fig. 8. $M$, pariter fi intermixtæ fint venæ ferri. Probatio optima eft, fi duo genera chalybis ad rubedinem candefacta ferruminentur vel complicentur : fi enim ad albedinem rubentem calefiat, incifuras oftendit : fi chalybs notæ deterioris fit, cum altero perfecte uniri'nequit, at vero chalybs bonæ indolis facile \& bene ferriminari poteft.

Signum etian deterioris chalybis eft, fi murmur quoddam raucum audiatur; quum enim in foco calefit, hic fonitus a ftrepitu flammæ \& venti internofci poteft, provenit hic a chalybe quafi ebullienti, hujus generis chalybş non bene excudi poteft.

Indicium etiam chalybis inutilioris eft, fi chalybs fuperinftrato pulvere carbonario in foco, ubi calcfit, appareat ficcus, nec quafi glutine quodam illitus.

Si chalybs ignitus fub malleo frangitur, fique cum alio frufto conjungendus in junctura rumpatur, fignum eft chalybis immitioris Tabul. XXXIII Fig. D.

Fabri Parifienfes illum chalybem præcipue æftimant \& pluris faciunt, qui rofam habet : rofa eft fpecies maculæ in fractura apparentis, interdum eft figuræ rotundx; interdum ovalis, interdum irregularis Fig. 4, 5, 6, 7 . Tali rofa conftat interdum centrum ejus, illa in quibusdam occupat multam partem, in quibusảm modo exiguan. Eft coloris coerulelcentis clari, in aliis eft color obfcure corrulefcens ; eft etiam color luteus \& flavefcens, \& jam reliqua parte paullum lividior. Rofie hx in fractura unius ejusdemque bacilli differunt qua colorem, magnitudinem \& figuram; in quibusdam plane non reperiuntur. Ufque tamen eft fignum admodum ambiguum, reperitur rofa in chalybe optimi generis, etiam in chalybe qualitatis mediocris; auctor rofam in chalybe rudiffmo reperiiffe dicit, quique vix nomen chalybis mereatur Fig. 4. Signum tantummodo eft, quod rofa dicta illi chalybis generi tantum infit, qui ex ferro crudo non malleato paratur. Si bacillum parumper calefiat, rofacea hæc figura ftatim difparet \& admodum debilitatur.

Probari etiam chalybs poteft, num ei ferreum quid infit, extendatur in bacillum fimile Fig. 8 \& extremitas $(F)$ frigida exftinguatur; inque medio manu teneatur, \& ab altera extremitate (L) malleo percutiatur; fi chalybs bone qualitatis fit, extremitas altera ex percuffione oppofita frangitur; fignum modo eft, nullas fibrás ferreas inibi refiduas effe.

Tria funt in chalybe examinanda : 1. Grana vel granulorum qualitas, 2. durities, 3. corpus flexibile five quod melius refiftat antequam frangitur, \& differt a duritie in eo, quia illud, quod durum eft, poteft frangi, 


\section{TABD: XXXIII. De ferro}
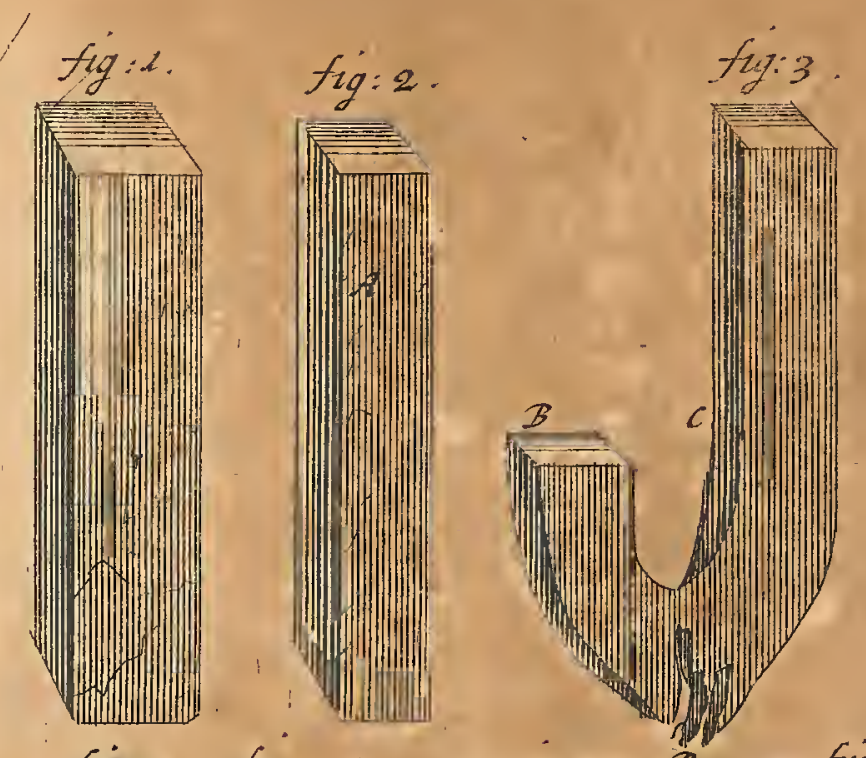

fig: $t$
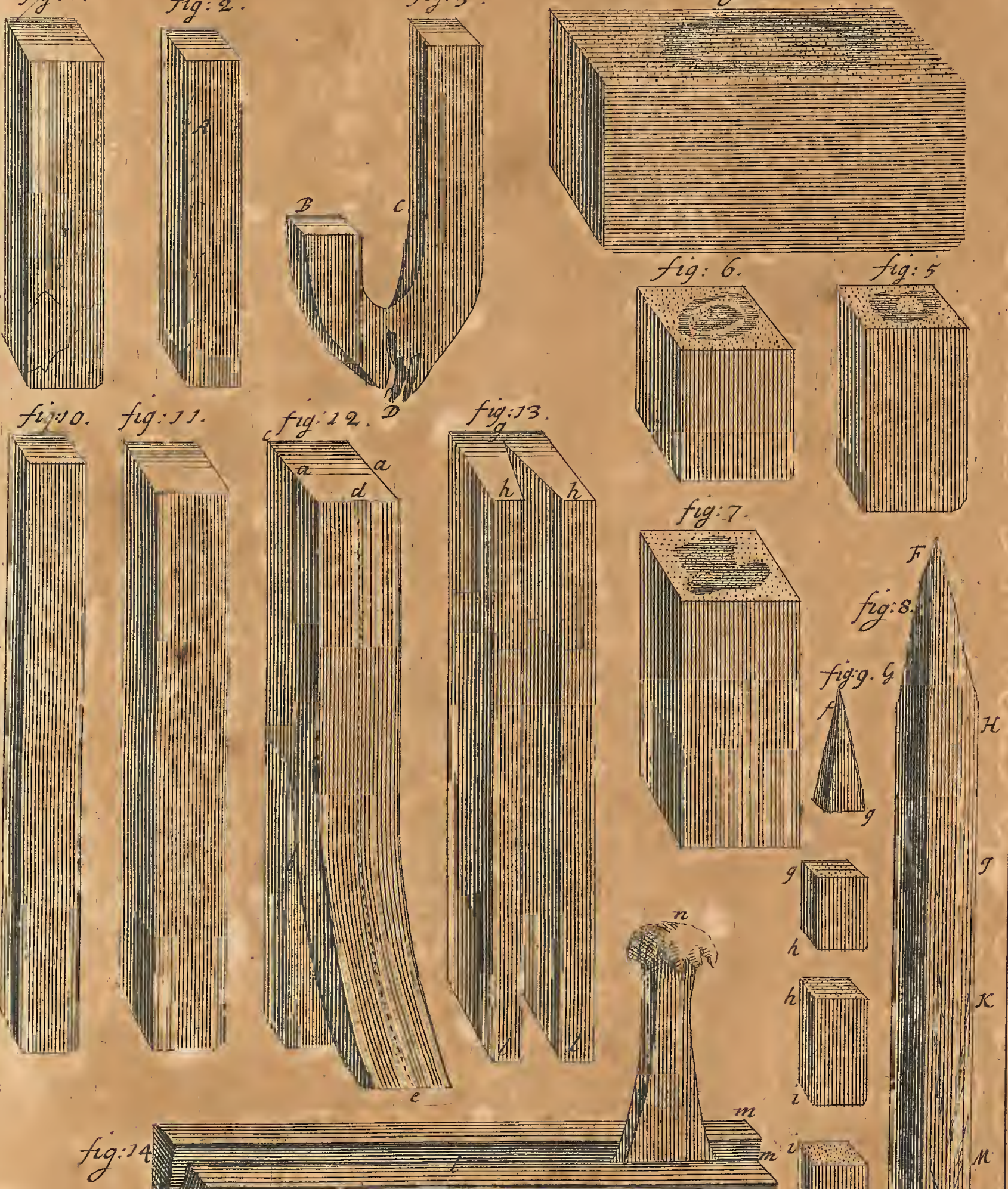


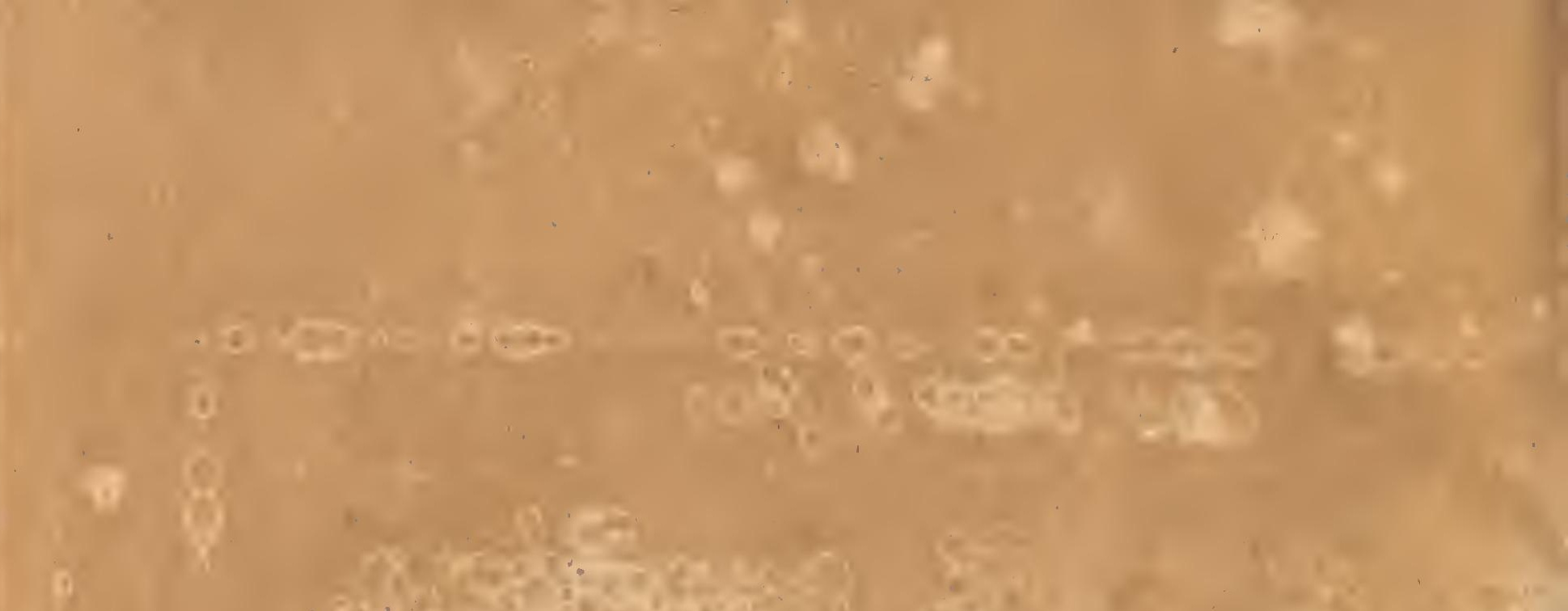

9

$\theta$

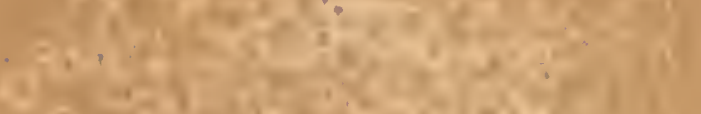

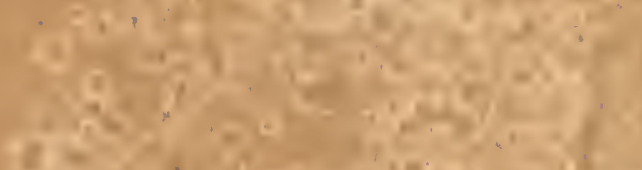
$6+1$,

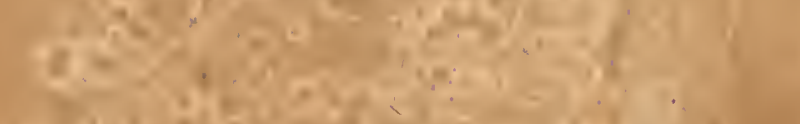

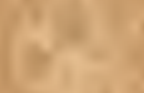

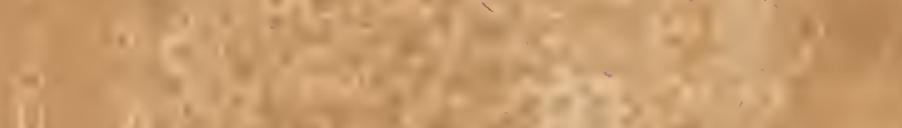

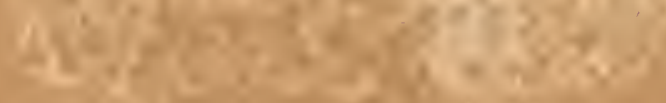

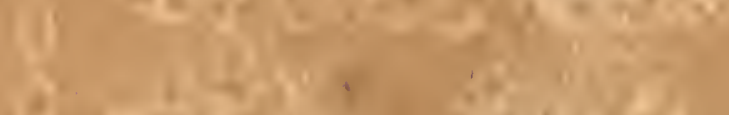

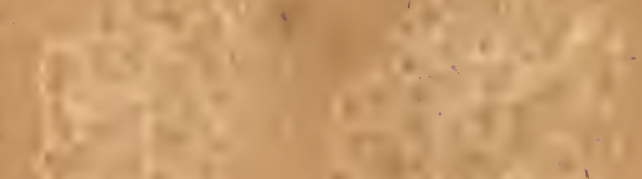

in

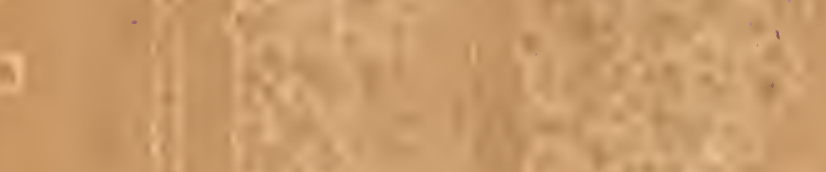

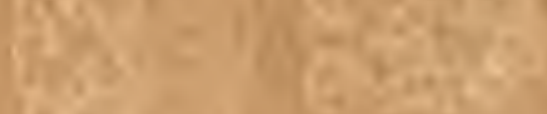

(1) 8

$x^{2}+n^{2}$

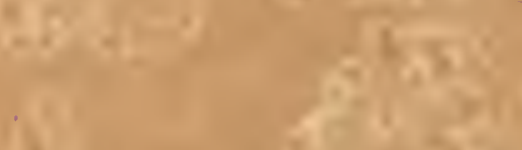

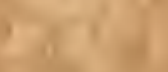

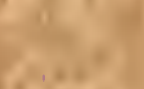

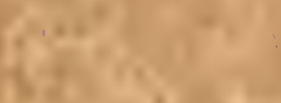

$\frac{17}{4}+2$

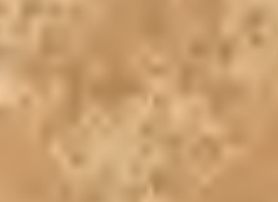

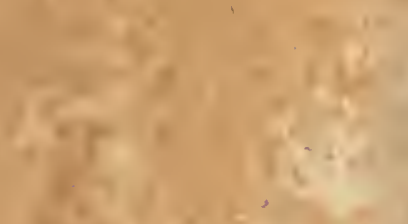
S.7.
4 tis sit. Q in:

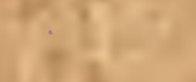
ing 4.91 4ist its ,

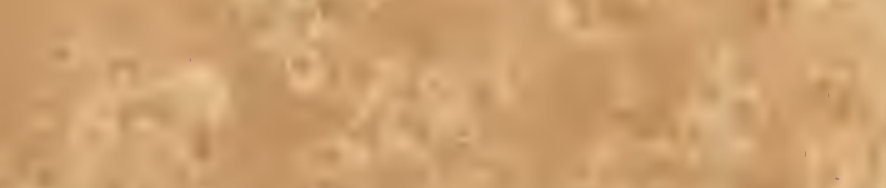

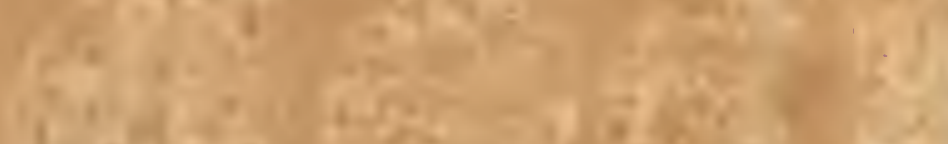

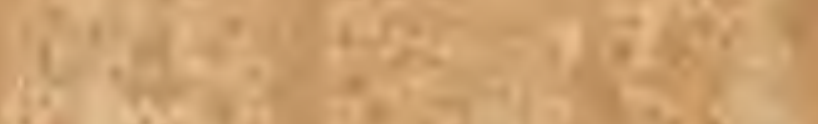

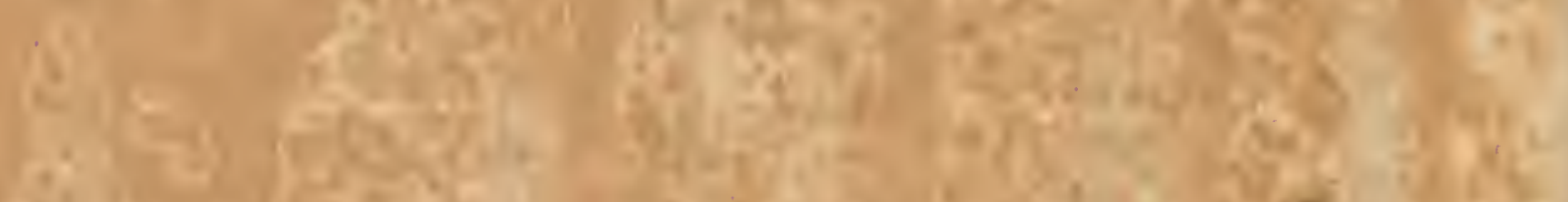

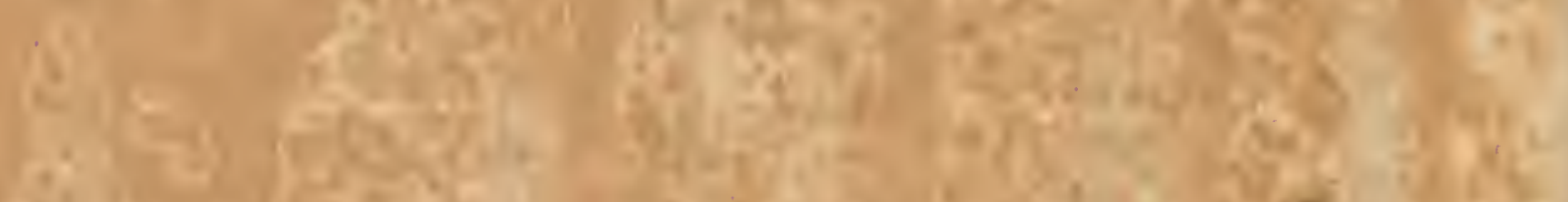

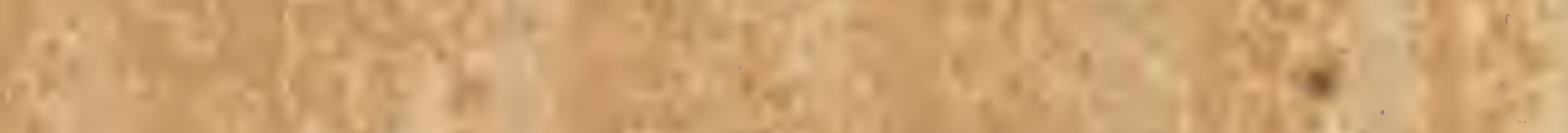

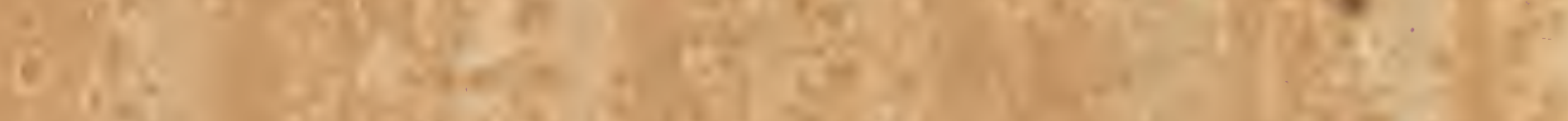

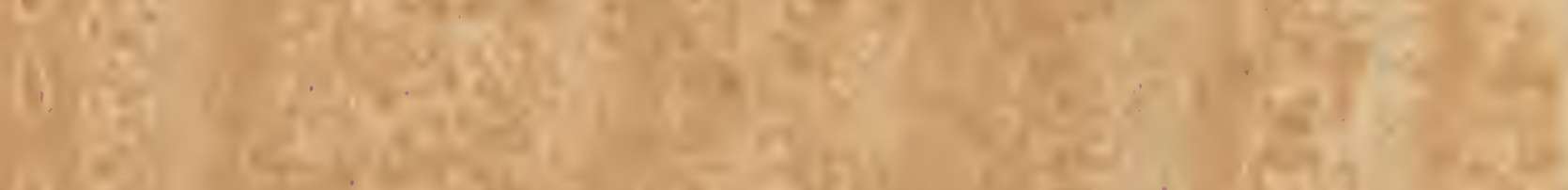

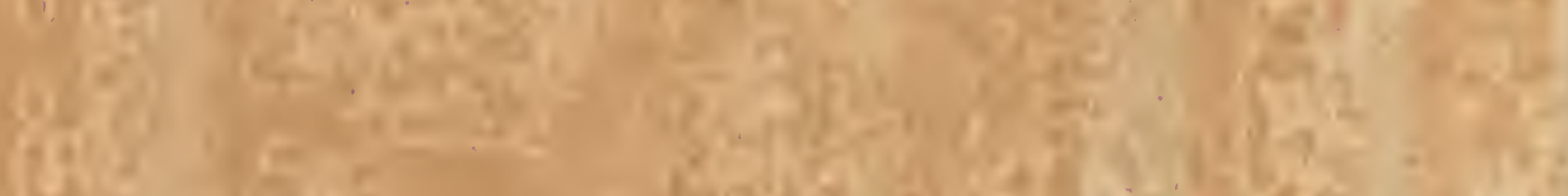

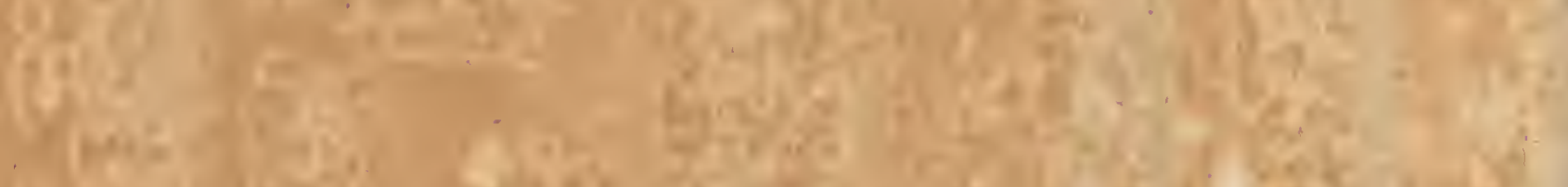

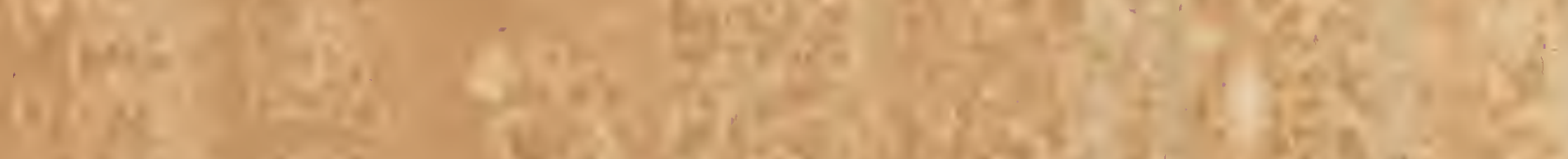

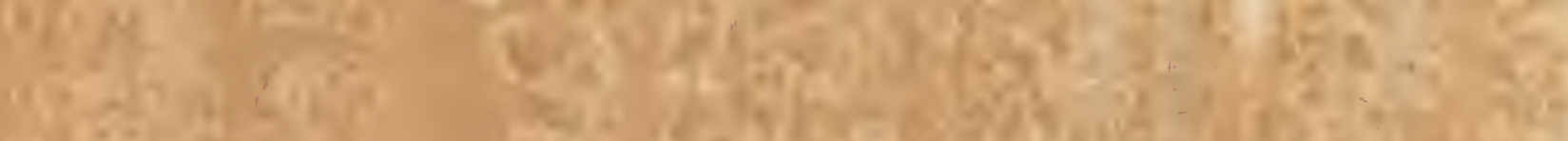

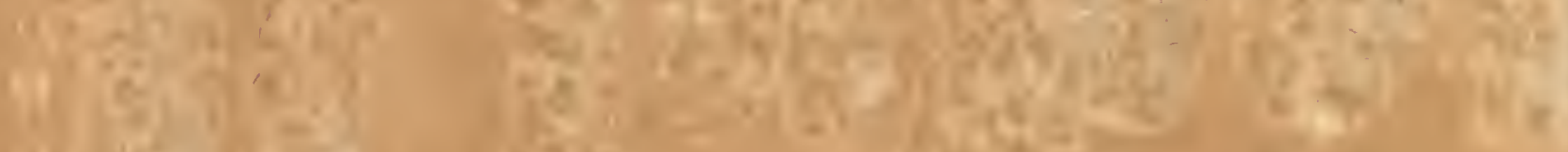

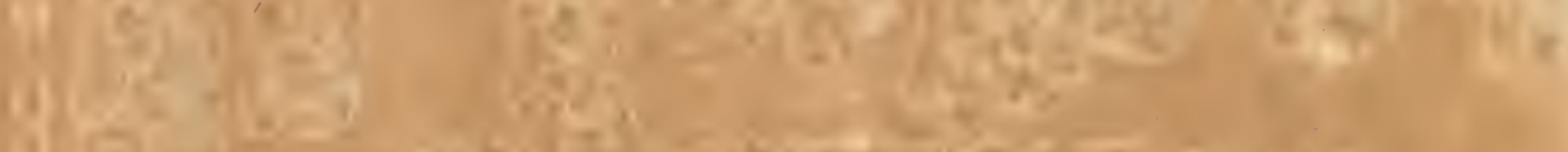

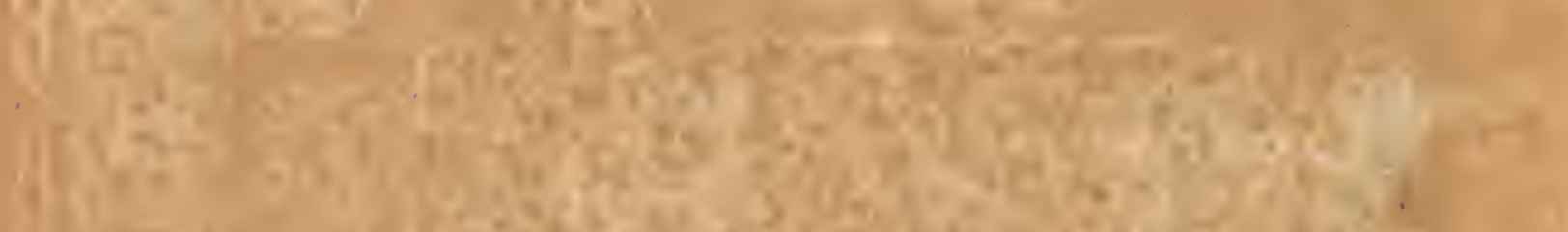

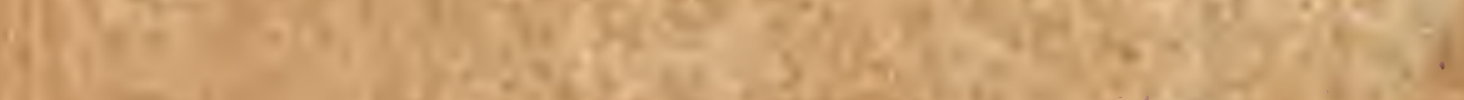

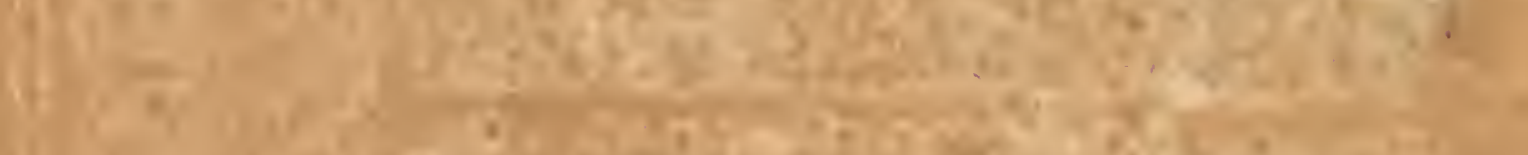

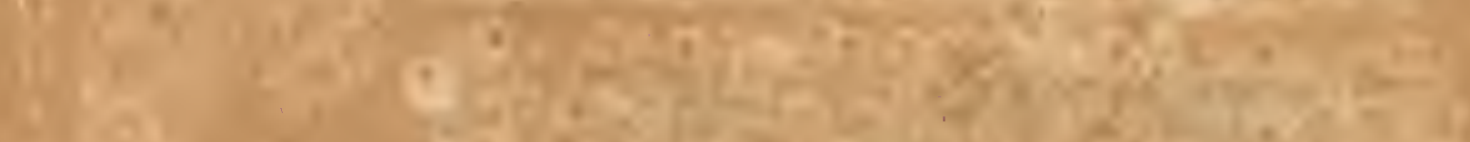

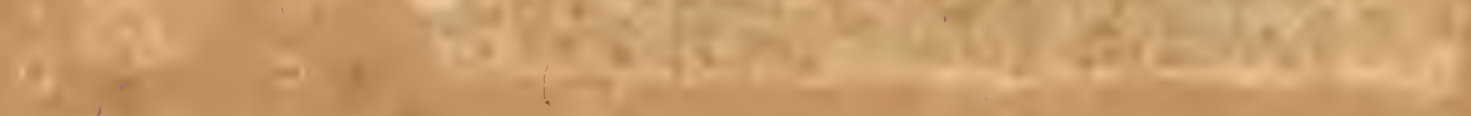
(4i) +1

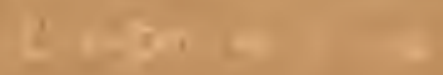


hoc vero non : quo majorem duritiem accipit chalybs, eo minus corporis five minorem granorum fubtilitatem poffidet.

Fatentur opifices a granis non cognofci poffe qualitatem chalybis, nam fi chalybs granis fubtilibus conftans ad albedinem calefiat, \& in hoc ftatu exftinguatur \& dein frangatur, apparebit nihil nifi granum craflum. Si chalybs mediocris bonitatis ad colorem cerafi calefiat, exftinguatur \& frangatur, grana fubtilia apparebunt; adeo ut granorum fubtilitas a gradu caloris accepto videatur provenire : difficultates non leves hic occurrunt.

Bacillum chalybeum per totam fuam longitudinem non æqualiter calefieri poteft; una enim extremitas calefieri poteft fecundum Fig. 8 (F) Tab. XXXIII, quum altera extremitas (L) adhuc frigida lit; fi frangatur, circa partem calefactam apparebit ut Fig. (G), fed ad diftantiam abinde ut Fig. 9 ( $\mathrm{f} g$ ), ubigrana non funt tam crafla; remotius adhuc funt grana fubtiliora Fig. 9 ( $\mathrm{g}$ h. hi.), adhuc remotius funt grana fubtilifima ut (i k). Hinc in tali bacillo chalybeo funt diverfi gradus granorum \& quot fere in chalybe reperiri poffint.

Ut granulationes variæ dignof́cerentur, contus quidam chalybeus Fig. to exculus eft, \& cum conto ferreo ejusdem dimentionis ferruminatus Fig. I 1. Sciffum eft ferrum fecundum longitudinem fuam Figur. I3. (ghhiik): cumque maffa hrc calefactafuerit, \& dein in frigida exfincta, \& fecundum longitudinem divifa, quod fieri poteft, fi combinetur cum ferro; ordo granorum in tali conto per medium divifo repræfentatur, ut Fig. 1 5, 0, 1 2, 34, r. Si velis fecundum longitudinem incifuram facere, \& dein contum illum calefactum frigida exftinguere, \& in medium fecundum dictam incifuram frangere Tab. XXXIV Fig. I (B C.). Hujusmodi conti divifi preparari debent, \& inftar lapidis Lydii a fabris in pyxide quadam confervari, ne aeri expofiti jaceant; exinde varietatem granorum \& qualitateś chalybis diverforum generum examinare poterunt. Chalyós qua grana in 4 claffes reduci potelt: 1 . Si conftet granis crafliufculis, nitidis \& corufcis, Tab. XXXIII Fig. I 5 (o.i.) Tab. XXXIV 9:(Li). 2.Si altera feries confiftat ex mixtura granorum nitentium \& corufcantium, ut \& granorum liventium, Tab. XXXIII Fig. 15, 1, 2, Tab. XXXIV Fig. $2,3,4,5,6.3$ tia claffis, fi conftet fpecie granorum fubtilium, lividorum, interdum coloris grifei, Tab. XXXIII Fig. I 5, 2, 3, Tab. XXXIV Fig. $2,3,4,5$. 4ta, fi conftet granis majufculis ; minus liventibus, quam illa, quorum mentio facta eft, Tab. XXXIII Fig. I 5, 3, 4: dantur etiam fubdivifiones, \& grana interniedia.

Oblervatum etiam eft, prout grana fint fubtiliora, granulationem tertix claffis eo longiorem extenfioremque effe granulatione fecundx, fed multum tamen differre; nam in meliori chalybe lineam'hanc extenliorem effe, quam in pejori; quod etiam fignum eft boni chalybis.

Grana primæe claflis nitent \& corufcant magis, fi chalybs per fe fit fubtilis \& bonus, quam fi chalybs fit craffior \& pejoris notæ: in chalybe craífiori funt grana nitida mixta lividis: fi chalybs fit fubtilis \& melioris indolis, grana etiam primæ claflis livent; modo extremitas una ad liquefactionem ufque pane fit calefacta: fed nitida funt propiora \& eo magis corufca.

Grana 
Grana claflis hujus in chalybe pejori quafi ftratim funt difpofita, quod in chalybe meliori vix reperire licet.

Durities chalybis diminuitur, quatenus grana fubtiliora fiunt. Durities ab operariis examinatur per limam, fed omne genus chalybis refiftit lime, hine probatio per limam infufficiens efle videtur.

Sed quoniam probari nequit chalybs per limam, \& ufque dantur alix materix chalybe duriores, hinc probationem per illas inftitui poffe arbitratur: ordine illia fequuntur, funtque feptem : i . Eft lima vulgaris, 2. eft chryftallus rupea, 3. eft lapis filiceus transparens \& durus, 4. eft agathus, 5. eft jafpis orientalis, 6. eft topazius orientalis vel etiam fapphirus, 7. eft adamas. Horum lapidum ope probari chalybs poteft, filicet ut fciatur, quo genere lapidis incidi \& a quo imprefliones fieri poffint.

Quod vero corpus flexibile chalybis attinet, five qualitatem refiftendi \& fimul fe plicandi, difficile probari poteft, fcilicet quo gradu ignis ante: exfinctionem chalybs potiri debeat: hinc auctor fila chalybea ejusdem dimenfionis in plumbo liquefacto calefecit, in cylindro fimili Tab. XXXIV Fig. I 2, longitudinis 8 vel 9 digitorum : optimum huic ufui effe canalem Cclopeti, ait, nam plumbum in parietes fe infinuat, fi materia fictili conftet cylindrus, in illo fundendum eft plumbum vel ftannum. Si ergo fila. ejusdem diametri \& magnitudinis eodem tempore in plumbum vel fannum fufum immittantur, \& fimul five codem momento eximantur, tunc in utroque idem gradus caloris obtinetur. Plumbum fulum maximum caloris gradum acquirit, cum ad fufionem \& coctionem quandam reducitur, pariter ut aqua, quæ cum femel ad ebullitionem calefacta fit, fummum caloris fui gradum attingit, prout dicit Dominus Amonton.

Corpus five flexibilitas juncta cum duritie probari poterit per machinam, quæ expofita eft Tab. XXXV, ibi enim cochlex funt, qu: invicem elongari ut \& propius admoveri poffunt, fi fila chalybea calefacta \& exftincta heic infertentur, adeo ut a 2 cochleis vel brachiis teneantur, quie ad invicem moveri poffint ; tunc if fila rumpantur, inde dignofcere licet, quodnam genus chalybis plus corporis poffideat : nam quo propius posfunt moveri \& confequenter plicari \& flecti, eo plus corporis adeft: led machina hac variari admodum poteft; operationem melius ex ipfa delineatione vides.

Chalybs, qui per hanc experientiam plus corporis poffidet, \& fimul grana majufcula, fignum eft, adhuc plus corporis flexibilis habere, fi fcilicet poftcalefaetionem mediocrem exftinguatur. Concludi etiam inde poteft, fi chalybs detur, qui minus corporis poffideat, fed grana grandiufcula, \& mediocriter calefactus exftinguatur, quod plus corporis vel ffexibilitatis junete cum duritie omnino habere debeat.

Probari etiam flexibilitas vel corpus chalybis per flexionem circa diverfi generis annulos vel peripherias annulares poteit, fi flum chalybeum ejusdem dimenifonis fit, ut \& fubtile \& admodum tenue, alias nullam flexibilitatem oftenfurum fit: vide Tab.XXXIV Fig. 14, I 5 , a.

Opifices forficem ex dato chalybe formant, qui ferrum frigidum fcindat, forfex dein calefit \& exftinguitur, ficque fit experimentum, colorem- 
TAB: AXXIV de ferro.
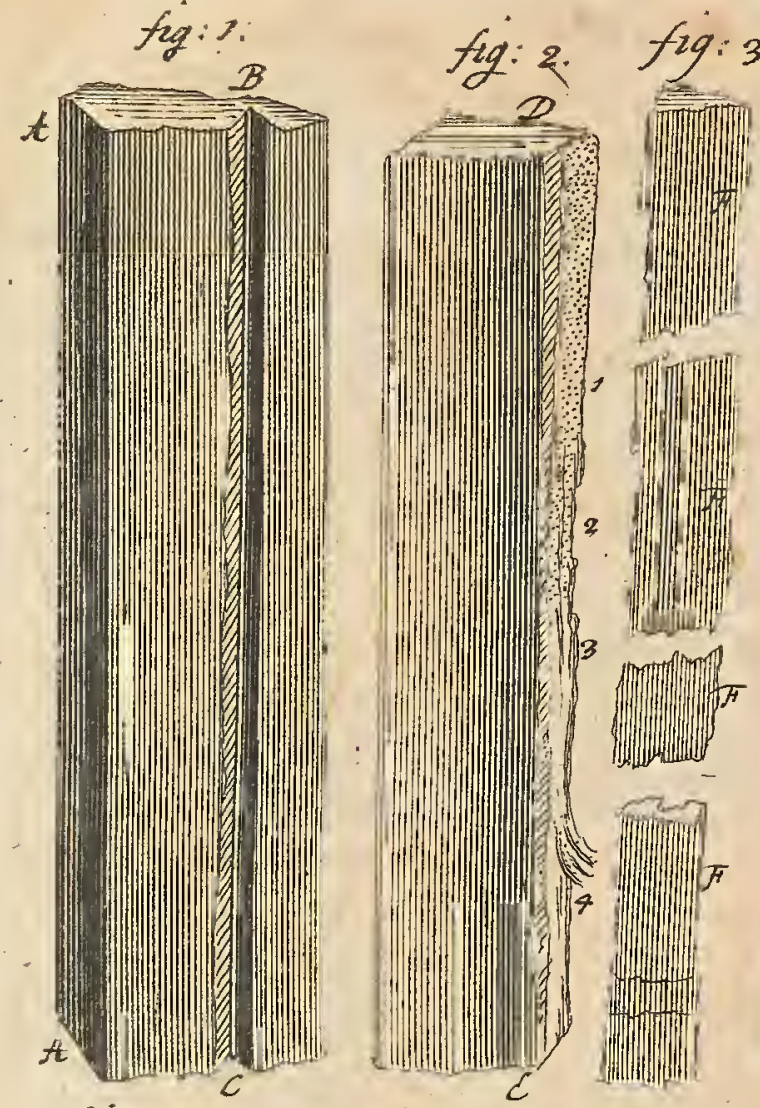

fig: 6 .
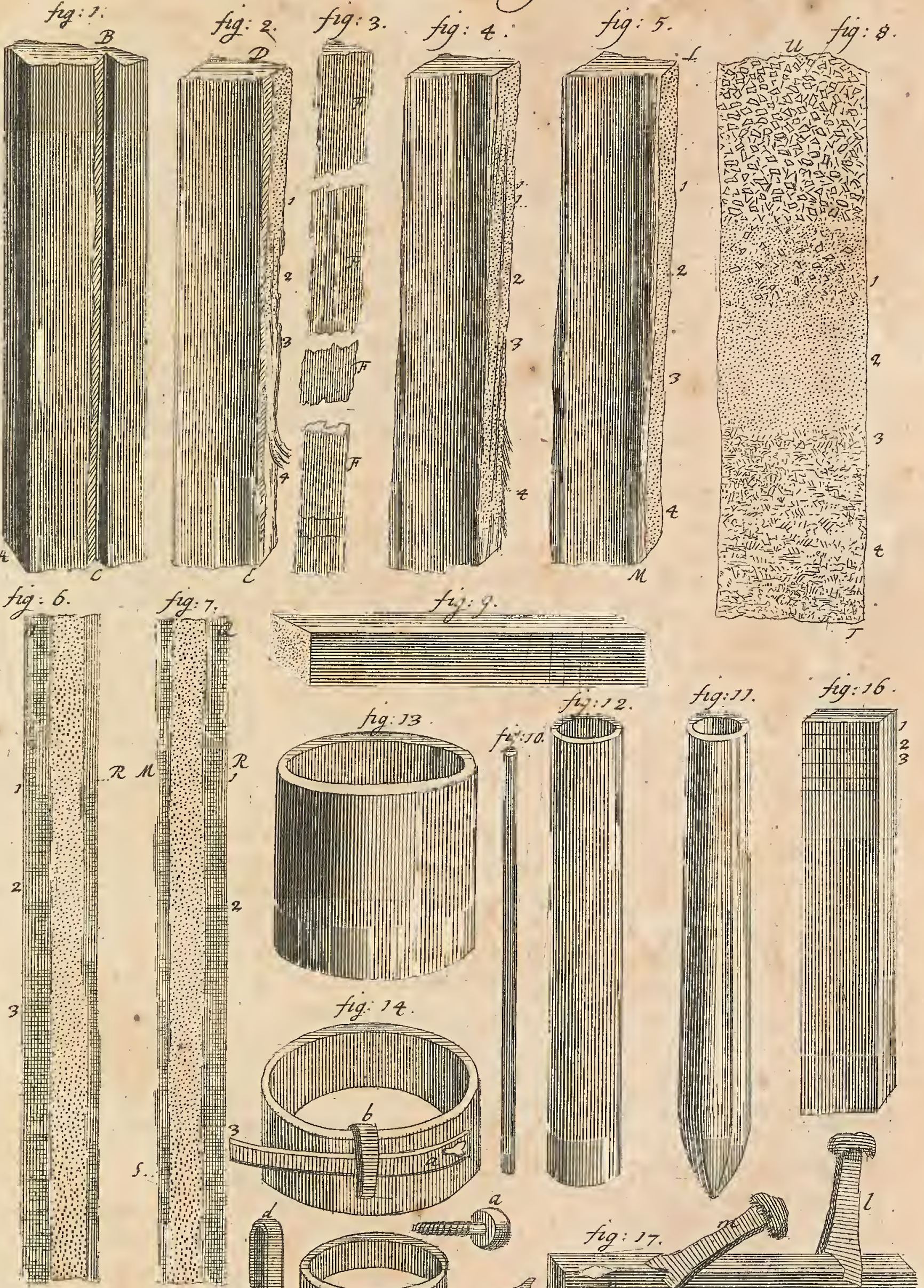

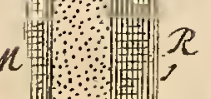

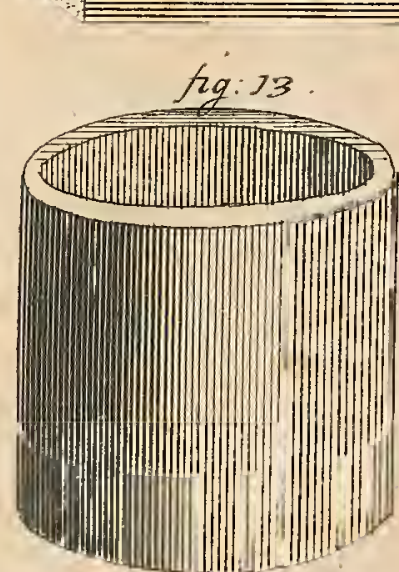

().

(घ)

-

.

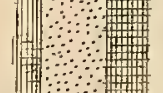

•

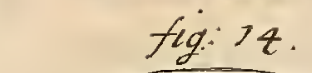

(1)

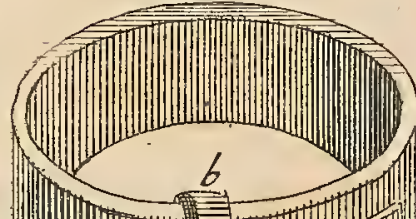

-

ร. .3 _.

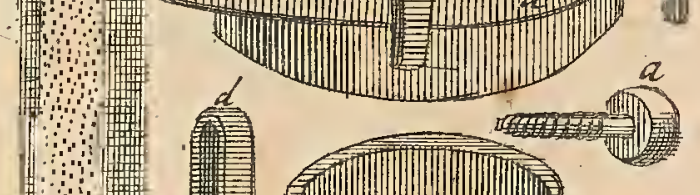

fis: 12

f(g: $17 . \quad f i g: 16$
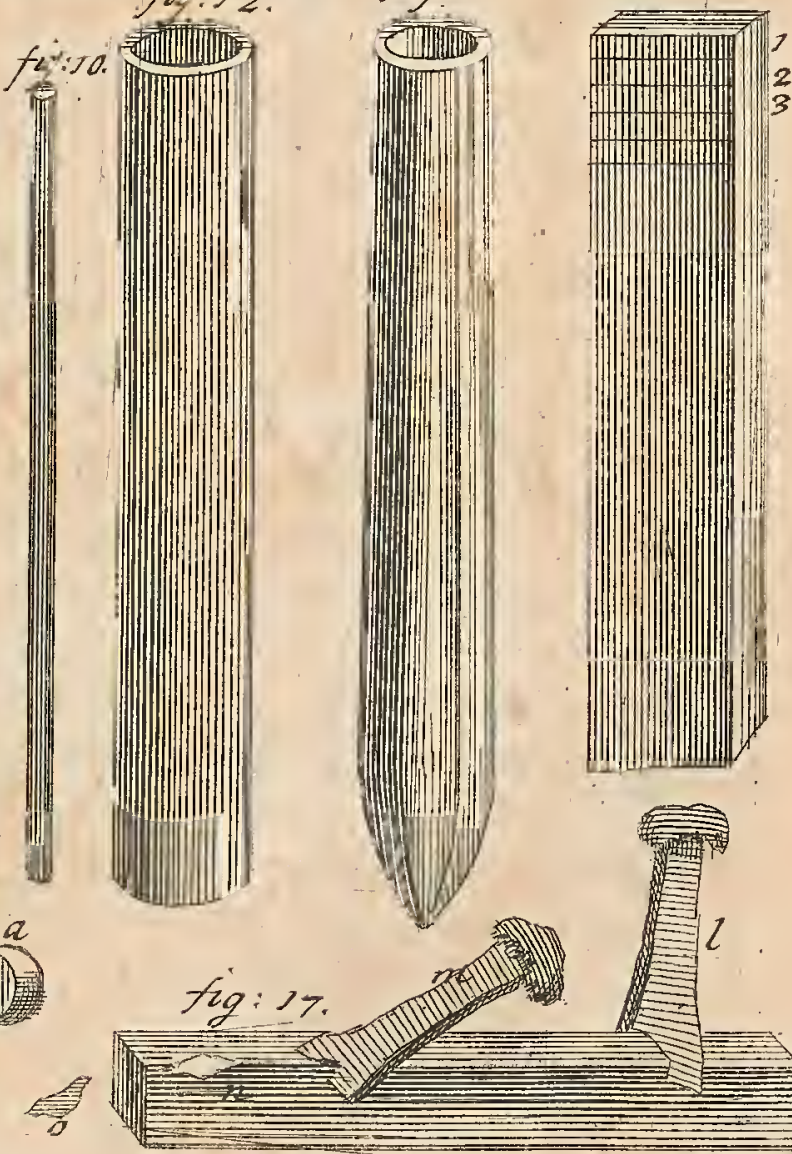

造

fin:

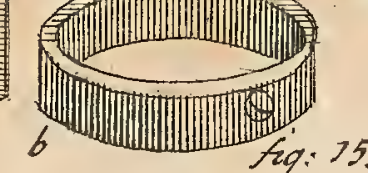

. 

que caloris, quem ante exftinctionem acceperat, exacte notant, fi recidit, iterum calefit \& exftinguitur, \& oblervatur, quinam caloris gradus fit; fi pars aciei diffilit, quum altera vice ferrum frigidum fecandum fit, fignum. eft, chalybem non adhuc fatis corporis vel flexibilitatis adeptum effe; hinc calor inter utrumque medius adhibendus eft; fi non, fignum eft, chalybem hujus generis non fatis corporis flexibilis poffidere, quamvis ei multa durities infit.

Ferrum per forficem oblique vel directe fecari debet; obliquam feEtionem videas Fig. $17(\mathrm{~m} \mathrm{n})$ Tab. XXXIV. Si etiam fectiones fint planæ \& nitentes, fignum eft duritiei in forfice chalybeo, alias non.

\section{Descriptio Figurarum.}

Tabula X X X III.

I.) Chalybs intractabilis incifuris refertus.

2.) Bacillum aliud chalybis fiff, fed minus quam prius : fffurse funt circa angulos ut ad (A), funt fefoure interdum fubtiles.

3.) Fruffum chalybis incurvatum, circa (D) fractum, difficilis eft chalybs tractatu, calidus cum incurbatur.

Fig. 4, 5, 6, 7.) Sunt diberfe fracture cbalybis, in quibus apparet rofa differentis coloris 60 figure.

Fig. 8.) Cbalybs acuminatis (F) E dein calefactus $E^{2}$ exfinctus : fo percutiatur in (L), fractio exiftit in (F G). (M) fignificat fciffuras; cum enim chalybs cum frufto alio ferruminatus eft, $\mathcal{E}$ dein, quambis fubtiliter, biare incipiat.

Fig. 9.) Sunt fragmenta, qua ex percusfione quadam provenerant Fig. 8, ut (fg.gh.hi.ik.) fractio fuccesfive fucta eft (G.H.I.K.) calefactionem magnam fuiffe neceffum eft. Fractura circa (F) grana majora posfidet, quam inde remotius, notantur per ( $\mathrm{gh}$. hi. ik.)

Fig. 10.) Eft lamina cbalybis cum lamina ferri ferruminanda, illum in fanem ut cbalybs fecundurn longitudinem dividatur.

Fig. I I.) Eft lamina ferri predicta.

Fig. 12.) Utraque lamina ferruminata reprafentatur in (a a), ufque ad (b), (d b a) eft lamina ferri; (cba) lamina chalybis: (de) eft linea, fecundum quam divifio eft inftituenda.

Fig. I 3.) Eft fruftum plane paratum (ghh. iik.), eft fiffura factain ferro, quod reftat, eft cbalybeum; extremitas una bujus maje jam modo calefacienda $e f, E$ frigida exfinguenda, $E$ dein fecundum longitudinem frangenda.

Fig. I4.) Eft eadem portio jam in binas partes dibifa ut in (11): Ev ope forficis urgetur, ut in $(\mathrm{m} \mathrm{m})$ E circumcirca aperiatur.

Fig. I 5.) Eft media pars ex dicta divifione proveniens, fuperficies (pqss) eft illa, que per forficem eff fitfa: (o pqr) eft fractura chalybis, in qua varietates ordine apparent; (o i) eft primus ordo, 12 eft lecusadus; 2,3 eft tertius: 3,4 eft quartus, ubi nulla calefactio vel exftindzio fuerat. Pars (o u ) compofita eft ex granis minus nitentibus quam illa que fequintur; quia extremitas ad fufronem fere eft calefacta.

Clafis II. de ferro.

Tabula 


\section{Tabula XXXIV.}

Fig. I.) Eft lamina cbalybea in aciem cultri cujusdam malleata, fcilicet ut fecundum longitudinem dividi posfit. (A A) eft dorfarm, (BC) eft fciffura cum forfice fecundum longitudinem facta.

Fig. 2.) Eft lamina pracedens in binas partes fecundum longitudinem divi$\int a(B C)$. In fractura (DE) clafes vel ordines dinerfe cbalybis apparent, eft genus chalybis crasforis. Granulatio primi ordinis 1,2 non eft tam nitens, ut in alio chalybe, fed grana bic fratiom quafi difpofica funt. Strata bec melius apparent in granulatione fecunda $(1,2)$ ubi etiam fibre ferri exftant; fed adbuc melius in ordine $(2,3)$. Eft etiam regula, quod ferrum bic mixtum cumchalybe plus in tertio ordine, quam in precedentibus appareat: in priori funt grana nitida, que non a granis cbalybis prius diflingui poffunt, quam cum lima terantur. Fractura 4 ti ordinis $(3,4)$ fimilis eft fracture ferri fibrofe.

Fig. 3.) Eft compofitio ex 4 fruffis (FFFF) que ex Fig. I funt feparata.

Fig. 4.) Eft lamina cbalybis, in cujus fractura apparent mice adbuc grandio. res, fed minus quam in Figura precedente. In fecundo ordine I, 2 apparet vena ferri (i). Bine majores vens in tertio ordine 2, 3. Grana tertii ordinis non funt eque fubtilia, ut illa in Figura fequente. 2uartus ordo $(3,4)$ ef compofitus partim ex granis, partim ex fibris.

Fig. 5.) Fractura chalybis (LM) adbuc fubrilioris granulationis eft, quam in precedentibus. Grana primi ordinis non funt mixta: grana fecundi ordinis ut $(1,2)$ funt mixta. Ordo 3 tius 2,3 ex granis fubilisfimis eft compifftus. Ordo quartus conftat granis multe fubtilitatis, que equant illa in 3 tio ordine, fed font coloris magis grifei. Magna granorum fubtilitas indicat cbalybem tractatu difficilem, quique non multum corporis flexibilis posfideat.

Fig. 6. 7.) Diverfas cbalybis fracturas reprefentat: Supponitur, quod bine chalybis lamella eque fint calefacte, ED in volumen ferri fuidi ufque ad (RRoi) merfe, eftque primws ordo granulationis; (QIM) eft primus ordo, granulationis alterius, in (3) terminantur tres granulationis ordines bel feries. Fig. 7 feriem. quandam granorum (Q3) longiorem granulatione o 3 Fig. 6: obfervandum etiam bic eft, quod in. (Fig. 7,3 ) obferbatum eft; quodque ordo granorum $(2,3)$ major fit in refpectu ad fecundum fuum granorum (2, I) yuam eft tertius ordo (Fig. 6) in refpectu ad furm fecundum ordinem. 4tus ordo (S) Figure 7 particulis fubrilioribus eft compofitus, quam ordo 4tus Fig. 6.

Fig. 8.) Eft tota granorum feries in chalybe craffe adriodum reprafentata. (ui) eft primus ordo compofitus ex micis, que fimiles funt illis, que alias in genere quodam ferri ad nudum oculum folent apparere. Ex quo concludi poffe videtur, chalybem a ferro minus in respectu ad figuram, quam ad fubtilitatem partium differre; $(1,2)$ eft fecundus ordo micis coruf cis mixtis cum granis lividi coloris conflans. In 3 tio ordine ( 2 ) vel (3) nibil apparet, nif jpecies granorum; mice ibi per microfcopium videntur in $(3,4$ T.)

Fig. 9.) Ef bacillum cbalybeum ad unam extremitatem fractum, cbalybs bic recalefactus eft. Peripheria confat ferro, interiona vero chalybe.

Fig. 10.) Eft filum chalybeum, cujus corpus flexibile probandum eft.

Fig. I I.) Eft canalis fclopeti, in quo plumbum lique factumeft, Ev ubi in plume bo calefacienda funt fla chalybea. 


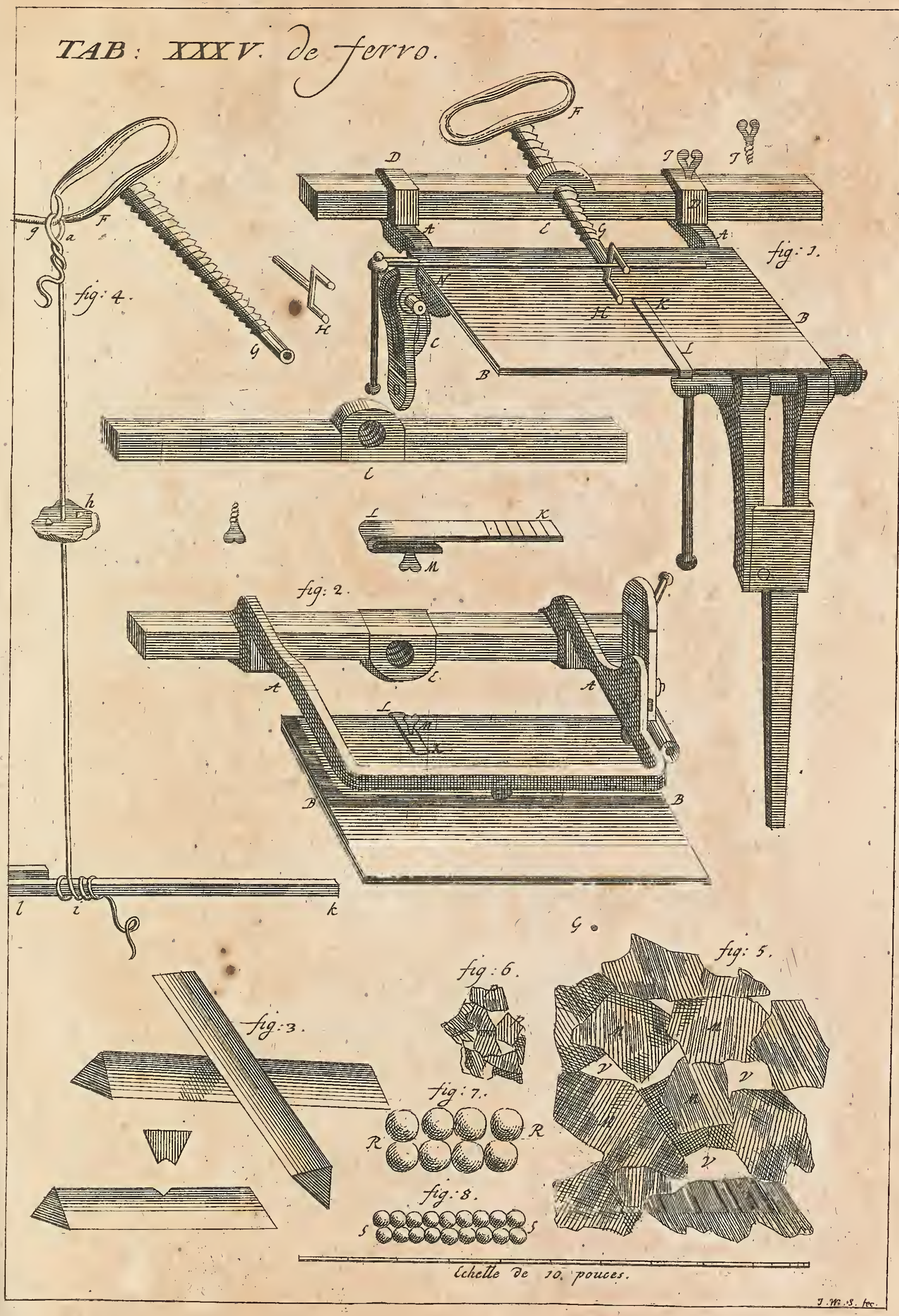



Fig. 12. 1 3.) Sunt capfula buic ufui inferbientes, fcilicet ut in illis plumbum in fufione teneri polfit.

Fig. I4.) Eft annulus vel cylindrus, circum quem fla cbalybea volvenda funt, ad probandum corpus illorum flexile.

Fig. 1 5.) Annulus parilis, fed minoris diametri.

Fig. I6.) Eft lamina chalybis deterioris bel ferri duri, cujus une extremitas exflincta oft in (f). Divifa ef per lineas parallelas $(1,2,3)$ per illam forceps probari poteft; optimus eft, qui propius ad (f) fcindit, cujus nec acies cedit aut difrumpitur.

Fig. 1 7.) Frufum ferri, fuper quod duo funt falpella, (1) perpcndicula. river pofitum, (m) oblique; (n) fciffura oblique facta, quoque concinnior Es ob. liquior fisfura, eo melior ef chalybs.

\section{Tabula XXXV.}

1.) Eft macbina ad probandam flexibilitatem corporis chalybei, znanu etiam teneri poteft, fi velis.

Fig. 2.) Eft eadem machina fupra reprafentata. Quedam partes Jeparatim funt expofite; eadem litera candem partem indigitant: partes reprasencanturper literas (A A.BB.C.DD.E.FG. HI. KL. M.)

No. Fig. ..) Eft flum ferri quod frangi debet.

Fig. 3.) Sunt duo prifmata, unum fupra alterum repofitum, utrumque per cundem ictum ponderis fupra illabentis vel impreffs incifum.

Fig. 4.) (ghi) Eft filum chalybis fixatum ad (g); ad (h) eft lamella. fuper quam carbones mitti poffunt, Es in illo loco calefieri, pariceribi exffingui. (kl) 10 . cus, ad quem pars ejus inferior eft fixata. Bracbium (ik) eft altero perrectius, adque necesfitatem adbuc prolongari poteft. Brachium (il) a corpore fuperiori (1) continetur. Bracbium (ki) oneratur, fcilicet ut flum chalybeum frangatur.

Fig. 5.) Reprafentat granum chalybis admodum ampliatum, magnitudo naturalis in $(G)$ fiftitur. (MMM) funt molecule vel mice, ex quibus granin funt compofita. ( VV) funi vacuitates inter illas relicte.

Fig. 6.) Elt pars bujus grani, E una mica Separatim reprefentata: (pp) funt partes, quibus conftat bac molecula.

Fig. 7.) Sunt duo ordines (RR) globorum equalium, quorum omnes mutuo fe non contingunt.

Fig. 8.) Sunt bind feries globulorum, qui ornines mutuo fe contingunt.

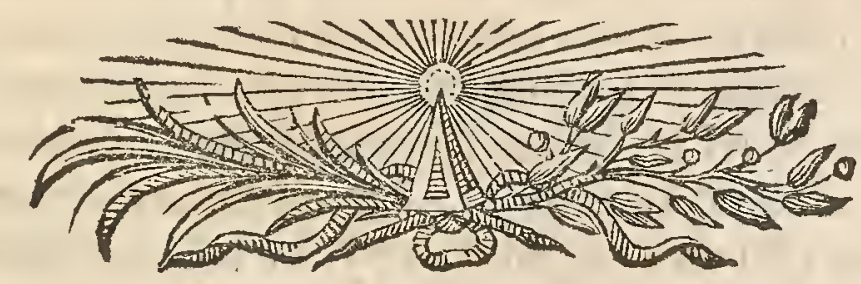

PARA. 


\section{PARAGRAPHUS VI. \\ Vena five minera ferri, छी plura ejus genera. \\ In Svecia.}

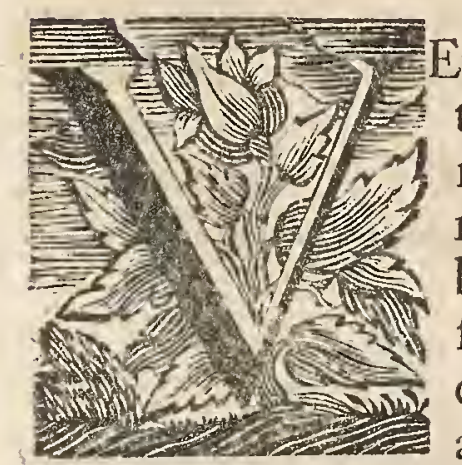

Enæ ferreæ per Sveciæ regnum non multa diverfitate ludunt, fed fimpliciore amictu \& fui coloris plerumque incedunt, nam propemodum omnia ejus genera funt coloris ferrei, qui tamen interdum in quibusdam fubcorulefcit, pariter etiam viridefcit. Differentia, quæ inter venas hujus generis intercedit, confiftit in eo: $\mathrm{I}$. quod una ferruginea magis quam altera facie fubnigrefcat, vel coerulefcat, quod a lapide ei commixto five a matrice utplurimum oriri videtur: $f_{1}$ enim lapis nigrior corneus aut alius infit, inde nigrefcit magis ; fi calcarius aut filiceus vel fpathi aut quartzii fpecies, cœrulefcit: datur etiam quæ paullulum viridefcat, quod etiam ex lapide ei inhærefcente viridi oritur : interdum amianthina quædam crufta aut lamella ei affixa apparet; plerumque tunc adhrerens vena in figuras rhomboidales frangitur, \& eft generis nobilioris, pariter ditioris, conftatque planis æqualiffimis, lævigatis, \& quafi politis, tanquam unguento oblitis. Secundum adhærentem petram vel ficcior aut difficilior liquatu eft vel fluidior, vel temperanda eft cum mixtura alius generis, ut in ferrum liquidum feparata abeat, vel cum majore aut minore copia calcis. 2. Multa etiam in eo differentia confiftit, quod unum genus pauperius, alterum ditius fit: dantur enim venæ, qux 10, 20,30,40, $50,60,70,80$ ufque fere ad 90 propemodum libras ferri in centumpondio continent. 3. Unum etiam genus multo fulphure ut \& ære fcatet, adeo ut particulæ fulphurex hinc \& inde eluceant, vel in textura interiore inclufe teneantur, exinde obtentum ferrum calidum facile frangitur : alterum genus omnis fere fulphuris \& æris expers eft, quod etiam plerumque dives, fed ferrum inde excoctum frigidum facile rumpitur. Verbo Mars hic aquilonaris femper torva \& fua facie incedit, nec ut aliis in regionibus diverficolori, jucunda \& per germinationes læta. Ufque tamen ubique fere præfens eft, \& free integros tractus \& montes folus occupat, ut Oftrogothix montem Taberg; Dalekarlia in parochia Norberg, præcipue in Grengierde, ubi integer mons ad plurium mille paffuum diftantiam, tam in latum quam longum, \& in quamcunque profunditatem ire lubeat, Martis vena ditiflima, 60 ad 80 libras in centumpondio continente pleniffimus eft, \& tumens; adeo ut totus mons nihil nifi ferreus fit, nec alius laborillam eruendi datur, quam ope pulveris pyrii e monte fragmenta divellere, perque præceps quanta velis copia, devolvere : ubi tanquam armamentarium Martis effe queat, \& unde per fiecula toti orbi arma, fi vena non fragilis indolis foret, parare poffet. Adeo ut fornacum cultoribus diftrictus \& campos montis admetiri in confilio fuerit, non fecus ac fundi poffeffor agros 
agros \& areas cultoribus \& agricolis. Secundum tentamina facta eft fimilis indolis vena in imis, qux in fummis montium regionibus.

Cæteroquin mixta adinvenitur vena ferri cum alius metalli venis ut: I. Præcipue cum vena cupri, ut Fhalunæ, Scbilo, \& ubique fere in mineris cupreis; interdum ad dimidiam partem, ut ad Scbilo vel Riddarbyttan Sveciæ \& alibi: ibi etiam adinventum fuit cuprum nativum cum admixta vena divite ferri; aque una cupri nativi parte purum cuprum apparuit, $a b$ altera vena ferri ditifima, in medio vel in confiniis crocus Martis fubfavus, five ferrum ab acido fulphuris quafi exefum, quod tandem in cuprum verfum eft; adeo ut natales cupri nativi in fruftis his liquide \& jucunde confpicere licuerit, félicet, quod ferrea pars in crocum quendam primo verteretur, antequam loco ejus cuprum fuccederet. 2. In pyrite utplurimum ferrum invenitur, \& quidem a 5 libris ad 40 in centumpondio, quod in vena fulphurea \& molliore Fhalunæ videre licet. 3. In vena argenti multa pars ferri etiam recondita jacet, ut Sali \& alibiSveciæ; dantur etiam venæ argenti in aliquibus fodinis, quæ 20 ad 30 libras ferri in centumpondio poffident \& 5 lemuncias argenti, pariter ubi ferri vena eft, cujus centumpondium 70 ad 80 librarum ferri dives fit, \& $\mathrm{I}$ ad 2 fenunciarum argenti. 4. Magnefia etiam Svecix adinventa eft, cujus centumpondium I2 libras ferri continuit.

Dantur etiam venæe ferri in paludibus, de quibus fupra in \$. III claffis primæ actum eft; merito appellari poteft vena, quia venarum \& arteriarum inftar paludes percurrit ; \& hoc præcipue in locis verfus leptentrionem nivalibus \& frigidiffimis; folum ejus natale eft maxime in Jemptia \& Dalekarlia, \& in Bothnia occidentali; alibi quidem veftigia ejus etiam confpicua funt: vocatur etiam vena paluftris, fimilis terre cuidam rubræ aut ochræ, quæ in maffas conflata fub humo paludis fuperficiali latet. Minera hæc lutofa ad primum confpectum coloris obfeure rufefcentis, aut caftanei feu badii eft; verum humore expulfo \& fub dio ficcata rubefcit, fed tamen albentius, eique ineft gravitas (pecifica major, quam alius generis terris \& lutis. Aliquibus in locis, ut in parochia Garboauls in Wermelandia eruitur dieti generis minera in paludibus \& locis udis, fed etiam in pratis \& viretis admodum ficcis, in ipfis fylvis, præcipue in planis declivibus feu obliquis collium; inque vallibus jam exficcatis; fortaffis ubi antiquitus aq̣ua ftagnans paludem formaverat, fed tempore arefcens ficcum folum reliquerat, unde adhuc in paludis vetuftx acclivo margine \& finuofo limite confpicuus eft fundus hujus ochræ ferax; eft etiam fimiliter coloris rufi, fed vergit tamen ad album; fed tamen adhuc in locis illis non pinguis herba venit. Paludes hujus generis præitant; quæ devexæ \& declivæ folem meridianum profpiciunt, humus ibi melioris fanguinis venam five ochram recondit; fed fi folum declive boream fpectat, datur vena vilioris pretii \&.fulphuris egena vel expers, quæ ferrum fragile fuppeditat. Datur nigra féu furva carbonis inftar, fed peffimi generis; datur, quæ virefcit, inftar coloris fubbuxei five praffini fpadicei, cui aliquid acutum \& fali non ablimile ineffe videtur, quod genus altius fe recondit; vocatur etiam terra ferri viridis, eftque media fortis \& ferri magis ferax: datur, que obfcure Claffis II. de ferro. $\mathrm{Cc}$ ec rubet, 
rubet, ad tactum eft tanquam fal craffe granulatum, fed dente tenax tanquam refinofum, conflaturque per fe in fruftula, eft dives ut ex roo reftituat fape 49 ferri. In Angermannia datur hujus generis triplex vena, una coloris badii vel fere bruni, ex quo ferrum fragile quum ignitum eft, coquitur; altera eft coloris a rubro brunei ditifima \& ferri feracifima, tertia coloris fulci \& fubnigri, cujus ferrum fit fragile dum friget. Ex ipfa forma \& planitie paludum gnari exploratores fiunt, an fubter crefcat ferrum; pariter ex fruticibus \& gramineo genere, quod infuper vegetat; quam maxime arborum radices fe circumdat: nec magneti obfequitur, nifi prius ignem combutorium pertranfierit. Cumque vena hac paluftris quafigenerationem ferri in finu \& matrice telluris reprefentet; hine etiam fulus ejus tam notas \& characteres, quam indolem in ftratis fuis defcribere volui fupra in 6 . III vel pag. 105, 106, 107, 108, in claffe hujus operis prima, quix videas.

Praterea dantur ejusdem fere generis venæ in lacubus per totam fere Smalandiam \&. Oftrogothiam Svecix, qux exinde exantlantur; in Angermannia etiam; eftque formæ rudis \& inæqualis five infar fpongiarum, coloris bruni; feparation in fuis locis invenitur; jam in fruftis parvis adlatx palmx magnitudinem; jam figurx planæ five rotundx; in fractura refert plerumque colorem \& fpeciem fecti corii : non duritie multa pollet, fed inter digitos quafi friabilis eft; derivatur utplurimum ex palude vicina, unde fe fub fpecie fucci fubtilioris in aquam exonerat; a ripa plerumque ad I 8 ulnas cubile fuum eligit, nec aliunde per aquas inque fundum alium divagatur: affigitur utplurimum faxis \& lapillis fundi: repeririideo licet fruftula ejus cum inclulo lapide, \& cujus lateriadhæret lapis; pariter exantlatur inter cannas \& arundines lacus, \& videtur radices illarum libenter quafi amplexari velle. Vena hæc lacuftris alioquin diverfformis eft, ut globola, figuræ ovalis, vel inæqualiter granulata; particulæ rotundiores grana hordei, tritici aut fabas figura \& magnitudine imitantur : in medio \& in fractura lunt coloris flavi \& rubiginoli, fed pondere leves; vel etiam circumdantur crufta feu cortice leviori, non aliter ac glans five nux avellana, in qua putris nucleus inclufus eft: in perplurimis particulis evolutis \& fractis confpicitur appofitio quedam partium \& convolutio crebra cruftalis. Admodum levis eft, nec pondere nec colore indicat ferrum in finu, fed plura de hac videas $\$$. IV claffis primæ.

Innumeris in locis fub varia fpecie \& colore fe præfentat ochra; procipue circa fontes vitriolatos \& medicates, quorum ingens numerus datur; vel eft flavefcens \& lutea, vel magis rubefcens, quxque calcinata primum fequitur magnetem. Mars per omnes Svecix provinciasfparfus eft, adeo ut fere nullum minerale aut metallum alius generis fe incomitatum linquat; ex quo fortaffis concludi poteft, ferrum in locis feptentrionalibus \& nivalibus aque firio \& fole autrino remotioribus majore copia \& meliore indole concipi, excludi \& ad maturitatem fuam perduci.

Proterea datur in quibusdam lacubus minera ferri vere arenaria, coloris fui pulla \& nigra, \& multi ponderis \& ferri. 
Præter dictas ferri venas in Svecia funt quædam alix, quarum recenfionem fuperfedeo, quoniam in nulla quantitate funt, fed parfim hinc \& inde collectus lapillus circumfertur : horum ut \& aliorum mineralium Svecix infigne \& perpulchrum penum, celeberrimus archiater beatæ memorix Dominus Magnus Bromeliius poffedit, quod etiam publico fiftere pollicitus eft.

Magnetes etiam in Lapponia, in Dalekarlia, inque diverfisfodinis, \& quidem infignium virium, lubinde franguntur; unum etiam vidi, qui conftaret $\frac{3}{4}$ partibus lapidis quartzii flavefcentis coloris, infperfis glandulis ferreis. Infuper datur rubrica, datur hæmatites \& fchiftus nigra botryoides, fed non in copia. Dantur granatx ferri feraces. Sed flores \& chryftallos ferri vegetantes nondum in Svecia mibi videre contigerat; quia nullibi apparent cryptæ \& fpatiola inania, per quæ fuccus Martialis germina \& ramos fuos expandere \& explicare queat.

\section{In Silefia ut छे circum Danubium.}

DOminus Volckman in Silefia fua fubterranea recenfionem facit venarum ferri in Silefia repertarum, ut in Scbreisbersen, quod fint grana rubefcentia, qux non modo ferrea fint, fed etiam aurea: quod ad Lebn fodiatur lapis bruneus aut magnefia, quæ ferrum contineat. In Modlau minera ferri rubefcens \& flavefcens. Ad. Buntzlau minera ferri grifei coloris. 'Ad Grüntbal rubefcens in fontibus, ut \& extra fontes. Ad Goldberg minera Martis arenofa obfcure rubefcens. Addunt alii, in Silefia etiam legi mineram Martis globularem, pariter etiam hæmatiten.

In Tomo Illtio Danubii Pannonico-Myfici Dominus Aloyfus Ferd. Com. Marfil. de venis ex fodinis Koniftbergenfibus \& aliis agit, \& ipfas figuris affabre in ære fculptis illuftrat; dicit fe ferri prolem aut mineram pofidere auri granis locupletatam, exque auro, quod arte feparari poffit argentum. Exhibet fpeciem, in fodinis prope flumen Gran fupra Netudal, ac præcipue linea illa magna five Grosgang dicta, erutam; mirabili fpecie ad formam globi, etiam cylindri; quæ formæ pluribus acuminibus afper$f_{x}$ fint, omnino uti chryftallus, ac multoties iffi globuli in fe continent marchefitam. Cylindrica vero illa conformatio foramine per medium tranfeunte, eft excavata, ac totum cylindrum pervadit. 2. Exhibetetiam ferri maffivi fruftum, quod per omnialigni quercini fpeciem, lineisac fibris fuis æmuletur, optimæ qualitatis, coloris atro-flavi. 3 . Aliud ponderofiffimum coloris flavi, 4 . aliud coloris dilute flavi, 5 aliud coloris atro - furvi maculis albis notatum, 6. lapidem fanguineum, qui ex parte qua incubet, rubefcat, quemadmodum languis, quodque hanc ipfi tincturam det tophus vicinus ruber cum fplendente ferro mixtus, quique quoad exteriora videtur effe lapis ruber, at enim eft illo multo durior, 7. flores ferri cinnabari infeeti; fruftum illud crefcit in cavitatibus lapidis, cavitas autem continetur illo tractu nigro maculofo, qui tractus eft ferrum iplum, fed naturæ fragilis, ut vitrum, "\& cinnabari admixtum, 8. radicem cinnabaris ferri fruftum, fi quidem pura cinnabaris parvula in cavitate poteft confpici, fruftumque lapidis referentisgypfum, 9. fruftum mineræ ferri plum- 
bo turgens: de floribus refert, quod potifimum reperiantur, ubi fodinarum cava patent; I o.ferrilapidis fruftum grandius, quod fractum, permedium minil feu native cinnabaris puncta feu granula hic illic diffeminata exhibet: cujus color non tam vividus fit, ut in reliquis fui generis fpeciebus, I I ferri mineræ fruftum, in quo conjunctim cinnabaris ac plumbum, illa quidem vividiffimi coloris; I 2. ferri lapidem coloris fulphure, oblongum, in formam S.S.S. quem zona ambit vividiffimx cinnabaris, ex fodina penes Solts; I 3. ferri lapidis fragmentum ex fodina penes Solts; eft lapis faponarius, qui tabulatim, fuperne ac inferne, zonam ambit interiorem, qua \& cinnabaris nativæ \& ferri lapidis frufula, hic \& illic participat; Mercurio maxime refertus. Figuris etiam Marcafotas exhibet, ut marchefitam, quæ intra quartfium feu flicem crevit. Marchefitam corticatam, quoniam ceu cortex tartari fuper filicem creverit, diciturque elle fedimentum aquarum, in profundis fodinarum Schemnizenfium, \& naturam plumbi quodammodo participare. Marchefitam ex granis fingularibus, \& ad naturam fui mineralis primo gradu tendentem, cum ferro fuperinducto. Marchefitam pariter ex granis magis quidem unitis, \& ad naturam fui metalli propius tendentem, cum ferri armatura fuperindueta. Sed de marcafitis videas cuprum.

\section{Anglia.}

Ominus Lifter in tractatu de fontibus medicatis Anglix mentionem minerarum ferri facit \& recenfet fequentes: I. magnetem, 2. venam rubram fcintillantem tanquam arenariam, 3. aliam venam ferri rubram, interdum molliorem inftar argillæ, 4. hæmatiten, de quo infra, 5. venam ferri in arena foluta ac lapide arenaceo, 6 . in vicinia \& inter ipfos carbones foffiles ex meris rupium ftratis folidis \& dilatatis, 7. in marga, 8. ochram rufefcentem ex pyrite fere natam, 9. pyriten. Addunt alii in Anglia dari mineram Martis lolarem. In Scotia mineram Martis nigram; etiam chalybis inftar nitentem. Mineram Martis rubram cum álba armatura. Rubricam fabrilem \&c.

\section{Stiria.}

N Stiria chalybem nativum inftar chalybis nativi nitentem reperirinar1 rant, qui magnetem non attrahat, antequam miffus fit in ignem, fed rarun effe: \& præter mineras Martis diverfi generis, etiam mineram ferri, in qua appareant particulz auri. Pariter grana ferri nativi in aquis fluviatilibus. Flores Martis nativi albiffimos, de quibus infra. Etiam qui appareant tanquam cornua cervi vel inftar coralliorum, ex quibus frufta 20 vel $30 \mathrm{zb}$. ponderis interdum reperiri.

\section{In Franconia.}

DErhibent in Franconia dari chalybem \& ferrum nativum. Mineram Martis globularem cineream, nigram botryoides, scbwartzkopff. Mineram 
neram Martis albam \& flavam. Mineram Martis nigram inftar canalium longam, flavam levem inftar terræ cujusdam. Mineram nitentem flavam cum figuris. Mineram ferri rubram \& duram cum minera cupri. Mineram ferri, qux colores iridis \& pavonis repralentet, five mineram cum coloribus lazuri. Nitidifimam lievigatam ferri rubri coloris. Mineram ferri coloris violacei. Mineram nitentem cum nitidis ferri, Eifenglimmer, Eifenmann appellatam. Mineram ferri nitentem coloris brunei cum minera cupri \& venis fpathi, quæ tamen hodie non magis frangatur.

\section{In Ilmenau ad Sulam.}

Atur minera Martis rubra, ut \& coloris ferrei. Minera ferri cum rubris micis nitidis, quæ per microfcopium inftar rubinorum fplendent. Lapis Martialis pififormis \& verticolus, qui inftar craniorum apparet, \& in quo parvi dendrites confpiciuntur, eftque ferri minera optima.

\section{In comitatu Hohenfein.}

Rferente Domino Bruchmanno, in Hercynia ad Zuerge erit fchiftus 1. five Glaskopff: pariter ad Fifchbach, Bennikenftein \& Hartznig fchiftus major, ad Krippenberg apparebit inftar ferri nativi. In montibus Ilefeldienfibus fchiftus craflior globolus, etiam pififormis \& hordei inftar, etiam ad inftar cerebri, partim ruber, partim fcifilis. Ad Lindenberg; Branden. berg, Braufendivaffer, Holunder, fchiftus minutim globofus; centumpondium continebit $60 \mathrm{ft}$; ex Ilefeldien $/ 2$ 92. In ferrifodinis eruetur interdum jalpis, \& minera rara quæ vocatur Eifenmann, quæ ab alchymiftis multum quæritur.

\section{In Archiepiscopatu Trevirenfo.}

TN archiepifcopatu Trevirenfi reperiri dicitur faxum albicans relucens, 1 fufione ferrum exhibens. Etiam Stabl-Ertz five minera chalybea, cujus centumpondium contineat $80 \mathrm{H}$. Ad Mufen funt fodinx, ubi minera reperitur, qua I f $\mathrm{f}$. argenti, 42 plumbi, \& 12 chalybis \& 34 cupri in centumpondio contineat.

\section{Varia genera minerce ferri.}

DRæter magnetem, hæmatiten \& fchifum aliaque genera ferri ditiora” dantur etiam variis in locis alia, qux a mineris ferri vulgaribus valde differre videntur, fcilicet quæ coloris fint grifei, ut \& quæ coloris fint fubalbidi cum aliqua tinctura flavi, adeo ut fere fpathum referant, fed quxe pondere ferrum vel metallicum quid prodant, quxque in centumpondio contineant 24 ad 32 ib. ferri.

In bolis, marga, ochra \& plurimum in argilla \& fpeciebus terræ adinvenitur ferrum: dendritæx etiam \& alii lapides figurati ferrum etiam in fe continere folent. Genus etiam minerx multis in locis fe offert, quod proxime ad ferrum nativum accedit, politum, vel angulare \& teffellatum vel 
globofum; quod teffellatum eft \& figuræ planæ politum, in Svecia plurimum adinvenitur, ut in fodinis ad Grengierde, Danmorienfibus \& aliis, cujus centumpondium 70 ad 85 th. ferri poffidet; in Helvetia dari mineram ferri fabarum inftar dicitur. In Marchionatu Byrutbino mineram Martisjecoris colore, in qua bracter puriffimi auri fint. Ad Wonfledel ferrum nativum, \& mineram ferri nigram quafi nativam \& inftar auri fplendefcentem.

Dominus König in regno fuo minerali plurium fpecierum venæ ferrex mentionem facit, dicitque: 1 . in comitatu Sarunetano in monte Guntzen dicto, ubi ferrifodin w fint antiquiflimæ, reperiri cornu Hommonis ferreum; hocque non conftare ex ferro fulo, fed fub infolita mineræ ferrex figura in matrice fua delitefcere; matricem hanc apertam \& feparatam partim elegantifimum \& rariffimum cornu Hammonis in conlpectum dare, fex fuis circumvolutionibus, quibus fit dotatum, quam maxime blandiri oculis : partim vero ectypon five potius matricem interiorem ejusdem cornu Hammonis in confpectum cadere, quæ cornu illud in cavitate fua per lineamenta diftincte confpiciendum præbeat. 2. Lapidem Syriacum five $\jmath^{u-}$ daicum ferreum: Lapidum Judaicorum feu Syriacorum vulgo dictorum magnam effe differentiam; aliquot ejus fpecies Helvetiam fuppeditare; ferreum autem figura fua prope accedere ad fructum pruni fylveftris, qui teres \& Atriis deftitutus fit: hunc in monte Legerio ditionis Tigurina reperiri. 3. Cubos feu tefferas parbas ferreas, feu ferri mineras fub cuborum parvorum feu tefferarum exiguarum figura; iisdem montem Legefium effe fertilem. 4 . Legumina ferrea, fabas, lupinos E pifa ferrea. Aliam ferrimineram ad pagum, Bollenwaar, infra Brugas, oppidum Argovie ad Arolam fitum, ditionis Bermenfis, exftare ibi montem ex ochra pallida conftantem; mineran ferri pififormem five globulos mineræ ferricopiofe in fefe continere, ita ut mons piforum vere appellari poffit : terram hanc fublutean, friabilem, matricem effe horum piforum, diverfie autem eam effe figuræ; aliam enim figuram fabarum, aliam lupinorum ac cicerum, aliam piforum majorum ac minorum figuram exhibere colore ferrugineo. 5. Teftaceam mineram ferream, cocbleam fefflem ferream inftar planæ marinæ vel in fe retortæ ac revolutx inftar buccinx ob raram fuam fpeciem \& fingulare naturæ opificium etiam admiratione dignam. Tales cochleas ferreas concinne \& affabre elaboratas jam commemoratum montem Legerium quoque proferre. 6. Strombum ferrum, ex cochleis \{trombos ferreos parvos, elegantibus radiis infignitos; eundem montem fuppeditare hoc cochlearum genus, non taritate minus quam venuftate quoque effe commendabile. 7. Fructus exoticos, cubebas ferreas, magnitudine, colore, figura atque petiolis cubebas, exoticum fructum reprefentare, quas montem Legerium etiam fuppeditare. 8. Piper rotundum ferreum, pari modo piper rotundum nigrum ferreum crilpatum, \& figura ac magnitudine fua effe commendabile. 9. Anacardium ferreum, mineram hanc ferream fruetum illum arboris exoticx, anacardium dictum, exquifitiflime exhibere, quæ quoque. Legerii fit fotus. io. Confectiones coriandri magni ferreas: globulos hos ferreos perelegantes confectioni coriandri magni crifpatimulos fplendore fuo corufcosatque nitidos efle, quos natura ex ejusdem montis facrario proferat, \& fingulare 
ejus opificium exiftant. II. Confectiones cinnamomi ferreas; confectionem hanc cinnamomi ferream fub Martis nigricantis minera apparere, qui ob fingularem quoque figuram hic mereatur commendari, quam inter bellaria lua Legerius mons itidem offerret.

\section{Flos ferri.}

FLos ferri eft lapis coloris nivei \& nonnunquam argentei, precipue propullulans ex vena ferri, fpeciem chryftallifationis referens, fecundum Figuram appofitam Tab. XXXVI: prefertim in ferri lapidibus in altum crefcit; \& vel teneros ramufculos, coralliorum fruticem, decerptas chryftallos \& alias figuras repræentat : reperitur utplurimum in fuperiore Stiria in confinio Auftrix, \& quidem in fodinis multa copia ; at vero ubi venæ ferri pæne omnes calcaria quadam materia contectæe funt; unde flos dictus non durus, fed friabilis eft \& inftar lapidis calcarii : quod etiam inibi fit ferrum quid, patet ex eo, quod fubtrahatur a magnete, \& quod virtute adftringente polleat. Valentini ex Beslero \& mifcell. acad. nat.curiof. Præterire velim vegetationes aut chryftallifationes venæ ferrex coloris brunei, fubnigri, nec abfimiles fxpe chryftallis reliquorum metallorum, pariter cruftaceas \& incurve lamellatas, \& læpe quafi exefas, \& plures alias.

\section{Ferrum natioum.}

Nulti prædicant, hinc \& inde in fodinis reperiri ferrum nativum feu purum; ut in globulis, ut Saxoniæ; aliqui vero ambigunt: in granulis tantum inveniri perhibent, ut Saltzburgi, ad Eifel, in montibus Silefie, \& quidem granula, qux ftatim fub malleo poffint excudi. Wormius etiam memorat reperiri in fodinis Norwegis, inque fodinis Stiris fecundum Rulandum etiam in fluviis, \& fecundum neotericos multis in locis; fed an ita purum, ut ferrum in foco excoetum, multus dubito. Alias minera ferri teffellata tam dives in Svecia reperitur, ut ferro nativo, quamvis id non fit, tamen affimilari poffit.

\section{Venee ferri commixtio cum aliis metallis.}

FErrum adhærefcere folet nulli non mineræ metallicx, adeo utaffiduus comes fit metallorum : ut I in minera victrioli \& fulphurea multum hofpitetur, ut etiam prius dictum eft, adeo ut in centumpondio pyritis fxpe Ioad 40 libræ ferri contineantur; de qua re optime egit clarif. Dominus Henckel in fua Pyritologia \& præfertim in capite ejus 6to, ubi variis argumentis concludit, etiam in iplo fulphure crudo terram quandam ferream reperiri, qux non modo per magnetem fubtrahatur, fed etiam in metallum redigi poffit: fir enim fcorix vel fxces poft purificationem fulphuris relictæin catillo vel tigillo fundantur, videri terram cineritiam ferream, quæ a magnete auferatur, \& quæ in regulum ferreum poflit conflari, alias fi pyrites probetur, qualiscunque generis fit, multam partem ferri obtineri, quam- 
vis fpeciem fulphuris ferri expertis præferat; fed de his melius in tractatione de fulphure \& victriolo, ubi natura pyritum plenius exponetur. 2. In cupro quam plurimum refidet ferrum, adeo ut circa omnes fere operas cupreas multa ars in eo confiltat, ut a ferri portione liberetur, quod fit præcipue per calcinationem, alibi per ipfam fufionis methodum, etiam per purificationem. Multa pars ferri in ipfis fornacibus in fundo \& ad angulos remanet. 3. In minera argenti multa pars ferri delitefcere folet, quod experiri licet circa argenti operas fuforias; inque ipla minera ferri etiam pars argenti refidere folet. Norwegix, ubi argentum nativum effoditur, dicitur illud a ferrea quadam minera jugiter comitari. In fodina Uthoenfi Svecix reperiuntur hinc \& inde fruftula, pariter etiam ftrata venæ argentex. In fodina ferri Danmorienfi pariter. Quodque dignius eft in fodina Noormarckienfi in Wermelandia ftratum quoddam aliquot pollices craffum fodinam trantiiffe deprehenfum eft, in quo argentum nativum multa fatis copia repertum fit, de qua re fupra copiofius actum eft, frufta argenti nativi in collegio regio metallico Stockholmix adhuc confervantur. 4. Circa venas ftanni, ut \& plumbi, antimonii, Mercurii, \& nullas non aliorum metallorum fpecies, tanquam hofpitem vulgarem le offert ferrum, cujus rei documenta infinita poffent afferri, fi operæ pretium foret. Aurum etiam ferrum multum comitari dicirur \&c.

\section{Ferrum in terra, limo E argilla.}

TN locis paluftribus invenitur frepenumero materia ferrea, adeo ut exiItat ibi in limo, humo \& argilla: quibusdam in locis eft ochra varii coloris, quæ ferrum continet: etiam ferrum in bolis animadvertere licet, ut de terra figillata Laubacenfi annotatur : alias Hellmontius junior afferuit, fibi innotuiffe modum, ex quovis limo \& fulphure ferrum producendi. Beccherus vero ferrum ex oleo lini \& limo produxit: quod experimentum repetiit Godofredus, limum arefactum in pulverem comminuens \& oleo lini permixtum in maffam redigens, globulos confeetos in crucibulo igne aperto urgens atque aduftos in mortario conterens, quo facto nigras obfervavit particulas a magnete attractas, quemadmodum legitur in commentariis academ. reg. fcientiarum pro anno I 704. Idem experimentum, fed cum limo Laubacenfi, quidam repetiiffe non abfque fucceffu perhibetur. In Siberia \& regno Ruffico mineram ferri ex ipfa argilla, in qua delitet, erui. Alias nullum metallum tam facile reduci poteft in terram quam ferrum; in crocum \& ochram fola humiditate dilabitur; lentius hoc circa reliqua metalla fuboritur. Vidi in prædio Norberkienfi Svecire forficem quandam ferream in humo 40 vel 50 annis reconditam, quæ plane in pyriten quendam effet verfa, ipfa fractura retulit pyriten aquaticum prout vocatur, qui etiam facile in terram \& pulverem dilabi folet.

\section{Ferrum in animalibus Eீ vegetabilibus.}

Bfervatur multis in locis, quod terra arborum \& graminis admodum ferax fit, ubi reconditum eft minerale ferri, ut circa fodinas, fupra 
cumulos fcoriarum ferri \& alibi, ubi materia quadam ferruginea \& ochracea locus eft repletus, quod paffim videre eft Svecix; exinde etiam deduci poteft, particulas ferreas in nutrimentum rerum vegetabilium cedere poffe. Confirmatur etiam hoc a more Japonenfium, qui íecundum relata certum genus arborum limatura ferri \& aren: crefcere faciant.

Dominus Lemmeri per experimenta oftendere fatagit, plantis materiam quandam ferream ineffe, hinc quasdam in cineres reduxit, quibus dein per magnetem ferrum ineffe compertus eft ; pariter etiam partes animalis caftoris : cineres enim dieti per fpeculum uftorium eadem ph: Łlomena oftendebant, qux limatura ferri ; ftricturas enim emittebant, \& in globulum confluebant; adeo ut quxttio oborta fit, num cineres dari posfint fine ferro, \& num ferrum inibi ante ignitionem plante vel dein exftiterit.

Clariff. Wollfius mentionem facit ligni cujusdam non petrificati, fed quod propter copiam viEtrioli inibi delitentis dilaberetur. Myliuslignum oftendit, quod in ferrum effet mutatum. Scippius narrat non procul a Pieremont in cavernis quibusdam adinventum fuiffe lignum petra \& minera ferri imprægnatum, quod 2 femunciarum pulverifatarum \& ope menftrui nigri in furno fufarum fedimentum daret, quod ope magnetis attraheretur; unde lignum ferro conftitiffe innotuit. Dominus Liebeknecht mentionem \& defcriptionem facit metamorphofeos cujusdam ligni in mineram ferri, de qua re tractatum edidit: quod lignum fuerit, teftatur auctor oculatus teftis, corticem \& fibras haud difficulter a fe invicem feparandas animadvertit; maffa integra fuit firmiffima \& duriffima, ita ut chalybi allifa ignis fcintillulas emiferit; medulla $a b$ altero fine multo labore feparari \& comminui potuit : truncus fagi fuilie videbatur, color ferreus erat \& idem fplendor qui poliendo induci potuit; ftridor \& refiftentia in mortario cum contunderetur. Gravitas fpecifica fuperavit gravitatem fpecificam minere ferri : ut adhuc magis experiretur, num ferrum effet, portiones æquales maffæ ac alterius cujusdam mineræ ferreæ in mortario contudit, \& aqux pulverem immifit, ut a particulis terreis utraque liberaretur; tunc particulæ mafiæ hujus lignex celerius fundum petebant, quam particulæ merx ferrex, qui tamen defcenfus, ablutione fepius repetita, xqualis fere deprehenfus eft. Quum pulverem torrendo ulterius expurgaret; aquam cum oleo vietrioli affudit, ebullitionem cum calore notabili halitumque inde affurgentem edidit; minera vero ferri calorem multo: minorem produxit; partes etiam non modo ebulliebant per oleum victrioli, fed etiam a magnete fubtrahebantur. Maffam etiam in pulverem. majufculum redactam \& poftmodo torrefactąm fali tartari fixo commifcuit, ignique contumaci aperto \& ventolo impofuit, quo poftmodum liquefacta cono fuforio infula fuit; inter transfundendum, conum calefactum feboque illitum malleo concuffit; quo facto regulus Martis in fundo inventus, mediante malleo a fcoriis feparatus erat.

Offa humana ferrea facta Londini etiam confipici poffunt.

Clafiss II. de ferro.

Ee ee

Minzre 
A Gricola genuinam tradit narrationem de quodam patrix fux Germanix loco : in Lygiis inquiens ad Sagam oppidum in pratis eruitur ferrum, foffis ad altitudinem bipedaneam actis, id decennio renatum denuo foditur, non aliter ac Ilvæ ferrum. Dominus Gerhardus dicit fibi relatum effe a foffore metallico, fi fides narratis habenda fit, ad ferrarias, qua non longe Amberga diftant, terram inanem cum ferri minera erutam, quam vocant Gummer, mixtam cum recrementis ferri, qux appellantur Sinder, congeftam in cumulos, inftar magni cujusdam valli, folibus pluviisque exponi, \& decimo quinto anno denuo excoqui eliquarique ferrum tantex tenacitatis, ut folæ laminæe inde producantur. Interim de ferri renafcentia in maris Tyrrheni infula non procul a litore Tolcanix, non modo prifci auctores Plinius \& Strabo notas fuas nobis tradiderunt, fed \& metallographi moderni fide digni, puta Fallopius \& Cæafalpinus rem eandem diferte atteftantur: hæc Dominus Boyle.

Silefix ad Malmitz obfervari dicitur minera ferri finulofa, ut prius in Lauf fitz poft r o annorum elapfum renata. Idem refert Dominus Stanislaus Rein. Acktellmejer in infula Ella circa Florentiam. Minera prædicta fiftulofa eft coloris flave brunei, admodum dura, digitum craffa \& longa, fecundum delineationem Aldrovandi in mufeo metallico, quam vocat Stelechitim fiftulofam; hæc frangirur cum alio lapide ferreo \& commifcetur, inque bonum ferrum una funditur. Georgius Fabricius \& multi alii affirmant, in Silefia ferrum effoffum nova incrementa recipere, \& terram arborumque truncos in illis incrementis materiam ferri acquirere, primum liquori cuidam denfo fimilem, poftea magis magifque indurefcentem. De qua re Dominus Henckelius, filicet quod in Silefia, qua Saganum eft, e pratis eruatur ferrum decennio renatum, \& denuo fodi non aliter ac Ilvæ ferrum, five plumbum in monte Fefulano \& 2 s prope Apolloniam in Dalmatia. Quod mineram ferream Silefienfem prius memoratam concernit, narratur in Breslutif. Natur-und Medicin-Gefchicbten illam effe coloris flave brunei, friabilem, ponderofam effe optimam, præcipue coloris albe cœrulefcentis, quæ inftar fmalti appareat. Efre etiam alia frufta interfperfa pyritis inftar dura, nec multi emolumenti, nifi quod fuorem in furno fuppeditent.

Alias Svecix admodum vulgare eft, præcipue Smalandix \& Oftrogothix, in fuviis aut lacubus mineram ferream intra I 5 ad 20 annorum fpatium renafci, \& quidem in eodem lacus loco, unde mineram folent expifcari tanquam fedimentum \& fubolem quandam aquarum, defluere

enim illuc videtur ex proxima palude ; pariter etiam in locis paludinofis, de quibus prius copiofe clafie prima \$. S. III \& IV actum eff.

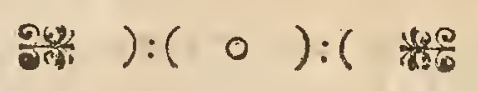




\section{PARAGRAPHUS VII. De lapide bamatite \& fobito.}

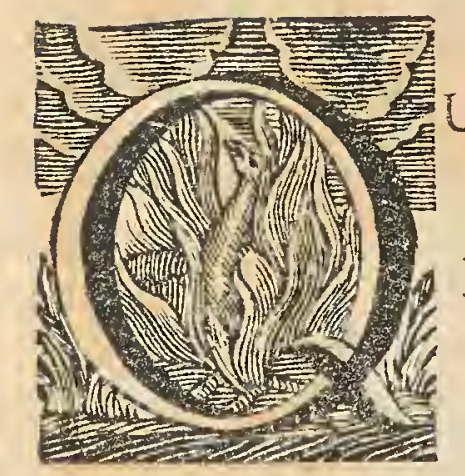

Uoniam inter mineras ferri hæmatites etiam numeratur inque eandem claflem vènit, hinc de illo feorfim hic agere conftitui. Et quia Dominus Joh. Laurentius Baulchius in Schediafm. de bematite \& atite plurima ex Agricola, Encelio, Boodt , Plinio aliisque collecta habet, hinc colleetanea ejus primum adducere volo: verba enim ejus funt.

Hæmatites a coloris fimilitudine id nomen fortitus eft, putatur etiam, quod tritus cum aqua, ut cotibus aquariis, fuccum fanguineum reddat; dicitur etiam quod fanguinem fiftat.

Differt hæmatites loco natali, eft enim Moravicus, Bohemicus, Polonicus, Italicus, Ethiopicus, Africanus, Arabicus : in quibus locis invenitur, \& quidem in propriis benis, ut Germanix fylva Hercynia, vel Northufix, Hartzgerodx, Mifnix, Annabergæ, Geuro, Zeblicio, Saxonix Hildeshemio, Goísharia. Italix in agro Brixienfi, qui tamen bonitate peregrinis cedit. Vel invenitur inter rubricas, quas hrematitum parentem effe dicit Agricola, ut in rubrica finoptica, in rubrica Mifnica, in rubrica Norico-Sultzbachiana. Vel invenitur in ferrifodinis, ut Bohemicis ad Leffam pagum, non procul a Schlackewerda, Noricis cisdanubianis.

In ferrum excoqui poteft hic lapis, ut fere nihil aliud fit quam ferri materia. Invenitur etiam in illis locis, ubi invenitur magnes, cujus fpecies hrematites effe dicitur: \& quoniam magna eft cognatio ferri \& magnetis, animadvertitur interdum, fed obfcure ferrum trahere; in ferro attrahendo non eadem quæ magneti, hæmatitx natura eft; hæmatites 1 ithiopicus magnetem alium a fe trahit: Invenitur etiam hxmatites in fodinis lapillorum, quibus ftannum feu plumbum album excoquitur. Vel etiam in fodinis argenti ballis foacbinnica; in tractu Hildefiaco natura ex obftracite facit hrematiten.

2. Differt hematites figura; habet enim ftrias inftar antimonii; globofus fere femper ert, \& hinc interdum cavernulis plenus, ut Hildeshemius : interdum uvarum modo concrefcit, ut Hercynius, vocatur talis hrmatites botryites; metallici follores \& hunc vocant Glaskopff. Interdum cerebri detecti formam præbet ut Hercynius \& Cherufcus Northufiæ \& Hartzgerodx, qui reperitur in lapide duro fubcinereo cum corio ferricoloris obducto \& foraminibus in fuperficie pleno. Videatur Tab. XXXVII. Niger, turritus, ftalactiticus \& erinacei modo aculeatus effoditur circa vallem. Domini. Joachimi, niger, turbinatus quafi Geurenfis, Annebergenfis, Salfeldenfis; figuram videas hic adjunctam.

3. Differt hrmatites colore \& quidem vel lapidis vel fucci, quem reddit lapis, ratione lapidis: habet enim colorem vel Janguinis vel ferri, \& tum interdum aliqure partes extimx imitantur colorem, qualem gignit Mifena. 
Vel niger eft ut Gofslarianus, Annebergicus, Salfeldenfis, Ambergenfis. Vel purpureus ut Haffus. Vel flarus antipatbes gemma, quæ nigra non translucet, non videtur aliud effe, quam hæmatites niger; quidam putant efle corallium nigrum.

Ratione fucci : alii facile reddunt fuccum ut plerique ; alii difficulter, ut Arabicus \& Mifenus, nimis duri. Quanquam vero fere reddat fanguineum, tamen Arabicus dat croco fimilem. Golslariani pars, quæ uvarum. modo concrevit, nigrum reddit fuccum, altera in croceo nigrum. Niger Golslarienfis reddit fuccum croceum; eftque procul dubio Medus niger Alberti.

Huc refertur etiam Tricbrus ex Africa, qui niger eft, fed 3 fuccos reddit, a radice nigrum, medio fanguineum, fummo candidum fecundum Plinium. Germanicum Trichrum, Geuri, Annebergæ \& Salfeldiæ reperiri afferit Encelius, qui turbinatus fit \& durus. Niger \& pondere infignis \& Androdamas a nonnullis vocatur Androas. Trichrus alias eft lapis compofitus ex duplici hæmatite, nigro fcilicet \& rubro, ac ut videtur galactite \& affmili. Verum Trichrum Dominus Boodt inter ignotos lapides recenfet.

Dum uritur hæmatites vinoque afpergitur, minii vel cinnabaris colorem imitatur, fi fanguinis concreti fimilis fuerit, fi nigri mutatur in profundiorem : uritur autem ut Phrygius, irrigato vino; alii dicunt, quod nullo vino irrigandus fit. Modus vero uftionis eft, ut modice levis fiat, \& bullis quibusdam intumefcat: uftus dein abluitur aqua vel fimplici, vel quod melius deftillata plantaginis, portulacæ \&c. aquam fixpius mutando; quamvis \& non uftus, pulverifatus tamen, hoc modo abluatur : diverfie funt vires hujus loti \& non loti.

Hæmatites factitius fit vel ex magnete adufto vel igni artificiali. Aliqui enim fubtiliant in adurendo magnetem, \& quod provenit inde, eft lapis hæmatites in operationibus fuis.

Schifus lapis \& hæmatites cognationem habent: Schiftus lapis fuperiori confimilis eft, adeo ut pecies hæmatitis fit, vocatur fchifus, quia videtur quodammodo fifus. Mutua enim fuarum partium compolitione, quæ ligni inftar recta creverunt, fimilis eft fali ammoniaco, ut dicit Agricola : Schifus lineas pectinum modo per longitudinem divifas habet, hæmatites vero eas habet, utfors tulerit. Oribas dicit, quod lapis hic crocei coloris fit, fi optimus, alias nigricat, laminas habens teinues invicem hærentes, ut lapis 1pecularis, (plendentes \& perfpicuas, per quas fi fol infpiciatur, videtur croceus. Videtur talci quxdam fpecies effe, fed hac ratione a talco differt, quod in rectas laminas fcindatur : talci vero laminæ flexiles funt \& vario modo complicatæ.

Differentix fchifti exden funt cum hæmatite ob maximam cognationem, quam ad fe invicem habent, ut qui ex una eademque materia conglutinati; figura tantum \& aliis quibusdam differunt. I ma differentia eft ex loco natali vel generationis, reperitur verus Romæ in Vaticano effoffus e fundamentis ; \& in monticulo prope Anglarium, nam ejus montis cacumen ex hoc lapide conftat. Effoditur etiam lchiftus in Mifnia Anneberge \& Zeblicii, qui in fe aurum continere dicitur, \& in pago Hohetanne, milliari 
TAB: XXXY de ferro.

Flores Marlis natizi, in Fodinis, ex albicante Matrice, repullantes, Befleri.

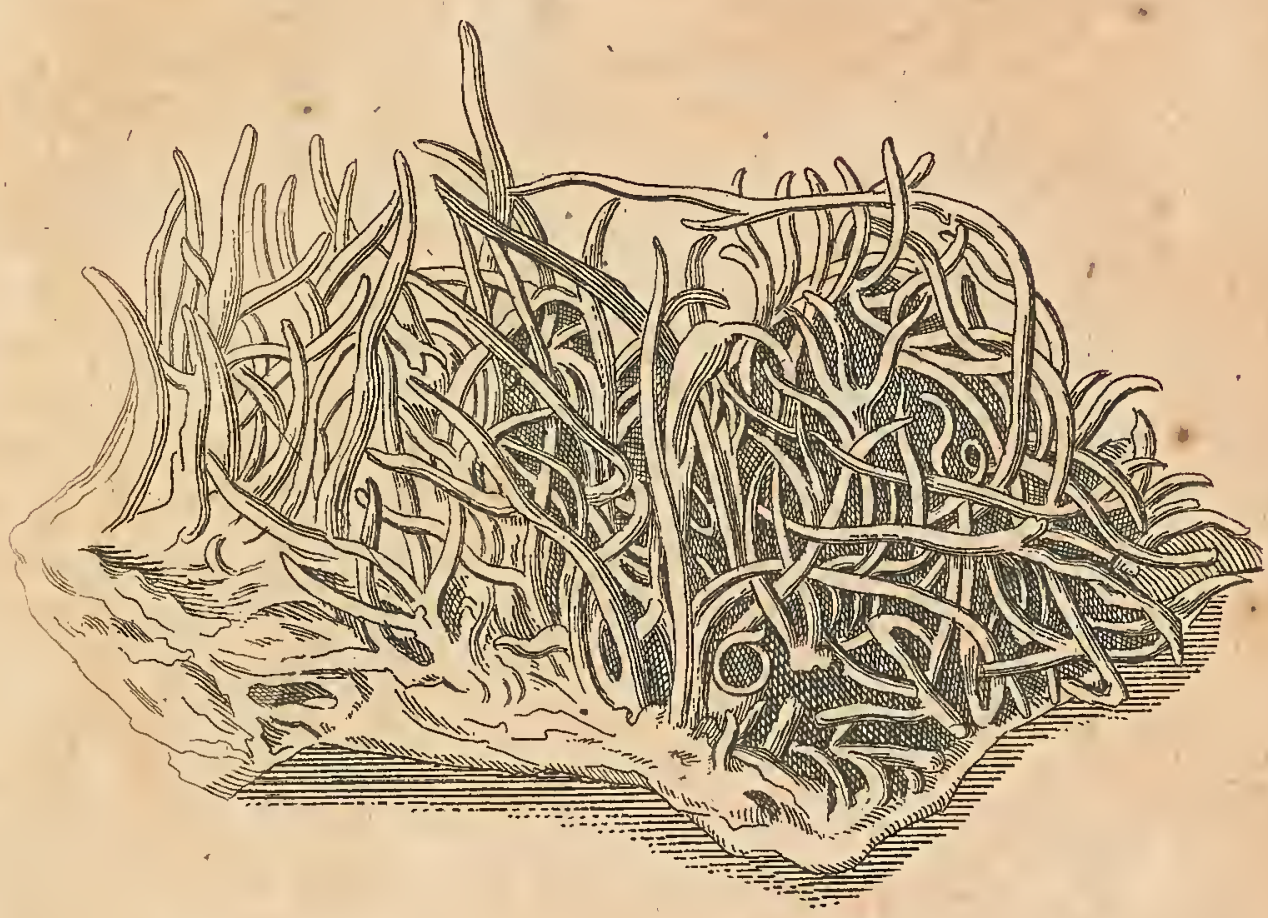

TAB: XXXVIWI.

Hcematites botryites

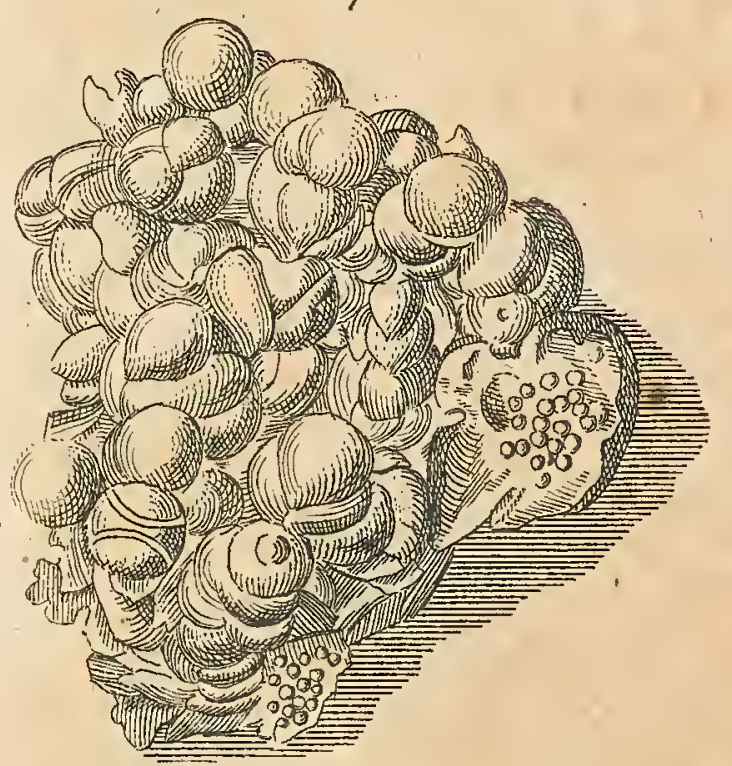

Hromatites ferri politi inftarfplenden cum macula cinabarina.

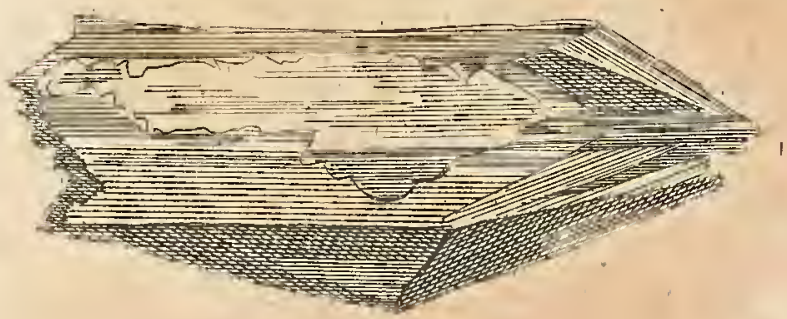

TAB: XXXNII

Hamatites.
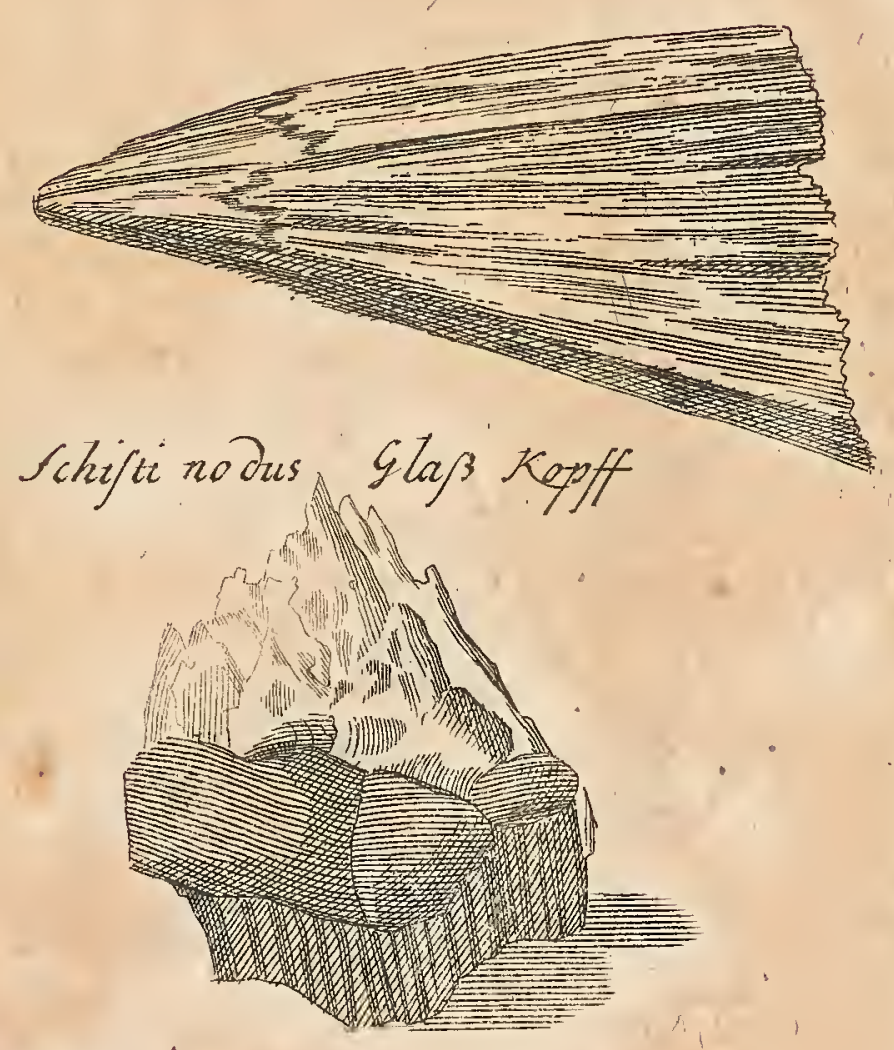

milliari uno Freiberga diftante in propria vena: item in copia Mariebergi Golderana: in Hercynia juxta Hacekorodam, \&alibi ut in Bohemia, Saxonia, Hifpania, Africa \&c. Differt deinceps fchiftus ab hæmatite figura, nam aut altera parte, aut utrinque cuncatur. Quomodo cunei modoftriCi, modo lati, modo parvi, nunc vero inveniuntur magni : Mifenum vidiffe fe auctor dicit 14 libras pendentem. Aut firiarum infar concrefcit affimilis belemnitæ, qualis interdum Gofslarianus \& plerumque Bohemicus, effoffus ex metallis ferrariis, qux funt ad Leffam pagum. Aut upas reprefentat, ut interdum Hercynius, interdum Gofslarianus nigerrimus. Aut dimidiati globifigura eft, cerebri fpeciem præfe ferens. Aut denique magis latus quam longus eft, ficut Hercynius. Non raro extrinfecus livvis eft \& ferri politi inftar fplendet, quandoque maculam cinnabarinam habet. Quin fractus etiam intrinfecus, fed minus, folet nitere. Idem fchiftus interdum extra non fplendet, intus inftar minii factitii, quod etiam cinnabarim vocant pictores, micat, qualis in Hercynia fylva nafcitur. Atque is etiam in pulverem tritus nitet non aliter, ac fi argento vivo effet oblitus. In Mifeno fcbifto Aodi quidam nafcuntur magnitudine nucis juglandis adeo duri, ut incudi impoliti refpuant ictus. Quibus, cum politi fuerint, aurifices argentum, cui induxerunt tenuiffimas auri bracteas, poliunt; \& perpoliunt illas coloratas bracteas, qux fubdunturgemmis, ut per eas transluceant, fecundum Agricolam. Aliquando natura leves funt $E$ rotundi inftar calvarixe vel cranii. Schifti glebæ duræ \& rotundatæ, fchifti radices vocantur, quibus uftis hæmatites olim adulterari folebat. Differt 3 tio colore vel lapidis vel fucci; lapidis color eft vel croceus vel nigricans, qualis nafcitur in Africa, quem ab exfincti carbonis colore vocant antbraciten, vel nigerrimus tanquam botryites Gofslarienfis. Crocei eft hic lapis coloris, fi optinius fuerit, alias nigricat, laminas habens tenues invicem hærentes, ut lapis fpecularis, fplendentes \& perfpicuas, per quas fi fol infipiciatur, videtur croceus. Colore magis pallido ab hæmatite dignofcitur. Schiftus fi fanguinis concreti fimilis fuerit, uftus, cinnabaris initatur colorem, finigri, mutatur in profundiorem. Omnis alius fchiftus uftus floridum habet colorem. Succum quanquam fere reddat fanguineum', tamen fchiftus Africanus ab ea parte, quæ fuerit ab radice, nigri coloris, ab altera croci. Similiter Gofslariani pars, qux uvarum modo concrevit, nigrum reddit fuccum, altera in croceo nigrum : coti attritus fuccum fanguineum reddit vel croceum eumque aditringentem. Differt 4 to duritie, cum denfus \& plerumque durus lit, quo magis ferri inftar fplendet, co durior effe folet, ut in Mifena \& Hercynia fylva.

Hematites /purius tria habet genera, qualia funt I. Silefanus friabilis, Blutfein, Braunftein: invenitur non procul ab arce Lehnenfi ad Boberum fluvium; non procul a Neydeck in Bohemia: figuli eo, addito lapide plumbario, fictilia nigro colore tingunt. Conciliatur autem eo, addita fquama æris, ruber vel croceus color vitro, vel puniceus urceis, e quibus muftum bibitur. Uftus crocum Martis colore \& effectu refert. 2 dum genus in ferri metallis reperitur globofum, colore partim rubricx, partim ferri nigricantis : videatur Tab. XXXVIII : hic friabilis ob inæquaClafis II. de ferro. Ffff 
litatem, durus tamen eft. 3tium genus lapis eft ferrugineus, gravis, obductus rubrica, \& fupra rubricam creta pallida; ultimo tectus crufta fimili xtiti tenuiore \& fragiliore, qux \& fepti modo pervadit ad intima. Lapis hic ad cotem croceum \& fanguineum fuccum parit : reperitur Aretii, ubi fons eft acidulx, congener oftraciti. Hrc Dominus Baufchius.

Alias Rulandus fex genera hæmatitis memorat : I. Hæmatiten fosfilem optime rubrum. 2. Hrmatiten nigrum, fuccum faffranei coloris prebens duriorem reliquis. 3. Hæmatiten foffilem purpureum. 4. Hæmatiten foffilem pulcherrimum, cujus ope $a b$ aurifabris ad politionem ufurpatur. 5. Folfilem nigrum trichufum, qui cote attritus triplices colores fuppeditat. 6. Hixmatiten rubrum pulcherrimum ex Africa venientem.

Dominus Lemmery etiam defcriptionem hæmatitis faciens, ait, lapidem effe durum \& gravem, coloris bruneo-rubentis, fed magis \& magis rubefcere, quum pulverifetur : optimum ex Ilifpania, aque Compoftellis ab oppido ibi venire, qui fit purus \& ponderofus, acumina bruneo-rubentia habens, extrinfecus ftrias \& lineas nigricantes, intrinfecus vero fimilem effe cinnabari. Ex Anglia etiam venire genus hrematitis, qui fpurius dici poffit; fed differre in eo, quod nulla acumina poffideat, nec tam durus fit, nam facile in partes, tanquam creta fecatur, unde etiam vocatur creta rubra. Hæmatitem eligendum effe dicit, qui fit coloris bruneo-rubri, ponderofus, denfus \& fimilis ubique, lævis contactu.

Dominus Barchufen ex victriolo Martis \& faccharo Saturni, fi una multum coquantur, rubram quandam maffam parari poffe refert, ipfi nativo hæmatiti forma admodum fimilem; quare nonnullos fufpicari dicit ex iisdem principiis lapidem hunc ortum traxiffe.

Smiris eft proximus hxmatiti coloris ferrei, \& quoniam durus admodum inftar adamantis eft, eo vitra fcindi \& ferri utenfilia poliri. Tritus cote non fecus ac hæmatites, fuccum fanguineum præbebit.

\section{FINIS CLASSIS SECUND压.}

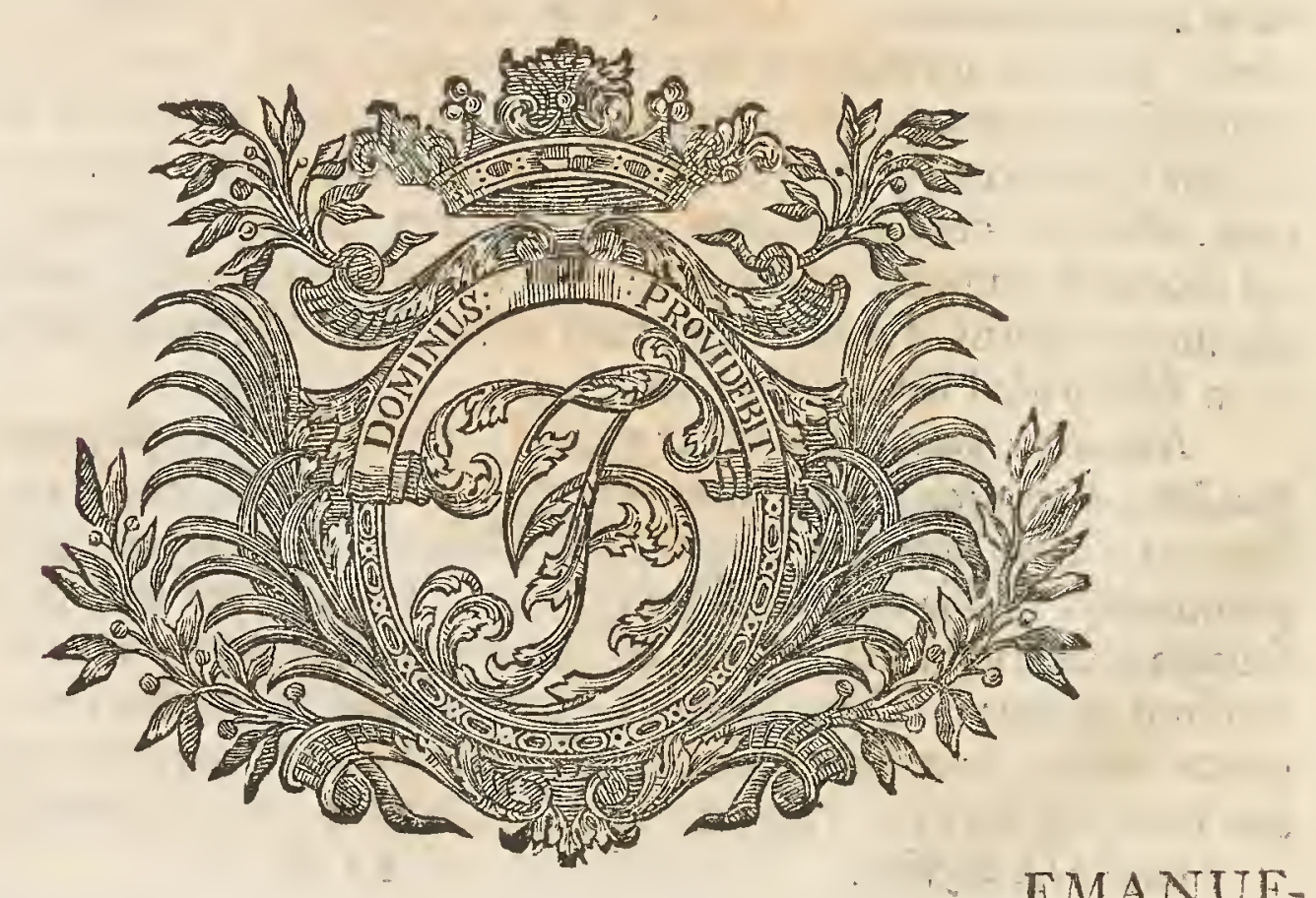

EMANUE- 


\section{EMANUELIS SWEDENBORGII,}

ASSESS. COLLEGII METALLICI SAC. REGIÆ MAJEST. REGNIQUE SVECI

\section{REGNUM SUBTERRANEUM}

S I V E

M I N E R A L E

D E V A R II S

$C \cup M$

\section{FERRO ET EJUS VICTRIOLO \\ CHYMICIS PRÆPARATIS}

$\mathrm{E} \mathrm{T}$

FACTIS EXPERIMENTIS.

C L A S S IS TERTIA.

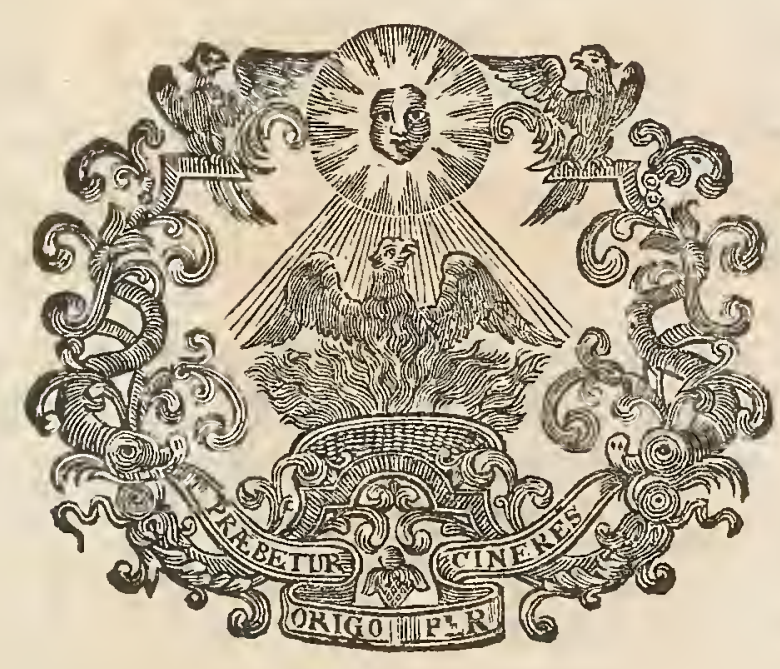

DRESD屟 \& LIPSI E, APUd FRIDERICUM HEKELIUM, bibliopol, REgiUm M DCC XXXIV. 


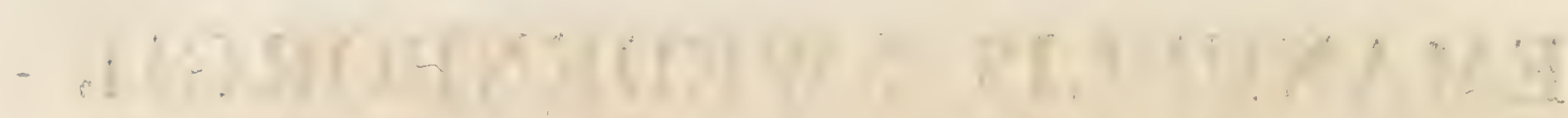

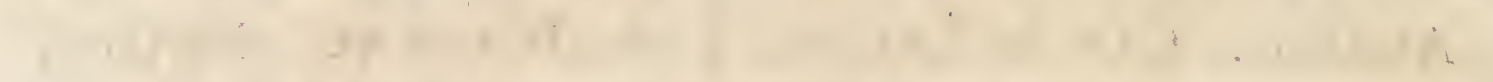

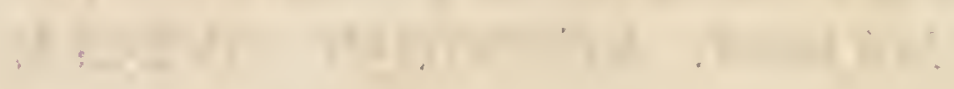

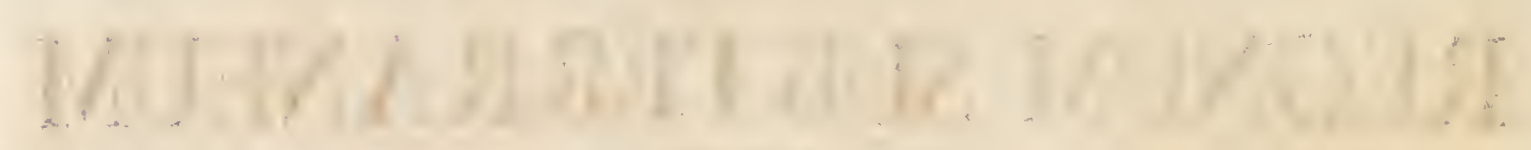

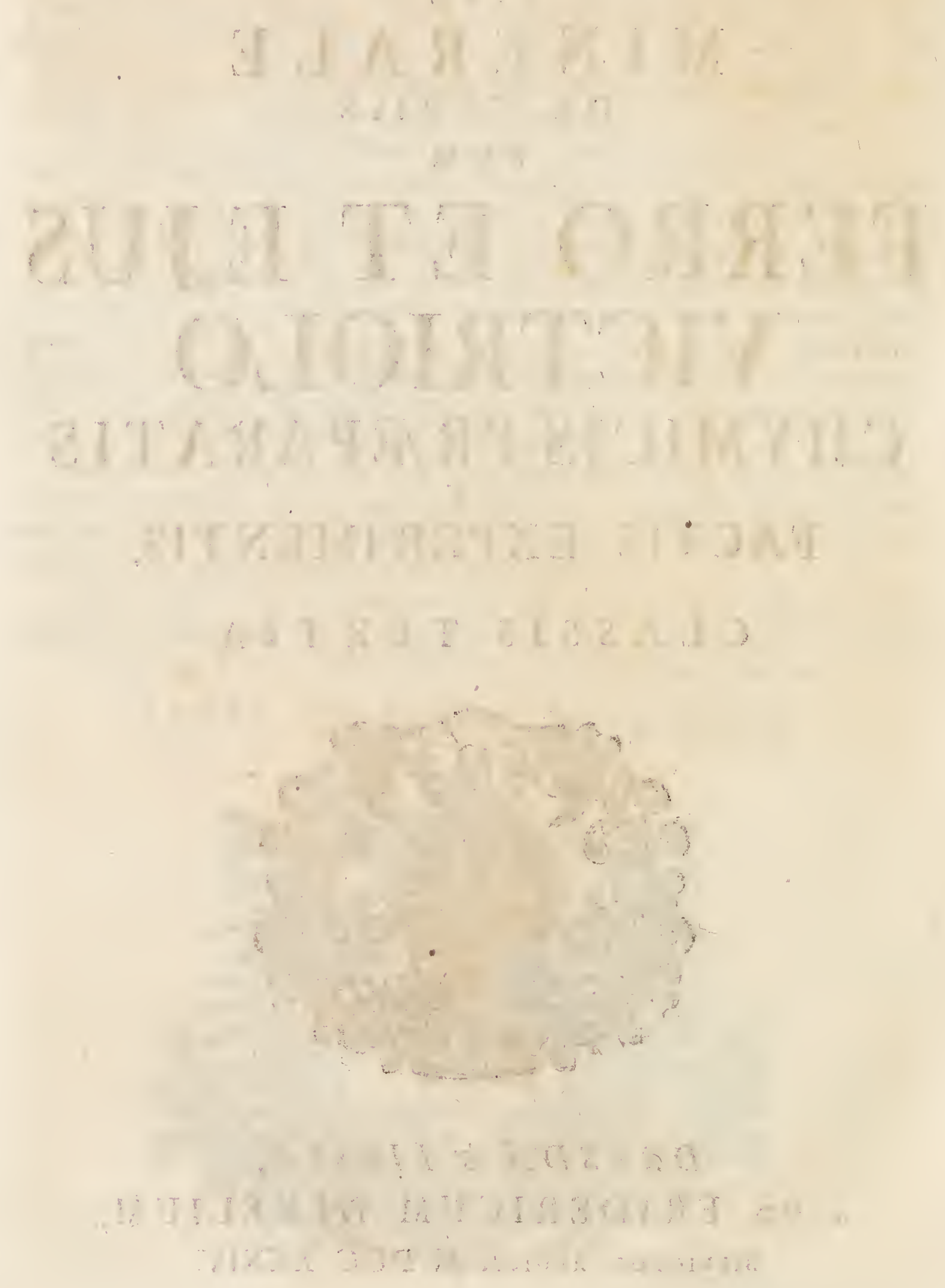




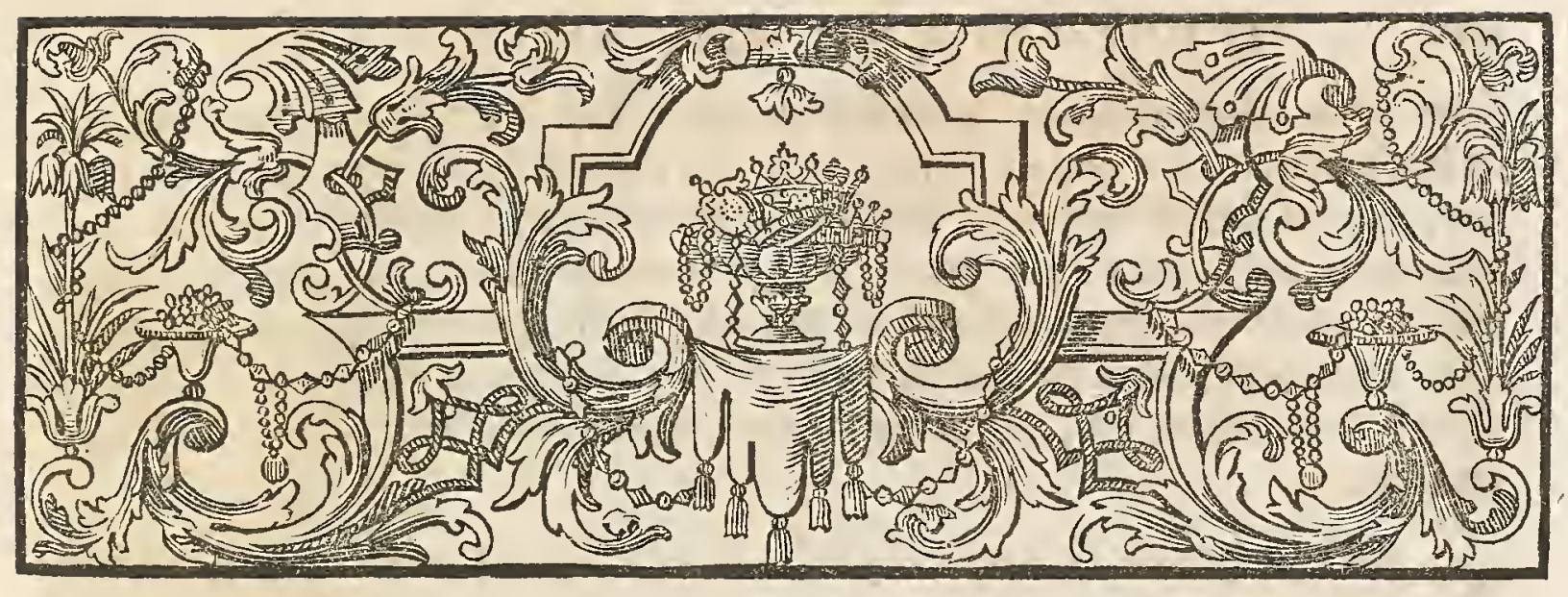

\section{CLASSIS TERTIE PARAGRAPHUS I.}

\section{De limatura Martis aut chalybis.}

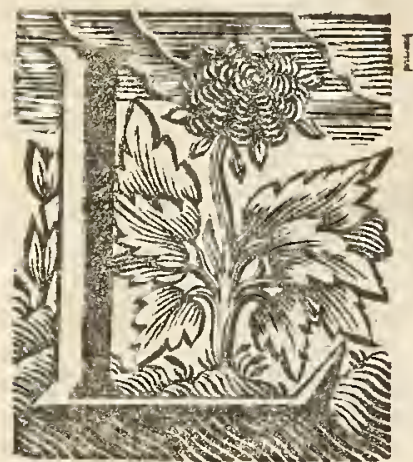

Imaturæ, croci, tincturæ \&c. Martis, a diverfis auetoribus chymicis fub nomen \& titulum tam Martis quam chalybis referuntur; adeo ut exdem limaturx, croci \& tincturæ ab aliis appellentur chalybis, ab aliis vero Martis: ratio eft, quia nonnulli fuadent eadem præparata ex Marte, nonnulli vero ex chalybe conficiendi, non aliter fit cum fpeculorum quorundam generibus, quæ communi nomine vocantur Specula cbalybea, licet ne hilum chalybis eis infit, fpecula enim vulgo chalybea dicta parantur ex 3 libris ftanni, I libra æris, 6 unciis tartari rubri, $1 \frac{\mathrm{T}}{2}$ uncia nitri , 2 drachmis aluminis \& 2 unciis arfenici; materia inde conflata chalybem quodammodo refert.

Quod limaturam chalybis aut Martis attinet, quam chymici feu medici multi faciunt, nihil aliud eft, quam ramenta Martis aut chalybis, qux optima habentur penes opifices, qui chalybem tractant, præfertim penes acuum confectores. Qualitas limaturx ita folet probari; fi limatura dieta igni candelæ admota ad mediam partem fere ignefcat candelamque exftinguat, pro inutili rejicitur. Quæ habetur fubtilifime pulverifata, \& in pollinem quafi impalpabilem redacta, omnibus inde preparatis anteponitur : aliqui vero præferunt limaturam factam ex ferro limaturæ factæe ex chalybe. vide Kœnigii regnum minerale, qui, limatura Martis cruda fubtilifine pulverifata, ait, melius ex ferro fimplici, quam chalybe ferro duriori; (igne enim alteratus rarefactufque, multum fpirituum \& fulphuris volatilis deperdit, \& a textura fua naturali declinat), vel etiam ex batitura, Clafis III. de ferro. 
(ceu cui acidum affufum fuum faporem nihilominus retinet, minime vero limaturæ, ceu a qua intra paucas horas dulcedinem contrahit), affumitur; ceu in quod humores rodentes facilius agere, feque in poros ejus ampliores ablcondere, ficque capi \& cicurari poffunt, vel etiam facilius connubium cum ejus particulis inire, adeo ut longe præftantior fit omnibus crocis aperientibus \& adfringentibus ; quare \& noftro judicio præftantiffima hinc ea eft, eique haud prævalet crocus Martis cum fulphure præparatus.

Alii præparant aliter limaturam, fcilicet illam probe aqua \& tandem vino ablutam in crucibulo cum aceto coquendo \& igniendo, tandemque fuper marmore pulverifando.

De diverfis aliis præparatis \& mixturis cum limatura vide Dominum König in regno minerali \& alios.

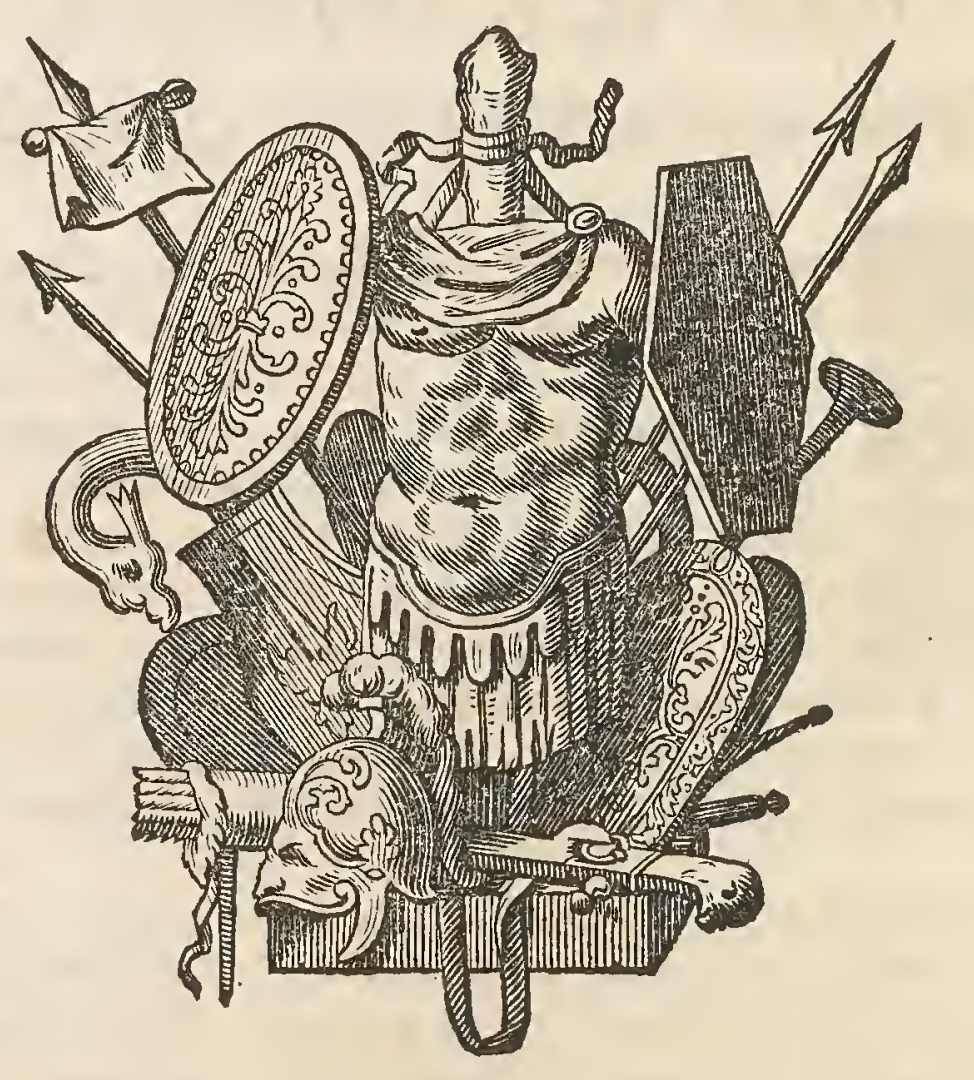




\section{PARAGRAPHUS II. Crocus Martis vel cbalybis aperiens.}

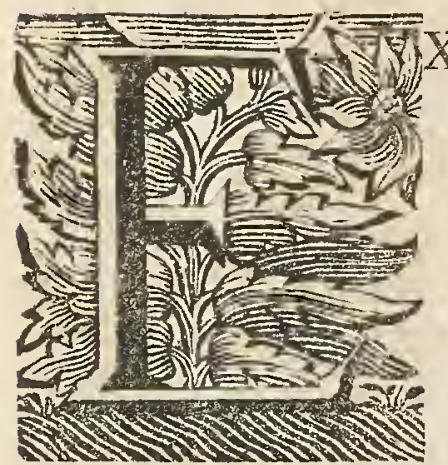

limatura prodicta facile proparatur crocus Martis aperiens cum fülphure, quando enim xqualis pars fulphuris addita igne bene deflagrare permittatur. Alii vero præparant hunc crocum cum fulphure, fcilicet

II. Recipiatur limatura Martis \& fulphur pulverifatum, quæ in paftam fubigantur: mixtura hæc in vafe fictili per fpatium 4 vel 5 horarum digeratur; vas dein fuper ignem ponatur, \& materia inibi contenta fpathula ferrea circumagitetur, exinde tandem accenditur mixtura \& pars fulphurea comburitur, remanente materia quadam nigri coloris. Si magno igne urgeatur, \& per fpatium bihorii circumagitetur, fanguineum colorem recipit, refrigefcat dein \& confervetur. Si crocus hic ad quantitatem 25 vel 30 librarum fimul preparetur, mixtura folet calefieri \& per le calcinari ad jacturam fiepe partis dimidix, antequam igni creditur. Ex dimidia libra limaturæ ferri obtinetur ad minimum I libra \& 4 unciæ croci Martis. Lemmery.

III. Alii fumunt chalybem in officina bene ignitum, cui fulphuris magdaleones admovent, inde chalybs vel ferrum inftar butyri liquefcit, inque fuppofitam aquam decidit, quem igne reverberii tam diu faciunt ignefcere, donec pulvis ruber evadat. Valentini.

IV. Accipiatur bacillus vel lamina Martis elongata, ifque in officina fabrili vel furno folle inftructo igni fuforio vehementiori injiciatur, donec penitus excanduerit, tunc igni exemptus \& forcipe firmiter apprehenfus, fine ulla mora magdaleoni uni alterive fulphuris admoveatur ; fic in momento, fulphure accenfo, fundetur, \& fub fpecie fcintillarum micantium cum fulphure liquefcendo, granulatim decidet in fuppofitam patinam terream aqua fontana repletam. Jam quando tantum Martis, quod defideratur, per granulationem fufum fuerit, decantata aqua, \& leparatis fulphureis inftar filamentorum contactis adh:erentibus particulis grumos Martis exime, \& fupra tabulam marmoream in pulverem impalpabilem læviga, qui crocus aperitivus vocatur. Hoffmannus.

V. Accipiantur limaturæ Martis non rubiginofæ, fulphuris puri ana partes æquales; hæc contrita irrorentur tali aquæ communi copia, ut paft: inftar polfint tractari: Reponatur tunc in vafe fictili, intra horam circiter concipiet calorem fummum, quo fponte definente, habetur ferrum in crocum converium. Si huic croco affundatur aqua \& coquatur \& educatur folutio; tunc hre lege artis infpiffata, conftituit victriolum Martis. Boerhave.

VI. Laminæ ferri per multum temporis auræ roriferæ vel humori roris matutini exponantur, exinde in ferruginem paullatim abit ; ferrugine illa abrafa, lamina ferri iterum exponatur rori, quod continuetur, dum copia croci five ferruginis fit collecta, quæ præparatio reliquis præfertur. Alii exponunt ferrum aqux pluvia. Lemmery. 


\section{DE CROCO MARTIS APERIENTI.}

VII, Limatura Martis in ollam fictilem non vitrificatam mittatur \& fic exponatur aquæ pluviali, dum in paftæ cujusdam confiftentiam lique1cat; fi dein reponatur olla cum fua mixtura in loco ficco \& umbrolo, in ferruginem vertitur; pulverifetur hæc ferrugo, \& in olla fictili iterum pluviis exponatur, dum in craffam quandam confiftentiam abicrit; dein iterum ut prius in loco umbrofo repolita mixtura in ferruginem finas abire, qux operatio duodecies repeti poteft, tunc limatura fatis foluta in crocum. Loco aqua communis etiam ufurpari poteft aqua mellis. Lemmery.

VIII. Fiat lixivium ex fale lixivo herbarum aperientium card. bened. fumarix, agrimonii, abfinthii \&c. Id fuperaffundatur limaturæ Martis, exficcetur, denuo affundatur, donec limatura in fubtilem pulverem flavefcentem abierit, qui ad colorem rubrum obtinendum aliquandiu reverberari poteft. Vedelius parare docet crocum Martis emmenagogum fpecifit cum, fi recipiatur borax foluta in aqua meliffe \& artemifix, ac per vices afpergatur Marti, quoufque hic in crocum vertatur. Hoffmannus.

IX. Recipiantur limaturæ Martis 2 drachmæ, in vitrum longiulculum mittantur, \& aqua fontis guttatim infundatur, dum ceffat ebullitio; quum liquefcit, obfervatur, quod vitrum calidum fit factum, fpumelcat \& tetrum odorem fpargat, \& chalybs magis \& magis refolvatur : digeratur hoc per noetem, \& ad ficcum dein evaporetur, exinde habetur pulvis rubefcens, qui fi reverberetur in crucibulo, rubefit, \& fit pulvis vel crocus infipidus. Reverberatio calcis fic peragitur; mittatur calx dicta \& bene ficcata in crucibulum, \& hoc fuper prunas flammantes reponatur, adeo ut flamma in crucibulum vibret, in hoc igne, dum ceflat fumus, teneatur, agitetur diligenter fpada ferrea, dum fatis fit, eximatur dein calx \& in pollinem fubtilem contundatur, qui levis, ruber \& infipidus eft, vocaturque crocus Martis aperiens. Collect. Leidenfia.

X. Sume crocum modo præparatum : fundatur falpetra in crucibulo, \& crocus dictus per vices immittatur, \& dimidix hor:e fpatio fimul fluant ; effundatur dein \& nitrum a croco feparetur, ficcetur \& in pulverem comminuatur; inde habetur crocus chalybis fubtilis \& coloris purpurei. Colleet. Leidenf. \& Koenig.

XI. Recipiatur quantum velis victrioli chalybis, quod per oleum victrioli paratum fit, calcinctur primum igne leni, dein majori in olla fictili fundi plani, ufque dum habeatur pulvis rubefcens. Collect. Leidenf:

XII. Acetum deftillatum fortifimum in crucibulum vel tigillum angufti orificii infundatur, in quo pendeat lamina chalybea : crucibulum in arena calida reponatur, unde vapores ftringunt laminam appenfam, inde crocus vel rubigo e lamina folvitur, qua abftergenda eft.

XIII. Recipiatur una uncia victrioli artificialis chalybis vel Martis, \&. folvatur per quantitatem fufficientem aquæe, folutum pracipitetur per dimidiam unciam olei tartari per deliquium, exinde primum præcipitatur pulvis albus, qui cum frepe edulcoretur, \& toties ficcetur, colorem rubrum accipit. Collect. Leidenfia.

Crocus alias fubtilis evadit ope fpiritus falis vel falis Armeniaci, fed fixus ope olei victrioli, fpiritus nitri \& aquæ fortis. 


\section{PARAGRAPHUS III. \\ Crocus ferri vel chalybis adfringens.}

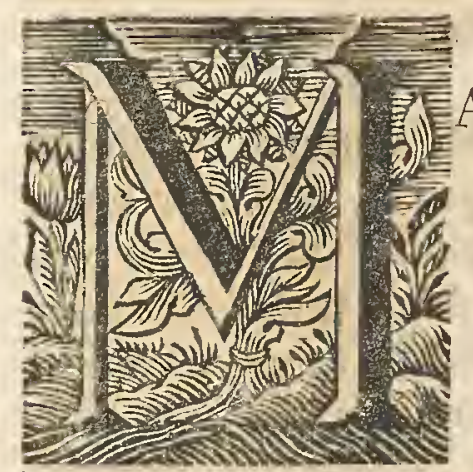

Artis crocus adftringens præparatur igne fortifimo per reverberationem: Dominus Kunckelius parat illum ex limatura Martis pura in ollam altitudine digiti faltem indita \& probe tectam in igne fortiflimo in fornace cxmentatoria exponendo, fic enim intumelcet Mars \& in altum fublimatur flos rubens tenerrimus, quo exempto Mars compactus denuo taliter reverberatur, repetiturque hoc quoufque croci fufficiens quantitas obtinetur. Konig.

II. Paratur commodifime crocus adftringens folo igne reverberii, fi bacilli chalybei furno ita apte imponantur, ut illos flamma undique polfit lambere; tunc enim continuata per aliquot dies calcinatione, crocus leviufculus \& pulcherrimus in fuperficie apparebit, refrigeratus leporino pede abftergendús.

Si huic carbones feorfim impendere nolis, laminas chalybis in furno reverberii vitriario officinarum transverfim collocare, vel dum deftillas fpiricum victrioli infra \& fupra retortam furno deftillatorio imponere poteris.

Crocum etiam talem comparare folent a fabris ferrariis, eundem in laminis ferreis igni vehementifimo expolitis colligentibus.

Alii limaturam Martis cum fale communi permiftam ; alii eandem aqua forti folutan, dein igne vehementiffimo eoulque reverberant, donec in crocum elevetur leviffimum \& rubicundifimum. Hoffm. in Laborat.

III. Modo Rolfinciano præparatur ille e croco Martis faccharino, \& modico piritus victrioli vel fulphuris crucibulo indito; leni calcinatione quoque paratur. Notandum eft, quod in calcinatione pondus luum augeat.

IV. Sume crocum apparentem præparatum modo præcedenti in $\$$. II n. 2, lava illum quinquies vel fexies in aceto vini forti, \& femper vel quavis vice per fpatium unius hor:e una digerantur, calcina dein in olla vel in latere cavato mediante igne fortiori \& per fpatiuin 5 vel 6 horarum continuante, refrigeretur dein \& bene confervetur. Quo enim magis calcinatur ferrum, eo magis aditringit. Si diu \& igne fortiori peraeta fit deftillatio, apparet fuper bacillos ferreos, quibus fuperinjacet retorta in furno reverberii pülvis fubtilis \& tenuis rubri vel brunei coloris, quiabftergi poteft, \& pulvis inde colleetus lavetur aqua calidiffima \& dein ficcetur. Lemmery.

V. Victriolum Martis inditum crucibulo imponatur igni ut ficcetur, fimulac ficcum eft, perdit omnem viriditatem, \& evadit pulvis albus, vel etiam liquefcit in maffam folidam, \& ex hac in materiam cineritiam, quæ vocatur victriolum Martis ad albedinem calcinatum. Si tunc majoriigne urgeatur, abibit in pulverem rubrum, qui vocatur colchotar victrioli vel calx rubra: præparata hæc calx, quæ vocatur vietrioli Martis crocus ada. Clasfis III. de ferro. $\mathrm{Hh}$ hb

frrin- 


\section{DE CROCO MARTIS ADSTRINGENTI.}

Atringens, fi tandem violentiffimo igne urgeatur, magis magisque calcinatus fit ferrum verum. Boerhave.

Si calx rubra vietrioli Martis futella vitrea excepta exponatur aeri aperto, humefcit \& attrahit aquam, quemadmodum fal alcalinus fixus, \& diffuit in olei rubri fpeciem, \& vocatur hoc victrioli Martis oleum per deliquium.

VI. Solvatur falpetra in crucibulo fuper prunas, cumque in fufione ftat, immittantur ramenta ferri, quantum admitti poffit, teneatur fuper ignem, unde brevi accenditur; eximatur dein crucibulum, edulcoretur pulvis aqua calida, unde ramenta in fundo remanent. Aqua turbulenta facta per fpatium 24 horarum relinquatur, unde colligitur \& ad fundum fubfidit. pulvis rubefcens, cujus ficcati una drachma totum pugnumadimplet. Collect. Leidenfia.

VII. Ex chalybe \& ferro paratur alias remedium adftringens, fi fcilicet in limaturam Martis infundatur fpiritus falis ad altitudinem 3 vel 4 digitorum, digerantur, dum limatura cum fpiritu pugnaverit $\&$ dulcis facta fit. Evaporetur ad dimidium, adjiciatur huic faccharum Saturni ana; humiditas deftillatione per retortam expellatur igne leni, alias ebullit maffa \& illa retorta repletur; quumque omnis humiditas rejecta fit, remanet maffa coloris rubri; confervetur dein, ne ab aere humorem attrahat.

VIII. Reverberatio per falem facilitatur, ideoque folent aliqui ferrum primo irrorare urina puerili, aqua falis vel aceto, \& dein ficcetur, fic reverberetur, unde conficitur crocus a ferro fpatio I vel 2 dierum, \& ne confumatur \& nigrefcat, inde quotidie abftergi debet. Quum aliqux partes nondum jufte calcinatx funt, fuperinfundi aqua potelt $\&$ circumagitari, \& fi relinquatur ut crocus fundum petat, aqua per inclinationem effun. datur, obtinetur inde crocus levis.

Ut in copia conficiatur, atque ideo vili pretio hujusmodi crocus venire poffit, debet fcobis uftio in fornace figulina, vel in qua lateres coquuntur, inftitui : \& fi prima vice pulvis non fatis fubtilis fuerit, oportet eum de novo, quando figulina coquenda funt, fornaci imponi. Quin minus ejufcemodi uftio poteft inftitui, fifpiritus victrioli vel nitri \&c. ex igne aperto deftillandi funt; ubi tum fcobs fupra bracteam vel tegulam ftrata, fuper ventrem retortæ intus in fornace collocatur. Proinde tali in pulverem converfo ferro aliquis fapor vietriolo fimilis eft, quem ut medicamentum adftringens paretur, tolli debet pulverem cum aqua abluendo. Barchufen.

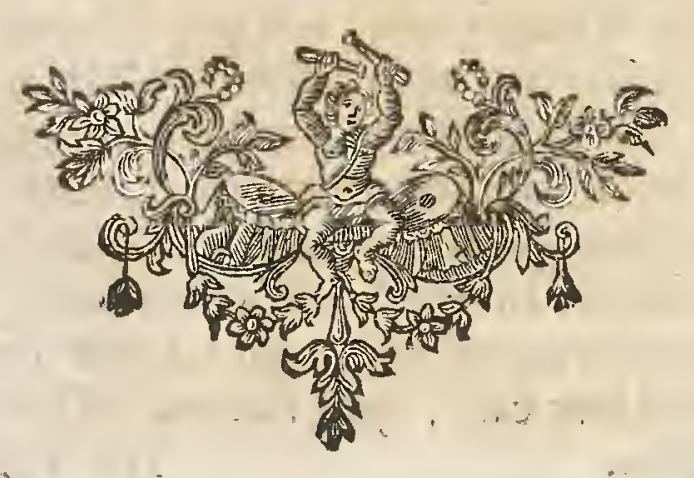




\section{PARAGRAPHUS IV.}

\section{Crocus ad vitriarium ufum parandus.}

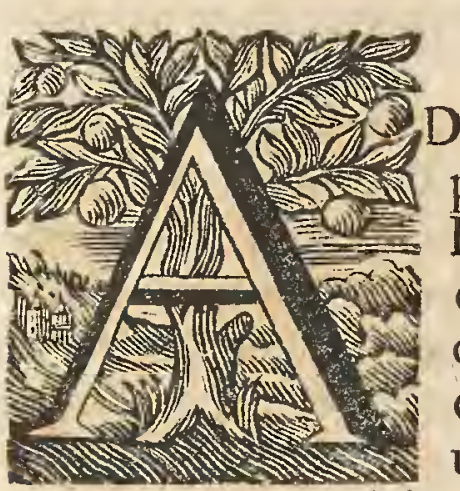

D vitri confectionem multi ufus etiam eft crocus, præcipue fi vitra colorari debeant, unde Dominus Kunckel, Neri, Meretti aliique tradunt modos parandi tales crocos, qui non modo optimi ufus fint, fed qui etiam pulchriorem reliquis colorem dent : hinc quamvis modi prædictis aliqua ex parte fimiles fint, ulque tamen feorfim tradi merentur.

Mediante calcinatione ferri tinctura ejus, qux in vitro rubicundifima eft, ita recluditur, ut communicata vitro non ipfa modo fefe manifeftet, fed hoc etiam efficiat, ut omnes alii colores metallici, qui alias in vitro occulti \& quafi mortui interciderent, formofi \& fplendidi appareant : hoc illud remedium eft, quo occulta metallica in lucem producuntur; ergo 4 modos tradit Dominus Neri.

1. Recipiatur limatura ferri, vel quod melius eft, chalybis ; mifceatur cum tribus partibus pulverati fulphuris \& in crucibulo calcinetur, omneque fulphur comburatur, id quod propere fit, \& inter carbones ardentes per horas 4 detineatur: poltea extrahatur redigaturque in pulverem, \& per cribrum anguftum trajiciatur. Dein mittatur in crucibulum apertum \& lutatum, ftetque in camera fornacis prope foramen ochio dictum per dies i 5 vel plures, \& colorem affumet ex fubrufo puniceum \& quafi purpurafcentem, fervetur vafe claufo ad tingendum vitrum, plures enim egregios effectus præftat.

1I. Recipiatur limatura ferri, vel quod melius eft, chalybis, mifceatur bene in vafis fictilibus aceto forti, hoc eft, irroretur hactenus, ut masfa tota humeetetur \& madefiat. Poftea extendatur in vafe, exponaturque foli, ut ficcefcat, vel abfente fole relinquatur in aere. 'Ubi jam ficcata fuerit, tundatur; conglobata enim erit, irroreturque recenti aceto, ficcetur \& tundatur, ut antea, idque oeties repetatur, ac tandem contufa tranfeat per cribrum anguftum, \& pulverem dabit fubtilifimum, colore lateris contufi, qui vafe bene claufo fervetur ad coloranda vitra. Crocus hac ratione factus efficit, ut vitrum languineum colorem efficiat.

III. Ferri vel chalybis limatura in vale terreo vitreato irroreturaqua forti \& ficcetur in fole; deinde redigatur in pulverem, confpergatur aqua forti \& ficcetur, idque frepius repetatur. Affumpto poiteá colore fubrufo, ut de croco Martis fulphure facto dictum eft, teratui, cribretur \& tingendo vitro fervetur. Quum crocus Martis hoc modo paratur, iftiusmodi eft, ut intimius color ferri leipfum, magis quam credibile eft, manifeftet, id quod in vitro apparet.

IV. Solvatur limatura chalybis vel ferri in vafe vitreo bene claufo aqua forti regia, fale ammoniaco, ut moris eft, facta; fervetur per tridu- 
um, ut quotidie bene agitetur, advertendo ut fenfim limaturam addas, valde enim intumefcit ; \& nifi caute tractetur, vitro periculum ruptur: minatur, vel omnia foras evomit. Exacto triduo aqua ad ignem lentum evaporet, atque in fundo crocum Martis nobiliffimum invenies, quo vitra ftupendum in modum tinguntur, in ufus tuos fervabis, eftque hic modus optimus Domini Neri in arte vitriaria.

V. Modi hi prædicti optimi quidem funt, fed præferendus ille eft, qui Gine omni additione heterogenea paratur. Limatura Martis vel chalybis in ollam fictilem indatur, nec nifi ad i digiti altitudinem; olla in fornace calcinatoria five in cineribus, vel in calore adque flammam reponatur, exinde intumefcit pulvis optime rubefcens in altitudinem, adeo ut repleatur non modo olla, fed etiam operculum excutiat: hæc pars eximenda eft, fed in fundo pars ferri agglutinata adhuc remanet, qu: rurfus ollæ immiffa intumefcit ut prius ; hoc fieri poteft, dum fufficiens copia habetur: eftque crocus hic optimi generis : fed ufque tamen affeverare nolit, num in arte vitriaria illum ufum præftet crocus fic præparatus; quem crocus per acetum factus, diverfos enim colores præbent. Kunckel.

VI. Præparationes croci ad fumma capita referri poffunt ut: I. Ad fimplicem reverberationem, citra mifturam, qualem in ferreis cratibus videre licet, quibus fornaces fuftinentur: atque adeo colorum optimus \& maxime profundus hac ratione factus eft in fornace, qux deftillationi aqux fortis continue infervit, cratibus ferreis fenfim in crocum refolutis, cujus verrendo fatis magnam copiam colligere licet. 2. Ad calcinationem, vel reverberationem fulphure, fale, urina vel aceto facta. 3. Ad folutionem in aqua forti, regia, fpiritu falis vel nitri; qua ratione, exhalante aqua, colorem obtinebis rubicundum. Solutum ferrum in fpiritu victrioli vel fulphuris, victriolum Martis fit, chalcanto Anglico bonitate fere par, fed viribus in arte tinctoria \& medicina minus : ex hoc victriolo calcinato colchotar fit, communi victriolo non abfimile, quod pictoribus fubminiftrare materian fraudulenti coloris poteft, fed in vitriariis fornacibus nulli ufui eft: omne enim colchotar plurimum terreftreitatis habet, qux vitrum reddit obfcurum \& fordidum. Quantum ad tincturam Martis, acida omnia, \& quicquid fuccorum corradendi vim habet \& in cuprum agit, eundem in ferrum effectum prieftat, fed ita ut femper rubrum colorem, aliud tamen alio magis translucidum \& excellentem producat, ut jam infervire multis coloribus \& mifceri cum metallicis aliis varia ratione poffit. Sic croco Martis aceto mediante facto convenit cum viridi ; nec non cum fmaragdo \& vitro plumbi ; idemque crocus in paftis xrugini plerumque additur. At vero ut rubrum elegans habeas, crocus Martis fulphure; ut elegantius crocus Martis aqua forti factus defideratur. Cexterum quomodo victriolum vel Venus optimus in ære color eft, ita primus \& precipuus ferri vel chalybis color is eft, qui aqua regis fit, inde partim ob mifturam falis Armeniaci, partim ob folutionem magis exactam. Meretti in Neri artem vitriariam.

VII. Dicente Domino Stahlio minera Martis in lithargyrio \& filice, aut cum minio vel ceruffa \& pyrite, aut arena aquatili, in vitrum nigrum, 
in tenuibus fragmentis fubfufcum colliquata pro vitro gradatorio commendari poffe ait; interim prudens chymicus prefcriptiones ita moderari noverit, ut vitrum fuum: I. fatis tenuiter fluat, 2. fatis diu cum nobiliori metallo confluat, \& fi fiffelcat, novo debito additamento illud denuo diluere, ejusque perpetuitatem longiorem adjuvare, quibus bene intellectis \& adminiftratis, certus eft, nulli parti orbis mineram auri fatis divitem defuturam. Stahlius.

VIIl. Permulta fatis copia parari crocus poteft circa opera fublimatoria fulphuris, ubi retortæ ferrex in ufi funt; fublimatione facta, ope fulphuris corroduntur parietes interiores retortarum, \& exinde abftergi \& corradi quantitas poteft; tandem enim finita fublimatione, retortw per corrofionem talem nec ullius ufus effe folent, quod videre licet ad Dylta Svecix.

IX. Per fe calcinari in crocum ferrum poteft, admiftis fulphure \& aqua, qua mixtura, fi copiofa paratur, incendi folet, \& fic ferrum fponte calcinari $\&$ in crocum quendam Martis verti, fed de his vide tractatum de fulphure.

\section{Quiomodo preparatur color ruber ex Jedimentis \& reliquiis victrioli. Ad Dylta Sveciae.}

D Ubedo hre, qux pracipue ex victriolo Martis preparatur, proxime accedit ad crocum pariter ex Marte paratum, propter affinitatem utriufque rubedinis hujus natales breviter tradere libet.

Ex materia illa, quæ in alveis \& vafis refidua eft, præparatur color ruber, pari modo ex materia, quæ in victriolum infpiffatur. Materia dicta in alveum ligneum quadrangulum vel in puteum quendam mittitur, \& inibi continuo agitatur; aqua turbulenta inde emiffa in receptaculum aliud ligneum defluit, quumque pars turbulentior vel craffior ad fundum fubfiderit, iterum in aliud vas derivatur, \& fic in campum quendam fpatiofum vel in paludem lignis incarceratam, per quam defluit plane aqua, fed ad fundum fubfidet interea materia quxdam in colorem dictum rubrum cremanda, qux tamen ufque fubtilis eft : cum aqua, quæ ultimo remanet, mifcetur pulvis in victriolum elixandus, loco illius aquæ quæ in fodinis eft, adeo ut utraque pars huic ufui poffit infervire. Materia in colorem rubrum cremanda, admodum fubtilis effe debet, eftque coloris rubri lateritii, faporis victriolici: fruftula quædam pugni magnitudinem æquantia ex inateria hac confecta in furnum longum reverberii fublimatorium, five in eundem, in quo per retortas fublimatur fulphur, fitque eodem igne; hæc fpatio 24 horarum in colorem ruberrimum cremantur : conftructionem furni videas in tractatione de fulphure. Locus quidam editus in furno eft, tanquam fubfellium aut pavimentum, a tergo eft janua, quæ claudi \&aperiri poteft, prout res poftulat, per illam injicitur dicta materia in globulos formata feu fubacta, \& eodem igne, quo fublimatur fulphur, comburitur? Clabis III. de ferro. Ii ii Hodie 


\section{DE CROCO MARTIS AD USUM VITRIARIUM.}

Hodie 2 hujufcemodi fedilia conftructa effe in foco dicitur, unde majore quantitate coloris rubri intra idem tempus \& codem igne potiri poffunt, quam prius. Obfervandum etiam eft, quod materia dicta aliquoties circumverti debeat, alias ope igni vehementis in frufta majora confluit, qux tamen ufque æqualis bonitatis cum. minoribus effe dicuntur.

\section{Color ruber Scanice in Svecia.}

HOdie quidem non multa pars hujus rubedinis circa opus magnum alu1 minis Scanicum preparatur, ut olim, ufque tamen ad ufum œeconomicum aliquantula pars conficitur. Sedimentum in alveis refrigeratoriis five fxx, quodque poft lotionem aluminis aquam emanantem in lacum, ubi freces, Slamm dictx, colliguntur, fequitur: hocinquam fedimentum bis vel ter quotannis in locum ab officinis remotiorem defertur : ab operariis in frufta globofa formari folet, \& in focum aut ignem fub cortinis plumbeis conjici, ficque in terram rubram vel in rubiginem cremari. Globuli confeet $\frac{I}{2}$ pedis diametro funt, \& tres hujufcemodi in ignem focalem quavis vice conjiciuntur, \& circumjectis prunis per fpatium 8 horarum cremantur; hæc terra rubra dicitur melioris \& fubtilioris indolis effe. Ante tempus aliquod ad hunc ufum conftructus erat furnus reverberii longitudinis $4 \frac{T}{2}$ ulnarum, latitudinis 3 , altitudinis $I_{2} \frac{T}{2}$; craffities muri \& arcus erat $\frac{3}{4}$ ulnne, a tergo I ulnæ : apertura anterior $\frac{5}{8}$ partes ulnæ alta, longitudinis $\frac{3}{4}$ uln latitudinis $\frac{5}{8}$, cum fuis aperturis pro aeris admiffione : flamma apte perftringere potuit materiam injectam. Hic intra biduum cremari potuerant I 2 vel I 3 tonnæ rubedinis five colchotaris, confumta una menfura 3. cubitorum ligni. Alias dicitur, materiam crudam in rubedinis hujus genus cremandam eo convenientiorem effe, quo diutius fub coelo jacuerit; quod magis magisque pars aluminis inde exftillet, ad colorem intenfiorem \& bonitatem contribuere. Globi prædicti ex materia vietriolica feú fedimenti ejus confecti prius humectantur.

\section{Rubedo beec ad Gejer.}

Uum lixivium victriolicum in prima cortina calefit, antequam in alteram emittitur, materia quædam craffior ad fundum fubfidere folet, quæ flavi coloris eft, quum fuperior lixivii pars limpida inde exhaufta fit, craffum hoc lixivium in vas quoddam ligneum conjicitur, \& ad ufum. hunc confervatur, inque vafe illo fit glutinis aut argillæ mollioris inftar; materia hrc inde in urnas vulgares feu vetuftas circa victrioli lixivium ufurpatas mittitur ; in furno fietili dein crematur, fitque inde coloris fanguinei \& rubicundiffimi vel inftar cinnabaris. Rubedo dein pulverifata cadis inditur, \& fic divenditur.

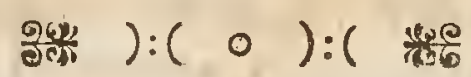




\section{PARAGRAPHUS V.}

\section{Crocus Martis victriolatus ut \& Jaccharinus.}

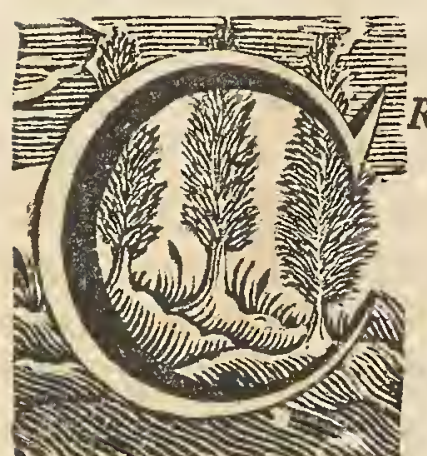

Rocus Martis victriolatus paratur vel ex victriolo Martis artificiali ad rubedinem ufque in crucibulis calcinato, vel ex remanentia folutionis Martis pro viEtriolo diEto parando intra filtri parietes relicto leni calcinatione in crucibulo commiffa impetratur : in utraque autem partes ochrex \& fulphurex cum fale viktriolaceo expanfxe crocum conftituunt. Hoffman. in Laborat.

Capiatur victrioli ad libitum, \& diffolvatur in aqua communi, ac igni bullire mittatur, verum in ebullitione demergantur ferri laminæ, \& tamdiu fervefcere omittantur in prædictam aquam victriolatam, donec rubeo quodam cæno oneratæ deprehendantur, tunc igitur elevantur laminæ rubefa$\varepsilon x, \&$ ab cis detergatur illa tinetura, ita ut decidat in alterum vas mundum, \& aqua limpida femi-plenum, petet enim fundum inftar luti rubei: mox iterum laminæ ferri obruantur in aquam victrioli, quæ confeftim bulliat, inde deradatur tinctura, \& hoc tamdiu iterari exigit opus, quoad totum extrahatur opus, demum auferatur ab aqua dulci exficceturque, fiet enim inftar pulveris rubei; at fi forte aliquid nigri, vel immundi reperiatur, fedulo fegregetur \& abjiciatur, fed rubeum tantum colligatur, quod ut perficiatur optimo vini fpiritu circulari oportet inde fervari ad opus neceffitatis : vocatur hoc fulphur victriolatum Martis, vide Petrum Mariam Caneparium de atramentis.

Crocus Martis faccharinus. Accipe laminas Martis latas \& tenues, obline easdem bis terve, vel quoties libuerit, cum fpiritu victrioli, \& fupra vitrum aliquod depreffum repone : fic aliquot dierum fpatio efflorefcet cro-

cus albicans leniter abradendus \& affervandus, dum exdem laminæ iterum prædicto fpiritu illiniri poffint, ut novus crocus colligatur. Hoffm. in Laborat.

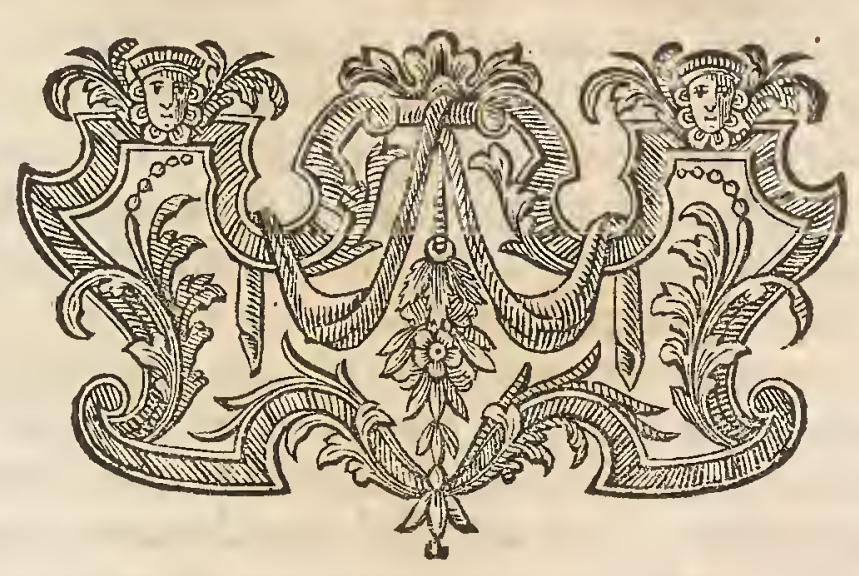




\section{PARAGRAPHUS VI.}

\section{Crocus Martis antimoniatus.}

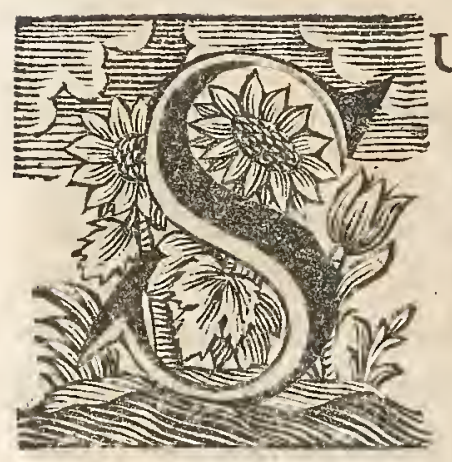

Umatur antimonii pars $\mathrm{I}$, fundatur tenuiter cum antmonii partibus 2 , addita vel ftatim in principio vel fub fufone, 8va vel ioma parte falis tartari aut cinerum: clavellatorum depuratorum, ubi totum liquido fluit; effundatur cito obtentus regulus cam fcoria leviter fcintillante fufci coloris: hac five ita integre repofita, five \& quidem commodius fruitulatim contula, five aeri umbrofo humidula tempeftate five cello expofita, delabitur fatis prompte in pulverem fubnitidum. Pulvishicaqua frigida vel tepida multa agitatione collutriatus, ita feparetur, ut quicquid ejus diu aque turbidum innatat, tenuifimum, cum hac effundatur, crafiore parte fedimenti inftar in fundo remanente, hocque negotium repetatur, donec quicquid hujusmodi tenerum amplius fecedere recufet: Exit ita tenerioris hujus fubftantixe, in proportione ad craffiorem illam refiduan revera oppido parum: funt vero differentes utriufque hujus fubftantix qualitates fequentes : nimirum tenerior pulvis abfque alio additamento leni uftulatione acquirit dilute rubicundum colorem, fubfidens autem altera portio, fi finiliter tractetur, nancifcitur nigro-purpureum colorem; porro pulvis prior tenerior elutriatus cum triplo nitri detonationi fubjectus in crucibulo levifime candefcente pot edulcorationem pulveren relinquit dilute rubentem dilutiffinx rubricx inftar; alter pofterior craflior cum nitro accenfus pulverem concedit obfcurioris \& nigricantis coloris. Ex Domiino Stahlio, Hoffmannus in Laborat.

II. Recipiatur nitri \& reguli Martialis ana, comtula invicem in tigillum leviter candens injiciantur fuccefive, \& fi tota quantitas mixturæ fit injecta, materia vero adhuc molliufcula \& pultacea in tigillo appareat: reguli prædicti pulverifati particula adhuc ingeritul, donec intenfo etiam candore mafla dura reftiterit. Relinquatur hac in igne ad horam unam vel alteram, fedulo tamen cavendo ne' carbones illabantur: exempto dein crucibulo confractoque, adhuc calens abradenda \& in vitreis vafis ftatim probe obturandis aftervanda. De hoc fale notabilia quedam occurrunt, quod fulphuri Martis metallico, quicquid hic fubeft cauftici, tribuendum. $\sqrt{1 t}$, infervit hoc confans phænomenon, quod ex regulo antimonii fimplici fal tale minime obtineatur. Cæterum falis hujus proprietates \& phænomena funt; quod afpectui album hinc inde viridefcens aut corulefcens ad morem alcalium aliorum bene calcinatorum fefe offerat, \& licet multum pulverulentic fublantix, quafi ceruffix reguli Martialis contineat, lucidum tamen feu requabiliter nonnihil tranlparens obfervetur. Fixitas ejusdem exinde confpicitur, quod per complures horas calcinatum, irem intenffimo repetito igne fulum \& refrigeratum de pondere fuo nihil quic- 


\section{DE CROCO MARTIS ANTIMONIALI. 3I3}

quam amittat. Caufticum vero adeo eft, ut particula ejus leviter humeEtata intenfe incalefcat, guftu linguam ita feriat, ut ex unico attactu folutio continue totos dies durans refultet. Et hoc ipfo jocularem effectum præftat, \& volæ manus impofitum ficcum levihumectatione ardorem quafi prunæ ardentis inferat. Interim ab aeris contactu defendendum eft, if enim vel per deliquium vel aqua communi affula refolvatur, pulvis copiofus exinde præcipitatur ; fal vero ab hoc pulvere fequeftratum intenfiffme quidem, non tamen rque ut antea, caufticum eft. Spiritum viniaffufum paucarum horarum patio colore fanguineo faturatifimo \& fapore cauftico imbuit, eumque fimul notabilem effectum præftat, quod partes vini rectificatiffimi conftituentes divellat, eumque pauco tempore ad dimidiam propemodum partem phlegmaticam efficiat. Sal hoc caufticum, intenfiffimo igne per fe non liquabile, illapfa vel injecta pruna ftatim fluit aut potius diffluit. Si recipiatur fal hoc pellucidum \& fluenti in tigillo adjiciatur pruna, qua confumta fal effufum denuo obfcurum \& nihil caufticum, una vero regulus in proportione fatis copiofus, rudis tamen, \& ob admixtionem fulphuris carbonum, denuo volatilis, \& refpectu prioris fux puritatis impurus apparebit. Stahlius in fundam. chym. dogmat.

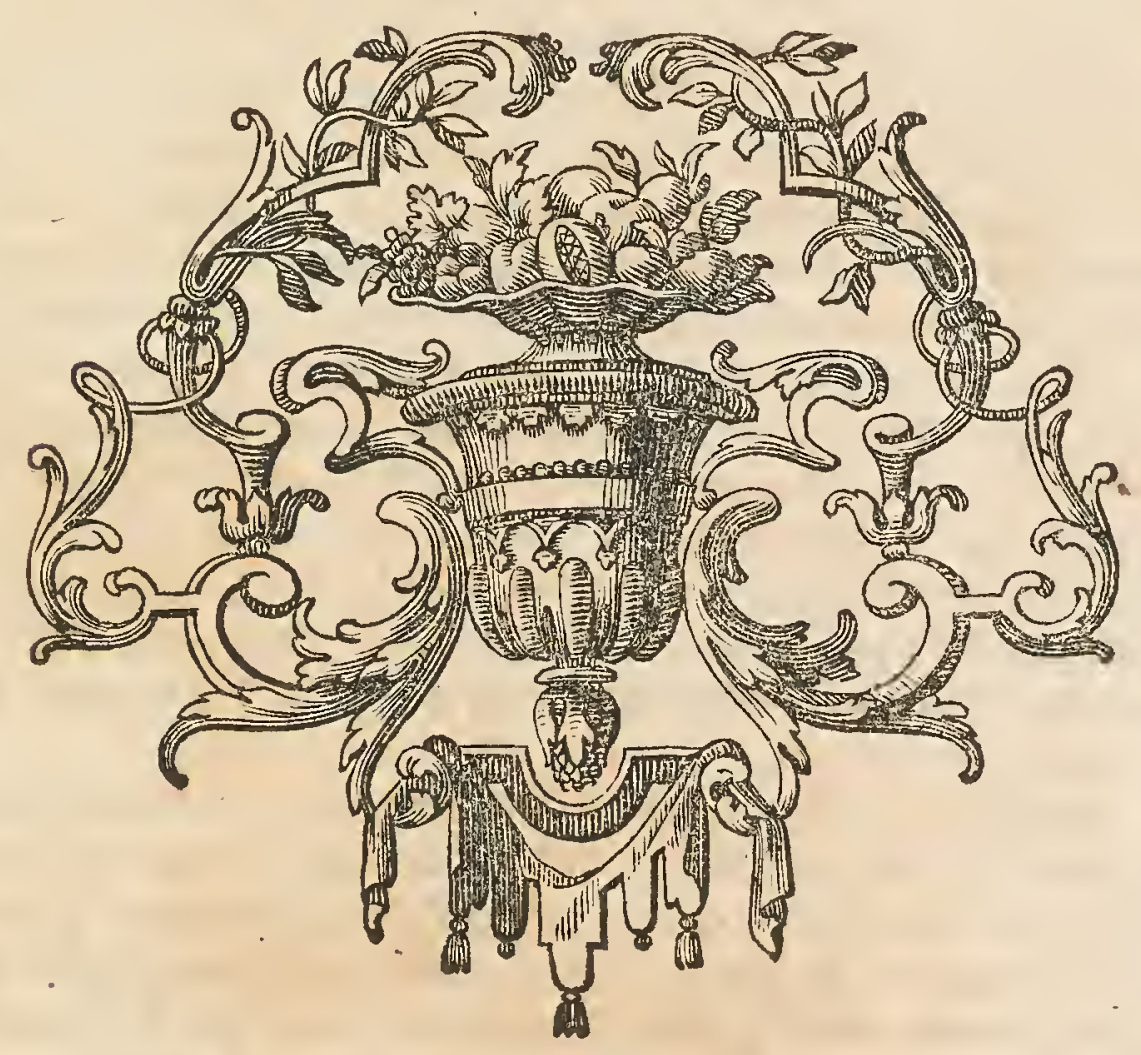

Clafis III de ferro. 


\section{PARAGRAPHUS VII. Mars diapboreticus.}

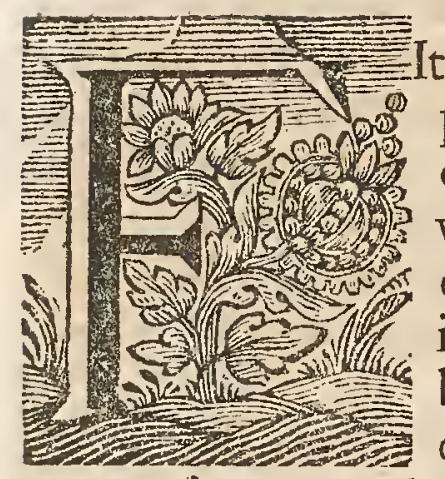

It ex limatura Martis \& antimonio pulverifata ana, quæ per continuas agitationes, ad reguli concretionem præcavendam, in fcorias rediguntur; mafla vero hinc pulverifata (ex qua affuíne fpiritus falis \& dein aqua communis vietriolum, \& ex hoc fpiritus educi potef, imo melior Martis effentia), cum triplo nitri in crucibulo candentifuccelfive detonatur, detonataque affula calida (ad nitrum feparandum) edulcoratur \& in pulverem fuper porphyrite teritur fubtiliffimum colore hepatis; unde vocatur Bezoardicum Martiale flavum. Konig.

II. Recipiantur Martis uncix 2 \& in crucibulum candens mittantur; quumque ferrum vel chalybs benecandefactus fit, immictatur antimonium pulverifatum unciarum 4 ; in igne fuforio per horam teneatur, five ufque dum Mars liquefactus cum antimonio fluat; hoc cum factum fit, adjiciatur I vel plures partes nitri, fcilicet ut in fluorem eo melius poffit redigi materia, quod rutabulo experiri licet; eximatur crucibulum igni, \& caute immittatur frigida, ut nimirum prxecipitetur regulus; tigillum frigefaEtum diffringatur, regulus, quinon purus jamdum effe folet, pulverifetur in mortario, \& ftatim iterum fundatur in crucibulo, apponendo parum nitri.

III. $\frac{1}{2}$ drachma limaturæ Martis , 2 fcrupuli fulphuris, 3 fcrupuli nitri mifceantur, mixtura in concretum nigrum friabile fulphurei odoris \& 1 poris detonetur, hoc mifceatur cum antimonii fcrupulis 5 , nitri 2 , injiciatur per vices in crucibulum \& edulcoretur ut antimonium diaphorcticum fimplex; idem quoque hoc antimonium diaphorecicun Martiale non rubicundi fed albi coloris paravit modo fequenti: recipiatur limatura Martis q. v. confpergatur frepius aqua pluviali fimplici, ut abeat primum in fubftantiam guandam mucilaginofam, \& dein poft ejus cxficcationem in pulverem fubtilem terreftrem, ita ut linatura Martis ab aqua fere in decuplo multiplicetur, dein recipe pulveris hujus $\&$ antimonit ana, \& cum nitro detonetur in antimonium Martiale egregium non rubicundum fedalbicoloris. Konig.

IV. Recipiantur clavi ferrei, \& antimonium optimum friatum $\mathrm{H}$ ungaricum ana 1 ib; clavi in furno venti in crucibulo igniantur donec fluant, tum injice per cochleare ferreum fuccefive antimonimm pulverifatum, omnia fimul igniantur in fine, ut fluant, addendo parum nitri \& tartari \& nitri ana detonatione facti, dein effunde materiam in mortarium xneum calidum \& omnia fimul pulverifa; pulveri huic adde nitri ficci triplum, detona, edulcora, \& pulverem in filtro refiduum brunei coloris ferva ad ufum. Koxnig.

V. Reguli antimonii Martialis ex antimonio $3 \mathrm{x} v$, limatura Martis ZIVB, falis, tartari, nitri $z x$, fcorix remanent nigerrimie, quibus pulve- 
DE MARTE DIA PHORETICO. 3I

rifatis, \& cum triplo nitri exacte mixtis \& detonatis tandem poft edulcorationem, \& ea quæ ad complimentum operis fieri decet, refultat bezoardicum Martiale egregium, efficax \& facuratum colorem cinnamomi referens.' Exdem fcorize fi aliquandiu libero exponantur aeri, deinde omne fal \& fulphur elixetur, fulphur aceto deftillato pracipitetur, acetum deftillacum affundendo ad punctum faturationis ufque \& tandem ulterius procedatur, ut artis eft, largiuntur terram foliatam tartari cum fubtilifimoantimonii fulphure combinatam, ufus certe haud contemnendi. Ipfeauctor pro majori compendio fuadet, antimonii pulverifati \& limatura Martis purifimi (vel hujus loco tantum mineram Martis pulverifatam) ana, verbi gratia 3jii, nitri puriflimi pulverifati 3 i 8 , per füccelfivas, ut in antimonii diaphoretici in olla aut crucibulo faltem vulgatioris argillæx, fed (ob validas ebullitiones) capaciffimo ac prius candefacto rite continuatifque per rudiculam fubactionibus, detonare, relictam maffam (rejectis tamen circa oras crucibuli fcoriis quibusdam minus calcinatis furgentibufque fimul foribus antimonio infectis) elutriare \& edulcorare, remanente quadam Martis non adeo refoluti parte (unde etiam $\xi_{3}$ vel $\xi i$ ejus amitti forfan poffet) reliquo tamen antimonio inter fubitaneum illum conflictum vel congreffum fufficientiffime hinc faturato, ut nec colore nec effectu a fupra dicto paulum operofiori differat. Id quoque curiofum eft, nimirum oblervabile edulcorati pulveris fuperpondium a folis Vulcani effuviis humiditate extrinfecus attracta \& portione rudicule vix deducendum. Kœnig, fed de his vide plura in antimonio.

VI. Sume.crocum ferri vel rubiginem \& fal Armeniacum, inde mixturam in crucibulo ferream, in furno exiguo repone, claude infra luto \& argilla, adeo ut ignis modo per aliquot foramina fefe in furnum poffit infinuare : cucurbit: impone capitellum, \& urge primum igne leni dein intenfiori, ufque dum candefiat cucurbita, continuetur cum illo gradu ignis, donec fumi non amplius alcendunt. Refrigeretur vas, excipiatur capitellum, colligantur flores, folvantur in aqua fufficienti, filtretur folutio, \& guttatim infundatur oleum tartari per defcenfum factum, five fpiritus falis ammoniaci, inde in fundo vafis obtinetur precipitatum. Liquor fuper-

natans per inclinationem effundatur, \& prxcipitatum vel materia fundi ficcetur. Lemmery: fed de his vide melius traetationem meam de antimonio.

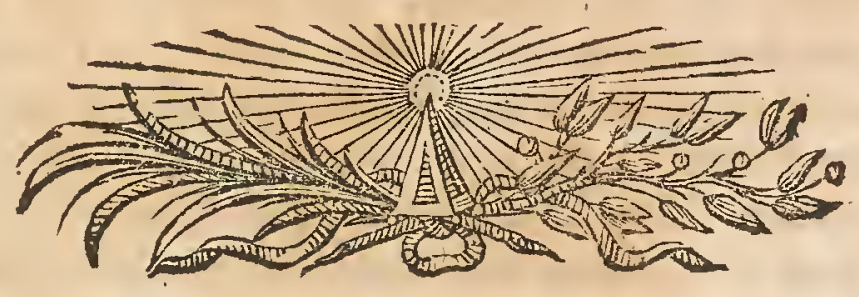




\section{PAR A GR A PHUS VIII. Regulus Martialis vel chalybeus.}

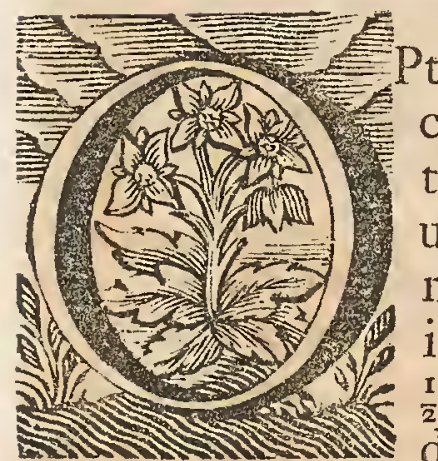

timi chalybis filamenta accipe penes opifices operum chalybeorum 4 unciarum, qux candefiant per quadrantem horæ in crucibulo igne fatis vehementi, adjice 8 uncias antimonii pulverifati; crucibulum tamdiu teneatur in igne, dum chalybs una cum antimonio fluat in igne; injice per vices aliquid nitri pulverifati filicet $\frac{1}{2}$ uncix, ut maffa inftar aqux fluat; crucibulum candefactum exime igni, \& frpe percutiatur, interea refrigefcat : crucibulum refrigeratum \& fractum dat in fundo maffam metallicam albam fimilem regulo antimonii Martialis, fupra funt fcoriæ reguli. Regulus hic in pulverem contundendus eft, \& pulvis in novo crucibulo fundendus, quod parum ignis requirit, inde purior \& elegantior fit, prefertim fi exigua pars falpetræ adjiciatur. Regulus hic a chymicis ulurpatur, preparatur inde butyrum Martiale \& bezoardicum : hujus etiam ope putant augeri poffe aurum \& argentum, fi verum fit, ut \& Mercurium coagulari. Sicque paratus eft regulus chalybeus. Collectan. Leidenf.

II. Clavi ferrei veteres, lamella aut limatura Martis crucibulo immittantur, crucibulum igni fatis valido exponatur, \& ubi probe incanduerint, fuperingeratur cochleare antimonii duplum ( fi limatura affumenda fit, illa cum ana antimonii conteri \& ita cochleatim in crucibulum candens ingeri poteft, \& tunc reliquum antimonii fecundum pondus addi) crucibulum carbonibus tegatur, \& ignis tamdiu validus fervetur, donec omne ingeftum antimonium in pultem colliquatum fit, tunc pugillus nitri adjiciatur, bacillo ferreo coagitetur, \& poft momentum alter pugillus, \& ita ad tertium, quartum, donec pondus, ponderi metalli affumpti leu fubtriplo potius refpondeat; ignem interim impetu fuo ftudiofe conlervando. Fifufa mafla in conum exhibebit regulum \& copiofas fcorias fulcas vitrefcentes veluti, qux comminutx aqua calida coqui, decoctum calidum filtrari, reliquum fedimentum edulcorari, edulcoratum reverberari debet, \& habebitur crocus vel Martis vel Veneris admodum fubtilis.

Aut alcali cinereum vel nitri fixi vel falis tartari aliquid in crucibulo valido igne fundatur, ut liquido fluat, huic immittantur predicti clavi \& momento poft duplum ad clavos pondus antimonii \& igne valido fervato omnia colliquentur in tenuem maffam, quod rudicula experiri licet : tunc effufa in conum exhibebunt regulum \& fcorias, quæ uti predictæ tractatæ fimilem crocum valde fubtilem exhibebunt metallicum. In hac preparatione notetur, ut alcali pondus antimonio refpondeat, antimonium vero non nifi parvis cochlearibus fucceffive ingeratur, cæteroquin ebulliens. Dominus Stahl.

III. Recipiantur thji antimonii pulverifati, mittatur pulvis in crucibulum, \& infuper adjiciatur I uncia ferri in ramenta vel fruftula divifi, 
fundatur \& immittatur per vices falpetra 2 unciarum, effundatur dein materia fufa in conum pinguedine vel cera illitum, ad fundum tunc habebis regulum, qui lavandus eft ab omnibus impuritatibus, \& 2 uncix falpetræx denuo per vices injiciendx, unde obtinetur regulus ftellatus, qui regulus Martis flellatus Lancilotti vocatur.

obfervandum eft, quod alii recipiant I partem Martis \& 2 antimonii pulverifati; quod alii ament ferrum novum, alii vetufum. Quod ferrum facilius liquefcat, fi in crucibulo candefiat omnium primo, \& dein fuperimmittatur antimonium. Tigillum etiam cooperiundum fit. Dein I 6 partibus antimonii adjiciantur 3 partes nitri, lcilicet ut regulus inde feparabilis reddatur \& fcoriæ purificentur. Cumque decrepitatio defierit, quod tigillum debeat concuti, : unde regulus ad fundum e fcoriis fe recipiat. Cumque hic regulus adhuc impurus fit, quod rurfus in tigillo fundatur cum 2 partibus antimonii novi; quæ cum adhuc fula fint, 3 partes nitriadhuc adjiciantur, unde habetur regulus Martialis adhuc purior. Quod tertia aut quarta vice cum nitro fundi poffit, unde adhuc purior redditur, quoque fxpius, eo purior; tunc etian ftella habetur : obfervatum a quibusdam eft, quod dicta ftella ægre obtineatur in aere fereno, non item aere humido.

Ipfum proceffum regulos antimonii parandi melius adhuc tradit Dominus Lemmery in tractatu de antimonio, modo quo fequitur:in tigillum 亏 v I I clavorum ferreorum indidit, qui per horam prius candefierent \& quidem ad albedinem, dein $\xi x v I$ antimonii pulverilati immifit, fed per vices \& cochleatim, exinde fundebatur ferrum cum antimonio : dein per vices indidit $\jmath_{j}$ ii falpetræ, peracta detonatione, optime fimul fluebant. Materiam in mortarium calidum effudit, \& mortarium percuffit, ut ad fundum materia regularis fe reciperet. Materia refrigerata fcorias feparavit a regulo, qui pondere $\xi x$ pulcherrime nitebat, durior erat omnibus aliis regulis, qui de antimonio participant. Scorix vero maffa quadam compacta

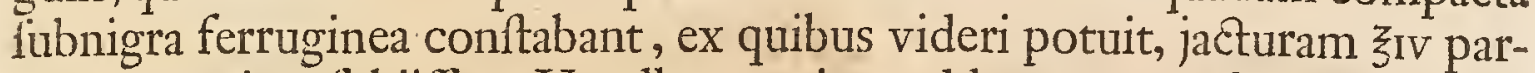
tium materiam fubiiffe. Ut adhuc purior redderetur, regulum illum pulverifatum iterum liquefecit, additis $\zeta$ I I antimonii \& $j_{j}$ i i lalpetr $x$, peracta detonatione mixtura optime fluebat : in mortarium inunctum effudit, \& obtinebat regulum 3 v I I priori pulchriorem \& puriorem; fcoriæ fupranatantes jam cineritii coloris erant ponderis $\xi_{\text {III }} 3 \mathrm{VI}$, \& jactura $\xi_{j i}$ 3II. Iterum in tigillo regulum hunc fudit adjectis $\xi j i i$ falpetræ, exinde lenis quæedam detonatio exftitit, \& exinde obtinebat regulum $\xi$ V III 3 I I II $\beta$ pendentem cum jactura 3IIIf; fcoriæ coloris erant cineritii aut grifei. Regulum tertia adhuc vice fudit, inque conum fuforium effudit, \& regulum

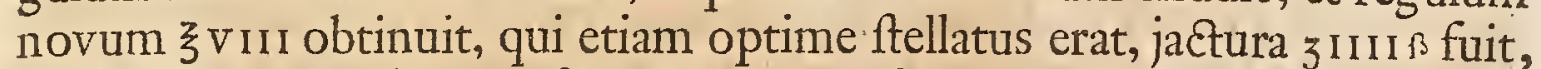
\& lcoriæ coloris albe flavefcentis. Quod ferri particeps fit regulus hictoties purificatus, patet tam ex duritie ipfius reguli, quam quod a magnete in altum tolli poffit. Scorias dein collectas in pulverem contudit, \& $1 \mathrm{pa-}$ tio horario aqua coxit, liquor dein filtratus coloris fubrubri erat. Liquor dictus per affufionem aceti turbabatur, \& ad fundum flavum quid præcipitabatur, quod odoris tetri erat. Pulvis præcipitatus filtrum transmiffus, Clafis III. de ferro. 
edulcoratus, ficcatus $\exists$ jiii dabat : materia hæc rubra erat \& fulphuri aurato communi perfimilis; num aliquid ferri ineffet, non potuit animadverti.

\section{Aliter.}

$\xi x \vee$ I antimonii crudi, $\zeta$ vil chalybeorum ramentorum, qux pulvewifata commifcebantur adjcetis $\xi j i$ tartari, \& $\xi v$ I falpetrx, qux mixtura cochleatim per vices in tigillum mittebatur, peracta detonatione bene liquefcebat. Regulus inde factus \& in mortarium calidum effufus ponderis 3 XII 3 vi I erat, qui optime nitebat, compactus \& ponderofus \& chryftallinus erat, fupra marmoratus, intus vero coloris violacei, purpurei \& flave nitentis. Scorix vero ponderis 3 x I I I coloris fubnigri ferruginei, ponderis mediocris, jactura omnis $\bar{\xi} \times \mathrm{V}$ I erat. Regulus hic iterum li-

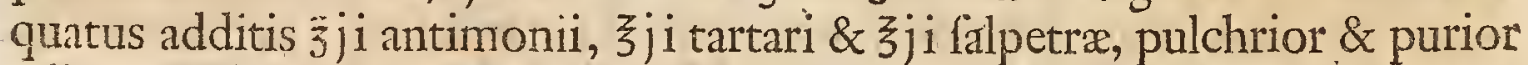
adhuc evafit ponderis $\xi \times x$; cum fcoriis $\xi$ I I $\beta$ coloris ferrei, \& cum jactura I I I 3 I I I, altera vice idem regulus fufus cum 3 ji falpetræ \& $j$ j tartari dabat regulum adhuc pulchriorem \& puriorem ponderis $\xi$ x I, \& f corias tan nigri quam albi \& flavi coloris $3 j i \mathrm{i}$ j, jactura erat $3 j$ 3v I I I. tertia vice fufus regulus prodibat alter ftellatus puriffimus $\xi \mathrm{I} x$ ponderis, cum fcoriis flavis.

\section{Aliter.}

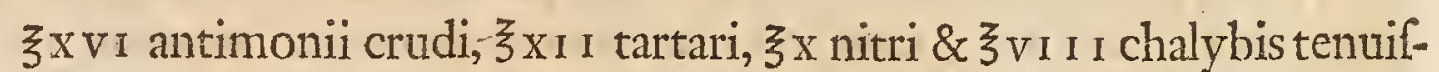
fimi, qux pulverifata \& cochleatim in tigillum miffa, dabant regulum ftellatum pulchrum $\bar{\zeta} \mathrm{v}$ I ponderis, qui etiam puriffimus erat; fcorix ponderis $\xi x x I I$ erant, jactura fic $\xi x \perp 1 x$. Per hanc operationem minus reguli obtinebatur quam per prædictam, fed operatio promptius fic peragitur, ftatim etiam regulus ftellam repræfentabat.

\section{Aliter.}

TN tigillum candefactum $\xi$ v i i clavorum ferreorum frve acuminum eo1 rundem, $3 \times x \times 1$ I antimonii pulverifati per vices, 3 jii falpetræ cochleatim immittebantur; exinde obtinebatur maffa 3 x xxIx, \& jactura ${ }_{3} 11$; \& f coriæ $3 \times x$ v r I, quæ coloris grifei \& ferruginei erant, \& ex quibus feparari potuit regulus 3 XI I. Regulus hic cum $3 j$ ii falpetræ fufus fuppeditabat regulum pulchrum $\xi x$ ponderis, \& fcorias 3 jii 3 I I ; qux coloris effent flave brunci, jactura $\xi^{\prime} 3 \mathrm{~V}$ I erat. Regulus hic iterum cum $\xi$ jii falpetræe fufus fuppeditabat $\xi$ v I I 3 V I reguli, $\& \xi_{j}$ i 3 ji i fcoriarum lutearum, jactura erat $\xi_{1} 3$ V I I. Ultimo regulus fufus cum $\jmath_{j}$ ii nitri dabat regulum

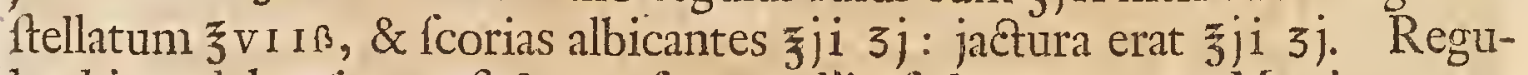
lus hic pulcherrimus eft \& corufcans radiis, fed non tantam Martis partem poffidet, quoniam modo 3 ji i i Martis ad $\mathrm{tb}$ I antimonii admixta fint, cum in preparatis prædictis duplum affumptum fit. 


\section{Stella.}

PRæcipue repræfentatur in regulis his puris ftellaris figura, qux radios a centro quodam verius peripherias f pargit; centralis pars elevatior folet effe partibus circumcirca ; in aliquibus vero apparet in centro excavatio quædam; in aliquibus nulla differentia altitudinis in plano effe folet. Radii a centro exire folent tanquam folia vel laminx enfium, qux fe magis magifque extendunt, fed verfus peripherias ultimas rurfus contrahi videntur; diverfia admodum figur: funt, fpeciem referunt venarum in foliis. Aliqui putant regulum hunc per totum fuum corpus ftellatum effe, fed regulo quodam fracto, nihil apparuit nifi maffa quedam confufa infinitis chryftallis referta; in quibusdam verfus centrum quoddam refpicere videbantur chryitalli, non vero in omnibus chryftallifationes dictxaliquam affinitatem habere videntur cum figura exteriore ftellari, quamvis non unum centrum refpiciant: ftella hrc tantum extrinfecus apparet, non vero intrinfecus; ex fcoriis regulo proximis oriunda; hinc etiam tam in regulis parvis quam in majoribus forma talis ftellaris apparet : ftellam hanc non tam facile recipit regulus Martialis, quam regulus antimonii communis; fed obtinetur, fi optime fluat materia. Interdum etiam ftella confufim formata apparet, precipue fi mortarium vel conus pauxillum obliquetur, tunc figuram quandam determinatam non recipit; in quibusdam regulis dimidia quædam ftellula apparet, in quibusdam fpecies quædam arbufculi repræxfentatur; in aliquibus confpiciuntur radii fine ordine regulari ; in quibusdam circa peripherias veftigia ftellæ apparent. Hæc Lemmery de antimonio.

De regulis antimonii Martialibus, de deftillatione ejus varia \& aliis chymicis operationibus cum regulo $M$ artiali inftitutis videas tractationem meam de antimonio.

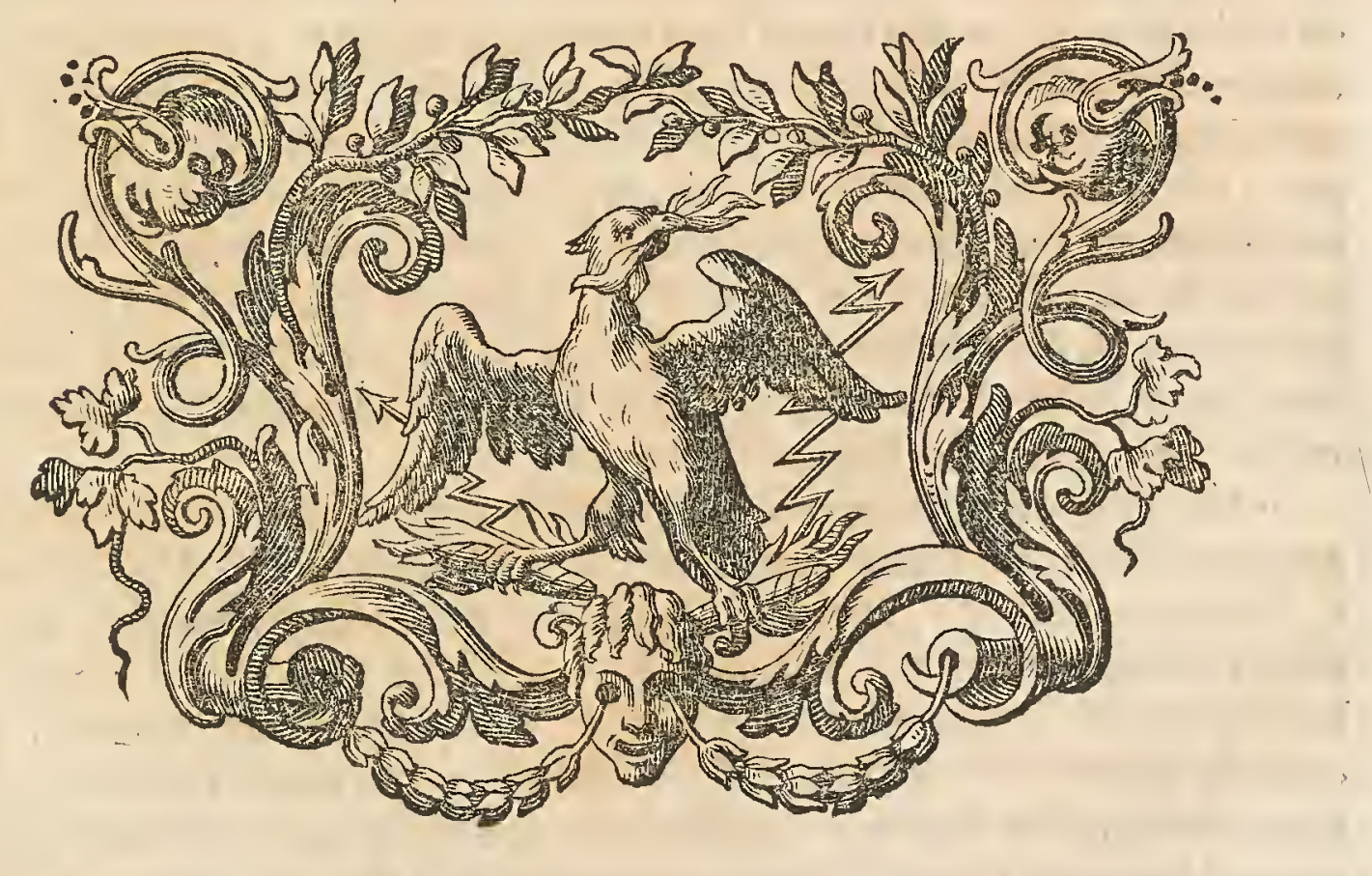

PARA- 


\section{PARAGRAPHUS IX.}

\section{Tinctura Martis aperiens.}

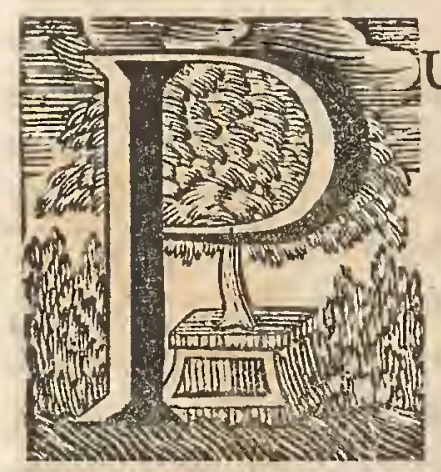

Ulverifentur \& commifceantur 12 uncix croci Martis \& 32 uncix tartari albi, mixtura coquatur in vale ferreo cum I 2 vel i 5 libris aqua pluvialis fpatio i 2 horarum; cum fpada ferrea circumagatur nateria, cumque aqua prior incoquitur vel abftrahitur, infundatur loco ejus aqua alia calidiffina ; tranquille dein relinquatur, \& liquor niger fupra apparebit, qui filtretur, $\&$ in patina vel olla fictili abftrahatur fuper ignem ad mellaginem vel fyropi confiftentiam, unde 44 uncix obtinentur. In fundo remanet materia albicans, qux tanquam inutilis rejicitur, mixtura enim eft craffiorum partium tartari \& Martis, vocatur tinctura Martis tariarifato \& fropus Martis dulcis, eftque fumme aperitiva. Lemmery.

I1. Scobis Martis portioni uni, tartari crudi optimi portionibus 2, magna copia aquæ affundatur, junetimque in aheno ferreo fat capaci coquantur, quo diutius eo melius; \& fi ad pultis formam forfitan fpiffata fuerint, denuo tum iis aqua affundi oportet, tandem degufta decoetionem, num faporem falfum habeat, \& liquor fupernatans nigricet, fique ita fit, per pannum coletur \& coquatur ad fyropi liquidioris fipifitudinem. Quidam ex hoc cum fpiritu vini rectificato tincturam eliciunt, verum hæc virtute longe illo inferior eft. Ubi id craflamen, quod initio in panno reftabat, exficcaveris, quoad non amplius fumarit, habebis crocum Martis Jubfalf vaporis : eftque hæc tincture Martis tartarifata vel tinctura tartari chalybeata. Barchuf.

III. Accipe 8 uncias rubiginis ferrex, quæ rore matutino afpergenda eft, milceatur in olla ferrea cum 3 th aquæ mellis \& 4 libris fucci ex uvis maturis, \& adjiciantur 4 uncix fucci lemonum, olla cum operculo ferreo tecta exponatur igni mediocri, \& inibi per 3 dies digeratur, coquatur dein per 3 aut 4 horas, operiatur, \& fpada identidem circumagitetur, aft tegatur ftatim, ne humiditas, celerius quam oportet, abftrahatur; cumque nigrefcit liquor, inde ignis removeatur; fubftantia adhuc calida per linteum percoletur, \& humiditas dein igne arenæe ad ficcum abftrahatur in vafe vitreo, unde habetur tinctura; quod in fundo ollæ remanet, eft materia terreftris ferri, nullius utilitatis. Lemmery.

IV. Recipiantur 2 unciæ victrioli Martis pulverifati \& cum æqualibus partibus falis tartari mixti, etiam in mortario in pollinem fubtilem contriti, jucundum eft vifu, quamvis bina falis genera coloris fint albi, mixta tamen evadant coloris albe rubefcentis, mafla hæc agitanda eft, unde in bullas fe refolvit, \& expofita aeri humido, in liquorem abit mixtura, qui liquor in ufu medico optimus eft. Materia rubra ponderanda eft, etiam tunc cum materia in liquorem abierit, \& pondus humoris differens per balneum Marix abftrahatur, illum enim humorem ab aere attraxerat, \& loco 
ejus infundatur tantum fpiritus Veneris, \& digerantur fimul in balneo vaporofo per circulum fpatio 24 horarum ; abftrahatur fpiritus ad mellaginem \& fuperinfundatur fpiritus vini tartarifati ad eminentiam 4 digito. rum, \& per 3 dies \& noctes digerantur, dein filtretur tinctura frigida, \& dimidia vel $\frac{2}{3}$ partes lento calore evaporetur, unde habetur tandem remedium aperitivum optimum. Febure.

V. Scoriæ Martis, quæ a fabris ferrariis rejiciuntur, contundantur modo craffo, affundatur acetum ad eminentiam 3 vel 4 digitorum, reponatur in digeftione per triduum, ut acetum colore rubicundo tingatut, decantetur tunc a fcoriis \& iterum reponatur, donec limpida evalerit; decantetur tum iterum a frcibus, \& habebis tincturam Martis pellucidam. ex Boe Sylvio Kœnig.

VI. Limaturam Martis aqua clara purificatam fuperinfunde fuccum pomorum Borsdorffianorum, per aliquot dies in loco calido repone, fxpiufque rutabulo agita, polt per linteum exprime, ac in loco calido ad confiftentiam digere, tunc eft effentia Martis dulcis vel extractum Martis duk ce; huic fi fuperaffundis fpiritum vini ac iterum digeris \& filtras, habebis effentiam Martis dulcem \& liquidam.' Kœnig \& Hoffman.

Dominus Valentini ita defcribit hanc tincturam vel effentiam, quod tunc primum pro vera habenda fit, quando primum limatura Martis cum fucco pomorum Borsdorffianorum in loco calido infunditur, donecomnia inftar atramenti nigrefcant, dein fuccus coctione in extractum redigatur, quod in fpiritu vini vel fpiritu cochlearix folvatur. Valentini.

VII. Victriolum Martis ad rubedinem calcinatum fuperinfundatur acetum deftillatum ad eminentiam 2 digitorum, digeratur, dum rubefcit acetum, percoletur \& ad mellaginem abftrahatur, infundatur fpiritus vini rectificatus, digeratur iterum, dum fpiritus vini tincturam traxerit, filtretur fpiritus vini \& in balneo Marix ad tertiam partem abftrahatur. Colleet. Leidenf.

VIII. Spiritus nitri dulcis 3 partium in ramenta reverberata I partis infundatur, per biduum digerantur, ufque dum mixtura colorem rubrum attraxerit. Collect. Leidenf.

IX. Recipiantur I 4 uncix ramentorum, I uncia fpiritus falis communis, 8 uncix aquæ per 3 vel 4 dies digerantur, circumagitetur bis quovis die, adjiciantur 3 uncix chryftallorum tartari contuforum, \& aqua communis, quantum fat eft, in olla ferrea per bihorium coquatur, \& adjiciatur nova aqua, percoletur, vel relinquatur in quiete, dum craffiora fubfiderint, liquor clarus fupernatans per inclinationem effundatur, \& ad fyropum tenuem abftrahatur, qux ad ufum confervetur, fuperaffulo rectificato vini fpiritu ad dimidiam partem.

Vel rimenta ferri 3 partium, chryftallorum tartari 8 , aqua quantum velis, per 3 vel 4 horas coquantur, mixtura rutabulo jugiter circumagitetur \& aqua nova infundatur, dum fatis colorata fic ; abitrahatur ad pultis confiftentiam; cdve ne materia comburatur, in loco tranquillo fubfidet pars craffior, clarior fuperiora tenet, quæ effundatur \& in confiftentiam olei abitrahatur, unde habetur tinctura.

$$
\text { Clafis III. de ferro. }
$$

$\mathrm{Mmmm}$ 


\section{DE TINCTURA MARTIS APERIENTI.}

$V e l$ fi accipiantur flores Martis \& hæmatitis I uncix, aqua vitæ communis 2 vel 3 unciarum, \& tinctura modo fuperiori preparetur.

$X$. Tinctura laudatur tanquam optima, qux etiam elegantifima \& inftar fanguinis rubicunda eft, parata ex victriolo Martis \& fale effentiali vini, ex quo extrahenda eft tinctura per fpiritum vini more nimirum Rollfinciano; fcilicet recipiatur pulvis fpiritus Martis non calcinati \& tartari ana, mifceantur \& in cella frigida aut loco humido per 3 dies vel noctes collocentur ; fic color mutatur \& aliquo modo fluida redditur, aere fe in poros infinuante, huic coloratæ mixturæ affundatur fpiritus vini, \& ftatim tinctura exturgit elegantifima, qux vino infufa gratum odorem fpirat, tincturafque alias etiam exaltat. Konig.

XI. Ramenta chalybis purificata fuperinfundatur acetum ex vino leni \& dulci factum, quantum fatis eft. Mifceantur invicem fpatiohoræ vel bihorii, humor in olla leniter abntrahatur, e novo infundatur acetum, quod aliquotics repetatur; omnes dein tincturx commifceantur, \& in loco tranquillo relinquantur, ut crafliora ad fundum fubfidcant, per inclinationem effundatur pars aquofior \& aflervetur; vocatur effentia Martis aperiensnigra.

XII. Dominus Barchufen tincturas has aperitivas fic tradit : I. Horibus Martialibus fale ammoniaco paratis affundatur alcohol vini, ad duorum vel trium digitorum transverforum altitudinem, poft fiat horum debito calore extractio : tinctura per chartam colata dicitur tinctura Martis aperiens volatilis. 2. Tinctura Martis a Zwelfero bera dicta, fit, fi paribus portionibus victrioli Martis, \& terræ tartari foliatæ, vel quæ præftantior eft, fi victrioli Martis unciæ uni vel terræ foliatx fefquiuncix, fuperignem leviter in patella ferrea in maffam fpadicis colore fubactis, addicur firitus vini rectificati fextuplum aut octuplum, digerantur per aliquot dies, poft tinctura per pannum colata in vitro affervetur. 3. Praftans eft Wedelio tinctura, antifcorbutica dicta, qux fic conficitur: aqualibus partibus bene inter fefe commixtis victrioli Martis \& florum ammoniaci Martialium, affunditur fpiritus cochlearix optime rectificati fextuplum, digerantur, poftea colcntur. 4. Nec' minoris facienda eft ea, quæ refertur ad auctorem le Mortium: recipiantur fcobis chalybis $\xi_{1} \mathrm{~V}$, tartari albi $\overline{3} \mathrm{X} 1 \mathrm{I}$, fpiritus falis

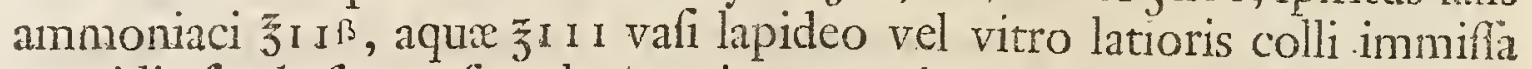
quotidie fpada ferrea femel atque iterum agirentur, admifcendo una fingulis diebus fpiritus vini ordinarii drachmas duas circiter. Opus tale duas vel 3 hebdomadas continuandum eft. Poftea antememoratis infuper fingulis diebus admifcendx tunt uncix quatuor feọmentis : Recipe aqux ro-

farum $\overline{3} x I$, fpiritus falis ammoniaci $\tilde{5}$ VII I, quibus peractis in fine addantur olei caryophyllorum gr. $\mathrm{x}$ : colentur dein per pannum. Barchufen.

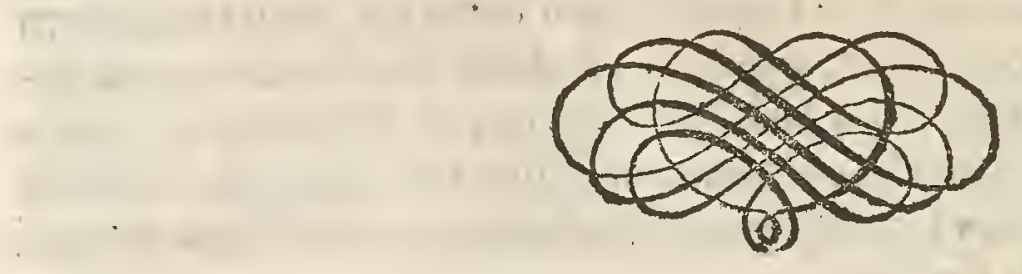




\section{PAR A G R P H US X.}

\section{Tinctura Martis Ludoviciana.}

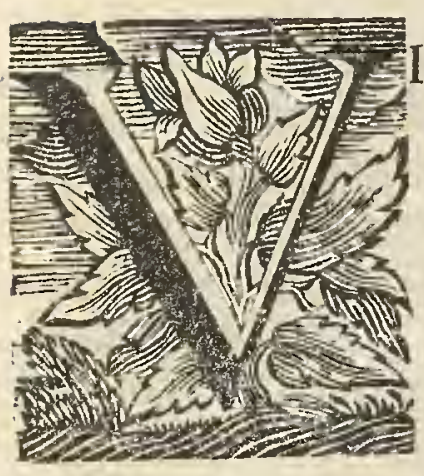

ICtrioli Martis rite parati recipe partem unam, cremoris vel chryftallorum tartari partes 4 , aqu $x$ partes 20 , in olla fimul ebulliant, pergatur coquendo, donec fit maffa inftar mellis fpiffa \& firma, qux indatur phiolæe altæ; affundatur fpiritus vini femel rectificati duode; cuplum, ebulliant 24 horis aut ultra, fupernatabit tinctura rubella, quæ a fæcibus fubfidentibus feparata eft. Si hujus tinctur:e dimidia pars deftillando aufertur, concrefcunt in fundo chryftalli, ex quibus rurfus, aqua vel fpiritu vini folutis educitur tinctura. Boerhave.

\section{Tinctura Martis cydoniata.}

R Ecipe limaturæ Martis fubtiliffimæ \& per ablutionem a fordibus adhærentibus repurgandx 3 , affunde illi in vitro amplioris fundi fucci cydoniorum expreffi $\bar{\zeta}^{\mathrm{V}}$ I vel $\mathrm{J}_{\mathrm{VI}} \mathrm{I}$, mifta ftent in leni digeftione per aliquot dies \& noctes, donec tertia vel dimidia pars iucci evaporando fit abfumpta, \& refiduus fapore fuo victriolico lufficientem extractionem factam efle teftetur, tunc filtratio inflituatur, \& addito tantillo fpiritus vini \& fpiritus cochlearise digeftio leniffima repetatur; vitrum hinc inde mo-

vendo \& exagitando : fic parata erit dicta tinctura.

Hoffman.

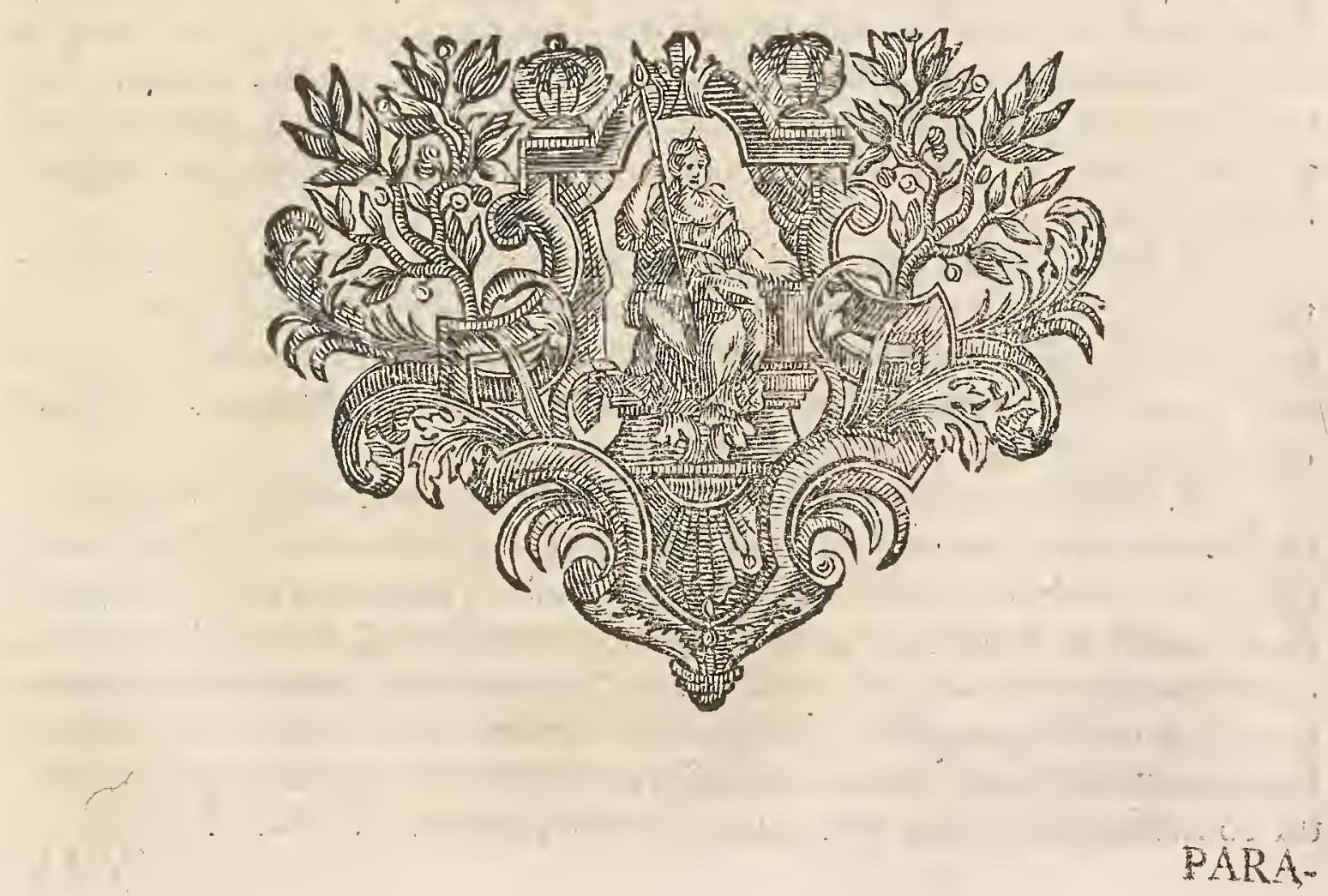




\section{PA R A GR A P HUS XI.}

\section{Tinctura Martis vel cbalybis adfringens.}

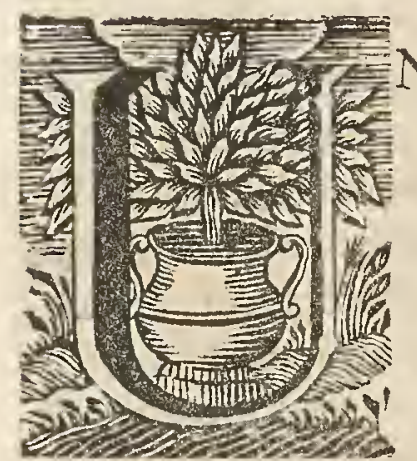

Nciæ tres limaturæ puræ Martis recipiantur, \& in cucurbitam vitream mittantur, infundatur fpiritus Veneris, dum modo humectetur \& in unum colligatur, cucurbitæ imponatur capitellum, \&igne leni abftrahatur ad ficcum, cohobetur fi faporem habeat, fi non, Mars cum fpiritu Veneris amplius humectetur \& ficcetur ut prius, quod 3 vicibus repetatur, vel ufque dum Mars in crocum fubtilem \& rubrum mutatus fit, quo facto, terendus eft crocus fuper porphyrum \& remittendus in cucurbitam \& infundendus fpiritus Veneris ufque ad 4 digitorum eminentiam, \& in bahneo Mariæ, ufque dum fpiritus evadat coloris rubri, abftrahatur, feparetur tinctura \& novum menftruum immittatur, commifceantur omnes tinctur:x, \& ufque ad confiftentiam fyropicraflioris abftrahantur, fuper quam infundatur fpiritus vini ad eminentiam 3 digitorum; qui digeratur in balneo \& abftrahatur, dein filtretur \& cum eodem menftruo abftrahatur, ufque dum extractum obtineatur, filtrentur tincturæ, \& $\frac{3}{4}$ partes liquoris abftrahantur, tunc reftabit tinctura Martis adffringens. Amplam hanc præparationem traditDominus Febure.

II. Recipiantur recrementa velfcoria ferri vel carbones e foco fabrili a fabris rejecti, in quibus ferrum effe folet; vel fi tanta pars Martis carbonibus non infit, ante follis ventum calcinentur, pulverifentur, \& pulvis in phiolam mittatur, infuper acetum deftillatum vel fpiritus aceti; digeratur mixtura in vitro claulo per 14 dies \& noctes, vel ufque dum fpiritus aceti coloris bruneo-rubentis factus fit ; liquor a fcoriis feparatus effundatur, \& per noctem in vitro relinquatur, ut craffora fundum petant. Effundatur inde pars clarior, unde habebis tincturam rubram, puram, limpidam omnisque impuritatis expertem : eftque tinetura hæc adftringens. Collect. Leidenf.

III. $\tilde{3}$ ji ramentorum ferri aut chalybis recipiantur, \& 3 uncix fpiritus aceti, in phialam vitream mittantur, \& in arena per diem \& nocten digerantur; ignis per gradus augeatur, fcilicet ad tertium gradum, ut vocatur; hinc fpatio unius diei obtinebis tincturam rubram, filtretur per chartam \& confervetur. Collect. Leidenf.

IV. Mifceantur pulvis hæmatitis \& ramentorum Martis 2 unciarum, fal Armeniacum 3 unciarum, mifceantur in crucibulo, \& crucibulum in igne per bihorium, ufque dum vapores definunt, teneatur; ignis principio fit lenis, qui ad candefcentiam crucibuli demum intra $\frac{x}{2}$ horam intendatur, quodque reliquum eft, pulverifetur: recipe hunc pulverem fic obtentum vel caput mortuum poft fublimationem hrmatitis in flores 2 unciarum, fuperinfundatur fpiritus vini Gallici 6 unciarum, quoque diutius digeruntur eo melius, tinctura a materia in fundo feparetur. Collect. Leidenf. 


\section{TINCTURA MARTIS ADSTRINGENS. 325}

$\mathrm{V}$. Limaturæ Martis recentis non rubiginofix fuperaffundatur vigecuplum boni vini Rhenani; reponantur in frigore per 3 vel 4 feptimanas, vafe claufo, frepe concutiendo, orietur nigredo in vino cum fapore faccharino, ftiptico, quod effundatur pro ufu ; finovum vinum huic freci affundatur, vix amplius hanc tincturam educes. Vel, decoquatur Mars in phiala alta, \& accipies eandem tincturam, quæ filtrata fervetur in ufus. Boerh.

VI. Si loco vini Rhenani limaturæ Martis affundatur firitus aceri deftillati duodecuplum, habebitur tinctura fanguinei coloris faturatifima, faporis naufeabundi, ftiptici, dulcis, ipius Martis quam ditifima. Debent autem aliquot horis una coqui, fi freci iterum affundatur acetum, nulla amplius tinetura fanguinea, fed fingularis tantum pars compofita prodibit. Si uncia hujus vel præcedentis admifceatur unciis duabus craffi alicujus fyropi, habebitur fyropus Martis potabilis. Boerhave.

VIl. Aqua chalybeata, vel aqua, in qua exftinguitur chalybs, eft adfrringens, quoque fepius exitinguitur, eo melius, optimi eft ufus in medicina.

V III. Seligantur flores falis ammoniaci Martiales puriores, colore aurantio infigniter tincti, hifque fuperaffundatur firitus vini rectificatus, fic extrahetur, obftetrice calore digeftivo, tinetura aurei coloris per filtrum transmittenda, \& in vitro bene claufo recondenda. Hoffmannus.

Vel recipiatur $\frac{T}{4}$ pars libre limature Martis, $\frac{I}{2}$ libra falis ammoniaci in arena per phiolam fublimati, feorfim conferventur hi flores, ut \& flores flavi feorfim, \& a contactu aeris cuftodiantur, ne in deliquium abeant: feorfim etiam conferventur flores nigri, qui in aere deliquefcunt, quique multum adftringentes funt.

IX. Ex fcoriis Martis fabrorum conficitur tinctura adftringens, fi diChis vel acetum deftillatum vel fpiritus æruginis affundatur, digerantur fimul quoufque rubefcat menitruum, poftmodo id ollix ferreæ immiffum decoquatur ad confiftentiam mellis, ex quo deineeps ope fpiritus vini tinCura eliciatur. Alia fit, fi refiduo a fublimatione florum Martialium, imprimis vero iftis flofculis nigricantibus, qui medix vitri, in quo fublimatio inftituta eft, regioni adhærent, affunditur alcohol vini : fed hæ \& aliæ famofx ex ferro tincturx adfringentes dubix operationis funt; hinc contingit, ut \& ipfi auctores has defcribentes fe inter non conveniant, dum alter eidem tincturæ adfringendi, alter aperien di vim affignet. Barchuf.

\section{Extractum Martis adfringens.}

Umantur 8 uncix croci pulverifati, \& in tripode ferreo fuperinfundantur 4 uncix vini rubri, vinum adhiberi poteft, quod vocatur vin de teinte \&c. tripus teetus mittatur fuper ignem, ut materia inibicoquatur, rutabulo circumagitetur \& ad remanentiam $\frac{\mathrm{I}}{3}$ partis abftrahatur, quod clarum eft, per linteum filtretur, \& tanta pars humoris evaporetur, dum remanet extraEtum ficcum. Lemmery.

II. Recipiantur fucci acetofxe 玷 $1, v$, tamarindorum 钻 $\mathrm{I}$, ebulliant fimul in olla ferrea, dein per pannum colentur ; in liquore colato exftinguatur fcobis Martis candefactæ $1 \mathrm{t}$ I. Coquantur denuo in olla ferrea, donec fuccus fapore victriolico imbuatur, poftea idem de novo coletur, donec craffitiem fyropi craffioris adeptus fuerit. Barchuf.
Clablis III. de ferro.
$\mathrm{Nn} n \mathrm{n}$
PARA- 


\section{PARAGRAPHUS XII.}

\section{Aqua Martialis five acidulas referens: vel aci- dule artificiales.}

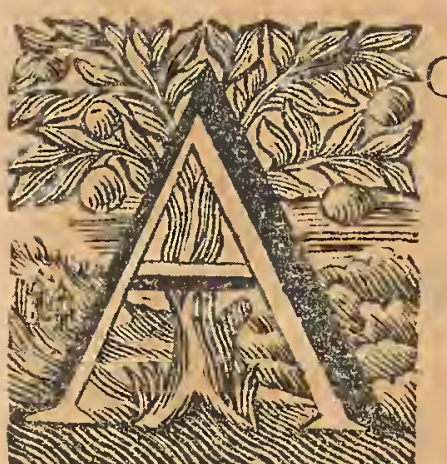

Qua artificialis acidularum obtinetur, fi dum minera Martis, poftquam per plures annos ad vietrioli (quod ut aliud victriolum, poltquam cum aqua fuerit folutum \& infpiflatum \& deftillationi commiffum fpiritum præbuerit \& caput mortuum reliquerit; quod nihil eit aliud quam crocus Martis in verum Martem liquatione reducibilis) fufficientem produCtionem expofita fuerit, cum aqua roris majalis vel alia aliqua deftillata infunditur, atque quod folvitur, filtratur; idque quod filtratum eft, denuo huic mineræ victriolicx affunditur, donec nihil hujus falis amplius folvere atque imbibere poflit, qualis dein liquor, tales acidulas artificiales conftituere poteft. Quo autem citius productio victrioli obtineatur, debes mineram contufam in loco humido reponere, ut folvatur, quo pacto pinguis fulphuris materia ejusdem in halitus abit, acidum vero fulphuris rodit Martem, \& fic fit victriolum : cum vero in victriolum abiverit, immittitur ollæ non vitriatæ feponiturque ín cella aliisve locis fubterraneis vel humidis, fic enim per ollam vietriolum purius inftar lanuginis transfudat, remanente quod craffius vel purius fuerit. Lanugo vero victriolacea cum penna tandem de olla abraditur ac in rore majali folvitur, ut obtineatur prædictus liquor.

II. Ex minera Martis recenti, melius fi aliquandiu aeri fuerit exporita, ut eft Haffiaca \&c. deftillatur fpiritus, qui capiti mortuo reaffufus aliquotque cohobiis fuper eodem rectificatus, odorem tandem ambram mofchumque æmulantem habere perhibetur, \& non fecus ac fpiritus victrioli Martis aqux fontane ad gratum acidulum faporem affufius, miftione per minima transvalatione facta acidulas æmulatur, \& in variis effervelcentiis humorum corporis noltri exhibetur. Konig.

I I I. Ramenta fubtilifima chalybis vel Martis cum tartaro vini Rhenani ana mifceantur, fuperaffundatur quantitas aqux pluvialis filtratre, cx his globuli poffunt formari, qui ficcentur cum lale \& pane in furno panifico mifcendi, in pulverem iterum contundantur \& formentur globuli pari modo ut prius, cum aqua pluviali \& cum pane mif́ceantur; repetatur hoc dum chalybs in quolibet liquore folvi poffe videatur.

IV. Una pars ramentorum fubtilium, 2 partes florum fulphuris, pulverifentur, \& quantitas aquæ pluvialis ad pultis confiftentiam infundatur, digerantur in leni calore per 12 horas, quumque hoc factum fit, infundatur e novo aqua pluvialis ad eminentiam 3 vel 4 digitorum, coquatur dein 
ufque ad tincturam flavam, effundatur, percoletur, abftrahatur ad $\underset{f}{\mp}$ partis remanentiam, hinc poft aliquot dies pulcherrima rubedo exiftit. Colleet. Leidenf.

V. Dominus Hoffmannus aquas acidularum artificiales fic præparat, dicens, difficilius negotium fuccedit cum acidularum imitatione, ut vere tales præparentur, \& quæ non folum faporem eundem præferant \& cum acidis pugnent, fed etiam copiolo fpiritu æthereo elaftico imbut: fint, effuf $æ$ bullulas rejiciant \& penetranti odore nares compungant; id quod obvium eft in Selteranis, Buchenfibus, Arronianis \& Wildungenfibus, nihilominus tamen artificiofam earundem elaborationem hunc in modum molitus fum. Infudi nempe aqua fimplicis, \& qua obtineri potuit, optimæ menfuram in figulinum vas, anguftiori collo inftructum, eidemque inftil lavi primum falis tartari probe calcinati iterumque foluti drachmam unam vel etiam plus adhuc, deinde adjeci victrioli fpiritus, prout magis vel minus dilutus fuit, quantitatem \& quidem talem, ut facta ebullitione \& mixtione alcalinorum quodammodo emineret, ac demum agitatione facta vas probe claufi : prodiit hoc artificio fapor acidulis affinis cum bullulis fub effufione alte falientibus, refpondit quoque virtus \& effectus, ita ut iisdem fummo cum fructu in morbis, qui acidularum temperatum potum poftulabant, \& harum tamen copia deerat, ufus fim. Eadem prorfus ratione Emfenfium aquarum imitationem adornari poffe reor, nifi quod aqua levior \& purior fit adhibenda \& major falis tartari portio. Si vero Pyrmontanis, quæ Martialis ochreæ materix confortio imbutæ, fimiles conficere animus eft, aqux Martiatx vel naturales vel artificiales adhibendx, \& paulo major falis tartari \& fpiritus victrioli copia admifcenda, ita tamen, ut pariter alcalium elementum emineat. Hoffmannus.

VI. Præterea aliæe funt acidulæ, qux alvum follicitantem virtutem exferunt, ut Egranæ, ac licet cum acido effervefcant, fal tamen tertium amaricans poft exhalationem relinquunt : hx etiam non alia ratione quam dictax acidulæ artis ope concinnantur, adjicienda tamen eft falis Ebfamenfis, Sedlicenfis, Glauberiani vel ejus, quod ex magnefia \& fpiritu victrioli parare foleo, portio. Haud abfimili ratione artificiole concinnari poffunt aquæ, fale exquifite medio foetæ \& efficaciter purgantis efficacitatis, fcilicet quando aquæ fimplicis optimæ notæ fal Glauberianum injicitur, ut in ea liquefcat, vel melius adhuc fi per mixturam magnefix \& olei victrioli ex calcarea terra \& acido victriolico fal eodem modo, ut in nativis fit, paretur, \& aqua eodem imprægnetur, ita quidem \& pondus falis inditi xquet quantitatem illam, qux per evaporationem ex aquis paratur, ac in libra medica ad duas minimum drachmas accedit. Ac denique fi quis curiofus Carolinas aquas valde alcalinas, \& laxante virtute præditas \& imbutas, 'fibi artis minifterio comparare velit, is id potiffimum agere videtur, ut nonlevem \& fubtilem aquam, fed materia calcarea onuftam eligat, eidemque pariter prius folutionem falis tartari\& poftea victrioli, quoufque alcalina portio manifeftius emicet, infpergat, quo terra calcaria cum fpiritu victrioli congrediatur, \& in fal neutrum tranfiens, purgantem effectum exfequatur. Hoffinannus. 


\section{DE AQUA ACIDULAS REFERENTE.}

VII. Mars potabilis Willifit. Recipe tartarum album purgatum \& limaturas Martis puriffimi ana, contundatur fubtile in mortario ferreo, affundatur aqua theriacarum \&lumbricorum, contundatur dein fortiter maffa, hæc cum piftillo ferreo perfemihoram, in globulum redacta includatur papyro albo duplicato \& arete ligetur circumcirca, fufpendatur in loco tepido clanfo per 3 vel 4 dies, dum in maffam duram concreverit, pulverifetur, cribretur, ad fcrupulum unum ąddantur 2 libræ aquæ, \& habebis ferreas acidulas Willifii, quales in magna quantitate ex tempore parari poflunt. Konig.

VIII. Mars potabilis Willifii etiam fit ex paribus portionibus ferri \& cremoris tartari pulverati, junctilque aqua aliove liquido, ut vino, aceto \&c. interveniente in globulis formatis inque fumo coetis; qualis labor pulverando globulos, \& fubigendo pulverem liquido aliquo, ut globuli rurfus ex maffa confici poffint; toties iterandus eft, donec hi penitus aqua tabefcant. Mars hic potabilis non differt, neu fapore, neu virtute, neu compofitione a tinctura tartari chalybeata, de qua alias, fiquidem utraque ex iisdem rebus primordia ducunt. Barchuf.

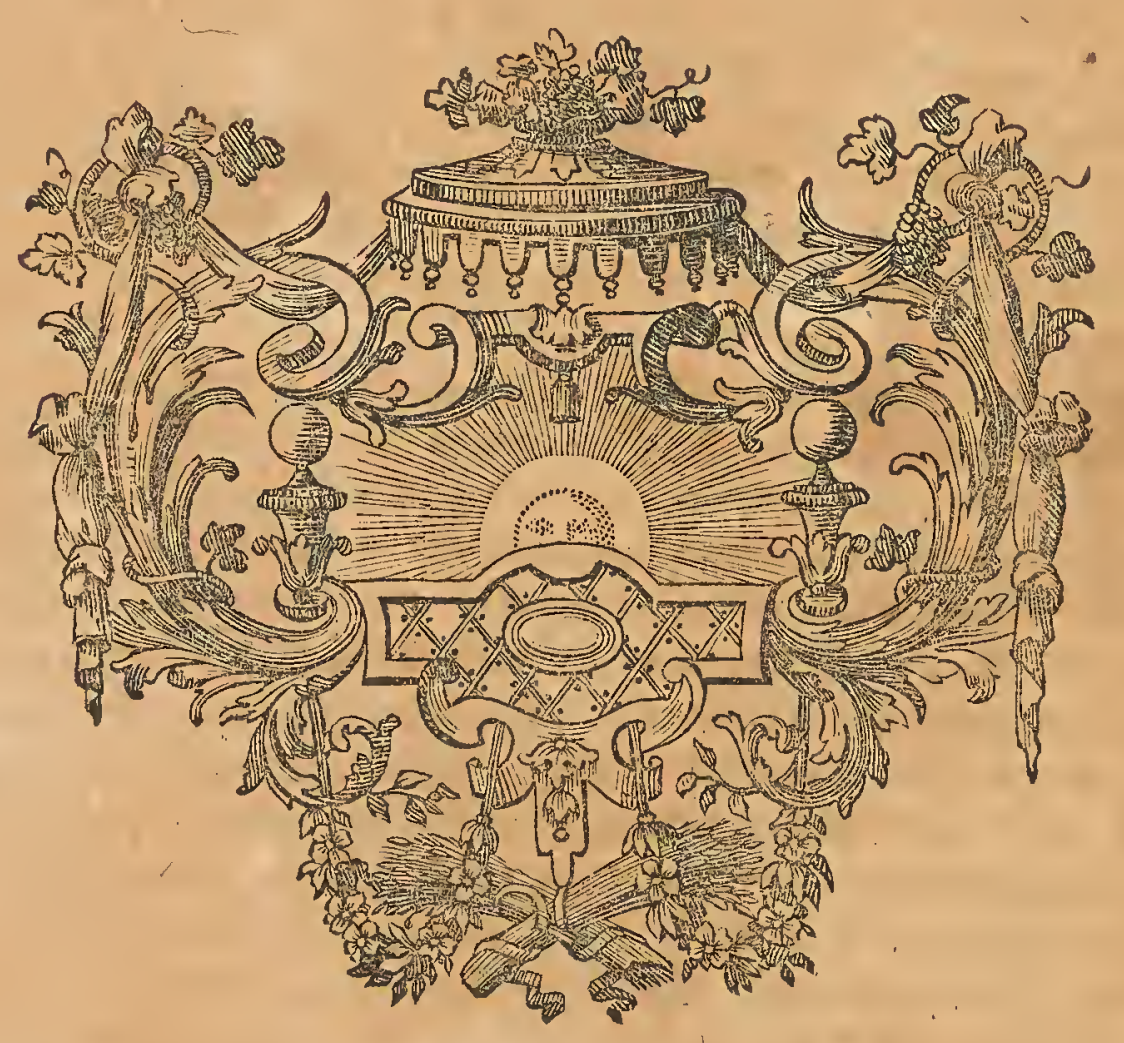

PARA- 


\section{PARAGRAPHUS XIII.}

\section{Flores chalybis \& Martis.}

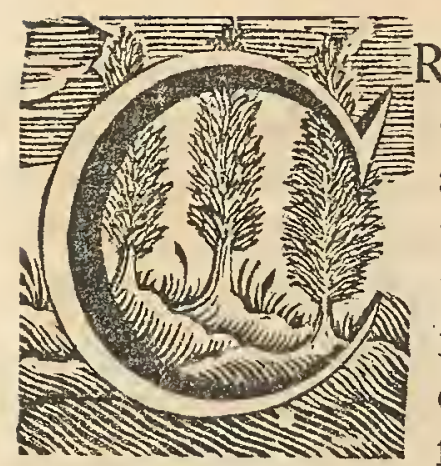

Roci Martis cum fulphure reverberati \& falis Armeniaci pulverifati partes æquales in cucurbita vitrea balneo arenæ commiffa fuperimpofito capitello diligenter luto obducto \& igne per gradus adhibito fublimando; ubi pars croci \& falis Armeniaci furfum evecta fub fpecie florum flavorum apparet, qui triti \& cum fubfidentia remixti iterum fublimandi, quod quinquies vel fexies aut toties repetendum, quoulque crocus Martis fere totus cum fale Armeniaco in flores furfum elatus lit. Hoffiman.

II. Accipe limaturæe Martis non rubiginolix, falis ammoniaci ficci partes æquales, conterantur fimul in pollinem fubtiliffimum, quo diutius eo melius : tunc fiat in cucurbita vitrea cum alembico vitreo igne arenæ fummo fublimatio: exibit primo liquor igneus, acerrimus, volatilis fere fuffocans, quo expulfo folent afcendere fumi albi, qui concrefcunt in flores falis ammoniaci. Aucto dein valide igne, elevantur flores omnis fere generis \& coloris, qui dicuntur flores Martis a varietate coloris. In fundo manebit ipfum Martis corpus penitus apertum, adeo a fale ammoniaco penetratum, ut aeri commiffum fere fermentelcat : ergo mutatum mirabiliter eft in fua fubftantia, nam tumet, fpongiofum fit, folvitur, \& tandem quafi in oleum deliquefcit. Si flores hi exponuntur aeri humido aperto, folvuntur in oleum : id autem, quod in fundo remanet, dat tincturam. Boerhave.

Recipe fcobis ferri, qux dum ferrum candens malleo percutitur, decidit, \& falis ammoniaci partes æquales, pulverata cucurbitæ vitrex loricatæ immittantur, eque igne aperto, ut moris eft, fublimentur, prodibit primo fpiritus quifpiam ammoniaci urinofus, in fine autem affurgent flores colori aurantiorum fimiles, qui finita operatione protinus eximendi, vitroque bene claufo refervandi; aer alias fi ad eos accefferit, colorem \& formam mutant. Iidem flores conficiuntur lapide hæmatite fubtiliffime trito, de quibus infra; flores cum lapide hæmatite parati colorem elegantiorem habent, quam qui cum ferro confecti funt. Refiduum a fublimatione aeri expofitum diffluit in liquorem, exterius vim adfitringendi, interius aperiendi habentem. Barchuif.

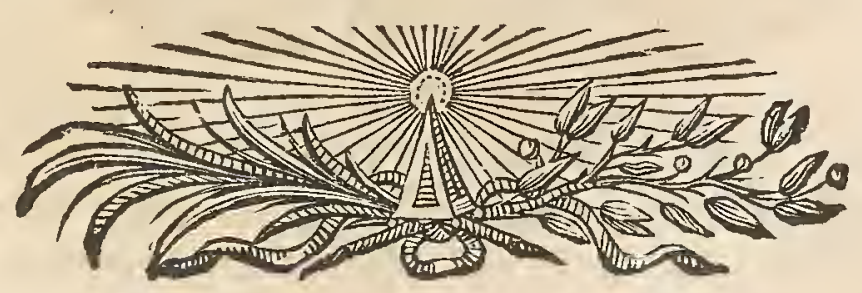

Claffis III. de ferro.

Oo o o

PARA. 


\section{PARAGRAPHUS XIV. Oleum Martis.}

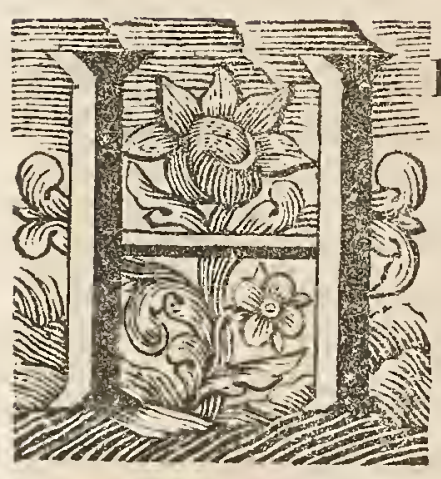

Ic recipiatur crocus Martis per reverberationem factus, eidemque affundatur fpiritus victrioli philofophici, digeratur \& extrahatur aliquoties recenti lpiritu rubedo, addita aqua fontana. Tincti liquores abftrahantur ad mellaginem : hrc ex cucurbita non nimis alta fublimetur, \& acquiruntur flores, qui aeri humido expofiti in liquorem aureum folvuntur, hicque liquor vocatur oleum Martis.

II. Alii fumunt crocum Martis ex Martis in victrioli in jii aqua tepida foluti paratum ad omnimodam laminarum ferri confumptionem, cui deinde addunt filicum calcinatorum $\mathrm{zb} j \mathrm{i}$, \& per retortam bene lutatam lento igne per 12 horas dein intenfiori deftillant, unde oleum coloris fanguinei habetur.

III. Sumatur ferrum quantum velis, folvatur in fpiritu falis ammoniaci, folutio per retortam deftilletur, inde obtinetur fpiritus, qui virtute ferrea pollet \& laporis dulcis eft, vocatur oleum Martis album.

IV. Victriolum Martis per deliquitum : fi calx rubra victrioli Martis foutella vitrea cxcepta exponatur aeri aperto, humefcit \& attrahit aquam, quemadmodum fal alcalinus fixus \& difluit in olei rubri fpeciem, eftque hxc productio oleorum metallicorum : hinc patet ars ex metallis quibuscun que butyrum vel oleum per deliquium faciendi : quo fiepius metallum hoc liquefacias \& iterum exficces, eo magis aperies, ita ut tandem metallum volatile fiat. Boerhave.

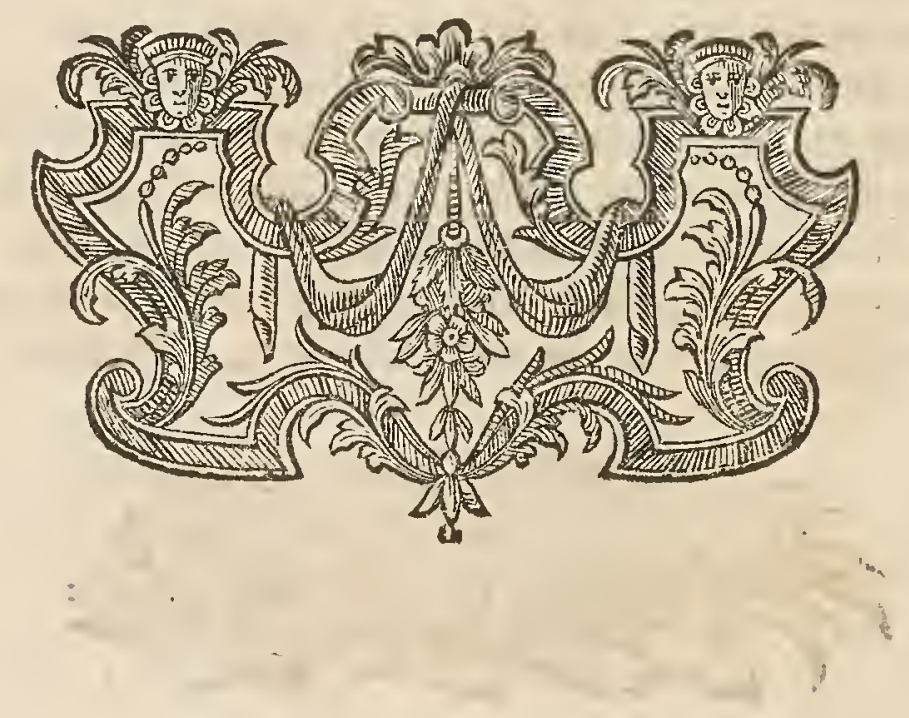




\section{PARAGRAPHUS XV. \\ Sal Martis Seu vidtriolum ex Marte \\ paratum.}

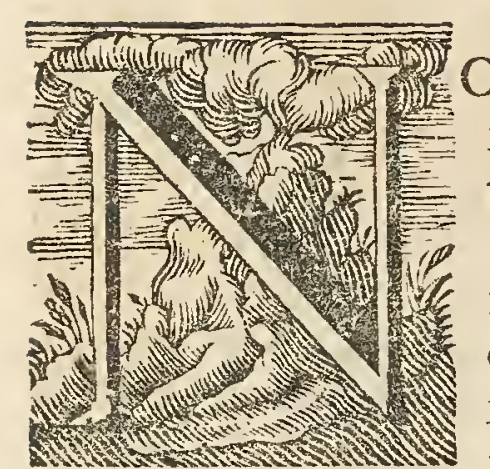

On fermo hic eft de victriolo Martis proprie dicto; fed potius de fale Martis; de victriolo alias feparatim agendum in fuo loco eft.

I. Si ferro candefacto albicanti \& fcintillanti admovetur fruftum fulphuris citrini, e veftigio acidum, in fulphure latens, ferri corpus corrodit, hinc id liquefcit, \& in vas fuppofitum frigida repletum ftillat, hancque victrioli fapore illico imbuit. Quæ aqua, $\mathrm{fi}$, donec cruftula in fuperficie apparet, evaporetur, \& poftea in loco frigido reponatur, concrefcit in vietriolum. Barchul:

II. Omnium frequentiffimus eft modus, fi f́cobi ferri vel fpiritus fulphuris vel oleum vietrioli inftillatur, cum non amplius efferbuerint, affundatur iis aqua \& in olla ferrea fimul coquantur, hinc per chartam colentur, evaporentur, \& ut mos eft, evaporentur. Pari modo fit etiam ex ferro falinum concretum, fi ei fpiritus falis vel fpiritus nitri, vel acetum deftillatum, vel aliud quodvis acidum affunditur'; differunt tamen hujusmodi victriola ratione affufi acidi; acido namque luus cuique partium fitus atque figura eft, quocirca etiam unumquodque fibi propriam formam a mutuato ferri corpore afcifcit, quam quoque fequitur diverfus cujufque generis tum color tum fapor.

Scobi ferri etiam nunc cum acido vietrioli effervefcenti, fi fruftulum chartex incenfum applicueris, videbis in illorum fuperficie cum murmure quodam flammam, illico tamen interftincturam exoriri. Barchuf.

III. Fit per prracipitationem ex victriolo, cui plurimum ferri ineft; hujusmodi victriolo aqua diffoluto, fruftula ferri candefacta immerguntur, donec amaricans a particulis cupreis ortum trahens fapor penitus fublatus, ac folutio vietrioli dulcis tantum faporis fuerit. Convenit ad hanc operationem potius victriolum Anglicum vel aliud fubdulce ac viride, quam Gofslarienfe, ac Hungaricum aut Tyrolenfe \&c. cupro refertum; attamen fi quodlibet quantum fatis aqua folutum cum fcobe ferri in olla ferrea coquitur, cuprex particulæ tunc precipitantur atque ferro adhæxrent. Si prima vice particule cuprex non omnino fuerunt fux fpontis facta, oportet tunc coctionem recenti ferri fcobe repetere, quoufque voti tui fueris compos factus. Barchuf.

IV. Victriolum Martis ex firitu victrioli vel fulphuris, ut dictum, affufione \& corrofione particularum Martis falinarum, maxime in chryftallos, paratur compendiofe ex lamellis tenuibus, fic tamen ut fpiritui viEtrioli, ceu qui particulis terreis metallicis conftat, merito præferatur fulphuri, cujus tbis mixta limaturæ Martis zjiii afperfione aque in vitro confervati poft fex horas incalefcit \& in maflam bruno-nigricantern abit, qux exempta 
exempta \& carbone accenfa folutione victriolum album faporis gratifimi largitur. Konig.

Sal Armeniacum cum deliquio folutum Martem fimiliter diffolvit, \& ad chryftallifandum difponit, dicente Willifio, qui etiam refert victriolum faporem fubdulcem cum afpera quadam ftipticitate referre. Kœnig.

V. Aquæ puræ calefactæaffundatur quarta pars olei victrioli, tunc injiciatur limatura Martis, incalefcet fubito cum magna effervefcentia \& odore-fulphureo, qui in fodinis eft; vas crepabit nifi prius calefiat. Liquor tunc non eft acidus, fed faporis dulcis victriolici, acrimonia ab oleo victrioli integre feparata eft. Hoc vocatur metallorum calcinatio humida, per quam aque mifcibilia, adeoque potabilia funt. Dum huic mixturx injicitur limaturæ Martis non rubiginofx paullulun, orietur uno momento ingens effervefcentia, cum odore quafi allii \& ovorum corruptorum totus illico lactefcet liquor; pergatur fic injiciendo ferri limaturam, donec ultimo nulla amplius notabilis fiat effervefcentia. Liquor ille faporis dulcis eft, omnisque aciditas fublata eft. Liquor hic fundamentum eft omnis atramenti. Si liquor hic trajicitur per filtrum, evadit fubviridefcens, qui, fi leni igne, ad pelliculam deducatur, concrefcet in glebas chryftallinas virides, dulcis faporis, victriolum vel magifterium Martis; diverfa obtinent nomina ha chryftalli, funtque in aqua integre diffolubiles \& ad ignem facile liquefcunt. Vietriolum hoc diffolutum in magna aqux copia perfecte aquas Spadanas refert, ut vix diftinguatur a nativis; grana tria hujus, \& gutta una olei victrioli inftillata in aquæ puræ libris tribus facit talem aquam. Boerhave.

VI. Si croco Martis, ex limaturæ Martis \& florum fulphuris portionibus æquis, confecto affundatur aqua \& educatur folutio, tunc hæc lege artis infpiffata, conftituit victriolum Martis.

VII. Si tripos vel vas ferreum purum recipiatur, \& infundatur fpiritus vini \& oleum victrioli ana, inque fole per aliquantum temporis quiete, dein in umbra reponatur, \& licebit videre, quomodo liquor uniatur cum Marte vafis vel tripodis, falemque conftituat, ficcetur dein \& eximatur vafi \& in phiola bene claufa confervetur. Pritat fi vas novum ferreum fit, exque 2 unciis fpiritus vini \& 2 unciis olei victrioli hoc modo 5 unciæ victrioli Martis obtinentur. Si enim victriolum Martis folum vafi immittatur, ferrum illo facile penetratur, exiguoque tempore aduritur, adeo ut fal vel victriolum impurum obtineatur. Liquor ad I digiti altitudinem immitti poteft \& per biduum relinqui ; tempore æeftatis facilius paratur quam tempore hyemis; hoc enim tempore requirere frpe folet tempus is dierum. Si fal vel victriolum hoc in cella reponatur, abit in liquorem, qui vocatur oleum Martis. Lemmery.

VIII. In amplum matracium mittantur 8 unciæ ramentorum ferri, \& fuperinfundantur 2 libræ aquæ communis, \& I libra fpiritus victrioli, mixtura circumagitetur; matracium in arena calida per tempus 24 horarum digeratur, interea pars purifima ferri refolvitur. Liquor per inclinationem effundatur, ejiciatur materia terreftris fundi, filtretur liquor, ad pelliculam in arena calida miffus in cucurbitam abftrahatur; vas dein collo- 
cetur in loco frigido, unde formantur chryftalli viridefcentes, qui eximi poffunt, quum liquor fupernatans lente \& caute effundatur: liquor hic ad pelliculam iterum evaporetur, \& ut prius in loco frigido chryftallietur., quod continuetur \& repetatur, dum omnis pars chryftallina inde exemta fit, quæficcanda eft \& in phiola vitrea teeta ad ufum bene confervanda. Quum perftat folutio, incalefcit multum liquor \& coquitur. Lemmery.

IX. Limatura Martis cum decuplo aceti deftillati digeritur, donec vel tota vel maxima ex parte foluta fit: folutio faccharinam dulcedinem referet; fin minus, cum nova limaturæ portione ulterius faturanda eft. Solutio deftillando ex balneo Mariæ abftrahatur ad tertiæ vel quartæ partis remanentiam, qux calida in phiolam effufa, obturato orificio, lente refrigefcat, \& tum in cella reponatur, ubi aliquot dierum mora chryftallos falis Martis nomine exhibebit, a quibus liquor effundendus, chryftalli, filo ferreo liberandx; fuper chartam leniter reficcatæ affervandx funt. Stahl.

$X$. Limatura puriffima acuum mittatur in cucurbitam vitream, \& infuper affundatur per vices fpiritus acidus victrioli non dephlegmatus, ufque dum limatura fatis imbuta fit, agitetur cum fpathula ferrea, caveatur tamen ne vitrum frangatur, infundatur dein ftatim aqua pluvialis deftillata, vel quæ ceciderat tempore æquinoetii non deftillata, fed calida prius effe debet \& fere ebulliens, relocetur cucurbita in arena calida, teneatur ibi in digeftione \& diffolutione per tempus i 2 horarum, hoc cum factum fit, liquor calidiffimus filtretur \& lente dein ad dimidiam partem evaporetur, in loco frigido dein chryftalliietur, tempore fequenti videbis Martem in fundo \& circumcirca latera vafis chryftallifatum ; chryftalli funt elegantes, coloris viridis, quæ intra papyrum complicatum relocandæ funt \& calore lento ficcandx. Si major pars defideratur, idem opus continuandum eft cum limatura refidua mediante fpiritu victrioli, dein affufa aqua calida, filtrandus eft liquor, evaporandus \& chryftallifandus, ụfque dum totum corpus metalli in victriolum vel in terræ cujusdam genus, quæe exigua admodum copia remanet, fi ferrum fit purum, pertranfierit. Sed quantitas victrioli fuperat valde pondus limaturæ, quantitas interdum triplicatur, quod oritur a f́piritu vietrioli, qui cum Marte fe incorporare folet. Obfervandum etiam eft, quod victrioli hujus genus excellentius fit victriolo communi; eft etiam majoris efficacix in medicina, \& celerius agit quam crocus aperiens. Qui præparare volunt crocum Martis optimum \& uriliffimum, calcinare debent 4 uncias hujus victrioli Martis in pyxide igne aperto, \& perftabit calcinatio, dum pulvis admodum pulcher obtineatur, quique fubtilis \& ruber fit \& nullius faporis. Dominus Febure.

X I. Recipiatur $\frac{\mathrm{r}}{2}$ libra limaturæ Martis vel chalybis fubtilioris \& purioris, mittatur in ollam terream, -irroretur acetum defillatum, ufque dum in paftam redigatur, quod in balneo Mariæ vaporofo ficcari debet ; cumque ficcatum fit, fuper marmor teratur ; \& dein cum codem aceto humectetur ; poftea ficcetur, teratur \& humectetur toties, dum per laporem cognolici poffit, quod fal dulcis habeatur: dein in cucurbitam pulvis immittatur, \& phlegma aceti ufque ad eminentiam 6 digitorum infundatur, \& cucurbita in arena reponatur, \& liquor ad Clalfis IIL de ferro. 
ebullitionem calefiat, fcilicet ut Mars eo melius extrahatur : obfervetur, quod femper e novo infundendum fit phlegma aceti calidum, loco ejus quod per coetionem exhalat, ufque dum menftrum fatis imprægnatum fit : . liquor dein frigefactus filtrandus eft, \& fic purior factus in balneo $\mathrm{Ma}$ riæ reponendus, \& inibiad $\frac{I}{3}$ vel ${ }_{4}^{x}$ partem ufque abftrahendus, mittatur dein cucurbita in loco frigido, 1 cilicet ut in fal chryftallifetur, liquor chryftallos fupernatans adhuc evaporetur, \& cum evaporatione \& frigefactione continuetur, dum major adhuc pars chryfallorum obtineatur; chryftallidein ficcandx funt, cumque ficciores facte fint, eis immittendum eft alcohol vini ufque ad 3 digitorum eminentiam, lutetur bene vas \& in balneo vaporolo lente digeratur per fpatium filicet 7 dierum; poftea recludatur vas \& imponatur capitellum, \& fpiritus vini eodem manente calore abftrahatur; quo facto in fundo vafis habebitur fal Martis in medicina optimum pro obftructionibus \&c. vocatur fal Martis. Febure.

XII. Primum præparetur aqua fortis optimi generis, partibus æquis victrioli \& falpetræ conftans; inque una libra talis aquæ fortis diffolvantur. 4 uncix falpetræ purx \& ficcatæ; poftea 6 uncix chalybis verfus fundum cucurbitx fuper cineres calidos relocatæ immittantur; fruftula chalybea effe poffunt 2 digitos longa \& unum craffa ; immittatur infuper aqua fortis, \& permittatur, ut operationem fuam exerceat; obfervandum eft, quod ampla effe debeat cucurbita, quodque melius fit, ut inibi folvantur fruftula chalybis quam ramenta, nam celere fatis incalefcit vas, \& inopina ebul-' litio exoritur; quum vero chalybs majufculus fit, ab acido non tam facile penetratur, unde etiam aqua in ferrum lentius agit ; ufque tamen calorem quendam impertiri debes; cumque folutio videatur peraeta, acetum defillatum calidum 2 librarum in cucurbitam infundendum eft, fed per vices \& quavis vice pars exigua, materia fundi etiam lente circumagitanda eft. Solutio hæc per 3 dies in balneo Mariæ digeratur, unde admodum rubefcit; poftea vero per chartam emporeticam filtretur, adeo ut per deftillationem in balneo $\frac{2}{3}$ partes menftrui abftrahantur, cucurbita dein in loco frigido mittenda eft, unde formantur chryftalli rubræ, qux impuritatum quarundam adhuc participes funt, impuritates eximantur; refidua pars liquoris etiam evaporetur, fcilicet ut illud obtineri pofft, quod adhuc chryftallifetur. Omnes chryfalli dein in unum mittantur \& in debita quantitate aceti deftillati folvantur, folutio filtretur, \& dimidia quantitas menfrui lento calore balnei Marix abftrahatur, dein reliquum ad chryftallifandum in loco frigido reponatur; continuetur hæc operatio, fcilicet folutionis, filtrationis, deftillationis \& chryftallifationis, ufque dum chryftallielegantes obtineantur, quæ rubræ \& tranfparentes fint, \& ufque dum nullum amplius fedimentum in fundo vafis chryftallifatorii reperiatur : chryftalli inter papyrum complicatum ficcentur calore lento, \& in phiolam mittantur, \& fic ad ufum conferventur. Sal hoc aperitivum eft optimum, vocatur victriolum \& chryftalli Martis. Febure.

XIII. Solvatur tartarus in aqua, in qua ferrum a fabris chalybeis exftinguitur, immittantur ramenta ferri, unde acidum tartari aggreditur Mar- 
tem; filtretur, evaporetur \& folvatur, \& in loco frigido chryftallifetur; optimum remedium aperitivum eft, \& refertur inter arcana majora.

Refert infuper Dominus Brandt, fe limaturam Martis in aqua forti folviffe, \& folutionem ad ficcum fere evaporaffe; ex refiduo in retortam miffo igne primum leni, dein intenfiori expulfum fuife phlegma, dein afcendiffe fpiritum, qui æque urens ac fortis effet ac oleum victrioli.

\section{Appendix.}

Nnumera illa præparata chymica ex victriolo Martis prætereo, quæ in confiderationem \& recenfionem veniunt, quum de viotriolis agendum fit: ut de gilla victrioli, de /piritibus diperfffsmis ex victriolo factis, de fpiritu ejus dulci, de Jpiritu ejus tartarifato, fulpbureo, coagulato, aperienti Penoti, tartaro victriolato, fpiritu ejus volatili, pbilofopbico, antepilepizco Paracelfi ut \& Quercetani, anodyno \& narcotico Pinerii, Mynficbti. De fulpbure victrioli anodyno, fixo E bolatili, de fulpburis ejus tinctura E effentia, de balfamo faporifero, de floribus fulpburis rubri ex victriolo. De terra metallica vel ocbra victrioli, de terra dulci victrioli, de fale victrioli; de aqua fiptica, lapide medicinali, admirabili, lapide Driff Hellmontii, pbilofopbico; arcano duplicato, lvictrioli Martis tincturis \& oleis, crocis, anima Mynfichti, panacad ex victriolo, pulvere Gmpatbetico, \& plurimis aliis, de quibus videas tractationem de victriolo.

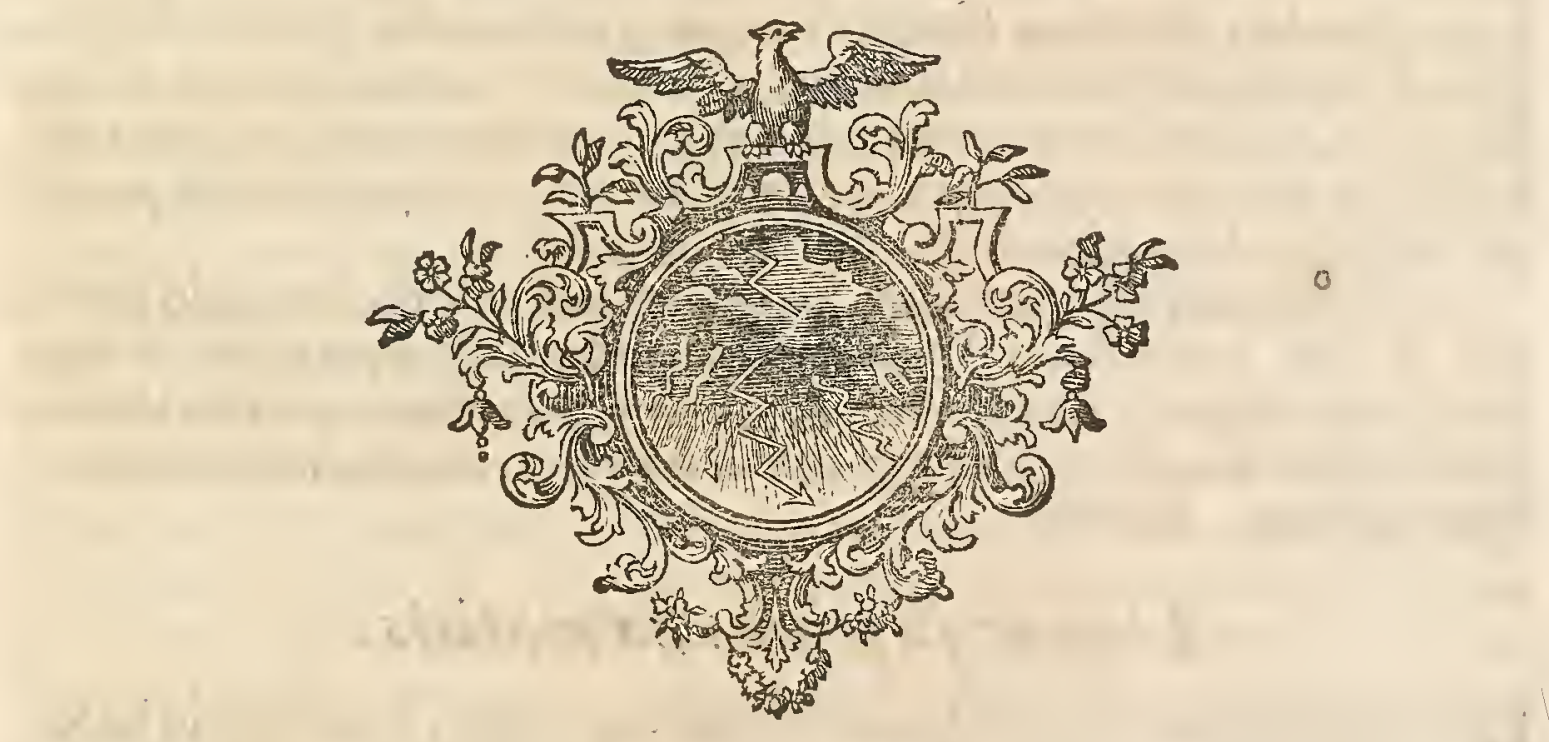




\section{PARAGRAPHUS XVI. \\ De homatite.}

\section{Sublimatio bomatitis in flores.}

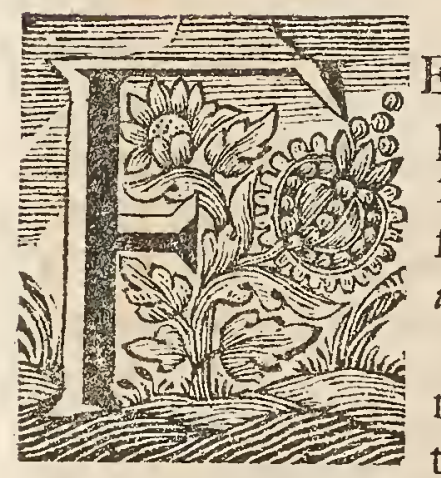

Errum quod concernit, putant aliqui fublimari illud poffe in flores fubtilifimos, quos nivem ferri vocant, fed alii negant ex ferro nifi ex antimonio ei admixto florem five nivem poffe obtineri. Brefslauif. Naturund Medic. Gefcbichte.

I. Recipiatur una pars lapidis hæmatitis fubtilifime pulverifati; partes 2 falis ammoniaci tenuifime triti, quam optime mifceantur, per alembicum in arena igne forti fublimentur, fpiritus falis ammoniaci egreffus feorfim fervetur; fublimatum eluatur aqua, filtretur per chartam emporeticam, pricipitetur infufione olei tartari per deliquium, donec aqua fiat alba \& clara, precipitatum edulcoretur ; fic habebis flores lapidis hæmatitis.

2. Sumatur I pars ex hæmatite, $\frac{1}{2}$ falis ammoniaci, in pollinem fubtilem terantur, filtrentur, \& bene in mortario mifceantur per fpatium quadrantis horæ; mixtura mittatur in cucurbitam, lutentur bene juncturæ, ignis per gradus intendatur \& fiat fublimatio, cum leni igne tranfeunt fpiritus falis ammoniaci, dein aucto igne afcendunt flores hæmatitis \& inhærent parietibus alembici, funtque coloris pomerantzii; quum refrigeratum eft, a vafe fublimatorio feparetur alembicum, eximantur flores, \& conlerventur, ne contingant aerem; in fundo reperitur caput mortuum hæmatitis, in quo micx pulcherrimæ nitentes funt; ope magni ignis potuiffet ferrum ex hxmatite fundi. Collect. Leidenf.

In fublimatione paullulum fpiritus urinofi volatilis principio prodibit, in fine autem flores flavi afcendent, qui peracta operatione in vitro claulo cuftodiantur; humefcunt enim facile \& pallefcunt: qui fi ita fuerint, immittantur ollæ, \& leniter fupra ignem ficcentur, flammeolum recuperabunt colorem. Barchuf.

\section{Liquor Ripticus bomatitis.}

Efiduum a fublimatione hæmatitis aeri exponatur, quoufque in liquorem fuerit converfum, vel ei tantum aqua affundatur, ut fiat liquor fpiflus, qui colatus fervetur. Barchufen.

\section{Tinctura bomatitis.}

A D ufum chymicum optimus eft ille hæmatites, qui eft velociter frangibilis \& friabilis, æqualis duritiei, cui non admifcentur fordes \& in quo funt venx, \& cui fanguinis concreti color. 
Caput mortuum poft fublimationem hæmatitis in flores, quod in fundo cucurbitæ remanfit, folvatur aqua, donec non amplius tingitur; folutiones calidx filtrentur; coagulentur igne forti, \& extrahatur poftea cum fpiritu vini (præftaret fumere firitum cydoneorum vel prunorum fylveftrium) affundendo toties, quoties tingitur, tinctura, quæ per chartam filtranda eft. In hac tinctura progreffu temporis fubfidet pulvifculus fubtilis ; hic affufa tinctura ficcandus; ficcato affundenda aqua, ut fal ammoniacum, quod adhuc, dum ipfi adhreret, imbibat ; qui pulvifculus denuo ad ufum medicum ficcandus, \& vel feorfim fervandus, vel floribus immifcendus. Aqua vero illa evaporanda, ut coaguletur fal ammoniacum, quod depuratum, diaphoreticum in febribus effe poteft, cum conftet ex fale ammoniaco \& himatite, unde vocare licet fal ammoniacum diapboreti. sum bamatiticum. Ultimum caput mortuum hæmatitis feu corpus hæmatitis, e quo \& flores fublimati, \& tinctura extracta, poffet uri \& lavari. Ex fcoriis tive hrmatitis five fchifti, e quibus ferrum excoetum, eo modo, quo Crollius, ex fcoria ferri cœrulea primo tincturam extrahit, poftea croci Martis effentiam parat, etiam tincturam extrahi poffe nullus dubitat. Baufchius.

I I. Refiduo a fublimatione affunde alcohol vini ad altitudinem 2 transverforum digitorum; digeratur per aliquot dies noctesque tinctura colata, poftmodum in vitro bene clauí affervetur. Loco, qui inter flores \& refiduum medius eft, adhærent flofculi nigricantes, fapore maxime auftero præditi, qui fi alcohol vini abluantur, impertient dictæ tincturæ majorem adffringendi potentiam, Barchul.

III. Recipiantur lapidis hæmatitis lævigati partes 2 , falis ammoniaci partes 3 , exacte mixta in, crucibulum mittantur, \& in leni igne per horam unam alceramve detineantur, donec vapores ceffare incipiunt; tunc per horam dimidiam augeatur ignis, ut crucibulum incandefcat, maffa refidua in pulverem teratur, atque hujus drachma I mifceatur cum 3 fpiritus vini rectificati, per 24 horas fimul digerantur, dein clarum a fififo ad ufum fervetur. Hoffman. in Laborat.

IV. Sumatur caput mortuum poft fublimationem hæmatitis cum fale ammoniaco in flores; reponatur fpatio 3 feptimanarum in cella, inde in deliquium abit; hic liquor eft coloris aurei vel flavi, eftque admodum adftringens. Si liquor hic ad ficcum evaporetur, obtinetur inde menftrum, cujus ope metalla folvuntur: fed preparatur tunc hoc modo ; fi fumatur dictum hoc fal i 2 unciarum, \& fpiritus vini rectificatus 6 unciarum, mifceantur \& per aliquot dies digerantur, fal remanens mifceatur cum fufficiente copia argill: \& terræ communis \& per retortam vitream deftilletur, adeo ut candefiat retorta, inde obtinetur firitus acidus, qui in vitro confervari debet: ufurpatur circa extractiones partium fubtiliorum vel fulphurum ex metallis, ut auri, antimonii, talci. Collect. Leiden1.

V. Super flores hæmatitis craffiuicule contufi effundatur fpiritus vini rectificatus ad eminentiam 2 digitorum; mixtura diebus 6 vel 7 digeratur, quo diutius eo melius, inde obtinetur tinetura aurei coloris, \& vocatur effentia aperitiva. Si tinctura vel flores vilipendantur, tunc flores dicti hæClafis $I I I$.de ferro. 
matitis cum novo hæmatite loco falis Armeniaci fublimari poffunt, \& eadem hæc tinctura ex capite mortuo obtineri poteft. Colleet. Leidenf.

\section{Magifterium hematitis.}

PUlveris hematitis $\bar{\xi}$ I calcinantur cum fulphuris puriffmi $\xi_{\text {V I I I vel }}$ pluribus,-donec fulphur abfumptum ht: huic rurfus pulverifato fuperinfunditur acetum deftillatum bene acuatum cum fpiritu victrioli poft aliquot dierum cxtractionem in loco calido vel arena calida precipitatur cum oleo tartari per deliquium. Præcipitatum cum repetita affufione aqux calidæ edulcoratur, edulcoratum ficcatur, ficcatum, quod rubei eft coloris, ad ufum fervatur. Baufchius.

\section{Spiritus bamatitis \& Martis.}

DEr retortam exhibet hæmatites fpiritum, odore \& fapore fpiritum viEtrioli æmulantem. Baufchius.

II. Hæmatites \& fal ammoniacum fubtiliffime pulverifata \& optime mixta deftillentur; afcendit fpiritus falis ammoniacus igneus, urinofus : aucto igne fublimatur fal ammoniacum \& fecum rapit flores hæmatitis inftar corticum aurantiorum coloratos: hoc reduc in tenuifimum pulverem, fuperfunde fpiritum vini rectificatifimum, ut tincturam extrahat, idque toties repete, quoties coloratur fpiritus vini ; fpiritus hos tinctos deftilla ex balneo, manebit in fundo cucurbitx fal pulcherrimorum colorum odore croci, quod ferva. Caput mortuum tere fubtilifime, projice in firitum vini optimum (poffet fpiritus vini a fale deftillatus fumi) qui coloratur : repete aliquoties ulque ad extractionem omnis tincturæ: fpiritus hos deftilla per alembicum ex balneo, remanebit iterum in fundo fal ut prius : hoc deftilla lento igne, per retortam vitream lutatam, in furno venti exibit $\int j i$ ritus Salis ammoniaci acidus, corrofious, duplicatus, aucto igne prodeunt flores: finita deftillatione conjunge fpiritum corrofivum cum floribus in collo retortæ hærentibus; deftilla lente per retortam vitream, exibit fpiritus \& flores manebunt in fundo; hos flores mifce cum fuperioribus, repone in cella, ut liquefcant in liquorem. Baufchius.

IIl. Ex victriolo facto ex Marte fpiritus acidus poteft extrahi, fi pari modo igne reverberii in retorta deftilletur, prout victriolum commune; eadem vis huic fpiritui, quæ fpiritui victrioli communis, adjicitur. Caput mortuum in retorta refiduum peracta deftillatione conftat ferro, quod a fpiritu victrioli dicto folvi poteft. Eftque fpiritus Martis acidus. Lemmery.

IV. Victriolo Martis e mineris educto mifce æquam partem falisammoniaci, affundeque ad aliquot digitorum eminentiam fpiritum vini fimplicem, digere per 8. dies, dein folutionem per inclinationem effunde, \& tamdiu fuperfulionem \& extractionem reitera, donec omnis color \& fapor eductus fit : folutiones has immitte retortæ \& igne evoca fpiritum vini, fortiori tandem prodit fpiritus Martis acidus cum nebulis albis odoris fulphurei gratifimi. Ex Hoffmanno Kœnig. 


\section{Oleum ex bamatite.}

THmatites fubtiliffime conteratur, \& vel rquali vitri vel fulphuris pondere commixtus in calcem aduratur; hxe deinde ex aqua pluviali ftillatitia lavetur aliquoties, rurfufque ficcetur; poftea fpiritus vini fuperfundatur, macereturque, tunc deftilletur rurlis, \& quod in fundo remanet, iterum calcinetur, lavetur, deftilleturque toties, donec in.vino eliquefcat inftar nivis; tandem in coquendo fal provenit, quod in loco humido relolvitur in liquorem. Baufchius.

\section{Reductio bamatitis in quintam elfen- tiam Eal.}

Apidem hæmatiten cum duplo fulphuris tere in pulverem impalpabi-

lem, cxmenta per horas 6 , poftea fub tegula in fornace probatoria candefac per horas 2 femper movendo, materiam ignitam projice in acetum acerrimum deftillatum, pulveren cum aqua communi deftillata edulcora, ficca; dein cum aqua rolarum globulos parvos forma, quibus fuperinfunde fpiritum juniperi, digere aliquandiu, donec omnis effentia extracta fit; filtra per chartam; fpiritum in balneo Marix abltrahe, ut effentia maneat in fundo; caput mortuum edulcora; foperfunde aquam mellis corrofvam; abftrahe aquam; fal cum firitu vini per iteratam deftillationem. edulcora. Baufchius.

\section{Anima bomatitis.}

Fcipe hæmatitis partem I, falis Armeniaci partes 2, fublima, egregium fublimatum rubrum acquires, edulcora, anima Martis remanebit in fundo, ex auro extrahe fal, animam fige per 6 feptimanas, bene ita abibit in argentum, fal vero inftar rubinorum erit fplendidum. Ex Wittighio Baufchius.

\section{Homatites ufus.}

H Ematites igniendo \& in felle bubulo exftinguendo præparetur, \& hic eft lapis hæmatites uftus \& preparatus. Baufchius.

\section{Homatites trocbifcatus.}

DUlverifetur hæmatites minutiflime, coquatur in aqua communi \& plantaginis deftillata per horas 7 vel 8 , ut fiat inftar terre lutolæ, quæ poftea effufa \& evaporata aqua in trochifcos formari \& figillari potent.

Galenus eum præparat folutione in fuccum perattritionem ad cotem. Baufchius.

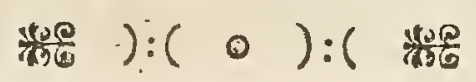

PARA- 


\section{PARAGRAPHUS XVII. Obfervationes varice \& collectanea circa ferrum. \\ Pondus $\sqrt{p e c i f i c u m}$ ferriut Fे incrementum $^{\text {ponderis ejus. }}$}

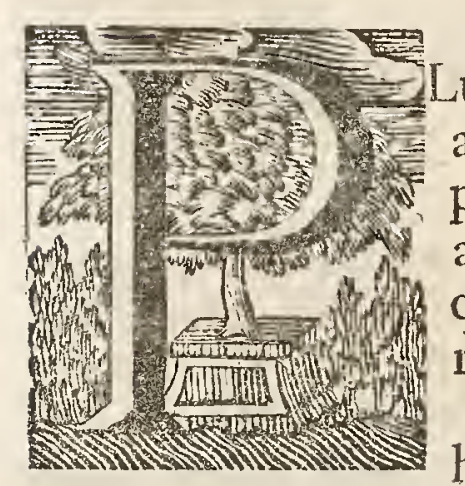

Luvialis aqua ad ferrum malleatum ponderat ut 1000 ad 7817: alii vero per experimenta facta differentian ponderum adinvenerunt ut 1000 ad $7645:$ alii ut 1000 ad 7914; alii ut 1000 ad 8000, alii ut 1000 ad 8166; quæ diverfitas tam aquis, quam ipfimet ferro, quod varii generis \& ponderis eft, adfcribenda venit.

Ramentorum chalybeorum drachmæ 4 per duas horas in catino fub tegula fornicata detentz, incrementum ponderis acquifiverant I drachmæ $\sigma_{\frac{\pi}{4}}^{\mathrm{I}}$ granorum, auctore Boyelo, de ponderat. Alamma.

Hic etiam adjicere libet pondus fpecificum victrioli, oleorum \& fpirituum ejus, propter multam affinitatem victrioli cum Marte tanquam fuo. Victriolum Dantifcanum ad aquam ponderare compertum eft ut 1815 ad 1000 .

Vietriolum Anglicanum ad aquam pluvialem, ut 188 ad 100.

Oleum victrioli ad aquam pluvialem ut $1877 \frac{1}{2}$ ad 1000 , ab aliis dicitur tantum ut 1700 ad 1000 . Alioquin menfuratum eft pondus oleorum victrioli diverfis temporibus, \& oblervatum pondus illorun temporexeftvo fuiffe ut 7 groff. 59 gran. tempore vero hyemali 7 groff. 7 I grana.

Spiritus victrioli æxtate effe folet 5 groff. 33 granorum, hyeme vero 5 groff: 38 granorum.

Quod reliquos firitus acidos concernit, compertum ef fpiritumnitri æftate 6 groff. 24 grana: hyeme 6 groff. 44 grana pependiffe. Spiritum falis xftate 5 groff. 49 grana : hyeme 5 grofl. 55 grana. Aquam fortem eftate 6 groff. 23 grana; hyeme 6 groff. 35 grana. Spiritum fulphuris xitate 5 groff. 34 grana; hyeme 5 groll. 39 grana. Acetum xftate 5 groff. 5 grana; hyeme 5 grolf. 2 I grana. Acetum deftillatum 5 groff: Is grana; hyeme 5 groff. I 5 grana, quod eft ejus liquoris pondus, cum fit menfura unius pollicis cubici Parifienfis ; ex Domino Eifenfchmidio vide Acta Lipf. anni 1.708. Quod proportionem attinet dictorum Spirituum \& aque, eft aque fortis pondus ad aqux ut $1300 \mathrm{ad}$ I000 : fpiritusnitri ut 1315 ad 1000 . Olei victrioli ut 1700 ad 1000.

Corpora aliqua novas quasdam particulas ex aere imbibere, evincitur ex calce viva, itemque ex capite mortuo falis, nitri, aluminis, vietrioli; quodque terra, ex qua nitrum fuit extractum, fpatio 7 annorum in 


\section{OBSERVATIONES VARIÆ CIRCA FERRUM. 34I}

loco umbrofo accumulata plene per aerem imprægnetur. Circa oleum victrioli notabile in hac re eft experimentum; quidam 3 drachmas olei victrioli in tantum dephlegmati, ut filum craffus corrodendo diffolveret, vitro aperto, cujus diameter 3 pollicúm erat, infüdit, illudque bilanci accuratie impolitum ftatuit in loco a fole \& igne libero, pofteaque pondus aliquoties examinavit \& confignavit, annotatis infimul bene tempeftatum ventorumque varietatibus; fenfit itaque pondus indies augeri, in tantum ut intra fpatium 5.7 dierum a 3 drachmis ad drachmas 9 \& 30 grana afcenderet: incrementum hoc nec xquale quotidie fuit, fingulis diebus decrevit, \& adeo quidem ut primi diei incrementum fuerit unius grani : cum ultima dies vix dimidium granum adjeciffet ponderis, notatum fit, quo ma'gis enim liquor faturatus eft, eo minus quotidie incrementum ei accedere vifum eft, non xqua quidem defcenfus proportione: obfervatum enim eft, incrementum longius fuiffe tempeftate humida, nebulofa \& nivofa; flante item auftro aut zephyro, quam tempore gelido, claro \& ficco, eurove aut borea lpirante, noeturnis itidem quam diurnis horis. Color hujus liquoris antea faturate rubebat, poftea vero evafit limpidior; materia etiam hxe deftillationis examini fubjecta, liquor primum prodiit xque infipidus ac aqua pura, poftea vero igne magis intenfo, guttæ evaferunt acidæ: remanens in retorta oleum eandem corrodendivim retinuit, ac initio habucrat. Obfervatum etiam eft, quo amplior liquoris fuperficies, proportione habita ad ejusdem quantitatem, aeri patuerit, eo celerius fuiffe incrementum. Sic tria hujus olei grana frufto vitri infula ad latitudinem $\frac{3}{4}$ pollicis, mox primis 6 horis alia 3 grana attraxerunt, \& intra minus quam 48 horarum fpatium liquor jam tantum non plene faturatus plus quam triplum primi ponderis exhibuit. Idem etiam putatur exiftere circa oleum fulphuris per campanam, oleum tartari per deliquium, item liquorem nitri fixi \&c. de his Wilh. Gould in iranfact. Anglic. phil. EJ ACtis Lipfrenf. pro anno 1685.

Vietriolum Veneris per aliquot feptimanas in aere qua pondus augeri ab una uncia ad I unciam \& 4 $\frac{\mathrm{T}}{2}$ grana : \& a 6 unciis ejus ad rubedinem calcinati per 6 menfes ad soo grana aitBoyleus : ejus verba funt; immifit victrioli ad rubedinem calcinati 8 uncias vafi metallico nonnihil lato \& plano, expofuitque aeri latiorem pulveris fuperficiem alteri vafi metallico minori quam prius colchotaris 2 uncias: \& hoc tempore Junii; tunc 8 uncix acquiliverunt I drachmam \& I 7 grana; \& 2 unciæ acquirebant idem pondus grano uno minus; hæ duæ unciæ acquifiverunt tempore Augufti ultra 2 uncias \& I granum, etiam 42 grana, adeo ut minori quam 6 menfium patio ultra roo granorum incrementum proindeque ultra decimam priftinifui ponderis partem acquifiverit. Boyleus.

Sumfit victrioli Venerei colchotar curate edulcoratum, relictum in mufeo menfibus Januarii \& Februarii, unciamque ejus exacte appenfam aeri expofuit, invenitque poft feptimanas aliquot, pondus auctum fuife granis $4 \frac{1}{4}$ circiter, preter pulvifculi aliquam portiunculam vitro adhæerentem, Boyleus. Calx victrioli Dantifcani, unde oleum diu fuerat deftillatum, edulcorata, aqua fuit affufa binis ejus copiofis portionibus, ut liquor ille particulis victriolatis in calce reftitantibus gravidaretur. Aqua harum Chalfis III. de ferro. Rrrr portio- 
portionum uni affufa, poftquam fatis imprægnata effet, mox filtrata fenlimque abftracta fuit, qua ratione complures præbebat drachmas cujusdam falis victrioli, quod parum a victriolo calcinato differre videbatur; aqua vero, quæ alteri portioni victrioli calcinati fuerat affufa, in vale patulo expolita fuit aeri, \& per 4 vel 6 feptimanas relicta, quo tempore elaplo, cum inodo jamjam dicto abftraheretur, multas largiebatur drachmas falis, quod neque tunc, neque diu poft, communis victrioli vel etiam prioris falis fpeciem prx le ferebat, led in chryftallos nitro fere vel alii cuidam fali non tincto fimiles abibat. Boyleus.

Marcafita coloris partim nitentis, partim obfcuri victriolo apprimis fota 2 unciarum, affervata per 7 feptimanas in conclavi ad aerem aperto augebatur pondere ad 2 uncias \& 12 grana. Boyleus.

Oleum victrioli pondere prius examinatum, verba funt clariff. Fred. Hoffmanni, fi diutius aeri exponitur, \& poftea rurfus ad lancem pondus exigitur, illud dupla vel tripla quantitate increviffe deprehendimus, eaque propter quafi magnes fit humidi aerei, humiditas atmolphæræ hoc iplo indagari poteft, fed tamen ejusmodi oleum, quod ex aere imbibit humiditatem fufficientem, non amplius cum aqua xefum movet; idem obfervatur in calce viva, qux diutius aeri expofita, non amplius ab aqua affufa ebullit vel æftum producit. Hoc quoque fingulare phænomenon eft, quod oleum victrioli vehementi ignis tortura ex calcinato victriolo expreffum, \& demum per retortam vitream igne arenæ rectificatum, limpidum ac pellucidum fit inftar aquæ, omnis caloris expers, nihilominus facili negotio tam ex aere quam etiam adjectione aliarum rerum, qux pauxillum principii inflammabilis continent, colorem faturate rubicundum contrahat.

\section{Solutiones ferri in acidis $E^{2} c$.}

$\mathrm{D}^{\mathrm{O}}$ Oetor Brandt in obfervatorio chymico collegii metallici Stockholmenfi fequentia de folutionibus ferri obfervavit. Ramenta ferri I femuncia folvebantur in 20 femunciis fpiritus aceti, unde folutio evafit coloris rubre brunei; affulo alcali quodam fixo, nulla effervefcentia exiftebat, quod fignum erat ferrum cum acido intime commixtum fuiffe, unde folutionis color nec mutabatur, nec quicquam inde precipitabatur, led per alcali volatile, ut per fpiritum falis ammoniaci, turbabatur folutio \& exfitit precipitatio.

Una femuncia ramentorum ferri folvebatur in $2 \frac{1}{2}$ femunciis aqux fortis, unde calor exiftebat \& folutio effervefcebat : folutio vel menftruum inde evafit coloris obfcure viridis, quæ folutio cum filtraretur \& oleum fartari per deliquium affunderetur, precipitabatur inde calx coloris obfcure bruni. Ramenta Martis in aqua regis folvebantur, inde fiebat folutio coloris rubre bruni, affulo oleo tartari \& concuffo vitro nullà effervelcentia exiftebat, color tamen mutabatur in fufce grifeum five canitiem obfcuram, \& calx ejusdem coloris precipitabatur. Præter dicta menftrua ferxum etian folvitur in oleo victrioli, in fpiritu vietrioli, item in fpiritu ful- 
phuris per campanam, in fpiritu falis, in fpiritu aluminis \& pluribus aliis acidis.

Ferrum calcinatum in acetum 20 partium miffum, dabat tincturam coloris flave bruni; folutio per affufum oleum tartari non effervelcebat nec turbabatur, unde etiam nulla exiftebat præcipitatio; fed per fpiritum falis ammoniaci precipitabatur.

Ferrum calcinatum non folvi potuit in aqua forti, non enim ab hoc menftruo arripiebatur, nec turbabatur ita ut ejus color mutaretur. Affufo oleo tartari effervefcentia fatis magna exiftebat: nec ulla dabatur procipitatio.

Ferrum calcinatum nec folvi potuit in fpiritu nitri Glauberi, qui tamen maxime acidus eft; cum tamen ferrum non calcinatum bene inibifolutum dilaberetur vel corroderetur.

Quarta pars femuncix ferri calcinati optime folvebatur in aqua regis, rubefcebat folutio; fed poft elapfum aliquot horarum fpatium color flave rubefcens, nec tenui oleo diffimilis erat. Affufo oleo tartari effervefcentia exiftebat, \& folutio evafit coloris rubefcentis five inftar rubini, pellucida ac pulchra cum nulla præcipitatione. Per fpiritum falis ammoniaci turbabatur folutio, \& quxdam effervefcentia exoriebatur cum calore, \& calx obfcure bruna præcipitabatur. Doctor Brandt in labor. chym. coll. metall. Stockholm.

$\mathrm{Ab}$ aliis itidem obfervatum eft, quod fpiritus falis folvat ferrum \& chalybem, led fi ignis vi fiat crocus, licet tenuiffimi fit pulveris, quod amplius a firitu falis non folvatur, fed quod extrahatur modo tinctura flava vel potius rubra, quum alias folutio ejus fit viridis. Nec quod crocus hic Martis ab oleo vietrioli alteretur, cum tamen ipfum ferrum cum fpuma \& effervefcentia folvatur. De quibus clariff. Dominus Stahlius.

Spiritus falis in eo habet præ fpiritu vietrioli \& nitri, quod non tam prompte \& celeriter folvat limaturam Martis, dicente Hoffimanno, hæmatiten vero \& crocum Martis etiam fubtiliffimum intactum relinquat; cum tamen fal commune, vel adhuc melius fal ammoniacum longe promptius \& potentius in mineras Martiales item hæmatiten \& limaturam Martis agat, eaque folvendo in victriolum fortiter adftringens fatifcat, modo invicem mixta in crucibulo per tempus detineantur in igne, quod neque cum victriolo neque cum nitro contingat.

Ad fpiritum nitri, narrante celeberrimo Domino van Muffchenbroek, adjecta fuit limaturæ ferri drachma, quæ dedit ingentem effervefcentiam fpumantem, cun fumis copiofis, flavis, fretentibus, calorem vero a gradu 46 ad 1 45, abiit maffa in fpeciem nigrefcentis pultis. Ad æqualem copiam limaturæ ferri affufus eft in vacuo fpiritus nitri, qui valde quoque ebulliret excitatis fumis denfis flavis; calor increvit a gradu 46 ad I 20 ; mifture color fuit ut fupra rubiginofus, fpiffus, fpumofus. Fumi volatiles interim erant elaftici, ideo enim Mercurius in indice defcendit $4 \frac{1}{2}$ pollices: cum hoc fpiritu nitri fatis tuto experimentum fit, verum cum fpiritu nitri more Geoffroyano aut Glauberiano fit tam fubito vehemens calor, ut disfiliat illico thermofcopium, nec ejus ope calor menfurari posfit. Ad fpiritum 
nitri etiam adjecit drachmam lapidis hæmatitis, qui non dedit effervéfcentian confpicuam, nullam fuppeditavit tincturam : nequaquam lapidis color fuit mutatus, calor aliquis auctus ex gradu $46 \frac{\mathrm{r}}{2}$ ad $47_{\frac{\mathrm{T}}{2}}$, nec conjectare potuit, aliquid fuiffe folutum. In vacuo tantundem permifcuit lapidis hrematitis cum fpiritu nitri, ubi notabiliter ebulliit lapis, fed absque fpuma, diu tamen: dedit quafi tincturam rubram \& calorem ex $46 \frac{x}{2}$ ad $47 \frac{1}{2}$ : color lapidis reliqui erat jam rubicundior; index mercurialis itetit immotus. Tres drachmæ fpiritus falis marini affufex funt ad limaturæx ferri drachmam, unde exigua, confpicua tamen effervefcentia calida; quæ folutio fiebat turbida, lurida, fucceffu tamen temporis fubfedit metallum relicto fpiritu fatis limpido; increvit calor a gradu 47 ad 57 . Repetiit hoc experimentum in vacuo cum æqualibus eorundem corporum quantitatibus, dedit tum ferrum magnam \& fpumefcentem effervefcentiam, diu durantem, \& multo plus metalli folventem, quam fupra; quippe eratfolutio opaca, nigra, interim multum augebatur calor, nam increvit a gradu 47 ad 70; index mercurialis, durante hoc ebullitionis motu, ftetit immutatus. Ad aque forcis unciam adjecit duas drachmas limaturæ ferri, hinc extemplo vehementiffima producta fuit effervefcentia, fumos eruetans denfos, rubros, calidos, nequaquam tamen adeo copiofos quam ftannum; mixture calor increvit a gradu 44 ad I 88 ; maffa nigrefcebat, admodum fpifla, \& ita perftitit per menfem, fubfidente tamen parte craffiore metallica: calidiorem effervefcentiam huc ufque cum aqua forti non obfervavit. Huge. nius æqualem aqua fortis copian duobus vafculis infudit, unum aeriexpofuit, alteruin vacuo inclufit, fimul immifit parem ferri copiam, ut videret, quænam citius corroderetur, hic contrarium quid eveniffe, quam in cupro notavit; nam citius corrofum fuit ferrum in vacuo quam in aere aperto. Ad marcafitx aurex drachmam affudit aquæ fortis unciam, hinc ingens quoque effervefcentia fubitanea cum aliqua fpuma \& fumo denfo fiavo, copiolo, calor autem ortus a gradu 44 ad 99 , fere omne metallum poft menfem folutum fuit. Mutationes cum oleis, fpiritibus acidis cum magnete vide Principiorum noftrorum Claffe 2 da.

Mifceatur I pars limaturæ Martis, $\frac{\mathrm{r}}{2}$ olei victrioli, ro aquæ, oleum victrioli lento prius igne calefiat, dein limatura dicta immittatur, exinde oritur ingens ebullitio, \& diu odorem fulphuris fpirat; fapit etiam dulce victriolum, fi evaporatio fiat ad pelliculam, fiunt chryftalli virides pellucid $x$, qux cito diffolvuntur in aqua $\&$ fimul ad ignem facile liquefcunt, \& vocatur chryftallus, faccharum, victriolum \& fal ferri. Hoc fal Martis in leni igne perdit virorem, pelluciditatem, \& flavefcit fuperne; fique majori igne urgetur, albefcit \& calcinatur; fique adhuc majori, rubefcit \& vocatur colchotar victrioli; fi adhuc majori igne, vocatur crocus adftringens Martis. Si crocus ruber exponitur aeri, liquefcit in oleum aureum. Solvitur etiam in aceto, vino Rhenano, \& aqua calida, fed ut per i 2 horas ebulliat.

Si in ramenta ferri vel chalybis 2 drachmarum. infundatur guttatim aqua fortis, eousque dum non amplius ebulliat, \& dum folutum fit ferrum; interea obfervandum eft, quod vitrum admodum incalefcat, adeo ut fpumelcat, 
mefcat, \& odorem fpargat, \& ferrum magis \& magis friabile evadat. Digeratur hæc folutio per diem \& noctem, \& dein in vitro evaporatorio ad ficcum abitrahatur, coit tunc in pulverem rubrum, qui reverberatus dat pulverem rubrum \& infipidum, eftque crocus Martis aperiens, five calx ferri aut chalybis. Collect. Leidenf.

Si limatura Martis in aqua forti folvatur \& folutio dein ad ficcum evaporetur, \& materia in retortam miffa igne primum leni expellatur phlegma, dein intenfiori, afcendit fipiritus qui æque urens ac fortis eft acoleum victrioli; hinc propter affinitatem tradere mox lubet vim corrofibam victrioli $\boldsymbol{E}^{3}$ olei ejus precipue Martis in diverfas corpora. Acidiffimum liquidum idque fumme corrofivum fola mixtione cum terra nempe phlogifta infipida, in infipidum converti poteft. Fried. Hoffmann.

\section{Varice effervefcentice colorumque $8^{\circ}$ alice muta- tiones pracipitationesque per ferrum, victrio- lum Martis, ejus oleum S $^{3}$ piritum oriunda.}

Leum victrioli fi abftrahatur a corporibus fulphureis, five ex vegetabilium five ex animantium claffe fuerint, verbi gratia, $a b$ opio, $a b$ auripigmento, ab antimonio, ignisque adminiculo deftillatio adornetur, fixum illud vehementifimum acidum, fumme volatilis indolis in fpiritum evaporabilem, omnis fere aciditatis expertem, refolvitur, tantum exiguo relicto in capite mortuo acidi veftigio. Spiritus nofter, qui infufus oleis deftillatis flammam profert, fumme corrofivus eft, adeo ut brevi temporis intervallo metalla folidifima corrofione fua adoriatur, ea diffolvendo: attamen totus exfirirat in auras, qui vix ac ne vix quidem firmis obturaculis compefci poteft. Fried. Hoffman.

Oleum victrioli leniter \& fuperficiali faltem contaetu cuti manus inunctum ingenti cum rofione \&igneo ardore adfert dolorem, quando vero majore portione \& paullo preffius applicatur, nullus fere dolor vel erofio percipitur. Idem.

Utut oleum victrioli certa enchircfi omnia poffit folvere metalla, tamen nullum promptius quam ferrum, deinde cuprum aggreditur, \& quia cuprum longe facilius folvit, quam ipfum argentum, hinc moneta quax ex cupro \& argento eft conflata, pure argentea reddi poteft, fi oleum vietrioli affundatur, quod admoto calore incalefcit $\&$ antea limpidum, obfcure nigrum \& inftar picis evadit, eminentis Venerei faporis, quando moneta aquia eluitur, argenteum fplendorem habet. Idem.

Oleum victrioli acidum precipitat omnia foluta, five fint metalla five lapides, animalis etiam pifciumque lapides, corallia \& margaritas, falis fpiritu vel nitri, eoque reducit in pulverem levifimum elegantiorem præcipitatis cum fale tartari: cumprimis corallia \& margaritæ redigentur in pulverem nitidiffimum, nec non mater margaritarum \& cochlearum teftx, Clatis III. de ferro. 
margaritis orientalibus fimillimum; pulvis prædicus adhuc pulchrior redditur, fi prxcipitetur cum fpiritu fulphuris acido, ita ut loco colmerici cutis nigræ ulurpari poffint. Glauberus.

Oleum victrioli exiguo calore vertit Mercurium in calcem candidam; affula vero aqua in flavam calcem: ignis \& agitatio juvat folutionem. Oleum victrioli cum fpiritu vini ana fimul digefta \& deftillata dant liquorem parum corrofivum, plane quafi fit una pars olei victrioli \& 10 partes aqux.

Olcum victrioli folvit fal gemmæ, cuprum, ferrum, antimonium, zincum, panem, camphoram, lapidem calaminarem, carnes, oftrearum conchas, cretam, cornu cervi. Crocus Martis ignis vi factus non folvitur ab oleo victrioli, nec alteratur, ipfum vero ferrum cum fpuma \& effervefcéntia folvitur.

Mercurius vivus per fe præcipitatus diu \& difficillime in oleo victrioli folvitur, nec nili intra plurimas horas.

Sal commune folvitur ab oleo victrioli cum ftridore; emiffis vaporibus \& bullis.

Caput mortuum poft deftillationem aque fortis vel victrioli loco menftrui eft in fufione metallorum, \& reddit metalla fluibilia.

Si aqua mixta oleo victrioli infunditur in cuprum vel in ferrum, extrahit novum quoddam victriolum corulcum \& viride. Hiarne.

Solutio Lunæ cum vietriolo Martis dat colorem opalinum fubflavum.

Sublimatum cum folutione Martis ex calce viva \& cineribus clavellatis parata dat colorem fubcroceum, inftar gummi guttæ.

Solutio Martis per alumen cum fale tartari dat canum faturatum.

Saccharum Saturni cum folutione Martis puniceum inftar granatarum.

Spiritus tartari cum folutione Martis dat oblcure rubeum diaphanum.

Nitrum fixum cum folutione Martis dat ex albo caftaneum, ubi umbra eft cum albo temperata.

Nitrum cineribus clavellatis \& calce viva fufum cum folutione Martis commixtum dat pullum feu fulcum fubnigrum.

Vietriolum Martis \& folutio Martis cum fpiritu falis ammoniaci \& fpiritu vini dat praffinum oblcuriorem.

Victriolum Martis \& folutio Martis cum fpiritu falis ammoniaci\& falis deftillati per minium dat praffinum fpadiceum.

Gallse cum Domini Sparmanni lapide Martiali dat praffinum nigricantem.

Urina cum victriolo Martis \& folutione Martis ; fcoriæ reguli antimonii cum victriolo Martis dant colorem piceum five atrum.

Scorix reguli antimonii cum folutione Martis per alumen, dant pullum obfcuriorem. Hæc Dominus Hiærne archiater Sveciæ.

Solutio ferri per fpiritum nitrinon dat admodum infuavem faporem, potius dulcem.

Solutio ferri dat chryftallo colorem hyacinthicum.

Ferrum aceto injectum \& intra hujus fubftantiam corrofione imbibitum, acorem ejus in faccharinam dulcedinem convertit; narrante celeber. 
Stahlio. Aqua fortis deftillata per retortam ferream fit coloris aurei altioris, fit etiam inde aqua fortis purior.

In unciis duabus aquæ communis ope olei fulphuris in aciditatem. verfis , 4 dierum patio fuerant 2 clavi ferrei, dein ex appofita galla atramentaria poft horam aliqua nigredo obfervata eft ; \& fpatio diei velutiatra mentum apparuit. Grilonius.

oleum victrioli : Quando oleum victrioli reetificatione limpidum \& acerrimum factum cum oleo deftillato lavendulæ milcetur, mixtura mox flammeum colorem acquirit, cum fumo fulphuris eructante; liquida vero manet, nec fpifam coniftentiam acquirit.

Idem fit cum oleo majoranx, firmixtio adornetur, hactantum cum differentia, ut hic dilutus magis fit color, confiftentia etiam fluidior.

Oleum menthx acquirit colorem obfcuriorem fubnigricantem, fumus vero magis penetrans fulphureus eft.

Oleum de cedro, de pergamotto, non valde effervefcit, mixturamanet diluta, flavi faturati coloris.

Oleum caryophyllorum purum fi mifceatur huic oleo in æquali quantitate, intenfus excitatur calor, fortiter fulphur mixtura olet, \& color fit faturate fanguineus, \& mox coagulatio fit in corpus refiniforme.

Cum oleo ligni fuffafras puro \& per aquam deftillato idem oleum mixtum mox etiam coagulatur in piceam nigricantem materiam, colore intenfo \& fotore comite,

Oleum juniperi verum flavefcit, \& f piffioris fit confiftentire, nec adeo fortis excitatur calor \& fumus, fed fi idem experimentum cum adulterino, cui plerumque templinum immixtum eft, inftituitur, intenfiffimus cum copiolo vapore excitatur calor fub confiftentia facta fiffiori. Si vero fimiliter oleum juniperi ex ligno paratum tractetur, mox facta agitatione vitri mutatur color in nigricantem, \& ebullitio ingenti calore ftipata oritur, quæ ad orificium ufque vafis afcendit.

Oleum therebinthinx a mixtione hujus olei \& facta commotione maximam cum bullulis \& acerrimo calore ebullitionem efficit, copiolo vapore fulphureo in auras fublato.

Baliamum de Cupaiva facit cum hoc oleo magnam ebullitionem præcedente agitatione vitri calidam, cum colore obfcure rubicundo, fubnigricante \& fumo fœtido.

Cum balfamo Peruviano emergit mixtura rubicundiflimi \& coccinei coloris, fine ullo calore, confiftentia eft inftar fyrupi.

Victrioli oleum concentratum ipfam etiam camphoram, qux eft oleum quafi deftillatum in forma ficca, aggreditur, eamque folvit in liquorem craffum ex flavo rubicundum.

Olea expreffa raparum, olivarum, amygdalarum dulcium ad mixturam hujus olei rubefcunt quidem, fed fine calore \& ebullitione. Hątenus Fried. Hoffmannus.

A floribus leviter faltem tinctis, verbi gratia, cyani, lavendulæ, viola rum, bellidis, rofarum, tuncx, affundendo ipfi aquam fpiritu victrioli imbutam, elegantifimam rubicundam produci tincturam. Patet etiam hinc ratio, 
ratio, cur omnes fpiritus deftillati acidi \& oleofi, procedente tempore vel etiam fub digeftione valde rubicundi fiant, cum limpidi prius eflent, ut id fieri folet cum fpiritu tartari, mannæ, facchari, mellis, lignorum.

Oleum victrioli vel etiam oleum falis five fpiritus falis valde concentratus affufa aqua frigidifima in debita proportione cum intenfifmo calorefortem producere effervefcentiam; quin etiam frigidiffma glacies oleo victrioli injecta igneum quafi motum producit : obfervandum tamen eft, fi nimia quantitas aquæ oleo victrioli adjiciatur, quod valde imminuatur calor, quum is vehementer intendatur, tantoque fiat validior, quandonon adeo magna portio aqux admifcetur : nam fi ad unciam femis olei tantum drachma aqux affunditur, non tantus calor nec tanta ebullitio \& f pumefcentia fit, quam in dux drachmæ adminæ fuerint, neque tantus gradus altus provenit, ac fi dimidium uncie fuerit adjectum, imo major adhuc, fi ad oleum concentratum uncia integra affunditur. Si vero major quantitas fiat, ita ut anciam dimidiam olei vierrioli uncix dux vel 4 aqux adjiciantur, valde languida fit effervefcentia. Idem auctor.

Si fpiritus vini rectificatifimus cum oleo victrioli mifceatur, xhus producitur, licet fine fingulari cbullitione \& cum mutatione coloris, dum mixtura rofeum colorem inducit, neque tanta wfus vehementia oblervatur. ac in aqua fuerit adjecta. Oleum vero deftillatum cum oleo victrioli \& fpiritu nitri fumanti fortiter ebullit non fine magno xftu \& coloris mutatione. Eundem in modum effervefcentia fit calidiffma cum fpiritu-nitri acido \& cum fpiritu vini rectificatifimo, item cum oleis deftillatis. Idem.

Si oleum vietrioli fali ammoniaco vel communi admifcetur, ita mox albus penetrantiflimus fumus exiftit, quum ex mixtura hujus olei \& nitri ficcati denfús, ex flavo rubefcens vapor exfurgat, fortiter nares feriens. Ubi notandum, quod victrioli oleum arcano duplicato vel tartaro victriolato aut nitro antimoniato, quæ etiam mediæ naturæ falia funt, admixtum, neutiquam id perficiat, fed falva \& integra mixtura maneat. Idem.

Spiritus falis fumofus valde concentratus, qui ex fale ammoniaco \& oleo victrioli conficitur, cum victrioli oleo vehementem ebullicionem cum frepitu \& afcenfrone fumorum albicantium excitet, quum, quod mirum videtur, nullum aliud acidum prater hoc, \& ne quidem fpiritus nitri fumans, eundem effectum exhibeat. Idem.

Si oleum victrioli cum fale tartari foluto mifcetur ad punctum faturationis, tunc prodit fpiritus, per retortam leni igne deftillandus, infipidus quidem, nihilominus indolis fubtilifimx, quia longe citius leni calore avolat in auras, quam aqua communis, qui Nicdnero fpiritus mundi appellatur, quo auctor multum argenti lucratus fit. Idem.

Oleum victrioli limaturæ Martis puræ \& a rubigine liberatæ in phiala affufum, adjecta conveniente aqux quantitate, ingentem æefum atque effervefcentiam excitat, ita ut vapor valde fulphureus exhalet, qui, poftquam orificium pollice.prius fuit obturatum \& deinde reclufum, candelx flamma admotus, cum magno Atrepitu accenditur, \& quafi fulgur emittit, quin imo in ipfo tubuli orificio ardet. Iden. 
Si oleo victrioli adjicitur fal commune, ita ut æquali pondere invicem in cucurbita mifceantur, verbi gratia, ad libre dimidium, tunc protinus fumus exfurgit, ceu vapor copiofus, albus, fubtilis, penetrantis acidæ indolis, alembico applicato, fi igni committitur arenæ, prodit fpiritus \& fuperafcendit alembicum (quod rarius vifitur in acidis mineralibus fpiritibus) acidifimi faporis, valde concentratus atque volatilis, nam fubtilem vaporem calore admoto emittit. Atque hic eft genuinus fipiritus falis, qui levi labore deftillatur ex arena, aliis acidis mineralibus merito preferendus. Idem.

Quandoque oleum victrioli nitro optimo, quale eft Rufficum vel Indicum, prius exficcato, in retorta vel etiam cucurbita affiunditur, tum fumus ftatim affurgit ruber copiofus : in arena fi adornatur deftillatio, fpiritus prodit, qui \& alembicun \& vas recipiens faturato flammeo colore obducit, concentratiffimus, acidifimus, qui nihil nili aqua fortis eft faturatiffma lenifimoque igne elicitur: \& quoniam nullum phlegma conjunctum habet, fortiterque concentratus eft, hinc admiffo aere libero fumat: in fundo vafis relinquitur fal coagulatum durifimum, inftar glaciei diaphanum fed acidiffrmum. Spiritus hic recte preparatus non modo cun omnibus oleis deftillatis, \& fpiritu vini rectificatiffimo vehementem fufcitat effervefcentiam, copiofo rubicundo vapore ftipatam, fed \& ipfa olea deftillata graviora aromatica, quæ fundum in aqua petunt, luculenta flamma accendit, inque cineres ficcos ea convertit, qua de re fupra fufius actum eft. Idem.

Oleum victrioli auripigmento in pulverem contrito affufum, ex retorta vitrea quando deftillatur in arena, liquor prodit glaciatus craffus, inftar butyri antimonii, fed penetrantifimi odoris fulphurei : brevi tamen tempore vapor hic penetrantifinus in auras avolat, \& relinquitur acidum ftagma, inftar fpiritus victrioli, omnis faporis expers, cui lamellæ fulphurex innatant; in collo vero retortæ confpiciuntur flores, qui odore perfectum fulphur vulgare redolent, \& hi fatis quidem copiofi, adeo ut ex unciis 4 auripigmenti \& olei victrioli unciis tribus, ad minimum uncia una florum poffit obtineri. Hi flores funt infipidi \& fudoriferi, vapor, quem emittunt, fulphureus, albus eft: caput mortuum ex atro brunum relinquitur, omni fapore privatum, flammæ vero admotum quodammodo ardet. Idem.

Oleum victrioli opio crudo in fruftula difcifo fuperfufum, fi mixtura retortie vitrex committitur atque deftillatio per ignem adornatur, ita ut ambo mininum 6 uncias expleant, præbet liquorem fotidifimun, faporis acidi ingrati, pellucidum circiter ad uncias duas ; remanet in retorta caput mortuum nigri coloris, levis \& fpongiolie materiæ, fere infipidum, quod flammx admotum odorem fulphuris vulgaris exfpirat.

Si oleum vietrioli dulcis (cujus preparationem videas in tractatione de victriolo) aromaticum per aliquot menfes in vitro detinetur, vefica fuilla óperto, eam fucceffive arrodit exeditque, \& quod in phiola manet, rubedinem induit faporemque acidum contrahit. 2. Si admifceatur argento vivo in phiola, accedente coctione, illud aggreditur. 3. Hoc oleum 
aromaticum recens exquifite folvitur in fpiritu vini rectificatifimo, ipfque faporem, odorem \& virtutem confert anodynam ac fedativam. 4. Hic fpiritus oleo victrioli dulci imprægnatus, fi pauca quantitate mifcetur folutioni auri, flavam efficit tincturam, quæ ferro infillata illud aureo colore inficit. 5. Quando folutio hæc auri per 12 horas ftat, pulvis niger in fundum demittitur, indicio, fulphur victriolicoire cum pulvere falis \& ambo pracipitari ad fundum.

Si lixivio falis oleum victrioli affunditur, mox vehemens cum exhalatione fpiritus falis fubtilifimi effervefcentia concitatur, \& liquor, non fecus ac id evenit cum lixivio nitri, in album coagulum convertitur, cui if fufficiens aque communis quantitas affunditur, pulvis candidus copiofus in fundo fubfidet. Hactenus Dominus Fried. Hoffinan.

Sequentia cum victrioli oleo a le inftituta experimenta adducit clariff. Dominus van Muffchenbroek. Mixturas, ait, captas effe menfe Junio, barofcopio elevato ad $29 \frac{\mathrm{T}}{\mathrm{T}} \mathrm{p}$ pollices, flante euro, calo fereno, tempeftate ficca.

Permifcuit in vafe aperto 3 olei victrioli drachmas cum aquæ pluviæe pari copia, in mixtura nullus motus, nullave effervefcentia obfervabatur, increvit tamen calor a gradu 48 ad 92.

Ad aqua cochlearix 3 drachmas affudit tantundem olei victrioli, quo facto non quidem oblervabatur effervefcentia aut motus, fed calor \& intenfior, quam in priori experimento, quo afcendit thermofcopium a gradu 48 ad 98 , limpida peritante mixtura.

Tum ad aqux fambuci drachmas tres affudit tantundem olei victrioli, nulla excitata fuit effervelcentia, fed calor auctus a 48 ad 70.

Poftquam mixturæ binæ prædictx refrigeratx effent fequenti die ufque ad gradum 43, ambas inter fe promifcuit : ipfo tempore mixtionis aliquem motum dederunt, non tamen fpumantem effervelcentiam, \&denuo increvit calor ufque ad gradum 60.

Olei victrioli drachmæ 3 mifte fuerunt cum puri vini Rhenanidrachma fesqui in vale aperto, inde quidem nulla excitata fuit effervefcentia; attamen increvit calor a gradu 59 ad $80 \frac{\pi}{2}$.

Tum olei victrioli drachmæ 3 iterum mifcebantur cum ejus viniRhenani 3 drachmis, mixtura non dedic vifibilem motum, fed calorem a 59 gradu ad $99 \frac{x}{2}$, colore mutato in obfcuriorem.

Tum olei victrioli drachmæ 3 iterum permiftx fuerunt cum ejusdem vini Rhenani 6 drachmis, mixtura non edidit confpicuum motum, fed calorem a gradu 59 ad 97 . Tandem olei victrioli drachmæ 3 affufæ funt ad drachmas 9 ejusdem vini Rhenani; calor inde increvit a gradu 59 ad $95 \frac{\pi}{2}$.

Ad 3 drachmas olei victrioli affudit 3 drachmas fpiritus vini rectifcati, nulla quidem orta fuit effervefcentia, fed fubitaneus calor a gradu 50 ad 90.

Ad 3 drachmas olei victrioli adjecit drachmam tartariRhenani in pulverem contufi; nulla oborta fuit effervefcentia, fed calor, qui lente producebatur, increvitque tantum I 2 gradibus. 
Sumfit olei vietrioli 3 drachmas, quibus affudit aceti vini Gallici tantundem, inde quidem confpicua non excitabatur effervefcentia, fed calor notabilis a gradu 58 ad $95 \frac{3}{4^{\circ}}$. Ad fpiritus aceti fortilfimi drachmas 3 affufa fuit olei victrioli drachma una, calor inde increvit a gradu 58 ad 72 .

Ad olei victrioli 3 drachmas adjecit oculorum cancrorum drachmam, illico fufcitata fuit magna \& fpumefcens effervefcentia, quam calor comitabatur, a gradu 54 ad 98 . Repetitum fuit hoc idem experimentum in vacuo, excitataque fuit ingens effervefcentia, atque adeo fpumans, ut gradum caloris diftinguere non potuerit, imprimis cum diu perftaret tenax fpuma.

Ad olei victrioli 3 drachmas adjecit marmoris albi contriti drachmam, excitata fuit effervefcentia, corrofumque marmor, increvit calor a gradu 54 ad 68.

- Ad lapidis corulei Namurcenfis triti drachmam addidit 3 olei victrioli drachmas, orta fuit notabilis effervefcentia ; increfcente. calore a gradu 54 ad 66.

Lapidis Bremenfis rufi I drachma cum olei victrioli 3 drachmis, nullum motum aut effervefcentiam dabat; vix calorem.

Ad cretæ albie drachmam affulie olei victrioli 3 drachmæ excitavere magnam effervefcentiam, \& calorem a gradu 54 ad 86 . Ad cret: rubræ drachmam miftx 3 olei victrioli dederunt nullum motum, nullumque calorem.

Ad 3 olei victrioli drachmas adjecta una carbonis folfilis Britannici, nullam effervefcentiam præbuit confpicuam, fed exiguum calorem a gradu 54 ad $57 \frac{\mathrm{r}}{2}$.

Ad 3 olei victrioli drachmas afperfa coralliorum rubrorum drachma fufcitavit vehementem effervefcentian, \& calorem a 54 ad 78 .

Ad tres olei victrioli drachmas adjecta lapidis calaminaris drachma edidit aliquem motum, fed vix vifibilem effervefcentiam, calorem tamen a gradu 60 ad 79 .

Olei victrioli 3 drachmis injecta fuit limaturæ ferri drachma, qux vix fenfibilem motum aut effervelcentiam produxit, \& exiguum calorem, a gradu 64 ad 7 I, vix etiam aliquid ferri videbatut folvi: craffius enim hoc oleum pene agere nequit in metalla; quamobrem diluebat aliud victrioli oleum in tripla quantitate aqux, elabi fivit diem, ut bene frigefceret, nam ab aqua affula fervet diu: tum 3 drachmis hujus diluti olei victrioli injecit drachmam limaturæ ferri; qux illico effervefcere fpumareque copic, increvit perpetuo effervefcentia, donec poft horam maxima evaferit, caloremque fufcitaverit a gradu 64 ad 80 , fpirans odorem fortem fulphureum, folvensque metallum, perduravit vero ultra 6 horas. Tandem diluebat aliud oleum victrioli in fexies majore aqux quantitate, refrigeratæque per diem mixturs injecta fuit ferri limatura, copia eadem ac in prioribus periculis, tum lentifime afcendebat thermofcopium a gradu 64 ad 72 , fed effervefcentia oborta fuit, affurgentibus fumis albis, qui admota candelæ flamma incendebantur, atque fulminationem cum frepitu producebant; licuti quoque memorix proditum eft in du Hamel, hift. reg. acad. fcient. lib. 6. c. 2. tum in l'hift. de l' academie royale an. 1700 . 


\section{O B S E R A T I O N E VAR I E}

Ad olei victrioli drachmas 3 adjecta fuit cupri limatura drachma, nulla hro dedit effervefcentiam, nullamque folutionem, manente fplendore limaturæ per' 24 , horas plane eodem ac ante; dubitat an quis calor ortus fuerit, fi aliquis, non excedit gradum.

Ad 3 olei victrioli drachmas adjecta fuit marcafit: aurex drachma; hæc nullam præbuit effervefcentiam, imo ne quidem folvi vifa fuit elapfo triduo, calor tamen aliquis oriebatur a gradu 59 ad $6 \dot{\mathrm{I}}$. Hoc non contentus periculo affudit ad marcafitam oleum victrioli in tripla copia aque dilutum, tum aliqua excitata fuit effervefcentia, cum exiguo motu, parvaque folutione metalli, vix tamen increvit calor, afcendente tantum thermolcopio a gradu 59 ad $60 \frac{\mathrm{r}}{2}$.

Ad olei victrioli 3 drachmas adjecit nitri pulverifati drachmam, extemplo aliqui fumi affurrexerunt corroivi, flavelcentes, atque thermofcopium 3 gradibus afcendebat ob auctum calorem. Deinde fumfit oleun victrioli, quod præcedenti die in tripla aquæ copia dilutum fuerat, ejusque tribus drachmis injecit nitri drachmas 2 , non obfervavit tum fumos, fed frigus, quippe defcendebat thermofcopium gradibus o. Poftquan ambæ hx miftur: ad eundem calorem elaplis aliquot horis pervenerant, nempe ad 60 gradus, eas fecum permifcuit, calorem vero excitaverunt ufque ad gradum 75 , nam fortiori victrioli oleo fic quafi aqua affundebatur, qux in diluta miftura fuerat, atque ita generari debebat calor.

Ad 3 drachmas olei victrioli adjectx fuermat 2 drachmæ falis ammoniaci, illico oborta fuit ingens effervefcentia, valde fpumefcens, eructans fumos copiofiflimos, qui totum locum impleverunt acerrimeque nares feriebant, adeo calidi autem erant, ut thermolcopium fupra eos pofitum ad Io gradus afcenderit; cum interim thermofcopium alterum mifturæ impofitum, defcendebat propter frigus a 60 gradibus ad 48 , peracta efrervefcentia erat maxima halis copia foluta. Si autem, quo tempore fal cum oleo effervefcit, thermometrumque defcendit, affundatur aliquantum aqux, illico oritur calor, \& thermometri liquor rarefcens afcendit. Dein unum thermofcopium fuppendit fupra mifturam ad eam alcitudinem, ut fpuma effervefcentis mixturæ illud non attingere pofiet, fed ab ipfo 4 vel 5 lineis pollicis abeffet: aliud thermofcopium pofuit in valculo capiente falis ammoniaci drachmam : in phiola mobili mifit 3 olei victrioli drachmas : tunc omni hoc apparatu tecto recipiente, eduxit follicite aerem, \& per horam fic cuncta reliquit, ut ad calorem xquabilifimum reducerentur : deinde in vacuo affudit oleum victroli ad falem ammoniacum, illico ingens effervefcentia fufcitata eft cum copiofis afcendentibus fumis totum vas implentibus, ita ut vix gradus in thermolcopio cognolci potuerint, elapfo tamen femiminuto magna pars vaporis fe parietibus virri applicuerat, pars decidebat ad fundum, pars implebat recipiens, quod tamen fatis tum pellucebat : defcenderat liquor thermofcopii in ipfa effervefcente miftura pofiti, a gradu 67 ad 46 , manente liquore in thermolcopio fupramiPuram pendente immoto in gradu 67 , ad quem ante experimentum hæferat: perfabat ad gradum 46 liquor in thermolcopio mifture fpatio I minuti, tumque incepit alcendere, pofquam pervenerat ad gradum 58 , 
afcenderat liquor in altero fufpenfo thermofcopio ad gradum 69 , immifo autem thermofcopio fuperante gradum 60 , afcenderat liquor fufpenfi ther:mof copii ad gradum $69 \frac{3}{4}$. Sed elapfis 2 minutis, \& liquore immilfi thermofcopii fuperante gradum 68, pervenerat liquor fufpenfi thermofcopii ad gradum 70; elaplo iterum minuto afcenderat in utroque thermofcopio liquor ad grad. 70 , poft 5 minuta afcendit liquor immiffi thermofcopii ad grad. 72 , manente eo fufpenfi thermofc. in gradu 70 ; imo poft horæ quadrantem, \& ceffante jam effervefcentia afcenderat liquor thermofcopii ad grad. 74, manente fufpenfo ad gradum 70 : folet durare effervefcentia ad minimum fpatio 20 minutorum. Repetiit hoc experimentum bis, ut ipfi tutius confideret, eundemque fucceflum habuit. Vapor afcendens proinde in vacuo calorem fecum tulit 3 graduum, miftura refrigerata 2 I gradibus.

Ad olei victrioli 3 drachmas adjecta fuit falis gemmæ drachma, a qua nulla effervefcentia, qux conipici poterat, fufcitata fuit; calor tamen, dum. vel tantillum falis pedetentim folvebatur, increvit 3 gradibus, a 60 ad 63 .

Ad olei victrioli 3 drachmas adjecit facchari vulgaris fufci drachmam, nulla vifibilis effervelcentia inde oriebatur, fed parum facchari folvebatur, atque interim increvit calor $3 \frac{1}{2}$ gradibus. In vacuo dedit faccharum aliquam effervelcentiam, \& calorem 4 graduum.

Ad olei vietrioli 3 drachmas affudit falis ammoniaci tantundem, hinc infignis \& 1 pumans effervefcentia fulcitabatur, illico tamen fedata, calor vero increvit a gradu 42 ad 92, mixtura manente limpida, \& abfque colore; hoc factum eft tempore hyemali.

Ambas precedentes mixturas ex faccharo \& fpiritu falis ammoniaci, calentes ad gradum 42, permifcuit, hæ denuo fpeciem effervefcentiæ præbuerunt, excitatis multis dereis bullis, \& caloris incrementum ufque ad gradum 52. Saccharo interea coeunte \& natante in medio liquore, deftituto fuo folvente menftruo.

Cum ad 3 drachmas olei victrioli affunderet drachmam falis volatilis urinæ, ingens, fpumefcens fumanique excitata fuit effervefcentia frigida, qua thermolcopium defcendit ex gradu 60 ad 44 , omnibus manentibus limpidis.

Olei victrioli 3 drachmas permifcuit cum olei deftillati foniculi drachma, illico perfeeta horum fluidorum fiebat mixtura, nullus tamen indé motus effervefcens, fed calor increvit a gradu 62 ad 70 . Mixturæ adjecit oculos cancrorum, mox affurgebat magna effervefcentia, calorem intendens ufque ad 86; picis tamen fimillima evafit maffa, atque probe unita; fed maffa hæc igni alendo erat inepta, exftinxitque prunas ad medium ufque huic materix impofitas.

Olei anifi ftillatitii drachma mifta fuit cum 3 drachmis olei victrioli, omne oleum perfecte mixtum non fuit, fed pars quædam, qux in maffam nigram abiit, hæc in igne accendi potuit, \& arfit aliquo ufque : miftura autem non efferbuit, fed produxit aliquem calorem, nempe a gradu 62 ad 69.

Clafis III. de ferro.

Uu uu 


\section{OB S E R V T I O N S V A R I}

Ad olei victrioli 3 drachmas affudit drachmam olei deftilati roris narini, dubitat an in principio mixtionis aliquod frigus adfuerit, poftea generatus fuit calor a gradu 62 ad 70 , nulla tamen effervefcentia confpicua fuit, fed maxima pars olei roris marini intime fuit mixta cum oleo victrioli.

Tandem ad olei victrioli 3 drachmas affudit olei de lateribus fcrupulum; abiit maffa in piceam, homogeneam fubftantiam, fed abfque effervefcentia, calor tamen productus fuit $\mathrm{s} \circ$ graduum. Hactenus clariff. van Muffchenbroek.

Si fpiritus victrioli per aliquantum temporis fuper ferrum ftet, oritur inde victiolum quoddam fixum, pariter ac fi fpiritus nitri affundatur ad fal tartari, oritur inde fpecies quædam nitri. Lemmery.

Si oleum victrioli forte fit, \& affundatur ad aliud victrioli oleum vel in fpiritum acidum victrioli vel in aquam, vel in oleum terebinthinæ, tantus inde calor exiftit, ut phiala fape rumpi valeat. Idem.

Si aliqux guttæ fpiritus victriolivel oleum ejus in modicum aquæ calidæ inftillentur, in qua rol $x$ rubræ emollitæ funt, intra breve tempus rubefcit aqua inftar vini rubri. Idem.

Si phiala vitrea repleatur decocto ligni nephritico purificato, \& verfus lumen tranficiciatur, flavum apparet; fi vero tergum verfus lumen vertas, cœrulum eft : fi aliqux guttæ olei victrioli inftillentur, ab omni parte flavum apparet: fi etiam tantilla pars olei tartari affundatur, ad priftinum colorem redit. Si in tincturam quandam violaceam vel coruleam aqua factam inftilles guttas fpiritus vietrioli, ftatim rubefcit ; fi vero immittas aliquid falis alcalini, priftinum colorem recuperat. Si in tincturam coruleam inftilles liquorem alcalinum, ut fpiritum volatilem falis armoniaci, vel oleum tartari, momento viridefcit; at fi adjicias parum fpiritus victrioli, fufce ftatim rubefcit. Si fpiritus victrioli in decoctum ligni Indici infundatur, flavefcit ; fi adjicias aliquid ex fpiritu falis armoniaci, illico nigrefcit. Si lignum Indicum per 3 vel 4 horas cum fucco citri digeratur, color plane non alteratur : fi adjicias aliquas guttas olei tartari per deliquium, accipit ftatin colorem brunum ; fi vero dein adjicias fpiritum victrioli, ad priftinum colorem redit. Si gutt: olei tartari in vinum rubrum infundantur, viridefcit vinum, fi vero adjicias aliquid fpiritus victrioli, recuperat colorem priftinum. Idem.

Victriolum Veneris indicat quidem omnia alcalia, imprimis vero volatilia; alcalia enim fixa victrioli Veneris folutioni adfufa mox illa præcipitant fub forma fedimenti coerulei viridis ac craffi; volatilia vero illud ad fundum dejiciunt fub fpecic fubfidentix fapphirinæ tenuioris; adeo ut nihil æque falia prodat volatilia ac hocce victriolum Veneris. Victriolum Martis pari modo alcalia indigitat, fed non ita manifefte: hoc fingulare obtinet victriolum Martis, quod quicquid vim polfidet adfrictoriam, mox manifefte oftendat, folutione filicet ejus inde vel nigrefcente, vel ad fubnigrum aut obfcure violaceum vergente colorem. Solutiones Veneris $\mathcal{E}^{2}$ Martis per aquam fortem \& dilutx per aquam pluviam deftillatam, eundem præftant effectum ac ipfa victriola, hoc faltcm cum difcrimine, quod. 
nifi fal volatile adfit copiofius, non fingularem patiantur immutationem, fed tantum exiguum \& vix fenfibilem fubeant inteftinum motum, de cetero quoad colorem ac confiftentiam prorfus intactæ. . Hiærne.

Saccharum Saturni cum uncia aquæ deftillatæ, cui guttula Spiritus victrioli indita fuerit, dat colorem diaphanum fubturbidum inftar aqux tantillum lutulentæ. Idem.

Mercurius fublimatus cum liquore ex victriolo \& calce viva parato dat colorem opalinum. Idem.

Spiritus victrioli cum fpiritu vini fimplici dat colorem opalinum faturatiorem. Idem.

Solutio lunæ cum victriolo Martis dat opalinum fubflavum. Idem:

Victriolum cypricum cum lixivio ex oftreis calcinatis parato, dat opalinum ad colorem thalaffinum feu seruginofum vergentem. Idem.

Sal rutæ cum fpiritu vietrioli dat colorem flavum dilutum \& diaphanum. Idem.

Scorix reguli antimonii additx uncix aqux, cui 5 guttulæ fpiritus victrioli adfufie fuerint, dant colorem croceum. Idem.

Sal falicis cum firitu falis aut fpiritu victrioli dat colorem flavum fubrubeum. Idem. Idem.

Sal card. bened. cum fpiritu victrioli dat colorem obfcure flavum.

Sal pulmonariæ hortenfis cum fpiritu victrioli dat colorem fubfufce flavum. Idem.

Solutio fulphuris cum calce viva fi addatur fpiritui victrioli in oleo anifr digefto dat colorem grifeum fubalbum inftar favillx. Idem lixivium oftrearu m calcinatarum cum victriolo Martis. Idem.

Victriolum Martis cum fpiritu falis ammoniaci dat colorem fubviridem inftar corticis fraxini feu populi. Idem.

Spiritus victrioli oleo anifi digeftus cum cineribus clavellatis dat colorem puniceum inftar florum granatorum. Idem.

Sal fcabiofx, fal falviæ, fal abrotani, cum fpiritu victrioli, dat colorem fufcum dilutum. Idem.

Solutio boli Armenæ cum fpiritu viatrioli, ubi fali tartari admifcetur, dat candide fufcum. Idem.

Victriolum Veneris cnm rore majali deftillato dat viridem fubflavum. Idem.

Salia fixa cum victriolo Veneris dant colorem thalafinum feu Venetum. Idem.

Sal cardui benedicti cum victriolo Veneris dat colorem thalaffinum clariorem. Idem.

Spiritus victrioli cum oleo anifi digeftus cum folutione lunæ, dat viridem fubbuxeum. Idem.

Spiritus victrioli cum fale faniculx; item fal anethi, victriolum Martis \& folutio Martis cum fpiritu falis ammoniaci \& fpiritu vini : victriolum Veneris cum faccharo Saturni, dant colorem praffinum obfcuriorem. Idem. 
Victriolum Martis \& folutio Martis cum fpiritu falis ammoniaci \& falis deftillati per minium dat praffinum fpadiceum. Idern. Idem.

Sal anethi cum victriolo Veneris dat colorem viridem ingratum.

Sal ammoniacum \& tartarus deftillata per minium cum vietriolo $\mathrm{Ve}$ : neris dant cyaneum dilutum. Idem.

Sal tartari cum victriolo Veneris dat cyaneum clarum. Idem.

Omnia falia pure volatilia cum vietriolo Veneris dant colorem Indicum feu cyaneum ad purpureum inclinantem. Idem.

Victriolum Veneris cum nitro fixo dat colorem Venetum fubcœruleum. Idem.

Sal fumarix cum victriolo Veneris dat cœruleum fubviridem. Idem.

Urina cum victriolo \& folutione Martis dat colorem piceum five atrum. Idem. Idem.

Scoriæ reguli antimonii cum viEtriolo Martis dant colorem atrum.

Spiritus euphorbii cum victriolo Martis dat colorem nigrum tantillum ad viriditatem vergentem. Idem.

Victriolum Martis cum folutione metallorum facta cum aqua forti \& urinofis dilutis, ut exempli gratia, aqua deftillata argillæ teffulatæ dat primo obfcurum tum clarum. Idem.

Spiritus vietrioli cum folutione fulphuris per fal tartari dat colorem incarnatum tum ex rubeo fubfufcum. Idem.

Solutio fulphuris cum calce viva, adfufa victriolo Martis, dat colorem primo nigrum tum fubcinereum. Idem.

Solutionem gallarum fac five tincturam ex gallis infignem; huic infufioni agitando inmifce quantitatem admodum fortis folutionis victrioli, mixtura in atramentum nigerrimum tranfibit ; huic mixturæ fi inftillaveris exiguam quantitatem olei vietrioli, agitata phiala, videbis liquorem clarum \& transparentem reddi, fed nigredinem reftitues per exiguam folutionis falis tartari quantitatem; non cum fucceffu experiri potes propter gummi, quod fua tenacitate operationibus prædictorum liquorum falinorum refiftit. Boyleus.

Si oleo victrioli rectificato fenfim commificeas convenientem olei effentialis ut abfinthii quantitatem in alembico cum aliqua aquæ copia transductam, mixtura follicite deftillata in retorta, reftabat ficce materix, atrore carbonareo, vix credibilis quantitas; loco olei abfinthii fubftituebatur oleum purum effentiale faturejæe, hocque liquore cum æquali pondere predicti olei victrioli rectificati paullatim commixto totoque hoc compofito in retorta, ut prius, deftillato, præter id quod tranfibat in recipiens, etiam hi duo liquores limpidi fatis infignem relinquebant quantitatem fubftantix, piceam nigredinem referentis, quam etiamnum inter rariora affervare fe dicit. Boyleus.

Oleum victrioli frepius præcipitat multa corpora, tum mineralia, tum alia non modo in aqua forti fed fpeciatim in fpiritu aceti diffoluta, calx vel pulvis hoc liquore precipitatus elegans albufque eft. Idem. 
Si tincturæ rofarum rubrarum per aquam factæ folutio minii inftilletur, liquor in turbidam fubftantiam viridem vertitur, plane ut fit ab oleo tartari; addita quantitate olei vietrioli, gemina oftenditur operatio; plumbum in pulveris albi formam præcipitatur, \& mixtura turbida clarificatur, \& rubedo redit \& vehementer intenditur. Idem.

Victriolum in fucco rofarum nigrefcit, accedente vero fpiritu falis ammoniaci flavefcit : fi oleum vel fpiritus vietrioli maceretur cum rofarubra ficca in aqua, rubefcit aqua.

Tinctura coerulea a fpiritu victrioli plerumque rubefcit, fed adjecto fale alcalino reftituitur color coeruleus. Tinctura corrulea ab alcohole \& urinofis viridefcit, accedente fpiritu vietrioli rubefcit. Quod rubrum eft, a fpiritu vietrioli plerumque flavefcit, accedente vero urinofo nigrefcit.

Solutio Mercurii per aquam fortem a victriolo Martis fit fufce viridis \& precipitatum nigrum.

Si oleo vietrioli inftilletur oleum tartari per deliquium, poft effervefcentiam precipitatur fal ad fundum. Si filtretur aqua, evaporetur \& chryAtallifetur, fiunt inde chryftalli tartari vietriolati, non acidi nec acres, fed ab utroque compofiti. dilutum.

Sal commune mutat colorem folutionis victrioli Veneris in viridem

Spiritus \& oleum victrioli luctatur maxime cum alcalibus, fique aliquid fulphuris mineralis adfit, fit fpiritus vietrioli obfcurior \& magis fufcus.

Solutio victrioli Veneris præcipitatur ab alcalibus viride \& craffe, ab urinofis vero tenuiter ad fundun. Victriolum Martis precipitatur a fale communi, fed non in oris feptentrionalibus.

Saccharum Saturni in uncia aquæ deftillatæ folutum a guttula fpiritus vi尺trioli fit diaphanum fubturbidum.

Mercurius fublimatus cum folutione vietrioli aut calcis vivæ fit coloris opalini.

Solutio argenti a victriolo Martis fit coloris opalini fubflavi.

Solutio vietrioli Martis cum fpiritu falis armoniaci fit coloris grifei vel cani. Victriolum Martis \& folutio Marcis cum fpiritu falis ammoniaci \& fpiritu vini fit coloris viridis. Urinofa cum victriolo vel folutione Martis fiunt coloris nigri.

Spiritus vietrioli cum folutione fulphuris per fal tartari, fit primum colorisincarnati, dein ex rubeo fubfufci.

Si una pars olei victrioli mifceatur cum 3. partibus aquæ \& agitetur, fubitus fit calor, qui diu perfeverat. Si fruftulum glaciei in oleum victrioli immittitur, adhæret oleum guttis glaciei, \& illam cum fumo refolvic, adeo ut vitrum, in quo continetur glacies, maxime incalefcat. Si vero oleum vietrioli mittatur fuper glaciem, cum glacie coagulatur.

- Dominus Hawksbee poft Dominum Hookium obfervavit, aqua volumen, admixto oleo vietrioli, decrefcere; utut incalefcat, nec ponderis aliquam partem, nifi fub initio amittere. Act. Lipfanni 27 I 9. 
Colchotar vel victriolum ad rubedinem calcinatum partium 2 cum partibus 2 olei victrioli intra minutum incalefcunt.

Petreolum rectificatum cum oleo victrioli ana, unum in fuperficiem alterius cum motu \& ebullitione agit, \& dein incalefcit. calefcit.

Oleum victrioli cum uvis paffis, cum pane, cum carne admodumin-

Mercurius folutus in oleo victrioli \& per deftillationem extracto oleo, refiduum in pulverem redactum in aqua fenfibilem calorem dat.

Oleum victrioli a fale armoniaco fit frigidum. Olei victrioli pars 1 , \& aqux partes I 2 dant mixturam calidam, fed immiffo in hanc aquam thermometro \& fuperinjecta aliqua parte falis armoniaci, defcendit thermometrum. Salis armoniaci partes I 2 , \& aqux I 2 , frigiditatem producunt, fed injectis I 2 partibus olei victrioli, fit fubito calidum.

Si fal commune in aquam conjiciatur, fentitur frigus, fed fi ad falis partes 8 immittantur olei victrioli partes 3 , fit calidum.

Si pars una olei victrioli mifceatur cum dimidia parte fpiritus vini \& agitetur, incalefcit valde cum fumo. Quoque rectificatior eft fpiritus, eo major eft calor. Maximus eft calor, cum oleum victrioli mifcetur cum oleo terebinthina.

Oleum vietrioli cum vino Hifpanico digeftum dat odorem fuavem.

Oleum victrioli \& fpiritus vini ana per menfem digefta fi deftillentur, fragrantem \& dulciffimum odorem circumcirca fundunt.

Gemnulæ diffolutæ cum fpiritu victrioli, aperto dein orificio, odorem molcheti fpargunt.

Oleum victrioli \& oleum terebinthinæ ana deftillata dant caput mortuum carbonis inftar atrum, \& habet magnam fixitatem. Si poft digeftionem abftrahatur oleum fpiritus victrioli \& fpiritus vini rectificati, fit magna \& fixa quantitas fubstantix nigræ.

Camphora \& oleum victrioli defillata in fundo retort:e inftar filicis eft, nec quicquam inde fublimari poteft.

Vietriolum coerulum fi uratur, ufque dum fiat friabile, fit coloris albi; fi calcinetur adhuc diutius, fit coloris cœfii, dein fubfiavi, tunc rubri, mox obfcure purpurei, ultimo nigri.

Si oleum victrioli rectificatum mifceatur cum oleo effentiali abfinthii \& cum aqua deftilletur, fit caput mortuum coloris nigerrimi.

Spiritus urinæ in cuprum pulverifatum fit viridis; fed injecto oleo victrioli parum, vertitur in fpeciem aquæ.

Mercurius \& olei victrioli partes 2 vel 3 , quæ in retorta abftrahantur, fit calx nivex albedinis, fi affundatur multum aqux limpidæ, ex colore latcteo in pulcherrimum flavum abit, ut nullibi dari poffit melior flavedo. guineum.

Oleum feminis anifi cum oleo victrioli dat confeftim colorem fan-

In deftillatione victrioli viridis fiunt vapores vel fpiritus albi : in deftillatione vero nitri certo tempore fit ruber fumus.

Victriolum Veneris in lamina ferrea dat maculam rubram, non ita victriolum Martis.

Campho- 
Camphora pulverifata cum oleo victrioli cœrulefcit primum, dein rubefcit, fic fit obfcure rubrum, nec quicquam odorat. Affufa aqua precipitatur verfus fuperficiem camphora \& reftituitur. Quum mixtura camphor: \& olei victrioli per retortam deftillatur, odorem camphor: reftituit, maffa refidua fit coloris nigerrimi.

Si lamina chalybea vel ferrea immittitur in folutionem vietrioli coerulei, præcipitatur aliquid cupri in laminam fquamarum inftar, quae craffores \& craffiores fiunt. Si ferrum injicitur in aquam cœruleam victriolatam una cum Mercurio, precipitatur cuprum in ferrum : diffolvitur ferrum, \& cuprum amalgamatur cum Mercurio: aqua cœrula fit inde pallide corula, fi omnis pars cupri precipitatur, fit liquor coloris viridis. ViEtriolum præcipitat plumbum ad fundum, poftquam plumbum precipitarat ferrum. Pari modo Mercurius præcipitatur ab oleo vietrioli, poft. quam folutio ejus per aquam fortem præcipitarat aurum.

Ex mixtura nitri \& victrioli lentitur odor, tanquam odor aqua fortis.

Aurum in aqua regis folutum \& præcipitatum ab oleo tartari per fe fulminat, \& mofchati ac fragrantem odorem dat.

Oleum victrioli cum pulvere camphoræ primum coloris fit cœrulei, dein rubri, tum fufce rubri \& amittit odorem, affufa aqua emergit camphora. Mixtura in retorta deftillata reddit odorem, mâffa reliqua fit nigerrima.

Spiritus victrioli \& vini lente deftillata ut intra 2 vel 3 feptimanas, primum dant bonum odorem, dein odorem fortem \& fulphureum, refiduum eft inftar picis \& fragile, non accipit flammam, nullius odoris, per multos dies in aqua non poteft folvi. Plura de his colorumque mutationibus ex oleo vietrioli, ut \& ex aqua forti, f́piritu nitri aliisque acidis oriundis, videas in vietriolo, nitro, aceto \&c.

\section{Commixtio ferri cum metalls ut $\&$ Julpbure.}

FErrum cum plumbo mifceri nequit, fed femper fupernatat. Ferrum tamen intrare folet in ftannum; cum quo regulum clarum conftituit, in quem agit quam maxime magnes. Ferrum cum zinco efficit regulum durum \& ufque malleabilem argenti fimilem. Ferrum etiam quam optime intrare folet in bismuthum \& conftituit regulum fragilem bismuthicum; \& quamvis $\frac{3}{4}$ partes bismuthi infint, ufque tamen a magnete attrahi folet. D. Henckel in Pyrithologia. Ferrum alias metallo alio incruftari nequit, auro puta atque argento, nifi ei intermedium fuerit æs, cujus particulæ maxime adhærent ferro, ceu id experimur, fi ferrum tantum victrioli de profapia cupri fricetur, ubi extemplo in illa fricta parte cupri color offenditur. Barchuf.

Mercurius ferro commifceri nequit. Ferrum \& cuprum non posfunt amalgamari, hoc eft, mifceri cum Mercurio \& dein reduci in pulverem minutiffimum. Si cuprum milceatur cum ferro, five argentum cum ferro, dure admodum cohærent. Cuprum ferro commixtura ad orichalcum eft inutile, reddit etiam cuprum durum. 
Quod vero commixtionem ferri \& fulphuris attinet, en fequentia: Dominus Lemmery experimentum fecit, commifcendo fulphur, limaturam ferri \& aquam, tam in ollis exiguis quam majufculis \& altioribus, exinde incaluit materia, \& expanfa extra ollam fe conferre voluit. Ollam majorem tempore æftatis materia dicta 5 librarum replevit, \& ollam linteo contexit, \& in terram infodit \& fuperingeffit terram ad $\frac{\mathrm{r}}{2}$ ulnæ altitudinem, elapfo 8 vel 9 horarum fpatio intumefcere incepit humus \& incalefcere, \& prodierunt non modo vapores fulphurei, fed etiam flammæ ignex; quxe rimam prius factam dilatarunt, \& terram pulvere flavo nigricanti aperiit: terra diu fatis incaluit, quum effoderetur rurfus olla, reperiebatur pulvis iterum niger; experimentum hoc melius ficcedit tempore xftatis quam hyemis. Dominus Henckel.

Lemmery illuftrat genefin fulguris \& tonitru per experimentum, fcilicet fi fpiritus victrioli aqua limpida affundatur, \& Martis limatura addatur, halitus producitur fulphureus, qui admoto cereo inflammatur \& tonitru inftar fragorem edit. Experti etiam funt, quod halitus, fi orificio vitri obturato exitus negaretur, ipfum perfoderit. Cumque aliquando in vitro atis amplo copiofum accenderent, tanto id fragore in mille frufta disjecit, ut in adftantibus ad tempus furditatem efficeret. Idem evenit, fi oleum viotioli fpiritui fubftituas; enimvero matéria femel accenfa diffipatur, novoque fulguri producendo novus deftinatur halitus. Ex hiftor. acad. reg. fcient. vid. Acta Lipf. pro anno 17 10 p. 204.

Si limatura ferri mifceatur ana cum fulphure, \& mixtura humećtetur aqua, ufque dum pultis inftar fiat, fponte fua tunc calorem quendam concipit. Sique fuper prunas in cochleari teneatur, corripere ignem folet, fitque cóloris rubentis, reliquum eft modo crocus. Si copia fit, qux commilcetur, fponte fua calefcere poteft, \& feipfum calcinare ufque ad crocum, \& diminuitur fere ad dimidium : licet maffa diminiatur ad dimidium, ufque tamen ex una parte ferri obtinentur $\mathrm{I}_{\frac{1}{2}}$ croci, adeo ut acida fulphuris fe receperint ad ferrum. Plura de his vide in tractatione de fulphure.

\section{Objervationes collectanece de ferro.}

FErrum, quod continetur contra ignem vitri cauftici, oportet effe tenue, I ita enim bractea ferrea momento excandefcit, \& parvo tempore a cono radiofo quafi perterebratur, ut multa foramina acquirat. Acta Lipf: anni I 697. Ante fpeculum caufticum Leonienfe folvebatur clavus ferreus fpatio 30 minutorum fecundorum.

Notum eft, quod ferrum ignitum fub malleo pofitum, quum tandem ab illa parte, qux extra incudem \& malleum tenetur, frigefcere \& obfcurari incipiat, fub malleo tamen candefcit magis \& magis, quod imprimis in officinis \& præfertim illis videre licet, in quibus ferrum in virgas tenuiores extenditur, qux dein in fila funt extenuandx. Pariter etiam ferrum tam malleo percuffum, quam etiam lima raium \& ferra fectum valde incalefcit. In Brefslcuitf. Natur - F Medicin -Gefchichten referunt quendam Haut f ch nominatum arten illam calluife per 5 vel 6 percuffiones mallei 
ferrum candefaciendi : ferrum enim per mallei percuffiones facile alias candefit, $f$ in formam quadratam percutiatur ; \& fuper incudem, percusfiones fiant fuperlatitudinem ejus, non vero fuper angulum aliquem, unde illi quam optime hoc facere poflunt, qui huic reiaflueti funt, ut fabri: ferrum etiam fi preparetur melius eft, filicet fi in aqua non cxftinguatur, fed fi-per fe refrigefcat, quum malleo \& incudi eximitur.

Quum vulgo notum fit ferrum urgente xftu expandi, \& quafi per gradus verfus folutionem partium fuarum tumefcendo \& rarefiendo ire velle; particulis ejus precipue laxius infidentibus \& fubtile fulphureis in motum citatis, urgente jugiter xthere jam rigidiflimo \& citatiflimi motus, fe ad quemvis gradum celeritatis fic muniente, fed de his videas Part. III. principp. de atbere. Verbo, ferrum non modo fed etiam omnis metallorum familia expandi vult, \& fuis particulis ligantibus lora remittit, urgente \& intendente fe calore; \& pariter quia ex prolapia metallorum unum genus citius per eundem ignis gradum particulatim a fe recedit, quam alterum, feu liquefcit, nam expanfio calida eft liquationis gradus, dum f́cilicet partes fubtiliores \& minus ligantes jam magis \& fenfim fluere aut moveri incipiant, \& quidem in unda ætherum jam citatiflimorum \& majore copia fluentium; hinc experientiflmus van MUSSCHENBROEK machinulam ingeniofam fibi paravit, cujus beneficioiplum gradum expanfionis cujuscunque metalli, pariter folutionis calidx, fecundum augmenta caloris ut \& frigoris, in quodam indice fuper difcum quendam verlatili \& a rotis \& tympanis dentatis, non aliter ac in horologiis circumacto, notare liceret; cujus tympana \& rotulæ a regula pariter dentata \& horizontaliter applicata circumaetx indicem ad exiguiffimum caloris gradum \& unguem fenfibiliter moverent; regulx applicuit fecundum longitudinem filum feu parallelopipedum metallicum æquæ ubivis craflitiei, ab una parte fuper tendinem in bifidum foramen vel crenam infertum, ab altera per cochleam regulæ rotarum motrici dentatæ applicatum : infra vero per fpiritus in ellychniis accenfa flamma, per quorum numerum ab I ad 5 ignis intenfior aut remiffior, citior aut tardior, ad libellam fuperextenfo flo, \& inter plures aut pauciores flammas laboranti fuppeditari poffet: ex periculis factis cum fuo pyrometro, ut vocat, fequentia de ferro obfervavit, \& quidem tempore, quum thermometrum notaret 32 gradum, (pirante vento occidentali, cælo nubilo, barometro ad $29 \frac{\mathrm{x}}{3}$ poll. elevato.

Ferrum per unam flammam alcoholis vini expanfum eft ad 80 gradus indicis fui; a duabus flammis ad II 7 ; a tribus ad 142 ; a quatuor ad $2 I_{1}$, a quinque ad 230 gradus ejusdem indicis. Chalybs vero ab una flamma ad 85 gradus; a duabus ad 123 ; a tribus ad 168 ; a quatuor ad 270 ; a quinque ad 310.

Obfervavit ferrum omnium minime inter metalla rarefieri, five id ab una five a pluribus flammis calefiat; idcirco eft commodiffimum ad conftruendas machinas, quæ a calore \& frigore minime mutandx forent, pariter etiam pendula horologiorum; menfuræ ulnarum \& pedum.
Clades III. de ferro.
I y y
Expan 


\section{OBSERVATIONES VARIÆ}

Expanfio plumbi \& ftanni ab eadem flamma eft fere duplo major quam ferri.

Deprehendit cohærentias metallorum in tractatu de frmitate corpo. rum, cupri filicet ut $299_{4}^{\mathrm{T}}$, orichalci uti 360 ; ferri 450 ; plumbi $29_{4}^{\mathrm{I}}$; ftanni $49 \frac{1}{4}$; quorum gravitates fpecificx funt, cupri 9000 ; orichalci 8000 ; ferri 7645 ; plumbi i 325 ; ftanni 7320 . Nempe fila ferrea diverfæ crasfitieiadhibuit, quxe effent in ratione ut 1.2 .3 .4 : qux notata funt literis D. C. B. A, ubi (A) eft $\frac{\mathrm{I}}{\mathrm{To}}$ pars pollicis Rhenland: ferrum (A) a 450 libris lente \& parum elongatum eft, cujus coni truncati diameter fieret 0,07 poll. ferrum $(B)$ a 3 I o libris appenfis attenuabatur in diametrum 0,08 poll. coni truncati diam. $\circ, 06$. ferrum (C) a 230 libris attenuabatur in diametrum 0,06 pollicis; ferrum (D) a libris r 30 elongatum in diametrum $\circ, 05$ poll. cohærentix fecundum craffities fic forent $\mathrm{A}=45 \mathrm{O}$. $\mathrm{B}=337 \frac{\mathrm{I}}{\mathrm{\Sigma}} . \mathrm{C}=225 . \mathrm{D}=1 \mathrm{I} 2 \frac{\mathrm{r}}{\mathrm{2}}$. Addit, fila omnia metallorum in attenuatione infignem calorem concepiffe.

Exploravit etiam, quantus foret calor plumbi incipientis liquefieri; adeoque in eandem capfulam, qux virgam ferream cepit, pyrometro fuo impofitam, infudit plumbum, quod in crucibulo ad principium liquefactionis erat redactum, \& vix vix fluebat; id virgam ferream 217 gradibus expandit: ftannum vero primo liquidum rarefecit ferrum I 09 gradibus, duplo minus quam plumbum. Bismuthum vero liquidum ad 300 gradus. Marcafita aurea ad $\mathrm{I} 69$. ferrum vero a frigore incipientis glaciei $\mathrm{ab}$ aqua ebulliente rarefactum eft 53 gradibus, chalybs ad 56 . Obfervandum eft, quod quilibet gradus pyrometri ejus notet $\frac{T}{\mathrm{~T} z 500}$ pollicis, unde in aqua fervente increvit ferrum $\frac{\mathrm{T}}{\mathrm{T} 3 \mathrm{k}}$ part. pollicis : virgæ cujuslibet metallicæ longitudo fuit $5 \frac{4}{5}$ pollicis.

Obfervavit dein temporum momenta, intra quæ expanderetur ferrum uni flammæ alcoholis vini expofitum ( $\mathrm{I}$.) ab una flamma ad tempus 9 minutorum fecundorum expandebatur in I gradum indicis fui: ad tempus I minuti primi \& 2 fecund. in 19 gradus fui indicis: ad tempus $2^{\prime} 4^{\prime \prime} \mathrm{ad}$ $34^{\circ}$ : ad tempus $3^{\prime} 4^{\prime \prime}$ ad $47^{\circ}:$ ad tempus $4^{\prime} 2^{\prime \prime}$ ad $55^{\circ}$ : ad tempus $5^{\prime} 3^{\prime \prime}$ in $62^{\circ}$ : ad tempus $6^{\prime} 6^{\prime \prime}$ in $68^{\circ}$ : ad tempus $7^{\prime}, 2^{\prime \prime}$ in $71^{\circ}$ : ad tempus $8^{\prime} 2^{\prime \prime}$ in $73^{\circ}$ : ad tempus $9^{\prime} 3^{\prime \prime}$ ad $76^{\circ}$ : ad tempus $10^{\prime} 15^{\prime \prime}$ in $78^{\circ}$, cum ceflaret expanfio. Quum vero ferrum calefieret ope 5 flammarum, fequens obfervata eft ratio temporis \& expanfionis, ad tempus 5 minutorum fecundorum, index promotus eft per 5 gradus; ad tempus $\mathrm{I}^{\prime} 3^{\prime \prime}$ in gradum $80^{\circ}$ : ad tempus $2^{\prime} 6^{\prime \prime}$ in $145^{\circ}$ : ad tempus $3^{\prime \prime} 3^{\prime \prime}$ in $200^{\circ}$ : ad tempus $4^{\prime} 9^{\prime \prime}$ in $230^{\circ}$ gradus. Preter adhuc plura experimenta, de quibus videas auctorem. Sed collatis experimentis fuis obfervavit tempora \& expanfiones perpetuo difcrepare : pariter expanfiones non fequi proportionem flammarum, fed effe proportionaliter majores $a b$ I flamma, quam a 2 , a 2 proportionaliter majores quam a 3 flammis, a 3 majores quam a 4 , \& fic porro.

Obfervavit, etiam omnium citiffime rarefieri ftannum, tum plumbum, tum orichalcum, dein cuprum rubrum, tardiffme ferrum, quippe 
elapfis 4 temporis minutis fecundis expanderetur ftannum 5 gradibus, ferro poft 9 min. fec. duntaxat producto ad unum gradum, unde plus quam novies velocius a primo applicato igne expanditur ftannum, quam ferrum; hoc eft, novies minore ignis copia ftannum rarefcere incipiet quam ferrum frigefactum ad 32 gradum thermofcopii : expanfionis primæ velocitas in plumbo erit ad eam in ferro uti 9 ad $\mathrm{I}$; in orichalco ad eam in ferro, uti 5 ad I. Expanfionis gradus obfervati funt fecundum fequentem tabellam

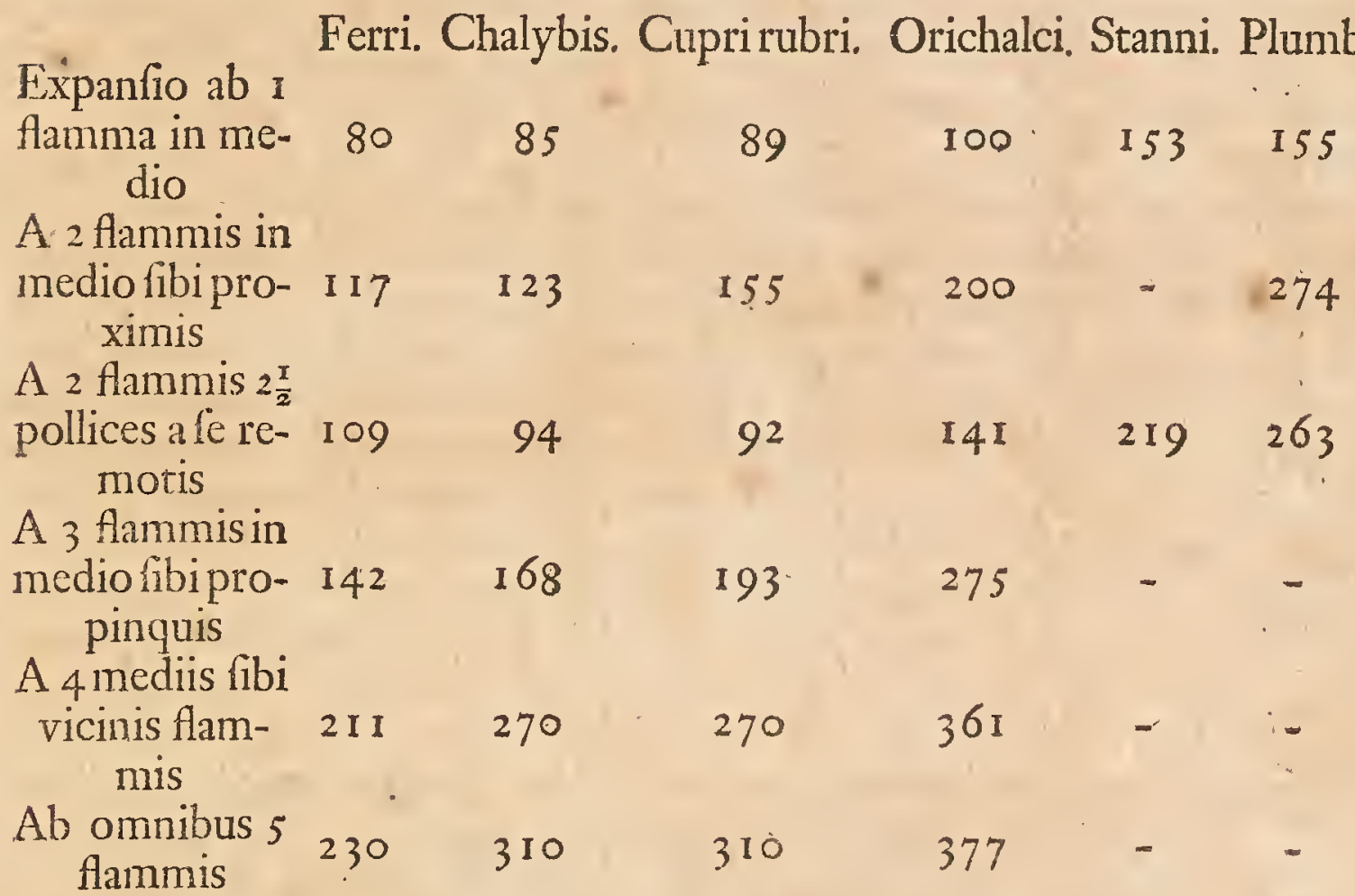

Inftituit etiam per idem pyrometrum experimenta, quomodo ferrum \& reliqua metalla a fummo calore condenfentur \& contrahantur; elegit diem, quo gelu glaciem formare inciperet, thermometrumque indicaret $3^{2}$ gradum inque loco amplo, ab omni parte claufo; factumque eft tentamen cum ferro \& metallis fere ad ruborem ufque in igne carbonis calefactis : obfervavit, quo metalla effent calidiora, eo citius fublato igne contrahi; quo autem minus calida, eo tardius : pariter quæ metalla citiflime ab eodem igne expandantur, ea quoque fublato igne, citiffime contrahi: examinatum etiam eft, qualis refrigerii ratio \& gradus in vacuo obtineret, in quen finem fimillimi cubi parati funt, quorum quilibet pollicis magnitudinem æquaret; \& ad æquale temporis intervallum impofitierant plumbo liquefacto, ut pari caloris gradu impregnarentur, unus dein fufpendebatur in aere medio, alter in recipiente vitreo evacuato; \& obfervatum eft in vacuo fufpenfum corpus diutius calorem fervaviffe, quam id, quod in aere aperto effet. Sed ut accuratius examen inftitueret, per pyrometrum fuum idem in aere \& vacuo expertus eft, \& obfervavit fequentia. 
Ferrumin Ferrum in Chalybs Chalybs Plumbum Plumbum $\frac{\text { Vacuo }}{\text { Gradus in- }}$ aere aperto in vacuo in aere in vacuo in aere dicis in pyrometro

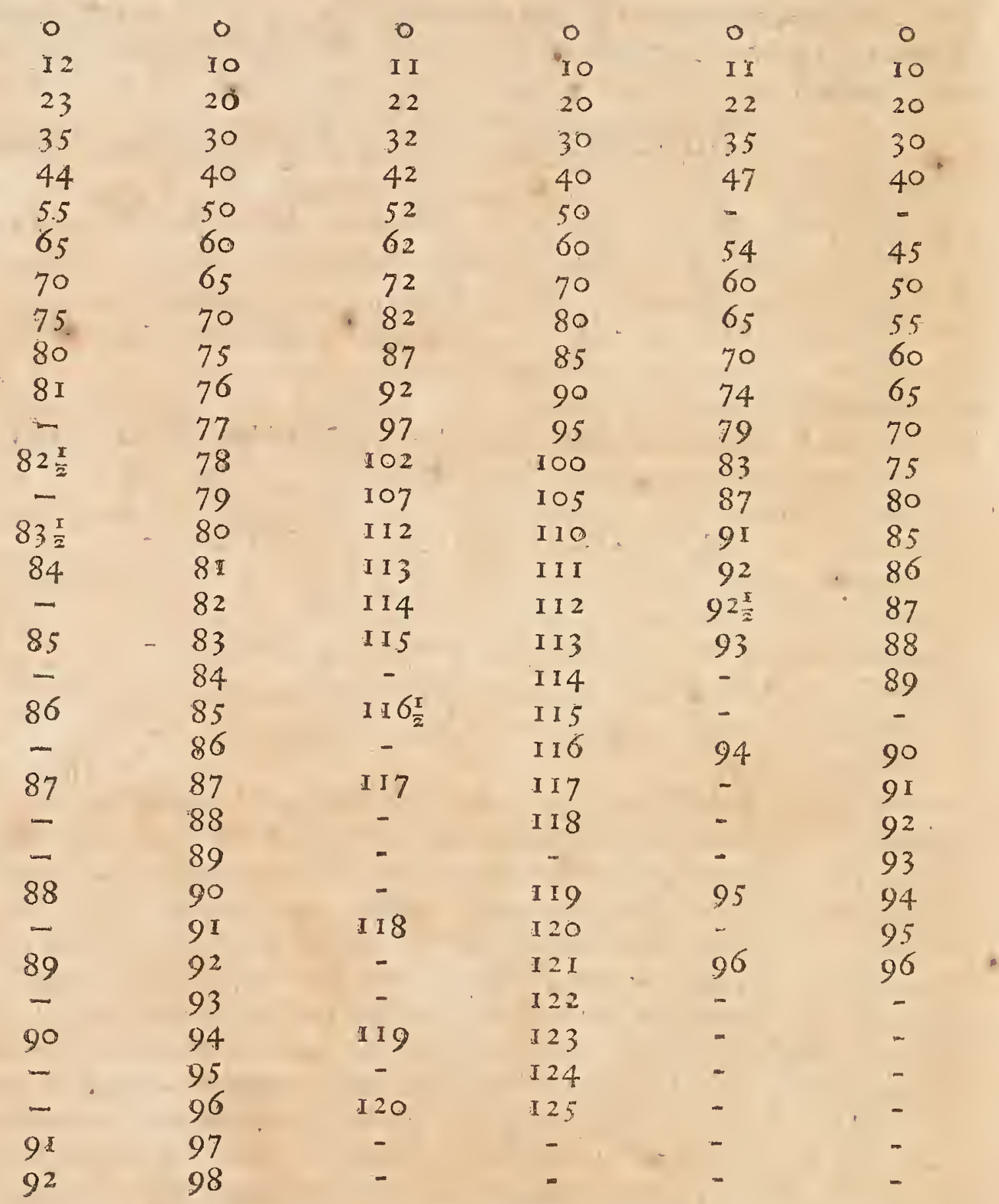

Confecife fe ait pyrometra æque magna, denfa \& longa \& fimillima, quibus obfervationes in aere \& vacuo fecerat, pariter elegiffe virgas aque longas, craffas gravefque. Hactenus experientiffimus van Mufchenbroek. Johannes Zanichelli tradit, ferrum fufum in fua concretione particaJas minimas oftendere figura pyramidali 4 lateribus infructas, quam depietam etiam oftendit. 
Vidi ferrum quod diu \& ut putem ultra 70 annos fub terra in loco humidiori jacuerat reconditum, exefum \& fragiliffimum, cumque frangerecur, in fractura inifar marcafitx aquaticæ appareret, cum teffulis \& colore flavo nitenti.

Ferrum vetuftum ferrugine commefum in foco quodam fub cineribus, fulphur fubtiliffimum \& tenuifimam flammam fpargit \& quam diutiflime.

Si vena Mercurii teneatur in cochleari, \& hoc fuper ignem, ut Mercurius inde abigatur per fumum, fi fumus lit nigre flavefcens, fignum eft mineram ferrum fecum habere. teft converti.

Ferrum, fi ei diu multumque ignem adhibueris, per fe in vitrum po-

In argillæ \& olei lini, item in olei vißtrioli \& olei terebinthinæ mifcela ignis interventu aliquid ferri de novo produci Godofredus prolixe defendit, qui ipfe partem inter metalla ignobilia folum ferrum in fpiritu nitri folutum a certa olei tartari per deliquium quantitate affufa, circa vitrum fuperius in arbufculi formam excrefcere annotat, partim victrioli differentiam atramentique colorem nigrum a folis particulis Martialibus refultare, dum acidum victrioli. a gallis fimilibusque concretis . terreis \& alcalibus fulphureis declarat." Ex acad. reg. f́cient. vide acta Lipf. anni I 709.

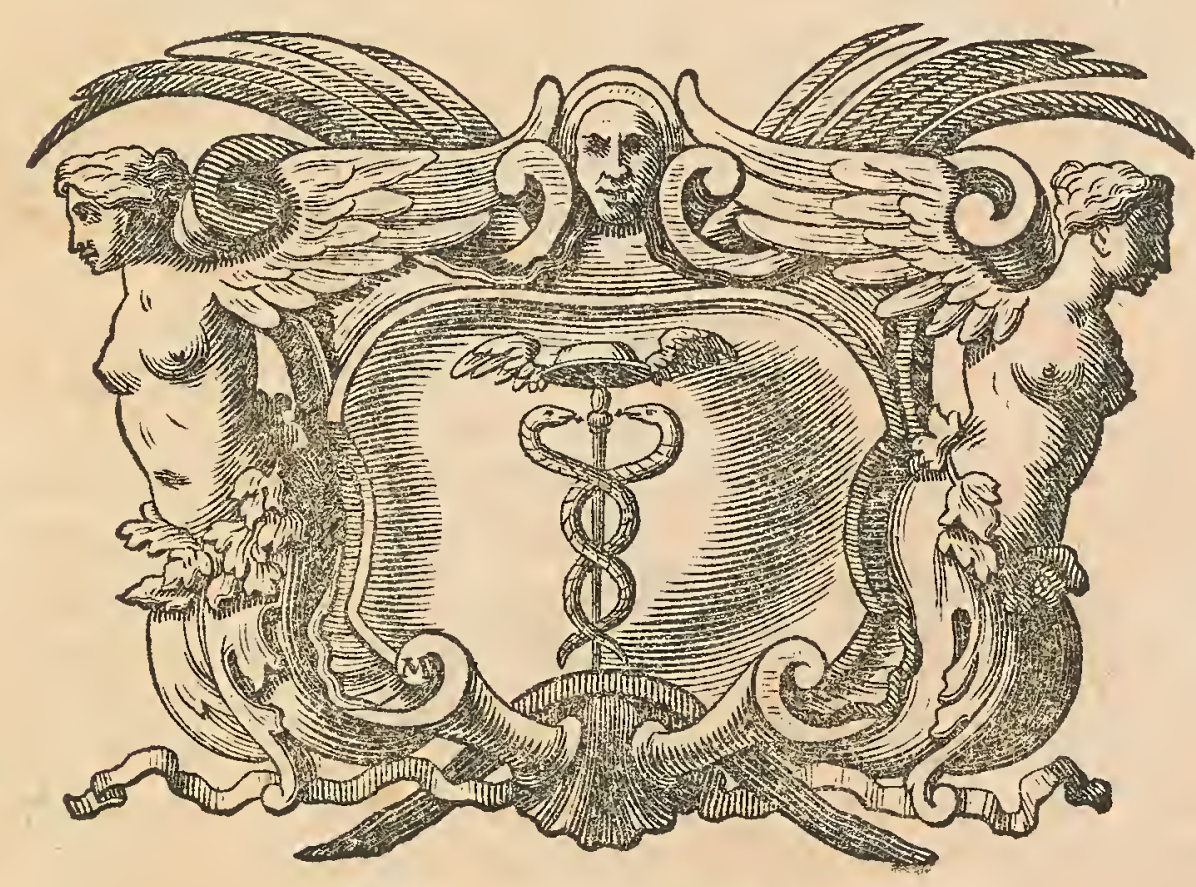




\section{PARAGRAPHUS XVIII.}

\section{Particula \& elementa ferri $\&^{2}$ victrioli Martis in aquis lacuftribus, Aluvialibus \& fontanis; Eे quomodo dicte aquce a variis aucto- ribusprobata Junt.}

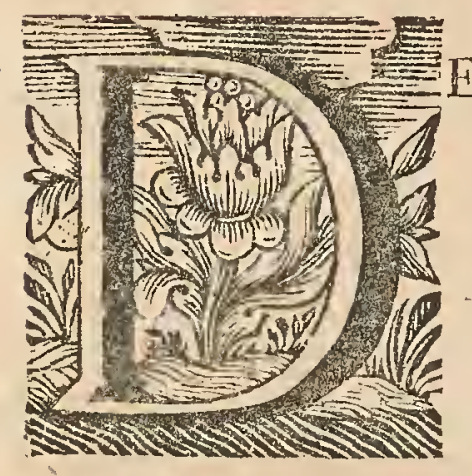

aquis aliis non agere conftitui, quam de illis quæ ferro impregnatx funt, nec de lacubus, quorum in fundo vena arenaria ferri invenitur; fed de aquis \& fontibus, quibus elementa ferrea infunt. Plura quidem de his videre licet in tractatione de victriolo, ufque tamen quia tam ex victriolo \& fulphure, quam etiam ex ferro participant particulæe, funtque tanquam prima illorum elementa, hinc locum etiam hic merentur.

Quum enim probandx funt aqux, num illis victriolum Martis infit, fiet hoc per adftringentia ; unde folutio ejus vel nigrefcit vel purpurefcit, prout acidum victrioli colorem alcalinarum particularum vel diminuit vel intendit; fed de probis his melius videbis fequentia. Notum enim eft, victriolum ex puro ferro factum cum gallis mixtum colorem brune rubrum ad nigrum vergentem aquis inducere; at vero fi cuprum fit ferro admixtum, folutionem tunc nigerrimam apparere.

Aqux medicatæ Sveciæ \& acidulx multiplices funt; funtque ommes fere victriolo Martis imprægnatæ, \& atramentum victriolicum fapiunt; circa quas multa experimenta facta funt, qux omnia in medium afferre prolixum foret.

\section{Aque Pafiacre.}

$\mathrm{E}$ fontibus in Gallia multa videas in Hiftoria Academix Regia fcieniiarum, \& quidem de illis qui funt in Paffracis \& Autolienfibus vicis; illos fpiritu victrioli fulphureo aliquantum imprægnari ex eo concluditur, quod pulvis gall injectus aquam recentem rubeo colore inficiat, qui ftatim evanefcit; quum igni aut calori admovetur. Spiritus falis armoniaci, qui una cum tartaro calcinato extractus eft, affufus aquæ colorem lacteum impertitur, finul etiam parum pulveris albi \& fubtilis præceps decidit. Ex iis conjicere licet quiddam bictriolicum iis aquis inefle; nam ex gallæ admixtione idem fere color præbetur, qui aquæ communi, cui bictriolum ferrugineum adjicitur; nifi quod color ejus atro vicinior fit. Verum fi aquæ quid victrioli habent', id omne in fpiritu aliquo volatili confiftit, quia hic color ftatim evanefcit, ubi igni admoventur: neque tamen acidum fpiritum effe exhinc concluditur, quod fpiritus victrioli una cum gallæe pulvere aqux minerali affulus perfpicuitatem non adimat. Quum feptem 
hujus aquæ libræ in balneo Marixe effent exftillatæ, in imo cucurbitæ, terra fubflava multis fibris pellucidis \& lamellis admixta, qux talco non erant abfimiles, refedit 5 circiter fcrupulorum pondere : hæc terreftris materia crebris lotionibus purgata \& a flavo foluta, pulveris talci pellucidi fpeciem prabuit : idque maxime cum microlcopio fubjecta \& ferro candenti impofita in igne perfpicuitatem fuam amilit ; atque infar gypfi calcinati vifa eft. Pulvis fubflavus \& levis ex lotione gypieæ materiæ fuperftes in alterum fcyphum vitreum transfufus inftar limi flavi fubfedit, fed vix vicefima gypfi ponderis pars ea fuit : candenti ferro ad ignem impofitus rubiginis ferrex fpeciem pr:buit, adeo ut fufpicandi locus fuerit, hanc rubiginem ex marcafitis ferrugineis duci, qux iis in locis copiofe occurrunt. Nihil falis aut victrioli aut nitrofi apparuit ; cum autem iftiusmodi aquæ perparum ferrugine materiæ habeant, multum gyplex, palam. eft, eas vix ullius efle utilitatis.

\section{Aque de Forges.}

A

Quas percelebres in Normannia videlicet de Forges dictas ferri vena adhuc molli five ente primo, ut loquuntur, ferri effe imprægnatas, ex additione pulveris gall:e, ex fale fuperftite \& fulphureo colligitur. Nam fuccum parvæ iridis denfatum viridi colore tingit. Spiritus falis ammoniaci nullam in is efficit præcipitationem, perpaucum falis fulphurei poft deftillationem extractum.

Dominus Morin aquas de Forges etiam probavit \& invenit illas ferro \& vietriolo imbutas : alias ab experimentis vulgaribus conftare ait, folutionem vietrioli cum gallarum tinctura miftam nigrorem fubito inducere, non autem ejusdem victrioli fpiritum, ut \& eandem tincturam gallarum ferri limaturis fuperfulam nigrorem quidem contrahere, fed minus prompte, quam fi folutioni victrioli mifceatur. Quum pulvis gallarum aquis de Forges infunditur, puniceo coloreftatim tinguntur, qui quidem color per hor: dimidium adhuc intenditur, donec fubniger fiat; argumento, has aquas non wictriolo quidem imbutas effe, fed vel tenuilfomi ferri particulis, vel victrioli quodam spiritu, qui ferri naturam habet. Hoc in loco tres fontes reperiuntur, la Cardinale, la Royale \& la Reynette. Victrioli fpiritus, quo hie aqu:e impregnantur, 4 vel 5 dierum tpatio ab is fe expedit; nam poft id tempus infufione tincturæ gallarum rullo colore inficiuntur, atque omnis earum vis una cum fpiritu evanefcit. Hi tres fontes flocculos quosdam colore rubiginem referentes continuo emittunt, eofque adeo leves ac tenues, ut digitis comprehenfi tactu imperceptibiles fint, qui tamen ab aqua non folvuntur ac figuram fuam tuentur : hi crocum Martis prorfus æmulantur, quem non aliud effe confat, quam ferri rubiginem rore aut pluvia confectam. Superficies minerarum ferri, quas hæ aquæ præterfluunt, ab earum humiditate manifefte eroditur, ac leves hujus rubiginis membranulæa $a b$ iisdem aquis abripiuntur. 


\section{Fontes Vicbi.}

D fontibus Vicbi obfervavit Dominus Geffroy, \& notavit aquas Borbonenfes lento igne in vaporem folutas fingulis phyalis, quæ 18432 grana pendent, continere $\sigma_{3}$ grana materix cujusdam terreftris ac falinæ, qux in fundo vafis fubfidet; aquas vero de Vichi, quæ graviores funt, duplam. in eadem quantitate materiæ cujusdam mineralis habere : harum aquarum. foeculentam materiam nihil aliud eqfe quam falem acrem lixivialem omni ex parte fimilem ei, qui a plantis extrahitur, quique cum omnibus acidis fermentefcit, aliquam ei fulphuris qualitatem immifceri, quod manifefte fe prodit per lumen, quod fatis fenfibile \& duraturum enittit, fi hæc falina materies ferventi fartagini obfcuro aere exiftente imponatur; in aquis de Vicby majorem hujus falis copiam contineri ; præterea portionem aliquam falis victrioli in iis effe. Aquas etiam Bourbonen/es \& oppidi de Vicby examinavit etiam Dominus Burlet; feptem funt, fed 6 fontium aquas examini fubjecit; aqua in 2 Capucinorum puteis impenfe calet : in ipfo fontis cratere oblcura \& fubalbicans apparet, intra poculos tamen fatis perfpicua eft. Ejus odor gravis admodum, odorique vulgaris uftique fulphuris perfimilis : guftu falfa admodum \& potui ingrata, calorem diu confervat. Thermometrum tubum 9 pollices præter phyalam longum habebat: hoc aeri expofito, ejus liquor ad 24 lineam afcenderat; eo intra magnum puteum quadratum demerfo, idem liquor ad 50 lineam; demerfo vero in parvo puteo ad 5 I cum femiffe pervenit. Aqua horum puteorum diffolutioni aluminis \& fpiritus victrioli permifta notabilem cum his fermentationem habuit: mifta vero cum aqua calcis turbida tantum faeta eit. Nullam papyro cœruleo rubedinem induxit ; \& cum tinctura nucis gallarum debilem colorem contraxit ; nullam indidit folutioni heliotropii mutationem, fyropum violarum viridem fecit. Quatuor libræ hujus aquas in catino terreo per cvaporationem folutæ duas drachmas \& 60 grana fæcis præbuere. Dominus Chamel ex $8 \mathrm{Hb}$. aqux 5 drachmas cum dimidia ejusdem frecis extraxit; dein per calentes cineres 6 drachmas \& 32 grana hujus aquæ ad evaporandum pofuit, evaporatione finita, fubfidentiam quandam albam, ficcam, tum fundo vafis tum lateribus adharentem invenit : vas iterum pendens ejus pondus 3 granis cum dimidio majus repertum eft; hinc rationem conclufit phyalam hujus aquæ. 26 circiter grana fubfidentix dare. Aqua de Grille minus calet quam aqua Capucinorum, immerfo thermometro ejus liquor 5 omam lineam attigit, eandem ferme fubfidentix quantitatem continet, lixivialem falem fapit; perfpicua admodum eft, a fonte fcaturiens ingentes bullas excitat, fulphur fufum olet, calorem fuum æque ac aqua Capucinorum confervat, \& in omnibus nullum inter illas difcrimen invenit. Aqua de Gros - bullet tepens eft, perfpicua admodum, acutioris faporis, quam aqua de Grille, odoris vero, qui aliquid Martis participare videtur. Lutum quod hujus aquae rivulus, per quem fons ipfe exoneratur, interfluit, nigrorem habet. Hujus luti exficcati partem a magnete trahi vifum eft. Infulione nucis gallarim eadem aqua intenfus tingitur \& turbatur. Hujus aque phyala, facta evaporatione, fub- 


\section{E.T V I C T R I O L I I N A QUIS.}

fidentiam præbet I 8 grana majorem ea quam præbet aqua de la Grille. Cum omnibus acidis fermentefcit. Cœruleus papyrus, qui ruborem per acidum induerat, colorem fuum his aquis acquirit. Sal quo aquæe de Vicbiimprægnatæ funt, idem in omnibus fontibus videbatur, \& deprehenfum eit, eum effe falem alcalicum mineralem, qui in calidis fontibus volatiliores quasdam partes probabiliter habet cum fulphureis partibus conjunetas. Sulphur tamen hoc nulla induftria nullifque experimentis omni a parte colligere datum eft. Auctor fulphureum quid in fubfidentia harum aquarum reperiiffe fe putat, nam huic pruna in loco fatis obfcuro fuperinjecta, præter crepitum, quem falinæ ejus partes edebant, cœruleas quasdam flammulas emifit, quæ accenfum pulverem pyrium olebant. Præterea cưm eandem fubfidentiam in firitu vini per aliquod tempus folutam fervaffet, particulas quasdam pingues eandem fupernatantes vidit : demum id quod fenfibilius fulphuris indicium eft, terreftrem ejus partem, poftquam ab omni fale purgaflet, in fpiritum vini injecit, poft aliquot dies oleofa quxdam membranula in liquoris fuperficie apparuit. Præter fulphuris partem aliquas etiam ferri particulas in earum fubfidentia deprehendit, pr:fertim in fubfidentia aquarum de la Grille, du Grosbullet \& fontium Gorgnier. Magnes etiam aliquot ejus partes attraxit : dein expertus eft, cratem fontis, qui ab ea nomen habet, nec non parvum puteum Capucinorum quadratum, papyro-corulei coloris, qui heliotropii colore tinctus erat, cooperiit, ibique eo per noctem relicto, fequenti die nullam in eo coloris mutationem notavit. Eidem papyro victrioli fpiritu ruborem induxit, eodemque fontes iterum cooperiens, fequenti die cœruleum colorem ab eo recuperatum vidit : hoc experimento confirmari videtur nullum in his aquis acidum volatile contineri.

\section{Aqua de Corenjac.}

DOminus Lemmery examinavit aquam mineralem de Corenfac dans, le bas Roverque; faporem tantum fubacrem \& victriolicum habuit; frigida plane \& odoris expers erat: hujus aqux uncix I 2 in vaporem refoluthe I 8 grana falis cujusdam fubfufci ad albedinem accedentis, falfi ac parum victriolici præbent.

\section{Aque Poguienes.}

A Qux Poguienfes five de Pougues in agro Nivernenfi non multum aciditatis præ fe ferebant, nec injectu gallæ pulveris rubeum colorem induebant, \& tamen ubi recens eft aqua, non parum rubet eo pulvere adjecto: aqua valde acida eft. Ex aliquot fpiritus ammoniaci guttis huic aquæ inftillatis præcipitatio alba \& denfa facta eft. Aqua exhalata, quod refiduum fuit in folia diductum \& falfum idque aquæ communis \& calidæe affufione diffolutum \& filtratum fuccum florum parvæ iridis viridi colore tinxit: cum oleo victrioli nullam fecit effervefcentiam, fed levem duntaxat freClaffis III. de ferro. mitum. 
mitum. Ex quo fufpicio fuit aquam illam mineralem per terras bituminofas tranfire, in quibus minus eft bituminis fed major victrioli copia.

\section{Aque balnei de Avione.}

$\mathrm{D}^{\mathrm{O}}$ Ominus Theophilus Grifonius de aquis balnei de Avione fcripfit, \& obfervavit, quod limpidx \& guftui aufteræ fint aquæ e fonte recenter hauftx. Dominus Mengus multum aluminis \& minus ferri illis ineffe dixit. Savanarola opinatus eft conftare ferro, alumine, ære. Baccius æque ferreas \& aluminofas exiftimavit. De ferri minera dubitat auetor, fed ufque ex probationibus fequentibus demonftrare vult, prater fulphur etiam inibi effe tartarum victriolatum; fed ufque excludit ferrum, quum tamen raro pyrites \& victriolum detur, ubi non admifta fit portio ferri. Aqua admixta decoctis gallæe flavedine non nigredine inficiebatur. A portione concreti grumi hujus balnei minutiffime pulverifata infufa in aqua communi curn pulvere gallæ nulla nigredo aquæ eft impertita. In hujus aquæ unciam $\mathfrak{I}_{2} \mathrm{inftillavit}$ oleum tartari \& turbata eft, fed cito clarefcens colorem flavum vergentem ad rubrum adepta eft, \& in vafe terreo verfata \& exficcata color apparuit, vel aurantii ficci maturi aut æruginis ferri, hoc evenit cum aqua Ompbatice a Mathiolo dicta, non vero cum aqua de Abione, qux permixta oleo tartari, ftatim converfa eft in album colorem, ut lac, donec ab ea decantata fuit in fundo vafis non pauca quantitas terræ albæ. Deinde æquam portionem aquæ pofuit in duobus vafis vitreis, in alterutrum inftillavit guttulas fpiritus urinæx, in aliud guttas fpiritus falis, \& utraquelactea apparuit, non fubrubra aut aurantii coloris, quod eveniffe dicit fi ferrea effet. In vitreo vafe uncix dimidium aqux permiffuit cum drachma calcis albæ vivæ \& poft 8 horas adhuc aqua alba erat, fed aquæ ferrat: inducit colorem fubflavum. Parum fpiritus vietrioli a pharmacopolis Senenfibus naturalis dieti, qui ab oppidulo Silvena defertur, in vas vitreum inftillavit, \& ex additis guttis olei tartari maxima ebullitio fermentativa exorta eit, paullatim vero fedata, fubftantia falina precipitavit coloris fubrubri, \& eft ferrum quod in eo liquore delitefcit. Iterum cum uncia aqux communis una cum guttulis hujus fpiritus victrioli naturalis pulverem gallæx permifcuit, \& cito nigredo fuborta. Sublimata portione terræ cujusdam flavæ vallis Rofie in Senenfi ditione, qux ferrea habetur, una cum xqua portione falis ammoniaci \& frigefacta, color corticum aurantii maturi ficci obfervatus eft, \& in operculi concava parte falinæe particulæe ejusdem coloris repertæ: quod non evenit, eodem habito experimento de grumo concreto balnei de Avione; colorem enim album reperta fuperficietenus præ fe ferebant, tum in operculo cum in fundo alembici : difpupta autem colore intus erant leucophæo; \& ut certior fieret de abfentia ferri, fupra grumum extractum ab igne inftillavit oleum tartari, nec per hoc coloris ulla fecuta eft mutatio, \& tamen in atreum aut arugineum permutari oportebat. Nec alumen ei ineffe ab experimentis conftat, nam ex infufo per noctem ligno Brefilio minutiffme incifo in aquacommuni, per ebullitionem extracta tinctura \& in vafe vitreo permixta cum portio- 


\section{E T. VIC T R I O L I' I N A QUIS.}

ne aluminis rochx, diffoluti in aqua communi, multum fux rubedinis amifit, quod non evenit ex admiftione grumi aquæ hujus: præterea in vinum mali punici ex facta mixtione aluminis minutiffime pulverifati, nullus illatus fermentativus motus, nulla coloris mutatio, a mixtione vero hujus vini cum pulvere grumi balnei, maxima exorta fermentatio ex ebullitione \& fpumefcentia apparens, \& paulo poft vinum clarius quam antea obfervatum. Rurfus ex multa aqua harum thermarum igne abfumta habuit in fundo vafis uncias duas frecum, coloris fulvi obfcuri leonati dicti, faporis dulcis \& fubfalfi; fi vero de ferri \& aluminis minera particeps effet aqua, repertæ fuiffent particula nigræ \& fubrubræ ratione ferri, \& circum vitri parietes ad inftar chryftalli ratione aluminis, nam ex diffoluta aluminis libra in 6 libras aqua communis in vafe quercino, \& per plures dies ibi detenta, aqua guttatim per ligni poros permeavit, remanente alumine chryftallifato : idemque obfervavit difloluta portiuncula aluminis rochæ in calice aquax communis. Dein fupra alumen rochæ minutiffime pulverifatum, pofitum in vafe chryftallino oleum fulphuris inftillavit, \& nulla introducta commutatio eft. Poft hac fupra grumum aquæ Avenionis minutim pulverifatum infperfit parum olei fulphuris \& fuborta eft maxima fermentatio. Perfequentia experimenta excludit præfentiam æris; annulum ferri terlum in aqua per 3 dies detinuit, \& nulla rubigo apparuit. E contra in aqua communi parumper calida diffoluta aliqua parte victrioli Cypri, in quo exftat cuprum \& ab eo extrahitur, in immerfo cultello ferreo ftatim ærugo vifa fuit. Præterea hæc eadem aqua ex additis guttulis fpiritus falis ammoniaci colorem thalaffinum feu coruleum Turcbino dictum adepta eft: quod minime evenit ex appofito fpiritu falis ammoniaci in aqua Avenionis, qua lactea evalit. 6 libr: hujus aquæ percolatæ per chartam bibulam, vel minimum terræ albæ depofuerunt confiftentiæ butyrofx \& infipidx: deinde igne miti confumpta aqua, fxes ad drachmas 3 confiftentix mellis, faporis dulcis ingrati, \& adinftar liquiritiæ elicitæ funt, quas nomine mellaginis indigitat; reliquix autem iftæ diffolutx in aqua communi, abfumpta poltea per evaporationem ad ignem, fæeces reperta funt, non variato colore, lapore, confiftentia, \& detentæ in vitro per 2 dies, exficcatæ \& per 4tam partem hor: calcinatæ, nullam contraxerunt flammam neque ftrepitum, fed femotæa ab igne, fulphuris odorem ftatim \& polt refrigerationem etiam emiferunt, \& deguftatie erant faporis falfi, quod non contigit ante calcinationem, quia particulæe falinæ \& fulphurex velut intextæ in terreftribus latebant. Deinceps in rubram tincturam baccarum contufarum amaranthi bacciferi inftillavit aquis calcis parum, \& ftatim rubedine abeunte faturata flavedo introducta eft. Exploravit etiam an aquie hrec infperfo fupra tincturam amaranthi reftituat illi ruborem deperditum, \& res pro voto fucceffit. Acutiem aqua ardentis refractam obfervavit ex fruftulis fupradicta mellaginis fulphureo-faline calcinatze in eam projectis, idemque eveniffe fpiritui vini tartarifato optime dephlegmato. Aquæ portione libris filicet 15 ad ignem evaporata, frecem diffolvit in aqua communi, \& per 3 horas detenta prope ignem, ut melius folveretur, colavit per chartam, opufque hoc ter repetitum eft, \& inyenit 


\section{$372^{\circ}$ DE PARTICULIS FER I}

invenit femiunciam terræ fubfalfæx coloris ambræ gryfex, tandem evaporata hac aqua in balneo confueto, frx inventa coloris leonati obfcuri, faporis falfi acris \& fere muriatici, \& quo magis in ore folvebatur, fubdulce quoddam guftabatur, fix reliqua ad drachmas 3 circiter noctis tractu valde induruit, faporis falfi. Semidrachma vero igni valido calcinata, odorem fulphuris fpiravit, \& cito in nihilum abiit : ex quo infertur abundare partibus admodum volatilibus. Calcinata altera portione igni nimis forti maxima exorta ebullitio, \& poft hor: quadrantem ab igne femota fuit adhuc faporis falifi. Hæc rurfus fubtiliter pulverifata \& foluta in aque communis unciis I $x$, per horam calore moderato, \& per chartan percolata uncia femis terræ dedit parum falfx coloris cœleftis : rurfus evaporata ad ficcitatem, inventa I uncia falis fubacidi albi adinftar tartari bictriolati. Ex nullo autem elato odore foetido in his calcinationibus deducitur fulphur impurum non effe fed volatile. Tandem dicit præter falem \& fulphur adeffe plurimum terre Travertinæ aut confimilis, ex quibus tribus balneigrumus conftet : grumus enim ut \& terra extracta \& colata ebullit, \& fermentatur ex fuperaffufo oleo fulphuris, quod fere prorfus privatur fua aciditate, ac in hac terra non fecus ac in illa Travertini abditx funt particulæ acres. Qua vero quantitatis proportione in thermis Abinionis fal \& fulphur exftent, ei patefecit deftillatio 9 librarum hujus aquæu ufque ad remanentiam unius libræ \& dimidix, qux percolata depofuit terræ infipidx fere drachmas I I coloris ambræ gryfex. Evaporata inde aqua percolata reliquit fcrupulos 5 mellaginis, \& calcinata femidrachma folum reperta, abfumtis 3 fcrupulis cum dimidio partium volatilium \& craffarum ; in unciis duabus aqux iterum diffolvit \& per chartam colavit, \& ab ea feparata funt grano i 5 terræ infipidæ coloris cœleftis, \& evaporata aqua in balneo confueto ad perfectam ficcitatem, relicta funt grana 20 falis adinftar tartari victriolati tum quoad faporem, tum quoad colorem.

\section{Fons Lauchftadienfis.}

Ominus Friedericus Hoffmannus de fonte martiato Laucbftadienfe fcripfit prout fequitur : fons ad alvei latera ochram flavef́centem egerebat; vitro excepta aqua turbulentam tantifper faciem exhibebat, \& guftu explorata faporem Martialem \& victriolicum linguæ imprimebat : infperfo autem gallarum pulvere, purpureo perfundebatur colore : levitatem aquie invento $\mathrm{ab}$ ipfo hydrometere, animadvertit eundem capto ad fontem tentamine, gravitatem quandam mentiri, \& pondere pluvialem aquam fuperare, domum autem delatam, hac leviorem effe \& inftrumentum altius mergi. Affudit dein fpiritum victrioli \& nitri, quorum utrumque aqua fine pugna five conflictu excepit, quod tamen folenne eft, fi alcalinum elementum eandem incolit. Porro Mercurii fublimati folutionem adjecit, fed pariter neque rubicundus, neque flavefcens, neque lacteus color, qui alcalinum fixum vel cum acido ruptum vel etiam volatile elementum prodidiffet, in confpectum prodiit. Tum addidit folutionem Martis, itidem fine ulla fubfequente mutatione, qux fi flocculos flavos protrudit, aut colorem nigrefcentem induit, terra 
calcarix \&adftringentis principii index eft. Preterea oleum tartari per deliquium inftillavit, quod quidem nullam edidit ebullitionem, nihilominus tamen pellucidam faciem tantilper conturbavit, \& leves albefcentes floccos eructavit, ob tenue terreum in aqua contentum elementum. Denique gallarum folutionem infudit, qux tincturam fufcepit ex atro brunam, nihil tamen ad ima dejectum, luculento indicio, hofpitari in aquæ fnu principium Martiale : indicia Martis luculentius perfpexit, quod indulia balneantium flavo colore inficerentur, \& ovum humori injectum, brevi tempore quoad omnem putaminis ambitum, flavedinem indueret. Imprimis autem terra illa rubra bolaris, qux non folum canalium, per quorum alveos aque decurrunt, parietes inveltit, fed etiam in conceptaculi lapidei, in quo aqua per hyemem affervatur, fundo copiofe fubfidet \& colligitur, Martialem indolem teftatius prodidit. Qux, quod nihil aliud fit, quam fubtilis fulphureo Martialis terra \& verum Martis crocum implicitum foveat, his compertum habuit tentaminibus. Cepit hujus terræ uncias duas; eandemque aqua prius elotam \& a craffioribus fabulofis partibus liberatam, in crucibulo primum leni igne ficcavit, quo elapfo horæ quadrante, colorem fufcum exhibuit, \& audo polthac caloris gradu, perufta intenfus rubere copit, $\&$ in genuinum Martis tranfiit crocum. Hunc poft refrigerationem exemit, \& addito dimidix ejus parti tantundem falis ammoniaci iterum igni debito modo fubmifit, fublatis haud ita multo poft nicidifimis floribus, qui ad 4 fcrupulorum pondus accedebant. Tum his affudit fpiritum vini rectificatifimum \& præftantiffimam Martialem tincturam extraetam efle animadvertit, quam tam folam, quam melius adhuc effentix amare ruptam fubinde ad ftomachum roborandum adhibuit. Præter Martiale autem hoc elementum, aquam fontis incolit etiam aliud quoddarn, omnibus mineralibus aquis medica virtute nobilitatis, commune principium, fubtilifimus fcilicet ille fulphureus \& æthereus fpiritus, cujus prefentiam plura phænomena planam faciunt atque teftatam; fcilicet fuperius jam memoravit lancem hydrometricam aqua recenter hauftxe injectam, furfum ferri \& gravitatem monftrare, quæ mota \& aeris acceffui patente eadem difparet. Porro aqua hæc vitro infufa \& longe magis patinæ ftannex inmiffa carbonibufque impolita, innumeras bullulas emittit, in margine \& fundo valis collectius confidentes, quæ nihil aliud funt, quam fubtilifimæ aereo xtherex in aqux finu contentæ partes : præterea eidem fubtiliffimo huic elemento in acceptis referendus tenuis ille halitus \& vapor, quem aquæ exfpirant, quo fit, ut fi copiofus ingurgitentur, caput quafi temulentia \& fomnolentia afficiatur. Eadem etiam caufa fubeft, quod latex algidifima quoque hyeme frigore non condenfetur, \& humoti, fi curiofius aeris arceatur allapfus, diu fine corruptione fua conftet integritas.

Alia adhuc de fonte Lauchfadienf f facta funt experimenta, fcilicet quod cum folutione aluminis nilhil principio alteraretur, fed dein aliquæ bullæ exfurgerent. Cum folutione luns coloris opalini fieret, qui ad rubrum vergeret. Cum folutione Mercurii fublimati nulla mutatio, nec cum fpiritu victrioli, nec cum fpiritu nitri. Cum oleo tartari per deliquium Claffis III. de ferro. $\mathrm{Bbb} \mathrm{bb}$ 
cum albis floccis fupranatantibus. Per folutionem auripigmenti cum calce viva nigre viridefceret, fed diaphanum ufque remaneret. Per folutionem fulphuris cum calce viva nigre grifee præcipitaretur. Cum folutione gallarum coloris e nigro rubri fieret. Cum folutione lacmi parum alteraretur in rubrum.

\section{Fontes Carolini.}

Ominus Johannes Bergerus de fontibus Carolinis cap. 3, dum rationem inveftigandi materiem \& temperationem thermarum Carolinarum proponit, accuratius ante omnia examinanda putat varia fofflia ejus regionis, in qua hæcalidx manant, quæ in pyrite, ferri \& falis cujusdam, nitrofi, ejusque generis faxi calcarei, quod vocatur gypfum, venis potifimum confiftere pro comperto habet. Aquas ad libram circiter modo ex fonte hauftas, injecto tantillo pulvere gallarum ad 2 vel 3 grana illico purpurefcere, infufo oleo tartari per deliquium femper laetefcere ; cum folıtione falis petræ \& communis amice mifceri, ex fale armoniaco autem falem volatilem liberare, cum folutione victrioli non fine conflictu confundi, obfervavit. Exhalatione librx thermarum unius fedimentum albidum drachmæ tantum dimidix ponderis, \& iterata folutione falem præbere chryftallinum granorum circiter 25, faporis nitrofi expertus eit. Dein capite 4to in genere has aquas ex fale nitrofo per minima foluto \& ramentis gypfi, ac diverfis tenuiflime particulis pyritis fulpbureis ac ferreis conftare, ea quidem proportione, ut fextarius vel libra una aquxe grana falis minimum 25, pollinis vero gyplei grana circiter 4 vel 5 , minimumque partium pyritis complexu fuo contineat, daret. In fpecie autem falem nitrofum thermarum pro aphronito habet.

Non enim inde, ait, procul fitæ funt aluminis fodinæ, quæ infignem pyritre copiam oftendant. Tophus, qui intus inferiufque, in tubis iis reperitur lapis ruber \& lateritius, is magnam partem ferreus eft ex ochra pyritx: fi tophus ille uratur \& in pulverem teratur, affula aqua, \& agitato vale, videbitur pulvis gravis, fplendens \& ferrugineus fubfidere, eique pulvis rubricofus \& albicans infidere: admoto magnete tractum fuiffe dicit, eique tenuiffimæ inftar fcobis chalybex adhæfiffe : in aquas calidas injectis gallis, illico dilute purpurafcere, eo modo quo aqua vulgaris, limato affula ferro, injectis gallis folet. Abit autem color hic una cum calore, isque, cadente ad fundum pulvere gallarum, ob conjunctionem ochræ rubello, primum in jucunde viridem, dies aliquot durantem, ac demum fenfim in aureum, vel fuccineum. Sed ubi pulvis gallarum in aquas has frigefactas injicitur, nihil purpureicoloris apparet; fed paullatim aqua primum turbida redditur, deinde albicans evadit, \& fimul lactei coloris aliquid ad fundum demittit : cumque ita per noctem relinquitur, fit primo viridis, poftea aurei coloris. Aqux licet femel refrigeratx iterum calefiant, tamen ab injectis gallis non purpurafcunt, fed ut prius color albicans, viridis \& fuccineus color ordine fuccedit : fed five caleant five frigeant, $a b$ infufo oleo tartari per deliquium, aut fale fimili liquato, fine lucta in mọdum emulfio. 
emulfionis laetefcunt : fyropum violaceum brafficæque rubræ fuccum viridem ac herbaceum reddunt; tincturam rubram ligni Brafilienfis exaltant; cœruleum heliotropii colorem, ab acidis mutatum \& rubentem, inftaurant; folutionem Mercurii colore mali aurei præcipitant. Mifcentur aquæ amice cum folutione falis communis, cum fpiritu falis ammoniaci, falibus volatilibus aliis. Aurum ex aqua regia deturbant; \& cum acidis omnibus vehementer luctantur, cum eructatione bullularum diu perdurantium; a fpiritibus fulphuris \& victrioli faporem recipiunt acidularum æmulum, nulla coloris facta mutatione. Quum exhalaretur, \& dimidium per alembicum tranfiiffet, odor acer, volatilis \& fulphureus nares tanta vehementia feriebat, ut perferri nequiret: fedimentum erat albidum cum aliquo rubello, flavo, faporis alcalici \& falfi, odoris nullius, quod fortiter cum acido ebulliret, dedit admoto magneti quasdam pyrite ferreas moleculas ; aqua pura folutum \& colatum, fal dedit alcalicum, fixum \& nitrofum, figura Atriata \& plumofa, coloreque albo partin, partim dilute flavefcente. Iterata ejus folutio odorem præbebat fuavem violaceum, inftar lixivii falis tartari, nitrique fixati ; factaque, quanta fatis eft, liquoris exhalatione, fal purior fiebat \& chryftallinus, atque in tenues longasque nitri ftirias, cum intertextis falis communis cubis apparebat, faporis penetrantis alcalici, falfi, \& cum amarore quodam refrigerantis five nitrofi, relicto in filtris polline albo, ejusdem naturæ calcarix, ac innatans aquis in balneis \& folutionibus tophorum uftorum, cuticula. Cum fale illo, quod notandum eft, omnia phrenomea, quæ aquarum ipfarum cum fyropo violaceo, Mercurio fublimato, rebusque aliis, mixtione fierent, melius evenire; admifto eodem liquoribus quibusque acidis, infignem oriri ebullitionem, cum fpiritu viotrioli tantam, ut vitrum incalefcat. Inde vero fal emergit compofitum, fimile nitro victriolato, five arcano duplicato, fi cum acido victrioli, vel nitro cathartico, \& arcano tartari, fi cum acido aceti conjunctio facta fuerit. Tumultuatur idem fal cum folutione viEtrioli, unde feparata ochra, nitrum quoddam victriolatum pariter confurgit. Sed acrius effervefcit cum folutione auri in aqua regia, \& aurum vehementer fulminans præcipitat, ac loco falis tartari, additum duabus fulphuris, \& tribus falis petræ partibus, pulverem reddit fulminantem. Idem fal laminæ candenti ferrex impofitus, illico liquefcit, \& inflatur ac tumet in bullulas, uftusque penitus falis alcalici albi cum amarore folito aliquid relinquit, qui cum acidis effervefcit, \& candenti laminæ denuo impofitus , haud liquefcit, crepitat tamen \& faltat. Hæc clariffim. Joh. Goth. Bergerus.

Prudel circa Carlsbad, 2 libris aqua evaporatis remanfit 1 drachma, qux dabat I fcrupulum falis, grana 8, \& grana terræ 1 5. "Per folutionem aluminis non multum præcipitabatur. Per folutionem lunæ lactefcebat, led dein corulefcebat. Per folutionem Mercurii fublimati parumper precipitabatur. Per folutionem facchari Saturni lactefcebat \& ftatim precipitabatur. Per folutionem victrioli Martis habebatur precipitatum pallide viridefcens. Per fpiritum victrioli fortiter effervefcebat. Per fpiritum nitri non tam multum; per oleum tartari per deliquium fuppedita- 
bantur flores albi. Per aquam calcis vivæ copia infufam prxcipitabatur. Per folutionem auripigmenti cum calce viva præcipitabatur albe fed parum. Per folutionem fulphuris cum calce viva plane lactefcebat \& turbabatur. Cum folutione fulphuris cum fale tartari turbide flavefcebat. Cum folutione gallarum nulla mutatio : cum fyropo violarum flavefcebat.

Acidule calide circa Prudel. Aqua per folutionem aluminis albefcebat. Per folutionem lunx lactefcebat, dein amethyfti inftar coerulefcebat, ad fundum præcipitabantur albi flocci. Per folutionem Mercurii fublimati nulla fiebat mutatio. Per folutionem facchari Saturni lactefcebat \& cito prsecipitabatur. Per fpiritum victrioli fortiter effervefcebat. Per fpiritum nitri parum. Per oleum tartari per deliquium lactefcebat, dein albe pracipitabatur ad fundum. Per aquam calcis vivx turbabatur, dein clarefcelbat. Per folutionem auripigmenti cum calce viva præcipitabaturaliquid album ad fundum. Per folutionem fulphuris cum calce viva fiebat coloris pulchre opalini. Per folutionem fulphuris cum fale tartari, albide flavefcebat, fed parum precipitabatur. Cum folutione gallarum nulla fiebat mutatio. Syropus violarum corula remanfit. De his in Brefslawif. Natur - und Medicin-Gefchicbten.

\section{Aque Atgrance.}

FX $3 \frac{\pi}{2}$ ib. evaporatis remanfit I drachma, 2 fcrupuli; ex quibus feparatis habebantur 4 fcrupuli, 3 grana falis \& 10 grana ochre. Cum folutione aluminis ebulliebat, fed tine precipitatione. Cum folutione lunæ laetefcebat \& album remanebat cum floccis craffioribus. Cum folutione Mercurii fublimati parum albefcebat cumbullulis \& pellicula. Cum folutione facchari Saturni lactefcebat \& celeriter deturbabatur. Cum folutione victrioli Martis præcipitabatur.in pulverem album cum cauda pavonis. Cun folutione Veneris præcipitabatur ad album viride. Cum fpiritu victrioli ebulliebat mediocriter. Cum fpiritu nitri debiliter effervefcebat. Cum oleo tartari per deliquium præcipitabatur albe. Cum aqua calcis vive remanebat pellucida. Cum folutione auripigmenti cum calce viva plane nigrefcebat \& fotebat inftar ovi foetidi. Cum folutione fulphuris cum calce viva pracipitabatur albe, fupra vero plane nigre. Cum folutione gallarum primum flavelcebat, dein per vices bruneo rubrum colorem adipifcebatur. Cum fyropo violarum viridefcebat: vide Bre/slauif. Naturund Medicin - Gefclbicbte.

\section{Acidulae ad klein Engltinger.}

DEr folutionem aluminis lente evafit coloris opalini, fed tandem precipitabatur inftar floccorum. Per folutionem lunæ aliquantifper effervefcebat, fed per vices rubefcebat, tandem rubeum plane evafit. Cum folutione Mercurii fublimati-limpidum remanfit cum aliqua cuticula. Cum folutione facchari Saturni ftatim fiebat opalum \& opacum, \& precipitabatur ad fundum. Cum folutione victrioli Martis primum nulla reagentia, 
tandem præcipitabatur. Cum folutione Veneris per vices fiebat viride inftar celadon. Per firitum vietrioli effervefcebat cum bullulis. Per fpiritum nitri parum effervefcebat. Per oleum tartari per deliquium turbabatur, fed clarefcebat iterum, cumque plus injiceretur, iterum turbabatur. Per folutionem fulphuris cum calce viva lente flavefcebat, tandem præcipitabatur albe cun foetore. Per folutionem fulphuris cum fale tartari lente fiavefcebat, tandem albefcebat. Cum folutione gallarum per gradus obfcurum evafit cum cuticula. . Cum fyropo violarum viridefcebat. Cum folutione lacmi ftatim limpidum \& rubrum fiebat. Brejshanif. Natur-" und Medicin. Gefcbicbte.

\section{Fons Tscbagunenfis.}

DOminus Jacobus Francifcus Vicarius in bydropbylacio novo de aquis fontis Tscbagunen/is etiam egit; in fuperiori loco duplicem comparuisfe venam dicit, lulphuream unam, alteram bictriolaceam: aquam vitro exceptam odorem acidulum exhalaffe, vix autem notabili acore linguam titilaffe, ac ultra menfuram hauftam appetitum ftimulaffe; fexto ad fontis featuriginem bolarem quandam terram rubram five ex flavo rubellam copiofiffime fubfediffe; aquam vero nec pifcium vitæ protrahendæ, nec ciceribus emolliendis accommodatam, lac coagulaffe. In aquæad prædictam methodum ponderat: uncia qualibet duo fere grana mineralium delituiffe. $A b$ aqua ad normam veterum deftillata merum phlegma infipidum, a nullo alio liquore alterabile prodiiffe, capite mortuo pariter infipido relicto. Evaporatam eandem aquam chryftallos minimas cufpidales \& infipidas exhibuiffe, qux nec cum alcalinec cum acido ebullierint, ab acido tamen f piritu fine ftrepitu diffolutæ; ultimo ab oleo tartari per deliquium \& (piritu urinæ, neutiquam vero ab acidis fpiritibus, nec a nitri, falis communis \& aluminis folutionibus turbatam aquam fuifle, cum defcenfu coaguli quafi albi æqualis illi, quod pars prorfus modo ex vietriolo albo confuevit præcipitari.

\section{Fontes Spadani.}

TNter fontes Spadanos eft unus Geronfter dictus ob ferreum \& fulphureum nidorem preter bictriolica effluvia, fulphuris etiam ferrique minera faturatus. Communis \& omnibus quatuor Spadanis fontibus eft multicolor quædam iridifque coleftis æmula pinguedo, aquæ vafe terreo conclufie innatans, quæ liquidum fuccitrum videtur, ob ejusdem fáporem flammamque fulphure clariori editam. Id etiam commune habent, ut eorum alvei aut canales rubro vel fubflavo colore inficiantur a ferri maire feu rubrica deducto : præterea ranas injectas, aftacos ac pifciculos occidunt, nondum circa majores periculo facto.

Aquxe hx alias faporem acidum \& ferrugineum pre fe ferunt, aceti rubri colorem gallx additione induunt; nulla ex affufione fpiritus ammoniaci facta eft in iis precipitatio. Poft deftillationem pulvis inftar ferrea rubiginis, fal itidem ferrugineus extractus eft.

Clalfis III. de ferra.

Cec cc 


\section{Aqua Provinenfes.}

Ominus Giure in libro de aquis mineralibus, quxe Provini reperiuntur, eandem in his aquis faporem inefie ait, quem in aquis' fabrorum, ubi ferrum exftinctum eft, ac diverfis in glebis varios coctionis gradus animadvertit, cum alibi flavæ, alibi rubre, interdum nigrxappareant. Hanc ferri venam cum per bigluum foli expoluifet, mollis inftar argilla aqua dilutx permanfit, fed exficcata ad ignem ferrum redolebat: fula velut fcoriam ferri exhibuit: cum ex ferri vena mollior eft, \& aqua diluitur, tum fpecien præ fe fert amurcæ aut frecis olei. Ubi aeri diutius exponitur, durior eva. dit $\&$ in grana concrefcit, quæ nullam vim aquis tribuunt.

\section{Aqua minerales Ilmingtonen $\int e s$.}

Dminus Samuel Derrham de aquis mineralibus Ilmingtonenfibus fcribens illas de bictriolo Martis participare putat: fcilicet aquas Imingtonenfes in fe luftratas colore multo pallidiori apparere, miftas vero cum violarum fyropo in viridem mutari : cum pulvere autem gallarum colorem modo purpureum, modo etiam nigrum contraxiffe; quippe a decima lexta grani gallarum parte vel integrum aqux fextarium feu pintam colore tinctum fuiffe purpureo, quem magis tamen conficuum, ac fyropo rofarum Damafcenarum cum aqua fimplici mifto perquam fimilem, octava faltem grani gallarum pars adjecta reddiderit. Non fecus ac major pulveris gallarum quantitas addita obfcuriorem ac atramentofum penitus aqua colorem induxerit. Ab aque ejusdem pinta ficciori tempore trutinata, pintam aqux communis dimidiam fere drachmam fuiffe fuperatam: humidiore autem tempeftate, \& ubi ocbra jamdum fubfederat, æquilibrium utramque inter aquam adfuiffe, unde fere nullum certum cujuslibet aquæ fontanæ definiri poffe pondus conjicit. Aluminis nihil aquis his ineffe e comparatione harum cum aquis aluminofis facta perfuadet, aluminis fiquidem folutionem oppido lacti inferre coagulum, non item aquas llmingtonenfes. $\mathrm{E}$ diverfo aquas apud Ilmington fxces alvinas inficere nigredine fecus ac aquas imprægnatas alumine, cui ipfi folenne alias effet, fi cum fpiritibus urinofis, verbi gratia, fpiritu cornu cervi effervefceret, cum pulvis tamen rubellus poft evaporationem aquæ Imingtonenfis relictus non nifi cum acidis in effervefcentix abiret motum. Pulvis etiam poft evaporationem refiduus multum a nitro difcrepare obfervatur ; deinde vero deftillatæ aquæ exdem partim aquam fundant prorfus infipidam, nec odore fulphureo nares ferientem; partim autem fuppeditent remanentiam, quæ uti \& fedimentum carbonibus vivis aut ferro candenti impofita, fulphuris communis adinftar nequaquam concipiat flammam. Quod vero aquæ prædicte, ubi aliquandiu ftagnaverint, cuticulam five cremorem quendam fubcceruleum in fuperficie contrahant odoremque tetrum exhalent, non tam fulphuri cuidam adjudicat communi, quam putrefactioni fulphuris embryonati, cum minerali fimul apportati tantillum exaltanti; concludit proin e mutationibus, quibus e pulvere gallarum fons llmingtonenfis potitus, 


\section{E T, VICTR I O L I N A QU IS.}

hunc, ingredi omnino vidtriolum : cumque aqua Ilmingtonenfes talem ochram obtineant, qua ad terram mineralem potius ferri quam cupriaccedat, hinc victriolum Martiale ineffe putat: quod ut demonftret, fubnectit: 1. aquam vulgarem vietriolo Martis impregnatam eodem propemodum fapore infeciffe linguam. 2. Utramque aquam a minorigallarum portione colorem acquifiviffe purpureum, fub hactantum difparitate, ut purpureus aquæ mineralis color ad rubrum, folutionis vero victrioli ad cœeruleum magis accederet, quod tamen difcrimen ab ochra fubrubra faltem aqux minerali combinata, provenire, nec diverfam arguere materiam, prolixe fatis evincere fatagit. 3. Aquam utramque a majore gallarum copia atramentofo colore ita fuife tinctam, ut nigredinem hanc, ob rationes additas, modo cum transparentia priftina adjecto acido commutarit, modo etiam ab alcali inftillato denuo recuperaverit. 4. Aquam neutram lacti conciliafe coagulun ; 5. vero utramque aquam parum ab oleo tartari per deliquium fuife præcipitatam. 6. Terram fubrubram poft evaporationem relictam, item ochram fponte fua fubfidentem, cum paucis aliquot guttulis fpiritus nitri æque ac victrioli inftillatis, notabilem \& cum fpuma fumoque fociatam concepiffe ebullitionem, cui fimilem quoque in victriolo Martis a fpiritu nitri, non tamen a firitu victrioli, cum ab hoc ferrum in victriolo Martis perfectius jamdum, ac quidem in aqua minerali ab acido efurino faturatum fit, annotatam fuiffe effervefcentiam. 7. Denique fal \& terra infipida poft evaporationem multam fuperftite, convenienter extractum, colorem quidem pallidum, figuramque irregularem obtinuiffe, eosdem tamen cum bictriolo Martis dediffe effectus.

\section{Balnea Pifana.}

DOminus Jofephus Zambeccari balneis Pifanis ineffe putat fal commune, nitrum, talcum, gypfum aut terram albam ac victriolum fimul: primo quxfita eft temperies exactifimo thermometro 50 graduum, \& compertum eft thermalem æftum ad 36 gradum afcendere; ad quem etiam Syrius ardens \& humanus calor perveniunt. Secundo chryftallinus emicuit nitor. Tertio infipida pene deprehenfa eft, nullam inducens naufeam epota. Quarto aquæ plumbeis organis deftillatæ \& Mercuriifublimati folutioni immixta, vel etiam oleo tartari permixta, lacteum colorem exhibet, qui ad flavedinem vergit; fi folutionem victrioli in aqua communi factam recipiat. Quinto dum in vapores refolvitur, fedimentum unius denarii ponderis ad quamlibet aquæ libram partim parietibus vitrei vafis partimque fundo velamenti adinftar inhæret, albiffimi ac veluti gypfei coloris, tenuiffimis ac perfpicuiffimis filamentis, chryftallorum in modum, diftinctum. Sexto, antequam hoc fedimentum penitus exficcaretur, acuti falis faporem præferebat, qui tamen brevi evanefcens, granulorum arenæ infipiditatem æmulabatur. Septimo cum victrioli firitu effervefcentiam init eidem fimilem, quam idern fpiritus cum oleo tartari aggreditur. Octavo idem fedimentum victrioli aqua folutum, ejus virorem \& claritatem obfcuro ac flavo colore intenfiori turbat. Nono at cum gallæ tinctura 
commixtum, hanc colore imbuit obfcure virenti, materia quadam cinerea fundum petente gypfo fimili, quo etiam gallæ tinctura diluitur. Io. Hoc \& itidem præftitit idem fedimentum diligentiflime edulcoratum omnique fale ac fapore denudatum. I 1 . Infipidum hoc fedimentum nullo modo a gypfo differre, \& potiffimum idem effe cum eo, quod circa fupradicti balnei vicina loca reperitur, \& quo utitur natura, ceu thermali aqua potiori elemento. 12 . Illa vero tenuifima ac perfpicuiffima filamenta talco efformantur in ftamina quidam fufo vulgo specbio d'afno dicta, cujus feraciffima eft circumftans tellus. 13. Aqua, qua ad infipidicatem ufque edulcoratum eft fedimentum, per chartam trajeeta, fal gemmx vel commune exhibuit, fapore \& cubica figura obvium : uti etiam fal nitrum hexagonis chryftallis \& acuto quodam frigorifico fapore manifeftum; quod nitri parietibus inhærens etiam occurrit, nexu quodam fe contextu filamentorum fundum occupante, quod forfan matricis adinftar hexagona nitri prifmata concludit. I4. Huic aqua fingularis vis ineft; alba lintea colore inter flavum atque æruginofum medio, aqua victrioli in modum tingere iplaque faxa balnei fundo indita. I 5. Circa parietes, qui aquarum fuperficie perluuntur, fubftantia quiedam heret victriolici coloris faporisque auferi ac fiptici. I 6 . Denique unctuofa quædam materies hac aqua vehitur, qua perfufa tellus ita oblinitur, ut gliffenti pedi calcar addat. Cum autem thermale fal ignitis laminis admotum accendatur, haud æegre evincitur, eidem ineffe florem quendam fulphuris aut bituminis puriffimo oleo, petroleo aut fimili fubftantix refpondentem.

Idem auctor defcribit etiam Balnea Pifana montis Sancti Fuliani dicta; primum balneum Bagnetto, balneum parvum dictum in thermometro 50 graduum, 37 gradum caloris attingit. Secundum balneum calidum, Bagno caldo, 39 gradum. Tertium balneum grande, Bagno grande, feubalneum ad fcabiem, 37. Quartum balneum parvi putei ipfius balnei magni del Pozzetto del Bagno grande, 37. Quintum \& fextum, balnea de Duciis de la Daccia, quorum unum maribus, alterum freminis dicatur, 36. Septimum balneum Reginx 40. Oetavum fons hujus balnei 37 . Nonum balneum nervorum 34. Decimum balneum ad tineam 36 gradus incalefcunt. Quo tantum videntur differre, cum ratione milcibiliumnon multum diffentiant. Carent tamen rubrica ac talco, quibus exceptis cum balnco de aquis integre conveniunt, dum fal commune, nitrum, bictriolum, bitumen, fulphur ac gyplum in ipfo monte fancti Juliani abundans contineatur. Nidorem fulphuris redolent, lenem tamen atque olfactui innoxium.: Ex ipfis balneorum duetibus fal nitrum efflorefcit; quod calidam cum calchanto ebullitionem init; atque ex ipfis aquis omnibus unetuofitas quxdam bituminofa fecedit fundo ac lateribus continentium vaforum infixa, quarum fedimentum analyfi per ignem adeptum cum oleo tartari neque effervefcit, nec bullulas aut fpumam effundit, quod a milcibilium numero alumen excludit. Harum aquarum mixtio cum aqua victrioli flavam exhibet tincturam, ac multo faturatiorem redditam ab aquis parvi putei ipfius majoris balnei : cum fublimato foluto dealbantur: 
\& gallarum aut aluminis folutioni permixti colorem non mutant, quem lacteum reddit oleum tartari atque aqua rofarum. Sedimenta harum aquarum quantitate differunt : nam ex I 3 libris aqux parvi putei balnei majoris totidem tantum denaria deprompta funt : \& 13 libræ balnei Reginæ 5 denaria exhibuerunt. Hæc omnia, exceptis iis ab aquis putei parvi fecedentibus, infipida deprehenfa funt, aut faltem minus intenfe falfa : dum illud aquarum ipfius putei parvi manifefte falfum elt, fale tamen facile faliva folubili ac minus acuto. Hoc etiam fedimentum aquam victrioli ad flavedinem denfiorem mutat, ac prævia fermentatione materiem flavam. vividiorem præcipitat : idemque folutum communi aqua fimul cum fub. limato fubalbidum colorem promit, ac cum gallæ tinctura ad virorem accedit, victriolica mixtura haud levi argumento.

In aquis balnei nervorum certa fulphuris portio fpeciatim diffolvitur, quod argenteos nummos aureo colore tingit, non fecus ac aquax $B z-$ thenfes in Anglia. Tartarum vero Pifanis Duciis inhærens duorum generum eft, unum craffum ac fixum eft tartaro vini fimile; alterum tenuiffimum fub vaporis fpecie ex aquis elatum; atque in earum fuperficie fubtiliffimi filamenti adinftar concretum, facile in tenuifimum pollinem friabile, lenis faporis nitrofi. Hic pulvis ipfis aquis commixtus farcoticus fit, a quo lota ulcera validiffime exterguntur.

\section{Aque Bliandule.}

DOminus Valisnerius de aquis Blandulis facta aquæ leni ad folem evaporatione, in fundo vafis fedimentum nigrum, vifcidum, tenerum atque floribus caffix fapore \& colore fimillimum remanfiffe ait. Grata aciditate linguam feriiffe, nec ad folem, ut terreftria folent, exficcari, fed femper tenellum apparere; credibile inde exiftimat conftare bitumine balfamico \& foribus victriali.

\section{Aque in agro Mutinenfi.}

VAlifnerius de fontibus victriolatis in rure dicto victriola in agro Mutinenfl, dicit ob partes vietriolicas \& atramentofas eis veftes albas immergi \& nigras extrahi : aqua alias limpida eft, faporis omnis expers, terram tamen lacultresque herbas, quas lambit, flavo ferrugineo colore inficit. Innatat illi, telæ adinftar fubtiliffinæ materia levis, iridis colores æmulans, qux exficcata pollinem aureolum dabat. Lutum in imis nigerrimum eft aptifimumque operi tinctorio. In his medicatis fontibus agreftis populus pannos lineos laneosque nigrat, non fine tamen aliqua pracedente praparatione, ut intimius faturentur.

\section{Fons Weftrogotbicus ejusdem indolis, Svecice.}

N Weftrogothia Svecix eft receptaculum quoddam aquarum, exigui lacus inftar, in quod aqua ex tribus fontibus influunt, fontes invicem Clafis IIT. de ferro.

Ddd dd non 
non diftant ultra 4 vel 5 ulnis, ex uno fonte faturit aqua dulcis \& omnis faporis expers ; ex altera aqua parum vittriolata; ex tertio aqua admodum sictriolica, quod ex fapore ut \& ex ochre \& rubrica abundantia colligi poteft, quæ fontem circumcirca obfidet \& præfertim tramitem alveumque inde fluentis aqux: hæ, cicatebræ aquas fuas in unum receptaculum exonerant commilcentque; in fundo hujus receptaculi eft terra vel humus nigra, cujus ope denigrari folent veftimenta, \& nigredine pulchra \& nitidifima imbui, fed prævia quadam præparatione, non aliter ac in aquis præmemoratis Mutinenfibus; ubi etiam veftes luto fontium immerguntur.

\section{Fons Lalius.}

Do

Ominus Gratianus Bergomenfis de fonte Lalio acido Recobarii fcripfit, quod accuratum fontis examen inftituerit, \& illum coloris chryftalli infar pellucidum adinvenerit, odorem fulphureum \& ferruginofum, faporem qui gratum admodum acorem lingux imprefferit. Tactilium qualitatum, quæ præter mirandam frigiditatem, afperitatem haud modicam præ fe tulerunt, non aliter ac fi calcbantum ibi nitrumve folutum fuifict, pondus ejus communibus aquis eft levius, inito per æreometrum ac bilancem experimento : dein inductis de induftria variis coloribus, facta aquxe evaporatione, infolatione, putrefactione ac deftillatione exploravit, nihil aliud ibi delituiffe quam fpiritum quendam fubtilem, penetrantem, acidum ac fumme diffolubilem, ferri benam corrofam \& fponte fubfidentem, atque effectus fere omnes, qui ex victriolo haberi confveverunt.

\section{Fontes 8 balnea Italica.}

BAccius mentionem faciens aquarum ferruginearum, dicit : Bona Latii B pars atque Campanix, fi qualitas foli ac venarum quarundam refpiciatur, tota pulvere illo Puteolano fcatet, nigro, ficco acferri metallo quam fimillimo; \& ex aquis perraras idcirco hæc tellus obtinet finceras, \& qure non fint aut acidæ, aut fallie aut ferrugineolipore. In Bajanis plures ejusmodi venxe ferrugines dictx, fuccellaria, \& qux olim cognomento folis \& lun erantinfignes.

Balneum Avinionis in Senenfi, ferruginee eft nature, nec minus id fordes ipfie, qux juxta canales indurantur, fignificant, partim rubiginolix \& duri, partim vilcoli, virides \& lividie. .

Ficuncella aqua temperate calida ac limpidiffima eft, ac guftui non ingrata, nifi ferrugineo quodam fapore ac ficco. Minera ferri pluri ex parte eft, quod \& fapore \&reliquiis æruginofis, ochræ inftar, ubi incurrit aqua, percipitur.

Aquabalnei de buxo pariter eft calida', minoris tamen acuitatis debiliorisque operationis quam prædicta ponitur, minera gaudet pluri ferri portione, fed non fine aliqua nixtura auri, ut putat. 
Pariter aqua balnei magni, ut \& Sanci Georgii, quam putat participare de ferro \& ære, quamobrem viride quoddam lutum, ubi incurrit hæc aqua, refidet, quod fub folis calore nigreĺcit.

Sic etiam Caldanelle aque, ut \& aque Balneorum de Rufellis, quxe pofterior clariffima eft nec valde cálida, quin ubi refrixerit, fuavis adeo guftanti apparet, ut vix eam mineralem agnofcas, ac jucunde admodum cum vino diluta bibitur.

Aqua ville in agro Lucenfi nullis in Italia balneis poftponenda : minera ftatuitur imprimis ferrea ; aqua ipfa clára \& calida elt, cexterum colore inculpabili quidem ac fapore ferratæ aquæ ac ftiptico percipitur, quod \& lutum ipfum circa alveos confirmat, ferrugineum quidem ac purum, fcobibus quibusdam lapidum aluminis intermiltum ac ftipticum.

Caldane in Pifano actu calidx funt, ac mineræ naturaliter ferrex ac aluminofx. Aqua balneorum regina in Pifano, etianı de ferro \& alumine participant.

Aqua balnei Caldinaris in Veronen/i mineram procipue ferri posfidere cum alumine \& fale \& potius nitri fubftantia \& quodam fulphuris vapore.

Aqua balnei longi in Bullicano ex cumulorum, unde tranfeunt, natura, ferreas particulas continet atque aluminofas, atque eas actu calidas, fed in operationibus temperatas : \& mirum videtur, quod in horis varios colores mutent, modo aurei ac Pplendidi coloris, ut fui natura funt, modo atri ac turbulenti pro heterogeneis, qui eas continuo exagitant, vaporibus.

Aqua balnei ad Narnin fuvium, eft clara, frigida, cum quodam faporis fenfu \& fine ullo odore : quidam accuratiffime hanc aquam deftillavit \& recrementa diligenter examinavit, qux alba erant \& guftu acria \& in igne crepitabant : plures in eo funt partes falfæ, nitrofæa atque aluminofix, ferro item atque alumine participat.

Pergit adhuc Dominus Baccius aliafque \& aliarum regionum aquas ferratas \& vietriolicas defcribens, his verbis: Aqua Tungri, qux hodie eft ad Leodium in Belgis, Plinius dicit, Tungri fontem habet infignem, pluribus bullis exftillantem, cujus aqua igne admodum turbidefcit, ad poterum rufa redit, ferruginei faporis, quod ipfum non nifi in fine potus percipitur. Craffefcunt hæ aqux admoto igne, ex mixtura nimirum aliqua vel falis vel aluminis, ut fapor ipfe refidui poft deftillationem oftendit, ruffefcuntque fimiliter ad finem ut præfcriptx fub Narnia ex ferrugineis excrementis.

Ferrata in Bajanis, unde etiam nomen habet, pariter alix quxdam aqua in Bajanis. 
Eft etiam aqua ferrata in Luculliano juxta Neapolin, eft enim, qux in dextra oritur parte, colore limpida, quamquam paullo poftea albefcat in vafe, fapore acri, acidulo, ftiptico, nec fatis grato: fubftantia pingui ac certo pariter odore. Siniftra autem colore fere lactea emanat, pinguiorque fapore \& minus acris. Attamen ubi quodam fonticulo colligitur, vel fi in vafe refideat, violaceo quodam ad fuperficiem fplendet nitore, qua etiam fpecie \& lapides, ubi ambæ decurrunt, inficiunt crufta duriffima. Minera quidem mifta multifariam ent, cineream enim ponit, \& calcinatam cum fulphuris quadam portione ac ferri mediocrimiftura; fine fulphure quidem hxc aqua non eft, quod indicant tam regionis natura fupra \& infra Puteolos fulphurea, tum unctuofitas illa, qua hæc aqua fubpinguefcit, \& præterea aliqualis ejus odor; qui tamen a penitiffimis aquis a pluri aque frigidæ quantitate fuffocatus varisque contemeratus vaporibus teterrimus fit, quorum tincturæ illa, quæ in defide ruffelcit aqua, foboles effe videtur. Ferrum vero imprimis indicant, natura montis tota lapidofa \& faxa \& glebæ, qux exinde eruuntur, ponderis graviffmi, colore fufco, cruftis quibusdam oblongis ac fplendidis incurfancibus ftibii colore. Quibus plane rebus \& canalis ipfe, unde fluit aqua, rubrica illa duriore inficitur, quæ ex ferro fcatet incruftaturque tenaciffme, \& quæ juxta refident craffufcula aliqua recrementa, arenula fribii inftar colligitur, livida ac lucida \& graviffima. Quod genus recrementi ex deftillationis experimento relinqui in vafe minus confentaneum fit, fed candidum duntaxat pollinem: quoniam illud arenofum, ut decidit, per ipfam aquam ex lapide, non commilicetur aquie, fed fuapte gravitate demergitur in rivum: quinimo ad ignem expolite craffefcunt, tenuemque ad fundum vafis pollinem deponunt albiffimumque. Sunt etiam aquæ ferratæ in infula Enaria, pariter aqua Plaga Romana itidem. Hre Baccius.

\section{Aque in Stiria.}

IN ducatu Stiria, \& quidem ibi in comitatu Cillienfi circa Croatix con1 finia prope urbem Roitefchenfem fcaturiunt aqux, quæ reprefentant odorem modice fulphureum \& ferruginofum, quoad onnia fimillimum cidem, qui ex fpiritus victrioli fupra fcobem aut limaturam Martis infufione refultat, naresque fuaviter ferit \& vellicat, ratione fuavifimæ fuæ aciditatis guftui funt gratiffimæ, ratione coloris funt pellucidæe inftar chryftalli; per fyropum violarum vel per rofas ficcas viriditatem, inftillatum victrioli fpiritum rubedinem, ex rubedine vero per inftillatum oleum tartari ex deliquio, viriditatem iterum ludicro naturx fpectaculo adeo miraberis refultantem, ut ex reiteratis affufionibus quandoquidem liquor inftar lactis albefcat. Ex gallarum admixto pulvere tincturam præbet obfcuram atque nigricantem eoque magis intenfam, quo liquor diutius fteterit, cui aliquot additis vietrioli granis atramentum fcriptorium refultat. 


\section{E T VICTRIOLI I N A QUIS. \\ Fontes Anglice.}

Ominus Martinus Lifter de fontibus medicatis Anglix refert, in illis
raro victriolum maturum aut nunquam reperiri; pyriten autem, qui in aere in merum vietriolum propria germinatione ex toto convertatur, eundem ipfum lapidem five metallum ex tota natura fieri fpiritum five halitum fulphureum ochramve, pyrite \& lapidis calcarei halitibus, \& intra aquas fontium quorundam ligna craffe facile penetrantibus, petrificationem adfcribit, $a b$ iisdem vaporibus thermas Anglicas calere fatagit evincere.

\section{Fons Raderbergenfis.}

DOminus Joh. Chrift. Lehman circa aquas hujus fontis plura experimenta inftituit, \& in illis abundantiam minere Martis five victrioli comperiit: quod non modo ab experimentis fed etiam ex vicinia ejus concludit, qux ferro admodum imprægnata eft.. Quod alias ipfum fontem attinet, eft aqua ejus limpida, clara \& chryftallina; nec turbatur \& putrefcit, quamvis fpatio 6 vel 8 feptimanarum phiolæ inclufa teneatur: fed in aere operto ad vitri latera intra 24 horas ochraceum quoddam fedimentum deponit: bullulæ quiædam fundum vafis, non vero latera occupant. Odoris eft puri, quamvis inde remotius fed in vafe claufo feratur'; at vero fi phiola non bene obturata fit, odorem fulphuris victrioli Martis fpargit: nec faporis eft ingrati, adeo ut nullam naufeam moveat. Syropum violarum diluit modo pallidioremque facit; nec tornam folis cœruleam alterare videtur. $\mathrm{Ab}$ affufione fpiritus falis nullæ in fublime erumpunt bullulæ. Cum fpiritu vietrioli limpida remanet, nec fpumefcentiam aut fervorem quendam caufatur; a firitu nitri adhuc magis limpidefcit: nec a folutione aluminis alteratur: ex vino regionis aliquantisper turbabatur. Ex folutione fulphuris cum fale tartari fubflavefcit. Cum lacte vaccino cocta non coagulatur. Pix admodum folvitur \& cum aqua unitur, adeo ut cum pice unita tranfeat retortam \& aquam fapore piceo imbuit. Ex decocto ligni Brafilienfis obfcure rubefcit. Ex folutione victrioli cuprei turbatur, \& calx cœerula ad fundum precipitatur. Ferrum in aqua fontis rubiginem attrahit, fed nulla Venere incruftatur. A folutione facchari Saturni turbatur aqua, fed immiffa folutione Mercurii fublimati, ftatim clarefcit. Ex aqua calcis præcipitatur ochra \& pars ferrea, pariter ex fale tartari, fed non ita cito. A firitu falis ammoniaci turbatur, fed non ftatim; ex liquore Thee appellato colore obfcure bruneo tingitur. Ex decocto florum balauftiorum bruna fit. Ex decocto gallarum ex flavo abit in colorem obfcure brunum. In vacúo antliæ bullulas plures ejicit quam aqua communis. Ocbra ejus calcinata a magnete attrahitur: inque igne fpeculi cauftici in Jcorias ferreas convertitur.

\section{Conclufio.}

A Dhuc plura \& infinita ex auctoribus collectanea experimenta circa aquas ferro five victriolo Martis imbutas inftituta, in medium afferre Clalis III. de ferro.

Eee ee pos- 
poffem; fed quia hoc nihil aliud effet, quam eandem continuo operam agere \& lectori tædium creare, hinc fuperfedeo pluribus hujus generis experimentis \& reagentiis traftatulum noftrum onerare; nulla enim regio datur, in qua non ferrum aut natales ferri exftent, \& pariter ubi non aquæ dentur, quæ Martem aut victriolum quoddam fapiant, fed cum illo difcrimine, quod in aliquibus victriolum magis purum \& maturum five unitum exftet quam in aliis; in aliquibus cum fulphureo falinis \& calcareis particulis mixtum: in aliis immaturum adhuc, nec nifi meris elementis \& entibus, ex quibus Mars aut victriolum ejus tandem conflatur conftans: hinc quia tantum difcrimen intercedit, non abs re fuiffe putavi, cirça plures aquas facta experimenta \& indagines fiftere; ut ex illis concludi poffit, quænam in aquis vietriolicis differentia fit, \& qua ratione differentia illa a variis eruditis chymice explorata fit.

\section{F I N I S.}

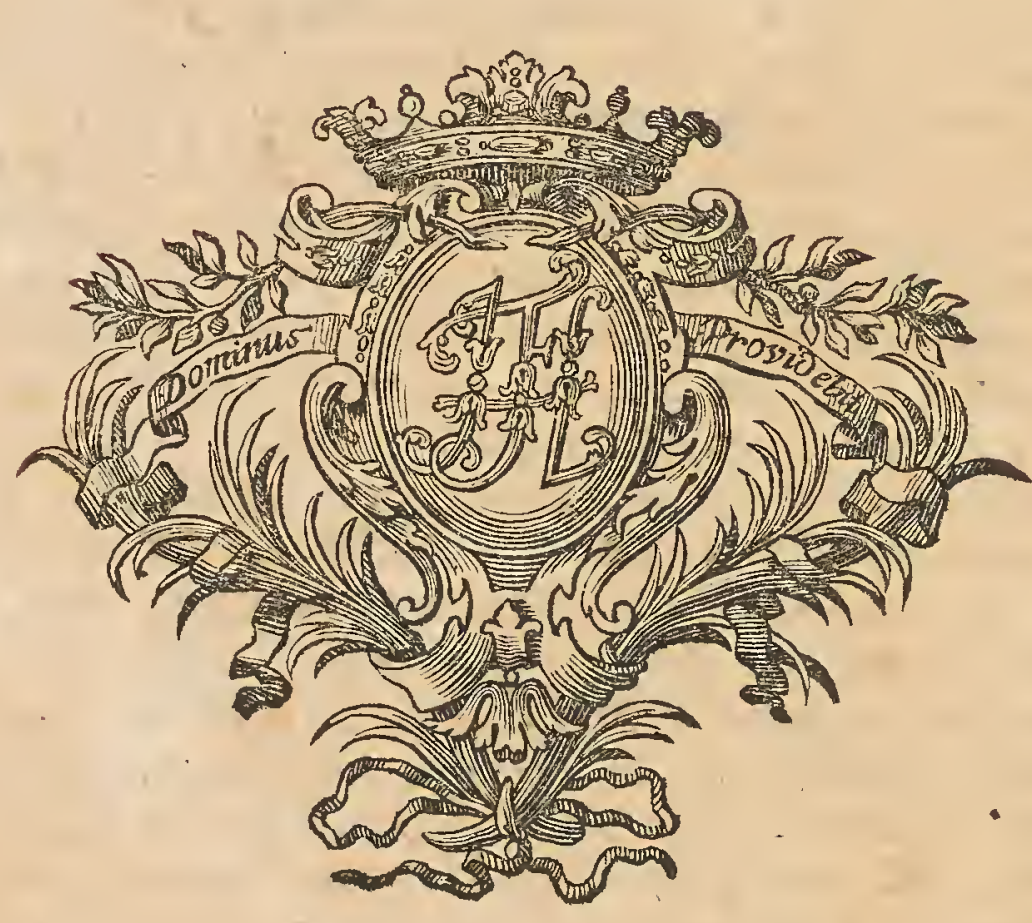




